\title{
Catrin Corell
}

\section{Der Holocaust als Herausforderung fuir den Film}

Formen des filmischen Umgangs mit der Shoah seit 1945.

Eine Wirkungstypologie 
Catrin Corell

Der Holocaust als Herausforderung für den Film 
Catrin Corell (Dr. phil.) studierte Diplom-Romanistik mit wirtschaftswissenschaftlicher Qualifikation (BWL) an der Universität Mannheim sowie an der Ecole Supérieure de Commerce de Grenoble, promovierte im Fachbereich Romanistik an der Universität Mannheim, lehrte dort romanistische Film- und Literaturwissenschaft und publizierte diverse Artikel zum europäischen bzw. französischen Kino. Derzeit arbeitet sie in München in der Film- und Fernsehbranche. 
Catrin Corell

Der Holocaust als Herausforderung für den Film.

Formen des filmischen Umgangs mit der Shoah seit 1945.

Eine Wirkungstypologie

[transcript] 
Schriftenreihe des Fritz Bauer Instituts, Band 20

Dissertation an der Universität Mannheim, Dezember 2006 Philosophische Fakultät

Erstgutachter: Prof. Dr. Rolf Kloepfer

Zweitgutachter: Prof. Dr. Jörg Türschmann

\section{Bibliografische Information der Deutschen Nationalbibliothek}

Die Deutsche Nationalbibliothek verzeichnet diese Publikation in der Deutschen Nationalbibliografie; detaillierte bibliografische Daten sind im Internet über http://dnb.d-nb.de abrufbar.

(C) 2009 transcript Verlag, Bielefeld

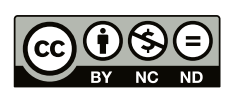

This work is licensed under a Creative Commons Attribution-NonCommercial-NoDerivatives 3.0 License.

Umschlaggestaltung: Kordula Röckenhaus, Bielefeld Umschlagabbildung: Grischa Andreew, Berlin, (C) PhotoCase 2009

Korrektorat: Adele Gerdes, Bielefeld

Satz \& Druck: Majuskel Medienproduktion GmbH, Wetzlar ISBN 978-3-89942-7I9-6

Gedruckt auf alterungsbeständigem Papier mit chlorfrei gebleichtem Zellstoff.

Besuchen Sie uns im Internet: http://www.transcript-verlag.de

Bitte fordern Sie unser Gesamtverzeichnis und andere Broschüren an unter: info@transcript-verlag.de 


\section{Inhaltsverzeichnis}

Vorwort und Dank 11

\section{Film als zentrale Form des Holocaust-Gedenkens}

I.I Mimesis versus Bilderverbot:

Positionen und Tendenzen in der Auseinandersetzung

mit dem Holocaust von der Entnazifizierung bis heute

I.2 Filmtheorie -

zur filmischen Gestaltung als Wirkungsangebot

I.2.1 Vernachlässigung des Sich-Einlassens auf den Holocaust,

Mimesis-Orientierung und >Emotionalisierung <

als »black box« - zum Stand der Forschung

I.2.2 Filmische Gestaltung als Wirkungsangebot im Prozeß zur methodischen Tradition der Arbeit

I.2.3 Aufdeckung simultaner und sukzessiver Wirkungsangebote

durch computergestützte Filmanalyse -

zur methodischen Vorgehensweise und zum Aufbau der Filmkapitel

\section{Typen von Holocaust-Filmen}

II.I Umerziehung durch Greuelfilme mit Schockästhetik? ................................................... 47

II.1.1 »Images blessures« - Schockbilder: Die TodesmüHLeN

(Death Mills, Hanuš Burger, USA 1945) .......................................................... 50

II.1.1.1 Die gescheiterte Schock-Politik der Alliierten ...................................................... 50

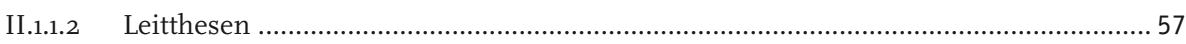

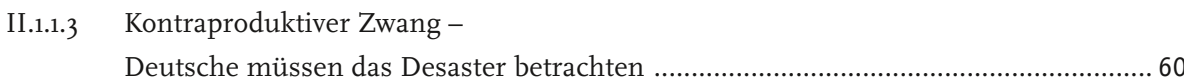

II.1.1.4 Latente Aufforderung zur Ergänzung -

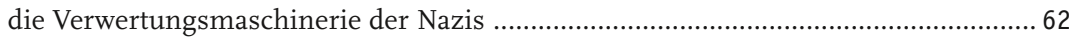

II.1.1.5 Kollektivschuld und Erfahrbarmachung der Lager -

»Elfhundert Kreuze für elfhundert frische Gräber « ............................................. 65

II.2 »Sprechende« Erinnerungsorte und Zeitzeugen? ................................................... 71

II.2.1 Kontraproduktive Über-Ästhetisierung: NACHT UND NEBEL

(Nuit et Brouillard, Alain Resnais, F 1955) 
II.2.1.1 Ein Filmemacher, ein Literat und ein Musiker -

Ästhetik auf allen Ebenen ........................................................................... 73

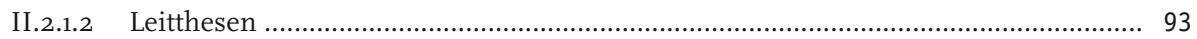

II.2.1.3 »Ruhe« über dem verlassenen Schreckensort - die Exposition .............................. 96

II.2.1.4 Die Lagerhierarchie im Stakkato-Rhythmus ...................................................... 100

II.2.1.5 Leere Schlafkojen - »stumme « Relikte ............................................................ 102

II.2.1.6 »Fehl-Forderung« des Zuschauers -

Spuren des Todeskampfes in den Gaskammern .................................................... 106

II.2.1.7 Kontraproduktive Ästhetisierung -

die Verwertungsmaschinerie der Nazis ................................................................. 111

II.2.2 Ein Film, gemacht, nicht (zu Ende) gesehen zu werden: Sнонн

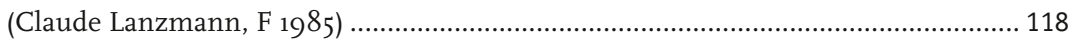

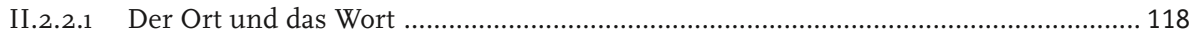

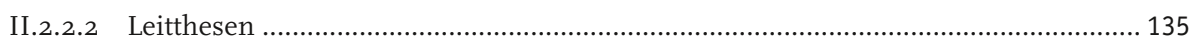

II.2.2.3 Empathische Ansteckung - Filip Müllers bewegende Erzählung ........................... 139

II.2.2.4 Überforderung des Zuschauers -

fehlende Analogie zwischen Lageraufnahmen und Zeugenbericht ....................... 145

II.2.2.5 Kontraproduktive Indiskretion -

Lanzmanns Kampf mit Abraham Bomba ........................................................ 153

II.2.2.6 Erschütternde Beschaulichkeit -

Simon Srebniks Rückkehr an die einstigen Orte des Schreckens ............................ 161

II.3 Intensives Miterleben durch Identifikation -

Authentizitätseindruck durch realistische Inszenierung

II.3.1 Ein-Blick in Freundschaft und Holocaust im Alltag:

Auf Wiedersehen, Kinder

(Au Revoir Les Enfants, Louis Malle, F 1987).

II.3.1.1 »Réinventer le souvenir « - neuerfundene Erinnerung ........................................ 171

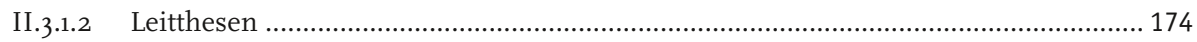

II.3.1.3 Exposition: Aus der Welt der Mutterliebe in die

»Männerwelt « des Karmeliterinternats .................................................................... 188

II.3.1.4 Die erste Stunde des Films - spannende Auflösung des Rätsels

um Jean und aufkeimende Freundschaft zwischen den Rivalen .............................. 197

II.3.1.5 Mit-Bangen um Jean und Erleben der gespaltenen

französischen Gesellschaft - »Mardi Gras« im Restaurant

II.3.1.6 Höhepunkt und Ende des Films:

»Au revoir les enfants «, >Au revoir, l'enfance $<-$

Einbruch des Holocaust in die »heile Welt« des Internats

II.3.2 Fesselnde Spannung - erfüllte Hoffnung: SCHind LERS Liste

(SCHIndLER's List, Steven Spielberg, USA 1993) .............................................. 233

II.3.2.1 Inszenierte Authentizität .............................................................................. 233

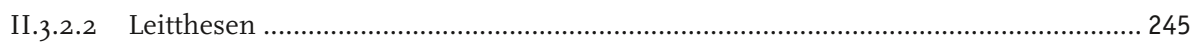

II.3.2.3 Exposition: Auftakt zur Vernichtung - Geheimnisvoller Schindler ........................ 261

II.3.2.4 Bangen mit und um den jüdischen Häftling und dessen mißglückte Hinrichtung .......................................................... 271

II.3.2.5 Erzeugte Authentizität - die Selektion im Konzentrationslager ............................ 275

II.3.2.6 Miterlebte Todesangst in der vermeintlichen Gaskammer .................................... 281

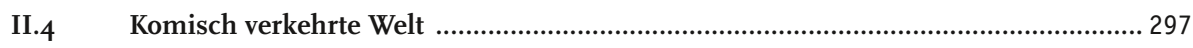


II.4.1 Lachen und Weinen -

Arlecchino im Vernichtungslager: DAS LEBEN IST SCHÖN

(LA VITA È BELLA, Roberto Benigni, I 1997)

II.4.1.1 „Ein Märchen zwischen Horror und Komik « ................................................... 306

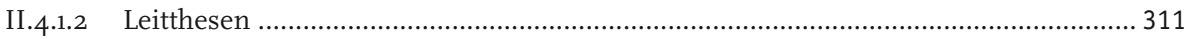

II.4.1.3 Exposition: Behutsame Einstimmung auf den Holocaust ........................................ 317

II.4.1.4 Hauptteil des Films: Kraft der Phantasie versus Lagerrealität ............................... 332

II.4.2 Ver-rückter (Über-)Lebens-Zug: Zug DES LEBENS

(Train de Vie, Radu Mihaileanu, F/BEL/ROM/NL 1998) ........................................ 356

II.4.2.1 Jüdischer Humor und nostalgischer Blick auf die Schtetl-Welt ............................. 356

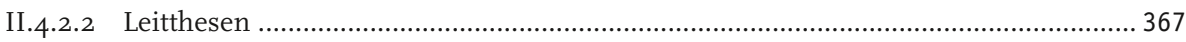

II.4.2.3 Der erste Teil des Films:

Schlomos geniale Idee und ihre Umsetzung ..................................................... 369

II.4.2.4 Hauptteil des Films: »Zug um Zug« nach Palästina ................................................ 382

II.5 Rückkehr an den Ort des Schreckens, die Gegenwart der Vergangenheit zu be-greifen: BIRKenAU und RosenFELD

(La Petite Prairie aux Bouleaux, Marceline Loridan-Ivens, F/D/POL 2003) ........ 398

II.5.1 Erschreckende Beschaulichkeit .......................................................................... 398

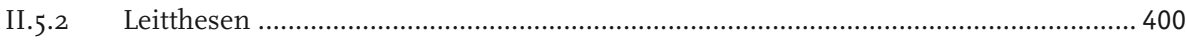

II.5.3 Exposition: Geheimnisvolle Einführung des Holocaust ........................................ 410

II.5.4 Spuren der Vergangenheit - Be-Greifen, um zu erinnern ................................... 416

II.5.5 »Annäherungen« an das Lager -

Ge-Denken und In-sich-Gehen versus »Spurenversessenheit « ............................. 426

II.5.6 Möglichkeiten und Schwierigkeiten besonderer visueller

bzw. musealer Inszenierung ...................................................................... 441

\section{Auf- und Annahme des Holocaust im Spielfilm}

III. Auf- und Annahme des Holocaust im Spielfilm 449

\section{Anhang}

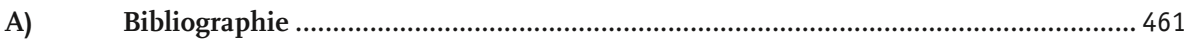

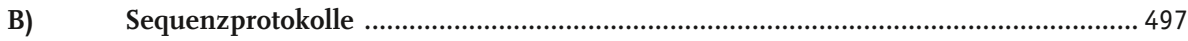

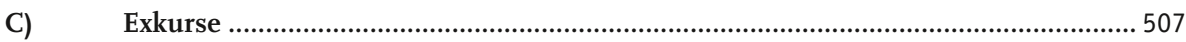

C1) Exkurs zu Peirce' Konzept der Semiose und seiner

Unterscheidung der drei Interpretanten-Typen ............................................... 507

C2) Exkurs zum Dialog zwischen Sender und Empfänger und der damit einhergehenden sympraktischen Dimension in künstlerischen Werken nach Kloepfer

C3) Exkurs zum Rhythmus in künstlerischen Werken und dessen Auswirkungen auf das menschliche Bewußtsein

C4) Exkurs zu den Perzeptions-, Konzept- und Stereotypengeleiteten Filmstrukturen nach Wuss 

[Semprún:] Das wirkliche Problem ist nicht das Erzählen,

wie schwierig es auch sein mag ...

Sondern das Zuhören ... Wird man unseren Geschichten zuhören, auch wenn sie gut erzählt sind? [...]

[Überlebender A:] - Was heißt hier >gut erzählt<?

Man muß die Dinge sagen, wie sie sind, ohne Kunstgriffe! [...]

[Semprún:] - Gut erzählt heißt: daß man gehört wird. Das gelingt nicht ohne ein paar Kunstgriffe. Genügend, daß es Kunst wird. [...] Hört zu.

Die Wahrheit, die wir zu sagen haben

- falls wir überhaupt Lust dazu haben, viele werden nie welche haben ist nicht sehr glaubwürdig ... Sie ist sogar unvorstellbar. [...]

Wie soll man eine so wenig glaubwürdige Wahrheit erzählen, wie eine Vorstellung von dem Unvorstellbaren wecken, wenn nicht dadurch, daß man an der Wirklichkeit arbeitet, ihr eine Perspektive gibt? Also mit ein paar Kunstgriffen. [...]

[Überlebender B:] - Ihr redet von Verstehen ... Aber um welche Art von Verständnis handelt es sich? [...] Ich kann mir vorstellen, daß es eine Fülle von Zeugnissen geben wird [...]

Und außerdem wird es Dokumente geben ...

Später werden die Historiker die einen wie die anderen

zusammentragen und analysieren:

sie werden gelehrte Werke darüber schreiben ... Alles wird darin gesagt, niedergelegt sein ... Alles darin wird wahr sein ... außer daß die wesentliche Wahrheit fehlen wird, an die keine historische Rekonstruktion je herankommen wird, so vollkommen und allgemeinverständlich sie auch sein mag... [...]

Die andere Art des Verstehens, die grundlegende Wahrheit der Erfahrung, die läßt sich nicht wiedergeben ...

Oder vielmehr nur durch das literarische Schreiben ... [...]

Durch den Kunstgriff des Kunstwerks natürlich. [...]

Der Film scheint die geeignetste Kunstform zu sein, [...]. [...]

Jedenfalls sind dem Dokumentarfilm unüberwindliche Grenzen gesetzt ...

Nötig wäre eine Fiktion, aber wer wird sich trauen?

Das beste wäre, noch heute einen fiktiven Film zu drehen,

in der noch sichtbaren Wahrheit von Buchenwald ...

Dem noch sichtbaren, noch gegenwärtigen Tod.

Keinen Dokumentarfilm, sondern eine Fiktion ...

Aber das ist undenkbar. [...]

Es bleiben die Bücher. Vor allem die Romane.

Zumindest die literarischen Berichte,

die über die bloße Zeugenaussage hinausgehen

und eine Vorstellung wecken,

auch wenn sie nichts zeigen. [...]

[Semprún:] - Aber dabei kann es nicht um die Beschreibung des Grauens gehen. [...] Jedenfalls nicht nur, nicht einmal hauptsächlich.

Es wird um die Erforschung der menschlichen

Seele im Grauen des Bösen gehen.

(Semprún 1995: 150-155

zur Diskussion unter den Überlebenden unmittelbar nach ihrer Befreiung, wie man von dem Geschehenen berichten sollte) 



\section{Vorwort und Dank}

Der vorliegende Band enthält die Ergebnisse meines Dissertationsprojektes an der Universität Mannheim zum Thema »Der Holocaust als Herausforderung für den Film«. Angeregt durch die Beschäftigung mit dieser Thematik im Rahmen meiner Diplomarbeit - Roberto Benignis besonderen Spielfilm LA VITA ì BELLA -, lag die Ausweitung der Frage nach den unterschiedlichen »Formen des Umgangs als Wirkungsangebot« nahe.

Mein ganz persönlicher Dank gilt Prof. Dr. Rolf Kloepfer für die Betreuung dieser Dissertation. Die von ihm geleiteten Promotionskolloqiuen zu methodischen Fragen sowie konkrete Filmanalysen und zahlreiche Einzelgespräche regten den intensiven fachlichen Dialog in bezug auf die Leitthesen der vorliegenden Arbeit an. Bei PD Dr. Jörg Türschmann bedanke ich mich für die unterstützende Beratung und die Übernahme der Zweitkorrektur, ebenso bei Prof. Dr. Guy Stern für seinen Vortrag zum Thema Holocaust im Film an der Universität Mannheim sowie weiterführende Gespräche.

Meinen Kolleginnen Nicole Kallwies-Meuser, Mariella Schütz und Marina Sheppard danke ich ganz herzlich für ihre fachliche und menschliche, Dr. Harald Simmler für die technische Unterstützung.

Tief empfundener Dank gebührt meinen Eltern, die mir die Promotion ermöglichten und mir, ebenso wie mein Bruder Christian, jederzeit mit Rat und Tat zur Seite standen.

Der Landesgraduiertenförderung Baden-Württemberg, die mir ein einjähriges Dissertationsstipendium gewährte, danke ich für die finanzielle Unterstützung sowie Prof. Dr. Rolf Kloepfer und Prof. Dr. Dietrich Hardt für die Erstellung der entsprechenden Gutachten.

Dem Fritz Bauer Institut - insbesondere Ronny Loewy, Projektleiter der »Cinematographie des Holocaust « und Werner Renz aus dem Bereich Dokumentation, Archiv und Bibliothek - gebührt größter Dank im Zusammenhang mit der Aufnahme des vorliegenden Bandes in die Schriftenreihe des Studien- und Dokumentationszentrums zur Geschichte und Wirkung des Holocaust. 
Herzlich danke ich NBC Universal Global Networks Germany, allen voran Wolfram Winter und Roger Schneider, für die großzügige finanzielle Unterstützung im Zusammenhang mit der Publikation meiner Arbeit.

Catrin Corell

München, den 10. Oktober 2007

1. Dieses Kapitel lehnt sich an die verschiedenen Beiträge von Gisinger und Chéroux in der von Chéroux herausgegebenen Publikation »La mémoire des camps« (2001) an, weshalb ich im folgenden lediglich den Autor sowie die Seitenzahl angebe. Besonderer Dank gilt Herrn Prof. Dr. Rolf Kloepfer, der für den folgenden Text Anregungen und Hilfestellung gab.

2. Unter dem kommunikativen Gedächtnis verstehen Assmann/Assmann die lebendige Speicherung von Erinnerung, die durch leibhaftige Kommunikation im Rahmen von drei bis vier Generationen erfolgt. Träger dieses Gedächtnisses sind die kommunizierenden und sich erinnernden Menschen als Zeitzeugen (1994: 191ff.). Wird das Wissen von Zeitzeugen dergestalt medial gespeichert, daß Bilder und Schrift die zentrale Rolle spielen, nennen dies Assmann/ Assmann das »kulturelle Gedächtnis« einer Gemeinschaft (1994: 191ff.).

3. Vgl. bspw. die Rezeption von Steven Spielbergs Spielfilm SchIndLers Liste, die Goldhagen- bzw. Finkelstein-Debatte, die Frage der Zwangsarbeiter-Entschädigung, die Walser-BubisKontroverse, die Debatte um die Wehrmachtsausstellung bzw. das Berliner Holocaust-Mahnmal, die zurückgezogene Plakat-Aktion >Den Holocaust hat es nie gegeben sowie die Diskussionen um das Jüdische Museum in Berlin. Insgesamt fällt auf, daß der Holocaust wiederholt als eine Art Modell für weitere, häufig jüngere Genozide wie in Südafrika (Ruanda) und Ex-Jugoslawien gesehen und zitiert wird (Levi/Sznaider 2001).

4. Vgl. bspw. die heftigen Auseinandersetzungen um die Konzeption des im Frühjahr 2005 fertiggestellten Berliner Holocaust-Mahnmals. 


\title{
I. Film als zentrale Form des Holocaust-Gedenkens
}

\author{
I.1 Mimesis versus Bilderverbot: \\ Positionen und Tendenzen in der Auseinandersetzung mit \\ dem Holocaust von der Entnazifizierung bis heute ${ }^{1}$
}

»0utre les témoignages oraux,
les documents écrits et ce qui reste des camps,
ce sont aujourd'hui avant tout
les images photographiques ou cinématographiques
qui façonnent nos représentations de ces événements.»

(Gisinger 2001: 183)

Während die Nachkriegszeit eher von Sprachlosigkeit gekennzeichnet war, ist der Holocaust und das Gedenken an ihn gerade in jüngerer Zeit als Thema omnipräsent. Wie läßt sich diese »Diskurswucherung « (Kramer 1999: 2) erklären? Jan und Aleida Assmann sprechen in diesem Zusammenhang vom Übergang des kommunikativen in das kulturelle Gedächtnis einer Gemeinschaft (vgl. Assmann/Assmann 1994: 119ff.). ${ }^{2}$ Das altersbedingte Sterben der ehemaligen Lagerinsassen steht unmittelbar bevor und damit auch die Möglichkeit, Zeitzeugen befragen zu können. Dieser zeitlichen Begrenzung des kommunikativen Gedächtnisses versuchen Kollektive durch eine verstärkte Erinnerungsarbeit zu begegnen. Primärerfahrungen, d.h. lebendige Erinnerungen, werden durch vielfältige mediale Speicherung in das kulturelle Gedächtnis überführt, so daß sie auch nachfolgenden Generationen zur Verfügung stehen. Diese gesteigerte Aufbewahrungsarbeit erleben wir heute; ein Blick in Zeitungen, Fernsehund Kinoprogramme und das Verfolgen zahlreicher öffentlicher Diskussionen zeigt, daß der Holocaust in unterschiedlicher Form allgegenwärtig ist und die Erinnerung an ihn zu äußerst kontroversen Stellungnahmen führt. ${ }^{3}$

Mit dem Übergang vom kommunikativen Kurzzeit-Gedächtnis zum kulturellen Langzeit-Gedächtnis verstärkt sich die Diskussion über die >richtige bzw. angemesseneく Erinnerungsform (Levy/Sznaider 2001: 33; Assmann in ders./Hölscher 1988: 15).4 »Seit den achtziger Jahren ist die Frage nicht mehr >ob<, sondern >wie< der Holocaust in Forschung und Literatur, Film und Kunst darzustellen ist.« (Huyssen in Köppen/ Scherpe 1997: 171, H.i.O.) Norbert Frei drängt sich sogar der Eindruck auf, »als lege sich dieses Interesse an den Verarbeitungsformen über die Aufmerksamkeit für das historische Geschehen selbst« (Frei in ders./Steinbacher 2001: 7). 
Das grundsätzliche Problem der »Darstellung des Undarstellbaren« verschärft sich im Bereich der visuellen Künste. Im Unterschied zur Literatur schränkt die visuelle Konkretion die ästhetische Freiheit des Adressaten tendenziell ein. Angesichts einer Thematik wie dem Holocaust werden die Chancen und Grenzen visueller Medien notwendigerweise äußerst kontrovers diskutiert.

5. «Si la chambre à gaz se situe à l'épicentre de l'extermination, il semble logique que son image soit également la représentation la plus appropriée de l'entreprise génocidaire. Ainsi, cette image intégrale et radicale serait probablement celle qui montrerait les déportés dans la chambre à gaz au moment de leur agonie.« (Chéroux 213)

6. Ihren Ursprung hat diese Debatte im jüdischen (auch islamischen und radikal-christlichen) Streit um das Bild allgemein und seine Tabuisierung.

Das Problem verschärft sich, wenn die Bilder von Tätern aufgenommen wurden. Vgl. hierzu das berühmte Foto des Jungen mit erhobenen Händen bei der Liquidierung des Warschauer Ghettos (s.u.), an dem gezeigt wurde, »wie ein klassisches >Täterbild durch entsprechende Kontextualisierung und Betextung zu einem quasi überzeitlichen >0pferbild - und damit zu einem allgemein gültigen Identifikationsobjekt - gemacht wurde« (Gisinger 1998: 475, H.i.0.).

7. Levy/Sznaider bspw. stellen eine allgemeine Visualisierung der Kultur durch Ausstellungen, Filme und Gedenkstätten fest und zeigen, wie sich der Holocaust in den vergangenen Jahren durch seine massenmediale Verarbeitung - v.a. durch die amerikanische TV-Serie HoLOCAUST (1978) oder auch Spielbergs Spielfilm SCHINDLERS LISTE (1993) - aus dem »nationalstaatlichen >Container« herauslöste (2001: 30, H.i.0.).

8. In bezug auf Holocaust vgl. Märthesheimer/Frenzel 1979; Knilli/Zielinski, Siegfried 1982; Siedler 1984; hinsichtlich SCHINDLERS LISTE vgl. Weiß 1995; Loshitzky 1997; Noack 1998.

9. «Si le point de départ de notre réflexion est ici le film, c'est parce que le cinéma est le médium qui, dans le domaine du visuel, a probablement eu le plus d'impact sur les débats publics; mais aussi parce que la photographie n'a pas jusqu'à présent donné lieu à une discussion d'une telle ampleur.« (Gisinger 179) Interessant ist in diesem Zusammenhang, daß die Repräsentation im Sinne einer Reproduktion oder gar Widerspiegelung, Abbildung etc. als Ausgangspunkt unhinterfragt angenommen wird. Mimesis als a) nachahmendes Tun (und damit eigene »Aufführung« kommt nicht ins Blickfeld, ebenso wenig wird sie gesehen als b) Versuch einer Modellierung, welche, dem Anspruch gemäß, je nach Relevanzgesichtspunkten ganz unterschiedlich ausfallen muß und - so schon bei Aristoteles - durch die Art der Beteiligung »philosophisch« sein kann (Poetik 6).

10. Siehe hierzu insbesondere den Exkurs zur unterschiedlichen Inszenierung der Gaskammern in Holocaust-Spielfilmen in II.3.2.6.

11. Auch und gerade in bezug auf Lanzmanns SHOAH formulierte Lyotard seine Bedenken: »Zu befürchten ist, daß Wort- (Bücher und Interviews) und Sachvorstellungen (Filme, Fotografien) von der Ausrottung der Juden [...] durch die Nazis gerade das, wogegen sich jene leidenschaftlich wehrten, in den Umkreis der sekundären Verdrängung ziehen, anstatt es, jenseits allen Status, als ein Vergessenes im >Inneren< zu belassen. Daß es, durch seine Darstellung, zu einem gewöhnlich >Verdrängten< wird.«(1988: 37f., H.i.0.) 
A.

Während Ikonophile und Fotohistoriker wie Clément Chéroux Aufnahmen aus den Gaskammern für das ultimative Dokument des Holocaust halten', gehen Bilderkritiker, wie Claude Lanzmann, davon aus, daß die visuelle Darstellung des Ungeheuerlichen unstatthaft ist und entsprechende Dokumente der Vernichtung zu vernichten seien:

»Wäre mir ein unbekanntes Dokument in die Hände gefallen, ein Film, der - heimlich, da Filmen streng verboten war - von einem SS-Mann gedreht worden wäre, und der gezeigt hätte, wie dreitausend Juden, Männer, Frauen und Kinder, gemeinsam starben, erstickt in einer Gaskammer der Krematorien Auschwitz II - hätte ich so einen Film gefunden, ich hätte ihn nicht nur nicht gezeigt, ich hätte ihn zerstört. Ich bin unfähig zu sagen, warum. Das versteht sich von selbst.« (Lanzmann zit.n. Gisinger 1998: 473)

Die angeführte Meinungsverschiedenheit ist Ausdruck einer seit 1945 geführten Debatte über Mimesis und Bilderverbot. ${ }^{6}$

Die weltweite Diskussion um Steven Spielbergs Holocaust-Spielfilm Schinder RS Liste (SCHIndLeR's List, USA 1993) - mit der Frage nach Aufklärung oder Ausnutzung durch Hollywood - mit Entlastungsfunktion der ehemaligen nationalsozialistisch regierten Länder, Deutschland und Österreich (Weiß 1995) -, muß geführt werden im Hinblick auf die grundlegenden Implikationen von Film und Fotografie. »Dans l'approche visuelle de l'Histoire, aucun autre sujet ne semble autant opposer la croyance en un pouvoir didactique de l'image et la conviction de l'impossibilité de représenter le passé à l'aide de documents iconographiques.«(Gisinger 181) Verglichen mit anderen medialen Umgangsformen, wie beispielsweise der Literatur, erfreuen sich visuelle Künste, wie die Foto- und die Kinematographie, großer Beliebtheit und prägen im wesentlichen unsere Vorstellungen vom Holocaust.7 Man erinnere sich in diesem Zusammenhang an die kontroverse Diskussion um die amerikanische TV-Serie Holocaust (1978/79) und Spielbergs SCHIndLERs Liste (1993; s. II.3.2).8 Erst das Medium Film erzwang aufgrund seines weltweiten Erfolgs eine intensive, nationen-übergreifende Auseinandersetzung mit der Frage nach der Darstellung bzw. Darstellbarkeit sowie der ästhetischen Transformation des Holocaust. 9

Darf man ein Zentrum der systematischen Vernichtung als Überraschungselement einsetzen (vgl. II.3.2.6 zu Spielbergs Sequenz in der vermeintlichen Gaskammer in Schindlers Liste)? ${ }^{10}$ Ist Schindlers Pseudorealismus und dieser ästhetische Mißbrauch nicht Beweis für die oben zitierte These Lanzmanns? Ist es »besser«, wenn dieser einen seiner Protagonisten dieses Zentrum der Vernichtung detailliert beschreiben läßt (s. II.2.2.4)? Ist das Psychodrama, in der theoretischen Nachfolge von Sartre, geeignet für eine »Vorstellung vom Unvorstellbaren«?

Die Kontroverse zwischen häufig tiefenpsychologisch orientierten Verweigerern der Mimesis und ihren Kritikern, welche behaupten, die »Verweigerung der Mimesis [leiste] der Mystifizierung Vorschub « (Gisinger 181), ist Anfang des neuen Jahrtausends noch im Gange. Sind nicht alle medialen Repräsentationen der Vernichtung - so Lyotard überspitzend - Mittel der Verdrängung (zit.n. Gisinger $181) ?^{11}$ 
Unter der Oberfläche dieser scheinbar unlösbaren Problematik scheint sich in jüngerer Zeit das Interesse vom historischen Geschehen zur Art und Weise des Umgangs mit dem Holocaust zu verlagern (s.o.). Für die neuere Holocaust-Literatur konstatieren

12. »Merkwürdig bleibt die Leidenschaftlichkeit, mit der wir plötzlich mit dem salttestamentarischen Bilderverbot` konfrontiert werden, denn darauf läuft des Bildermachers Lanzmann Kritik im Grunde hinaus und schließt somit an das >Musikverbot des Musiktheoretikers Adorno< an, als dieser sich schön klingende Worte nach oder über Auschwitz verbat. So wie einmal der Name und das Antlitz Gottes sunaussprechlich und sunvorstellbarı waren, so heute angeblich der Holocaust, obwohl sich doch Gewalttätigkeiten deutlich aussprechen und vorstellen lassen. Eine gutgehende Schreib- und Filmindustrie lebt ja von diesen Aussprech- und Vorstellbarkeiten. Die Vokabel >dürfen< besagt, es gäbe eine anerkannte geistige Autorität, die über erlaubtes und unerlaubtes Erinnern bestimmt. Die negative Kritik setzt Maßstäbe an, ohne diese Maßstäbe selbst der Kritik auszusetzen. Die Voraussetzung ist jedoch notwendigerweise, daß es einen sreinen<, srichtigen< Umgang mit der SHOAH gäbe, also mit einem Thema, vor dem wir doch zugegebenermaßen nach einem halben Jahrhundert noch ziemlich ratlos stehen, so daß uns jedes neue Experiment willkommen sein sollte, solange es nicht als der Weisheit letzter Schluß auftritt. Was aber die Beurteilung einzelner Werke betrifft, so ist der wohlbekannte Unterschied zwischen Kitsch und Kunst auch bei diesem heiklen Thema dienlich.» (Klüger 1995: B4, H.i.0.)

13. »Man denke an Lanzmanns Verachtung für Spielbergs SCHINDLERS LISTE, vergleichbar mit der Reaktion des eifersüchtigen Gottes des Alten Testaments. Ist es nicht so, daß SHOAH, dieses Paradox eines Dokumentarfilms mit der selbstauferlegten Beschränkung, kein dokumentarisches Filmmaterial zu verwenden, auf diese Weise alle Paradoxa des bilderstürmerischen Verbots verordnet, auf denen das Judentum basiert? >Du sollst Dir kein Bild machen ... denn Ich bin der Herr, dein Gott, ein eifersüchtiger Gottı - Du sollst keine fiktionale Erzählung verfilmen oder anschauen oder irgendwelches dokumentarisches Filmmaterial über den Holocaust verwenden, denn Ich, Lanzmann, bin ein eifersüchtiger Autor. Und wird diese Anmaßung nicht von der Tatsache untergraben, daß eine Hollywood-Produktion wie die Serie HoLOCAUST, obwohl oder gerade weil sie kommerziell und melodramatisch ist, zweifellos mehr als SHOAH dafür getan hat, das Bewußtsein für den Holocaust in weiten Kreisen der Bevölkerung zu erhöhen, vor allem in Deutschland? Eine nähere Untersuchung von SHOAH müßte daran erinnern, daß sich die meisten Kritiker auf einige Szenen konzentrieren, etwa auf das Interview mit den alten Polen bei Auschwitz, die ihre antisemitische Einstellung heute noch offen zeigen. Das Problem dieses Interviews ist die Prämisse, die Ursachen, die zum Holocaust geführt haben, seien noch heute lebendig. Aber bahnt diese Prämisse nicht der Gefahr den Weg, populäre antisemitische Ressentiments mit der unvergleichlich schrecklicheren, staatlich organisierten 〉Endlösungく der Nazis gleichzusetzen?« (Žižek 2000: 15, H.i.0.)

14. "L'intérêt particulier porté depuis les années 1980 au national-socialisme, à la guerre et au génocide, qui s'exprime dans les formes de la mémoire et du souvenir les plus diverses (images, musées, monuments etc.), en est une illustration particulièrement frappante [de la mobilisation de la mémoire collective].« (Gisinger 183)

15. Vgl. die Kritik des französischen Theaterregisseurs und Lager-Überlebenden Armand Gatti: »Mich stört nicht nur, daß es sich um ein fälschlich typisiertes Bild von der Vernichtung handelt, weil [...] die Wahrheit der Vernichtung gerade in der Nicht-Existenz solcher Bilder besteht. In der Logik des nationalsozialistischen Vernichtungsprozesses mußten alle Spuren verwischt werden. Alles verlief ordentlich und streng geregelt. Die Bilder, die Resnais verwendet, drücken einen - zwar realen - Aspekt der Grausamkeit des Lagers aus, einen Aspekt, der jedoch nicht im Zentrum des Vernichtungsprozesses steht. Das eigentlich Inakzeptable an diesen Bulldozern ist, daß sie allen Opfern 


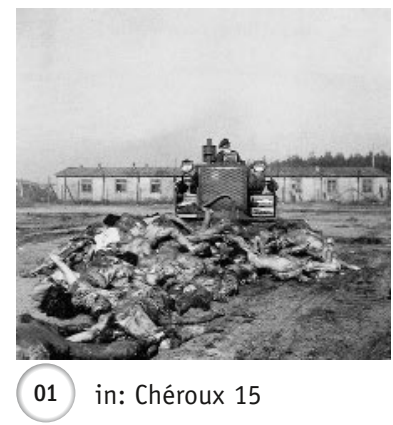

Köppen/ Scherpe, daß es dort inzwischen weniger »um Bildersegen oder Bilderverbot « geht; die Herausforderung, die in diesem Bereich mobilisierend wirkt, sei nicht mehr das »angeblich Nicht-Darstellbare«, sondern das »angeblich Nicht-Erfahrbare« (1997: 6) - Erfahrbarmachung gilt als zentrale Schwierigkeit und Ziel künstlerischer Formen des Umgangs und bildet das Zentrum der vorliegenden Arbeit. Selbst von Seiten der Überlebenden ${ }^{12}$ wird die Kritik an dogmatischen Verboten zunehmend lauter.13

$B$.

Sowohl für Befürworter als auch für Verweigerer mimetischer Darstellung gilt: Archivbilder sind fundamentaler Bezugspunkt für die Tatsächlichkeit der Geschichte und haben eine, dem Medium zugemutete und ihm zugeschriebene, Authentizitätsfunktion (s. II.1). Lanzmann versucht z.B. über die Berichte Überlebender und unter bewußtem Verzicht auf Archivbilder, den Zuschauer zu involvieren. Es stellt sich jedoch die Frage, ob wir anhand dieser Schilderungen und Landschaftsaufnahmen in der Lage sind, Vorstellungen - über die "gewohnten « Archivbilder hinaus - zu entwickeln? Ist NACHT Und NeBEL (Nuit et Brouillard) nicht zuletzt deshalb ein Klassiker, weil Resnais mittels Bildmontage (Schwarzweiß-Archivbilder versus nachträgliche Farbaufnahmen) versuchte, das kollektive ikonische Wissen des Zuschauers in Erinnerung zu rufen (s. II.2.1)?

In welcher Relation stehen solche Filme zum kollektiven Gedächtnis an diese Ereignisse, welches sich in den Nachkriegsjahren und -jahrzehnten durch mediale Erinnerungsformen angesichts seiner Unterentwicklung bzw. seiner Auslöschung durch die »pédagogie par l'horreur « (Chéroux 13) erst einmal hätte aufbauen müssen? ${ }^{14}$ Nicht einmal auf europäischer Ebene konnte sich also »natürlicherweise« ein kollektives Gedächtnis aufbauen - ein häufig übersehenes Problem im Umgang mit und dem Gedenken an den Holocaust.

Die Kritik an der Bilderflut unmittelbar nach dem Krieg geht davon aus,

- daß die Bildermassen durch Reproduktion an Informationswert verloren haben,

- daß die Kontexte der Bilder fehlen und sie daher als Dokumente an Tauglichkeit verloren haben,

- daß nicht ihr Informationswert, sondern das »Horrorpotential« gesucht war,

- daß gerade durch das »Spektakuläre« die Substanz verloren ging (Chéroux 13fff.).

Die »infamie visuelle « (Chéroux 15) war nur darauf ausgerichtet, an wenigen »Fakten«, welche visuell »authentifiziert« waren, das Ausmaß an Nazi-Greueln symbolisch zu ballen. Ein aus dieser Zeit stammendes, sehr bekanntes Foto zeigt einen Bulldozer, der leblose Körper vor sich her schiebt - zentral in NACHT Und Nebel (s. II.2.2) und heftig kritisiert. ${ }^{15}$ Wie sind solche Aufnahmen zu bewerten, wenn diese Maßnahme, 
aufgrund von Seuchengefahr, der möglichst raschen und effizienten Beseitigung der Leichen diente und es unklar ist, ob dies auf Veranlassung der Nazis oder der britischen Armee geschah (Chéroux 15, Gisinger 1998: 475) - Überlegungen, die das Problem der sogenannten Beweisfotos verschärfen. ${ }^{16}$

Waren diese Aufnahmen tatsächlich Teil einer »débauche des moyens médiatiques« (Chéroux 127)? Wurde damit erstmals ein Tabu gebrochen, das vorher eingehalten wurde - »celui de le représentation de la mort de masse« (ebd.; vgl. auch Kramer 2003: 230ff.)? Drücken diese Bilder nun den Schock der Befreier und damit den unsrigen aus (Gisinger 1998: 475) oder verliert sich alles »in der Uniformität und Anonymität des Grauens« (Gatti zit.n. ebd. 474)?

»Die entscheidende Frage ist hier also eine ethisch-moralische, nämlich wie die Bilder des Grauens, auch und gerade angesichts ihrer Aktualität, heute auf uns wirken und was wir in Zukunft mit ihnen machen werden. « (Gisinger 1998: 474) (17 $^{17}$ Ermöglichen sie uns die Vorstellung des Grauenhaften - zumindest im Ansatz? Im komplexen Vorgang des Sehens spielt demnach nicht nur das Bild selbst, mit all seinen Entstehungskonstituenten, eine entscheidende Rolle, »sondern auch das betrachtende Subjekt. Dies gilt auch und gerade für die Betrachtung und Analyse von bildmechanisch hergestellten Artefakten, also den vermeintlichen >Abbildern der Realität<.«(Ebd. 475, H.i.O.)

So bedauert Chéroux, daß die Bilder nicht genutzt wurden, um ein kollektives Gedächtnis in den deutsch-, englisch- oder französischsprachigen Ländern aufzubauen (Chéroux 19). Dazu wäre nötig gewesen, weniger auf das »Symbolisch-Spektakuläre«, als auf das Dokumentarische zu achten, was für diejenigen nützlich sein kann, die gerade nicht den »Mördern des Gedächtnisses« folgen wollen (Vidal-Naquet zit.n. ebd.): Indem sie Fotos von Verhungerten mit dem bürokratischen Eintrag »natürlicher Tod« versahen, betrieben die Nazis eine systematische Legalisierung des Genozids. Die »Flucht« eines Gefangenen bedeutete, daß er bis zur Lagergrenze geprügelt und dort niedergeschossen wurde (Chéroux 32ff.). Beide signifikanten Beispiele des Mißbrauchs verdeutlichen die generelle Ambivalenz von Bildern.

genau das verweigern, was ihnen auch die Nazis nicht gewähren wollten, nämlich eine Bestattung [vgl. Kramer 2003, eigene Anm.]. Sie sind nur noch Körper, ২Figuren<. Welche Erinnerung kann es für die Nachkommen jener so übereinandergeschichteten Männer und Frauen geben? Alles verliert sich in der Uniformität und Anonymität des Grauens." (Gatti zit.n. Gisinger 1998: 474, H.i.0.)

16. Gemäß der Leitthese meiner Arbeit ist diese Abbildung bewußt klein gehalten, damit der Leser selbst entscheiden kann, in welchem Umfang er die Details erkennen möchte.

17. »Man denke etwa an manche Fernsehbilder oder Pressefotografien aus Ruanda und Ex-Jugoslawien, die eindeutige ikonographische Anleihen bei bekannten Bildern des Zweiten Weltkrieges nahmen.« (Gisinger 1998: 477)

18. „Es gab für alliierte Kameramänner die Anweisung der Militärregierung, beim Filmen der befreiten Konzentrationslager darauf zu achten, daß immer auch die Umgebung zu sehen ist. Empfohlen wurde, viel zu schwenken, damit auf keinen Fall gesagt werden könne, die Aufnahmen seien gefälscht.« (Bernstorff 2002: 16)

19. »[...] il semble bien que la mise en scène intervienne dans tous les stades de l'acte photographique. Le choix du cadrage, de la focale ou plus particulièrement du point de vue, dont on sait combien il modifie la physionomie d'un visage, combien il peut le rendre hiératique ou grotesque, n'est-il pas déjà une forme de mise en scène?« (Chéroux 116) 
Die Informationen über die Konzentrationslager waren zunächst - nach der Befreiung der Lager - nicht für die französische oder amerikanische Öffentlichkeit zugänglich, wurden dann aber zur Aufklärung, zur Umerziehung, für die Nürnberger Prozesse bzw. die »auto-promotion« des Militärs eingesetzt (Chéroux 114). Es ist wichtig, in diesem Zusammenhang hervorzuheben, daß nicht nur die Pressefotografen (ebd. 108), sondern auch die militärischen Fachleute - neben der Dokumentation der »Wahrheit« -, Inszenierungsabsichten bis zur Nachstellung von Lagerbefreiungen hatten (ebd. 114ff.). ${ }^{18}$ So stellt sich schon hier die Frage, ab welchem Zeitpunkt die mediale Aufbereitung eigentlich beginnt. ${ }^{19}$

Aufgrund des Beschriebenen ist es zentral, die frühen Dokumente mit ihren Implikationen zu erkennen - und zwar für das jeweilige aufzubauende kollektive Gedächtnis (ebd. 117) sowie für die »pédagogie de l'horreur« (Matard-Bonucci zit.n. ebd. 117). In diesem Zusammenhang ist bemerkenswert, daß sich die Presse wiederholt weigerte, die »Bildberichte« oder Auszüge zu veröffentlichen. Es gab eine Diskussion »To Print or Not To Print« und Versuche, den grauenhaften Bildern mit moralischer Verantwortung zu begegnen (ebd. 119f.).

Diese Einstellung wurde jedoch bald aufgegeben, selbst Kindern sollten sich diese Aufnahmen einprägen (ebd. 119). Als Teil der Hypothese von der Kollektivschuld (Morgenthau-Plan) wurden systematisch Filme und Fotos für eine umfassende Medienstrategie hergestellt. Wenn ein SS-Wächter für die Presse gezwungen wurde, einen Toten zu einem »Massengrab(en)« zu tragen (ebd. 122f.), dann nicht nur zur Information, sondern zur Erzeugung von Schuldgefühlen auf Seiten des »Tätervolks«. Dieses Ziel wurde jedoch nicht erreicht (Brink zit.n. Gisinger: 124; s. II.1). Es ist hierbei wichtig, daß selbst das britische bzw. amerikanische Publikum davon ausging, daß die Berichte »übertrieben « seien (Chéroux 124) - vielleicht, weil bereits im Ersten Weltkrieg von der englischen Propaganda behauptet wurde, die Deutschen machten aus den Toten Seife. Auf Ingmar Bergmann beispielsweise wirkten die Bilder der befreiten Lager »comme des mensonges orchestrés par la propagande« (zit.n. ebd. 125).

Die Reaktion dauerhafter Be- bzw. Getroffenheit auf die, so Susan Sontag, »negative Epiphanie« (zit.n. ebd. 126) ist in vielerlei Hinsicht wichtig, insbesondere, wenn sie - im Unterschied zu ihrer jüngeren Publikation »Das Leiden anderer betrachten« (2003) - schreibt:

»Nichts, was ich damals gesehen habe - ob auf Fotos oder in der Realität -, hat mich so jäh, so tief und unmittelbar getroffen. Und seither erschien es mir ganz selbstverständlich, mein Leben in zwei Abschnitte einzuteilen: in die Zeit, bevor ich diese Fotos sah (ich war damals zwölf Jahre alt) und die Zeit danach [...].« (Sontag zit.n. Kramer 2003: 228)

»[...] il me fallût encore plusieurs années avant de pouvoir comprendre complètement leur signification. À quoi bon les avoir vues? Ce n'étaient que des photos: photos d'un événement dont j'avais à peine entendu parler et auquel je ne pouvais rien changer, d'une souffrance que je pouvais à peine imaginer et que je ne pouvais en rien soulager. Quand j'ai regardé ces photos, quelque chose s'est brisé. Une limite avait été atteinte, et qui n'était pas seulement celle de l'horreur; je me sentis irrémédiablement endeuillée, blessée, mais une partie de mes sentiments commença à se raidir; ce fut la fin de quelque chose; ce fut le début de larmes que je n'ai pas fini de verser.« (Sontag zit.n. Chéroux 126) 
»Als ich diese Fotos betrachtete, zerbrach etwas in mir. [...] etwas starb; etwas weint noch immer.« (Sontag zit.n. Kramer 2003: 228)

Die zentrale Frage lautet in diesem Zusammenhang: Unter welchen pragmatischen Bedingungen ist Schock überhaupt gerechtfertigt (s. II.1.1 u.a. zu Erich Kästners Reaktion auf Die TodesmüH Len)? Kann man durch ihn umerziehen, Verstockung lösen, kollektiven Unglauben brechen - oder sind die »Kollateralschäden « nicht größer durch die Brutalität der Vermittlung, welche den Betrachtern jedes Maß an Freiheit nimmt, sich so einzulassen, daß die eigene Psyche nicht beschädigt wird (s. Sontag)?

20. „Es gab auch Bilder aus Buchenwald, die ich wiedererkannte. Oder vielmehr: von denen ich mit Bestimmtheit wußte, daß sie aus Buchenwald stammten, ohne sicher zu sein, sie wiederzuerkennen. Oder vielmehr: ohne mit Sicherheit zu wissen, daß ich sie selbst gesehen hatte. Dennoch hatte ich sie gesehen. Oder vielmehr: ich hatte sie erlebt. Verwirrend war der Unterschied zwischen dem Gesehenen und dem Erlebten. [...] Bilder [...], an die meine Erinnerungen nicht heranreichten.« (Semprún 1995: 237f.)

21. Gleichzeitig weist Brumlik auf die Schwierigkeit echten Trauerns hin: »Ich bin überzeugt, daß die industrielle Vernichtung und gewerbliche Verwertung der Leichen von mehreren Millionen Juden in den Vernichtungslagern der Nationalsozialisten unser Vermögen zu echter Trauer in jeder Hinsicht übersteigt.« (Brumlik 1993: 199)

22. "[Die schrecklichen Verbrechen] kann man nicht dokumentieren. Um es begreiflich zu machen, was geschah, braucht es eben die literarische und dramatische Form." (Benz 1995: 147)

Im übrigen laufen ästhetische Auseinandersetzungen mit dieser Geschichte »weniger Gefahr, der Täuschung zu unterliegen, man habe begriffen, als die ihrem Wesen nach totalitären wissenschaftlichen« oder dokumentarischen Zugänge, »die von der prinzipiellen Begreifbarkeit jedes Phänomens ausgehen müssen.« (Welzer 1995: 189) Vgl. Marcel Ophuls: »Mais surtout, [...] les documentaires (ou ce que leurs auteurs appellent de ce nom) ne sont pas ma forme favorite de cinéma: pour être tout à fait franc, je n'ai pas une grande confiance dans ces produits douteux. Je me méfie beaucoup de toutes les raisons parfois avancées pour les proclamer supérieurs aux films de fiction, de leur prétention à occuper le marché de la vérité, de cet incroyable statut de respectabilité bourgeoise dont il se parent, et qu'ils ne méritent nullement.« (1990: 177)

23. Vgl. auch Ruth Klüger, ebenfalls Befürworterin eines fiktionalen Umgangs mit dem Thema; sie verteidigt denselben aufs heftigste, wobei sie auf ihre eigenen Erfahrungen als unmittelbar Betroffene rekurriert: "So gut reden hab ich wie die anderen, Adorno vorweg, ich meine die Experten in Sachen Ethik, Literatur und Wirklichkeit, die fordern, man möge über, vor und nach Auschwitz keine Gedichte schreiben. Die Forderung muß von solchen stammen, die die gebundene Sprache entbehren können, weil sie diese nie gebraucht, verwendet haben, um sich seelisch über Wasser zu halten.« (Klüger 2001: 127) Hinsichtlich der ebenso regelmäßig wie hart kritisierten Ästhetisierung verweist Ruth Klüger auf eine notwendige Unterscheidung: »Es gibt aber zwei Arten des Ästhetisierens, die eine ist Wahrheitssuche durch Phantasie und Einfühlung, also Interpretation des Geschehens, die zum Nachdenken reizt, die andere, die Verkitschung, ist eine problemvermeidende Anbiederung an die vermeintliche Beschränktheit des Publikums. (Klüger 1996: 38) »Aus diesem Dilemma [der Erinnerungsrituale] gibt es keinen Ausweg. Aber vielleicht vermag letzten Endes doch die Kunst, als Form eines reflexiven, eines skeptischen, sich seiner Ausdrucksmittel bewußten Rituals, noch am ehesten sowohl unserer Skepsis und Distanz zu allen Ritualen, aber zugleich unserem Bedürfnis nach starken expressiven Ausdrucksformen zu genügen.« (Brumlik 1993: 203) 
Man kann wohl keinem Menschen etwas gegen dessen Willen in »Herz und Hirn« hämmern und dann erwarten, daß bei ihm »aus tiefster Scham [...] Läuterung« einsetzt (anonymer »Times«-Reporter zit.n. Brink 1998: 52).

Der Buchenwald-Überlebende Jorge Semprún sprach zwar ebenfalls von einer »Dimension maßloser, erschütternder Realität«, betonte jedoch in krassem Gegensatz zu Sontag, daß es sich dennoch um »stumme« (1995: 239) Bilder handele, daß sie

»bis zur Verbitterung die Schwierigkeit [verschärften], sie zu vermitteln, und wenn nicht transparent, so doch mitteilbar zu machen. [...] Denn die Bilder, auch wenn sie das blanke Entsetzen, den körperlichen Verfall, die Arbeit des Todes zeigten, waren stumm. Nicht nur weil sie, gemäß den damaligen Mitteln, ohne Ton gedreht worden waren. Stumm vor allem deshalb, weil sie nichts Genaues über die gezeigte Wirklichkeit sagten, weil sie nur wenige Splitter davon mitteilten, wirre Botschaften.« (Ebd. 239)

Wenn die Bilder der befreiten Lager selbst für Überlebende, wie Semprún, »stumm« waren bzw. deren Erinnerung gar übertrafen ${ }^{2 \circ}$, wie sollten sie dann für die deutsche Bevölkerung »sprechend « sein und wie sollte die internationale Völkergemeinschaft sie bewerten?

Im Zusammenhang mit dieser komplexen Thematik muß auch der Begriff »Trauerarbeit« aufgegriffen werden, den der Erziehungswissenschaftler Micha Brumlik Mitscherlichs »Unfähigkeit zu Trauern « gegenüberstellt. ${ }^{21}$ Bei dieser »Aufnahme-Arbeit« und diesem Lernen von Menschlichkeit ex negativo bedarf es angemessener Hilfsmittel.

Nicht die Historiker, sondern die Künstler sind für diese Aufgabe zuständig - diese Unterscheidung erinnert an Aristoteles und wird auch von führenden Historikern bzw. Holocaustforschern gefordert. ${ }^{22}$ »Barbarisch wäre es, nach Auschwitz >kein< Gedicht zu schreiben«, faßt Marcel Reich-Ranicki diese Position zusammen (2002: 35, H.i.O.). »Wer wäre berufen und auch imstande, das Unvorstellbare zu zeigen oder anzudeuten und äußersten Schrecken zu vergegenwärtigen oder ahnen zu lassen, wenn nicht die Literatur und die Kunst, wenn nicht der Film?« (Ebd.) Stellvertretend für alle Befürworter von Kunst angesichts des Holocaust sei hier erneut Semprún zitiert, der eine fiktionale Herangehensweise in bezug auf Vergegenwärtigung befürwortet:

»Wie soll man eine so wenig glaubwürdige Wahrheit erzählen, wie eine Vorstellung von dem Unvorstellbaren wecken, wenn nicht dadurch, daß man an der Wirklichkeit arbeitet, ihr eine Perspektive gibt? Also mit ein paar Kunstgriffen.« (1995: 151)

»Zu dieser Substanz, dieser transparenten Dichte werden nur diejenigen vordringen, die es verstehen, ihr Zeugnis in ein Kunstwerk, einen Raum der Schöpfung zu verwandeln. Oder der Neuschöpfung. Nur die Kunstfertigkeit eines gebändigten Berichts vermag die Wahrheit des Zeugnisses teilweise zu übermitteln.« (Ebd. 23) ${ }^{23}$

Kunst und Fiktion als Mittel, Chance, Möglichkeit, den damals Überlebenden sowie heute Lebenden eine zunächst individuelle, dann kollektive Auf- und Annahme der Schrecken des Holocaust zu ermöglichen, in Freiheit und nach eigenem Maß.

Bereits im Zusammenhang mit den »stummen« Bildern der befreiten Lager hatte Semprún für einen künstlerischen Umgang mit dem »Rohmaterial« plädiert: 
»Es wäre nötig gewesen, den Film im Ganzen, in seinem filmischen Material selbst zu bearbeiten, in seinem Ablauf mitunter anzuhalten: das Bild zu fixieren, um bestimmte Einzelheiten zu vergrößern; in einigen Fällen die Projektion in Zeitlupe wieder aufzunehmen, andere Male ihren Rhythmus zu beschleunigen. Vor allem hätte man die Bilder kommentieren müssen, um sie zu entschlüsseln, sie nicht nur in einen historischen Kontext, sondern in eine Kontinuität von Gefühlen und Erregungen einzufügen. Und damit dieser Kommentar so nahe wie möglich an die erlebte Wahrheit herankäme, hätte er von den Überlebenden selbst gesprochen werden müssen: den Wiedergängern dieser langen Abwesenheit, den Lazarussen dieses langen Todes. Man hätte die dokumentarische Wirklichkeit letztlich wie einen fiktiven Stoff behandeln müssen.« (Ebd. 239)

»Fiktion « bedeutet in diesem Zusammenhang, reale Grausamkeiten so zu vermitteln, daß die Chance einer tatsächlichen Integration ins soziale Gedächtnis besteht. Damit würde auch der Gegensatz von Dokument versus Kunstwerk aufgehoben. Kracauer wird von Gisinger als Autorität dafür zitiert, daß die Aufgabe der Medien keine Spiegelung dessen sein kann, was wirklich war (weil das verfehlend sein muß), sondern ein wirksames Mittel, in die tiefe Wirklichkeit ein wenig mehr einzudringen, indem man dem »Rohmaterial« Form gibt (Gisinger 187). ${ }^{24}$

Im Unterschied zu Kunstwerken können Geschichtsbücher den Leser aufgrund ihrer tendenziellen Universalisierungüberfordern(Hannig1998:11ff.). Wenn selbst Historiker den Dokumentcharakter der Medien bezweifeln und werden diese - wie im Fall des be-

24. »[...] tout comme le photographe, l'historien n'entend pas négliger son devoir de constatation des faits en dépit de ses connaissances préalables, ni absorber totalement le matériau brut auquel il cherche à donner forme. « (Kracauer zit.n. Gisinger 185) »Cette conception envisagerait plutôt la photographie comme un réservoir de mémoire culturelle; cela supposerait d'analyser toutes les photographies se rapportant à un sujet donné comme des formes d'expressions visuelles autonomes s'inscrivant dans un discours tenu par l'ensemble de la société sur le passé et la mémoire.« (Gisinger 185)

25. »Welche Rolle spielt ein Bild als spezifischer Erinnerungsspeicher innerhalb eines breiten sozialen Gedächtnisses in bezug auf eine bestimmte historische Epoche? [...] Die eigentliche Aufgabe der Historikerinnen und Historiker wäre dann die Untersuchung der kulturellen Funktionalisierung von Bildern im Rahmen einer etwa von Peter Burke bereits Ende der achtziger Jahre geforderten »Sozialgeschichte des Erinnerns«, die das Phänomen des kollektiven Gedächtnisses als eine geschichtliche Erscheinung begreift (Gisinger 1998: 476, H.i.0.).

26. U.a. Kracauer hat darauf hingewiesen, daß weder die Geschichtswissenschaft noch die Fotografie objektiv neutral seien (und daß darin eine fundamentale Analogie beider Disziplinen bestehe): »[...] tout comme le photographe, l'historien n'entend pas négliger son devoir de constatation des faits en dépit de ses connaissances préalables, ni absorber totalement le matériau brut auquel il cherche à donner forme. « (Kracauer zit.n. Gisinger 185) »Der >GedenkRaum zwischen Denkmal und Betrachter ist wichtiger als das monumentale Denkmal [...].« (Young zit.n. Köppen/Scherpe 1997: 7, H.i.0.)

27. Vgl. Semprúns Beschreibung der Auswirkung seines Blicks, welcher sich in dem der Befreier spiegelt: »In ihren Augen lese ich blankes Entsetzen. Es bleibt also nur mein Blick, schließe ich daraus, der sie derart beunruhigen kann. Es ist das Grauen meines Blicks, das der ihre offenbart, von Grauen erfüllt. Wenn ihre Blicke ein Spiegel sind, dann muß ich einen irren, verwüsteten Blick haben.« (1995: 12) 


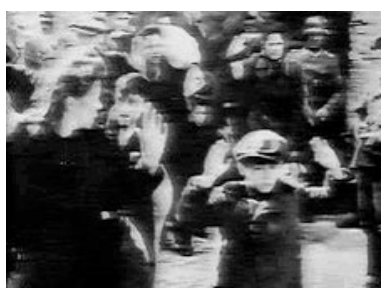

(02) $0: 03: 55 \mathrm{~h}$

(NACHT Und Nebel)

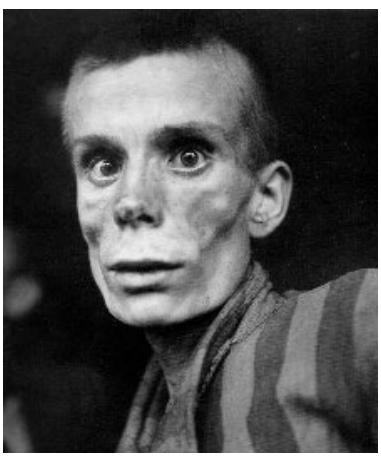

03 in: Chéroux 147

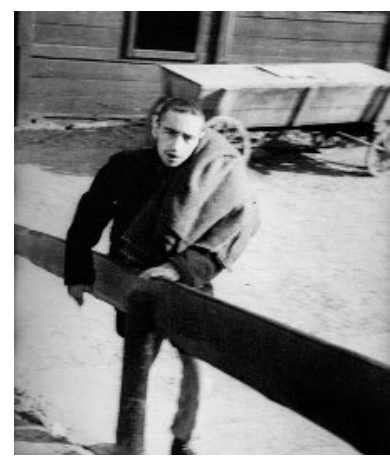

04 in: Chéroux 159

kannten fotografischen Ikons, des Warschauer Jungen mit erhobenen Händen während der Ghettoräumung - kontextfrei veröffentlicht, dann ist deren Funktion zumindest fraglich. »Il ne s'agit plus, en effet, de se demander si telle image est l'expression de la réalité d'un fait historique donné [dans le sens d'une vérité photographique], mais plutôt de s'interroger sur le rôle que joue cette image dans le réservoir de mémoire de la collectivité, à une époque précise.« (Gisinger 184) »Realitätsabbildung« ist also kein denkbares Ziel, wohl aber »Nahrung für das kollektive Gedächtnis«: statt mechanischer, vergewaltigender Einprägung, das Angebot zur eigenen An- und Aufnahme, welche durch das individuelle kommunikative Gedächtnis im freiheitlichen Maß der eigenen Möglichkeiten wachsen kann (dynamische Konzeption bei Burke; s. I.2.2 zum Sich-Einlassen). ${ }^{25}$ Nicht nur produktionsästhetische Betrachtung des Mediums, sondern vor allem rezeptionsorientierte - mit Blickrichtung auf die Kreativität des Adressaten (»Was will der Fotograf, Informationsspezialist, Volkserzieher ...?«; Gisinger 184f.; s. I.2.2). ${ }^{26}$

Auch der Aspekt Hoffnung sollte in diesem Zusammenhang Beachtung finden, da er Schutz und Ausgleich bedeuten sowie Voraussetzung für das Einlassen sein kann. Dies gelingt beispielsweise dem Fotografen Eric Schwab, der im Mai 1945, mit dem Bild eines jungen russischen Überlebenden, ein »Gegen-Bild« zur Schockästhetik der Lagerfotografien zeigte. Indem er dem Zuschauer das Zu-Ende-Denken überläßt (Chéroux 144ff.; s. I.2.2 zu Kloepfers Sympraxis-Begriff), kann sich dieser zumindest auch einen glücklichen Ausgang für den jungen Mann vorstellen. Gleichzeitig läßt der Blick des jungen Russen den Betrachter jedoch erahnen, was er gesehen und durchgemacht hat. ${ }^{27}$

In bezug auf das Wirkungsangebot gibt auch die damalige Fotografin Germaine Krull den Handlungen ihrer Gestalten die Möglichkeit der Hoffnung: Obwohl er sich nur am Zaun Halt suchend fortbewegen kann, geht der Mann auf die Befreier zu auch er gehört zu den wenigen, die überlebt haben (ebd.). 
C.

Insbesondere zeitgenössische Fotografen versuchen, sich dem Holocaust über unterschiedliche künstlerische Wege zu nähern, wobei es einer gewissen »Produktivität« seitens des Künstlers wie seitens des Betrachters bedarf (s. I.2.2 zur Sympraxis nach Kloepfer). Der Künstler kann »den vergangenen Dingen ein neues Präsenz geben, [...] sie zu neuem Leben [erwecken], zu einem >sekundären< Leben, dessen Ort unser Bewußtsein ist.« (Schörken 1995: 12f., H.i.O.) Der Betrachter kann durch das Gezeigte zu Eigenleistung aufgefordert werden, indem er Erinnerungen und Vorstellungen nach seinem individuellen Vermögen aktiviert.

Die Fotografin Naomi Tereza Salmon beispielsweise beschäftigt sich mit der »mémoire des choses « (Salmon zit.n. Gisinger 188), den Dingen als Pars pro toto. Aus einer Auftragsarbeit - sie sollte ursprünglich nur die Relikte der Naziverbrechen, wie Brillen, Schuhe etc. zu Archivierungszwecken aufnehmen - wurde eine künstlerische Herausforderung und Entdeckung (Gisinger 188):

»La technicité de ce travail destiné aux archives m'a permis de voir les choses, c'est-à-dire d'entendre leur silence. Ces choses se sont alors animées, chacune d'entre elles représentait une personne à qui on avait refusé le statut d'être humain, le droit à la vie et le droit d'être sujet de commémoration. Il ne restait rien de cette personne, sinon un objet qui était à la fois l'emblème horrible de son assassinat et l'emblème horrible de son destin. Plus j'ai pris conscience de ce caractère des choses, plus j'ai tenté de me rendre invisible en tant que photographe« (Salmon zit.n. Gisinger 188).

Der Versuch, als Künstler hinter die Dinge zurückzutreten, ist jedoch nur bedingt möglich, eine gewisse Ästhetisierung, allein durch die Position der Kamera, ist unvermeidlich. Die Beispiele experimentieren mit dem Indizcharakter von Dingen (s. I.2.2), die - wenn richtig aufgenommen - im Wahrnehmungsprozeß eine Schlußfolgerung ermöglichen. Salmon macht sich nahezu unsichtbar und ist reine Dienerin des Phänomenalen, das unserem Vorstellungsvermögen die nötige »Nahrung « gibt. In Holocaustfilmen kommt das Pars-pro-toto-Prinzip häufig zum Tragen (s. II)28: in Die TodesmüH Len (s. II.1.1.4), Nacht und Nebel (s. II.2.1.7), Shoah (s. II.2.1.7, Exkurs) und Schindlers Liste (s. II.2.1.7, Exkurs) direkt, in DAS LEBEN IST SCHÖN (s. II.4.1.4.ba) Sowie BirKENAU UND Rosenfeld (s. II.5.6.b) indirekt. Außer Die Todesmühlen sowie Nacht und Nebel setzen die zitierten Filme ganz auf die Aufnahmen und verzichten auf verbale Erklärungen - die Gegenstände allein sollen die Vorstellung anregen.

28. Siehe hierzu insbesondere den Exkurs zum Umgang mit der Verwertungsmaschinerie der Nazis in II.2.1.7.

29. »Depuis la libération des camps, et peut-être plus encore depuis les deux dernières décennies, les images des lieux constituent la composante majeure de l'iconographie du génocide nazi. [...] Les photographies fonctionnent donc comme les visites effectuées sur place [...].« (Gisinger 188)

30. Vgl. auch Hanno Loewys ironischen Kommentar zur Mehrzahl der heutigen Gedenkstätten, insbesondere Buchenwald: »Der Besuch des Mahnmals endet. Abgeschlossen die Therapie der kollektiven Erinnerung, in der die Identifikation mit den Tätern durch die Verschmelzung mit dem Widerstand aufgehoben wird. Heilung vom Tode, Sieg der Welt über das Böse. Sieg Deutschlands, das vom Torwächter des Hades zum Hüter des Paradieses reüssiert.« (1993: 29) 


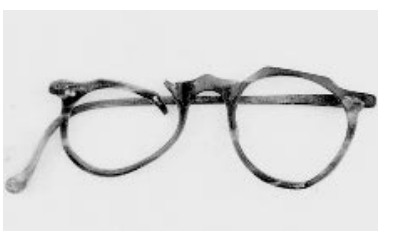

05 in: Gisinger 209

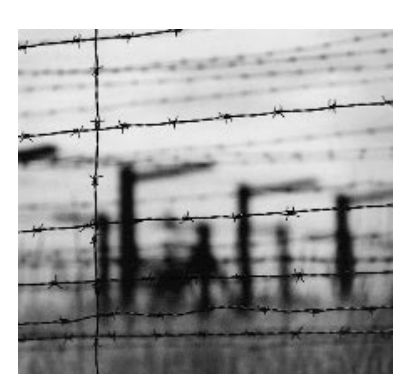

08 in: Gisinger 186

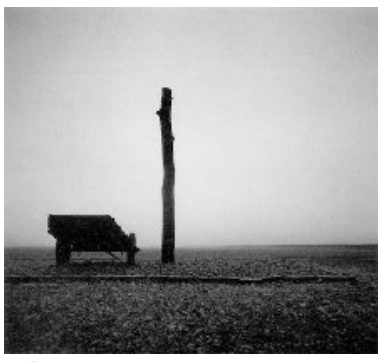

06 in: Gisinger 211

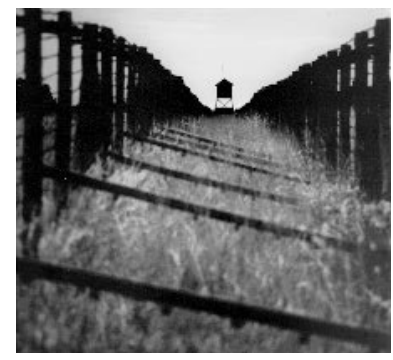

09 in: Gisinger 189

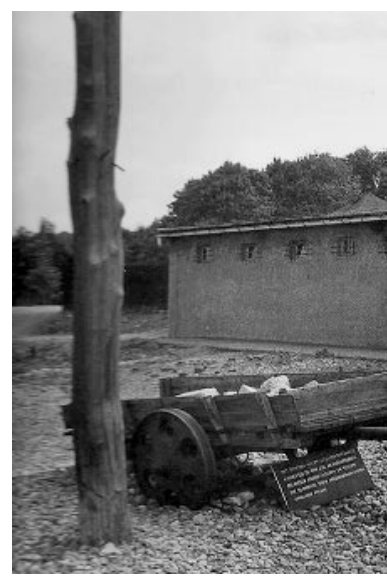

07 in: Gisinger 211

Ist dies die »angemessene« Ästhetik oder aber sind die Fotos »vor Ort« der richtige Weg (s. II.2 und II.5) - jedenfalls ist letzterer einer der meist beschrittenen. ${ }^{29}$ Sind diese Lageraufnahmen Auslöser von Vorstellungsbildern oder rufen sie nur historisches Wissen ab und sind Projektionsanlaß fertiger Gedächtnisbilder? James E. Young konstatiert: »Fotografierte Schauplätze an sich vermitteln keine Erinnerung; sie schweigen, sind ohne Leben.« (1993: 17). Entsprechend fordert er eine Kontextualisierung, um die Aufnahmen für den Betrachter zum Sprechen bringen (ebd.). Kann damit wirklich verm ieden werden, daß bestimmte Bilder die Vorstellungskraft des Betrachters nicht in gewünschter, sondern in u.U. kontraproduktiver Weise anregen wie von Ruth Klüger und Claude Lanzmann provokativ für die einstigen Lager und die heutigen Gedenkstätten formuliert (s. II.2)?30

Offensichtlich bedarf es einer besonderen künstlerischen Herangehensweise, um die Vorstellungskraft des Betrachters anzuregen (Gisinger 193). Der zeitgenössische Fotograf Michael Kenna beispielsweise wählt die bewußte Ästhetisierung (technische Perfektion der Bildkomposition und Präzision des Abzugs) - Bilder, die an Aufnahmen aus Dif Todesmühlen (s. II.1.1.5) und Nacht und Nebel (s. II.2.1.3) erinnern und die, so Kenna, den Zuschauer »verführen« sollen: »[...] il m'est apparu que la nature séductrice de mon travail est le moyen de forcer les gens à le voir. Si les gens le regardent et le critiquent, ils sont finalement concernés et impliqués. Si les images sont séduisantes, elles vont rester dans leur esprits.« (Kenna zit.n. Gisinger 188)

Es sind nicht zufällig Fotografen der dritten Generation (wie im Film BirkenAU und Rosenfeld, s. II.5), die das »Denk mal!« über das visuelle Medium wagen und den Betrachter zum Sich-Vorstellen, Sich-Versetzen und Schlußfolgern einladen bzw. auffordern (Gisinger 193). Die Versuche des zeitgenössischen französischen Fotografen Gilles Cohen sind betont individueller Art. Sein Stilmittel ist nicht die Abstraktion und Verallgemeinerung, sondern die Konkretisierung und Individualisierung. So zei- 
gen seine Porträts Überlebende, deren tätowierte Körper gleichzeitig ihre Geschichte wiedergeben.

Andere Künstler, wie z.B. Christoph Dahlhausen, ermöglichen deautomatisierende Distanzierung, indem sie Verschwommenheit, Farbumkehrung, extreme Abstraktion einsetzen. »Une première observation de cette photo ne permet d'identifier que des abstractions et ce n'est qu'en se replaçant dans un certain contexte historique que l'on resitue dans l'ensemble de la série certaines données historiques visuelles.« (Gisinger 198) Verständlich sind diese Fotos demnach nur für Betrachter mit entsprechendem Vorwissen (ebd. 200).

Die bewußte Abkehr von Stereotypen - ikonographischen Leitmotiven (z.B. Wachttürme) - ist als ein Verfahren der »Brechung « abstrakt, intellektuell - wie der Titel »Mein Kampf« für die Serie des zeitgenössischen Fotografen zeigt. Sie birgt die Gefahr allegorischer Setzungen, die besonders deutlich werden bei der Behauptung: Die Verschwommenheit der Bilder entspreche dem langsamen Verschwinden aus dem kollektiven Gedächtnis.

Die beschriebene fotografische Erinnerungsarbeit läßt einen Zusammenhang erkennen zwischen dem Übergang von der - mit Kracauer gesprochen (zit.n. Gisinger 185) - »realistischen« zur »kreativen Tendenz« und dem Übergang vom kommunikativen zum kulturellen Gedächtnis (s.o.).

Daher ist die Schlußthese Gisingers auch für die vorliegende Arbeit zentral: Die Fotografie - und andere mediale Werke wie der Film - sind für den Historiker v.a. Speicher, für den Künstler jedoch »Motor einer Entwicklung des kulturellen Gedächtnisses« (Gisinger 200), und, so sei ergänzt, eigener Einlassungs-/Annahme-/Vorstellungs- und Erinnerungsarbeit - in Freiheit, ohne Zwang. ${ }^{31}$ Kunst kann den Menschen ganzheitlich, d.h. mit all seinen Vermögen - Kognitionen, Emotionen und insbesondere »Volitionen« (Kloepfer 2001a: 48; s. I.2.2) - erfassen und ihm auf diese Weise intensive Erfahrungen vermitteln:

»Gegenüber allen anderen Formen der Kommunikation hat die ästhetische den Vorteil, daß sie den ganzen Menschen in das gemeinsame Handeln einbeziehen kann. Wir kontrastieren diese Form, Wissen zu erwerben, mit anderen, indem wir hervorheben, daß gleichzeitig Erfahrung, Erleben, Erkennen ermöglicht wird, wobei die Vorsilbe Er- den Prozeßcharakter und die dynamische Einbeziehung der ganzen Person hervorhebt.« (Kloepfer 2005: 93)

31. „Denn >die moderne kritische Theorie gestattet uns८, so Hayden White, szuversichtlicher denn je daran zu glauben, daß das >Poetisieren k kein Schweben über den Dingen, keine das Leben oder die Wirklichkeit transzendierende, von diesen abgespaltene Tätigkeit ist, sondern eine Form der Praxis darstellt, die als unvermittelbare Grundlage aller kulturellen Aktivität dient [...].« (White zit.n. Young 1992: 13, H.i.0.) 


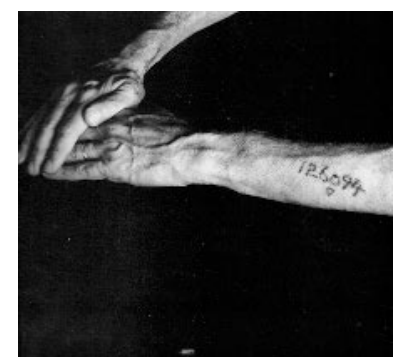

(10) in: Gisinger 197

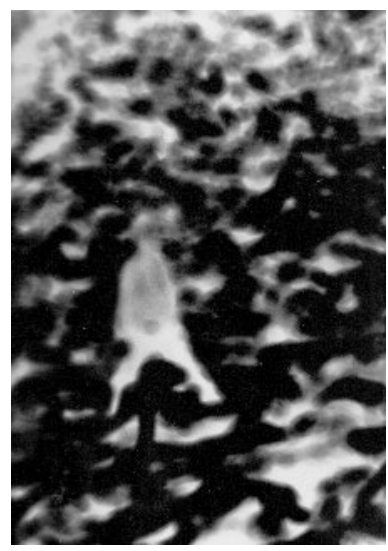

(11) in: Gisinger 199

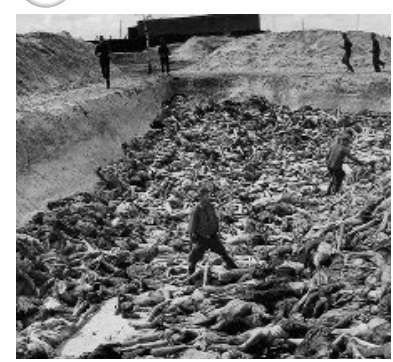

(12) in: Gisinger 198

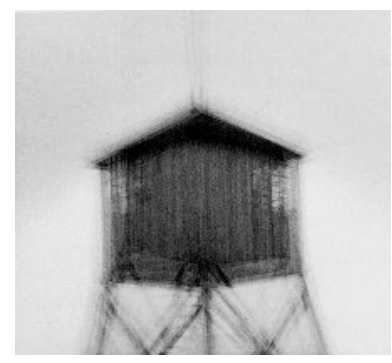

(13) in: Gisinger 200 
32. Vgl. Knilli, Friedrich/Zielinski, Siegfried (Hg.), Betrifft: Holocaust. Zuschauer schreiben an den WDR, 1983; Märthesheimer, Peter/Frenzel, Ivo (Hg.), Im Kreuzfeuer: Der Fernsehfilm Holocaust. Eine Nation ist betroffen, Frankfurt a.M. (Fischer Taschenbuch Verlag) 1979; Weiß, Christoph (Hg.), >Der gute Deutscher. Dokumente zur Diskussion um Steven Spielbergs SCHINDLERS LISTE in Deutschland, St. Ingbert (Röhrig Universitätsverlag) 1995; Thiele, Martina, Publizistische Kontroversen über den Holocaust im Film, Münster (LIT) 2001.

33. Vgl. Avisar, Screening the Holocaust. Cinema's image of the unimaginable, Bloomington (Indiana University Press) 1988; Baron, Lawrence, Projecting the Holocaust into the present. The changing focus of contemporary Holocaust cinema, Lanham (Rowman \& Littlefield Publishers) 2005; Doneson, Judith E., The Holocaust in American film, 22002; Insdorf, Annette, Indelible shadows. Film and the Holocaust, Cambridge (Cambridge University Press) 2003; Kramer, Sven, Auschwitz im Widerstreit. Zur Darstellung der Shoah im Film, Philosophie und Literatur, Wiesbaden (Deutscher Universitätsverlag) 1999.

34. Siehe die zahlreichen, nach Filmen aufgelisteten Titel in der Bibliographie im Anhang.

35. Vgl. Bannasch, Bettina/Hammer, Almuth (Hg.), Gebot der Bilder - Gebot der Erinnerung. Mediale Repräsentationen der Schoah, Frankfurt a.M. (Campus) 2004; Berghahn, Klaus L./Fohrmann, Jürgen/Schneider, Helmut J. (Hg.), Kulturelle Repräsentationen des Holocaust in Deutschland und den Vereinigten Staaten, New York/Washington D.C./Baltimore/Bern/Frankfurt a.M./Berlin/Brussels/Vienna/Oxford (Lan) 2002; Erler, Hans (Hg.), Erinnern und Verstehen. Der Völkermord an den Juden im politischen Gedächtnis der Deutschen, Frankfurt/New York (Campus) 2003; Giesenfeld, Günter/Koebner, Thomas (Hg.), Augen-Blick. Marburger und Mainzer Hefte zur Medienwissenschaft, Heft 36: „Kinematographie des Holocaust«, Dezember 2004; Haggith, Toby (Hg.), Holocaust and the moving image. Representations in film and television since 1933, London (Wallflower Press) 2005; Köppen, Manuel (Hg.), Kunst und Literatur nach Auschwitz, Berlin (Erich Schmidt Verlag) 1993; Köppen, Manuel/Scherpe, Klaus R. (Hg.), Bilder des Holocaust. Literatur - Film - Bildende Kunst, 1997; Lange, Sigrid, Authentisches Medium. Faschismus und Holocaust in ästhetischen Darstellungen der Gegenwart, Bielefeld (Aisthesis Verlag) 1999, S. 142-148; Martínez, Martías (Hg.), Der Holocaust und die Künste. Medialität und Authentizität von Holocaust-Darstellungen in Literatur, Film, Video, Malerei, Denkmälern, Comic und Musik, Bielefeld (Aisthesis) 2004; Reichel, Peter, Erfundene Erinnerung. Weltkrieg und Judenmord in Film und Theater, München/Wien (Carl Hanser Verlag) 2004.

36. Cuau, Bernard (Hg.), Au sujet de SHoAH, Paris (Belin) 1990; Loshitzky, Yosefa (Hg.), Spielberg's Holocaust. Critical perspectives on SCHINDLER'S LIST, Bloomington/Indianapolis (Indiana University Press) 1997.

37. Vgl. Korte, Helmut, »3. Hollywoodästhetik und die deutsche Geschichte: Schindlers Liste (Spielberg 1993)«, in: ders., Einführung in die systematische Filmanalyse, Berlin (Erich Schmidt) 1999, S. 147-194; Noack, Johannes-Michael, SCHINDLERS LISTE - Authentizität und Fiktion in Spielbergs Film. Eine Analyse, Leipzig (Leipziger Universitätsverlag) 1998; Wuss, Peter, »Das Leben ist schön ... aber wie lassen sich die Emotionen des Films objektivieren?«, in: Sellmer, Jan/Wulff, Hans J. (Hg.), Film und Psychologie - nach der kognitiven Phase?, Marburg (Schüren) 2002, S. $123-142$. 


\section{I.2 Filmtheorie - zur filmischen Gestaltung als Wirkungsangebot}

\section{I.2.1 VeRnACHLÄSSIgUng DES Sich-EINLASSENS AUf DEN HOLOCAUST, MIMESIS-ORIENTIERUNG UND >EMOTIONALISIERUNG ALS »BLACK BOX« - ZUM STAND DER FORSCHUNG}

Filme über den Holocaust bewegen und erregen seit ihrem Erscheinen die Öffentlichkeit und führen zu unterschiedlichen Reaktionen und kontroversen Diskussionen. Dies belegen zahlreiche Rezensions-Sammlungen, insbesondere zur TV-Serie HoloCAUST (Chomsky, USA 1978) und dem Kinospielfilm Schindlers Liste (SCHindler's List, Spielberg, USA 1993). ${ }^{32}$ Abgesehen von wenigen Ausnahmen³, besteht die filmwissenschaftliche und publizistische Literatur zum Thema >Holocaust im Film Beiträgen zu einzelnen Filmen ohne übergreifende Fragestellung. ${ }^{34}$ Diese liegen häufig als Artikel in Sammelbänden und in der Presse bzw. als Einzelkapitel in Monographien vor, teils zum allgemeinen Verhältnis zwischen Holocaust und Kunst35, teils zu einzelnen Holocaustfilmen. ${ }^{36}$

Neben den angesprochenen Publikationen konzentriert sich die Forschung überwiegend auf die Beschreibung der dargestellten Welt (Mimesis), zum geringeren Teil auf die filmische Gestaltungsweise (Diskurs). Fundierte Filmanalysen ${ }^{37}$, Voraussetzung jeder seriösen wissenschaftlichen Auseinandersetzung mit dem flüchtigen Filmerleben (s. I.2.3), bilden jedoch eher die Ausnahme.

Die zentrale Frage, in welcher Form das jeweilige Werk eine Brücke zum Zuschauer zu schlagen versucht, um ihn zu einem Sich-Einlassen auf den Holocaust zu bewegen (s. I.2.2), wird oft vernachlässigt. Möglicherweise verbirgt sich dahinter die generelle Schwierigkeit, die jede wissenschaftliche Beschäftigung mit ästhetischen Werken mit sich bringt: Sie erfordert einerseits Nähe zum künstlerischen Gegenstand, den Willen zum Sich-Einlassen, andererseits Distanz als Voraussetzung für Analyse, Interpretation und Synthese. Der wichtige erste Schritt wird häufig nicht ausreichend beachtet; man scheint davon auszugehen, daß das Publikum automatisch von dem thematischen Hintergrund »abgeholt« wird. Aus diesem Grund wurde im Rahmen der vorliegenden Arbeit mit der Filmanalysesoftware »Akira« gearbeitet, die als Hilfsmittel, sowohl für die Intuition des Betrachters als auch für die systematische Analysetätigkeit, fungiert (s. I.2.3).

Lediglich als »black box« fungierende Ausdrücke wie »Emotionalisierung« bzw. »Erlebnispotential« oder auch »Identifikation« deuten auf die Existenz von Wirkungsangeboten hin. Selbst wenn - was eher selten der Fall ist - spezifische Zuschauerreaktionen angesprochen werden, handelt es sich meist:

- um auf Emotion reduzierte Reaktionen; anstatt die vielfältigen Wirkungsdimensionen zu untersuchen, die von der Aktivierung bis zur Verarbeitung im Gedächtnis eine Rolle spielen, beschränkt man sich vorwiegend auf augenfällige innere Bewegungen;

- um den - verglichen mit dem Anteil vorbewußter Wirkungspotentiale - geringen Anteil bewußter und somit verbalisierbarer Emotionen (s. I.2.2);

- um eindimensionale und statische Reaktionen; daß ein Film in seinem Verlauf und sogar zu einem bestimmten Zeitpunkt dem Zuschauer unterschiedliche semiotische Angebote zur Eigenleistung unterbreiten kann (s. I.2.2 zur Sympraxis 
nach Kloepfer und I.2.3 zur Simultaneität und Sukzessivität von Filmen), wird weitgehend übergangen;

- um die automatische Gleichsetzung von vermuteter Wirkungsabsicht (aufgrund spezifischer Gestaltung) und Zuschauerreaktion während der Projektion bzw. nach dem Film; $3^{8}$

- um vom Regisseur geäußerte Wirkungsabsichten, die keinesfalls deckungsgleich mit den tatsächlichen Wirkungsangeboten seines Werks sein müssen, was oft übersehen wird.

Der bei dieser Thematik entscheidende »Dialog« (s. I.2.2 zur Dialogizität) zwischen Werk und Adressat - Zentrum der vorliegenden Arbeit - bleibt mit den aufgezählten Vorgehensweisen bislang unterbewertet. Die vorliegende Arbeit versucht in ihrem Ansatz, diese Lücken zu schließen.

\section{I.2.2 Filmische Gestaltung ALS Wirkungsangebot im Prozess - ZUR METHODISCHEN TRADITION DER ARBEIT ${ }^{39}$}

Die Theorie zu den in I.1. vorgestellten zentralen Thesen meiner Arbeit gibt es ansatzweise seit längerer Zeit, sie ist jedoch nicht wissenschaftliches Gemeingut. Film-, Literatur- und allgemein Kunstwissenschaft sind selten ganzheitlich, d.h. auf den Einbezug der drei Vermögen des menschlichen Gemütes (Wille, Gefühl, Verstand) orientiert (Kloepfer 2002: 275). Zwar wird inzwischen - neben der traditionellen Ausrichtung auf Kognition - auch den Emotionen mehr Beachtung geschenkt, doch beschränkt man sich häufig auf die augenfälligen inneren Bewegungen wie Sympathie/ Antipathie, Freude/Schmerz, Spannung/Entspannung (s. I.2.1).

Im Falle des Holocaust bedingen sich das Maß an Hoffnung und das Maß an Verzweiflung gegenseitig. Die Dimension der »Volition« (Kloepfer 2001a: 48) - des Willens, »sich mehr oder weniger [...] einzulassen« (ebd. 49) bzw. neugierig, interessiert zu sein (Kloepfer 1990: 140) - wird jedoch fast völlig ausgeklammert. Dieser mit dem »motivierenden Wertesystem « zusammenhängende Willens-Bereich kommt häufig vorbewußt zum Tragen und entzieht sich daher der Kontrolle bzw. der einfachen Verbalisierung (Kloepfer 2001a: 54; s.u. sowie I.2.3 zum Vorbewußten). Gerade dieses Vermögen

38. Je künstlerisch anspruchsvoller das filmische Werk ist (s. II.2.2 zu Resnais' NACHT UND NebEL und II.2.2 zu Lanzmanns SHOAH), desto automatischer wird den künstlerischen Verfahren ein »Funktionieren« zugeschrieben - ehrfurchtsvolle Verneigung vor dem deutlich intellektuellen Anspruch des jeweiligen Filmemachers.

39. Die folgenden Ausführungen stützen sich insbesondere auf die zahlreichen Publikationen Kloepfers zum Spielfilm und anderen narrativen Künsten (s. Bibliographie).

40. Künste - insbesondere narrative - kompensieren die Trennung der Kommunikationspartner durch Integration von Kontextbedingungen - u.a. »Norm und Wert« bei Mukařovskýs - dergestalt, daß die wechselseitige Steuerung der Versetzung in Zeiträume, Beziehungssysteme (z.B. empathetisch) und Konstruktionsbedingungen teilweise die Referenzfunktion überformen (vgl. Souriau 1954 zum filmischen (Diskurs-)Universum und Möller 1987 zum »Kontexttheorem«).

41. Siehe den Exkurs zu Peirce' Konzept der Semiose und seiner Unterscheidung der drei Interpretanten-Typen im Anhang. 
des Menschen ist ausschlaggebend für seine Bereitschaft, sich mit Personen, Gegenständen und Sachverhalten - auch schwer zugänglichen - auseinanderzusetzen. Voraussetzung hierfür ist, daß dem Adressaten die Freiheit eingeräumt wird, das Maß des Sich-Einlassens selbst zu bestimmen, so daß er sich frei dem Kunstwerk öffnen kann.

Die vorliegende Arbeit steht in einer Forschungstradition, die den Zusammenhang zwischen ästhetischer Gestaltung und Wirkungspotential bzw. -angebot analysiert. Sie fokussiert den Rezeptionsprozeß und geht dabei von der Prämisse aus, daß die Werkstruktur eines Films dessen Wirkung zu lenken vermag. $4^{\circ}$ Die Formulierung Wirkungs>angebot< deutet darauf hin, daß es sich bei dieser methodischen Herangehensweise nicht um empirisch belegte Wirkungen handelt, sondern um ein Potential, das vom Adressaten angenommen werden kann. Vor dem Hintergrund der schwierigen Thematik des Holocaust beruht die Zielsetzung der vorliegenden Arbeit auf der pragmatisch-semiotischen Prämisse der ästhetischen Ausrichtung auf ganzheitliche Fragestellungen und dem Primat des Volitiven (s. I.1), der Motivation zum Sich-Einlassen auf ein Werk, hier einen Film. Das Maß an Wirksamkeit und an wirklicher Erfahrungsmöglichkeit über Kunst steigt, wenn »neben dem Verstand (Erkenntnisvermögen mit Antizipation und Erinnerung) auch das Gefühl (von Lust und Unlust, Zweifel und Beruhigung) und vor allem der Wille (Begehrungsvermögen: Neugier, Interesse, Lust auf Wissen) aktiviert werden« (Kloepfer 1990: 140).

Seit den 1980er Jahren widmet sich Kloepfer, alle narrativen Kunstformen umspannend, dieser Thematik unter dem Begriff Sympraxis, in Anlehnung an Kant und Novalis. Darunter versteht er »die ganze Breite dessen [...], was zeichengelenkte Gemütsregung im Sinne Kants sein kann« (Kloepfer 1990: 140), und zwar >während < des Verarbeitungsprozesses:

»Ein Text deutet an...wir denken aus; er behauptet...wir widersprechen; er bricht ab...wir führen fort; er nennt uns etwas unsagbar...wir versuchen, es zu erfassen; er suggeriert...wir formulieren aus; er verhält sich lügnerisch...wie weisen dies nach; er übertreibt...wir reduzieren etc. Wichtig ist, daß dieses unser Tun selbst vom Text wieder genutzt werden kann, ja daß dies textinterne Wechselspiel eines der Mittel ist, den Leser an direkten Formen des Dialogs zu beteiligen« (Kloepfer 1982: 375).

Sympraxis als zeichengelenktes inneres Verhalten (wie z.B. Fühlen), spezifisches Wollen (wie z.B. in der Antizipation) und vor allem Schließen (wozu vor allem Indizsysteme einladen; s.u.) beruht demnach auf der künstlichen Steigerung bzw. Nutzung dessen, was Charles Sanders Peirce - Begründer des Pragmatismus sowie der modernen Semiotik - im Zusammenhang mit seinem Konzept der Semiose, den »emotionalen«, »energetischen« und »logischen « Interpretanten genannt hat (1983: 282 u.ö.). ${ }^{41}$

Die Entwicklung von Sinn bei Peirce beruht auf einem immer wieder vollzogenen Semioseprozeß, mit dem die Zeichen der Welt in immer komplexeren Bedeutungen generiert werden. Der Pragmatismus legt dabei einen prinzipiell unendlichen Lernprozeß zu Grunde, in dem sich der handelnde Mensch immer wieder einen >Begriff< von der Welt macht und befähigt ist, progressiv zu immer größerer Erkenntnis voranzuschreiten.

Ähnlich wie Peirce zielt Kloepfer weniger darauf ab, die Zunahme immer komplexer werdender Bedeutungen zu analysieren, als vielmehr der vielschichtigen Wirkung von Zeichen auf den Adressaten nachzugehen. Neben Mimesis und Diskurs setzt er 
den Akzent vor allem auf die angesprochene Sympraxis, als durch Zeichen ermöglichtes Mithandeln. ${ }^{42}$ Hierdurch wird nicht nur ein Weltausschnitt modelliert und erfahrbar, sondern es wird das eigene Vermögen aufgeführt und entwickelt - Kognitionen im engeren Sinne, Emotionen und Volitionen (s.o.). Ganz nach aristotelischem Verständnis kann auf diese Weise Sinn und eine kathartische, heilende Wirkung entstehen.

Peirce aufgreifend, beschreibt Kloepfer die Entfaltung von Sinn als ein prozessuales, intersubjektives In-Spannung-Setzen von Bewußtsein und Welt - im besten Falle mit Hilfe der Kunst. Dabei sind das Zeichenangebot sowie das zeichengelenkte Mithandeln ästhetisch wirksam, indem sie ineinandergreifen und Wirklichkeitsausschnitte immer wieder neu modellieren. Dies setzt einerseits eine gewisse ästhetisch-poetische Qualität des Kunstwerks voraus, die das Potential des Adressaten zu stimulieren vermag, und andererseits die grundsätzliche Bereitschaft des Rezipienten, sich zunächst beeindrucken zu lassen, des weiteren in einem dynamischen Lernprozeß die mangelnde Sinnfülle des Wahrgenommenen zu empfinden sowie sinnstiftend mitzuhandeln. In einer prozeßhaften Wechselrede erfährt der Mensch die Welt, deren Teil er gleichzeitig ist. Das Potential eines Textes, im Leser sympraktisch einen Weltausschnitt aufzuführen und ihn zu einer Potenzierung seiner Vermögen anzuleiten, nennt der russische Formalist Michail M. Bachtin Dialogizität (Bachtin 1979: 168ff./232f./s.u.). Der bulgarische Sprach- und Literaturwissenschaftler Tzvetan Todorov formuliert in diesem Zusammenhang:

»Intentionellement ou non, chaque discours entre en dialogue avec les discours antérieurs tenus sur le même objet, ainsi qu'avec les discours à venir, dont il pressent et prévient les réactions. La voix individuelle ne peut se faire entendre qu'en s'intégrant au chœur complexe des autres voix déjà présentes.« (Todorov 1981: 8)

Unter Bezugnahme auf Bachtin, auf den Prager Strukturalisten Jan Mukařovský sowie auf den Philosophen Martin Buber arbeitet Kloepfer die Grundlagen des >dialogischen

42. Kloepfers Sympraxis-Modell definiert das Ästhetische als Energie, die im Spannungsverhältnis der drei Dimensionen dargestellter Welt (»Diegesis« in der frz. Tradition, »Mimesis« in anderen), Diskurs (stilistische Verfahren in der Schule von Wisconsin) und Sympraxis entsteht (1990: 144).

43. Siehe den entsprechenden »Exkurs zum Dialog zwischen Sender und Empfänger und der damit einhergehenden sympraktischen Dimension in künstlerischen Werken nach Kloepfer« im Anhang. Vgl. u.a. die zahlreichen Artikel im ersten Abschnitt der Bibliographie.

In Betonung des gleichzeitig gesellschaftlichen und subjektiven Charakters von Kunst bzw. Literatur entsprachen die Prager Strukturalisten den Forderungen Bachtins, der Textstruktur als die Aufführungsform von Dia- bzw. Polylogizität zu sehen lehrte (= Volosinov 1930=1975: 83-7; 175f.). Es liegt hier ein gemeinsames romantisches Erbe vor (s.u. zu Schleiermacher und der Relation von Hermeneutik und Semiotik), nicht ein direkter Einfluß.

44. Vgl. hierzu auch Sartres Aussagen zur Ko-Autorschaft des Lesers: »Es ist also nicht wahr, daß man für sich selbst schreibt. [...] Aber der Vorgang des Schreibens schließt den des Lesers ein als sein dialektisches Korrelat, und diese beiden zusammenhängenden Handlungen erfordern zwei verschiedene Handelnde. Die gemeinsame Anstrengung von Autor und Leser wird jenen konkreten und imaginären Gegenstand auftauchen lassen, der das Werk des Geistes ist. Kunst gibt es nur für und durch andere. [...] So appelliert der Schriftsteller an die Freiheit des Lesers, daß sie an der Produktion seines Werks mitarbeite.« (Sartre 1981: $39 \mathrm{ff}$ )

45. Vgl. Bühler 1927=1978: 42, 121, 130 zu Einstellung, vgl. Stichwort Kontakt. 
Prinzips < des »Dialogs zwischen Autor und Leser« zunächst für literarische (Kloepfer 1982: 358), später für filmische Texte heraus (Kloepfer).43

»Die angedeutete Auffassung vom dialogischen Prinzip beruht auf der Annahme, daß der dialogische Austausch mehr in dem >Wecken der Produktivität auf dem Hin und Her von Informationen. [...] daß gerade im Dialog >das Verstehen ganz auf der inneren Selbsttätigkeit beruht, und [daß] das Sprechen miteinander nur ein gegenseitiges Wecken des Vermögens des Hörenden< ist.« (Kloepfer nach Humboldt 1982: 368f., H.i.0.)

Die Möglichkeit der besonderen Nutzung der poetischen Funktion in der ästhetischen Kommunikation hat zur Folge, daß der Autor mehr der Inspirierende als der Inspirier-

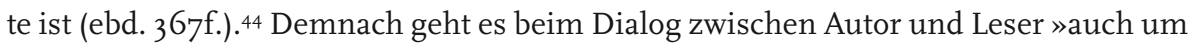
eine besondere Zeichensetzung, die mehr oder weniger die ganze Person der Beteiligten mit ihrer Geschichte aktiviert, also um eine besondere Form der >Aneignung «.« (Ebd. 366 H.i.O.) Die Wichtigkeit dieser Eigenleistung entspringt der Auffassung, daß »Kunstwerke Aufforderungen sind, zeichengesteuert mitzuhandeln, mitzufühlen, mitzuverwirklichen wie - pointiert formuliert - ein dressierter Affe oder souverän in der (Ko-)Autorschaft.« (Kloepfer 2000: 374)

Entscheidende Prämisse für den Glauben an die Semiosefähigkeit ist, daß Menschen erst einmal in der sozialen Gewohnheit (>Lebenswelt $<$ ) mehr Zeichen >sind $<$ als sie diese >haben< (Kloepfer 1975). Dies korrespondiert mit den Überlegungen von Anthropologen (Plessner 1982, Bateson s.u.) sowie dem amerikanischen Pragmatismus (Dewey, Mead), der in den wesentlichen Annahmen mit der östlichen Semiotik, insbesondere Eisenstein, übereinstimmt.

Unabdingbare Voraussetzung für das Gelingen des Dialogs zwischen Werk und Adressat ist dessen Bereitschaft, das Wirkungsangebot des künstlerischen Textes anzunehmen. Kloepfer umschreibt dieses Gewillt-Sein mit dem Begriff des Sich-Einlassens:

"Soll der Leser affiziert werden, muß er zeitweise ssein Ohr leihen<, d.h. Willen, Einbildungskraft und Konzentration anheimgeben und auf das Risiko des Mißbrauchs eingehen. Sich auf einen Text wirklich einzulassen, kann ein Wagnis sein. [...] Nur wenn die ganze Person involviert ist, kann es wirklich abenteuerlich werden.« (Kloepfer 1982: 377, H.i.0.)

Diesen Aspekt hatte, in den 193oer Jahren, bereits ein später, pragmatischer »Schüler« von Peirce hervorgehoben:

»Wer zu faul oder untätig oder wer zu sehr in Konventionen erstarrt ist, um diese Arbeit zu bewerkstelligen, der wird weder sehen noch hören. Seine sanerkennende Bewertung wird ein Gemisch sein aus Resten von Angelerntem, Konformität, von Normen konventioneller Bewunderung und konfuser, wenn auch echter emotionaler Erregung." (Dewey 1934=1980: 69, H.i.0.)

In der Tradition seit Hume heißt dies, den Kontakt - Jakobsons Grundfunktion (1979) - zuzulassen, mit Aufmerksamkeit auf den ästhetischen Gegenstand einzugehen und eine Einstellung zu entwickeln bzw. eine Haltung einzunehmen - eine Ausrichtung und Konzentration der eigenen Vermögen.45 
Wirkliche Wahrnehmung und somit Wirkung ästhetischer Filmkommunikation - so können wir u.a. mit Jakobson $(1933+1967=1988)$ zusammenfassen - beruht, neben dem beschriebenen Sich-Einlassen, zunächst auf der Erzeugung eines Bedürfnisses, welches mittels Inszenierung und Komposition befriedigt oder stimuliert werden kann. Die Verweigerung wiedererkennbarer Referenz - Differenzqualität, Leerstelle, Ambiguität - dient nicht dem Selbstzweck, sondern ist ein Angebot, den Kognitionsprozeß eigenständig wahrzunehmen und zu vollziehen. Diese Einschätzung zieht sich von den Russischen Formalisten bis zu den Prager Strukturalisten und zu allen Arbeiten, welche die Brücke von der Semiotik zu den Kognitionswissenschaften seit Jakobson zu schlagen suchen: Die ästhetischen Werkeigenschaften sind nicht als »Dekoration«, sondern als Steuerungsbedingung der gesamten Informationsverarbeitung anzusehen. ${ }^{46}$ Ästhetische Kommunikation, in diesem radikalen Sinn, definiert sich mit der systematisch erstellten Möglichkeit, etwas erneut als potentiell zeichenhaft wahrzunehmen - Dynamisierung des Bewußtseins mit dem Ziel neuer, tatsächlicher Wahrnehmung und Aufnahme. Insbesondere die Russischen Formalisten sahen darin Wesen und Chance von Kunst:

»Ziel der Kunst ist es danach, ein Empfinden des Gegenstandes zu vermitteln, als Sehen, und nicht als Wiedererkennen; das Verfahren der Kunst ist das Verfahren der >Verfremdung der Dinge und das Verfahren der erschwerten Form, ein Verfahren, das die Schwierigkeit und Länge der Wahrnehmung steigert, denn der Wahrnehmungsprozeß ist in der Kunst Selbstzweck und muß verlängert werden. [...] Dinge, die man mehrere Male wahrnimmt, beginnt man durch Wiedererkennen wahrzunehmen; der Gegenstand befindet sich vor uns, wir wissen davon, aber wir sehen ihn nicht. Deshalb können wir nichts über ihn sagen. - In der Kunst kann der Gegenstand durch verschiedene Mittel aus dem Automatismus der Wahrnehmung herausgelöst werden [...].« (Sklovskij 1969: 12ff., H.i.0.)

Im Sinne einer Öffnung des Adressaten für das künstlerische Angebot und gegen die Gefahr der Gewöhnung ist diese Forderung nach Deautomatisierung berechtigt.

46. Vgl. Lotman 1977, Bateson 1972=1981, Jakobson 1933, 1967 und 1973 in 1988, sowie 1981.

47. Subjektivität wird in dieser Tradition umfaßt von Intersubjektivität gesehen (und nicht als Gegensatz von »gesellschaftlich« oder »objektiv«).

48. Dies ist genau der Terminus - »afford«/»affordance«, leider nicht mit »Aufforderung«, sondern mit »Angebot« übersetzt - , den James Gibson in der Tradition der Gestaltpsychologie wählt (Koffka 1935: 7), um jene Verlockungen zu beschreiben, welche im Wahrnehmbaren gegeben sind (Höhlen zum Hineinkriechen, Berge zu Ersteigen, Duft zum Riechen, Briefkästen, um etwas Hineinzuwerfen etc.). Peirce spricht in ähnlichen Kontexten von »Trächtigkeit«: Gegenstände sind für Beobachtungen »fruchtbar«, weil sie den »schlußfolgernden Instinkt« anregen, sich immer weiter »ratend« zu entfalten (3: 489f.). Genau in diesem Sinne entwickelt Eisenstein aus einem zuerst »behavioristisch « erscheinenden Ansatz die »Attraktion« als Grundelement wirkungsorientierten Filmschaffens (Wuss 1993, Kloepfer 2000a und b).

49. Vgl. Kloepfer 1975 zu dem, was er das »autodidaktische Prinzip« von Kunst nannte, $1988,2000 \mathrm{~b}$.

50. Siehe unten zu Batesons Überlegungen zum Unbewußten im Unterschied zur verengten Vorstellung im Sinne Freuds. 
Grundlage für die umfassende Beteiligung sind zunächst der beschriebene Wille zum Sich-Einlassen (s.o.), sodann die Emotionen: man erschrickt, ist überrascht oder angeregt und entwickelt Aufmerksamkeit. Wenn man die Emotionen zuläßt, folgen dieser vorausgehenden Affizierung komplexe innere Handlungsmuster: man vermutet, erinnert sich an Vergangenes und schließt auf Künftiges, d.h. man versucht, das Wahrgenommene intuitiv zu strukturieren (s.u.). Die Wirkungen dieser Handlungen sind entweder bestätigend oder verändernd, d.h. sie modifizieren das Bewußtsein derart, daß entweder eine Einstellung beibehalten oder geändert wird. Spricht die zeichengelenkte Führung möglichst viele Sinne an und knüpft im günstigsten Fall an das Vorwissen des Zuschauers an, verstärkt sich ihre Wirkung. Es erfolgt eine Eigenleistung, in scheinbar größter Freiheit - aufgrund semiotischer Lenkung.

Kunst- und Filmtheorien, welche die Relation zwischen Werkgestaltung und Wirkungsangebot ins Zentrum stellen, gehen i.a.R. von folgender energetischer Prämisse aus: Das Werk ist eine Organisation - der Terminus wird von der Gestaltpsychologie und in den 1930er Jahren von so unterschiedlichen Denkern wie Dewey, Eisenstein und Merleau-Ponty gebraucht -, welche in sich Energie speichert, und zwar für die Subjektivität dessen, der sich darauf einläßt (s.o.). ${ }^{47}$ Das Werk entspricht damit der Semiosefähigkeit des Menschen (gemäß Peirce), welche als Prinzip der Selbstorganisation darauf angelegt ist, hervorgerufen zu werden..$^{8}$

Wahrnehmen als Informationsentnahme (Gibson) bzw. als unbewußtes Schließen (Peirce' Abduktionstheorie) wird bei Kunst-Werken vor allem durch eine Formung wirkungsvoll, welche den Aufforderungscharakter der Dinge, Geschehnisse, Personen etc. hebt bzw. potenziert (vgl. »photogénie« in der französischen Theorie). Daher beruht (Film-)Kunst wesentlich auf der Herstellung von Kontexten, die diesen »Hunger« erzeugen (Möller-Naß 1986).

Die angesprochene Tradition ästhetischer Theorie erklärt demnach, wozu die aufwendige Gestaltung des filmischen Diskurses jenseits tatsächlicher Wahrnehmung und Illusionsbildung dienen kann und soll: der Einbeziehung und Aktivierung der vielfältigen Vermögen des Adressaten. Diese ist dann besonders wirkungsvoll, wenn das eigene Lernen hierbei lustvoll ist (Souriau 1951 und 1954). Die Entdeckung des Erkennbaren beginnt bei der individuellen Entwicklung des Sinns für Wahrnehmbares - ein romantisches Theorem, das Nietzsche in viele Richtungen vertieft hat (Kloepfer 1979) und das als »Funktionslust« (Bühler 1929) bzw., spezifiziert, als »ästhetische Zeichenfunktion« im Prager Strukturalismus den angemessen zentralen Stellenwert bekommen hat. 49

Bereits den russischen und tschechischen Forschern in den 1930er Jahren war klar, daß Semiose zwar im Bewußtsein stattfindet, deshalb jedoch nicht unbedingt dem bewußten Zugriff zur Verfügung steht (Wygotski 1964: 304) ) $^{50}$ die Gestaltpsychologie nennt dies >Anmutungen $<$, die Semiotik im Sinne von Peirce >Abduktion $\prec$, die Prager Strukturalisten >semantische Geste< (Mukařovský 1943=1977: 49 u.ö.).

Abduktion als »Imagination der möglichen Gesetzmäßigkeit« und als »kreativer instinkt-geleiteter Prozeß « bezieht sich auch auf die Zeichenhaftigkeit von Welt, die - insbesondere durch Kontiguität und Ikonizität - sich selbst dem Ratenden verrät (Nöth 1999: 68f.). Künstlerische Werke, insbesondere der Film, nutzen diesen »Instinkt« systematisch. Entscheidend für alle relevanten Autoren dieser Zeit, allen voran 
Eisenstein, ist die pragmatische Evidenz, »daß vieles semiotisch funktioniert, auch wenn - und teilweise zuerst einmal weil ... - wir nicht wissen, was mit uns geschieht.« (Kloepfer 2001b: 5) Da diese Formen der Kommunikation mit den in einer Gesellschaft selbstverständlichsten Werten verbunden sind (ebd. 200), sind sie besonders wirkungsvoll und daher zentral für die Analyse (s. I.2.3).51

Der Diskurs der Erzählung und seine oftmals sehr vielschichtige Struktur in Literatur und Film erscheint im Lichte der Theoreme von Jakobson (1960=1979) als komplexe Form der Steuerung der semiotischen Vermögen, die sich primär der linken Gehirnhälfte und damit der leicht verbalisierbaren Kontrolle entziehen. Weil diese Eigenleistung jedoch nicht reflexiv-bewußt und unmittelbar zugänglich ist, nennt man sie $»$ Intuition $\ll .52$

Es geht gerade nicht - wie auch Freud annahm - um ein »Wortbewußtsein « (1985: 199), sondern um motivierte - d.h. indizielle und ikonische ${ }^{53}$ - Semiosen verschiedenster Art, die nur unter besonderen Bedingungen verbalisiert werden können. Dies betrifft unterschiedliche Bereiche, die man in Nachfolge von Baumgartners Ästhetik >sinnliches Denken < genannt hat. Sie finden nicht nur in und zwischen linker und rechter Hemisphä-

51. Dies ist eine These, die sich in der östlichen Semiotik von Bachtin und Eisenstein, Jakobson und Mukařovský bis zu Lotman und Ivanov zieht.

52. Intuition gründet auf einem wertenden Grundverhalten, das den Menschen zwischen Möglichkeiten auswählen läßt: »Das komplexe Wertungssystem des Menschen [...] ist [...] sschöpferischく: Es (er-)findet günstige Wahlmöglichkeiten, welche durch das Denken geprüft und verwirklicht werden können.« (Kloepfer 1999b: 7, H.i.0.)

53. Siehe den entsprechenden Exkurs zu Peirce im Anhang.

54. Siehe die Darstellung des gesicherten Forschungsstandes in Birbaumer/Schmidt 1996, Kapitel 22-27. Das Gedächtnis als eine erworbene Gewohnheit umfaßt mehrere Dimensionen: vom sensorischen Gedächtnis zum Kurzzeitgedächtnis oder vom prozeduralen zum deklarativen Langzeit-gedächtnis und alle in ihrer unterschiedlichen Ökonomie, verschiedenen Aufbauformen und Zugänglichkeit für bewußte Erinnerung.

55. Vgl. die einschlägigen Artikel in »medien-av« u.a. Filmzeitschriften sowie Bateson: Bewußtsein, »muß aus offensichtlichen mechanischen Gründen immer auf einen ziemlich kleinen Ausschnitt des geistigen Prozesses begrenzt sein« (1967=1983a: 192f.), denn kein Organismus könne es sich leisten, »sich der Dinge bewußt zu sein, mit denen er auf unbewußten Ebenen umgehen könnte« (ebd. 201).

56. Insofern erscheint es sinnvoll, auf solche Überlegungen von Filmpraktikern zurückzugreifen, auf Gedanken in der Traditionslinie von Gad (1919: 1920), Delluc (1920), Dulac (1927), Kuleschow (1929:1979), Eisenstein (1964-71), Pudowkin (1983) bis hin zu Hitchcock (1966:1986), Truffaut (1991) oder Tarkowskij (1989) (alle aufgearbeitet in Wuss 1990a).

57. Erinnert sei an die Traditionslinie, die mit Canudo (1911:1966) und dem jungen Lukács (1913), Lindsay (1915), Balázs (1924), Moussinac (1925) einsetzt und später von der russischen formalen Schule (in Beilenhoff 1974) - Sklovskij (1927), Eichenbaum (1927), Tynjanov (1927) -, von Richter (1929), Arnheim (1932), Benjamin (1936/1984), Spottiswoode (1935), Iros (1938), Bazin (1958-62) und Kracauer (1960) bis in die 1960er Jahre weitergeführt wurde.

58. Siehe die Vertiefung von Eisensteins Rhythmus- und Pathos-Theorie in II.4.1.2. sowie im entsprechenden Exkurs zum Phänomen des Rhythmus im Anhang.

59. Ihr Epizentrum dürfte vor allem im Umkreis des sog. Wisconsin-Projekts (vgl. Wulff 1991) liegen (getragen von Bordwell, Carroll, Thompson, Branigan, Plantinga), wichtige Versuche 
re geistiger Verarbeitung statt ${ }^{44}$, sondern darüber hinaus »frontal«, d.h. in der Region, wo Wertintuitionen gebildet, gespeichert und verändert werden (Damasio 1994).

»Nur ein Bruchteil dessen, was mental vor sich geht, ist wirklich klar und deutlich genug, um bemerkt zu werden, und doch ist es vorhanden, gar nicht so weit entfernt und vielleicht verfügbar, wenn Sie es versuchen.« (Damasio zit.n. Kloepfer 2001a: 53)

Die großen filmwissenschaftlichen Schulen - wie die von Wisconsin (um Bordwell) oder Paris (in der Nachfolge von Metz) - lassen jedoch an Wirkung tendenziell nur das gelten, was Zuschauer auch verbalisieren können. ${ }^{5}$

Frühe Ansätze zur Filmwirkungsforschung seitens der Praktiker, Kritiker und Filmtheoretiker erkannten die Dialektik von Gestaltung und Wirkung als zentral. Oft bruchstückhaft und verstreut, aber auch in einer großen inneren Kontinuität wie bei Eisenstein (s.u. sowie II.4.1.2), finden sich in den Aussagen der Filmemacher Angaben zu gesetzmäßigen Zusammenhängen zwischen gestalterischen Entscheidungen und psychologischen Wirkungen des Films beim Zuschauer, die für die Filmanalyse fruchtbar gemacht werden können. ${ }^{6}$

Ansätze der Filmtheorie im engeren Sinne haben noch manchen Beitrag für die heutige Theoriebildung anzubieten. ${ }^{77}$ Diese, von Peter Wuss (1990a) analysierten, Theorieansätze waren wegweisend für die Dramaturgie und Gestaltungslehre des Films, für die Morphologie, die Theorien der Kunstgattung Film, für Genres und Stile.

Filmpsychologische Ansätze im engen Sinne setzten bereits 1916 mit Münsterbergs »The Photoplay« (»Das Lichtspiel«, 1996) ein, wurden später von Malraux (1939), Merleau-Ponty (1945), den Mitstreitern der französischen Zeitschrift »Filmologie« - CohenSeat (1947), Wallon (1953), Michotte van den Berck (1948) und Souriau (1951,1954) - weitergeführt, bis sie im Werk von Mitry, »Esthétique et psychologie du cinéma (1963/65), ihren einstweiligen Höhepunkt erreichten, der zugleich einen Endpunkt tradierter psychologischer Methoden und Verfahrensweisen markierte (Lewis 1984; Wuss 1990a: 435-448).

Für die vergleichsweise junge Filmwissenschaft wurde die Frage nach der Relation von Werkorganisation und Wirkungspotential vielleicht am radikalsten von Eisenstein gestellt. Ganz im Sinne des Peirceanischen Semiose-Konzepts (s.o.), sieht er den Zeichenkörper als Mittel zur Bewegung des Zuschauer-Bewußtseins, zur Erzeugung von »Einwirkungen, Erregungen [und] Effekten« (Eisenstein 1988: 72ff.). Was die Komposition eines Kunstwerks betrifft, kann die Art und Weise der Gestaltung die Haltung zu dem Sachverhalt wiedergeben (Eisenstein 1960: 72). Dabei geht es Eisenstein nicht primär um die Haltung des Protagonisten zur Tatsache, sondern vielmehr um die Einstellung des Autors und dessen Wunsch, wie »der Zuschauer die dargestellte Tatsache aufnehme, empfinde und auf sie reagiere« (ebd.). Zentrales Verfahren für eine wirkungsvolle Komposition ist, so Eisenstein in Übereinstimmung mit Dewey, die Verwirklichung des rhythmischen Prinzips. ${ }^{8}$

Die heutige Wiederentdeckung der Zeichen- und der entsprechenden Sprach- und Literaturtheorien der 1930er Jahre, die zugleich auch Bewußtseinstheorien waren, beruht auf der pragmatischen Wende, die inzwischen zumindest Teile der Filmwissenschaft erreicht hat. Die Öffnung hin zu den Kognitionswissenschaften, die im Bereich der Filmwissenschaft die Cognitive Film Theory vollzogen hat ${ }^{59}$, kann an den 
Diskussionsstand dieser zitierten Forschungs- und Denkschulen anknüpfen, weil dort zentrale Theoreme formuliert wurden, welche inzwischen auch empirisch von Neurowissenschaftlern erprobt werden.

Der methodische Ausgangspunkt dieser eher filmästhetisch orientierten Kognitiven Filmtheorie besteht darin, daß sich die ästhetisch orientierte Untersuchung auf die Relation Werk-Rezipient stützt und diesen Zusammenhang über einen kognitiven Prozeß zu approximieren sucht. Das sehr weit gefaßte kognitive Geschehen wird dabei als Informationsverarbeitungsprozeß interpretiert, und die Bestrebungen gehen dahin, diesen Prozeß als phasische Erscheinung zu analysieren. Neben bewußten Rezeptionsbeziehungen können auch relativ unbewußte in die Analyse einbezogen werden. Immer deutlicher wird außerdem die Tendenz, eine Brücke zwischen Kognition und Emotion zu schlagen; auch bahnt sich ein Übergang zur Theorie der Vorstellungen und Phantasie an.

Zentrale Forschungsergebnisse im Bereich der Kognitiven Filmwissenschaft sind Peter Wuss zu verdanken, der in seinem Buch »Filmanalyse und Psychologie. Strukturen des Films im Wahrnehmungsprozeß « $\left(1993,{ }^{2} 1999\right)$ unter dem Einfluß von Eisenstein Filmkompositionen seit den 1980er Jahren auch als Rezeptionsvorgaben betrachtet. $^{6 \circ}$ Diese skizzieren, so Wuss, »in ihrem Strukturangebot bestimmte Erlebnisweisen, bestimmte filmische Wahrnehmungsprozesse beim Zuschauer vor « (Wuss 1990: 68). Der praktische Wert dieses sog. PKS-Modells besteht darin, daß neben den auffälligen und relativ bewußt rezipierten filmischen Strukturen, auf welche die Filmanalyse traditionellerweise rekurriert (wenn sie klassische Narration beschreibt), nun auch solche einbezogen werden, die sich bisher erfolgreich einem analytischen Zugriff entzogen hatten, weil sie relativ unbewußt rezipiert wurden (etwa im Rahmen offener Erzählformen). Letztere nennt Wuss im Unterschied zur bewußten Oberflächenstruktur Tiefenstruktur.

In welchem Maße Kloepfers Sympraxis-Modell komplementär zu Wuss' PKSModell ist, läßt sich dann erfassen, wenn man sich vor Augen führt: Das Organische in der Kunst bezeichnet das Wechselverhältnis von besonderer Organisation des Werkes und der organischen Entfaltung der Vermögen in der Subjektivität der Adressaten. ${ }^{6}$

finden sich aber auch an der Universität von Atlanta (J.D. \& Barbara Anderson), in England (Smith) und Kopenhagen (Grodal); in der BRD wurden sie durch einen informellen Zirkel um Wulff, Ohler, Nieding, Schumm und Wuss befördert, zu dem in neuester Zeit Kloepfer gestoßen ist.

60. Siehe auch den Exkurs zu den perzeptions-, konzept- und stereotypengeleiteten Filmstrukturen nach Wuss im Anhang.

61. Der Mensch ist leibhaftig organisierter Austausch mit Welt (vgl. Merleau-Ponty 1945=1966 bzw. in 1969 ganz spezifisch zum Film und seiner Art, besondere Angebote zu realisieren; vgl. Panofsky 1967 und den Überblick in Kloepfer 2000a). In diesem Zusammenhang hat Eisenstein bahnbrechende Theoreme vorgelegt, die er nach den jeweiligen Filmen formulierte (2: 150-196, vgl. Kloepfer 1985, 2000a, b, c, Ivanov 1985 zu Re- und Progression bei Eisenstein).

62. Die gewisse historische Unabhängigkeit ästhetischer Wirkungsangebote ermöglicht eine Beschäftigung mit der pragmatischen Dimension von Filmen, ohne auf die mit empirischer Filmwirkungsforschung zusammenhängenden Schwierigkeiten eingehen zu müssen (vgl. bspw. Suckfüll 1997). Zudem wird vermieden, Wirkung hauptsächlich über den Erfolg, etwa über die Laufzeiten eines Films im Kino, und/oder Auszeichnungen, darstellen zu wollen. 
Die vorliegende Arbeit fragt nach einer zentralen Komponente der Wirkung von Filmen: der Werkorganisation, und zwar in ihrer Relation zu nachweisbaren kurz- und mittelfristigen Effekten, wobei die komplexen sozio-historischen Bedingungen weitgehend ausgeklammert werden. Ausgangspunkt hierfür ist die Prämisse, daß dem Adressaten Wirkungsangebote unterbreitet werden, die - aufgrund der besonderen künstlerischen Formung - historisch bis zu einem gewissen Grad unabhängig sind, d.h.

»[...] daß die Um>wege<, die Verıfahren<, die >Figuren<, die >Anordnungen<, die >Kompositionen< - oder wie die Bewegungsmetaphern sonst noch heißen mögen - von Texten der einzige Weg sind, um dauerhaft und das heißt: unabhängig von der chronologischen Zeit ein Bewußtsein in einer bestimmten Fülle aufzuführen, zu entfalten, zu verwirklichen.« (Kloepfer 1999: 38, H.i.0.)

»Indem der ursprüngliche Autor - beispielsweise - nicht nur die Antwort des Adressaten auf seine Frage antizipiert, sondern im Text darauf seine möglichen Entgegnungen niederlegt für das ko-autorhafte Gegenüber, das sich seinerseits in den Autor versetzt, ist tatsächlicher Dialog über Raum und Zeit möglich. So sah Sokrates die einzig positive Möglichkeit dauerhafter Zeichen (Phaidros 276d sqq.).« (Kloepfer 1994: 269)

Auf mögliche Einwände gegenüber dieser Herangehensweise wird ebenfalls mit Kloepfer geantwortet:

»Ich werde nicht explizit auf Einwände eingehen, welche das >Fiktiveく des Films, die >Beliebigkeitı der Rezeption und die >Relativität meiner Wertungen des Kunstwerks betreffen, weil es keinerlei Argumentation gegen die These gibt, daß bei entsprechender Anstrengung mit einem Zeichen alles Mögliche - auch gegen alle Intentionalität, Struktur des Zeichens und Sicherung von Kodes - gemacht werden kann. Die These ist so schlicht wie richtig. Ganz im Gegenteil sei nachgewiesen, daß es gerade diese >Manipulierbarkeit ist, welche den Film und die Kunst auszeichnet. Sie können allerdings nur wirken, wenn sich der Adressat auf den besonderen kommunikativen Pakt einläßt, was sich auf ganz elementare Weise plausibel machen läßt.« (Kloepfer 1994: 49, H.i.0. $)^{62}$

Die Formulierung Wirkungs >angebot < deutet an, daß es sich bei dieser methodischen Herangehensweise an Filmwirkung um ein Potential handelt, das vom Adressaten angenommen werden $>$ kann $<$, nicht jedoch angenommen werden $>$ muß<. Entscheidend ist hierbei, ob sich der Zuschauer während des Betrachtens auf das Werk einlassen kann und ob der Künstler dies durch besondere Gestaltung ermöglicht, vielleicht sogar nahelegt (s.o.).

Ziel der vorliegenden Dissertation ist:

- die unterschiedlichen Wirkungsdimensionen zu erhellen, die von der Aktivierung bzw. der Erregung hin zu den Verarbeitungen im Gedächtnis eine Rolle spielen, d.h. Wirkung komplex zu betrachten - denn diese wird meist auf Emotion reduziert, wobei a) nur die gröbsten inneren Bewegungen mit ihrer vielfältigen Wirkung erfaßt werden und b) die komplexen, widersprüchlichen Zustände übergangen werden (s. I.2.1); 
- die Dialektik von relativ bewußtem und un- bzw. vorbewußtem Wissen anzugehen und gegenüberzustellen;

- die Zusammenhänge zwischen zeichenbedingter Kognition im engeren Sinne, Emotion und Volition herauszuarbeiten;

- den Prozeßcharakter der Verarbeitung filmischer Kommunikation insbesondere im Hinblick auf die immanent dialogische Anreicherung zu verdeutlichen;

- die unterschiedlichen Strategien offenzulegen, mit denen Künstler versuchen, den Adressaten für die schwer zugängliche und schwer vermittelbare Holocaust-Thematik zu gewinnen.

\section{I.2.3 AUfDECKUNG SIMULTANER UND SUKZESSIVER WIRKUNGSANGEBOTE DURCH COMPUTERGESTÜTZTE FILMANALYSE - ZUR METHODISCHEN VORGEHENSWEISE UND ZUM AUFBAU DER FILMKAPITEL}

»Da der Film [...] die Möglichkeit besitzt, alle anderen vorfilmischen Kunstformen direkt oder übersetzt aufzunehmen und im Licht- und Tonspiel des Kinoereignisses zu potenzieren, wird er zur mächtigsten Zeichenmöglichkeit seiner Zeit.« (Kloepfer 1994: 50 $)^{63}$ - auch zu einer der komplexesten ${ }^{64}$, gesteigert durch das Miteinander von Simultaneität (Raum- oder Körperkunst) und Sukzessivität (Zeit- und Dauerkunst).

Das daraus resultierende »Symphonische der Bewußtseinsmodifikationen« (Kloepfer 2001a: 53) auf Seiten des Adressaten faßt Antonio R. Damasio, einer der führenden neurologisch kognitionswissenschaftlichen Forscher, in ein musikalisches Bild:

»Man kann sich das, was ganz vage einmal als innere >Verhaltenspartitur< bezeichnet werden soll, wie die Aufführung eines Orchesterstücks vorstellen. Es gibt unterschiedliche Instrumente, die gleichzeitig und sich durchdringend Tönungen, Harmonien, Melodien etc. erzeugen und sich zu umfassenden Gestalten zusammenfügen. Das gilt in gleicher Weise für die umfassende >kognitive Partiturı.» (Damasio zit.n. Kloepfer 2001a: 53, H.i.0.)

63. Für den Film wurde komplementär zu seiner besonderen Unmittelbarkeit der »synkretische Charakter« von Erzähl- und Filmkunst betont: Die Aufnahme und Verarbeitung aller möglichen vorgegebenen Zeichensysteme und Künste (Mukařovský 1932 und 1938=1967: 34-54). Lotman bezeichnet dies als das »Aufsaugen« der verschiedensten Typen von Semiosen in einem einzigen System (1977: 145).

64. »Der Film macht Gebrauch von anderen Zeichensystemen (Sprache, Gesten, Architektur usw. mit ihren Semiotiken) und anderen Künsten, weshalb Literatur-, Theater- oder Kunstsemiotik zu integrieren wären.« (Kloepfer 1999: 2)

65. Ein Index (Anzeichen, Hinweis) verweist auf sein Objekt durch eine tatsächliche (räumliche, kausale u.a.) Verbindung. Von Ikon(izität) spricht Peirce, wenn ein Zeichen als Körper der Gestalt ähnlich ist, die unsere Wahrnehmungsgewohnheit dem Objekt zuschreibt. Symbole im semiotischen Sinne nach Peirce sind Zeichen, bei denen die Relationen zwischen Zeichenkörper und Objekt konventionell und willkürlich (geworden) sind. Siehe auch den Exkurs zu Peirce im Anhang.

66. Vgl. Lorenz 2003: 289 zu den »Reality-Bedürfnissen in der Medienwelt der Neunzigerjahre«. 
Hierbei ist zentral, daß die Bewußtseinsmodifikationen, Kognitionen im weiteren Sinn, sehr unterschiedliche Aspekte haben - »Wachsein, Vorstellungserzeugung, Aufmerksamkeit, Arbeitsgedächtnis, konventionelles Gedächtnis, Sprache, Intelligenz« (Damasio 1999: 151) - und bei aller heuristischen Trennung stets zusammenwirken.

Mit Lotman stellt sich die Frage, wie die »semiotische Komplexität des Kinematographen mit Zugänglichkeit und Verständlichkeit für ein breites, unterschiedliches Publikum vereinbar « ist (1973=1977: 145f.).

Panofskys »Prinzip des kombinierten Ausdrucks« aufgreifend (1934=1967: 347), erklärt Kloepfer die Parallelität von Film und primärer Kommunikation von Angesicht zu Angesicht an der Relation zwischen Zeichenkörper und Objekt, den drei Zeichentypen nach Peirce: »Der Film geht - wie wir es auch im Alltag tun - von komplexen Gestalten aus, die gleichzeitig indizieren, ikonisieren und konventionellsymbolisch funktionieren.« (Kloepfer 1999: 8) ${ }^{65}$ Aufgrund dieser synästhetischen Komposition und Wirkung kommt das Medium Film den alläglichen Wahrnehmungsgewohnheiten am nächsten und kann so vergleichsweise leicht - oft jedoch vorbewußt (s. I.2.2) - verstanden werden; Film ist gerade kein Reflexionsmedium. Nur so ist zu erklären:

- weshalb Monaco zur zunächst absurd anmutenden Schlußfolgerung kommt: »Der Film ist schwer zu erklären, weil er leicht zu verstehen ist « (Monaco 1995: 175);

- weshalb der Zuschauer gewisse bewußt so gestaltete Filme als besonders authentisch bzw. realistisch empfindet (s. II.3, insbesondere SchindLeRs Liste in II.3.2); 66

- weshalb Zuschauer unterschiedlichen Alters und unterschiedlicher kultureller Bildung bzw. Prägung gewisse Filme übereinstimmend schätzen können.

Entscheidend ist beim angesprochenen Übergang von gegenwärtiger zu audiovisueller Kommunikation, daß das, was in der kommunikativen Dyade funktional angelegt ist, durch die technischen Medien »erweitert, entfaltet, entwickelt und keineswegs reduziert oder gar vernichtet« wird (Kloepfer 1995: 9f.). Dies wird an Balázs' Beschreibung der filmischen Großaufnahme im Stummfilm, die - im Prinzip - jedoch auch für den Tonfilm gilt, besonders deutlich:

»Die Großaufnahme ist das eigenste Gebiet des Films [...] und die Kunst der Betonung. [...] So nahe muß uns ein Gesicht gerückt sein, so isoliert von aller Umgebung, welche uns ablenken könnte, so lange müssen wir bei seinem Anblick verweilen dürfen, um darin wirklich lesen zu können. Der Film fordert eine Feinheit und Sicherheit des Mienenspiels [...]. Denn in der Großaufnahme wird jedes Fältchen des Gesichtes zum entscheidenden Charakterzug, und jedes flüchtige Zucken eines Muskels hat ein frappantes Pathos, das große innere Ereignisse anzeigt. Die Großaufnahme eines Gesichtes [...] muß ein lyrischer Extrakt des ganzen Dramas sein.» (Balázs 1924=2001: 48ff.)

Die Darbietung von bewegten Bildern und das gleichzeitige Ansprechen der beiden dominanten Wahrnehmungssinne - Seh- und Hörsinn - binden den Zuschauer ganzheitlich für einen bestimmten Zeitraum in einen Wahrnehmungs- und Rezeptionsprozeß ein. Bereits Eisenstein wies in diesem Zusammenhang auf die verstärkte Nutzung der rechten - konkreten, analogen, intuitiven, synthetischen, in der ursprüng- 
lichen Bedeutung emotionalen - Gehirnhälfte des Adressaten hin. ${ }^{67}$ Da der Film dem grundlegend ganzheitlich orientierten Menschen auf diese Weise eine Alternative zur abendländischen analytischen Dominanz bieten könne, sagte er ihm eine große Zukunft voraus. Neben Eisenstein haben Münsterberg (1916), Canudo (1927), Dulac (1927), Arnheim (1932) und viele andere das Wirkpotential des Films mit der Tatsache verbunden, daß er erfahrbar macht, »was nicht in der Sprache - ja nicht einmal in der Literatur als Sprachkunst - artikulierbar ist« (Kloepfer 1999: 5).

Zentraler Grund für die >Attraktivität< des filmischen Mediums ist demnach die besondere, auf der potentiellen Integration aller Kunstformen basierende, »Sinnenfreudigkeit der >moving pictures<, deren Spezifikum u.a. ist, daß sie etwas vor den Sinnen und für sie bewegt« (Kloepfer 1999). Bereits von den Theoretikern des Stummfilms wurde der Film als Medium der sabsoluten Gegenwart< bezeichnet, in dem die sinnliche Präsenz der Filmbilder nur das Tempus des Präsens kennt, - und weder das distanzierende, erkennbar auktoriale epische Präteritum des Romans noch die Annalistik des Historikers:

»[Der Film als Medium] hat die fixierte Distanz des Zuschauers aufgehoben: jene Distanz, die bisher zum Wesen der sichtbaren Künste gehört hat. [...] Die Kamera nimmt mein Auge mit. Mitten ins Bild hinein. Ich sehe die Dinge aus dem Raum des Films. Ich bin umzingelt von den Gestalten des Films und verwickelt in seine Handlung, die ich von allen Seiten sehe. [...] Mein Blick und mit ihm mein Bewußtsein sidentifiziert sich mit den Personen des Films. Ich sehe das, was sie von ihrem Standpunkt aus sehen.» (Balázs 1924=2001: 15, H.i.0.)

Im Unterschied zu literarischen Texten, die Vorstellungsbilder evozieren, zeichnet sich der audiovisuelle Film durch Wahrnehmungsbilder aus, deren unmittelbare sinnliche Macht dominiert. In diesem Zusammenhang sei erneut auf die für den Film - im Unterschied zu den konventionellen Sprachzeichen (»Symbol« bei Peirce) der Literatur so wichtigen indiziellen und ikonischen Formen hingewiesen (Kloepfer 1999: 5f.). Auf der Basis von Peirce kann das Ikon mit Deleuze »als Möglichkeit des unmittelbaren Affektes« gesehen werden und das Indiz »als eine Spannung, die den Adressaten zur eigenen Tätigkeit verführt« (Kloepfer nach Deuleuze 1999: 5f.).

Darüber hinaus bietet der Film, gerade angesichts der belastenden Thematik des Holocaust, eine »leichtgängigere« Auseinandersetzung (Blothner 1999: 38). Im Unterschied zum Fernsehen erleichtern dem Zuschauer insbesondere das Dunkel des Kinos und die geringe Ablenkung vom Geschehen auf der Leinwand ein Eintauchen in den Film (vgl. die filmophane Dimension bei Souriau 1951/1997: 140ff.).

67. Die linke menschliche Gehirnhälfte hingegen ist dominant auditiv und die ihr zugeordnete Sprache abstrakt, digital, (reflexiv-)mental, analytisch, rational.

68. Siehe den Exkurs zum Rhythmus-Phänomen im Anhang.

69. Vgl. Hickethier 1996, Kloepfer 1999, Korte 1999, Kuchenbuch 1978, Wulff 1998.

70. Vgl. Faulstich/Poggel 1988, Giesenfeld/Sanke 1988 mit einer Übersicht der Anforderungen, Rambott/Sauter 1988 und Weisse 1998.

71. Diese Software wurde seither in vielen Diplom- bzw. Magisterarbeiten in Mannheim sowie im CIP-Pool zur Lehre eingesetzt, von vielen Einzelforschern (darunter Peter Wuss) sowie der Filmhochschule Babelsberg erworben. 
Aufgrund des angesprochenen symphonischen Charakters des Mediums Film intensiviert sich das Problem des Unbewußten (s. I.2.2) gegenüber vergleichbaren Formen ästhetischer Kommunikation, wie der literarischen. Die unbewußte Einprägung ins Gedächtnis - ohne die Hebung ins Explizite - kann jedoch besonders effizient sein und wird von Filmregisseuren gezielt angelegt. Für die sich mit »Zeit-Künsten« befassenden Wissenschaften ist daher besonders interessant, was u.a. Schacter das >implizite Gedächtnis< genannt hat, d.h. der »Umstand, daß Menschen von einem vergangenen Erlebnis beeinflußt werden, ohne sich im mindesten bewußt zu sein, daß sie sich erinnern.« (Schacter zit.n. Kloepfer 2001a: 51) Dieses Rhythmus-Phänomen wurde insbesondere in den $1930 e r$ Jahren als zentrales Problem diskutiert ${ }^{68}$, während es heute eher in den Hintergrund getreten ist. Rhythmen wurden von Eisenstein und Dewey nicht als Wiederholung verstanden, sondern als Variation von Semioseprozessen dergestalt, »daß wir zwischen den einzelnen Ergebnissen durch Schließen der Spannungsbögen zu jeweils ganz eigenen, privaten, subjektiven und doch - in der Gemeinschaft der Rezipienten - zu intersubjektiv geteilten oder zumindest teilbaren Vorstellungen kommen.«(Kloepfer 2001a: 60)

Die Komplexität des Mediums Film sowie seine teilweise vorbewußte Wirkung erfordern daher eine detaillierte Analyse - aufzufassen als »Ausdruck einer Kompetenz und selbst [als] eine Kunst, sich auf das Exemplarische, das Besondere einzulassen, den Strategien nachzuspüren«(Wulff 1998: 19, H.i.O.). Filmanalyse in diesem Sinne dient der Fixierung des flüchtigen Filmerlebnisses und ist daher Voraussetzung für jede wissenschaftliche Beschäftigung mit Film. Ihr Hauptanliegen ist die Veranschaulichung des Filmerlebens mit dem Ziel, dieses intersubjektiv nachprüfbar zu machen. ${ }^{69}$

Die Zugänglichkeit und wiederholte »Lesbarkeit« von Filmen war jedoch lange Zeit eine zentrale Schwierigkeit der Filmwissenschaft. Nachdem mit der Entwicklung der Video-Rekorder das »minutiöse Eingehen auf filmische Eindrücke und eine bessere Aufmerksamkeitskontrolle« möglich geworden war (Kanzog 1991: 15f.), erweiterte computerunterstützte Filmanalyse diese Möglichkeiten in den 1980 or Jahren. ${ }^{70}$

Durch die Entwicklung von Technologien zur Digitalisierung von Filmen in den 1990er Jahren wurde die Erfassung von Simultaneität und Sukzessivität in ersten Schritten konkretisierbar. Eisensteins Forderung nach gleichzeitiger Abspielmöglichkeit, buchähnlicher Verfügbarkeit des Werks und partiturähnlicher, paralleler Darstellung von Film wurde in Mannheim in den 1990er Jahren erprobt (»FilmAss«) und seit 1998 mit »Akira - Arbeitsplatz kinematographischer Rundumanalyse - verwirklicht (Kloepfer/Goetze 1998). ${ }^{71}$

Entsprechend bietet »Akira« die Möglichkeit, jene gleichzeitig bzw. im Nacheinander wirkenden Zeichenprozesse sichtbar zu machen, die man als Ursache für eine vermutete oder gegebene Wirkung annimmt (s.o.). Zunächst ist dieses Computerprogramm demnach ein Instrument, um - gemäß der Intuition als »Nachschöpfung « (Kloepfer 1992: 476; s. I.2.2) - Stellen im Film für eine spätere Analyse zu markieren. Diese ersten, vagen Eindrücke dienen als Ausgangspunkt für eine vertiefte empirische Erfassung, indem aus ihnen Untersuchungskriterien für die Analyse abgeleitet werden 
(s. die Eintragungen im Fenster links unten in folgender Abbildung). Mit »Akira« können auf diese Weise - ähnlich wie in der Musik - Filmpartituren individuell erstellt werden, welche dem für den jeweiligen Film charakteristischen Miteinander von Simultaneität und Sukzessivität gerecht werden. Sowohl für einen bestimmten Zeitpunkt als auch für den gesamten Filmverlauf können Auftreten und Anordnung der Untersuchungselemente nachvollzogen werden (s. das größere Fenster im unteren Bildbereich mit den unterschiedlichen Eintragungen). Zentral ist hierbei, daß durch die Gesamtschau der einzelnen Komponenten systematisch die Kompositionsstrukturen (»Cluster«, Bordwell 1997) hinsichtlich der Zuschauerreaktionen sichtbar gemacht und auf diese Weise verfolgt werden kann, wie sich der »ästhetische Gegenstand [...] in fortschreitender Erfahrung abspielt« (Dewey 1980: 210), zentrales Charakteristikum bei dominant räumlichen wie zeitlichen Kunstwerken.

Dabei reiht sich die vorliegende Arbeit in ein filmanalytisches Forschungsumfeld ein, das die Offenheit des Verfahrens je nach Erkenntnisinteresse fordert und der naiven Vorstellung einer Totalanalyse entgegensteht (Kloepfer 1999, Marie/Aumont 1988, Wulff 1998).

Insgesamt konzentriert sich die Analyse der in der vorliegenden Arbeit ausgewählten Filme auf die Wirkungsangebote, welche von einzelnen Stellen ausgehen, in denen sich typische Bündelungen nachweisen lassen, weil es Wendepunkte in der dargestellten Welt, der diskursiven Gestaltung und der Beteiligung des Adressaten sind - kurz: Schlüsselszenen.

»Apparatehandlungen und Inszenierung werden [...] vor allem an den Knotenpunkten des Werkes verdichtet. Narrativisch sind dies Stellen, wo sich verschiedene Handlungsstränge vereinen und sich zu einem (Problem- oder Konflikt-)>Knoten< zusammenziehen. Diese Stellen werden mit allen filmsemiotischen Mitteln aber auch deshalb besonders gestaltet, weil mit ihnen der Zuschauer gleichsam das für die gesamte Rezeptionszeit wichtige Verhalten beigebracht bekommt. Wir nennen das >Rezeptionsprägung<, denn der Zuschauer wird alle nachfolgenden Szenen - bis auf Widerruf oder Neuprägung - unter dieser Prämisse wahrnehmen, antizipieren, sich darauf einlassen etc. Wenn man dies mit der Novellentradition Wendepunkte nennt, dann betrifft das nicht nur den >Plot in der Mimesis, sondern auch die Beteiligungsgeschichte in der Sympraxis. [...] Wendepunkte sind sympraktisch Stellen, wo das Schwanken der Bewertung komprimiert wird.« (Kloepfer 1995: 82, H.i.0.)

Bereits Eisenstein hatte auf den repräsentativen Charakter von Sequenzen hingewiesen, vorausgesetzt, daß das »Baugesetz eines jeden Kompositionselementes mit dem Baugesetz des grundlegenden Bestimmungsfaktors, des Inhalts « korrespondiert (1984: 220). Dabei ging es ihm, wie später Kloepfer, insbesondere um die Tatsache, daß »die Organik des Films, die in einer Zelle innerhalb des Films geboren wird, [sich] nicht nur durch den Film als Ganzes [verbreitet], sondern gleichsam jenseits seiner physikalischen Grenzen [erscheint] - im Publikum.« (1960: 86) An diesen >Eckpunkten< der Textverarbeitung - Bordwell bezeichnet diese sog. plot points als »portions most salient in comprehension « (1989: 189) - sind sowohl die Strategien der gezielten Informationsvergabe und damit die Zuschauerlenkung durch den Text als auch die Informationsverarbeitungsprozesse des Zuschauers der Beschreibung besonders gut zugänglich (Hartmann 1995: 103). 


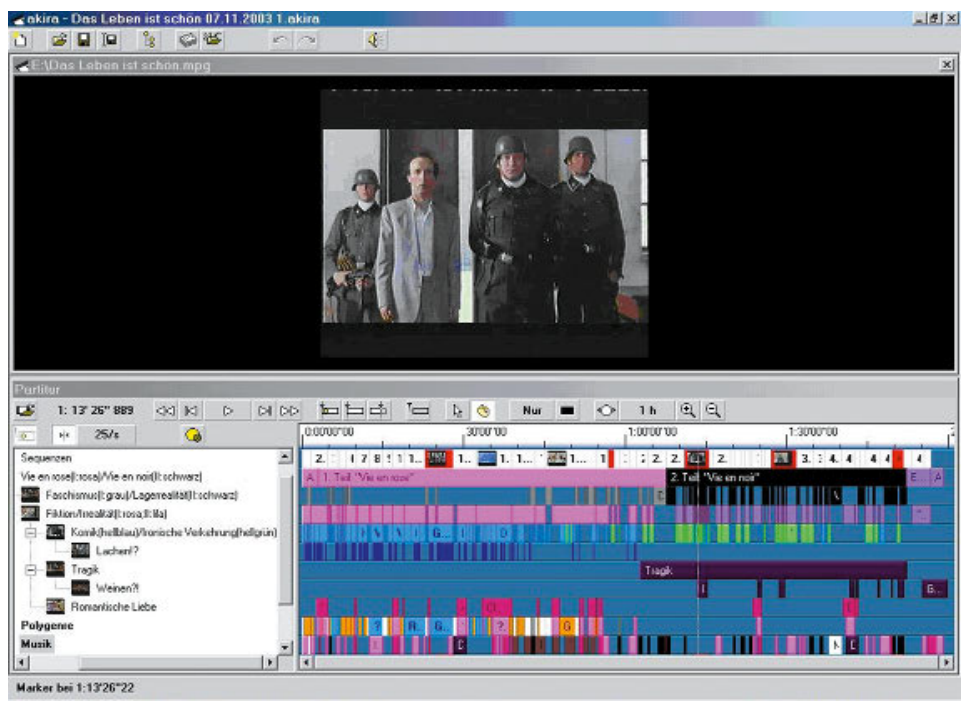

Abb. I.2.3.a

»Die Steuerung der interpretierenden, schemabildenden und -aktivierenden und Erwartungen produzierenden Tätigkeit des Rezipienten erfolgt an kaum einer Stelle des Textes so deutlich nachvollziehbar wie am Textanfang.«(Wulff 1990: 1030) Aufgrund dieser »Priming«-Funktion des Textanfangs wird die Exposition in der vorliegenden Arbeit stets detailliert analysiert (Bordwell 1985: 36, Hartmann 1995: 104ff./111ff.). Mit Kloepfer sei in diesem Zusammenhang darauf hingewiesen, daß die Exposition nicht nur der Orientierung für die Mimesis dient, »sondern ebenso wichtig für die Einübung in die Bedingungen des Diskurses « ist (Kloepfer 1995: 33). Insbesondere, wenn ein Filmanfang »auf neue Weise spricht«, gibt er die »neue >Grammatik < zum Lernen vor« (Kloepfer 1995: 33, H.i.O.), d.h. er liefert die Bedingungen seiner angemessenen Verarbeitung mit:

»Dies geschieht durch seine Selbstzuordnung zu einem Genre oder Subgenre, sei es durch paratextuelle Mittel vom Plakat bis zu den Dossiers, die bei seinem Marketing verteilt werden, sei es durch das, was man früher simmanente Poetikı genannt hat und was Genette den Architext nennt. [...] Bei signifikanter Abweichung von solchen durch filmische Sozialisation gelernten Gestalten gibt der Film normalerweise ähnlich wie moderne Literatur an hervorragenden Stellen rautodidaktisch< eine Einführung in das spezifische System und leitet durch einen Strang kontinuierlicher Zeichen zum Lernen an. In der Regel werden die drei Orientierungsweisen additiv, teilweise gleichzeitig, gemischt und je nach Stelle des Films unterschiedliche hierarchisch gebraucht.« (Kloepfer 2002: 280, H.i.0.)

Angesichts der Holocaust-Thematik ist es für Filme mit diesem Hintergrund besonders wichtig, den Zuschauer in den ersten Minuten zu »gewinnen«. Die Analyse der Exposition vermittelt einen ersten Eindruck, wie der jeweilige Regisseur das Publikum zu dem zentralen Sich-Einlassen auf den Holocaust zu bewegen versucht (s. I.2.2).

Abschließend sei der Aufbau der - den Hauptteil der Arbeit bildenden - fünf Filmkapitel erläutert: 
(1) Die Einleitung jedes Filmkapitels i.w.S. besteht aus einer Darstellung der Gemeinsamkeiten und Unterschiede der zu einer Gruppe zusammengefaßten Filme (s. II.1, II.2, II.3, II.4).

(2) Die Einleitung jedes Filmkapitels i.e.S. (s. II.1.1, II.2.1, II.2.2, II.3.1, II.3.2, II.4.1, II.4.2, II.5) besteht aus zwei Unterkapiteln: (a) einer kurzen Analyse des Titels, da dieser - vergleichbar mit der Exposition, gleichwohl in komprimierter Form - die Haltung des Zuschauers beeinflußt, sowie einleitender Bemerkungen, Informationen und Hinweise zur aufgearbeiteten Literatur des jeweiligen Filmkapitels; (b) der Präsentation meiner übergreifenden Leitthesen in bezug auf das jeweilige Werk - synthetisiertes Ergebnis der umfangreichen Analyse.

(3) Der Hauptteil jedes Filmkapitels i.e.S. besteht aus unterschiedlich vielen DetailAnalysen repräsentativer Schlüsselsequenzen bzw. -szenen, je nachdem, ob sich ein Film durch wenige repräsentative Sequenzen/Szenen fassen läßt (s. II.2.1, II.2.2, II.3.2, II.4.2) oder eher eine Entwicklung im zeitlichen Verlauf aufgezeigt werden muß (s. II.3.1, II.4.1). Generell wird hierbei (a) einleitend die besondere Bedeutung des jeweiligen Wendepunktes interpretierend zusammengefaßt sowie auf Gemeinsamkeiten und Differenzen im bezug auf andere Filme hingewiesen, bevor (b) die Sequenz/Szene mikrostrukturell analysiert wird ${ }^{72}$, d.h. im Detail das den Zuschauer lenkende, simultane und sukzessive Zusammenspiel filmischer Verfahren aufgedeckt wird. Die Einbindung zentraler Standbilder dient der Veranschaulichung des verbal Analysierten.

(4) Ein Sequenzprotokoll des jeweiligen Films findet sich im Anhang der Arbeit.

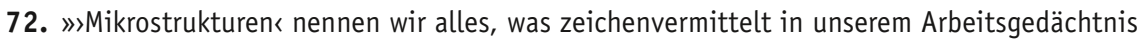
bis zu 3 Minuten oder etwas länger simultan verarbeitet wird.« (Kloepfer 2005 nach Birbaumer/ Schmidt 1999: 110, H.i.0.)

1. Anonymer »Times«-Reporter zit.n. Brink 1998: 52. 


\section{Typen von Holocaust-Filmen}

\section{II.1 Umerziehung durch Greuelfilme mit Schockästhetik?}

Die ersten Monate der Besatzung Deutschlands durch die Alliierten standen im Zeichen der Direktive 1067 der Vereinigten Stabschefs, des Potsdamer Abkommens und der Nürnberger Prozesse, welche die Entnazifizierung, Entmilitarisierung und Entindustrialisierung Deutschlands vorsahen (Nagl 1999: II). Der Begriff der >Re-education<, der sich insbesondere aus dem Ziel der Entnazifizierung ableitete, war in den Jahren 1945/46 untrennbar mit der in der Sprache des Siegers formulierten Kollektivschuld-These verbunden (ebd.). Umerziehung hieß für die alliierten Militärs vor allem, die deutsche Bevölkerung mit den Bildern aus den befreiten Lagern zu konfrontieren und sie so von ihrer Schuld am Aufstieg des Nationalsozialismus und am Holocaust zu überzeugen (ebd.). Durch eine gezielte »pédagogie par l'horreur« (Chéroux 2001: 13) sollten den Deutschen die Nazi-Greuel schonungslos vor Augen geführt werden zur Strafe und vor allem zur Läuterung bzw. Abkehr vom Nationalsozialismus:

»Wer es mit dem deutschen Volk gut meint [...] der muß dafür sorgen, daß jedem Deutschen (auch der Jugend) diese von Gewalthabern ohne menschliches Fundament, von Verächtern aller Menschenwürde verübten Grausamkeiten in Herz und Hirn gehämmert werden. [...] Aus tiefster Scham muß die Läuterung wachsen [...] Das ganze deutsche Volk wird dafür leiden müssen. ${ }^{1}$

»Die Deutschen sollten - so Dagmar Barnouw - verwundet werden svon den Wunden, die sie zugefügt hatten. Die Strafe, die solche Reue und Gewissensbisse bewirken könnte, mußte selbst überwältigend physisch sein^.» (Kramer 2003: 233/Barnouw zit. nach ebd.)

Die Motive für diese »Politik des >viewing the atrocities«« waren vielschichtig (Kramer 2003: 229, H.i.O.): Nicht nur die deutsche Bevölkerung sollte mit den in ihrem Namen verübten Grausamkeiten konfrontiert und zur geläuterten Abkehr vom Nationalsozialismus gebracht werden, sondern »auch die Weltöffentlichkeit sollte das Unglaubliche sehen.« (N.N. 1997: 61) Es sollte zudem vermieden werden, daß die Nazis in der Nachkriegszeit das Ausmaß des Verbrechens negierten (ebd.). Darüber hinaus dienten die Schockbilder auch der Rechtfertigung des Krieges gegen Deutschland (Chéroux 2001: 122).

Im Unterschied zu schriftlichen Dokumenten galten Aufnahmen als »unmittelbares Abbild der vorgefundenen Wirklichkeit« (Brink 1998: 90), was sich im Titel der er- 
sten bewegten Bilder von den befreiten Lagern, Atrocities, the evidence, besonders deutlich zeigt. Bei diesem rund 6-minütigen Film handelt es sich um einen Wochenschaubeitrag, der ab dem 30. April 1945 in England ausgestrahlt wurde. In der »Sittengeschichte des Zweiten Weltkriegs« (Gaspar Andreas) beispielsweise ist über die Vernichtung der Juden in Polen zu lesen: »Die Tatsachenberichte klingen zwar unglaublich, doch die von der Kamera festgehaltenen Bilder bezeugen die traurige Wahrheit.« (Zit.n. Reifahrth/Schmidt-Linsenhoff 1995: 476) In Fachkreisen herrscht heute die übereinstimmende Meinung, daß diese dem Foto unterstellte Beweiskraft trügerisch ist; für den Laien verleiht der Abbildcharakter dem Medium Foto im Vergleich zu Texten immer noch einen höheren Grad an Überzeugungskraft und Beweisstärke, selbst wenn die amtliche Korrespondenz der Todesfabriken bzw. die Protokolle von Geständnissen und Zeugenaussagen oft mehr und Detaillierteres aussagen (ebd.). ${ }^{2}$

In Zusammenhang mit der Authentizitätsunterstellung darf jedoch nicht übersehen werden, daß die Bilder die Lager »im letzten Stadium zeigen« (Arendt zit.n. Welzer 1995: 181). Somit dokumentieren sie die Folgen der Vernichtung (Leichenberge, Massengräber und befreite Überlebende) und geben über die alltäglichen Verhältnisse an diesen Orten nur bedingt Aufschluß (Hüppauf 1995: 504).

Problematisch ist darüber hinaus, daß die Bildpolitik der Alliierten eindeutig auf das »photo-choc « (Chéroux 2001: 15) setzte und das Bild als Dokument in den Hintergrund rückte (s. I.1). Auf diese Weise verkamen die dekontextualisierten Bilder zu »symboles de l'horreur absolue« (ebd.) mit extrem anklagendem Charakter, der durch schriftliche bzw. vorgetragene Kommentare noch hervorgehoben wurde.

Diese Bildpolitik wurde von Augenzeugen der Lager gegensätzlich beurteilt. Während ihr der Buchenwald-Überlebende Jorge Semprún »eine Dimension maßloser, erschütternder Realität [zuschreibt], an die meine Erinnerungen nicht heranreichen« (1995: 238), schreibt Mavis Tate in einem Leserbrief an die britische Zeitschrift »Picture Post«, die Bildberichte von der Befreiung veröffentlicht hatte:

»So entsetzlich Ihre Fotografien aus den Konzentrationslagern auch sind, so sind sie doch unendlich weniger schrecklich als die Realität, die wir sahen. [...] Sie können uns beim Wort nehmen, daß selbst Ihre Fotos das ganze Ausmaß des Entsetzlichen nicht würdigen und ausdrücken, weil man nur die Folgen des Leidens fotografieren kann, aber niemals das Leiden selbst.« (Zit.n. Brink 1998: 31)

Im Rahmen dieser Bildpolitik setzten die Alliierten neben Fotos in Zeitungen, Broschüren und auf Plakaten insbesondere auf das Medium Film. ${ }^{3}$ Durch diese sog.

2. Für den Betrachter von heute wird die der Fotografie unterstellte Authentizität durch das historische Schwarzweiß der Aufnahmen noch verstärkt (Kramer 2003: 228). Dies ist gut zu beobachten, wenn man heute Resnais' Kompilation NACHT UND NEBEL ansieht und mit dem wiederholten Wechsel von Farbe und Schwarzweiß konfrontiert ist (s. II.2.1).

3. Zu den Plakaten vgl. insbesondere Brink 1998, Kapitel 1.

4. Gemäß meiner Grundüberzeugung, daß ein gewisses Maß an Diskretion unerläßlich ist, wurde die Größe der Abbildungen deutlich verringert.

5. Vgl. Roß, Heiner in seinem Kurzbeitrag auf: www.femmetotale.de/fv03/meinensie.html (10.03. 2006). 


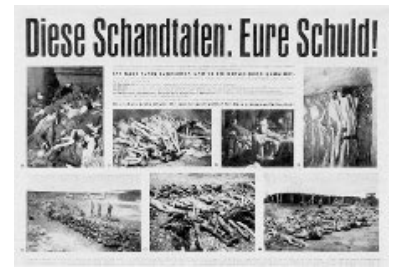

15. A in: Brink 1998: $75^{4}$

Greuelfilme wurden erstmals zahllose Menschen in Deutschland mit den Aufnahmen von den Nazi-Verbrechen konfrontiert (Braese 2003: 72; Hahn 1997: 100). Zu diesem Zweck scheuten die Alliierten keinerlei Aufwand: »Welch hohen Stellenwert die amerikanischen Offiziellen dieser politischen Bildungsarbeit beimaßen, läßt sich daraus ablesen, daß die Behörden über 1700 Projektoren nach Deutschland brachten, um die Filme zeigen zu können.« (Blechschmidt 2002: 23) Von April bis Juni 1945 erfuhr so die große Mehrheit der Deutschen von den in den Konzentrations- und Vernichtungslagern begangenen Verbrechen, denn Deutschland war mit Photographien von Leichen »überschwemmt« (Morin zit.n. Brink 1998: 46).

Wenn die deutsche Bevölkerung nicht einmal den Plakaten besondere Aufmerksamkeit schenkte - die heimkehrenden deutschen Soldaten bemerkten, »daß kaum jemand an diesen Plakaten stehen blieb, und wenn es dennoch einer tat, dann geschah es mit einem raschen Seitenblick « (Brink 1998: 84) -, wie konnten die Alliierten dann erwarten, daß sie Filme mit unzähligen Schockbildern ansehen und annehmen würde? Schließlich konfrontieren die bewegten Bilder der befreiten Lager den Zuschauer mit einer ungleich größeren Anzahl an Schockbildern, als es auf den UmerziehungsPlakaten der Fall war. Die politische Devise lautete: Das Bild des Unmenschlichen sollte die Deutschen aufrütteln, ihnen die Augen öffnen.

Wenn jedoch selbst die alliierten Soldaten den Anblick der Lager kaum ertrugen (Brink 1998: 27ff.), wie konnte man dann von den Tätern und von der deutschen Zivilbevölkerung, die Bombenangriffe, Zerstörung, Vertreibung, den Verlust Angehöriger erlitten hatte, erwarten, daß sie die Bilder der Vernichtung aufnehmen, geschweige denn verarbeiten würden?

Den angesprochenen und besonders prägnant in Plakatunterschriften - »Diese Schandtaten: Eure Schuld« (Brink 1998: 73) - verwirklichten Aspekt der Anklage und des Vorwurfs der Kollektivschuld wurde bereits fünf Jahre nach Kriegsende von Hannah Arendt als der »gravierendste Irrtum der amerikanischen Entnazifizierungspolitik« bezeichnet (zit.n. N.N. 1997: 61). Schon 1942 hatte ein in »Sight and Sound « erschienener Artikel »Re-educate Germany by film « auf die vielfältigen Gefahren der Schockpolitik hingewiesen. ${ }^{5}$ Als einen zweiten Aspekt machte der Autor deutlich, daß die Kriegsschuldfrage nicht anklagend zu behandeln sei. Als weiteren Punkt führte er an, daß es für die Umerziehungsfilme ganz zentral sei, den Deutschen eine positive Perspektive zu bieten, denn sonst hätte die Filmpolitik keinen Sinn. Weder das eine noch das andere wurde im Rahmen der Entnazifizierung umgesetzt - ganz zu schweigen von der angesprochenen bildpolitischen Schockstrategie. 
Neben dem anklagenden Charakter weist Günther Anders im Zusammenhang mit den Entnazifizierungs-Dokumentarfilmen auf eine weitere zentrale Schwierigkeit hin und reagierte damit auf Hanuš Burgers Die Todesmühlen (s. II.1.1): »Diese Bilder konnten [...] in einem genauen Sinne nicht wahrgenommen werden, weil sie >zu viele Leichen zeigten und das Grauen vor dem Tode, auch vor dem Morde, mit der zunehmenden Zahl der abgebildeten Leichname abnimmt; und deshalb nicht, weil man auf den Bildern immer nur die Ergebnisse der Verbrechen, also die Leichenberge, gezeigt hatte [...] immer nur anonyme Tote, nicht Tote, die man als Lebende gekannt oder denen man gar nahegestanden hätte.« (Zit.n. Welzer 1995: 182f.) ${ }^{6}$

\section{II.1.1 »IMAGES BLESSURES «7 - SCHOCKBILDER: »Die TOdeSMÜHLEN« (»DEATH MillS«, HANUŠ BURGER, USA 1945)}

\subsubsection{Die gescheiterte Schock-Politik der Alliierten}

Der Titel von Hanuš Burgers knapp 23-minütiger Dokumentation aus dem Jahre 1945 ist Programm: Im amerikanischen Original lautet er Mills of DeAth, in der deutschen und jiddischen Version entsprechend Dif Todesmühlen bzw. Di Toit Milen. Als zentraler Film des Re-education-Programms in der amerikanischen Besatzungszone macht bereits der Titel keinen Hehl aus der beabsichtigten Wirkung des Films.

6. Vgl. Marcel Ophüls gleichgerichtete Äußerung in III.

7. Lowy 2001: 143.

8. Vgl. Blechschmidt 2002: 23 in II.1.

9. In der Mitte des Films spricht der Off-Kommentator im Zusammenhang mit den Todesstatistiken von »Totenfabriken« $(0: 11: 25 \mathrm{~h})$.

10. Damit folgt er dem von Schreitmüller analysierten »Prinzip Assoziation« bei der Wahl eines Filmtitels (1994: 99f.), das sich durch besonderen Einbezug des Zuschauers auszeichnet: »Dieses Verfahren hat den Vorteil, daß eine semantische Spannung zwischen reigentlicher< und >übertragener< Be-deutung aufgebaut wird.« (Schreitmüller 1994: 100) Dies bedeutet, daß mit der Präsentation eines bestimmten Begriffs unter Umständen beim Rezipienten ein ganzes >Wortfeld aktiviertı wird.« (Ebd. 99, H.i.0.)

11. Der von Eisenhower in Auftrag gegebene und insbesondere hinsichtlich des Bildmaterials sehr vergleichbare Dokumentarfilm GERMANY AWAKE!/DEUTSCHLAND ERWACHE! (D/USA 1945) war dagegen ein Film von Militärs für Militärs, denn er richtete sich primär an deutsche Kriegsgefangene. Ab 1946 wurde er in den USA nicht mehr gezeigt, da sich dort keine deutschen Kriegsgefangenen mehr aufhielten (Roß 2004). Im Unterschied zu DiE TOdESMüHLEN fällt bei DeUtSCHLAND ERWACHE! das Alternieren zwischen der Motivation zum Neuaufbau und der anklagenden Entrüstung auf.

12. »Burger, 1909 in Prag geboren, in Deutschland aufgewachsen, arbeitete als Dramaturg und Regisseur. 1938 produzierte er den Film CRISIs über den Angriff Deutschlands auf die tschechische Republik.« (Blechschmidt 2002: 23)

13. Atrocities, the eVIDENCE (GB 1945) und »K.Z.«, die 5. Ausgabe der Wochenschaubeitragsserie WeLt IM FILM vom 15.06.1945, sind die ersten bewegten Bilder der Lagergreuel, die die Öffentlichkeit im Rahmen von Wochenschauen erreichten. 
Als der Film in die Kinos kam und mit großem Aufwand ${ }^{8}$ auch auf andere Art und Weise in »Gefangenenlagern, Schulen, Konzerthallen und Scheunen « vorgeführt wurde (Kilb 1995: 153), kannten die Deutschen zwar noch nicht den heute geläufigen Ausdruck >Todesfabriken als Synonym vor allem für die nationalsozialistischen Vernichtungslager ${ }^{9}$, machten sich jedoch, nicht zuletzt aufgrund des Titels, auf das Schlimmste gefaßt. >Todes-Mühlen<, >Mühlen des Todes<, allein der Titel vermittelt ein Gefühl der ununterbrochenen, unentrinnbaren Folter - schließlich verbindet man mit Mühlen eine nur äußerst schwer zu unterbrechende, unaufhaltsame Stetigkeit. ${ }^{10}$ Damit bezieht der Titel sich, wie sich bereits in der Exposition, aber auch im weiteren Filmverlauf herausstellen wird, auf die nationalsozialistischen Konzentrations- und Vernichtungslager.

Die Todesmühlen ist nicht nur der erste, für die deutsche Zivilbevölkerung produzierte, Dokumentarfilm", er gilt auch als der zentrale Beitrag des »Office of Military Government for Germany United States« (OMGUS) im Rahmen des amerikanischen Umerziehungs-Programms (Hahn 1997: 99): »Seine Bedeutung bezieht TodESM Ü HLEN vor allem durch die Tatsache, daß der Film [...] ein wichtiges, an Indizienmaterial reiches Zeugnis der schrecklichen Verbrechen der Konzentrations- und Vernichtungslager an eine breite Öffentlichkeit gebracht hat und damit seither jede Behauptung, die in den Lagern begangenen Greueltaten seien erfunden, eindeutig widerlegt.« (Ebd. 112)

Daß dieser Film als Beweis für die Naziverbrechen verstanden werden sollte, zeigt sich besonders deutlich an der Texteinblendung zu Beginn und am Ende des Films. Der Filmvorführschein im Vorspann besagt: »Es wird hiermit bescheinigt, daß TODESMÜHLEN zur öffentlichen Vorführung zugelassen ist. Bescheinigung ausgestellt im Auftrag der alliierten Behörden.« Auch im Nachspann soll der Zuschauer daran erinnert werden, daß es sich um Bilder von offizieller Seite handelt: »Wir zeigten einen Film über die Konzentrationslager, die einen Bestandteil des Nazi-Regimes seit seinem Anfang im Jahre 1933 bildeten. Alle Aufnahmen in diesem Film wurden zur Zeit der Befreiung von beglaubigten Kameraleuten der alliierten Armeen gemacht.«

Neben der zentralen Stellung im Umerziehungsprogramm stellt Dif TodesmüH LEN ein »Paradigma der unterschiedlichen politischen Interessen im Rahmen der Re-education in den Westzonen dar« (Blechschmidt 2002: 23), denn die im Sommer 1945 mit der Produktion des Aufklärungsfilms über die nationalsozialistischen Todesfabriken beauftragten Regisseure Billy Wilder und Hanuš Burger ${ }^{12}$ hatten unterschiedliche konzeptionelle Vorstellungen. Wilder war der Ansicht, daß nur ein knapp gehaltener Kompilationsfilm, auf dem Filmmaterial des Wochenschaubeitrags »K.Z. «basierend ${ }^{13}$, produziert werden sollte: »einmal wegen des Zeitdrucks, doch insbesondere wegen der Befürchtung, daß eine ausführliche Dokumentation der Greuel und eine allzu aufdringlich formulierte Anklage der Kollektivschuld beim deutschen Zuschauer Abwehrreaktionen hervorrufen würden [...]« (Hahn 1997: 101). Burger hingegen wollte die dokumentarischen Teile des Films in eine fiktionale Rahmenhandlung einbetten, um so die politischen Hintergründe der Ereignisse in Deutschland zwischen 1933 und 1945 kritisch zu beleuchten (Blechschmidt 2002: 23).

Burger konnte jedoch seinen Ansatz nicht durchsetzen und so wurde der Film unter Wilders Verantwortung im November 1945 fertiggestellt, ohne Einbezug der politischen Hintergründe der Vernichtungslager. Die Endversion von Dí Todesm ÜHLEN basiert auf Burgers Skriptvorlage ohne Rahmenhandlung, auf Bildern aus dem 
Wochenschaubeitrag »K.Z.« und auf den Filmaufnahmen, die ein Team des amerikanischen Signal Corps (im September 1945) in verschiedenen Lagern gedreht hatte (Hahn 1997: 102). ${ }^{14}$

Noch während des Schnitts von Die Todesmühlen begann selbst Billy Wilder daran zu zweifeln, daß Dokumentarfilme geeignet seien, die Deutschen umzuerziehen: »Werden die Deutschen [...] Woche für Woche ins Kino kommen, um den schuldbewußten Schüler zu spielen? Wir werden sie wahrscheinlich apathisch durch diese Dokumentarfilme und erzieherischen Wochenschauen dösen sehen.« (Wilder zit.n. Gallwitz 2002: 23)

Damit sollte er Recht behalten: Die deutsche Bevölkerung reagierte mehrheitlich ablehnend auf Die Todesmühlen und auf die Bildpolitik der Alliierten allgemein. Diese Ablehnung reichte vom Wegsehen bzw. Sich-Abwenden über Mißtrauen bezüglich der Authentizität der Aufnahmen bis hin zu einer generellen Abwehrhaltung oder gar eines Abstreitens der Greuel.

- Das Wegsehen bzw. Sich-Abwenden war eines der häufigsten Reaktionsmuster auf die gezielte »Schock-Politik« der Besatzungsmächte (Kogon zit.n. Brink 1998: 9815: »Sie [die heimkehrenden deutschen Soldaten] bemerkten, daß kaum jemand an diesen Plakaten stehen blieb, und wenn es dennoch einer tat, dann geschah es mit einem raschen Seitenblick [...].« (Kogon zit.n. Brink 1998: 84) Auch den alliierten Soldaten bzw. Fotografen fiel das ablehnende Verhalten der deutschen Zivilbevölkerung auf (Brink 1998). ${ }^{16}$ Häufig ging es ihnen selbst nicht anders: »Geschorene Köpfe und eingefallene Wangen [...] es ist kaum möglich, sie als Menschen anzusehen. Unter solchen Umständen versuchte man zu vermeiden, sie zu viel zu sehen. Es ist zu schwer.« (King zit.n. Brink 2003: 52) (17 $^{17}$

- Von »Staunen oder ungläubigem Kopfschütteln« (Kogon zit.n. Brink 1998: 84) und »Mißtrauen « (Darmstädter 1995: 119) den Aufnahmen gegenüber war es nicht weit zu einer Abwehrhaltung oder gar dem Abstreiten der Greuel. Zahlreiche Berichte belegen die ablehnenden Reaktionen auf die in Dif TodesmüHLen gezeigten Schrecken: »Dies sei doch nur Propaganda der Amerikaner und stimme alles nicht.« [...] Man wollte es nicht glauben, wollte es nicht wahrhaben [...].« (Hickethier 2003: 117) Erich Kästner, damals Feuilletonchef der »Neuen Zeitung«, fielen unter den Besuchern von Die TodesmüHlen neben den betreten Schweigenden vor allem jene auf, die aus dem Kino kamen und »Propaganda « murmelten. Hierbei ging es wohl »weniger um ein Nichtwissenwollen als um ein Nichtertragenkönnen dessen, was man - wie ungenau auch immer - oft längst gewußt oder doch vermutet hatte.« (N.N. 1997: 61) Die

14. Ein Großteil des Filmmaterials ist darüber hinaus identisch mit dem des Films NAZI Concentration Camps (George Stevens, USA 1945), die Aufnahmen zu Majdanek stammen beinahe ausnahmslos aus MaJdanek/CMEnTARzYSKo EURopy (Aleksander Ford, POL 1944) und die Aufnahmen zu Auschwitz aus Auschwitz/OswiEcim (1945 SU). (www.cine-holocaust.de)

15. Siehe in 1.1.3 die Standbilder aus Die TODESMÜHLEN von den Weimarer Bürgern, die nur zum Teil die aufgebahrten Leichen betrachten.

16. »Ich fotografierte es. [...] Aber sie wollen es nicht glauben. Sie schließen ihre Augen.» (Futtermann zit.n. Brink 1998: 29)

17. Vgl. auch Semprún 1995: 19.

18. N.N. zit.n. ebd. 
abwehrende Haltung gegenüber den Fotografien und Plakaten führt Brink schlüssig auf deren Appellcharakter zurück: »Nicht die >faktische< Argumentation, sondern der spezifische Appell, der darin [in den Fotos] lag und sich an sie richtete, wurde ihnen zum Problem, das abgewehrt werden mußte. Die Fotografien legen die Nerven bloß. Wie auf einen >Reiz<, der einen der >Nervenpunkte der Schuld $<$ traf, reagierten die Deutschen auf die Bilder.« (Brink 1998: 94, H.i.O.) Die ablehnende Haltung vieler Deutscher bedeutete sicherlich »nicht nur, daß man sich reinwaschen will, sondern ebenso auch, daß man, was begangen ward, eben doch unrecht fand, und darum ablehnt. Wäre das nicht der Fall, so bedürfte es nicht des Eifers der Distanzierung. $\ll^{18}$

- Neben Ablehnung gehört das Schockiert-Sein zu den häufigsten, belegten sowie beabsichtigten Reaktionen auf die »Schockästhetik« der Alliierten und damit auch auf Die TodesmüHlen (Kramer 2003: 233, Hahn 1997: 110f.). Nach Überzeugung der amerikanischen Umerziehungspolitiker sollte »die volle Aufdeckung der im deutschen Namen verübten Verbrechen im deutschen Volk einen tiefen Schock hinterlassen und daher eine viel grundlegendere Wirkung haben [...] als alle Umerziehungsmaßnahmen [...]« (Morgan zit.n. Hahn 1997: 103). Den alliierten Soldaten war es bei der Befreiung der Lager kaum anders ergangen: »Meine erste Reaktion war, daß ich es nicht glauben konnte. Eine Schockwelle durchlief jeden und die, die es zuerst traf, gaben es weiter an die Nachfolgenden. In der Art, >Ihr werdet es nicht glauben, was ihr sehen werdet.« (Malachowsky zit.n. Brink 1998: 27)»Je n'ai jamais, de ma vie, éprouvé un choc aussi profond«, äußerte General Eisenhower bei seiner Besichtigung des befreiten Lagers Ohrdruf in Thüringen (zit.n. Chéroux 2001: 10). Kästner, der einen Artikel über Die TodesmüHlen schreiben sollte, beschreibt seinen Zustand nach dem Filmbesuch: »Ich bringe es nicht fertig, über diesen unausdenkbaren, infernalischen Wahnsinn einen zusammenhängenden Artikel zu schreiben. Die Gedanken fließen, so oft sie sich der Erinnerung an die Filmbilder nähern.« (Kästner zit.n. Kramer 2003: 228)

- Mit der Schockwirkung gehen ebenso zahlreich belegte Reaktionen wie Fassungslosigkeit, Entsetzen, Unerträglichkeit, Widerwille und gar Abscheu einher (Brink 2003: 51 und Mitscherlich 2001: 49). Bereits die amerikanischen Frontsoldaten reagierten in dieser Weise auf den Anblick der Lager: »Wir konnten nicht verstehen, was wir im Lager sahen. Auch nach einigen Monaten im Kampf konnten wir den grausigen Anblick und den Gestank der Leichen nicht ertragen.« (Wright zit.n. ebd. 51f.; Brink 1998: 68) Als amerikanischen Streitkräften das Dachauer Krematorium gezeigt wurde, »kämpften viele von ihnen mit Brechreiz oder waren einer Ohnmacht nahe«, so der Journalist Hugh Carleton Greene (zit.n. Brink 1998: 51). Daß die alliierten Soldaten mit den Überlebenden, einer »seltsamen, affenartigen Schar« (Sington zit.n. ebd. 28), kaum Mitleid verspüren konnten, führt Kramer auf deren Entstellt-Sein, deren »Häßlichkeit« zurück: »Häßlichkeit mobilisiert bis heute Widerwillen. [...] Wie kann es zur Identifikation der Betrachter mit einem häßlichen Opfer kommen, so daß sie mitleidend auf seine Seite treten?« (Kramer 2003: 232f.)

- Von den beschriebenen Reaktionen auf die »pédagogie par l'horreur« (Bonhomme/ Chéroux 2001: 9) ist es nicht weit zur Erstarrung (s. 1.1.3), zu Distanzierung, Abstumpfung, sogar Unberührtheit. In einem ihrer Romane beschreibt Graziella Hlawaty die Beobachtungen der Hauptfigur bei der Vorführung von Die Todes- 
MÜHLEN: »Sie blickte zu den anderen Zuschauern in ihrer Bankreihe, um deren Reaktion zu beobachten. Es kam ihr vor, als stemmten sich alle Kinobesucher von der Filmleinwand weg, als wären sämtliche Menschen im Saal plötzlich erstarrt, als wären sie leblos und zu Stein geworden.« (Zit.n. Paech/Paech 2000: 167ff.) Auch die alliierten Soldaten erlebten, »wie ihre Gefühle nach Stunden oder Tagen erstarrten, oder wie sie sich vom Anblick der Toten und auch von Überlebenden innerlich zu distanzieren begannen.« (Brink 2003: 52) Der Anblick entstellter Leichenmassen bzw. gezeichneter Überlebender, menschlicher Skelette, »schloß Mitleid und ähnliche Empfindungen keineswegs aus, bot aber wenig Anlaß, sich den Opfern als Subjekten weiter zu nähern.« (Knoch 2003: 111) Bartov formuliert in diesem Zusammenhang pointiert: »[...] quasi-human creatures [...] do not arouse empathy.« (Bartov 1997: 53)

Wo der Besuch von Dif TodesmüH Len freiwillig war, stieß der Film auf geringes Interesse bei der deutschen Zivilbevölkerung (Hahn 1997: 110):

»So sehr man jeder statistischen Rezeptionsforschung mißtrauen mag, ist die Wirkung der TODESMÜHLEN relativ gut belegt. Film Control Officer Peter Van Eyck schrieb im März 1946: >0bgleich die TodesmüHLEN langsam mahlen, bekommen sie doch keine Kundschaft.ı Die deutsche Bevölkerung blieb dem Film in Scharen fern, um, in der Sprache der Psychologen, wohl semotivkognitive Dissonanzen« zu vermeiden [...].« (Eyck zit.n. Nagl 1999: II, H.i.0.)

Obwohl sich die amerikanische Militärregierung nach intensiven Diskussionen für den Filmbesuch auf freiwilliger Basis entschieden hatte, machten manche Militäroffiziere aufgrund der lokalen Autonomie der Informationskontrollbüros den Erhalt von Nahrungsmitteln auf Lebensmittelkarte vom Besuch des Films abhängig (Hahn 1997: 110). In manchen Kinos Bayerns wurde das Publikum mit der unangekündigten Vorführung von Die Todesmühlen erwiesenermaßen überrascht (ebd.). In Berlin

19. Vgl. auch Culbert zit.n. Chéroux 2001: 124.

20. Vgl. ebd. zu weiteren Motivationen für die Abmilderungen: »[...] außerdem wollten sowohl die Alliierten wie die Sowjets die Besiegten als Bundesgenossen in dem bald nach der Befreiung einsetzenden kalten Krieg gewinnen und meinten, man dürfe dem deutschen Publikum nicht zuviel zumuten.« (Ebd. 93)

21. Im Unterschied zu den weiteren genannten Umerziehungsfilmen war die Resonanz auf LES CAMPS DE LA MORT gering, hat die französische Produktion »kein auch noch so behördlich protegiertes Eigenleben in Kinosälen und später durch televisuelle Ausstrahlung entfaltet.« (Feindt 2005: 97) Dieser >moyen métrage` mit einer Länge von 19 Minuten, der nur sporadisch in der immer noch wenig erschlossenen Literatur zur französischen Besatzungspolitik auftaucht, wurde bereits am 18. Mai 1945 in Auftrag gegeben und wahrscheinlich schon vor September 1945, vor Beginn des Belsen-Prozesses fertig gestellt. Er besteht aus dem Material, das Kameraleute der englischen und französischen Alliierten von der Befreiung verschiedener Konzentrationslager gedreht hatten (Bernstorff 2002: 16). Im Unterschied zu anderen Entnazifizierungsfilmen zeichnet sich LES CAMPS DE LA MORT dadurch aus, daß er auf den suggestiven Gestus begleitender Musik verzichtet und über weite Strecken kommentarlos bleibt (Feindt 205: 101). Daß »von nackten Leichen [...] kaum Bilder zu sehen « seien (Bernstorff 2002: 16), kann jedoch nicht bestätigt werden - die visuelle Schockwirkung dieser französischen Produktion ist kaum geringer als in DIE TODESMüHLEN. 
sollte der Filmbesuch Voraussetzung für die Zuteilung von Lebensmittelkarten sein; aufgrund des geringen Interesses der Berliner war dies jedoch nicht durchführbar (Wagner 1999: BS6).

Insgesamt war diese Bildpolitik der Besatzungsmächte im Rahmen des Re-education-Programms kontraproduktiv, »die Bilder, die das Gewissen der Deutschen mobilisieren sollten, bewirkten das Gegenteil« (Brink 2003: 65). ${ }^{19}$ »Die >Schock $<$ Politik hat nicht die Kräfte des deutschen Gewissens geweckt, sondern die Kräfte der Abwehr gegen die Beschuldigung, für die nationalsozialistischen Schandtaten in Bausch und Bogen mitverantwortlich zu sein. Das Ergebnis ist ein Fiasko.« (Kogon zit.n. Brink 1998: 98, H.i.O.) Auch an den damaligen empirischen Begleituntersuchungen zu DiE TODESMÜHLEN läßt sich die kontraproduktive Wirkung ablesen:

"Sein eigentliches Ziel hat der Film allerdings verfehlt. Kaum ein Betrachter fühlte sich an den dargestellten Verbrechen persönlich in irgendeiner Form mitschuldig oder auch nur mitverantwortlich, wie Brewster Chamberlin in seiner Auswertung der Rezeptionsanalysen von 0MGUS ermittelt hat: $>83 \%$ derjenigen, die sich für nicht verantwortlich erklärten, begründeten ihre Antwort mit der Behauptung, von Greueltaten nichts gewußt, diese Dinge nicht gewollt und nicht nationalsozialistisch gewählt zu haben (oder Gegner des Regimes gewesen zu sein) [...].« (Chamberlin zit.n. Hahn 1997: 111)

Als Grund für das Desinteresse an Die Todesmü hlen gab eine beachtliche Zahl von Befragten in Bayern an: »Too gruesome, have seen enough horrors [...].« (Zit.n. ebd. 110)

$\mathrm{Ob}$ »die aufgezwungenen Umerziehungsbemühungen den Wunsch nach Verdrängung der Verbrechen in Deutschland nicht ungewollt befördert « haben (Blechschmidt 2002: 23)? Silbermann/Stoffers sprechen daher von »psychischen und sozialen Schutzmechanismen«, die durch die Brutalität und Unmenschlichkeit der Naziverbrechen ausgelöst werden können (2000: 84):

»Der [...] individuelle Schutzmechanismus ist die Ohnmacht. [...] Die Überflutung der individuellen Wahrnehmung mit brutalen Details aus den Randzonen menschlicher Existenz, wie sie uns in Bildern und verbalen Schilderungen der Quälereien und Tötungen in den Konzentrationslagern entgegentreten, kann dazu führen, daß man Informationen trotz körperlicher Anwesenheit im kognitiven Wachzustand nicht mehr an sich heranläßt. [...] Weder böswillige Negation noch Ignoranz sind die Motive ihres Verhaltens, sondern die Unerträglichkeit dessen, was ihnen andere oder sie sich selbst zumuten wollen.« (Ebd. 85)

Die kontraproduktive Wirkung des »viewing the atrocities« (Kramer 2003: 229, H.i.O.) ist auch an den von den Alliierten gezogenen Konsequenzen zu erkennen: Die grauenvollsten Bilder wurden sehr bald aus diesen Filmen herausgeschnitten (Leiser 1996: 93). ${ }^{20} 1946$ wurden anklagende Filme wie Die Todesmühlen und Germany Awake! aus dem Programm genommen (Bühler 1999: 23): Aus re-edukationspolitischer Sicht waren Die TodesmüHlen also insgesamt ein »Fehlschlag« (Hahn 1997: 112).

Wie Germany Awake! (D/USA 1945), Memory of the Camps (GB 1945) sowie der im Rahmen der »actualités françaises « produzierte französische Dokumentarfilm LES CAMPS De la mort (F 1945) $)^{21}$, setzt Die TodesmüHlen in besonderem Maße auf die 
Wirkung schockierender, unerträglich grauenhafter Aufnahmen - Bilder »ohne jedes Hoffnungsmotiv« (Wrocklage zit.n. Kramer 2003: 247). »Das Schockierende an den Bildern von den Opfern liegt in ästhetischer Hinsicht darin, daß - gegen die herrschenden Dezenzregeln - das Grauen nicht bloß angedeutet, sondern drastisch und direkt ins Bild gesetzt wird.«(Kramer 233f.): Die Toten sind hier häufig in einer Weise zu sehen, wie sie in abendländischen Gesellschaften nicht präsentiert werden durften: Sie sind vielfach nackt, ihre Augen sind zum Teil geöffnet, ihre Genitalien deutlich erkennbar, die Verrenkungen ihrer Körper sind teilweise erheblich, zum Teil sind Spuren der Gewalt deutlich sichtbar, selbst verkohlte und halb verweste Körper werden dem Betrachter zugemutet, Bestattungsrituale werden mit Füßen getreten (Massengräber, Bulldozer etc.) (ebd. 23off.; s. 1.1.2). Neben dieser Zurichtung der Menschen durch die Nazis schockiert den Betrachter auch »die Übertretung des Schicklichen durch den fotografischen Blick« (ebd. 233). Hinzu kommt, daß die grauenhaftesten Bilder der nackten Toten dem Zuschauer regelmäßig als Nah- bzw. Großaufnahmen buchstäblich vor Augen geführt werden (Hahn 1997: 102f.). Insbesondere bei Aufnahmen von Leichenbergen und -massen fängt die Kamera diese den Bildrahmen sprengenden Greuel durch Schwenks ein - die Vernichtung sollte dem Publikum in seinem ganzen Ausmaß vorgeführt werden. ${ }^{22}$ Aufgrund dieser besonders grauenhaften Aufnahmen sprach Joseph Pulitzer von den »schrecklichsten Aufnahmen, die jemals gemacht wurden« (zit.n. N.N. 2001: 59).

Neben der Wahl der Fotos bzw. Filmausschnitte ist die Schockwirkung von DiE TodesmüHLen durch das diskursiv-kompositorische Arrangement derselben unterstützt. Wie später NACht und Nebel sind Die TodesmüHlen extrem schnell geschnitten, im Unterschied zu Resnais' Film, jedoch ohne nennenswerte Unterbrechung dieses rasanten Tempos. Auf diese Weise werden dem Zuschauer die »Grausamkeiten in (Herz und) Hirn gehämmert [...] (anonymer »Times «-Reporter zit.n. Brink 1998: 52; s. II.1). Besonders schnelle Einstellungswechsel weisen vor allem die Sequenzen auf, in denen der Zuschauer mit den Schockbildern konfrontiert wird (s. 1.1.2). Unterstützt wird dieser »Dauerbeschuß « durch ausnahmslos harte Schnitte innerhalb der Sequenzen; lediglich zwischen deutlich getrennten Filmeinheiten zu Beginn und gegen Ende der Todesm ÜH len setzen Burger/Wilder Ab- und Aufblende ein, um die Zäsur zu markieren. Weiche Übergänge, wie Überblendungen, sind in diesem Film nicht eingesetzt ${ }^{23}$ - sie paßten nicht ins Konzept des harten StakkatoRhythmus, der dem Publikum weder Raum noch Zeit läßt, das eine oder andere auf sich wirken zu lassen.

Hinzu kommt, daß der - verglichen mit NACHT und NeBEL - ebenfalls von einem Mann aus dem Off gesprochene Kommentar deutlich weniger und kleinere Pausen aufweist. So werden dem Zuschauer auch auditiv durchgängig Details über die Vernichtung zugemutet, gesteigert durch monotone Aufzählungen des Off-Sprechers (s. 1.1.4 und 1.1.5). Was die Pausen betrifft, fällt deren relative Häufung in den Sequenzen mit den grauenhaftesten Aufnahmen auf, so z.B. bei Bildern von völlig geschwäch-

22. »Es gab für alliierte Kameramänner die Anweisung der Militärregierung, beim Filmen der befreiten Konzentrationslager darauf zu achten, daß immer auch die Umgebung zu sehen ist. Empfohlen wurde, viel zu schwenken [...].« (Bernstorff 2002: 16)

23. Lediglich in einer Szene werden Überblendungen eingesetzt, nicht jedoch um weichere Übergänge zu schaffen, sondern um die Kollektivanklage visuell zu inszenieren (s. 1.1.5). 
ten Überlebenden, von menschlichen Skeletten und von Leichenmassen. Sollte dies der Versuch sein, die Annahme-Möglichkeiten des Zuschauers nicht zu überfordern, so darf er angesichts der Bilderwahl und des Schnitt-Tempos stark bezweifelt werden. Während sich die Filmmusik der Todesmühlen in aller Regel zwischen Melodramatik und Schwermütigkeit bewegt, fällt im Zusammenhang mit den unerträglichsten Bildern eine dissonante musikalische Begleitung auf (s. 1.1.2), die in NACHT UND NEBEL verstärkt zum Einsatz kommen wird. Weder dies noch die gelegentlich eingesetzte und an NACht und Nebel erinnernde Ironie bzw. der Sarkasmus (s. 1.1.3 und 1.1.4) vermag den Zuschauer zu einem Hinsehen zu bewegen, denn: »Der Mensch kann nur ein bestimmtes Maß an Grauen aufnehmen.« (Darmstädter 1995: 115) Insbesondere in Verbindung mit der Anonymität der Opfer ist tatsächliche Wahrnehmung extrem unwahrscheinlich (s. Anders in II.1).

Neben der Auswahl schockierendsten Bildmaterials und dessen diskursiv-kompositorischem Arrangement trägt verstärkt die anklagende Haltung, hinter der sich die These von der Kollektivschuld der Deutschen verbirgt, zur »Unerträglichkeit« der TodesMÜHLEN bei (s. 1.1.5, insb. die Schlußsequenz). Dies trifft vor allem auf die unmittelbare Nachkriegszeit zu, etwa für Kommentare zu Leichenbergen, wie »Das waren einst Menschen, Gottes Kinder, Millionen zu Tode gequält von deutschen Henkern ...« (०:05:06-0:05:09 h), mit denen sich unschuldige Deutsche kaum abfinden konnten. Darüber hinaus »ist der Film eher dazu angetan, das Auslösen eines starken Schuldgefühls und einer echten, ernsten Betroffenheit beim Zuschauer zu blockieren «, denn er stellt »die Schuldfrage nicht auf der Ebene der historisch-politischen Ereignisse«, sondern verlagert sie »auf eine metaphysisch-abstrakte, religiöse Ebene. Statt eine geistig und emotional verarbeitete Form von Ergriffenheit zu ermöglichen, erweckt der eine nachhaltige Schockwirkung anstrebende Film ein lähmendes Betroffenheitsgefühl, das die Disposition für einen anschließenden Verdrängungsprozeß schafft.« (Hahn 1997: 109)

Daran ändern auch die, meines Wissens bisher noch nicht angesprochenen, aber durchaus beobachtbaren ästhetischen Ansätze zur Erfahrbarmachung des Grauenhaften nichts - schließlich bilden sie die Ausnahmen (s. 1.1.5, insb. den zweiten Teil der Exposition) und werden von der Schockästhetik massiv in den Hintergrund gedrängt. Dennoch handelt es sich hierbei um ästhetische Verfahren, die in späteren Filmen - vor allem in Nacht und Nebel, Shoah und Birkenau und Rosenfeld - und medialen Erinnerungsformen aufgegriffen und zum Teil weiterentwickelt werden. Während Die TodesmüHlen eindeutig von den Schockbildern dominiert werden, sind es interessanterweise diese ästhetischen Ansätze zur Erfahrbarmachung, die in der Folge verstärkt zum Tragen kamen.

\subsubsection{Leitthesen}

In der Sequenz »Leichenmassen« tritt die im Zusammenhang mit dem Film zitierte Schockstrategie besonders geballt in Erscheinung.

Darüber hinaus handelt es sich um eine Szenenfolge, die mit der Sequenz »Als die Alliierten die Tore öffnen« in NACHT UND NEBEL in gewisser Weise vergleichbar ist (s. 2.1.1). Hier wie dort werden die grauenhaften Bilder schnell und hart hintereinander geschnitten; bei einer Aufnahme handelt es sich sogar um dieselbe (s.u. Standbild o:13:18 h). In gewisser Hinsicht geht Resnais bei der Wahl schockierenden Archivmateri- 
als sogar noch einen Schritt weiter als Burger. ${ }^{24}$ Während der Kommentator in der vorliegenden Sequenz von Dif TodesmüHlen die Bilder regelmäßig kommentiert, schweigt er in NaCht und Nebel über weite Strecken, nachdem er die Szenenfolge mit den Worten »Quand les alliés ouvrent les portes... / Als die Alliierten die Tore öffnen...« eingeleitet hatte. Auch die Musik ist bei Resnais/Eisler vom Beginn der Sequenz an durch das Geigen-Pizzicati dissonant. In Die TodesmüHlen verursacht die an Nacht und Nebel erinnernde zirpende Violine erst gegen Ende schmerzhafte Empfindungen.

Mit knapp drei Minuten gehören die »Leichenmassen « durchaus zu den längeren Sequenzen von Dif Todfsmühlen, plaziert an einer zentralen Stelle, der Mitte des Films.

\section{Detaillierte Sequenzanalyse:}

Nachdem der Zuschauer sowohl in der Sequenz »Liquidierungen kurz vor der Befreiung « als auch in »Lagerwachen, SS-Offiziere und -Ärzte « mit Aufnahmen von unzähligen Leichen konfrontiert wurde, erreicht diese Entwicklung des Films hin zu Schockfotos in der Sequenz »Leichenmassen « ihren unerträglichen Höhepunkt - eine Sequenz, an der die immer wieder zitierte Schockstrategie besonders deutlich wird.

Die unheimlich rasch wechselnden, hart geschnittenen Einstellungen werden von zwischen Melodramatik und Dissonanz wechselnder Musik begleitet. Der von Aufzählungen bestimmte und monoton vorgetragene Off-Text kommentiert das Bildmaterial ${ }^{25}$ :

»Über 300 Lager - Totenfabriken eins wie das andere. 20 Millionen Tote ... Tote in Nordhausen, verhungert und erschossen. Oft genug noch Lebende - oder besser - nur Halbtote, achtlos unter die Leichen geworfen. [Pause] Tote in Ohrdruff, erschossen. [Pause] In Lambach, erschossen. [Pause] In Landsberg, verhungert. [Pause] In Dachau, verbrannt, vergast, verhungert. [Pause] In Auschwitz, vergast, erschossen und verhungert. Und neben den gemordeten Müttern die Leichen neugeborener Kinder. ${ }^{26}$ In Ebensee, verhungert. [Pause] In Belsen, verhungert und erschossen. [Pause] In Mauthausen, vergast, verhungert und erschossen. [lange Pause] In Leipzig, verkohlt an den Hochspannungsdrähten, umgekommen im Stacheldrahtgeflecht [Pause].« $(0: 11: 22-0: 14: 17 h)$

Während dieses knapp dreiminütigen visuellen »Beschusses « alternieren Aufnahmen einzelner Toter - zum Teil in unerträglich naher Einstellungsgröße - mit Bildern von unüberschaubaren Leichenmassen. Insbesondere bei letzteren schwenkt bzw. fährt die Kamera über die unzähligen Opfer, um erneut das Ausmaß der Vernichtung einzufangen. In regelmäßigen Abständen macht der Kommentator eine Pause und läßt die Bilder sprechen. Hierzu müßten sie jedoch »ansehbar« sein - ein Problem, das offensichtlich auch viele Deutsche hatten, die von den Alliierten zur Besichtigung der Konzentrationslager bzw. deren Folgen gezwungen wurden, wie einige Aufnahmen

24. Den beabsichtigten Höhepunkt seines Films stellen die in der Einleitung der Arbeit angesprochenen Aufnahmen von Leichenmassen dar, die durch Bulldozer in Gruben geschoben werden (s. 2.1.1).

25. Gemäß meiner Grundüberzeugung, daß ein gewisses Maß an Diskretion unerläßlich ist, wurde die Größe der Abbildungen deutlich verringert.

26. Lediglich bei diesem Satz hebt der Sprecher die Stimme als Zeichen der Entrüstung ein wenig an. 


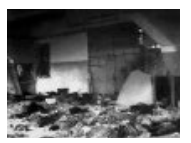

15.B $0: 11: 32 \mathrm{~h}$

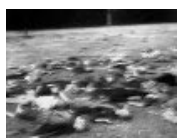

15.H $0: 12: 09 \mathrm{~h}$

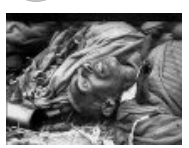

15.N $0: 12: 36 \mathrm{~h}$

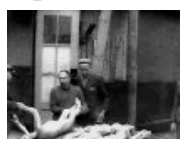

(20) $0: 12: 59 \mathrm{~h}$

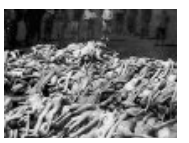

(26) $0: 13: 29 \mathrm{~h}$

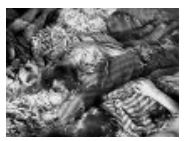

15.c $0: 11: 48 \mathrm{~h}$

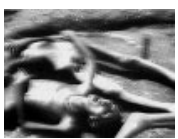

(15.I) $0: 12: 12 h$

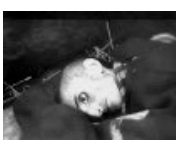

15.0 $0: 12: 38 \mathrm{~h}$
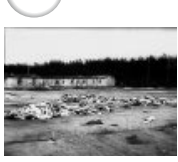

(21) $0: 13: 07 \mathrm{~h}$

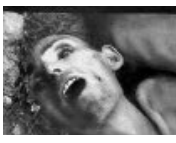

(27) $0: 13: 42 \mathrm{~h}$

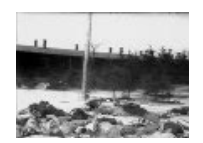

15.D $0: 11: 50 \mathrm{~h}$

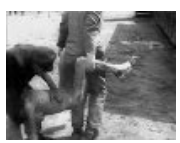

15. $0: 12: 18 h$

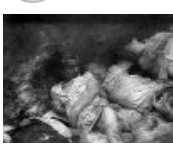

(16) $0: 12: 41 \mathrm{~h}$

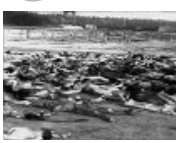

(22) $0: 13: 10 \mathrm{~h}$

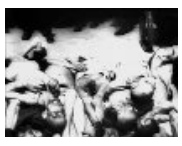

(28) $0: 13: 45 \mathrm{~h}$

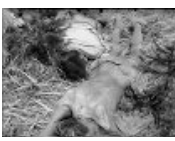

15.E $0: 12: 01 \mathrm{~h}$

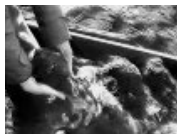

15.K $0: 12: 24 h$
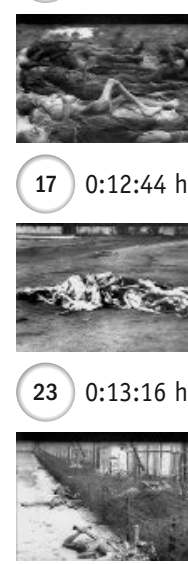

(29) $0: 13: 57 \mathrm{~h}$

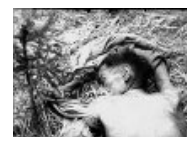

15.F $0: 12: 03 \mathrm{~h}$

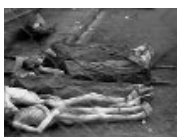

15.L $0: 12: 30 \mathrm{~h}$
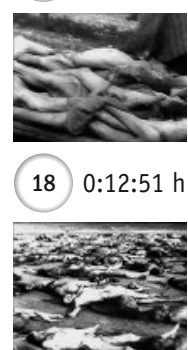

(24) $0: 13: 18 \mathrm{~h}$

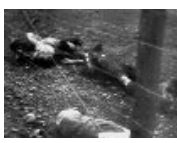

(30) $0: 14: 06 \mathrm{~h}$

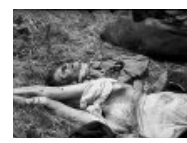

15.G $0: 12: 05 \mathrm{~h}$

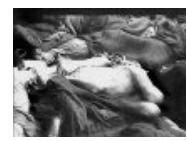

15.M $0: 12: 33 \mathrm{~h}$

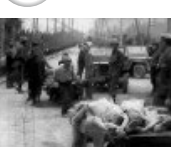

(19) $0: 12: 55 \mathrm{~h}$
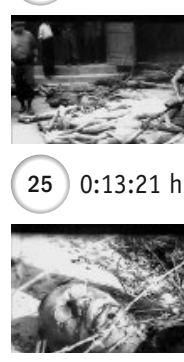

(31) $0: 14: 16 \mathrm{~h}$

der Sequenz »Deutsche müssen das Desaster betrachten« verdeutlichen (s. 1.1.3, insb. o:18:31 u. o:19:36 h). Insbesondere die unbekleideten Körper, zum Teil in Verrenkungen, sind in ihrer schockierenden Wirkung unerträglich:

»Nackte Tote sind nämlich in den abendländischen Gesellschaften kaum je zu sehen und werden auch kaum abgebildet. [...] Diese gesamte Fürsorge für die Toten findet auf den Bildern der KZ-Opfer in der Regel nicht statt. Üblicherweise werden den Toten die Augen verschlossen; auf den Bildern aber sind sie häufig geöffnet. Tote werden verhüllt [...]. Auf den Bildern begegnen sie uns oft nackt - zum Teil sind selbst die Genitalien zu sehen. Verstorbene werden für den letzten Blick der Angehörigen hergerichtet. Die KZ-Fotos präsentieren sie jedoch in grotesken Verrenkungen. [...] Selbst verkohlte oder exhumierte, halb verweste Körper werden fotografiert $[\ldots] . \lll($ Kramer 2003: 230)

»Daß dieses Verfahren hier geboten war, um die Ausbreitung der Seuchen zu stoppen, erzählen nicht die Bilder, sondern allenfalls die Bildunterschrift oder der Kommentar.« (Ebd. 230f.)

»Die Bilder zeugen von einem Umgang mit den Toten, der alle Regeln verletzt, die in unserem Kulturkreis als zivilisiert gelten. Indem sie diese Vernachlässigung des elementaren Umgangs mit den Toten zeigen, gewinnen die Bilder ein starkes appellatives Moment. Sie drücken jene Dehumanisierung der Opfer aus, die die Nazis ins Werk gesetzt haben. Allerdings gehörte es zur Bildpolitik der Alliierten, diese Dehumanisierung durch die rhetorische Strategie der 
Bilder zu wiederholen. Und erst durch die Kombination beider Elemente lösen die Bilder den oft beschriebenen Schockeffekt aus. Es ist hier auch der Blick des Fotografen, der schamlos verfährt.« (Ebd. 231)

»Die Fotos von Unbekleideten machen diese Körperspuren sichtbar.« (Ebd. 232)

Die Aufzählung nach der immer gleichen Struktur (Angabe des Ortes, dann der Art und Weise der Ermordung) unterstreicht die entsetzliche, unerträgliche Bilanz nationalsozialistischer Vernichtungspolitik und übernimmt ikonisierend den Gestus des Filmtitels - >Todes-Mühlen< (s. 1.1.1). Lediglich bei einem Satz (»Und neben den gemordeten Müttern die Leichen neugeborener Kinder.« 0:13:58 h) hebt der Sprecher die Stimme als Zeichen der Entrüstung und Anklage leicht an; ansonsten trägt er die Liste auffällig monoton, in nüchtern-ruhigem Tonfall vor. Parallel zur Häufung von Leichenmassen wechselt die musikalische Begleitung von melodramatisch schwermütigem zu dissonant-zirpendem Charakter. Dies bereitet dem Zuschauer allenfalls zusätzliches Unbehagen, vermag jedoch die Wahrnehmung der Bilder kaum zu unterstützen.

\subsubsection{Kontraproduktiver Zwang - Deutsche müssen das Desaster betrachten}

Die gegen Ende des Films angesiedelte, knapp dreiminütige Sequenz »Deutsche müssen das Desaster betrachten« zeigt die Reaktion der Deutschen auf den Zustand der befreiten Lager, auf das Ausmaß der Vernichtung. Es handelt sich hierbei um Aufnahmen, die in dieser Ausführlichkeit meiner Kenntnis nach in keinem späteren Film zu sehen sind und die in bezug auf die Wirkung dieser schockierenden Anblicke sehr aufschlußreich sind (s. die Anmerkungen zu Reaktionen in 1.1).

Wie in der Verwertungs-Sequenz (s. 1.1.4) ist der Kommentar auch hier punktuell von beißender Ironie gekennzeichnet und erinnert so an NACHT und NeBEL (s. II.2.1).

27. Vgl. den Off-Kommentar: »Von den vielen Millionen überlebten nur wenige Tausende die Jahre der Pein. In die Gesichter dieser Frauen von Mauthausen ist ihre Leidensgeschichte eingegraben. [Pause] In Wernsdorf, umgeben vom Massensterben, umgeben von dem vergiftenden Gestank tausender Leichen, fand man kranke Frauen zusammengepfercht. Kranke, mit Wunden wie diese. [Pause] Kinder in Auschwitz, ihre Eltern und Verwandten sind längst vergast, ihre Namen haben die meisten vergessen. Sie sind nichts als Nummern, die die Nazis ihnen auf die Arme (s. 0:15:06 h) gebrannt haben. [Pause] (s. 0:10:15 h) Überlebende in Holzen. Einem dieser Männer sind von den Lagerwachen die Augen ausgeschlagen worden. [Pause] In Ebensee, Opfer jahrelanger Unterernährung, wandelnde Skelette, ja in den meisten Fällen Skelette, die viel zu ausgezehrt sind, um noch zu wandeln. [lange Pause] Schloßenburg [Pause], Rebelin [Pause], Belsen: Hier starben noch in den Wochen nach der Befreiung 13.000 Menschen, die durch jahrelangen Essensentzug so geschwächt waren, daß alle Sorgfalt und Pflege sie nicht mehr retten konnte.« $(0: 14: 17-0: 16: 57 \mathrm{~h})$.

28. Vgl. den Kommentar: »Auf Befehl der alliierten Militärbehörden werden hohe Partei- und Amtswalter gezwungen, das benachbarte Konzentrationslager zu besichtigen. Mit eigenen Augen müssen sie die Verbrechen sehen (s. 0:17:19 h), deren Existenz so viele von ihnen abzuleugnen (s. 0:17:20 h) versuchten.« 


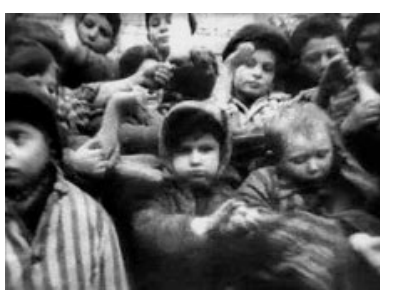

(32) $320: 15: 06 \mathrm{~h}$

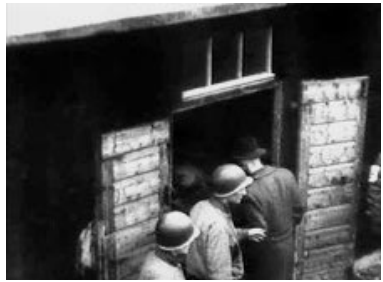

(35) $0: 17: 19 \mathrm{~h}$

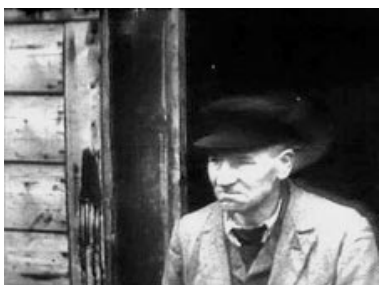

(38) $0: 17: 29 \mathrm{~h}$

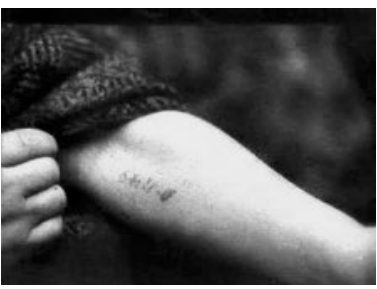

(33) $0: 15: 10 \mathrm{~h}$

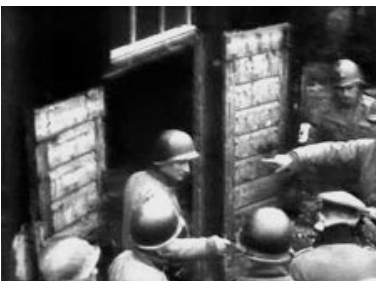

(36) $0: 17: 20 \mathrm{~h}$

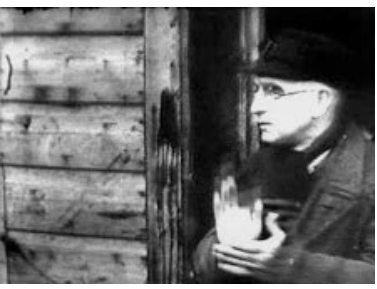

(39) $0: 17: 32 \mathrm{~h}$

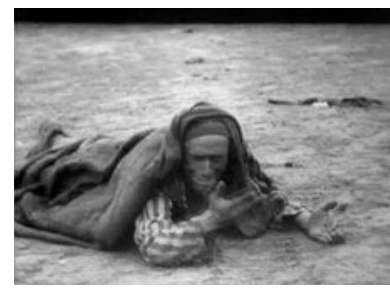

(34) $0: 16: 36 \mathrm{~h}$
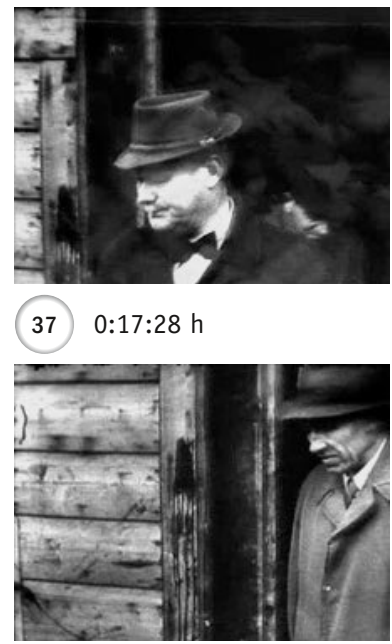

(40) $0: 17: 34 \mathrm{~h}$

Detaillierte Sequenzanalyse:

Nachdem der Zuschauer im Anschluß an die Leichenmassen mit Aufnahmen der wenigen Überlebenden konfrontiert wurde ${ }^{27}$ - darunter ebenso unerträgliche von tätowierten Kindern (s. o:15:06 u. o:15:10 h), menschlichen Skeletten und jammernden Häftlingen (s. 0:16:36 h) -, zeigt die Folgesequenz »Deutsche müssen das Desaster betrachten« die Reaktion der Deutschen auf das Ausmaß der Vernichtung.

Insbesondere zwei Bilder verdeutlichen die Zwangsdidaktik der Alliierten auf anschauliche Weise: Mit einer Handbewegung verhindert ein alliierter Soldat das Zurückweichen eines Deutschen in Zivil (s. o:17:19 h), während ein anderer Deutscher durch den Zeigefinger eines Militärs ganz offensichtlich zum Betreten der Baracke aufgefordert werden muß (s. o:17:20 h, rechter Bildrand)..$^{28}$

Nachdem eine kurze Einstellung einen Berg von Leichen im Inneren der Baracke erkennen ließ, zeigen die folgenden, rasch hintereinander geschnittenen Aufnahmen die Reaktion verschiedener Deutscher auf den fürchterlichen Anblick. Dies war offensichtlich von Interesse für die Alliierten, da sie die Funktionäre und Beamten in relativ naher Einstellungsgröße aufnahmen, wobei eine deutliche mimische Erstarrung (durch beispielsweise zusammengepreßte Lippen) zum Ausdruck kam (s. 0:17:28, 0:17:29 u. o:17:34 h). Lediglich ein Mann drückt vor allem gestisch seine Fassungslosigkeit aus (s. 0:17:32): Bevor er den Kopf schüttelt, schlägt er seine Hände ungläubig ineinander. Dadurch, daß der Kommentator während dieser Aufnahmen pausiert, wird die Konzentration des Zuschauers ganz auf die Körpersprache dieser Deutschen gelenkt. 
Im weiteren Verlauf der Szenenfolge sehen wir Teile der Weimarer Bevölkerung auf ihrem Weg ins benachbarte Lager Buchenwald und ihr Verhalten angesichts der massenhaften Vernichtung. Diese Einstellungen sind mehr oder weniger durchgängig und in nüchternem Tonfall kommentiert:

»Nach dem Besuch der höheren Funktionäre und Beamten sollen alle Bürger der Stadt Weimar Zeugen der im Lager Buchenwald begangenen Greuel werden, so befiehlt der kommandierende General. [...] Sie ziehen aus wie zu einem Ausflug, zu einem vergnüglichen Waldspaziergang, einem kurzen Fußmarsch (s. 0:18:05 h) - denn es ist ja von keiner deutschen Stadt weit bis zum nächsten Konzentrationslager.« (0: 17:51 - 0:18:09 h

Für den heutigen Zuschauer sind die gut gelaunten jungen Frauen besonders irritierend, befinden sie sich doch auf dem Weg ins benachbarte Lager, dessen Zweck ihnen vermutlich bekannt war. Angesichts der aufgebahrten Leichen (außerhalb des Bildrahmens, in Verlängerung der rechten unteren Bildecke) wenden die meisten wenig später den Blick ab (s. 1.1), die vorherige Heiterkeit ist ernsten Minen gewichen (o:19:36 h). ${ }^{29}$

1.1.4 Latente Aufforderung zur Ergänzung - die Verwertungsmaschinerie der Nazis Was nach der Exposition (s. 1.2.4) vergleichsweise harmlos mit Aufnahmen der Begeisterungsstürme bei Befreiung der Lager beginnt (s. o:01:10, ০:01:40 u. o:01:43 h) Bilder, die in späteren Filmen kaum zu sehen sind und auf die auch Resnais nicht zurückgegriffen hat -, entwickelt sich über die Bilder der halb verhungerten (s. 0:02:21 u. 0:02:24 h) 30 $^{\circ}$ und der Ersten Hilfe bedürftigen (s. ०:02:43 u. ०:02:55 h) Überlebenden

29. »Aber die Deutschen, die nach der Befreiung durch die Konzentrationslager geführt wurden, wendeten sich mit heftigen Bewegungen ab. Sie wollten nicht sehen. Der Anblick des Grauens übersteigt tatsächlich jede Fassungskraft.« (Darmstädter 1995: 117) »Schaut man die Fotografie [`Auf ihrer Führung durch das K.Z. Buchenwald blicken Weimarer Bürger auf einen der hoch mit Leichen beladenen Wagen.८] jedoch genauer an, so zeigt sich schnell, daß dies nur eingeschränkt stimmt, daß die Bildunterschrift mehr von der Absicht derjenigen verrät, die das Foto publizierten, als vom fotografierten Augenblick. Tatsächlich blickt nur einer der Weimarer auf die Toten [...]. Seine eindeutige Hinwendung zu dem Haufen gestapelter Leichen ist deutlich gegen Blickrichtung und Körperhaltung der übrigen gerichtet. Diese nämlich schauen auf die Soldaten oder auf den Boden.« (Brink 1998: 61)

30. Vgl. den Off-Kommentar: »[...] haben diese Menschen zu Tieren erniedrigt. Und doch waren sie einst Menschen, wie du und ich.... [...] und für viele kam die Hilfe zu spät.«

31. Vgl. seine Reaktion in II.1.1.1.

32. »Das waren einst Menschen, Gottes Kinder, Millionen zu Tode gequält von deutschen Henkern ...« (0:05:06-0:05:09 h), kommentiert der Sprecher. Dem Leser der vorliegenden Arbeit sollen die Bilder hier erspart werden und im Rahmen »Leichenmassen«-Sequenz (s. 1.1.2) in hoffentlich einigermaßen erträglicher Weise präsentiert werden.

33. Während Spielberg darauf explizit Bezug nimmt, indem er in einer Sequenz das Warenlager inszeniert (s. II.2.1.7), entlarvt Benigni in einer Schlüsselszene seines Films (- »Knöpfe und Seife« -) die Absurdität der Vernichtungsmaschinerie (s. II.4.1.4.ba).

Siehe II.2.1.7 zu den unterschiedlichen Formen des Umgangs mit diesem Verwertungsaspekt in Lanzmanns SHOAH, Spielbergs SCHIndLERS LISTE und Resnais' NACHT UND NEBEL Sowie II.4.1.4.ba zu Benignis DAS LEBEN IST SCHÖN und II.5.6.a zu Loridan-Ivens' BIRKENAU UND ROSENFELD. 


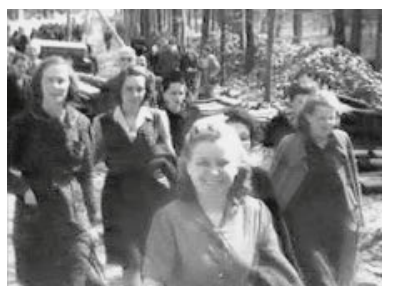

(41) $0: 18: 05 \mathrm{~h}$

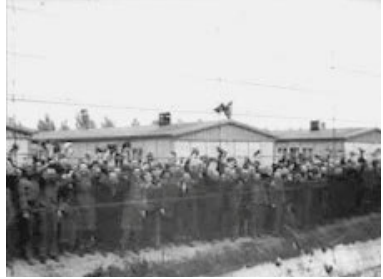

(43) $0: 01: 10 h$

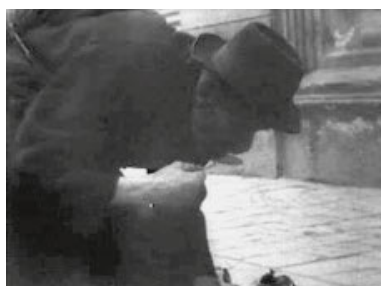

(46) $0: 02: 24 \mathrm{~h}$

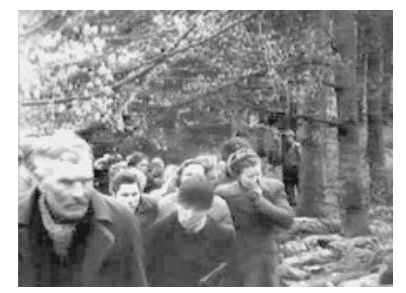

(42) $0: 19: 36 \mathrm{~h}$

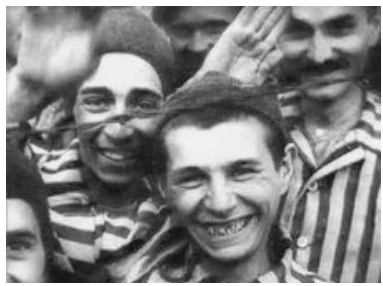

(44) $0: 01: 40 \mathrm{~h}$

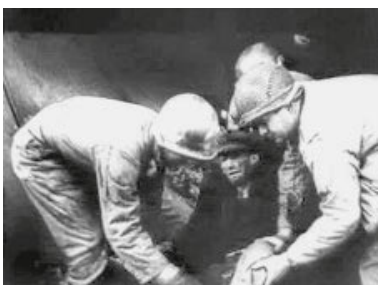

(47) $0: 02: 43 \mathrm{~h}$

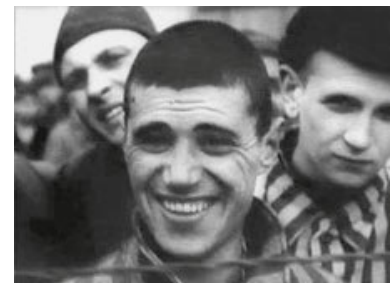

(45) $0: 01: 43 \mathrm{~h}$

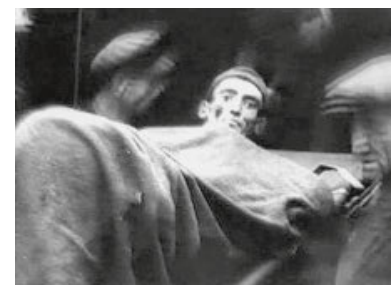

(48) $0: 02: 55 \mathrm{~h}$

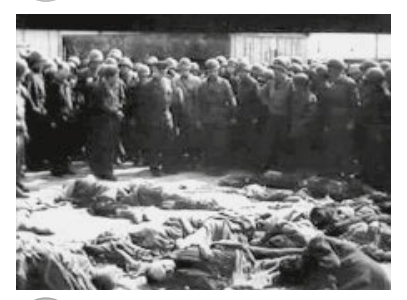

(49) $0: 04: 21 \mathrm{~h}$

recht schnell und spätestens mit der Besichtigung der befreiten Lager durch alliierte Offiziere, wie beispielsweise der alliierte Oberstkommandierende, General Eisenhower ${ }^{31}$, im Lager Ohrdruff (s. 0:04:09 u. 0:04:21 h), zu einer dichten Folge zunehmend unerträglicherer Aufnahmen. ${ }^{32}$

Bevor jedoch diese häufig zitierte, rund dreiminütige Kaskade von Schockfotos auf den Zuschauer einprasselt, schließt sich an die Sequenz »Folterkammern und -geräte, Gaskammern« eine Sequenz an, die in ähnlicher Weise und zum Teil mit gleichem Bildmaterial in Resnais' NACHT UND NeBel vorkommt (s. II.2.1.7), in Lanzmanns Sнонн gegen Ende des Films zitiert wird und in leicht abgewandelter Form in BirKeNAU Und Rosenfeld ihren Platz hat (s. II.5.6.b); auch in Spielfilmen wie Schindeers Liste oder DAS LEBEN IST SCHÖN wird die Verwertungsmaschinerie der Nazis thematisiert - Filme, auf die an anderer Stelle eingegangen wird. ${ }^{33}$ Das wirkmächtige Prinzip 
des Pars pro toto wird hier also zum ersten Mal im Medium Film eingeführt und in späteren Filmen oft zitiert bzw. weiterentwickelt. Darüber hinaus weist der Kommentar in dieser Sequenz erste Ansätze von Ironie bzw. Sarkasmus auf, die in Resnais' NACHT UND NeBEL aufgenommen und intensiviert werden.

Diese »Verwertungsmaschinerie«-Sequenz, mit etwas mehr als zweieinhalb Minuten Dauer durchaus eine der längeren des Films, präsentiert zunächst das Ergebnis der am Ende der vorangegangenen Sequenz angesprochenen Gaskammern: Während der Zuschauer zu melodramatischer Musik mit Aufnahmen eines Krematoriumsschlotes und vor allem mit Kamerafahrten (zunächst) über die zahlreichen Krematoriumsöfen ${ }^{34}$ konfrontiert wird, erläutert ihm der Off-Kommentator die rasch wechselnden Einstellungen:

»Noch ehe die Leichen erkaltet waren, wurden sie in gewaltigen Öfen verbrannt. In Auschwitz allein gab es vier, sie brannten Tag und Nacht. Die Zahl der im Vernichtungslager Auschwitz allein Verbrannten wird auf vier Millionen geschätzt (s. 0:06:52 h) und die Knochen wurden vermahlen (s. 0:06:53) und als Düngemittel an deutsche Bauern verkauft. Ja, die Todesmühlen waren ein einträgliches Geschäft. Hier ${ }^{35}$ sind Tausende von Kleidungsstücken, die man in Dachau den Internierten abnahm, um sie gewinnbringend zu verkaufen (s. 0:07:07 h). Schuhe (s. 0:07:13 h) - Schuhe, in allen Größen, Kinderschuhe. Ja selbst Spielzeuge (s. 0:07:19 h) und Puppen (s. 0:07:21 h) ${ }^{36}$. Aus dem Jammer gequälter Menschen wurde reiches Kapital geschlagen. Das (s. 0:0729 $\mathrm{h}^{37}$ ) ist: Frauenhaar. Den weiblichen Gefangenen abgeschnitten, bevor man sie umbrachte. Sorgfältig gebündelt, um verkauft und verarbeitet zu werden. Der große Lagerschuppen von Buchenwald - und jedes der Lager hatte einen solchen Schuppen. Schmuckstücke, Uhren, Eheringe, Berge von Brillen (s. 0:07:55 $\mathrm{h}^{38}$ ), Goldzähne (s. 0:07:57 h), die den Toten und Lebenden ausgebrochen wurden. Und das sind die Instrumente, mit denen man sie den Opfern ausriß. ${ }^{39}$ Ein reicher Ertrag - Gold aus dem Munde Ermordeter.« $(0: 06: 36-0: 08: 08 \mathrm{~h})$

Diese, wie der gesamte Film, schnell geschnittene Sequenz überhäuft das Publikum geradezu mit einer Vielzahl von Gegenständen und Körperteilen der Ermordeten, die den Deutschen zur Wiederverwertung zugeführt wurden. Die vollständige Verwertung der Opfer läßt den Zuschauer erschaudern; die Berge von Gegenständen und Körper-

34. Vgl. die sehr ähnlichen Aufnahmen in Resnais' NACHT UND NEBEL, ebenfalls vor der Verwertungssequenz.

35. Die entsprechende Einstellung zeigt einen Soldaten der alliierten Streitkräfte vor einer Stange mit unzähligen Kleidungsstücken (0:07:02 h).

36. Vgl. dieselbe Aufnahme in Resnais' Nacht und NebeL.

37. Vgl. ebd.

38. Vgl. ebd.

39. Die entsprechende Einstellung zeigt einen Haufen von Reißzangen (0:08:02 h).

40. »Der Kern des Films wird vom christlichen Symbol des Kreuzes umrahmt; in der filmischen Anfangssequenz steht das Kreuz allein für die in den Lagern umgekommenen Menschen, während in der Schlußsequenz auf das Kreuz der Schuld angespielt wird, das laut Kommentar Millionen Deutsche [...] auf sich nehmen und dazu für die Opfer der Verfolgung Sühne leisten müssen.« (Hahn 1997: 108) 


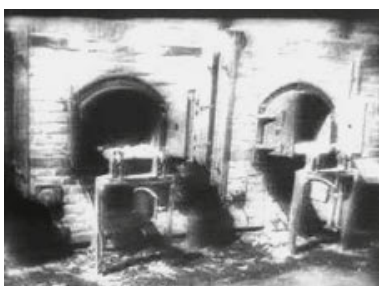

(50) $0: 06: 52 \mathrm{~h}$

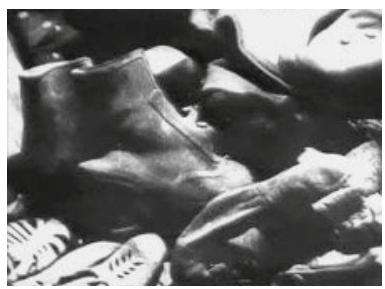

(53) $0: 07: 13 \mathrm{~h}$

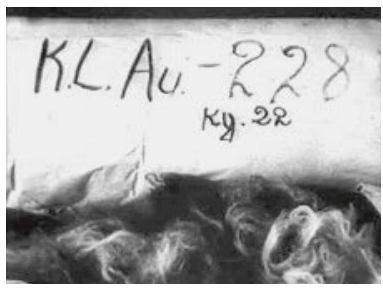

(56) $0: 07: 29 \mathrm{~h}$

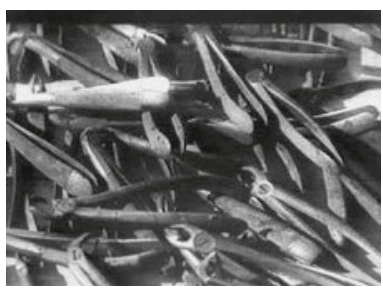

(59) $0: 08: 02 \mathrm{~h}$

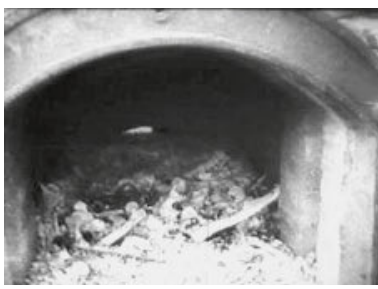

(51) $0: 06: 53 \mathrm{~h}$
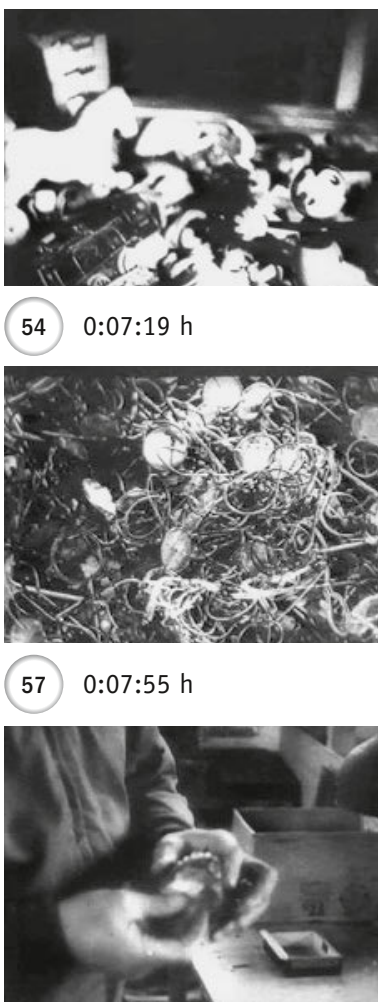

(60) $0: 08: 06 \mathrm{~h}$

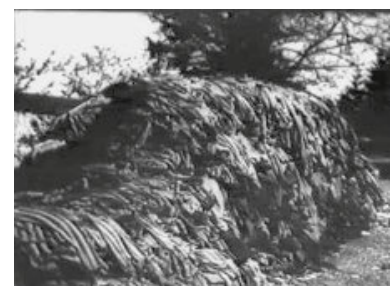

(52) $0: 07: 07 \mathrm{~h}$

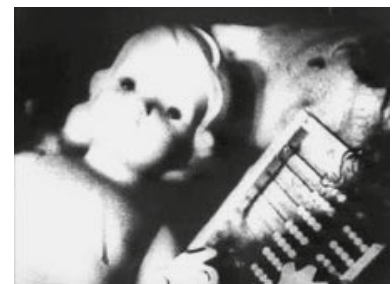

(55) $0: 07: 21 \mathrm{~h}$

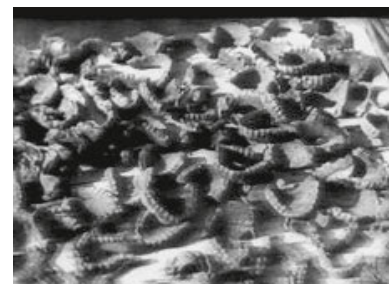

(58) $0: 07: 57 \mathrm{~h}$

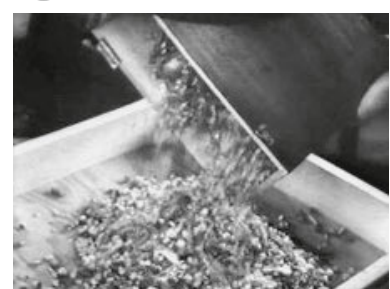

(61) $0: 08: 17 \mathrm{~h}$

teilen lassen ihn das unbegreifliche, unermeßliche Ausmaß der Vernichtung und die Skrupellosigkeit der Nazis erahnen. Ironie und Sarkasmus sprechen aus Sätzen »Ein reicher Ertrag - Gold aus dem Munde Ermordeter.« (०:08:06 h) und »Ja, die Todesmühlen waren ein einträgliches Geschäft.« (o:०6:56 h) Auf diese Weise nehmen sie den häufig ironisch-sarkastischen Kommentar in Resnais' NACHT Und NEBEL vorweg (s. II.2.1.1 und II.2.1.3).

\subsubsection{Kollektivschuld und Erfahrbarmachung der Lager -} »Elfhundert Kreuze für elfhundert frische Gräber«

Die 15-sekündige Anfangs- und die 25-sekündige Endszene bilden aufgrund derselben und sich vom Rest des Films leicht abhebenden Thematik den Rahmen der TodesMÜHLEN. In dessen Mittelpunkt steht die christliche Kreuz-Symbolik ${ }^{\circ}$ und der damit verbundene Vorwurf der Kollektivschuld. Letzteres trifft insbesondere auf das Film- 
ende zu. Neben dem Bildmaterial spielt der von Zahlen und Wiederholungen geprägte Kommentar hierbei eine zentrale Rolle.

Die Rahmenszenen sind jedoch nicht völlig vom Mittelteil des Films abgekoppelt, sondern bilden mit der jeweils folgenden bzw. vorangehenden Szene die Exposition bzw. die Schlußsequenz.

Die auf die Anfangsszene folgende Sequenz hebt sich von weiten Teilen des restlichen Films ab, da sie auffällig inszeniert und montiert ist. Dem Zuschauer wird so der Gefängnischarakter der Lager erfahrbar gemacht. Daher ist es kein Zufall, daß vergleichbare Aufnahmen von den Stacheldrahtzäunen der Konzentrationslager in späteren Filmen (NACHT Und Nebel, BirkenAu und Rosenfeld) oder der zeitgenössischen Lagerfotografie wiederkehren.

Auch die Schlußszene fällt durch eine besondere Inszenierung auf. Wie Resnais in NaCht und Nebel montiert auch Burger Aufnahmen aus Leni Riefenstahls Triumph Des Willens (1934-1935) zwischen die Bilder von 1945 und versucht auf diese Weise, die damals Hitler zujubelnde Menge mit den 1945 durch die Lager geführten Bürgern gleichzusetzen, ihnen ihre Schuld vorzuhalten.

\section{Detaillierte Sequenzanalyse:}

Die Aufblende zur Eröffnungssequenz zeigt eine lange Schlange von Menschen, die, große Kreuze tragend, einen kleinen Ort durchqueren (s. ০:০০:16 h). Unmittelbar danach - und begleitet von leise untermalender, schwermütiger Musik sowie zahlreichen schnellen Einstellungswechseln mit zum Teil kunstvollen Bildkompositionen (s. v.a. ০:০০:20 u. ০:০০:25 h) - setzt aus dem Off die pathetische Stimme eines männlichen Kommentators ein, der dem Zuschauer erklärt, was im Bild zu sehen ist:

»An einem Apriltag des Jahres 1945 trug man (s. 0:00:20 h) elfhundert Kreuze hinaus zur Scheune (s. 0:00:23 h) von Gardelegen. Elfhundert (s. 0:00:25 $\mathrm{h}^{41}$ ) weiße Holzkreuze für elfhundert frische Gräber; elfhundert Tote - [Abblende] (s. 0:00:31 h) und doch nur [Aufblende] ein winziger Bruchteil der Opfer (s. 0:00:34 h) deutscher Konzentrationslager.» (0:00:15 $0: 00: 34 \mathrm{~h})$

Es handelt sich um 1100 Kreuze, bestimmt für die 1100 Opfer von Gardelegen - eine große Anzahl von Toten, die durch vierfache Nennung betont wird und durch die Relativierung (»und doch nur ein winziger Bruchteil der Opfer deutscher Konzentrationslager«) gleichzeitig die Gesamtheit der Opfer erahnen läßt. Beim Off-Kommentar der knapp einminütigen Exposition fällt die Betonung von Zahlen besonders auf, was dem Zuschauer auf schonungslose Weise das Ausmaß der Vernichtung offenbart. Im ersten Teil wiederholt der Sprecher die Zahl elfhundert innerhalb von zwei Sätzen vier Mal, im zweiten Teil der Exposition betont er, daß Millionen interniert und getötet wurden. Darüber hinaus nennt er die Anzahl der Konzentrationslager.

41. Die Art und Weise, wie hier die die Kreuze tragenden Männer aufgenommen werden - sie laufen auf eine ihnen im Weg stehende Kamera zu und an ihr vorbei - erinnert an die Inszenierung in Leni Riefenstahls TRIUMPH DES WILLENS (D 1935). Entsprechende Ausschnitte verwendet Alain Resnais zu Beginn seines filmischen Essays NACHT UND NEBEL (fahnentragende Männer laufen auf die Kamera zu). 


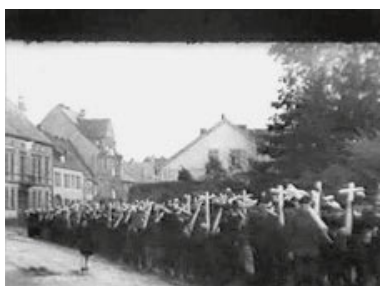

(62) $0: 00: 16 \mathrm{~h}$

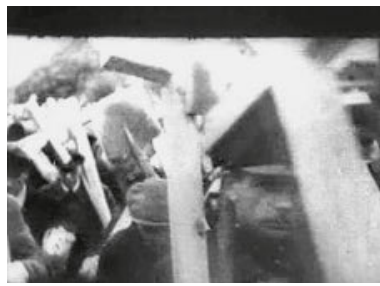

(65) $0: 00: 25 \mathrm{~h}$

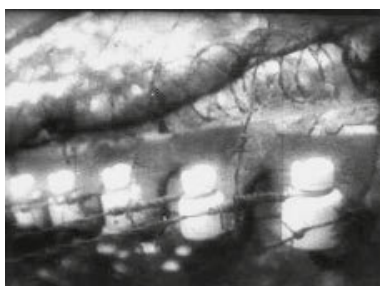

(68) $0: 00: 36 \mathrm{~h}$
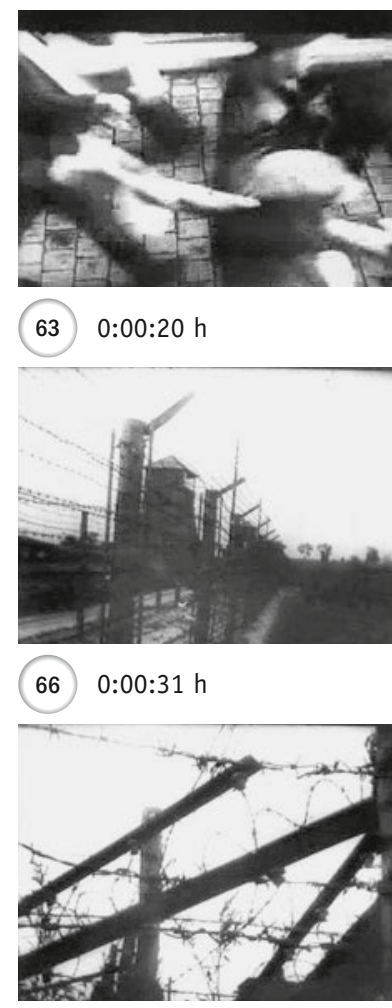

(69) $0: 00: 37 \mathrm{~h}$
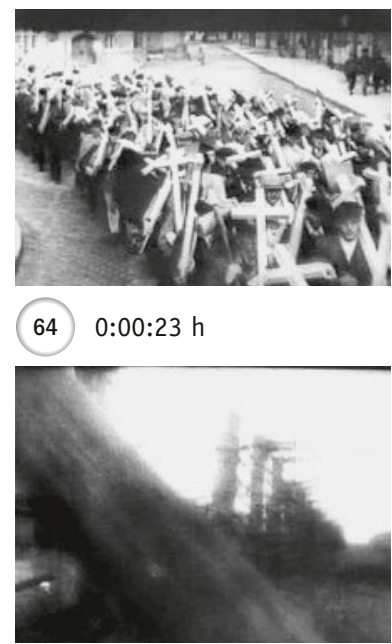

(67) $0: 00: 34 \mathrm{~h}$

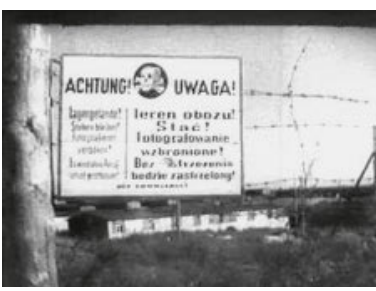

(70) $0: 00: 39 \mathrm{~h}$

Bereits in der ersten Hälfte der Exposition waren die zahlreichen schnellen Einstellungswechsel mit zum Teil kunstvollen Bildkompositionen von leiser, untermalender, schwermütiger Musik begleitet, die in der zweiten Hälfte der Exposition fortgeführt wird und beim Pausieren des Sprechers lauter wird. Wie beim »KreuzMarsch « fällt schon bei den ersten Einstellungen der aktuellen Szenenfolge (»Die KZ’s als Gefängnis«) die künstlerische filmische Inszenierung auf, die sich in späteren Filmen (insbesondere) von Resnais (NACHT UND NEBEL), Lanzmann (ShoAh) und Ivens (BIRKEnAu Und Rosenfeld) in vergleichbarer Weise wiederfindet: Die filmische Annäherung an die Lager erfolgt - wie in der Exposition von NaCht und Nebel (s. II.2.1.3) - durch wiederholte Kamerablicke von außen nach innen, die zum größten Teil den Stacheldraht und somit die Abgeschlossenheit dieser Lagerwelt erfahrbar machen (s. v.a. o:00:34, 0:00:36 u. 0:01:03 h). Wie zuvor die weißen Holzkreuze (s. insb. ০:00:25 h) sticht dem Zuschauer in diesen Aufnahmen im Bildvordergrund der Stacheldraht förmlich ins Auge, insbesondere in o:૦०:34 h - eine Einstellung, die darüber hinaus mit einer tastenden Kamerabewegung verbunden ist, wodurch die Dichte des Stacheldrahtzauns deutlich und der Gefängnischarakter der Lager spürbar wird (s. auch o:००:36 u. ०:००:37 h). Nachdem bei diesen Bildern das Publikum ahnen kann, daß der Stacheldraht elektrisch geladen ist (s. v.a. ০:০০:36 h), sichert der in der folgenden Einstellung wieder einsetzende Kommentator diese Vermutung ab. Beginnend mit der Aufnahme eines Warnschildes (s. ০:००:39 h) erläutert er: 
»Unter elektrisch geladenem Stacheldraht (s. 0:00:41 h) wurden Millionen gefangengehalten, (s. 0:00:44 h) wurden nach bisherigen Schätzungen 20 Millionen Menschen gemordet. In allen Teilen Deutschlands und den (s. 0:00:50 h) besetzten Gebieten gab es Konzentrationslager, zusammen waren es mehr als dreihundert ... Todesmühlen sie alle.« (0:00:38 - 0:01:00 h)

Explizit liefert der Text am Ende der Exposition die Erklärung für den Filmtitel: >Todesmühlen< wird demnach synonym und metaphorisch für die nationalsozialistischen Konzentrationslager gebraucht (s. 1.1.1 und 1.1.2). Während die musikalische Untermalung allmählich ausklingt, inszenieren zwei weitere Einstellungen den Stacheldrahtzaun der Schreckensorte (s. 0:01:02 u. 0:01:03 h). Vor allem die vorletzte Einstellung fällt durch ihre besondere ästhetische Gestaltung auf (s. 0:01:02 h): In einer klassischen Zentralperspektive wird der doppelte Stacheldrahtzaun in seiner Länge durch eine beeindruckende Bildflucht und in seiner Eigenschaft als Trennelement zwischen außen und innen im Bildvordergrund besonders in Szene gesetzt. Ähnliche Bildkompositionen findet man noch heute in der künstlerischen Lagerfotografie, wodurch dem Zuschauer das gewaltsame Eingeschlossen-Sein, das GefangenSein vermittelt wird.

Nachdem im letzten Drittel der Sequenz »Deutsche müssen das Desaster in den befreiten Konzentrationslagern betrachten« (s. 1.1.3) die Schuld des »deutschen Volkes« dreifach begründet wurde und der Zuschauer in die Kollektivschuld durch den hier einmaligen sowie gezielten Einsatz der ersten Person Singular (»ich«) zwangsweise einbezogen wurde ${ }^{42}$, wird die Anklage in den folgenden Schlußszenen noch gesteigert. Mittel hierzu ist der Einsatz von Rhetorik dort, wo die Fakten schon extrem deutlich sind:

»Erinnert Ihr Euch noch (s. 0:19:52 h) - 1933, 1936, 1939? War ich dabei? Was habe ich dagegen getan? Millionen Deutsche (s. 0:20:07 h), die dem Bösen (s. 0:20:08 h) zujubelten. Millionen Deutsche, die sich an Haß und Rachegesängen berauschten. (s. 0:20:16 h) Millionen Deutsche, die dem freien Wort, dem freien Geist Tod und Verderben schworen. Millionen Deutsche, die ihre Hand liehen, um unschuldige Menschen, wehrlose Völker zu überfallen und zu morden. Die Saat (s. 0:20:35 h) ist aufgegangen - Kreuze - hundert Kreuze, tausend Kreuze, Millionen (s. 0:20:46 h) Kreuze für die Opfer der deutschen Todesmühlen.« (Eigene Hervorhebung; 0:19:51 - 0:20:49 h)

Das »ich« aus der vorangehenden Szene beibehaltend, redet der Kommentator dem Zuschauer zunächst mit rhetorischen Fragen ins Gewissen, indem er ihn fragt, was er

42. "Sie mußten sterben, weil das deutsche Volk sich widerstandslos in die Hände von Verbrechern und Wahnsinnigen begab. Weil das deutsche Volk zuließ, daß in seinem Namen, Recht und Gerechtigkeit mit Füßen getreten wurden. Weil das deutsche Volk in brutaler Machtgier der Ehrfurcht vor Gott und der Ehrfurcht vor dem Mitmenschen abschwor. Ja, das war damals. Beim Siegeszug der S.A. durchs Brandenburger Tor, da marschierte ich mit. Ja, ich erinnere mich. Beim Nürnberger Parteitag hab ich >Heil geschrien. Und dann, an einem andern Tag, als die Gestapo meinen Nachbarn holte, hab ich mich abgewendet und gefragt, >was geht's mich an<? « (Eigene Hervorhebung; 0:18:54-0:19:50 h) 

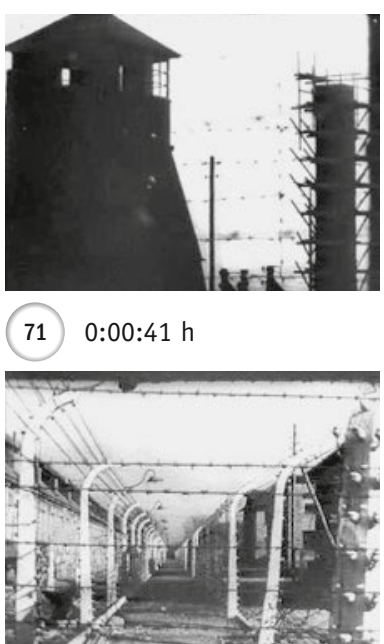

(74) $0: 01: 02 \mathrm{~h}$

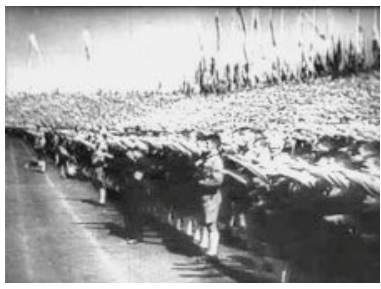

(76) $0: 19: 52 \mathrm{~h}$

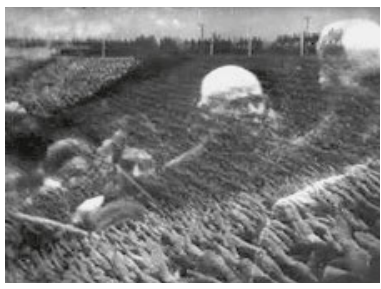

(79) $0: 20: 16 \mathrm{~h}$

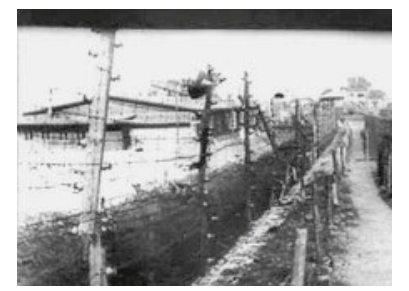

(72) $0: 00: 44 \mathrm{~h}$

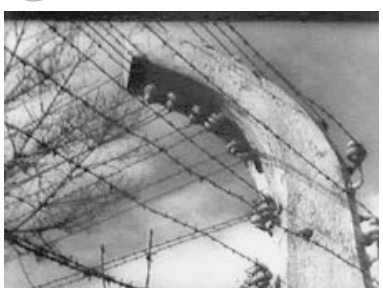

(75) $0: 01: 03 \mathrm{~h}$

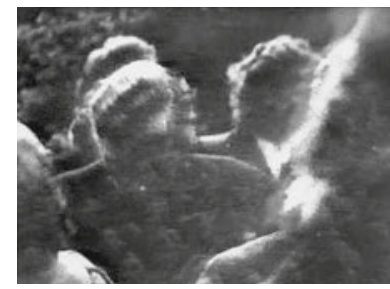

(77) $0: 20: 07 \mathrm{~h}$

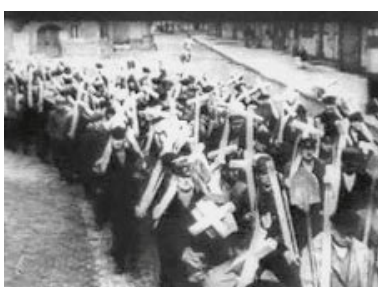

(80) $0: 20: 35 \mathrm{~h}$

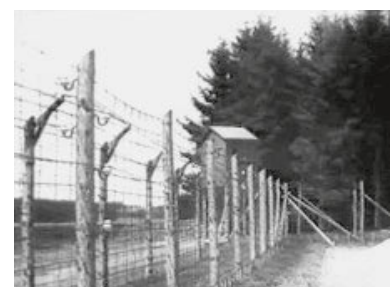

(73) $0: 00: 50 \mathrm{~h}$

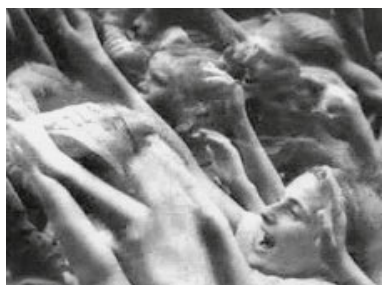

(78) $0: 20: 08 \mathrm{~h}$

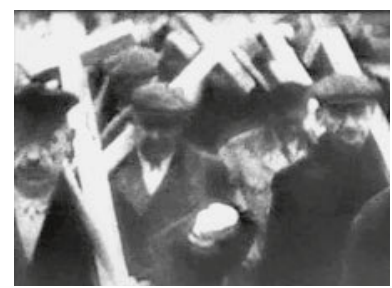

(81) $0: 20: 46 \mathrm{~h}$

gegen die Nazis unternommen habe. Parallel hierzu wird er mit Aufnahmen aus Leni Riefenstahls Triumph Des Willens (1935) vom Nürnberger Parteitag 1934 konfrontiert. In einer Kamerafahrt zeigen sie die dem Führer mit dem Hitlergruß die Ehre erweisenden Menschenmassen (s. 0:19:52 h).

Die anklagende Aufzählung, wie »Millionen Deutsche« Hitler zujubelten und seine Vernichtungspolitik unterstützten, wird auf besondere filmische Art und Weise in Szene gesetzt: Wiederholt überblendet Burger die bereits bekannten Aufnahmen der deutschen Zivilbevölkerung beim Betrachten des Desasters (s. o:20:07 h) mit Bildern des Hitlergrußes in näherer Einstellungsgröße. Die sich für Hitler begeisternde Menge aus dem Jahre 1934 wird so mit den abgebildeten deutschen Bürgern von 1945 sowie dem Zuschauer ausnahmslos und ohne Nuancierung gleichgesetzt, jeder Deutsche wird zum Mittäter, zum Schuldigen gemacht. 
Die letzten Einstellungen greifen den »Kreuz-Marsch« von Gardelegen aus den ersten Bildern des Films auf (s. 0:20:46 h), der Rahmen schließt sich mit zum Teil gleichem Bildmaterial (s. o:20:35 h). Im Unterschied zum Filmauftakt informiert der Sprecher hier nicht über die spezifische Situation, sondern benutzt sie symbolisch für das Ausmaß der nationalsozialistischen Vernichtung. Daher wiederholt er nicht die exakte Anzahl von Holzkreuzen, sondern spricht zunächst von hundert, dann von tausend und schließlich von Millionen - die Steigerung ikonisiert das Ausmaß der Vernichtung ebenso wie sie die Größe der Schuld unterstreichen soll. Auch das Schlußwort des Kommentators sowie des Films unterscheiden sich vom Filmanfang: die »deutschen Konzentrationslager« werden durch die »deutschen Todesmühlen« ersetzt. In dieser Formulierung steckt neben stärkerer Anschaulichkeit auch erheblich mehr Anklage (s. 1.1).

43. Auch in seinem späteren, eineinhalb Stunden dauernden Dokumentarfilm, SOBIBOR, 14. OKTOBER 1943, 16 UhR (F 2001), läßt Lanzmann Aufnahmen des Überlebenden mit denen des einstigen Vernichtungslagers alternieren.

44. Vgl. insbesondere die Übertragung der Gedenkveranstaltung am 27.01.2005 vom 60 . Jahrestag der Befreiung des Lagers Auschwitz-Birkenau sowie die Bilder entsprechender Gedenkveranstaltungen aus anderen ehemaligen Konzentrations- und Vernichtungslagern. Vgl. auch die unzähligen Dokumentationen im Fernsehen, u.a. auch LAGERSTRASSE AusCHwITZ von Ebbo Demant (BRD 1979).

45. Vgl. Lanzmanns Auffassung, daß die Orte nicht von selbst sprechen (1990: 290); vgl. den Film Birkenau und Rosenfeld, in welchem Lagerbesucher sich darüber wundern, daß die Orte sie nicht »ansprechen« (s. II.5.5.d).

46. »Die Vernichtungslager sind traumatische Orte, weil der Exzeß der dort verübten Greueltaten menschliches Fassungs- und Darstellungsvermögen sprengt. [...] Traumatische Orte, Erinnerungsorte und Generationenorte überlagern sich in dieser Gedächtnislandschaft [...].« (Ebd. 27) 


\section{II.2 «Sprechende« Erinnerungsorte und Zeitzeugen?}

Neben Fotografen (s. I.1), haben sich nach Alain Resnais (NACHt Und NebeL, F 1955, s. II.2.1) weitere Filmemacher an die einstigen Schreckensorte und somit auf Spurensuche begeben:

Rund drei Jahrzehnte nach Resnais' filmischem Essay griff Claude Lanzmann dessen Verfahren (der Rückkehr an die Vernichtungsstätten) auf und drehte in etlichen Vernichtungslagern, darunter Auschwitz-Birkenau, Belzec, Chelmno, Sobibor und Treblinka - Aufnahmen, die in seinem neunstündigen Dokumentarfilm Sнонн (F 1985, s. II.2.2) die Schilderungen zahlreicher Holocaust-Überlebender begleiten. ${ }^{43}$

Vergleichbar mit dem Dokumentarfilm KitTy's RETU Rn to Auschwitz (USA 1979) und den Sequenzen um Simon Srebnik aus Lanzmanns Sнонн (s. II.2.2.6) erzählt die Holocaust-Überlebende Marceline Loridan-Ivens in ihrem Spielfilm BIRKENAU Und Rosenfeld (La petite Prairie aux Bouleaux, F/D/POL 2003, s. II.5) die Rückkehr ihres fiktiven Alter ego nach Auschwitz-Birkenau.

Die einstigen Schreckensorte üben insbesondere auf Medien eine gewisse »Faszination« aus. ${ }^{44}$ Oder handelt es sich hierbei um eine gewisse Hilflosigkeit, d.h. man hofft, dort könne einen etwas anwehen, wenn man schon nicht weiß, wie man die Lagerrealität begreifen soll. Aber »die Steine schreien nicht« (Klüger zit.n. Thiele 2001: 392), das heißt: Es reicht nicht, eine Kamera die Ruinen-Landschaft dieser Orte einfangen zu lassen. Wie für die zeitgenössische Lagerfotografie (s. I.1) stellt sich die Frage: Wie - wenn überhaupt (Young 1993: 17) - können diese ehemaligen Vernichtungsstätten »zum Sprechen gebracht« werden, wenn Aleida Assmann schreibt, diese sogenannten Erinnerungsorte seien »erklärungsbedürftig« (1996: 16)?:45 Durch eine Montage verschiedener Gestaltungsmittel wie in NACHT und NEBEL, darunter der elaborierte Off-Kommentar eines Überlebenden, vorgetragen von einem Sprecher? Oder durch einen zum Teil vage zusammenhängenden Off-Bericht (SHOAH)? Oder aber durch die von Zeit zu Zeit auf sie hereinbrechende, verbalisierte Erinnerung einer fiktiven Überlebenden, deren Rückkehr an den einstigen Schreckensort inszeniert wird, wie in BIRKENAU und Rosenfeld? Zentral ist in diesem letztgenannten Spielfilm, daß der Erinnerungsorten allgemein zugeschriebene »Status als Kontaktzone« (ebd. 25) wörtlich genommen wird: Auslöser für die Erinnerungen der Protagonistin ist die mit den einstigen Vernichtungsstätten einhergehende »sinnliche Konkretion« (ebd.), insbesondere das Be-Greifen (s. II.5.2). Der »unmittelbare Kontakt mit der Vergangenheit« (ebd.) ist demnach nicht per se an sogenannten auratischen Orten anzutreffen, er muß zum Teil mit erheblicher Mühe und Anstrengung hergestellt werden. Hierbei wird die Vergangenheit, so BiRKENAU und Rosenfeld, keineswegs zwangsläufig »durch die Augen, die auf Relikte stoßen [sinnlich erfahrbar]« (ebd. 17). Dieser Film macht deutlich, daß es sich bei den einstigen Vernichtungslagern um »traumatische Orte« handelt, deren »Bindungskraft auf einer Wunde [basiert], die nicht vernarben will« (ebd. 16). ${ }^{46}$

Sind die Aufnahmen der Lager, wie besonders im Zusammenhang mit NACHT UND NEвеL und Sноан behauptet, Anlaß für Vorstellungsbilder oder rufen sie - zumindest heute - schlicht historisches Wissen ab? Oder werden gerade solche Aufnahmen Pro- 
jektionsanlaß der fertigen Gedächtnisbilder bzw. riskiert die »Schönheit« der Bilder nicht, das Grauen der historischen Ereignisse zu verbergen?

Nach Resnais' Nacht und NeBel, spätestens jedoch nach Loridan-Ivens' BiRKeNAU UnD RoSENFELD sollte deutlich geworden sein: Entgegen Lanzmanns Glaube an die Wirkkraft der Orte bleibt die immense Herausforderung im Umgang mit den sogenannten Erinnerungsorten ungelöst.

Aus Birkenau und Rosenfeld und den Führungen von Schulklassen durch Überlebende läßt sich schließen, daß es einer gewissen Lenkung sowie der Identifikation mit einer Person bedarf, um die Orte zum Sprechen zu bringen.

Ist es daher nicht vielleicht das Naheliegendste, Zeitzeugen zu befragen bzw. zu Wort kommen zu lassen, zumal man ihnen in der Nachkriegszeit kaum zugehört hat? Würde aus dieser Sicht nicht das Spielbergprojekt »Survivors of the Shoah « eine, wenn nicht gar die einzige Möglichkeit darstellen, ein audiovisuelles Archiv zur lebendigen Erzeugung von Erinnerung aufzubauen?

Oder geht dieses, Lanzmanns Sнонн nachempfundene Projekt nicht von der zu hinterfragenden Prämisse aus, daß jemand, der überlebt hat, am besten zur Vermittlung geeignet ist und »Deutungsautorität « hat?47 Könnte es sich nicht auch umgekehrt verhalten, d.h. daß möglicherweise ein »Außenstehender«, der sich, aus welchen historischen Gründen auch immer, involvieren läßt, mehr Verständnis und damit Vermittlungsformen für ein Publikum entwickeln kann, das, wie die dritte Nachkriegsgeneration, in einer historischen Distanz von etlichen Jahrzehnten zu den Geschehnissen lebt?

Oder aber sind die Überlebenden des Holocaust, wie Primo Levi schreibt, >falsche< Zeugen, da sie im Vergleich zu den »Untergegangenen« eine »verschwindend kleine«, vor allem jedoch eine »anormale Minderheit« sind - diejenigen, »die aufgrund von Pflichtverletzung, aufgrund ihrer Geschicklichkeit oder ihres Glücks den tiefsten Punkt des Abgrunds nicht berührt haben « (1990: 83)? Aber reichen andererseits die Augenzeugenberichte dieser »Ausnahmen « (ebd. 84) nicht aus, sich die grauenhaften Lagerbedingungen, die systematische Vernichtung vorzustellen?

47. »Bis SCHINDLERS LISTE galt die >Deutungsautorität der Überlebenden<. Eine wahre Darstellung des Holocaust ist an die unmittelbare Erfahrung der überlebt Habenden in den Konzentrationslagern geknüpft. Deren Darstellungen sind gesellschaftlich legitimierter Ausdruck einer >magischen Authentiziätı." (Krankenhagen 2001: 210, H.i.0.)

48. Damit folgt er dem von Schreitmüller analysierten »Prinzip Assoziation« bei der Wahl eines Filmtitels (1994: 99f.), das sich durch besonderen Einbezug des Zuschauers auszeichnet: »Dieses Verfahren hat den Vorteil, daß eine semantische Spannung zwischen seigentlicher und >übertragener` Bedeutung aufgebaut wird.« (Schreitmüller 1994: 100) Dies bedeutet, daß mit der Präsentation eines bestimmten Begriffs unter Umständen bei Rezipienten ein ganzes >Wortfeld aktiviertı wird.« (Ebd. 99, H.i.0.)

49. Vgl. Raskin 1987: 15ff., van der Knaap 2002: 69, Avisar 1988: 14f. Hinsichtlich des eigentlichen Ursprungs des Ausdruckes »Nacht und Nebel« in Richard Wagners »Rheingold« vgl. Raskin 1987: 18ff.

50. »The words >night and fog were used by Hitler and the Nazis as a military code name to indicate their will to hide and make disappear any possible trace of the Holocaust [...]« (Colombat 1993: 143) Um die 15. Filmminute wird eine dieser Nacht-und-Nebel-Aktionen im Film inszeniert, als Lastwagen KZ-Insassen unbemerkt zur Vernichtung abholen. 
Im Vergleich zu Resnais und Lanzmann thematisiert Loridan-Ivens in BIRKENAU UND Rosenfeld explizit und wiederholt die Probleme musealer Inszenierung der einstigen Vernichtungslager, wie sie beispielsweise von Ruth Klüger und Claude Lanzmann aufgezeigt wurden:

»Dachau hab ich einmal besucht [...]. Da war alles sauber und ordentlich, und man brauchte schon mehr Phantasie, als die meisten Menschen haben, um sich vorzustellen, was dort vor vierzig Jahren gespielt wurde. Steine, Holz, Baracken, Appellplatz. Das Holz riecht frisch und harzig, über den geräumigen Appellplatz weht ein belebender Wind, und diese Baracken wirken fast einladend. Was kann einem da einfallen, man assoziiert eventuell eher Ferienlager als gefoltertes Leben. [...] Aber das KZ als Ort? [...] Heute verschweigen sie oft ebensoviel, wie sie vermitteln.« (Klüger 2001: 77)

»Mais musée et commémorations instituent l'oubli autant que la mémoire.« (Lanzmann in seinem Vorwort zu SOBIBOR, 14. OKTOBER 1943, 16 UHR, F 2001)

Loridan-Ivens begegnet diesem Aspekt abwägend. Während sie das positive Potential gewisser musealer Inszenierungen durch filmische Inszenierung besonders entfaltet (s. 5.6. b), macht sie ebenso eindringlich die Probleme anderer Formen der Gestaltung erfahrbar (s. 5.6.a und 5.6.c). Assmann faßt das Problem nüchtern zusammen: »Die zu Gedenkstätten und Museen umgestalteten Erinnerungsorte unterliegen einem tiefgreifenden Paradoxon: Die Konservierung dieser Orte im Interesse der Authentizität bedeutet unweigerlich einen Verlust an Authentizität. Indem der Ort bewahrt wird, wird er bereits verdeckt und ersetzt.« (1996: 22)

»Groß ist die Kraft der Erinnerung, die Orten innewohnt«, demnach nur unter bestimmten Bedingungen ... (Cicero zit.n. Assmann 1996: 13)

\section{II.2.1 KONTRAPRODUKTIVE ÜBER-ÄSTHETISIERUNG: »NACHT UND NEBEL« (»NUit et BROUILLARD«, Alain ResNais, F 1955)}

\subsubsection{Ein Filmemacher, ein Literat und ein Musiker - Ästhetik auf allen Ebenen}

Bereits mit der Wahl des in allen Versionen gleichlautenden Titels - im Original NuIT ET Brouillard, in der deutschen Version NaCht und Nebel und in der englischen Night AND Fog - grenzt sich der französische Regisseur Alain Resnais von den genannten alliierten Entnazifizierungsfilmen (s. II.1) deutlich ab. Während diese auf die Orte der systematischen Vernichtung hinweisen, bietet Resnais' Filmtitel unterschiedliche Assoziationsmöglichkeiten. ${ }^{48}$

Für sachkundige Zuschauer verweist der Titel auf den sogenannten »Nacht und Nebel Erlaß« von 1941; dieser Verordnung zufolge mußten Regimegegner, ohne Aufsehen zu erregen, beseitigt werden. ${ }^{49}$ Es sollten also gerade keine Spuren der Vernichtung hinterlassen werden, was zumindest das deutsche Publikum an den Ausdruck >bei Nacht und Nebel davon gehen< bzw. > Nacht-und-Nebel-Aktion< erinnert; letzterer hat in den alltäglichen Sprachgebrauch Einzug gehalten..$^{\circ}$ Nach dem didaktischen Fehlschlag der Re-education-Filme und im Zusammenhang mit dem 
Beginn des Kalten Kriegs war eine massive Verdrängung des Holocaust zu beobachten. Mit der Wahl des Titels wollte Resnais daher die Gefahr andeuten, daß sich die Naziverbrechen zehn Jahre nach Kriegsende in Nacht und Nebel auflösten bzw. bereits in Vergessenheit gerieten - eine Anklage der Verbrechen, ein Aufschrei gegen das Vergessen..$^{1}$

Vor allem dem französischen Publikum konnte der intertextuelle Bezug zu Jean Cayrols 1945 erschienenem Gedichtband »Poèmes de nuit et brouillard« auffallen, in welchem der für den Kommentar des Films verantwortlich zeichnende, ehemalige Mauthausen-Insasse seine Lagererfahrungen veröffentlicht.

In den ersten Jahrzehnten nach dem Krieg wurde der Ausdruck »Nacht und Nebel« in Frankreich als Synonym und Umschreibung für den Holocaust verwandt (vgl. Thiele 2001: 168), was nicht zuletzt mit einem bekannten Song von Jean Ferrat zusammenhängt: Nacht und Nebel »became the title of a very famous French song written and sung by the rengagé< French singer and poet [...] to remember the atrocities of the Holocaust« (Colombat 1993: 143, H.i.O.).

Alain Resnais' filmischer Essay NACHT Und NeBEL ist sowohl der erste westeuropäische (Dokumentar-)Film nach den Entnazifizierungsfilmen (s. II.1), in dem ausschließlich die Verbrechen in den Konzentrationslagern thematisiert wurden (vgl. Knoch 2001: 518), als auch der erste Film, der in Deutschland »eine bundesweite und mehrere Monate andauernde publizistische Kontroverse über die Darstellung des Massenmordes im Film ausgelöst hat« (Thiele 2001: 167).

Ausgehend vom Scheitern der Entnazifizierungsfilme stellt er gleichzeitig den ersten deutlichen Versuch dar, die psychischen Barrieren der Annahme des Holocaust durch eine künstlerische Herangehensweise erfahren zu überwinden. »NACHT UND NEBEL bekennt sich dezidiert zum ästhetischen Code. Er beharrt auf seiner Artifizialität, will Kunstwerk sein [...] (Jochimsen 1996: 225).52 Auf diese Weise versucht Resnais, im Unterschied zu den Entnazifizierungsfilmen, die Menschen tatsächlich zu erreichen, sie zu einer »Haltung zu provozieren« (Heller 1997: 225): »Les courts

51. In diesem Sinne ist Avisars Interpretation des Films als Versuch, „to penetrate the Kingdom of the Night through the fog of the present« interessant (Avisar 1988: 12f.). Vgl. auch Dümling 1993: 117 und Thiele 2001: 167f. Darüber hinaus könnte der Titel den Zuschauer u.U. an die gespenstische Inszenierung der nächtlichen Ankunft im Lager erinnern. Dies wird in Sequenz vier bestätigt. Die »Razzien- und Deportations«-Sequenz endet mit Aufnahmen der Transporte in Güterwaggons, während der Kommentator erklärt: »La mort fait son premier choix. Un second est fait à l'arrivée dans la nuit et le brouillard.« (0:06:56-0:07:02 h)

52. Nach eigener Aussage wollte Resnais mit NACHT UND NEBEL einen »film lyrique« machen (Resnais auf Original-DVD). »In der deutschen wie in der internationalen Literatur wird NACHT UND NEBEL als erste künstlerisch gelungene filmische Auseinandersetzung mit dem Naziterrorsystem gelobt. Dieser nur dreißigminütige Film habe Maßstäbe gesetzt.« (Thiele 2001: 206) Vgl. auch Heller 1997: 224.

53. Inwiefern dies gelingt oder nicht, wird insbesondere im Rahmen der detaillierten Sequenzanalysen untersucht (s. II.2.1.3-II.2.1.7).

54. »[...] the documentary's presentations inside a camp of a symphonic orchestra, a zoo, green houses, Goethe's oak, an orphanage, a hospital for invalids etc. (Prédal zit.n. Colombat 1993: 127) 
métrages en 45 et 46 n'ont atteint aucun public. Avec NuIT ET BRouillard, j’ai eu la volonté de faire un film susceptible d'atteindre un grand public.« (Resnais zit.n. Raskin 1987: 136)

Der Regisseur verbindet in diesem Film Information mit Meditation sowie Vergangenheit mit Gegenwart. Daraus resultiert ein vielschichtiges Werk »mit drei Aussageebenen - über das Vernichtungslager als Prototyp des Massenmordens, über die Grenzen der Sagbarkeit und des Versuchs, einen Dokumentarfilm darüber zu machen, und über die Verschränkung von Gegenwart und Vergangenheit in der Erinnerung « (Knoch 2001: 519f.).

Neben der informierenden Darstellung der Vergangenheit will der Film vor allem zur Auseinandersetzung mit dem Holocaust aufrufen und seinem Verdrängen bzw. Vergessen entgegenwirken, indem er die Vorstellung bzw. Erinnerung des Zuschauers anzuregen versucht:

»Das eigentliche Thema des Films ist nicht das Geschehene selbst, sondern die Erinnerung daran, der Prozeß der Spurensuche, die sich der Übermacht des Verschweigens, Vergessens und Verdrängens entgegenstemmt.« (Dümling 1993: 117)

»[...] stellt der Film das historische Erinnern und die daraus vermeintlich ableitbaren Lektionen für die Zukunft in sein Zentrum.« (van der Knaap 2002: 74)

»Während Spielberg das Vergangene als eine Geschichte erzählt, die sich in unserem Beisein entwickelt, inszeniert Resnais die Problematik des Erinnerns. Statt den Zeitsprung einzuebnen, stellt er ihn heraus; statt die Möglichkeit des Begreifens einzuräumen, zeigt er, wie es sich immer wieder entzieht.« (Kramer 2000: 20)

In deutlicher Abgrenzung von den Entnazifizierungsfilmen setzt der Regisseur auf eine Mischung aus Ausbalancierung des Grauenhaften und deautomatisierender Diskrepanz, die den Zuschauer zur Auseinandersetzung, zum Nachdenken anregen soll.53 Versucht wird dies vor allem durch Kontrastwirkung. Colombat nennt in diesem Zusammenhang vier »rupture lines of NIGHT AND FOG: the emergence of horror in the heart of banality; the reverse emergence of frightening banality in the heart of horror ${ }^{54}$; the ambivalent reactions of the spectator, both intellectual and sensitive; and the insistence that the horror is still present among us today [...].« (Colombat 1993: 129)

Diese »explosive oppositions « sollen vor allem den kritischen Verstand des Zuschauers wachrufen (Prédal zit. ebd. 127), »forcing them to consider different aspects without letting them be hypnotized by an overwhelming feeling of horror « (Colombat 1993: 147). Auf diese Weise - so der Regisseur und zahlreiche Rezensenten - richtet sich Nacht und Nebel weniger an dessen Emotionen; der Zuschauer sollte »mit dem Kopf statt mit den Nerven [...] reagieren« (Truffaut zit.n. Paech 1993: 128):

$»[\ldots]$ Resnais's film addresses the audience's intelligence [...].« (Insdorf 2003: 36)

»[The film] addresses both the spectator's intellect and imagination in both the present and the future of the viewing." (Colombat 1993: 123) 
»Was wir wollten, war: ein Zuschauer, den man zu einer Handlung veranlassen kann, statt ihn nur gefühlsmäßig zu erregen [...].« (Resnais zit.n. Dümling 1993: 123)

Der zentrale Kontrast des Films besteht zwischen (a) der Gegenwarts- und (b) der Vergangenheitsebene: Beinahe idyllisch anmutende Lageraufnahmen in Farbe aus den fünfziger Jahren und historisches Archivmaterial in Schwarzweiß sind in aller Regel schnell nach- bzw. ineinander geschnitten und steigern sich dadurch wechselseitig in ihrer Wirkung. ${ }^{5}$

$»[\ldots]$ Resnais joue au maximum de cette opposition contraction-décontraction. [...] elle évite aussi notre accoutumance à l'horreur. Les séquences en couleurs, contrepoint subtil, font ressortir davantage l'atrocité des images en noir et blanc.» (Pinel zit.n. Raskin 1987: 143)

Fraglich ist jedoch, ob beide Ebenen in der von François Truffaut beschriebenen Weise interagieren, als Mittel der Distanzierung wirkt diese Gegenüberstellung jedenfalls: »Als er [Resnais] eine Farbreportage mit schwarzweißen Zeitdokumenten verband, kam es für Resnais darauf an, letzteren ihre makabre Theatralität zu nehmen, das schreckliche Pittoreske, das ihnen eigen ist [...].« (Truffaut zit.n. Paech 1993: 128)

Hinsichtlich des Verhältnisses zwischen beiden Zeitebenen machen verschiedene Rezensenten darauf aufmerksam, daß diese nicht nur miteinander kontrastieren, sondern durchaus auch komplementär sind:

»Er inszeniert das Erinnern, indem die Kamera in rastlosen Fahrten die Originalschauplätze absucht. Das Erinnerte aber fällt in bezug auf die visuellen Parameter des Films mit dem schwarzweißen Material zusammen. Es bietet die grauenhafte Antwort auf die fragenden Kamerafahrten.« (Kramer 2000: 17)

»Kaum sind Spuren des Geschehens sichtbar, kippt das Farbbild abrupt ins schwarzweiße Bildmaterial und diese Bewegung ins Schwarzweißbild markiert zeichenhaft die Memoria." (Jochimsen 1996: 224f.)

»Resnais sagt im Interview: >In der Erinnerung denkt man ein wenig in Grau oder jedenfalls in einer weniger klaren Farbe`.« (Resnais zit.n. ebd. 225)

»Das historische Filmmaterial dient nicht als Beweis, als Dokument einer vergangenen Wirklichkeit, sondern als ästhetisches Medium zur Darstellung von Erinnerung. Durch dieses Kontrastverfahren, durch den Wechsel zwischen dem Suchen in der farbigen Gegenwart und den

55. „Diese Spannung zwischen Damals und Heute, zwischen Geschehen und Vergessen ist das Gliederungsprinzip des Films. (Jochimsen 1996: 224) Vgl. Hattendorf zur »makrostrukturellen Ordnung von Farb- und Schwarz/weiß-Sequenzen [...]: 12 Farbsequenzen umklammern und unterteilen die 11 Schwarz/weiß-Sequenzen im Inneren des Films." (1999: 209) Vgl. Richard Raskins Sequenzprotokoll, das sich exakt an dieser Zweiteilung des Films orientiert (Raskin 1987: 69-130).

56. »Zum Ausgangspunkt des filmischen Erinnerns wird dadurch die Abwesenheit des historischen Ereignisses, nicht dessen inszenierte Präsens.« (Kramer 2000: 18) 
>gefundenen Schwarzweißbildern, erhalten die Archivaufnahmen ihre Authentizität, ihre Authentizität als Spuren der Erinnerung.« (Ebd. 225, H.i.0.)

Ergebnis dieser Gegenüberstellung von Gestern und Heute ist eine kunstvolle Kompositionsstruktur, »eine filmische >Recherche du temps perdu< zwischen Dokumentarfilm und Essayfilm« (Hattendorf 1999: 206, H.i.O.).

Um die künstlerische Komplexität von NACHT und NeBEL zu erfassen, ist es zweckmäßig, zwischen visueller (A.) und auditiver (B.) Ebene zu unterscheiden, innerhalb letzterer zusätzlich zwischen Off-Kommentar (B.1) und musikalischer Begleitung (B.2).

\begin{tabular}{|c|c|c|c|}
\hline \multicolumn{3}{|c|}{ NACHT UND NEBEL } \\
\hline \multicolumn{2}{|c|}{ A. visuelle Ebene (Resnais) } & \multicolumn{2}{c|}{ B. auditive Ebene } \\
\hline $\begin{array}{c}\text { A.1 Farbe } \\
(1955)\end{array}$ & $\begin{array}{c}\text { A.2 Schwarzweiß } \\
(1933-1945)\end{array}$ & $\begin{array}{c}\text { B.1 Kommentar } \\
\text { (Cayrol) }\end{array}$ & $\begin{array}{c}\text { B.2 Musik } \\
\text { (Eisler) }\end{array}$ \\
\hline
\end{tabular}

Abb. II.2.1.a

Zunächst zur visuellen Ebene, für die Alain Resnais verantwortlich zeichnet:

\begin{tabular}{|c|c|c|}
\hline \multicolumn{3}{|c|}{ A. Visuelle Ebene (Resnais) } \\
\hline A.1 Farbe/Heute (1955) & \multicolumn{2}{|c|}{ A.2 Schwarzweiß/Gestern (1933-1945) } \\
\hline bewegte, tastende Kamera i.a.R. & $\begin{array}{c}\text { statisches } \\
\text { Archivmaterial / } \\
\text { unbewegte Kamera }\end{array}$ & $\begin{array}{c}\text { bewegte historische } \\
\text { Aufnahmen / } \\
\text { bewegte Kamera }\end{array}$ \\
\hline \multirow[t]{2}{*}{ ca. 10 min. (14 Szenen) } & \multicolumn{2}{|c|}{ ca. 20 min. (21 Szenen) } \\
\hline & $\begin{array}{l}\text { ca. } 11,5 \text { min. } \\
\text { (14 Szenen) }\end{array}$ & $\begin{array}{l}\text { ca. 8,5 min. } \\
\text { (17 Szenen) }\end{array}$ \\
\hline
\end{tabular}

Abb. II.2.1.b

\section{A.1 - Farbe/Heute (1955):}

Die Farbaufnahmen, die Resnais 1955 in den polnischen Konzentrationslagern Auschwitz und Maidanek gedreht hat (vgl. Hattendorf 1999: 206 u. Raskin 1987), machen rund ein Drittel des Films aus und werden hauptsächlich dort eingesetzt, »wo kein Originalmaterial vorlag, etwa für das Barackenleben oder das Morden in den Gaskammern« (Knoch 2001: 521).56

Deren überwiegende Beschaulichkeit läßt den Zuschauer die Problematik von Erinnerungsorten erfahren:

»Die mit den Lagern zitierte industrielle Massenvernichtung wird im Film kontrastiert mit der Tatsache, daß die gezeigten Orte des Schreckens von der Natur rückerobert werden. Die Rückeroberung scheint nur eine Frage der Zeit: Überwuchertes wird zum Symbol für das Ausradierte. War diese Bildsprache [...] in den fünfziger Jahren [...] noch ein ästhetisches Novum, so ist sie mittlerweile längst zur tradierten, auf nationalsozialistische Greueltaten verweisenden Chiffre geworden.« (van der Knaap 2002: 71) 
»Als Resnais [...] in Auschwitz drehte, war er sich des zeitlichen Sprunges von zehn Jahren bewußt und machte das allmähliche Verschwinden des historischen Ereignisses aus der gelebten Erfahrung zu einem Thema seines Films.« (Kramer 2000: 17)

")No landscape, I have always believed, can recall what happened, for the stones don't cry outı. Ich glaube, daß Ruth Klüger Recht hat.« (Leiser 1996: 105, Klüger zit. nach ebd.)

Ob der Zuschauer zudem spürt, »that today's rich green rises from the soil fertilized by the gray ashes of millions «, darf jedoch bezweifelt werden (Avisar 1988: 13).

Im Zusammenhang mit der historischen Filmebene und den anderen künstlerischen Mitteln birgt die »Ungerührtheit der ersten Natur gegenüber den Schrecken der zweiten « jedoch prinzipiell eine Projektionsfläche für die Vorstellungsleistung des Zuschauers (Koch 1992: 153) 57:

»Erst durch die Gegenüberstellung der toten Ruinenlandschaft auf den Farbaufnahmen und der schwarzweißen historischen Fotos von überfüllten Baracken, Arbeitskommandos im Freien, verhungerten Gefangenen und Toten im Stacheldraht erreicht [...] NACHT UND NEBEL seine starke Wirkung.« (Leiser 1996: 105)

»Die Leere der `öden Landschaft des heutigen Auschwitz markiert die Leerstelle, die mit authentischer Erinnerung angefüllt werden muß. Sie ist eine Erinnerungslandschaft dadurch, daß ihre landschaftlichen Merkmale als Markierungen für diejenigen Bilder dienen, deren Wirklichkeit an diesem Ort vorgestellt werden muß.« (Paech 1993: 128, H.i.0.)

$»[\ldots]$ die Anwesenheit einer Abwesenheit in den Imaginationen der Vergangenheit verbindet sich mit dem Konkretismus der Bilder gegenwärtiger Orte. Vergangenheit und Gegenwart greifen ineinander, das Vergangene wird vergegenwärtigt, das Gegenwärtige in den Bann der Vergangenheit gezogen.« (Koch 1992: 152)

»Daher gibt es zwei Filme, deren gemeinsame Wahrheit erst aus der Erinnerungsarbeit entsteht, die szwischen< ihnen vom Zuschauer geleistet werden muß.«(Paech 1993: 126, H.i.0.)

»Die Bilder sollen nicht mehr schockieren, sondern [...] Bausteine für die notwendige Erinnerungsarbeit werden.« (Ebd. 129)

»Ziel und Inhalt des Films ist es, hinter dieser Fassade die grausame Wahrheit erkennbar werden zu lassen.« (Dümling 1993: 117)

57. Obwohl auf Lanzmanns SHOAH bezogen, trifft diese sowie die folgende Äußerung von Gertrud Koch auch ins Zentrum von Resnais' NACHT UND NebeL.

»Die ständigen am Material eklatant sichtbaren Zeitsprünge zwischen der historischen und der damaligen Jetzt-Zeit verweisen immer wieder auf die Stummheit der steinernen Zeugnisse, über die das Gras zu wachsen begonnen hat." (Darmstädter 1995: 121)

58. Vgl. Jochimsen 1996: 224 und Lowy 2001: 172.

59. In diesem Punkt unterscheidet sich Erwin Leiser in seiner Dokumentation MeIN KamPF (1960) deutlich von NACHT UND NEBEL: »Offensichtlich kannte Leiser die Wirkungspsychologie schreckenerzeugender Filmbilder, denn obgleich er über das Archivmaterial verfügen konnte, verzichtete der Regisseur auf die grauenvollsten Aufnahmen.« (Jochimsen 1996: 223) 
Die verlassenen Ruinen und leeren Relikte sprechen jedoch nur das aus, »was die Betrachter in sie hineinlesen « (Knoch 2001: 522).

»Like Resnais and Cayrol, the audience is looking for possible traces, signs that would give any information about the millions of people who have been exterminated in this place." (Colombat 1993: 157, H.i.0.)

»The first necessary task for both the filmmaker and the spectator who wish to comprehend what happened is to interpret traces and signs in their metamorphoses.« (Ebd. 129)

Diese angesprochene Eigenleistung des Zuschauers hängt jedoch von der gesamten Gestaltung der jeweiligen Szene ab, sie kann keineswegs auf ein einziges Stilmittel zurückgeführt werden (s. hierzu die Analyse der Schlüsselsequenzen in 2.1.3 bis 2.1.7).

Im Unterschied zu dem historischen Bildmaterial ist die Farbkamera der Gegenwartsebene fast immer in Suchbewegung, die Ruinen und Relikte in einem Travelling nach vorne bedächtig abtastend. ${ }^{8}$ Auf diese Weise wird der Zuschauer in die Suche nach Spuren der Vergangenheit einbezogen und auf bestimmte Details - wie die von Fingernägeln zerfurchte Decke der Gaskammern (s. 2.1.2.4) - regelrecht »draufgestoßen«. Wiederholt versucht Resnais, dem Zuschauer mit langen Kamerafahrten die massenhafte Vernichtung visuell erfahrbar zu machen: Nicht enden wollende, den Bildrahmen sprengende Aufnahmen entlang an Bettgestellen, Latrinen, Fingernagelspuren und Krematoriumsöfen zeugen vom Ausmaß des Holocausts. Neben Kommentar und Musik könnte vor allem die völlige Entindividualisierung dieser Aufnahmen der Erfahrbarmachung im Wege stehen.

\section{A.2 - Schwarzweiß/Gestern (1933-45):}

Die Vergangenheitsebene von Nacht und Nebel bestimmt rund zwei Drittel des Films. Das Ausgangsmaterial hierfür bilden die Bilder, die unmittelbar nach der Befreiung der Öffentlichkeit gezeigt wurden (vgl. Resnais 2000: 173): vor allem Filmaufnahmen der Alliierten, insbesondere englische Dokumente, Bilder aus französischen, niederländischen und polnischen Archiven sowie dokumentarisches Bildmaterial aus den Museen von Maidanek und Auschwitz (Braese 2003: 77, Raskin 1987, Resnais 2000: 73 und Thiele 2001: 166). Darunter fallen jedoch auch Einstellungen, »die Resnais 1955 in schwarz-weiß gedreht hat, um sie [...] als Dokumente $\mathrm{zu}>$ fingieren $<$, die der Vergangenheitsebene zugerechnet werden sollen« (Hattendorf 1999: 206, H.i.O.; s. 2.1.2.5). Neben Wochenschaumaterial, Fotografien und diesen fingierten Quellen sind Ausschnitte aus zwei längeren Filmen in die Vergangenheitsebene des Films montiert, ohne Übernahme der ursprünglichen Tonspur: So zitiert Resnais Leni Riefenstahls TRIUM PH DES WILLENS (D 1935) sowie Wanda Jakubowskas Rekonstruktionsfilm Die LETZTe ETAPPE (PL 1948) über das Frauenlager von Auschwitz (vgl. Hattendorf 1999: 207).

Abgesehen von der charakteristischen hohen Schnittfrequenz dieser Schwarzweißaufnahmen weist die Vergangenheitsebene des Films bewegte und statische Bilder auf, je nach Quelle bzw. - was die fingierten Dokumente betrifft - Absicht des Regisseurs.

Ganz entscheidend für die historische Ebene von NACHT UND NEBEL sowie für die Gesamtwirkung des Films ist jedoch die gezielte Integration und Aneinanderreihung von Schockbildern. 59 In diesem Punkt hebt sich Resnais' Film kaum von den Umerziehungsfilmen ab, im Gegenteil: er weist noch schockierendere Aufnahmen als 
Die Todesmühlen auf. Ungefähr ab der Mitte des Films beginnt der Einsatz dieser Aufnahmen - Sterbende im Krankenbau, Leichen im Stacheldraht -, sich steigernd im letzten Drittel mit einer Häufung unerträglichen Archivmaterials, wie Bilder von Bulldozern, die Leichenmassen in eine Grube schieben (s. 0:26:45 h). ${ }^{60}$ Eine erste Akkumulation folgt auf die Sequenz in der Gaskammer (s. 2.1.6), eine zweite gegen Ende der Verwertungs-Sequenz (s. 2.1.7), eine dritte und vierte in der Sequenz »Als die Alliierten die Tore öffnen ...«, eine letzte in der Schuldfrage-Szene (zu den letzten beiden Sequenzen siehe die sechs Standbilder ${ }^{62}$ ). Der Höhepunkt dieser »ästhetischen Schock-Strategie « (Kramer 2000: 19) ist demnach die Sequenz, die den Anblick bei Befreiung der Lager thematisiert. Erstens beinhaltet sie zwei Bilder-Akkumulationen, zweitens ist es die mit einer halben Minute längste Ansammlung und drittens sind es - wie mit Kramer bereits für Die TodesmüHlen festgestellt (s. II.1.1, insb. II.1.1.2) - die aufgrund »der Vernachlässigung des elementaren Umgangs mit den Toten« (2003: 231) unerträglichsten Aufnahmen: »Hinter den geöffneten Toren bot sich den Befreiern - wie nun auch den Zuschauern des Films - ein Bild des Grauens: Die Kamera zeigt verstreute Leichen, Detailaufnahmen von Verstümmelungen und Verwesung, eine Planierraupe, die Leichen und Leichenteile in ein Massengrab schiebt.« (van der Knaap 2002: 73$)^{63}$

Interessanterweise hatte die französische Zensurbehörde versucht, solche Bilder zu verhindern, »on the grounds that those shots are too violent« (Raskin 1987: 9). Diesem Wunsch kam Resnais nicht nach - schließlich wollte er »très directs et très forts « arbeiten (Resnais 2000: 73):

»[...] je n'ai supprimé aucun document violent.« (Resnais zit.n. Raskin 1987: 58)

»Le bulldozer: dans certaines bobines anglaises que j'ai visionnées, il y en avait ainsi pendant une heure.« (Ebd. 136)

»Über die Zumutbarkeit der Bilder befragt, antwortete [...] Resnais [...], daß die von ihm benutzten Aufnahmen nicht eigens für den Film komponiert wurden, um die Zuschauer zu schockieren.« (van der Knaap 2002: 68)

Ob jedoch Resnais' Entscheidung und die damit einhergehende Ballung der angesprochenen Bilder im letzten Drittel von NACHt und NeBel den Zuschauer tatsächlich einbeziehen, wie Ewout van der Knaap behauptet ${ }^{64}$, ist aufgrund der unerträglichen Wucht und Masse der Bilder in Verbindung mit extremer Entindividualisierung stark zu bezweifeln.

60. Zur Kritik hieran s. I.1.

61. Vgl. dieselbe Aufnahme in Resnais' Die Todesmühlen (s. II.1.1.3).

62. Gemäß meiner Grundüberzeugung, daß ein gewisses Maß an Diskretion unerläßlich ist, wurde die Größe der Abbildungen deutlich verringert.

63. Vgl. Kramer 2003: 230 in II.1.1.

64. »Die ästhetische Strategie des Films - die Zuschauer mit nahezu wortlosen visuellen Eindrücken zu konfrontieren - ist allerdings beredter als jeder Kommentar; allein gelassen mit Bildern, die an die Grenze des Zumutbaren gehen, wird der Zuschauer gezwungen, einen eigenen Kommentar zu dem Gesehenen zu finden.« (van der Knaap 2002: 73) 


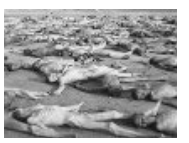

82 0:26:16 $h^{61}$

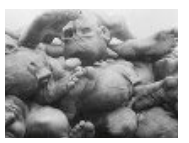

83 ) $0: 26: 27 \mathrm{~h}$

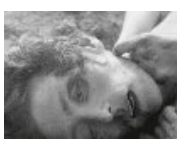

84 0:26:30 h

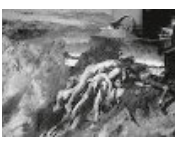

85 0:26:45 h

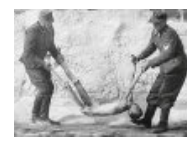

86 $0.27: 18 \mathrm{~h}$

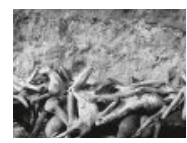

87 $0: 27: 20 h$

»En montrant pour la première fois, dans le cadre d'un film construit, des images particulièrement atroces, qui furent et demeurent sans aucun doute les images les moins soutenables jamais apparues sur un écran, Resnais expose le spectateur. L'accumulation des détails épouvantables qui marquent la perception spectatorielle, tant sur le fil narratif que sur celui des images, dans le dernier tiers du film laisse le spectateur abasourdi et choqué, sans réponse [...] L'image qui revient naturellement à l'esprit de tout spectateur de ce film, c'est celle du bulldozer qui déblaie les cadavres des victimes: c'est l'simage-blessure par excellence, parce que personne ne peut soutenir cela du regard.« (Lowy 2001: 142f., H.i.0.)

»Supreme artistic restraint« kann Resnais im Umgang mit dem fraglichen Archivmaterial nicht zugeschrieben werden (Avisar 1988: 17).

Wie zuvor bei Die TodesmüHlen läuft auch Resnais' Film aufgrund dieser »ästhetischen Schock-Strategie« (Kramer 2000: 19) Gefahr:

- die Vorstellung des Zuschauers zu konterkarieren: »Mit diesen historischen Schwarzweißaufnahmen setzt Resnais Bilder ein, wo er zunächst auf die Imagination vertraute. Er nutzt das Schockpotential der Dokumente, das sich in den Leichensequenzen bis heute erhalten hat« (ebd. 18);

- bei den Zuschauern Erschütterung, Lähmung und Erstarrung hervorzurufen: »[...] das Geschehene erschüttert sie so sehr, daß sie sich weinend übergeben müssen « (Dümling 1993: 122), kommentiert Dümling die Reaktionen der Zuschauer auf Szenen aus Nacht und Nebel im Spielfilm Die bleierne Zeit von Margarethe von Trotta (1981). »Nach dem Ende rührt sich lange niemand, einige weinen« (Thiele 2001: 184), berichtet Thiele von der ersten Aufführung des Films in Deutschland. »Als der Film zuende ist, sitzen alle wie gelähmt da« (ebd. 190), so die Beschreibung der Schülerreaktionen auf Nacht und Nebel in Christian Petzolds Spielfilm Die inNere Sicherheit (D 2001);

- einem Abnutzungseffekt zu unterliegen:

»Die Bilder verlieren die Schockwirkung, die sie beim ersten Sehen erreichen konnten; sie veraltern. Manche verfestigen sich gar zu Symbolen und Ikonen.« (Kramer 2000: 21) »En même temps, chacun s'habitue sournoisement à l'horreur, cela rentre un peu dans les mœurs, et fera bientôt partie du paysage mental de l'homme moderne; qui pourra, la prochaine fois, s'étonner ou s'indigner de ce qui aura cessé en effet d'être choquant?« (Rivette zit.n. Lowy 2001: 181)

- die Zuschauer zum Wegsehen zu bringen (vgl. Sanders zit.n. Braese 2003: 81): »[...] un film qui brûlait le regard [...].« (Daix zit.n. Raskin 1987: 141)

- und - im schlimmsten Fall - eine Verweigerungshaltung beim Zuschauer oder gar ein Verlassen des Vorführsaals auszulösen: »Non que les auteurs aient rien édulcoré - comment le pourrait-on? - je sais de mes amis qui ont dû quitter la salle ou fermer les yeux.« (Bazin zit.n. Raskin 1987: 139) 
Das damalige deutsche Branchenblatt »Der Filmbeobachter« jedenfalls empfand Nacht und Nebel aufgrund der Schockbilder für Jugendliche und »empfindliche Frauen völlig ungeeignet [...] (zit.n. Knoch 2001: 527).

Die auditive Ebene (B.) von NACHT Und Nebel besteht aus einem Off-Kommentar (B.1) und musikalischer Begleitung (B.2).

\begin{tabular}{|c|c|}
\hline \multicolumn{2}{|c|}{ B. Auditive Ebene } \\
\hline B.1 Kommentar (Cayrol) & B.2 Musik (Eisler) \\
\hline ca. 17 min. & Gesamtdauer des Films \\
& abzüglich einer Unterbrechung von ca. 13 Sek. \\
\hline
\end{tabular}

Abb. II.2.1.c

\section{B.1 - Kommentar (Cayrol):}

Den Kommentar schrieb Jean Cayrol, ein Überlebender der Konzentrationslager Mauthausen und Guben. Aufgrund dieser spezifischen Erfahrung, die er bereits 1945 in »Poèmes de la nuit et du brouillard « und 1954 in »Les rêves lazaréens « verarbeitet hatte (vgl. Thiele 2001: 180), betrachtete Renais Cayrol als »garantie d'authenticité« (Resnais zit.n. Raskin 1987: 48) ${ }^{65}$; die Mitarbeit Cayrols war für den französischen Regisseur Voraussetzung für die Annahme des Filmauftrags. ${ }^{66}$

Im Unterschied zur wochenschauartigen, informierenden und aggressiv-anklagenden Kommentierung von Dif TodesmüHlen zeichnet sich Resnais' Film durch einen teilweise auffallend poetischen und zum Teil beinahe sanft gesprochenen Text aus, dessen Eindringlichkeit von zahlreichen Rezensenten gelobt wurde und wird (vgl. Thiele 2001: 175). Das mag nicht zuletzt an seiner polyfunktionellen Anlage, orientiert am Modell der klassischen Rhetorik nach Horaz, liegen: »Über Bewegen (movere), Unterrichten (docere) und Beweisen (probare) sollen die Zuschauer dazu angeregt werden, das Gesehene zu akzeptieren, nicht weg zu schauen und sich damit auseinanderzusetzen« (van der Knaap 2002: 73).

Verglichen mit der besonderen visuellen Montage des Films, kann die Ebene des Kommentars als noch komplexer beschrieben werden.

65. Siehe II.3 zum Aspekt und Problem der Authentizität in Holocaustfilmen.

66. Intertextuelle Bezüge lassen sich vor allem zwischen Filmkommentar und Cayrols Werken, aber auch zu Henri Michel und Olga Wormsers 1954 herausgegebener »Tragédie de la Déportation 1940-1945. Témoignages de survivants des camps de concentration allemands« feststellen (vgl. van der Knaap 2002 : 71). Die Übersetzung des Kommentars ins Deutsche erfolgte durch Paul Celan, Überlebender eines rumänischen Arbeitslagers und bekannt durch die Verarbeitung seiner Lagererfahrung im Gedicht »Die Todesfuge«. Im Original wird der Text vom französischen Schauspieler Michel Bouquet vorgetragen, in der deutschen Version vom Schauspieler Kurt Glass. Der französische Kommentar ist in Raskin 1987: 73-130, der deutsche in Thiele 2001: 169-175 vollständig abgedruckt.

67. So sollte der damals übliche und beispielsweise in DIE TODESMÜHLEN zu beobachtende deklamatorische, pathetische Stil vermieden werden (vgl. Thiele 2001: 180). 


\begin{tabular}{|c|c|c|c|}
\hline \multicolumn{4}{|c|}{ B.1 KomMENTAR (Cayrol) } \\
\hline $\begin{array}{c}\text { B.1.1 } \\
\text { Intonation }\end{array}$ & $\begin{array}{c}\text { B.1.2 } \\
\text { poetische Verfahren }\end{array}$ & $\begin{array}{c}\text { B.1.3 } \\
\text { Erzählperspektive }\end{array}$ & $\begin{array}{c}\text { B.1.4 } \\
\text { grammatische } \\
\text { Zeitformen }\end{array}$ \\
\hline ruhig, langsam, sanft & Ironie/Sarkasmus & auktorial & $\begin{array}{c}\text { Présent } \\
\text { (Präsens) }\end{array}$ \\
\hline $\begin{array}{c}\text { nüchtern-distanziert } \\
\text { hochenschau-artig } \\
\text { schnell und laut }\end{array}$ & $\begin{array}{c}\text { Sprechpausen, } \\
\text { Ellipsen, Verstummen }\end{array}$ & Opferperspektive & $\begin{array}{c}\text { Imparfait } \\
\text { (Präteritum) }\end{array}$ \\
\hline \multirow{2}{*}{$\begin{array}{c}\text { Aufzählungen } \\
\text { spiegelverkehrter } \\
\text { Gebrauch von } \\
\text { Présent u. Imparfait }\end{array}$} & Täterperspektive & \\
\cline { 2 - 2 } & $\begin{array}{c}\text { (rhetorische) Fragen } \\
\text { vorstellungsanregende } \\
\text { Adjektive }\end{array}$ & (mehrdeutiges »on«) & \\
\hline
\end{tabular}

Abb. II.2.1.d

\section{B.1.1 - Intonation:}

Was den Kommentar von Nacht und Nebel ganz besonders auszeichnet, ist die Art und Weise, wie der Text vorgetragen wird, das heißt Tonfall, Tempo, Lautstärke, Betonung etc.

Vor allem der »Ton einer >grausamen Sanftheit«« und der nüchtern-distanzierte Tonfall des Sprechers stehen in hartem Kontrast zu der ernsten Thematik und werden nach damaligen Hörgewohnheiten als unpassend empfunden (Truffaut 1997: 407, H.i.O. ${ }^{67}$; heute noch irritieren diese beide Formen des Textvortrags.

Insgesamt sowie im Zusammenspiel mit der Bildspur können mit Colombat drei Intensitätsstufen unterschieden werden, die die Wirkung der jeweiligen Szene/Sequenz entscheidend beeinflussen:

»The first is quiet, slow and raffectively silentı, intoning long sentences, asking the spectator to imagine what happened in the now mute camp. This voice is used for imagining, for evoking what cannot be shown but only suggested, like the extreme and suffering [...]. The same slow tone is also used for the final meditation and interpretation in the present of the consequences of the Holocaust. Accompanying the narration of events [...] the rhythm is faster, the sentences shorter, the voice a little louder, often with >pizzicati< or sstaccati in the background. [...] When the voice imitates the reading of orders or slogans by the Nazis, it becomes both louder and faster, accompanied by louder music [...].« (Colombat 1993: 144, H.i.0.)

Diese Kommentierungsmuster müssen jedoch zusätzlich in ihrer Entwicklung im Filmverlauf untersucht werden. Insgesamt dominiert die nüchtern-distanziert-unbeteiligt wirkende Vortragsweise.

Nicht unerwähnt bleiben sollte im Zusammenhang mit der Vortragsweise von Cayrols Kommentar der Unterschied zwischen dem deutschen und dem französischen Sprecher: »Der deutsche Sprecher ... ist eine Spur zu eigen, zu akzentuiert, zu ironisch [...].« (Heynig zit.n. Thiele 2001: 18of.) 


\section{B.1.2 - Poetische Verfahren:}

Die lyrische Dimension von Cayrols Kommentar ergibt sich aus dem gezielten Einsatz wirkungsvoller poetischer Verfahren.

Besonders auffällig ist die Distanzerzeugung durch von Ironie bzw. Sarkasmus geprägte Bemerkungen. Damit greift Cayrol bewußt oder unbewußt einen bereits in DIE Todesmühlen kurz feststellbaren Ansatz auf. Dort hatte der Sprecher Aufnahmen der Leichenverwertungsmaschinerie mit »Ja, die Todesmühlen waren ein einträgliches Geschäft« und »Ein reicher Ertrag [...]« kommentiert (s. II.1.1.3).

In Nacht und Nebel wird die Verwendung dieses Stilmittels sowohl quantitativ als auch qualitativ gesteigert. So erklärt der Kommentator im Zusammenhang mit dem Baustil der Lagerwachtürme trocken: »Pas de style imposé. C'est laissé à l'imagination. Style alpin, style garage, style japonais, sans style.« (০:03:13 - 0:03:21 h) Als die Farbkamera das Krematoriumsgebäude ins Bild rückt, bemerkt der Kommentator zynisch: »Un crématoire, cela pouvait prendre, à l'occasion, un petit air carte postale. Plus tard - aujourd'hui -, des touristes s’y font photographier.« (0:20:14 - 0:20:22 h) In der Schlußansprache erläutert der Sprecher: »Les ruses nazis sont démodées.«(0:29:04 - 0:29:05 h)

Den Zuschauer vermag dieser wiederholte (und vor allem im mittleren Drittel des Films) auftretende Zynismus aufgrund des Kontrasts zwischen diesem Stilmittel und dem, wovon die Rede ist, unangenehm zu berühren. ${ }^{68}$

Er spürt, daß Cayrol auf distanzierenden Zynismus zurückgreift, da er offensichtlich nur auf diese - unernste - Weise mit der Thematik umgehen kann.

Daß NaCht und Nebel die Schwierigkeit, die Erfahrungen der Überlebenden zu übermitteln, thematisiert, unterscheidet ihn von vielen Dokumentationen und Kompilationsfilmen (vgl. Kramer 2000: 19). Dem Zuschauer wird dieses Vermittlungsproblem im Off-Text auf zweierlei Weise näher gebracht.

Zum einen wird diese Schwierigkeit im Zusammenhang mit den unmöglichen Schlafbedingungen in den Lagern (s. 2.1.5) und den Leichenverwertungsmethoden der Nazis (s. 2.1. 7) explizit thematisiert. »Im Kommentar wird [...] das notwendige Scheitern der filmisch vollzogenen Suchbewegung, für die auch die langen Kamerafahrten der Farbsequenzen stehen, mitreflektiert« (Hattendorf 1999: 209):

»Ces blocks en bois, ces châlits où l'on dormait à trois, ces terriers où l'on se cachait, où l'on mangeait à la sauvette, où le sommeil même était une menace, aucune description, aucune image ne peuvent leur rendre leur vraie dimension, celle d'une peur ininterrompue.» $(0: 08: 26-0: 08: 58 h)$

»Avec les corps ... mais on ne peut plus rien dire ... Avec les corps on veut fabriquer ... du savon.« $(0: 25: 07-0: 25: 24 h)$

68. Als amüsant wird er ihn jedoch kaum empfinden können: "Such an irony was introduced at the very beginning of the film with the presentation of the different styles used in the construction of watchtowers. [...] the contrasts of the film very often push the spectators to snicker [...].« (Colombat 1993: 128)

69. Vgl. Mukařovskýs »semantische Geste« (1943=1974: 49) bzw. I.2.2. Vgl. vor allem Jutz 1991: 82ff., Heller 1997: 224. 
Zum anderen wird die Unsagbarkeit dem Zuschauer wirkmächtig erfahrbar gemacht, indem der Sprecher ins Stocken gerät oder ganz verstummt, ohne den Satz zu Ende zu führen. Letzteres, d.h. vollständige Ellipsen, treten zwar selten, dafür aber an ganz besonderen Stellen auf. Als die Selektion thematisiert wird, hält der Kommentator vor der Information des Schlimmsten inne: »Pour les autres, on trie tout de suite. Ceux de gauche iront travailler. Ceux de droite ...« (0:20:46 - o:20:51 h) Am Ende der Verwertungs-Sequenz bricht der Kommentar nach zunehmenden Schwierigkeiten seine Erklärungen letztlich ganz ab: »Quant à la peau ...« (०:25:29 h, s. 2.1.7) Daß Ellipsen erst im letzten Drittel des Films auftreten, geht einher mit den zunehmend grauenhaften Bildern von der systematischen Vernichtung und von der Befreiung der Lager durch die Alliierten.

Ein weiteres häufig anzutreffendes poetisches Verfahren stellen Aufzählungen dar. Eingesetzt werden sie von Cayrol insbesondere bei der Beschreibung der Lager. Im Zusammenhang mit den schnell hintereinander geschnittenen Schwarzweißaufnahmen und dramatischer Musik tragen sie zu dem Stakkato-Rhythmus der Vergangenheitsebene von NaCht und Nebez bei und ikonisieren den Organisations-Fanatismus der Nazis.

Mehrfach sprechen Cayrol/Resnais den Zuschauer direkt mit rhetorischen Fragen an. »Alors qui est responsable?« (0:27:54 - 0:27:55 h) fragt der Kommentator, nachdem mehrere Nazis ihre Schuld abgestritten haben. Im Unterschied zum direkt anklagenden Text von Dif Todesmühlen, vermag diese Frage den Zuschauer eher zu einem Nachdenken über Schuld zu bewegen. »Qui de nous veille dans cet étrange observatoire pour nous avertir de la venue de nouveaux bourreaux? Ont-ils vraiment un autre visage que le notre? « (0:29:15 - 0:29:22 h), fragt der Sprecher das Publikum in der Schlußsequenz und redet ihm auf diese Art und wiese ins Gewissen. Im Prinzip kann sich der Zuschauer diesen Formen der direkten Ansprache kaum entziehen. Aufgrund der vorangegangenen Bildgewalt ist er jedoch aller Wahrscheinlichkeit nach derart schockiert und gelähmt, daß er kaum Raum für eine wirkliche Beschäftigung mit diesen wichtigen Fragen hat.

Die »irritierend schöne« Dimension der vielfältigen verfremdenden Brechungen in Cayrols Kommentar ergibt sich insbesondere aus dem auffälligen Einsatz wirkungsvoller, die Vorstellungskraft des Zuschauers anregenden Adjektive (Jansen 1990: 82): »Abstraktes, Unbelebtes wird durch Personalisierungen belebt«. (Thiele 2001: 176, H.i.O.): »un ciel d'automne indifférent« (»ein gleichgültiger Oktoberhimmel«), »nuit qui claque des dents« (»diese zähneklappernde Nacht«). Die französische Passage »De ce dortoir de brique, de ces sommeils menacés, nous ne pouvons que vous montrer l'écorce, la couleur« (०:०9:18 - ०:०9: $21 \mathrm{~h}$ ) wurde von Paul Celan in poetischer Weise ins Deutsche übertragen: »Von Gefahren umlauerter, backsteinfarbener Schlaf.«

\section{B.1.3 - Erzählperspektive:}

Obgleich dominant auktorial, ist auch die Erzählperspektive in sich spannungsvoll, polyperspektivisch und changiert zwischen Täter-, Opfer- und allwissender Perspektive. ${ }^{69}$ Während die zwischenzeitliche Einnahme der Täterperspektive den Zuschauer 
unangenehm berührt (s. insb. 2.1.7, aber auch 2.1.670), vermag der Kommentar aus der Sicht der Opfer ihn stärker in deren Lage zu versetzen als der des auktorialen Erzählers (s. insb. 2.1.3). Letzterer zeichnet verantwortlich für die meditativen Momente des Films sowie die wiederholte direkte Ansprache des Zuschauers. ${ }^{71}$ Mit einer Ausnahme tritt diese »diskursive Instanz in Form eines >nous < auf « (Jutz 1991: 83), ein einziges Mal auch als >je< (in der Schlußsequenz). Hierbei bleibt jedoch unklar, »ob das >je < und das >nous < der verbalen Narration auf den Sprecher (Michel Bouquet), den Regisseur (Alain Resnais) oder den Autor des Textes (Jean Cayrol) verweisen« (ebd. 83, H.i.O.).

Das Pronomen >on<, das in sich bereits ambivalente Bezüge trägt ( $>$ man $</>$ wir $<$ ), nimmt im Kommentar eine Sonderstellung ein (vgl. ebd. 83ff.). Einerseits handelt es sich um das am häufigsten eingesetzte Personalpronomen, andererseits bezieht es sich auf unterschiedliche Personen, sogar innerhalb einer Sequenz. Mit Jutz lassen sich für das >on< je nach Kontext vier unterschiedliche Referenten ausmachen: »Es verweist auf die nationalsozialistischen Machthaber, auf die Deportierten, auf die diskursive Instanz, auf den universellen Referenten >Mensch<. [...] Somit steht das Pronomen >on< sowohl für Figuren der Geschichte als auch für den Erzähler [...].« (Ebd. 85, H.i.O.) Vor dem Hintergrund von Cayrols Lagererfahrung kann die Wahl der unpersönlichen Form an bestimmten Textstellen auch als eine Art »rhetorisches Alibi«, ein »autobiographisches >je«« verstanden werden, die es dem Autor gestattet, »sich von dem Erlebten zu distanzieren und es als >histoire < [...] zu präsentieren« (ebd. 85, H.i.O.).

Aufgrund dieser extrem komplexen Gestaltung sowie dem ständigen Wechsel der Erzählperspektive ist fraglich, ob der Zuschauer jeweils die entsprechende Zuordnung zu leisten vermag - schließlich muß er gleichzeitig den Bildern sowie der Musik Aufmerksamkeit widmen und kann sich nicht vollständig auf den Kommentar konzentrieren. Im übrigen läßt sich die Erzählperspektive selbst bei eingehender Analyse an manchen Stellen nicht eindeutig auflösen, sie bleibt ambivalent. ${ }^{72}$

Noch vielschichtiger wird das Phänomen der Erzählperspektive, wenn man sie im Zusammenhang mit dem unterschiedlichen Gebrauch grammatischer Zeitformen betrachtet (s.u.).

70. »0n observe $\ldots$ on ferme les portes.« $(0: 21: 44-0: 21: 49 \mathrm{~h})$

71. »Au moment où je vous parle.« $(0: 28: 18 \mathrm{~h})$

Zum Teil jedoch »mißtraut [er] der Kraft seiner Erzählung, zugleich dem Versuch, mit Hilfe authentischer Bilder den Massenmord begreifbar zu machen. `Kein Bild, keine Beschreibung gibt ihnen ihre wahre Dimension wieder.« (Jutz 1991: 82, H.i.0.)

72. Siehe Sequenz fünf und sechs im entsprechenden Sequenzprotokoll (s. Anhang). Die Vermischung der Erzählperspektiven kann auch positive Auswirkung haben (vgl. Thiele 2001: 175). »Il faut dormir vite.« (0:10:07 h); »Malheur à celui qui rencontrait un kapo ivre au clair de lune.« (0:12:17-0:12:19 h) Indem sich Erzähler- und Opferperspektive verbinden, wirkt der Bericht weniger distanziert auf den Zuschauer.

73. Das Präteritum erscheint demnach nicht »in einigen Passagen« (Jutz 1991: 84), sondern ausschließlich im Zusammenhang mit der Gegenwartsebene, den Farbsequenzen des Films.

74. Vgl. Thiele 2001: 175 und Lowy 2001: 173.

Am dritthäufigsten gebrauchen Cayrol/Resnais das Perfekt (passé composé), am vierthäufigsten das Futur, am seltensten das französische passé simple. 


\section{B.1.4-grammatische Zeitformen:}

Nacht und Nebel beinhaltet zwei Zeiten der Aussage: Die erste bezieht sich auf die Herstellungszeit des Films, die zweite auf die Epoche des deutschen Nationalsozialismus (vgl. Jutz 1991: 82). Für jegliche Projektion des Films in zeitlicher Distanz zum Erscheinungsdatum gilt, daß das »Heute« des Films (1955) darüber hinaus »zur Zeit des Filmbetrachters (die jeweilige aktuelle Gegenwart) in Opposition « steht (ebd. 83).

Bei näherer Betrachtung der grammatischen Zeitformen fällt der spiegelverkehrte Einsatz von Vergangenheit und Präsens auf: »In den Farbsequenzen des Mittelteils wird die Vergangenheit durch das >Präteritum< ausgedrückt, in den kompilierten Schwarzweiß-Sequenzen durch das >historische Präsens $<$ (dem seinerseits das >reflektierende Präsens< in den umrahmenden Farbsequenzen gegenübersteht) « (Hattendorf 1999: 211, H.i.O.). ${ }^{73}$ Auf diese Weise versuchen Cayrol/Resnais, den Zuschauer die Verwobenheit von Gestern und Heute erfahren zu lassen. Ob dies vom Publikum jedoch wahrgenommen werden kann, sei aufgrund der subtilen Gestaltung in Frage gestellt.

Um auf die Gegenwart der Vergangenheit zu verweisen, sie zu betonen und die zeitliche Distanz zu den Ereignissen einzuebnen, verwenden Cayrol/Resnais das Präsens als »Basistempus « des gesamten Films (Jutz 1991: 87).74 Das französische passé simple kommt insgesamt nur zweimal vor, da es auf abgeschlossene Ereignisse in der Vergangenheit verweist; gerade dies wollten Cayrol/Resnais mit NACHT UND NEBEL vermeiden.

Die aufgrund des vielschichtigen sowie ungewöhnlichen Gebrauchs der grammatischen Zeitformen zu befürchtende Orientierungslosigkeit des Zuschauers versuchen Cayrol/Resnais gelegentlich durch Temporaldeiktika zu vermeiden: »[Diese] eröffnen mehrfach die Farbsequenzen, um diese wichtigste Opposition des Films dem Wechsel von Schwarzweiß zu Farbe am Anfang und am Ende semantisch einzuschreiben: >Aujourd'hui< [...]; >Au moment où je vous parle< ([...] hier mit direkter Zuschaueradressierung) [...].« (Hattendorf 1999: 210, H.i.O.)

Das Verhältnis des Kommentars zu den Bildern ist ebenfalls vielschichtig. »Der Kommentar verhält sich nicht eindeutig zu den Bildern. Er ist von ihnen unterschiedlich weit entfernt, indem er sie interpretiert oder ignoriert, über sie informiert oder sie widerlegt, zwischen Vergangenheit und Gegenwart variiert « (Knoch 2001: 521). Vor allem in meditativen Momenten steht er ihnen »(manchmal) mißtrauisch, fragend und fassungslos gegenüber« (Jochimsen 1996: 225). Insgesamt, wenn der Sprecher die Aufnahmen kommentiert, sie erklärt oder aber verstummt, dominiert eine Komplementarität zwischen sprachlicher und visueller Ebene; dies ist angesichts der generellen Komplexität von Nacht und Nebel auch erforderlich. Im Prinzip trifft Pinels Äußerung hinsichtlich der verbindenden Kraft des Kommentars zu: »Alain Resnais [...] obtient grâce à cette utilisation du commentaire une grande fluidité, malgré le disparate des éléments utilisés et une liberté totale pour la composition.« (Pinel zit.n. Raskin 1987: 143)

\section{B.2 - Musik (Eisler):}

Für die musikalische Begleitung von Nacht und NeBel zeichnet der deutsche Komponist Hanns Eisler verantwortlich, der - zum großen Erstaunen Resnais' - der Mitarbeit am Film zustimmte. Auch wenn es extrem schwierig ist, angesichts des auf allen Ebenen künstlerischen Werkes eine Gewichtung derselben vorzunehmen, so sei doch betont, daß sich NACHT Und NEBEL nicht zuletzt durch Eislers eigenwillige Kompositionen auszeichnet. 
Diese entsprechen seiner - gemeinsam mit Adorno entwickelten - Forderung nach überwiegend kontrapunktischem Musikeinsatz im Film: »Selbst gute dramatische Momente werden durch übersüße Begleitung oder dramatische Überexposition zu Kitsch« (Adorno/Eisler zit.n. Thiele 2001: 181). So zeigte Eisler dem Regisseur vor allem, wie man den »musikalischen Pleonasmus« vermeiden kann (Resnais zit.n. ebd. 182).

»[Eisler] führte mir vor, wie man die Musik benutzen kann, um eine zweite Empfindung zu erzeugen, etwas Zusätz liches, Gegensätzliches. So kann man beispielsweise bei den dramatischsten Momenten des Bildes die Musik bis zum Äußersten vereinfachen, und umgekehrt arbeitet man sie groß aus, von dem Augenblick an, in dem das Auge nicht mehr gefesselt wird. Dadurch entsteht gewissermaßen eine Balance, in der sich der Zuschauer während der Filmvorführung zwischen dem Sehen und dem Hören befindet." (Resnais zit.n. Dümling 1993: 118)

Diese künstlerische Einstellung, übliche Methoden musikalischer Illustration, wie beispielsweise in Dif Todesmühlen, ebenso zu vermeiden wie Gefühlsausbrüche, finden sich in NACHT UND NEBEL vor allem in schwer erträglichen Momenten: Zu den grauenvollen Archivbildern von Leichen(bergen) im letzten Drittel des Films komponierte Eisler eine »bewußt unsentimentale Musik, [mit] kammermusikalischer, oft sogar solistischer Besetzung [und] fast zärtlichen Melodiebögen« (Dümling 1993: 122). »Je schrecklicher die Bilder um so freundlicher wird die Musik [...].« (Resnais zit. ebd. 122) Auf diese Weise versucht Eisler, dem Zuschauer angesichts des übermäßigen visuellen Schreckens eine gewisse Distanz zu ermöglichen (Dümling 1993: 122). Es darf bezweifelt werden, daß angesichts des übermäßigen visuellen Schreckens die Musik in der Lage ist, dem Zuschauer bei der Bewältigung bzw. Annahme solcher Aufnahmen zu helfen und Raum für Mitgefühl mit den Opfern zu schaffen.75 Aus dem gleichen Grund ist extrem fraglich, ob das Publikum die anspruchsvolle Absicht des Komponisten - »Eisler wollte zeigen, daß der Optimismus und die Hoffnung der Menschen sogar im Lager noch existierte« (Resnais zit.n. Dümling 1993: 122) - zu erkennen vermag.

Neben dieser »dünnstimmig lyrischen Musik« (Dümling 1993: 122) finden sich in Nacht Und Nebel jedoch weitere Formen der musikalischen Begleitung: »The music itself varies from the long, quiet, sorrow-laden violin strokes of the credits and

75. »Among other things, the soundtrack enables us to look at unbearable newsreels, such as living skeletons being prepared for hospital experiments. (Insdorf 2003: 37) »As the power of the image increases, the music always becomes more discreet. [...] When the mass graves are shown, the text disappears and the music does not produce the expected feeling of extreme violence or aggression. Slow, low, respectful and peaceful, the music gives background support to the necessary interprettation and fights any overwhelming feeling of horror that would prevent the viewers from thinking about what they see.« (Colombat 1993: 147) »Erst durch die Reduktion von der statistischen Menge auf einzelne Schicksale und durch Verzicht auf automatisierte Emotionen erhalten die Ereignisse ein Maß, das Mitgefühl mit den Opfern möglich macht.« (Dümling 1993: 122)

76. Vgl. insb. Hattendorf 1999: 208 und Colpi zit.n. Avisar 1988: 14.

77. Vgl. auch Lowy 2001: 118. 
conclusion to the rolls of drums and the nervous >pizzicato < or the very detached notes of a trumpet« (Colombat 1993: 146, H.i.O.). Mit Colpi, Dümling, Hattendorf und Lowy können insgesamt vier musikalische Motive unterschieden werden:

\begin{tabular}{|c|c|c|c|}
\hline \multicolumn{4}{|c|}{ B.2 MusIK (Eisler) } \\
\hline B.2.1 & B.2.2 & B.2.3 & $\begin{array}{c}\text { B.2.4 } \\
\text { Rahmenmotiv }\end{array}$ \\
\hline
\end{tabular}

Abb. II.2.1.e

\section{B.2.1 - Rahmenmotiv:}

Eingerahmt ist der Film von einer getragenen, beinahe schwermütigen Melodie eines Streicherorchesters, »il s'agit d'un ample mouvement mélodique, à la fois lyrique et amer« (Lowy 2001: 118, H.i.O.). Ob der Zuschauer im unbebilderten Prolog eine Bevölkerung der leeren Landschaft bzw. Lager durch das Orchester empfindet (vgl. Dümling 1993: 122), darf jedoch in Frage gestellt werden - vermutlich ist er von der Musik eher irritiert, u.U. gar unangenehm berührt.

\section{B.2.2 - Deportationsmotiv:}

Das Deportationsmotiv wiederum wird durch den Einsatz von Blechinstrumenten dominiert, insbesondere durch eine Solo-Trompete, die immer wieder spitz aus dem insgesamt dumpfen Klanghintergrund ausbricht und so beim Zuschauer Unbehagen auslöst und gar schmerzhaft wirken $k a n n^{76}$ : »Le thème de la déportation est aigre, cuivré, brutal, accompagné de douloureux coups de cymbales.« (Lowy 2001: 118; s. 2.1.3)

\section{B.2.3 - Konzentrationslagermotiv:}

Das Konzentrationslagermotiv schließlich besteht vornehmlich aus einem FlötenKlarinetten-Duo mit »kammermusikalischer Intensität« (Hattendorf 1999: 208).77 Regelmäßig bricht die Flöte aus der Melodie aus und spielt sich in den Vordergrund. Vor allem beim Einsatz dissonanter Töne wirkt dies tendenziell unangenehm auf den Zuschauer (s. 2.1.7). Daher ist es einerseits unwahrscheinlich, daß das Motiv als »heart-rending « wahrgenommen wird (Colpi zit.n. Avisar 1988: 14), andererseits ist zu bezweifeln, daß die Kombination aus Soloinstrument und Dissonanz »any sentimental effect « zu verhindern vermag (Colombat 1993: 146) - zumindest tendenziell hält sie den Zuschauer auf Distanz. Darüber hinaus fällt innerhalb dieses Motivs auch eine recht große Spannweite zwischen ruhigeren, getrageneren und schnelleren, rhythmischeren Passagen auf, je nach Bildinhalt und Kommentar.

\section{B.2.4 - Violinen-Pizzicati:}

Das Violinen-Pizzicati ist ebenso auffällig wie sparsam eingesetzt und wirkt aufgrund des Kontrastes zur Bildspur äußerst verstörend auf den Zuschauer, vor allem als »Untermalung « unerträglicher Aufnahmen gegen Ende des Films. In der zweiten Sequenz des Films versucht Eisler mit diesem nervösen Motiv den Aufmarsch der Nazis verfremdend zu brechen (Hattendorf 1999: 208):

»Ein traditioneller Filmkomponist hätte solchen Bildern [marschierende Truppen] einen pompösen Marsch oder das Horst-Wessels-Lied unterlegt [...]. Hanns Eisler aber verzichtete auf die 
gängige musikalische Schreckensdarstellung. Den propagandistischen Aufnahmen einer Parade zum Nürnberger Reichsparteitag unterlegte er eine dünne Pizzikati und fügte ihnen beim Schwenk auf Hitler und Himmler eine zirpend hohe Violinmelodie hinzu.« (Dümling 1993: 120)

»[...] zugleich zitieren leichte Trommelwirbel den ursprünglichen paramilitärischen Kontext der Aufmärsche.« (Hattendorf 1999: 208) ${ }^{78}$

Zwar entspricht NACHT und NeBel vor allem an dieser Stelle dem Charakteristikum von Kompilationsfilmen, »Bilder und Töne kritisch >gegen den Strich $<$ zu lesen, »von anderen Leuten $\mathrm{zu}$ anderer Zeit für andere Zwecke gedrehte Bilder« in einen neuen Kontext zu integrieren, der dem alten meist konträr entgegensteht « (Heller zit.n. Hattendorf 1999: 204, H.i.O.). ${ }^{79}$ Es darf jedoch in Frage gestellt werden, ob man die Aufmärsche der Nazis auf diese Weise ironisieren kann, ob eine solche Ironisierung nicht inadäquat, u.U. gar überfordernd wirkt angesichts der historischen Aufnahmen.

Ein weiteres Mal setzt Eisler das Geigen-Pizzicati in den beiden vorletzten Sequenzen ein (eineinhalb Minuten ohne Unterbrechung), das heißt im Zusammenhang mit den schockierenden Bildern bei Befreiung der Lager sowie mit der Schuldfrage. Durch die Wiederaufnahme dieser auffälligen Musik, d.h. allein aufgrund des kalkulierten Einsatzes dieses filmischen Mittels, wird - zumindest theoretisch - eine Verbindung zwischen der Machtergreifung der Nazis und dem Resultat ihrer Vernichtungspolitik geschaffen..$^{80}$

Für alle Motive gilt eine Beobachtung Colombats zum Verhältnis zwischen dem dominanten Instrument und dem musikalischen Hintergrund: »The melody of a flute, a clarinet or a trumpet, is always sustained in the background by the incessant repetition of a motif, a chord, a single note, a >pizzicato $<$ or a >staccato $<$ played by a trumpet or a piano.« (1993: 146)

Hinsichtlich der Entwicklung des Films fällt auf, daß die getragenen Melodien zunehmen, ebenso wie das Auftreten der zirpenden Violine, die dem Zuschauer regelrecht in den Ohren schmerzt und äußerst verfremdend wirkt - Kontrapunkte zu den immer grauenhafter werdenden Bildern.

78. Vgl. auch Jochimsen 1996: 225 und Lowy 2001: 118.

79. Es handelt sich hierbei ursprünglich um Aufnahmen anläßlich des Nürnberger Parteitages aus Leni Riefenstahls TRIUMPH DES WiLlens (D 1935).

80. \Later, the pizzicati accompanied one of the results of Nazis: the huge camps, the typhus, the corpses buried by bulldozers, the SS become prisoners in their turn.« (Colpi zit.n. Avisar 1988: 14)

81. »Nicht nur, daß er weitaus stärker in das vorgefundene Photo- und Filmmaterial eingreift und ummontiert; nicht nur, daß er den von Jean Cayrol, einem ehemaligen KZ-Häftling, verfaßten poly-perspektivischen, d.h. vor allem zwischen Täter- wie Opferperspektive changierenden Kommentar über und gegen die Bilder legt; nicht nur, daß die Musik von Hanns Eisler Kommentar- und Bildebene unterstreicht, kommentiert, kontrapunktiert, über Leitmotive scheinbar Unzusammenhängendes strukturiert und verbindet oder über Zitate zusätzliche Assoziationsräume schafft.« (Heller 1997: 224) Vgl. auch van der Knaap 2002: 71. 
Die Erzeugung von Diskrepanz durch den Einsatz kontrapunktischer Musik ist zwar dominant, stellt jedoch nicht die einzige Funktion der musikalischen Begleitung dar. Je nach Kontext unterstreicht und kommentiert Eislers Musik die Bild- und Kommentarebene. Über Leitmotive strukturieren und verbinden sie scheinbar Unzusammenhängendes oder sie schaffen zusätzliche Assoziationsräume über Zitate (vgl. Heller 1997: 224).

Nicht übersehen werden sollte die übergreifende Funktion der musikalischen Begleitung: »Eislers Musik tritt an die Stelle von Originalgeräuschen; sie verbindet farbige und schwarz-weiße Sequenzen ebenso wie die verschiedenen Argumentationsebenen des Films « (Hattendorf 1999: 208); vor allem im ersten Drittel von NACHT UND NEBEL akzentuiert sie jedoch auch den Kontrast zwischen den Farb- und den Schwarzweißaufnahmen: »At the beginning [...] the ruptures between these two series are extremely brutal and obvious. They are always reinforced by parallel ruptures in the soundtrack.« (Colombat 1993: 132) Erst in den letzten beiden Dritteln des Films überspielen Eislers Kompositionen regelmäßig den visuellen Wechsel von Heute zu Gestern und sorgen dafür, daß der Zuschauer die Übergänge von Vergangenheit und Gegenwart als zunehmend fließend erfährt, »in order to present a [...] past that is very active in the present « (ebd. 138).

Abgesehen vom Rahmenmotiv handelt es sich aufgrund der kontrapunktischen Konzeption um eine ausschließlich intellektuell verarbeitbare Musik, die weder Nähe noch Identifikation zuläßt. Ob dies dem Film tatsächlich zum Vorteil gereicht, sei stark bezweifelt (s. 2.1.7). Da auch auf der Ebene des Kommentars sowie des Bildes etliche Brechungen existieren, droht die insgesamt extrem komplexe und in sich widersprüchliche Gestaltung des Films den Zuschauer zu überfordern.

\section{Gestaltungscluster und Entwicklung der Verfahren}

Die vorangegangene heuristische Trennung der einzelnen Gestaltungsmittel war aufgrund der extremen Komplexität des Werkes ${ }^{8_{1}}$ zunächst notwendig und sinnvoll gewesen, um im Folgenden das minutiöse Zusammenspiel aller Ebenen in Wechselwirkung zu erfassen.

»In den farbigen Sequenzen begleiten langsam [und nüchtern, teilweise sanft; eigene Anm.] gesprochene, vielgliedrige Sätze die langsamen, gleitenden Kamerafahrten (nach vorn, rückwärts und seitwärts) in langen Einstellungen. In der ersten Einstellung [...] setzt eine langsame Kranfahrt nach unten den für die farbigen Sequenzen charakteristischen elegischen Rhythmus. [...] Demgegenüber sind die schwarz-weißen Sequenzen um ein Vielfaches rascher geschnitten und schneller kommentiert; die Stimme des Off-Sprechers nimmt dabei, etwa beim Beginn der 2. Sequenz, den schneidenden Tonfall der Wochenschau-Sprecher an. (Hattendorf 1999: 207f.)

Hinzugefügt werden muß, daß die Farbsequenzen oft von getragenerer Musik begleitet werden, während bei den historischen Aufnahmen - zumindest zu Beginn des Films - häufiger militärisch-energische Motive auftreten. Im zunehmenden Filmverlauf, d.h. mit fortschreitender Chronologie, sind solche festzustellen.

Der Übergang zwischen Gegenwarts- und Vergangenheitsebene wird insbesondere über die Gestaltung der Bildspur inszeniert: 
„Die Farbkamera ist fast immer bewegt, sie ist unterwegs auf dem Gelände, fast durchweg im Travelling nach vorn (der bevorzugten Kamerabewegung von Resnais), als sei sie auf der Suche. Sie ist es auch. Aus den grünen Wiesen, den roten Ziegelmauern, dem blauen Himmel, aus einem Meer gelber Blumen gehen die Schwarzweißbilder hervor wie aus dem Untergrund aller Farben, als habe die Kamera sie aufgespürt unter dem Grasboden, zwischen den Steinfugen, in den Trümmern und an den Tag gebracht. Ein roter Backsteinbau (heute) verwandelt sich in der Überblendung in dasselbe schwarz-weiße Gemäuer von gestern: Gegenwart und Vergangenheit, Vergangenheit und Gegenwart fließen ineinander. [...] der Eindruck, daß uns etwas gezeigt wird, was erst in diesem Augenblick des Suchens und Zeigens heraufkommt, wird verstärkt durch den anderen Bewegungsrhythmus der Fotografien (und der wenigen Dokumentarfilmaufnahmen) [...].« (Jansen 1990: 78)

Während zunächst abrupte Übergänge dominieren, gestaltet Resnais diese zunehmend weicher (vgl. Colombat 1993: 132ff.). Wie jedes einzelne der beschriebenen Gestaltungselemente entwickelt sich demnach auch der Übergang zwischen Heute und Gestern im Verlauf des Films.

Je entsetzlicher die thematisierten Ereignisse durch die - eine gewisse Chronologie einhaltende - Erzählstruktur werden (z.B. in der Gaskammer-Sequenz in 2.1.6 bzw. der Leichenmassen-Sequenz), desto stärker versucht Resnais, insbesondere über die

82. "As the power of the image increases, the music always becomes more >discreet «." (Colombat 1993: 147, H.i.0.)

83. Vgl. Daix zum Tonfall des Sprechers während der besonders grauenhaften Sequenzen: »[...] le ton convenait, un ton calme, serein, le ton qu'il faut en face de la souffrance, le seul ton possible devant les tortures." (Zit.n. Raskin 1987: 140)

84. Avisars folgende Äußerung ist daher zu bezweifeln: »[...] he achieved a nearly perfect equilibrium between the perception of visual horrors, the absorption of their context, and reflection on their significance.« (1988: 18)

85. Eine solche Zusammenarbeit dreier eigenständiger Künstler, die nur zum Teil im Filmbereich arbeiten, ist für den Holocaust-Film m.E. einzigartig.

86. Vgl. Resnais zit.n. Raskin 1987: 136 auf Seite 2 dieses Filmkapitels.

Noch heute gehört der Film in Frankreich und Deutschland zum Katalog der Landesbildstellen.

87. Besonders in diesem Punkt unterscheidet sich NACHT Und NebeL von Marceline LoridanIvens' ruhigen und einfachen BIRKENAU Und ROSENFELD (s. II.5).

88. »Pendant ce temps, Burger ouvrier allemand, Stern étudiant juif d'Amsterdam, Schmulszki marchand de Cracovie, Annette lycéenne de Bordeaux, vivent leur vie de tous les jours, sans savoir qu'ils ont déjà, à mille kilomètres de chez eux, une place assignée.«/(»Der Arbeiter aus Berlin, der jüdische Student aus Amsterdam, der Kaufmann aus Krakau, die Lycealschülerin aus Bordeaux - sie alle ahnen nicht, daß ihnen in einer Entfernung von 1000 Kilometern bereits ein Platz zugewiesen ist.«) (0: 03:31-0:03:45 h) »The text also quotes precise names of deportees and cities from all over Europe to insist that the anonymous corpses seen later in unmarked mass graves were once the bodies of individuals [...]." (Colombat 1993: 141)

89. »[...] ce film est construit sur les ruines fumantes du désastre [...]. Cela se traduit à l'écran par le vision d'images épouvantables que rien ne compense, surtout pas les images en couleurs qui sont des images de désolation et de silence [...]. Aucun film [...] n'avait été jusque là avare à ce point en signes d'espoir.« (Lowy 2001: 143f.) 
auditive Ebene, ein Aushalten des Grauenhaften zu ermöglichen: Irritierend getragene Musik-Kompositionen ${ }^{82}$ und eine ruhige, manchmal sanfte Off-Stimme ${ }^{8_{3}}$ begleiten die schockierenden Archivbilder im Unterschied zur teilweise harschen Kommentierung und den militärischen Rhythmen zu Beginn des Films. Vor allem im letzten Drittel von NACHT Und NeBEL häufen sich angesichts der Wucht der Bilder die angesprochenen Pausen, das Stocken und das Abbrechen von Sätzen auf der Kommentatorenebene: Das verbal Verschwiegene wird dem Zuschauer visuell vorgeführt.

Fraglich ist, ob diese Kompensationsversuche ausreichen, um eine Überforderung des Zuschauers zu vermeiden und ihn zu einem Hinsehen zu bewegen. ${ }^{8}$ Die visuell und auditiv gebotenen Fakten, denen er kontinuierlich ausgesetzt ist, können eher das Gegenteil bewirken.

\subsubsection{Leitthesen}

In bewußter Abgrenzung zu den Re-education-Filmen der unmittelbaren Nachkriegszeit (s. II.1) versucht Resnais mit NACHT und NeBEL, die psychischen Barrieren der Annahme des Holocaust durch eine deutlich künstlerische Herangehensweise und damit einhergehender ästhetischer Distanz zu überwinden. So zeichnet für jede gestalterische Ebene jeweils ein Künstler verantwortlich - Filmemacher Resnais für das Visuelle, Literat Cayrol für den Off-Kommentar und Komponist Eisler für die Musik. ${ }^{85}$ Entsprechend ist jede Gestaltungsebene in sich extrem komplex komponiert. Im Zusammenhang mit den anderen Ebenen ergibt sich ein vielschichtiges audiovisuelles Gestaltungsgefüge.

Zu bezweifeln ist, ob sich damit Resnais' Absicht, im Unterschied zu den alliierten Entnazifizierungsfilmen ein breites Publikum zu erreichen, erfüllt: ${ }^{86}$

- Die drei Gestaltungsebenen konkurrieren häufig untereinander um die Aufmerksamkeit des Zuschauers, was eine Überforderung zur Folge hat. Verantwortlich hierfür ist der Einsatz zu vieler künstlerischer Verfahren - simultan und sukzessiv; zur »Erholung « von der Überreizung dringend notwendige »Pausen« existieren kaum (s. insb. 2.1.4). Aufgrund des dem Film zugrundeliegenden Kontrastprinzips sind die Brechungen zwischen den unterschiedlichen, gleichzeitig eingesetzten Gestaltungselementen derart erheblich, daß es wiederholt zu einer kontraproduktiven Überästhetisierung kommt (s. insb. 2.1.7) ${ }^{87}$

- Die beschriebene Entwicklung der Gestaltungsmittel, insbesondere die Zurücknahme des Kommentars, lassen zwar insgesamt den Wunsch nach Kompensation der zunehmend grausamen Bilder erkennen. Insbesondere im letzten Drittel des Films wird:

(a) der Zuschauer zum Teil grauenvollerem Archivmaterial als in Dí TodesmüHLEN ausgesetzt (s. 2.1.1) - daher vermögen die Ausbalancierungsversuche den Zuschauer kaum zu einem Hinsehen zu bewegen,

(b) über ästhetische Gestaltung vom Zuschauer die Vorstellung des Todeskampfes in den Gaskammern (s. 2.1.6) und der Verwertung der leiblichen Überreste der Opfer (s. 2.1.7) gefordert - aus diesem Grund erweist sich die zunehmend diskretere Gestaltung als kontraproduktiv.

Erschwerend kommt hinzu, daß im Filmverlauf eine zunehmende Entmenschlichung und Entindividualisierung der Opfer zu beobachten ist, wo es anfangs durchaus Ansätze zur Hervorhebung von Einzelschicksalen gab. ${ }^{88}$ Angesichts dieser extremen audiovisuellen Zumutung absoluter Hoffnungslosigkeit ${ }^{89}$ wird sich der Zuschauer 
zum Selbstschutz der Thematik eher verschließen. Die Absicht, viele Menschen zu erreichen, wird eher verhindert, das Verdrängen vermutlich gefördert.

Eine stärkere Gewichtung der Gegenwartsebene wäre für das Erreichen eines breiteren Publikums sicherlich förderlich gewesen. Einige der regelmäßig zwischen die

90. Vgl. die Anfangs- und Endsequenz, aber auch die über die Schlafbaracken, die Gaskammer, die Krematoriumsöfen und die Frauenhaare. »Der Regisseur wußte sehr wohl, daß eine Häufung von Schreckensbildern abstumpfend wirken mußte. [...] Bewußt gingen Resnais und Cayrol von einer gegenwärtigen Erzählposition aus.« (Dümling 1993: 116f.)

91. „Der signifikante Parameter hierfür [Dehnung und Raffung in der Montage] ist die durchschnittliche Einstellungslänge. So nehmen die 28 Farbeinstellungen (das sind lediglich 9,4\% der insgesamt 297 Einstellungen) ein ganzes Drittel der Filmzeit ein (9 min. 20 sek.), während auf die 269 schwarz-weißen Einstellungen (90,6 \% der Einstellungen) nur die zwei verbleibenden Drittel kommen (20 min. 10 sek.). Bei einer mittleren Einstellungslänge von 20 Sekunden erscheint die Zeit in den Farbeinstellungen daher gedehnt gegenüber dem beschleunigten Montagerhythmus der schwarz-weißen Einstellungen (mittlere Einstellungslänge = 4,5 Sekunden). « (Hattendorf 1999: 211) »C'est ici que l'on comprend que la force de NuIT ET BROUILLARD venait moins des documents que du montage, de la science avec laquelle les faits bruts, réels, hélas ! étaient offerts au regard [...].« (Rivette zit.n. Lowy 2001: 181) »Der Regisseur [Resnais] behauptet von sich selbst, stärker durch die Eisensteinsche Attraktionsmontage als die Pudovkinsche Variante der additiven Montage inspiriert zu sein: >[...] jede Einstellung muß lebendig bleiben «." (Resnais zit.n. Thiele 2001: 177) »In NACHT UND NeBEL [...] ist jedoch entgegen der Äußerungen des Regisseurs eine konventionelle, logisch aufbauende und der Chronologie der Ereignisse weitgehend folgende Zusammenstellung der Bilder zu erkennen, also eher die Pudovkinsche, srealistische` Variante der Montagetechnik.« (Thiele 2001: 178, H.i.0.)

92. „Eine ältere Dame beschwert sich nach dem Film über die >Holzhammermethodeく.» (Geyer zit.n. Thiele 2001: 185)

93. Vgl. Jochimsen zum Unterschied von Erwin Leisers Dokumentation MeIn KampF (1960): »Offensichtlich kannte Leiser die Wirkungspsychologie schreckenerzeugender Filmbilder, denn obgleich er über das Archivmaterial verfügen konnte, verzichtete der Regisseur auf die grauenvollsten Aufnahmen.« (1996: 223)

94. Zu bezweifeln, da den Zuschauer überfordernd, ist jedoch Dümlings funktionale Interpretation: »Zu dieser Schlußsequenz erklingt der musikalische Epilog Eislers, der die zu Beginn erklungene Streichermelodie fortsetzt. Erst jetzt hat sich die Bedeutung dieser Musik völlig erschlossen: Sie erinnert an die Millionen von Toten, von denen nur noch Berge von Haaren, von Schuhen und von Gebissen übrig geblieben waren.« (Dümling 1993: 122)

95. »This time however the film is oriented towards the future." (Colombat 1993: 139)

96. »Et c'est alors que NUIT ET BROUILLARD devient non seulement un exemple sur lequel méditer, mais un appel, un >dispositif d'alerter contre toutes les nuits et tous les brouillards qui tombent sur une terre qui naquit pourtant dans le soleil, et pour la paix.« (Cayrol zit.n. Raskin 1987: 137) »NUIT ET BROUILLARD stellt dem Zuschauer explizit die Aufgabe der Erinnerungsarbeit und macht ihn verantwortlich für das Bewahren des historischen Gedächtnisses gegenüber neuen Formen des Rassismus.« (Paech 1993: 129)

97. »[...] l'herbe a repoussé, timide, rasé et rare entre les ruines du crématoire, assez pour affirmer que la vie est plus forte que le néant.« (Bazin zit.n. Raskin 1987: 139) 
Schwarzweiß-Sequenzen geschnittenen Farbaufnahmen ermöglichen dem Zuschauer, sich nicht von der Wucht des historischen Bildmaterials vereinnahmen zu lassen, zum Teil sich sogar ein wenig davon zu »erholen«. Letzteres trifft insbesondere für die farbigen Szenen zu, in welchen die Kamera in langen Einstellungen die Ruinen und Relikte der einstigen Lager bedächtig abtastet, mit getragener musikalischer Begleitung und ohne energischen Kommentar. ${ }^{\circ}$ Allein durch die niedrigere Schnittfrequenz kontrastieren die nachträglichen Aufnahmen mit dem - abgesehen von der Verwertungs-Sequenz - äußerst schnell geschnittenen Schwarzweißmaterial..$^{91}$ Aufgrund dieser Inszenierung der historischen Bilder weisen weite Teile des Films ein rasantes Tempo auf, das den Zuschauer tendenziell »erdrückt«, ihm wie eine Holzhammer-methode ${ }^{92}$ erscheinen und so Verweigerung auslösen kann.

So hätten in den Anfangsteilen die Vorstellungskraft und das Einfühlungsvermögen des Zuschauers dadurch angeregt werden können, daß man ihm ohne bzw. mit gekürztem Kommentar Zeit läßt, seine eigenen Gedanken und Empfindungen zu entwickeln (s. 2.1.5). Die Reduzierung von entindividualisierten Schockbildern'33, Stakkato-Rhythmen, Informationen und Kommentaren hätte das Sich-Einlassen auf das Leid, vielleicht sogar die eigene Schuld begünstigen können.

Stärker ausbaubares Potential steckt hingegen in der Thematisierung der Problematik sogenannter Erinnerungsorte (s. 2.1.5); nicht zufällig wurde gerade dieser fruchtbare Aspekt in Lanzmanns Sнонн (s. II.2.2.6) und Marceline Loridan-Ivens' Birkenau UND Rosenfeld (s. II.5.4-5.6) aufgegriffen und zum Teil weiterentwickelt.

Abschließend sei auf das sich abhebende Filmende eingegangen. Neben der Wiederaufnahme des musikalischen Anfangsmotivs ${ }^{94}$ beinhaltet die Schlußsequenz im Vergleich zum Rest des Films eine neue Dimension ${ }^{95}$ und enthält ein zentrales Anliegen - wenn nicht gar das zentrale Anliegen - des Werks. Resnais/Cayrol halten hier ein flammendes Plädoyer für die Notwendigkeit der Erinnerung, damit sich Vergleichbares nie wiederhole ${ }^{96}$, während das saftig grüne Gras - ähnlich wie in Claude Lanzmanns ShoAн und Marceline Loridan-Ivens' Birkenau und Rosenfeld - die Ruinen allmählich zu überwuchern beginnt:97

»Au moment, où je vous parle, l'eau froide des marais et des ruines remplit le creux des charniers. Une eau froide et opaque comme notre mauvaise mémoire. La guerre s'est assoupie, un œil toujours ouvert. L'herbe fidèle est venue à nouveau sur les Appellplatz, autour des blocks; un village abandonnée encore plein de menaces. Le crématoire est hors d'usage. Les ruses nazis sont démodées. Neuf millions de morts hantent ce paysage. Qui de nous veille dans cet étrange observatoire pour nous avertir de la venue de nouveaux bourreaux? Ont-ils vraiment un autre visage que le notre? Quelque part, parmi nous, il y a des kapos chanceux, des chefs récupérés, des dénonciateurs inconnus. Il y a tous ceux qui n'y croyaient pas, ou seulement de temps en temps. Et il y a nous qui regardons sincèrement ces ruines comme si le vieux monstre concentrationnaire était mort sous les décombres, qui feignons de reprendre espoir devant cette image qui s'éloigne, comme si on guérissait de la peste concentrationnaire, nous qui feignons de croire que tout cela est d'un seul temps et d'un seul pays, et qui ne pensons pas à regarder autour de nous, et qui n'entendons pas qu'on crie sans fin.« (0:28:18 - 0:29:58 h) 
2.1.3 »Ruhe« ̈̈ber dem verlassenen Schreckensort - die Exposition

Bereits in der Exposition führt Resnais den Zuschauer in die entscheidenden Unterschiede zwischen seinem Werk und den Entnazifizierungsfilmen - die besonders kunstvoll inszenierte Gegenwartsebene - ein: Im Vordergrund dieser 1955 aufgenommenen Bilder steht die Tatsache, »daß die gezeigten Orte des Schreckens von der Natur rückerobert werden « (van der Knaap 2002: 71). Prinzipiell birgt die Beschaulichkeit dieser Farbaufnahmen Aufforderungscharakter an die Eigenleistung des Zuschauers, sofern sie nicht durch den Kommentar vorweggenommen wird.

Der kurz nach den ersten Bildern einsetzende, auktoriale Off-Kommentar spielt eine zentrale Rolle hinsichtlich der Zuschauerlenkung..$^{98}$ Irritierend sanft vorgetragen und zum Teil von Ironie geprägt, bietet er uns wiederholt Empfindungen und Gedanken angesichts der »Diskrepanzerfahrung der Ungerührtheit der ersten Natur gegenüber den Schrecken der zweiten« an (Koch 1992: 153). ${ }^{99}$ Bereits die ersten Textzeilen führen den - weite Teile des Films bestimmenden - Aufzählungscharakter ein, in kurzer Zeit ist der Zuschauer einer Fülle von Informationen ausgesetzt. Hinsichtlich des Gebrauchs der grammatischen Zeitformen im Kommentar ist diese erste - ebenso wie die letzte - Farbsequenz nicht beispielhaft für die Farbsequenzen des Mittelteils von NACHT UND NeBEL. Im Unterschied zum konsequenten Einsatz des französischen Imparfait (Präteritum) in den Gegenwartssequenzen im Filmverlauf, weisen die farbigen Rahmensequenzen vor allem eine Mischung aus Präsens ${ }^{100}$ und Perfekt (Passé

98. Vgl. Colombat, der so weit geht, die Bilder dem Text unterzuordnen: »In these opening sequences, the images seem to illustrate ideas expressed by the text [...].« (1993: 125)

99. Obwohl auf Lanzmanns SHOAH bezogen, trifft diese sowie die folgende Äußerung von Gertrud Koch auch ins Zentrum von Resnais' NACHT UND NEBEL - schließlich hat Lanzmann diesen von Resnais entwickelten Ansatz aufgegriffen und weiterentwickelt.

100. »In den Farbsequenzen des Mittelteils wird die Vergangenheit durch das >Präteritumく ausgedrückt, in den kompilierten Schwarzweiß-Sequenzen durch das shistorische Präsens` (dem seinerseits das >reflektierende Präsens in den umrahmenden Farbsequenzen gegenübersteht)« (Hattendorf 1999: 211, H.i.0.).

101. „During the introduction, the parallel dissonant melodies played by a flute and a clarinet accompany the first confrontation of two incompatible presents [...]. The melody of a flute, a clarinet or a trumpet, is always sustained in the background by the incessant repetition of a motif, a chord, a single note, a spizzicato< or a sstaccato< played by a trumpet or a piano." (Colombat 1993: 146, H.i.0.)

102. Zu bezweifeln ist jedenfalls, ob Dümlings, den Zuschauer m.E. überfordernde, Interpretation der Musik zutrifft: »Die Musik erinnert daran, daß die völlig menschenleere Landschaft, die im Bild zu sehen ist, einmal von Millionen von Menschen bevölkert war. Als dramaturgischer Kontrapunkt zum Bild verweist die Musik gerade auf das, was nicht zu ssehen< ist. Sie läßt gleichzeitig etwas erahnen, was nicht zu shören< ist [...].« (1993: 120, H.i.0.)

103. »In den farbigen Sequenzen begleiten langsam gesprochene, vielgliedrige Sätze die langsamen, gleitenden Kamerafahrten (nach vorn, rückwärts und seitwärts) in langen Einstellungen. In der ersten Einstellung [...] setzt eine langsame Kranfahrt nach unten den für die farbigen Sequenzen charakteristischen elegischen Rhythmus." (Hattendorf 1999: 207)

104. "The first shot [...] indicates clearly that underneath the apparent normality and tranquility of a contemporary landscape lies traces of the atrocities of the Holocaust." (Colombat 1993: 124) 


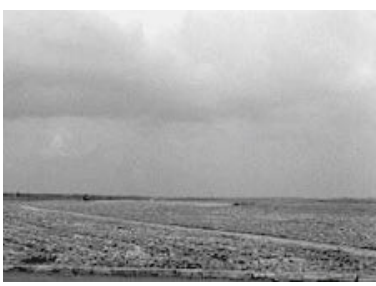

88 0:01:10 h

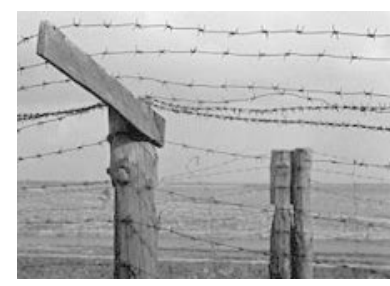

(89) $0: 01: 20 \mathrm{~h}$

composé) auf. So gibt es für den Zuschauer in bezug auf die Verwendung der grammatischen Zeitformen in den Rahmensequenzen des Films keine Desorientierung. Das die Eröffnungssequenz dominierende Perfekt läßt den Zuschauer ahnen, daß die Ereignisse noch nicht abgeschlossen sind. Auch durch den Gebrauch der Zeiten in der Exposition wird der Zuschauer in bezug auf eine zentrale Wirkungsabsicht des Films sensibilisiert - die nur ein Jahrzehnt zurückliegenden Greuel dürfen nicht vergessen werden, die Erinnerung daran darf nie vergehen.

Neben dem Kommentar fällt auf auditiver Ebene die laute musikalische Begleitung auf, die insgesamt unpassend wirkt und unangenehm berührt. Dies ergibt sich aus dem Kontrast der dissonanten Töne ${ }^{101}$ mit den zum Teil durchaus beschaulichen Aufnahmen und der sanften Kommentatorenstimme.

Die visuelle Ebene betreffend, ist die vorliegende Eröffnungssequenz mit der ersten Sequenz innerhalb des Rahmens von Die TodesmüHLEN (s. II.1.1.5) vergleichbar - eine vermutlich keineswegs zufällige Ähnlichkeit: Es ist anzunehmen, daß Resnais Burgers/Wilders Ansätze künstlerischer Inszenierung (s. II.1.1.4) studiert und aufgegriffen hat. Hier wie dort soll der Gefängnischarakter der Lager für den Zuschauer durch besondere ästhetische Gestaltung erfahrbar gemacht werden. Im Unterschied zu Die TodesmüHLEn überrascht Resnais mit dem sukzessiven Einblenden des Stacheldrahtzaunes und setzt damit auf die angesprochene Kontrastwirkung zwischen friedlich-beschaulicher Natur und drastisch-einbrechender Vernichtung - ein Verfahren, das auch große Teile von Lanzmanns SHоAн (s. v.a. II.2.2.6) und Loridan-Ivens' BirkenAu Und Rosenfeld (s. v.a. II.5.4.e) bestimmt.

\section{Detaillierte Sequenzanalyse:}

Kaum taucht nach einem harten Schnitt eine menschenleere, friedliche Landschaft in Farbe (s. o:01:10 h) auf - was den Zuschauer angesichts der Filmthematik verwundert -, setzen auf der Tonspur spannungserzeugende Paukenschläge ein, die nach kürzester Zeit von dissonanten Querflöten-Tönen und einer Klarinette im Hintergrund abgelöst werden. Diese musikalische Begleitung steht in krassem Gegensatz zur Bildspur und wirkt irritierend auf uns. ${ }^{102}$ Mit ihrem Einsetzen beginnt auch die Kamera sich zu bewegen: Sie neigt sich äußerst langsam ${ }^{103}$, um auf diese Weise Stück für Stück im Bildvordergrund Stacheldraht einzufangen, welcher den Blick auf diese »augenscheinlich friedliche >nature morte« zunehmend verwehrt (s. o:01:20 h) und dem Zuschauer den Glauben an die unschuldige Friedlichkeit der Umgebung sogleich wieder raubt (Heller 1997: 224, H.i.O.). ${ }^{104}$ Noch bevor man Zeit hat, diesen extremen Kontrast auf sich wirken zu lassen, setzt aus dem Off ein langsam und ruhig vorgetragener Kommentar ein, der exakt auf die Bildspur abgestimmt ist und 
eben diese »Diskrepanzerfahrung der Ungerührtheit der ersten Natur gegenüber den Schrecken der zweiten « verbal zu erzeugen versucht (Koch 1992: 153): »Même un paysage tranquille (s. erneut o:01:20 h), même une prairie avec des vols de corbeaux (s. ০:01:25 h), des moissons et des feux d'herbes (s. 0:01:40 h) ...« (०:01:20 - ०:01:29 h) Ohne, daß der Satz zu Ende gesprochen würde, macht der Sprecher eine Pause, um dem Zuschauer die Möglichkeit zu geben, die verstörende Situation auf sich wirken zu lassen. Parallel hierzu weicht die Kamera zurück ${ }^{105}$, um den Stacheldrahtzaun in seiner ganzen Länge im Vordergrund ins Bild zu rücken (s. erneut o:01:40 h), inklusive eines für die Konzentrationslager charakteristischen Wachturms. In der wiederum durch harten Schnitt eingeleiteten folgenden Einstellung, die nach dem gleichen Kontrastprinzip aufgebaut ist - statisches Bild einer friedlichen Landschaft, die sich durch Kamerabewegungen als Orte früheren Schreckens entpuppen ${ }^{106}-$, nimmt der Kommentator seinen Satz wieder auf, um ihn bedächtig zu Ende zu führen: »... même une route ${ }^{107}$ où passent des voitures, des paysans (s. 0:01:42 h), des couples, même un village pour vacances avec une foire et un clocher (s. 0:01:48 h) peuvent conduire tout simplement à un camp de concentration.« (s. 0:01:51; 0:01:41 ०:01:51 h). Die Gegenüberstellung von Liebespaaren und Konzentrationslagern könnte kontrastreicher nicht sein und verursacht bei uns Unbehagen. Der Text bildet die Klammer für die disparaten visuellen Eindrücke und spielt mit den extremen Polen Liebe und Tod.

105. Vgl. Colombats sensible Interpretation dieser Kamerahandlung: »[...] like a frightened spectator discovering an unexpected world [...].« (Colombat 1993: 124)

106. »[...] the movement of the beginning [...]. Each sequence starts with a different static shot of the same landscape, continuing with the juxtaposition of extremely different successive and partial images of the same landscape (inside the camp), creating the movement which begins the narration through the montage and movements of the camera itself. These three elements are woven through constant variations [...]." (Colombat 1993: 150)

107. »[...] this road could indicate a possible escape. However, in the very same movement, the camera discovers [...] rows of barbed wire. We are again, once and for all, trapped inside the camp [...].« (Colombat 1993: 126)

108. Vgl. die sehr ähnliche Archivaufnahme aus DIE TODESMüHLEN in II.1.1.4 (Standbild 0:00:05 h).

109. The eye of the spectator is now searching for traces that would facilitate an understanding of what had happened here [...].« (Colombat 1993: 126)

110. Vgl. Avisars interessante Anmerkung hierzu: »[...] the viewer is made to realize that today's rich green rises from the soil fertilized by the gray ashes of millions.« (1988: 13)

111. »The opening images of a beautiful and peaceful landscape in the Polish meadows are strikingly incongruous with the knowledge that this innocent-looking land was the setting of past horrors. [...] The blood has dried, the tongues are silent. The blocks are visited only by a camera. This emphasis on the distorting present sights [...] is the expression of the profound frustration and anguish on any sincere attempt to face the Nazi horrors and to apprehend the unspeakable and unimaginable.« (Avisar 1988: 7) Vgl. Schoenberner in seinem Vorwort zu seinem Buch »Der gelbe Stern. Die Judenverfolgungen in Europa 1933 bis 1945«: »Die Jahre vergehen. Die Baracken in Birkenau, die einmal bis zum Dach erfüllt waren von menschlicher Not und Qual, stehen leer und verfallen. Die Gruben, in denen man Menschen verbrannte, haben sich mit Regenwasser gefüllt und sind zu schilfumwachsenen 

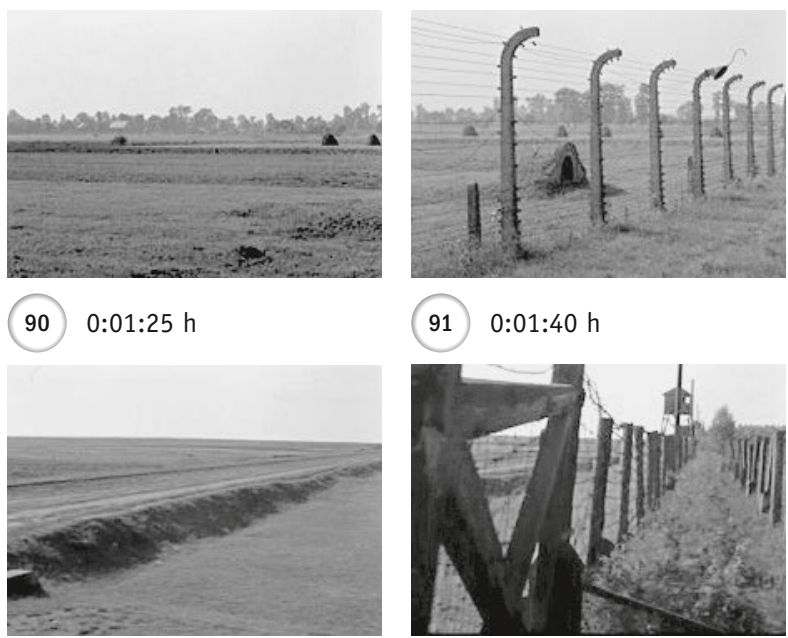

(92) $0: 01: 42 \mathrm{~h}$
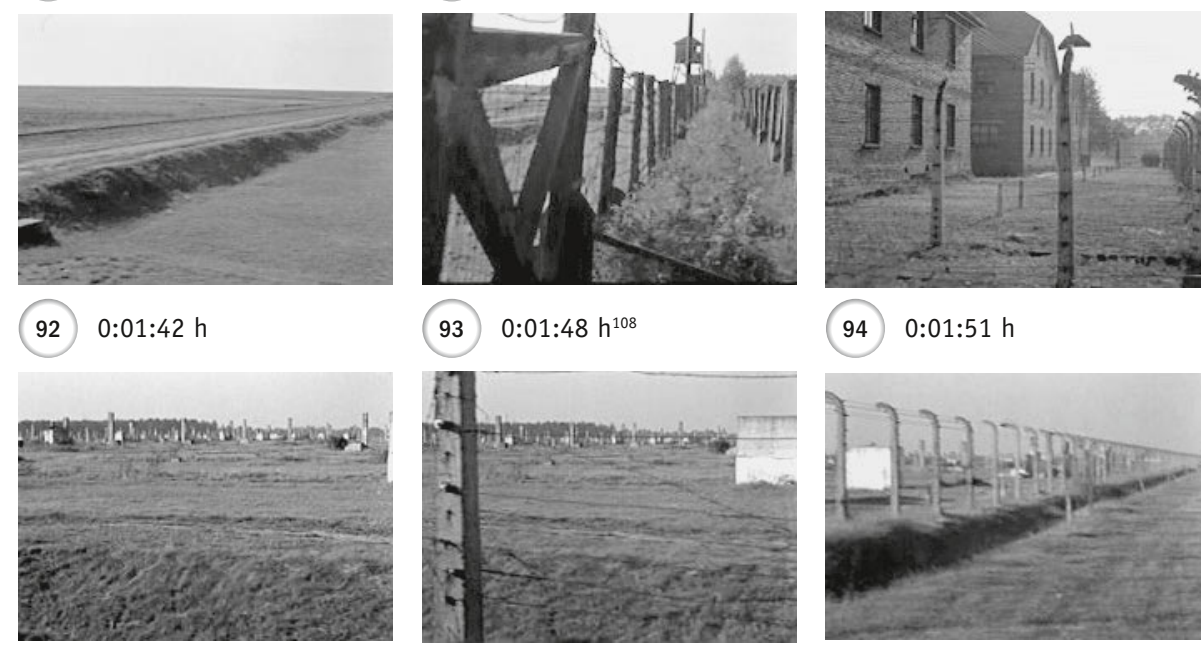

(95) $0: 02: 02 \mathrm{~h}$

(96) $0: 02: 09 \mathrm{~h}$

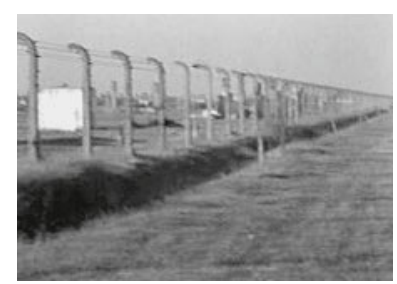

(97) $0: 02: 19 \mathrm{~h}$

Die folgende Einstellung, beginnend mit dem Wort Konzentrationslager (s.o.), führt die langsame Kamerafahrt von links nach rechts fort, nun jedoch die Blöcke der Lager (nach möglichen Spuren) absuchend (s. erneut 0:01:51 h). ${ }^{109}$ Die »Stummheit der steinernen Zeugnisse, über die das Gras zu wachsen begonnen hat « (Darmstädter 1995: 121), wirkt jedoch verstörend und gleichzeitig anregend auf unsere Vorstellung. Parallel zur abtastenden Kamerabewegung unterstreicht der ruhig vorgetragene Text den Kontrast zwischen dem Vorher und dem Nachher der Orte des Schreckens: »Le Struthof, Oranienbourg, Auschwitz, Neuengamme, Bergen-Belsen, Ravensbrück, Dachau furent des noms comme les autres sur les cartes et les guides.« (०:01:51 ०:02:01 h)

Die sich anschließende Einstellung funktioniert nach einem ähnlichen Konstruktionsprinzip, jedoch sind zu Beginn im Hintergrund bereits Zeichen der Vergangenheit - in diesem Fall Ruinen - erkennbar (s. 0:02:02 h). Durch das Fortsetzen der Kamerafahrt rückt im Vordergrund erneut ein Stacheldrahtzaun ins Bild und trübt unsere Sicht der satt-grünen ${ }^{110}$ Felder, während der Kommentator getragen ausspricht, was der Zuschauer vielleicht schon empfindet:

»Le sang a caillé (s. 0:02:02 h), les bouches se sont tues, les blocks ne sont plus visités que par une caméra. Une drôle d'herbe a poussé (s. 0:02:09 h) et recouvert la terre usée par le piétinement des concentrationnaires. Les bâtiments, les courant ne passe plus dans les fils électriques. Plus aucun pas, que le notre.«(S. 0:02:19 h; 0:02:02 - 0:02:19 h) ${ }^{111}$ 
Die Texte, insbesondere die Passage »la terre usée par le piétinement des concentrationnaires «, füllen die visuelle Leere und provozieren Vorstellungen: Auf der musikalischen Ebene werden gegen Ende die bedrohlich wirkenden Paukenschläge vom Anfang der ersten Sequenz wieder aufgenommen. Sie kündigen in Zusammenhang mit dem Aussetzen des Textes den Übergang zu einer neuen Szene an.

Auffälligerweise befinden wir uns während der letzten beiden Einstellungen - im Gegensatz zu den ersten drei Einstellungen - außerhalb des Lagers, in das wir durch Stacheldraht hineinspähen. Vorher war die Kamera - und so der Zuschauer - innerhalb positioniert bzw. bewegte sich dorthin, so daß wir durch den Stacheldraht nach draußen blickten. Mit dieser Zweiteilung korrespondiert der Text, der sich zunächst auf die Landschaft außerhalb des Schreckensortes konzentriert und später die Lager selbst fokussiert. Die ersten drei bis vier Einstellungen zeichnen sich überdies durch ein zunehmendes Verschwinden des Horizonts aus. ${ }^{112}$ Dadurch erfolgt eine Konzentration auf die Ruinen und Gebäude und unser Blick wird stärker auf die Spuren der Vergangenheit gelenkt.

\subsubsection{Die Lagerhierarchie im Stakkato-Rhythmus}

An dieser zweiten Schwarzweiß-Sequenz, die im ersten Drittel des Films plaziert ist, können charakteristische Inszenierungsformen der Vergangenheitsebene (insbesondere) zu Beginn von Nacht und NeBel gezeigt werden. ${ }^{113}$ Damit stellt diese Sequenz das Pendant zur in der Einleitung beschriebenen Leichenmassen-Sequenz dar (s. 2.1.1). Im Vergleich können Parallelen und Unterschiede nachvollzogen werden.

Aufgrund der spezifischen Inszenierung wirkt die vorliegende Sequenz insgesamt wie eine Art Unterrichtseinheit im Stakkato-Rhythmus - es geht um maximale Faktenvermittlung in kurzer Zeit: Die Schwarzweißaufnahmen sind extrem schnell hintereinander geschnitten, der Kommentar ist beinahe hastig und harsch vorgetragen sowie von Aufzählungen bestimmt. Bei der Musik handelt es sich aufgrund der kontrapunktischen Konzeption um eine ausschließlich intellektuell verarbeitbare Beglei-

kleinen Tümpeln geworden. Nur die weißgraue Färbung der Erde erinnert noch daran, wessen Asche hier verstreut wurde. Von den gesprengten Gaskammern und Krematorien sind noch einzelne geborstene Betonplatten übriggeblieben und verbogene Eisendrähte, die ihre rostigen Finger in die Luft strecken. Zwischen den Hütten wuchern große Sträucher blühender Heckenrosen. Und der von vielen Tausend Holzschuhen festgestampfte Boden, auf dem kein Halm wuchs, ist zu einer wogenden Wiese geworden, die im Sommer gemäht wird.« (1960: 8)

112. Darauf hat Colombat hingewiesen, wobei er diese Beobachtung fälschlicherweise auf die ersten fünf Einstellungen bezieht - die letzte Einstellung der Exposition zeigt wieder mehr Himmel: "In this introduction to the documentary, the line of the horizon has been successively placed at the lower, the middle and top third of the screen to disappear finally in the perspective of rows of barbed wire crossing the depth of the screen. [...] This progressive disappearance of the horizon [...] plunges the spectator suddenly into the history of Nazi Germany starting in 1933.« (1993: 127)

113. Vgl. hierzu insbesondere die Sequenzen »1933 - die Maschine setzt sich in Bewegung", die »Zwangsarbeit bei jeder Witterung und unter widrigen Umständen« und die »Erstaunliches in den Lagern« im entsprechenden Sequenzprotokoll im Anhang der Arbeit.

114. "C'était un autre monde«, schreibt ein von den Alliierten verpflichteter Fotograf über die Befreiung von Bergen-Belsen (Lawrie zit.n. Chéroux 2001 b: 108). 


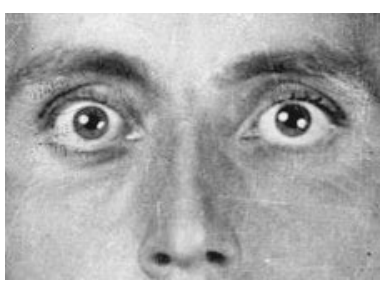

98 $0: 07: 31 \mathrm{~h}$

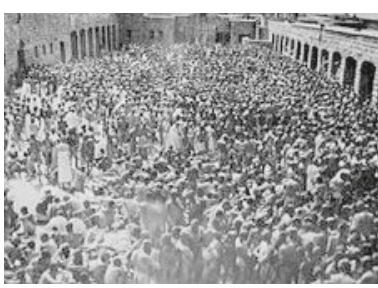

(99) $0: 07: 34 \mathrm{~h}$

tung, die weder Nähe noch Identifikation zulassen soll. Ob dies dem Film jedoch zum Vorteil gereicht, sei stark bezweifelt.

Da sowohl auf auditiver wie visueller Ebene etliche Brechungen existieren, drohen die Brechungen sich gegenseitig eher aufzuheben als zu steigern.

Wo Marceline Loridan-Ivens in Birkenau und Rosenfeld auf Einfühlung setzt und diese auch ermöglicht (s. II.5), wirkt diese Szenenfolge vor allem aufgrund des verbittert-sarkastischen Tonfalls und der extremen Künstlichkeit distanziert und kalt.

Darüber hinaus wird in der vorliegenden Sequenz mit dem Titel des Films gespielt und dem Zuschauer auf diese Weise einer der Gründe für dessen Wahl geliefert.

\section{Detaillierte Sequenzanalyse:}

Die Sequenz beginnt überraschend: Auf die Totale des »Arbeit macht frei«-Tores von Auschwitz aus der vorangegangenen Einstellung folgt mittels hartem Schnitt die Detailaufnahme zweier weit aufgerissener Augen, die direkt in die Kamera starren und damit den Zuschauer anstarren (s. 0:07:31 h). »Premier regard sur le camp: c'est une autre planète« (०: 07:30 - 0:07:33 h) $)^{114}$ erklärt der Sprecher in neutralem Tonfall die schwarz-weißen Aufnahmen und nimmt dabei punktuell die Opferperspektive ein. Auf diese Weise hilft uns der Kommentar, die Augen zuzuordnen und sie zu interpretieren: Es scheint sich um die aus Ungläubigkeit weit geöffneten Augen eines Lagerhäftlings zu handeln. Auf diese Weise sensibilisiert Resnais den Zuschauer für den - in seinem Film wiederholt thematisierten - »Unfaßbarkeits-topos«.

Die folgende Einstellung verschafft uns den im Kommentar angesprochenen Überblick (s. ০:07:34 h). Besonders wirkmächtig ist der Kontrast zwischen beiden Fotos dadurch, daß von einer Detailaufnahme unmittelbar auf eine extreme Supertotale gesprungen wird, von einem Individuum auf eine unüberschaubare Menschenmasse. Während in der vorange gangenen Einstellung die Musik - aufgrund des Sprechers - vergleichsweise in den Hintergrund getreten war, bestimmt sie die vorliegende, kommentarlose Einstellung. Es konkurrieren militärisch wirkende Trompetenklänge und rhythmische Xylophon-Töne miteinander. Insgesamt erzeugt diese auffällige musikalische Begleitung eine angestrengte, energische akustische Atmosphäre, die sich in den beiden folgenden Einstellungen fortsetzt.

Die Aufnahmen eines sogenannten »Bad und Desinfektions«-Raumes (Nahaufnahme) sowie einer Reihe nackter Männer (Totale) erläutert der Kommentator in weiterhin nüchternem Tonfall, jedoch in auktorialer Erzählperspektive: »Sous son prétexte hygiénique, la nudité, du premier coup, livre au camp l'homme déjà humilié.« (०:07:40 - 0:07:45 h) Im Unterschied zur Thematisierung der Nacktheit in BIRKENAU UND ROSENFELD (s. II.5.6.c) erschweren die rasch hintereinander ge- 
schnittenen Aufnahmen die Auseinandersetzung mit diesen Erniedrigungen. Auf diese Weise heben sich die Wahrnehmungs- bzw. Verarbeitungsangebote gegenseitig auf. ${ }^{115}$

»Rasé (s. 0:07:47 h), tatoué (s. 0:07:48 h), numéroté (s. 0:07:50 h), pris dans le jeu d' une hiérarchie encore incompréhensible, revêtu de la tenue bleue rayée (s. 0:07:57 h), classé parfois >Nacht und Nebel`, >Nuit et brouillard (s. 0:07:59 h). Marqué (s. 0:08:04 h) du triangle rouge des politiques, le déporté affronte d'abord les triangles verts, (s. 0:08: $07 \mathrm{~h}$ ) les droits communs, maître parmi les sous-hommes. Au-dessus: le kapo (s. 0:08:11 h), presque toujours: un droit commun (0:08:14 h). Au-dessus encore: le S.S., l'intouchable (s. 0:08:16 h). On lui parle à trois mètres. Tout en haut: le commandant (s. 0:08:21 h). Lointain il préside aux rites. Il affecte d'ignorer le camp.« (0:07:47 - 0:08:22 h)

Der Stakkato-Rhythmus dieser Einstellungsfolge ergibt sich jedoch nicht nur aus der schnellen Montage, sondern auch aus der spezifischen, unterstützenden Gestaltung der Tonspur. Der in harschem Tonfall, aus auktorialer Erzählperspektive vorgetragene und mit den Aufnahmen korrespondierende Kommentar hat - im Gegensatz zur zitierten Sequenz aus Birkenau und Rosenfeld - wissenschaftlichen Aufzählungscharakter. Dieser wird zu Beginn und gegen Ende der zusammenhängenden Kommentarpassage durch zusätzliche Paukenschläge akzentuiert; die ansonsten weiterhin kraftvolle Begleitung aus Trompeten und gezupften Streichinstrumenten scheint die Einstellungsfolge regelrecht anzutreiben und trägt so zum insgesamt schnellen Tempo der Szene bei.

\subsubsection{Leere Schlafkojen - »stumme« Relikte}

Noch deutlicher als in der zweiten Farbsequenz (»Bahnstrecke und Eingang von Auschwitz heute«) stellt die dritte und mit zweieinhalb Minuten längste Farbsequenz des Films eine zentrale Frage: Was können uns die einstigen Schreckensorte »heute« noch sagen? In diesem Punkt ist Nacht und Nebel mit bestimmten Szenen aus SHOAн (s. II.2.2.6) ${ }^{116}$ und insbesondere mit BIRKENAU UND ROSENFELD vergleichbar. In Marceline Loridan-Ivens' Spielfilm wird nahezu unablässig die Schwierigkeit thematisiert, die Orte »zum Sprechen zu bringen« - eine Aufgabe, die vor allem von der besuchenden Person und deren Vorgehensweise abhängt.

115. Die Gestaltung dieser Seite, d.h. die Überhäufung mit Bildern, ikonisiert den stakkato-artigen Gestus der Filmszene und versucht ihn damit dem Leser der Arbeit erfahrbar zu machen.

116. Weite Teile des Films über tut Lanzmann so, als sprächen die einstigen Schreckensorte »von sich aus«, als bedürfe es keiner angemessenen Lenkung des Besuchers (s. II.2.2.4).

117. „Doch Resnais' Film unterscheidet sich von vielen Dokumentationen und Kompilationsfilmen dadurch, daß er die Unmöglichkeit mitbedenkt, die Erfahrung der Überlebenden zu übermitteln. Cayrol beharrt darauf, daß die Erfahrung des Konzentrationslagers nicht kommunizierbar ist. [...] Resnais vertraut also einerseits auf die Schockwirkung der Bilder, doch andererseits nimmt er die Möglichkeit des Unglaubens in seinen Film herein.« (Kramer 2000: 19) »Im Kommentar wird [...] das notwendige Scheitern der filmisch vollzogenen Suchbewegung, für die auch die langen Kamerafahrten der Farbsequenzen stehen, mitreflektiert.« (Hattendorf 1999: 209) 


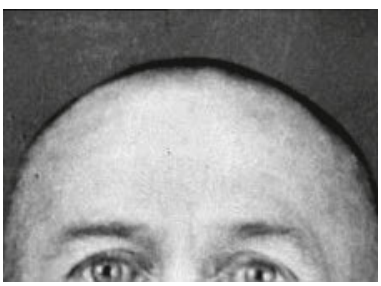

(100) $0: 07: 47 \mathrm{~h}$

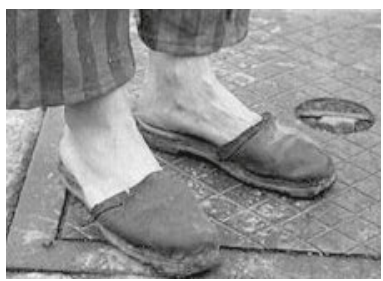

(103) $0: 07: 57 \mathrm{~h}$

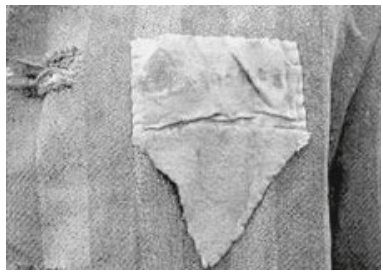

(106) $0: 08: 07 \mathrm{~h}$

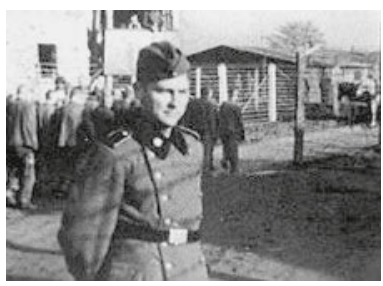

(109) $0: 08: 16 \mathrm{~h}$

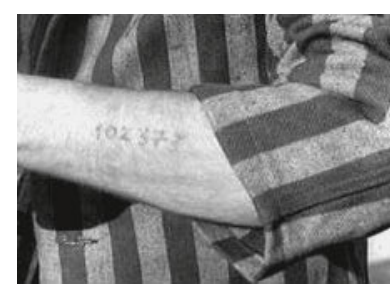

(101) $0: 07: 48 \mathrm{~h}$

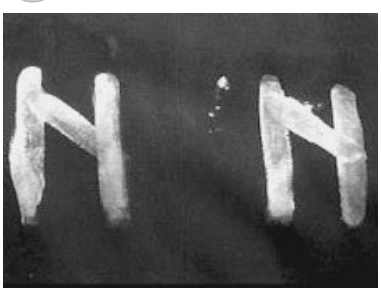

(104) $0: 07: 59 \mathrm{~h}$

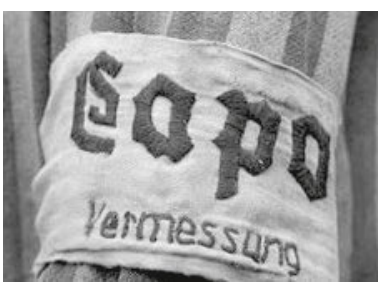

(107) $0: 08: 11 \mathrm{~h}$

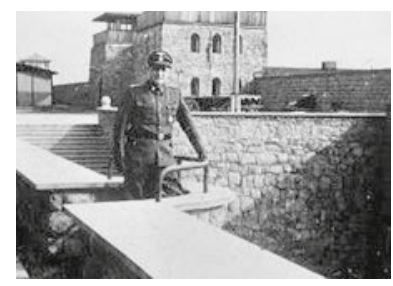

(110) $0: 08: 21 \mathrm{~h}$

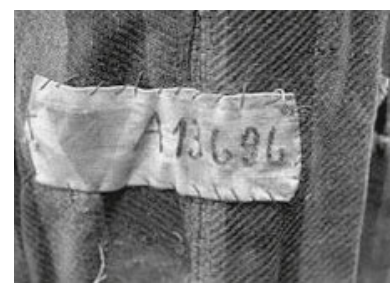

(102) $0: 07: 50 \mathrm{~h}$

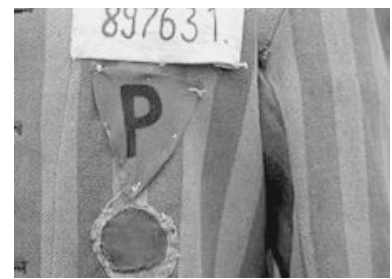

(105) $0: 08: 04 \mathrm{~h}$

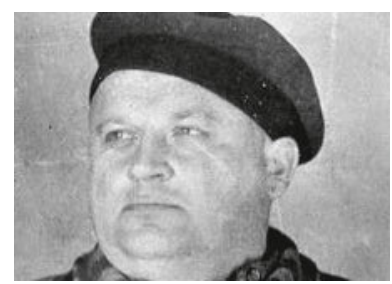

(108) $0: 08: 14 \mathrm{~h}$

Ein weiterer entscheidender Unterschied zwischen beiden Filmen besteht darin, wie die Nächte in den Schlafbaracken jeweils dargestellt werden. Während Marceline LoridanIvens den Barackeninsassinnen Namen gibt, thematisiert Resnais die Häftlinge als anonyme Gruppe, ohne jegliche identifikationsfördernde Individualisierung. Er konzentriert sich ganz auf die unwürdigen Schlafbedingungen und die Konkurrenz unter den Gepeinigten. Loridan-Ivens hingegen deutet im ersten Teil der entsprechenden Sequenz an, daß sich die Insassen - trotz oder gerade aufgrund aller Schwierigkeiten - untereinander durchaus auch halfen und zusammenhielten. Während Resnais dazu neigt, den Zuschauer insbesondere auf der auditiven Ebene zu überreizen (Informationsfülle in rasantem Tempo, Streßerzeugung durch Musik), konzentriert sich Loridan-Ivens auf wenige Details.

Nachdem Resnais/Cayrol in Sequenz vier zum ersten Mal explizit die Spurensuche thematisiert hatten, führt die vorliegende Sequenz den Unfaß- sowie Unsagbarkeitstopos explizit ein. ${ }^{17}$ Prinzipiell vermag der Unsagbarkeitstopos den Zuschauer zu 
animieren, sich die Lagerverhältnisse wesentlich grauenhafter vorzustellen. Die Leere der ehemaligen Orte des Schreckens bietet hierzu eine entsprechende Projektionsfläche. Andererseits läßt deren Stummheit aber auch Zweifel an dieser Möglichkeit der Vorstellung aufkommen. Unabdingbar für das Sich-Ausmalen seitens des Zuschauers wären jedoch Zeit, Ruhe und die Möglichkeit der Konzentration, was in der vorliegenden Sequenz nicht vorhanden ist. Kontemplative Meditation wird damit verhindert.

An dieser dritten Farbsequenz, die hauptsächlich im ersten Drittel des Films plaziert ist, können charakteristische Inszenierungsformen der Gegenwartsebene zu Beginn von Nacht und Nebel gezeigt werden. Damit stellt diese das Pendant zur späteren Sequenz in der Gaskammer dar, an welcher die Entwicklung der Inszenierung des Heute im Filmverlauf nachvollziehbar ist (s. 2.1.6). Im Vergleich beider Farbsequenzen wird deutlich, daß eine ruhigere Gestaltung bereits für die früheren von Vorteil gewesen wäre.

An dieser Sequenz kann der für Binnensequenzen charakteristische Gebrauch der Zeiten, die punktuelle Poetik des Textes von Cayrol demonstriert werden.

\section{Detaillierte Sequenzanalyse:}

Durch den scharfen Gegensatz zum aggressiven Tonfall der vorangegangenen Sequenz entfaltet der zunächst eher ruhige Ton in der folgenden Einstellung seine Kontrastwirkung in besonderem Maße - das Ausbleiben häufiger Schnitte tut sein übriges. Parallel zur nunmehr erneut das Gelände von Auschwitz-Birkenau absuchenden Farbkamera' ${ }^{118}$ sowie einer ebenso auffälligen wie verstörenden Flöte (wiederholt bricht sie aus dem musikalischen Motiv aus), verläßt der Kommentator teilweise seine Informationsrolle und meditiert über das unmögliche Erfassen der damaligen Lagerrealität:

»Qui ne l'ignore pas d'ailleurs. Cette réalité des camps, méprisée par ceux qui la fabriquent (s. 0:08:50 h), insaisissable pour ceux qui la subissent (s. 0:08:53 h), c'est bien en vain qu'à notre tour nous essayons d'en découvrir les restes (s. 0:08:56 h). Ces blocks en bois, ces châlits où l'on dormait à trois (s. 0:09:02 h), ces terriers où l'on se cachait, où l'on mangeait à la sauvette, où le sommeil même était une menace, aucune description, aucune image ne peuvent leur rendre leur vraie dimension, celle d'une peur ininterrompue. Il faudrait la paillasse de garde-manger et de coffre-fort, la couverture pour laquelle on se battait, les dénonciations, les jurons, les ordres retransmis dans toutes les langues, les brusques entrées du S.S. pris d'une envie de contrôle ou de brimade. De ce dortoir de brique, nous ne pouvons que vous montrer l'écorce, la couleur.« (0:08:45 - 0:09:39 h, eigene Hervorhebung)

118. Interessanterweise wählt Resnais hier eine im Vergleich zur Exposition partiell gegensätzliche Kompositionsstruktur: Der Stacheldraht rückt hier nicht allmählich ins Bild, sondern verstellt sofort den Blick auf die KZ-Gebäude (s. 0:08:50 h); freie Sicht stellt sich durch die Kamerabewegung ein (s. 0:08:53 h). Auch der Horizont wird umgekehrt verlegt.

119. Es handelt sich hierbei um die fünftlängste Einstellung des gesamten Films. 


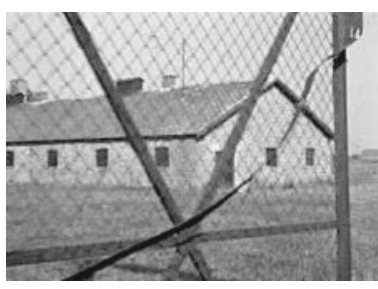

(111) $0: 08: 50 \mathrm{~h}$

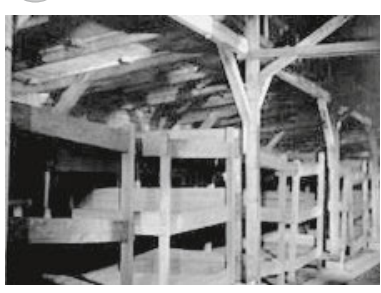

(114) $0: 09: 02 \mathrm{~h}$

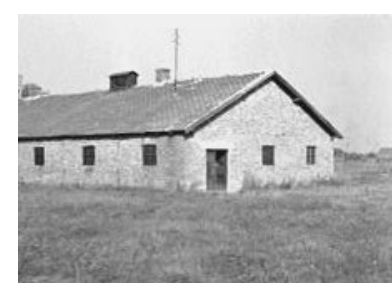

(112) $0: 08: 53 \mathrm{~h}$

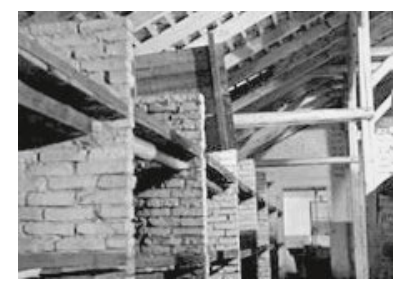

(115) $0: 09: 43 \mathrm{~h}$

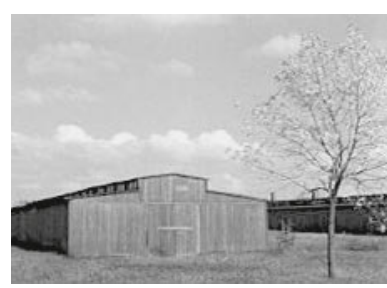

(113) $0: 08: 56 \mathrm{~h}$

Durch den abrupten Wechsel von lichtdurchfluteten, beinahe idyllischen Außen(s. ०:०8:5०, ०:०8:53 und ०:०8:56 h) zu dunklen Innenaufnahmen (s. ०:०9:02 und ०:09:43 h) wirken letztere besonders düster. Etwas weniger als eine halbe Minute fährt die Kamera in den Block hinein und inszeniert so die unzähligen Schlafkojen aus Holz bzw. Stein (s. 0:09:02 und 0:09:43 h). ${ }^{119}$ Im Unterschied zum Beginn der Sequenz treibt Resnais in den Innenaufnahmen das Tempo zunächst stark an und verfällt dabei fast in den Stakkato-Rhythmus der vorangehenden Schwarzweiß-Sequenz: Zum einen wird die Flöte durch die Trompete abgelöst, wodurch erneut eine militärische, beängstigende Färbung erzeugt wird. Zum anderen steigern sich Tempo und Tonfall des Sprechers bis zum Kommandoton. Auf den Zuschauer wirkt dies, als rede er sich durch die Aufzählungen des explizit als unerklärlich und unfaßbar Deklarierten in Rage. Oder versuchen Resnais/Cayrol durch die beschriebene Entwicklung des Kommentars und den Einsatz des ambivalenten »on« die Angst- und Streßsituation der Opfer zu ikonisieren und uns so zwischenzeitlich in deren Wahrnehmung zu versetzen? Visuell wird dies, falls überhaupt beabsichtigt, nicht abgesichert; die Kamera verharrt im auktorialen Gestus. Nach dieser erneuten inszenatorischen, kontraproduktiven Überfülle setzt im zweiten Teil der Kamerafahrt eine wohltuende Beruhigung ein. Parallel insbesondere zum letzten, eindeutig auktorialen und wesentlich ruhiger vorgetragenen Satz (»De ce dortoir de brique, nous ne pouvons que vous montrer l'écorce, la couleur.«) ersetzt die Flöte erneut die aggressive Trompete, nimmt die musikalische Begleitung weniger dissonanten Charakter an. Das Ausmaß der Einpferchung versucht Resnais hier zusätzlich über eine Weitwinkelperspektive erfahrbar zu machen - eine Form der visuellen Inszenierung, die beispielsweise in BIRKENAU UND ROSENFELD wiederholt aufgegriffen wird (s. II.5.5.c, Standbild o:32:31 h und II.5.5.d, Standbild o:34:44 h). Fraglich ist jedoch, ob sich der Zuschauer unmittelbar nach der vorangegangenen Überreizung sofort von dieser potentiell wirkmächtigen Form berühren lassen kann.

Die folgende Einstellung spannt den Bogen zum Beginn der Sequenz. Wieder im Freien schwenkt die Kamera bedächtig über die verschiedenen Baracken, begleitet von 
der getragenen Streicher- und Flötenmusik (s. ०:10:07 h). Auffällig ruhig und langsam spricht der Kommentator, erneut in distanziert-meditativem Gestus:

»Voilà le décor, des bâtiments qui pourraient être écurie, grange, atelier. Un terrain pauvre, devenu terrain vague, un ciel d'automne indifférent. Voilà tout ce qui nous reste pour imaginer cette [Schnitt] nuit coupée d'appels [...].« (0:10:07 - 0:10:21; eigene Hervorhebung)

Anstatt uns die Möglichkeit zu geben, die Aufnahmen der Blöcke und des auffällig grünen Grases auf uns wirken zu lassen, versucht der Text einmal mehr, unsere Gedanken zu lenken. Die poetische Beschreibung des Herbsthimmels kann ihre Wirkung nicht entfalten, da der in barschem Ton unmittelbar folgende Überleitungssatz zur nächsten Schwarzweiß-Folge den Zuschauer abrupt aus der meditativen Atmosphäre reißt: Dem Film abträglich ist zudem, daß Resnais/Cayrol die Möglichkeit verschenken, die Schwierigkeit der Vorstellung (»Voilà tout ce qui nous reste pour imaginer [...].«) auf den Zuschauer wirken zu lassen.

\subsection{6 »Fehl-Forderung « des Zuschauers - \\ Spuren des Todeskampfes in den Gaskammern}

Aus vielen Gründen ist die Sequenz mit den Farbaufnahmen der Gaskammer der Höhepunkt des Films (vgl. Colombat 1993: 138).

Mit dieser Szenenfolge wagt sich Resnais nicht nur ins Zentrum der Vernichtung vor, ihre Gestaltung ist beispielhaft für die Inszenierung der Gegenwartsebene von Nacht und Nebel, insbesondere hinsichtlich der Entwicklung der filmischen Gestaltung im letzten Drittel des Films. Im Zentrum findet die suchende Farbkamera augenfälligere Spuren der Vergangenheit als bisher: Die Decke der Gaskammer ist von Fingernagel-Furchen gezeichnet. Wie in den vorangegangenen Farbsequenzen $^{120}$ tastet die Kamera die Zeichen des Holocaust in einer langen Fahrt ab und versucht so, dem Zuschauer das Ausmaß desselben buchstäblich vor Augen zu führen.

Obgleich sich Resnais nach eigener Aussage deutlich von den Entnazifizierungsfilmen absetzen wollte (s. 2.1.1), können etliche Parallelen zu Dif TodesmüH len festgestellt werden. Diese reichen von identischem Bildmaterial (s.u. o:21:19 h) über eine vergleichbare schrittweise Annäherung an die Gaskammern (Zyklon-B-Behälter, Auskleideraum, Tür zur Gaskammer, Decke der Gaskammer) und Betonung ähnlicher Aspekte der Vernichtung (Täuschung der Opfer durch die Deutschen), bis hin zum

120. Vgl. insbesondere die Sequenzen zur Schlafbaracke, der Abortanlage und den Krematoriumsöfen.

121. »Die Symbolik verwandelt die Erscheinung in Idee, die Idee in ein Bild, und so, daß die Idee im Bild immer unendlich wirksam und unerreichbar bleibt und, selbst in allen Sprachen ausgesprochen, doch unaussprechlich bliebe. [...] Die Allegorie verwandelt die Erscheinung in einen Begriff, den Begriff in ein Bild, doch so, daß der Begriff im Bild immer noch begrenzt und vollständig zu halten und zu haben und an demselben auszusprechen sei.« (Goethe 1960: 470/749 bzw. 471/750) 


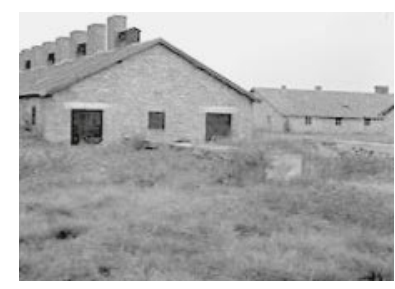

(116) $0: 10: 07 \mathrm{~h}$

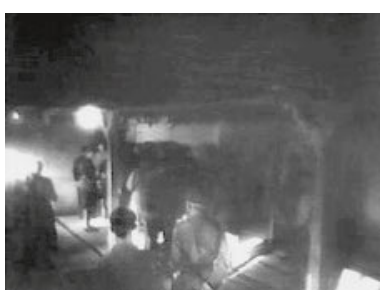

(117) $0: 06: 26 \mathrm{~h}$

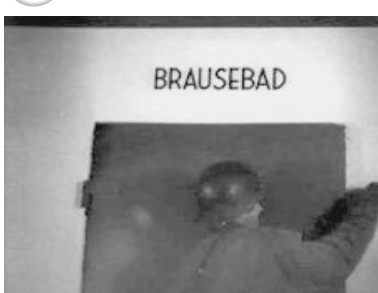

(118) $0: 06: 01 \mathrm{~h}$

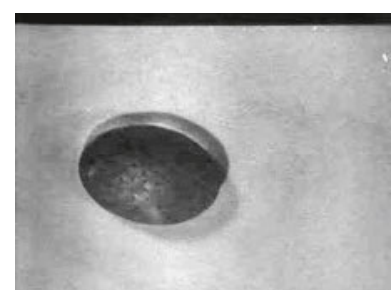

(119) $0: 06: 07 \mathrm{~h}$

nachträglichen Aufsuchen und Filmen gleicher Orte (s. die drei folgenden Standbilder aus Dif Todesmühlen und im Vergleich o:21:40 h unten aus Nacht Und Nebel). Hinsichtlich der Inszenierung des Inneren der Gaskammer unterscheiden sich die beiden Filme jedoch erheblich.

Wo Resnais auf ein hochkomplexes Gestaltungsensemble aus Bild, Off-Kommentar und Musik setzt, konzentriert sich Lanzmann in einer vergleichbaren Sequenz von Sнонн vor allem auf den Augenzeugenbericht eines Überlebenden, der über den Todeskampf in den Gaskammern berichtet (s. II.2.2.3 bzw. 2.2.4) - ein prinzipiell interessanter Ansatz, ginge es nicht um das absolute Zentrum der Vernichtung, den Todeskampf in den Gaskammern.

Die vorliegende Sequenz ist mit $\mathrm{S}$ нонн und daneben insbesondere mit der Aschensee-Sequenz in BirKenAu Und Rosenfeld vergleichbar (s. II.5.4.e). Während sich Resnais im Zentrum der Sequenz allegorisch verhält, verfährt Marceline LoridanIvens symbolisch, jeweils im Sinne Goethes. ${ }^{121}$ Anstatt das lebendige, leibhaftige Bild so aufzuladen, daß der Zuschauer nicht auf Begriffe kommt, sondern ganz bei der Idee ist, bringt Resnais das Bild (Spuren) per Setzung auf einen Begriff (Todeskampf) und richtet sich daher an den Verstand des Publikums. Auf diese Weise verhindert er die Entfaltung des prinzipiell in Spuren der Vergangenheit enthaltenen Sinnpotentials. Zudem läßt Resnais dem Zuschauer - im Unterschied zur vergleichbaren Sequenz in BIRKenau und Rosenfeld - wiederholt zu wenig Zeit zur sukzessiven Entdeckung der Sinntiefe, sondern gibt zu früh die Erklärung durch den Kommentar.

Im Unterschied zu Resnais' »unerträglichen« Spuren wählt Marceline LoridanIvens in einer weiteren Sequenz nicht zufällig halb verrostete Notenständer - ein weitaus dezenteres Zeichen der Vergangenheit, hier zur Erfahrbarmachung der Perfidität der SS-Inszenierungen. Sowohl die Asche als auch die Notenständer zeigen, daß Marceline Loridan-Ivens Resnais' Idee der Sichtbarmachung von Spuren aufgegriffen und weiterentwickelt hat. 
Zentraler Unterschied zwischen beiden Filmen ist: Resnais intendiert, daß der Zuschauer sich den Todeskampf der Opfer in den Gaskammern vorstellt - eine Forderung, deren Umsetzung man nicht erzwingen kann, die ins Leere zielt und die ihr Ziel verfehlt. Loridan-Ivens hingegen versucht in der Gaskammer-Sequenz erst gar nicht, die Vorstellung des Zuschauers auf den Todeskampf in den Gaskammern zu lenken, sondern läßt ihn am trauernden Gedenken der Protagonistin teilhaben (s. II.5.5.f). Auf diese Weise und dadurch, daß sie den Verstorbenen Namen gibt, grenzt sie sich von NaCht und NeBel ab und führt ihren diskreten, behutsamen Umgang mit dem Thema und so mit dem Zuschauer fort - zugunsten einer positiven Beteiligung des Publikums.

Es ist also zu bezweifeln, daß Resnais' Kompositionsstruktur - wie etliche Rezensenten es vertreten ${ }^{122}$ - den Zuschauer dazu bewegt, sich das Grauen auszumalen. Zudem ist die Gaskammer-Sequenz von Szenen eingerahmt, die ihn mit entsetzlichen Aufnahmen von Opfern kurz vor der Liquidierung (vorher) und von Leichenmassen (nachher) konfrontieren. Zu erwarten, daß der Zuschauer sich von einer Sequenz auf die nächste sofort um- und einstellen kann, ist gewiß zuviel verlangt. Auch die völlige Entindividualisierung der Opfer auf diesen Aufnahmen dürfte der Erfahrbarmachung im Wege stehen.

An der elften (von insgesamt vierzehn) Farbsequenz, die im letzten Drittel des Films plaziert ist, können charakteristische Inszenierungsformen der Gegenwartsebene gegen Ende von Nacht und Nebel aufgezeigt werden. Damit stellt sie das Pendant zur vorhergehenden Schlafbaracken-Sequenz dar und es kann an ihr die Entwicklung der Inszenierung des Heute im Verlauf des Films nachvollzogen werden.

\section{Detaillierte Sequenzanalyse:}

Nachdem in der vorangehenden Sequenz viele Schwarzweiß-Fotos zur Thematik »kurz vor der Liquidierung« schnell hintereinander geschnitten wurden und der pausierende Kommentar die Bilder für sich hatte sprechen lassen (s. o:20:58 h), setzt der Sprecher

122. »Resnais benutzt hier ein Verfahren, dessen sich später auch Claude Lanzmann bedienen wird, indem er mit dem gesprochenen Wort eine Handlung benennt, deren Resultat er zwar visuell zeigt, die er aber als solche nicht abbildet. Das ruft die Imagination der Zuschauer wach, deren innere Bildproduktion nun die Schrecken des Todeskampfes ausmalt." (Kramer 2000: 18) »[...] the spectators have to imagine and interpret what they see and hear« (Colombat 1993: 138). »Notice that Cayrol never spells out what the sign signifies, because it is, in the words of George Steiner, sthe kind of thing under which language breaks.« (Steiner zit.n. Avisar 1988: 10). »Here [...] the spectators have to imagine and interpret what they see and hear.« (Colombat 1993: 138)

123. Dieselbe Aufnahme war bereits in DIE TODESMÜHLEN im Zusammenhang mit den Gaskammern verwendet worden.

124. Im Unterschied zum Einsatz des Präteritums in der französischen Version verwandte Paul Celan, der die deutsche Übersetzung erarbeitete, hier und in der Folge das Präsens. Damit entschied er sich für eine ausschließlich auktoriale Erzählperspektive aus der Gegenwart, die dem Zuschauer mehr Orientierung bietet als das französische Original.

125. Aus zahlreichen Berichten ehemaliger Lagerhäftlinge weiß man, daß die Gaskammern sich von anderen Blöcken nicht unterschieden. 


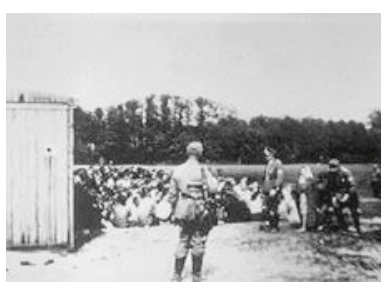

(120) $0: 20: 58 \mathrm{~h}$

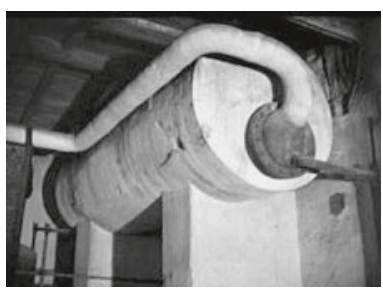

(123) $0: 21: 26 \mathrm{~h}$

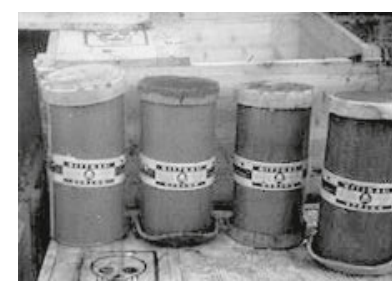

(121) $0: 21: 19 h^{123}$

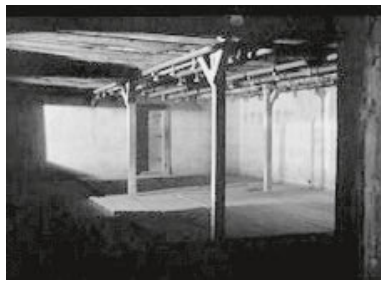

(124) $0: 21: 40 \mathrm{~h}$

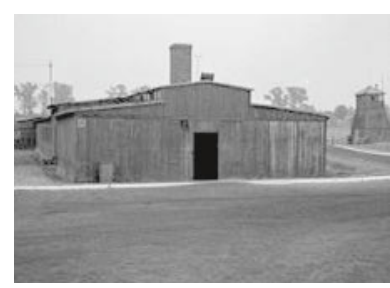

(122) $0: 21: 23 \mathrm{~h}$

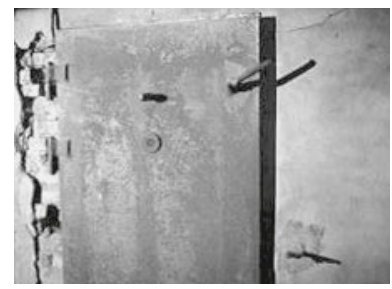

(125) $0: 21: 45 \mathrm{~h}$

mit den folgenden historischen Aufnahmen eines ganzen Lagerbestandes und dann einzelner Zyklon-B-Büchsen (s. o:21:19 h) wieder ein: »Tuer à la main prend du temps. On commande des boîtes de gaz zyklon.«(o:21:14 - o:21:18 h) Im Unterschied zu vielen anderen Szenen nimmt der Sprecher hier, unterstützt durch das Präsens, die Täterperspektive ein, um deren Logik und Gestus zu demonstrieren und gleichzeitig zu entlarven. In rigidem Sprachduktus kommentiert er die zunehmende »Optimierung « der Vernichtung. Die Wiederaufnahme des melodischen, ruhig-getragenen Rahmenmotivs kontrastiert in auffälliger Weise mit der Bildspur, vor allem jedoch mit dem sprachlichen Gestus.

Die folgende farbige Einstellung wechselt in die Gegenwartsebene: Während der Kommentator in nunmehr ruhigerem und neutralerem Tonfall erklärt, was wir sehen - »Rien ne distinguait la chambre à gaz d'un block ordinaire« (0:21:20 - 0:21:22 h) -, setzt eine Soloquerflöte ein, die Kamera fährt horizontal an einem Block entlang (s. 0:21:23 h). Obgleich dieser Satz aus einer Art Opferperspektive gesprochen ist - hierfür sprechen die getäuschte Wahrnehmung sowie das Präteritum ${ }^{124}$-, bietet die Kameraführung keine visuelle Analogie, so daß einmal mehr nur von einer semantischen Geste gesprochen werden kann. In der Tat sind von außen keinerlei Anzeichen auf eine Gaskammer zu erkennen, während man durch den Text geführt wird - zuvor hätte der Zuschauer im Zusammenhang mit dem Giftgas auch selbst darauf schließen können, aber dazu lassen ihm Resnais/Cayrol nicht den Raum.

In gleichem Sprachduktus leitet der Kommentator auch die nächste Einstellung ein: »A l'intérieur, une salle de douche fausse accueillait les nouveaux venus.« (0:21:25 0:21:28 h) Anstatt jedoch die sehr vage angedeutete Opferperspektive ${ }^{125}$, beispielsweise durch entsprechende Kameraführung, abzusichern und so fortzuführen, kehrt der Kommentar in die auktoriale Erzählperspektive zurück.

Diese wird auf visueller Ebene durch die künstlich, beinahe aufgesetzt wirkende Kameraführung abgesichert - eine Kamera, die die steinernen Überreste der Gaskammer 
streift: Parallel zu dem zitierten Satz und auffälliger Querflötenmusik gleitet sie über einen in Verbindung mit dem Text $u$.U. als Wasserreservoir identifizierbare Vorrichtung (s. 0:21:26 h; vgl. Raskin 1987: 117), um nach gemächlichem Schwenk den Blick auf einen leeren Raum freizugeben (s. o:21:40 h) - unaufhaltsam rücken wir also ins Zentrum der Vernichtung vor.

Bei mehr oder weniger gleichbleibender Musik zeigt eine neue Einstellung eine Eisentür mit Guckloch, massivem Riegel und Scharnieren (s. o:21:45 h). »On fermait les portes ... On observait.«(o:21:43 - 0:21:49 h), führt der Sprecher seine Beschreibung des Vernichtungsvorgangs in weiterhin ruhig-neutralem Tonfall fort, während die Kamera langsam nach links fährt, um schließlich auf einer ähnlichen zweiten Tür zu verharren. Wie zuvor stellt die Kamerabewegung nur bedingt eine Analogie zur im Kommentar eingenommenen und durch das erneute Präsens angedeuteten Täterperspektive dar. Die Spannung des Annäherungsprozesses an die Gaskammern erreicht hier ihren Höhepunkt.

Mit der nächsten Einstellung wechselt die Musik in auffälliger Weise. Das getragen-schwermütige Rahmenmotiv wird hier erneut aufgenommen und prägt die folgenden drei Minuten, beginnend mit deutlich dumpferen Tönen, die Tragik indizieren. Zunächst verharrt die Kamera auf einem vergitterten Kellerfenster (s. ○:22:0० h): Hätte man etwas Zeit, dieses Bild auf sich wirken zu lassen, könnte der Zuschauer assoziieren, daß sich die Kamera nun in der Gaskammer befindet. Einmal mehr, und im Unterschied zu BIRKENAU Und ROSENFELD, verhindert der Text, daß dem Zuschauer Zeit und Raum für eigene Gedanken eingeräumt wird: »Le seul signe, mais il faut le savoir, c'est ce plafond labouré par les ongles.« (0:22:00 - 0:22:26 h)

Während die Kamera zu Beginn der Einstellung eine Art Opferperspektive eingenommen hatte, paßt sie sich nun dem auktorialen Kommentar an und schwenkt vom Kellerfenster hinauf zu Decke. »Même le béton se déchirait.«(o:22:27 h): Der lakoni-

126. »The camera movement itself becomes more expressive, slowly going upward, slightly changing its course as if looking for something beyond the concrete, perhaps following these silent traces of immeasurable pain to register an anguished appeal to distant heaven.« (Avisar 1988: 10f.) Vgl. auch Kramer 2000: 18.

127. »En particulier, la dernière image de la chambre à gaz [...] est suivie du visage décomposé et in-soutenable d'une victime: il est évident qu'a la jonction elliptique de ces deux plans, le gazage a eu lieu. (Lowy 2001: 187) »Il est important de souligner cet effet de contiguïté causale entre la repré-sentation des chambres, constituée d'images en couleurs, images vides, minimalistes, quasiment abstraites, et les images en noir et blanc, saturées de cadavres atrocement intriqués, qui seront infli-gées au spectateur dans la dernière partie du film: il s'agit de créer un contraste brutal, insoutenable, entre deux types d'images dont le rapport instaure précisément un effet d'enchaînement. Il n'échappe a personne qu'elles ont une relation directe de cause à effet." (Ebd. 184)

128. In Lanzmanns SHOAH und Spielbergs SCHIndLeRs LISTE direkt, in Benignis DAS LebeN IST SCHÖN und in BIRKENAU UND ROSENFELD indirekt.

129. Auch in NACHT UND NEBEL leitet die Krematoriumssequenz mit einer Kamerafahrt an den Öfen entlang die Verwertungssequenz ein. 


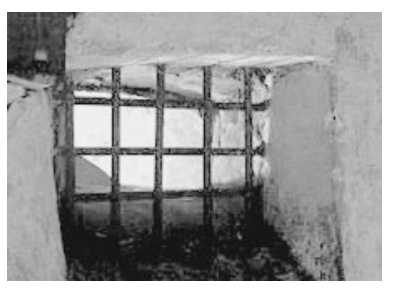

(126) $0: 22: 00 \mathrm{~h}$

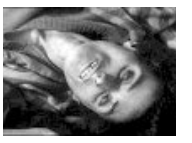

128 $0: 22: 48 h$

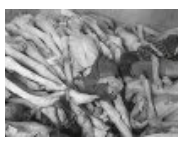

129 0:22:51 h

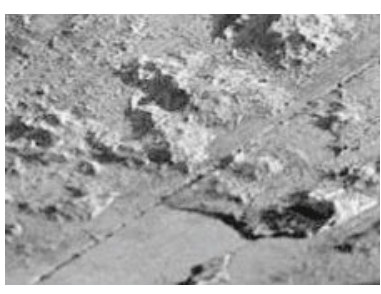

(27) $0: 22: 11 \mathrm{~h}$

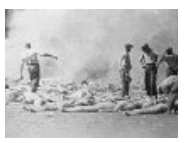

(130) $0: 22: 53 \mathrm{~h}$

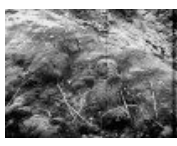

131 $0: 22: 58$

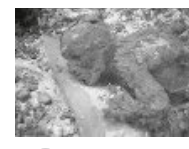

(132) $0: 22: 59 h$

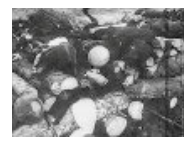

(133 $0: 23: 10 h$

sche Kommentar, in fast poetischem Stil, drückt aus, was der Zuschauer angesichts der Bilder - die Kamera fährt dicht an der zerkratzten Betondecke entlang (s. o:22:11 h) $)^{126}$ - selbst denken könnte. Nach dem meditativen Satz schwillt die getragene Streicherorchester-Musik an und bestimmt die 17-sekündige, demonstrative Kamerafahrt über die gezeichnete Decke.

Während das musikalische Rahmenmotiv in gleicher Lautstärke beibehalten wird, schneidet Resnais äußerst abrupt eine ganze Reihe grauenhaftester Leichenbildern hinter diese Gaskammernsequenz - gewissermaßen das Resultat der Vernichtung. ${ }^{127}$ Als vertraue er der Wirkkraft der Spuren nicht ganz, setzt Resnais einmal mehr auf das Schockpotential der Archivaufnahmen (s. die sechs Standbilder).

\subsubsection{Kontraproduktive Ästhetisierung - die Verwertungsmaschinerie der Nazis}

Aus verschiedenen Gründen handelt es sich bei der Verwertungs-Sequenz um eine wietere Schlüsselszene des Films. Dies nicht nur, weil sie filmintern von entscheidender Bedeutung ist, sondern weil auf sie in zahlreichen Rezensionen eingegangen sowie in späteren Holocaustfilmen intertextuell verwiesen wird ${ }^{128}$ und auch in der zeitgenössischen Holocaust-Fotografie das Pars-pro-toto-Prinzip einen wichtigen künstlerischen Ansatz darstellt (s. I.1).

Selten wird jedoch darauf hingewiesen, daß dieser Thematik - die Aufbewahrung der Gegenstände und Körperteile der Opfer und deren Verwertung durch die Nazis bereits in Dif Todesmühlen eine Sequenz gewidmet wurde (s. II.1.1.4). An Resnais' Inszenierung dieses Aspektes kann gezeigt werden, wie er sich von dem Entnazifizierungsfilm inspirieren läßt, sich jedoch gleichzeitig von ihm abgrenzt. So greift Resnais neben Kompositionsstrukturen ${ }^{129}$ das Potential des Pars-pro-toto-Prinzips hinsichtlich vergleichsweise schonender Erfahrbarmachung des Ausmaßes der Vernichtung (s. I.1) auf, bringt es jedoch durch die spezifisch ästhetische Gestaltung nicht zur Entfaltung, im Gegenteil: Während Burger/Wilder die abscheulichsten Verwertungspraktiken (Verwertung der Körper und der Haut) aussparen, thematisiert Resnais diese nicht nur, sondern inszeniert sie darüber hinaus mit dem Ziel der Vorstellungsanregung auf Seiten des Zuschauers. Wie bereits zuvor in der Sequenz in der Gaskammer (s. 2.1.6), verlangt Resnais vom Zuschauer auch hier das Unmögliche, vor allem im letzten Drittel der Sequenz: Gelenkt durch ein komplexes Gestaltungsensemble (ins- 
besondere der verzögerten Informationsvergabe bis hin zu Ellipsen ${ }^{130}$ ) soll er sich die - im Vergleich zu Die TodesmüH Len nicht minder grauenhaften - Verwertungspraktiken der Nazis in Erinnerung rufen ${ }^{131}$ bzw. - noch schlimmer - erschließen. Er soll damit die - auch durch oszillierende Erzählperspektive angedeutete - Täterlogik übernehmen: eine Forderung, der man sich beinahe notgedrungen verweigern muß. Zudem hält Resnais seinen Abgrenzungsversuch von beispielsweise Die TodesMÜHLEN nicht durch: Die im letzten Drittel der Sequenz eingesetzten Archivbilder übertreffen Burgers montierte Aufnahmen in der Schockwirkung und verhindern die beabsichtigte Vorstellungsanregung. Letztlich kann auch in dieser Sequenz von einer strukturellen Fehlentscheidung mit kontraproduktiver Wirkung gesprochen werden, denn der Zuschauer muß sich seelisch mehrfach abschotten, sich auf eine intellektuelle Ebene begeben und die Aufzählungen enzyklopädisch zur Kenntnis nehmen. Daran kann auch die Tatsache wenig ändern, daß die Verwertungs-Sequenz ruhiger gestaltet ist. Neben vergleichsweise sparsamer Kommentierung beinhaltet sie eine der längsten ungeschnittenen Einstellungen des gesamten Films. Im Unterschied zum Einsatz des Rahmenmotivs in der Gaskammersequenz zerrt die musikalische Begleitung hier jedoch buchstäblich an den Nerven des Zuschauers. Der Verfremdungseffekt bei Querflöte, Klarinette und Xylophon - teilweise durch Stakkato punktiert - ist für den Zuschauer, vor allem im letzten Drittel der Sequenz, durch die deutliche Dissonanz nur schwer zu ertragen.

130. In diesem Punkt unterscheidet sich NACHT Und NeBEL deutlich von der durchgehenden Kommentierung in Die TOdeSmüHLEN. Ob Resnais hierdurch die Unsagbarkeit des Gräßlichsten erfahrbar macht, sei bezweifelt.

131. Wie in II.1 bzw. II.1.1 beschrieben, steht dieser Forderung im Wege, daß DIE TODESMÜHLEN nicht wirklich wahrgenommen bzw. verdrängt wurden.

132. »IV« zeigt an, daß die Sequenz im letzten Viertel des Films lokalisiert ist und bei der Zeitangabe des Standbilds von Beginn dieses letzten Viertels an gezählt wurde.

133. In diesem Punkt ist SCHINDLERS LISTE insbesondere mit dem Aufbau der entsprechenden Sequenz aus Die TODESMüHLEN vergleichbar, denn auch in diesem Film stellen die herausgerissenen Goldzähne den traurigen Höhepunkt der Verwertungssequenz dar. 


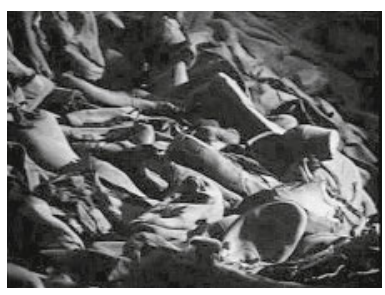

(134) $0: 59: 29 \mathrm{~h}(\mathrm{IV})^{132}$

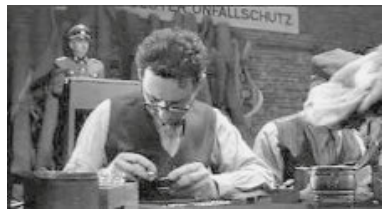

(137) $0: 47: 13 \mathrm{~h}$

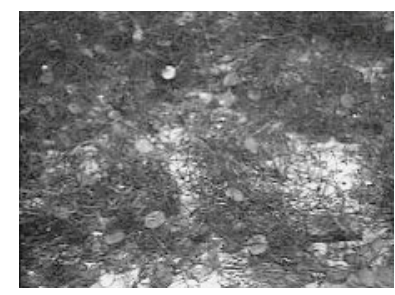

(135) $0: 59: 41 \mathrm{~h}(\mathrm{IV})$

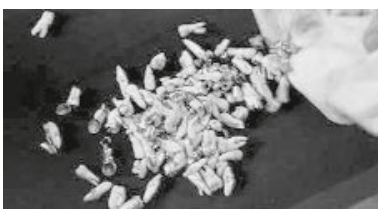

(138) $0: 47: 15 \mathrm{~h}$

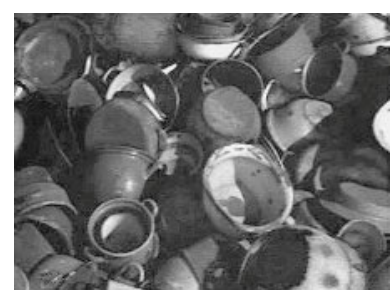

(136) $0: 59: 44 \mathrm{~h}(\mathrm{IV})$

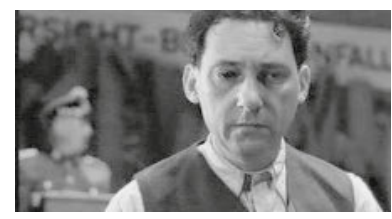

(139) $0: 47: 26 \mathrm{~h}$

Exkurs zum Umgang mit der Verwertungsmaschinerie in weiteren Holocaustfilmen: Mit der besonderen Inszenierung schlimmster Verwertungspraktiken unterscheidet sich NACHT UND NEBEL auch deutlich von der vergleichbaren Szene in Lanzmanns Sнодн. In Jan Karskis Bericht gegen Ende der Dokumentation schneidet Lanzmann unvermittelt Farbaufnahmen von den gegenständlichen Überresten der Opfer: den Bildrahmen sprengende Mengen von Schuhen (s. 0:59:29 h, IV), Zahnbürsten, Rasierpinseln, Brillen (s. 0:59:41 h, IV), (Trink)bechern und Schüsseln (s. o:59:44 h, IV). Im Gegensatz zu Resnais läßt Lanzmann auf der Tonspur Karskis Erzählung weiterlaufen, die jedoch nicht in direktem Bezug zu den Aufnahmen steht - eine den Zuschauer vergleichsweise wenig lenkende Form der Inszenierung der Überreste.

Auch Spielberg, der in Schindens Liste prinzipiell wenig Scheu vor dem Grauenhaften zeigt und sich historischer Rekonstruktion verpflichtet hat, spart in der entsprechenden Szene und im Unterschied zu Resnais die ungeheuerlichen Verwertungspraktiken aus. Nachdem Spielbergs Kamera Berge von Kleidern, Koffern, Brillen, Schuhen, Einrichtungsgegenständen, Puppen, Fotos, Uhren und Schmuck eingefangen hat, bilden Höhepunkt und Ende der Sequenz »lediglich « die den Opfern ausgerissenen Goldzähne ${ }^{133}$ - dies jedoch ebenso virtuos wie rein visuell und dadurch wesentlich wirkmächtiger für den Zuschauer: Das Entsetzen darüber, daß die Nazis den Opfern nicht nur deren Kleidung abnahmen, sondern auch Körperteile herausrissen, wird über eine Identifikationsfigur erfahrbar gemacht. Ein Juwelier, an seiner Armbinde mit dem Judenstern als Jude identifizierbar, wird in seiner Prüfung des Schmucks durch neues zu untersuchendes Material unterbrochen (s. 0:47:13 h). Hierbei handelt es sich um die besagten Goldzähne, die durch den Einstellungswechsel und die Annäherung [137-139] der Kamera als solche zu erkennen sind (s. o:47:15 h). Nachdem diese Einstellung auffallend länger als die vorangehende beibehalten worden war, wird das folgende Einfangen der Erschütterung des Juweliers dem Zuschauer noch länger zum Mitfühlen und -denken angeboten (s. 0:47:28 h). Im Unterschied zu NACHT und Nebel erreicht Spielberg durch diese relativ diskrete und doch eindeutige Inszenierung eine In- 
volvierung des Zuschauers, ohne Überforderung und mit Einräumung ästhetischer Freiheit. Hierfür förderlich ist die Tatsache, daß er diesem Zeit und Ruhe läßt, da die gesamte Sequenz mit dezenter Hintergrundmusik und ohne verbale Erläuterung des Gesehenen auskommt.

In der entsprechenden Sequenz in DAS LeBen IST SCHÖN führt Benigni seine indirekte Form des Umgangs mit dem Holocaust fort (s. II.4.1.4.ba). Aufgrund der tragikomischen Kontextualisierung sind für den Zuschauer selbst zwei der schlimmsten Verwertungspraktiken (Knochen werden zu Knöpfen, Körper zu Seife verarbeitet) »erträglich «.

Es ist wohl kein Zufall, daß anstelle der systematischen Verwertung der Leichen in Birkenau und Rosenfeld (»nur $\ll$ ) die die den Opfern abgenommenen Familienfotos, die fotografischen Überreste der Opfer dargestellt werden (s. II.5.6.b). Damit konzentriert sich Marceline Loridan-Ivens auf eine Art von Überresten, die den Opfern darüber hinaus ein Gesicht gibt, und vermeidet eine faktische Überladung durch Aufzählung aller Verwertungspraktiken.

(Ende Exkurs)

\section{Detaillierte Sequenzanalyse:}

Nachdem der Zuschauer in der vorangegangenen Farbsequenz zu getragenmelodischer Musik mit den unzähli gen (außer Betrieb genommenen) Krematoriumsöfen in einer einzigen langen Einstellung allein gelassen wurde ${ }^{134}$, erläutert der Sprecher in nüchterner Weise die folgenden, rasch wechselnden SchwarzweißAufnahmen: »Tout est récupéré ... Voici les réserves des nazis en guerre, leurs greniers.«( $0: 24: 12$ - 0:24:17 h) Bei zunächst statischer Kamera sehen wir riesige Berge von Brillen (s. o:23:52 h), Kämmen, Rasierpinseln, Bechern und Eßschalen, Kleidern, Schuhen (s. o: 24:07 h). Was die Tonspur betrifft, so wechselt die Musik mit Beginn dieser neuen Sequenz von vorangegangenen harmonischen Tönen hin zu dissonanteren, den Zuschauer verstörenden Tönen, wiederum erzeugt durch hervorstechende Soloinstrumente (Querflöte und Klarinette). Mit Ausnahme der vorletzten Einstellung, die vor allem Kleiderberge einfängt, füllen diese verschiedenen Gegenstände das gesamte Bild und sprengen aufgrund ihrer unfaßbaren Menge an mindestens drei Seiten den Bildrahmen. Aufgrund dieser Bildkomposition, aber auch der raschen Aneinanderreihung ähnlicher Aufnahmen, wird der Zuschauer für das Ausmaß der Vernichtung sensibilisiert. Unterstützt wird dies in den letzten drei Einstellungen (Becher und Schalen, Kleider, Schuhe) durch das Aussetzen des Kommentars.

134. Es handelt sich um die längste Einstellung des gesamten Films (56 Sekunden).

135. Vgl. Hattendorf (1999: 206) hinsichtlich der fingierten Dokumente in 2.1.1.

136. Ob diese Aufnahmen auf den Zuschauer stark wirken (»In some cases, as in the filming of a pile of women's hair, the camera moves slowly backwards to film a picture and then slowly rises, moving forward, to give a striking view of the totality of the victims' hair stocked in this place. Such a movement allows us to feel the reality of the non-representable number of victims [...].« (Colombat 1993: 163)), sei aufgrund der spezifischen Gesamtgestaltung bezweifelt. 


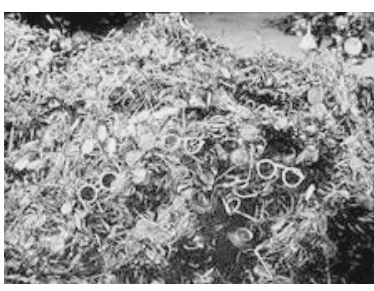

(140) $0: 23: 52 \mathrm{~h}$

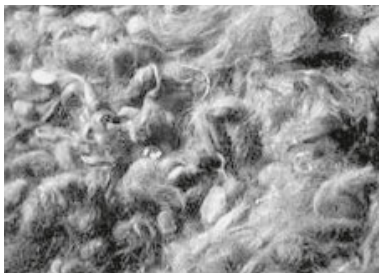

(142) $0: 24: 29 \mathrm{~h}$

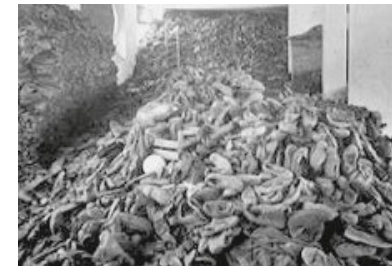

(141) $0: 24: 07 \mathrm{~h}$

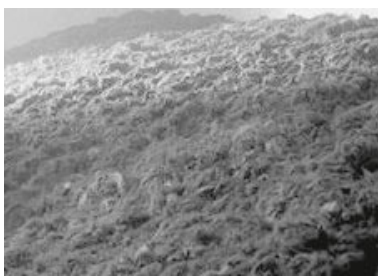

(143) $0: 24: 34 \mathrm{~h}$

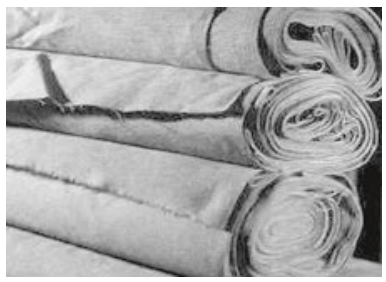

(144) $0: 24: 43 \mathrm{~h}$

In der folgenden Einstellung versucht Resnais, das ungeheure Ausmaß der Vernichtung für uns abzusichern: Entgegen der vorangegangenen Statik der SchwarzweißAufnahmen tastet die Kamera im Stil der Farbsequenzen das - trotz Bewegung nicht im Bildrahmen zu bändigende - »Meer« von Frauenhaaren eine halbe Minute lang bedächtig ab (Resnais zit.n. Raskin 1987: 136): ${ }^{135}$ »Rien que des cheveux de femmes ...« (०:24:29 h) Zu Beginn der Einstellung hilft der Sprecher dem Zuschauer bei der schwierigen Identifizierung des Sichtbaren (s. 0:24:29 h). Die vergleichsweise ruhige Musik aus Querflöte, Klarinette und Xylophon verursacht aufgrund des auffälligen Verfremdungseffektes Unbehagen. Erst gegen Ende ist durch die Einstellungs-Veränderung (von Naheinstellung zur Totalen) die Spitze des Berges am oberen Bildrand auszumachen (s. 0:24:34 h). ${ }^{136}$ Allein durch die Dauer dieser Aufnahme stellt das Frauenhaar den ersten Höhepunkt der Sequenz dar. Dies ergibt sich zudem aus der folgenden Einstellung, die eine neue Dimension zur bisherigen Lagerung einführt: die systematische Verwertung des von den Opfern Gesammelten. »A quinze pfennigs le kilo ... On en fait du tissu« (o:25:01 - 0:25:03 h), kommentiert der Sprecher nüchtern die folgenden Bilder, in welchen die Kamera an riesigen Stoffrollen entlangfährt (s. o:24:43 h). Unklar bleibt aufgrund des ambivalenten »on«, ob es sich hierbei um die auktoriale Erzähl- oder um die Täterperspektive handelt. Die angesprochene neue Dimension wirkt besonders abstoßend, da es sich hierbei nicht »nur« um abgenommene Gegenstände, sondern um den weiblichen Opfern zusätzlich Abgeschnittenes handelt - eine noch stärkere Mißachtung der Würde der Opfer, denn für Frauen ist Kahlheit eine Form der Nacktheit (s. II.5.6.c). Gleichzeitig leitet das Frauenhaar die totale Verwertbarkeit des menschlichen Körpers ein, die in den folgenden Einstellungen thematisiert wird.

Eine Bilderfolge, beginnend mit einem (statisch aufgenommenen) Skelett im Krematoriumsofen (s. 0:24:54 h), über einen durch die Kamera abgetasteten Knochenhaufen (s. 0:24:57 h), zu einem mit Gemüse übersäten Acker (s. 0:25:05 h) korrespondiert wiederum mit dem ruhig vorgetragenen Kommentar (»Avec les os ... des engrais. Tout au moins on essaie.«; 0:25:13 - 0:25:28 h). Hierbei fällt 
auf, daß der Sprecher nach dem Beginn des ersten Satzes und dem Rest des Textes eine Pause einlegt - als hätte er Mühe, weiterzusprechen. Dieses Innehalten fällt mit dem Bild des immensen Knochenberges (s. erneut 0:24:57 h) zusammen und fordert uns durch eine acht Sekunden dauernde Zurückhaltung des »neuen Produktes« (Dünger) dazu auf, uns auszumalen, was die Nazis daraus produzierten. ${ }^{137}$

Die Antwort (Dünger) korrespondiert dann auch mit der Einblendung des Gemüseackers (s. erneut 0:25:05 h) - aus unzähligen menschlichen Toten entstand neues pflanzliches Leben.

Der einmal mehr ruhig gesprochene Text (»Avec les corps ... mais on ne peut plus rien dire ...«; 0:25:28 - 0:25:31 h) - deutet an, daß Resnais auch weiterhin die gleiche Struktur der sukzessiven »Aufdeckung « anwendet. Erneut hält der Kommentator mitten im Satz inne, während auf der Bildspur ein Mann eine der zahlreichen großen Aufbewahrungstruhen öffnet (s. 0:25:09 h) und der Zuschauer aufgrund seiner Erfahrung Schlimmstes erwarten kann: Die folgenden unkommentierten, schnell hintereinander geschnittenen, statischen Aufnahmen zeigen zehn unerträgliche Sekunden lang einzelne Leichen bzw. ganze Gruppen, zum Teil verstümmelt (Körper ohne Kopf, abgeschnittene Köpfe): Hierbei fällt auf, daß Resnais ganz bewußt nähere Einstellungsgrößen ausgewählt hat, denn die Einstellungen vier, fünf und sechs zeigen Ausschnitte der dritten in näherer Einstellungsgröße. ${ }^{138}$ Rein inhaltlich hätte es der Regisseur demnach auch bei Einstellung drei belassen können, denn diese enthält bereits die Elemente der letzten drei Einstellungen, jedoch in distanzierterem Überblick. Daraus folgt, daß Resnais den Zuschauer gezielt mit diesen, über unerträglich nahe Einstellungsgrößen vermittelten, Bildern konfrontieren will. Im Vergleich zur vorangegangenen Einstellung besitzen sie keinen zusätzlichen Informationswert, sondern sollen dem Zuschauer das Grauenhafte durch den Zoomeffekt buchstäblich vor Augen führen. Ob der Regisseur mit dieser Schockstrategie von Seiten des Zuschauers tatsächlich ein Hinsehen, geschweige denn die eingeforderte Vorstellung erhält, sei extrem bezweifelt. Die Schwere dieser Aufnahmen läßt uns vermutlich eher

137. Schließlich hat man die Komposition aus der vorangegangenen Einstellungsfolge noch in Erinnerung, welche zunächst das den Opfern Abgenommene zeigte und kurz darauf das daraus Gewonnene.

138. Gemäß meiner Grundüberzeugung, daß ein gewisses $M a ß$ an Diskretion unerläßlich ist, wurde die Größe der Abbildungen deutlich verringert.

139. »[...] un effet de ssilenciation momentanée [...] Cette pause a lieu au moment où plusieurs images affreuses se succèdent: sur l'une d'entre elles, on distingue un alignement de corps décapité et sur la suivante une pile de têtes. Cette craquée instaure entre l'image et le texte un rapport spéculaire puisqu'à l'aspect illustratif traditionnel du commentaire vient s'ajouter cette sensation de pétrification qui se présente elle-même comme une émotion spectatorielle. En somme, la voix-off ne commente plus seulement les images, celui qu'elle incarne les perçoit au même titre que le spectateur et redouble par une suspension éphémère du commentaire la perception supposée de celui-ci.« (Lowy 2001: 127, H.i.0.)

140. »Darüber hinaus sieht der Zuschauer vom Körper gelöste Hautfetzen mit Tätowierungen. Die Stimme aus dem >0ff< schweigt nun.« (van der Knaap in Wende 2002: 73) 


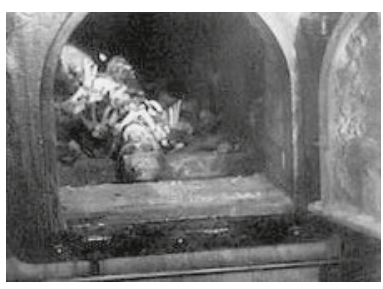

(145) $0: 24: 54 \mathrm{~h}$

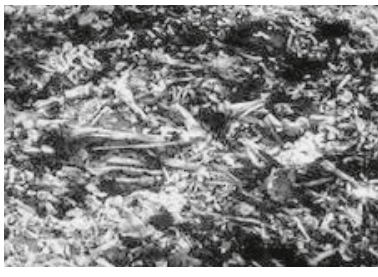

(146) $0: 24: 57 \mathrm{~h}$

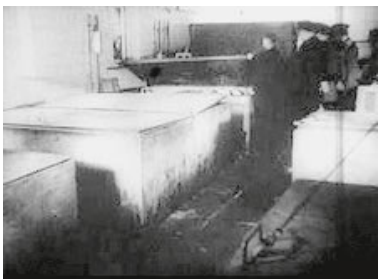

(148) $0: 25: 09 \mathrm{~h}$
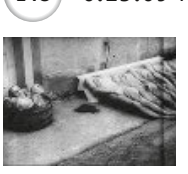

(151) $0: 25: 15 \mathrm{~h}$

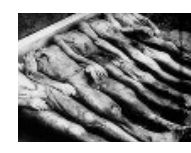

(152) $0: 25: 17 \mathrm{~h}$

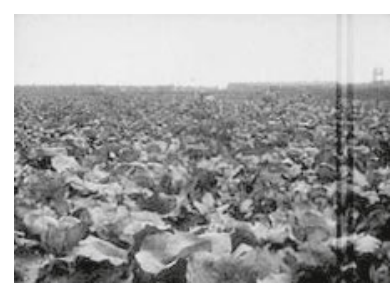

(147) $0: 25: 05 \mathrm{~h}$
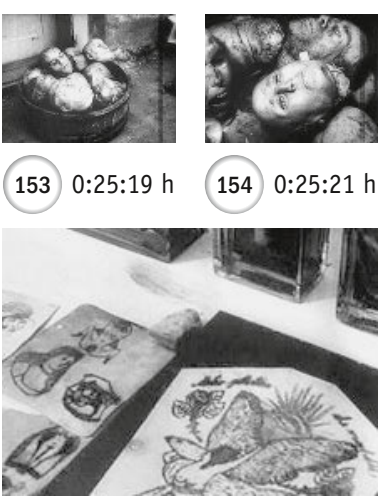

(157) $0: 25: 36 \mathrm{~h}$

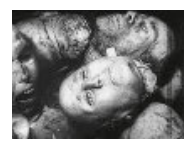
-

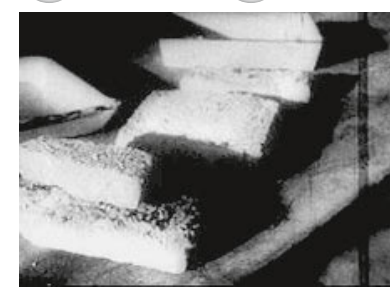

(155) $0: 25: 25 \mathrm{~h}$

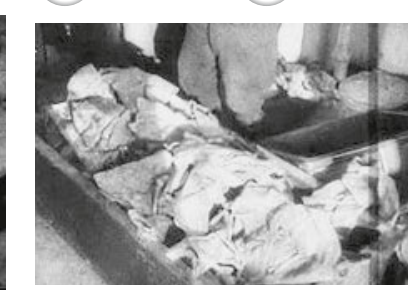

(156) $0: 25: 29 \mathrm{~h}$

den Blick abwenden, auf das Grauenhafte können wir uns in dieser Indiskretion kaum einlassen. Die noch stärker verfremdete musikalische Begleitung steigert die Unerträglichkeit der Bilderfolge.

Nachdem der Regisseur die Bilder hat sprechen lassen, läßt er den Kommentator den begonnenen Satz erneut aufnehmen und zu Ende führen: »Avec les corps on veut fabriquer ... du savon« (o:25:43 - o:25:46 h); die Aufnahmen zeigen Seifenstücke (s. 0:25:25 h). ${ }^{139}$ Auch das hätte sich der uninformierte Zuschauer wohl kaum ausdenken können, zumal die Vorstellungskraft von der lähmenden Schockwirkung des Bilderhagels (sechs Einstellungen in lediglich zehn Sekunden) überfordert wird. Noch völlig benommen von dem visuellen Schock und bereits konfrontiert mit dem nächsten, setzt der Kommentator nüchtern die Aufzählung fort - »Quant à la peau ...« (s. 0:25:29 h). Er verstummt erneut. Die folgende Einstellung ergänzt den nicht zu Ende geführten Satz: Knapp zehn Sekunden fährt die Kamera die im leichten Wind zitternden Zeichnungen ab (s. o:25:36 h). Mit diesem Stilmittel fordert Resnais, daß der Zuschauer, nach mehrfachem Erleben des Szenenaufbaus, den Satz selbst vollendet. ${ }^{14^{\circ}}$ Normalerweise ist dieser nicht bereit, die Täterlogik nachzuvollziehen und somit - wenn auch nur zeitweise - zu übernehmen. 


\section{II.2.2 EIN FILM, GEMACHT, NICHT (ZU ENDE) GESEHEN ZU WERDEN: ${ }^{141}$ »SHOAH« (CLAude LANZMANN, F 1985)}

\subsubsection{Der Ort und das Wort ${ }^{142}$}

Bereits mit der Wahl des in allen Versionen gleichlautenden Titels grenzt sich der französische Regisseur Claude Lanzmann von der amerikanischen TV-Serie HoLocausT aus dem Jahre 1978/79 ab, deren Repräsentationsversuch und Fiktionalisierung er äußerst hart kritisiert hatte. Während das hebräische Wort »die Shoah« unter Verwendung des bestimmten Artikels die gleiche Bedeutung hat wie das griechische »Holocaust« (dt. »Brandopfer« oder »Ganzopfer«), steht es - ohne diesen - einfach für »Katastrophe« (Felman 2000: 182).

»Holocaust« kannte das Publikum vor allem aus einer gleichnamigen Fernsehserie. Seit deren Riesenerfolg wurde »Holocaust« synonym für Judenvernichtung gebraucht. Als Lanzmanns Film in den Kinos anlief, war »Shoah« als Begriff dem nichtjüdischen Publikum fremd:143

\section{Vgl. Žižek, 31.08.2000: 15}

142. Vgl. Reichel 2004: 286 zum »ursprünglich vorgesehenen lyrisch-abstrakten Titel«.

143. „Der Titel des Films allerdings ist nicht französisch und beinhaltet daher eine weitere sprachliche Fremdheit, eine Entfremdung, deren Bedeutung rätselhaft und auch dem französischen Publikum der Originalfassung nicht unmittelbar zugänglich ist [...].« (Felman 2000: 182)

144. Damit folgt er dem von Schreitmüller als werbewirksam analysierten »Prinzip Irritation« bei der Wahl eines Filmtitels (1994: 102ff.).

145. »Doch wenn wir heute den außergewöhnlichen Film von Claude Lanzmann sehen, wird uns klar, daß wir nichts wußten. [...] Jetzt erfahren wir es zum ersten Mal an uns selbst - in unseren Köpfen, in unseren Herzen, am eigenen Leib. Es wird zu unserer eigenen Erfahrung. SHOAH ist weder Fiktion noch Dokumentation, es gelingt diesem Film, mit erstaunlich sparsamen Mitteln die Vergangenheit aufleben zu lassen [...]." (de Beauvoir 1986: 5) Vgl. allgemein Lowy 2001: 70f.; Colombat 1993: 299; Lowy 2001: 71 zur Resonanz in Frankreich; Thiele 2001: 400; Müller 1991: 35f. und Reichel 2004: 295f. zur Resonanz in Deutschland; Reichel 2004: 297 und Thiele 2001: 408ff. zur Resonanz in Polen; Lowy 2001: 71 zur Resonanz in den Vereinigten Staaten von Amerika. Zur negativen Kritik an Lanzmanns Darstellung der Polen vgl. Todorov 1993: 302.

146. »Lanzmann selbst und die Dolmetscher sind in einigen Szenen zu sehen, die Fragen und Übersetzungen sind - anders als beispielsweise in den Filmen Eberhard Fechners - zu hören. Der Regisseur nimmt sich nicht zurück, er ist mittendrin. Die Interview-Situation wird nicht negiert, sondern ist immer präsent. (Thiele 2001: 391). »Fechner historisiert, Lanzmann aktualisiert. [...] Die Ausrichtung auf die unwillkürlichen Körperregungen und das Konzept der Selbstdarstellung im Spiel gehen vom aktuellen Zustand der Überlebenden aus. [...] Wo Fechner ihre Emotionalität im Film nicht zeigen möchte, stellt Lanzmann genau auf diese ab [...].« (Kramer 2000: 62)

147. »Eine ähnliche Parteilichkeit findet sich in Marcel Ophüls Hotel Terminus (1988), der die Täter zusätzlich noch der Lächerlichkeit preisgibt und ihnen mit Sarkasmus begegnet.« (Kramer 2000: 63)

148. »Aber hätte ich zufällig einen dreiminütigen Film gefunden, gedreht von einem SS-Mann, der zeigte, wie dreitausend Menschen zusammen sterben in der Gaskammer des Krematoriums II von Birkenau - nicht nur, daß ich ihn nicht in SHOAH eingebaut hätte - ich denke, ich hätte diesen Film vernichtet. Ich hätte also genau das Gegenteil von dem getan, was Sie [Hannes Heer, Ausstellung »Verbrechen der Wehrmacht«; eigene Anm.] tun: Ich hätte Beweise vernichtet.« (Lanzmann 1998: 28) 
»J'ai pris SноAн parce que je ne parle pas hébreu, ni ne le comprend et que, par conséquent, je ne savais pas ce que le mot voulait dire. Le mot était court, opaque, pour moi en tout cas, comme une sorte de noyau impénétrable, infracassable. [...] Je voulais que personne ne comprenne, et je me suis battu pour l'imposer. C'est en cela que Shoah, le film, est un acte de nomination.« (Lanzmann zit.n. Brun 2003: 199f., H.i.0.)

Zur damaligen Zeit verunsicherte Lanzmanns Titel wohl die meisten Zuschauer oder aber machte sie neugierig. ${ }^{144}$ Heute - insbesondere nach dem Kritiker-Erfolg des Films - ist »Shoah« relativ geläufig und wird meist synonym zu »Holocaust« gebraucht.

Claude Lanzmann hat mit seinem ambitionierten Werk, an dem er insgesamt neun Jahre arbeitete, eine Grenzmarkierung hinsichtlich des ästhetischen Umgangs mit dem Holocaust gesetzt, »eine Grenze nicht der Darstellbarkeit, sondern eine Grenzmarkierung der Darstellungsmittel und -methoden der nachfolgenden Generationen darstellender Künstler, Schriftsteller und Holocaustpolitiker« (Köppen/Scherpe 1997: 4).

Aus diesem Grund fand er weltweit Beachtung - überwiegend anerkennende, vor allem von Intellektuellen. ${ }^{145}$ Lediglich Polen bildete eine Ausnahme. In den französischen Schulen scheint ShoAH allmählich Resnais' NACHT und Nebel abzulösen, dessen Ungenauigkeit und Einfachheit überholt seien (Chéroux 2001 und Lowy 2001: 71).

Im Unterschied $\mathrm{zu}$ vorausgegangenen bekannten Kompilationsfilmen - Alain Resnais' Nacht und Nebel (Frankreich 1955), Erwin Leisers Mein Kampf (Schweden 1960), Michail Romms Der Gewöhnliche Faschismus (Sowjetunion 1965) - und fiktionalen Werken -Frank Beyers NACKT unTER WÖLFEN (DDR 1962) bzw. JAKo d DER LÜGNER (DDR 1974) und Marvin Chomskys TV-Mehrteiler Holocaust (USA 1978) -, ist Claude Lanzmanns SноAн vor allem ein Film der Zeugenschaft (Reichel 2004: 287). In gewisser Weises vergleichbar mit Eberhard Fechners Der Prozess (BRD 1975-1984) ${ }^{146}$, vor allem aber mit Marcel Ophüls Le Chagrin et la Pitié (Schweiz/ BRD 1969) bzw. Hôtel TERminus (USA 1985 -1988) ${ }^{147}$, wählt Lanzmann in seinem neuneinhalbstündigen Werk eine Herangehensweise an das Thema Holocaust, die jeglichen Versuch, das Geschehene in rekonstruierte oder gar fiktionale Bilder zu bringen, strikt ablehnt und damit derjenigen von Schinder Rs Liste und von HolocausT diametral entgegensteht:

»Der Holocaust ist vor allem darin einzigartig, daß er sich mit einem Flammenkreis umgibt, einer Grenze, die nicht überschritten werden darf, weil ein bestimmtes, absolutes Maß an Greueln nicht übertragbar ist. [...] Die Fiktion ist eine Übertretung, und es ist meine tiefste Überzeugung, daß jede Darstellung verboten ist.« (Lanzmann 1994: 27)

Indem in Lanzmanns Film »kein Hitler, keine Leichenberge, keine prominenten Überlebenden « zu sehen sind, setzt er sich von den »üblichen >Vergangenheitsbewältigungsfilmen« «eutlichst ab (Thiele 2001: 378f., H.i.O.): »Sнонн ist wohl der radikalste ästhetische Versuch, das Grauen auszumessen, ohne auf die Bilder des Grauens zurückzugreifen« (Kramer 2000: 22). Lanzmann bezeichnet diese als »images sans imagination« (Lanzmann zit.n. Brun 2003: 193). Gegen das Archivmaterial spricht gemäß Lanzmann zweierlei: Zum einen, daß es ohnehin keine Bilder der Vernichtung an sich gibt - und selbst wenn, hätte er sie vernichtet. ${ }^{148}$ Zum anderen jedoch, daß gerade der 
Verzicht auf Bilder zugunsten von Leerstellen und Aussparungen eine Vorstellung des Unvorstellbaren anregen könne ${ }^{149}$, denn: »Bilder töten die Imagination « (Lanzmann 1994: 27). Die durchaus problematische Auffassung erinnert an das alttestamentarische Bilderverbot und wird von Lanzmann selbst mit dem Judentum in Verbindung gebracht.150 Mit Schörken sei jedoch die generelle Frage aufgeworfen, »ob der Mensch so angelegt ist, daß er auf die vermittelnde Bilderwelt verzichten kann« (Schörken 1995: 18).

Wo Resnais zumindest in der Vergangenheitsebene seines Films historisches Archivmaterial sprechen läßt, setzt Lanzmann durchgängig auf mündliche Zeugenschaft - neben »bystanders« (Hilberg 1961) und »>neutralen< Informanten« (Müller 1991: 47, H.i.O.) - vor allem der Holocaust-Überlebenden, auf das »Pathos des Primären « (Köppen 1997: 165). ${ }^{151}$ Gemäß Lange radikalisiert Lanzmann die Prämisse der Zeugenschaft zu einem »Konzept von subjektiver Authentizität« (Lange 1999: 142). So geht es ihm nicht um »die Darstellung vergangener Ereignisse« (ebd.), ihn interessieren vielmehr das Lesen von Spuren bzw. »>das Verschwinden von Spuren< - an den Orten des Verbrechens und im traumatisierten Bewußtsein der Überlebenden« (Reichel 2004: 286, H.i.O.). Gerade letzteres unterscheidet ShoAн von NAcht Und NEBEL, während sich beide Filme hinsichtlich der »non-lieux de la mémoire« (Lanzmann zit.n. Gantheret/Lanzmann 1990: 281) ähneln"152:

149. »C'est bien plus fort et bien plus irréfutable, cela permet d'imaginer infiniment plus que des images d'archives [...].« (Lanzmann zit.n. Brun 2003: 193)

150. »[...] SноAн est une œuvre talmudique; le Talmud interdit la représentation. SHOAH est une expérience allégorique du voyage des Juifs européens vers la mort. De leurs derniers instants. C'est une résurrection.« (Lanzmann zit.n. Lowy 2001: 131) Vgl. auch Schörken 1995: 17.

151. „Die für Lanzmann einzig denkbare und zulässige Form der Erinnerung ist die Rede der Zeugen. Er inszeniert die Reden der Zeugen, um den Gedächtnisraum seines Films zu füllen: nicht mit Bildern, sondern mit Sätzen, Aussagen, Mimik und Gesten, die das Abwesende bezeichnen, Zeichen setzen und verbinden, Spuren legen.« (Köppen/Scherpe 1997: 4) Vgl. auch Festenberg 1999: 238.

152. Vgl. Jochimsen 1996: 228 und Kramer 2000: 22.

153. „Ich bin an die Orte gefahren, allein, und habe begriffen, daß man die Dinge kombinieren muß. Man muß wissen und sehen, und man muß sehen und wissen. Das eine ist vom anderen nicht zu trennen.« (Lanzmann zit.n. Müller 1991: 38) »Ce constant mélange de passé et de présent, qui est beaucoup plus qu'une simple juxtaposition, cet effort permanent pour abolir le passage du temps et recréer une sorte de continuité vécue, est, me semble-t-il, le principe de toute la construction du film." (Ophuls 1990: 178)

154. »Gegen Sprachlosigkeit und Schweigen kämpfe Lanzmann an, und so erkläre sich auch das Motto, das er Shoah voranstellt [...].« (Scheel zit.n. Thiele 2001: 407)

155. »Finalement, je me suis dis que je n'avais pas à tout dire, que les gens devaient se poser des questions. Le film est fait aussi pour que les gens continuent à travailler. Pendant le déroulement de la projection, mais aussi après. Le massacre du camp des familles (pourquoi les ont-ils gardés six mois avant de les tuer?), même si on en connaît en gros les raisons, demeure mystérieux. Il fallait garder des mystères, faire travailler l'imaginaire: il n'y avait pas à tout expliquer.« (Lanzmann 1990: 305) 
»Quand je suis arrivé à Treblinka la première fois, je suis d'abord allé au camp. Il y avait plein de neige, on enfonçait jusqu'aux genoux. Il n'y a plus rien. Simplement ces pierres symboliques, dont la tête émergeait de la neige. J'ai vu ça, je n'étais pas particulière-ment ému. Une sorte de grande nécropole silencieuse. (Lanzmann 1990: 290) »Ce qu'il y a eu au départ du film, c'est d'une part la disparition des traces: il n'y a plus rien, c'est le néant, et il fallait faire un film à partir de ce néant.« (Ebd. 295)

Die den Film charakterisierende Gegenwart der Vergangenheit versucht Lanzmann durch die Kombination von Ort und Wort zu aktualisieren - im Gegensatz zu Resnais jedoch nicht durch einen lyrischen Kommentar, sondern durch persönliche Schilderungen der Überlebenden. ${ }^{153}$ Vor diesem Hintergrund verwundert es nicht, daß der Regisseur sein Werk ursprünglich »Der Ort und das Wort« nennen wollte, ein Titel, »der über die Intentionen und Erinnerungskonstruktionen des Autors mehr aussagt« (Reichel 2004: 286).

Nach eigenem Bekunden versucht Lanzmann mit SноAн verschiedene Ansprüche zu realisieren:

- So will er eine »Reaktivierung des Vergangenen in der Gegenwart« (Lanzmann zit.n. Reichel 2004: 299) erreichen und damit eher eine »l'abolition de toute distance entre le passé et le présent« (Lanzmann 1990: 301), denn:

- »Das schlimmste moralische und künstlerische Verbrechen, das man bei einem Werk über den Holocaust begehen kann, ist es, ihn als Vergangenheit zu betrachten.« (Lanzmann zit.n. Müller 1991: 130). »Der Film [...] ist eine Anti-Legende, ein Gegen-Mythos, das heißt eine Untersuchung über die Gegenwart des Holocaust oder zumindest über eine Vergangenheit, deren Narben noch so frisch und lebendig sind an den Schauplätzen und im Bewußtsein der Menschen, daß sie sich in einer halluzinatorischen Überzeitlichkeit offenbart. [...] Die Vernichtung zeigt sich unmittelbar, einerseits durch das Fortbestehen und das Vorhandensein der Schauplätze, andererseits durch die Wunden der Menschen, Wunden, die sie nie mehr schließen werden...« (Lanzmann zit.n. Müller 1991: 153a).

- »Einen ewigen Namen will ich ihnen geben, der nicht vergehen soll.« (Jesaja, ${ }_{5}^{6}$, 5), lautet das Motto, das Lanzmann seinem Film voranstellt. Lanzmann will den ermordeten Juden folglich ein filmisches Denkmal setzen. ${ }^{154}$

- Er will den Holocaust nicht darstellen, sondern in der Vorstellung des Zuschauers erstehen lassen:

»Und genau das ist die Stärke eines Filmes wie SHOAH - es ist ganz allein die Vorstellungskraft, mit der gearbeitet wird.« (Lanzmann 1998: 26)

»Le film fait travailler l'imagination. Quelqu'un m'a écrit, magnifiquement d'ailleurs: >C'est la première fois que j'entends le cri d'un enfant dans une chambre à gaz.ı C'est toute la puissance de l'évocation et de la parole.« (Lanzmann 1990: 297, H.i.0.) $)^{155}$

- Nicht nur das Wecken des Vorstellungsvermögens, sondern darüber hinaus das »Versenken« des Zuschauers in die Vernichtung ist Lanzmanns erklärtes Ziel: »Un des sens du film pour moi, c'était la résurrection des morts. Mais pas au sens chrétien du terme. Je les ai ressuscités, non pour les faire revivre, mais pour les 
tuer une seconde fois, afin qu'ils ne meurent pas seuls, pour que nous mourions avec eux.« (zit.n. Brun 2003: 197)

Lanzmann geht es nicht um das Überleben der ehemaligen Lagerinsassen, die er interviewt. Anders als in seinem späteren Film Сов вов ${ }^{156}$, ist Lanzmanns zentrales Thema in Sноан die Vernichtung ${ }^{157}$, die »Radikalität des Todes« (Lanzmann 1998: 15).

Die Auswahl der Überlebenden ergibt sich aus Lanzmanns zentralem Thema:

»Ich wollte nicht irgendwelche Zeugen. Ich suchte ganz bestimmte, die einst an den Schaltstellen der Vernichtung saßen und unmittelbare Zeugen des Todes ihres Volkes waren: Angehörige der Sonderkommandos.« (Lanzmann zit.n. Müller 1991: 132)

Im Unterschied zu Opfern, die nicht Mitglieder des Arbeits- bzw. Sonderkommandos waren $^{158}$, nehmen die Berichte von Filip Müller, Rudolf Vrba, Simon Srebnik, Abraham Bomba und Richard Glazar besonders viel Raum ein.

\begin{tabular}{|c|c|c|c|c|c|}
\hline \multirow{2}{*}{$\begin{array}{l}\text { Opfer/ } \\
\text { Zeuge }\end{array}$} & \multirow{2}{*}{$\begin{array}{l}\text { Persönliche } \\
\text { Geschichte }\end{array}$} & \multicolumn{2}{|c|}{ Auftritte } & \multirow[t]{2}{*}{ Sprache } & \multirow[t]{2}{*}{ Standbild } \\
\hline & & Gesamtdauer & Anzahl & & \\
\hline $\begin{array}{l}\text { Filip } \\
\text { Müller }\end{array}$ & $\begin{array}{l}\text { Überlebender der } \\
\text { fünf Liquidierungen } \\
\text { des Auschwitzer } \\
\text { Sonderkommandos; } \\
\text { als 20-Jähriger } \\
\text { mußte er dort in den } \\
\text { Krematorien arbeiten }\end{array}$ & $\begin{array}{c}\text { ca. } \\
49,5 \text { min. }\end{array}$ & 6 & deutsch & \\
\hline $\begin{array}{l}\text { Rudolf } \\
\text { Vrba }\end{array}$ & $\begin{array}{l}\text { Mitglied des } \\
\text { Auschwitzer } \\
\text { Arbeitskommandos } \\
\text { und der } \\
\text { Widerstandsbewegung }\end{array}$ & $\begin{array}{c}\text { ca. } \\
38,5 \text { min. }\end{array}$ & 6 & englisch & \\
\hline $\begin{array}{l}\text { Simon } \\
\text { Srebnik }\end{array}$ & $\begin{array}{l}\text { Überlebender } \\
\text { der zweiten } \\
\text { Vernichtungsphase } \\
\text { von Chelmno; als } \\
\text { 13-Jähriger mußte er } \\
\text { für die SS singen und } \\
\text { Leichen verbrennen } \\
\text { helfen }\end{array}$ & $\begin{array}{c}\text { ca. } \\
32 \mathrm{~min} .\end{array}$ & 4 & $\begin{array}{l}\text { deutsch/ } \\
\text { jiddisch }\end{array}$ & \\
\hline
\end{tabular}

156. Diesen eineinhalbstündigen Dokumentarfilm erstellte Lanzmann aus dem für $\mathrm{SHOAH}$ gedrehten, seinerzeit jedoch nicht integrierten Material.

157. Vgl. Klüger zit.n. Leiser 1996: 94 und Lowy 2001: 184.

158. Vgl. Müller 1991: 45.

159. „Vrba, Müller, Karski haben Bücher veröffentlicht, Glazar und Suchomel kamen ausgiebig in dem Buch von Sereny zu Wort [...].« (Todorov 1993: 295)

160. »[...] l'impossibilité de raconter cette histoire pour les survivants eux-mêmes, l'impossibilité de parler, la difficulté [...] d'accoucher la chose et l'impossibilité de la nommer [...].« (Lanzmann 1990: 295) »[...] soudain le savoir devient incarné.« (Lanzmann 1990: 298)

161. Vgl. Thiele 2001: 384 und Colombat 1993: 304. 


\begin{tabular}{|c|l|c|c|c|}
\hline $\begin{array}{c}\text { Abraham } \\
\text { Bomba }\end{array}$ & $\begin{array}{l}\text { Überlebender von } \\
\text { Treblinka; als Friseur } \\
\text { mußte er in der } \\
\text { Gaskammer bzw. dem } \\
\text { Auskleideraum den } \\
\text { Frauen die Haare } \\
\text { schneiden }\end{array}$ & 31 min. & 9 & englisch \\
\hline $\begin{array}{c}\text { Richard } \\
\text { Glazar }\end{array}$ & $\begin{array}{l}\text { Überlebender von } \\
\text { Treblinka; } \\
\text { im dortigen } \\
\text { Arbeitskommando }\end{array}$ & $\begin{array}{c}\text { ca. } \\
26,5 \mathrm{~min} .\end{array}$ & 8 & deutsch \\
\hline alle fünf Hauptzeugen der \\
Opfergruppe
\end{tabular}

Abb. II.2.2.a

Bei diesen Hauptpersonen handelt es sich um Überlebende, die sich überwiegend

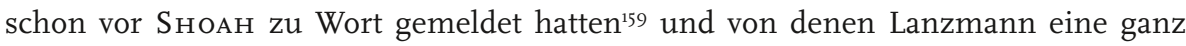
bestimmte Vorstellung hat:

»Trotzdem paßt der Begriff Überlebende nicht auf sie, vielleicht sollte man sie eher als Rückgekehrte bezeichnen. Leute, die zurückkommen aus dem Jenseits, nämlich jenseits der Schwelle zur Gaskammer. [...] Sie sind Sprecher der Toten.« (Lanzmann 1998: 15)

Um die Schwierigkeit zu sprechen zu überwinden und um ihre Geschichten verkörpern zu können ${ }^{160}$, nahmen die Zeugen ihre eigenen Rollen ein: »[...] il a fallu transformer ces gens en acteurs. [...] Il fallait qu'ils la jouent [leur histoire] [...].« (Lanzmann 1990: 301)

Als »Archäologe der Erinnerung« tastet Lanzmanns Kamera - wie die von Resnais - nicht nur die stummen Lagerruinen nach Spuren der Vergangenheit ab (Schröder 2001: 272). Beeinflußt von Raul Hilberg, dem Autor des historischen Standardwerkes »Die Vernichtung der europäischen Juden « - einer der wenigen interviewten Experten in Sнонн -, stellt Lanzmann seinen Zeitzeugen auffallend detaillierte Fragen. Diese Art der Fragestellung soll die Interviewpartner zum Sprechen bringen und kurze, distanzierte Antworten vermeiden. ${ }^{1{ }^{6}}$

Vor allem jedoch sollen diese Details dem Zeugen und mit ihm dem Publikum helfen, sich in das Undarstellbare zu versetzen. Was den Zuschauer betrifft, ist das Gelingen sicherlich nicht immer gegeben:

»Alors, pourquoi ces détails? [...] C'est ça qui réactive les choses, qui les donne à voir, à éprouver [...].« (Lanzmann zit.n. Gantheret 1990: 282)

»Lanzmann, jamais, ne pose une question lointaine. [...] Chaque réponse alors, devient si absolument précise, qu'elle se transforme en image.« (Cuau 1990: 17)

»In doing so he forces himself, the witness and the spectator to visualize in imagination what cannot be represented.« (Colombat 1993: 304f.) 
Jegliche »Komplizenschaft mit dem Schweigen des Zeugen [und] mitfühlende [...], wohlwollende Allianz« vermeidend (Felman 2000: 191), setzt Lanzmann die Interviews mit den Überlebenden problematischerweise auch dann fort, wenn diese die Fassung verlieren und um Unterbrechung bitten (s. 2.2.5):

»Die Kunst gewinnt dabei an emotionaler Kraft, aber die Menschen werden zu Werkzeugen degradiert. [...] da es hier aber um die Darstellung einer Welt geht, die sich vor allem dadurch auszeichnet, daß der individuelle Wille in ihr nichts galt, wünscht man sich doch, daß Lanzmann in der Wahl seiner Mittel etwas vorsichtiger gewesen wäre. [...] Lanzmann versucht eher, das Grauen wieder lebendig werden zu lassen, statt uns zu helfen, es zu verstehen.« (Todorov 1993: 299f.)

Vor allem im Zusammenhang mit den einstigen Opfern drängen sich vielmehr Zweifel auf, »ob es zulässig ist, die Überlebenden wie ein Kommissar mit Druck und guten Worten und unter allen Umständen dazu zu bringen, das Aufwühlendste, das ihnen widerfuhr, der Öffentlichkeit zu verraten« (Brumlik zit.n. Thiele 2001: 406) - auch auf das Publikum wirkt dies doch eher wie eine »Folter«, anstatt ihm eine »Ahnung jener Hölle« zu vermitteln (Kreimeier zit.n. Heller 1999).

Obwohl ऽнонн auf den ersten Blick und über weite Strecken des Films relativ uninszeniert wirkt ${ }^{162}$, wird der Inszenierungscharakter des gesamten Films zu Recht vom Regisseur selbst sowie von zahlreichen Rezensenten hervorgehoben:

162. „SHOAH [...] beruht auch auf anderen Überlegungen und einer anderen Haltung dem furchtbaren Geschehen gegenüber. In SHOAH geschieht neun Stunden lang nichts anderes, als daß Überlebende erzählen. Was sie erzählen, wird nicht im Bild dargestellt. Der Film enthält sich jeder Spielhandlung. [...] Überhaupt enthält sich Lanzmann konsequent aller Illusionswirkungen, es gibt keine Filmmusik oder andere künstlerische Zugaben, keine Schauspieler, keine nachgestellte Erlebniswelt, es gibt keine Spannung [...]. Das Maß der Inszenierung ist so gering gehalten wie überhaupt möglich, es ist allenfalls noch anzutreffen in der Art der Schnitte und der Aufeinanderfolge der Zeitzeugen.« (Schörken 1995: 16) An dieser Stelle sei kritisch angemerkt, daß Schörken jedoch die angesprochene direkte Inszenierung mehrerer Sequenzen unterschlägt.

163. »Zeugnis ablegen heißt, ein Zeugnis zu erzeugen, und das erinnert uns daran, daß das Zeugnis nicht einfach nur überliefert, sondern erzeugt wird und daß wir als Zuschauer an seiner Erzeugung beteiligt sind. Das Ziel besteht darin, den Zeugen selbst, sein Sicherinnern an die Ereignisse und den Vorgang des Mitteilens seiner Erinnerung daran, nicht aber die Ereignisse als solche zu dokumentieren [...]. Der Prozeß des Erinnerns, des Konstruierens, des Korrigierens, des Formulierens von Gedanken und des Suchens nach einer Ordnung, der in literarischen Texten zumeist unsichtbar bleibt, reichert das Videozeugnis mit jener schmerzhaften Selbsterkenntnis und Selbstbesinnung an, die dem literarischen Zeugnis fehlt.« (Young zit.n. Kramer 1999: 41)

164. Vgl. Colombat 1993: 324. Müller hingegen nennt noch eine vierte Bild-Ton-Anordnung, die jedoch weitaus seltener anzutreffen ist: »D. Auch hier ist die erzählende Person nicht im Bild. Es werden Aufnahmen gezeigt, die nicht in direktem Zusammenhang mit dem Text stehen, z.B. Einrichtungsgegenstände der Wohnung, in der das Interview mit Jan Karski stattfand, während dieser über das Warschauer Getto spricht. Oder die Aufnahmen können zu dem Text assoziiert werden: z.B. ist die Freiheitsstatue in New York zu sehen, während Karski über die ihm von Juden zur Weitergabe übermittelten Botschaften berichtet.« (Müller 1991: 54) 
- $\quad$ ».. der Film ist nicht dokumentarisch - das ist das Kino, Inszenierung. ... Was ich gemacht habe: Ich habe wirkliche Gestalten der Geschichte in Darsteller verwandelt, die dabei fast zu Gestalten der Literatur oder des Theaters werden.« (Lanzmann zit.n. Thiele 2001: 391) »Lanzmann [...] described his film as a >fiction of reality<. [...]« (Lanzmann zit.n. Loshitzky 1997: 107)

- »SноAн est donc une fiction. Fiction du réel sans doute, mais fiction.« (Cuau 1990: 14)

_ $\quad$ [...] ein Film, der selbst artifizielles Zeugnis der Zeugenschaft ist.« [...] (Reichel 2004: 288)

- »Andererseits ist nun gar nicht zu übersehen, daß auch Lanzmann gar nicht umhinkommt, zu inszenieren und zu spielen. Auch und gerade im Umgang mit seinen Darstellern, den Holocaustüberlebenden und Zeugen, ist - so Ruth Klüger - >alles gestellt, gezielt, beabsichtigt<.« (Klüger zit.n. Reichel 2004: 313)

- »Aus ShoAн scheint die Inszenierung eliminiert zu sein, alle Emphase liegt hier auf der Erinnerung, und zwar auf der individuellen Erinnerung der interviewten Zeitzeugen. Das bedeutet jedoch nicht, daß es in Sнонн keine Inszenierung gäbe.« (Kramer 1999: 23f.)

In einigen seltenen Fällen schreckt Lanzmann nicht einmal vor »direkter Inszenierung « zurück (Müller 1991: 58): Er läßt in der Eröffnungssequenz Simon Srebnik, wie damals, in einem Kahn auf der Ner singen (s. 2.2.6); den einstigen Friseur in den Gaskammern von Treblinka, Abraham Bomba, bittet er, in einem Friseursalon in Tel Aviv erneut Haare zu schneiden (s. 2.2.5); für Henrik Gawkowski, polnischer Lokführer, der Transporte von Bialystok und Warschau nach Treblinka brachte, mietet er eine Lokomotive und läßt ihn zur Rampe des Lagers fahren (Todorov 1993: 295).

Ziel dieser Rekonstruktion des einstigen Kontextes ist, den Überlebenden das Sich-Versetzen in die damalige Situation zu ermöglichen bzw. zu erleichtern: »Das sind derart grausame und fürchterliche Erfahrungen, die die Menschen so tief geprägt haben, daß man sie wieder in einen Zusammenhang stellen mußte, der diesen Akt des Gebärens, der Auferstehung möglich machte.« (Lanzmann zit.n. Müller 1991: 40)

Diese Form der direkten Inszenierung zielt vor allem darauf, den Opfern die »Erzeugung des Zeugnisses « zu ermöglichen (Young zit.n. Kramer 1999: 24) ${ }^{163}$, aber auch darauf, den Zuschauer an diesem Prozeß zu beteiligen.

Neben der auffälligsten Form der Inszenierung durch das bewußte Arrangement des Interviewsettings können drei weitere Bild-Ton-Anordnungen ${ }^{164}$, mit jeweils spezifischen Beteiligungsangeboten für den Zuschauer, unterschieden werden. Diese reichen von Lesen der Mimik und Gestik der Zeugen (s. 2.2.3), über Aushalten des Kontrastes zwischen grauenhaften Schilderungen auf der Tonspur und gleichzeitig fast beschaulichen Aufnahmen der einstigen Schreckensorte bis hin zu Weinen aus Mitgefühl bzw. einem gewissen Mit-Spüren der Erschütterung, wenn Überlebende an die Orte des Verbrechens erstmalig zurückkehren (s. 2.2.6).

(I) Die am häufigsten anzutreffende, den traditionellen Dokumentarfilm kennzeichnende, Bild-Ton-Konstellation läßt sich wie folgt beschreiben: 
„Die Person befindet sich an einem neutralen Ort, die Kamera fängt meist das Gesicht in der Gesichtstotalen ein, gleichzeitig wird der Text übermittelt (Ton on): z.B. sitzt Filip Müller in einem Wohnzimmer, und der Zuschauer kann ihn sehen und hören.« (Müller 1991: 54)

»In the first category, I include interviews in a setting that is familiar to the witnesses but not directly related to the extermination process. Such interviews are usually conducted in a room with one, two or three participants. Medium shots and close-ups play a key role in the segments." (Colombat 1993: 324) $)^{165}$

Durch diese Form der Darbietung wird die Aufmerksamkeit des Zuschauers auf den jeweiligen Augenzeugen, sein Erscheinungsbild, seine die Schilderungen begleitende Mimik und Gestik gerichtet, zumal die Umgebung in aller Regel so unauffällig ist bzw. so wenig im Bild erscheint, daß wir durch sie nicht abgelenkt werden (s. 1:02:05 h).

»Im Jetzt findet er einen Zugang zum Vergangenen, indem er Spuren aufsucht, die sich an den Orten des historischen Geschehens, vor allem aber in der Physis der Opfer, bis heute erhalten haben.« (Kramer 1999: 22f.)

»In den Interviews mit ehemaligen Häftlingen dokumentieren Bild und Ton den Schmerz, den die Erinnerung aktualisiert [...]. In den unwillkürlichen Artikulationen des Körpers findet Shoah seine wirkungsvollsten Authentizitätssignale, die sich auf der Rezeptionsseite als Evidenzerfahrung niederschlagen. [...] Dagegen treffen wir in Lanzmanns Film auf jene materialen Spuren, die die Erinnerung von der Inszenierung abheben.« (Ebd. 23)

»Dabei kommt dem Registrieren von Emotionen eine zentrale Stellung zu. Zeigen die Interviewten Emotionen, zoomt er häufig näher heran. Können sie nicht weitersprechen, redet er ihnen zu oder bedrängt sie sogar.« (Ebd. 39)

165. »Der Regisseur befragt die Zeugen überwiegend an ihrem aktuellen Wohnort [...] bzw. die polnischen Zeugen in ihren Heimatorten, Chelmno, Grabow, Treblinka, Auschwitz. Mit Simon Srebnik aber fährt Lanzmann nach Chelmno.« (Thiele 2001: 383)

166. »III« zeigt an, daß die Sequenz im dritten Viertel des Films anzutreffen ist und bei der Zeitangabe des Standbilds von Beginn dieses dritten Viertels an gezählt wurde.

167. »Elles [les larmes] attestent une émotion qui n'est pas reproductible, un traumatisme qui ne peut pas être simulé.« (Lowy 2001: 147)

168. Siehe die ausführliche Analyse der ersten Sequenz mit Filip Müller in 2.2.3.

169. "SНОAH ist ein ruhiger Film langer Einstellungen und gleichwohl einer der unablässigen Fahr- und Kamera- bzw. Zoombewegungen - Ausdruck einer inneren Ruhelosigkeit der suchenden Augen und des vielsprachigen Fragens. Denn Lanzmann sucht überall nach Spuren [...].« (Reichel 2004: 286)

170. »Wenn Ruth Elias ihre Ankunft in Auschwitz schildert, fährt die inszenierende Kamera durchs Lagertor; [...] immer wieder bewegt man sich auf die Lager zu, die Vernichtung ist nicht vorbei und zumindest etwas vom Schrecken und von der [...] >Annäherung vollzieht der Betrachter mit.« (Jochimsen 1996: 230, H.i.0.) »Der Eisenbahnzug, den er in Treblinka einfahren läßt, tut dies in einer subjektiven Einstellung. Der Zuschauer fährt mit: das ist auch eine schleichende Verführung. [...] mit einer verspäteten Schrecksekunde registriert schließlich der Zuschauer, daß er mit im Zug sitzt, der unweigerlich den Schienen in das Areal des Vernichtungslagers folgt.« (Koch 1992: 152) 


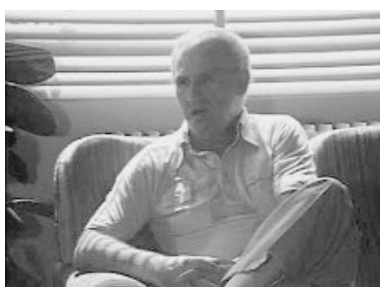

(163) $1: 02: 05 \mathrm{~h}$ (III) ${ }^{166}$

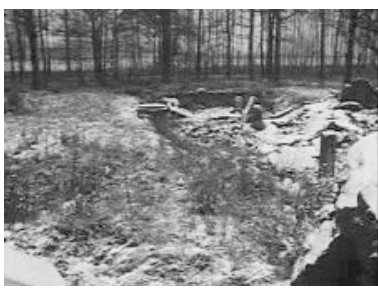

164) $0: 57: 59 \mathrm{~h}$

»Auch das Schweigen wird ssichtbarı gemacht, was nur im filmischen Medium möglich ist.» (Jochimsen 1996: 228)

Wenn der Zuschauer die Kamera sowie Lanzmanns Interviewtechnik nicht als penetrant und indiskret empfindet, bergen die Szenen, in denen Zeugen weinen ${ }^{167}$, Ansteckungspotential: Wenn landläufig behauptet wird, daß Lachen ansteckend sei, so muß man in diesem Fall sagen, daß dies auch für das Weinen gilt.

(2) Die - nach dem eher konventionellen Abfilmen der Überlebenden in ihrem Zuhause - zweithäufigste audiovisuelle Kombination ist eine für den heutigen Dokumentarfilm im Prinzip nicht mehr außergewöhnliche Kompositionsstruktur, eine »indirekte, mit den Mitteln der Montage durchgeführte« Form der Inszenierung (Müller 1991: 59):

»Die erzählende Person ist nicht im Bild, zu sehen ist nur der Ort, von dem der Text handelt bzw. wo sich die angesprochenen Ereignisse abspielten (Ton off): z.B. sind Bilder vom Gelände des Lagers Treblinka zu sehen, während die Stimme Abraham Bombas zu hören ist.« (Müller 1991: 54)

»Finally, [...] a site, a Polish landscape or what remains of an extermination camp, without showing the image of a witness." (Colombat 1993: 325)

»The basic movement of the film is to put in parallel words of the past said in the present with images of the same places filmed in the present.«(Colombat 1993: 314) ${ }^{168}$

Was diese Inszenierungsweise jedoch von geläufigen Gestaltungsformen im Dokumentarfilm abhebt, ist die Tatsache, daß Lanzmann parallel zu den detaillierten Zeugenberichten aus dem Off wiederholt eine ruhelose ${ }^{169}$, zum Teil subjektive Kamera einsetzt, die eine Annäherung an die Vernichtung durch Heranfahren ${ }^{170}$ (z.B. ans Lagertor) bzw. Mit-Begehen der Vernichtungsstätten (v.a. der Gaskammern; s. 2.2.4) intendiert (s. ०:57:59 h).

Um den Zuschauer in die Perspektive der Opfer einzubeziehen, ahmt sie in manchen Fällen die verbal beschriebenen Bewegungen der Gequälten nach und wackelt dabei leicht als Authentizitätssignal (s. II.3.2.1). Durch diese filmischen Inszenierungen versucht Lanzmann, die Vorstellungskraft des Zuschauers anzuregen. Ob er dies beim breiten Publikum erreichen kann, sei jedoch bezweifelt - schließlich bedarf es, selbst für einen filmversierten Zuschauer, eines mehrmaligen Betrachtens, um beispielsweise den Einsatz von subjektiver Kamera zu 
bemerken. ${ }^{17}$ Daß sich, wie neben dem Regisseur selbst zahlreiche Rezensenten behaupten ${ }^{172}$, Wort und Bild ergänzen würden, trifft bei weitem nicht immer zu (s. 2.2.4), sondern bildet eher die Ausnahme.

171. Dieses Problem wurde nicht zuletzt bei der Besprechung von SHOAH im Rahmen eines Doktorandenkolloquiums an der Universität Mannheim mehrfach betont.

172. »Durch diese Form der Montage [...] macht [die Stimme] Spuren sichtbar, nimmt der Landschaft die Neutralität und >Unschuld [...]. Sie [Wort und Bild] bereichern sich gegenseitig und steigern ihre Qualität, verstärken einander.« (Müller 1991: 59, H.i.0.) »Erst die Bild-TonMontage legt den aktuell durchlebten Schmerz über die Landschaftsbilder. Die Imagination bindet beides zusammen, und die Zuschauer projizieren nun den gegenwärtigen Schrecken in die Naturansichten. Lanzmann stellt durch die Montage das widersprüchliche Ineinander von gegenwärtiger Normalität und gegenwärtigem Schrecken her.« (Kramer 1999: 43, H.i.0.) Vgl. auch Koch 1990: 165.

173. »Er zeigt verfallene und überwucherte, eigentlich unspektakuläre Orte, an denen sich in der Phantasie der Überlebenden aber bis heute der Horror entzündet. Hier zwingt er die Zuschauer, snicht dem zu trauen, was sie sehen." (Kramer 1999: 43, H.i.0.). »Ihn [Lanzmann] interessierten vielmehr die Spuren oder besser: >das Verschwinden von Spuren - an den Orten des Verbrechens und im traumatisierten Bewußtsein der Überlebenden. Sein Film ist der Versuch, beide wieder zusammen- und zum Sprechen zu bringen." (Reichel 2004: 286, H.i.0.)

174. »Und genau das ist die Stärke eines Filmes wie SноAн - es ist ganz allein die Vorstellungskraft, mit der gearbeitet wird.« (Lanzmann in: Kulturamt der Stadt Marburg 1998: 26)

175. »Erst die Bild-Ton-Montage legt den aktuell durchlebten Schmerz über die Landschaftsbilder. Die Imagination bindet beides zusammen, und die Zuschauer projizieren nun den gegenwärtigen Schrecken in die Naturansichten. Lanzmann stellt durch die Montage das widersprüchliche Ineinander von gegenwärtiger Normalität und gegenwärtigem Schrecken her (Kramer 1999: 43, H.i.0.). »Les mouvements de caméra acquièrent une autonomie esthétique, la caméra n'est pas utilisée à des fins documentaires, mais pour susciter l'imagination." (Koch 1990: 165)

176. »[...] für den Zuschauer bringt der Film die Diskrepanz zwischen dem Wahrnehmbaren und Vorstellbaren zum Äußersten: mit der Vergegenwärtigung der Vergangenheit nicht über konkrete Bilder, die Historisches einzufangen versuchen, sondern allein über ein Verfahren der Evokation - von Vorstellungsbildern, die sich der Darstellung entziehen [...].« (Heller 1997: 226) »Die Imagination des Zuschauers tritt an die Stelle der Repräsentation des historischen Dokuments. [...] die Herkunft von Lanzmanns Begriff des Imaginären bei Sartre [...]: >eine Vorstellung von etwas Abwesendem<." (Koch zit.n. Lange 1999: 142) »Sartre definiert das Imaginäre als ein Produkt des vorstellenden Bewußtseins, das, anders als die Wahrnehmung, kein reales Objekt der Repräsentation voraussetzt, sondern dieses erst schöpferisch konstituiert.« (Lange 1999: 142f.) »[...] Sartres Imagination als Akt des kreativen Bewußtseins zur Vorstellung einer abwesenden Präsenz.« (Ebd. 147)

177. »Many [landscapes] are also shown without any commentary, explanation or testimony accompanying them. In such cases, silence, but not the absence of soundtrack, becomes an essential part of the film.« (Colombat 1993: 325) »[...] le silence. Pour créer en nous une vacance [...].« (Dayan-Rosenman 1990: 188)

178. »II« zeigt an, daß die Sequenz im zweiten Viertel des Films anzutreffen ist und bei der Zeitangabe des Standbilds von Beginn dieses zweiten Viertels an gezählt wurde.

179. Vgl. Colombat 1993: 324 und Müller 1991: 54. 


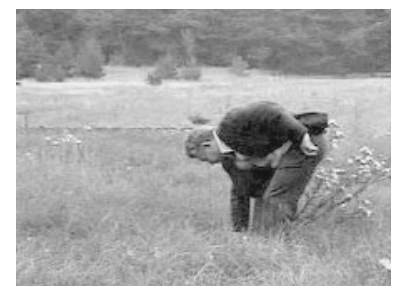

$165) 1: 45: 54 \mathrm{~h}$ (II)

Auf der Tonspur stößt Sнонн ins Zentrum der Vernichtung vor und »versenkt sich [...] in die Szenerie des Schreckens wie kein anderer der angesprochenen (Holocaust-)Filme« (Kramer 1999: 25). Da der Zuschauer Schilderungen der grauenhaften Vergangenheit verfolgt, muß er, vergleichbar mit Resnais Gegenwartsebene in Nacht und Nebel, den Kontrast zwischen dem friedlich-idyllischem Heute (visuell) und dem feindlich-grauenvollen Gestern (auditiv) aushalten. ${ }^{173}$ Diese detaillierte Schilderung damaliger Greuel, bei gleichzeitig unspektakulären Landschaftsaufnahmen, soll katalysierende Wirkung auf die Vorstellungskraft des Zuschauers haben - die Aussparung begleitender Visualisierung soll offenbar imaginativen Aufforderungscharakter besitzen. Dies behaupten - neben dem Regisseur selbst ${ }^{174}$ - zumindest zahlreiche Rezensionen ${ }^{175}$, denn so läßt sich auch Sartres Konzeption des Imaginären ${ }^{176}$ anführen, der ein enger Freund Lanzmanns war.

Dem Zuschauer wird es wohl höchstens ansatzweise gelingen, dem Aufforderungscharakter der Bild-Ton-Komposition zu folgen, die stumme Landschaft mit Leben zu füllen - und wenn, dann in erster Linie aufgrund der detaillierten, vorstellungsanregenden Schilderungen des jeweiligen Zeugen. Auch hier kommt es sehr darauf an, ob die berichtende Person ihre Geschichte »bildlich « und lebendig erzählt, wie beispielsweise Filip Müller in 2.2.3. Nur bei gewisser Analogie zwischen Bild- und Tonspur verknüpft die Imagination Wort und Bild.

Wenn der Zeuge innehält bzw. schweigt - was durchaus regelmäßig geschieht ${ }^{177}$ - ist eine Überforderung des Zuschauers äußerst wahrscheinlich; die Aufnahmen der einstigen Schreckensorte laufen dann Gefahr, für den Zuschauer zugewachsen, zum Teil sogar vereist zu bleiben. Aufgrund der zu geringen Zuschauerlenkung ist auch stark zu bezweifeln, daß gerade die Stille besonders vorstellungsanregende Wirkung hat: »[...] the long periods of silence used in Sнонн will play a central role as it is through this very silence recreated by the film that the audience will have to hear the cries nobody would hear less than half a century ago." (Colombat 1993: 321f.)

(3) Das vor allem in der ersten Hälfte des Films und insgesamt am dritthäufigsten eingesetzte Bild-Ton-Verhältnis ist in gewisser Weise eine Kombination der häufigsten und der zweithäufigsten Bild-Ton-Anordnungen. Wie bereits erwähnt, begibt sich Lanzmann mit den Überlebenden Simon Srebnik (s. 2.2.6; s. 1:45:54 h) ${ }^{178}$, Motke Zaidl und Itzhak Dugin (Überlebende von Wilna; sie mußten dort die Massengräber öffnen und die Leichen verbrennen) an die einstigen Schreckensorte und interviewt sie dort - eine inzwischen für Dokumentationen durchaus übliche Form der Gestaltung. ${ }^{179}$ 
Im Gegensatz zu den Aufnahmen des Zeugen in seiner vertrauten Umgebung sind hier der Regisseur sowie gegebenenfalls die Übersetzerin teilweise im Bild zu sehen, im Vordergrund steht jedoch die Rückkehr zu und die Konfrontation des Zeugen mit den einstigen Schreckensorten.

Auch hier versucht Lanzmanns Kamera wiederholt durch nahe Einstellungsgrößen, den Zuschauer auf die mimischen Dramen aufmerksam zu machen und ihn so die Erschütterung der Überlebenden mitspüren zu lassen. In den Fällen, in welchen die Augenzeugen nicht die Fassung verlieren, fällt dem Publikum diese Kameraführung auch nicht negativ auf, sondern soll die Traumatisierung erfahrbar machen.

Übereinstimmend mit dem vorangegangenen Bild-Ton-Verhältnis ist, daß der Zuschauer - ähnlich wie in Resnais' NACHT UND NEBEL - mit den inzwischen »leeren« Landschaften konfrontiert wird, welche durch Schwenks, Fahrten und zum Teil sogar subjektive Kamera filmisch inszeniert werden. ${ }^{180}$ Nur bedingt vermag die Konfrontation mit den heutigen Orten jedoch die Vergangenheit von Simon Srebnik aufleben zu lassen. Wenn nicht einmal der Betroffene selbst die einstigen Vernichtungsstätten wiederzuerkennen vermag, wie sollen diese Aufnahmen dann für den Zuschauer lebendig werden? Es bleibt äußerst fraglich, ob die Kameraschwenks uns tatsächlich das Sehen lehren. ${ }^{181}$

Mit dieser Form der Inszenierung entwickelt Lanzmann ein Verfahren der Rückkehr an die einstigen Vernichtungsstätten und des Umgangs mit ihnen, das Marceline Loridan-Ivens in BIRKENAU UND ROSENFELD aufgreift und in anderer, funktional stimmiger Form umsetzt (s. II.2.3).

Aus nachfolgender Tabelle ergibt sich, daß Lanzmann die Bild-Ton-Anordnungen innerhalb einer Sequenz in aller Regel alternieren läßt (s. rechte Spalte).

180. »Les mouvements panoramiques, aussi, tiennent dans SHоAн une place essentielle. Avec les panoramiques, nous sommes découvreurs d'espaces qui se taisent. [...] mouvements du non-savoir, du regard inutile, de la recherche vaine. [...] Rien ne se donne à voir.« (Cuau 1990: 15) »[...] il va utiliser de manière disproportionnée par rapport à un autre film les ressources de l'interview, du travelling, du panoramique circulaire, du plan-séquence.« (Lowy 2001: 148)

181. „Donner à voir ces endroits, c'est le sens des lents travellings latéraux de Resnais, c'est aussi celui des interminables panoramiques à 180 degrés qui ponctuent SHOAH.« (Lowy 2001: 172) 


\begin{tabular}{|c|c|c|c|}
\hline Opfer/Zeuge & $\begin{array}{l}\text { Reihenfolge } \\
\text { der Auftritte }\end{array}$ & $\begin{array}{l}\text { Dauer (in Minuten) und } \\
\text { Zeitpunkt des Auftritts }\end{array}$ & $\begin{array}{l}\text { Art und Weise der } \\
\text { Inszenierung }\end{array}$ \\
\hline \multirow{6}{*}{$\begin{array}{l}\text { Filip } \\
\text { Müller }\end{array}$} & 1 & $(7,5)$ II & $2,1,2,1,2$ \\
\hline & 2 & (22) III & Auschwitz-Modell, 2, 1, 2, 1 \\
\hline & 3 & (4) III & 2,1 \\
\hline & 4 & $(3,5)$ III & 2,1 \\
\hline & 5 & (5) IV & $2,1,2,1$ \\
\hline & 6 & $(7,5)$ IV & 2, 1, Auschwitz-Modell \\
\hline \multirow{6}{*}{$\begin{array}{l}\text { Rudolf } \\
\text { Vrba }\end{array}$} & 1 & (5) I & New York, 1, 2, 1, 2, 1 \\
\hline & 2 & $(4,5)$ III & $2,1,2$ \\
\hline & 3 & $(8,5)$ III & 2,1 \\
\hline & 4 & $(7,5)$ IV & $2,1,2$ \\
\hline & 5 & $(9,5)$ IV & $2,1,2,1$ \\
\hline & 6 & $(3,5)$ IV & 2,1 \\
\hline \multirow{4}{*}{$\begin{array}{l}\text { Simon } \\
\text { Srebnik }\end{array}$} & 1 & (8) I & 3 (\& direkte Inszenierung) \\
\hline & 2 & $(1,5) I$ & $2,3,2$ \\
\hline & 3 & (17) II & Kirche Chelmno \\
\hline & 4 & $(5,5)$ II & $2,3,2,3,2,3,2$ \\
\hline \multirow{9}{*}{$\begin{array}{c}\text { Abraham } \\
\text { Bomba }\end{array}$} & 1 & (2) I & $2,1,2$ \\
\hline & 2 & $(1,5) I$ & 2,1 \\
\hline & 3 & (1) I & 2 \\
\hline & 4 & $(1,5) I$ & 2,1 \\
\hline & 5 & (1) I & Wasser, 1 \\
\hline & 6 & (3) I & $2,1,2,1$ \\
\hline & 7 & (1) I & 2,1 \\
\hline & 8 & $(2,5) I$ & 1 \\
\hline & 9 & (18) III & $\begin{array}{l}\text { im Friseursalon } \\
\text { (direkte Inszenierung) }\end{array}$ \\
\hline \multirow{8}{*}{$\begin{array}{l}\text { Richard } \\
\text { Glazar }\end{array}$} & 1 & (3) I & 1,2 \\
\hline & 2 & (3) I & 2,1 \\
\hline & 3 & (2) I & 1,2 \\
\hline & 4 & (3) I & 2,1 \\
\hline & 5 & (2) I & $2,1,2$ \\
\hline & 6 & (1) I & 2,1 \\
\hline & 7 & (4) III & 1, Fluß (Schweiz), 1, Fluß \\
\hline & 8 & $(8,5)$ III & 2,1 \\
\hline
\end{tabular}

Abb. II.2.2.b

Die jeweiligen Sequenzen mit seinen Hauptzeugen leitet er beinahe ausnahmslos mit dem zweithäufigsten Bild-Ton-Typ ein, es sei denn, es handelt sich um das erste Auftreten des Zeugen im Film - und selbst hierbei kommt es im Fall von Filip Müller vor, daß er nicht sofort im Bild gezeigt wird. 
Auf die Einleitung durch Aufnahmen der Lager und Off-Ton des Überlebenden folgt im Verlauf der Sequenz die erste Bild-Ton-Anordnung. Zum Teil wechseln sich diese beiden Gestaltungsmuster auch mehrfach innerhalb einer Sequenz ab.

Die Aufnahmen des Augenzeugen schneidet Lanzmann dann an die Landschaftsaufnahmen, wenn dieser die sachliche Beschreibungsebene verläßt und persönlichere Eindrücke preisgibt bzw. Geschichten erzählt (Colombat 1993: 328).

Ist die Schilderung des Zeugen lang und zeigt er zwischendurch keine besonderen gestischen bzw. mimischen Regungen, so verbannt ihn Lanzmann erneut ins Off und zeigt uns statt dessen Aufnahmen der heutigen Lager:

»As Lanzmann thinks a long interview of a stalking headk (an expression often used by Ophüls) is boring, this kind of editing serves two purposes. It makes it easier to concentrate on a long film or on a long interview and, most of all, it links the testimony to a real place.« (Colombat 1993: 328, H.i.0.)

Der dritthäufigste Bild-Ton-Typ beschränkt sich auf Simon Srebnik - einen der wenigen Überlebenden -, mit dem Lanzmann an die einstigen Vernichtungsstätten zurückkehrt. In zwei der vier Sequenzen mit Simon Srebnik läßt Lanzmann diese Form der Inszenierung mit der zweiten Bild-Ton-Anordnung alternieren.

Als Film der Zeugenschaft läßt Lanzmann nicht nur Überlebende, sondern - gemäß der Einteilung des Holocaust-Experten Raul Hilberg - auch Täter und »bystander«, in aller Regel Polen, zu Wort kommen. Zudem führt er Gespräche mit »>neutralen< Informanten« (Müller 1991: 47), wie Hilberg (Historiker und Pro-

182. Vgl. Jochimsen 1996: 228.

183. Beziehungsweise angesichts des immer noch aktuellen, durchaus nicht nur latenten Antisemitismus zahlreicher polnischer Zeitzeugen, allen voran der Einwohner von Chelmno (vgl. hierzu Gantheret/Lanzmann 1990: 283f., Avisar 1988: 28f., Thiele 2001: 394 f). »Er [Lanzmann] will die Wahrheit der Lüge (nicht in der Lüge), die Objektivität der Selbsttäuschung, kurz die Wirklichkeit der Erinnerungs-Rituale aufspüren.« (Mergner in Müller 1991: VIII) »Beteuerungen, Ausflüchte, Versprecher und Minenspiel der befragten deutschen Mitläufer und Täter verraten, daß sie im allgemeinen mehr wissen, als sie sagen, und daß sie das, was sie sahen und wissen, nie verstanden, geschweige denn als politische und moralische Schuldlast angenommen haben.« (Reichel 2004: 300)

184. Dies ist mehrfach bei Suchomel und Bomba, Suchomel und Glazer, Stier und Glazer der Fall, auch wenn Lanzmann das Gegenteil betont: »Il était impossible que le nazis rencontrent les Juifs: non que je les fasse se rencontrer physiquement, ce qui aurait été plus qu'obscène, mais que le montage les fasse se rencontrer.« (Lanzmann 1990: 305)

185. »Durch die Montage des gefilmten Materials wechselt der Blick zwischen dem Gesicht Grasslers (der fortfährt, das Getto aus seiner eigenen Sicht darzustellen) und dem Gesicht Hilbergs (der fortfährt, den Inhalt des Tagebuchs darzustellen sowie die Perspektive, die der Tagebuchautor Czerniakow auf das Getto eröffnet).« (Felman 2000: 187)

186. »[...] je n'aime pas les voix off qui commentent des images ou des photos comme un savoir institutionnalisé: on peut dire n'importe quoi, la voix off impose un savoir qui ne surgit pas directement de ce qu'on voit, on n'a pas le droit d'expliquer au spectateur ce qu'il doit comprendre.« (Lanzmann 1990: 297) 


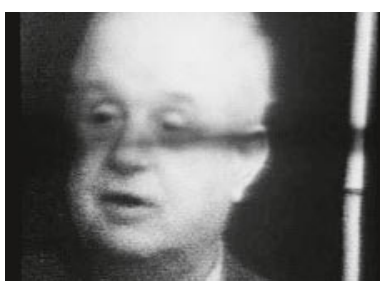

(166) Foto 1

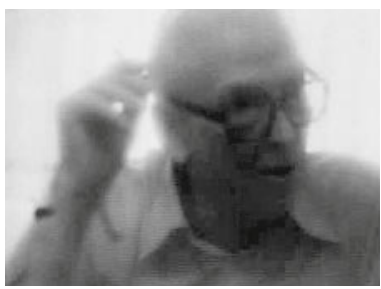

(169) Foto 4

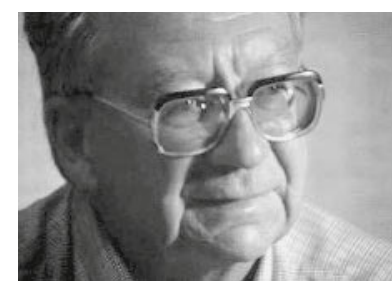

(167) Foto 2

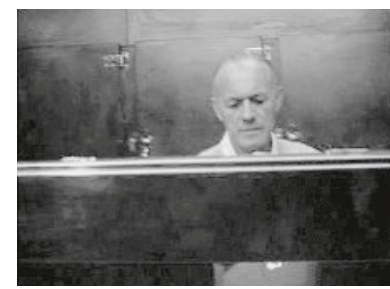

(170) Foto 5

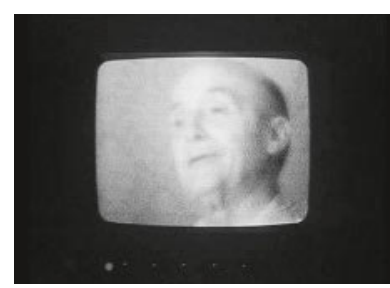

168 Foto 3

fessor der Politologie an der Universität von Vermont/USA), Alfred Spieß (Oberstaatsanwalt und in dieser Funktion Vertreter der Anklage in beiden TreblinkaProzessen 1960) und Hanna Zaidl (Tochter eines Überlebenden von Wilna, Motke Zaidl).

Die von Lanzmann befragten Täter sind in der Reihenfolge ihres quantitativen, nicht ihres chronologischen Auftretens angeführt: Franz Suchomel (SS-Unterscharführer und ab August 1942 Wächter in Treblinka; s. Foto 1), Franz Grassler (Stellvertreter des Nazi-Kommissars Auerswals für das Warschauer Ghetto; s. Foto 2), Walter Stier (ab Januar 1940 Kommissars Auerswals für das Warschauer Ghetto; s. Foto 2), Walter Stier (ab Januar 1940 bei der Generaldirektion der Ostbahn/Deutsche Reichsbahn in Krakau, ab Mitte 1943 in Warschau und verantwortlich für die Koordination der Todeszüge; s. Foto 3), Franz Schalling (Mitglied der Schutzpolizei, Bewachung der >Arbeitsjuden< in Chelmno; s. Foto 4) und Joseph Oberhauser (Fahrer von Globocznik, des Leiters der Aktion Reinhard und Mitarbeiter von Kriminalkommissar Wirth; s. Foto 5). Die Interviews mit den Tätern werden von denen der Opfer bzw. Zeitzeugen mit einer Ausnahme (Franz Grassler) durch eine auffällig andere Inszenierung abgegrenzt: SchwarzweißAufnahmen, schlechte, zum Teil sehr grobkörnige Bildqualität durch das Filmen mit versteckter Kamera, Aufnahmen des Übertragungswagens bzw. des kleinen Bildschirms im Inneren desselben. ${ }^{182}$ Durch diese zahlreichen aus dem Rahmen fallenden Aufnahmen und filmischen Mittel macht Lanzmann dem Zuschauer klar, daß zwischen diesen befragten Personen und den anderen keine Schnittmenge besteht. Die Reaktion, die Lanzmann mit der Integration der Täteraussagen beim Publikum hervorrufen will, sind Entsetzen oder Bestürzung angesichts der Ausflüchte, Selbsttäuschungen, Lügen und vor allem des Verschweigens der einstigen Helfershelfer. ${ }^{183}$ Wenn - vor allem in der zweiten Hälfte des Films - die Schilderungen der Täter an die der Opfer ${ }^{184}$ bzw. der Experten ${ }^{185}$ direkt angrenzen, ist der Zuschauer durch die Komposition gezwungen, die Kluft zwischen den gegenteiligen - und von Lanzmann bewußt nicht kommentierten ${ }^{186}$ - Aussagen auszuhalten und seine eigene Antwort darauf zu finden. Im Fall der Täter wird 
der Zuschauer Lanzmanns penetrantes Nachfragen und sein Beharren auf Details nicht als inadäquat empfinden, eher im Gegenteil ${ }^{187}$ - schließlich handelt es sich im Unterschied zu den Überlebenden des Holocaust nicht um schuldlose, schutzbedürftige Personen. Gleiches gilt vermutlich für das Heranzoomen bzw. das heimliche Filmen der Täter.

Nach eigener Aussage ist Lanzmanns Neueinhalb-Stunden-Werk insgesamt konstruiert »wie eine Symphonie. Musik wäre da ein Fremdkörper, fast obszön. Die Präzision der Montage - das ist der Rhythmus, das ist die Musik meiner Filme« (Lanzmann zit.n. Reinecke 2002: 25). Vor diesem Hintergrund und einem filmischen Rohmaterial von 350 Stunden verwundert es auch nicht, daß das Schneiden des Films überdurchschnittlich lange gedauert hat: »cinq ans « (Lanzmann 1990: 303).

Neben den unterschiedlichen, rhythmisch alternierenden Bild-Ton-Kombinationen ist $\mathrm{SHоAн} \mathrm{von} \mathrm{einem} \mathrm{Leitmotiv,} \mathrm{einem} \mathrm{Pars} \mathrm{pro} \mathrm{toto,} \mathrm{besonders} \mathrm{geprägt:} \mathrm{Immer}$ wieder konfrontiert Sнонн den Zuschauer mit Bildern von »Zügen, Lokomotiven, Schloten, Rauch, Eisenbahnschienen, Schranken, Bahnhöfen, Verladerampen « (Thiele 2001: 392), und einem »geradezu unerträglichen Rattern der Züge, die auf die Bilder zurollen« (Beauvoir 1986: 7)..$^{188}$ Hiermit geht die Einprägsamkeit dieser Bilder und Töne einher:

»All jene, die einen Tag im Kino verbracht haben, um Lanzmanns SHOAH zu sehen, werden kaum mehr unbefangen, ohne eindeutig gerichtete Assoziationen Schienenstränge, rauchende Lokomotiven und Industrielandschaften als Bilder des Films wahrnehmen können.« (Köppen 1997: 146)

187. »La plupart du temps, on pose à ces criminels des questions très précises, techniques, sur le détail de leurs activités passées, alors que si Lanzmann les avait interrogés sur leurs états d'âme, ils se seraient refermés comme des huîtres." (Ophuls 1990: 183)

188. "Vor allem die Blicke von der fahrenden Lokomotive - und auf die fahrenden Züge geben dem Film einen suggestiven Rhythmus und ziehen den Betrachter in seinen Bann. Nie zuvor ist in bewegten Bildern eine Vorstellung davon vermittelt worden, daß Europa 1942-1944 ein Kontinent pausenlos fahrender Deportationszüge war, die Millionen Juden aus West- und Mitteleuropa in sogenannten >Umsiedlungsaktionen in die östlichen Todeslager transportierten.« (Reichel 2004: 287, H.i.0.) »Die, die erinnern wollen, suchen Wege, in den Worten von Hannah Arendt, >das Nicht-greifbare in die Handlichkeit eines Dinghaften zu verwandeln. Die Erinnerung bedarf der >Verdinglichung für ihr eigenes Erinnern<. Wenn wir diese Verdinglichung >Denkmak nennen, dann hat Claude Lanzmann in SHOAH mit den Eisenbahnzügen den ermordeten Juden Europas ein Denkmal gesetzt, ein Denkmal, das nicht nur an die Ermordeten erinnert, sondern auch an das System des Mordens. " (Hoffmann 1996: 248f., H.i.0.)

189. Vgl. auch Jan Karskis weinende Zusammenbrüche gegen Ende des Films.

190. Dies wurde nicht zuletzt bei der Besprechung von SHOAH im Rahmen eines Doktorandenkolloquiums an der Universität Mannheim mehrfach betont.

191. »Le passage du >on « au >off est capital dans le film: la voix se met à exister sur le paysage et ils se renforcent l'un l'autre, le paysage donnant à la parole une tout autre dimension et la parole faisant revivre le paysage.« (Lanzmann 1990: 302, H.i.0.) 


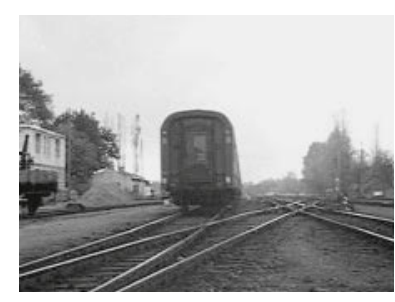

(171) $1: 57: 30 \mathrm{~h}$ (III)

»Claude Lanzmann hat die Aufnahme des fahrenden Zuges zum filmischen Symbol der Massenvernichtung gemacht, vor fünfzehn Jahren in seiner Dokumentation SHOAH. Lanzmann wählte dieses Bild als Stellvertreter für ein anderes, das es nicht mehr gab, weil die Täter es beseitigt hatten: das Bild der Gaskammer.« (Kilb 2002: 51)

»Nous sommes vrillés tant de fois par les sifflets, les jets de vapeur, le bruit des essieux sur les rails et le grincement des freins, que cette histoire se marque en nous, irrémédiablement.« (Cuau 1990: 15)

Inzwischen sind die Aufnahmen von Todeszügen und -schienen zur Holocaust-Ikonographie, zu »überstrapazierten [...] Superzeichen« des Holocaust geworden (Krankenhagen 2001: 223), nicht zuletzt durch deren bewußtes Zitieren in Spielfilmen wie Andrej Wajdas Korczak (1990), Steven Spielbergs Schindlers Liste (1993; s. II.3.2), Roberto Benignis DAS LeBEN IST SCHÖN (1997; s. II.4.1), vor allem jedoch in Costa-Gavras' Der Stellvertreter (2002) und dem Dokumentarfilm James Molls Die letzten Tage (1998). Auf diese Weise lebt Sнонн in heutigen Filmen zum Holocaust weiter.

\subsubsection{Leitthesen}

Sноннs prinzipielle Beteiligungsangebote an den Zuschauer unterscheiden sich je nach Zeuge, Sequenz und Bild-Ton-Kombination:

- Lesen der Mimik und Gestik der Zeugen bis hin zu Weinen durch Ansteckung (s. 2.2.3): Wenn der jeweilige Überlebende durch eindringliche Schilderungen zum »Modell« der Anteilnahme wird, kann sich der Zuschauer davon involvieren lassen und die beschriebene Situation mitvollziehen. ${ }^{189}$

- Im Unterschied zu 2.2.3 kann sich der Zuschauer in vielen Sequenzen nicht wirklich in die von den Überlebenden beschriebene Situation versetzen (s. 2.2.4). Entweder es besteht keine Analogie zwischen dem, was das Bild bzw. der Ton dem Zuschauer an Beteiligungen anbietet, oder aber sie ist erst nach mehrmaligem Filmbetrachten feststellbar. ${ }^{19 \circ} \mathrm{Da}$, wie Regisseur und zahlreiche Rezensenten behaupten, Wort und Bild einander bereichern würden ${ }^{191}$, trifft nicht immer zu, im Gegenteil: eine tatsächliche Synergie bildet eher die Ausnahme. Die sich wiederholenden Aufnahmen der Lagerruinen binden einen Teil der Aufmerksamkeit, die somit nicht mehr in vollem Umfang dem Zeugenbericht gewidmet werden kann. Wenn der jeweilige Zeuge darüber hinaus innehält bzw. schweigt, ist sehr wahrscheinlich, daß die Aufnahmen der einstigen Schreckensorte für Zuschauer »stumm« bleiben. Stark zu bezweifeln ist aufgrund $\mathrm{zu}$ geringer Zuschauerlenkung, daß gerade die Stille besonders vorstellungsanregende Wirkung erzielt. 
- Erinnerung an eine grauenhafte Vergangenheit erfordert eigene, freie Rückwendung, ohne Zwang. Den Druck, welchen Lanzmann wiederholt auf die Zeugen ausübt, indem er sie drängt, ihre Berichte trotz größter psychischer Belastung fortzusetzen kann beim Publikum - verstärkt durch das indiskrete Heranzoomen an die ergriffenen Überlebenden - eine kontraproduktive Wirkung erzielen (s. II.2.2.5) Im Falle von Abraham Bomba arrangiert er besonders künstlich das Interviewsetting, um den einstigen Zeugen in die damalige Situation zu versetzen, in der Hoffnung, daß dieses Vorgehen ein tatsächliches Wiederdurch- bzw. -erleben der grauenhaften Vergangenheit ermöglicht. Dies ist schon rein theoretisch nahezu auszuschließen, denn zum einen handelt es sich bei dem Friseursalon in Tel Aviv um eine gewöhnliche Situation des Haareschneidens, die mit dem Scheren der Frauen in den Gaskammern, seiner damaligen Aufgabe in Treblinka, wenig gemeinsam hat. Die bloße Tätigkeit des Haareschneidens vermag Abraham Bomba kaum in die damalige Situation zu versetzen. Allein das Drehen im Friseursalon kann als geschmack- und stillos, als eine Zumutung für den Überlebenden wahrgenommen werden. Zum anderen ist es therapeutisch äußerst fragwürdig, jemanden vor laufender Kamera bewegen zu wollen, seine Erzählbarriere zu überwinden und seine traumatischen Erlebnisse zu schildern. Lanzmanns Taktlosigkeit findet ihre filmische Entsprechung im indiskreten Heranzoomen an den Überlebenden, sobald dieser Zeichen der Ergriffenheit erkennen läßt - ein zentrales Gestaltungsmittel des gesamten Films.

- Mit-Spüren der Erschütterung und Erleben der Traumatisierung, wenn Überlebende, insbesondere Simon Srebnik, an die einstigen Orte des Verbrechens erstmalig zurückkehren (s. 2.2.6): Dieses prinzipiell wirkmächtige Verfahren der Konfrontation von Überlebenden mit den heute beinahe beschaulichen Landschaften bzw. Stätten wurde - wie bereits erwähnt - von Marceline LoridanIvens in BIRKENAU UND ROSENFELD (s. II.5) aufgegriffen und weiterentwickelt (s. II.5).

Es bleibt allerdings fraglich, ob der Film in seiner gesamten Länge »ansehbar « ist. Denn: Sнонн ist radikal konzipiert und komponiert - ohne Zugeständnisse ans $\mathrm{Pu}$ blikum:

192. Im deutschen Fernsehen wurde SHOAH - entgegen Lanzmanns Wunsch nach Zweiteilung - in vier annähernd gleich langen Teilen ausgestrahlt.

193. Vgl. hierzu auch Doneson 2002: 199 sowie: »It clearly filled a void felt by intellectuals of quality representations of the Holocaust, and although it did have a commercial release with an overall outstanding critique, much of the general public ignored it because of ist length and complexity. (Doneson 2002: 199) »It was critically hailed in America, Europe and Israel. Conferences were held by eminent academicians to examine Lanzmann's work. And despite its theatrical release, it was not considered at the academy awards. [...] Nine and one half hours is lengthy for classroom use, thought some instructors show it in segments.« (Ebd. 252)

194. Vgl. Reichel 2004: 293.

195. "SноAн est-il trop aride? Non, au contraire, c'est un film riche, aux innombrables variations, constamment surprenant comme toute grande œuvre d'art. Sa tension serait-elle alors trop forte ? Non, mail il a une grande charge émotionnelle, obstinée, implacable.« (Ophuls 1990: 186) 
»SHOAH war in gewisser Weise dazu gemacht, nicht gesehen zu werden (Žižek 2000: 15). Und generell ist zu fragen, ob die rational-aufklärerischen, auf jegliche publikumswirksamen Zugeständnisse verzichtenden und daher allenfalls vom Kreis der ohnehin Informierten wahrgenommenen dokumentarischen Bemühungen ausreichen.« (Korte 1999: 191)

»Doch setzt SHOAH eine Vorstellungskraft voraus, die den an Abbilder sich Klammernden, Geschwindigkeit, Farbe und Turbulenzen Gewöhnten systematisch ausgetrieben wurde.« (Darmstädter 1995: 135)

(I) Das Problem der Länge - vor allem was die Projektion im Kino betrifft ${ }^{192}$ - ergibt sich aus den insgesamt neuneinhalb Stunden Film.

»Seine abschreckende Länge garantiert, daß die meisten Zuschauer - einschließlich jener, die den Film loben - ihn nie vollständig gesehen haben und sehen werden, wofür sie sich ewig schuldig fühlen werden. [...] Auch muß man diese Länge zusammen mit der Tatsache sehen, daß sich SноАн als der ultimative, unübertroffene, unübertreffliche Film über den Holocaust darstellt.« (Žižek 2000: 15)

Vor diesem Hintergrund darf bezweifelt werden, daß es Lanzmann gelingt, die Ungeheuerlichkeit der Vorgänge durch die Länge des Films dem Zuschauer tief einzuprägen, »das Vergessen unmöglich zu machen« (Richter zit.n. Thiele 2001: 413). Der Regisseur war sich dieser Problematik durchaus bewußt. Die ungewöhnliche, keinem Genre entsprechende Filmdauer hängt wohl nicht zuletzt damit zusammen, daß er aus 350 Stunden Rohmaterial eine Auswahl treffen mußte:

»Il y avait des exigences de forme, d'architecture, qui font qu'il a cette durée-là. Il aurait pu être plus long: j'ai tourné 350 heures. [...] J'étais absolument affolé pendant le montage par les problèmes de longueur. Je disais: ISi c'est trop long, qui va le voir?«.« (Lanzmann 1990: 302, H.i.0.)

(2) Mit der Länge geht die Wiederholung bekannter Gestaltungsmuster einher, deren Beteiligungsangebote sich mit zunehmender und wenig variierter Wiederkehr abnutzen und an Aufforderungscharakter verlieren.

(3) Lanzmanns Verzicht auf explizite Lenkung und Wertung ${ }^{194}$ stellt hohe Anforderungen an die Eigenleistung des Zuschauers. Ist die Gefahr der Überforderung bei zu geringer bzw. fehlender Lenkung nicht extrem groß? Haben nicht gerade bestimmte ästhetische Bemühungen (suchend-abtastende bzw. indiskrete Kamera, penetrantes Nachfragen etc.) eher kontraproduktive Wirkung auf den Zuschauer? Es kann doch nicht beabsichtigt sein, daß ein Zuschauer den Film mehrfach ansehen muß, um u.U. das eine oder andere extrem subtile Versetzungsangebot überhaupt wahrzunehmen (s. 2.2.4)? Verhindern nicht häufig unpersönliche Schilderungen und anonyme Sachlichkeit, daß unsere Vorstellung anregt wird?

Entgegen der Hoffnung mancher Fachleute ${ }^{195}$ - und im Unterschied zu Resnais' Werk bzw. anderen Spielfilmen - richtet sich dieser Film, aufgrund seiner Tendenz zur Überforderung des Zuschauers, an ein intellektuelles und somit kleines Publikum: »Spielberg erreicht Millionen Menschen unterschiedlichen Bildungsgrades, 
Lanzmann erreicht diejenigen, die die Ichstärke und die intellektuelle und moralische Energie besitzen, seinen Film überhaupt durchzuhalten.« (Schörken 1995: 17) So ist zu erklären, daß Shoah »wahrscheinlich damals, wie auch heute, nur von wenigen gesehen wurde und gesehen wird [...] « (Kreimeier 1998: 20). »It clearly filled a void felt by intellectuals of quality representations of the Holocaust, and although it did have a commercial release with an overall outstanding critique, much of the general public ignored it because of its length and complexity.« (Doneson 2002: 199)

In gewisser Hinsicht könnte man sogar von einer falschen Zielgruppe sprechen, da diese ohnehin vergleichsweise gut informiert, »wie auch einig ist, daß diese Auseinandersetzung notwendig ist « (Kreimeier 1998: 20). Man kann im übrigen nicht mit Selbstverständlichkeit davon ausgehen, daß ein intellektuelles Publikum den extremen Forderungen nach Eigenleistung nachkommen kann.

Zudem erzeugen die Fülle an Einzelschicksalen und die Konzentration auf die Vernichtungsabläufe - trotz »positiven« Ausgangs für die Befragten - den Eindruck von Hoffnungslosigkeit und erschweren so das Ansehen dieses Films.

Generell sei zudem die Frage aufgeworfen, ob Lanzmann nicht von der fragwürdigen Prämisse ausgeht, daß jemand, der überlebt hat, am besten zur Vermittlung geeignet ist? Ist es möglicherweise eher umgekehrt, d.h. daß ein »Nicht-Betroffener « mehr Verständnis und damit Wirkungsangebote für ein Publikum entwickeln kann, das a) damals nicht unbedingt zu den direkt Schuldigen zählte, b) das schon zu nächsten Generation gehört und c) nun schon - wie die dritte Nachkriegsgeneration - durch 60 Jahre vom Holocaust getrennt ist?

Eine deutlich kürzere Dauer (maximal 120 Minuten) in Verbindung mit einer stärkeren Konzentration auf das Verstummen bzw. Weinen der Opfer hätte Lanzmanns Film vermutlich »erträglicher« und einem breiteren Publikum zugänglich gemacht - schließlich steckt in den Gefühlsausbrüchen der Zeugen ein wirkmächtiges Ansteckungspotential.

Daß so Landschafts- und Ruinenaufnahmen größtenteils für uns leer und zugewachsen bleiben, hätte u.U. durch eine deutlichere Analogie zwischen Bild- und Tonspur verhindert werden können. Aufgrund der häufigen Unverbundenheit zwischen den Lageraufnahmen und den Schilderungen aus dem Off fehlt uns der Bezug insbesondere zu den Bildern, auch die Berichte der Überlebenden verlieren hierdurch an Wirkung.

Der Ausbau von zumindest visuellen Kontrapunkten, wie beispielsweise die wohltuenden Aufnahmen der Hafenstadt Korfu (s. 2.2.4) bzw. des New Yorker Wassers, hätten dem Zuschauer das Einlassen auf die nächsten belastenden Augenzeugenberichte erleichtern können.

196. In etwas abgeschwächter Form zählt hierzu auch die Mehrzahl der Auftritte von Abraham Bomba, Richard Glazar und manche Passagen in Filip Müllers Schilderungen.

197. Vrba hat zum Thema bereits ein Buch veröffentlicht. Dies kann jedoch nicht die einzige Erklärung sein, sonst müßte auch Filip Müller ausschließlich distanziert und souverän wirken.

198. "IV« zeigt an, daß die Sequenz im letzten Viertel des Films anzutreffen ist und bei der Zeitangabe des Standbilds von Beginn dieses letzten Viertels an gezählt wurde. 


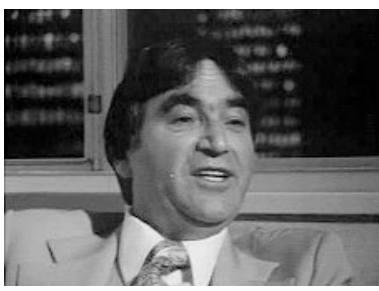

(172) $0: 22: 29 \mathrm{~h}(\mathrm{IV})$

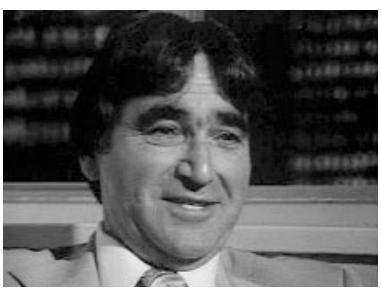

(173) $0: 27: 12 \mathrm{~h}(\mathrm{IV})$

Anhand der Dokumentation Sklaven der Gaskammer von Eric Friedler (Deutschland/SWR 2001), prinzipiell aufgebaut wie Sнонн, kann man sich überzeugen, daß der Verzicht auf penetrantes Nachfragen (s. 2.2.5) sowie auf das effekthascherische Heranzoomen (s. 2.2.5) auch SноAн gut getan hätte.

\subsubsection{Empathische Ansteckung - Filip Müllers bewegende Erzählung}

Nachdem die Geschichte eines tschechischen Familientransports nach Auschwitz von Rudolf Vrba (Mitglied des Auschwitzer Arbeitskommandos und der Widerstandsbewegung) eingeleitet und von Filip Müller (Mitglied des »Sonderkommandos« in den Krematorien von Auschwitz; s. 2.2.1) ausführlich wiedergegeben wird, entspricht die zweite Hälfte dieser Sequenz der in Sнонн am häufigsten anzutreffenden BildTon-Kombination (s. 2.2.1): Der Zeuge sitzt in einer neutralen Umgebung, und der Zuschauer kann ihn gleichzeitig sehen und hören, meist in sehr naher Einstellungsgröße.

Im Unterschied zu Filip Müllers spezieller Variante (bewegende Erzählung) dieser Grundkonstellation (s.u.), stellen die Szenen mit Rudolf Vrba in aller Regel die neutral-distanzierte Variante dieses audiovisuellen Grundmusters dar. ${ }^{196}$

Aus unterschiedlichen Gründen wirkt Vrba in seinen Schilderungen so, als würde er etwas Verarbeitetes, Abgeschlossenes referieren. ${ }^{197}$ Seine Berichte sind auffällig sachbezogen und äußerst nüchtern vorgetragen, mit fester, teilweise lauter Stimme. Da er recht schnell und in kurzen Sätzen spricht, ohne daß Lanzmann häufig nachfragen muß, wirken seine Schilderungen automatisiert.

Zumindest bei diesem Überlebenden hat man nicht primär den Eindruck, daß Lanzmanns Bezeichnung »Versehrter« zutrifft. Vrba wirkt außerordentlich distanziert und souverän. Er sitzt entspannt in seinem Bürosessel und legt den Kopf leicht in den Nacken (s. 0:22:29 h). Als er den Bestimmungsort des tschechischen Familientransports nennt (»Krematorium«), lächelt er ironisch (s. 0:27:12 h) - ein Zeichen der Distanzierung, das in seinen Schilderungen häufig zu beobachten ist. ${ }^{198}$

»The transport, the Czech family transport was gassed in the evening. They were put on tracks. All of them knew. They were put on tracks. They behaved very well. We didn't know, of course, where the tracks are going. They were being assured once more that they are going to Heidebreck and not to be gassed. And we knew that if they are going out of the camp, the tracks will turn right, when they leave the camp. And we knew that they turn left, there's only one way: 500 yards, and that was the Krematorium.« (0:26:45 $0: 27: 13 \mathrm{~h}$ ) 
Filip Müller setzt die von Rudolf Vrba begonnene Geschichte vom traurigen Schicksal eines tschechischen Transports fort.

Im Unterschied zu den meisten Szenen des angesprochenen audiovisuellen Grundtyps, wie beispielsweise Rudolf Vrbas Schilderung in der vorangegangenen Sequenz, stellt dieser Auftritt von Filip Müller eine positive Ausnahme dar: Der Überlebende ist und erzählt zum ersten Mal so bewegt, daß diese Gefühlsäußerungen auch den Zuschauer »anstecken «. ${ }^{199}$ Müller wird während des Interviews zum Ikon (s. I.2.2) seines Themas, zum Modell der Anteilnahme mit einem analogen Angebot für uns. In der Gegenwart verkörpert er seine Vergangenheit und macht sie für den Zuschauer mitvollziehbar. ${ }^{200}$

Lanzmann betont zu Recht, daß es sich bei dieser letzten, siebeneinhalb-minütigen Sequenz mit Filip Müller um eine Schlüsselszene von Sнонн handelt:

»[...] il y avait des scènes formidables qui constituaient des pivots autour desquels je devais construire le film, par exemple le massacre du camp des familles, lorsque Filip Müller se brise et pleure. C'est une histoire capitale parce qu'elle incarne un tas de choses fondamentales pour moi: savoir/non savoir, la tromperie, la violence, la résistance.« (Lanzmann 1990: 303)

Im Unterschied zu den vier vorhergehenden Sequenzen, in denen Müller Ereignisse schilderte, die eine anonyme Masse betrafen, berichtet er hier von ganz persönlichen Erlebnissen. Wie vielfältig der empathische Mitvollzug des Zuschauers ermöglicht wird, zeigt die folgende Detailanalyse.

\section{Detaillierte Sequenzanalyse:}

Nachdem Rudolf Vrba am Ende der Sequenz das letztes Wort (»Krematorium«) als Höhepunkt seines Berichts besonders betont hat, erinnert die folgende Einstellung den Zuschauer an bereits Gesehenes (s. 2.2.4): Abgesehen von einem einzigen kurzen Vogelruf, herrscht 30-sekündige, absolute Stille. Die wackelnde Kamera tastet sich an die Treppe zum Krematorium heran (s. 0:27:21 h und 0:27:26 h), um mit ihr und den von Vrba angesprochenen tschechischen Juden in den Auskleideraum hinabzusteigen (s. 0:27:27 h und 0:27: 35 h). Diese Einstellung unterscheidet sich jedoch von der vergleichbaren, rund eine Stunde zurückliegenden (s. 0:55: 11 - 0:55:40 h in 2.2.4) durch zwei Dinge: Zum einen sind die Ruinen des Krematoriums nun nicht mehr von Schnee bedeckt und für den Zuschauer daher erkennbar - die Relikte der Vergangenheit wirken greifbarer. Zum anderen inszeniert Lanzmann den Abstieg ins Untergeschoß wesentlich dramatischer und damit wirkungsvoller. Durch die subjektive Kameraführung läßt er den Zuschauer mit der Familie in den dunklen Schlund hinabstürzen - eine schwindelerregende Vorwärtsbewegung. ${ }^{201}$

199. Vgl. auch Jan Karskis Weinen gegen Ende des Films.

200. »Nous avons effleuré un instant, par la voix et le regard du témoin, le centre du film, l'axe de la roue de la Shoah.« (Torner 2001: 169)

201. Im Unterschied zur ersten - rein visuellen - Versetzung kann der Zuschauer diese zweite durch die Benennung (»Krematorium«) zuordnen, d.h. sie wird aus dem Kontext heraus verständlich. Die Spuren der Vergangenheit, geführt durch eine subjektive, authentisierend wackelnde Kamera, werden lesbar. 


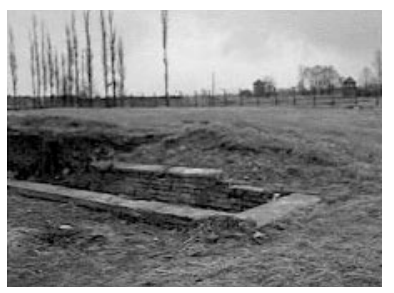

(174) $0: 27: 21 \mathrm{~h}(\mathrm{IV})$

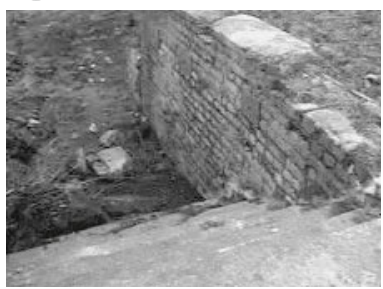

(176) $0: 27: 27 \mathrm{~h}(\mathrm{IV})$

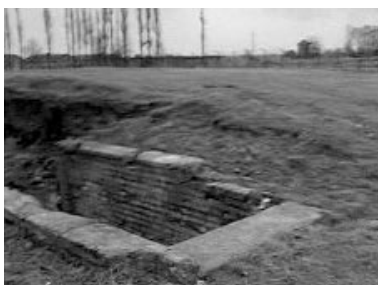

(175) $0: 27: 26 \mathrm{~h}(\mathrm{IV})$
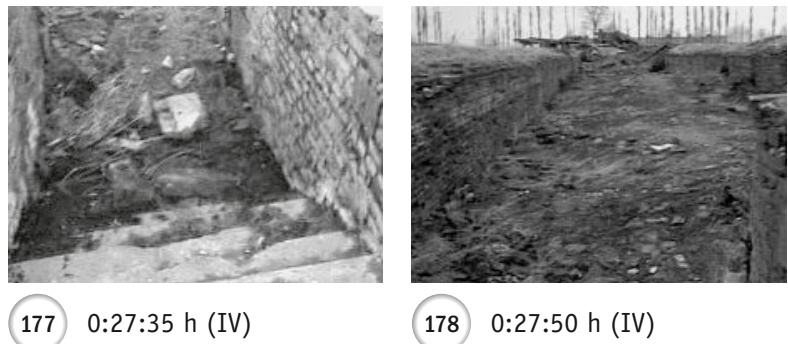

178

$0: 27: 50 \mathrm{~h}(\mathrm{IV})$

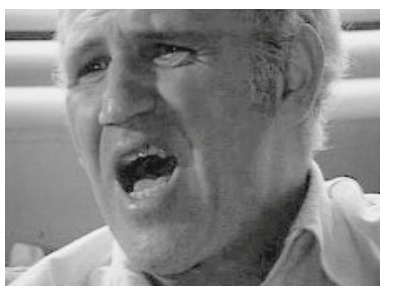

179) $0: 28: 19 \mathrm{~h}(\mathrm{IV})$

Im folgenden läßt der Regisseur den Zeugen Filip Müller zunächst aus dem Off mit der Schilderung seiner Arbeit im »Sonderkommando« einsetzen: »Diese Nacht war ich im Krematorium II«, während die Kamera den Blick vom Boden löst und den bereits bekannten Auskleideraum in seiner ganzen Länge aufnimmt (s. 0:27:50 h) - wir sind sozusagen erneut im Zentrum der Vernichtung angekommen.

Die folgende fünfminütige Einstellung zeigt Filip Müller, ordnet dem Ton das entsprechende Bild zu:

»Kaum sind die Menschen von den Lastwagen ausgestiegen, waren sie beleuchtet mit Reflektoren und müßten durch einen Korridor bis zu die Stiegen, wo, äh die ja, die ja da müden in den Auskleideraum, bis bis zu die Treppen, da beleuchtet durch also müßten die laufen. Sie waren geschlagen (s. 0:28:19 h). Wer nicht laufen könnte in Laufschritt, war also bis zum Tode geschlagen, also von der SS. Also es war ein außergewöhnlicher Gewalt auf diese Menschen aufgesetzt. Jetzt plötzlich [...] sind sie ausgestiegen aus den Lastwagen und da haute zu die SS auf diese Menschen. Als sie sich befanden in den Auskleideraum, war ich wieder in den [179] hintern Tür des Auskleideraums, stand ich hinter die hinteren Tir (Tür), äh, und äh könnte die schreckliche Szenerie zuschauen. Die Menschen waren verblutet, sie wußten jetzt, wo sie sich befanden. Sie guckten sich an die Säulen des sogenannten, wie ich schon vorher gesagt haben, internationalen Informationszentrum (s. 0:29:16 h). Der ihnen so viel Schrecken, der hat sie nicht beruhigt. Im Gegenteil: Der hat diesen Menschen einen Schrecken ge-, einge-, eingebracht, weil sie nämlich schon vorher gewußt haben und gehört haben diese Menschen in dem 
Lager B II B, was da geschah. Sie waren verzweifelt. Kinder umarmen sich, Töchter also Mütter, äh, Eltern, ältere Menschen, weinten. Sie waren unglücklich. Plötzlich könnte man sehen, daß von den Stiegen kamen einige SS-Offiziere an, unter anderem auch der Lagerführer Schwarzhuber, der vorher doch denen versprochen hat, mit einem Ehrenwort eines SS-0ffiziers, daß sie, daß hier in den, daß sie in Heidenbreck überstellt werden. Da hab' ich gesehen, wie sich eine, wie sie angefangen, sie fingen an zu schrien, appellieren: »Heidenbreck war eine Täuschung! Wir waren belogen (s. 0:30:28 h), wir wollen leben, wir wollen arbeiten! «, und guckten dabei in Gesicht den SS, der SS-Henkern. Aber die haben sich [Pause, s. 0:30:38 h], die waren ja wie nicht beteiligt, die haben nur zugeschaut, als plötzlich eine Menge ausbricht; wahrscheinlich wollte sie sich stellen in die Augen gegen den Schergen, SS-Schergen und denen sagen, wie man, wie sie belogen waren. Aber in dem Moment kamen einige Pot, äh äh, einige Posten und schlagen mit Knüppeln zu und einige waren auch verletzt, in Auskleideraum, in Auskleideraum. Unter diesen Umständen kam es also unter außergewöhnlicher Härte, die ja, äh äh, waren diese Menschen jetzt gezwungen, sich ausziehen. Einige haben sich ausgezogen, aber nur die kleine, eine eine ganz kleine Menge. Die Mehrheit, die die die haben, die haben nicht diesen Befehl be-, befolgt.« $(0: 27: 59:-0: 32: 07 h)^{202}$

Während Filip Müller die Ankunft und weitere Details im Auskleideraum beschreibt, kann der Zuschauer vor allem an den mimischen Regungen - hervorgehoben durch eine extrem nahe Einstellungsgröße - ablesen, wie präsent die Vergangenheit vor seinem inneren Auge ist und wie sehr er die jeweilige Situation erneut durchlebt.

Im Gegensatz zu Vrbas Schilderungen wirken Müllers in ihrer Dramaturgie wie eine Art Erlebnisbericht. Auf sprachlicher Ebene fallen in diesem Zusammenhang Wörter wie »plötzlich«, »da« etc. auf - Zeichen eines undistanzierten Erzählens. Als Mimos im traditionellen Sinne übernimmt er die Rollen der beschriebenen Opfer und ahmt gar deren verzweifelte Rufe kurz vor deren Ermordung in der Gaskammer nach (s. erneut 0:30:28 h). ${ }^{203}$

Auf diese Weise wird der Zuschauer in die fürchterliche Situation im Auskleideraum einbezogen, wobei es ihm überlassen bleibt, welches Bild in seiner Vorstellung entsteht. $^{204}$

Obwohl Müller trotz der Grauenhaftigkeit der Ereignisse bis zu diesem Zeitpunkt recht flüssig erzählt hatte, gerät er unvermittelt ins Stocken:

»Und plötzlich hörte ich, wie ein Chor (s. 0:31:37 h) fängt ... fängt an, wie ein Chor fängen an sich singen. Ein Gesang verbreitete sich in dem Auskleideraum, und da fing an zu klingen, sie singen die tschechische Nationalhymne und äh, äh die Hatikwa. Es hat mich sehr berührt (s. 0:32:03 h), dieser äh... dieser hm...« (0:31:34 - 0:32:07 h)

202. Bei der Transkription von Müllers Bericht wurde auf exakte Wiedergabe geachtet, weshalb »äh« auch aufgeführt ist bzw. auch die spezfische Aussprache bestimmter Worte beibehalten und nicht in Schriftdeutsch verwandelt wurde.

203. Vgl. Lanzmanns Äußerungen zum Schauspieler-Werden in 2.2.1.

204. Auf der Tonspur stößt SноAн ins Zentrum der Vernichtung vor und »versenkt sich [...] in die Szenerie des Schreckens wie kein anderer der [...] (Holocaust-)Filme.« (Kramer 1999: 25) 


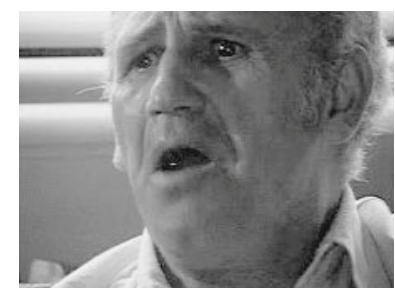

(180) $0: 29: 16 \mathrm{~h}$ (IV)

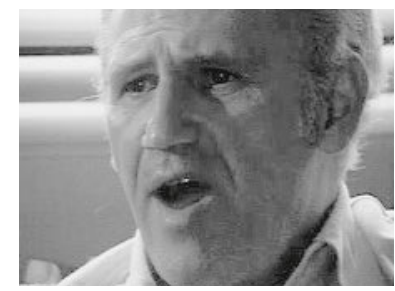

(181) $0: 30: 28 \mathrm{~h}$ (IV)

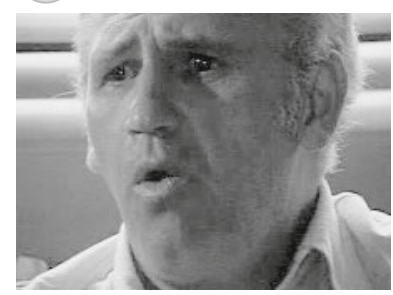

(183) $0: 31: 37 \mathrm{~h}$ (IV)

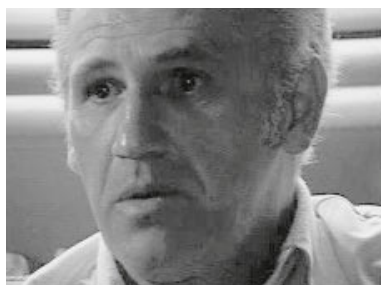

(184) $0: 32: 03 \mathrm{~h}(\mathrm{IV})$

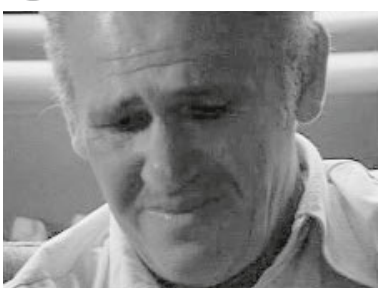

(185) $0: 32: 09 \mathrm{~h}$ (IV)

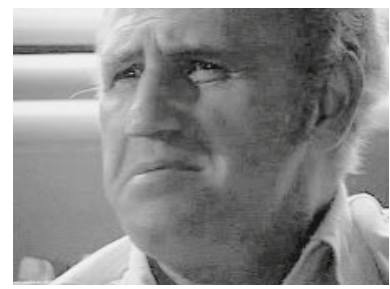

(182) $0: 30: 38 \mathrm{~h}$ (IV)

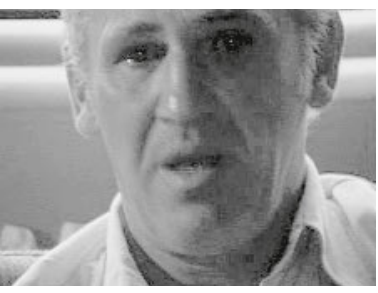

(186) $0: 32: 27 \mathrm{~h}(\mathrm{IV})$

Nachdem seine Stimme, vor allem bei der Nennung des Hymne, belegt geklungen hatte, verliert er die Fassung und bricht in Tränen aus (s. 0:32:09 h). In diesem Moment überwältigt die Häufung und das Zusammenwirken verschiedener Aspekte sowohl den Augenzeugen als auch den Zuschauer:

- Er/Wir vollziehen mit den Getäuschten die Enttäuschung (»Heidebrück war eine Täuschung!«) und erleben so den Übergang und Schock von Nicht-Wissen zu Gewißheit mit.

- Er/Wir vergegenwärtigen sich/uns die Schmach des Sich-Ausziehen-Müssens und die extreme Gewalt (Stockschläge).

- Es berührt ihn/uns sehr, daß die Menschen in einem solchen Moment die Nationalhymne singen - ein letzter Akt des Widerstands und der Versuch, in Würde zu sterben.

- Er/Wir haben das Ende des tschechischen Transports, den unweigerlichen Tod in den Gaskammern, vor Augen. 
Über den - die Vergangenheit verkörpernden - Zeugen werden uns demnach Schlüsse nahe gelegt, die als Wirkungsangebot von Lanzmann zu Recht benannt werden (s.o.; Lanzmann 1990: 303).

Müllers Verlust der über lange Zeit bewahrten Kontrolle bildet den Höhepunkt der Sequenz und ein wirkmächtiges Beteiligungsangebot für den Zuschauer. ${ }^{205}$ Weinen als gestuell zentrales Moment der Vergegenwärtigung leidvoller Erinnerung kann MitWeinen bewirken.

Die insbesondere in dieser Sequenz aufgebaute Nähe zu Filip Müller wird zudem dadurch ermöglicht, daß Müller - erneut im Gegensatz zu Vrba - deutsch spricht, und der Zuschauer daher keine Übersetzungen (Untertitel) lesen muß; er kann sich ganz auf die sprechenden Augen- und Mundpartien konzentrieren. Diese sind von Beginn der Szene an durch eine extrem nahe Einstellungsgröße (zwischen Groß- und Detailaufnahme) hervorgehoben; die Umgebung ist völlig ausgeblendet und kann daher nicht ablenken.

Im Unterschied zu zahlreichen anderen Sequenzen dieses audiovisuellen Grundtyps verzichtet Lanzmann hier auf das effekthascherische Heranzoomen an den Zeugen (s. insb. 2.2.5). Da Filip Müller bereitwillig von sich aus berichtet, muß Lanzmann nicht penetrant nachfragen. Somit fehlen in dieser Sequenz zwei Faktoren, die den empathischen Mitvollzug des Zuschauers behindern könnten.

Im Anschluß an seinen Kontrollverlust ringt Müller um Fassung, was ihm zunächst nicht wirklich zu gelingen scheint. Obwohl er das Abstellen der Kamera erbittet, setzt er - im Unterschied zu Abraham Bomba (s. 2.2.5) - von sich aus nach nur kurzer Pause seine Erzählung fort:206

»... also dieser Vorfall meine Land-, Landsleuten, und ich hab' mich erfaßt, daß mein Leben nicht mehr kein Wert hat (s. 0:32:38 h). Was soll ich machen, leben für was? Da ging ich in die Gaskammer, mit denen, und entschieden zu sterben (s. 0:32:53 h). Mit ihnen. Da kamen plötzlich zu mir einige Leute, die mich erkannt haben, weil ich war einige Male mit meinen Freunden von den mit den Schlosser in Familienlager. Und, äh, plötzlich kam eine kleine

205. »[...] le rapport particulier qui unit l'acte de pleurer et l'expérience exterminatrice: pleurer, c'est l'expression du chagrin, donc de la perte, du deuil. [...] Elles [les larmes] attestent une émotion qui n'est pas reproductible, un traumatisme qui ne peut pas être simulé.« (Lowy 2001: 147)

206. Vgl. Torner 2001: $167 f f$.

207. „Je regarde ces yeux qui ont vu, ce visage qui a attendu la mort, je ne peux pas croire et je suis malgré tout ancré devant ce visage qui parle.« (Torner 2001: 168)

208. »[...] the montage uses the most common techniques of the film, switching directly from a close-up of a witness to a panning or a tracking shot, in the present, of the place just evoked by the testimony which we continue to hear in juxtaposition. In some other cases, silent images will show a place in the present and only a few seconds later, a voice will start a testimony related to the images we see and just saw.« (Colombat 1993: 318)

209. Dies wurde nicht zuletzt bei der Besprechung von SHOAH im Rahmen eines Doktorandenkolloquiums an der Universität Mannheim mehrfach betont.

210. "Les mouvements de caméra acquièrent une autonomie esthétique, la caméra n'est pas utilisée à des fins documentaires, mais pour susciter l'imagination.« (Koch 1990: 165) 


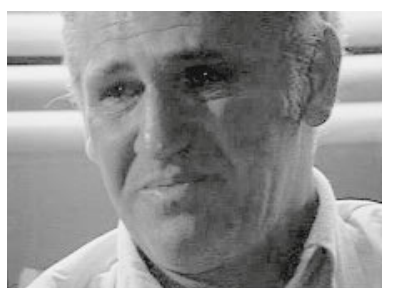

(187) $0: 32: 38 \mathrm{~h}(\mathrm{IV})$

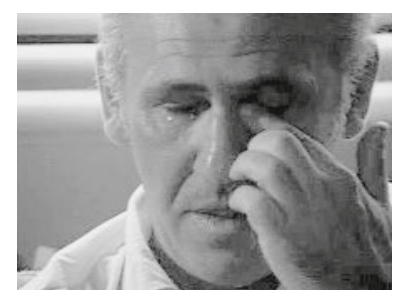

188 $0: 32: 53 \mathrm{~h}(\mathrm{IV})$

Gruppe von Frauen zu mir, guckte mich an und sagte, in den, schon in den Gaskammern [...] und sagte mir also [Pause]: »Das hat keinen... Du willst ja sterben. Aber das hat doch kein Sinn! Dein Sterben wird nicht unseres Leben bringen. Das is' keine Tat! Du mußt, äh, von hier raus, du mußt ja noch berichten, über den, was wir leiden, was für ein Ungerecht uns get..., geschehn ist.« (0:32:27 - 0:33:55 h)

Vor allem in diesem Moment ist die mitfühlende Nähe des Zuschauers mit dem Zeugen extrem ${ }^{207}$ - zumal er seine Schilderung nur unter größter Qual hervorbringt (s. 0:32:38 h u. 0:32:53 h): Mehrfach versagt ihm zwischenzeitlich die Stimme bzw. bricht er in Schluchzen aus. Glücklicherweise findet Müller zunehmend seine Fassung wieder, wobei die belegte Stimme und die Tränen in seinen Augen und auf seinen Wangen weiterhin vom schmerzvoll Erlebten zeugen - es wirkt so, als reiße die Wunde erneut auf.

\subsection{4 Überforderung des Zuschauers -}

fehlende Analogie zwischen Lageraufnahmen und Zeugenbericht

Filip Müllers insgesamt zweites Auftreten in Sнон nach rund drei Stunden Filmdauer - seine ausführliche Schilderung des Todeskampfes in den Gaskammern - stellt aus mehreren Gründen eine weitere Schlüsselszene des Films dar.

Die Sequenz ist beispielhaft für die den gesamten Film charakterisierende Komposition, die sich aus der Kombination der beiden häufigsten Bild-Ton-Anordnungen ergibt. ${ }^{208}$ Noch bevor der Augenzeuge im Bild gezeigt wird, ist er, parallel zu Bildern vom aktuellen Zustand der Vernichtungsstätten, aus dem Off zu hören.

Dieses zweithäufigste audiovisuelle Gestaltungsmuster bestimmt die Sequenz. Während diese Bild-Ton-Kombination beim insgesamt letzten Auftritt Filip Müllers (s. 2.2.3) den Zuschauer aufgrund des Kontextes sowie der Deutlichkeit der Inszenierung in die Perspektive der beschriebenen Opfer versetzt hatte, vermag sie hier - wie in der Mehrzahl der Fälle - kaum zu gelingen. Entweder es besteht keine Analogie zwischen Bild und Ton oder aber sie ist - wenn überhaupt - erst nach mehrmaligem Filmbetrachten feststellbar. ${ }^{209} \mathrm{Da}$ sich, wie neben dem Regisseur auch zahlreiche Rezensenten behaupten, Wort und Bild bereichern würden ${ }^{210}$, trifft nicht immer zu, im Gegenteil: Eine synergetische Wirkung ist eher die Ausnahme. Die sich wiederholenden Aufnahmen der Lagerruinen binden einen Teil der Aufmerksamkeit, die somit nicht mehr in vollem Umfang dem Zeugenbericht gewidmet werden kann.

Wenn Filip Müller innehält bzw. schweigt - zwischendurch immer wieder der Fall ist eine Überforderung des Zuschauers äußerst wahrscheinlich. Die Bilder können gar eine kontraproduktive Wirkung entfalten; die abstrakten Aufnahmen der einstigen 
Schreckensorte laufen dann Gefahr, für den Zuschauer »stumm« bleiben. Stark zu bezweifeln ist aufgrund der zu geringen Zuschauerlenkung, daß gerade die Stille besonders vorstellungsanregende Wirkung hat (Colombat 1993: 321f.).

Die Sequenz weist darüber hinaus zwei Besonderheiten und ein im Film regelmäßig wiederkehrendes Motiv auf.

Sie beginnt mit Aufnahmen aus dem Auschwitz-Museum, die ein Modell der Krematorien II und III zeigen. Diese Art visueller Rekonstruktion der Vernichtung kommt insgesamt zwar nur zweimal im gesamten Film vor (s. auch 2.2.4), ist jedoch für jemanden wie Lanzmann, der jeglichen Versuch der Darstellung äußerst strikt ablehnt (s. 2.2.1), inkonsequent.

Als einzige Sequenz in Sнон beinhaltet diese Sequenz eine rasante Kamerafahrt am Lager entlang - eine Form der Inszenierung, die dem Zuschauer das Ausmaß der Vernichtung zu vermitteln sucht und die zwei Jahrzehnte später in Marceline LoridanIvens' BIRKENAU UND ROSENFELD aufgegriffen wird (s. II.2.5.6).

Zudem inszeniert Lanzmann in dieser Szenenfolge das berühmt-berüchtigte Tor von Auschwitz in einer speziellen Variante.

In gewisser Weise kann die Sequenz als Lanzmanns »Antwort« auf Resnais' Gaskammer-Sequenz verstanden werden (s. II.2.1.6). Beklemmender Höhepunkt beider Sequenzen ist der Todeskampf. ${ }^{211}$ Wo Resnais auf eine Kombination visueller (Aufnahmen der Kratzspuren in der Decke der Gaskammer) und auditiver Mittel (Kommentar und Musik) setzt, konzentriert sich Lanzmann ganz auf seinen Augenzeugen (visuell) und dessen Bericht (auditiv).

Vor allem aufgrund der expliziten Thematisierung des Überreste, der Asche, ist die vorliegende Sequenz auch mit der Gaskammer-Sequenz in BIRKENAU Und RosenFELD vergleichbar (s. II.5.5.f). Während Loridan-Ivens diesen Aspekt ins Zentrum ihrer Sequenz rückt und ihn somit dem Zuschauer auf ebenfalls auditiver Ebene stärker ins Bewußtsein bringt, spricht Lanzmanns Augenzeuge ihn nur beiläufig an.

211. Nicht zufällig wird dieses Gräßlichste in dem diskreten Film Birkenau und RoSENFELD nicht explizit thematisiert.

212. Die durchschnittliche Dauer der anderen Szenen beträgt ca. fünfeinhalb Minuten.

213. »III« zeigt an, daß die Sequenz im dritten Viertel des Films anzutreffen ist und bei der Zeitangabe des Standbilds von Beginn dieses dritten Viertels an gezählt wurde.

214. Vgl. Dayan-Rosenman zum »timbre profond, inoubliable de Müller« (1990: 189).

215. „In Birkenau gab es vier Krematorien. [...] eine große Auskleideraum von etwa zweihundertachtzig Quadratmeter, und eine große Gaskammer, wo könnte man bis dreitausend Menschen auf einmal vergasen. [...] Im Krematorium IV und V waren drei Gaskammern. Mit einer Kapazität schon ... also höchstens könnte man hier tausendachthundert bis zweitausend auf einmal vergasen. Krematorium II und III hatten je fünfzehn Öfen. Krematorium IV und V je acht Öfen.« (0:50:51-0:54:23 h; eigene Hervorhebung)

216. Dies ist das erste, nicht jedoch das letzte Mal, daß sich Lanzmann an eine Art visuelle Darstellung der Vernichtung heranwagt. Es wird später im Film in der weiteren Schlüsselsequenz mit Müller am Ende kurz eingeblendet. Analysiert wird diese Besonderheit des Films jedoch nur hier, weil sie in dieser Sequenz wesentlich mehr Raum einnimmt. 


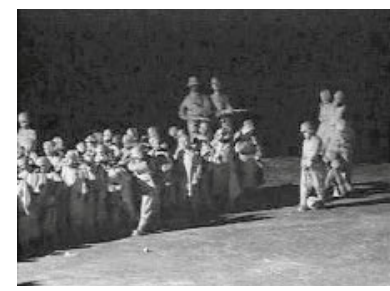

189 $0: 50: 39 \mathrm{~h}$ (III) $)^{213}$

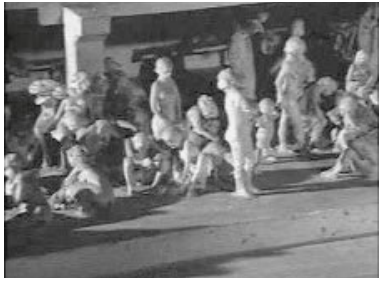

(190) $0: 52: 19 \mathrm{~h}$ (III)

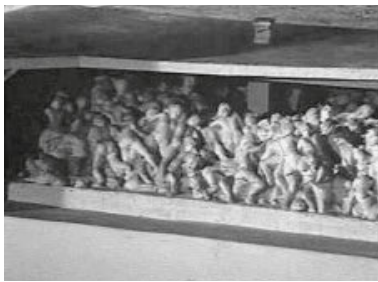

(191) $0: 53: 14 \mathrm{~h}$ (III)

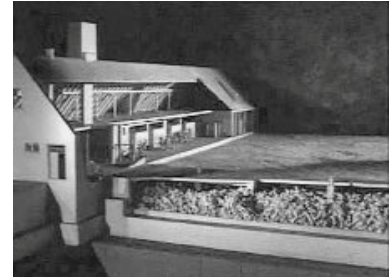

(192) $0: 53: 59 \mathrm{~h}$ (III)

Mit ihrer Dauer von ca. 22 Minuten ist diese Sequenz die längste der insgesamt sechs Filmszenen mit Filip Müller. ${ }^{212}$ Im Zusammenhang mit dem zuvor Angesprochenen ein deutliches Indiz dafür, daß es sich um eine zentrale Sequenz mit diesem Zeugen handelt. Nicht zufällig ist sie - ebenso wie die Szene im Friseursalon (s. 2.2.5) - mehr oder weniger in der Mitte von Sнон plaziert.

\section{Detaillierte Sequenzanalyse:}

Nachdem Rudolf Vrba erneut in sachlicher Art und Weise erklärt hat, daß die Neuankömmlinge im Lager möglichst im Unklaren über ihr bevorstehendes Schicksal gelassen werden sollten, zieht die erste Einstellung der Folgeszene die Aufmerksamkeit des Zuschauers in besonderem Maße auf sich.

Bei absoluter Stille fährt die Kamera zehn Sekunden lang und bedächtig an einer von Soldaten bewachten Menschenmenge, einer modellartigen Nachbildung, entlang, wobei die Figuren durch die gespenstische Lichtinszenierung (auffälliges Seitenlicht) nur schemenhaft zu erkennen sind und dadurch beinahe irreal wirken (s. 0:50:39 h). Im Zusammenhang mit den vorherigen Erklärungen von Vrba kann man schließen, daß es sich hierbei um einen im Lager ankommenden Transport handelt. Als eine männliche, uns aus vorangegangenen Sequenzen bereits bekannte Stimme214 aus dem Off zu sprechen beginnt, wird unsere Vermutung bestätigt und konkretisiert: Den zusammengetriebenen Menschen steht der Gastod im Krematorium bevor. Im Unterschied jedoch zur bewegenden Erzählweise bei seinem letzten Auftritt in Sнонн (s. 2.2.2.1) gleicht Müllers Text hier einem sachlichen Bericht, vergleichbar mit Vrbas Sprechweise. Diese detaillierte und auffällig von Statistik $^{215}$ geprägte Schilderung des Vernichtungsprozedere kommentiert - aufgrund der bedächtigen Kamerafahrt durchaus mit Pausen - den jeweiligen Abschnitt der Örtlichkeiten: die Treppe ins Untergeschoß, den Auskleideraum (s. 0:52:19 h), die Gaskammer (s. 0:53:14 h) und schließlich das Modell in einer Gesamtansicht (s. o:53:59 h). Vermutlich will Lanzmann mit der visuellen Darstellung des Vernichtungsprozesses den sonst hohen auditiven Zumutungsgehalt des Films punktuell durchbrechen. ${ }^{216}$ Möglicherweise will er zusätzlich dem allzu statistischen Charakter 
von Müllers Beschreibung mit bildlicher Konkretisierung entgegenwirken. Zeit zum Betrachten der Aufnahmen hat man jedenfalls, denn zum einen fährt die Kamera die Nachbildung langsam ab, zum anderen macht der Überlebende zahlreiche kleinere Pausen während des Sprechens. Im Unterschied zu den nahen Einstellungen der befragten Zeugen fällt hier der Einsatz von Totalen bzw. weiten Einstellungen auf. Dies hält uns auf Distanz zu den schemenhaften Figuren und vermeidet möglicherweise unerträgliche Nähe im Moment der Vernichtung. Gleichzeitig wird und wirkt jedoch die Darstellung dadurch ähnlich abstrakt wie der Off-Text von Filip Müller. Die Entpersönlichung in Bild und Ton vermag die Vorstellung des Zuschauers letztlich kaum anzuregen.

Die folgende Einstellung zeigt - entgegen unserer Erwartung gewohnter Kompositionsstrukturen - nicht den weiterhin aus dem Off zu hörenden Filip Müller, sondern zunächst die verschneite Wiese innerhalb des Stacheldrahtes, um kurz darauf zu Gebäuderelikten zu schwenken (s. o:55:11 h). Parallel zu Müllers wirkungsvoller Formulierung - »Aber niemand von denen könnte, nicht einmal im kleinsten, sich vorstellen, daß er vielleicht in drei, vier Stunden in Asche verwandelt würde.« (0:55:14 - o:55:24 h) -, steigt die Kamera die Stufen hinab in ein Untergeschoß (s. 0:55:21 h). Obwohl seit Beginn dieser Einstellung Müllers Erzählweise durch das erneute Durchleben der Situation lebendiger ist, wird die Vorstellung des Zuschauers durch Lanzmanns ausführliche Landschaftsaufnahmen kaum angeregt.

Höchstens ein Filmanalyst oder ein extrem aufmerksamer Zuschauer könnte aufgrund des Berichts sowie der leicht wackelnden Kamera den Eindruck gewinnen, er werde in die subjektive Perspektive der zur Vernichtung vorgesehenen Opfer versetzt. $\mathrm{Ob}$ dies vom breiten Publikum bei einem ersten Ansehen geleistet werden kann, sei jedoch stark bezweifelt - schließlich bedurfte es selbst für verschiedene filmversierte Zuschauer (filmwissenschaftliches Doktorandenkolloquium an der Universität Mannheim) eines mehrmaligen Betrachtens dieser Szene, um den Einsatz subjektiver Kamera identifizieren zu können.

Gleiches gilt für die folgende Szene, in der die im Untergeschoß angekommene Kamera innehält (s. 0:55:40 h), während Müller nach einer kurzen Pause weiterhin aus dem Off zu hören ist: »Wenn die in den Auskleideraum gekommen sind, haben sie da gesehen, daß der Auskleideraum hat ausgesehen wie ein internationales Informationszentrum.«(০:55: 31 - o:55:43 h) $)^{217}$ Jahrzehnte später läßt der Ort davon wenig erkennen. Nicht nur, daß Gras über die Ruinen der Schreckensorte gewachsen ist, darüber hinaus breitet eine Schneeschicht den Mantel des visuellen Schweigens über die ohnehin schon dürftigen Spuren.

Als sich die Kamera wieder in Bewegung setzt und sich auffällig der linken Wandmauer nähert (s. o:56:0o h), fragt man sich nach dem Grund hierfür. Der Zeuge liefert wenig später die Erklärung: »An den Wänden waren angebracht Haken und auf jedem Haken war eine Nummer.« (0:56:12 h) Auch diese Kombination aus OffInformationen und allwissender, bewegter Kamera dient kaum als besonderer Ka-

217. »[...] the camera produces in the present movements described in the past by the witness. The audience then is invited to imagine the episode described from what is left today of the same place.« (Colombat 1993: 327) 


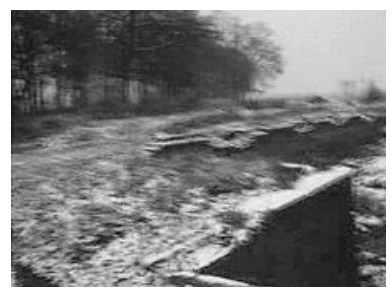

(193) $0: 55: 11 \mathrm{~h}$ (III)

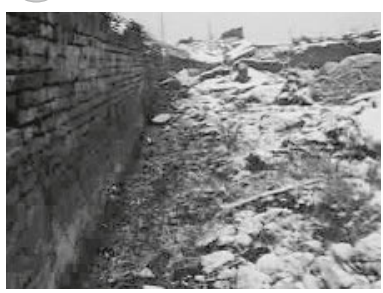

(196) $0: 56: 00 \mathrm{~h}$ (III)

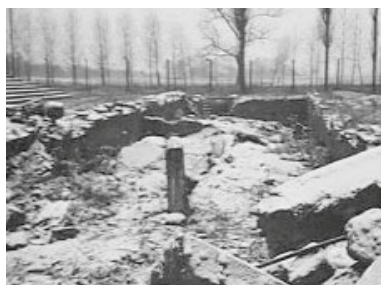

(199) $0: 58: 38 \mathrm{~h}$ (III)

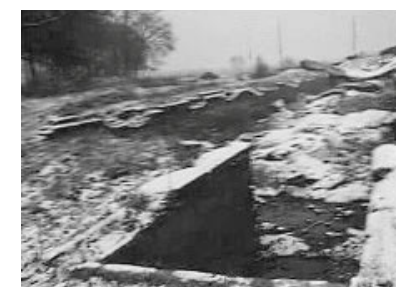

(194) $0: 55: 21 \mathrm{~h}$ (III)

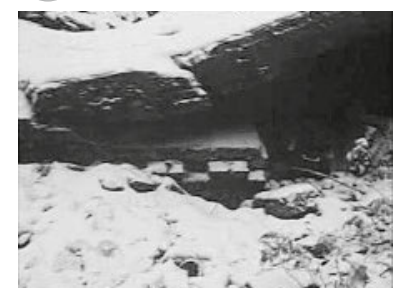

(197) $0: 57: 24 \mathrm{~h}$ (III)

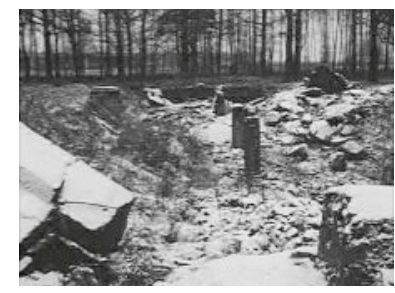

(200) $0: 59: 08 \mathrm{~h}$ (III)

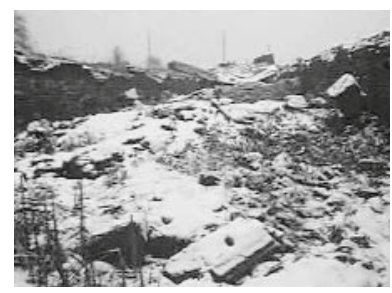

(195) $0: 55: 40 \mathrm{~h}$ (III)

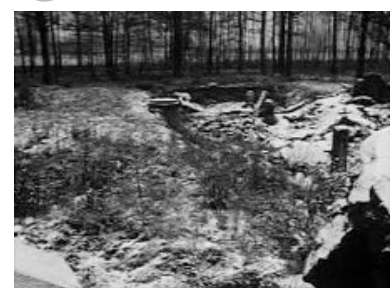

(198) $0: 57: 59 \mathrm{~h}$ (III)

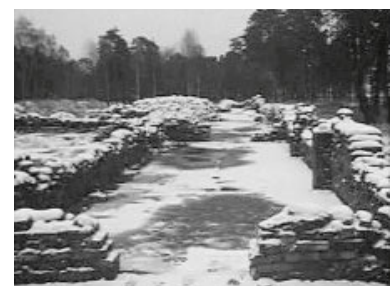

(201) $0: 59: 36 \mathrm{~h}$ (III)

talysator für die Vorstellung des Zuschauers. Wenn in der Folge die Kluft zwischen Bild und Ton zunehmend größer wird, erzielt diese komplizierte Inszenierung eine eher kontraproduktive Wirkung. Diese mangelnde Lenkung kann den Zuschauer überfordern und somit negativ stimmen. Parallel zu Müllers detaillierter, aber vom Bild zunehmend abgekoppelter Beschreibung des Auskleideraums versucht die Kamera unter die zwischenzeitlich eingestürzte - von einer Schneeschicht bedeckte - Decke zu blicken (s. 0:57:24 h). Dies wirkt auf den Zuschauer, als suche sie nach eindeutigeren Spuren der Vergangenheit unter den diversen Schichten aus Steinen, Gras und Schnee. In der Folge schwenkt sie, auffällig nah an der dicken Schneeschicht über der eingestürzten Decke entlangfahrend, zu einem unbekannten Ziel, bis Filip Müller ein weiteres Mal die Überforderung des Zuschauers unterbricht, indem er erklärt: »Und links gegenüber war die Gaskammer, mit eine massive Tür ausgestattet.« (0:57:55 h; s. 0:57:59 h)

In den folgenden Einstellungen kontrastiert das eingetretene »Übermaß an Stille« mit dem vorherigen Übermaß an Information - kommentarlos inszeniert Lanzmanns Kamera das Lagergelände (s. 0:58:38 h und o:59:08 h).

Als Filip Müller im Zusammenhang mit der Öffnung der Gaskammern äußert, »Einige Male habe ich das gesehen. Und das war das Schwerste überhaupt, aber auf das konnte man sich nie gewöhnen. Das war unmöglich. Unmöglich « (1:01:49 - 1:01:55 h), zeigt uns die folgende Einstellung schließlich den Augenzeugen (s. 1:02:05 h) - elf 
Minuten hatten wir vorher lediglich seine Stimme aus dem Off vernommen. Spätestens an dieser Stelle kann der Zuschauer den ihm bereits bekannten Überlebenden identifizieren.

Nach kurzer Pause und ohne daß Lanzmann ihn sonderlich befragen müßte, führt der Überlebende von sich aus die Schilderung des Grauenhaftesten, des Todeskampfs in den Gaskammern, fort:

»Man muß es so sehen, daß der Gas, wenn er eingeworfen hat, da hat er gewirkt doch, äh, so, daß er sich (s. 1:02:05 h) von unten nach oben stieg der. Und jetzt, äh, in diesen schrecklichen Kampf, der da entstand - das war ein Kampf, der da entstand, in in in in ... Die Lichter waren weg, also ausgeschaltet. Äh, es war dunkel da. Man hat nich gesehen. Und daß die Stärkeren wollte immer mehr nach oben, weil sie haben wahrscheinlich gespürt, daß wie mehr sie nach oben, äh, kommen, daß um so mehr kriegen sie Luft (s. 1:02:48 h), um so mehr also könnten sie atmen, ja?! Und da entstand ein Kampf. Und zweitens, die meisten haben sich gedrängt zu der Tür, ja. Psychologisch also, daß sie gewußt haben, die Tür ist da; vielleicht ausbrechen durch die Tür. Also ein Instinkt in, in den, in den Le-, also in den Todeskampf, der da durchgeführt war. Und dafür hat man auch gesehen, daß gerade Kinder und schwächere Menschen, ältere Menschen, die lagen unten. Und die Kräftigsten, die waren oben. Weil in den Leben-, äh, weil in den Leben-, also in den Todeskampf erkannte schon nicht der Vater, meines Achtens, der Vater, daß sein Kind hinter ihm liegt, unter ihm. [Lanzmann: Und wann man hat die Türe geöffnet?] Sind die Menschen herausgefallen, wobei, rausgefallen wie ein Stück Stein, große Steine, sagen wir, vor einen Lastwagen, wie ein Ballast. Und dort, wo der Zyklon wieder war, war leer. Wo die Kristalle von Zyklon war eingeschüttet waren, war leer, ja. Da war eine ganz leere Stelle. Wahrscheinlich haben die Opfer gespürt [nach vorne], daß hier des am stärksten der Zyklon wirkt.« (1:02:01 - 1:03:22 h)

Diese äußerst detaillierte Schilderung vermag den Zuschauer im Unterschied zu 2.2.3 jedoch kaum zu berühren - Filip Müllers Gesamtgestus steht in krassem Gegensatz zum Inhalt seiner Aussagen. Während der gesamten Schilderung sitzt Müller in entspannter Haltung auf seinem Sofa, das rechte Bein beinahe lässig über das linke ge-

218. Lediglich beim letzen Satz lehnt er sich nach vorne, die Ellbogen auf die Knie gestützt.

219. Das mag damit zusammenhängen, daß sich Filip Müller vor der Befragung durch Lanzmann bereits in seinem Buch »Sonderbehandlung. 3 Jahre in den Krematorien und Gaskammern von Auschwitz« (1979) Zeugnis seiner Lagererfahrung abgelegt hatte und sich daher bereits eine gewisse Routine im Berichten eingeschlichen hat. Vgl. hierzu auch Levi: »[...] die häufige Vergegenwärtigung, hält die Erinnerung frisch und lebendig, genauso wie man einen Muskel leistungsfähig erhält, wenn man ihn oft trainiert; aber es ist ebenso wahr, daß eine Erinnerung, die allzuoft heraufbeschworen und in Form einer Erzählung dargeboten wird, dahin tendiert, zu einem Stereotyp, das heißt zu einer durch die Erfahrung getesteten Form, zu erstarren, abgelagert, perfektioniert und ausgeschmückt, die sich an die Stelle der ursprünglichen Erinnerung setzt und auf ihre Kosten gedeiht." (Levi 1990: 20)

220. Müller spricht zunächst von der Sinnlosigkeit, den Menschen im Krematorium die Wahrheit zu sagen, später von einem bestimmten, im Auskleideraum ankommenden Transport. 


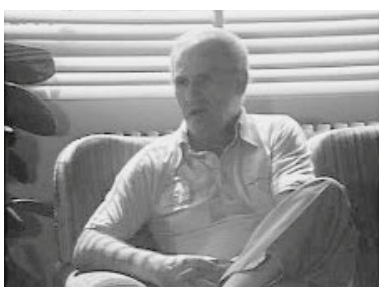

(202) $1: 02: 05 \mathrm{~h}$ (III)

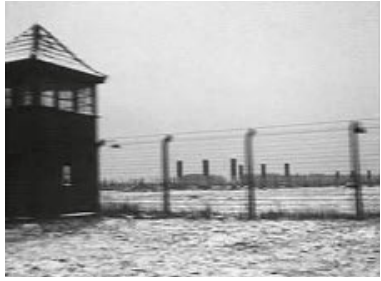

(204) $1: 06: 18 \mathrm{~h}$ (III)

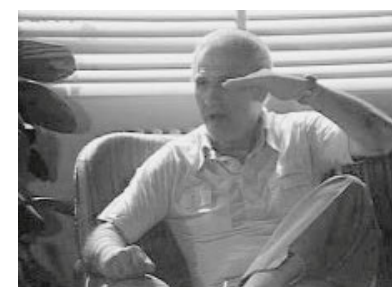

(203) $1: 02: 48 \mathrm{~h}$ (III)

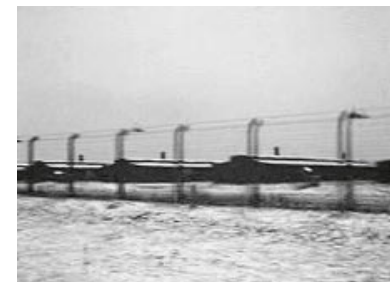

(205) $1: 06: 51 \mathrm{~h}$ (III)

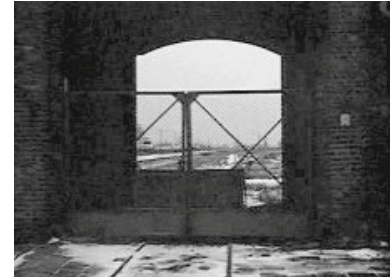

(206) $1: 07: 49 \mathrm{~h}$ (III)

schlagen. ${ }^{218}$ Zwei Auffälligkeiten in bezug auf seine Beschreibung des Todeskampfes haben regelrecht schizogene Auswirkung auf den Zuschauer: Zum einen der sanfte Tonfall, in dem er - wie er selbst sagt - »das Schwerste überhaupt« beschreibt, zum anderen sein distanzierter, beinahe wissenschaftlicher Diskurs. Er trägt systematisch vor (»zweitens«) und liefert gleichzeitig rückblickende Interpretationen (»psychologisch«, »Instinkt«). Wo Müller bei seinem letzten Auftritt (s. 2.2.3) völlig distanzlos und einem Erlebnisbericht gleich erzählt hatte, ist er hier nicht nur körperlich, sondern auch sprachlich »zurückgelehnt«: »man muß es so sehen«, »meines (Er-) achtens «, formuliert er nüchtern. ${ }^{219}$

Aus diesen Gründen bleiben die Opfer auch für den Zuschauer - wie Müller formuliert - »Steine«, der Zeuge vermag sie uns hier nicht näher zu bringen.

Nachdem Müller in den letzten eineinhalb Minuten dieser Einstellung den grauenvollen Zustand der Opfer nach ihrem Tod beschrieben hat, zoomt die Kamera an den im Sprechen innehaltenden Augenzeugen bis zur Nahaufnahme heran.

Die folgende Einstellung wird von einer sich in der Geschwindigkeit steigernden, insgesamt rasanten Kamerafahrt, von außen am verschneiten Lager AuschwitzBirkenau entlang dominiert (s. 1:06:18 und 1:06:51 h). Eineinhalb Minuten fängt die Kamera Wachtürme, Häftlingsblock und vor allem nicht enden wollenden Stacheldrahtzaun ein, bis sie vor dem verschlossenen Lagertor innehält (s. 1:07:49 h). Auf diese Weise wird dem Zuschauer ein erschreckender Eindruck von der Größe des Lagers und dem Ausmaß des Holocaust vermittelt. Der leicht verzögert einsetzende Text von Filip Müller, ohne Bezug zu den Bildern, kann erneut als eher störend empfunden werden. ${ }^{20}$ Es besteht einmal mehr keine Analogie zwischen auditiver und visueller Ebene, die eine synergetische Wechselwirkung hätte entfalten können. Vermutlich wäre das Ausmaß der Vernichtung für den Zuschauer noch stärker spürbar gewesen, wenn der unpassende Text ihn nicht abgelenkt hätte. 
In der nächsten Einstellung weicht die Kamera von eben diesem Tor langsam, beinahe eine Minute lang zurück (s. 1:07:58 h und 1:08:32 h), während Müller die Geschichte einer über ihr Schicksal in den Gaskammern informierten Jüdin weiter erzählt:

»Und sie is herumgelaufen und hat des erzählt den andern Frauen. Man wird uns [...], man wird uns vergasen. Die Müttern, die ihre Kinder auf 'n Schulter trag-, tun, die wollten des nicht hören und die haben geglaubt, daß diese Frau verrückt is. Sie haben sie abgeschlagen. Da hat sie sich gewandt auf die Männer und es hat nich genutzt. Nicht, daß sie des nicht geglaubt hätten. Sie haben schon vieles gehört in Wialostock, in dem Ghetto, Grotno und so. Aber wer wollte schon so was hören?« (1:07:57 - 1:08:50 h)

Auf den ersten Blick ist keine Verbindung zwischen Bild und Text erkennbar: Während der Überlebende von den Schwächsten unter den Opfern (Kinder und deren Mütter) spricht, zeigen die Aufnahmen Größe, Weite, Unendlichkeit. Trotz der fehlenden unmittelbaren Analogie zwischen visueller und auditiver Ebene ist auffällig, daß die Kamera sich hier vom Lagertor wegbewegt, während sie sich an mehreren anderen Stellen darauf zu bewegt, womit der Filmemacher u.U. das ungläubige Zurückweichen der Opfer in Bilder übersetzen wollte.

Filip Müllers Bericht vom Schicksal dieser Menschen wird auf der visuellen Ebene erneut durch einen Schwenk mit anschließendem Verweilen auf einer der Krematoriumsanlagen begleitet (s. 1:10:01 h). Als der Überlebende von sich selbst als Teil des »Sonderkommandos« erzählt, zeigt ihn Lanzmann durchgehend in einer Nahaufnahme und lenkt damit die Aufmerksamkeit des Zuschauers auf Müllers Mimik. Als dieser davon berichtet, daß sie sich im »Sonderkommando « Gedanken gemacht hätten, »wie man ... wie man überhaupt (s. 1:10:08 h) den Menschen das sagen ... konnte«, verrät das Zusammenspiel von Mimik und stockender Sprache, daß ihn diese Frage noch heute quält - Bild- und Tonspur steigern sich wechselseitig in ihrer Wirkung.

Nachdem Filip Müller ca. zweieinhalb Minuten lang die Frage erörtert hat, welche Opfergruppen vorgewarnt wurden und welche nicht, überrascht Lanzmann den Zuschauer erneut mit einem extremen Kontrast. Wie eine Postkartenansicht zeigt die folgende Einstellung ein beschauliches Städtchen am Meer (s. 1:12:54 h), und man fragt augenblicklich nach dem Zusammenhang zwischen dem auf der Leinwand Gezeigten und der Intention des Regisseurs. Nach längerem monotonem Motorengeräusch und der anschließenden Schrift-Einblendung »Korfu« wird die Vermutung zur Gewißheit. Müller hatte am Ende der Sequenz den Todeskampf und die Vernichtung von Juden aus Korfu erwähnt, die nach mehrtägigem Transport ausgezehrt in Auschwitz angekommen waren. In der kurzen Pause, in der passend zur Aufnahme das Motorengeräusch zu hören ist, kann sich der Zuschauer an das erste Auftreten von Abraham Bomba (Boote auf bewegtem Meer im Sonnenschein) erinnern und eine Annäherung an einen weiteren Zeugen antizipieren. Diese wohltuende Pause ist notwendig, damit wir uns auf den nächsten Augenzeugenbericht einlassen können.

221. Vgl. Avisar 1988: 27 und Heer 1998: 17. 


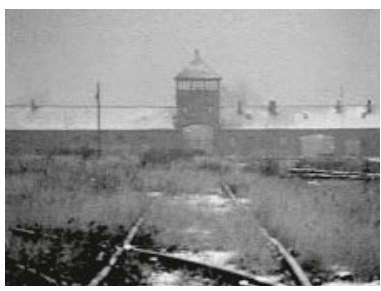

(207) $1: 07: 58 \mathrm{~h}$ (III)

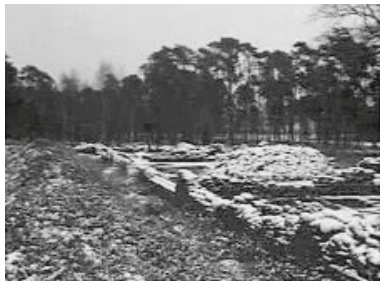

(209) $1: 10: 01 \mathrm{~h}$ (III)

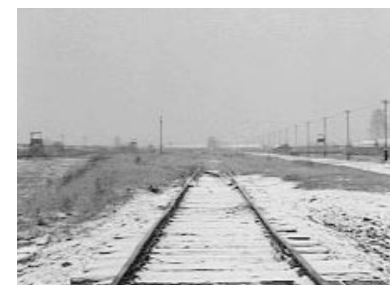

(208) $1: 08: 32 \mathrm{~h}$ (III)

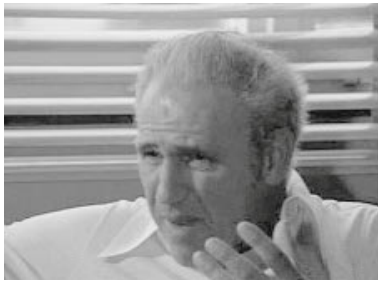

(210) $1: 10: 08 \mathrm{~h}$ (III)

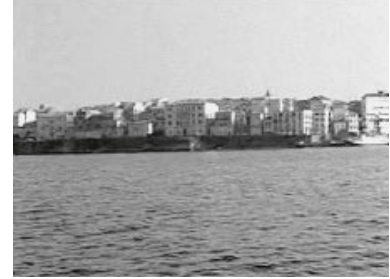

(211) $1: 12: 54 \mathrm{~h}$ (III)

\subsubsection{Kontraproduktive Indiskretion - Lanzmanns Kampf mit Abraham Bomba}

Lanzmanns Interview mit dem Friseur und Überlebenden von Treblinka, Abraham Bomba, in einem Friseursalon in Tel Aviv ist ebenfalls eine Schlüsselszene des gesamten Films. ${ }^{21}$ Neben dem auffälligen Arrangement des Interviewsettings läßt sich an dieser zentralen Sequenz mit Abraham Bomba vor allem die Umstrittenheit von Lanzmanns unerbittlicher Interviewmethode sowie seiner indiskreten Kameraführung besonders deutlich aufzeigen.

Zusammen mit der Eröffnungssequenz (s. 2.2.6) und zwei weiteren Szenen mit Simon Srebnik handelt es sich um die einzige Szene mit Opfern, in welchen Lanzmann das Interviewsetting bewußt arrangiert. In dieser Sequenz geht Lanzmann jedoch einen Schritt weiter. Er läßt den ehemaligen Friseur in den Gaskammern von Treblinka in einem Tel Aviver Friseursalon erneut Haare schneiden.

»Ça, c'est une scène de cinéma. Parce qu'en réalité, il n'était plus coiffeur: il était retraité. J'ai loué un salon de coiffure et je lui ai dit: >0n va tourner là. [ [...] Je savais que ce serait difficile et je voulais le replacer dans une situation de sgestes` identiques. (Lanzmann 1990: 298, H.i.0.)

Die künstlichen Situationen sollen das Wiederdurch- und -erleben ermöglichen, so Lanzmann:

»Das sind derart grausame und fürchterliche Erfahrungen, die die Menschen so tief geprägt haben, daß man sie wieder in einem Zusammenhang stellen mußte, der diesen Akt des Gebärens, der Auferstehung möglich machte.« (Lanzmann zit.n. Müller 1991: 40)

»[...] der Friseur hätte ohne die Inszenierung in einem Friseurladen weder sprechen, noch weinen können. Nur dort spürt man das Siegel, den Authentizitätsstempel der Wahrheit, der so wertvoll ist, wie das Blut.« (Lanzmann 1998: 16) 
Verschiedene Rezensenten übernehmen Lanzmanns Auffassung bzw. begrüßen sein »Konzept der spielenden Verkörperung seiner selbst« (Kramer 1999: 40) ${ }^{222}$ :

»Sie [diese Szene] dokumentiert [...] vor allem eine notwendige Inszenierung: >den Prozeß der Anamnese als Maschinerie, die unter experimentellen Bedingungen in Gang gesetzt wird, damit das Erinnerte sich befreien und Sprache werden kann.« (Zit.n. Heller 1999)

»Lanzmann [...] vertritt die Auffassung, daß die Personen in seinem Film spielen: sie spielen nach, was sie durchlebt haben, le vécu. Das meint jedoch etwas anderes als sich erinnern.» (Koch 1992: 148)

»Konfrontiert mit den traumatisierten Überlebenden übernimmt er auf andere Weise Verantwortung, er greift aktiv in ihre Leidenswirklichkeit ein, indem er mit Hilfe des Films bewußt Situationen erzeugt, die den Traumatisierten eine Möglichkeit eröffnen, das Erlebte zu artikulieren.« (Kramer 1999: 62f.)

Erinnerung an eine grauenhafte Vergangenheit erfordert jedoch im Allgemeinen eine eigene, freie Rückwendung - ohne Zwang. Daß Lanzmanns Arrangement des Interviews ein tatsächliches Wiederdurch- bzw. -erleben der grauenhaften Vergangenheit ermöglicht, ist daher äußert fraglich. Es kann auf den Zuschauer eine durchaus kontraproduktive Wirkung haben: Denn zum einen handelt es sich bei dem Friseursalon in Tel Aviv um eine gewöhnliche Situation des Haareschneidens, die mit dem Scheren der Frauen in den Gaskammern, seiner damaligen Aufgabe in Treblinka, wenig gemeinsam hat. Es ist auch nicht davon auszugehen, daß die bloße Tätigkeit des Haareschneidens Abraham Bomba in die damalige Situation im Lager zu versetzen vermag. Schon das Drehen im Friseursalon kann als geschmack- und stillos, als eine Zumutung für den Überlebenden wahrgenommen werden. Zum anderen ist es therapeutisch äußerst fragwürdig, jemanden vor laufender Kamera dazu bewegen zu wollen, seine Erzählbarriere zu überwinden und seine traumatischen Erlebnisse zu schildern.

Hinzu kommt, daß Lanzmann auf der Beantwortung seiner Fragen beharrt und sogar zum Weitersprechen drängt, auch wenn der Überlebende ganz offensichtlich nicht antworten möchte und sogar mehrfach den Abbruch des Interviews erbittet. ${ }^{223}$

222. »Lanzmann knüpft mit dem Konzept der spielenden Verkörperung seiner selbst an antifreudianische Thesen Sartres an.« (Kramer 1999: 40)

223. »[...] die Erinnerung an ein Trauma, ob es nun erlitten oder zugefügt wurde, ist an sich schon traumatisch, denn es schmerzt oder stört zumindest, wenn man es ins Gedächtnis zurückholt. Wer tief verletzt worden ist, neigt dazu, die Erinnerung daran zu verdrängen, um den Schmerz nicht zu erneuern; und derjenige, der diese Verletzung zugefügt hat, drängt seine Erinnerung in die Tiefe ab, um sich von ihr zu befreien, um sein Schuldgefühl zu beschwichtigen.«(Levi 1990: 20)

224. Dies stellt einen zentralen Unterschied zu Eberhard Fechners Majdanek-Dokumentation DER PROZESS (BRD 1975/81) dar: »Wo Fechner ihre Emotionalität im Film nicht zeigen möchte, stellt Lanzmann genau auf diese ab [...]. Fechner möchte die interviewten Überlebenden nicht bloßstellen, für Lanzmann artikulieren gerade solche Körperregungen das unaussprechliche Fortleben des Ereignisses.« (Lanzmann zit.n. Kramer 1999: 62)

225. Vgl. Deuleuze 1997 zum »Affektbild«. 
Angesichts dieses Insistierens wird es dem Zuschauer wohl wie zahlreichen Kritikern gehen, die geradezu aggressiv reagieren:

»[...] on voit Lanzmann insister, comme un bourreau bienveillant, et qu'on est pris alors de l'envie soudaine de bondir >et de lui donner une gifle.« (Murat zit.n. Ophuls 1990: 182)

»Da möchte man sie [die Zeugen] nur stumm in die Arme nehmen und vor dem lästigen Frager schützen.« (Buchka zit.n. Thiele 2001: 406)

»Lanzmann wollte mit dieser Szene erreichen, daß sich der Schmerz auf den Zuschauer überträgt. Aber er machte das Experiment auf Kosten eines überlebenden Opfers und begriff nicht, daß ein solcher Schmerz nicht von Menschen nachempfunden werden kann, die nie in einer ähnlichen Situation waren.« (Leiser 1996: 97f.)

»Das mag man bei der Befragung der Täter angesichts ihrer Ignoranz und gespielten Unschuld nicht unangemessen finden, geschweige denn anstößig. Gegenüber den traumatisierten Opfern erscheint dies unerbittlich, bisweilen unbarmherzig.« (Reichel 2004: 293)

Andere wiederum nehmen eine abwägende Haltung ein:

»Sein [Lanzmanns] Drängen auf die Aussage Bombas kann kritisch gewertet werden, weil das Wiederholen der schmerzhaften Situation neuen Schmerz mit sich bringt, ohne daß ein therapeutischer Erfolg absehbar wäre. Doch der Filmemacher signalisiert Bomba durch sein Vorgehen zugleich, daß die Erfahrung der Überlebenden nicht aus dem gesellschaftlichen Diskurs ausgeschlossen werden dürfe. Er macht sich nicht zum Instrument einer erneuten Isolierung der Überlebenden, sondern er geht auf sie zu. Er kämpft um jedes einzelne Zeugnis.« (Kramer 1999: 62)

Manche Rezensenten hingegen schließen sich dem Regisseur an und verteidigen seine Interviewmethode:

»Aber erst die Qual, die wir - als Zuschauer - angesichts dieser extremen Situation verspüren, vermittelt eine Ahnung vom Ausmaß des Grauens, das sich hinter ihr verbirgt.« (Heller 1999)

»Was der Interviewer v.a. vermeidet, ist eine Komplizenschaft mit dem Schweigen des Zeugen, eine Art mitfühlender und wohlwollender Allianz, in der Fragende und Befragte oft implizit übereinstimmen und zusammenarbeiten, um sich in der Vermeidung der Wahrheit gegenseitig Trost zu geben. Es ist die Todesstille des Zeugen, die Lanzmann hier historisch anfechten muß, um den Holocaust wiederzubeleben und um das >Ereignis-ohne-Zeugen ins Bezeugen, in Geschichte umzuschreiben [...] Lanzmann drängt Bomba, aus eben der Leblosigkeit auszubrechen, die das Überleben erst ermöglichte. Der Erzähler ruft den Zeugen auf, aus dem bloßen Modus des Überlebens zurückzukehren in den des Lebens - und des lebendigen Schmerzes. « (Felman 2000: 191, H.i.0.)

Lanzmanns verbale »Taktlosigkeit« findet ihre filmische Entsprechung im indiskreten Heranzoomen an den Überlebenden, sobald dieser Zeichen der Ergriffenheit erkennen läßt. ${ }^{224}$

Statt den Blick abwenden zu können, zwingt Lanzmann den Zuschauer, dem ohnehin schon gezeichneten und in diesen Momenten ergriffenen Abraham Bomba indiskret ins Gesicht zu blicken. ${ }^{225}$ 
$\mathrm{Ob}$ mit der Kameraführung angesichts erneut leidender Versehrter tatsächlich des Zuschauers »Lust am Erschauern« (Kramer zit.n. Reichel 2004: 313) geweckt bzw. gestillt wird oder gar SноАнs größter Verdienst erreicht wurde ${ }^{226}$, sei daher stark bezweifelt. Wenn die effekthascherische Kamera und deren unablässiger Blick mit Lanzmanns Drängen auf Weitersprechen einhergehen, wird sich die kontraproduktive Auswirkung auf das Publikum eher noch verstärken. Anstatt das Draufhalten und Heranzoomen der Kamera als ein positives Angebot zum Erfahren der Gegenwart der Vergangenheit wahrzunehmen, kann es das Publikum gar als unverschämt und als unerträgliche Quälerei der Überlebenden empfinden - schließlich handelt es sich um Menschen, die nicht erneut zum Opfer werden sollen. ${ }^{227}$ Es handelt sich daher gerade nicht um eine poetische Form der Inszenierung - »[...] cette mise en scène est le procès poétique du cinéma, c'est-à-dire la création d'une figure de l'impossible à représenter à partir de laquelle la vérité du témoignage va pouvoir s'incarner« (Brun 2003: 201) -, sondern um einen »Kampf « zwischen Lanzmann und dem Überlebenden: »Der Kampf währt quälende Minuten, während die Kamera unausgesetzt das Gesicht des Friseurs beobachtet, sein Leiden rückhaltlos gestisch und mimisch ausstellt.« (Heller 1999)

Dem wiederholt erhobenen Vorwurf, Interviewtechnik und filmische Aufnahme, insbesondere die insistierenden Großaufnahmen, würden Abraham Bomba »auch ein Stück weit vergewaltigen« (Lerch zit.n. Müller 1991: 149), entgegnet Claude Lanzmann in wenig überzeugender Weise:

»Es war eine brüderliche Zusammenarbeit. Und ich sagte ihm: Ich weiß, daß es hart ist. Ich entschuldige mich. Aber Du mußt es tun. Wir müssen es tun. Wir sind zusammen. Und schließlich hat er die Kraft dazu gefunden und im nachhinein war er mir sehr dankbar dafür.» (Lanzmann zit.n. Heller 1999)

Insbesondere Sven Kramer hütet sich vor vorschnellem Urteilen in bezug auf die Inszenierung des Opfers:

»0bwohl Lanzmann, der an Bomba heranzoomt, wenn bei diesem Tränen aufsteigen, ebenfalls Authentizitätssignale einsetzt, so ereignet sich in diesem Moment etwas, das nicht in der effekthascherischen Geste des Zooms aufgeht.« (Kramer 1999: 40)

226. »Das heißt, die Ohnmacht, das Nicht-sagen-Können, das Nicht-aussprechen-Können wird zum Bild in diesem Film. Und das ist eine der bedeutenden ästhetischen Leistungen, die der Film vollbracht hat. [...] Das ist eine Qualität, die [...] letztlich nur beschrieben werden kann als Erschütterung oder als Innewerden eines Unfaßbaren.« (Kreimeier 1998: 29)

227. »Das mag man bei der Befragung der Täter angesichts ihrer Ignoranz und gespielten Unschuld nicht unangemessen finden, geschweige denn anstößig. Gegenüber den traumatisierten Opfern erscheint dies unerbittlich, bisweilen unbarmherzig.« (Reichel 2004: 293)

228. Die durchschnittliche Dauer der anderen Szenen mit dem ehemaligen Friseur beträgt zwischen zwei und drei Minuten.

229. Im übrigen ist diese Sequenz gewissermaßen in die Filmgeschichte eingegangen (vgl. Avisar 1988: 27 und Heer 1998: 17). 
»Die authentische Dimension von Bombas Schweigen kann mit Klaus Briegleb Unmittelbarkeit im Diskursbruch genannt werden. [...] wird die Grenze immer dort erreicht, wo sich das dem Diskurs Inkommensurable artikuliert.« (Ebd. 41)

»Authentisch in diesem Sinne wäre also nicht die historisch korrekte Inszenierung des Vergangenen, sondern die Vergegenwärtigung der im Verborgenen weiterwirkenden Erschütterung. [...] Geht Authentizität, mit anderen Worten, in Authentisierungsstrategien auf oder zeigt sie sich in jener Weise, die Lanzmann emphatisch Wahrheit nennt? Verabsolutiert werden beide Alternativen falsch. Gegenüber der ersten wäre darauf zu beharren, daß trotz des Zooms, trotz der ostentativen Kamerageste, mit Bombas Verhalten etwas Vorfilmisches in den Film geholt wird, das den Effekt des schockhaft Erlebten physiognomisch und gestisch übermittelt. Gegenüber der zweiten Alternative wäre anzumerken, daß dies keineswegs mit reiner Unmittelbarkeit zusammenfällt oder daß sich hier Wahrheit ssans phrase zeigte. [...] Zu verteidigen wäre also die Intention auf das Authentische als heuristische Unterstellung einer Lektüre, die sich auf das Inkommensurable richtet.« (Ebd. 42, H.i.0.)

Verglichen mit Filip Müllers ergreifendem Weinen (s. 2.2.3) sind Bombas Tränen für den Zuschauer kaum ansteckend, da dieser Moment vom Kampf zwischen Lanzmann und dem Zeugen dominiert wird. »Die Tränen sind der Einbruch der Wahrheit, der Einbruch des Wahren« (Lanzmann zit.n. Kramer 1999: 40), kommentiert der Regisseur die Tränen Bombas. Wie dem auch sei: Der ehemalige Friseur wird in dem Moment von der grauenhaften Vergangenheit eingeholt, als er von ihm nahestehenden Personen und nicht mehr von einer anonymen Masse spricht. Daß sein Zusammenbruch, wie Claude Lanzmann und Gertrud Koch glauben, vor allem vom Nachspielen des Haareschneidens herrührt, sei daher stark bezweifelt.

Da Bombas innerer Kampf für Lanzmann mimisch so »attraktiv« ist, stellen diese 18 Filmminuten eine der seltenen Sequenzen von Sнон dar, die nur wenige Einstellungswechsel aufweisen und keine Verbannung des Augenzeugenberichts ins Off erfahren - Bomba ist schließlich kein - für konventionelle Dokumentarfilme charakteristischer - »talking head« (Ophuls zit.n. Colombat 1993: 328).

Zum Ausdruck kommt in dieser Szenenfolge in der Tat, »wie die gesamte Last der Vergangenheit wirkt « (Heer 1998: 17), wie qualvoll die Wunden der Vergangenheit in der Gegenwart wieder aufreißen können - die Traumatisierung ist keineswegs überwunden. Insofern hat Lanzmann Recht, wenn er im Zusammenhang mit seinen jüdischen Augenzeugen von »Rückgekehrten« (Lanzmann 1998: 15), nicht von Überlebenden, spricht.

Abschließend sei darauf hingewiesen, daß diese Sequenz mit Abstand die längste (ca. 18 Minuten) ${ }^{228}$ sowie die letzte der insgesamt neun Filmszenen mit Bomba darstellt, ein deutliches Indiz dafür, daß es sich nicht nur um die wichtigste Sequenz mit dem Überlebenden, sondern um einen der Höhepunkte des gesamten Films handelt. ${ }^{229}$

\section{Detaillierte Sequenzanalyse:}

Nachdem Bomba in den ersten eher kurzen Sequenzen ausnahmslos auf einer Terrasse vor der sommerlichen Kulisse von Tel Aviv und dem tiefblauen Mittelmeer aufgenom- 
men wurde, konfrontiert Lanzmann den Zuschauer hier zunächst mit einem neuen, inszenierten Setting des Interviews: Die erste Einstellung dieser Sequenz zeigt den Zeugen als Friseur in einem gut besuchten Friseursalon (s. o:17: 41 h). Fast eine Minute läßt uns Lanzmann mit dem konzentriert die Haare eines Kunden schneidenden und schweigenden Überlebenden alleine, bis er ihm schließlich auf Englisch zwei Fragen stellt, die das deutsche Publikum in den Untertiteln verfolgen kann. ${ }^{231}$ Während dieser Szene meidet Bomba eindeutig den Blickkontakt mit Lanzmann (s. 0:18:34 h) ${ }^{232}$, wohingegen er das Kommen und Gehen von Kunden durchaus registriert. Zum Teil wirkt es gar so, als drehe er der Kamera bewußt den Rücken zu, woraufhin diese ihn listig über die große Spiegelwand filmt (s. erneut o:17:41 h).

Vergleichbar mit seinem Antwortgestus aus den vorangegangenen Sequenzen - vielleicht noch deutlicher - ist Bombas Bericht über seine damalige Friseurstätigkeit »detailliert und von einer emotionslosen Sachlichkeit, seine Stimme fest, monoton und laut« (Heller 1999):

»Mit seiner schrecklichen Stimme redet Abraham Bomba vom Haareschneiden in Treblinka, und man mag es nicht hören, weil diese Stimme so schrecklich klingt.« (Hanika 19.01.2002: BS 6)

»Au début, il a une sorte de discours neutre et plat. Il transmet des choses, mais il les transmet mal. D'abord parce que ça lui fait mal à lui, et parce qu'il ne transmet qu'un savoir. Il échappe à mes questions.« (Lanzmann 1990: 297)

»At the beginning, Bomba speaks very loudly [...]. Such a tone of voice also reminds us of a child that would start talking very loudly because he is terrified by silence or the dark.« (Colombat 1993: 337)

Mit der Dauer der Schilderungen löst sich sein Blick immer wieder vom Kunden und verliert sich im Unbestimmten - Indiz dafür, daß er zunehmend von der Vergangenheit eingeholt wird. Im Unterschied zur halbnahen Einstellungsgröße zu Beginn der Sequenz, wird dies in einer Großaufnahme dokumentiert, d.h. unsere Aufmerksamkeit wird gezielt auf Bombas Mimik und Blick gelenkt.

Nachdem Lanzmann in bezug auf die Beschreibung der letzten Minuten vor der Ermordung insistiert hat - »Can you describe precisely? « (o:23:44 h) -, wird der Augenzeuge bei seiner folgenden Antwort zum ersten Mal unsicher, während er zuvor recht flüssig berichtet hatte: »Precisely to describe is when the transport came in, waiting there until the transport came in, the transport came in ... women with children ... and pushing in to that place ... where the barbers started to cut the hair $[. ..] \ll$ (0:23:49-0:24:02 h).

$\mathrm{Ab}$ diesem Moment stellt der Regisseur verstärkt und äußerst detaillierte Zwischenfragen, womit er ein Ablenken vermeiden und Bomba in die damalige Situation

230. "III« zeigt an, daß die Sequenz im dritten Viertel des Films anzutreffen ist und bei der Zeitangabe des Standbilds von Beginn dieses dritten Viertels an gezählt wurde.

231. Gleiches gilt für Bombas Antworten in englischer Sprache.

232. »[...] in order to avoid any eye to eye or emotional contact.« (Colombat 1993: 337)

233. Vgl. Torner zur »voix rompue d'Abraham Bomba« (2001: 156ff.). 


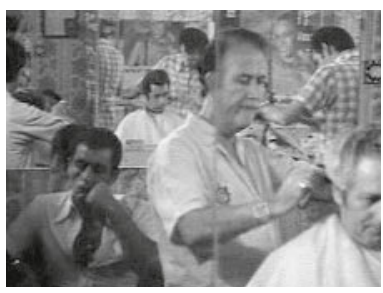

(212) $0: 17: 41 \mathrm{~h}(\text { III })^{230}$

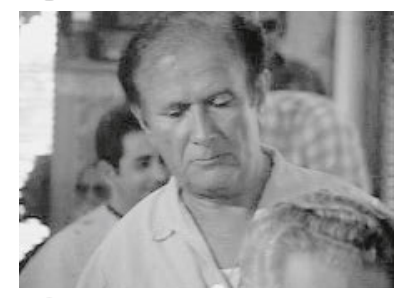

(215) $0: 29: 59 \mathrm{~h}$ (III)

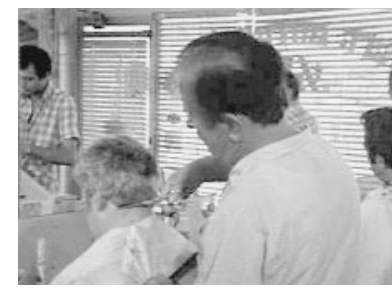

(213) $0: 18: 34 \mathrm{~h}$ (III)

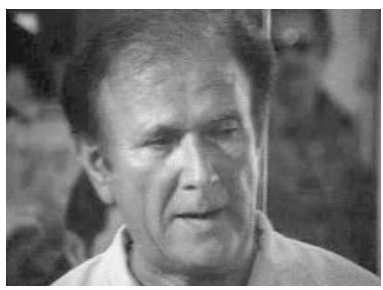

(216) $0: 30: 24 \mathrm{~h}$ (III)

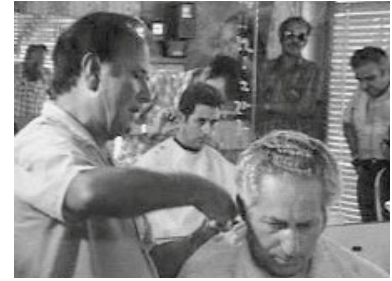

(217) $0: 31: 02 \mathrm{~h}$ (III)

versetzen will. Nachdem Bomba auffällig ausweichend geantwortet hat, fragt ihn Lanzmann explizit nach seinem Gefühl, als er Frauen und Kinder das erste Mal nackt in die Gaskammern kommen sah; einmal mehr geht der Zeuge nicht wirklich auf die Frage ein. Es sei in diesem Zusammenhang jedoch bezweifelt, ob die typische JournalistenFrage nach den Emotionen geeignet ist, tatsächlich etwas darüber zu erfahren.

Seinem theoretischen Konzept - der Verkörperung seiner selbst im Spiel - folgend, fordert Lanzmann den Zeugen dazu auf, die Art und Weise des damaligen Haareschneidens nachzuahmen. Obgleich von Lanzmann nicht sonderlich einfühlsam vorgetragen, kommt Bomba der Aufforderung nach. Der Regisseur betrachtet diesen Moment als entscheidenden Wendepunkt des Interviews:

»Ça devient intéressant au moment où, dans la seconde partie de l'interview, il répète la même chose, mais autrement, lorsque je le remets dans la situation en lui disant: >Comment faisiezvous? Imitez les gestes que vous faisiezı. Il attrape les cheveux de son client (qu'il aurait tondu depuis longtemps s'il lui avait vraiment coupé les cheveux puisque la scène dure vingt minutes!). Et c'est à partir de ce moment que la vérité s'incarne et qu'il revit la scène, que soudain le savoir devient incarné. C'est un film sur l'incarnation en vérité.« (Lanzmann 1990: 298, H.i.0.)

Erneut stellt Lanzmann die Frage nach Bombas Empfindung beim Anblick der entblößten Frauen und Kinder und erfährt: »I tell you something. To have a feeling over there, it was very hard to feel anything or to have a feeling [...] your feeling disappeared, you were dead with your feeling, you had no feeling at all« (0:29:58 - o:30:12 h; s. o:29:59 h). Als der Überlebende mit den Worten »And matter of fact, I wanna tell you something that had happened « (0:30:21 h) von sich aus fortfährt, zoomt die Kamera effekthascherisch noch näher an den Protagonisten heran, um dessen Regungen in einer Großaufnahme einzufangen (s. 0:30:24 h).

Als Bomba von einem Transport aus seiner Heimatstadt erzählt, versagt ihm plötzlich die Stimme ${ }^{233}$, er hält mitten im Satz inne - in diesem Augenblick wird die Ver- 
gangenheit aufgrund direkter persönlicher Betroffenheit in ihm lebendig: »A friend of mine, he worked as a barber, he was also a good barber in my home town. When his wife and his sister ... came in to the gas chamber ...«(o:30:5 - o:31:04 h; 0:31:02 h). Über eine Minute herrscht quälende Stille, während die Kamera unmittelbar nach seinem Verstummen an ihn heranzoomt (extreme Großaufnahme). So kann der Zuschauer beobachten, wie sich der wiederholt auf die Lippe beißt bzw. diese zusammenpreßt (s. o:31:11 h), sein Gesicht zwischendurch in einem Handtuch vergräbt, jeglichen Blickkontakt mit Lanzmann vermeidet und diesem sowie der Kamera schließlich demonstrativ den Rücken zukehrt (s. o:31:37 h) - nonverbale Signale dafür, daß er nicht weiter befragt werden möchte.

Nachdem er sich in einer Übersprungshandlung an der Nase gekratzt und in der Folge tief Luft geholt hat, widmet er sich mit künstlich wirkender Konzentration seiner Friseurstätigkeit, bis der Regisseur ihn schließlich wiederholt aus dem Off auffordert, weiterzusprechen. Er soll seinen Bericht fortsetzen, während die Kamera weiterhin hartnäckig und penetrant auf ihm verharrt: ${ }^{234}$

L.: $\quad$ (Go on, Abe, you must go. You have to.«

B.: [schüttelt gedankenverloren den Kopf] »Cannot. It's too hard ...«

L.: $\quad$ Please. We have to do it, you know it.«

B.: [schüttelt erneut den Kopf] »I won't be able to do it.«

L.: »You, you have to do it. I know it's very hard. I know and I apologize.« (s. 0:32:55 h und 0:33:03 h: Bomba beißt sich wiederum auf die Lippen und trocknet sich die offensichtlich tränenden Augen)

234. »Ces passages [...] restituent au spectateur épouvanté la réalité palpable et absolue d'une douleur éprouvée au présent. « (Lowy 2001: 129) Ob der Zuschauer hierzu angesichts der Konzentration auf den inneren Kampf des Zeugen Zeit hat, darf bezweifelt werden. Vgl. auch Colombat 1993: 337.

235. »[...] Bomba [...] demande à Lanzmann d'interrompre l'interview. Il le fait au terme d'un silence de plusieurs minutes, qui paraît interminable au spectateur, au sens propre du mot: ce silence exprime un deuil infini, inabordable.« (Lowy 2001: 128)

236. „Et, malgré la douleur et les larmes, malgré l'insupportable à revivre, Bomba poursuit.» (Brun 2003: 197)

»[...] schließlich spricht Abraham Bomba doch weiter, und plötzlich hat er eine ganz andere Stimme, eine weiche, die ganz anders weh tut, weil sie eine gebrochene ist. Das war wichtig. Weil man dabei die Verheerung begreift, die die Schoa bedeutet.« (Hanika 19.01.2002: BS 6) Zum einen ist »weich« nicht die adäquate Beschreibung seiner Stimme, zum anderen sei bezweifelt, daß es wirklich wichtig bzw. nötig war, den Zeugen ızu brechen<, um die »Verheerung« zu begreifen.

237. "Ce qu'il dira lorsqu'il pourra reprendre la parole semblera presque anodin à coté de ce trou sans mots dont nous ne pourrons jamais sonder la profondeur.« (Dayan-Rosenman 1990: 188)

238. Eine Kombination der häufigsten und der zweithäufigsten Bild-Ton-Anordnungen.

239. »Les mouvements panoramiques, aussi, tiennent dans SHOAH une place essentielle. Avec les panoramiques, nous sommes découvreurs d'espaces qui se taisent. [...] mouvements du non-savoir, du regard inutile, de la recherche vaine. [...] Rien ne se donne à voir.« (Cuau 1990: 15) »[...] il va utiliser de manière disproportionnée par rapport à un autre film les ressources de l'interview, du travelling, du panoramique circulaire, du plan-séquence.» (Lowy 2001: 148) 


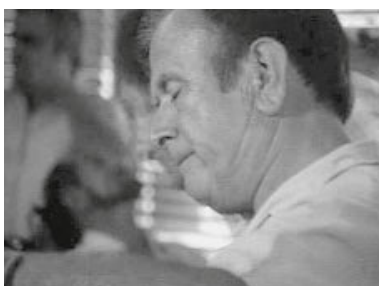

(218) $0: 31: 11 \mathrm{~h}$ (III)

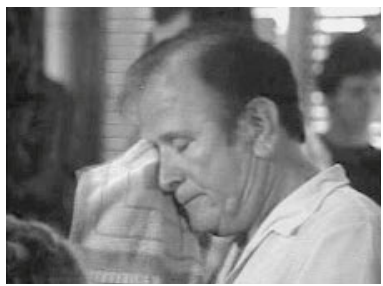

(221) $0: 33: 03 \mathrm{~h}$ (III)

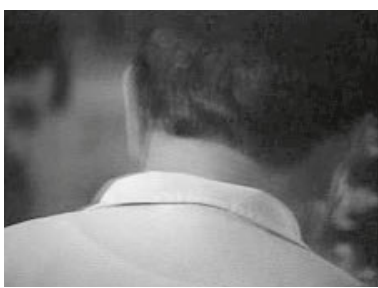

(219) $0: 31: 37 \mathrm{~h}$ (III)

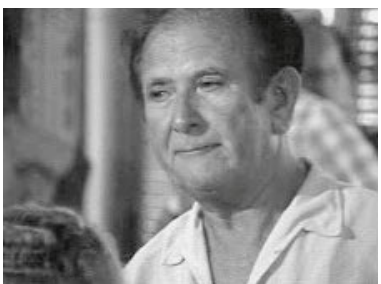

(222) $0: 33: 20 \mathrm{~h}$ (III)

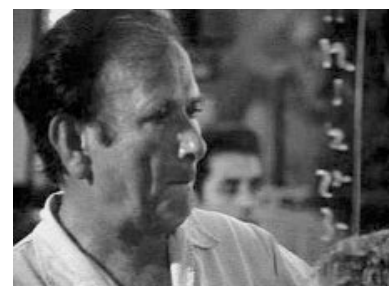

(220) $0: 32: 55 \mathrm{~h}$ (III)

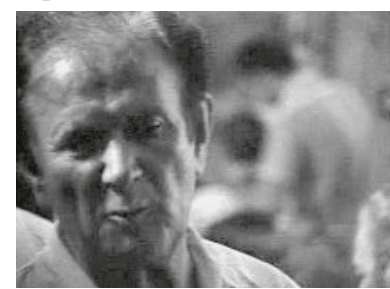

(223) $0: 33: 53 \mathrm{~h}$ (III)

B.: »Don't $[. .$.$] me along with that, please ...«(s. 0:33:20 h) )^{235}$

L.: »Please, you must go on. [...] Yes would be the answer when his wife or the sister came?« (0:32:09 - 0:34:34 h; s. 0:33:53 h)

Mit größter Mühe knüpft Bomba unvermittelt an zuvor Berichtetes an, jedoch mit weitaus leiserer und weniger fester Stimme: »It was taken in with bags and it was transported to Germany« (o:34:53 h). Nachdem er zwei unverständliche Sätze beiseite gesprochen hat, gewährt er Lanzmann etwas gefaßter die Fortführung des Interviews: ${ }^{236} » O k a y$, go ahead « (0:35:19 h). Die Fortsetzung vermittelt jedoch den Eindruck der Resignation und nicht einer positiven Bereitschaft. Auf dem Zuschauer lastet das Erleben des »Kampfes « zwischen den Interviewpartnern und die Phase des unerträglichen Schweigens, so daß er den weiteren Schilderungen vermutlich nur bedingt Aufmerksamkeit zu schenken vermag. ${ }^{237}$

\subsubsection{Erschütternde Beschaulichkeit -}

Simon Srebniks Rückkehr an die einstigen Orte des Schreckens

Den Überlebenden der zweiten Vernichtungsphase von Chelmno, Simon Srebnik, begleitet der Regisseur bei seiner Rückkehr an die einstigen Schreckensorte und interviewt ihn vor Ort. Im Vordergrund steht hierbei die Konfrontation des Zeugen mit einer Lichtung in der Nähe von Chelmno (Polen), auf der er als 13-jähriger bei Leichenverbrennungen helfen mußte.

Anhand dieser Eröffnungssequenz von Sнонн kann dieses insgesamt am dritthäufigsten eingesetzte Bild-Ton-Verhältnis beschrieben werden. ${ }^{238}$ Vergleichbar mit dem häufigsten audiovisuellen Gestaltungsmuster versucht Lanzmanns Kamera durch nahe Einstellungsgrößen, den Zuschauer auch in diesem Fall auf die mimischen Dramen aufmerksam zu machen und ihn so die Erschütterung von Simon Srebnik angesichts der beschaulichen Landschaft mitspüren zu lassen. Mit der zweithäufigsten Bild-TonKombination ist diesem gemeinsam, daß der Zuschauer - parallel zum Überlebenden - mit den friedlichen Landschaftsbildern konfrontiert wird, welche durch Schwenks, Fahrten und zum Teil sogar subjektive Kamera filmisch inszeniert werden. ${ }^{239}$ Nur be- 
dingt vermag die Konfrontation mit den heutigen Orten jedoch die Vergangenheit von Simon Srebnik aufleben zu lassen. Wenn jedoch nicht einmal ein unmittelbar Betroffener die einstigen Vernichtungsstätten zu erkennen vermag, wie sollen die Aufnahmen davon dann für den Zuschauer lebendig werden? Lehren uns die Kameraschwenks tatsächlich das Sehen? ${ }^{240}$

Simon Srebnik ist im übrigen der einzige von fünf Hauptzeugen, mit dem Lanzmann an den einstigen Ort des Schreckens zurückkehrt. Dessen ersten Auftritt leitet er mit einem Prolog ein und läßt ihn zumindest in dieser Eröffnungssequenz von polnischen Zeitzeugen einführen. ${ }^{241}$ Neben dem Opfer des Nationalsozialismus kommen in dieser Sequenz auch sogenannte »bystander« vor, unbeteiligte polnische Augenzeugen.

Lanzmann hat hier die Rückkehr eines Überlebenden an die einstigen Vernichtungsstätten und dessen Umgang damit dokumentiert, ein Verfahren, das Marceline Loridan-Ivens in BIRKENAU UND ROSENFELD aufgreift und weiterentwickelt (s. II.2.5). ${ }^{242}$

\section{Detaillierte Sequenzanalyse:}

Der Prolog der Eingangssequenz liefert historische Informationen zu Chelmno und den beiden Überlebenden von Chelmno, insbesondere zu Simon Srebnik, dem Protagonisten dieser Szenenfolge: »L'action commence de nos jours à Chelmno-sur-Ner, Pologne. [...] Chelmno fut [...] le site de la première extermination de Juifs par le gaz. Elle débuta le 7 décembre $1941 . \ll^{243}$

240. »Donner à voir ces endroits, c'est le sens des lents travellings latéraux de Resnais, c'est aussi celui des interminables panoramiques à 180 degrés qui ponctuent SHOAH. (Lowy 2001: 172)

241. Im weiteren Verlauf des Films wird er ihn sogar mit den polnischen Einwohnern von Chelmno zusammenbringen, eine Vorgehensweise, die Lanzmann nur in bezug auf Simon Srebnik anwendet.

242. In der Dokumentation SkLAVen der Gaskammer von Eric Fiedler (D 2001) wird dieses Verfahren in enger Anlehnung an SHOAH eingesetzt.

243. »The word raction< insists on the fact that this is a film, not a documentary.« (Colombat 1993: 311, H.i.0.)

»Diese Einleitung, die der Filmemacher selbst erzählt, versetzt die Geschichte in die Gegenwart und faßt eine Vergangenheit zusammen, die noch nicht als Geschichte präsent ist, sondern eher als Vorgeschichte.« (Felman 2000: 189)

244. "I« zeigt an, daß die Sequenz im ersten Viertel des Films anzutreffen ist und bei der Zeitangabe des Standbilds von Beginn dieses ersten Viertels an gezählt wurde.

245. "La violence absolue du film vient de ce qu'il déjoue, dès les premières secondes, toutes les attentes. [...] un silence de mort." (Cuau 1990: 14) »Le premier plan est d'une grande douceur [...].« (Ebd. 16) »Mais nous sommes les spectateurs horrifiés d'un remake terrible. [...] Dans le même paysage, derrière le même rideau d'arbres, nous voyons passer sur la même barque un enfant juif enchaîné et deux soldats nazis.« (Ebd. 17)

246. Vgl. Thiele 2001: 393, auch Lowy 2001: 118f. "La chanson de Srebnik sur la Ner, fantomatique et réelle à la fois, comme l'homme qui la chante, comme la barque qui la porte, témoignant de cette nouvelle mesure du temps à laquelle nous sommes confrontés: ni Passé, ni Présent.« (Dayan-Rosenman 1990: 189) 


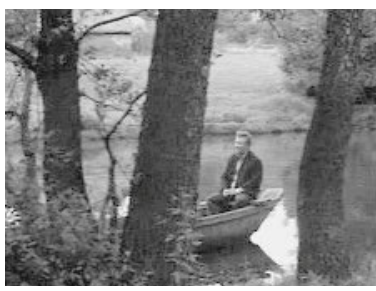

(224) $0: 03: 09 \mathrm{~h}(\mathrm{I})^{244}$

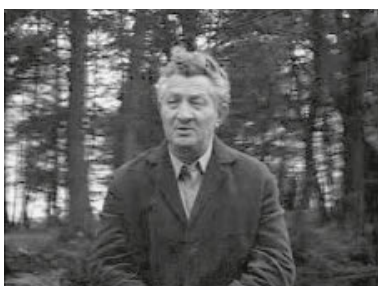

(225) $0: 04: 35 \mathrm{~h}(\mathrm{I})$

Am Ende des ca. zweiminütigen Textes (weiße Schrift auf schwarzem Hintergrund) fügt Lanzmann in Ich-Form hinzu: »Und in Israel habe ich ihn auch wiederentdeckt. Ich konnte den singenden Jungen von einst davon überzeugen, mit mir nach Chelmno zurückzukehren. Er war 47 Jahre alt.« (०:02:13 h)

Wo im Vorwort und Prolog mit sachten Auf- und Abblenden gearbeitet wurde, folgt die erste Einstellung der Eröffnungssequenz auf einen harten Schnitt. Eine Totale zeigt einen kleinen Fluß, auf dem ein Kahn fährt, der wiederum zunächst von Bäumen im Vordergrund verdeckt ist. In dem Maße, wie er sich im Wasser fortbewegt, werden seine Insassen sichtbar: Ein Mann sitzt ruhig am Bug des Bootes (s. ০:03:०9 h), während ein zweiter am Heck steht und den Kahn fortbewegt.

Um das Boot nicht aus den Augen zu verlieren, schwenkt die Kamera leicht nach rechts. Nach diesen ersten stillen Sekunden - der spätestens nach dem Prolog zu erwartende Teil über die Judenvernichtung steht im Widerspruch zum friedlichen Auftakt ${ }^{245}$ - hebt auf der Tonspur leise ein männlicher, ruhig-melancholisch klingender A-cappella-Gesang an. Da außer den beiden Männern niemand zu sehen ist, handelt es sich vermutlich um die Stimme des sitzenden Mannes.

Nachdem wir etwas mehr als eine Minute mit diesen beiden Männern, dem untertitelten Gesang und unseren Fragen (Ist das Simon Srebnik? Sind wir in Chelmno auf dem im Prolog zitierten Fluß? Was ist das für ein Lied? ${ }^{246}$ In welcher Sprache wird hier gesungen?) allein gelassen wurden, hören wir plötzlich eine lautere Männerstimme aus dem Off, in einer vermutlich osteuropäischen Sprache. Da nun keine schriftliche Übersetzung gegeben wird, harrt der Zuschauer einer Erklärung. Es folgen Worte eines Osteuropäers, die von einer Frauenstimme, ebenfalls aus dem Off, ins Französische übersetzt werden. In der deutschen Version des Films wird diese erst durch entsprechende Untertitel verständlich. Die Vermutung, es müsse sich bei dem singenden Mann um Srebnik handeln, bestätigt sich: »Er war $13^{1 / 2}$ Jahre. Er hatte eine schöne Singstimme. Wir hörten ihn.« (o:04:12 h) Aber wer ist der unbekannte Osteuropäer - ein unbeteiligter Zeuge, ein Pole vielleicht?

Ein wiederum harter Schnitt rückt den nun deutlicher hörbaren Sänger dichter ins Bild, in einer halbnahen Einstellungsgröße (s. o:04:35 h) - in der Tat, es ist der im Kahn sitzende Mann. Auffällig sind seine traurigen Augen und seine Regungslosigkeit. Nachdem er sein Lied beendet hat, verharrt die Kamera noch eine Weile auf dem Überlebenden und fängt ein, wie er sich nachdenklich, mit gequältem Gesichtsausdruck umsieht und wiederholt auf die Lippen beißt - Anzeichen dafür, daß ihn die Rückkehr sehr berührt. Indem die Kamera ganz nah an den Zeitzeugen heranzoomt, kann er in 
diesem erstarrten Gesicht lesen (s. o:04:59 h). Es ist von den Erlebnissen gezeichnet: traurig-leere, umränderte Augen, eine von Falten zerfurchte Stirn, zusammengepreßte Lippen - nicht das Bild eines 47-jährigen Mannes.

Während die weibliche Übersetzerin im Off die Reaktion von Zeugen auf die singende Rückkehr des Simon Srebnik ins Französische übersetzt, ist aus dem Off eine weitere osteuropäische Männerstimme mit den Worten zu vernehmen: »Als ich ihn wieder hörte, schlug mein Herz, denn was hier geschah, das war Mord. Ich habe alles noch einmal durchgemacht.« (0:04:58 - 0:05:04 h)

Die folgende, wiederum hart geschnittene, durch die Handkamera leicht wackelnde Einstellung zeigt Simon Srebnik auf einem friedlichen Waldweg. Erschüttert, mit zerfurchter Stirn, beißt er sich erneut auf die Lippen (s. 0:05:36 h) - durch die Nahaufnahme deutlich erkennbar. Nachdem er eine Minute lang schweigsam von der Kamera beim Gehen und Schauen eingefangen wurde und der Zuschauer zunehmend ungeduldig auf Erklärungen wartet (Wo genau befindet er sich? Wohin schaut er so intensiv?), hält Srebnik im Gehen inne; auch die Kamera kommt dadurch zur Ruhe. Andächtig nickt er mit dem Kopf, bevor er schließlich von sich aus zu sprechen beginnt, was ihm einige Sekunden vorher nicht gelungen war: »Schwer zu erkennen, aber ... das war hier.« (s. o:০6:09 h) Der Anblick dessen, was er - und der Zuschauer (noch) nicht - sieht, übermannt ihn. Nach kurzer Pause fährt er »in seinem gebrochenen Deutsch, in dem das Jiddische durchschimmert« (Reichel 2004: 288) fort: »Ja, da waren gebrennt Leute, viel Leute waren hier verbrannt.« Der Zuschauer kann ahnen, daß von der Leichenverbrennung die Rede ist. Nachdem Srebnik weitere zehn Sekunden den Anblick hat auf sich wirken lassen (s. ০:०6:32 h), bestätigt er noch einmal: »Ja, das ist das Platz ...«(o:06:39 h).

Die folgende Einstellung läßt den Zuschauer ohne weitere Erklärung mit den Augen des Protagonisten die Gegend betrachten (s. 0:06:36 h). ${ }^{247}$ Etwa einen halbe Minute überblicken wir in einem sanften, fast vollständigen $180^{\circ}$-Schwenk mit Srebnik den gesamten angesprochenen Platz, wobei die Kamera deutlich den Blick auf die Relikte der Vergangenheit lenkt (s. vor allem o:06:54 h, aber auch 0:07:11 h). Rein optisch wirkt die Landschaft in der warmen Abendsonne, mit dem grünen Gras und den Bäumen im Hintergrund überaus friedlich, fast idyllisch ${ }^{248}$ - wären da nicht Srebniks noch nachwirkender Kommentar sowie die steinernen Überreste der Ver-

247. »Following these words, the image switches from a medium shot on Srebnik to a slow and silent panning of the site of the camp. [...] the camera [...] shows the shock of a survivor's first encounter with a place he thought he would never leave alive and then thought he would not see again." (Colombat 1993: 316) »In this sequence, as it will often happen throughout the film, the panning of the camera reproduces the movements of the survivor's eyes discovering the site today, searching for some remaining traces and trying to imagine, to »re-present« to his imagination what happened here.« (Ebd. 316) Vgl. auch Lowy 2001: 171.

248. "Sie [die Totenklage] beginnt inmitten einer fast friedvoll idyllischen Landschaft mit Kiefern und Birken und Weiden und Wäldern. [...] in seinem gebrochenen Deutsch, in dem das Jiddische durchschimmert.« (Reichel 2004: 288) »Il n'y a pas de commentaire possible. Lanzmann en est conscient qui laisse planer sa caméra, après ces mots, dans le silence du lieu, serein, pacifique. Et pourtant c'est la Mort.« (Naïr 1990: 172) 


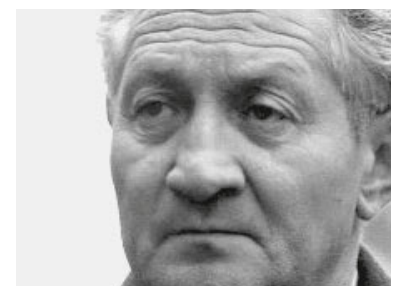

(226) $0: 04: 59 \mathrm{~h}(\mathrm{I})$
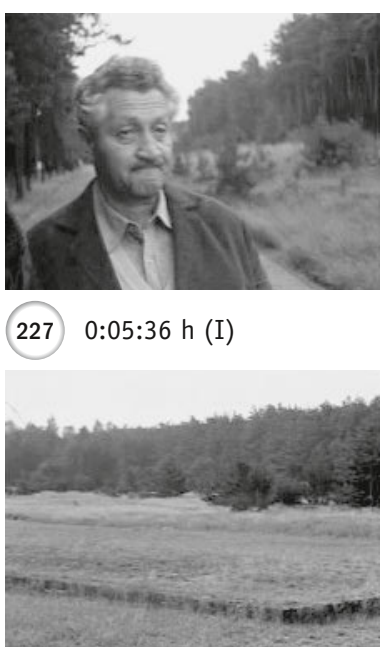

(230) $0: 06: 36 \mathrm{~h}(\mathrm{I})$

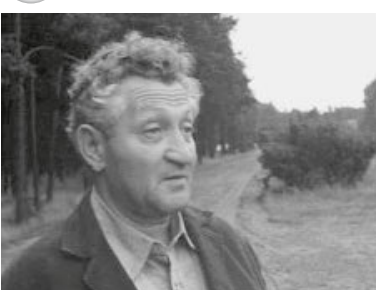

(228) 0:06:09 h (I)

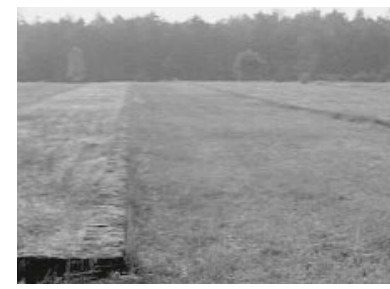

(231) $0: 06: 54 \mathrm{~h}(\mathrm{I})$

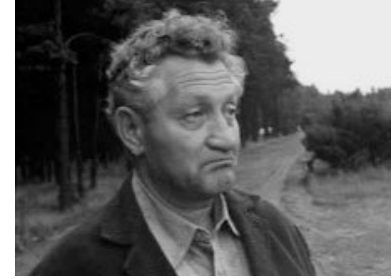

(229) $0: 06: 32 \mathrm{~h}(\mathrm{I})$

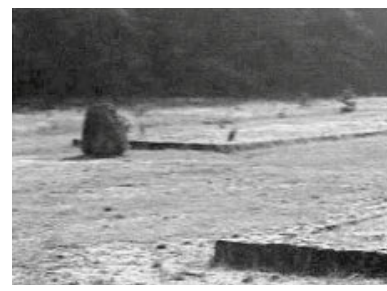

(232) $0: 07: 11 \mathrm{~h}(\mathrm{I})$

gangenheit (Steineinfassung in der Wiese als Abgrenzung der angesprochenen Massengräber vermutlich), die in krassem Gegensatz zur Beschaulichkeit der Szenerie stehen. Neben dieser impliziten Kontrastwirkung hatte Srebnik die Kluft zwischen Gestern und Heute bereits verbal hervorgehoben (»Schwer zu erkennen ...«). Wenn nicht einmal der Betroffene selbst den Platz wiederzuerkennen vermag, wie sollen diese Aufnahmen für den Zuschauer lebendig werden? Die, abgesehen von einem kurzen Krähenschrei, absolute Stille während des bedächtigen Kameraschwenks vermittelt allerdings eine gewisse unheimliche Stimmung.

Die sich anschließende Einstellung zeigt den Überlebenden, der von sich aus seinen Bericht fortsetzt:

»Die Gaswagen sind hier reingekommen. Da hier waren zwei große Ofens [Srebnik atmet tief durch]. Und, äh, nachher haben die hier die reingeschmissen in die ... in dem Ofen. Und das Feier (=Feuer) is gegangen zum Himmel. [Pause] Das war furchtbar.« (0:09:38 - 0:09:47 h)

Daß dem Überlebenden das Sprechen sehr schwer fällt, zeigt sich daran, daß er im Erzählen innehält und tief durchatmet, bevor er weiterspricht - die Nahaufnahme läßt dies deutlich erkennen. Als sehe er das einstige Bild vor sich, unterstützt Srebnik die Beschreibung des Feuers mimisch und gestisch: Sein Blick geht zum Himmel, seine linke Hand zeigt ebenfalls in diese Richtung (s. ०:07:38 h). 
In der nächsten Einstellung folgt die Kamera dem nunmehr den Platz begehenden Protagonisten und nimmt ihn beim lauten Nachdenken und Gestikulieren auf:

»Das ... das ... das kann man nicht erzählen (s. 0:07:59 h). Niemand kann das nicht, äh, bringen zum Besinnen (s. 0:08:11 h), was war so was da hier war. Unmöglich. Und kener kann das nicht verstehen. Und jetzt glaub ich auch, ich kann das auch schon nicht verstehen." (s. 0:08:15 h; 0:08:02 - 0:08:21 h)

Nachdem Srebnik vorher noch versucht hatte zu erläutern, was rund 30 Jahre zuvor an diesem Ort geschehen war, äußert er hier, nachdem er einige Schritte stumm gegangen ist und ohne danach gefragt worden zu sein, unvermittelt seine Gedanken über die Unmöglichkeit zu erzählen, geschweige denn zu begreifen (s. die letzten drei Standbilder). Damit spricht er das vielzitierte Dilemma der Unsag- und Unfaßbarkeit an. ${ }^{249}$ Seine bruchstückhaften Aussagen - gestisch unterstützt und besonders hervorgehoben durch die Detailaufnahme (s. 0:08:05 h) -, lassen den Zuschauer spüren, wie schwer es für den Überlebenden ist, bei der Rückkehr an die einstigen Stätten Erinnerungen zuzulassen. Nur bedingt vermag die Konfrontation mit dem Heute das Gestern aufleben zu lassen. ${ }^{250}$

Vergleichbar mit dem Kameraschwenk über den Platz zeigt die kontrastive Panoramaaufnahme den Zeugen jetzt in geraumer Entfernung, wie er die Steineinfassung der Massengräber abschreitet (s. o:08:17 h). Nachdem Srebnik nunmehr aus dem Off erneut zu hören war - »Ich glaube nich, daß ich da hier. Das kann ich nich glauben, daß ich bin hier noch einmal« (0:08:29 - 0:08:36 h) -, herrscht zwölf Sekunden lang absolute Stille. Aufgrund der friedlich Landschaft in der Abendsonne, aber auch der Zentralperspektive wirkt diese Bildkomposition besonders ästhetisch, beinahe schön auf uns - wäre da nicht die über die Tonspur vermittelte grauenhafte Vergangenheit, über die oberflächlich Gras gewachsen ist. Nachdem man die schmerzhaft-trügerische Stille regelrecht fühlen konnte, spricht Srebnik eben diese mit ruhig-melancholischer Stimme an, das Thema Massenverbrennungen aufgreifend und präzisierend:

»Das war immer so ruhig hier. Immer. Wenn die haben da jeden Tage verbrannt zweitausend

249. "These sentences introduce clearly the challenge of the film: to tell a story that is incommunicable, to name the unspeakable.« (Colombat 1993: 317)

250. Daß in den letzten Bildern dieser Einstellung eine weitere, zuhörende Person (Claude Lanzmann) im Hintergrund auftaucht, ist von geringerer Wichtigkeit. Man kann sich denken, daß es sich um den Interviewenden handelt. Den wenigsten ausländischen Zuschauern von damals wird das Gesicht des Regisseurs bekannt gewesen sein; dem französischen Publikum schon, denn Lanzmann war in Frankreich als Herausgeber der »Temps modernes« und Freund von Jean-Paul Sartre und Simone de Beauvoir kein Unbekannter.

251. »II« zeigt an, daß die Sequenz im zweiten Viertel des Films anzutreffen ist und bei der Zeitangabe des Standbilds von Beginn dieses zweiten Viertels an gezählt wurde.

252. Diese wird im weiteren Verlauf des Films im Zusammenhang mit Simon Srebnik noch von entscheidender Bedeutung sein, als er dort mit der immer noch von antisemitischen Vorurteilen belasteten polnischen Dorfbevölkerung zusammentrifft.

253. »Für Dietrich Leder ein >...Sinnbild des gesamten Films: Simon Srebnik befährt als Charon den Todesfluß Styx, als Grenzgänger zwischen dem Reich der Toten und der Lebenden, 


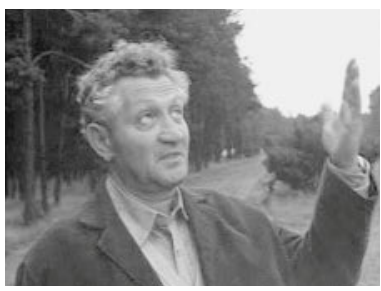

(233) $0: 07: 38 \mathrm{~h}(\mathrm{I})$

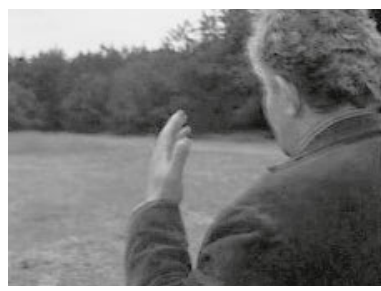

(234) $0: 07: 59 \mathrm{~h}(\mathrm{I})$

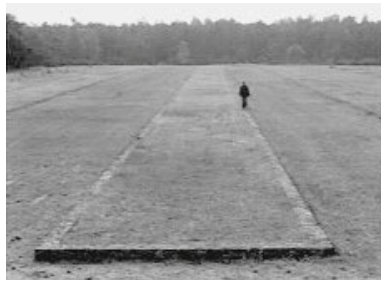

(236) $0: 08: 17 \mathrm{~h}(\mathrm{I})$

(238) $1: 45: 54 \mathrm{~h}$ (II)

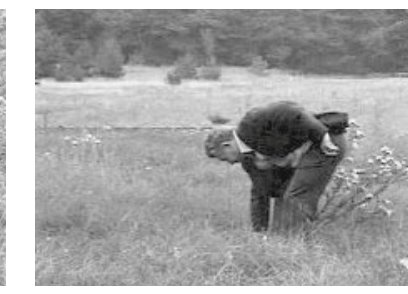

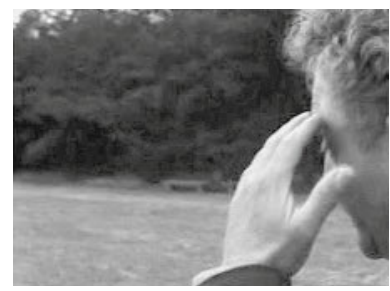

(235) $0: 08: 05 \mathrm{~h}(\mathrm{I})$

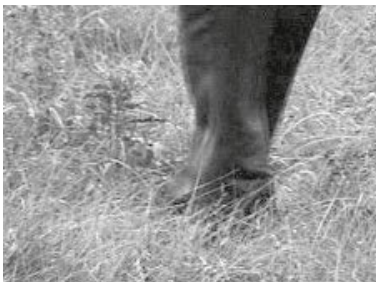

(237) $1: 45: 20 \mathrm{~h}(\mathrm{II})^{251}$

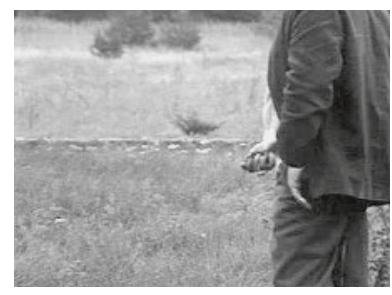

(239) $1: 46: 01 \mathrm{~h}$ (II)

Leute, Juden, es war auch so ruhig. Niemand hat geschrien. Jeder hat seine Arbeit gemacht. Es war still. Ruhig. So wie jetzt, so war es.« (0:08:49 - 0:09:12 h)

Was der Zuschauer als unvereinbar mit der Vergangenheit empfindet, war erstaunlicherwiese schon damals so; die Aufnahmen der Schreckensorte sind - zumindest was die Stille anbelangt - mit damaligen Verhältnissen in gewisser Weise vergleichbar.

Rund eineinhalb Stunden später zeigt Lanzmann weitere Aufnahmen von Simon Srebnik auf der Lichtung bei Chelmno. Im Unterschied zur Eröffnungssequenz registriert die Kamera hier, wie der Überlebende in der veränderten Landschaft nach eindeutigeren Spuren der Vergangenheit sucht - ein Verfahren, das Marceline Loridan-Ivens in BirkenAu Und RoSENFELD aufgreift und weiterentwickelt (s. II.5.5.g): Zunächst scharrt er mit dem Fuß im Gras (s. 1:45:20 h), später hebt er einen Stein auf und läßt ihn wieder fallen; schließlich nimmt er eine Handvoll Erde (s. 1:45:54 h), die er zwischen seinen Fingern gedankenverloren zerreibt (s. 1:46:01 h). Tastend versucht er, die Vergangenheit zu begreifen. Parallel hierzu hört man ihn aus dem Off vom Verbrennen der Leichen in den Öfen berichten.

Die Eröffnungssequenz endet, wie sie begonnen hat. In einer weiten Einstellungsgröße nimmt die Kamera erneut den kleinen Fluß auf; im Hintergrund ist vermutlich die Kirche von Chelmno zu erkennen (s. 0:09:46 h). ${ }^{252}$ Nachdem zunächst kein Laut zu vernehmen ist, hört man mit dem nahenden Boot wieder Srebniks Lied ${ }^{253}$ : 
»Wenn die Soldaten durch die Stadt marschieren, öffnen die Mädchen die Fenster und die Türen ...«. Beim zweiten Mal und vor dem Hintergrund des inzwischen Erfahrenen, wirkt die beschwingute Musik deplaziert, fast wie ein höhnischer Kommentar. Weder heute noch gestern lädt hier irgend etwas zu fröhlichem Trällern ein, so daß der Gesang eher Unbehagen bereitet und den Sadismus der Nazis erahnen läßt. Wie in den ersten Einstellungen des Films setzt plötzlich wieder die osteuropäische Männerstimme aus dem Off ein, ins Französische übertragen von der weiblichen Übersetzerin und als Untertitel für das deutsche Publikum eingeblendet - das Bild zeigt weiterhin den Kahn mit den beiden Männern. Der unbekannte Mann spricht davon, daß Simon Srebnik gar keine andere Wahl hatte als zu singen, denn er wurde von den Nazis dazu gezwungen: »Die Deutschen ließen ihn absichtlich auf dem Fluß singen. Er war ihr Spielzeug. Er mußte das machen. Er sang, aber sein Herz weinte« (०:11:03 h) und auch ihnen, den unbeteiligten Zeitzeugen tat dieses menschenverachtende Verhalten weh - schließlich sahen und wußten sie, was sich damals an diesen Schreckensorten abspielte. Nachdem die osteuropäische Männerstimme

ein Bote jener, die in Chelmno umgebracht wurden, ein Bote für diejenigen, denen er via Film von den Untaten Zeugnis ablegt.ı (Leder zit.n. Thiele 2001: 383)

254. »I« zeigt an, daß die Sequenz im ersten Viertel des Films anzutreffen ist und bei der Zeitangabe des Standbilds von Beginn dieses ersten Viertels an gezählt wurde.

255. Es hier wird jedoch nicht explizit aufgelöst, wer dieser Mann ist.

256. »Die Forderung nach authentischer Darstellung ist hier [bei der Shoah; eigene Anm.] in der Tat moralisch geboten. In ihr wirkt das Bestreben, die ganze Dimension des Geschehenen zu vergegenwärtigen und dem Verleugnen, Verdrängen und Schönreden entgegenzutreten.« (Kramer 2000: 42)

257. Vgl. Nackt unter Wölfen (Frank Beyer, DDR 1962/63), Kornblumenblau (Leszek Wosiewicz, POL 1988), TRIUMPH des GeISTES (Robert M. Young, USA 1989), Agnieszka Hollands Hitlerjunge Salomon (D/F/POL 1990), KorzCak (Andrej Wajda, PL 1990), Der Stellvertreter (Costa-Gavras, F/D/ROM/USA 2002), Der Pianist (Roman Polanski, F/DUK/POL 2002), Die RoSenStRASSE (Margarethe von Trotta, D/NL 2003) sowie die US-amerikanischen TV-Mehrteiler Holocaust (Marvin J. Chomsky, 1978) und War and Remembrance (Dan Curtis, 1988).

258. Insbesondere die europäische Koproduktion Der PIANISt (Le PIANISTE, F/D/UK/POL 2002) von Roman Polanski weist Gemeinsamkeiten mit SCHINDLERS LISTE auf. Wie Spielberg fühlt sich Polanski dem Prinzip einer detailgetreuen historischen Rekonstruktion verpflichtet und inszeniert das Überleben seines jüdischen Protagonisten. Aufgrund der starken Konzentration auf das lange Leiden des Helden ist jedoch zu befürchten, daß der Zuschauer im Verlauf des Films in bezug auf das Grauenhafte abstumpft.

259. "Somit gilt bereits für den historischen Dokumentarfilm die heutige Bilanz, die Authentizität nicht als immanente Eigenschaft des Genres, sondern als Effekt von Authentisierungsstrategien beschreibt.« (Lange 1999: 141) »Eine Dokumentation ist eben nicht die >unverfälschteく Selbstpräsentation von Geschehenem, sondern sie wird nachträglich arrangiert, sie ist das Ergebnis einer Inszenierung, und Authentizität ist letzten Endes eine Eigenschaft nur des Geschehenen selbst.« (Schulz 2002: 176, H.i.0.) Vgl. Oster/Uka 2003: 253 zu den Authentisierungsstrategien in Lanzmanns SHOAH.

260. Vgl. Adorno 1970: 32ff. und 354f., Wuss zum »Authentie-Effekt« (1990: 164ff.) und Valentin zur Entlarvung der Rede von der Authentizität als »Mythos« (2001: 127). 


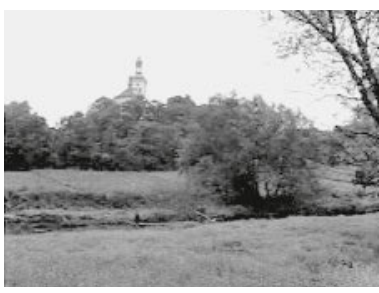

(240) 0:09:46 h (I) $)^{254}$

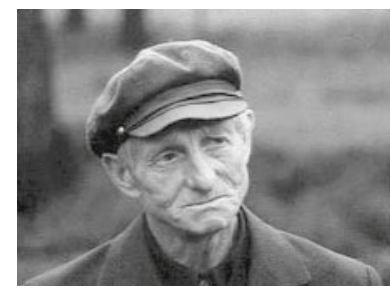

(241) $0: 11: 06 \mathrm{~h}(\mathrm{I})$

ungefähr eine halbe Minute aus dem Off eingespielt worden war und sich unsere Neugier auf die sprechende Person zunehmend gesteigert hatte, zeigt die folgende Großaufnahme den teilnahmsvollen Gesichtsausdruck dieses befragten Mannes (s. 0:11:06 h) ${ }^{255}$ - »es war Ironie der Deutschen«.

\section{II.3 Intensives Miterleben durch Identifikation - Authentizitätseindruck durch realistische Inszenierung}

Seit Kriegsende haben sich zahlreiche Filme mit dem Nationalsozialismus und der damit einhergehenden Judenvernichtung beschäftigt. Hierbei waren ernste, realistische Formen der Umsetzung vorherrschend, die häufig auch der weitverbreiteten Forderung nach Authentizität zu genügen versuchten. ${ }^{25}$ Hierzu zählen - neben zahlreichen anderen Spielfilmen 257 - auch die französische Produktion AuF WiEdersehen, KinDER (AU REVOIR LES ENFANTS, F 1987) von Louis Malle (s. II.3.1) sowie der US-amerikanische Spielfilm Schindle Rs Liste (Schindler's List, USA 1993) von Steven Spielberg (s. II.3.2)..$^{25}$ Diese ermöglichen ein intensives Miterleben und Nachvollziehen des Holocaust durch Identifikation und vermitteln einen Authentizitätseindruck durch realistische Inszenierungsweise.

Was ist jedoch im Einzelnen gemeint, wenn von Holocaust-Spielfilmen >Realismus bzw. >Authentizität< gefordert oder ihnen zugeschrieben wird?259

Es ist zentral, mit Hattendorf, Lange und Young darauf hinzuweisen, daß es hierbei um die Wirkung von »Authentisierungsstrategien « (Lange 1999: 141), von »erzeugten Zeugnissen« geht, d.h. um einen » Anschein v von Realität« (Young zit.n. Berghahn/ et al. 2002: 99, H.i.O.) und nicht um die exakte Wiedergabe der Realität, die ohnehin ein unmögliches, »naives« (Valentin 2001: 127) Ziel darstellt:

»Authentizität ist ein Ergebnis der filmischen Bearbeitung. Die `Glaubwürdigkeitı eines dargestellten Ereignisses ist damit abhängig von der Wirkung filmischer Strategien im Augenblick der Rezeption. Die Authentizität liegt gleichermaßen in der formalen Gestaltung wie der Rezeption begründet.« (Hattendorf zit.n. Kramer 1999: 32, H.i.0.)

»Authentizität bemißt sich aber nicht allein [...] am Werk selbst, vor allem an dessen Formgesetz, sondern kommt auch durch die Zuschreibung der Rezipienten zustande, also durch die nachfilmische Realität.« (Kramer 2000: 44) 260 
Das Attribut >realistisch< bzw. >authentisch< ergibt sich zum einen aus einer spezifischen filmischen Gestaltung, die Wahrnehmungsgewohnheiten entspricht (vgl. SCHindle Rs Liste in II.3.2); zum anderen daraus, daß an Kenntnisse des Zuschauers angeknüpft wird und dieser sich daher in die jeweilige Situation hineindenken und -fühlen kann (vgl. Auf Wiedersehen, Kinder in II.3.1). ${ }^{261}$ Auf diese Weise lädt Louis Malle den Zuschauer ein, sich aktiv in die dargestellte Welt zu versetzen, während Spielberg ihm eher eine passive Rolle zuweist, wenn er ihn in die Hektik der Ghettoräumung, Selektion (s. II.3.2.5) und Todesangst in den vermeintlichen Gaskammern (s. II.3.2.6) versetzt.

Im Unterschied zu Spielberg läßt Louis Malle den Zuschauer vergeblich hoffen, daß der in einem Kloster versteckte jüdische Junge von den Deutschen unentdeckt bleibt (der Film endet mit dessen Deportation), läßt Spielberg die sog. Schindlerjuden überleben und erfüllt damit die Hoffnung des Zuschauers. Hier schließt sich die Frage an, ob es erlaubt, gar notwendig ist - trotz oder gar wegen des Ausmaßes der historischen Last - die Ausnahme zu inszenieren und auf diese Weise Hoffnung zu ermöglichen? Mit anderen Worten: Ist dieses Angebot einer positiven Identifikation inklusive Rettung eine notwendige »Kompensation « inmitten allgegenwärtigen Schreckens? ${ }^{262}$

»Seit [...] Schindlers Liste nehmen Holocaust-Spielfilme wieder verstärkt Authentizität, Detailgenauigkeit und Faktizität als Gütesiegel für sich in Anspruch. Damit versuchen sie, dem von der Öffentlichkeit eingeforderten Gebot nach Realitätshaltigkeit des Fiktionalen in der Darstellung des Holocaust Genüge zu tun, das - ungeachtet der Veränderungen des öffentlichen Bewußtseins - weiterhin gilt.« (Fröhlich 2003:

261. »Filmische Kommunikation kann [...] Wahrnehmungs-, Erkenntnis- und Wertungsgewohnheiten entsprechen (und wird dann >realistisch genannt) [...].« (Kloepfer 1995: 41)

262. Dies verbindet SCHINDLERS LISTE mit zahlreichen früheren wie späteren HolocaustFilmen, beispielsweise ESCAPE FROM SOBIBOR (Jack Gold, JUG/UK 1987), KornblumenblaU (Leszek Wosiewicz, POL 1988), TRIUMPH Des GEISTES (Robert M. Young, USA 1989), HitLERJUnge SALOMOn (Agnieszka Holland D/F/POL 1990); SOBIBOR (Claude Lanzmann, F 2001), DeR PIANIST (Roman Polanski, F/D/UK/POL 2002), Die RosenstrasSe (Margarethe von Trotta, D/NL 2003) erzählen ebenfalls vom Überleben. Vgl. Insdorf 2003, insbesondere das Kapitel »Rescuers in Film«.

263. »Nun sind aber jene Filmemacher, die die Shoah thematisieren, mit einer in der Öffentlichkeit erhobenen Forderung nach Authentizität konfrontiert. Dies gilt paradoxerweise auch für Spielfilmregisseure.« (Kramer 2000: 31)

264. »[...] jede Erzählung, die die Ikonografie des Grauens benutzt, ist auch Teil eines Prozesses der Gewöhnung, der Trivialisierung." (Seeßlen 24.10.2002: 56) Vgl. hierzu auch die Äußerung von Andreas Kilb: »Die Zeit [...] verändert die historischen Perspektiven, und so läßt sich nicht übersehen, daß THE PIANIST, der vor zwei Jahrzehnten ein Ereignis gewesen wäre, heute um ebenjene Jahrzehnte zu spät kommt, daß das, was er sagt und zeigt, bereits schlüssig gesagt und gezeigt worden ist - auch wenn man es nicht oft genug sagen und zeigen kann.« (Kilb 2002: 43)

265. Malle zit.n. Philippe 2002.

266. Damit folgt er dem von Schreitmüller als spannend bezeichneten »Prinzip Offenheit« bei der Wahl eines Filmtitels (1994: 91ff.). 
246) ${ }^{263}$ Dabei übersehen die Filmemacher jedoch weitgehend, was Lorenz treffend beschrieben hat: »Will man nach diesem Film [Schindlers Liste; eigene Anm.] dem Holocaust-Film etwas Neues hinzufügen, so muß man entweder in der Radikalität der abbildenden Darstellung noch weiter gehen als Spielberg oder aber ein völlig anderes, ein nicht-naturalistisches, die historische Realität bewußt verfremdendes Konzept wählen.« (Lorenz 2003: 268) - eine Argumentation, die die Kritik an Polanskis DER PIANist (F/DUK/POL 2002) nachvollziehbar macht, der in bezug auf die detailgetreue historische Rekonstruktion Spielbergs SCHind LERS LISTE stark ähnelt. ${ }^{264}$

Steckt hinter dieser Tendenz zur Authentisierung, wie Krankenhagen vermutet, die Absicht, die Deutungsautorität der Überlebenden durch die Authentizität der sekundären Zeugenschaft zu ersetzen (Krankenhagen 2001: 210) - insbesondere angesichts des Versterbens derselben?

\section{II.3.1 EIN-BLICK IN FREUndSCHAFT Und HOLOCAUST IM AlLTAG: »AUf WiEdERSEHEN, KindeR« (»AU ReVOIR LES ENFANTS«, LOUIS MALLE, F 1987)}

\subsection{1 »Réinventer le souvenir « ${ }^{265}$ - neuerfundene Erinnerung}

Der Titel von Louis Malles Spielfilm lautet im Original Au Revorr Les Enfants, in der deutschen Version Auf Wiedersehen, Kinder und in der englischen Goodbye Children. ${ }^{266}$ Er verweist auf einen Abschied, wobei nicht näher bestimmt ist, ob diese Trennung kurzfristig oder endgültig ist, ob sie selbst gewählt oder aufgezwungen ist. Offenbar handelt es sich um Erwachsene, die sich verabschieden, sonst wäre »les enfants« nicht hinzugefügt. Kinder untereinander würden sich eher bei ihrem Namen nennen oder nur »Auf Wiedersehen« sagen. Darüber hinaus deutet der Plural darauf hin, daß es sich um mehrere junge Menschen handelt. Nimmt man daher eine Beziehung zwischen Erwachsenen und Kindern an, so stellt sich die Frage, ob eine Eltern-Kind-Beziehung oder ein anderes Verhältnis (z.B. eines zwischen Lehrer und Schülern) gemeint ist. Gleichzeitig kann man sich vorstellen, daß - vorausgesetzt es handelt sich um eine intensive, emotionale Beziehung - der Abschied schwerfällt, vor allem für ein Kind, aber auch für die jeweilige erwachsene Person. Eine Trennung kann eine äußerst einschneidende Erfahrung in der Entwicklung eines jungen Menschen darstellen: Fern seiner Bezugsperson muß sich ein Kind in einer möglicherweise fremden Welt zurechtfinden, u.U. behaupten; es herrschen dort Regeln, mit denen umzugehen man lernen muß. Ein solches Auf-sich-gestellt-Sein birgt jedoch auch die Wahrscheinlichkeit und die Chance neuer Erfahrungen und somit weiterer und vielleicht auch schnellerer Entwicklungsmöglichkeiten.

Wie die Auschwitz-Überlebende Marceline Loridan-Ivens knapp 20 Jahre später in B IRKENAU UND Rosenfeld (s. II.5), thematisiert auch Louis Malle eine Phase aus seiner Kindheit. Während Loridan-Ivens ihre traumatischen Erlebnisse in der (filmischen) Gegenwart aufleben läßt, erzählt Malles Geschichte vom Verlust seiner mehr oder weniger unschuldigen Kindheit in der Vergangenheit:

»Der Film wird von einem dramatischen Ereignis aus meiner Kindheit inspiriert, das vielleicht erschütterndste Erlebnis meiner Kindheit« (Malle zit.n. Philippe 2002), »vielleicht sogar meines Lebens.« (Malle 1998: 227) 
»En 1944, j'avais onze ans et j'étais pensionnaire dans un collège catholique près de Fontainebleau. L'un de mes camarades, arrivé au début de l'année m'intriguait beaucoup. Il était différent, secret. J'ai commencé à le connaître, à l'aimer quand, un matin, notre petit monde s'est écroulé.« (Malle zit.n. Ader 1993: 131)

$»[\ldots]$ er war Jude. Er wurde von der Gestapo im Januar 1944 festgenommen, in unserer Klasse, während des Unterrichts. Dieser Moment hat mich mein ganzes Leben lang nicht losgelassen. [...] Nach all den Jahren, mehr als 40 Jahre ist es her, hab ich mich entschlossen, diesen Film zu drehen. [...] Es ist für mich der wichtigste Film, den ich je gemacht habe.« (Malle zit.n. Philippe 2002)

Trotz genereller Treue gegenüber dem eigenen Erlebnis - »Der Film kommt dem, was ich tatsächlich selbst erfahren habe, sehr nahe.« (Malle 1998: 226) -, entscheidet sich Malle, ebenso wie Loridan-Ivens, gegen eine historisch exakte Rekonstruktion der Vergangenheit und für fiktionale Freiheit im Umgang mit dem zugrundeliegenden authentischen Erlebnis:

»Ich habe meine ganze Zärtlichkeit hineingelegt, meine ganzen Erinnerungen, meine ganze Vorstellungskraft, indem ich versucht habe, nicht so sehr der Wirklichkeit zu folgen, sondern meine Erinnerung neu zu erfinden.« (Malle zit.n. Philippe 2002)

»L'imagination s'est servie de la mémoire comme d'un tremplin, j'ai réinventé le passé, au delà de la reconstitution historique, à la poursuite d'une vérité à la fois lancinante et intemporelle.« (Malle zit.n. Moos/Frank 1992: 1)

Die Veränderungen zwischen Malles eigenen Erlebnissen und dem Film folgen insbesondere dem Prinzip des Wahrscheinlichen: So gab Malle beispielsweise seinem filmischen Alter ego den Vornamen Julien, während man die tatsächliche Identität des jüdischen Mitschülers (den Decknamen Jean Bonnet behält Malle für den Film bei) erst nach und nach erfährt (s. 3.1.4). ${ }^{267}$ Ersteres ist wahrscheinlich, weil Jean unter falschem Nachnamen im Internat versteckt wurde, und letzteres, weil die Beziehung beider Jungen im Film gegen Ende zu einer wahren Freundschaft gereift ist:

267. »Mein Bruder war älter und wußte davon, und er erzählte es mir. Er hätte es nicht tun sollen, doch er erzählte es mir, daß der Neue in meiner Klasse jüdisch war.« (Malle 1998: 241) Für weitere »Erfindungen« bzw. Details, die Malle nicht selbst erlebt hat, s. 3.1.4.cc, 3.1.4.df, 3.1.6.

268. "In der Haupterzählung geht es um die Ankunft des neuen Jungen und wie er und Julien zu Freunden werden; anfangs stehen sie sich feindlich gegenüber, doch dann sehen wir, wie sich Schritt für Schritt eine Freundschaft zwischen zwei Kindern entwickelt, die sich für die gleichen Dinge begeistern, die vielleicht ein bißchen intelligenter sind als die übrigen, wie sie nach und nach Gemeinsamkeiten entdecken.« (Malle 1998: 232) »A travers le regard de ce petit garçon qui me ressemble, j'ai essayé de retrouver cette première amitié, la plus forte, brusquement détruite [...].« (Malle zit.n. Ader 1993: 131)

269. »Als ich mir über die Struktur Gedanken machte, kam ich zu dem Schluß, daß es wichtig war, zu sehen, wie der Krieg ganz allmählich eindringt.« (Malle 1998: 232) »I tried to reveal [...] how, little by little, the film became darker and darker, as when clouds progressively accumulate in the sky.« (Malle zit.n. Colombat 1993: 267) 


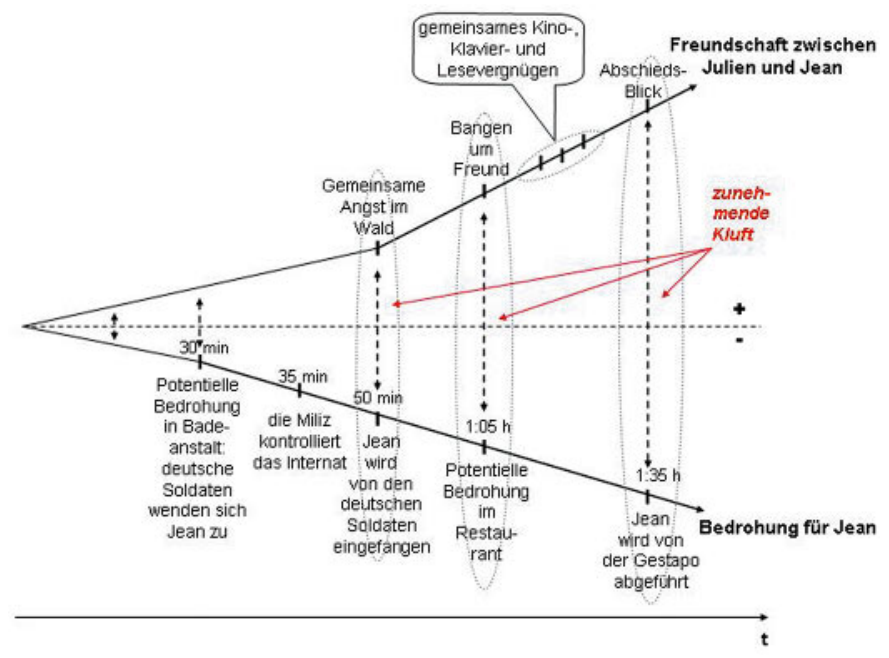

Abb. II.3.1.a

»Das sehr intensive Verhältnis zwischen den beiden Jungen im Film ist eher ein Produkt meiner Phantasie und stammt weniger aus meiner Erinnerung - ich wünschte, es wäre so gewesen, ich hätte ihn so gern näher gekannt [...].« (Malle 1998: 241)

»Ma relation avec Bonnet dans le film est plus compliquée et plus intéressante que dans la réalité, puisque ce qui nous a manqué, c'est le temps [...].« (Malle zit.n. http://nef-louis malle. com/aurevoir.htm)

»Als die Gestapo kam, war unsere Freundschaft gerade dabei, sich zu entwickeln. So weit, wie im Film dargestellt, ging unsere Beziehung nicht.« (Malle 1998: 241)

Dies wäre jedoch bei mehr gemeinsamer Zeit sehr wahrscheinlich gewesen, schließlich verband die von den Jungen im Film geteilte Leidenschaft für Bücher und Lesen auch Louis Malle mit seinem jüdischen Mitschüler (Malle 1998: 241).

In Auf Wiedersehen, Kinder geht es Louis Malle nach eigener Aussage in erster Linie um die sich entwickelnde, komplexe Beziehung zwischen den beiden besonderen Jungen (s. 3.1.4), nicht nur um eine »Variation des Holocaustthemas« (Malle 1998: 230). ${ }^{268}$

Zentrale Stationen in der Entstehung und Entwicklung der Freundschaft sind, gemäß der Graphik (s. Abb. II.3.1.a), ihre gemeinsame Angst beim Pfadfinderspiel im Wald (s. 3.1. 4.df), Juliens Bangen um und mit Jean, als die Miliz das Restaurant kontrolliert (s. 3.1.5), ihr gemeinsames Kino-, Klavier- und Lesevergnügen (s. 3.1.6) und ihr letzter Abschiedsblickkontakt (s. 3.1.6.d).

Am Ende des Films wird u.a. Jean von der Gestapo abgeführt (s. 3.1.6.d). Dies ist gleichzeitig der tragische Höhe- und Endpunkt einer Bedrohungssituation, die sich für den jüdischen Jungen im Filmverlauf sukzessive - über die potentielle Bedrohung in der Badeanstalt (s. 3.1.4.cb), die Kontrolle des Internats durch die Miliz (s. 3.1.4.da), das Eingefangen-Werden von deutschen Soldaten (s. 3.1.4.df) und die angesprochene Bedrohung im Restaurant (s. 3.1.5) - aufgebaut hatte. ${ }^{269}$ 
Die das letzte Drittel des Films prägende Freundschaft zwischen den beiden Hauptfiguren des Films entspricht nicht nur Malles nachträglichem Wunsch - »[...] présentant les événements >tels que j’aurais voulu qu'ils se soient passés« (Malle zit. n. Moos/Frank 1992: 49) -, sondern vergrößert sukzessive den Kontrast zwischen dieser positiven Entwicklung und dem drohenden Unheil. Am Ende des Films verstärkt diese maximale Kluft den einschneidenden Charakter des Kindheitserlebnisses, die Schmerzhaftigkeit des Verlustes sowohl für die Figuren als auch für den Zuschauer. An Auf Wiedersehen, Kinder kann nachvollzogen werden, daß der Tod einer einzelnen liebgewonnenen Figur - zumal wenn es sich um ein Kind handelt -, den Zuschauer mehr zu berühren vermag als die inszenierte Vernichtung Vieler. Dabei versucht Malle, den Zuschauer durch besondere Diskretion zu einem Hinsehen zu bewegen: »The audience is shown no image of graphic violence or obscenity.« (Colombat 1993: 284) $)^{270}$

Darüber hinaus verdeutlicht die Graphik die Polyfunktionalität insbesondere von drei der zitierten Schlüsselsequenzen: Das Pfadfinderspiel im Wald, die RestaurantSequenz und das Ende des Films sind sowohl für die Haupt- (Freundschaft zwischen Julien und Jean) als auch für die Nebenerzählung (Bedrohung für Jean) von entscheidender Bedeutung (s. die gestrichelten Ellipsen in der Graphik und die Analyse dieser Sequenzen in 3.1.2).

\subsubsection{Leitthesen}

Durch die Wiederaufnahme des Titels in der Schlußsequenz wird die Geschichte der sich - nach anfänglichen Hindernissen - entwickelnden Freundschaft der beiden Hauptfiguren vom Titel eingerahmt: Während im Prolog der Abschied des Protagonisten von seiner Mutter, ein Abschied mit Wiedersehen thematisiert wird (s. 3.1.3.a), inszeniert das Ende einen Abschied ohne Wiedersehen, die Deportation des einzigen Freundes und drei weiterer Figuren in Konzentrationslager (s. 3.1.6.d).

Durch diesen Filmschluß und der damit einhergehenden Dopplung des »Au revoir les enfants« erhält der Titel eine weiterführende Sinndimension, die für das Thema des Films von entscheidender Bedeutung ist (s.u. $)^{271}$ : Somit besiegelt der Titel das Ende der unbeschwerten Kindheit des Protagonisten, hervorgerufen durch ein traumatisches Erlebnis, »the brutal discovery of the reality of this period « (Colombat 1993: 265) und den damit einhergehenden Verlust des einzigen Freundes aufgrund nationalsozialistischer Vernichtungspolitik.

270. Diese Konstruktion ähnelt prinzipiell der von Benigni, in dem Sinne, als der Zuschauer die Möglichkeit geboten bekommt, den Holocaust sozusagen aus sich heraus zu entwickeln über Indizien.

271. "Only in the end of the film will [...] the audience understands the meaning of this prediction.« (Colombat 1993: 267)

272. "GOODBYE CHILDREN is generelly read as a personal telling of the discovery of the persecution of the Jews by an adolescent through the story of a friendship.« (Colombat 1993: 265)

273. »Man will dem Publikum nichts erklären, weil man es damit in die passive Rolle von Beobachtern versetzt. Man will die Geschichte nur Stück für Stück preisgeben und die Zuschauer so zum Mitspielen machen, weil sie dann die Geschichte auf dieselbe Weise erfahren wie die Figuren.« (Bill Wittliff zit.n. Howard/Mabley 1996: 59) 


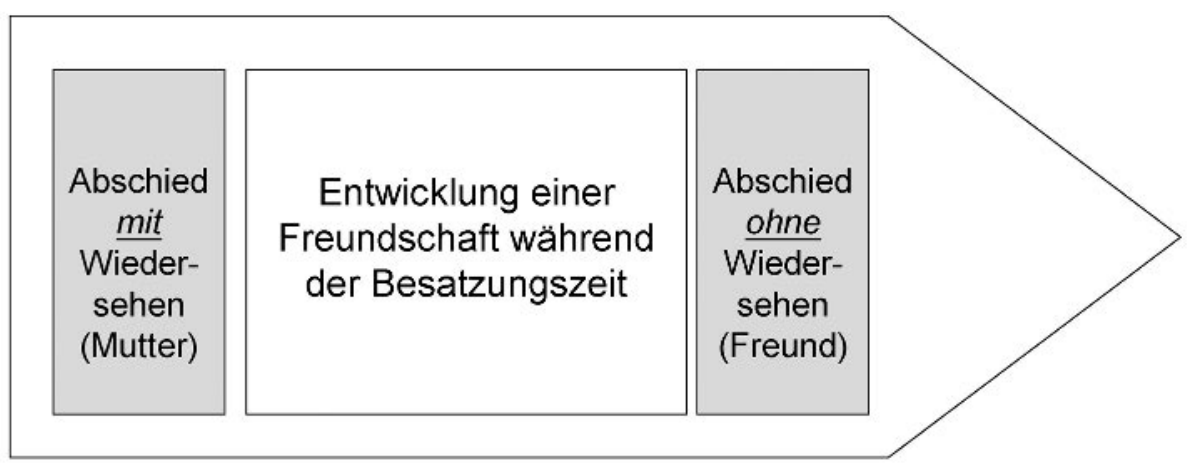

Abb. II.3.1.b

Durch Juliens sukzessives Verstehen der Realität (s. 3.1.4) ist der Film »auch das Porträt eines Kindes« (Malle 1998: 230) und ähnelt Grundprinzipien des Bildungs- bzw. Entwicklungsromans. In dessen Zentrum steht

»[...] die innere Entwicklung (Bildung) eines Menschen von einer sich selbst noch unbewußten Jugend zu einer allseits gereiften Persönlichkeit [...], die ihre Aufgabe in der Gemeinschaft bejaht und erfüllt. Dieser Bildungsgang [...] führt über Erlebnisse der Freundschaft und Liebe, über Krisen und Kämpfe mit den Realitäten der Welt zur Entfaltung der natürlichen geistigen Anlagen, zur Überwindung eines jugendlichen Subjektivismus, zur Klarheit des Bewußtseins.» (Schweikle/Schweikle 1990: 55)

Das Erwachsenwerden des Protagonisten Julien ist für das Thema des Films und für die Beteiligung des Zuschauers zentral: Mit und über Juliens erwachsen werdende Kinderaugen erhält der Zuschauer Ein-Blick in Freundschaft sowie in den Alltag des Holocaust und teilt sein Leid beim Verlust des einzigen Freundes. ${ }^{272}$

Daß sich der Zuschauer in Auf Wiedersehen, Kinder mit und über den Protagonisten hinaus entwickeln und dabei ein hohes Maß an Eigenleistung (s. I.2.1) beisteuern kann, liegt an der diskursiven Gestaltung der Mimesis, d.h. der Art und Weise, wie Louis Malle die Geschichte dramaturgisch und filmisch umsetzt.

Anstatt uns explizite Informationen über die Hauptfiguren und deren Seelenleben, über ihre sich entwickelnde Freundschaft und über den spezifischen sozio-historischen Kontext zu liefern, regt uns Malle an, die jeweiligen Sinn durch Andeutungen, Indizien, symbolische Aufladung und somit über aktives Sich-Versetzen selbst zu erschließen:

Zum einen nutzt er die dem Menschen »angeborene Neigung, bei entsprechender Motivation Fragmentarisches ergänzen zu wollen « (Kloepfer 1999: 53), »einem Text das zu entnehmen, was dieser nicht sagt (aber voraussetzt, anspricht, beinhaltet und miteinbezieht), und dabei Leerräume auszufüllen « (Kloepfer 1990: 139); mit anderen Worten: »Wenn der Autor mehr Aufmerksamkeit, Neugier etc. erzeugt, wird der Leser mehr mit dem Zeichenangebot leisten.« (Kloepfer 2005: 113) $)^{273}$ 
Zum anderen: Er »überläßt es ganz dem Betrachter, Schlußfolgerungen aus dem Geschehen zu ziehen « (Ader 1993: 132), ist also »loin de tout >message< pesant « (Coppermann zit nach Moos/Frank 1992: 48). Damit steht er in der Tradition der französischen Moralistik, welche die Phänomene beschreibt, ohne sofort zu werten.

Auf Malles Film trifft in besonderem Maße zu, daß Figuren über perspektivische Verfahren charakterisiert werden. Je nach Figur, mit der wir wahrnehmen, entsteht eine andere Sinnwelt, denn wir »übernehmen mehr oder weniger zwangsläufig deren Wahrnehmung, Rolle und Verarbeitungsform.« (Kloepfer 1999: 25) Ihr Interessens-, Wahrnehmungs-, Motivationszentrum wird vom Zuschauer »über ein System von Indizien selbst erfaßt und durch erfolgreiche Antizipationen bestätigt [...]: Ja, sagt ihm der Autor mehr oder weniger direkt, Du hast erfaßt, wie sich die Person die Welt ordnet.« (Kloepfer 2001b: 6) Das Wort >Ver-Stehen< impliziert nicht zufällig, daß man den Platz des Anderen einnehmen kann und damit im Prinzip seine Seh-, Hör- etc. und Verarbeitungsweisen bis hinein in die psychische Dimension, welche schon das Wort >Ein-Stellung « nahelegt.« (Ebd. 1)

Diese Möglichkeit bietet der Regisseur dem Zuschauer insbesondere in bezug auf die Hauptfigur des Films. Viele Schlüsselszenen des Films erleben wir vor allem aus und durch seine Perspektive, über die Schulter oder als subjektive Kamera (s. insbesondere 3.1.3 3.1.4.aa, 3.1.4.bc, 3.1.4.db, 3.1.4.df, 3.1.5 und 3.1.6.d) bzw. werden durch Einsatz von Off-Texten in sein Bewußtsein versetzt (s. 3.1.4.ca, 3.1.4.cb, 3.1.4.dc und 3.1.6.d) ${ }^{274}$. Besonders häufig ist hierbei folgendes, für das Medium Film klassische Verfahren des Einbezugs und der Absicherung desselben: »Indem wir in der einen Einstellung durch den Kamera-Blickpunkt den Handelnden sehen, in der nächsten dann, was er >mit seinen Augen< [zum Teil über seine Schulter; eigene Anm.] sieht, und dann wieder, wie er

274. »Wie kaum ein anderes filmisches Werk ist das Kino von Louis Malle auf Berührung instrumentalisiert, auf Berührungen mit Händen, der Haut oder den Augen, an denen dieser Regisseur den Zuschauer teilnehmen läßt, indem er indirekt auch den Zuschauer inszeniert. Das heißt: immer wieder wird der Zuschauer in die Blicke auf der Leinwand hineingenommen, so, wie Müller von der Gestapo in den heimlichen Blick von Julien und Jean Bonnet hineinkommt - und über diese Zwischenstation auch der Zuschauer.« (Jansen/Maerker 1990: 100)

275. Vgl. Colombat 1993: 266 (»[...] the functioning of this film is based on the identification of the audience to one character [...].« (1993: 266)) Hinzu kommen gezielt eingesetzte nahe Einstellungs-größen mit dem Protagonisten in entscheidenden Momenten.

Die kindliche Perspektive ermöglichte dem französischen Publikum im Erscheinungsjahr des Films (1987) das Sich-Einlassen auf die sogenannten années noires, ein buchstäblich schwarzes Kapitel ihrer Geschichte. Hätte Malle die alltägliche Ausgrenzung der Juden unter dem VichyRegime expliziter behandelt, hätte sich das erwachsene französische Publikum mit dieser 1987 kaum aufgearbeiteten Geschichte vermutlich noch nicht so positiv auseinandersetzen können: »Le film connut d'ailleurs un succès considérable (3,4 millions d'entrées), qui consacra le >grand retour de Louis Malle dans le cinéma français.« (Frodon 1995: 704)

276. »[...] children are so easily and quickly cute that you have to be very careful, especially with this subject. From the very beginning, Au REVoIR was meant to be tough ... it was important to show Julien as arrogant, a little spoiled, with moments of anguish and solitude." (Malle zit.n. Insdorf 2003: 84) Vgl. auch Malle 1998: 238.

277. Gezielt eingesetzte nahe Einstellungsgrößen von Jean verstärken im wahrsten Sinne des Wortes die Nähe zu dem bedrohten Jungen. 
handelt, erleben wir durch dieses zunehmend hoch entwickelte deiktische Mittel mit dem Helden bzw. er für und mit uns.« (Kloepfer 1995: 20) Julien ist daher unsere primäre Identifikationsfigur ${ }^{275}$, obwohl wir in der ersten Stunde des Films in der Bewertung seiner Handlungen (zwischen Sym- und Antipathie) schwanken. ${ }^{276}$

In regelmäßigen Abständen versetzt Malle den Zuschauer durch einen over-theshoulder-shot oder eine subjektive Kamera auch in die Perspektive der zweiten Hauptfigur, Jean, vor allem wenn es sich um eine potentielle Bedrohungssituation für ihn handelt (s. insbesondere 3.1.4.aa, 3.1.4.da und 3.1.5).277

Hinsichtlich unseres Miterlebens der sich entwickelnden Beziehung zwischen Julien und Jean ist die Phänomenologie ihrer Blicke zentral, an denen das jeweilige Stadium ihres Verhältnisses abgelesen werden kann. Auf Wiedersenen, Kinder wird rhythmisiert durch zahlreiche Stellen, in denen diese Blicke - häufig aus wechselseitiger Figurenperspektive - inszeniert werden. Hierbei nutzt Malle die potentielle Polyvalenz sowie den Indizcharakter, ohne verbale Erklärung:

»Blicke erscheinen als Formen des Umgangs wie des Suchens, Wählens, Wertens oder Ertappens beziehungsweise der Handlung. [...] Sie orientieren den anderen, denn sie bedeuten, was für jemanden wichtig ist, sie zeigen, wer mit wem in Relation steht. Sie zeigen die Fülle der Kontaktaufnahmen, die man mit dem seit 1960 gebräuchlich gewordenen Kommunikationsmodell von Jakobson als sphatisch bezeichnet. Sie sind die Wirklichkeit der gelebten Beziehung. Blicke [...] richten sich, ziehen Aufmerksamkeit auf sich, kreuzen sich, treffen sich, halten sich stand, laden zum Duell ein, bewegen sich in einer Finte auf etwas Ablenkendes, halten die Spannung nicht aus, verschanzen sich hinter Personen, so daß der andere diese fast fixieren muß, verstekken sich, fliehen, löschen sich durch Blick nach innen aus. Blicke sind voll (Haß, Verachtung, gespielter Gleichgültigkeit) oder leer. [...] Sie verlängern Augenblicke, sie brechen. Was man das Augenmerk nennt, hebt korrekt drei Gedächtnismomente hervor: Aufmerksamkeit, Merkmalerkennung und Einverleiben durch Sich-Merken.« (Kloepfer 2002: 292)

Die Phänomenologie der Blicke zwischen den beiden Hauptfiguren reicht von Aufmerksamkeit und Interesse (s. 3.1.3.c, 3.1.4.aa), über Verwunderung/Erstaunen (s. 3.1.4.ab), Blickvermeidung (s. 3.1.4.bb), Eifersucht (s. 3.1.4.bc), Rivalität/Konkurrenz (s. 3.1.4.ca, 3.1. 4.db), Neugierde (s. 3.1.4.cc, 3.1.4.da, 3.1.4.dc, 3.1.4.dd), Solidarität (s. 3.1.4.df, 3.1.6.a), Komplizenschaft (s. 3.1.4.dg, 3.1.4.dh), Provokation/Überlegenheit (s. 3.1.4.ca, 3.1.4.dg) bis hin zu Sich-Versetzen in den bedrohten Freund (s. 3.1.5) und Abschied (s. 3.1.6.d).

Rein quantitativ überwiegt in AuF WiederseHen, Kinder jedoch die figurenunabhängige, neutrale Perspektive (Ader 1993: 132). Aus ihr beobachten wir zunächst vor allem den Protagonisten Julien, im weiteren die verbale und nonverbale Interaktion zwischen den beiden Hauptfiguren. Zum Teil zeigt uns der Regisseur den jüdischen Jungen und sein besonderes Verhalten, ohne daß Julien in diesen Momenten unsere Beobachtungen teilt.

So ist unser Einbezug in Jeans Wahrnehmung aufgrund der Rätselstruktur der ersten beiden Filmdrittel von entscheidender Bedeutung, da sie dem Ratenden eine besondere Eigenleistung abverlangt:

»Die Tätigkeit des Ratenden haben wir mit dem Wort ENTRÄTSELN angedeutet. Um jedoch enträtselt werden zu können, muß das zu Enträtselnde zunächst VERRÄTSELT sein. [...] Was aber ist die Absicht, der Zweck dieser Verrätselung?« (Jolles 1982: 134, H.i.0.) 
»[Es] ergibt sich, daß die Lösung an sich nicht der eigentliche und einzige Zweck des Rätsels ist, sondern das LöSEN.« (Ebd. 134f., H.i.0.)

Aufgrund des Mangels an expliziter Information nimmt der Zuschauer, ebenso wie der Protagonist, jegliches Indiz in bezug auf den rätselhaften Jean wahr - Kennzeichen einer auf »Invarianten der Wahrnehmung « basierenden, »perzeptgeleiteten« Werkstruktur, die einen »bestimmten Typ des Wahrscheinlichkeitslernens« erfordert (Wuss 1990: 71f.). ${ }^{278}$ Das Rätsel wird somit zum Problem und darüber hinaus zur Lebensaufgabe. Dem Zuschauer kommt hierbei - gepaart mit seinen Vorkenntnissen gegenüber dem 12-jährigen Julien - die privilegierte Beobachterrolle bzw. der Einbezug in Jeans Wahrnehmung zugute. Zusammen führt dies zu einem höheren »Informiertheits «grad des Zuschauers (schwarze Linie in der Graphik) gegenüber Julien (rote Linie). Diese Diskrepanz (y-Achse) zwischen uns und dem kindlichen Protagonisten sorgt in der ersten Stunde des Films (x-Achse) für die zentrale Grundspannung (s. 3.1.4). Diese ist insbesondere zu Beginn des Films erheblich (große Kluft zwischen schwarzer und roter Linie, vertikaler Pfeil), da Malle dem Zuschauer vor allem in den ersten Sequenzen um Jean Indizien für dessen Andersartigkeit liefert und/ oder ihn wiederholt in dessen Wahrnehmung versetzt ${ }^{279}$ : Während Julien in bezug auf den neuen Mitschüler bis zur 2osten Filmminute keine Vermutung anstellen kann, entwickelt sich diese für den Zuschauer bereits zu einem Verdacht (s. 3.1.4.a und 3.1.4.b). Im weiteren Verlauf des Films nähern sich die Informationsgrade des Zuschauers und des Protagonisten durch vergleichsweise explizitere Indizien und parallele Wahrnehmung an (kleinere

278. »So wird aufgrund der häufigen Wiederkehr des Gleichen eine eigenständige Wirkung der Geschehnisse erreicht, die dem Rezipienten zwar nahezu unbewußt bleiben dürfte, aber eben auch die Invariantenbildung der Wahrnehmung beeinflußt und vermöge einer ganzen Reihe homologer Formen zur ssemantischen Gester wird [...].« (Wuss 1990: 77) »Die Strukturen sind in der Komposition kaum evident, und sie bleiben auch in semantischer Hinsicht noch sehr instabil. Nichtsdestoweniger werden sie ästhetisch wirksam. Ihnen haftet insofern eine bemerkenswerte sinnliche Kraft an. [...] Künstlerisch wertvolle Filme enthalten ganze Systeme von Tiefenstrukturen, die man freilich erst nach größeren Anstrengungen zu objektivieren vermag.« (Ebd.: 73) Vgl. auch I.2.2.

279. »Die diskrepante Informiertheit von dramatischen Figuren einerseits und dem Publikum andererseits ergibt sich nun im wesentlichen aus zwei Momenten. Zum einen ist das Publikum bei allen Situationen als Zuschauer anwesend, während die einzelnen Figuren in der Regel nur an einer Teilmenge der präsentierten Situationen unmittelbar partizipieren. Das Publikum ist also in der Lage, die jeweils nur partielle Informiertheit der einzelnen Figuren zu summieren und miteinander zu korrelieren.« (Pfister 2000: 81)

280. Insofern ist Colombats folgende Bemerkung nicht zutreffend, denn Louis Malle bietet dem Zuschauer systematisch Informationsvorsprünge an: »The audience can understand historical or cultural allusions only if it stops identifying completely with Julien in order to refer to what it knows now about this period or the general history of the Holocaust.« (1993: 265)

281. »Eines der besten Hilfsmittel, die Anteilnahme und dadurch das Interesse des Zuschauers zu wekken, ist die Enthüllung. Informationen, die ausschließlich den Zuschauern geliefert werden, die aber wichtig für die Figuren sind, werden als Enthüllungen bezeichnet. [...] Eine Enthüllung bringt den Zuschauer in eine überlegene Position, weil er fortan mehr weiß als die Figuren. Die Enthüllung markiert den Unterschied zwischen der narrativen Geschichte, der der Zuschauer/Leser nur folgen kann, und der Beteiligung des Zuschauers als >Wissensträger< an einer Geschichte.« (Schütte 1999: 88) 


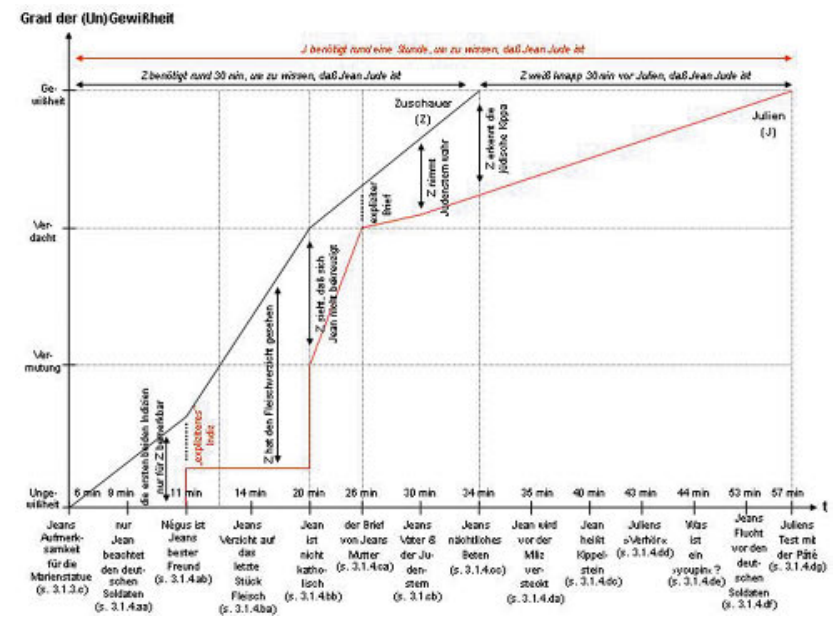

Abb. II.3.1.C

Kluft zwischen schwarzer und roter Linie; s. 3.1.4.bb und 3.1.4.ca), um im folgenden erneut auseinanderzulaufen: Aufgrund einer durch die neutrale Perspektive exklusiven Wahrnehmung (s. 3.1.4. cb) sowie seines größeren sozio-historischen Vorwissens (s. 3.1.4.cc) vermag er seinen Verdacht in Gewißheit umzuwandeln, während Julien kaum die Stufe des Verdachts erreicht hat. ${ }^{280}$ Letztlich benötigt der Zuschauer mit rund 30 Filmminuten halb so viel Zeit wie Julien, um sich in bezug auf Jeans tatsächliche Identität sicher zu sein (horizontale Pfeile am oberen Ende der Graphik).

Funktionell entscheidend an dieser Kombination aus perzeptgeleiteter Struktur und »Informations «diskrepanz ist, daß der Zuschauer dem Protagonisten immer einen Schritt voraus ist und so eine gewisse Überlegenheit (bei zum Teil gleichzeitiger mehr oder weniger starker Ungewißheit) genießen kann. ${ }^{281}$ So erlaubt ihm die Struktur des »Informations «vorsprungs, »die Diskrepanzen im Informiertheitsgrad der Figuren untereinander zu erkennen und vermittelt ihm so das Bewußtsein der Mehrdeutigkeit jeder Situation« (Pfister 2000: 82), wobei nur er die »komplementären Perspektiven zu einem Ganzen« zusammenfügen kann (ebd. 83).

Voraussetzung dafür, daß die hochkomplexe Struktur eines Films den Zuschauer nicht überfordert, ist das Zusammenspiel von kompositorischer Stimmigkeit und der besonderen Lernfähigkeit des Menschen.

Mikrostrukturell - so »nennen wir alles, was zeichenvermittelt in unserem Arbeitsgedächtnis bis zu 3 Minuten oder etwas länger simultan verarbeitet wird.« (Kloepfer 2005: 110) - muß der Film so angelegt sein, daß der Zuschauer innerhalb kurzer Zeit ausreichend Indizien wahrnehmen kann, um zwischen diesen mehr oder weniger vorbewußt Verbindungen herzustellen. Das heißt, daß wir erst perzeptgeleitet kleine Sympraxen leisten müssen, die im folgenden bestätigt werden und in größere Formen des Mithandelns führen, so daß sich im Gedächtnis Konzepte oder Schemata fixieren können. Auf diese Weise werden Inhalte aus dem Kurzzeitgedächtnis in das Langzeitgedächtnis überführt (Birbaumer/Schmidt 1999). Diese Konzepte wiederum bedürfen im weiteren Filmverlauf nur noch eines kleinen Hinweises, damit in unserem Bewußtsein »eine ganze Welt« zur Entfaltung kommt; letzteres nennt man stereotypische Schemanutzung. 
Die besondere Struktur von Auf Wiedersehen, Kinder kann letztlich nur funktionieren, weil Malle die Fähigkeit des Menschen zum Lernen des Lernens nutzt:

»Wir ssind Bewußtsein, Gedächtnis und Verarbeitungskompetenz für Wirklichkeiten immer unendlich viel mehr, als wir dies shaben<, begreifen oder gar darstellen können. [...] Wir sind extrem komplexe und schnelle Informationsverarbeitungsprozesse. [...] Die Kluft zwischen Verarbeitungskompetenz von Realitäten aller Art und der Fähigkeit, sie angemessen objektivierend zu erfassen, bleibt trotz allem wissenschaftlichen Fortschritt zumindest bei Kunst und Kommunikation deshalb oftmals gleich groß, weil das jeweils sintuitiv - also aus dem Lebensvollzug oder technisch oder sonstwie - Gelernte die Bedingungen unserer Verarbeitung verändert. Das gilt für längere Lebensphasen oder die Zeit, in der wir einen Film sehen. Und manche Künstler nutzen eben dieses Lernen gemäß der sich historisch erweiternden Zumutbarkeit mehr als andere. [Dem Regisseur] gelingt es [...], das im Verlauf des Films Lernbare dergestalt extrem in den Wahrnehmungsprozeß zu integrieren, daß sich unsere Kompetenz als Zuschauer nachweislich minutenweise steigert. [...] führt mitnichten zu einer Überforderung und der beim breiten Publikum üblichen Ablehnung. [Der Regisseur] nutzt unsere Fähigkeit, genießend zu lernen, ohne daß wir es merken. Unser Genuß besteht im Großteil in der Selbsterfahrung, für solches Lernen geeignet zu sein. Diese Lust am Lernen von gemeinsamer Innovation ist ein Zeichen extremer immanenter Dialogizität.« (Kloepfer 1994: 48)

Für Auf Wiedersehen, Kinder heißt das, daß es den Zuschauer zusätzlich anspornt, wenn er durch die Bestätigung erster Vermutungen merkt, daß er sich »auf der richtigen Spur« befindet; den Rhythmus der sukzessiven Aufdeckung - »Rhythmus setzt das Wechselspiel von Erwartung und Realisierung bzw. Durchbrechung voraus.« (Kloepfer 2001a: 56) - erfährt er als kompetent. Bestätigung bereitet dem Zuschauer, daß sich sein Verdacht im bezug auf Jean letztlich als richtig erweist: »Ja, unser Anteil wird um so lebhafter und stärker sein, je länger und zuverlässiger wir es vorausgesehen haben.« (Lessing zit.n. Pfister 2000: 82)

282. »Und die Jungen nahmen ihre Rollen hundertprozentig an und übersprangen vierzig Jahre. Das ließ mich hoffen, daß die Kinder von heute von den Geschehnissen auf der Leinwand gepackt sein würden, wenn sie den Film sahen, und daß sie sich mit den Jungen im Film identifizieren würden.« (Malle 1998: 240)

283. Wenn im folgenden vom sachkundigen Zuschauer gesprochen wird, sind diese Grundkenntnisse gemeint. Ebenso wie das Alltagswissen gehören sie, so Peter Ohler, zum »generellen Weltwissen«, mit dessen Hilfe der Zuschauer »aus den gezeigten Szenen Schlußfolgerungen hinsichtlich des nicht gezeigten Geschehens« sowie - müßte man ergänzen - des Gezeigten zieht (Ohler 1990: 48).

284. Beispielsweise, wenn der Name Laval (Synonym für die französische Kollaboration) im Gespräch zwischen den Jungen fällt.

285. »>Motiv nennen wir die funktionalen Bausteine, die natürlich an den Knotenpunkten besonders wichtig werden. Wir können tragende, stützende, absichernde etc. Motive unterscheiden. Umgangssprachlich könnte man sagen: Womit und wie baut sich die >Grundideer auf, wodurch wir das in uns erstellen, wozu der Film gemacht ist. (Kloepfer 2003: 1)

286. „Betrachtet man die anderen Agierenden - vielleicht mit Ausnahme der Patres und Lehrer - genauer, so stellt man schnell fest, daß sie fast durchweg nur auf den eigenen Vorteil aus sind." (Ader 1993: 135) 
Daß den Zuschauer sein hohes Maß an Eigenleistung nicht überfordert, ergibt sich auch aus Malles virtuoser Verknüpfung von historisch Spezifischem und Universellem.

Insbesondere das Anknüpfen an Alltagswissen und alltägliche Lebenserfahrung dient der Überbrückung der historischen Distanz - »1944 est loin, mais je sais qu'un adolescent d'aujourd'hui peut partager mon émotion.« (Malle zit.n. Moos/Frank 1992: 1) ${ }^{282}$ - und macht die Wirklichkeit des Holocaust im Alltag erfahrbar. Systematisch läßt Malle den Zuschauer sein Wissen um die Beziehung zwischen Eltern und Kindern, um Freundschaft und den Umgang unter Kindern einbringen. Wer je die Trennung von einer geliebten Person erlebt hat, wird Juliens Trauer zu Beginn und am Ende des Films mitempfinden können. Im übrigen bietet Malle die Möglichkeit, sich Gefühle wie Trennungsschmerz über den Film zu erschließen (s. insb. 3.1.3 und 3.1.6):

»Wir können in den allermeisten Fällen davon ausgehen, daß ein Film die Bedingungen seiner angemessenen Verarbeitung mitliefert. [...] gibt der Film normalerweise ähnlich wie moderne Literatur an hervorragenden Stellen rautodidaktisch< eine Einführung in das spezifische System und leitet durch einen Strang kontinuierlicher Zeichen zum Lernen an.« (Kloepfer 2002: 280)

Das spezifisch historische Vorwissen in bezug auf den Zweiten Weltkrieg, inklusive des Holocaust, das Malle beim Zuschauer voraussetzt, beschränkt sich auf ein Grundwissen. ${ }^{283}$ Auch wenn die eine oder andere Wissenslücke, insbesondere von jungen nicht-französischen Zuschauern, nicht unbedingt geschlossen werden kann ${ }^{284}$, ist es gerade die Stärke des Films, die Tragweite dieser Zeit erfahrbar zu machen.

Neben der Rätselstruktur liegt es insbesondere daran, daß Malle die Auswirkungen des Zweiten Weltkriegs auf eine elementare Ebene, die eines französischen Karmeliter-Internats im Jahre 1944, herunterbricht. Man hat dort im Prinzip (a) mit kriegsspezifischen Schwierigkeiten zu kämpfen, aber auch (b) mit allgemeinen, alltäglichen Problemen, die durch die Kriegssituation verschärft werden. ${ }^{285}$

\begin{tabular}{|c|c|}
\hline $\begin{array}{l}\text { (a) spezifische Schwierigkeiten in } \\
\text { Frankreich im Januar } 1944 \text { und daher } \\
\text { auch im Karmeliter-Internat ... }\end{array}$ & $\begin{array}{l}\text { (b) ... oft fußend auf universellen } \\
\text { Gegebenheiten, die durch den Krieg } \\
\text { lediglich verschärft werden }\end{array}$ \\
\hline $\begin{array}{l}\text { Deportation von Juden, } \\
\text { hier von Jean und seinen beiden } \\
\text { Freunden (s. 3.1.6.d) } \\
\text { Judendiskriminierung (und -verfolgung), } \\
\text { hier v.a. im bezug auf M. Meyer } \\
\text { im Restaurant (s. 3.1.5) }\end{array}$ & $\begin{array}{l}\text { Verlust von Freunden, Schulkameraden etc. } \\
\text { Ausgrenzung von Unbekanntem } \\
\text { (s. insb. 3.1.4.ab) }\end{array}$ \\
\hline $\begin{array}{l}\text { Schwarzmarkthandel (s. die schwarzen Ein- } \\
\text { tragungen in der »Motive“-Spur) bis hin zu } \\
\text { »offizieller" Kollaboration (»collaboration“), } \\
\text { hier Joseph und die Miliz }\end{array}$ & $\begin{array}{l}\text { Opportunistentum, Nutznießen aufgrund des } \\
\text { Leids anderer }{ }^{286}\end{array}$ \\
\hline $\begin{array}{l}\text { erste Formen des Widerstandes bis hin zu } \\
\text { »offizieller" Résistance, } \\
\text { hier von François und Pater Jean (Flugblätter) }\end{array}$ & Zivilcourage im Alltag \\
\hline
\end{tabular}




\begin{tabular}{|c|c|}
\hline $\begin{array}{l}\text { Konfrontation zwischen Kollaboration und } \\
\text { Résistance, } \\
\text { hier in der Konfrontation zwischen Julien } \\
\text { und der Krankenschwester (s. 3.1.6.b) } \\
\text { Bestrafung der Widerständler, } \\
\text { hier die Deportation von Pater Jean } \\
\text { (s. } 3.1 .6 . d \text { ) }\end{array}$ & --- \\
\hline $\begin{array}{l}\text { Präsenz deutscher Soldaten (Besatzungs- } \\
\text { macht) bzw. der Gestapo und Fliegeralarm, } \\
\text { hier bei der Kontrolle der Ausgangssperre } \\
\text { (s. 3.1.4.df) und bei Verhaftung am Ende } \\
\text { (s. 3.1.6.d) }\end{array}$ & --- \\
\hline \multicolumn{2}{|c|}{$\begin{array}{l}\text { Trennungs- und Abschiedsschmerz, Leiden unter dem Getrennt-Sein von der Mutter/ } \\
\text { den Eltern aufgrund der Unterbringung der Kinder in Internaten außerhalb der stark } \\
\text { bombardierten Städte; hier von Julien, Jean und den anderen } \\
\text { (s. die Darstellung in der folgenden Graphik) } \\
\text { Anfälligkeit von Außenseitern und sozial schwach Gestellten für totalitäres } \\
\text { Gedankengut; hier Joseph, der zu den Kollaborateuren überwechselt (s. 3.1.6.c) }\end{array}$} \\
\hline --- & $\begin{array}{l}\text { ständige Angst, Alpträume bis hin zu Aus- } \\
\text { einandersetzung mit dem Tod }\end{array}$ \\
\hline --- & $\begin{array}{l}\text { Energieknappheit bzw. schwierige Versor- } \\
\text { gungslage (s. die grünen Eintragungen in } \\
\text { der »Motive“-Spur) und dadurch blühender } \\
\text { Schwarzmarkt, } \\
\text { hier von Julien, François u.a. über Joseph }\end{array}$ \\
\hline --- & $\begin{array}{l}\text { Solidarität der Kirche mit Verfolgten und } \\
\text { Arbeitsdienstverweigerern }{ }^{287} \text {; } \\
\text { hier des Karmeliterordens in bezug auf Jean } \\
\text { und seine Freunde und auf Moreau }\end{array}$ \\
\hline --- & $\begin{array}{l}\text { Kluft zwischen Armen und Reichen, } \\
\text { hier von Pater Jean wiederholt angepran- } \\
\text { gert, insbesondere in einer Messe am } \\
\text { Faschingsdienstag }\end{array}$ \\
\hline
\end{tabular}

287. Das, am 16. Februar 1943 von Laval unterzeichnete, Gesetz verpflichtete die zwischen 1920 und 1922 geborenen Männer für zwei Jahre zum Arbeitsdienst in Deutschland, »um, so der Wortlaut einer offiziellen Verlautbarung, >die Verpflichtungen gerecht auf alle Franzosen zu verteilen, die aus den Bedürfnissen der französischen Wirtschaft entstanden sind , die in Wirklichkeit aber die der deutschen Wirtschaft waren.« (zit. nach Baruch 1999: 149) »[...] die Verweigerer des STO flüchteten in Scharen, so daß zunächst die Präfekten, später die Miliz mit der Jagd auf die Verweigerer beauftragt wurden.« (Ebd. 151)

288. «Wie das von den literarischen Verfahren schon lange behauptet wird, die ebenfalls mit dem in Zeichenkörpern materialisierten kollektiven Gedächtnis umgehen, erstellt der Künstler aus den beiden Potentialen vor und mit den Apparaten Quintessenzen von hoher Konzentration und Depotwirkung. Wir nennen dies >Aufladen<, weil der Terminus in allen mir bekannten Sprachen nicht nur quantitativ und eindimensional das Hinzufügen auf das zeichenkörperliche Vehikel meint, sondern auch qualitativ die Möglichkeit von Sprüngen impliziert [...].« (Kloepfer 1995: 85)

289. Hier und im folgenden steht das Herz für eine freundschaftliche bzw. liebevolle Beziehung, der Blitz für ein negativ spannungsvolles Verhältnis. 


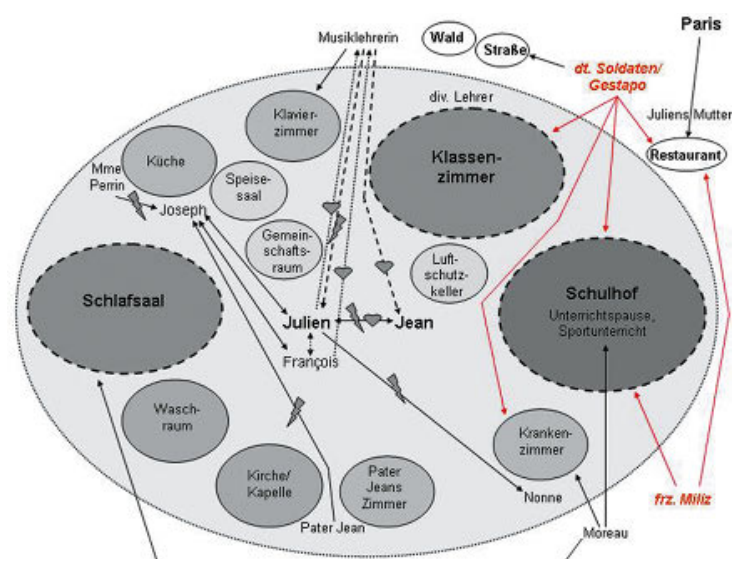

\begin{tabular}{|c|c|}
\hline--- & $\begin{array}{l}\text { Religion und Glaube als Zufluchtsort/ } \\
\text {-möglichkeit, } \\
\text { hier auch aufgrund des Karmeliterordens } \\
\text { häufig präsent, aber auch für Jean wichtig }\end{array}$ \\
\hline--- & $\begin{array}{l}\text { Flucht in literarische Welten bzw. in die } \\
\text { Musik; } \\
\text { hier v.a. Julien und Jean }\end{array}$ \\
\hline--- & Liebe/Sexualität/Pubertät \\
\hline--- & $\begin{array}{l}\text { Tod (Colombat 1993: } 267 \text { zur »constant } \\
\text { presence of death“) } \\
\text { hier durch Juliens vorgetäuschtem Selbst- } \\
\text { mordversuch (s. 3.1.4.cb), seinem Denken } \\
\text { an den Tod (s. 3.1.4.df), Jean Tötung eines } \\
\text { Insekts und dem Schicksal der Abtranspor- } \\
\text { tierten (s. 3.1.6.d) }\end{array}$ \\
\hline--- & $\begin{array}{l}\text { Lüge/Unaufrichtigkeit; } \\
\text { hier bspw. Juliens Imponiergehabe } \\
\text { (s. 3.1.4.dg), die widersprüchlichen Äuße- } \\
\text { rungen der Mutter (s. 3.1.5) }\end{array}$ \\
\hline
\end{tabular}

Dadurch, daß diese zahlreichen Motive im Verlauf des Films in Variation wiederholt auftreten, werden sie sukzessive zu kleinen Systemen »aufgeladen « und so organisch zum Wachstum gebracht. ${ }^{288}$

Die Beschränkung des Handlungsortes sowie fast des gesamten Geschehens auf das Internat ermöglicht dem Zuschauer, die Figuren und das Leben innerhalb der Klostermauern eingehend zu studieren (s. 3.1.2):

»Indem der Regisseur die Handlung in einen eng umgrenzten Raum verlagert, in dem die Kamera (der Erzähler) ständig und überall ungehindert zugegen ist, treten die wahren Charaktereigenschaften und Motive der Kinder - und der Erwachsenen, die sich in ihnen wiederentdecken - um so deutlicher zutage. [...] Die Verlagerung des Handlungsortes und fast des gesamten Geschehens in ein Internat bietet dem Zuschauer die Möglichkeit, das Gesamtgeschehen wie auf einer Bühne zu überblicken [...]« (Ader 1993: 137). ${ }^{289}$ 
»Diese in sich geschlossene und scheinbar ganz aus sich heraus lebende Welt hat nur vordergründig keinen Bezug zur Außenwelt. Im Gegenteil: Sie bildet sie im kleinen ab.« (Ebd. 138)

Dabei stellt man mit Entsetzen fest, daß - abgesehen von den Patres, den LehrerInnen und den drei jüdischen Kindern - die Figuren in dieser zumindest vergleichsweise behüteten Welt »fast durchweg nur auf den eigenen Vorteil aus sind « (Ader 1993: 135). Durch ihr Handeln sind sie letztlich gleichermaßen »Täter und Opfer « (ebd. 133), denn - auch unterlassene - Verhaltensweisen, selbst unter Druck, sind unentschuldbar, weil jeder für sein Handeln verantwortlich ist (ebd. 140):

\section{- Julien:}

Wie sein Bruder François und andere Schüler aus großbürgerlichen Familien handelt Julien über Joseph mit seinen zusätzlichen Essenvorräten um Briefmarken, Murmeln etc., anstatt sie - der Aufforderung von Pater Jean entsprechend ${ }^{2}{ }^{\circ}$ - mit seinen ärmeren Mitschülern zu teilen (s. Abb. II.3.1.d/ II.3.1.2.d; s. 3.1.4.ba). Durch diese »eher naive Mittäterschaft in der Schwarzmarktaffäre« (Ader 1993: 133) stützt er zu seinem eigenen Vorteil das (opportunistische) System des Schwarzmarktes; für Ader ist Julien deshalb »auch zum Kollaborateur geworden« (ebd. 133).

- François:

Wie Julien und andere Schüler aus großbürgerlichen Familien handelt François über Joseph mit seinen zusätzlichen Essenvorräten, vor allem um Zigaretten (s. Abb. II.3.1.d/II.3.1.2.d).

- Joseph:

Obgleich körperbehindert und nicht zuletzt deshalb von allen geschunden und gequält, ist dieser Küchengehilfe (und Underdog) kein »positiver Held [...]: Alles Verbotene, auch das Sexuelle, mit dem er sich vor den anderen zu brüsten sucht, gelangt über ihn in das Kloster. Er ist der heimliche Vermittler zwischen Außenund Binnenwelt und trägt entscheidend zur Korruption und schließlich Vernichtung der Internatsgemeinschaft bei.« (Ader 1993: 137) Letzteres, indem er sich mit der Denunzierung dafür rächt, »auf nicht ganz gerechte Weise« (Malle 1998: 229) aus der Schule geworfen worden zu sein.

- Pater Jean:

Trotz seines bewundernswerten Einsatzes für Verfolgte des kollaborierenden Vichy-Regimes ist auch Internatsleiter Pater Jean nicht unfehlbar. In bezug auf die entdeckten Schwarzmarktgeschäfte im Internat begeht er bewußt - »Je suis obligé de renvoyer Joseph, mais je commets une injustice.« (1:17:26 h) - eine Ungerechtigkeit, als er den Küchengehilfen entläßt, die »Kinder der >besseren Gesellschaft«« (Ader 1993: 137) nur milde bestraft und sie damit in Schutz nimmt: »Si je ne savais

290. »Je rappelle à ceux qui ont des provisions personnelles qu'ils doivent les partager avec leurs camarades. (Ich erinnere diejenigen, die persönliche Lebensmittelvorräte haben, daß sie sie mit ihren Kameraden teilen sollen.)« (0:14:06-0:14:11 h)

291. Selbst der Schlafsaal stellt im Internatsleben nur bedingt einen Zufluchtsort dar, worauf Ader hingewiesen hat: »Die Aufteilung des Internats in die verschiedenen Säle und Innenhöfe mit ihren spezifischen Funktionen zeigt, daß es hier kein eigentliches Refugium gibt. Alles, was geschieht - auch die heimlichen Schwarzmarktgeschäfte der Schüler mit Joseph -, ist der Öffentlichkeit preisgegeben.« (Ader 1993: 138) 
pas tous les problèmes que cela poserait à vos parents, je vous mettrais à la porte tout de suite, vous et votre frère.« (1:17:18 - 1:17:21 h) »Gerade in diesem Kontext hat der Zuschauer das widersprüchliche Verhalten des Priesters zu hinterfragen: Ist nicht auch er korrumpiert « (ebd. 137), wenn er wie beschrieben handelt?

- Moreau (s. Abb. 3.1.d/.3.1.2.d):

Als die kontrollierende französische Miliz sich Zugang zum Internat verschafft, versteckt er sich rasch, ohne Jean mitzunehmen (s. 3.1.4.da). Am Ende des Films hingegen versucht er, Négus vor der Gestapo zu verstecken (s. 3.1.6.b).

- Madame Perrin:

Sie meldet die Schwarzmarktaktivitäten ihres Küchengehilfen Joseph, den sie regelmäßig und zum Teil vor den Augen aller erniedrigt, dem Pater Jean, stiehlt jedoch selbst mehr Vorräte als dieser (s. 3.1.6.c).

- Nonne:

Die als Krankenschwester arbeitende Nonne und einzige im Internat lebende Frau verrät am Ende des Films Négus an die Deutschen (s. 3.1.6.b). »Damit verwirft Louis Malle so vordergründige Ausreden wie: >gegen das Schicksal kann man sich halt nicht wehren $<[\ldots] . \ll($ Ader 1993: 139)

Mit Ausnahme weniger Sequenzen (s. 3.1.3 3.1.4.cb, 3.1.4.df, 3.1.5) spielt der Film innerhalb der Internatsmauern. Dabei kommen den unterschiedlichen Räumen innerhalb des Mikrokosmos spezifische (Wichtigkeit und) Funktionen zu (s. Abb. II.3.1.d, wobei die Größe der Räume der Häufigkeit ihrer Inszenierung entspricht):

- Schulhof:

Dieser am häufigsten (8) vorkommende und über den Film auffällig regelmäßig verteilte Schauplatz ist vor allem ein Ort der Aggression: Hier tragen die Jungen ihre Stelzenkämpfe aus (s. 3.1.4.ab), wird Joseph vor den Augen aller von der Köchin gedemütigt, kulminiert die Rivalität der beiden Hauptfiguren in einer Rangelei (s. 3.1.4.dh), werden die drei jüdischen Jungen und Pater Jean am Ende abgeführt (s. 3.1.6.d).

- Klassenzimmer:

Dieser am zweithäufigsten (6) vorkommende und über den Film relativ regelmäßig verteilte Schauplatz ist vor allem ein Ort intensiver Blicke zwischen Julien und Jean, des fachlichen Imponierens, der Rivalität um die Position des Klassenbesten, aber auch der Ort des unbeabsichtigterweise verratenden Blickes bei Jeans Verhaftung (s. 3.1.6.a).

- Schlafsaal:

Dieser ebenfalls am zweithäufigsten (6) vorkommende und über den Film relativ regelmäßig verteilte Schauplatz ist vor allem ein Ort der Intimität (einsames bzw. gemeinsames Lesen mit Taschenlampe, s. 3.1.3.c u. 3.1.6; Lesen von Briefen, s. 3.1.4.dc), des versteckten Handelns (Beten im Schutze der Nacht, s. 3.1.4.cc; Schnüffeln in anderen Schränken, s. 3.1.4.dc) und des Unterbewußtseins, das sich nachts Ausdruck verschafft (Alpträume und leichter Schlaf, s. 3.1.4.cc; Bettnässen, s. 3.1.4.cc u. 3.1.6). ${ }^{291}$

- Kapelle:

Dieser dreimal (3) und eher kurz vorkommende Schauplatz ist vor allem ein Ort der Besinnung und des Glaubens.

- Waschraum:

Dieser ebenfalls dreimal (3) und eher kurz vorkommende Schauplatz ist ein Ort 
der Streiche/des Piesackens (Wasserspritzen etc.), der Vor- (Eltern kommen zu Besuch) und Rückschau (Bettnässerei der zurückliegenden Nacht, s. 3.1.6).

- Krankenzimmer:

Dieser nur selten (2) vorkommende, jedoch vergleichsweise in längeren Sequenzen inszenierte Schauplatz ist vor allem ein Ort der Konfrontationen und Spannungen (s. 3.1.4.dg u. 3.1.6.b).

- Pater Jeans Zimmer:

Dieser ebenfalls nur selten (2) vorkommende Schauplatz ist vor allem ein Ort der Ehrlichkeit und Aufrichtigkeit, der deutlicheren Worte (s. insb. Pater Jeans Standpauke an die in Schwarzmarktaktivitäten verwickelten Schüler).

- Speisesaal:

Dieser auch nur zweimal (2) vorkommende Schauplatz ist zunächst ein Ort der Lebensmittelknappheit und der Kluft zwischen Reichen und Armen (s. 3.1.4.ba), später ein Ort der gemeinsamen Freude und Sehnsüchte, der Ort- und Zeitenthobenheit (s. 3.1.6).

- Klavierzimmer:

Dieser ebenfalls selten (2) vorkommende, jedoch überaus wichtige Schauplatz in bezug auf die Beziehung zwischen Julien und Jean ist zunächst ein Ort der Rivalität um die Anerkennung der Klavierlehrerin (s. 3.1.4.bc sowie die Darstellung in Abb. II.3.1.d), später ein Ort tiefster Freundschaft (s. 3.1.6).

- Küche:

Dieser auch nur selten (2) vorkommende Schauplatz ist vor allem ein Ort der niederen Bediensteten und der dunklen Geschäfte, insbesondere des Schwarzmarkthandels.

Der Mikrokosmos Internat (dunkelgraue Ellipse in folgender Graphik) ist in bezug auf den Makrokosmos Frankreich (hellgraue umfassende Ellipse in folgender Graphik) jedoch nicht ganz so geschützt, wie es zunächst erscheint. Die von der Besatzung beherrschte Außenwelt wird im Film zwar explizit wenig präsentiert, dringt jedoch auf vielfältige Weise (a) in das Internatsleben (Hauptpfeil und Pfeile in bezug auf die beiden Hauptfiguren) und (b) die umliegenden Schauplätze ein (Einzelpfeile vom linken Rand der Graphik ausgehend):

ad (a):

- Julien wird von einem Mitschüler aufgrund seiner Schwarzmarktgeschäfte mit Joseph gehänselt (s. 3.1.3.c). Wie sein Bruder François und andere Schüler aus großbürgerlichen Familien handelt Julien über Joseph mit seinen zusätzlichen Essenvorräten um Briefmarken, Murmeln etc. (s. 3.1.4.ba). ${ }^{292}$

- Das erste Gespräch zwischen Julien und Jean wird kurzfristig von einem Stromausfall unterbrochen (s. 3.1.3.c).

- Ein deutscher Besatzungssoldat will die Beichte bei einem Pater im Internat ablegen (s. 3.1.4. aa).

292. „Durch seine eher naive Mittäterschaft in der Schwarzmarktaffäre ist Julien auch zum Kollaborateur geworden.« (Ader 1993: 133)

293. Dieser Punkt wird unter (b) aufgeführt, da er, auch wenn er nicht zu den das Internat unmittelbar umgebenden Schauplätzen gehört, am ehesten hier einzuordnen ist. 


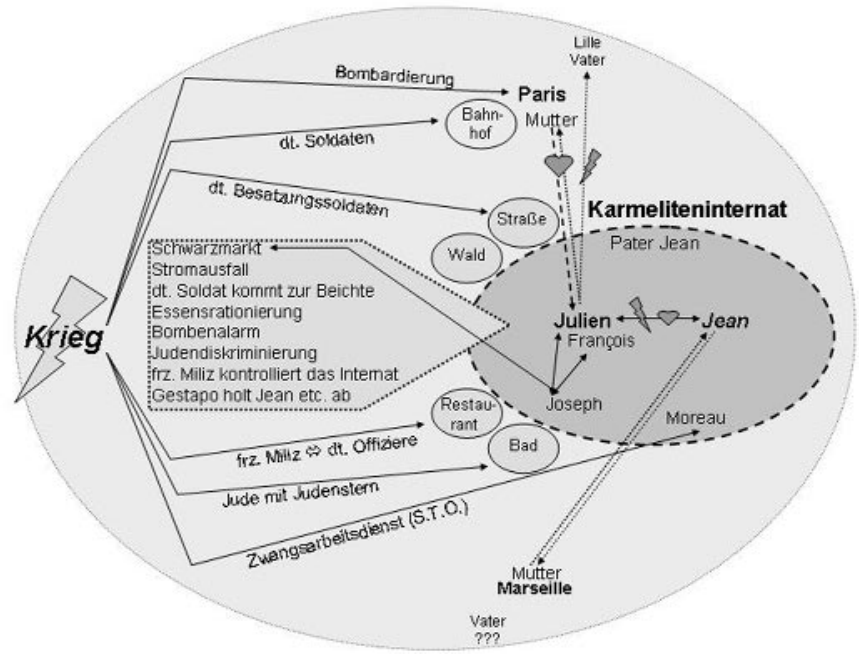

Abb. II.3.1.e

- Während des gemeinsamen Mittagsessens wird die Essensrationierung deutlich spürbar (s. 3.1. 4.ba).

- Ein Fliegeralarm zwingt Juliens Klasse, sich in den Luftschutzkeller zu begeben (s. 3.1.4.bb).

- Juden dürfen, so ein Schild, die Badeanstalt nicht betreten (s. 3.1.4.cb). Der jüdische Stammgast M. Meyer wird von der Miliz beinahe des Restaurants verwiesen (s. 3.1.5).

- Die französische Miliz kontrolliert das Internat (s. 3.1.4.da).

- Die Gestapo holt Jean, seine beiden Freunde und den Internatsleiter Pater Jean ab (s. 3.1.6.d).

- Moreau wurde als Arbeitsdienstverweigerer unter falschem Namen von Pater Jean im Internat aufgenommen und beschäftigt, um ihn vor der Verfolgung zu schützen (unterer Einzelpfeil in Graphik; s. 3.1.4.da).

- Julien leidet unter der Trennung von seiner Mutter und umgekehrt; Madame Quentin versucht diese Trennung mit Briefen zu überbrücken (s. 3.1.4.dc). Den in Lille arbeitenden Vater scheint Julien schon länger nicht mehr gesehen zu haben; insbesondere aufgrund seiner frühpubertären Phase leidet er auch unter dessen Abwesenheit, ein Gefühl, das sich mit der Zeit in Ablehnung und Frustration verwandelt.

- Jean leidet unter der Trennung von seiner Mutter und seinem Vater, die sich mit Ungewißheit über deren Situation mischt: Die Mutter hat ihm seit drei Monaten nicht mehr geschrieben, den Vater, der sich in Gefangenschaft befindet, hat er seit knapp zwei Jahren nicht mehr gesehen.

ad (b):

- Ein Jude mit Judenstern verläßt die Badeanstalt (s. 3.1.4.cb).

- Die kollaborierende Miliz gerät mit deutschen Besatzungsoffizieren im Restaurant in Konflikt;

Juliens Bruder François beschimpft sie als Kollaborateure (s. 3.1.5).

- Deutsche Besatzungssoldaten kontrollieren die Einhaltung der Ausgangssperre (s. 3.1.4.df).

- Deutsche Besatzungssoldaten patrouillieren im Bahnhof von Paris (s. 3.1.3.a).293 
Bei näherem Hinsehen entpuppt sich die Welt des Internats, ganz im Sinne Lotmans, als Modell für die spezifische Lage in Frankreich im Januar 1944:

»)Modellbildend ist Literatur [und Filmkunst; eigene Anm.], weil sie nicht einfach abbildet oder - wie es oft leider heißt - >widerspiegelt<, sondern die mit ihr für die Vorstellung erstellte Welt (oder ein Ausschnitt, natürlich) gibt ein Modell wieder. Und wie wir an einem Modell nicht nur den wiederholten Gegenstand haben, sondern die Prinzipien seines Funktionierens, so ist die Welt der Kunst - wenn sie funktionstüchtig ist - dichter als das, was wir so alltäglich von der sogenannten >Realitätı mitbekommen.« (Kloepfer nach Lotman 2005: 40)

Insofern und aufgrund seiner extremen Forderung der Zuschauer-Eigenleistung handelt es sich bei Auf Wiedersenen, Kinder um einen in der Tradition von Goethe hoch symbolischen Film294: Er läßt den Zuschauer die Prinzipien dieser spezifischen sozio-historischen Situation in Verdichtung erschließen, indem er ihm Begriffe überwiegend vorenthält. Aufgrund dieser Überführung des Zuschauers in den unbegrenzten Prozeß von Analogieschlüssen ist Malles Film darüber hinaus ein Modell für potentielle menschliche und unmenschliche Verhaltensstrukturen in Kriegs- und Krisenzeiten.

Somit geht es in Auf Wiedersehen, Kinder nicht nur um die Schwierigkeiten einer Kinderfreundschaft vor dem Hintergrund der Judenverfolgung im Zweiten Weltkrieg, sondern um die Erkenntnis, daß das »Virus « Nationalsozialismus bzw. Totalitarismus überall lauerte und nahezu alle infiziert hatte - nicht nur in Deutschland, sondern auch in Frankreich.

\subsubsection{Exposition:}

Aus der Welt der Mutterliebe in die »Männerwelt« des Karmeliterinternats

Die Exposition des Films erstreckt sich über drei Sequenzen, den Prolog (s. 3.1.3.a), den Vorspann (s. 3.1.3.b) und die Eröffnungssequenz (s. 3.1.3.c) und damit über insgesamt sieben Minuten.

Insbesondere in den ersten beiden Sequenzen des Films wird der Zuschauer im Hinblick auf seine Haltung gegenüber dem Protagonisten geprägt. Über seinen extremen und als solchen inszenierten Trennungsschmerz wird Julien dem Zuschauer nahe gebracht. Filmisch wird diese Nähe und Empathie durch den verstärkten Einsatz von Nah- und Großaufnahmen sowie durch den Einbezug in seine Perspektive angelegt. Er kann den Jungen nicht nur verstehen, sondern leidet mit ihm, denn dieser muß sich mit zwölf Jahren von seiner geliebten Mutter trennen. Gleichzeitig mit diesem Trennungsschmerz wird das zentrale Motiv von Auf Wiedersenen, Kinder eingeführt, das zusammen mit dem Filmende den Rahmen bildet und das Thema des Films mitbestimmt (s. 3.1.2). Die Exposition führt zudem in beinahe alle weiteren wichtigen Motive des Films ein (Colombat 1993: 269; s. 3.1.3.a, 3.1.3.b und 3.1.3.c).

294. Siehe hierzu Goethe in II.2.1.6.

295. Vgl. Kloepfer 2002: 280 in I.2.3.

296. »[...] the audience is led to believe that the meaning of the title lies in the story of a separation in which a small group of children and Père Jacques will play a key role." (Colombat 1993: 267) Colombat ist hier ein Fehler unterlaufen: Er meint Père Jean, ein Père Jacques existiert im Film nicht, so hieß jedoch Louis Malles Internatsleiter. 


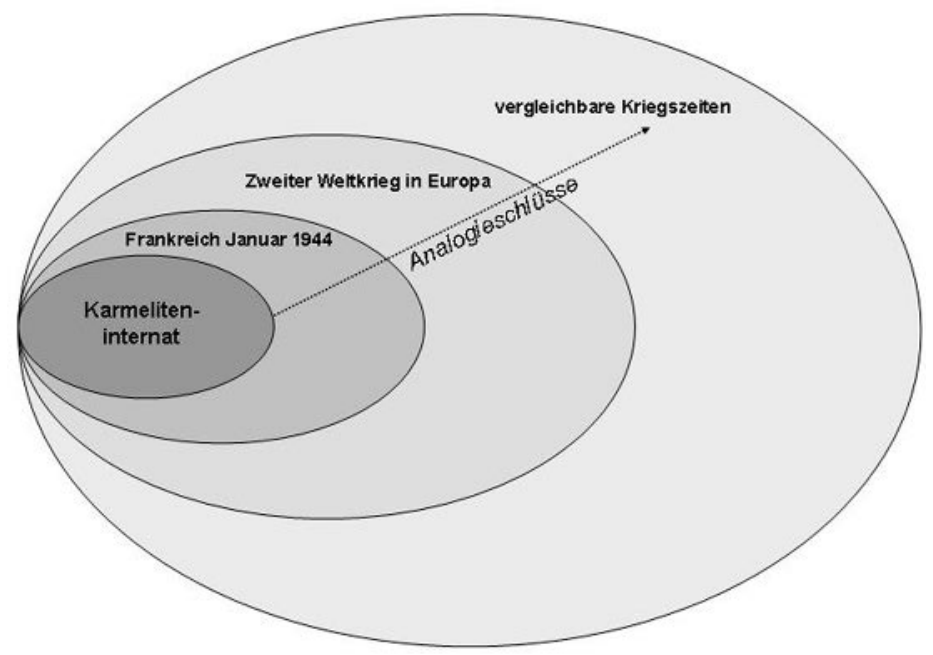

Abb. II.3.1.f

Seiner Rätselstruktur entsprechend (s. 3.1.2), beginnt der Film mittendrin, so daß sich der Adressat fragen muß: »Wie kam es zu dieser Situation, die offenbar eine Folge wichtiger Ereignisse ist? «(Kloepfer 2005: 111) Damit führt die Exposition den Zuschauer in ein zentrales diskursives Charakteristikum des Films - die Zurückhaltung expliziter Information zugunsten verstärkter Eigenleistung (s. 3.1.2): »Weil der Anfang so irritierend ist, stimuliert er ein verstärktes Mitgehen und Mithandeln des Zuschauers (Sympraxis), weshalb dieser wiederum mehr erwartet, wahrnimmt und verarbeitet an Informationen über die dargestellte Welt (Mimesis), was wiederum seine Antizipationen oder sonstigen Handlungen bestätigt, verstärkt und sein Lernen anregt und so weiter.« (Kloepfer 1994: 62) ${ }^{295}$

Trotz des Mangels an expliziten Informationen wird bereits in der Exposition deutlich, daß der spezifische sozio-historische Kontext in das Private eingreift, das persönliche Leben erheblich beeinträchtigt.

Darüber hinaus macht die Exposition den Kontrast zwischen Juliens Verhalten in der Welt der Mutterliebe und dem in der Männerwelt des Internats erfahrbar. So können die Abreise und die Zugfahrt zum Bestimmungsort mit Lotman als »Schwelle« interpretiert werden (1972: 332).

Zweimal wird der Zuschauer in der Exposition an den für das Thema zentralen Filmtitel erinnert, zunächst wörtlich (s. 3.1.4.a), danach in abgewandelter Form (s. 3.1.3.c). ${ }^{296}$

In der dritten Sequenz der Exposition (s. 3.1.3.c) wird die sich im weiteren Verlauf des Films rasch zum Antagonisten von Julien entwickelnde Figur eingeführt.

\section{a) Juliens Trennungsschmerz}

Neben den bereits in 3.1.3 angesprochenen zentralen Motiven deutet Malle im Prolog weitere wichtige Motive des Films an: »Some of the main themes presented during the introductory scene preceding the opening credits are: the absence of the father (in the train station), the physical love of the mother [...], initiation to adult life by sibling and friends (the brother smoking on the platform with a friend) [...].« (Colombat 1993: 269) Es kommen hinzu das Motiv der Lüge bzw. Unaufrichtigkeit sowie die Präsenz deutscher Besatzungssoldaten eingeführt. 
Diese Sequenz ausführlich zu analysieren, ist zentral, da sie - neben dem Motiv der schmerzhaften Trennung von einer geliebten Person - auch aufgrund der besonderen Erzeugung von Empathie mit Julien in Analogie zur Schlußszene steht.

\section{Detaillierte Sequenzanalyse:}

Auf Wiedersehen Kinder beginnt mit einem Prolog. Eine Totale zeigt mehr oder weniger in der Bildmitte eine elegant gekleidete Dame und einen Jungen, der mit gesenktem Kopf vor ihr steht (s. ০:০০:44 h). Da das Kind einen Rucksack trägt und im Hintergrund ein Zug zu erkennen ist, vermutet der Zuschauer eine Abschiedsszene zwischen Mutter und Sohn. Sowohl die Frau als auch der Junge haben die Hände in den Manteltaschen vergraben; es ist wohl Winter. Das Kind vermeidet sogar den Blickkontakt, den die Frau sucht. Gesprochen wird nicht, lediglich das typische dumpfe Hallen in Bahnhöfen prägt akustisch diesen Auftakt.

Dem Treiben auf einem Bahnhof entsprechend, füllt sich wenige Sekunden später das Bild mit umher eilenden Menschen; Stimmengewirr bestimmt die Tonspur. Dabei laufen viele - darunter auch mehrfach deutsche Soldaten in Uniform, ein noch vages Indiz für den sozio-historischen Kontext -, dicht an der Kamera vorbei, so daß die Aufmerksamkeit des Zuschauers für die beiden Hauptfiguren gestört und gleichzeitig intensiviert wird.

Nachdem wir auf der Tonspur die Stimme der Frau vernehmen können, die das Kind in mildem Ton tadelt - »Julien, tu vas pas recommencer. C'est pas raisonnable.« (०:00:52 h) -, folgt das Bild der Tonspur und zeigt die beiden in Nahaufnahme. Der Junge versichert, er weine nicht, was der Zuschauer aufgrund seines immer noch gesenkten Blickes und der tonlosen Stimme bezweifelt. Die Vermutung verfestigt sich, es handelt sich um einen, insbesondere für den Jungen, sehr schmerzhaften Abschied von der Mutter. Auf deren Aufmunterungsversuch - »)'irai vous voir dans trois semaines. [...] Tu verras, ça va passer très vite!« (०:০1:13 h) -, reagiert der Junge mit trotzigem Unverständnis (s. o:01:16 h). Aus einer anderen Perspektive, der Mutter angenähert (over-the-shoulder), sehen wir, wie Julien den Kopf hebt, nicht nur um den Blick seiner Mutter mit traurig-leeren Augen zu erwidern:

297. Daß der Junge seine Mutter siezt, deutet auf eine deutlich zurückliegende Zeit hin.

298. Ihre Aussage enthält im übrigen einen eindeutigen Hinweis darauf, daß sie die Mutter des Kindes ist, unsere Vermutung wird also bestätigt: »Ton père et moi, nous t'écrivons souvent.« (0:01:23 h)

299. Ob dies primär als »revolt against her authority« (Colombat 1993: 269) interpretiert werden kann, sei bezweifelt, denn dieses widersprüchliche Verhalten - unmittelbar danach schmiegt er sich an seine Mutter - wirkt eher wie eine frustrierte Trotzreaktion.

300. Diese Umwertung wird der Zuschauer im weiteren Verlauf des Films erneut vornehmen müssen (s. 3.1.4.bc).

301. »Zunächst sprach ich auch am Beginn aus dem Off. [...] In der Bahnhofsszene sollte meine Stimme sagen, daß ich zur Schule zurückfuhr und wie sehr ich es haßte - aber das erwies sich als überflüssig, denn das, was meine Mutter sprach, drückte alles aus, und ich verwarf die Idee. " (Malle 1998: 244)

302. So erklärt sich auch die Abweichung zwischen Film und Drehbuch: Im Unterschied zum Drehbuch küßt die Mutter Julien im Film nicht auf die Wange, sondern auf die Stirn und hinterläßt dort einen deutlich sichtbaren Abdruck. 


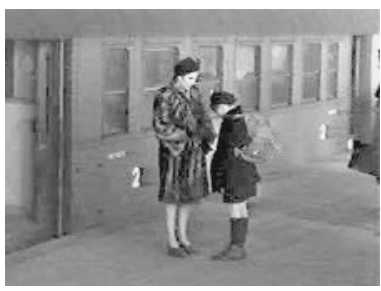

(242) $0: 00: 44 \mathrm{~h}$

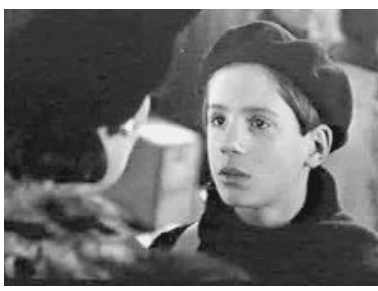

(243) $0: 01: 16 \mathrm{~h}$

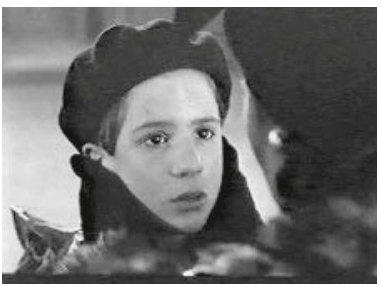

(245) $0: 01: 55 \mathrm{~h}$

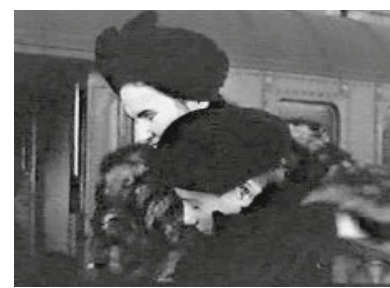

(244) $0: 01: 34 \mathrm{~h}$

»Pourquoi vous dites ça? Vous savez très bien que ça ne va pas passer vite.«(०:০1:19 0:01:21 h) ${ }^{297}$ Auf diese Weise führt Malle das Motiv der Unaufrichtigkeit bzw. der Lüge bereits zu Beginn des Films ein. Auch die Beteuerung der Mutter, sie werde regelmäßig schreiben ${ }^{298}$, kann das Kind nicht aufmuntern: »Je vous déteste« $\left(0: 01: 25\right.$ h) ${ }^{299}$, entgegnet er. Der Kontrast zwischen Juliens nonverbalem Verhalten und seinem letzten Satz stellt diese Äußerung jedoch in Frage. Die feuchten Augen, der Gesichtsausdruck und die offensichtlich nicht vorhandene Freude auf die Zeit fern seiner Mutter, deuten auf das Gegenteil hin ${ }^{300}$ : Der Junge scheint sehr an seiner Mutter zu hängen und unter der bevorstehenden Trennung extrem zu leiden. ${ }^{301}$

Als Schulkameraden Julien grüßen und in den Zug steigen, taucht zum ersten Mal der Titel des Films auf: »Au revoir, les enfants« (০:01:29 h) ruft Juliens Mutter den anderen Kindern hinterher und ermuntert ihren Sohn, sich doch ein wenig auf die Mitschüler zu freuen. Vergeblich: einer der beiden Kameraden sei ein richtiger »crétin« (०:01:31 h), so Julien. Im Unterschied zu den Schulkameraden ist Julien untröstlich.

Schließlich drückt die Mutter ihren Sohn fest an sich, worauf der Zuschauer schon seit Beginn der Sequenz gewartet hat (s. o:01:34 h) - die erste Initiative, auf die der Junge positiv reagiert. In seinem Verhalten spüren wir, daß er genau diese Form der körperlichen Zuwendung braucht, keine verbalen Aufmunterungen. Dankbar und besänftigt vergräbt er sein Gesicht im Mantel der Mutter und schließt dabei wie sie die Augen, um diesen Moment der Nähe auszukosten - ganz im Gegensatz zu seinem etwa vier Jahre älteren Bruder François, der sich, seinem Alter entsprechend, mit einem kurzen Abschiedsküßchen begnügt und gut gelaunt den Zug besteigt.

Durch den Kontrast zu seinem Bruder wird Juliens Kindlichkeit für den Zuschauer besonders deutlich. Es fällt ihm sichtlich schwer, sich von seiner Mutter loszureißen. Während der Schaffner zum Einsteigen auffordert, blickt der Junge seine Mutter mit großen traurigen Augen an (s. ০:01:55 h), aufgrund der angenäherten Figurenperspektive auch uns. Mit der Mutter verspüren wir die Notwendigkeit, dem unter dem Abschiedsschmerz leidenden Jungen einen Kuß auf die Stirn zu geben, was sie schließlich auch tut - Zeichen ihrer liebevollen Fürsorge. ${ }^{302}$ 
Im Anschluß lenkt Malle die Aufmerksamkeit für kurze Zeit auf die Tonspur, um dem Zuschauer ein akustisches Indiz in bezug auf Ort und Zeit der Geschichte zu liefern: »Soldaten der 35. Division auf Gleis 3 und dort die Abfahrt antreten« (0:02:04 h), ertönt es über den Bahnhofslautsprecher. Bereits dreimal waren deutsche Soldaten im Film zu sehen, aber erst diese Durchsage bestätigt die Vermutung des Zuschauers, daß es sich um die Zeit des Zweiten Weltkriegs handeln müsse, in dessen Verlauf weite Teile des Landes von den Deutschen besetzt waren. Die Uniformen, die Kleidung der Protagonisten und Passanten, der Gebrauch des Plural bei der Anrede der Mutter sowie die allgemeine Farblosigkeit der Umgebung ${ }^{303}$ entsprechen dieser Vorstellung.

Eine weitere Bestätigung für die schwierige Trennung des Jungen von seiner Mutter stellt die Szene dar, in der er sich ein letztes Mal in ihre Arme wirft und einen Kuß auf die Stirn erhält, der sichtbare Spuren hinterläßt. Die Kamerapositionierung und die Einstellungsgröße lenken den Zuschauerblick ganz gezielt auf diesen Abdruck, ein Symbol der Prägung (s. ০:02:13 h). Während dieser Umarmung erfahren wir, daß Julien auf dem Weg in ein Internat ist, da er wegen der Besetzung der französischen Hauptstadt nicht bei seiner Mutter bleiben kann.

Parallel hierzu setzt eine getragen-melancholische Klaviermusik ${ }^{304}$ ein, die wir der Gefühlslage, insbesondere von Julien, zuschreiben, der sich, anstatt zu sprechen, ganz der Umarmung hingibt. Ein schrilles Pfeifen als Abfahrtssignal beendet den Prolog und das flüchtige Glück.

\section{b) Juliens Trauer und Isolation}

Der Vorspann von Auf Wiedersehen, Kinder ist zweigeteilt: Zunächst sichert der Regisseur Juliens Trauer über die Trennung ab, danach inszeniert er die Rückkehr der Jungen an den Bestimmungsort.

Im ersten Teil des Vorspanns, der ohne Dialog auskommt, erläutert die aus dem Prolog weitergeführte Klaviermusik »in ganz wörtlichem Sinne, was jeweils das beherrschende Motiv und die sich daraus ergebende dominante innere Bewegung ist.« (Kloepfer 1999: 28) Durch den Einsatz subjektiver Kamera, im Unterschied zum overthe-shoulder-shot mit Julien im Prolog, versetzt Malle den Zuschauer unmittelbarer in Juliens Wahrnehmungswelt. »The dead and cold landscapes« (Colombat 1993: 269), die vor seinen Augen vorüberziehen, ikonisieren seinem Gemütszustand, der Zuschauer stellt automatisch eine Verbindung zwischen der Kargheit der Landschaft und Juliens Innenleben her. Die Einblendung des Titels wird im ersten Teil des Vorspanns durch Kontextualisierung konkretisiert.

Darüber hinaus sichert der Vorspann Juliens, im Prolog bereits angedeutetes, geringes Interesse an seinen Mitschülern ab und führt gleichzeitig sein großes Interesse an Literatur ein.

303. »Was mir von der Besatzungszeit optisch vor allem im Gedächtnis geblieben war, war die Tatsache, daß es keine Farben gegeben hatte. [...] Mir war klar, daß ich den Film in Farbe drehen mußte, daß es aber ein Film fast ohne Farbe werden würde. [...] das einzige Rot, das ich im Film sehen wollte, die Lippen der Mutter seien." (Malle 1998: 235)

304. Hierbei handelt es sich um Schuberts »Moment Musical $n^{\circ} 2 \ll$.

305. Im Drehbuch weint er und wischt sich automatisch den Lippenabdruck von der Wange, nachdem er ihn in der Scheibe gesehen hat. Im Film werden sein Leid sowie der »Übergang« in eine andere Welt weniger explizit dargestellt. 


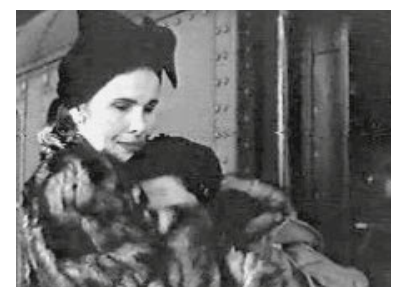

(246) $0: 02: 13 \mathrm{~h}$

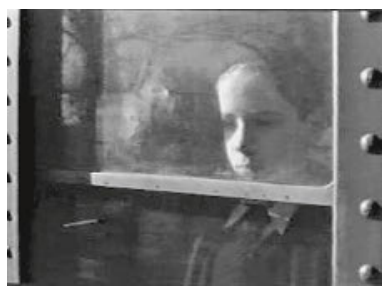

(247) $0: 02: 32 \mathrm{~h}$

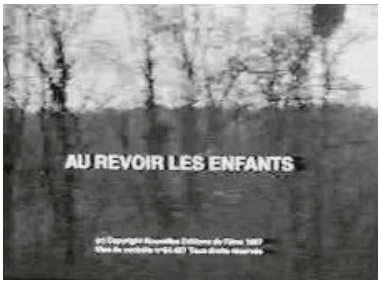

(248) $0: 02: 47 \mathrm{~h}$

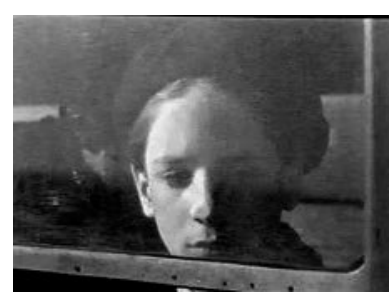

(249) $0: 03: 10 \mathrm{~h}$

Detaillierte Sequenzanalyse:

Zunächst inszeniert Malle den Trennungsschmerz und die Einsamkeit des Jungen, indem er ihn verloren, mit leerem Blick, aus dem Fenster schauen läßt. Die Nahaufnahme betont seinen Gesichtsausdruck, Einstellungsgröße und Lichteinfall lassen den Lippenabdruck auf seiner Stirn hervortreten und verdeutlichen, was in ihm vorgeht und ihn in den Augen seines Bruders und der Mitschüler zum »Muttersöhnchen« stempelt (s. 0:02:32 h). ${ }^{305}$ Juliens Trauer wird nicht nur durch die weitergeführte angesprochene Klaviermusik, sondern auch durch die Bildkomposition unterstützt: Aufgrund der Fensterstreben, die sich zwischen ihm und der Kamera befinden, wirkt er wie gefangen in einem Transportmittel, das ihn - wie wir bereits erfahren haben - an einen ungeliebten Ort bringt; er wird »abtransportiert«.

Der Zuschauer erlebt den Blick des Jungen durch den Einsatz subjektiver Kameraführung: Die Landschaft rauscht vor seinen Augen vorbei, ohne daß er ein Objekt fixieren würde (s. ○:02:47 h) - Julien, so unser Schluß, ist in Gedanken bei seiner Mutter. Die Einblendung des Titels erinnert an den Satz der Mutter im Prolog und intensiviert so das Motiv des Abschieds und der Trennung.

Die folgende Großaufnahme macht den Seelenzustand des Jungen nochmals wirkungsvoll erfahrbar, »geprägt« durch den immer noch sichtbaren Lippenstiftabdruck, preßt er das Gesicht gegen das Zugfenster und verstärkt den Eindruck des IsoliertSeins (s. ०:03:10 h).

Juliens Verhalten steht in krassem Gegensatz zu dem seiner Mitschüler. Diese sind im Hintergrund zu vernehmen und auch schemenhaft zu erkennen, wovon dieser jedoch völlig unberührt bleibt. Unaufhaltsam rollt der Zug in Richtung Bestimmungsort, drängt das Zugrattern auf der Tonspur in den Vordergrund und entfernt den Jungen immer weiter von seiner Mutter. Aus dem Prolog weiß der Zuschauer, daß es für Julien wesentlich Wichtigeres als das Wiedersehen mit seinen Mitschülern gibt. 
Das Eingangsmotiv wird im zweiten Teil des Vorspanns, der die Ankunft der Schüler am Bestimmungsort zeigt, zunächst fortgesetzt: Noch bevor der Zuschauer die Jungen sieht, hört er sie im Chor ein französisches Pfadfinderlied singen: »Il y a longtemps que je t’aime, jamais je ne t’oublirai ...«(0:04:06 h), was Juliens Gemütszustand entspricht.

Gleichzeitig liefert Malle, wie im Prolog, weitere visuelle Indizien für den soziohistorischen Kontext: Am Bildrand sieht man zwei Soldaten die Straße hinunterlaufen, am Straßenrand ist ein Militärlaster geparkt. ${ }^{306}$ Offensichtlich befindet sich auch dieser Ort in der besetzten Zone Frankreichs.

Als die Schülergruppe singend um die Straßenecke biegt, fällt auf, daß sie von Mönchen begleitet wird (s. 0:04:13 h). Unsere Vermutung, daß es sich um eine religiöse Institution handelt, wird wenig später bestätigt (s. ০:04:48 h): Die Kamera fängt das Türschild - »Couvent des Carmes. Petit Collège St. Jean de la Croix« (०:04:48 h) - ein. Um unsere Aufmerksamkeit zu steigern, wird der Blick auf das Schild durch Störfaktoren beeinträchtigt. Es ist nur für kurze Zeit lesbar, da Schüler wiederholt durch das Bild laufen, so daß der Zuschauer besonders konzentriert hinschauen muß, um den spezifischen Charakter der Institution zu erkennen.

Kurz zuvor hatte Malle dem Zuschauer einen ersten Hinweis darauf gegeben, wofür sich Julien interessiert: Als ein Mitschüler ihn fragt, was er zu Weihnachten bekommen habe ${ }^{307}$ - lautet die äußerst knappe Antwort: »Des bouquins.« (0:04:25 h), Bücher; offensichtlich hat Julien keine Lust auf Kommunikation mit den Kameraden.

\section{c) Der Alltag im Internat - Ankunft eines »Neuen «}

Zunächst nutzt Malle diese dritte und letzte Sequenz der Exposition dazu, einige zentrale Motive dieser von männlichen Elementen geprägten Internatswelt in Zeiten des Krieges anzudeuten (Colombat 1993: 270): pubertäres Verhalten unter den Jungen (Rivalität, Imponiergehabe, Sexualität), Schwarzmarktgeschäfte ${ }^{308}$, Engagement der Patres, die Bedeutung von Religion und die Ausgrenzung von Unbekanntem ${ }^{309}$. Zusammen mit dem angesprochenen Schwarzmarkthandel führt die vorliegende Sequenz das Motiv der Versorgungsengpässe - hier durch einen Stromausfall ${ }^{110}$ - ein.

In den letzten beiden Dritteln dieser Sequenz wird die sich im weiteren Verlauf des Films rasch zum Antagonisten von Julien entwickelnde Figur eingeführt. Die erste Begegnung der beiden ist für die weiteren 45 Minuten exemplarisch: Julien spielt den

306. Im Unterschied zum Drehbuch ist die Szene im Film dezenter inszeniert, denn das Drehbuch sieht vor, daß die beiden Soldaten stehen bleiben, um den Jungen hinterherzusehen (Ader 1993: 10).

307. Womit der Zuschauer auch über die Jahreszeit informiert wäre.

308. Aufgrund der extrem angespannten Versorgungslage florierte der Schwarzmarkt. Seine Ausbreitung führte zur Gründung einer für die Versorgung zuständigen Polizei, den sogenannten "Service du contrôle économique» (»Wirtschaftlicher Kontrolldienst«) (Baruch 1999: 171).

309. Diese Abneigung wird in der Stelzenkampf-Sequenz besonders deutlich (s.3.1.4. $\mathrm{ab})$.

310. Der Mangel an Energie »war auch im täglichen Leben spürbar, sei es bei Stromausfällen oder bei den Schwierigkeiten der Versorgung mit Heizmaterial«. (Baruch 1999: 170)

311. Vgl. Colombat 1993: $269 f$. 


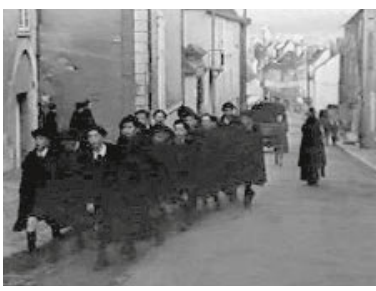

(250) $0: 04: 13 \mathrm{~h}$

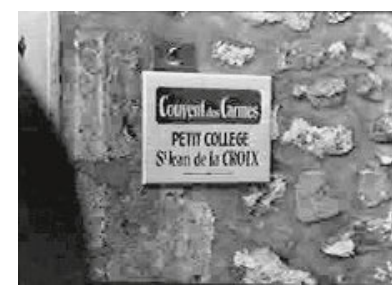

(251) $0: 04: 48 \mathrm{~h}$

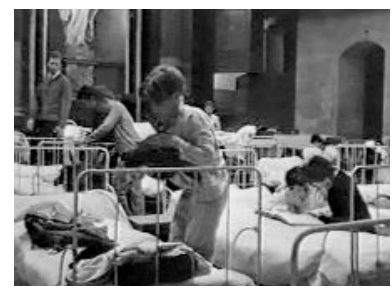

(252) $0: 05: 15 \mathrm{~h}$

distanziert Überlegenen, interessiert sich als »Leseratte« jedoch gleichzeitig für die Bücher seines neuen Mitschülers und Bettnachbarn. Damit manifestiert Malle Juliens Begeisterung für Literatur und deutet ein zentrales verbindendes Motiv zwischen den beiden Hauptfiguren an. ${ }^{\text {11 }}$ Auch der häufige Wechsel zwischen Blickkontakt und Blickvermeidung wird sich im weiteren Verlauf des Films wiederholen, ebenso zahlreiche Indizien für Jeans Andersartigkeit, die in seiner mysteriösen Ankunft als Rätsel angelegt wurde (Colombat 1993: 270).

Diese erste Sequenz verschafft dem Zuschauer einen höheren »Informations «grad bezüglich Jeans besonderer Situation und legt den Grundstein dafür, daß dieser Mikrokosmos als Modell für den Makrokosmos erfahren werden kann (s. Abb. II.3.1.e).

\section{Detaillierte Sequenzanalyse:}

Die Eröffnungssequenz spielt im Schlafsaal des Internats, in dem sich die Jungen nach den Weihnachtsferien wieder einrichten. Zunächst entwickelt Malle das, im zweiten Teil des Vorspanns eingeführte, Motiv der Leidenschaft für Literatur weiter: Während Julien in der ersten Einstellung, im Bildvordergrund, seinen Rucksack auspackt, unterhalten sich im Hintergrund zwei Mitschüler über Geschichten von Jules Verne; am rechten Bildrand beugen sich zwei Jungen über ein großes Buch (s. 0:05:15 h).

Ebenso beiläufig wie spielerisch folgt das Motiv des Schwarzmarkthandels: Als Julien unter anderem Marmeladengläser in seinem Schrank verstaut, beschlagnahmt diese ein Mitschüler mit den Worten: »Marché noir, M. Quentin, je vous arrête!« (0:05:24 h) - ein erster Hinweis auf den blühenden Schwarzmarkt im Internat. Im krassen Gegensatz zu seinem bisherigen Verhalten gibt er sich kämpferisch und droht, seinem provozierenden Kameraden das nächste Mal »die Fresse zu polieren« (०:05:31 h).

Drei Mitschülern, die gebannt auf ein Bild starren, entwendet er dasselbe, um es gespielt souverän zu kommentieren: »Elle a même pas de nichons.«(०:05:36 h) Offenbar handelt es sich um die Abbildung einer leicht bekleideten Frau. In dem von Mönchen geleiteten Internat müssen sich die Jungen, die sich für das andere Geschlecht zu interessieren beginnen, mit Fotos begnügen.

In der folgenden Einstellung inszeniert Malle die bereits erwähnte mysteriöse Ankunft von drei neuen Mitschülern, darunter Juliens neuem Bettnachbarn: Dieser wird von Pater Jean, dem Internatsleiter, als neuer Mitschüler namens Jean Bonnet vorgestellt und abschließend auf das Haar geküßt (s. ০:০6:25 h) - Zeichen besonderer Fürsorge. Wie die Jungen normalerweise mit Neuankömmlingen umgehen, demonstrieren sie, nachdem der Pater mit den Worten des Filmtitels »Bonsoir, les enfants« 
(०:06:32 h) den Raum verlassen hat, indem sie den schüchtern wirkenden Neuling mit Kopfkissen bombardieren (s. ০:06:34 h). Nur Julien enthält sich dieser Form der Initiation und Ausgrenzung; er beteiligt sich auch nicht an den Hänseleien über Jeans Nachnamen. Die noch im Raum anwesende männliche Aufsichtsperson, Moreau, unterbindet das Ärgern und Verspotten unverzüglich, denn der Neue zeigt auffälligerweise keinerlei Anzeichen, sich zu verteidigen.

In der folgenden Szene inszeniert Malle das direkte Aufeinandertreffen der beiden Protagonisten in einer für die erste Stunde des Films charakteristischen Weise: Während Jean ein Schrankabteil zugewiesen bekommt, wird Julien auf die Bücher seines neuen Bettnachbarn aufmerksam und nimmt sie, ohne zu fragen, kurzerhand zum Betrachten aus dessen Koffer. ${ }^{312}$ Diesen scheint das nicht zu stören, im Gegenteil, er fragt Julien schüchtern nach seinem Namen (s. o:06:52 h). Anstatt zu antworten, liest Julien den Titel eines der Bücher vor, das er noch in der Hand hält. Dieser erste Kontakt wird für einige Sekunden unterbrochen, als das Licht plötzlich erlischt und die Jungen zu schreien beginnen; es handele sich um einen Stromausfall, beruhigt sie Moreau - eine unmittelbare Auswirkung des Krieges.

In der Sicherheit der Dunkelheit antwortet Julien schließlich seinem neuen Bettnachbarn in überheblich-forschem Tonfall: »Je m'appelle Julien Quentin. Et si on me cherches, on me trouves.« (0:07:03 - 0:07:05 h) Um seiner Warnung Nachdruck zu verleihen, läßt er Jeans Bücher provozierend aus der Hand fallen und wendet sich kommentarlos ab. Erneut fällt auf - im Unterschied zu den ersten beiden Sequenzen -, daß Julien gegenüber seinen Mitschülern den Starken spielt. Als Reaktion auf die Provokation eines Mitschülers, findet der Zuschauer Juliens Verhalten durchaus verständlich; nicht jedoch in bezug auf Jean.

Das Ende der Sequenz verschafft dem Zuschauer wiederum einen »Informations «vorsprung gegenüber Julien; diesen stellt sie vor ein Rätsel: Die letzte Aufnahme zeigt Jean, der sich für eine in die Wand eingelassene Marienstatue zu interessieren scheint (s. 0:07:19 h). Der Zuschauer nimmt mit ihm die Skulptur wahr (over-theshoulder-shot) und fragt sich, weshalb der Neuling diese, trotz der Dunkelheit, nur ausgiebig betrachtet, anstatt sich zu bekreuzigen oder zu beten.

Diese Beobachtung ist Julien entgangen, weil er sich mit Hilfe einer Taschenlampe seinem Buch widmet - eine erneute Bestätigung seiner Leidenschaft für Literatur.

312. Juliens Interesse an Büchern war bereits in der zweiten Hälfte des Vorspanns angedeutet worden: Als ein Mitschüler von ihm wissen will/wollte, was er zu Weihnachten bekommen hat, antwortete Julien knapp: »Bücher«. Im Unterschied zum Drehbuch, in dem Julien Jean beim Auspacken seiner Bücher beobachtet, nimmt er im Film die Bücher von sich aus in die Hand, ohne Jean zu fragen. Auf diese Weise wird er im Film als forscher und stärker Überlegenheit vorgebend präsentiert.

313. »Leurs caractères diffèrent profondément: tandis que Jean est discret, introverti et très intelligent, Julien est un enfant plutôt extraverti et un peu rusé.« (Moos/Frank 1992: 1)

314. Nachvollziehbar ist die Entwicklung ihrer Beziehung vor allem an der Qualität der Blicke, die sie sich zuwerfen bzw. austauschen, und an ihrer gemeinsamen Leidenschaft, dem Lesen. 


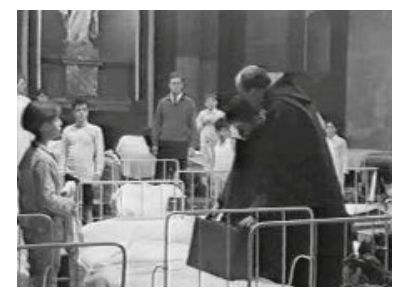

(253) $0: 06: 25 \mathrm{~h}$

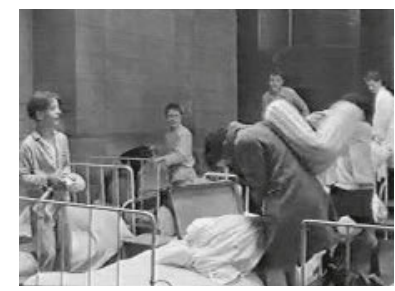

(254) $0: 06: 34 \mathrm{~h}$

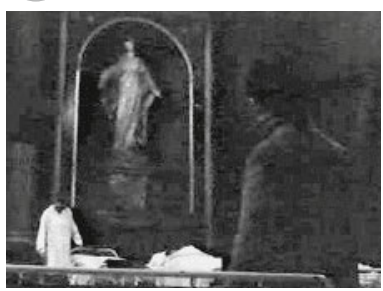

(256) $0: 07: 19 \mathrm{~h}$

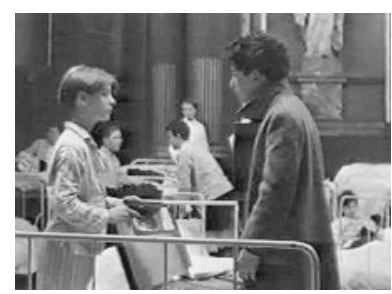

(255) $0: 06: 52 \mathrm{~h}$

3.1.4 Die erste Stunde des Films - spannende Auflösung des Rätsels um Jean und aufkeimende Freundschaft zwischen den Rivalen

Neben der bereits erwähnten Intention, den Zuschauer den Mikrokosmos Internat als Modell für den Makrokosmos Frankreich erfahren zu lassen, versucht der Regisseur in der ersten Stunde des Films, vor allem die allmählich aufkeimende Freundschaft zwischen Julien und Jean sowie sukzessive die Lösung des Geheimnisses um letzteren aufzuzeigen (s. Abb. II.3.1.c). Ebenso wie Julien versuchen auch wir über weite Teile, das Rätsel um Jean zu lösen.

Die erste Stunde des Films widmet sich demnach - neben der Inszenierung des Mikrokosmos Karmeliter-Internat als Modell für den Makrokosmos Frankreich im Januar 1944 (s. Abb. II.3.1.e) - vor allem der allmählich aufkeimenden Freundschaft der Jungen und der sukzessiven Aufdeckung des Rätsels um den jüdischen Jungen.

Die erste Stunde des Films wird durch mehrere Spannungsverhältnisse getragen:

- die diskrepante Informiertheit zwischen dem Zuschauer und dem Protagonisten, Julien;

- die zwischen den Polen Sym- und Antipathie schwankende Haltung des Zuschauers Julien gegenüber;

- die unterschiedlichen Charaktere der beiden Hauptfiguren ${ }^{313}$ und insbesondere das zwischen Interesse und Konkurrenz oszillierende Verhältnis zwischen Julien und Jean, das sich gegen Ende der ersten Filmstunde aufgrund gemeinsamer Interessen, einer gewissen Seelenverwandtschaft, in Richtung Freundschaft entwickelt ${ }^{314}$;

- die das Internatsleben kennzeichnenden Machtgefälle zwischen älteren und jüngeren Schülern, zwischen eingesessenen, französischen und neuen, »anderen« Jungen;

- die Abgeschlossenheit des Internats von der Außenwelt, die zunehmend in die scheinbar behütete Welt eindringt (s. Abb. II.3.1.d). 
a) Gegenseitiges Interesse von Julien und Jean -

Vermutungen des Zuschauers versus Juliens Unwissenheit

Zwischen der siebten und der dreizehnten Filmminute bestätigen zwei Sequenzen das, gegen Ende der Exposition angedeutete, gegenseitige Interesse beider Jungen. Nach beiden Sequenzen kann der Zuschauer in bezug auf Jean bereits erste Vermutungen anstellen, während Julien den neuen Mitschüler noch als geheimnisvoll empfindet (s. Abb. 3.1.c).

\section{aa) Jean bemerkt als einziger den deutschen}

\section{Soldaten und wechselseitiges Interesse von Jean und Julien}

Ein weiteres Indiz dafür, daß Jean sich von seinen Mitschülern unterscheidet, bleibt von Julien ebenfalls unbemerkt. Während einer Unterrichtsszene im Klassenzimmer (Sequenz 6) versetzt uns Malle zum ersten Mal im Film unmittelbar in Jeans Wahrnehmung und verschafft uns dadurch einen weiteren »Informations «vorsprung sowie ein Identifikationsangebot.

Während wir Jean und seinen Tischnachbarn aus neutraler Perspektive beim Schreiben beobachten, hören wir auf der Tonspur eine männliche Stimme »Pater« (o:10:13 h) rufen. Auffälligerweise reagiert Jean sofort und als einziger auf diesen Ruf in deutscher Sprache, der offensichtlich von draußen kommt. Er blickt in Richtung Fenster und beugt sich zum besseren Sehen nach vorne (s. o:10:21 h). Während die Spannung des Zuschauers auf den Urheber der Störung steigt, verfolgt er mit Jean (subjektive Kamera), wie ein junger Mann in Uniform mit einem der Mönche spricht: »Bitte Pater, ich möchte die Beichte ablegen. Je voudrais me confesser« (s. 0:10:25 h). Aussehen (arischer Typ, Uniform) und Sprache (perfektes Deutsch, gebrochenes Französisch) legen den Schluß nahe, daß es sich um einen Angehörigen der Besatzungsmacht handelt. ${ }^{35}$ Für den Zuschauer stellt sich die Frauge, weshalb Jean die Szene vor dem Fenster so intensiv verfolgt, während seine Kameraden dafür keinerlei Aufmerksamkeit zeigen. ${ }^{316}$

Nach diesem Zwischenfall arbeitet Jean weiter, während Julien mit seinem Zirkel spielt und sich kleine Stiche zufügt. Ohne ersichtlichen Grund dreht er sich zu Jean um (s. o:10:30 h), wobei die Kameraperspektive (subjektive Kamera mit Julien) dem Zuschauer vermittelt, daß dieser den fixierenden Blick spürt und schließlich erwidert (s. o:10:34 h). Zum zweiten Mal im Film versetzt uns Malle unmittelbar in Jeans Wahrnehmung, er hält Juliens forschendem Blick stand (s. o:10:35 h). So tasten sich beide in diesem ersten intensiven Blickkontakt mit den Augen ab, bevor Julien sich wieder

315. Vgl. Aders hellsichtige Interpretation in bezug auf das Auftauchen des Deutschen im Internat: »[...] sein Erscheinen zeigt, daß diese Welt nicht so abgeschlossen ist, wie es den Anschein hat. Auch die Tatsache, daß er beichten will, trägt nicht dazu bei, beim Betrachter Erleichterung auszulösen.« (1993: 133) Ab dem 11.11.1942 war ganz Frankreich von deutschen und italienischen Truppen besetzt, nicht mehr nur das Gebiet nördlich der Demarkationslinie (Baruch 1999: 144ff.). Hinweise auf die deutsche Besatzungsmacht erhielt der Zuschauer bereits in der Exposition (s. 3.1.3).

316. Im Unterschied zum Drehbuch entgeht Julien im Film Jeans Interesse für den deutschen Soldaten. 


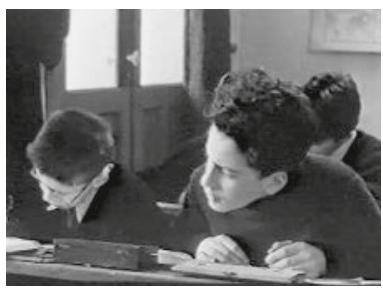

(257) $0: 10: 21 \mathrm{~h}$

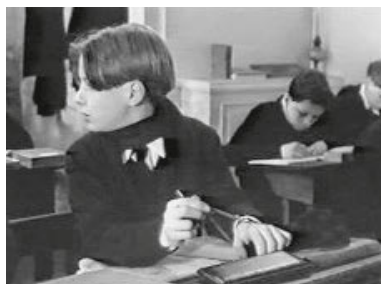

(259) $0: 10: 30 \mathrm{~h}$

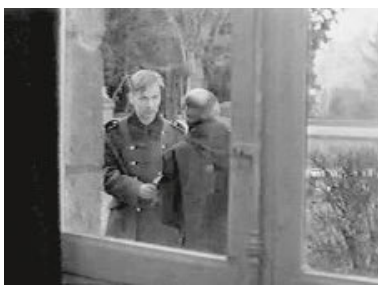

(258) $0: 10: 25 \mathrm{~h}$

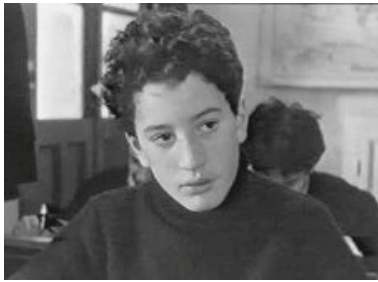

(260) $0: 10: 34 \mathrm{~h}$

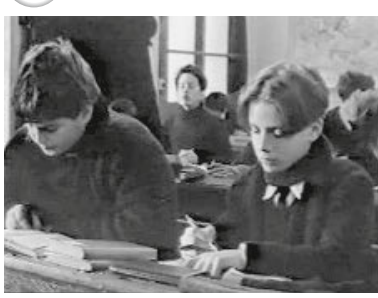

$2620: 10: 48 \mathrm{~h}$

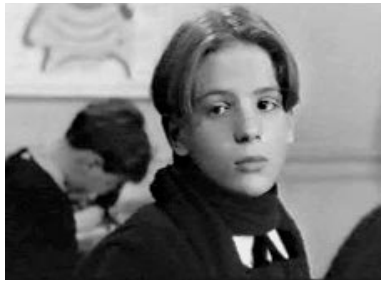

(261) $0: 10: 35 \mathrm{~h}$

seinen Zirkelexperimenten widmet. Durch den Einsatz der subjektiven Kamera, den schnellen Schnitten sowie die nahen Einstellungsgrößen wird der Zuschauer in diesen Moment eingebunden und spürt intensiv das aufkeimende gegenseitige Interesse der beiden Jungen. Die anderen Schüler schenken dem Neuen, verglichen mit Julien, deutlich weniger Aufmerksamkeit.

Eine weitere Bestätigung des gegenseitigen Interesses erfährt der Zuschauer durch folgende Wahrnehmung: Jean reckt sich von seinem Stuhl in die Höhe, um besser sehen zu können, was Julien mit seinem Zirkel ausprobiert (s. ০:10:48 h).

\section{ab) Außenseiter Négus ist Jeans bester Freund - der Stelzenkampf}

zwischen Christentum und Judentum als Modell für den sozio-historischen Kontext Im Zentrum der Folgesequenz (Sequenz 7) im Schulhof steht ein Stelzenkampf zwischen zwei älteren Jungen, den Malle als Modell für das konfliktreiche Leben, die Abneigung gegenüber und die Ausgrenzung von Fremdem inszeniert. Nachdem Julien von Laviron, einem älteren Internatsschüler, von den Stelzen gestoßen und dabei verletzt wurde, attackiert ein Schüler in vergleichbarem Alter den Aggressor:

Négus: „En garde, Laviron, lâche, traître, félon. C'est moi, Négus, le chevalier noir, protecteur des faibles et des orphelins.« 
Laviron: «Arrière, moricaud. Je suis Richard Cour de Lion, l'orgueil des la Chrétienté. Je vais te bouter hors de Jérusalem. Sarazin infidèle, fils de chienne.«

Négus: „Allah et Dieu et Mahomet est son prophète. Tu trembles, monzami. Cœur de Lion, tête de lard, peau de vache, cul de poule ...« (0:12:01 - 0:12:25 h)

Daß es sich bei diesem Kampf nicht um einen gewöhnlichen Machtkampf unter Schülern in der Unterrichtspause handelt, sichert Malle mehrfach ab: Zum einen sind die mit Verbalinjurien versehenen Schlachtrufe der Kontrahenten religiös konnotiert: Islam (Négus, Titel der Kaiser Äthiopiens) gegen Christentum (Richard Löwenherz, König von England). ${ }^{317}$ Zum anderen macht Malle die Aggressivität dieser Konfrontation filmisch erfahrbar: Im Kontrast zur vorher ruhigen Kameraführung ikonisiert die wakkelnde Kamera die hoch-aggressive Atmosphäre - »le combat devient une joute médiévale« (Malle zit.n. Ader 1993: 22)..$^{318}$ In Kombination mit den zunächst vergleichsweise nahen Einstellungsgrößen, insbesondere jedoch dem Einbezug in die jeweilige Figurenperspektive, bezieht Malle den Zuschauer maximal in die dramatische Situation ein (s. 0:12:09 h und o:12:17 h). Darüber hinaus bilden die anderen Internatsschüler einen Kreis um die beiden Widersacher und schlagen sich lautstark auf die ihnen sympathischere Seite (s. o:12:20 h). ${ }^{319}$ Hierbei fällt auf, daß die meisten Jungen hinter Laviron stehen - offenbar ist er fester Bestandteil des Internatslebens, trägt die entsprechende Kleidung und gibt sich als Verteidiger des Christentums aus. Négus hingegen unterscheidet sich rein äußerlich bereits von den anderen Jungen: Er hat dunklere Haut - weshalb ihn Laviron auch mit »Mohr« bezeichnet (s.o.), schwarzes, krauses Haar ${ }^{320}$ und trägt - wie Bonnet - keine Schuluniform. Darüber hinaus verteidigt er für die Jungen fremde und vermutlich unbekannte religiöse Werte. Obgleich die Auseinandersetzung die Grenzen eines Spiels deutlich überschreitet, greifen weder die Schüler noch die erwachsenen Aufsichtspersonen (Moreau, Pater Michel) frühzeitig ein: »Sie tolerieren großzügig das aggressive Spiel und scheinen darin aufkeimende Abneigung gegen alles Fremde nicht zu bemerken.« (Ader 1993: 136)

Als Jean den Kreis der zuschauenden Schüler betritt, schlägt er sich als einer der wenigen auf Négus' Seite: »Allez, Négus!« (o:12:30 h) $)^{321}$ Völlig verdutzt starrt der zufällig neben ihm stehende Julien ihn daraufhin an (s. o:12:36 h). Ebenso wie wir ist er erstaunt darüber, daß Jean sich für den Außenseiter einsetzt. Die sich anschließende kurze Unterhaltung zwischen beiden liefert erste Erklärungen für Jeans sonderbares Verhalten:

317. »Die Schlachtrufe [...] zeigen aber, daß es dem Regisseur zugleich um mehr geht als um das Spiel.« (Ader 1993: 136)

318. »Der Kampf entwickelt sich zu einem mittelalterlichen Lanzenstechen.«

319. „Im übrigen löst Négus' Eintreten für einen Schwächeren unter den anderen Jungen und insbesondere bei Julien große Verwunderung aus. Hier wird die Diskrepanz zwischen dem als normal empfundenen Miteinander und dem Fremden, das abgelehnt wird, besonders deutlich.« (Ader 1993: 136)

320. Vgl. die entsprechende Beschreibung im Drehbuch: »cheveux noirs crêpus« (Ader 1993: 22).

321. 》Jean [...] hides but protects and never denies his Jewish faith and identity. [...] During a game in the courtyard, he openly takes the defense of his friend >Négus fighting >Richard Coeur de Lion`.« (Colombat 1993: 262) 


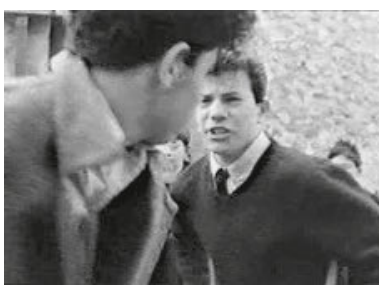

(263) $0: 12: 09 \mathrm{~h}$

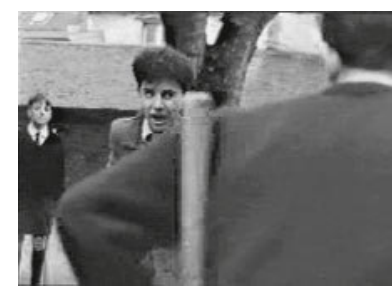

(264) $0: 12: 17 \mathrm{~h}$

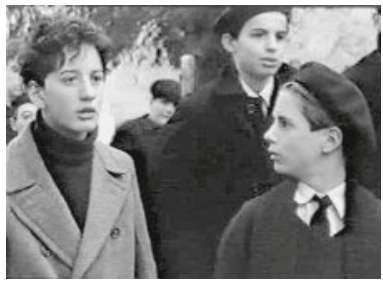

(266) $0: 12: 36 \mathrm{~h}$

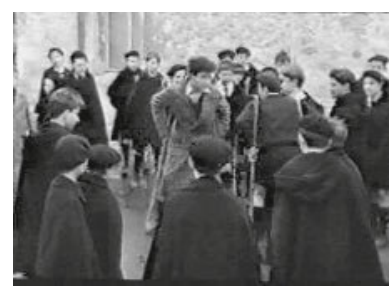

(265) $0: 12: 20 \mathrm{~h}$

Julien: „C'est son vrai nom, Négus?«

Jean: „ $\quad$ Qu'est-ce que tu crois?«

Julien: „ Il a une sale gueule. Tu le connais?«

Jean: „ »Il s'appelle Lafarge et c'est mon meilleur ami!« (o:12:39 - o:12:47 h)

Die Tatsache, daß Jean Négus als seinen besten Freund bezeichnet, bestätigt die Außenseiterrolle der beiden. Der Zuschauer kann sich in diesem Moment erinnern, daß Jean in der Eröffnungssequenz zusammen mit zwei anderen Jungen neu angekommen war, die jedoch in einen anderen Schlafsaal geführt wurden (s. 3.1.3.c). Auffälligerweise tragen Jean und Négus in dieser Sequenz einen ähnlichen Mantel, was einen Zusammenhang zwischen beiden erkennen läßt.

Wenig später, zu Beginn von Sequenz 10, wird deren Verbundenheit erneut abgesichert. In einer anderen Unterrichtspause registriert Julien, daß sich Jean mit Négus und dem dritten Neuankömmling im Internat angeregt und freundschaftlich unterhält.

Indizien, daß die offensichtlichen Außenseiter Angehörige einer anderen Konfession sind, kann man den verbalen Attacken während des Stelzenkampfes bzw. dem Verhalten von Jean angesichts der Marienstatue entnehmen (s. 3.1.3.c).

Im Unterschied zu den vorangegangenen Szenen, in denen dem Zuschauer ein »Informations «vorsprung eingeräumt wurde, nimmt er hier die beschriebenen Ereignisse parallel zu Julien wahr, kann sie jedoch aufgrund seines höheren »Informations «grades sowie seines größeren generellen Vorwissens besser einordnen.

\section{b) Gegenseitige Rivalität zwischen beiden Jungen -}

aufkommender Verdacht des Zuschauers versus Juliens zunehmende Vermutung Zwischen der 13. und der 26. Filmminute entwickeln drei Sequenzen das Konkurrenzverhalten von Julien gegenüber Jean um die Position des Klassenbesten (s. 3.1.4.ba, 3.1.4. bb, 3.1.4.bc). Während beim Zuschauer in bezug auf Jean ein Verdacht aufkommt, nähert sich Julien erst der Vermutung (s. Abb. 3.1.c/.3.1.2.c). 
ba) Jeans Verzicht auf das letzte Stück Fleisch - gemeinsames Mittagessen im Speisesaal Eine kurze Szene, während des gemeinsamen Mittagessens im Speisesaal (Sequenz 9), läßt den »Wissens«vorsprung des Zuschauers weiter anwachsen, da Julien diese Situation einmal mehr nicht wahrnimmt: Als Jean seinem Tischnachbarn das letzte Stück Fleisch überläßt, ist der Zuschauer zunächst reichlich verwundert. Da wir jedoch durch die vorangegangene Ansprache von Pater Jean wissen, daß das Essen extrem knapp ist ${ }^{322}$, kann man vermuten, daß es sich bei Jeans eigenartigem Verhalten kaum um bloße Freundlichkeit handelt. Im Zusammenhang mit der Folgesequenz kommt daher der Verdacht auf, daß Jean Jude ist und daher kein Schweinefleisch essen darf.

In Sequenz 10 geht es um Schwarzmarktgeschäfte zwischen Julien und Joseph (s. o:17:25 h), Lebensmittelknappheit, Schweineschlachten, akustisch untermalt durch die Tierlaute. Auf diese Weise läßt Malle »Musik und Geräusche wirken, ohne daß wir uns der Färbung und Steuerung des Bewußtseins bewußt sind.« (Kloepfer 1999: 27) Hierbei nutzt der Regisseur die Fähigkeit des Menschen zum Wahrnehmungslernen und zur vorbewußten Informationsverarbeitung (s. 3.1.2). Aufgrund der Tatsache, daß Jeans Verzicht auf das Fleisch und die Inszenierung des Schlachtviehs mehr oder weniger unmittelbar aufeinanderfolgen, stellt der Zuschauer vorbewußt einen Zusammenhang zwischen beidem her. ${ }^{323}$ Josephs abfällige Randbemerkung über Juden - hier in Form einer Beleidigung, weil Julien unerbittlich handelt ${ }^{324}$-, führt nebenbei und zum ersten Mal im Film die Diskriminierung von Juden ein. Während Julien mit dieser Beleidigung sichtlich wenig anfangen kann, liefert sie dem Zuschauer das dritte Element in der logischen Kette (Fleischverzicht - Schweinefleisch - Jude).

\section{bb) Juliens Konkurrenzverhalten im Mathematikunterricht und Jeans Andersgläubigkeit} Sequenz 11 und 12 enthalten eindeutige Hinweise darauf, daß Jean nicht der katholischen Religion angehört. Der erste wird von Julien wahrgenommen und auch für den Zuschauer auf besondere Weise inszeniert, so daß er Jean gleichzeitig mit dem Protagonisten beobachtet.

322. »Die Situation war vor allem in der Versorgung besonders kritisch. [...] Die Aufteilung in zwei getrennte Zonen, dazu die englische Blockade und die deutschen Entnahmen verursachten während der gesamten Dauer der Besatzung eine Unterernährung der Bevölkerung.« (Baruch 1999: 170f.)

323. »>Mikrostrukturen nennen wir alles, was zeichenvermittelt in unserem Arbeitsgedächtnis bis zu 3 Minuten oder etwas länger simultan verarbeitet wird.« (Kloepfer 2005: 110)

324. »T'es un vrai juif, toi.« (0:16:59 h)

325. »Ab 1943 gehörten [die Luftangriffe] endgültig zum täglichen Leben; sie forderten insgesamt 60.000 0pfer.« (Baruch 1999: 173)

326. Jean: »Tu m'éclaires?« - Julien: »Fous-moi la paix!« - Jean: »Lève un peu la lampe, je vois rien.« - Julien: »Je vais me faire piquer. Ah, tu me fais chier.« (0:20:30-0:20:34 h)

327. Man erinnere sich an seine Faxen im Französischunterricht (Sequenz 6) und während des Mittagessens (Sequenz 9).

328. Darin unterscheidet sich der Film vom Drehbuch, in dem dieses Indiz auf Jeans Andersgläubigkeit nicht enthalten war.

329. Siehe Wuss zur Invariantenbildung der Wahrnehmung in 3.1.2. 


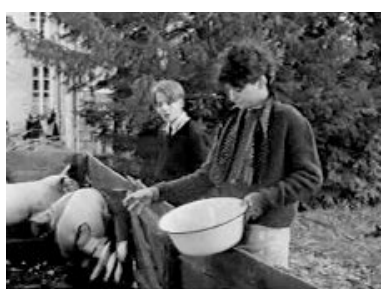

(267) $0: 17: 25 \mathrm{~h}$

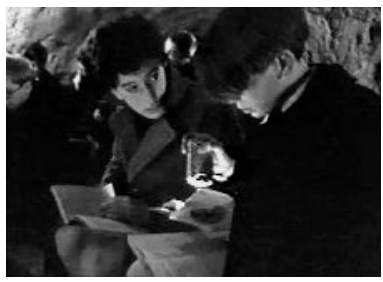

(269) $0: 20: 31 \mathrm{~h}$

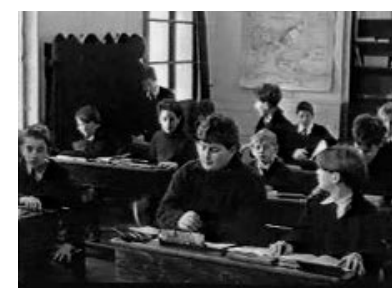

(268) $0: 19: 24 \mathrm{~h}$

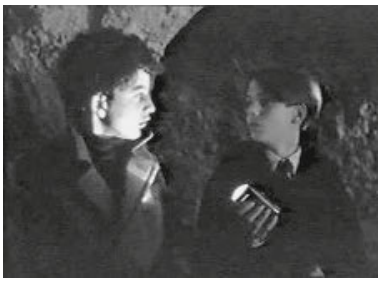

(270) $0: 21: 04 \mathrm{~h}$

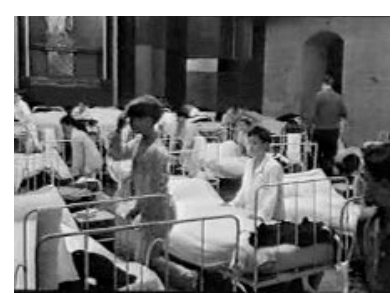

(271) $0: 21: 37 \mathrm{~h}$

Nachdem Jean im Mathematikunterricht eine Aufgabe an der Tafel souverän lösen und erklären konnte, scheint Julien, ebenso wie der Zuschauer, von den fachlichen Qualitäten des neuen Mitschülers tief beeindruckt zu sein. Jean, der Juliens Blick spürt, erwidert diesen kurz (s. o:19:24 h). Daß Julien der einzige ist, der Jean besondere Aufmerksamkeit widmet, könnte daraufhin deuten, daß er in ihm einen Rivalen um die Position des Klassenprimus fürchtet.

Diese vage Vermutung wird eine Minute später bestätigt. Als Julien nach Fliegeralarm ${ }^{325}$ im Luftschutzbunker vom Schein seiner Taschenlampe profitiert, verweigert er Jean, an diesem Licht teilzuhaben (s. 0:20:31 h). Er vermeidet den Blickkontakt und dreht ihm trotzig den Rücken zu. ${ }^{226}$ Trotz dieses egoistischen Verhaltens spürt der Zuschauer darin keine grundsätzliche Boshaftigkeit, sondern den für Kinder charakteristischen Umgang mit Rivalen - schließlich steht Julien, wie wir aus vorangegangenen Szenen wissen ${ }^{327}$, gerne selbst im Mittelpunkt (s. 3.1.4.bb).

Aufgrund des angesprochenen Fliegeralarms müssen die Kinder mit ihrem Lehrer in den Bunker, wo sie - als sie die dumpfen Einschläge von draußen hören - gemeinsam »Je vous salue Marie« (»Ave Maria«) beten. Nur Jean spricht das Gebet nicht mit. Indem Julien ihn provozierend mit seiner Taschenlampe anleuchtet, wird Jeans außergewöhnliches Verhalten auch für Julien deutlich (s. o:21:04 h). ${ }^{328}$ Nach dem intensiven Betrachten der Marienstatue (s. 3.1.3.c), seinem Verhalten beim Stelzenkampf (s. 3.1.4.ab) und dem Verzicht auf das Schweinefleisch (s. 3.1.4.ba) ist dies ein weiteres Indiz dafür, daß Jean einer anderen Konfession angehört.

In der Folgesequenz wird Jeans Andersgläubigkeit für den Zuschauer abgesichert. Die Vermutungen des Zuschauers hinsichtlich Jeans Andersgläubigkeit erhärten sich, Perzeptuelles schlägt in Konzeptuelles um²9, denn Jean ist der einzige, der sich beim abendlichen Gebet nicht bekreuzigt (s. 0:21:37 h), was Julien allerdings entgeht (s. Abb. 3.1c). 
Jeans ständige Wachsamkeit, die sich bereits in der Reaktion auf den deutschen Soldaten zeigte (s. 3.1.4.aa), wird gegen Ende der vorliegenden Sequenz bestätigt: Als mitten in der Nacht ein Junge plötzlich wild um sich schlägt und »Nein, nein, nein!« ruft, ist Jean der einzige, der aus dem Schlaf gerissen wird und auf den Alptraum des Mitschülers reagiert - Zeichen seiner eigenen ständigen Angstzustandes: »Quoi! Qu'est-ce que c'est? « Julien, der zuvor infolge seines Bettnässens - Indiz auch seiner insbesondere vorbewußten Angst - aufgewacht war, registriert Jeans extreme Ruhelosigkeit. Als Jean Juliens Aufmerksamkeit bemerkt, wechseln sie einen intensiven, aber stummen Blick des Verständnisses (s. $0: 23: 50 \mathrm{~h}$ ), wohl aufgrund ihrer gemeinsamen Ängste.

\section{bc) Mitleid mit Julien - Juliens schwere Enttäuschung in der Klavierstunde bei der attraktiven Klavierlehrerin}

In Sequenz 14 wird Juliens Schwierigkeit, sich mit der Rolle des jetzt Zweitbesten anzufreunden, abgesichert und für den Zuschauer als besonders erfahrbar inszeniert: Nachdem die Klavierlehrerin in der vorangegangenen Sequenz unmißverständlich als Objekt pubertären Begehrens inszeniert wurde - sie ist nicht nur die einzige junge Frau im Internat, sondern darüber hinaus äußerst attraktiv -, versucht Julien, ihr während des Klavierunterrichts zu gefallen. Da er noch nicht sehr gut spielen kann, ist das Gegenteil der Fall: Gelangweilt schaut die junge Frau aus dem Fenster oder widmet sich ihren Fingernägeln; sie schenkt Julien kaum Beachtung, geschweige denn ein nettes Lächeln. »Tu devrais essayer le violon« (0:25:46 h), lautet ihr ebenso vernichtender wie herzloser Kommentar. Dies schmerzt den Jungen um so mehr, als er erleben muß, wie sich die Lehrerin für Jeans Klavierkünste begeistert. Sie widmet ihm ihre volle Aufmerksamkeit und zollt ihm wohlwollende Anerkennung bzw. Begeisterung für sein Spiel. ${ }^{330}$ Anstatt sofort ins Hauptgebäude zurückzukehren, beobachtet Julien diese Szene. Der Zuschauer erlebt die Situation einerseits unmittelbar mit dem Protagonisten, aus seiner Perspektive und Einstellung heraus (s. 0:26:34 h). Andererseits lenkt die Nahaufnahme - von Malle eher sparsam eingesetzt und daher besonders wirkungsvoll - aus neutraler Perspektive unsere Aufmerksamkeit auf seine Reaktion (s. o:26:43 h): Ähnlich wie im Vorspann (s. 3.1.3.b) läßt sein Gesichtsausdruck auf eine Mischung aus tiefer Enttäuschung gescheiterte Hoffnung schließen. Dieser Eindruck wird durch die spezifische Bildkomposition unterstützt: Bleich in der Kälte stehend, durch die Glasscheibe von den Musizierenden getrennt, wirkt Julien, wie schon bei der Zugabfahrt (s.3.1.3.b), äußerst isoliert. Die Tatsache, daß ein anderer etwas besser kann als er und dadurch die Zuneigung und Anerkennung erhält, nach der er sich selbst sehnt, läßt den Zuschauer mit dem Protagonisten fühlen. Ein solches Erlebnis kann fast jeder aufgrund eigener Erfahrung nachvollziehen. Aufgrund der über den Film bereits aufgebauten Versetzung in den Protagonisten und der hier nahegelegten Identifikation

330. Im Unterschied zum Drehbuch, in dem die Klavierlehrerin Jean explizit lobt - »Tu te débrouilles, dis donc. Ça fait plaisir d'avoir un élève doué.« -, läßt Malle im Film den Zuschauer diese Gedanken hinzudenken.

331. »Mon petit chéri, comme tu comprends bien, il m'est très difficile de t'écrire. Monsieur D. allait à Lyon, il a bien voulu poster cette lettre. Nous sortons le moins possible ta tante et moi.« $(0: 27: 28-0: 27: 33 \mathrm{~h})$ 


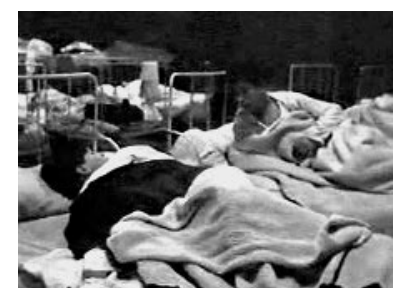

(272) $0: 23: 50 \mathrm{~h}$

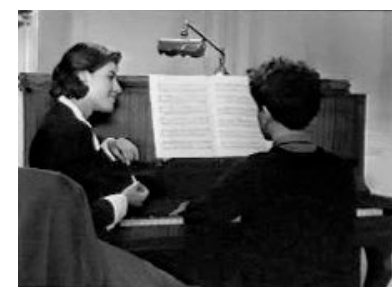

(273) $0: 26: 34 \mathrm{~h}$

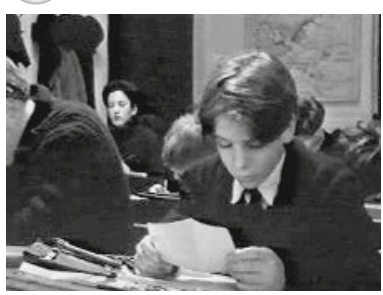

(275) $0: 27: 26 \mathrm{~h}$

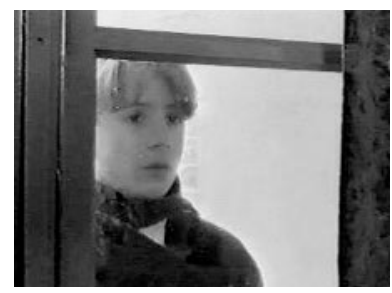

(274) $0: 26: 43 \mathrm{~h}$

mit ihm verstehen wir, daß sich Julien mit dem leisen Kommentar »Quel lèche-cul« (0:26:44 h) seine wahre Befindlichkeit zu verdrängen sucht: »Inzwischen hat der Zuschauer - der Möglichkeit nach - das System [...] verstanden. Daher kann die Spanne der Versetzung vergrößert werden.« (Kloepfer 2002: 288) Julien ist wesentlich weniger souverän bzw. erwachsen, als er vorgibt, was sich bereits in vorhergehenden Szenen zeigte (s. 3.1.4.bb, 3.1.3.c).

c) Juliens gesteigertes Interesse - Gewißheit des Zuschauers versus Juliens Verdacht Zwischen der 26. und der 34. Filmminute sichern drei Sequenzen die von Julien empfundene Konkurrenz mit Jean um die Position des Klassenbesten (s. 3.1.4.ca), Juliens Sehnsucht nach Zuneigung (s. 3.1.4.cb) und sein gesteigertes Interesse an Jean (s. 3.1.4.cc) ab. Während der Zuschauer in der letzten Sequenz in bezug auf Jean Gewißheit erlangt, beginnt Julien erst, einen Verdacht zu hegen (s. 3.1.4.cc; s. Abb. 3.1.c/3.1.2.c). Darüber hinaus liefert die nach der Exposition erste außerhalb des Internats spielende Sequenz Indizien für den sozio-historischen Kontext jenseits der Klostermauern (s. 3.1.4.cb).

ca) Der Briefvon Jeans Mutter und Juliens »Rache« an Jean im Unterricht Die unmittelbar folgende Sequenz (15) bestätigt explizit den Eindruck, daß Jean etwas Gravierendes zu verbergen hat: Als Jean versehentlich ein Brief seiner Mutter auf den Boden fällt und von den Jungen reihum weitergegeben wird, ist Julien derjenige, der das Papier auseinanderfaltet und liest (s. 0:27:26 h), ein durchaus übliches Verhalten für dieses Alter. Den Inhalt des Briefes erfahren wir durch Juliens Stimme aus dem Off ${ }^{331}$, wodurch wir ganz in sein Bewußtsein einbezogen werden. Der angstvolle Blick zu Julien (s. erneut o:27:26 h) sowie die Zeilen bekräftigen unseren Verdacht und Juliens Vermutung, daß sich Jean und seine Familie in einer besonderen Situation befinden: Im Unterschied zu Madame Quentin scheint Jeans Mutter - irgendwo versteckt - die Briefe auf Umwegen zu schicken. Seine momentane Machtposition ausnutzend, provoziert Julien den Jungen, indem er ihm den Brief hinwirft und ihm ein Überlegenheit demonstrierendes »Elle (n')a pas la conscience tranquille, ta mère« 
hinwirft (s. o:27:44) - eine Szene, die den Sympathiebonus der vorangegangenen Sequenz wieder reduziert. Verglichen mit Jean geht es Julien in bezug auf die Trennung von der Mutter schließlich relativ gut: sie kann ihm regelmäßig schreiben (s. 3.1.4.dc) und ihn von Zeit zu Zeit, wie im Prolog angekündigt, besuchen (s. 3.1.5). Da sich Jeans Mutter offenbar verstecken muß, läßt sich erahnen, daß sie ihrem Sohn auf absehbare Zeit keinen Besuch wird abstatten können.

cb) »Die drei Musketiere«, Jeans Vater, Juliens Träume von der Klavierlehrerin und der Judenstern - die Badeanstalt

Nachdem Malle den Zuschauer zu Beginn von Sequenz 17 eine kurze Unterhaltung einiger Schülern über die aktuelle politische Lage hat verfolgen lassen - Panorama des gespaltenen Frankreichs ${ }^{32}$-, widmet er sich wieder der Beziehung zwischen Julien und Jean. Trotz des kränkenden Zwischenfalls verhält sich Jean nicht nachtragend, sondern spricht Julien auf dessen Lektüre, »Die drei Musketiere«, an. Das Interesse für Bücher konnte man aus seinem Kofferinhalt bei der Ankunft erschließen (s. 3.1.3.c) sowie in Sequenz 7 bemerken, als er sich während des allgemeinen Stelzenlaufens lieber seinem Buch widmete. Im Unterschied zum vorangegangenen Ausnutzen seiner Machtposition (s. 3.1. 4.ca) verhält sich Julien Jean gegenüber wieder aufgeschlossen.

332. »Pétain, il est gâteux.« - »J'uis pas d'accord.« - »Si on n'avait pas Pétain, on serait dans la merde.« - »Qui est-ce qui dit ça ?« - »Mon père.« - »Mon père dit que Laval est vendu aux Allemands.« - »Les juifs et les communistes sont plus dangereux que les Allemands.« »C'est Ton père qui dit ça?« - »Non, c'est moi.«

Auf der Basis des, [von der Nationalversammlung der scheidenden Dritten Republik erlassenen,] Ermächtigungsgesetzes proklamierte sich Pétain zum Chef des `État françaisı und ernannte Laval zu seinem >Dauphin<. Mit der, von den Deutschen erzwungenen, Rückkehr Lavals im April 1942 setzte, von Pétain gedeckt, eine Phase verstärkter Kollaboration mit den Deutschen ein. Als Regierungschef mit den Vollmachten eines Diktators weitete Laval die Unterstützung der Gestapo bei der Repression von Regimegegnern aus, ebenso die Mitarbeit bei der Erfassung der nichtfranzösischen Juden, die nun fast alle nach Auschwitz transportiert wurden. Auf die deutsche Forderung nach Stellung von Arbeitskräften zum Ersatz für eingezogene deutsche Wehrpflichtige reagierte Laval mit verstärkter Propaganda und Schließung von französischen Betrieben. (Vgl. Baruch 1999: 190f., Martens 2000: 405, Loth 1992: 120)

333. In der unmittelbar vorangegangenen Sequenz war Julien von Pater Jean dazu aufgefordert worden, sich dem neuen Mitschüler Jean Bonnet gegenüber nett zu verhalten. Père Jean: »Soyez très gentil avec lui. Vous avez de l'influence sur les autres. Je compte sur vous." - Julien: »Pourquoi, il est malade?« - Père Jean: »Mais pas du tout. Allez, sauvez-vous ...« (0:28:54-0:29:04 h)

334. »[...] ohne daß von der Seite der Deutschen hier auch nur der geringste Druck ausgeübt wurde, [begann in Frankreich] die Jagd auf die Juden: Schon im Oktober 1940 wurden die ১Juden französischer Nationalitätı einem besonderen Statut unterworfen, das sie von allen öffentlichen Ämtern ausschloß. Im Juni 1941 verloren sie darüber hinaus das Wahlrecht, wurden sie aus der Armee ausgeschlossen und von allen Posten im kulturellen Bereich verjagt; ihr Zugang zu den Universitäten und zu den freien Berufen wurde rigoros beschränkt, und ihre Unternehmen konnten fortan sarisiert werden. Die ausländischen Juden, vielfach Flüchtlinge aus dem Deutschen Reich, wurden gleichzeitig in Internierungslagern gesammelt, aus denen es dann später für die meisten kein Entkommen mehr geben sollte.« (Loth 1992: 116) 


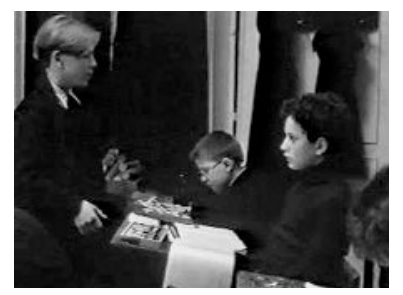

(276) $0: 27: 44 \mathrm{~h}$

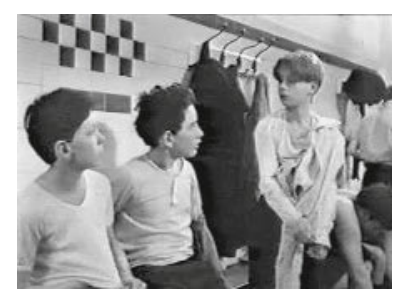

(277) $0: 32: 25 \mathrm{~h}$

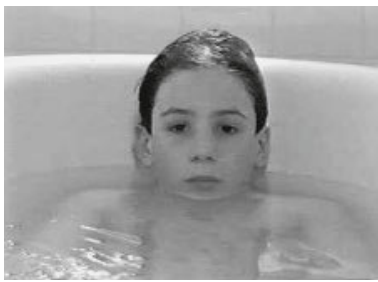

(278) $0: 33: 16 \mathrm{~h}$

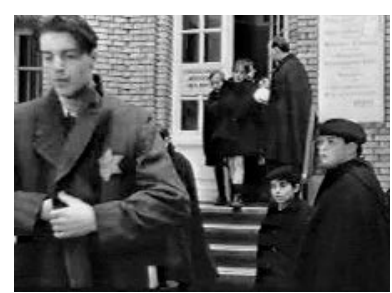

(279) $0: 34: 10 \mathrm{~h}$

Dies hat vermutlich mit dem Gesprächsthema (Literatur), aber auch mit Pater Jeans Bitte an Julien zu tun. ${ }^{333}$ Da beide im Begriff sind, Dumas' Abenteuerroman - nicht zufällig ein Roman über starke, mutige Männer, die nach dem Motto »einer für alle, alle für einen « zusammenhalten - lesen, können sie sich über einzelne Figuren austauschen. Offensichtlich sind beide »Leseratten«, für den Zuschauer ein stark verbindendes Motiv.

Im Anschluß an das Gespräch über »Die drei Musketiere« fragt Julien unvermittelt nach Jeans späterem Berufswunsch. Dabei stellt sich heraus, daß dessen Vater Buchhalter war. Dies kann der sachkundige Zuschauer als weiteres Indiz für Jeans jüdische Abstammung werten - schließlich war Buchhalter ein typisch jüdischer Beruf, was Julien jedoch noch nicht bekannt sein dürfte. Die Tatsache, daß Jean in der Vergangenheit von seinem Vater spricht - »Mon père >était< comptable « (eigene Hervorhebung; o:30:45 h) -, wirft für Julien und den Zuschauer die Frage auf, weshalb Jeans Vater seinen Beruf offensichtlich nicht mehr ausübt, vielleicht sogar nicht mehr lebt. 334

In unmittelbarer Folge erlebt der Zuschauer, daß sich Juliens Interesse für Jean nicht nur auf die bestehende Rivalität beschränkt. Als Jean einem Mitschüler antwortet, er sei evangelisch, schaltet sich Julien mit einer Zweifel signalisierenden und so seinen Verdacht bestätigenden Bemerkung ein: »C'est pas un nom protestant, Bonnet!« (s. 0:32:25 h) Hierdurch liefert Malle auch dem Zuschauer ein weiteres Indiz dafür, daß Jean seine tatsächliche Konfession zu verbergen sucht.

Wie sehr Julien unter dem Mißerfolg bei der Klavierlehrerin nach wie vor leidet, wird für uns in der Badewannen-Szene erfahrbar und läßt uns wieder mit Nähe auf den Protagonisten reagieren. Der Junge liegt mit auffallend abwesendem Gesichtsausdruck in der Badewanne, besonders deutlich erkennbar durch ein Heranzoomen bis zur Nahaufnahme (s. o:33:16 h). Julien ist in Gedanken versunken, was die leisen Klaviertöne zusätzlich indizieren. Hierbei handelt es sich um das Stück, das Jean der Klavierlehrerin vorspielte (s. 3.1. 4.bc). »Tu devrais essayer le violon« ist aus dem Off zu hören, diesmal von der Klavierlehrerin jedoch wesentlich sanfter und liebevoller gesprochen, als es tatsächlich der Fall war und wie er es sich gewünscht hätte (s. 3.1.4.bc). 
Auf diese Weise bestätigt und vertieft Malle erneut Juliens immense Sehnsucht nach weiblicher Zuneigung und Anerkennung. Die Szene steht daher auch in Verbindung mit dem emotionalen Abschied von der Mutter zu Beginn des Films (s. 3.1.3).

In dieser Sequenz vermehrt Malle Hinweise auf das Schicksal französischer Juden unter deutscher Besatzung. Neben der abfälligen Bemerkung eines Jungen über Juden (und Kommunisten) zu Beginn der Sequenz, der Frage nach dem Beruf von Jeans Vater und dem Türschild des Bads (»Etablissement interdit aux Juifs«335) fällt am Ende der Sequenz ein junger Mann mit gelbem Judenstern auf (s. o:34:10 h). Um dies dem Zuschauer unübersehbar vor Augen zu führen, läuft der junge Mann beim Verlassen der Anstalt beinahe in die Kamera, so daß sein gelber Stern besonders hervorsticht. Hinzu kommt, daß zwei Schüler die Begebenheit kommentieren: »Il a du culot, celuilà!« $(0: 34: 12 \text { h) })^{336}$

cc) Absicherung von Jeans Andersgläubigkeit - heimliches Beten im Schutze der Nacht337 Juliens Verdacht, daß Jean einer anderen Konfession angehört, bestätigt sich in Sequenz 18 ebenso wie der Verdacht des Zuschauers, in bezug auf Jeans jüdische Identität, zur Gewißheit wird: Während Julien schläft, ist auf der Tonspur ein monotones, zunächst nicht einzuordnendes Murmeln zu vernehmen. Aufgrund des andauernden Geräuschs wacht Julien schließlich auf und wendet sich in Richtung der Geräuschquelle. Nachdem sich der Zuschauer mit Julien fragte, von wem das Murmeln stam-

335. Gemäß zweier Judenstatute vom 3. Oktober 1940 und vom 2. Juni 1941 mußten Juden unter anderem den Judenstern tragen und durften öffentliche Räume nicht betreten (Baruch 1999: 16f.)

336. »In 1942, we would see children my age wearing the yellow star. I would ask, >Why? Why him and not me?« No one had a good answer. From that moment on, I felt that the world of adults was one of injustice, deception, false explanations, hypocrisy and lies.« (Malle zit.n. Insdorf 2003: 86)

337. »Die Szene zum Beispiel, in der Bonnet mitten in der Nacht aufsteht, um seine Gebete zu sprechen, beruht auf der Erzählung eines Freundes." (Malle 1998: 233)

338. Dies hatte Jean in der vorangegangenen Sequenz als seine Konfession angegeben (s. 3.1.4.cb). »Jean is the only student shown praying with fervor." (Colombat 1993: 268)

339. »Die Gesetze, durch die [die Miliz] am 30. Januar 1943 geschaffen wurde, legten die Aufgabe der aus dem von Joseph Darnand geführten Ordnungsdienst der >Légion< (>Service d'ordre légionnaires, SOL) hervorgegangenen Miliz eindeutig fest. Darnand war der Generalsekretär der neuen Gruppierung, die als gemeinnützig anerkannt war und unter der Leitung von Laval stand.« (Baruch 1999: 151f.) »Innerhalb weniger Monate wurde die Miliz zu einem wichtigen Element des Repressionsapparates, wie es der Wortlaut einer Erklärung verdeutlicht, die Marschall Pétain an ihre Mitglieder richtete: ১Die Miliz [...] muß vor allem mit Prestigeaufgaben bedacht werden, insbesondere solchen, die die Aufrechterhaltung der Ordnung, die Bewachung der sensiblen Punkte des Staatsgebietes und den Kampf gegen den Kommunismus betreffen.< [...] Als regelrechte Hilfstruppe der deutschen Polizei machte sie den Kampf gegen die Résistance [...] zu ihrer vordringlichsten Aufgabe.« (Ebd. 153)

»Neben dem [...] blutigen Kampf gegen den Widerstand führte die Bekämpfung des Schwarzen Marktes und die Suche nach den Verweigerern des STO zu einer ständig steigenden Zahl von Durchsuchungen und Kontrollen, die den größten Teil der Bereiche des täglichen Lebens betrafen.« (Baruch 1999: 174) 


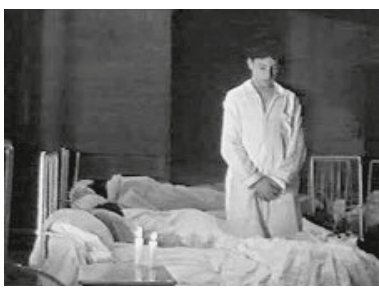

(280) $0: 34: 41 \mathrm{~h}$

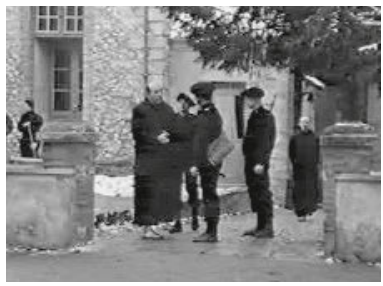

(282) $0: 36: 01 \mathrm{~h}$

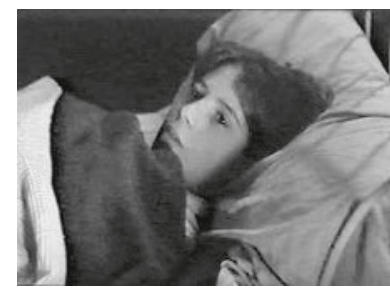

(281) $0: 34: 56 \mathrm{~h}$

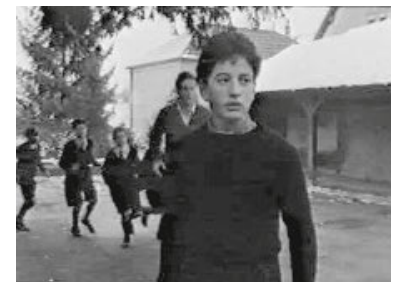

(283) $0: 36: 02 \mathrm{~h}$

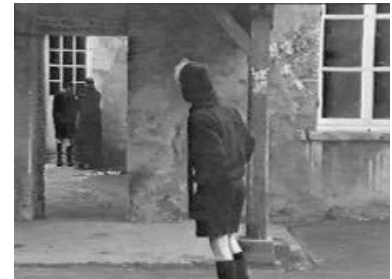

(284) $0: 36: 28 \mathrm{~h}$

men könnte, kommt Jean allmählich ins Bild: Er steht betend neben zwei Kerzen vor seinem Bett und trägt dabei eine besondere Kopfbedeckung. Der Zuschauer nimmt diese Entdeckung unmittelbar mit Juliens Augen wahr (s. o:34:41 h), der den ins Gebet versunkenen, in einer fremden Sprache murmeln den Bettnachbarn intensiv beobachtet (s. 0:34:56 h). Dies bestätigt Juliens Zweifel daran, daß Jean evangelisch ist. ${ }^{33^{8}}$ Der Zuschauer erkennt vermutlich die Kippa, die typisch jüdische Kopfbedeckung, was den Schluß nahelegt, daß Jean als Jude unter falscher Identität hier versteckt wird. Offensichtlich hat der Junge die Sicherheit der Nacht gewählt, um bei seinem inbrünstigen Beten nicht entdeckt zu werden - ein Detail, das in sich eine ganze Sinnwelt birgt.

\section{d) Die langsame Entwicklung der Freundschaft - Juliens langer Weg vom Verdacht zur Gewißheit}

Zwischen der 34. und der 63. Filmminute inszenieren acht Sequenzen die Steigerung von Juliens Interesse über Neugierde bis hin zu konkreten Nachforschungen in bezug auf Jean; am Ende hat Julien sein Ziel erreicht und weiß um Jeans wahre Identität (s. Abb. 3.1.c). Parallel hierzu entwickeln sich zwischen den beiden Jungen allmählich erste Ansätze freundschaftlicher Verbundenheit (s. insb. 3.1.4.df). Darüber hinaus läßt die zweite außerhalb des Internats spielende Sequenz den Umgang jenseits der Klostermauern erahnen (s. 3.1.4.df).

\section{da) Erste Bedrohung für Jean und Moreau - gemeinsames Verstecken} vor der Kontrolle durch die Miliz

Als fremde Uniformierte in Sequenz 19 zum ersten Mal das Internatsgelände betreten, erfährt der Zuschauer aus einem kurzen Wortwechsel unter den Schülern (»C'est la milice.« - »Qu'est-ce qu'il veulent, les collabos?« 0:35:52 - 0:35:54 h), daß es sich um die französische Miliz handelt und daß sie ein Instrument der Kollaboration mit der deutschen Besatzungsmacht darstellt. 339 In der Folge erlebt er die Situation zunächst teils aus neutraler, teils aus der Perspektive eines - wie sich herausstellen wird - Betroffenen, nämlich Jean (s. o:36:01 h): Auffällig aufmerksam und ernst verfolgt der Junge (s. 0:36:02 h), wie die Milizionäre sich mit Pater Jean auseinandersetzen 
(s. erneut 0:36:01 h)..$^{34}$ Aufgrund unseres Wissens um seine tatsächliche Identität sowie seiner besonderen Wachsamkeit können wir antizipieren, daß Gefahr für ihn im Verzug ist. Systematisch ermöglicht uns Malle die Identifikation mit Jean im Moment der ersten akuten Bedrohung, d.h. geleitet durch den filmischen Diskurs werden wir eingeladen, seine Rolle einzunehmen, aus seinen perspektivischen Bedingungen diese Situation »verstehen« zu lernen.

Wenig später verfolgen wir nunmehr mit Julien, wie Jean, als einziger aus der Schülergruppe, von Pater Michel eilig hinter einer Tür versteckt wird (s. 0:36:28 h). Offensichtlich soll ihn die Miliz nicht entdecken. Für Julien häufen sich demnach die Indizien dafür, daß Jean etwas zu verbergen hat: Welche Gruppierungen dürfen die Milizionäre auf keinen Fall finden und wer wird hier in dem katholischen Internat versteckt, obwohl er offenbar nicht gleicher Konfession ist, fragt er sich?341

Zumindest die erste Frage wird ihm teilweise beantwortet: Im Gespräch mit Joseph erfährt der neugierig nachfragende Julien, daß die Miliz nach Arbeitsdienstverweigerern $^{342}$ fahndet - Moreau sei einer davon, so Joseph. Das Rätsel um Jean bleibt jedoch weiterhin bestehen, besonders hinsichtlich des Nachnamens, da nach Aussage Josephs Moreau unter falschem Namen hier lebt (s. 3.1.4.cb).

\section{db) Intensiver Blickkontakt zwischen Julien und Jean - Absicherung des} Konkurrenzkampfes um die Position des Klassenprimus

Die Folgesequenz (Sequenz 20) bekräftigt Juliens Interesse sowie den Konkurrenzkampf beider um die Position des Klassenbesten. Als Jean, nachdem er vor der Miliz

340. »Réquisition!« - »Vous avez pas le droit d'entrer ici. C'est une institution privée. Il $n^{\prime} y$ a que des enfants et des religieux.«, entgegnet Pater Jean (0:35:10-0:35:18 h).

341. Nach den brutalen landesweiten Razzien im Sommer 1942 und nachdem Laval versichert hatte, »sich nicht für das Schicksal der jüdischen Kinder zu interessieren« (zit.n. Baruch 1999: 106), kam es zu öffentlichen Protesten der Kirchen, sowohl von katholischer wie von evangelischer Seite (Baruch 1999: 107).

342. »Des types qui se cachent parce qu'ils veulent pas aller faire leur travail obligatoire en Allemagne. Moreau et ... [Julien] Oui, Moreau, c'est pas son vrai nom.« (0:35:06 h)

Das, am 16. Februar 1943 von Laval unterzeichnete Gesetz verpflichtete die zwischen 1920 und 1922 geborenen Männer für zwei Jahre zum Arbeitsdienst in Deutschland, »um, so der Wortlaut einer offiziellen Verlautbarung, >die Verpflichtungen gerecht auf alle Franzosen zu verteilen, die aus den Bedürfnissen der französischen Wirtschaft entstanden sindk, die in Wirklichkeit aber die der deutschen Wirtschaft waren.« (Zit.n. Baruch 1999: 149)»[...] die Verweigerer des STO flüchteten in Scharen, so daß zunächst die Präfekten, später die Miliz mit der Jagd auf die Verweigerer beauftragt wurden.« (Ebd. 151)

343. „Den Höhepunkt erreichten sie [die Bombardierungen] im ersten Halbjahr 1944: Allein zwischen April und August 1944 zählte man 7000 Tote in der Pariser Region. Paris und seine Vorstädte erlebten mehrere große Wellen von Bombardements, angefangen mit dem wirkungsvollen, aber auch mörderischen Luftangriff auf das Fabrikgelände von Renault in Boulogne-Billancourt vom März 1942, dann das Bombardement vom April 1943 oder jenes, dem am 21. April 1944 640 Pariser Bürger des `Quartier de la Chapelle` zum Opfer fielen. (Baruch 1999: 173) Einmal mehr wird durch inn angedeutet, was Kriegszeiten im Alltag (hier in Paris) mit sich bringen und weshalb Julien und sein Bruder im Internat sind. 


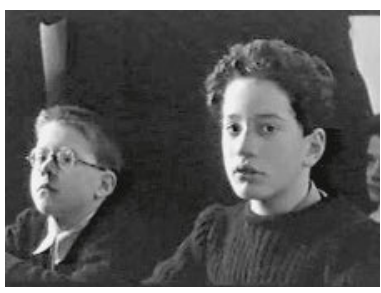

(285) $0: 37: 47 \mathrm{~h}$

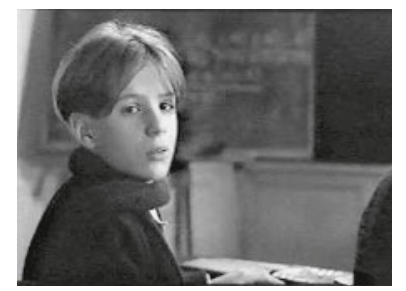

(286) $0: 37: 50 \mathrm{~h}$

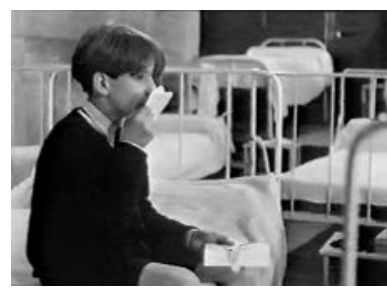

(287) $0: 39: 37 \mathrm{~h}$

versteckt wurde, verspätet in den Französisch-Unterricht zurückkehrt, läßt ihn Julien nicht aus den Augen (s. 0:37:47 h). Jean, der den forschenden Blick bemerkt, erwidert ihn (s. 0:37:50 h). Begleitet wird dieser lange und intensive nonverbale Kontakt von den aus der Badeanstalts-Szene bekannten Klaviertönen, die das Knistern zwischen beiden akustisch ikonisieren. Daß diese Spannung - zumindest für Julien - zum Teil auch aus Rivalität besteht, wird durch den Lehrer explizit angesprochen, als er Jeans »sehr guten« Aufsatz in den Händen hält: »Quentin, vous allez avoir de la compétition!« (०:37:59 h) Besonders wirkungsvoll ist der lange Blickkontakt zwischen beiden Jungen aufgrund unseres unmittelbaren Einbezuges in deren jeweilige Wahrnehmung und somit Sinnwelt (subjektive Kamera). Hinzu kommt der Einsatz weiterer filmischer Mittel (Nahaufnahmen, vergleichsweise hohe Schnittfrequenz, Musik), mit der Malle die Wirkung dieser Szene erhöht und - im Vergleich mit dem ähnlichen, zurückliegenden Blickkontakt im Schulunterricht - intensiviert (s. 3.1.4. aa). Aufgrund dieser besonderen Inszenierung sowie der inzwischen größeren Vertrautheit mit beiden Figuren kann der Zuschauer diesen längeren Blickkontakt mit der zurückliegenden »Beziehungsgeschichte« und den unterschiedlichen Motivationen füllen. Im Unterschied zu den ersten Blickkontakten geht es hier nicht mehr »nur « um neugieriges Interesse - Interesse im Sinne »der wirklichen und sich erfüllenden Bezogenheit« (Kloepfer 1994: 51) -, sondern um ein zwischen Rivalität und Verbundenheit alternierendes Empfinden.

\section{dc) Der sehnsüchtige Briefvon Juliens Mutter und die Entdeckung von Jeans falscher Identität}

Aufgrund der Tatsache, daß Julien im Internat unter den Gleichaltrigen in aller Regel ein überlegenes Verhalten demonstriert, ist das Motiv des Trennungsschmerzes aus der Exposition ein wenig in den Hintergrund getreten. Sequenz 21 erinnert den Zuschauer zunächst daran, wie sehr Julien unter der Abwesenheit seiner Mutter leidet. Nachdem er den neu eingetroffenen, liebevollen und von der Bombardierung der französischen Hauptstadt ${ }^{343}$ berichtenden Brief seiner Mutter gelesen hat, ballt sich die Sehnsucht nach ihr in einer einzigen Handbewegung: Bedächtig führt er den Briefbogen an seine Nase, um den Duft der Mutter einzuatmen (s. 0:39:37 h) - eine Geste, die der Zuschauer kennt und von der er weiß, daß über den Geruchssinn eine ganze Welt wieder auferstehen kann. Auf diese Weise baut Malle - nach der Exposition (3.1.3) und der Enttäuschung in bezug auf die Klavierlehrerin (s. 3.1.4.d bzw. 3.1.4.cb) - erneut eine große Nähe zu Julien und ein starkes Mitfühlen auf.

Im weiteren Verlauf der Sequenz machen Zuschauer und Julien eine entscheidende Entdeckung, die den Verdacht hinsichtlich Jeans falscher Identität bestätigt. Julien ist allein im Schlafsaal und sucht zunächst in dessen Bett und 
danach in dessen Schrank nach Hinweisen auf Jeans wahre Identität. In der Widmung eines Buches wird er fündig. Aus seiner unmittelbaren Perspektive nehmen wir wahr, daß Jeans Nachname in der Urkunde sorgsam durchgestrichen ist (s. 0:41:12 h, linke Bildhälfte), daß die ursprüngliche Schrift jedoch auf der gegenüberliegenden Seite einen Abdruck hinterlassen hat (s.0:41:12 h, rechte Bildhälfte). Da er den kleinen Spiegel an der Schranktür geschickt zu nutzen weiß (s. 0:41:21 h), entdecken wir mit ihm Jeans tatsächlichen Namen (s. 0:41:26 h). Zur Absicherung und Hervorhebung murmelt Julien beim Entziffern: »Jean Kippel... Kippelstein, Jean Kippelstein. «344 Dem Zuschauer liefert Jeans tatsächlicher Nachname, neben der nächtlichen Betszene (s. 3.1.4.cc), einen weiteren entscheidenden Hinweis auf dessen jüdische Identität - schließlich ist die Nachsilbe »-stein « kennzeichnend für jüdische Nachnamen. Da Julien beim Namen Bonnet an dessen evangelischem Ursprung zweifelte (s. 3.1.4.cb), kann auch er hier möglicherweise auch Jeans tatsächlichen Namen entsprechend interpretieren. Aus seiner unmittelbaren Reaktion ist jedoch nicht eindeutig zu erkennen, ob er sich darüber im Klaren ist.

dd) Mitleid mit Jean während Juliens »Verhör« in der Unterrichtspause In der Folgesequenz (22) erfahren wir mit und durch Julien Genaueres über Jeans Situation und die seiner Eltern. Nach dem Griechisch-Unterricht greift Julien eine kurze Unterhaltung über »Die drei Musketiere« auf (s. 3.1.4.cb) und nutzt somit ein zentrales verbindendes Motiv, um mit Jean ins Gespräch zu kommen. Rasch entwickelt sich der Meinungsaustausch jedoch zu einer Art Verhör, einem Minidrama, in dessen Verlauf der wißbegierige Julien den rätselhaften Jean nach seinem Geburtsort, der Herkunft seiner Eltern sowie dem Aufenthaltsort seiner Mutter ausfragt (s. $0: 44: 20$ h):

Julien: „Pourquoi tu fait pas de grec?«

Jean: »Je faisais le latin-moderne.«

Julien: Où ça?«

Jean: „Au lycée, à Marseille.«

Julien: »T'es marseillais? T’as pas d'accent.«

Jean: J'uis pas né à Marseille.«

Julien: „Où t'es né?«

Jean: „Si je te disais, tu saurais pas où c'est. C'est dur le grec?«

Julien: »Pas tellement, une fois que t'as pigé l'alphabet. Tes parents sont de Marseille?«

Jean: „Mon père est prisonnier.«

Julien: „Il s'est pas évadé ? Et ta mère, elle est où ta mère?Tu veux pas me dire où elle est ta mère?«

Jean: „Elle est dans la zone libre.«Julien: »Il n’y a plus de zone libre!«

344. „Den Moment, als Julien durch das Preisbuch entdeckt, daß Bonnet nicht Jeans wirklicher Name ist, und daraus schließt, daß er Jude ist, habe ich mir ausgedacht.« (Malle 1998: 241)

345. Im Zusammenhang mit dem Inhalt ihres Briefs (s. 3.1.4.ca) können wir zusammen mit Julien vermuten, daß sie untertauchen mußte oder gefaßt wurde. 


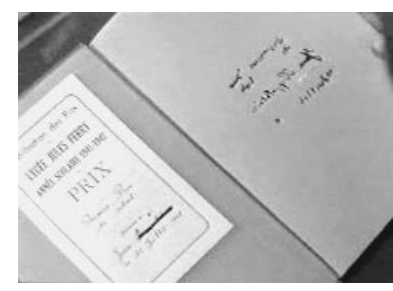

288

$0: 41: 12 h$

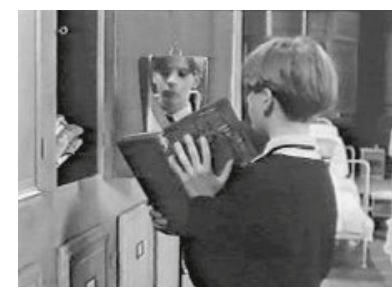

(289) $0: 41: 21 \mathrm{~h}$

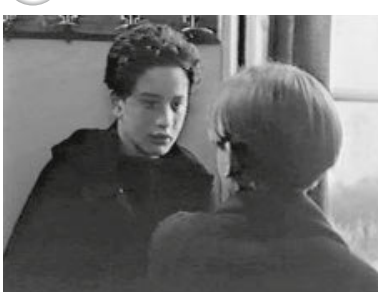

(291) $0: 44: 20 \mathrm{~h}$

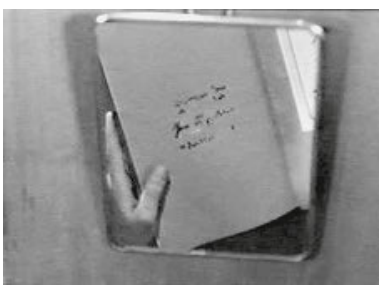

(290) $0: 41: 26 \mathrm{~h}$

Jean: „Je sais, fous-moi la paix! Je te demande rien, moi. J'sais pas où elle est. Elle m’as pas écrit depuis trois mois. Là, t’es content?!« (o:44:09 - 0:44:29 h)

Aus Juliens »Verhör« ergibt sich, daß Jean außerhalb Frankreichs geboren wurde und er vom Beruf seines Vaters in der Vergangenheit gesprochen hat (s. 3.1.4.cb), weil dieser in Gefangenschaft ist und seinen Beruf daher nicht ausüben kann. Auffallend ist, daß Jean insgesamt nur sehr spärlich Auskunft gibt, was Julien jedoch nicht davon abhält, auf der Beantwortung seiner Fragen zu bestehen. Als es um seine Mutter geht, antwortet Jean erst, als Julien ihn verbal wie körperlich in die Enge treibt, so daß er im wahrsten Sinne des Wortes mit dem Rücken zur Wand steht (s. 0:44:20 h): Seit drei Monaten sei er ohne Nachricht von ihr und wisse daher nicht, wo sie sei345, bricht es aus ihm heraus - Höhepunkt und Ende des von Julien inszenierten Minidramas, das der Zuschauer - im Unterschied zum Beginn der Szene - aus Juliens Perspektive erlebt. Erst in diesem hochdramatischen Moment, in dem Jean seine Unwissenheit in bezug auf den Verbleib seiner Mutter gesteht, verstummt Julien und stellt »keine weiteren Fragen«. Zum ersten Mal scheint er zu realisieren, in welch grauenhafter Situation Jean sich befindet - schließlich sehnt auch er sich nach seiner Mutter. Während Julien, obwohl er regelmäßig Briefe von ihr erhält, sehr unter der Trennung leidet, hat Jean nicht einmal mehr Nachricht von seiner unter ständiger Bedrohung lebenden Mutter. Im Unterschied zu seiner egoistischen Motivation, Jeans Geheimnis ohne jegliche Rücksicht zu lüften, entwickelt Julien hier zum ersten Mal Mitgefühl mit Jean. Da der Zuschauer Julien nur von hinten sieht, muß er dessen Reaktion, die sich in seinem Gesichtsausdruck manifestiert, durch maximale Versetzung in den Protagonisten und die spezifische Situation aus sich heraus entwickeln.

$$
\begin{gathered}
\text { de) »Qu'est-ce que c'est un >youpin<? «-Juliens Befragung } \\
\text { seines älteren Bruders in bezug auf Juden }
\end{gathered}
$$

Die Folgesequenz (Sequenz 23) zeigt, daß Juliens Verdacht in bezug auf Jean in die richtige Richtung geht. Während der Pause sucht er seinen Bruder François auf, 
um diesen zu fragen, was ein »youpin« sei - vermutlich hat er diese abfällige, »rassistische« Bezeichnung für Juden von einem Mitschüler bzw. Joseph gehört (»Petit Robert« 1995: 2427). ${ }^{346}$ So erfährt er unter anderem, daß diese kein Schweinefleisch essen und im übrigen intelligenter seien. Den Zuschauer kann die Thematisierung der spezifischen Eßgewohnheiten an den Beginn des Films erinnern (s. 3.1.4.ba) und ihn so nachträglich in seiner Interpretation bestätigen.

df) Erste freundschaftliche Entwicklung aufgrund geteilter Angst und Lebensgefahr für Jean - das Pfadfinderspiel im Wald als retardierendes Element

Nachdem die Beziehung der beiden Jungen bis zu diesem Zeitpunkt zwischen Interesse, Rivalität und Neugierde schwankte, spürt der Zuschauer in Sequenz 24 erste Ansätze freundschaftlicher Verbundenheit aufgrund geteilter Angst. ${ }^{347}$

Diese Schlüsselsequenz stellt nicht nur die mit Abstand längste Sequenz des gesamten Films dar, sie bildet darüber hinaus die Mitte des Werks und teilt es auf diese Weise in zwei Hälften ${ }^{38}$, die dem Wandel in der Beziehung der beiden Jungen entsprechen. ${ }^{349}$ Zum ersten Mal verbringen Julien und Jean mehr Zeit miteinander. Zusammen mit der Exposition (s. 3.1.3), der Sequenz in der Badeanstalt (s. 3.1.4.cb) und der noch folgenden im Restaurant (s. 3.1.5) ist sie eine der wenigen, die außerhalb der Internatsmauern spielen.

\section{Detaillierte Sequenzanalyse:}

Auf der Suche nach einem versteckten »Schatz« im Rahmen des Pfadfinderspiels haben sich Julien und Jean getrennt voneinander verlaufen und treffen sich in der Dunkelheit zufällig wieder. Die Mitschüler sind vermutlich längst wieder im Internat, das Fehlen der beiden Jungen wurde offenbar übersehen.

So irren Julien und Jean durch den inzwischen finsteren Wald (s. 0:52:25 h), begleitet von angsteinflößenden Tiergeräuschen, welche die beiden zu umzingeln scheinen. Ohne auf Juliens Imponiergehabe - »'ai trouvé le trésor, tout seul!« (0:52:41 h) - einzugehen, flüstert Jean voller Angst: »Il y des loups dans cette forêt?« (०:52:44 h)

346. Man erinnere sich in diesem Zusammenhang an die abfällige Bemerkung eines Mitschülers in 3.1.4.cb.

347. "The turning point in their relationship is when the two teenagers experience together the same fear of death. [...] At this point, the friendship between the two boys deepens as they understand better each other's basic fear.« (Colombat 1993: 269)

»Die Szene im Wald zum Beispiel beruht auch auf einer eigenen Erinnerung. So seltsam es sich für diese ja nicht ungefährliche Zeit ausnimmt: Unsere Lehrer schickten uns, wahrscheinlich zur Abhärtung, in den Wintermonaten, wenn die Tage kurz waren, am späten Nachmittag, vor dem Abendessen, zur Schatzsuche in den Wald von Fontainebleau. Ich erinnere mich, wie ich mich mit einem Freund verirrte und schreckliche Angst hatte.» (Malle 1998: 232)

348. Vgl. u.a. Eisenstein 1973: 159f. zum sog. goldenen Schnitt.

349. »Zentrum heißt auch ganz wörtlich die Mitte des Films.« (Kloepfer 2002: 283)

350. Hierbei handelt es sich ironischerweise um ein den Maréchal Pétain verherrlichendes Lied mit dem Titel »Maréchal, nous voilà».

351. »Den ironischen Zwischenfall mit den äußerst freundlichen deutschen Soldaten, die die Kinder zurückbringen, habe ich erfunden.« (Malle 1998: 232) 


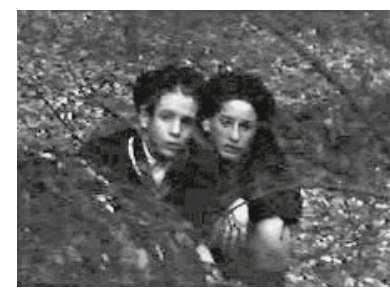

(292) $0: 53: 30 \mathrm{~h}$

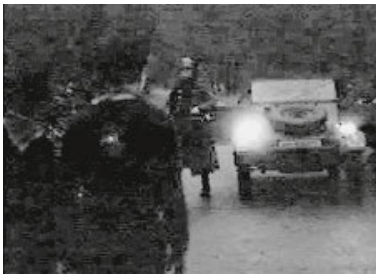

(293) $0: 54: 11 \mathrm{~h}$

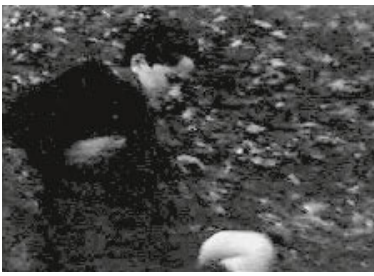

(294) $0: 54: 23 \mathrm{~h}$

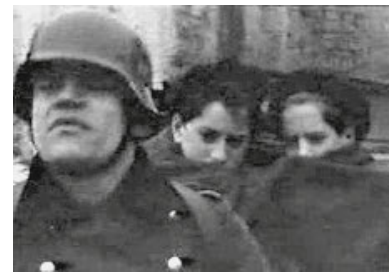

(295) $0: 54: 38 \mathrm{~h}$

Parallel hierzu sind laute Geräusche zu vernehmen, die sich wie das entfernte Heulen von Wölfen anhören.

Während sich die beiden durch das Dickicht kämpfen, summen sie leise und gemeinsam ein Lied vor sich hin ${ }^{30}$ - ein auch dem Zuschauer bekannter Mechanismus, um Furcht zu unterdrücken.

Eine besonders gefährliche Situation - die Begegnung mit einem Wildschwein meistern sie, indem sie sich rechtzeitig hinter einem Felsbrocken verstecken (s. 0:53:30 h). Mit den Jungen sind auch wir erleichtert, daß das Tier in eine andere Richtung davonläuft; als die Jungen nach langem Umherirren letztlich die Straße erreichen, scheint das Schlimmste hinter ihnen zu liegen.

Malle verstärkt in diesen Bildern die Identifikation des Zuschauers mit den Protagonisten, da er eigene Erlebnisse und den kulturell hoch aufgeladenen Topos Wald reflektieren kann.

Die Lage verschlechtert sich jedoch sofort, als ein Militärfahrzeug, besetzt mit zwei deutschen Soldaten, auf sie zusteuert und direkt vor ihnen anhält. Als die beiden aussteigen (s. 0:54:11 h), ergreift Jean die Flucht und rennt in den Wald. Der Zuschauer befürchtet das Schlimmste, denn die Deutschen nehmen die Verfolgung auf, Jean fällt zu Boden und versucht, kriechend zu entkommen (s. 0:54:23 h). Aufgrund derspezifischen Inszenierung dieses dramatischen Vorgangs - Höhepunkts der Sequenz - wirkt Jean wie ein verletztes Tier, das zu fliehen versucht. Dies wird intensiv erfahrbar durch die wackelnde Handkamera, die unmittelbare Perspektive mit dem deutschen Soldaten und die extreme Aufsicht auf das Opfer.

$\mathrm{Zu}$ unserer großen Erleichterung sehen die Soldaten von jeglicher Bestrafung $\mathrm{ab}$ und bringen die beiden Jungen in ihrem Militärfahrzeug nach Hause. ${ }^{351}$ Eingehüllt in Decken, aneinandergekauert, den Schreck noch in den Knochen, sitzen sie auf dem Rücksitz des Fahrzeugs (s. 0:54:38 h). Dieses Bild wurde bewußt für das Filmplakat gewählt: Zum ersten Mal stecken beide nach überstandener Todesangst »buchstäblich« unter einer Decke, bildliches Zeichen einer »An-Näherung«, einer aufkeimenden Freundschaft. 
dg) Verbundenheit aufgrund überstandener Gefahr und Juliens entscheidender Test: Jean lehnt seine Schweine-Pâté ab

In der Folgesequenz (25) bestätigt sich, daß dieser hochdramatische Zwischenfall verbindende Wirkung auf die beiden Jungen hat. Als Julien Mitschülern gegenüber das Erlebte heldenhaft darstellt, sieht der Zuschauer zum ersten Mal ein Lächeln auf Jeans Gesicht, eingefangen durch eine der insgesamt seltenen Nahaufnahmen (s. o:57:17 h). Die Freude ist verständlich, schließlich entspricht es weder bei ihm noch bei Julien den tatsächlichen Verhältnissen. ${ }^{352}$ Dieselbe Sequenz macht jedoch auch deutlich, daß Julien entschlossen ist, Jeans Geheimnis zu lüften, selbst wenn dies die aufkeimende Freundschaft zu gefährden droht. Nachdem Jean wiederholt das ihm angebotene (s. 0:58:22 h) Schweine-Pâté-Brot ablehnt ${ }^{353}$, konfrontiert ihn Julien mit seinem Verdacht, spricht jedoch sehr leise, um ihn nicht zu verraten:

Julien: »Parce que c'est du cochon?«

Jean: $\quad$ Pourquoi tu me poses toujours des questions idiotes?«

Julien: »Parce que tu t'appelles Kippelstein, pas Bonnet. Au fait, on dit Kippelstein ou Kippelsteyn?« (०:58:31 - 0:58:37 h)

Aus Angst vor Entdeckung stürzt sich Jean auf Julien und beginnt, mit ihm zu kämpfen (s. 0:58:48 h). Mit dieser Reaktion der Hilflosigkeit bestätigt er Juliens Verdacht in bezug auf seine tatsächliche Identität. Eine halbe Stunde nach dem Zuschauer erfährt nun auch der Protagonist, daß Jean Jude ist.

\section{dh) Eskalation und Versöhnung - im Schulhof}

Sequenz 28 markiert gleichzeitig Höhepunkt und Ende der von Julien ausgehenden Rivalität zwischen den beiden Jungen. Unsicher, wie er mit seinem Wissensvorsprung umgehen soll, schließt sich Julien - als ihn zufällig eine ruckartige Armbewegung von Jean trifft - seinen unwissenden Mitschülern an, die in dem Außenseiter Jean ein Opfer zum Quälen haben.354 Schnell wird daraus ein Zweikampf zwischen Julien und Jean, der erbittert geführt wird (s. 1:03:20 h), bis Juliens Mutter, die die gerade anwesend ist, eingreift und die beiden trennt. Als sie sich um Juliens verschmutzte Ausgehgarderobe sorgt, solidarisieren sich Julien und Jean plötzlich lachend (s. 1:03:42 h) und wir spüren, daß sie sich trotz gewisser Rivalität in besonderer Weise verbunden fühlen - insbesondere die gemeinsame Erfahrung im Wald haben sie nicht vergessen (s. 3.1.4.df).

352. Man erinnere sich an Juliens Bettnässen (s. 3.1.4.bb).

353. »Non, j'te dis! J'aime pas le pathé!«

354. »Tape-cul pour le parpaillot.« (1:03:07 h)

355. »Filmkunst beruht nach Eisenstein auf dem damit spezifisch gegebenen Möglichkeiten, den Raum über die Zeit und die Zeit über den Raum zu entfalten. >Die Merkmale der Zeit offenbaren sich im Raum, und der Raum wird von der Zeit mit Sinn erfüllt und dimensioniertı.« (Bachtin zit.n. Kloepfer 1999: 15) 


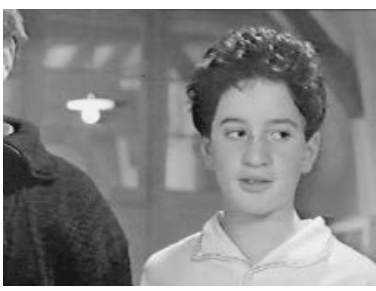

(296) $0: 57: 17 \mathrm{~h}$

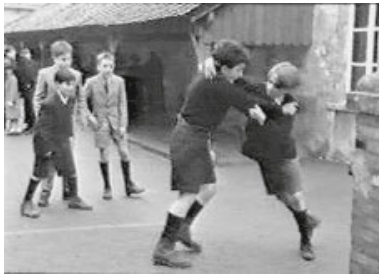

(299) $1: 03: 20 \mathrm{~h}$

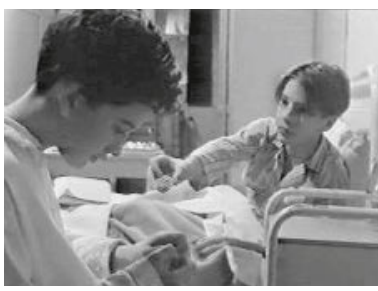

(297) $0: 58: 22 \mathrm{~h}$

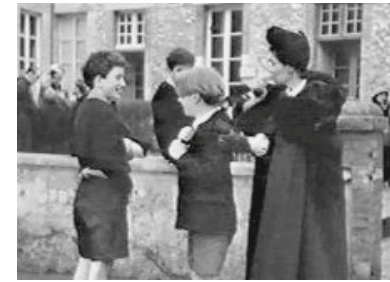

(300) $1: 03: 42 \mathrm{~h}$

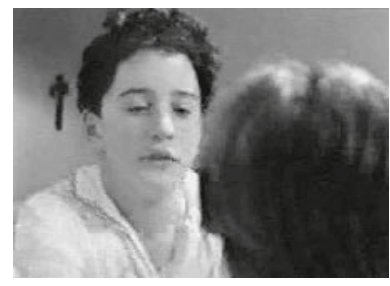

(298) $0: 58: 48 \mathrm{~h}$

\subsubsection{Mit-Bangen um Jean und Erleben der gespaltenen französischen Gesellschaft -} »Mardi Gras«im Restaurant

Die Restaurant-Sequenz (29) stellt eine entscheidende Etappe auf dem Weg zur Freundschaft dar. Sie ist, wie das Waldabenteuer (s. 3.1.4.df), eine der längeren, selteneren Sequenzen, die außerhalb des Internat spielen. In der vorliegenden »Schlüsselszene« (Malle 1998: 230) nutzt der Regisseur in besonderem Maße die Möglichkeit, dem Zuschauer zu zeigen, wie es in dieser Zeit außerhalb der schützenden Klostermauern zuging. So läßt er uns die Auswirkungen des Holocaust im Alltag sowie die gesellschaftlichen Positionen und gegensätzlichen Reaktionen in bezug auf Kollaboration und Widerstand auf engstem Raum (Restaurant) erfahren.355 Der Zuschauer registriert mit staunendem Entsetzen, daß sich die französischen Kollaborateure weitaus »aggressiver und aktiver als die deutschen Soldaten « verhalten - eine Darstellung, die der Erinnerung des Regisseurs entspricht (Malle 1998: 232). Das Ausmaß der zwischen Kollaboration und Résistance liegenden Grauzone reicht von lautstarker Unterstützung der Kollaboration und Judendiskriminierung (eine Restaurantbesucherin), über mehr oder weniger deutliches Wegsehen (Mutter), solidarischen Blickkontakt mit dem in Lebensgefahr schwebenden Jean (Julien) und sachlich vorgetragener Kritik an der Judendiskriminierung (der Restaurantbesitzer) bis hin zu gewagter Rebellion gegen die Miliz (Juliens Bruder François). Seinem Anspruch, mit Auf Wiedersenen, KINDER »ein vergleichsweise genaues Bild der französischen Gesellschaft, vor allem des Großbürgertums« (Malle 1998: 233) zu zeichnen, scheint der Regisseur demnach insbesondere in der vorliegenden Sequenz - sowohl für den Zuschauer als auch für die Figuren - auf beeindruckende Weise gerecht zu werden.

Entscheidend und an dieser Sequenz am eindringlichsten belegbar ist die Art, wie Malle den Zuschauer über gezeigte Blicke und Einbezug in verschiedene Perspektiven das Interessens- und Motivationszentrum der jeweils wahrnehmenden Figur sowie die Beziehungen zwischen den Figuren erschließen läßt (s. die einzelnen Figuren und unseren Einbezug in die unterschiedlichen Perspektiven anhand der Pfeile). 
Durch diese hochkomplexe filmische Deixis über Blickführung macht Malle dem Zuschauer Welt-Anschauung als einstellungsgeleitet erfahrbar und vermeidet bewußt einen monoperspektivischen, das heißt extrem eingeschränkten Blick auf die vielschichtige Wirklichkeit:

»Man muß erwägen, sagt Bachtin, >daß eine einzige Wahrheit eine Vielfalt von Bewußtseinen fordert, da sie prinzipiell für ein Einzelbewußtsein unfaßbar ist, daß sie sozusagen Ereignischarakter hat und im Berührungspunkt verschiedener Bewußtseine entsteht. Alles hängt davon ab, wie man sich die Wahrheit und ihr Verhältnis zum Bewußtsein vorstellt [...].« (Bachtin zit. n. Kloepfer 1999: 32)

»Seine beiden zentrale Begriffe - Chronotopos und das Dia- bzw. Polylogische - besagen, daß das Eingetauchtsein in eine Vielfalt von Weltsichten und eine Vielfalt kommunikativer Praxen nicht das Unnormale, nicht das künstlich Extraordinäre, sondern ganz im Gegenteil das Alltägliche und Selbstverständliche sind.« (Bachtin zit.n. Kloepfer 1999: 33)

»Gregory Bateson hat als Ethnologe und Anthropologe die Eigenart von Kunst, svielfältige Versionen der Weltı zu konstruieren, früh bemerkt [...]« (Bateson zit.n. Kloepfer 1999: 33).

»Er fragt: Warum tut sie das? Die Antwort ergibt sich für ihn aus der Tatsache, daß die menschliche Natur ihren Reichtum im Zugang zur Welt außerhalb und innerhalb des Gemüts aus der Kombination von teilweise widersprüchlichen Informationsquellen und -weisen gewinnt.« (Kloepfer nach Bateson 1999: 33f.)

»Die Spannung, Gegensätzlichkeit, die widersprüchliche Vielfalt sind nicht von Übel, sondern grundlegende Bedingung für den Erwerb von mehr Wirklichkeit.« (Kloepfer 1999: 34)

Auffällig häufig, im Vergleich zu anderen Szenen, versetzt uns der Regisseur in Jeans Wahrnehmung. Auf diese Weise wird Jean in dieser Sequenz, neben Julien, zur hauptsächlichen Identifikationsfigur: Die extrem gefährliche Situation, in der er sich befindet, läßt uns gleichzeitig mit ihm und mit seinem Freund Julien bangen.

\section{Detaillierte Sequenzanalyse:}

Als die Familie Quentin (Julien, seine Mutter und sein Bruder) zu Beginn der Sequenz das Restaurant betritt, fällt auf, daß Jean sie begleitet. Somit wird das kleine Rätsel aus der vorangegangenen Sequenz gelöst: Unhörbar für den Zuschauer hatte Julien seiner Mutter etwas ins Ohr geflüstert. In diesem Moment wissen wir, er wollte verhindern, daß Jean allein im Internat zurückbleiben muß - schließlich war ihm aus einem kurzen Gespräch mit Jean bekannt, daß dieser keinen Besuch erwartete (s. Sequenz 26). Nach den zahlreichen Provokationen und dem ausgeprägten Konkurrenzverhalten empfinden wir hier wieder Sympathie für Julien, der Gespür für die Situation beweist, obwohl er beim vorangegangenen Raufen unterlegen war. Dankbar lächelt ihm Jean daher auch zu, während er sich auf den zugewiesenen

356. François: »Il y de la verdure aujourd'hui [abschätzige Bezeichnung für die deutschen Soldaten in ihren grünen Uniformen]).« - Mutter: »Je croyais qu'ils étaient tous sur le front russe.« - François: »Vous leur avez tapé dans l'oeil.« (1:04:57-1:05:01h) 


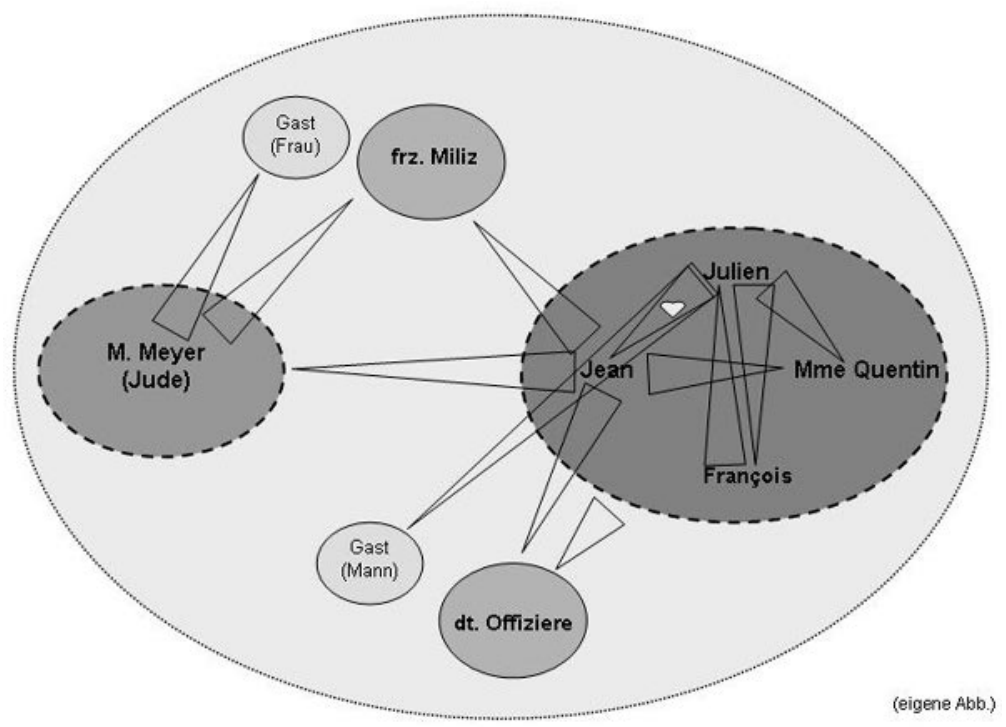

Abb. II.3.1.g

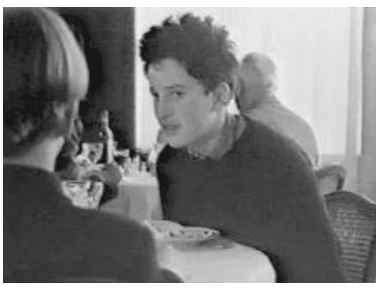

(301) $1: 04: 15 \mathrm{~h}$

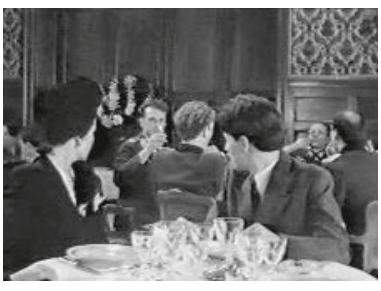

(302) $1: 04: 49 \mathrm{~h}$

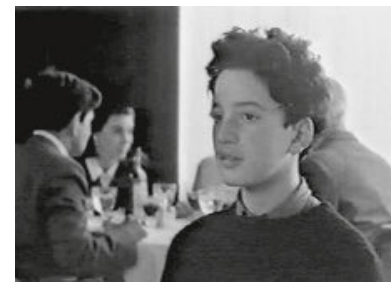

(303 1:05:07 h

Stuhl setzt (s. 1:04:15 h). Einmal mehr nehmen wir diesen auffällig langen, beinahe komplizenhaft wirkenden, Blickkontakt aus Juliens Perspektive wahr (over-the-shoulder-shot).

Während der aus einer neutralen Perspektive eingefangenen Essensbestellung weist Malle erneut auf die schwierige Versorgungslage hin: Fisch, so der Restaurantbesitzer, habe es schon sehr lange nicht mehr gegeben, er könne jedoch den Hasen empfehlen.

Aus der Sicht vor allem von Mutter und Bruder nehmen wir im folgenden wahr, daß im Bildhintergrund eine Gruppe deutscher Luftwaffenoffiziere - »Aristokraten des Kriegs « (Malle 1998: 232) - das Glas auf den Sieg erhebt und einer von ihnen der attraktiven Madame Quentin zuprostet (s. 1:04:49 h). Bereits hier erstaunt den Zuschauer das keineswegs feindselige, eher galant-überhebliche Verhalten des Deutschen.

Nachdem sich François und seine Mutter kurz über die Deutschen ausgetauscht haben ${ }^{356}$, erkundigt sich Madame Quentin nach Jeans Eltern. »Pauvre petit« (1:05:03 h), lautet ihre Reaktion, als sie erfährt, daß diese nicht kommen konnten; bei dieser Form der Anteilnahme huscht Jean ein leises, dankbares Lächeln über das Gesicht, den wir (in diesem Moment) mit den Augen Juliens intensiv beobachten (Nahaufnahme; s. 1:05:07 h) - schließlich kennt nur Julien die näheren Umstände. 
Das folgende Gespräch zwischen Madame Quentin und ihren Söhnen über den Vater bzw. Ehemann verfolgt der Zuschauer aus Jeans Perspektive (over-the-shouldershot; s. 1:05:09 h). Als François seine Mutter fragt, ob der Vater immer noch PétainAnhänger sei, wird dies kurzerhand abgestritten (»Personne n’est plus pétainiste!«; 1:05:28 h) und rasch das Thema gewechselt - erstes Anzeichen dafür, daß die Mutter die Wirklichkeit zu verdrängen scheint.

Unmittelbar mit Jean nehmen wir wahr, wie wenig später die französische Miliz das Restaurant betritt (over-the-shoulder-shot; s. 1:06:09 h), die als Bedrohung aus Sequenz 19 bekannt ist (s. 3.1.4.da). Malle versetzt den Zuschauer in diesem Moment demnach in die Figur, für die das Auftauchen der Kollaborateure die größte gefahrenvolle Relevanz hat. Kaum haben die beiden Milizionäre die Türschwelle passiert, hat Jean sie auch schon bemerkt: Auf diese Weise wird für uns erfahrbar, in welch ständiger Angst und Angespanntheit der Junge als untergetauchter Jude lebt.357 Auch Julien ist aufmerksam, und zwar im bezug auf seinen neuen Freund, dessen angstvollen Blick er bemerkt (s. ebenfalls 1:o6:09 h) und kurzerhand folgt. Gemeinsam beobachten beide, wie die französische Miliz die Ausweise der Restaurantbesucher zu kontrollieren beginnt. Mit besorgtem Blick wendet er sich wieder Jean zu, der jedoch - verständlicherweise - weiterhin das Verhalten der Milizionäre verfolgt. Glücklicherweise, wir atmen förmlich mit auf, wendet sich der Franzose an einen Herrn am Nachbartisch, der bereits zu Beginn der Sequenz als Herr Meyer, ein Stammgast, eingeführt worden war - eine Szene, die wir hauptsächlich mit den Augen Jeans verfolgen (s. 1:06:39 h). Als der Milizionär feststellt, daß der ältere Herr Jude ist, herrscht er ihn unvermittelt an: »Dis-donc, toi. Tu sais pas lire? Ce restaurant est interdit aux youtres!« (1:०6:0० 1:06:03 h) ${ }^{35}{ }^{8}$ Während er den Herrn zuvor noch höflich angeredet hatte (»Vos papiers, Monsieur.«; 1:06:42 h), erniedrigt er ihn neben der abwertenden Bezeichnung (youtres), indem er ihn duzt.

Bestürzt auf den Freund blickend, nimmt der Zuschauer mit Julien das Schweigen des älteren Herrn wahr (subjektive Kamera; s. 1:06:51/a h). Offensichtlich hat Julien begriffen, daß auch dieser durch das Auftauchen der Miliz in Gefahr schwebt und daß Jean ebenfalls kontrolliert werden könnte. Währenddessen verfolgt dieser die Konfrontation zwischen dem Juden und dem Milizionär mit angstvoll-starrem Gesicht, durch die Nahaufnahme deutlich zu erkennen (s. 1:05:51/b h). Trotz seiner Angespanntheit bemerkt er den sorgenvollen Blick des Freundes und erwidert ihn wortlos (subjektive Kamera; s. 1:05:53 h). Im Unterschied zu vorangegangenen Blickkontakten hat dieser eine neue, tiefergehende Dimension: denn beide sind sich - neben dem Zuschauer der drohenden Gefahr bewußt.

Die folgende Einstellung versetzt den Zuschauer erneut in Jeans Wahrnehmung (subjektive Kamera): Nachdem er für kurze Zeit Juliens empörter Mutter - »Qu'est-ce qu'ils ont besoin d'embêter les gens. Il a l'air si convenable, ce monsieur.« (1:06:57 1:06:59 h) - Aufmerksamkeit geschenkt hat, wendet er sich wieder dem Konflikt um seinen Leidensgenossen zu, der vom Restaurantinhaber verteidigt wird (s. 1:07:03 h):

357. Später wird er diese Julien gegenüber zugeben (s. Sequenz 37).

358. >Youtres stellt eine abwertende Bezeichnung für Juden dar.

359. »Ihnen geht es darum, sich persönlich hervorzutun, auch wenn ihr Handeln durch die Aussage des älteren euphemistisch überhöht wird [...]«. (Ader 1993: 134). 


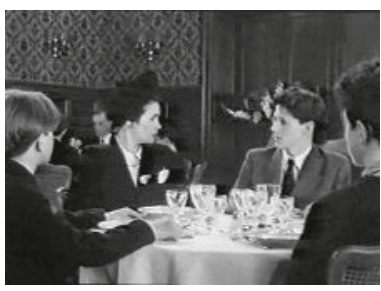

(304) 1:05:09 h

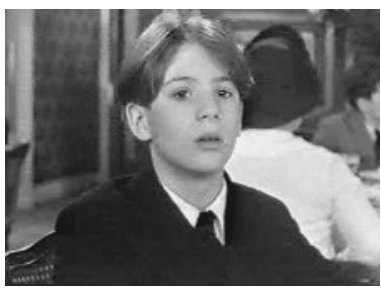

(307) $1: 06: 51 / \mathrm{a} \mathrm{h}$

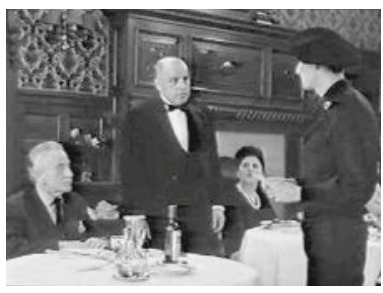

(310) 1:07:03 h

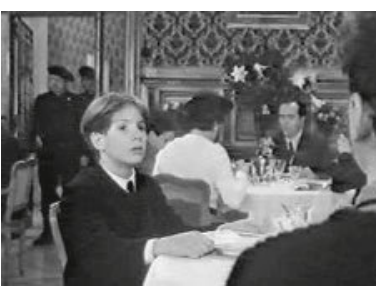

(305) $1: 06: 09 \mathrm{~h}$

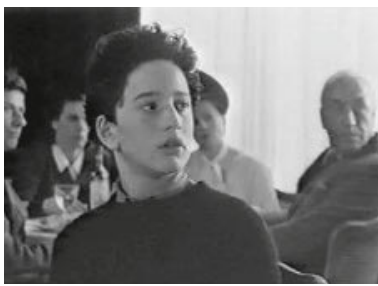

(308) $1: 06: 51 / \mathrm{b} \mathrm{h}$

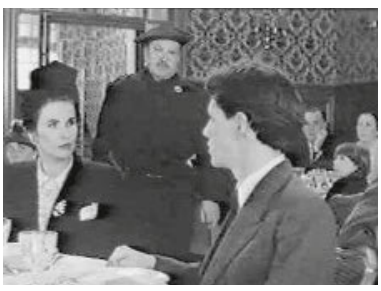

(311) $1: 07: 13 \mathrm{~h}$

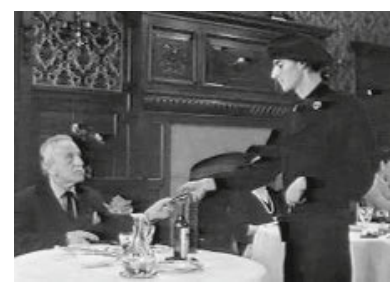

(306) $1: 06: 39 \mathrm{~h}$

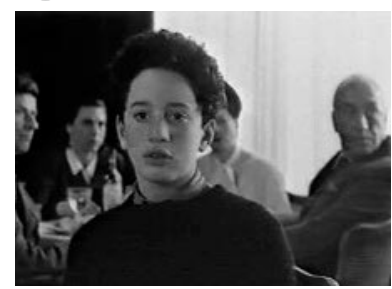

(309) $1: 05: 53 \mathrm{~h}$

»Monsieur Meyer vient ici depuis vingt ans. Je peux pas le mettre à la porte quandmême?!« (1:07:04 - 1:07:06 h) - eine ebenso riskante wie menschliche Verhaltensweise, die angesichts des entschiedenen Auftretens der Miliz sowie ihres Rufs von großer Zivilcourage zeugt. Dieses mutige Eintreten für den Gast veranlaßt den Milizsoldaten zu einem noch stärkeren Maß an Machtdemonstration: »Toi, le loufiant, ferme-la. Si je veux, je peux faire révoquer votre licence!« (1:07:08 h) Mit Entsetzen stellt der Zuschauer fest, daß der Milizionär in der Rolle des Ordnungshüters aufzugehen scheint, seinen Landsleuten begegnet er ebenso grob wie dem jüdischen Gast.

In diesem Moment spricht François halblaut aus, was wir und einige Restaurantbesucher möglicherweise bereits denken: »Collabos!« (1:07:10 h) Den Zuschauer ebenso wie Jean, aus dessen Perspektive wir den Zwischenfall wahrnehmen, trifft dieser beleidigende, halblaut vorgetragene Kommentar wie ein Schlag - es ist bekannt, welche Folgen eine solche Bemerkung haben könnte.

Gemäß unserer Befürchtung nähert sich der zweite Milizionär dem Tisch der Quentins, um François zur Rede zu stellen (s. 1:07:13 h): „C'est toi qui a dit ça?« (1:07:15 h) Aufgenommen ist diese Szene erneut aus Jeans Perspektive, denn die Gefahr rückt auch räumlich näher. Noch bevor ihr älterer Sohn dem Milizionär antworten kann, spielt Madame Quentin die Situation herunter - „C'est un enfant, il sait pas ce qu'il dit.« (1:07:17 - 1:07:19 h) -, so daß sich dieser mit dem Hinweis begnügt: »Nous rendons service à la France, Madame!« (1:07:22 h) Auf diese Weise entlarvt Malle dem Zuschauer die paradoxe Logik der Kollaborateure.359 
Das aufkommende Stimmengewirr zeigt, daß diese Bemerkung das gesamte Restaurant in Unruhe versetzt hat und daß vor allem Gegenstimmen laut werden: »Allez vous en!« - »Foutez le camp.« - »Vous avez pas le droit.« - »C'est ignoble, ça.«-»Bravo, la milice!« (1:07:29 - 1:07:33 h) Während ein Mann sich explizit für Herrn Meyer einsetzt - »Laissez ce monsieur tranquille!« (s. 1:07:36/a h) -, schlägt sich eine Frau ebenso lautstark wie engagiert auf die Seite der Kollaborateure: »Ils ont raison, les Juifs à Moscou!« (s. 1:07:36/b h). In diesem Tumult läßt uns Louis Malle das bürgerkriegsähnliche Klima aufgrund der gespaltenen Haltung der französischen Gesellschaft - insbesondere des Großbürgertums - gegenüber der Kollaboration intensiv miterleben.

Aus einer Jean angenäherten Perspektive beobachten wir einmal mehr, wie der deutsche Luftwaffenoffizier, der zu Beginn der Sequenz Madame Quentin zugeprostet hatte, seinen Kollegen »Dieses Arschloch!« (1:07:49 h) zuraunt, bevor er den Milizionär des Restaurants verweist: »Foutez le camp! Vous m'avez compris? Foutez le camp!« (s. 1:07:51 h) Darauf reagiert der Zuschauer äußerst überrascht, ebenso wie der Milizionär, der wie angewurzelt vor dem Deutschen steht und ihn verständnislos und grimmig ansieht (s. 1:07:52 h). Aufgrund des sich anschließenden Blickkontaktes zwischen Madame Quentin und dem deutschen Offizier sowie dessen großspuriger Geste, begleitet von einem selbstgefälligem »Voilà« (s. 1:०8:०० h), ahnen wir den Grund seines überraschenden Einschreitens. Er zeigt, »daß die >Jagd auf Juden< [in diesem Fall; eigene Anm.] eine Frage der Laune ist, sonst nichts. (Ader 1993: 134): Während François, wie der Zuschauer, das Verhalten des Deutschen durchschaut und als Imponiergehabe interpretiert - »Il a fait ça pour vous épater.« (1:08:27 h) -, kommentiert die Mutter nur naiv: »On peut dire ce qu'on veut, mais il y en a qui sont bien.« (1:08:25 h)

Nachdem die französische Miliz das Restaurant verlassen hat und somit die Gefahr, auch für Jean, zunächst gebannt ist, fragt Julien seine Mutter unvermittelt:

Julien: „On n'est pas Juif, nous?«

Mutter: »Il ne manquerait plus que ça?«

Julien: „La tante Reinach, c'est pas un nom juif?«

Mutter: [indigniert] »Les Reinach sont alsacien.«

François: »On peut être alsaciens et juifs.«

Mutter: „Fichez-moi la paix. Les Reinach sont très catholiques ... s'ils nous entendaient. Remarquez, je n'ai rien contre les Juifs, au contraire. A part Léon Blum, bien entendu. Ah, celui la, ils peuvent le pendre!« (1:08:26 - 1:08:41 h; s. 1:08:40 h)

360. Die Schlüsselsequenz endet also mit der Figur, aus deren Perspektive wir weite Teile der Sequenz wahrnehmen durften.

361. Vgl. Malles Anmerkungen über das Verhalten der Mutter: „Sie spricht über Léon Blum - das Bürgertum haßte Léon Blum - und meint: ১Ich habe nichts gegen Juden.« (Malle 1998: 232) »Doch als Julien fragt: ıSind wir denn nicht jüdisch?८, ist sie schockiert. Diese Unterhaltung stammt direkt aus meiner Kindheitserinnerung.« (Ebd. 233) 


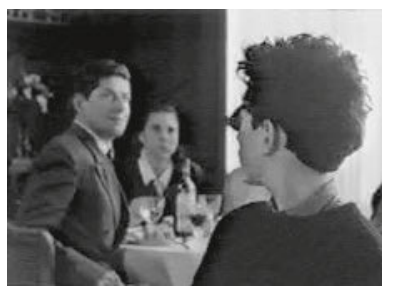

(312 $1: 07: 36 / \mathrm{a} \mathrm{h}$

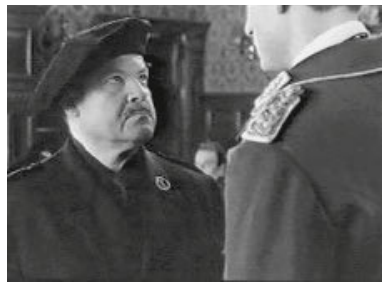

(315) $1: 07: 52 \mathrm{~h}$

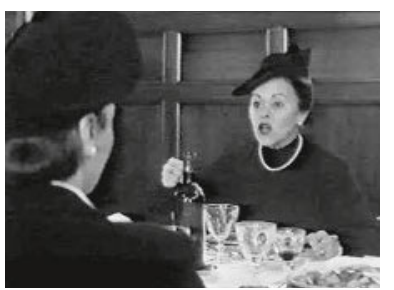

(313 $1: 07: 36 / \mathrm{b} \mathrm{h}$

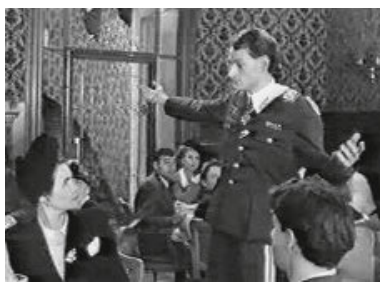

(316) $1: 08: 00 \mathrm{~h}$

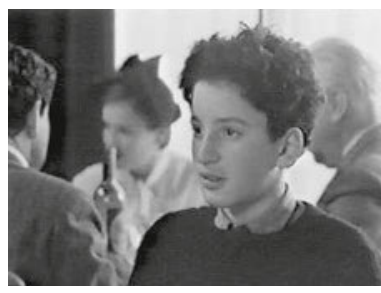

(318) $1: 08: 50 \mathrm{~h}$

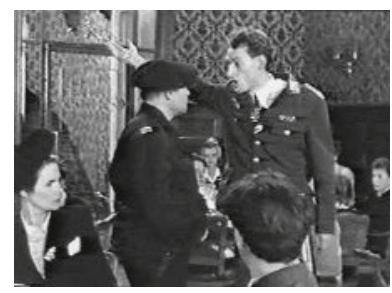

(314) $1: 07: 51 \mathrm{~h}$

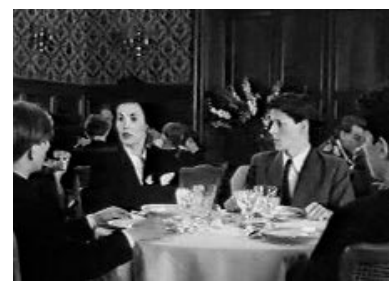

(317) $1: 08: 40 \mathrm{~h}$

Die sich an die Unterhaltung anschließende letzte Einstellung der Sequenz zeigt erneut Jeans Gesicht in Nahaufnahme, worauf der Zuschauer erneut Zuneigung für Juliens Mutter ablesen kann (s. 1:08:50 h). ${ }^{360}$ Offensichtlich erinnert sie ihn an seine eigene Mutter. Dem Zuschauer jedenfalls ist nicht entgangen, daß sich Madame Quentin in bezug auf das Thema Juden widersprüchlich verhält: Zwar gibt sie vor, generell nichts gegen diese Gruppierung zu haben, und auch Herrn Meyer gegenüber ist sie wohlwollend eingestellt (s.o.), in der eigenen Familie möchte sie offensichtlich keine Juden haben. Anhand dieser »Selbstverleugnung « der Mutter entlarvt Malle auch die Haltung des französischen Großbürgertums zur Judenproblematik: »[...] ich versuchte, die Mutter als liebenswürdig zu schildern und zur gleichen Zeit zu zeigen, daß sie mit all den Vorurteilen ihrer Klasse behaftet ist.« (Malle 1998: 233) $)^{361}$

3.1.6 Höhepunkt und Ende des Films: »Au revoir les enfants«, >Au revoir, l'enfance<Einbruch des Holocaust in die »heile Welt « des Internats

Nach den dramatischen Szenen im Restaurant und der wegen seiner Schwarzmarktaktivitäten ausgesprochenen Entlassung von Joseph richtet sich das Hauptaugenmerk des Regisseurs auf die Intensivierung der Freundschaft zwischen Julien und Jean. Nach den gemeinsam überstandenen Gefahren scheint sich alles zum Guten zu wenden; die beiden Jungen können ihre Freundschaft genießen.

So können sie bei der Filmvorführung von Chaplins Einwanderer in Sequenz 31 
gemeinsam lachen (s. 1:14:26 h). ${ }^{362}$ Als Julien eines Morgens von seinen Mitschülern aufgrund seines Bettnässens gehänselt wird, ist Jean der einzige, der ihn tatkräftig verteidigt; beim Zähneputzen im Waschraum offenbart Julien seinem neuen Freund das Bettnässen (s. 1:16:16 h). Nachdem Julien Jean das Laufen mit Stelzen beigebracht hat (Sequenz 34), weiht Jean ihn in das flotte Klavierspielen ein (Sequenz 37): Während des Fliegeralarms erleben und feiern sie ihre Freundschaft beim gemeinsamen Boggie-Woogie - eine Szene, in der »die wunderbare Kameradschaft [...] zum Ausdruck kommt « (French 1998: 238) und die das positive Pendant zu Juliens Enttäuschung in bezug auf das Klavierspielen darstellt (s. 3.1.4.bc); gemeinsam »überspielen« sie im wahrsten Sinne des Wortes ihre Angst (s. 1:21:12 h). Diese gesteht Julien seinem Freund nun ebenso offen ein, wie dieser kurz zuvor sein Bettnässen zugegeben hatte. Nachdem sie in Sequenz 38 die Abwesenheit des Vaters als Gemeinsamkeit entdeckt ${ }^{363}$ (s. 1:22:01 h) und sich komplizenhafte Blicke zugeworfen haben (s. 1:22:52 h), gehen sie, während die anderen schon schlafen, ihrer gemeinsamen Leidenschaft nach, der Literatur (s. 1:23:45 h): Während Jean die Taschenlampe hält, liest Julien eine besonders erotische Passage aus »Tausendundeine Nacht« vor - nicht zufällig die letzte Sequenz vor Jeans Verhaftung und Höhepunkt ihrer Freundschaft und Intimität.

Im Kontrast zu diesem intensiven Moment entfaltet die Tragik des - sich über insgesamt vier Sequenzen erstreckenden - Filmendes ihre maximale Wirkungskraft. Obgleich sich Malle bei diesem tragischen Höhe- und Endpunkt des Films besonders stark an seinem Kindheitserlebnis orientierte ${ }^{364}$, wich er aus dramaturgischen Gründen punktuell davon ab (s. 3.1.6.a, 3.1.6.c): »Malle admitted that he deleted the real slapping of a boy by a member of the Gestapo at the end because sit's more frightening if the

362. Auf Philip Frenchs Frage, wie er auf diesen Film und die Musik gekommen sei, antwortete Malle: »Erinnerungen - einschließlich dichterischer Freiheit. In Wirklichkeit war es erst in den darauf-folgenden Jahren, daß sonntags Filme gezeigt wurden [...]. Während des Krieges, unter der deutschen Besatzung war Chaplin natürlich verboten, nicht nur weil er jüdisch war, sondern auch weil er den Grossen DiKTATOR gemacht hatte.« (Ebd. 234)

363. Julien: »Y a combien de temps que tu l'as pas vu ?« - Jean: »Mon père? Ça fait presque deux ans.« - Julien: »Moi, mon père non plus, je ne le vois jamais.« (1:21:24-1:21:35 $\mathrm{h}$ )

Der sachkundige Zuschauer kann Jeans Zeitangabe als Verweis auf die sogenannte $>$ Rafle du Vel d'hive verstehen, eine Polizeirazzia am 16. und 17. Juli 1942: Unter der Leitung des »ehrgeizigen Generalsekretärs der Polizei« (Baruch 1999: 105), René Bousquet, wurden mehr als dreizehntausend jüdischer Männer, Frauen und Kinder verhaftet; die Mehrzahl davon wurde zunächst in die überdachte Radrennbahn von Paris (Vélodrome d'hiver) verfrachtet, bevor sie von dort in die Durchgangslager von Pithiviers und von Beaune-la-Rolande im Loiret gebracht wurden - Bestimmungsort für fast alle war Auschwitz (ebd. 106). Ziel dieser Razzia - wie auch der in allen anderen großen Städten Frankreichs durchgeführten Razzien - war es, »auf dem gesamten französischen Territorium so viele Juden ausländischer Herkunft [zu verhaften], wie [die Deutschen] verlangten«. (Serge Klarsfeld zit.n. Baruch 1999: 105f.)

364. »Als ich das Drehbuch schrieb, fing ich mit den letzten Szenen an; das waren die Szenen, die ich auf keinen Fall ändern wollte.« (Malle 1998: 228) »Ich schrieb direkt aus dem Gedächtnis. [...] Diese Szenen machten den Film aus. Ich arbeitete sozusagen in umgekehrter Reihenfolge.« (Ebd. 229) 


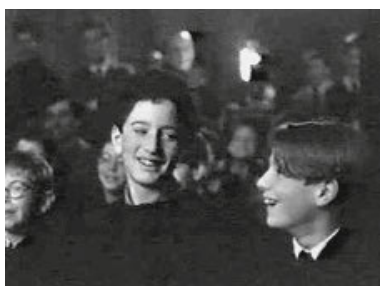

(319) $1: 14: 26 \mathrm{~h}$

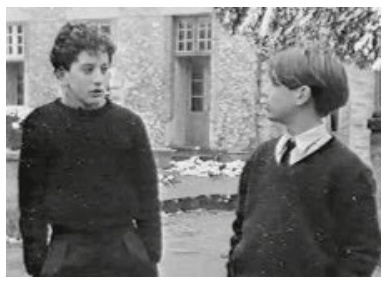

(322) $1: 22: 01 \mathrm{~h}$

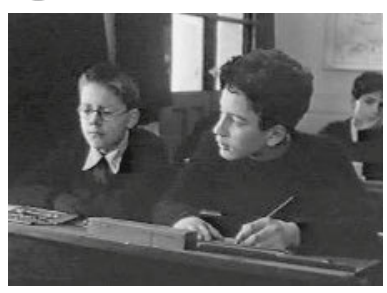

(325) $1: 24: 22 \mathrm{~h}$

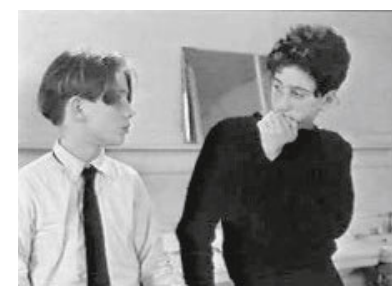

(320) $1: 16: 16 \mathrm{~h}$

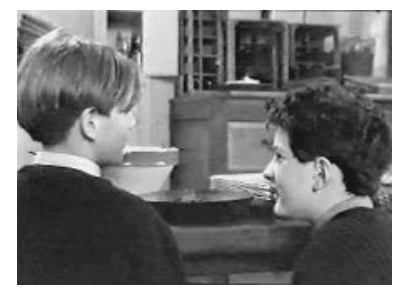

(323) $1: 22: 52 \mathrm{~h}$

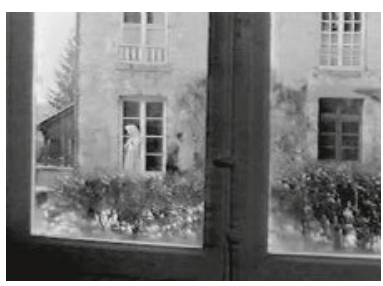

(326) $1: 24: 23 \mathrm{~h}$

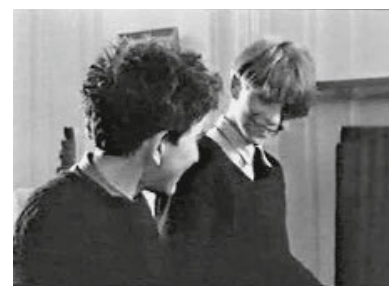

(321) $1: 21: 12 \mathrm{~h}$

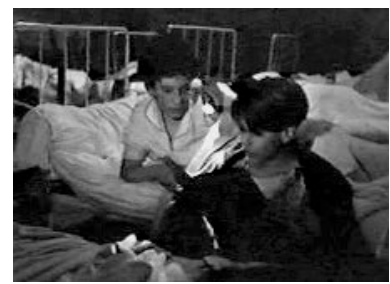

(324) $1: 23: 45 \mathrm{~h}$

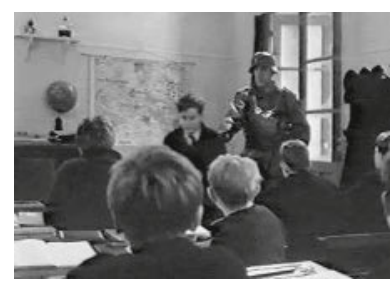

(327) $1: 25: 07 \mathrm{~h}$

Germans are so >correct< [...] this rather ordinary side of fascism is precisely what renders it unbearable «.« (Malle zit.n. Insdorf 2003: 86)

a) Juliens verhängnisvoller Blickkontakt mit Jean und dessen Verhaftung

In Sequenz 40 verkehren sich die Vorzeichen der Entwicklung ins Gegenteil, findet die wohltuende Freundschaft zwischen Julien und Jean ein jähes Ende.

Während der Mathematiklehrer zu Beginn der Unterrichtsstunde die von Radio Paris ausgestrahlten neuesten Meldungen über den Frontverlauf mitteilt, sieht der Zuschauer, wie Jean - ebenso wie zu Beginn des Films (s. 3.1.4.aa) - intensiv aus dem Fenster schaut (s. 1:24:22). Da nur Jean seine Aufmerksamkeit nach draußen richtet, antizipieren wir etwas Bedrohliches. Aus seiner unmittelbaren Perspektive verfolgen wir das Geschehen im Hof und sehen Moreau, der sich offensichtlich versteckt (1:24:23 h).

Daß die Klassenkameraden die aktuellen Frontmeldungen mit dem Slogan »Radio Paris ment, Radio Paris ment, Radio Paris est allemand « (1:24:25 h) kommentieren, läßt erkennen, daß sie diese verlogene Welt der Erwachsenen durchschauen.

Als ein Schüler das Klassenzimmer verläßt, um zur Toilette zu gehen, hören wir auf der Tonspur ein barsches »Halt! Halt, mein Junge.« (1:25:04 h) Ein deutscher Soldat taucht in der Tür auf und schickt das Kind zurück auf seinen Platz (s. 1:25:07 h). Dem Zuschauer wird klar, daß Moreau offensichtlich im Auftauchen der Deutschen eine Gefahr sah und sich deshalb versteckte. 
Erneut ist es die Tonspur, die unsere sowie die Aufmerksamkeit der Schüler erregt. Am Ende des Klassenzimmers wird eine Tür aufgerissen, alle Köpfe fliegen in die Richtung, aus der das Geräusch kommt. In Begleitung eines bewaffneten Soldaten betritt ein Herr in Zivil mit energischem Schritt den Raum (s. 1:25:15 h) - die Klasse ist umzingelt, beide Ausgänge sind nun versperrt. »Dr. Müller, Gestapo Müller« (1:25:19 h) stellt er sich dem Lehrer kurz vor und schreitet dabei durch das Klassenzimmer, als suche er eine bestimmte Person.

Den Schülern zugewandt, fragt er ohne Umschweife und in investigativem Ton: »Lequel d'entre vous s'appelle Jean Kippelstein?« (1:25:23 h) Unsere Befürchtung, als wir Gestapo - Synonym für Judenverfolgung - hören, bewahrheitet sich: Jean ist in größter Gefahr. Wie wird sich Julien verhalten, der als einziger Jeans richtigen Namen kennt, fragt sich der Zuschauer und verspürt gleichzeitig Angst, dieser könne zum Verräter werden. Während die anderen Schüler mehrheitlich Dr. Müller ansehen, vermeidet Julien zunächst den Blickkontakt (s. 1:25:38 h), was ihn in gewisser Weise verdächtig macht. Nachdem er zunächst keine positive Antwort auf seine Frage erhält, entfernt Dr. Müller zähneknirschend die Markierungen der voranrückenden russischen Truppe auf der den Frontverlauf nachzeichnenden Landkarte (s. 1:26:05 h). Dies nimmt der Zuschauer unmittelbar mit Julien wahr und hegt mit ihm die Hoffnung, Jean möge unentdeckt bleiben. Auch der Lehrer äußert nur: »Il n'y a personne de ce nom dans la classe.« (1:24:58 h)

Die kurze Zeit, in welcher sich der Deutsche der Karte zuwendet - vermutlich eine bewußte Falle -, nutzt Julien, um seinem Freund rasch einen Blick zuzuwerfen (s. 1:26:09 h). Voller Bangen fragen wir uns, ob der Deutsche die Blickrichtung verfolgt hat, und erschrecken, als seine Augen in Jeans Richtung wandern. Dieser, von Malle erfundene, besorgte Blick wird Jean zum Verhängnis. Müller hat diesen flüchtigen Blick registriert (s. 1:26:10 h).

Ohne jeglichen Kommentar geht der Deutsche gemessenen Schrittes auf Jean zu, bleibt vor ihm stehen und fixiert ihn (s. 1:26:30 h), wobei die eisige Stille quälend wirkt. ${ }^{365}$ Nach einem langen, wortlosen Blickkontakt, bei unerträglicher Stille, packt

365. »Malle admitted that he deleted the real slapping of a boy by a member of the Gestapo at the end because sit's more frightening if the Germans are so >correct< [...] this rather ordinary side of fascism is precisely what renders it unbearabler." (Malle zit.n. Insdorf 2003: 86)

366. Zu der Frage, ob er mit dieser Erfindung Julien bzw. sich selbst schuldig sprechen oder zumindest verantwortlich machen wollte, äußerte sich Malle widersprüchlich: »Nie hatte ich die Absicht, Julien - oder mich - für Bonnets Verhaftung verantwortlich zu machen. Obwohl ich im Unterbewußtsein vielleicht gerade dies ausdrücken wollte.« (Malle 1998: 242) »Malle confessed that, although he swrote the last classroom scene exactly as it happened ... I added Julien's look. Unconsciously, I was trying to express something very obvious - my guilt, or at least sense of responsibility.« (Malle zit.n. Insdorf 2003: 85) Aufgrund letzterer Darstellung ist Auf WiederSEHEN, KINDER für Jansen/Maerker »die Befreiung von einem Trauma der Kindheit, praktizierte Trauerarbeit« (1990: 93), für Frodon die Geschichte von »Julien Malle et du péché originel du regard« (1995: 704).

367. »Tout est dit au delà des paroles.« (Chalais zit.n. Moos/Frank 1992: 48) 


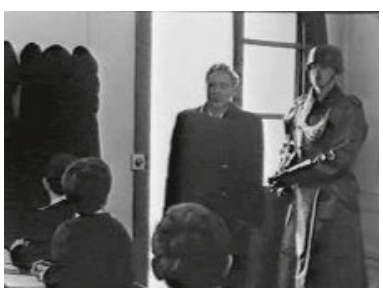

(328) $1: 25: 15 \mathrm{~h}$

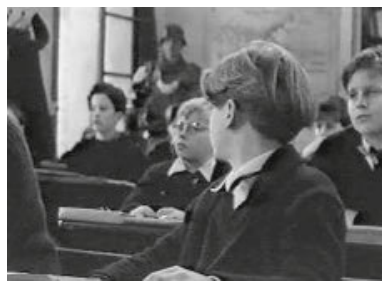

(331) $1: 26: 09 \mathrm{~h}$

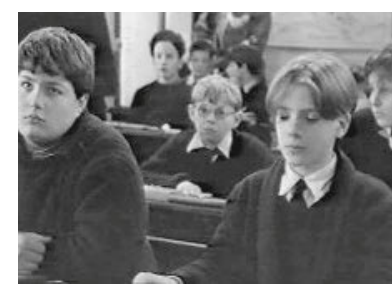

(329) $1: 25: 38 \mathrm{~h}$

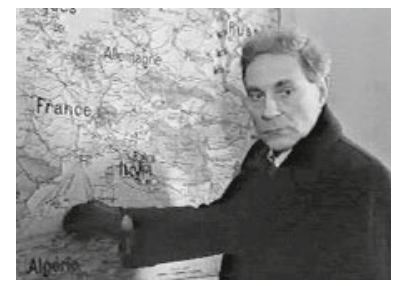

(332) $1: 26: 10 \mathrm{~h}$

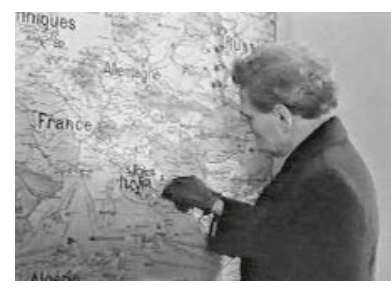

(330) $1: 26: 05 \mathrm{~h}$

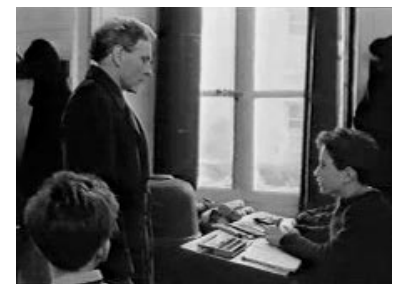

(333) $1: 26: 30 \mathrm{~h}$

der Junge seine Sachen. Das Spiel ist aus - Jean ist aufgespürt, Juliens Blick hat ihn verraten: »Ich hatte die Szene gleich im ersten Entwurf so geschrieben und beließ es dabei [bei dem erfundenen Blick], weil die Situation für Julien dadurch emotional viel aufwühlender wurde.« (Malle 1998: 242)366 Auch für den Zuschauer gewinnt die Tragik der Situation durch Juliens »Unschuldig-schuldig-Werden« an Wirkkraft. Wie zuvor in der Restaurant-Sequenz (s. 3.1.5) ist Juliens Blick zu seinem Freund ein Zeichen seines Sich-Versetzens in Jeans Lage und daher seines Bangens um den Freund. In diesem Moment ist Juliens spontanes, die Konsequenzen nicht bedenkendes Verhalten dem Freund zum Verhängnis geworden, eine tragische Verstrickung, mit der Malle an den Erfahrungsschatz des Zuschauers anknüpft und ihn so, und weil alles jenseits von Worten »gesagt« wird $^{367}$, die Motivation für Juliens Blick aus sich heraus entwickeln läßt:

»Which of us cannot remember a moment when we did or said precisely the wrong thing, irretrievably, irreparably? The instant the action was completed or the words were spoken we burned with shame and regret, but what we had done never could be repaired. Such moments are rare, and they occur most often in childhood, before we have been trained to think before we act. AU REVOIR LES ENFANTS [...] is a film about such a moment, about a quick, unthinking glance that may have cost four people their lives.« (Ebert 1988: 1)

Nach diesem tragischen Vorfall kann sich Julien nicht einmal richtig von seinem Freund verabschieden, denn als sich beide stumm die Hand geben (s. 1:27:01 h), wird Jean von den Soldaten weggezogen - sie werden durch diesen als extrem brutal empfundenen Eingriff abrupt voneinander getrennt. Durch drei schnelle Schnitte und Jeans deutlich hörbares Stolpern wird für den Zuschauer klar, daß die Freundschaft zwischen Julien und Jean in diesem Moment ein tragisches Ende findet. Er leidet mit beiden, insbesondere mit Julien, dessen Reaktion von der Kamera eingefangen wird: leere, tieftraurige Augen, den Arm zum Freund ausgestreckt, bleibt er zurück (s. 1:27:07 h). 
Auch die Erklärungen von Pater Michel ${ }^{368}$ und das gemeinsame Gebet für die Festgenommenen (neben Jean auch seine beiden Freunde und Pater Jean) können Julien nicht aus seiner Erstarrung lösen (s. 1:28:34 h). Es wirkt so, als realisiere Julien nur langsam, daß sein besorgter, freundschaftlicher Blick Jean verraten hat, daß er im Begriff ist, seinen einzigen Freund zu verlieren, daß das Internat nicht mehr der behütete, von der Außenwelt relativ abgeschlossene Ort ist, daß nichts mehr wie früher sein wird - Interpretationen, die auch der Zuschauer durch Versetzung in den Protagonisten aus sich heraus entwickelt.

\section{b) Kollaboration versus Widerstand - Juliens bewußter Akt der Résistance}

In der vergleichsweise kürzeren Folgesequenz (Sequenz 41) haben die Freunde noch Zeit, sich gegenseitig Bücher zu schenken, versucht Jean, Julien das Schuldgefühl zu nehmen ${ }^{369}$, bevor er vom deutschen Soldaten mit einem barschen »Schnell, Jude« (1:30:48 h) zur Eile angetrieben wird, während Julien im Schlafsaal zurückbleibt.

Im Anschluß hieran erlebt Julien in der im Krankenzimmer spielenden Sequenz 42 den Kontrast zwischen Widerstand und Kollaboration: Während Moreau Négus in einem freien Krankenbett versteckt, wird letzterer von der Nonne und Krankenschwester an die deutschen Soldaten verraten. Als Julien noch ein »On n'a vu personne.« (1:31:08 h) zum Schutz der Versteckten vorbringt, erlebt der Zuschauer, aufgrund des unmittelbaren Einbezugs in dessen Perspektive, wie die Nonne dem Soldaten etwas zuflüstert (s. 1:32:10 h). Die Befürchtung wird zur Bestätigung, als der Soldat Négus am Ohr aus dem Bett zerrt (s. 1:32:30 h). So stellt man fest,

»daß Verhaltensweisen unentschuldbar sind, weil jeder für sein Handeln verantwortlich ist [...]. [...] Damit verwirft Louis Malle so vordergründige Ausreden wie: >gegen das Schicksal kann man sich halt nicht wehren [...]. [...] Der Film zeigt, wie sich nicht nur bewußte, son-

368. Pater Michel: »Ecoutez-moi. Ils ont arrêté le Père Jean. Il semble que nous ayons été dénoncé.« - Julien: »Et Bonnet?« - Pater Michel: »Bonnet, Dupré et Lafarge sont israélites. Le Père Jean les avait recueilli parce que leurs vies étaient en danger.«

369. "T'en fais pas. Ils m'auraient eu de toute façon.«

370. Wir erinnern uns an Josephs Verzweiflung bei seiner Entlassung in Sequenz 35: „Et où je vais aller, moi? J'ai même pas où coucher. [...] C'est pas juste.« (1:17:43 h)

Vgl. Jansen/Maerker und Colombat zur Figur des Joseph: »Ähnlich wie Lucien in LACOMBE LUCIEN erliegt er aus der Ohnmacht des sozialen Außenseiters heraus der Verführung der Macht.« (1990: 94)»[...] one of the most controversial aspects of both of Malle's films: the feeling that the key actions of his heroes are only the results of circumstances. [...] in both Films, the French boys who became members of the Gestapo (Lucien in LACOMBE LUCIEN, and Joseph in GOODBYE CHILDREN) are both presented as being led by a chain of circumstances of accidents to collaborating with the Nazis.« (Colombat 1993: 263)

371. Joseph: »Tout ça, c'est de votre faute. Si j'avais pas fait l'affaire avec vous, ils m'auraient jamais foutu à la porte. La Perrin, elle volait plus que moi.«

»Er wird aufgrund eines Schwarzmarktskandals auf nicht ganz gerechte Weise aus der Schule geworfen, und er rächt sich, indem er die Anwesenheit jüdischer Kinder in der Schule den Deutschen meldet.« (Malle 1998: 229) »Ça ne m'a pas intéressé de juger Joseph.« (Malle zit.n. Prédal 1989: 160) 


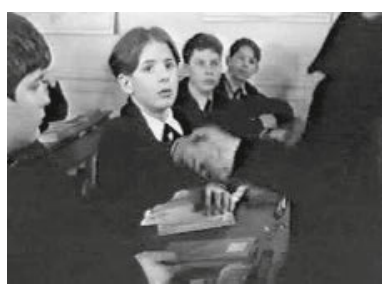

(334) $1: 27: 01 \mathrm{~h}$

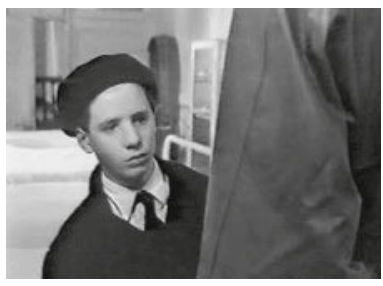

(337) $1: 32: 09 \mathrm{~h}$

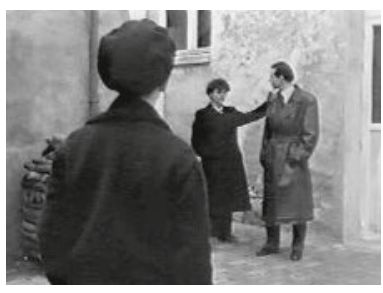

(340) $1: 33: 24 \mathrm{~h}$

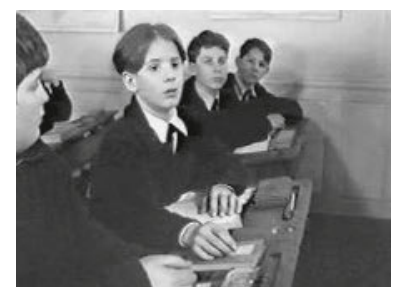

(335) $1: 27: 07 \mathrm{~h}$

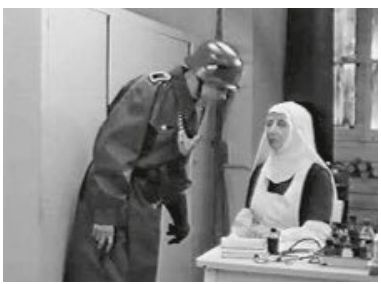

(338) $1: 32: 10 \mathrm{~h}$

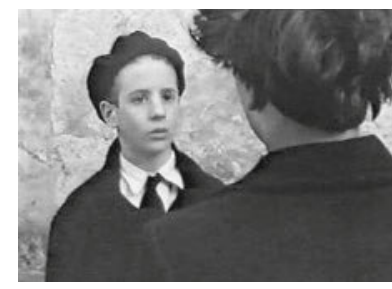

(341) $1: 34: 13 \mathrm{~h}$

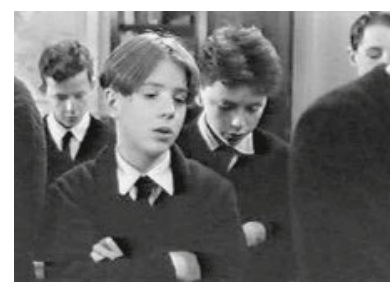

(336 $1: 28: 34 \mathrm{~h}$

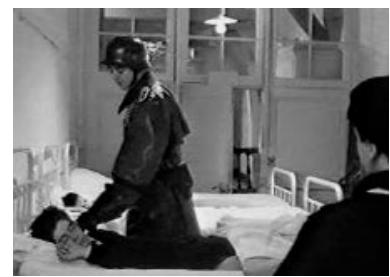

(339) $1: 32: 30 \mathrm{~h}$

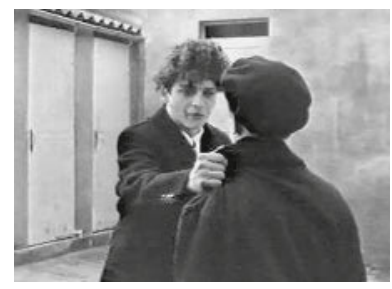

(342) $1: 34: 21 \mathrm{~h}$

dern auch unterlassene Handlungen mit aller Unerbittlichkeit auf unschuldige Dritte auswirken.«(Ader 1993: 139f.)

c) Verzögerung und Vertiefung: Juliens Ent-Täuschung

Nachdem das Verhalten der Nonne in Julien einen Prozeß des Bewußtwerdens in Gang gesetzt hat, wird er in der Sequenz 43 weiter desillusioniert - eine Szene, die der Vertiefung der Enttäuschung dient und gleichzeitig die Auflösung von Jeans Schicksal hinauszögert.

Julien trifft im Hinterhof den aufgrund seiner Schwarzmarktaktivitäten des Internats verwiesenen Joseph in Begleitung eines Gestapo-Mannes (s. 1:33:24 h) und begreift, daß dieser als Außenseiter und Underdog leicht in die Fänge dieser Leute geraten konnte. Julien und dem Zuschauer wird vor Augen geführt, daß Ausgestoßene der Gesellschaft leicht der Verführung durch Macht, vor allem totalitärer Macht, erliegen. 370

Als Joseph eine abfällige Bemerkungen über Juden macht - »Ne t'en fais pas, c'est que des Juifs!« (1:34:11 h) -, starrt Julien seinen früheren Kumpel entgeistert an (s. 1:34:13 h) und weicht dann wortlos vor ihm zurück. »Or l'horreur que lui inspire le geste de Joseph est d'autant plus grande que ce garçon lui avait été auparavant sympathique.« (Prédal 1989: 152) Völlig schockiert (s. 1:34:28 h) scheint ihm und uns in wenigen Sekunden klar zu werden, daß sich Joseph auf die andere Seite geschlagen, deren Logik übernommen und Pater Jean und das Internat aus Rache denunziert hat (s. 1:34:21 h) 371: 
»Pour moi, c'est une scène clef du film [...].« (Malle zit.n. Prédal 1989: 160)

»[...] wenn Julien plötzlich begreift, daß Joseph es gewesen ist. Auch hier geht es um die Entdeckung des Bösen. [...] Für Julien und, wie ich glaube, auch für den Zuschauer war gerade dies so verstörend: daß alles mit einer im Grunde bedeutungslosen Schwarzmarktsache anfing und damit, daß der Pater so streng dagegen durchgreift.« (Malle 1998: 230).

\section{d) Das Ende von Juliens Kindheit - Abschied im Schulhof}

Die letzte Sequenz (Sequenz 44) bildet den tragischen Höhe- und Endpunkt des Films. Gleichzeitig steht sie, wie in 3.1.4 erläutert, in thematischer Analogie zum Prolog (s. 3.1.3.a) und bildet den Rahmen des Films. Hier wie dort erleben wir mit dem Protagonisten eine prägende Trennung, am Ende einen Abschied ohne Wiedersehen von seinem einzig wirklichen Freund:

»Es ist schwer zu erklären, doch es war ein solcher Schock, daß ich mehrere Jahre brauchte, darüber hinwegzukommen, überhaupt den Versuch zu unternehmen, es zu verstehen - natürlich `konnte ich es gar nicht verstehen. [...] Ich konnte nicht darüber sprechen. Ich dachte daran - in all diesen Jahren verfolgte es mich. Doch ich konnte die Geschichte niemandem erzählen. [...] Das konnte ich erst in den siebziger Jahren, also nachdem fünfundzwanzig Jahre vergangen waren.« (Malle 1998: 227)

\section{Detaillierte Sequenzanalyse:}

Auf dem Schulhof haben die Schüler, Lehrer und Aufsichtspersonen auf Anweisung von Dr. Müller Aufstellung genommen (s. 1:34:57 h). Die Suche nach weiteren Juden wird fortgesetzt. Wie schon im Klassenzimmer (s. 3.1.6.a), schreitet Dr. Müller an der Reihe der Jungen vorbei und durchbohrt sie mit forschendem Blick, bis er willkürlich einem Jungen befiehlt, sich an die gegenüberliegende Wand zu stellen (s. 1:35:58 h). In der Folge verliest einer der deutschen Soldaten eine Liste verdächtiger Schüler, die sich ebenfalls an die Mauer begeben müssen - dort stehen sie angsterfüllt im wahrsten Sinne mit dem Rücken zur Wand. Der Zuschauer nimmt diese Situation zum Teil aus der Perspektive der Betroffenen, der Schülerschaft, wahr (s. 1:35:58 h), zum Teil aber auch aus einer figurenunabhängigen Perspektive, welche die Reaktion Juliens zeigt: Mit leicht geöffnetem Mund und unbewegter Miene - Zeichen seiner Fassungslosigkeit, die wir mit ihm verspüren - verfolgt er, wie zahlreiche Jungen mit »erschreckender Korrektheit« ausgesondert werden und sich die Reihen lichten (Malle zit.n. Insdorf 2003: 86; s. 1:36:16 h). Sein Banknachbar verbalisiert die Furcht der Kinder, die auch die unsere ist, demonstriert aber gleichzeitig seine diskriminierende Einstellung gegenüber Außenseitern: »Tu crois qu'ils vont nous emmener? On n'a rien fait, nous.« (1:36:19 h) $)^{372}$

Die Verlesung der Liste endet damit, daß Pater Jean und die drei jüdischen Kinder, Jean, Négus und Dupré, über den Hof, an der aufgereihten Schülerschaft vorbei abge-

372. Dieser zweite Satz läßt erkennen, daß er sich von den Festgenommenen deutlich abgrenzt, ihnen vielleicht sogar unterstellt, sie hätten etwas getan.

373. »[...] das waren die letzten Worte des Paters, Le Père Jacques, als er vom Hof der Schule abgeführt wurde - das war es, woran ich mich bei dieser entscheidenden Szene auf dem Schulhof erinnerte.« (Malle 1998: 226) 


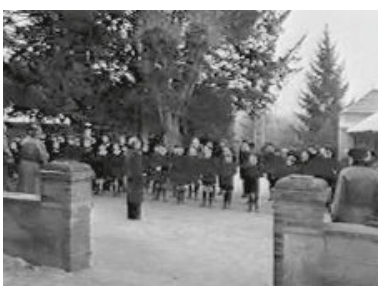

(343) $1: 34: 57 \mathrm{~h}$

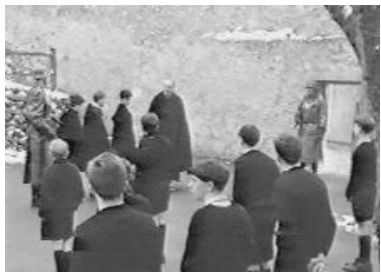

(346) $1: 38: 01 \mathrm{~h}$

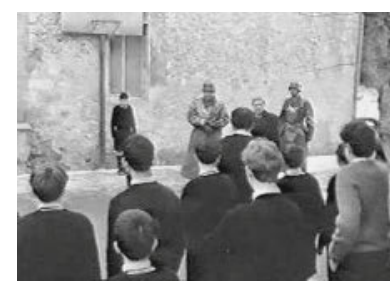

(344) $1: 35: 58 \mathrm{~h}$

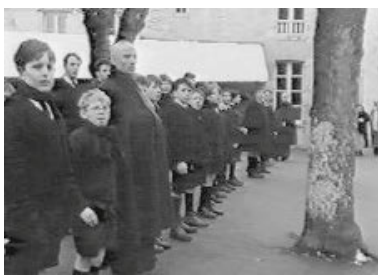

(347) $1: 38: 04 \mathrm{~h}$

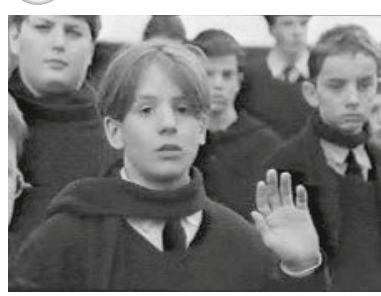

(349 $1: 38: 17 \mathrm{~h}$

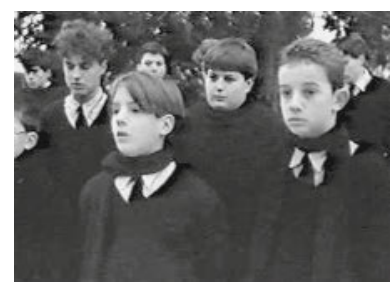

(345) $1: 36: 16 \mathrm{~h}$

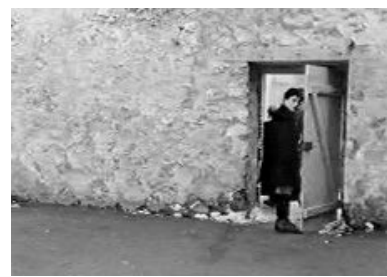

(348) $1: 38: 16 \mathrm{~h}$

führt werden. Nach und nach rufen die Schüler dem Internatsleiter, der die Augen nicht von ihnen wenden kann, »Au revoir, mon père $\mathrm{zu}$ (s. 1:38:04 h). Was dünnstimmig beginnt, schwillt zu einem gewaltigen Stimmenchor an. Zum ersten Mal hat man den Eindruck, die Schüler seien mit Inbrunst bei der Sache. »Au revoir, les enfants, à bientôt « (1:38:09 h) ${ }^{373}$, erwidert Pater Jean äußerlich ruhig und gefaßt die Abschiedsgrüße (s. 1:38:01 h) - ein äußerst ergreifender Moment, denn in dem beinahe einstimmigen Rufen der Kinder liegt ein gewaltiger Schmerz über den Verlust des Ersatzvaters und im »à bientôt « von Pater Jean eine bewundernswerte Haltung: Angesichts seines unheilvollen Schicksals hat er die Größe, seinen zurückbleibenden Schülern ein Gefühl von Hoffnung zu geben, auch wenn er selbst um die Unwahrscheinlichkeit eines Wiedersehens weiß. Der Eindruck des endgültigen Abschieds wird auf der Tonspur durch Glockenläuten abgesichert, das den Zuschauer an ein Totengeläut erinnert.

Dramaturgisch stimmig verläßt Jean als letzter das Internat, nicht jedoch ohne sich auf der Türschwelle nach Julien umzudrehen (s. 1:38:16 h). Immer noch völlig fassungslos und tieftraurig hebt dieser mechanisch die Hand zum Gruß (s. 1:38:17 h). Wie zuvor im Klassenzimmer wird auch diese Verabschiedung, dieser letzte stumme Blickkontakt von den Deutschen unterbrochen: Abrupt wird Jean von einem der Soldaten weggezogen (s. 1:38:18 h). Ähnlich wie in der zurückliegenden Klassenzimmerszene, wird dieser Abschied durch den Einsatz von nahen Einstellungsgrößen, von jeweils subjektiver Kamera, sowie zwei bis drei schnellen Schnitten als äußerst 
tragisch erfahrbar: Jean wird aus seiner mittlerweile vertrauten Umgebung herausgerissen, Julien verliert seinen neuen, einzigen und wirklichen Freund. Vergleichbar mit Menschen, die angesichts des nahen Todes die wichtigsten Momente vorüberziehen sehen, füllt sich dieser letzte Blickkontakt der Freunde mit den Stationen auf dem Weg zu ihrer einzigartigen Freundschaft. Schmerzlich spürbar wird dieser Verlust bzw. die entstandene Leere für Julien und uns durch seinen auf der Tür verweilendem Blick (s. 1:38:26 h). Diese mehrere Sekunden andauernde und dadurch besonders hervorgehobene Inszenierung der Leere und der absoluten Stille wirkt in diesem Moment höchster Identifikation mit Julien auf ihn wie auf uns unerträglich.

Die Absicherung dessen, was dieser Abschied sowohl für Julien als auch für Jean bedeuten wird, folgt als Off-Kommentar, bedächtig gesprochen von Louis Malle als Erwachsenem; er setzt zu Juliens Wahrnehmung der Leere ein und begleitet in der Folge die Inszenierung seines Gesichts:

»Bonnet, Négus et Dupré sont morts à [s. 1:38:29 h] Auschwitz, le Père Jean au camp de Mauthausen. Le collège a rouvert ses portes en octobre 1944. Plus de quarante ans ont passé, mais jusqu' à ma mort, je me rappellerai chaque seconde de ce matin de janvier.« (1:38:27 $1: 38: 36 \mathrm{~h})$

Ab dem Wort Auschwitz verharrt die Kamera auf Julien, dessen Gesicht durch die kontinuierliche Veränderung von einer Nah- (s. 1:38:29 h) zu einer Großaufnahme (s. 1:38:53 h) und die lange Einstellungsdauer (ca. 40 Sekunden) aufgeladen wird:

»Die Großaufnahme ist die technische Bedingung der Kunst des Mienenspiels und mithin der höheren Filmkunst überhaupt. So nahe muß uns ein Gesicht gerückt sein, so isoliert von aller Umgebung, welche uns ablenken könnte, so lange müssen wir bei seinem Anblick verweilen dürfen, um darin wirklich lesen zu können. Der Film fordert eine Feinheit und Sicherheit des Mienenspiels [...]. Denn in der Großaufnahme wird jedes Fältchen des Gesichtes zum entscheidenden Charakterzug, und jedes flüchtige Zucken eines Muskels hat ein frappantes Pathos, das große innere Ereignisse anzeigt. Die Großaufnahme eines Gesichtes [...] muß ein lyrischer Extrakt des ganzen Dramas sein.« (Balázs 1982: 82)

Durch diese - neben der Exposition zum zweiten Mal eingesetzte - extreme Annäherung an den Protagonisten (Großaufnahme ${ }^{374}$ ) sowie durch die Wiederaufnahme des aus dem Vorspann bekannten melancholischen Klavierstücks375 wird auch der

374. Interessanterweise setzt Malle nur am Anfang und am Ende Großaufnahmen von Julien ein und begnügt sich im Filmverlauf mit maximal Nahaufnahmen.

375. »Die Musik läßt die Vergangenheit in der Gegenwart anwesend sein.« (Kloepfer 1999: 27)

376. »Ich schloß den ersten Entwurf ab [...], um ihn Candice und meiner Tochter Justine vorzulesen. Als ich mit dem Lesen fertig war, weinten sie beide. [...] Plötzlich begriff ich, wie unglaublich emotional es auf andere wirken könnte." (Malle 1998: 228)

377. »Pour André Tournès, Au REVOIR LES ENFANTS est $l^{\prime}$ 'évocation d'un hiver 44 où un enfant préservé et choyé a vu son univers s'effondrer devant l'irruption de l'injusticer.« (Zit.n. Prédal 1989: 151) 


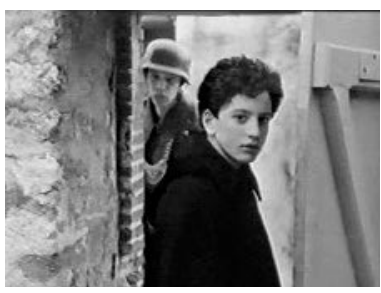

(350) $1: 38: 18 \mathrm{~h}$

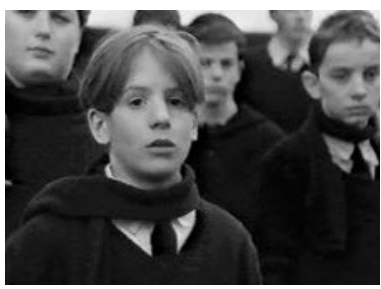

(352) $1: 38: 29 \mathrm{~h}$

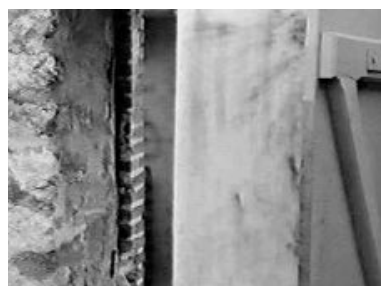

(351) $1: 38: 26 \mathrm{~h}$

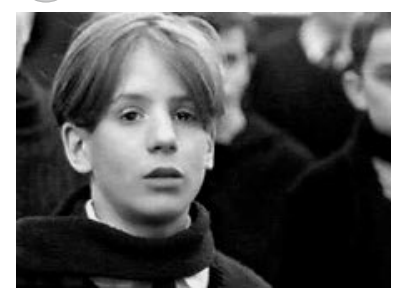

(353) $1: 38: 53 \mathrm{~h}$

Zuschauer ganz in Juliens Gemütszustand einbezogen und reagiert wohl wie dieser schließlich mit Tränen auf den Abschied bzw. den Verlust des Freundes (s. erneut 1:38:53 h). ${ }^{376}$

So schließt sich mit der letzten langen Einstellung auf Julien der Kreis zum Anfang des Films. Auch hier haben wir Juliens Trennungsschmerz mitempfunden und seine feuchten Augen durch die erste Großaufnahme des Films bemerken können. Am Ende des Films besitzt seine Gefühlslage jedoch eine neue Dimension und eine vergleichsweise prägendere Qualität: Man hat den Eindruck, als habe er seine kindliche Naivität und Unschuld verloren, als sei er innerhalb kürzester Zeit »wissend und erwachsen « geworden, (als handele es sich für Louis Malle alias Julien Quentin um das »bedeutsamste Ereignis [...], vielleicht sogar [s]eines Lebens« (Malle 1998: 227). Bekräftigt wird dieser Eindruck durch die traurigen Abschiedsworte von Pater Jean gegen Ende des Films: »Au revoir les enfants « verweist nun auf eine definitive Trennung - nichts wird mehr so sein, wie es war, das Ende der naiven Kindheit ist besiegelt:

»In 1942, we would see children my age wearing the yellow star. I would ask, >Why? Why him and not me? No one had a good answer. From that moment on, I felt that the world of adults was one of injustice, deception, false explanations, hypocrisy and lies. [...] And following that morning in January 1944 when Bonnet left, the feeling became a certitude.« (Malle zit.n. Insdorf 2003: 86) $)^{377}$

\section{II.3.2 FesSELNDE SPANNUNG - ERFÜlLte HOFFNUNG: »SCHINDLERS Liste« (»SCHINDLER'S LiST«, StEVEn SPIELBERG, USA 1993)}

\subsubsection{Inszenierte Authentizität}

Während die Filmtitel Das LeBen ist SCHÖN und Zug Des LeBens beinahe poetisch klingen und Auf Wiedersehen, Kinder eine persönliche Geschichte erwarten läßt, wirkt Spielbergs Titel nüchtern und sachbezogen - erstes Indiz für den Realitätsanspruch des Films. Offenbar geht es um eine Person namens Schindler und deren 
Liste; sie wird daher wohl die Hauptfigur des Films darstellen, kann der Zuschauer schließen. Oskar Schindler dürfte nur denjenigen Zuschauern bekannt gewesen sein, die Thomas Keneallys gleichnamige »documentary novel« aus dem Jahre 1982 gelesen bzw. von dem Tatsachenroman gehört hatten (Oehlenschläger 2002: 97ff.). ${ }^{378}$ Mit der Vorinformation Holocaust-Film liegt die Vermutung nahe, das Thema des Films habe zu tun mit einer Todesliste, mit der bürokratischen Vernichtungspolitik der Nationalsozialisten. Andererseits handelt es sich bei dem Namen Schindler nicht um einen der bekannten Nazis. ${ }^{379}$

378. »Auch in der Bundesrepublik wurde SCHINDLERS LISTE schon damals bekannt. Der IStern< veröffentlichte den Tatsachenroman 1983 in 15 Folgen, die Resonanz blieb - wie auch für die von Bertelsmann verlegte deutsche Buchausgabe - gering." (Reichel 2004: 362) Als der Film 1994 in den deutschen Kinos läuft, wird das Buch »als gebundene Ausgabe 90.000 mal verkauft, als Taschenbuch 1.000.000 mal. Zwischen 1982 und dem Filmstart 1994 sind in Deutschland gerade einmal 5.000 Exemplare von Keneallys Roman verkauft worden.« (Thiele 2001: 432)

379. In Verbindung mit dem Regisseur, der für groß angelegtes Hollywoodkino mit »HappyEnd« steht, wäre eine Rettungsliste nicht auszuschließen. Diese Vermutung würde sich bei Betrachten des Filmplakats zum Verdacht erhärten, denn dieses zeigt ausschnitthaft eine starke Männerhand, die eine schwache Kinderhand (wie vor dem Ertrinken) rettet. Das dominierende Schwarzweiß des Plakats dient als weiteres Indiz für eine authentische Geschichte.

380. Vgl. u.a. Köppen zur »Newsreel-Ästhetik« (1997: 158; s.u., Punkt 1) sowie den Titel seines Artikels (»Von Effekten des Authentischen - SCHINDLERS LISTE«) und Kortes variierende Formulierungen diesbezüglich: »hochgradige Authentizitätsillusion« (1999: 173), »ungewohnt intensiver Realitätseindruck« (ebd. 161), »außergewöhnliche starke Realitätsillusion« (ebd. 176).

381. "Sie läßt sich ein auf eine Rhetorik des Tatsächlichen, deren Diskurs die historischen Fakten durchgängig transformiert und einen >Anschein von Realität produziert.« (Young zit.n. Oehlenschläger 2002: 99, H.i.0.)

382. Vgl. Hansen zur »sensory experience« (2001: 134) und Weiß zur »sinnlichen Erinnerung« (2001: 71).

383. Vgl. Weiß' Rezensionssammlung: >Der gute Deutscher. Dokumente zur Diskussion um Steven Spielbergs SCHINDLERS LISTE in Deutschland, 1995.

384. Vgl. Wuss zum »Authentie-Effekt« (1990: 164ff.).

385. Die Darstellung folgt weitgehend Noack 1998.

»Er [Spielberg] setzt bewährte filmische Strategien der Authentisierung ein.« (Lange 1999: 155) »Nun scheint sich nach dieser Lektüre von Spielbergs Film Authentizität auflösen zu lassen in Authentisierungsstrategien, die sich mehr oder weniger bewußt bereitliegender Elemente der filmischen Rhetorik bedienen, um den Eindruck des Authentischen hervorzurufen.« (Kramer 1999: 38) »[...] er [Spielberg] produziert eine kompakte Authentizitäts-Fiktion, deren beträchtliche Illusions-Kraft suggeriert, eine exakte Abbildung der Faktizität selbst zu sein.« (Oehlenschläger 2002: 98) »Der Konsument empfindet den Film [SCHINDLERS LISTE] samt Inhalt weniger unterhaltend, als viel mehr informierend und berichtend.« (Noack 1998: 101)

386. NACKT UNTER WöLfEn (Frank Beyer, DDR 1962/63), Holocaust (Marvin J. Chomsky, USA 1978), War and Remembrance (Dan Curtis, USA 1988), Kornblumenblau (Leszek Wosiewicz, POL 1988), Hitlerjunge Salomon (Agnieszka Holland, D/F/POL 1990), KorzCak (Andrej Wajda, POL 1990), Der Stellvertreter (Costa-Gavras, F/D/ROM/USA 2002), Der Pianist (Roman Polanski, F/D/UK/POL 2002), Die Rosenstrasse (Margarethe von Trotta, D 2003). 
Im Unterschied zum ersten globalen, filmischen Medienereignis in bezug auf die Judenvernichtung, der TV-Familiensaga Holocaust (Marvin J. Chomsky, USA 1978), war bei SChindere LiSTE >authentisch< das Attribut, das »vielen Kritikern nun die Wirkung des Films am deutlichsten zu begründen schien. [...] Doch nicht nur die Enthusiasten dieses Films, bezeichnenderweise gerade auch seine wenigen Gegner insistierten auf dem Eindruck des Authentischen.« (Köppen 1997: 149) $)^{380}$ Ersten Ansätzen des vier Jahre zurückliegenden Spielfilms Triumph des Geistes (Robert M. Young, USA 1989; s.u. Punkt 1) sowie dem zentralen Charakteristikum der Romanvorlage folgend ${ }^{381}$, versuchte Spielberg den jungen Deutschen etwas zu ermöglichen, was sie als Nachgeborene nicht selbst erlebt hatten: »to feel the Holocaust« (Spielberg zit.n. Reichel 2004: 315). ${ }^{382}$

$»[\ldots]$ das ist kein Film, das ist ein Erlebnis. Ein Dokument der Wahrheit. [...] Schon nach den ersten zehn Minuten hatte ich vergessen, daß es sich um einen Film handelt. Ich achtete nicht mehr auf den Winkel der Kamera und all das technische Zeug - ich war nur gebannt von diesem totalen Realismus. [...] Und glauben Sie mir, diese Szenen sind so authentisch, es läuft einem kalt den Rücken runter.« (Wilder 1994: 42f.)

»Spielberg erzählt nichts, was über den Holocaust nicht schon längst bekannt wäre, aber er macht ihn für dreieinviertel Stunden zu einem hautnahen Erlebnis [...].« (Koar 1993: 25)

Mit Hattendorf sowie zahlreichen Rezensenten ${ }^{383}$ muß hervorgehoben werden, daß es sich um eine von Spielberg, insbesondere über systematische Versetzung des Zuschauers in die dargestellte Welt, erzeugte Authentizität handelt:

»[...] Spielberg rekurriert nicht nur laufend auf die Realitätshaltigkeit des Gezeigten, er macht das Konzept Authentizität sogar für besondere emotionale Effekte fruchtbar. Die Aura des Dokumentarischen stellt er mit Hilfe filmischer Mittel her, die im Sinne von Manfred Hattendorf als Authentizitätssignale gelesen werden können. Hattendorf verortet die Authentizität eines Dokumentarfilms nicht in erster Linie in der Echtheit eines Ereignisses, welches den Filmbildern zugrunde liegt, nicht also in der Quelle, sondern er schreibt: >Authentizität ist ein Ergebnis der filmischen Bearbeitung. Die >Glaubwürdigkeit eines dargestellten Ereignisses ist damit abhängig von der Wirkung filmischer Strategien im Augenblick der Rezeption. Die Authentizität liegt gleichermaßen in der formalen Gestaltung wie der Rezeption begründet.< Folgerichtig betont er, daß diese Dimension der Authentizität in die Rhetorik und die Wahrnehmungspsychologie falle.« (Kramer 1999: 32, Hattendorf zit.n. ebd.) $)^{384}$

Die, von Spielberg eingesetzten, »dokumentarischen Codes« (Steinmetz 1995: 171f.) bzw. »Authentizitätssignale« (Hattendorf 1994: 72) sind vielfältig:385

- $\quad$ Newsreel-Effekt« (Korte 1999: 177), insbesondere durch den Einsatz einer wackelnden Handkamera:

Im Unterschied zu den meisten vergleichbaren Spielfilmen und TV-Produktionen ${ }^{386}$ zeichnet sich SCHINDLERS LISTE in besonderem Maße dadurch aus, daß Spielberg »in sehr eindringlichen, gewaltvollen und angsterfüllten Szenen« (Noack 1998: 111) eine »Newsreel-Ästhetik imitiert, die an CNN-Aufnahmen von Vietnam bis Kroatien erinnert« (Köppen 1997: 158). Diese verbindet der Regisseur 
darüber hinaus »mit avancierten Mustern der Gewaltrepräsentation im Kinofilm, wobei in vielen Sequenzen Parallelen insbesondere zum modernen Kriegsfilm nachzuweisen wären« (ebd. 159). ${ }^{387}$

Das damit einhergehende »Gefühl des unmittelbaren Dabeiseins«, »einer unmittelbaren Teilhabe an den geschilderten Ereignissen « (ebd. 177) wird neben dem Toneinsatz durch die gezielte Kombination aus Bildaufbau, Montagerhythmus, schnell wechselnde Erzählperspektiven und insbesondere durch die wackelnde Handkamera herbeigeführt (ebd. 176) (s. 3.2.3.b und 3.2.5).

Der - wie bereits in Robert M. Youngs Triumph Des Geistes punktuell beobachtbar (s. 0:16:26 h und o:16:29 zur Hektik bei der Ankunft in Auschwitz) -, gezielte Einsatz der »sehr >nervös < wirkenden und stark bewegungsbetonten Handkamera « (Korte 1999: 177, H.i.O.) versetzt den Zuschauer in »den verzweifelt nach Halt suchenden Blick« (Seeßlen 1995: 163) der Opfer und macht die Situation auf diese Weise für ihn miterlebbar - schließlich entspricht die bewegte Handkamera »den eigenen alltäglichen Sehgewohnheiten oder den Rezeptionserfahrungen bei Dokumentarfilmen « (Noack 1998: 64). . $^{88}$

- Binnenhandlung in Schwarzweiß:

Wie die Spielfilme Nackt unter WöLfen (Frank Beyer, DDR 1962/63) und KorzCAK (Andrej Wajda, POL 1990), jedoch im Unterschied zu den meisten ebenfalls vergleichbaren Filmen ${ }^{389}$, ist die sich über zwei Stunden und 56 Minuten erstrekkende Binnenhandlung von Schindlers Liste - abgesehen von zwei kleinen Ausnahmen (s.u.) - in Schwarzweiß gedreht. Spielberg wollte damit dem Archiv-

387. Erste Ansätze einer solchen Form der Inszenierung finden sich beispielsweise bereits in René Cléments Kriegsdrama Brennt PARIS? (PARIS BRÛLE-T-IL, USA/F) aus dem Jahre 1966.

388. »Ich wollte die Ereignisse aus einem eher journalistischen Blickwinkel schildern und nicht, wie beim Spielfilm üblich, nachdrücklich auf Spannung, Action oder Pathos setzen. Das Schwarzweiß-Material und die Verwendung von Handkameras erzeugen eine dokumentarische >Cinéma vérités-Stimmung, was den Realismus entscheidend steigerte.« (Kameramann Kaminski zit.n. Noack 1998: 80, H.i.0.). »Alles sieht auf diese Weise irgendwie wirklichkeitsnaher aus.« (Spielberg zit.n. Begleitinformation in DVD 1993) »Die Handkamera ahmt die Zeugenschaft eines Reporters nach, ist auch ein sauktorialer Erzählerı, der weiß, wo sich die dramatischen Höhepunkte abspielen.« (Köppen 1997: 158f., H.i.0.)

389. Kornblumenblau (Leszek Wosiewicz, POL 1988), TRIUMPH des Geistes (Robert M. Young, USA 1989), Agnieszka Hollands Hitlerjunge Salomon (D/F/POL 1990), Der Stellvertreter (Costa-Gavras, F/D/ROM/USA 2002), Der Pianist (Roman Polanski, F/DUK/POL 2002), Die RosenstrasSe (Margarethe von Trotta, D/NL 2003) sowie die US-amerikanischen TV-Mehrteiler HoLoCAUST (Marvin J. Chomsky, 1978) und War and Remembrance (Dan Curtis, 1988) sind in ausschließlich Farbe gedreht.

390. »Praktisch alles, was ich über den Holocaust gesehen habe, war in Schwarzweiß.» (Spielberg zit.n. Begleitinformation in DVD 1993)

391. Vgl. Köppen zur »Fehlleistung« vieler Kritiker, die dem Film zuschrieben, er erinnere an alte Wochenschauen: »Mit den grobkörnigen 35mm-Aufnahmen der 40er Jahre hat dieser hochauflösende Breitwandfilm allenfalls den Umstand gemein, daß er [...] eben kein Farbmaterial verwendet.« (1997: 158)

392. »Dieser Augenblick sei so wichtig, betont Spielberg immer wieder, weil in ihm >die ganze Ungeheuerlichkeit sichtbar wird, die Schindler nicht ertrug^.» (Spielberg zit.n. Noack 1998: 68) 


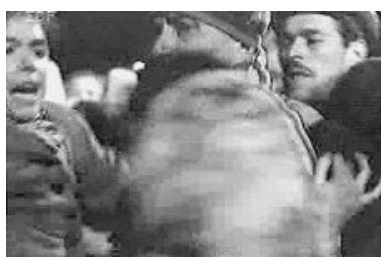

(354) $0: 16: 26 \mathrm{~h}$

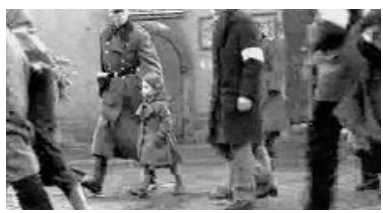

(356) $1: 06: 01 \mathrm{~h}$

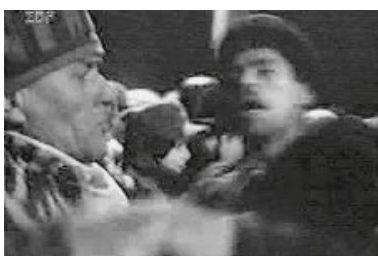

(355) $0: 16: 29 \mathrm{~h}$

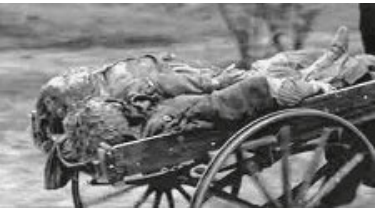

(357) $2: 20: 30 \mathrm{~h}$

material der damaligen Zeit entsprechen ${ }^{390}$ und beim Zuschauer eine »anachronistische« Anmutung verursachen (Korte 1999: 157):

"Schon der Schwarzweißfilm rückt das Gezeigte in die Nähe der zumeist ebenfalls in schwarzweiß überlieferten Bilder aus der Zeit. Die Farblosigkeit wirkt deshalb im Sinne eines historischen Schwarzweiß. Sie ruft auch Assoziationen aus der Alltagswelt der Rezipienten wach, indem sie etwa an das photojournalistische Schwarzweiß in den Tageszeitungen erinnert.« (Kramer 1999: 32).

»0bwohl der Farbfilm viel realistischer wirkt, da er eher unseren Sehgewohnheiten entspricht, gilt der Schwarzweißfilm noch immer als der Parameter für die authentische Dokumentation. [...] Der Schwarzweißfilm assoziiert beim Zuschauer die Wiedergabe von Realität meist in Form einer Dokumentation, während der Rezipient mit Farbe den Eindruck einer Illusion gewinnt, meist in Form eines Spielfilms. « (Noack 1998: 59) 391

Angesichts des weit verbreiteten Lobes in bezug auf diesen Authentizitätseffekt darf jedoch nicht übersehen werden, daß Spielbergs Entscheidung für einen Film in nahezu durchgängigem Schwarzweiß Anfang der goer Jahre als durchaus mutig bezeichnet werden kann - schließlich war dies, insbesondere für eine Regisseur-Ikone aus Hollywood, nicht üblich und daher für das Publikum äußerst ungewohnt und somit nicht spontan annehmbar.

Im Unterschied zu Nackt unter Wölfen und KorzCaK setzt Spielberg - neben dem Pro- (s. 3.2.3.a) und Epilog (s.u.) - in der Binnenhandlung zweimal Farbe als »Kontrastmotiv« ein (Reich-Ranicki 2002: 35) - mit besonderer Kontrastwirkung. Zunächst geschieht dies in der zentralen Ghettoräumungs-Sequenz: »In Spielbergs Film Schindlers Liste fällt in einer furchtbaren, einer unvergeßlichen Schwarzweiß-Szenerie inmitten der unzähligen getriebenen Juden ein einziger, greller Farbfleck auf: der rote Mantel eines kleinen Mädchens.« (ebd. 35; s. 1:06:01 h). Ungefähr eine Stunde später entdeckt Schindler den Leichnam dieses Mädchens, das sich vorher wundersamerweise in einem leer stehenden Haus verstecken konnte, auf einem Leichenkarren (s. 2:10:30 h) ${ }^{392}$ - eine wirkungsvolle Individualisierung inmitten anonymer Vernichtung. 
- Sprung am Filmende in die Gegenwart zu den realen sog. Schindlerjuden:

Im Unterschied zu den meisten angeführten, tendenziell vergleichbaren Spielfilmen ${ }^{393}$ inszeniert Spielberg im Epilog die realen sog. Schindlerjuden als beeindrukkende Anzahl Überlebender (s. 2:57:33 h) am Grab von Oskar Schindler (s. 1:15:40 h), wobei die zentralen Schauspieler von den realen Personen begleitet werden (s. 3:00:40 h). Auf diese Weise läßt der Regisseur die Zeitzeugen Schindlers LISTE »beglaubigen « und »signieren« (Kramer 1999: 37) - zentrale »Geste der Authentisierung« (ebd. 37). Mit ihrer moralischen Autorität als Überlebende der Vernichtungslager, so Krankenhagen, authentisieren die realen Personen den Film »als eine primäre Darstellung des Holocaust.« (2001: 216) - »Authentisieren heißt, die Echtheit bezeugen.« (Kramer 1999: 37)

Neben ihrer bloßen Anwesenheit ist es auch ihr Handeln, das diesen Authentisierungseffekt hervorruft. Nach jüdischer Sitte legen sie einen Stein auf Schindlers Grab: »Diese rituelle Handlung dokumentiert das Verhältnis der gezeigten Personen zu Schindler, der hiermit von ihnen als Retter anerkannt wird.« (Kramer 1999: 36 )

- Schrifteinblendungen mit Orts- und Zeitangaben:

Wie insbesondere Der Pianist, aber auch Triumph des Geistes, Korzcak, Der Stellvertreter und Die Rosenstrasse, gibt sich Schindlers Liste durch den wiederholten Einsatz von Schriftinserts authentisch (s.o. 0:01:51 h, 0:16:51 und 2:30:33 h sowie 3.2.3.b). 394 Die präzisen Orts- und Zeitangaben installieren »eine Rhetorik der Nachprüfbarkeit [...], welche den Eindruck hervorruft, das angegebene Koordinatengitter verbürge die historische Faktizität.« (Kramer 1999: 33) 395

393. Nur das Ende von Agnieszka Hollands Spielfilm Hitlerjunge Salomon (D/F/POL 1990) ist mit dem Epilog von SCHIndLers LISTE vergleichbar. Sally Perel, auf dessen Memoiren Hollands Film basiert, greift in den letzten Einstellungen die als Off-Text den Film begleitende Ich-Erzählung auf und wird kurz darauf im Bild inszeniert; der Film endet mit einem, von ihm A-capella vorgetragenen, hebräischen Lied, wobei die gesamte Inszenierung in diesem Moment deutlich an die Exposition um Simon Srebnik in Lanzmanns SHOAH erinnert (s. 2.2.4).

394. Im Unterschied zu vorangegangenen und den meisten nachfolgenden, zitierten Filmen weist Spielberg in seinen Schriftinserts weder explizit darauf hin, daß der Film auf authentischen Begebenheiten beruht (vgl. hierzu TRIUMPH DES GEISTES und DIE ROSENSTRASSE), noch begnügt er sich mit ein bis zwei Texteinblendungen (vgl. hierzu Triumph des Geistes, Korzcak, Der Stellvertreter, Die RoSenStRASSE), sondern setzt diese im Filmverlauf über 20 Mal ein. In TRIUMPH des GEISTES sind Schriftinserts am Anfang und am Ende eingesetzt, in KORZCAK nach der Exposition und am Ende des Films, in Der Stellvertreter erst am Ende und in Die Rosenstrasse nur am Anfang des Films.

395. Vgl. darüber hinaus Krankenhagen zur Authentisierung der Schlußszenen durch den verstärkten Einsatz von Zwischentexten (2001: 215f.).

396. 1987 war Dafoe für den »0scar« in der Kategorie des besten Nebendarstellers in Oliver Stones Kriegsepos PLATOON (USA 1986) nominiert.

397. Er hatte in Peter Sehrs in Locarno mit dem »Silbernen Bären« ausgezeichneten Spielfilm LOVE THE HARD WAY (D/USA 2001) und Ken Loachs Cannes-Beitrag BREAD AND ROSES (UK/F/D/ES/I/ CH 2000) die männliche Hauptrolle gespielt.

398. Der Ire war zu diesem Zeitpunkt ein ausgebildeter Theaterschauspieler, der seit Mitte der achtziger Jahre in den USA lebte. Bis zu diesem Zeitpunkt hat er am Broadway gespielt und kleinere Filmrollen übernommen (Thiele 2001: 430). 


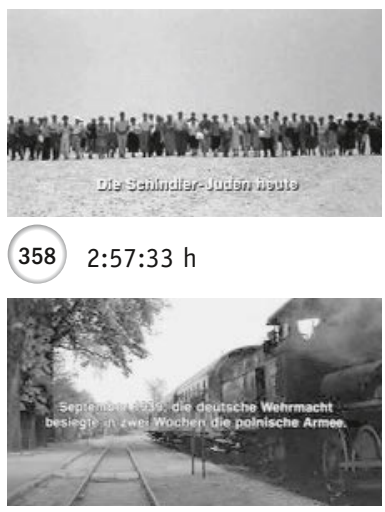

(361) $0: 01: 41 \mathrm{~h}$

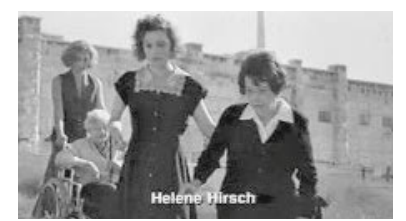

(359) $2: 59: 46 \mathrm{~h}$

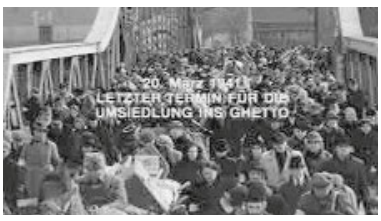

(362) $0: 16: 51 \mathrm{~h}$

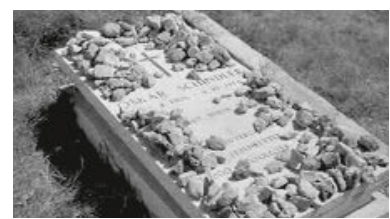

(360) $3: 00: 40 \mathrm{~h}$

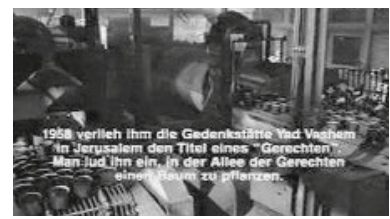

(363) $2: 30: 33 \mathrm{~h}$

- Verzicht auf den Einsatz sehr bekannter Schauspieler:

Wie viele der vergleichbaren Spielfilme verzichtete Hollywoods Regie-Ikone auf den Einsatz von Filmstars und somit auf jeglichen »Starappeal« - ein großes Wagnis angesichts der schwierigen Holocaust-Thematik, offensichtlich jedoch auch eine Chance aufgrund fehlender, festgelegter Schauspieler-Images. Auf diese Weise lenken die Darsteller die Aufmerksamkeit des Zuschauers nicht »auf sich selbst als Persönlichkeit, sondern auf die Figur, die sie verkörpern « (Noack 1998: 106) und auf den historischen Hintergrund des Films (Thiele 2001: 430).

Im Unterschied zu Triumph des Geistes mit dem »Oscar«-nominierten Willem Dafoe ${ }^{396}$ in der Hauptrolle und vergleichbar mit DER PIANist mit dem unbekannteren Adrien Brody ${ }^{397}$, traf Spielberg in bezug auf die Besetzung seiner Titelfigur eine weitere mutige Entscheidung, »whereas the rumors in 1992 suggested that Spielberg was going to cast a >star< as Schindler - for example, Kevin Costner or Mel Gibson« (Insdorf 2003: 259): Er entschied sich für Liam Neeson, »a brilliant actor rather than a star, and a European whose face was not familiar to the public« - ein weder für das amerikanische noch für das europäische Publikum bekanntes Gesicht. ${ }^{398}$

Auch der britische Schauspieler Ralph Fiennes, Lagerkommandant Amon Göth im Film, hatte sich zwar als Theaterdarsteller bereits einen Namen gemacht, stand aber noch am Anfang seiner Filmkarriere (Korte 1999: 163).

Die zentralen Figuren unter den sog. Schindlerjuden - durchweg unbekannte Gesichter - wurden nach ihrer Ähnlichkeit mit den historischen Gestalten besetzt (Schulz 2002: 16f.).

Einzig die Figur des Itzhak Stern, Schindlers Buchhalter, besetzte Spielberg mit einem bekannteren Schauspieler, dem Briten Ben Kingsley, der trotz seines »Oscar« für den besten Hauptdarsteller in Richard Attenboroughs GHANDi (UK/ India 1982) nicht als Kassenmagnet bezeichnet werden konnte. Zudem war er in seiner Rolle aufgrund seiner Brille sowie seines zurückgenommenen Spiels nicht selbstverständlich als Ben Kingsley erkennbar. 
- Rekonstruktion belegter historischer Fakten, Orte und Kostüme:

Wie Polanski in seinem knapp zehn Jahre späteren Spielfilm Der PiAnist (F/DUK/ POL 2002), legt Spielberg in Schindle Rs Liste extremen Wert auf die Genauigkeit der historischen Rekonstruktion. 399 Viele Filmbilder - wie beispielsweise die Szene, in der deutsche Soldaten einem jüdischen Ghettoinsassen lachend Bart und Schläfenlocken abschneiden -, basieren auf solchen Fotodokumenten (s. ০:10:07 h und o:10:10 h; Thiele 2001: 426) Das Arbeitslager Plaszow (s. 1:12:15 h) wurde von Produktionsdesigner Allan Starski nach den Plänen des ursprünglichen Lagers rekonstruiert: »Wir haben Plaszów nicht nur als Kulisse, sondern so realistisch wie möglich aufgebaut $[\ldots] . \ll 400$

- Drehen an Originalschauplätzen:

SCHINDLERS LiSTE wurde an Originalschauplätzen gedreht, auf dem Bahnhof Krakow Glowny (s. o:01:51 h), im alten Stadtkern von Krakau, in dem Haus, das Schindler bewohnte, in der ehemaligen Fabrik Schindlers (s. 0:30:25 h; Thiele 2001: 420f.). Die Innenansichten des Lagers Auschwitz-Birkenau entstanden vor der Kulisse des Tores von Auschwitz, »einem der ikonischen Superzeichen des Holocaust« (Köppen 1997: 155, s. 2:25: 33 h)..$^{401}$

- Tatsächliche Begebenheiten als Ausgangspunkt der erzählten Geschichte:

Wie die Spielfilme Kornblumenblau (Leszek Wosiewicz, POL 1988), Triumph des Geistes (Robert M. Young, USA 1989), Agnieszka Hollands Hitle Rjunge SA-

399. »Ich habe mit Anna Sheppard [Kostümdesignerin] und Christina Smith [Maskenbildnerin] Fotos und Geschichtsbücher aus der Zeit studiert [...], damit unsere Frisuren und Kostüme so authentisch wie möglich aussehen.« (Spielberg zit.n. Begleitinformation in DVD 1993)

400. Starski zit.n. Begleitinformation in DVD 1993.

401. Im Unterschied zu Spielberg durften Robert M. Young (TRIUMPH DES GeISTES) und Marceline Loridan-Ivens (BIRKENAU UND ROSENFELD) sogar im Lager Auschwitz-Birkenau drehen.

402. Zur kritischen Auseinandersetzung mit dem Verhältnis zwischen Film und Buchvorlage vgl. Oehlenschläger 2002: »Ich empfehle die Lektüre von Keneallys Buch als nüchterne Demontage des Überbaus, den Spielberg auf ihm errichtet hat.« (109) »Sein Titelheld fährt selbst nach Auschwitz, um dort die Frauen seines Betriebes loszukaufen. Eine solche Begebenheit ist nicht bezeugt. [...] Spielberg erfüllt ebenso die Konvention, wenn er mit dem wiedervereinten Ehepaar Schindler seiner Hauptfigur auch noch den Weg zur bürgerlichen Tugend weist.« (Rother 1995: 106) Zu den gravierendsten Unterschieden zwischen Buch und Film vgl. Noack 1998: $77 \mathrm{f}$.

403. Vgl. auch die Spielfilme NACKT UNTER WöLFEN und JAKOB DER LÜGNER, die auf gleichnamigen Romanvorlagen basieren.

404. Vgl. Schreitmüllers auf der Analyse zahlreicher Filmtitel basierende Ergebnisse: »in Filmtiteln [könnten] eigentlich nur solche Eigennamen herangezogen werden, die sich auf etwas beziehen, das den Titelautoren und -rezipienten gleichermaßen bekannt ist« (Schreitmüller 1994: 111). Im Fall von SCHINDLERS LISTE ist diese breite Bekanntheit nicht gegeben (s.o., Fußnote 1). Objekte in Titeln, wie hier die Liste, »klingen oft sehr banal, zu sehr nach Alltag« (Schreitmüller 1994: 123). 


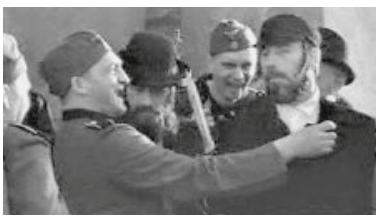

(364) $0: 10: 07 \mathrm{~h}$

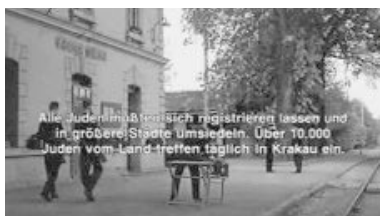

(367) $0: 01: 51 \mathrm{~h}$

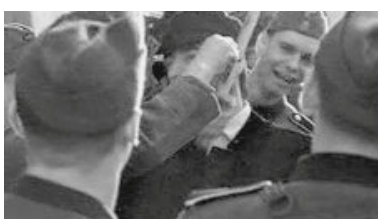

(365) $0: 10: 10 \mathrm{~h}$

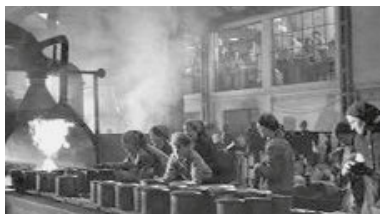

(368) $0: 30: 25 \mathrm{~h}$

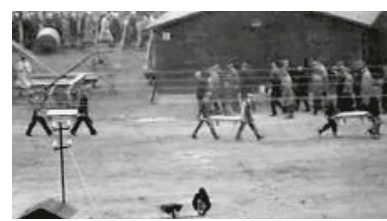

(366) $1: 12: 15 \mathrm{~h}$

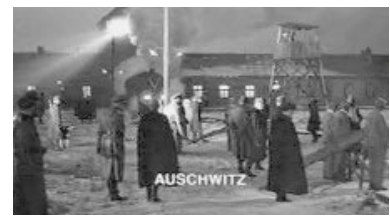

(369) $2: 25: 33 \mathrm{~h}$

lomon (D/F/ POL 1990), Andrej Wajdas Korzcak (POL 1990), Der StellvertreTer (Costa-Gavras, F/D/ ROM/USA 2002), Der Pianist (Roman Polanski, F/D/ UK/POL 2002) und Die Rosenstrasse (Margarethe von Trotta, D 2003) basiert auch SCHINDLERs LiSTE auf wahren Begebenheiten, gemäß der gleichnamigen »documentary novel« von Thomas Keneally aus dem Jahre 1982. Dieser hatte den Tatsachenroman auf der Basis der Erinnerungen eines sog. Schindlerjuden, Leopold Pfefferberg, erstellt. Im Film fällt auf, daß Spielberg - so sehr er sich in den Grundzügen an den Roman hält - mit dem Ziel einer spannungsvollen dramaturgischen Struktur des Films bestimmte, zum Teil knapp abgehandelte Details ausschmückt (s. 3.2.4) oder ganz von der Buchvorlage abweicht. ${ }^{402}$

- Verwendung von Original-Tonmaterial:

Im Unterschied zu den angeführten, tendenziell vergleichbaren Spielfilmen setzt Spielberg gegen Ende des Films einmalig Original-Tonmaterial ein. Hierbei handelt es sich um Churchills Radio-Ansprache, in der er die Kapitulation NaziDeutschlands bekanntgab: »Dieser O-Ton erhebt die Bilder, die während der Rede zu sehen sind und alle vorherigen sowie die folgenden Bilder, zum Dokumentarfilm (zumindest im Bewußtsein der Zuschauer).« (Noack 1998: 101)

- Verzicht auf einen spannenden, Aufmerksamkeit erregenden Titel:

Jenseits der »dokumentarischen Codes« nach Steinmetz (s.o.) fällt auf, daß sich Spielberg mit der exakten Übernahme des Romantitels ${ }^{403}$ SCHIndLERs's List und dessen Kombination aus Eigenname und Objekt gegen einen attraktiven, werbenden Titel entschied.404 Damit unterscheidet er sich deutlich von Youngs heroischem Triumph des Geistes, Hollands Interesse weckendem Originaltitel Europa Europa und Costa-Gavras' Der Stellvertreter, der im Original provokativ Amen heißt. In seinem schlichten Charakter ähnelt er eher Wajdas KorzCAK, Polanskis Der Pianist, aber auch von Trottas Rosenstrasse.

Bei einigen dieser Authentizitätssignale konnte sich Spielberg nicht sicher sein, ob sie sich nicht negativ auf den Kassenerfolg des Films auswirken würden:

- unattraktiver Titel (s.o.),

- kein »Starappeal« (s.o.), 
- dokumentarischer, die Narration unterbrechender Gestus (s.o., insbesondere die Schriftinserts und den nächsten Aspekt),

- anachronistisches Schwarzweiß der Binnenhandlung versus Unterbrechung der Spielhandlung durch zweimaligen Farbeinsatz (s.o.) sowie den Filmrahmen in Farbe,

- Spielberg als Hollywood-Starregisseur versus Holocaust,405

- ambivalenter Protagonist und Antagonist (s. 3.2.2), womit sich Spielberg bewußt dem »geschönten Gut-Böse-Schema üblicher Hollywood-Produktionen« entzieht (Korte 1999: 190),

- unübliche drei Stunden Filmdauer.

Trotz - oder gerade aufgrund - dieser mutigen Entscheidungen, die sich insgesamt als bewußter Verzicht auf Erfolgsfaktoren des Hollywood-Mainstream-Kinos interpretie-

405. Nach Hollywood-Blockbustern wie DER WEISSE HAI (1975), E.T. (1982), verschiedenen INDIANA-Jones-Filmen (1984, 1989), Hook (1991) und dem wenige Monate vor SCHINDLERS LISTE angelaufenen Boxoffice-Rekordfilm JURASSIC PARK (1993) konnte man nicht davon ausgehen, daß das Publikum Spielberg einen Film vor dem Hintergrund des Holocaust »zutrauen« und daß Spielberg dieser gewichtigen Thematik gewachsen sein würde.

406. Vgl. www.imdb.com/boxoffice/alltimegross?region=world-wide (24.04.2005). Mit diesem Einspielergebnis rangiert der Film als erster sogenannter Holocaust-Film an Platz 116 des weltweiten Box-Office-Rankings, nur drei Plätze hinter Crocodile DundeE (1986) - und X-MeN (2000), Superman (1978), SATurday Night Fever (1977) und Das fünfte Element (1997) hinter sich lassend, um nur einige Beispiele zu nennen.

407. Vgl. Everschor, der beinahe provokativ darauf hinweist, »daß auch ein unvollkommener SCHINDLERS LISTE in einem einzigen Monat im Kino mehr Menschen erreichen und zum Nachdenken bringen kann als Alain Resnais' NACHT UND NEBEL vermutlich in den ganzen 39 Jahren seit seiner Entstehung« (2003: 44).

408. "Since Holocaust, however, no American film has raised such unprecedented consciousness about the destruction of European Jewry or interpreted the Final Solution from a more historically situated perspective than has SCHINDLER'S LIST.« (Doneson 2002: 200)

409. Vgl. zur US-amerikanischen und internationalen Resonanz auf den Film v.a. den Sammelband mit wissenschaftlichen Beiträgen von Loshitzky 1997 und den wissenschaftlichen Beitrag von Hansen in Zelizer 2001: 127ff., speziell zu deutschen Reaktionen die Dokumentation repräsentativer Filmkritiken von Weiss 1995 sowie die Auswertung der publizistischen Kontroverse von Thiele 2001 und zu den israelischen Reaktionen Bresheet 1997.

410. "In our post-Holocaust world two major requirements can be detected in public taste for representations of the past. First is the demand for a shuman< story of will and determination, decency and courage, and final triumph over the forces of evil. Second is the quest for authenticity, for a story which sactually< happened, though retold according to accepted conventions of representation. Now, there is obviously a contradiction between these two demands, since authentic stories rarely happen according to conventional representations and even less frequently culminate in the triumph of good over evil. [...] Schindler's story manages to be both authentic and conventional [...]." (Bartov 1997: 46, H.i.0.) »Spielberg therefore tells an sauthentic story that (almost) never happened.« (Ebd. 47) Nicht zufällig betitelt Schulz seinen Aufsatz über Spielbergs Film und die TV-Serie Holocaust mit »Docu-Dramas« (Schulz 2002: 159), um genau auf dieses Zwittergenre abzuzielen, das auf SCHINDLERS LISTE im Unterschied zu Chomskys TV-Vierteiler zutrifft. 
ren lassen, war SCHindlers Liste gerade beim breiten Publikum mit weltweit über 300 Millionen Zuschauern und einem weltweiten Box-Office-Ergebnis von über 321 Millionen ein ebenso überraschender wie grandioser Erfolg. ${ }^{406}$ Im Unterschied zu den besprochenen Dokumentarfilmen, Resnais' NACHT Und NeBEL (s. II.2.1) und Lanzmanns Sнонн (s. II.2.2), erreichte Spielberg »nicht nur ein ausgewähltes Publikum« (Schirrmacher 1994: 105) - schließlich richtet er sich nicht, wie insbesondere $\mathrm{S}$ нолн, »an ein kleines intellektuelles Publikum « (Thiele 2001: 442).407

SChindlers Liste genügte darüber hinaus nicht nur seinem generellen Ziel der »Massenwirksamkeit« (Spielberg zit.n. Nicodemus 2004: 34), sondern übertraf sogar die Wirkkraft des bis zu diesem Zeitpunkt populärsten und gleichnamigen TV-Mehrteilers, Holocaust (USA 1978)408 - nicht zuletzt durch intensivste wissenschaftliche Auseinandersetzung (Doneson 2002: 199).409 Im Unterschied zum ersten globalen Medienereignis fiel bei SCHIN DLERs LISTE auf, »daß im Vergleich zum >Holocaust<-Diskurs von >Betroffenheit< im Sinne eines kollektiv-verbindlichen Angehens kaum mehr die Rede war. An die Stelle der öffentlichen und inhaltsbezogenen Emotionalität von damals war die Abgeklärtheit eines Diskurses getreten, dessen Medium Fragen der Darstellung bildeten.« (Weiß 2001: 88, H.i.O.) Darüber darf jedoch nicht vergessen werden, »daß Filme, gleich welcher Art, nicht für die Kritiker und erst recht nicht für wissenschaftliche Analysen produziert werden. [...] Denn dort, in den Köpfen der Kinobesucher, spielt sich der eigentliche Film - das >Erlebnis Film < ab.« (Noack 1998: 14, H.i.O.)

Der Hauptgrund dieses Erfolgs an den Kinokassen rund um den Globus liegt v.a. an Spielbergs virtuoser Komposition aus dokumentarfilm- und spielfilmkennzeichnenden Codes (s.o. bzw. 3.2.2), mit der er die Stärken beider Genres vereint und nutzt:

"Spielberg relativiert den Bruch zwischen Fiktion und Fakt, er nimmt die suggestive Kraft des Dokumentarischen für die Fiktion in Dienst, die nun erst den Höhepunkt ihrer persuasiven Kraft erreicht.« (Kramer 1999: 15)

»Für die breite Massenwirkung dagegen dürfte gerade die spezifische Mischung aus erprobter - auf emotionale Teilhabe des Betrachters zielende - Spannungsdramaturgie und dem durch Kamera- und Toneinsatz ungewohnt intensiven Realitätseindruck wesentlich gewesen sein, als plastisch miterlebbare, zudem höchst authentisch wirkenden Aktualisierung mehr oder weniger bekannter, verdrängter oder als >Vergangenheit» bereits abgetaner historischer Ereignisse.« (Korte 1999: 161, H.i.0.)

Mit der Integration dokumentarischer Codes sowie der Rettung der sog. Schindlerjuden (s. 3.2.2) erfüllt Spielberg, so Bartov, darüber hinaus zwei zentrale, aktuelle Forderungen des Publikums an Formen des Umgangs mit dem Holocaust: Menschlichkeit bzw. Triumph des Guten über das Böse und Authentizität durch Anlehnung an wahre Begebenheiten. ${ }^{410}$

Ausschlaggebend für die außerordentliche Wirkkraft von Schindlers Liste ist zudem die »Gewalt der Bilder« (Korte 1999: 161), die Tatsache, daß Spielberg Bilder geschaffen hat, die sich dem Zuschauer ins Gedächtnis einschreiben:

»An einzelne Bildfolgen und Handlungsdetails erinnert man sich noch Jahre später, - etwa an die Listen, die zur >weiteren Verwertung، aufgehäuften Habseligkeiten der Deportierten, 
die >Räumung des Ghettos und die verzweifelten Versuche, dem Morden zu entgehen, die Leichenberge oder Göths frühmorgendliche Menschenjagd, die Selektion im Lager Plaszow und die Kinder, die Todeszüge, die Frauen in Auschwitz etc.» (Ebd. 161, H.i.0.)

411. »Jenseits der Frage, ob das Verbot, den Holocaust mimetisch nachzubilden, das historische Ereignis sakralisiert, ist das Kernargument Lanzmanns bedenkenswert: Spielberg shat Bilder eingesetzt, wo in SHOAH keine waren, und Bilder töten die Imagination<." (Lanzmann zit.n. Köppen 1997: 164) Vgl. darüber hinaus Lowy zu den beiden unterschiedlichen Weltsichten von Lanzmann gegenüber Spielberg - »la parole contre l'image« (2001: 195) - und Reichel zur Gemeinsamkeit beider Filme: »Beide Filme haben die Hoffnung nicht weniger Überlebender gestärkt, daß nun ein größeres, nichtjüdisches Publikum eine Ahnung von der Art und dem Ausmaß ihres Leidens bekommen würde. Zugleich fühlten sie sich bestärkt, Zeugnis abzulegen. Beide Filme sind [...] eben auch exemplarische Zeugnisse dieser Zeugenschaft.« (Reichel 2004: 286)

412. "Die in Anspruch genommene Realitätsnähe kaschiert die oben herausgearbeitete Eigenwertigkeit der Inszenierung. [...] Spielbergs Meisterschaft zeigt sich daran, daß es ihm gelingt, die Inszenierung hinter der Realitätssuggestion verschwinden zu lassen, ohne auf seiten der Zuschauer Scham über den unangemessenen Versuch hervorzurufen.« (Kramer 1999: 15) »Im Spielfilm ist die Konstruktion einer Plotstruktur vorausgesetzt, doch Spielberg macht sie nicht kenntlich, sondern versucht sie durch den Rekurs auf Faktizität und Authentizität in Vergessenheit geraten zu lassen.« (Ebd. 33)

413. Vgl. hierzu u.a. NACKT UnTER WölfEN (Frank Beyer, DDR 1962/63), KORNBLUMEnBLAU (Leszek Wosiewicz, POL 1988), TriUmph des Geistes (Robert M. Young, USA 1989), Agnieszka Hollands HitlerJunge Salomon (D/F/POL 1990), Andrej Wajdas KorzCak (POL 1990), Der StelLVertreter (Costa-Gavras, F/D/ROM/USA 2002), Der PiAnist (Roman Polanski, F/DUK/POL 2002) und Die Rosenstrasse (Margarethe von Trotta, D 2003).

414. Angesichts der mit dem Holocaust verbundenen maximalen Sinnkrise versöhnt die gelungene Rettung der sog. Schindlerjuden durch den geläuterten Schindler zwar nicht mit der Welt, bietet dem Zuschauer jedoch einen wohltuenden Funken Hoffnung inmitten der Verzweiflung: »Und nur darum kann es in einem Spielfilm gehen: um das Überleben, und vielleicht noch darum, was das Überleben in den Menschen anrichtet.« (Loewy 1995: 209)

Vgl. White zum Begriff des semplotmentı: »Die Ereignisse werden zu einer Geschichte ıgemacht durch das Weglassen oder die Unterordnung bestimmter Ereignisse und die Hervorhebung anderer, durch Beschreibung, motivische Wiederholung, Wechsel in Ton und Perspektive, durch alternative Beschreibungsverfahren und ähnlichem - kurz mit Hilfe all der Verfahren, die wir normalerweise beim Aufbau einer Plotstruktur eines Romans oder eines Dramas erwarten.« (Zit.n. Kramer 2000: 33, H.i.0.)

415. »[...] ein stimmiges Verhältnis von Spannung und Suspense [...]. Bilder des Schreckens mußten von emotional entlastenden Passagen aufgefangen, Bilder melodramatischer Intensität durch eine witzige oder leicht ironische Wendung konterkariert werden - bis zum finalen Gefühlsappell an die Zuschauer.« (Köppen 1997: 151)

416. Vgl. die szenische Anordnung von Raum, Zeit und Handlung (s. das Sequenzprotokoll im Anhang), die komponierte Filmmusik (Schlüter 2002: 43ff.), den überwiegenden Einsatz einer allwissenden Kamera (s.u., Punkt 6) sowie das Aufladen eines Leitmotivs, der bürokratischen Vernichtungsmaschinerie, in Gestalt von Namenslisten (vgl. u.a. Klüger 1994: 23 und Noack 1998: 79). Zu den Spielfilme kennzeichnenden Codes im allgemeinen vgl. Steinmetz 1995: $172 f$. 
"Szenen wie die Selektion an der Rampe von Birkenau, wo der rauchende Schlot des Krematoriums buchstäblich den Himmel verdüstert, Exekutionen hilfloser Greise und Kinder, die im Schnee verbluten, der Abtransport der Kinder aus Plaszow, die erst gejagt, dann auf Lastwagen fröhlich winkend abfahren, während ihre schreienden, entsetzten Mütter mit Kolbenhieben zurückgeschlagen werden (zur Selektion ertönt das damalige Kitschlied »Mamatschi, schenk mir ein Pferdchen«) - solche Szenen wird, wer sie sah, nicht mehr los.» (Karasek 1995: 455f.)

Die zitierten Szenen zeichnen sich interessanterweise durch eine besondere »Authentizitätsillusion« (Korte 1999: 173), einen »Live-Dabei«-Effekt aus (s.o., Punkt a). Anders als bei Lanzmann war es Spielbergs Absicht, gestützt auf Fakten und erzählte Erinnerungen beteiligter Personen, »für die Nachgeborenen >Bilder zu erfinden« (Rother 1994: 107). ${ }^{41}$

\subsubsection{Leitthesen}

Trotz des dokumentarischen Inszenierungs-Gewandes (s. 3.2.1) handelt es sich bei Schindiers Liste vor allem um einen Spielfilm, der das Potential dieses Genres zu nutzen weiß.412

Der die Handlung bestimmende Rettungsversuch von 1.200 Krakauer Juden durch den Industriellen Oskar Schindler bildet den tragenden Spannungsbogen und führt zur Konfrontation zwischen den beiden Antagonisten des Films - Retter Schindler versus »Vernichter« Amon Göth (s.u., Punkt 1).

»Schindler hat 1200 Juden gerettet [...]. Das ist einer der wenigen Lichtblicke in der Geschichte des Holocaust. Natürlich hatte ich die Wahl: Erzähle ich die Geschichte der Überlebenden, oder erzähle ich die Geschichte derer, die in den Ofen kamen und zu Asche wurden? Hätte ich die Geschichte der Toten erzählt, hätte niemand diesen Film sehen wollen. Keiner wäre im Kino sitzen geblieben.« (Spielberg zit.n. Nicodemus 2004: 34)

Spielbergs Werk ist kein Film über das Morden und Sterben, sondern über das Retten und Überleben. ${ }^{413}$ »Spielberg rückt die Rettung in den Vordergrund, nicht die Auslöschung, die Sinngebung, nicht den Verlust aller Sinngebungsstrategien nach Auschwitz. Dies ist zweifellos die wichtigste >emplotment<-Entscheidung seines Films.« (Kramer 1999: 34, H.i.O.) $)^{414}$

Auf diese Weise vermeidet der Regisseur eine ausschließliche Konzentration auf das Grauenhafte (s.u., Punkt 4), sein Film ist »nicht unerträglich« (Rother 1994: 106), sondern bietet dem Zuschauer einen Hoffnungsanker und ein Gegengewicht inmitten allgegenwärtiger Vernichtung. Wann immer eine Szene den Zuschauer »in ihrer Tragik oder Gewalttätigkeit zu erdrücken droht, folgt eine Erleichterung, die unsere Aufmerksamkeit wieder belebt. [...] Das verhindert dann das Erstarren bei den drastischen Szenen der Massentötung und Verschleppung [...] (Klüger 1994: 36).415 Aufgrund dieses Wechsels von Erschütterung, Erleichterung und »Empörung« (ebd. 36) zeichnet sich der Film, so Klüger, durch »Dynamik, Fülle des Lebens, Spannung, Identifikationsangebote« aus (ebd. 34).

Neben der angesprochenen virtuosen Kombination aus dokumentarischen (v.a. der Newsreel-Ästhetik; s. 3.2.1) und Spielfilme kennzeichnenden Codes ${ }^{416}$ zeichnet sich SCHindlers Liste durch die besondere Spannungsdramaturgie - zentrales Gestaltungselement fiktionaler Werke - aus (Korte 1999: 161). 
Nur durch diesen hohen Grad an dramaturgischer Spannung läßt sich eine intensive Involvierung des Zuschauers über Stunden Filmdauer erreichen. Auf unterschiedlichen Ebenen können in SCHINDLERS LISTE systematisch angelegte, rhythmische Spannungsverhältnisse aufgedeckt werden:

\section{1) Spannung innerhalb der Figurenzeichnung und -konstellation:}

Im Unterschied zu Keneallys Romanvorlage, in der, neben den Haupthandlungsträgern, viele Nebenfiguren ausführlich dargestellt werden, fokussiert Spielberg die Handlung und somit die Spannung auf die Interaktion zwischen seinen drei Hauptfiguren und deren Innenleben: Oskar Schindler (s. 2.1) Amon Göth (s. 2.2) und Itzhak Stern (s. 2.3). ${ }^{47}$ Während der Regisseur in der Charakterisierung von Schindler und Göth im wesentlichen dem Tatsachenroman folgt, ist die Figur des Itzhak Stern »in dieser Form eine reine Erfindung der Filmautoren« (Korte 1999: 165; s. 2.3).

Das komplexe, konfliktbeladene Innenleben, insbesondere von Schindler und Göth, wird hauptsächlich über deren Handlungen sichtbar gemacht - ein dramaturgisches Mittel, das die Eigenleistung des Zuschauers wesentlich stärker fordert als explizite Informationen..$^{48}$

Besonders im Fall der Titelfigur muß sich der Zuschauer das »Innenleben« des Protagonisten aus den in Schlüsselmomenten eingesetzten Großaufnahmen erschließen (s.u. 1.1: 0:42:26 h, 1:06:27 h, 2:10:40 h"19):

417. Vgl. Korte 1999: 162 und Oehlenschläger 2002: 104. »Hiervon deutlich abgesetzt erhalten allenfalls noch Göths Hausmädchen Helene Hirsch, sein Bursche Lisiek sowie der korrupte jüdische Hilfspolizist Goldberg und Schindlers Frau Emilie oder sein Schwarzmarktbeschaffer Pfefferberg in einigen Episoden ein gewisses Eigenleben. Die Masse aber sowohl der Täter als auch der Opfer bleibt weitgehend anonym [...].« (Korte 1999: 162)

418. »Eine [verglichen mit dem Mittel des Dialogs; eigene Anm.] viel bessere Lösung des Problems besteht darin, dem Publikum durch die Aktionen einer Figur Einblick in ihr Innenleben zu gewähren.« (Howard/Mabley 1996: 51) Das ist das wesentliche Element jeder Figurenzeichnung: zu enthüllen, was sich im Innern der Figuren abspielt. Ihre Handlungen, die von ihren Absichten und Zielen bestimmt werden, stellen die Anhaltspunkte dar, an denen sich unser Verständnis vom Innenleben der Figuren orientiert.« (Ebd. 88)

419. »Als der das Mädchen in Rot auf einem der Leichenkarren entdeckt, vollzieht sich (für den Zuschauer nur in seiner Mimik zu erkennen) die Wandlung zum >Retter«. Die dramaturgische Besonderheit bildet hier das Mädchen in Rot, das die beiden Plot Points in einen Zusammenhang stellt und somit Rahmen und Leitmotiv zugleich ist.« (Noack 1998: 96, H.i.0.)

420. Vgl. Kloepfer zur Faszination als » Kitzel der Unsicherheit« (2005: 105, H.i.0.). Vgl. Korte 1999: 164 zum »schillernden Charakter« sowie Köppen 1997: 154 zur »Faszination durch Ambivalenz«. Vgl. auch Lueken zit.n. Thiele 2001: 423 und Bartov 1997: 48 zu Schindlers »Mephistophelean character«. Auf diese Weise erfüllt Spielbergs Hauptfigur die Bedingungen eines »guten Protagonisten«, denn er »ruft eine starke emotionale Reaktion beim Publikum hervor» (Howard/Mabley 1996: 65).

421. »Für den Betrachter bleibt der Zweifel: Ist es eine Ausrede von Schindler, um nicht in den Verdacht zu geraten, mit den Juden gemeinsame Sache zu machen, oder ist es ein ernstgemeinter Versuch, aus dem Tod des Einarmigen eine Entschädigung für sich herauszuschlagen?« (Korte 1999: 176) 
1. Figuren:

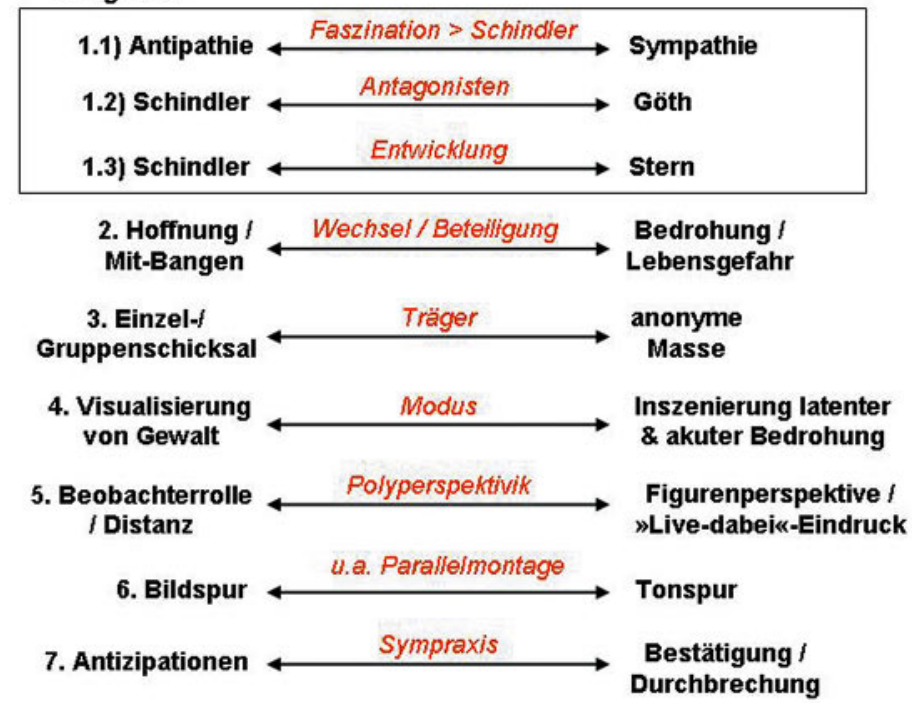

Abb. II.3.2.a

»Da der [Stumm-]Film [eigene Anm.] keine psychologischen Erklärungen zuläßt [und diese auch im Tonfilm als unelegante Verfahren der Informationsvermittlung gelten; eigene Anm.], muß die Möglichkeit jeder seelischen Wandlung im Gesicht von vornherein sichtbar sein. Das Spannende ist dann gerade, einen verborgenen Zug, etwa um den Mundwinkel, zu entdecken und zu sehen, wie aus diesem Keim der neue Mensch sich über das ganze Gesicht entfaltet." (Balázs 2001: 47)

»Und wir sehen auf dem Gesicht - wie auf einem offenen Schlachtfeld - das Ringen der Seele mit dem Schicksal, wie es uns keine Literatur darstellen kann.« (Ebd. 42)

\section{1) Spannung zwischen Anti- bzw. Sympathie - Faszination in bezug \\ auf die Hauptfigur Oskar Schindler:}

Bis zur Mitte des Films und zum Teil darüber hinaus ist Schindler eine ambivalent gezeichnete Figur.

In den ersten vierzig Minuten des Films reagiert der Zuschauer auf den Protagonisten sogar mit Antipathie. Dies ist insbesondere der Fall, als er:

- bei seinem ersten Auftritt erfolgreich um die Gunst von SS-Offizieren buhlt;

- es sich selbstzufrieden in der vornehmen Wohnung einer enteigneten jüdischen Familie bequem macht;

- seiner Ehefrau seine profitorientierten und machtgierigen Vorhaben schildert;

- den Dank des von ihm geretteten einarmigen Schlossers harsch zurückweist.

In der folgenden Stunde ist der Zuschauer unsicher, welche Haltung er dem Kriegsgewinnler gegenüber einnehmen soll, er schwankt zwischen den Extremen Anti- und Sympathie. ${ }^{420}$ Dies ist insbesondere der Fall, als Schindler:

- die Erschießung eines seiner jüdischen Arbeiter einem SS-Offizier vorwirft: »Ich habe einen Arbeiter verloren!« (0:41:45 h) ${ }^{421}$; 
- mit einer riskanten Einschüchterungsstrategie seinen Buchhalter, Itzhak Stern, aus einem der Deportationszüge rettet und diesem vorwirft: »Was ist, wenn ich fünf Minuten später gekommen wäre? Dann wäre ich jetzt der Dumme!« (o:45:49 - 0:45:52 h);

- mit zunehmendem Entsetzen die mit äußerster Brutalität vollzogene Räumung des Krakauer Ghettos von einem Hügel aus beobachtet;

- seine jüdischen Arbeiter vom Lagerkommandanten Amon Göth in einer intensiven Verhandlung mit der Erklärung »Die gehören mir!« (1:16:03 h) und »Jeder Arbeiter, der erschossen wird, kostet mich Geld!« (1:16:07 h) zurückkauft;

- auf Drängen von Stern einen - der Hinrichtung wundersam entgangenen - Schlosser für seine Fabrik einfordert und somit aus dem Lager befreit;

422. Stern gegenüber erklärt er aufgebracht, »daß es gefährlich ist, es kostet mich Kopf und Kragen.« (1:31:48-1:31:50 h) - gleichzeitig nimmt er Göth in Schutz: »[...] im Krieg, der die schlimmsten Eigenschaften zum Vorschein bringt, nie die guten, sondern die schlimmen, die schlimmsten des Menschen. Aber unter normalen Umständen wäre er ganz bestimmt nicht so, er wäre ganz umgänglich, dann gäbe es eben nur die guten Seiten von ihm [...].« $(1: 32: 11-1: 32: 26 \mathrm{~h})$

423. »Ohne ein Ziel und ohne daß wenigstens für eine Figur irgend etwas auf dem Spiel steht, kann keine dramatische Wirkung von irgendeinem in einer Geschichte geschilderten Ereignis ausgehen [...].« (Howard/Mabley 1996: 71) »Die Beschaffenheit des Ziels bestimmt im großen Teil die Haltung, die das Publikum dem Protagonisten gegenüber einnimmt. Wenn das Ziel heroisch ist, werden wir den Protagonisten vermutlich bewundern [...].« (Ebd. 67) »[...] daß unser Interesse daran, ob der Protagonist erreicht, was er sich vorgenommen hat, sich normalerweise direkt proportional zu dem Interesse verhält, das diese Figur selbst an diesem Ziel hat. Je heftiger sie danach verlangt, desto größer unsere Anteilnahme.« (Ebd. 65)

424. Um die Eltern von Regina Perlmann schließlich doch aus dem Lager und in seine Fabrik zu holen, hatte er seine Uhr als Einsatz geopfert; Helene Hirsch hatte er nicht, wie zunächst vermutet, verführen, sondern aufgrund von Göths Unberechenbarkeit trösten wollen.

425. Dies wurde kontrovers diskutiert: Während Lothar Baier unterstellte, daß ein guter Nazi als Held das Gewissen vieler Deutscher reinwaschen werde, weil »sie jetzt auch alle ein bißchen `Judenretter« seien (1994: 237, H.i.0.), zwinge der Film, so Frank Schirrmacher, »den Zuschauer zu der Frage, wieso, was einem 0skar Schindler möglich war, nicht auch andere versuchten« (1994: 105).

426. »Spielberg hält Schindler [...] von allen Zweifeln frei. Mit dem Gewicht des historiographischen Fakts weist er auf den ihm in Yad Vashem verliehenen Titel eines >Gerechten ." (Kramer 1999: 34, H.i.0.) Vgl. auch Kilb 1995: 157, Köppen 1997: 154 und Oehlenschläger zum differierenden Ende im Roman, im dem es »keinen tränenreichen Kollaps« gibt (2002: 106).

427. Göth ist »die entgegengesetzte Kraft, die sSchwierigkeit, die den Bemühungen des Protagonisten, sein Ziel zu erreichen, aktiven Widerstand leistet. Diese beiden gegeneinander gerichteten Kräfte bilden den Konflikt der Geschichte. (Howard/Mabley 1996: 49, H.i.0.) »Die Figur Schindler wird in der Auseinandersetzung mit ihrem Gegenspieler Göth profiliert. Die wechselseitige Spiegelung beider Figuren intensiviert die dramatische Spannung, beginnend mit dem Parallelschnitt der beiden Antagonisten beim morgendlichen Rasieren vor dem Spiegel.« (Lange 1999: 157) »Die zweite Stunde des Films gehört Amon Göth. Er ist der schwarze Gegenspieler Schindlers, die dunkle Hälfte des Doppelgestirns, der Teufel, der den anderen erst wirklich zum Engel macht.« (Kilb 1995: 155) 
- eine junge jüdische Frau, Regina Perlmann, erst empfängt, nachdem sie sich hübsch zurecht gemacht hat, ihr Flehen, er möge doch ihre Eltern für seine Fabrik anfordern und sie somit vor dem sicheren Tod im Lager retten, jedoch harsch zurückweist: »Ich frage nur nach einem, ob ein Arbeiter sein Handwerk beherrscht oder nicht. Das ist das einzige, was ich verlange und was mich interessiert. [...] Wenn Sie heulen, laß ich Sie sofort verhaften, das schwör' ich Ihnen!« (1:30:48-1:31:02 h);422

- Göths Hausmädchen, Helene Hirsch, zunächst zu beeindrucken versucht: »Wissen Sie, wer ich bin? ... Ich bin Schindler.« (1:35:07 - 1:35:18 h);

- während seiner Geburtstagsfeier mehrere Frauen leidenschaftlich küßt.

Erst in der letzten Stunde des Films scheint das Gute - im Sinne der Entwicklung vom fähigen Opportunisten zu einem mitfühlenden, mutigen Menschen - in Schindler endgültig gesiegt zu haben: »Je brutaler die Nazis wüteten, desto sensibler wurde er für das Leiden der Juden [...].« (Schultz 2006: 15) Angesichts zunehmend größerer Schwierigkeiten setzt er sein gesamtes Vermögen und sogar sein Leben für die Rettung seiner jüdischen Arbeiter aufs Spiel (Insdorf 2003: 266), so daß der Zuschauer ihm uneingeschränkte Sympathie entgegenbringen kann. ${ }^{423}$ Nachdem der Protagonist ab der Hälfte des Films bereits eindeutige Anzeichen der positiven Entwicklung hatte erkennen lassen ${ }^{424}$, wird er in der letzten Stunde zum vorbildhaften Helden, zur positiven Identifikationsfigur. ${ }^{425}$ Dies ist insbesondere der Fall als Schindler:

- den Selektierten in den Viehwaggons Linderung von der brütenden Hitze verschafft - vor den Augen mehrerer SS-Offiziere, darunter Göth;

- mit blankem Entsetzen auf die Massenexhumierung und die großen Scheiterhaufen reagiert;

- gegen ein erhebliches Bestechungsgeld Göths Zustimmung erhält, seine Fabrik mitsamt den Arbeitern und deren Kindern nach Westen zu verlagern;

- mit Sterns Hilfe die Liste seiner Arbeiter, die titelgebende Liste, zusammenstellt;

- Göth darüber hinaus noch drängt, ihm Helene Hirsch als Arbeitskraft anzuvertrauen und sie somit aus dem Lager zu befreit;

- seine weiblichen Arbeiterinnen gegen Diamanten beim Lagerkommandanten von Auschwitz freikauft;

- seiner Frau verspricht: »Kein Portier oder Oberkellner wird dich je wieder verwechseln, das verspreche ich dir.« (2:39:53 - 2: 40:00 h);

- kurz vor seiner Flucht in Sterns Armen weinend niedersinkt und dabei unter Schluchzen hervorbringt: »Ich hätte einen Menschen mehr retten können und hab's nicht getan. Ich hab's nicht getan, ich hab’s nicht getan!« (2:53:02 - 2:53:12 h)

Diese Szenen der letzten halben Stunde des Films (s. g und f) heroisieren den Protagonisten in einer Weise, daß Spielberg u.a. vorgeworfen wurde, er winde »einen Strahlenkranz nach dem anderen um Oskar Schindlers Haupt« (Kilb 1995: 157).426

\section{2) Spannung zwischen Oskar Schindler und Amon Göth:}

Insgesamt ist das Verhältnis zwischen Schindler und Göth dynamisch, es entwickelt sich im Verlauf des Films.

$\mathrm{Ab}$ der zweiten Stunde von Schindlers Liste ist der Untersturmführer Schindlers Antagonist. ${ }^{427}$ Als Kommandant des 1943 errichteten Plaszower Konzentrations- 
lagers benötigt er Arbeitskräfte, darunter auch Schindlers jüdische Arbeiter, die im März desselben Jahres von Krakau nach Plaszow deportiert wurden.

Während dieser Konflikt die beiden Widersacher zum ersten Mal zusammentreffen läßt und es Schindler gelingt, seine Arbeiter zurückzukaufen (s. 1:18:14 h), konkurriert er als zunehmender Lebensretter wiederholt mit dem »Vernichter« Göth, - »Verbundenheit der Gegensätze« (Schütte 1999: 45). ${ }^{428}$ In diesem Zusammenhang:

- versucht Schindler, Göth von willkürlichen Hinrichtungen abzubringen und ihm stattdessen zu Begnadigungen zu bewegen, indem er letzteres geschickt als Kennzeichen wahrer Macht deklariert (s. 1:41:25 h);

- gelingt es Schindler durch geschicktes Verhalten gegenüber Göth (s. 2:03:13 h), den Selektierten in den Viehwaggons Linderung von der Hitze zu verschaffen, indem er den Zug mit Wasser bespritzen läßt;

- erhält Schindler nach großem rhetorischem Einsatz und gegen Bestechung Göths Zustimmung, seine Fabrik mitsamt den Arbeitern und deren Kindern nach Brünnlitz zu verlagern (s. 2:14:55 h);

- gelingt es Schindler letztlich durch ein Glücksspiel mit Göth, dessen Hausmädchen, Helene Hirsch, aus ihrer Zwangsarbeit zu befreien und somit dem höchstgefährlichen Einflußbereich Göths zu entziehen.

»Spannung bezieht der Film nicht zuletzt daraus, daß er - in Bezug auf Psychologie und Charaktergestaltung - Schindler und Göth als gleichermaßen schwer zu durchschauende und darum auch schwer berechenbare Personen darstellt [...].« (Schulz 2002: 169) Wie Schindler wird auch Göth, »die Verkörperung des >bösen Deutschen«« (Korte 1999: 164, H.i.O.) mit durchaus ambivalenten Zügen geschildert, die jedoch keine Wandlung zum Guten durchmacht: Nachdem er zunächst als SS-Scherge mit einer nahezu perversen Lust an der Ausübung extremer Macht (s. 3.2.4) eingeführt wurde - »Er spürt sich fast nur noch, wenn er schießt.« (Kilb 1995: 156) ${ }^{429}$-, zeigt er unter Schindlers Einfluß Anzeichen von Menschlichkeit:

- Auf Schindlers Zureden (s.o.) läßt er eine bei der Zwangsarbeit unerlaubterweise eine Zigarette rauchende Lagerinsassin leben. Der Zuschauer hofft daher, Göth würde auch seinen Burschen Lisiek nach dessen Ungeschicklichkeit verschonen: Nachdem Göth selbstverliebt seine Begnadigungsgeste vor dem Spiegel wiederholt hat (s. 1:44:19 h), erschießt er den Jungen nach einigem Zögern letztlich doch.

428. Aufgrund seiner Macht und seines entgegengerichtetes Ziels erfüllt Göth die Bedingungen eines »)guten< Antagonisten« (Schütte 1999: 44, H.i.0.): „Zuerst einmal muß auch er ein Ziel verfolgen. [...] Entscheidend ist, daß sich die Ziele gegenseitig ausschließen. [...] Dabei ist wichtig, daß der Antagonist ebenso stark ist wie der Protagonist. [...] Zwei starke, kompromißlose Kräfte sind die Basis für einen lebendigen, wachsenden Konflikt. [...] Der Konflikt muß unausweichlich sein [...], weil sich sonst der Zuschauer fragt, warum die Personen dieses Spiel überhaupt mitspielen.« (Ebd. 44f., H.i.0.)

Vgl. Lange 1999: 157 zu den »mythischen sieben Begegnungen zwischen Schindler und Göth, die jeweils um ein thematisches Zentrum aufgebaut sind."

429. "Spielberg bindet die Entfesselung des Schreckens an die Person Göth, deren Handeln gleichzeitig von den SS-Instanzen weit stärker abgekoppelt wird als bei Keneally.« (Oehlenschläger 2002: 104) 


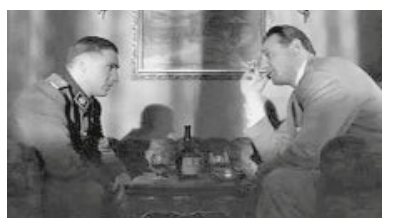

(370) $1: 18: 14 \mathrm{~h}$
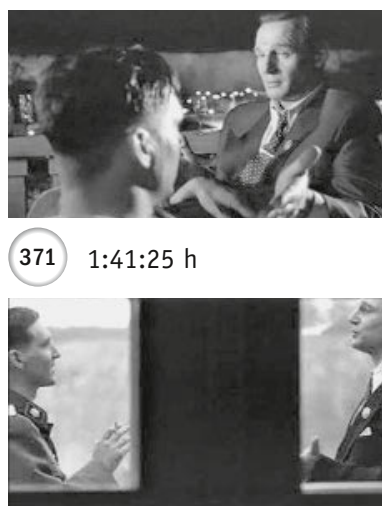

(373) $2: 14: 55 \mathrm{~h}$

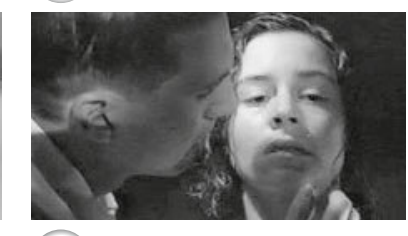

(375) $1: 50: 22 \mathrm{~h}$

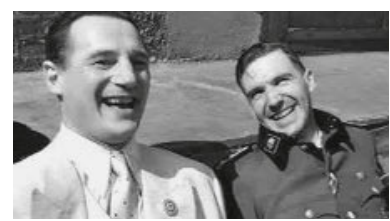

(372) $2: 03: 13 \mathrm{~h}$

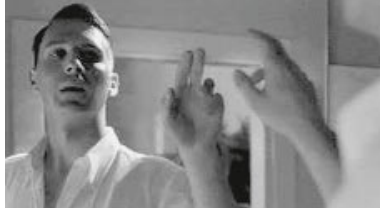

(374) $1: 44: 19 \mathrm{~h}$

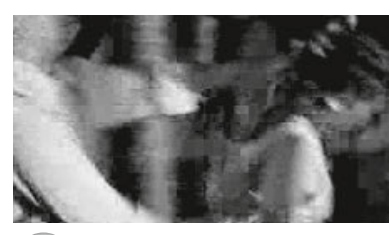

(376) $1: 50: 52 \mathrm{~h}$

- Auch als er sich wenig später bei seinem Hausmädchen, Helene Hirsch, für ihre gute Arbeit bedankt und sich ihr zunächst mit Zuneigung nähert (s. 1:50:22 h), wendet er sich im letzten Moment ab und mißhandelt sie in brutaler Weise (s. 1:50:52 h).

Neben dem ambivalenten Charakter beider gibt es zwischen Protagonist und Antagonist weitere Parallelen - »vor allem in dem unbedingten Vorteilsdenken und der Vorliebe für jeden erdenklichen Luxus « (Korte 1999: 165) -, so daß ihre Beziehung zwischen Konkurrenz aufgrund gegenläufiger Ziele (s.o.), gewisser Sympathie aufgrund ähnlicher Interessen und freundschaftlichen Ansätzen oszilliert. Dieses komplexe, spannungsvolle Verhältnis - einem Duell gleichend - vermag den Zuschauer in jeder ihrer Begegnungen zu fesseln.

1.3) Spannung zwischen Oskar Schindler und Itzhak Stern:

In den ersten beiden Stunden des Films ist das Verhältnis zwischen Schindler und seinem jüdischen Buchhalter angespannt, vor allem Itzhak Stern verhält sich seinem Chef gegenüber reserviert: »Stern becomes an audience surrogate, a complicitous witness to Schindler's acts who remains wary nonetheless. Like the viewer, he wonders what Schindler is up to - Profit? Altruism? Both?« (Insdorf 2003: 264) So ist zu beobachten, daß:

- Stern bei ihrer ersten Begegnung ablehnend auf Schindler reagiert - die Distanz zwischen beiden wird durch die spezifische Bildkomposition betont (s. O:13:12 h);

- Stern auch bei seinem zweiten Treffen mit Schindler dessen Drink ablehnt (s. 0:22:26 h) - Sinnbild seiner Ablehnung; er - wie der Zuschauer - unsicher ist, wie er Schindlers Eingreifen bewerten soll, als dieser ihn durch »wichtigtuerisches « Auftreten aus dem zur Deportation bereiten Zug zu retten vermag (s. 0:45:07 h). 
Erst nach knapp mehr als zwei Stunden Filmdauer nimmt Stern Schindlers Drink an - Zeichen eines positiveren Verhältnisses (s. 2:12:36 h);430 ungetrübtes Vertrauen und freundschaftliche Gefühle bringt er Schindler jedoch erst in der letzten halben Stunde des Films entgegen, nachdem dieser alle sog. Schindlerjuden in Brünnlitz vereinen konnte (s. 2:40:47 h) und unmittelbar vor seiner Flucht weinend in Sterns Armen niedersinkt, weil er noch mehr Leben hätte retten können und müssen (s. 2:53:03 h).

Mit der Filmfigur des Itzhak Stern, die sich aus den Handlungen und Charakteristika mehrerer historisch belegter Personen zusammensetzt431, stellt Spielberg den beiden Deutschen, Schindler und Göth, einen »ausgesprochen starken jüdischen Antagonisten gegenüber. Denn dieser Itzhak Stern ist in der Tat der eigentliche Motor für die Rettung der >Schindler-Juden<.« (Korte 1999: 166, H.i.O.) Indem er Schindler beharrlich über die tatsächlichen Umstände im Plaszower Lager, insbesondere über Göths Gewaltherrschaft informiert, trägt er entscheidend zu Schindlers Wandlung bei (ebd. 167; s. 3.2.4) und

430. Vgl. Doneson 2002: 209.

431. »Die meisten der dem >Film-Stern< zugeschriebenen Aktionen und Ereignisse betreffen dagegen Schindlers tatsächlichem Buchhalter Bankier, der im Film nur einmal kurz erwähnt wird." (Korte 1999: 165, H.i.0.) »Im Roman ist Stern nur gelegentlich, dann freilich immer mit Nachdruck im Text präsent, ratgebend, warnend, Zuspruch erteilend, ein Aktionsbündnis Schindler/Stern produziert Keneally nicht." (Oehlenschläger 2002: 101) Vgl. auch Schultz 2006: 15 zum Anteil des Holocaust-Überlebenden Mietek Pemper an der Figur Sterns.

432. Vgl. insbesondere Doneson, die dies auch generell als ein Verhaftet-Sein in falschen Klischees kritisiert: "SCHINDLER'S LIST perpetuates the image of a week, feminized Jew, the passive figure so negatively described by 0tto Weininger, and later, Bruno Bettelheim, at the expense of truth." (Doneson 2002: 201) Vgl. auch Bartov 1997: 49 und Horowitz 1997: 121ff.

433. »Ähnlich wie die behauptete Seelenverwandtschaft Göth/Schindler läßt sich auch diese Interpretation allenfalls aus Hinweisen bei Keneally ableiten [...].« (Ebd.)

434. Insofern ähnelt die Spannungsdramaturgie Spielbergs Psycho-Thriller Der WEISSE HAI (JawS, USA 1975): »In beiden Fällen geht es um eine existentielle Bedrohung der Handelnden, die sehr schnell eskaliert, dabei den Akteuren und Zuschauern erst langsam bewußt und mit allen Mitteln der Populärkultur während der Vorführung als unentrinnbaren Realität sam eigenen Leiber erfahren wird. Denn gerade der sogenannte Psycho-Thriller mit den einkalkulierten, vom Publikum selbst auszufüllenden semotionalen Leerstellen<, funktioniert ja nur, indem eigene Ängste und Gefühle während des Filmerlebnisses gezielt wachgerufen und mit den Leinwandereignissen zu einer Einheit verschmolzen werden.« (Korte 1999: 189, H.i.0.) »Was ist also der Trick, mit dem man das Publikum dazu bringt, mitzugehen, mit dem man die emotionale Wirkung hervorruft, ohne die es kein Drama gibt? Mit einem Wort: Ungewißheit. Ungewißheit, was die unmittelbare Zukunft betrifft, Ungewißheit auch im Hinblick auf das Ende. Eine andere Möglichkeit, diese Idee zu formulieren, lautet: Hoffen und Bangen. [...] Geschichten, die uns mit der richtigen Mischung aus Hoffnung und Furcht erfüllen, schlagen uns notwendig in ihren Bann.« (Howard/Mabley 1996: 60) »Was aber während des zweiten Akts die Geschichte mit Nachdruck vorantreibt, ist die Reihe von Hindernissen, die dem Protagonisten im Moment mehr zu schaffen machen als die Auflösung der Geschichte, Hindernisse, die zusammengenommen den eigentlichen Spannungsbogen ausmachen.« (Ebd. 76) »Diese Vorstellung von zunehmender Spannung, die sowohl die Hoffnungen als auch die Befürchtungen immer größer werden läßt, ist genau der Punkt, der das Publikum die ganze Geschichte über bei der Stange hält.« (Ebd. 91) 


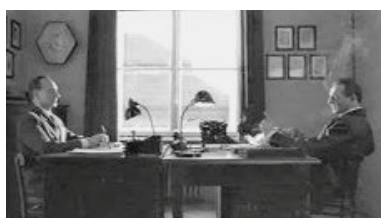

(377) $0: 13: 12 \mathrm{~h}$

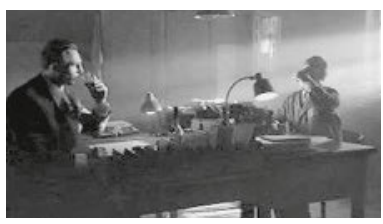

(380) $2: 12: 36 \mathrm{~h}$
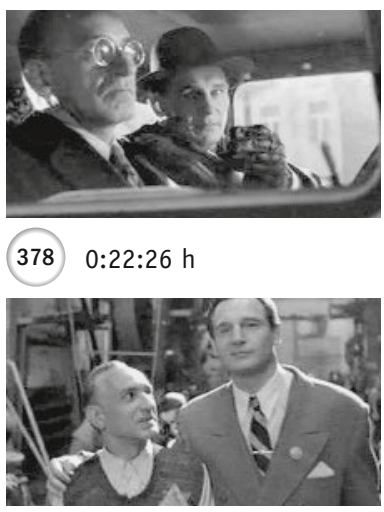

(381) $2: 40: 47 \mathrm{~h}$

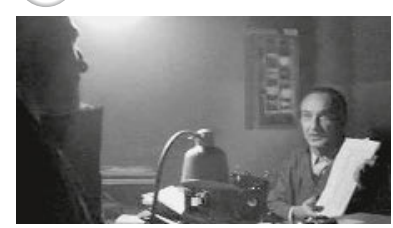

(383) $2: 19: 06 \mathrm{~h}$

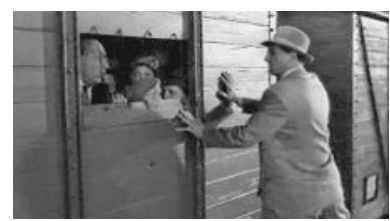

(379) $0: 45: 07 \mathrm{~h}$

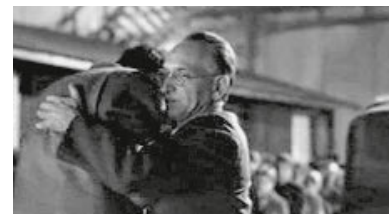

(382) $2: 53: 03 \mathrm{~h}$

zieht in dessen Schatten »die Fäden für das Überleben seiner Leidensgenossen« (ebd. 166). Höhepunkt dieser Zusammenarbeit ist die Erstellung der titelgebenden Liste, von der Stern sagt, sie sei das Leben (s. 2:19:06 h). »Von der unterschwellig erotischen Beziehung des > weibisch<schwachen Stern zum >männlichen< starken Schindler, wie mehrere Rezensenten konstatieren ${ }^{42}$, kann bei den gleichnamigen filmischen Figuren nicht die Rede sein.«(Korte 1999: 167, H.i.O.) ${ }^{433}$

2) Spannung zwischen Hoffnung auf Rettung und Bedrohung der sog. Schindlerjuden: Spätestens mit der Erschießung des einarmigen Schlossers (ca. 40. Filmminute) schweben auch die sog. Schindlerjuden in akuter Lebensgefahr. Zwischen diesem Moment und ihrer Zusammenführung durch Schindler in Brünnlitz gegen Ende des Films (ca. 160. Filmminute) durchleben sie ein ständiges Schwanken zwischen der Hoffnung auf Rettung und der Furcht vor neuer Bedrohung (s. 3.2.4, 3.2.5, 3.2.6).

Diese häufig sequenzübergreifende Spannungsdramaturgie bezieht den Zuschauer, der mit um die Opfer bangt, maximal ein:434

»Der Film stellt sich wie alle Spielfilme als eine Aneinanderreihung von Situationen dar; der Zuschauer tritt in diese Situationen ein und agiert gewissermaßen mit, indem er Spannung, Schmerz, Ausweg-, Hoffnungslosigkeit und Erleichterung nacherlebt [aufgrund Spielbergs spezifischer Inszenierung eher miterlebt; eigene Anm.]. Genau hier liegt die eigentliche Wirkung des Films: Die Gefühle und Empfindungen des Zuschauers werden durch dieses sekundäre Dabeisein bis zur äußersten Grenze aktiviert und involviert. Dazu trägt auch die immanente Zeitstruktur des Films bei; in jedem Augenblick sind Protention und Retention fühlbar, d.h. der Horizont einer auf Zukunft gerichteten Spannung oder Furcht und gleichzeitig das Bewußtsein dessen, was hinter einem liegt.« (Schörken 1995: 15) 
Der »Wert des Mitleids« wurde von einigen Kritikern jedoch »mit allen intellektuellen Mitteln zu verkleinern« versucht (Göckenjan 1994: 201), so zum Beispiel von Sigrid Löffler, die dem Film vorwarf, er nutze die »Einfühlungstechniken des HollywoodKinos « und funktioniere »als seelische Schnell-Reinigung, als Instant-Absolution, als Gefühls-Quickie. Dreieinviertel Kinostunden lang mit Schindlers Juden zu bangen, zu leiden, zu weinen und schließlich miterlöst zu jubeln und zu jauchzen, ist nur wohlfeil.« (Löffler 1994: 58f.) - eine Argumentation, die von Gunter Göckenjan widerlegt und von Henryk M. Broder ad absurdum geführt wurde:

»Ihre Argumente, im Wust polemischer Arabesken versteckt, sind sehr einfach: [...] Der Film ruft Gefühle hervor; das ist schlecht, weil Gefühle a) nichts verändern und b) zu Tränen führen. Sie nennt das: seelische Schnellreinigung. [...] all die obengenannten Argumente umspielen nur den zentralen Widerwillen gegen das Mit-Leiden.« (Göckenjan 1994: 200)

»Interessanterweise verzichtet SCHINDLERS LISTE auf eine zentrale Leidensfigur, mit der sich der Zuschauer identifizieren könnte (und die die klassische Hollywood-Dramaturgie gefordert hätte). Spielberg fragmentiert die Wege und erzählt (für die sentimentale Identifikationslust) zu viele Geschichten.« (Ebd. 201)

»Dem [Löfflers Kritik; eigene Anm.] könnte man entgegenhalten, der Film sei nicht in Hollywood, sondern an Hollywood vorbei und gegen Hollywood produziert worden; daß seit der ersten Liebesszene im ersten jemals produzierten Film Kino und Gefühle zusammengehören wie Essen und Appetit; daß der Vorwurf, ein Regisseur würde >Gefühlskino< machen, so unsinnig ist, als würde man einen Koch dafür tadeln, daß er Gewürze zum Kochen nimmt.« (Broder 1994: 185, H.i.0.)

\section{3) Spannung zwischen dem Einzel- bzw. Gruppenschicksal der sog. Schindlerjuden und anonymer Massenvernichtung:435}

Obgleich das, einen überwiegend glücklichen Ausgang nehmende, Schicksal der sog. Schindlerjuden im Vordergrund steht, thematisiert Spielberg in regelmäßigen Abständen die Vernichtung anonymer Opfer. Dem Zuschauer ruft dieser Kontrast immer wieder in Erinnerung, daß Spielberg mit seinem Film ein außergewöhnliches Geschehen inszeniert.

435. „Vielmehr stellt er [Spielberg; eigene Anm.] die individuelle Geschichte Schindlers und der um ihn gruppierten Personen und den Holocaust gegeneinander. Wo Schindler um das Leben seiner Arbeiter bemüht ist, zeigt die vom Himmel rieselnde Asche der 10000 verbrannten Leichen die Diskrepanz zwischen dem Vernichtungswerk und seiner Rettungsaktion auf [...].« (Lange 1999: 156)

436. Vgl. Baier 1994: 230 sowie Lanzmann 1994: 173f.: »Und wie soll er [Spielberg; eigene Anm.] sagen, was der Holocaust gewesen ist, indem er die Geschichte eines Deutschen erzählt, der 1200 Juden gerettet hat, während doch die überwältigende Mehrheit der Juden nicht gerettet wurden? [...] Verzerrt Schindlers Liste das Gesamtbild, die historische Wahrheit? Ja [...].« Siehe auch die Einleitung zu 3.2.6.

437. Grundlage folgender Ausführungen ist Korte 1999: $183 \mathrm{ff}$. 
Häufig zeigt der Regisseur entgegengesetzte Schicksale innerhalb einer Sequenz. Dies ist der Fall, als:

- die Kamera, nachdem Schindler seinen Buchhalter aus dem Deportationszug gerettet hat, den Koffern der Deportierten zu einer Lagerhalle folgt und dort Gegenstände, sogar Goldzählne der Opfer (s. 0:47:19 h und II.5.6.b) in Szene setzt;

- einem kleinen Mädchen in rotem Mantel inmitten des Massakers zunächst die Flucht gelingt (s. 3.2.1);

- der Selektion anonymer Opfer (s. 3.2.5) das Überleben von Schindlers Arbeiterinnen gegenübergestellt wird;

- Schindler bei der Exhumierung unzähliger anonymer Toter das kleine Mädchen im roten Mantel unter den Opfern entdeckt;

- Schindlers Arbeiterinnen ihrem Schicksal von Auschwitz entkommen, während eine anonyme Gruppe von Opfern in der Gaskammer von Auschwitz ermordet wird (s. 3.2.6).

In einigen selteneren Fällen inszeniert Spielberg das Schicksal einzelner jüdischer Zwangsarbeiter, so zum Beispiel als:

- Göth die Hinrichtung eines Schlossers mißlingt (s. 3.2.4);

- sich Göth seinem Hausmädchen, Helene Hirsch, zunächst mit Zuneigung nähert (s.o.), um sie im nächsten Moment in brutaler Weise zu mißhandeln.

An den zitierten Beispielen fällt auf, daß Spielberg insbesondere in bezug auf die zentralen Stationen der Vernichtung (Deportation, Ghetto-Räumung, Selektion, Gaskammer) darauf achtet, dem glücklichen Ausgang des Schicksals von Einzelnen das tödliche Los anonymer Opfergruppen gegenüberzustellen. Die wiederholt geübte Kritik, sein Film verharmlose den Holocaust und bestätige dadurch Holocaust-Leugner ${ }^{436}$, ist demnach in dieser Form unzutreffend.

\section{4) Spannung zwischen Visualisierung von Gewalt und}

der Inszenierung »latenter « und »akuter Bedrohung ( Korte 1999: 181):437

SCHINDlERs Liste zeichnet sich durch eine spezifische Spannung zwischen latenter und akuter Bedrohung sowie visualisierter Gewalt aus:

»Die Abbildung [...] verdeutlicht entlang der Zeitachse des Films den jeweiligen Bedrohungsgrad der Juden, der hier nach drei Intensitätsstufen eingeschätzt wurde: Entrechtung, Entwürdigung und Ausgeliefertsein als fast durchgängig vorhandene >latente Bedrohungく, direkte Übergriffe, Willkürmaßnahmen und die Vorbereitung der » Endlösung« als sakute Bedrohung bis hin zu den im Bild gezeigten >Tötungsdelikten<.« (Korte 1999: 181, H.i.0.)

Im Hinblick auf das Einbeziehen des Zuschauers und das Verhindern möglichen Wegsehens hat Korte eine wichtige Entwicklung im Verlauf des Films herausgearbeitet, die Spielbergs Absicht entspringt, die Visualisierung von Gewalt - im Unterschied zum US-amerikanischen TV-Mehrteiler WAR ANd REMEMBrance (1988) - zu begrenzen: 
»Entgegen der nach einmaliger Filmbetrachtung vorherrschenden Annahme ist zunächst festzustellen, daß der höchste Eskalationsgrad, der Mord an den Juden, im ersten Filmdrittel und allenfalls bis zur Filmmitte auftaucht und im weiteren Verlauf die ausführlich präsentierten latenten und akuten Bedrohungssituationen ausreichen, um diese Stufe im Bewußtsein des Publikums wachzuhalten und das gezeigte Geschehen entsprechend zu ergänzen.« (Korte 1999: 181)

- Erstmalig wird diese »höchste Eskalationsstufe« (ebd. 183) erreicht, als der einarmige jüdische Schlosser auf offener Straße hingerichtet wird, weil er weniger effizient als die anderen Zwangsarbeiter Schnee räumen kann (s. o:41:41 h).

- Nachdem Göth die für die Errichtung des Plaszower Lagers verantwortliche jüdische Ingenieurin hat hinrichten lassen, ...

- ... stellt das Massaker während der ca. fünfzehnminütigen Räumung des Krakauer Ghettos den Höhepunkt der Eskalation dar. In dieser »Phase absoluter Willkür mit exzessiver Gewaltausübung « (Korte 1999: 184) alterniert die Ermordung einzelner Ghettoinsassen (s. 1:00:51 h) mit Massenerschießungen (1:09:37 h).

- Unmittelbar nach dem Ghettomassaker erschießt Göth vom Balkon seiner Villa aus zwei Lagerhäftlinge (s. 1:12:33 h).

- Um der Suche nach einem Hühnerdieb Nachdruck zu verleihen, tötet er willkürlich mehrere Häftlinge (s. 1:27:11 h).

- Erbost über die Flucht eines Häftlings erschießt er jeden zweiten aus dessen Barakke (s. 1:32:58 h).

Das Problem an solchen - im Unterschied zum TV-Mehrteiler HolocausT ${ }^{438}$ visualisierten Eskalationen von Gewalt ist jedoch, daß sie eine Schockwirkung erzeugen können439, möglicherweise »in ihrer Menschenverachtung und Realistik kaum zu ertragen « $\operatorname{sind}^{44^{\circ}}$ (Korte 1999: 184) und auf Dauer eher abstumpfend wirken. Dramaturgisch gesehen ist es daher von Spielberg durchaus geschickt, nach der

438. »[...] Akte der Folter, des Tötens oder der Vergewaltigung werden szenisch verdeckt oder elliptisch ausgespart und so stets der Imagination des Zuschauers überlassen.« (Köppen 1997: 163)

439. "Spielberg schockiert mit Bildern des Todes, geht bis an die Schmerzgrenze, wenn bei Hinrichtungsszenen die Kamera bis zum Ende dranbleibt. Er zeigt die Demütigung von Menschen durch andere so hautnah, daß der Zuschauer nur noch Wut empfindet.« (Noack 1998: 89f.) Vgl. auch Seeßlen zur Kamera, die den Blick nicht vom Sterben wenden kann (1995: 164) - eine schonungslose Form der Inszenierung, die zum Teil bereits in TRIUMPH DES GEISTES und in dem rund zehn Jahre späteren DeR PIANIST zu beobachten ist. Vgl. auch Rosner, der - wie Noack (1998: 102) - das Vorführen der Brutalität mit authentischer Wirkung in Verbindung bringt: »Die Hinrichtungsszenen besitzen eine solche Authentizität, daß sie wie reale Wochenschauaufnahmen wirken, die aber wegen ihrer Brutalität kein Fernsehsender zeigen würde. Nach Kopfschüssen spritzen die Blutfontänen.«(Zit.n. Köppen 1997: 166f.)

440. »Allerdings besteht hier auch die Gefahr, daß die Wirkung umkippt, daß der Zuschauer sich verschließt." (Noack 1998: 102f.)

441. Die Inszenierung dieser Lust am willkürlichen Töten wird von Polanski in Der PIANIST ähnlich drastisch in Szene gesetzt.

442. Köppen bezeichnet dies als »elliptische Gewaltdarstellungen« (1997: 159). 


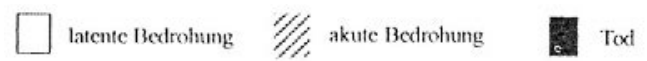
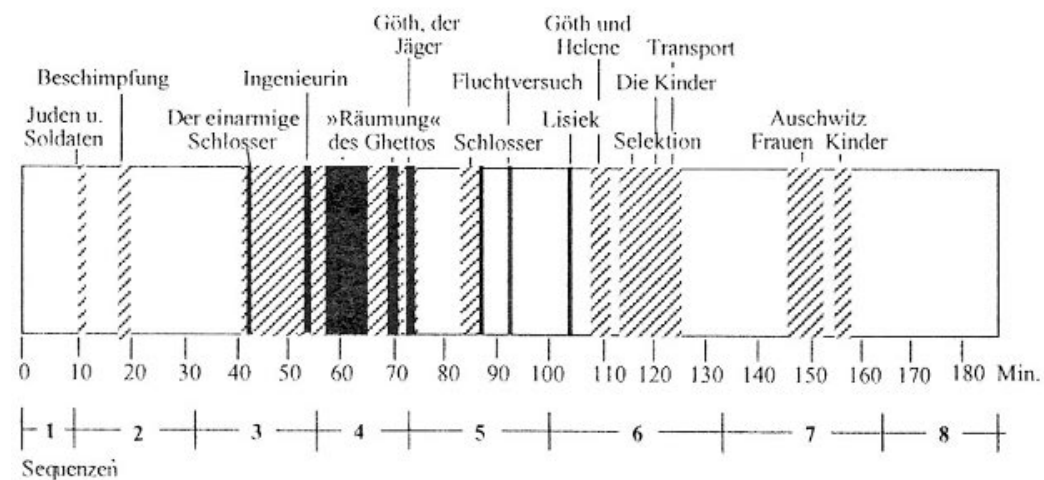

Abb. II.3.2.b (Korte 1999: 181)

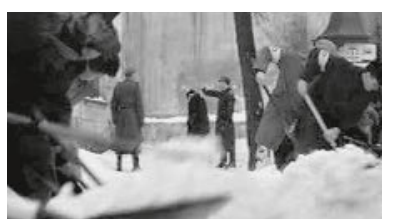

(384) $0: 41: 41 \mathrm{~h}$

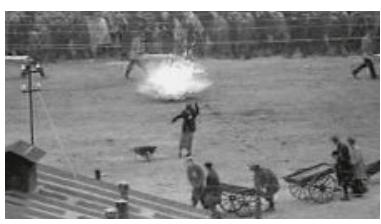

(387) $1: 12: 33 \mathrm{~h}$
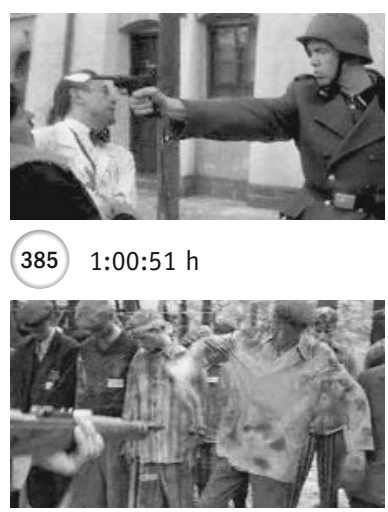

(388) $1: 27: 11 \mathrm{~h}$

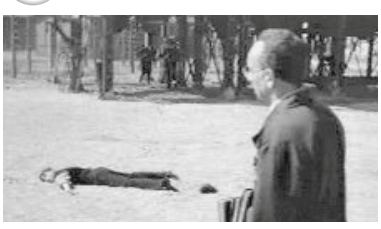

(390) $1: 44: 58 \mathrm{~h}$

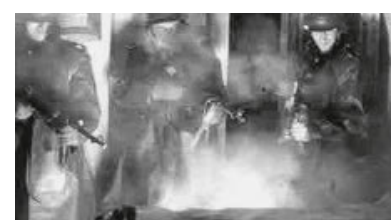

(386) $1: 32: 58 \mathrm{~h}$

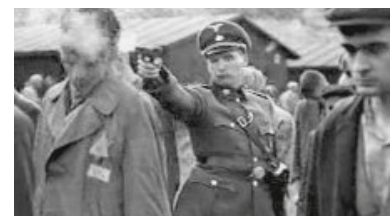

(389) $1: 32: 58 \mathrm{~h}$

Bewußtmachung äußerster Brutalität und der »Lust am willkürlichen Töten« (Fohrmann 2002: 54) im weiteren Filmverlauf mit der Erinnerung an das Geschehene zu arbeiten. ${ }^{441}$

Den, so Korte, »letzte[n] im Bild gezeigten[n] Mord « (ebd. 181) stellt die Erschießung des Burschen Lisiek durch Göth dar; es muß jedoch präzisiert werden, daß - im Unterschied zu den vorangegangenen Hinrichtungen - nicht die Tat selbst, sondern deren schreckliches Resultat visualisiert wird (s. 1:44:58 h).

Auch wenn nach dieser 105. Filmminute Tötungen nicht mehr ins Bild gesetzt, sondern angedeutet werden ${ }^{42}$, bedeutet dies keineswegs, daß der Film in seinem weiteren Verlauf für den Zuschauer erträglicher würde - im Gegenteil, die Bedrohung für die sog. Schindlerjuden wird zunehmend akuter (s. 3.2.5 und 3.2.6). 
5) Spannung zwischen unterschiedlichen Erzählperspektiven, insbesondere einer distanzierten Beobachterrolle und einem unmittelbaren »Live-dabei«-Eindruck: Spielberg läßt in SchindLERS Liste - v.a. in den Schlüsselsequenzen (s. 3.2.3-3.2.6) unterschiedliche Erzählperspektiven, insbesondere die figurenunabhängige (s. o:16:51 h) mit der figurenabhängigen, alternieren. ${ }^{443}$ Während erstere dem Zuschauer einen Überblick über die Situation ermöglicht bzw. ihn in eine Beobachterrolle versetzt, bietet letztere unterschiedliche Identifikationsmöglichkeiten - Distanz und »Live-dabei«Eindruck wechseln sich ab und steigern sich wechselseitig in ihrer Wirkung. Neben der positiven Identifikation v.a. mit den sog. Schindlerjuden (s. o:54:०6 als Beispiel für eine subjektive Erzählperspektive mit Itzhak Stern), läßt uns der Regisseur punktuell auch mit den Tätern blicken, insbesondere mit Göth (s. 1:13:13 h), aber auch mit den SS-Ärzten (s. 1:57:00 h) - Erzählperspektiven mit Brisanz.444 Insgesamt überwiegen jedoch die positiven Identifikationsangebote, vor allem mit Schindlers in Auschwitz besonders bedrohten weiblichen Arbeiterinnen (s. 2:25:04 h und 3.2.5 und 3.2.6) und der zunehmend sympathischen Titelfigur (s. 1:05:38 h445).

Je nachdem, ob uns Spielberg durch die Ästhetik der Live-Berichterstattung einen »Live-dabei«-Eindruck ermöglicht oder uns, durch eine ruhigere Inszenierung, eine gewisse Distanz zu den Geschehnissen verschafft, bangen wir mit bzw. um Schindlers weibliche Arbeiterinnen.

\section{6) Spannung zwischen Bild- und Tonspur:}

"So werden in Erweiterung klassischer Hollywood-Erzähltechnik etwa die letzten Bilder eines ausführlicher geschilderten Vorgangs bereits mit der Tonspur der folgenden unterlegt und ohne Spannungsabfall gleitende Übergänge geschaffen oder aber - indem das Bild den Dialog konterkariert - die verbalen Aussagen ironisierend zugespitzt, in ihrer Phrasenhaftigkeit entlarvt.« (Korte 1999: 173)

443. »[...] drittens kann es zu einer \Konfrontation verschiedener Weltısichten« kommen, so >daß der Zuschauer nicht nur verschiedene Weltsichten einbringen kann, sondern ihre Inkompatibilität aushalten mußく; wobei er sich an den Spannungen zwischen allen möglichen ideologischen und moralischen Systemen entfalten kann« (Kloepfer 1982: 367f., H.i.0.)

444. »[...] what does it mean that point-of-view shots are clustered not only around Schindler but also around Goeth, making us participate in one of his killing sprees in shots showing the victim through the telescope of his gun? Does this mean that [...] the viewer is nonetheless urged to identify with Goeth's murderous desire on the unconscious level of cinematic discourse?" (Hansen 1997: 83)

445. »[...] aus drei Erlebnisperspektiven [...] wird der Zuschauer nicht nur situativ in die wechselnden Positionen von Täter, Opfer und Zeuge eingebunden.« (Köppen 1997: 159)

446. Vgl. Kortes aufschlußreiche Analyse der Sequenz um den einarmigen Schlosser (und dessen unglücklichem Schicksal) (1999: 173ff.). Bereits Robert M. Young hatte dieses Stilmittel der Parallelmontage verstärkt eingesetzt, um in TRIUMPH DES GEISTES das Schicksal der voneinander getrennten Männer und Frauen zu erzählen und die Trennung dadurch erfahrbar zu machen.

447. Man denke in diesem Zusammenhang beispielsweise an die erstmalige In-Bezug-Setzung von Schindler und Göth durch das abwechselnd gezeigte morgendliche Rasieren der beiden. 


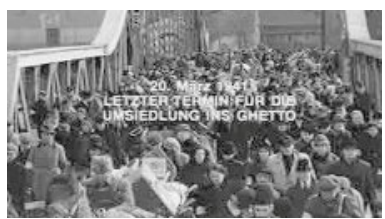

(391) $0: 16: 51 \mathrm{~h}$

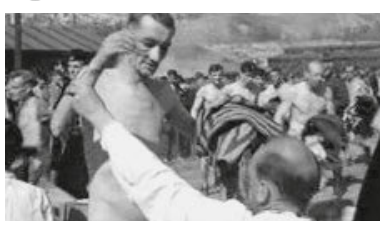

(394) $1: 57: 00 \mathrm{~h}$

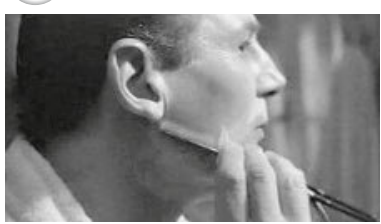

(397) $0: 53: 07 \mathrm{~h}$

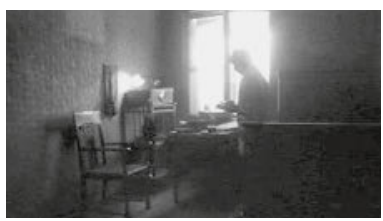

(400) $0: 53: 29 h$

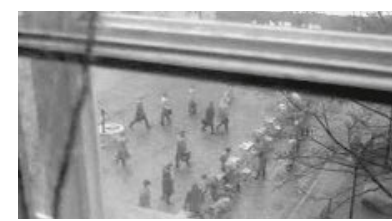

(392) $0: 54: 06 \mathrm{~h}$

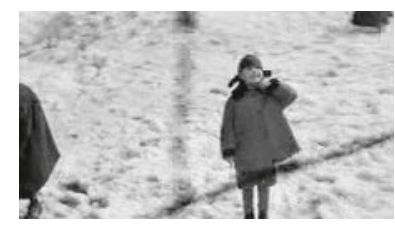

(395) $2: 25: 04 \mathrm{~h}$

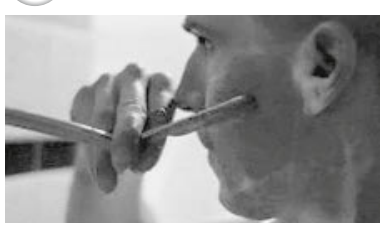

(398) $0: 53: 08 \mathrm{~h}$

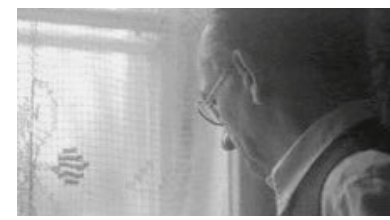

(401) $0: 53: 54 \mathrm{~h}$

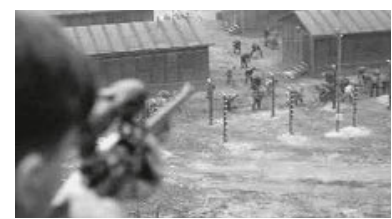

(393) $1: 13: 13 \mathrm{~h}$

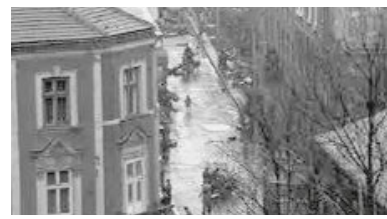

(396) $1: 05: 38 \mathrm{~h}$

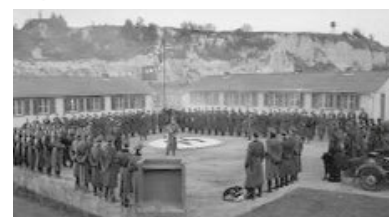

(399) $0: 53: 15 \mathrm{~h}$

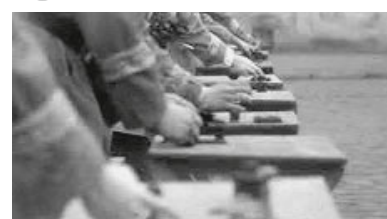

(402) $0: 54: 02 \mathrm{~h}$

Gerade angesichts der deutlichen Überlänge des Films unterstützt diese Beschleunigung des Erzähltempos das durchgängig hohe Spannungsniveau und somit den »vergleichsweise extremen Erregungszustand« des Zuschauers (ebd. 173ff.).

Durch die Asynchronität zwischen Bild- und Tonspur können darüber hinaus zwei parallel ablaufende Handlungen, die sich an verschiedenen Orten vollziehen, verdichtend erzählt werden - häufig im Zusammenhang mit einer klassischen Parallelmontage. ${ }^{446}$ Auf diese Weise ist der Zuschauer aufgefordert, eine Verbindung zwischen beiden Handlungen bzw. Situationen herzustellen, selbst wenn diese zunächst nicht unmittelbar naheliegend ist. ${ }^{447}$ Zentrales Beispiel hierfür ist die extrem vielschichtige Sequenz um Göths Rede vom »historischen Tag« (Hansen 2001: 136ff.), in der zu Beginn die - sich zu diesem Zeitpunkt noch fremden - Antagonisten (Schindler und Göth) parallelisiert werden (s. o:53:07 h und o:53:08 h), bevor die Furcht der Krakauer Juden vor der in Göths Ansprache (s. 0:53:15 h) angesprochenen nationalsozialistischen Vernichtungspolitik in Szene gesetzt wird: Manche beten (s. 0:53:29 h), Itzhak Stern beobachtet voller Sorge die erneuten vernichtungsbürokratischen Schritte (s. o:53:54 h und o:54:02 h) - im Hintergrund ist durchgehend Göths Rede zu hören. 
7) Spannung zwischen dem gezielten Aufbau von

Antizipationen und deren Bestätigung bzw. Durchbrechung:

Neben dem allgemeinen Handlungskontext werden Antizipationen häufig durch Groß- bzw. Detailaufnahmen ermöglicht, »mit Vorahnungen aufgeladene Details, die erst später ihre Bedeutung entfalten« (ebd. 188). Hierbei knüpft Spielberg zum Teil - insbesondere bei der Inszenierung sogenannter Ikonen der Vernichtung448 - an das gene relle Vorwissen des Zuschauers ${ }^{449}$ bzw. an innerhalb des Films gelieferte Informationen an. In aller Regel werden die Antizipationen des Zuschauers bestätigt (s. 3.2.3 und 3.2.4) 450 $^{\circ}$, an manchen exponierten Stellen jedoch auch durchbrochen (s. 3.2.4 und 3.2.6). Insgesamt fällt jedoch auf, daß der Regisseur die Erwartungen teilweise zu rasch bestätigt, so daß der Zuschauer kaum ausreichend Zeit hat, selbst bzw. aus sich heraus Antworten zu finden, sich selbst einzubringen.

Wie bereits angedeutet, sei mit Korte erneut betont, daß sich ScHindLers Liste insgesamt durch eine »stark verdichtete Erzählweise« (ebd. 173) auszeichnet, die den Zuschauer extrem fordert und so trotz der erheblichen Überlänge des Films einen Spannungsabfall verhindert: Diese Dichte beruht »auf dem intensiven Zusammenwirken mehrerer, sich gegenseitig steigernder inhaltlicher und formaler Faktoren, die dem Betrachter kaum Zeit zum Atemholen lassen « (ebd. 173). Zentrales Stilmittel ist in diesem Zusammenhang das angesprochene Auseinanderklaffen von Bild- und Tonspur beim Szenen- und Sequenzwechsel (s.o., Punkt 6).

448. Vgl. die gleichnamige Publikation von Cornelia Brink aus dem Jahre 1998 zum öffentlichen Gebrauch von Fotographien aus nationalsozialistischen Konzentrationslagern nach 1945.

449. "Spielbergs fiktive Dokumentation kann als solche nur funktionieren, wenn die heutigen, informierten Nachgeborenen bereits vorab in der Lage sind, solche Bilder zu entschlüsseln [...].« (Lange 1999: 155)

450. Siehe hierzu insbesondere die Analyse der vermeintlichen Gaskammer in 3.2.6.

451. Damit folgt die vorliegende Arbeit dem Sequenzprotokoll von Korte (1999: 157) und grenzt sich von Noacks struktureller Analyse ab, der die Exposition erst vor der Räumung des Krakauer Ghettos, d.h. nach knapp einer Stunde, enden läßt (Noack 1998: 96).

452. »The triadic introductory structure of SCHINDLER'S LIST (which can be shymed by the triadic concluding structure) moves from a candle, to a list, and - finally - to a man.« (Insdorf 203: 261, H.i.0.)

453. »Eine [verglichen mit großzügiger Informationsvergabe zu Beginn eines Films] weit bessere Taktik ist es, mit Andeutungen und teilweisen Enthüllungen zu arbeiten, mit kleinen Geheimnissen und Rätseln, mit Lügen und widersprüchlichen Aussagen verschiedener Figuren in Sachen Exposition. All das sind Methoden, mit denen man das Publikum dazu bringt, sich selbst das Hintergrundwissen zu den Ereignissen auf der Leinwand zu verschaffen, und es somit stärker in die Geschichte einbindet.« (Howard/Mabley 1996: 86) 
3.2.3 Exposition: Auftakt zur Vernichtung - Geheimnisvoller Schindler

Die Exposition von Schindlers Liste erstreckt sich über drei Sequenzen, den Vorspann (s. 3.2.3.a), die Eröffnungssequenz (s. 3.2.3.b) und die sich anschließende Szenenfolge (s. 3.2.3.c) und damit über knapp zehn Minuten. ${ }^{451}$ Diese »triadische

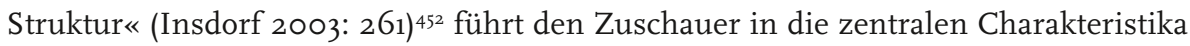
und Spannungsverhältnisse des Films ein. Gleichzeitig lehrt sie ihn - gemäß dem »autodidaktischen Prinzip« nach Kloepfer (s. I.2.3) -, wie er sich dem Film gegenüber verhalten soll:

»Wie in vielen früheren Spielbergfilmen auch, wird der Betrachter in SCHINDLERS LISTE von Beginn an in die Handlung suggestiv hineingezogen, durch die schnell wechselnden visuellen und auditiven Eindrücke extrem gefordert und mit gezielt provozierten Ahnungen über das kommende Geschehen konfrontiert.« (Korte 1999: 167)

»Es sind zunächst mehr oder weniger identifizierbare Assoziationsangebote, undeutliche Gefühle, aufkommende Ängste oder auch vage Erinnerungen an schon einmal Gesehenes, die sich ins Bewußtsein drängen [...].« (Ebd. 170)

Indem der Zuschauer des weiteren durch den Mangel an expliziter Information in die jeweilige Situation eingebunden wird ${ }^{453}$, findet er seine auf diese Weise provozierten Antizipationen teils in der Exposition, teils im weiteren Verlauf bestätigt - ein zentrales Kompositionsprinzip in SchindleRs Liste.

\section{a) Sabbatgebet als farbiger Vorspann}

Zusammen mit der Schlußsequenz an Oskar Schindlers Grab in Jerusalem stellt der eineinhalb Minuten dauernde Vorspann den Rahmen sowie die einzigen vollständig in Farbe gehaltenen Bilder des Films dar. Aufgrund des Verzichts auf jegliche explizite Information ist der Zuschauer mit einem rätselhaften Auftakt konfrontiert, der mit der Inszenierung eines bekannten Kollektivsymbols endet und in die Eröffnungssequenz übergeht.

\section{Detaillierte Sequenzanalyse:}

SCHindere Liste beginnt mit einem schwarzen Bildschirm und absoluter Stille. Diese wird durch ein dem Zuschauer vertrautes Geräusch aufgehoben, dem Reiben eines Streichholzes an der Streichholzschachtel. Begleitet wird dieser akustische Reiz vom Aufflackern einer Flamme, mit der in der Folge zunächst eine Kerze (s. ০:০০:30 h) und später eine zweite angezündet wird. Dabei konzentriert sich die Kamera auf die beiden Kerzen (Groß- bzw. Detailaufnahme), die nicht zuordenbare Hand bleibt eher im Hintergrund. Die Bedächtigkeit des Anzündens läßt den Zuschauer eine religiös motivierte Handlung vermuten. Diese Antizipation wird kurz darauf bestätigt, als auf der Tonspur ein gebetsartiger Text von einer Männerstimme vorgetragen wird: Da in einer fremden - für Sachkundige als hebräisch identifizierbaren - Sprache rezitiert wird, könnte man auf einen jüdischen, religiösen Ritus schließen, vor allem wenn man über den Inhalt des Films vorinformiert ist. Auch diese Vermutung wird wenige Sekunden später bestätigt: Durch einen Schnitt wird der Zuschauer in die religiöse Zeremonie einer Familie hineinversetzt (s. ০:00:43 h). Um einen Tisch, auf dem die beiden Kerzen stehen, sind drei Generationen versammelt, die Männer mit Bart und 
Schläfenlocken, in schwarzer Kleidung und Kippa, so daß der Zuschauer auf das jüdische Sabbatgebet schließen kann (Korte 1999: 168).

Während auf der Tonspur weiterhin und mit gleicher Lautstärke das Gebet zu vernehmen ist, gibt eine Überblendung den Blick frei auf die gleiche Örtlichkeit, mit einem, jedoch entscheidenden, Unterschied: Die Personen und was sich auf dem Tisch befand (Tischdecke, Flasche etc.) haben sich »in Luft aufgelöst« - nur die beiden brennenden Kerzen stehen noch an derselben Stelle (s. ০:০০:55 h). Überrascht fragen wir uns, wohin die Familie verschwunden ist bzw. wie das plötzliche Verschwinden zu interpretieren ist. Bereits hier könnte man erahnen, daß Spielberg mit diesem Trick das Schicksal der Juden unter Hitler visuell andeutet. Während der Einblendung des Verleihers, der Produktionsfirma und des Filmtitels werden, mittels erneuter Überblendungen, die beiden brennenden Kerzen ins Zentrum der Aufmerksamkeit gerückt (s. o:01:13 h).

Eine letzte Überblendung läutet das Ende des farbigen Prologs ein. Eine Nahaufnahme läßt den Zuschauer mitverfolgen, wie die Flamme einer der beiden Kerzen allmählich erlischt, während parallel das Gebet mit dem deutlich zu vernehmenden Wort »Schabaß« endet. Damit macht Spielberg unmißverständlich deutlich, daß es sich bei dem religiösen Ritus um das jüdische Sabbatfest handelt. Kurz darauf wird die andächtige Stille durch ein Knistern aufgehoben, welches den aufsteigenden Rauch der erlöschenden Flamme begleitet (s. 0:01:27 h) - ein weiterer, möglicher Verweis auf das jüdische Schicksal. An diesem sich vor dem schwarzen Hintergrund deutlich abhebenden Silberstreifen schwenkt die Kamera zunächst bedächtig nach oben, um den sich windenden, emporsteigenden Rauch zu verfolgen. ${ }^{454}$

\section{b) Eröffnungssequenz: Erfahrbare Hektik bei der Registrierung der Juden}

Die Eröffnungssequenz bildet den Auftakt der Binnengeschichte, verdeutlicht durch den Wechsel von Farbe in historisches Schwarzweiß sowie zwei, über Ort, Zeit und Geschehnisse informierende Texteinblendungen. Nach einem ruhigen Sequenzbeginn lädt Spielberg die bürokratische Vernichtungsmaschinerie durch auffällige Inszenierung symbolisch auf und führt damit ein Leitmotiv des Films ein. ${ }^{455}$ Auf diese Weise macht er den industriellen Charakter der Vernichtungspolitik für den Zuschauer erfahrbar, verschafft er uns ein »Gefühl des unmittelbaren Dabeiseins « (Korte 1999: 171), indem er uns während der Registrierung unzähliger Juden mitten in das hektische Geschehen versetzt - ein filmisches Verfahren, das den gesamten Film besonders kennzeichnet und hier eingeführt wird.

454. »Thus the candles symbolize the extinguishing of European Jewish life and the burning of Jews in the crematoria." (Horowitz 1997: 124)

455. »Wie das von den literarischen Verfahren schon lange behauptet wird, die ebenfalls mit dem in Zeichenkörpern materialisierten kollektiven Gedächtnis umgehen, erstellt der Künstler aus den beiden Potentialen vor und mit den Apparaten Quintessenzen von hoher Konzentration und Depotwirkung. Wir nennen dies >Aufladen<, weil der Terminus in allem mir bekannten Sprachen nicht nur quantitativ und eindimensional das Hinzufügen auf das zeichenkörperliche Vehikel meint, sondern auch qualitativ die Möglichkeit von Sprüngen impliziert [...].« (Kloepfer 1995: 85, H.i.0.) 


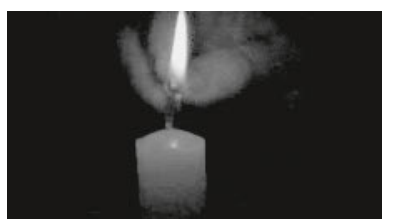

(403) $0: 00: 30 \mathrm{~h}$

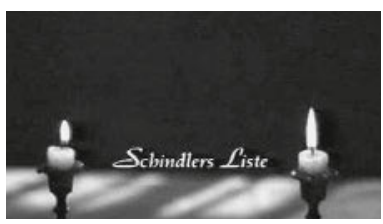

(406) $0: 01: 13 \mathrm{~h}$
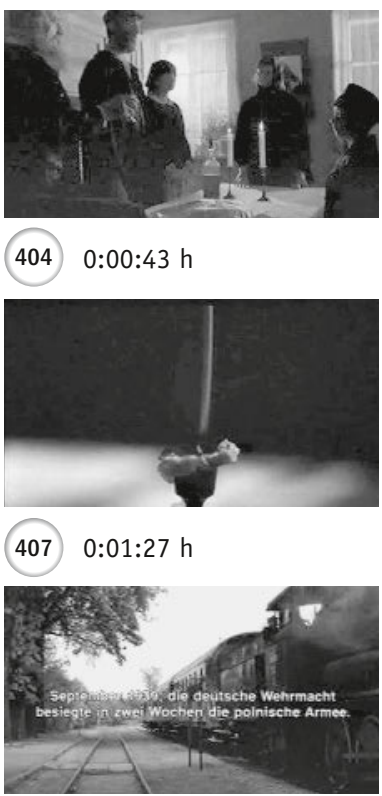

(409) $0: 01: 41 \mathrm{~h}$

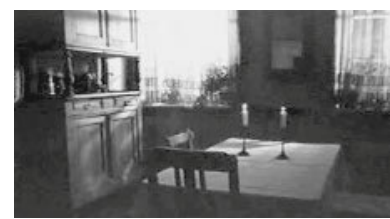

(405) $0: 00: 55 \mathrm{~h}$

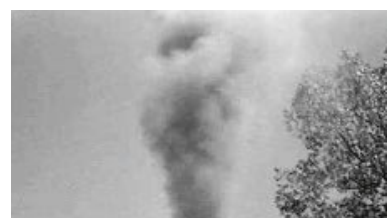

(408) $0: 01: 32 \mathrm{~h}$

Detaillierte Sequenzanalyse:

Nachdem der Prolog mit einem harten Schnitt beendet wurde, bringt die erste Einstellung der Eröffnungssequenz zentrale Veränderungen mit sich: Die gedämpfte Farbigkeit wird von einem Schwarzweiß abgelöst - Hinweis darauf, daß die BinnenGeschichte beginnt und daß sie in der Vergangenheit spielt (s. 3.2.2). Die Kamera bewegt sich, verglichen mit dem Ende des Prologs, in umgekehrter Richtung. Der von oben nach unten verlaufende Vertikalschwenk läßt den Zuschauer kräftige Rauchwolken erkennen (s. o:01:32 h). Ein Schlot, schrilles Pfeifen, aufsteigender Rauch und das Geräusch des Dampfablassens lassen darauf schließen, daß es sich um eine Lokomotive und nicht, wie man zunächst befürchten konnte, um den Schornstein eines Krematoriums handelt. Die fortgeführte Kamerabewegung sowie die Tonspur sichern diese Vermutung ab.

Noch bevor diese sukzessive Auflösung der Situation, vor allem durch die Entwicklung der Einstellungsgröße von Detailaufnahmen zur Totalen, auf uns wirken kann, gibt eine Texteinblendung auch schon Aufschluß über die Ausgangssituation: »September 1939, die deutsche Wehrmacht besiegte in zwei Wochen die polnische Armee« (s. o:01:41 h). Damit nimmt Spielberg dem Zuschauer die Möglichkeit, den virtuosen Sequenzübergang in sich nachklingen zu lassen, das heißt, Antizipationen über Ort, Zeit und Handlung anzustellen und seinen Assoziationen freien Lauf zu lassen.

Auch die sich an einen auffällig ruhigen Schwenk vom Zug zum Bahnsteig anschließende Texteinblendung nimmt uns die gedankliche Eigenleistung ab, indem sie unmißverständlich klarstellt: »Alle Juden müssen sich registrieren lassen und in größere Städte umsiedeln. Über 10.000 Juden vom Land treffen täglich in Krakau ein.« (s. ০:01:51 h) Atmosphärisch ist die Einstellung vom lauten Dampfablassen der Loko- 
motive "getönt «.$^{45}$ Auch wenn die Lokomotive nicht im Bild zu sehen ist, so graben sich ihre Geräusche und ihr spezifischer Sinn in unser Bewußtsein ein. Die Registrierung (s. o:01:51 h) ist der erste Schritt in Richtung Holocaust.

Um das zentrale Leitmotiv des Films einzuführen, geht Spielberg nun zu Detailaufnahmen - »Pars pro toto«, ein in vielen Filmen angewandtes Stilmittel (s. II.2.1.7) - über und zeigt Utensilien der bevorstehenden Registrierung - wie Stempelkissen, Hefter, Stempel (s. o:02:01 h), Tintenfaß etc. (Korte 1999: 172). Die hohe Schnittfrequenz erzeugt beim $\mathrm{Zu}$ schauer eine Unruhe, vor allem durch den Kontrast zu den vorherigen, langen Einstellungen mit getragener Kamerabewegung. Gleichzeitig haftet diesen Vorbereitungen durch die monoton wiederholten Handgriffe und Geräusche beim Hinstellen der Utensilien etwas Mechanisches an und nicht zufällig erinnert die diskursive Gestaltung an die inzwischen geläufige Formulierung >bürokratische Vernichtung im Zusammenhang mit dem Holocaust. 457

Ein erneuter Schwenk gibt den Blick frei auf eine Familie, die sich dem Registrierbeamten nähert und durch eine besondere Kameraposition auch uns. Aufgrund der Texteinblendungen und der laufenden Vorbereitungen vermutet man Juden, was durch das Äußere insbesondere des voranschreitenden Familienoberhauptes (Kleidung und extrem auffälliger Bart), betont wird (s. ০:02:10 h) - »at first glance, a Roman Vishniac photograph come to life« (Doneson 2002: 205).

Ein erneuter kontrastiver Einstellungsgrößenwechsel ${ }^{45^{8}}$ von einer halbnahen hin zur Detailaufnahme hat retardierende Wirkung: Sorgsam schraubt der Beamte sein Tintenfaß auf und taucht den Federhalter hinein (s. ০:02:14 h) - die sprichwörtliche Ruhe vor dem Sturm, wie sich kurz darauf herausstellen wird.

Ein überraschender Reißschwenk von der Hand auf das Gesicht des Beamten kann gerade noch seine knappe Frage einfangen (»Name?«; ০:02:15 h), bevor die Kamera, nach einem harten Schnitt und parallel zum erneuten Pfeifen der Lokomotive, ex-

456. »Ich möchte dieses [...] Phänomen der kontinuierlichen Erinnerung an eine Prämisse der Bewußtseinsebene >Tönung nennen. Die filmische Tönung nutzt die Tatsache, daß wir gleichzeitig auf vielen Ebenen oder Registern hören und sehen können. Insbesondere das Hören ist ein Raumphänomen. Es geschieht ungemein komplex und ist vor allem bei der Orientierung ein unbewußter, aber deshalb nicht weniger wirklicher und wirkungsvoller Vorgang. [...] Das Alltagswort >Tönung< ist insofern günstig als wissenschaftlicher Terminus, weil es in gleicher Weise die akustische wie die visuelle Durchdringung eines Ganzen mit einer leitenden Modifikation bezeichnet.« (Kloepfer 1995: 56, H.i.0.)

457. »Auch die noch häufiger auftauchenden Requisiten der Registrierung, die Klappstühle und -tische, die Schreibutensilien und Listen werden hier bereits eingeführt und erhalten zunehmend symbolische Bedeutung, stellvertretend für den sachlich-bürokratisch durchgeführten >Vorgang der systematischen Vernichtung der Juden.« (Korte 1999: 172)

458. »Bei Sprüngen über mehr als zwei Einstellungsgrößen hinweg wird ein stärkerer optischer Reiz provoziert als bei einem Wechsel von einer Einstellungsgröße zur nächst höheren oder tieferen.« (Noack 1998: 64)

459. Diese Einstellungen werden dem Zuschauer im weiteren Filmverlauf wieder begegnen - in positivem Zusammenhang, als Schindler mit Stern die titelgebende und lebensrettende Liste erstellt. 


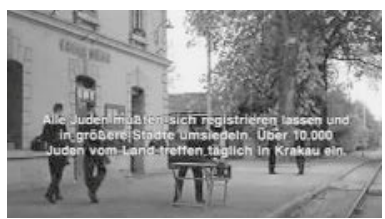

(410) $0: 01: 51 \mathrm{~h}$

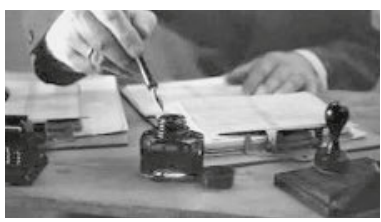

(413) $0: 02: 14 \mathrm{~h}$

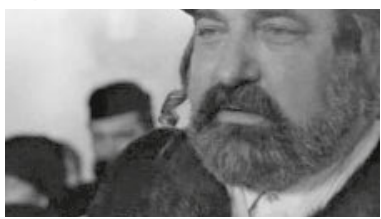

(415) $0: 02: 33 \mathrm{~h}$
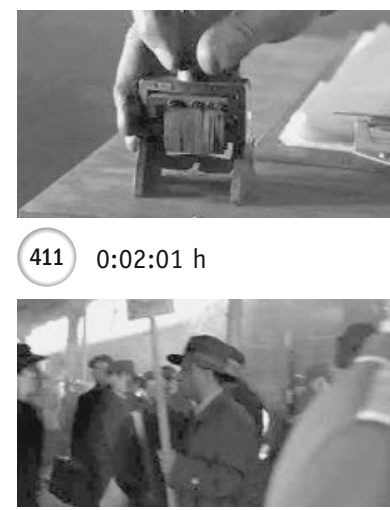

(414) $0: 02: 27 \mathrm{~h}$

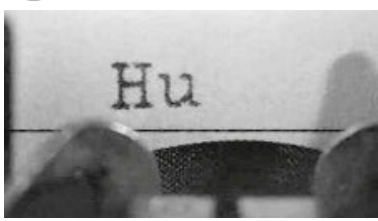

(416) $0: 02: 34 \mathrm{~h}$

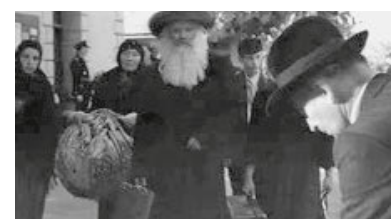

(412) $0: 02: 10 \mathrm{~h}$

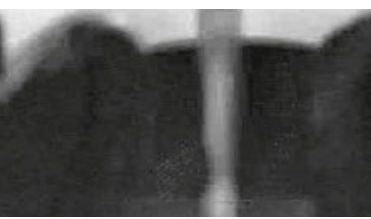

(417) $0: 02: 34 \mathrm{~h}$

trem nervös zu wackeln beginnt: Sie »schwenkt ruckartig nach links, zeigt weitere Tische, Beamte, ankommende Juden, >fährt< an einer Gruppe Uniformierter vorbei in die Bildtiefe [...] (Korte 1999: 170, H.i.O.; s. 0:02:27 h). Menschen laufen durchs Bild, es herrscht lautes Stimmengewirr, Namen werden gerufen; die Registrierung ist inzwischen in vollem Gange. Wie einzelne Figuren, irrt auch der Zuschauer orientierungslos durch die Menge - Spielberg versetzt ihn durch seine ästhetische Gestaltung wirkmächtig in die dargestellte Welt, plaziert ihn mitten ins turbulente Geschehen:

»Kaum hat man sich auf die ersten sehr ruhigen Bilder eingelassen $[\ldots]$, wird man $[\ldots]$ unvermittelt in eine extrem hektische und unvollkommen unübersichtliche Situation hineingeworfen, die jegliche Bemühung, sich zurechtzufinden, zunichte macht. Neben den Bildinhalten und dem durch alternierende Einstellungslängen ständigen Tempowechsel ist dafür die hochgradige Bilddynamik bedeutsam, die den Betrachter in ein zunächst verwirrendes Geschehen hineinschleudert, das er erst langsam begreifen kann. Die in alle Richtungen sich bewegende Handkamera [...], die sich in zahlreichen Reißschwenks, ruckartigen Blickveränderungen und bewegungsbetonten Kamerafahrten bemerkbar macht, vermittelt in Verbindung mit den bevorzugten Naheinstellungen und entsprechendem (realistischen) Toneinsatz das Gefühl des unmittelbaren Dabeiseins im Sinne eines authentischen Dokumentarberichts.» (Korte 1999: 170f.)

Gesteigert wird die Hektik und unser damit einhergehender Streß in der Folge durch ein virtuoses, rhythmisches Zusammenspiel von Bild- und Tonebene: Nah- bis Großaufnahmen jüdischer Männer und Frauen, die ihren Namen nennen (s. 0:02:33 h), alternieren mit Detailaufnahmen der Schreibmaschinen, deren Typenhebel abwechselnd die Buchstaben in das Papier stanzen (s. 0:02:34 h)459 - durch das Bild und dem 
Zuschauer beinahe ins Auge sausend (s. 0:02:34 h). Wie das Bereitstellen der Registrierutensilien vorher, empfindet der Zuschauer die Erstellung der Listen als einen beklemmend-bürokratischen Ablauf und ahnt, daß sich die Vernichtungsmaschinerie erst in Bewegung setzt. 460

Diese drückende Wirkung verändert sich erst, als der Schreibmaschinenlärm von einer »»wimmernden<, melancholischen Musik (Geige, Akkordeon) verdrängt« wird (Korte 1999: 170, H.i.O.). Hierbei handelt es sich um das »Lied vom traurigen Sonntag ${ }^{4{ }^{61}}$, das zunächst als kommentierende und emotional einstimmende Filmmusik aus dem Off einsetzt. Auffälligerweise verharrt die Kamera mit dem Einsetzen des Lieds auf den jüdischen Namen - einer nach dem anderen wird so fixiert, sorgsam und beharrlich, ohne Ausnahme. Durch diese Kombination von Bild- und Tonspur lädt Spielberg diese Liste dem Zuschauer als Todesliste auf: »Es ist Hitlers Liste, die Todesliste, die da entsteht, aber die Opfer, die Gezeichneten wissen es noch nicht.« (Kilb 1995: 151)

\section{c) Nazi oder Opportunist? Die geheimnisvolle Einführung der Titelfigur}

In der auf die Eröffnungssequenz folgenden Sequenz wird die titelgebende Hauptfigur als »geheimnisvoller Fremder« (Korte 1999: 172), als zwielichtig eingeführt:

Geheimnisvoll, weil Spielberg dem Zuschauer im ersten, knapp einminütigen Teil der Sequenz Gesicht und Stimme des Protagonisten vorenthält und ihn ausnahmslos in Ausschnitten präsentiert. Erst am Ende des fünfeinhalb Minuten dauernden, zentralen zweiten Teils der Sequenz wird das Rätsel um die Identität der Figur gelöst.

Zwielichtig einerseits, weil sich die Figur am Ende des ersten Teils der Sequenz ein NSDAP-Abzeichen ans Revers steckt und im zweiten Teil gezielt um die Gunst

460. „Die Kamera swandertı durch die Situation, zeigt die Schreibtischtäter, die mit bürokratischer Sachlichkeit ihre Arbeit verrichten, die Attribute der Unterdrückung und die Gesichter der Opfer sowie ihre (gerufenen und) sorgsam zu Listen geordneten Namen.« (Korte 1999: 171, H.i.0.).

461. Das Lied zum gleichnamigen Spielfilm von Rolf Schübel GLOomy SUNDAY - EIN LIED vON LIEBE UND TOD (D/HON 1999).

462. »The ambiguity of the character is expressed by the lighting. During the first hour, many shots present Schindler's face half in light, half in shadow [...].« (Insdorf 2003: 261)

$»[\ldots]$ the opening scene $[. .$.$] is shot in dramatic contrasting black-and-white, which cre-$ ates a chiaroscuro interplay of light and shadow associated with German Expressionism and film noir [...]. [...] influenced by the Hollywood studio film, particularly as realized in the work of Joseph von Sternberg, Orson Welles and Max Ophuls.« (Loshitzky 1997: 109)

463. Durch diese besondere Inszenierung hat dieser erste Teil der Sequenz die von Balázs für den Stummfilm beschriebene Wirkung auf den Zuschauer: »Beim Film urteilen wir ausschließlich nach dem Äußeren, und weil uns keine Worte Aufschluß geben, muß jeder Charakter seine Symbole an sich tragen, sonst werden wir die Bedeutung seines Handelns nicht verstehen.« (Balázs 2001: 38)

464. Vgl. die ähnlich wirkende Aufrüstung der beiden Protagonisten in der Exposition von Stephen Frears Verfilmung der DANGEROuS LIASONS (USA/UK 1988). "Schindler will gefallen, er präpariert sich, um zu verführen.« (Harms 2002: 62) 


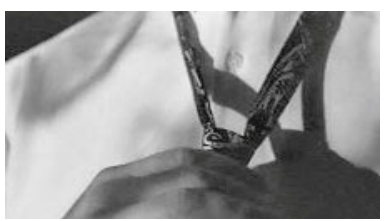

(418) $0: 03: 39 \mathrm{~h}$

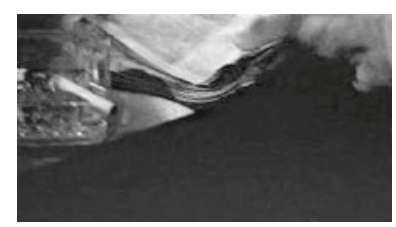

(419) $0: 03: 52 \mathrm{~h}$

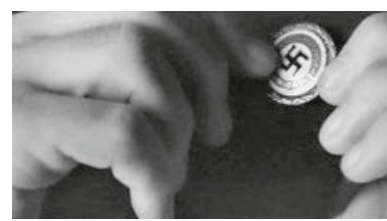

(420) $0: 04: 11 \mathrm{~h}$

von SS-Offizieren buhlt, und andererseits, weil der Protagonist durch die visuelle Inszenierung zwielichtig wirkt. ${ }^{62}$ Durch den Einsatz eines auffälligen ikonischen Zeichens veranlaßt Spielberg den Zuschauer, von den Äußerlichkeiten auf Inneres zu schließen.

\section{Detaillierte Sequenzanalyse:}

Zu Beginn der Sequenz sieht der Zuschauer in naher und bildkompositorisch begrenzter Aufnahme, wie eine Hand ein Schnapsglas füllt, während aus dem daneben stehenden Radio - im Unterschied zur vorangegangenen Registrierungsszene nunmehr aus dem On - das »Lied vom traurigen Sonntag« erklingt. Nach der vorangegangenen hektischen Betriebsamkeit »[...] scheint es eine kleine Besinnungspause zu geben. Die Dynamik geht deutlich zurück [...]« (Korte 1999: 171), auch durch die nun wieder ruhige Kameraführung sowie die bedächtig ausgeführten Handlungen der Figur: Ohne Hektik wird der Alkohol eingegossen. Die Person, von der wir lediglich die Hüfte sehen, geht gemächlich und nah an der Kamera vorbei. Obwohl ihm die Figur nur sehr ausschnitthaft präsentiert wird, kann der Zuschauer anhand unterschiedlicher Indizien erschließen, daß es sich um einen Mann handelt: Die Person trinkt Schnaps, trägt ein Hemd mit hochgekrempelten Ärmeln und hat einen gewichtig-männlichen Schritt. Die folgenden Einstellungen bestätigen di ese Annahme, geben jedoch gleichzeitig Anlaß zu neuen Vermutungen und führen in die Persönlichkeit des Unbekannten ein: Er legt Krawatten zurecht, wählt Manschettenknöpfe, bindet eine der Krawatten (s. o:03:39 h), streift ein Sakko über, steckt sich ein Einstecktuch in das Sakko, richtet zwei dicke Bündel Banknoten (s. 0:03:52 h) und heftet sich ein NSDAPAbzeichen ans Revers (s. ०:04:11 h). ${ }^{463}$

Während dieser knappen Minute ist man »unvermittelt in die Rolle des Voyeurs gedrängt, der ohne weitere Orientierungsmöglichkeit (ausschließlich Detailund Großaufnahmen) einer männlichen Person aus nächster Nähe beim Ankleiden zusieht, und registriert langsam, daß eine zweite Geschichte begonnen hat.« (Korte 1999: 171) Dadurch, daß die Figur uns als »geheimnisvoller Fremder (Korte 1999: 172) präsentiert wird, beobachten wir genauer und stellen - in dem Maße, wie uns explizite Informationen vorenthalten werden - Vermutungen über sie an: Beispielsweise, daß es sich um die titelgebende Figur handelt. Offensichtlich ist es ein Mann in gehobener sozialer Stellung, der Lust an Genußmitteln (Alkohol, Zigaretten) und Stil (Manschettenknöpfe, Einstecktuch) hat. Es wirkt so, als bereite er sich auf ein wichtiges Treffen oder einen bedeutsamen Auftritt vor, denn er wählt sorgsam ganz bestimmte Accessoires aus. ${ }^{464}$ Aufgrund der Tatsache, daß er wiederholt dicke Bündel Banknoten richtet, könnte man auf ein Geschäft schließen. 
Als er sich am Ende der Szene besonders sorgfältig und auffällig inszeniert465 ein Hakenkreuz-Abzeichen ansteckt (s. erneut o:04:11 h), erschrickt der Zuschauer und fragt sich, ob es sich bei der Person um einen Nazi handelt oder das Anstecken des Abzeichens Teil einer Inszenierung ist?

Als »intimer Begleiter « (Korte 1999: 171) folgt man in der nächsten Einstellung und Szene einem Mann in einen Nachtclub, was durch den Bildhintergrund und die On-Musik rasch erkennbar ist. Aufgrund des Kontextes sowie der vorangegangenen Einstellungen sind wir davon überzeugt, den geheimnisvollen Unbekannten zu seinem Treffen zu begleiten. Hierbei plaziert Spielberg den Zuschauer unmittelbar hinter den Mann, er betritt sozusagen mit ihm das Etablissement und nimmt zwangsläufig dessen Perspektive ein. Da man sich in seinem Rücken befindet, bleibt das Gesicht ein Rätsel. Auch seine Stimme, als er auf den Kellner trifft, können wir nicht hören, da die Musik dominiert. Hinzu kommt, daß sich die geheimnisvolle Person verbal wenig Mühe gibt, sondern Geldscheine sprechen läßt (s. O:04:23 h). Unsere vage Vermutung, es könne Bestechungsgeld sein, wird bestätigt. 466

Erst als der Mann an einem leeren Tisch Platz genommen hat, kann der Zuschauer sein Gesicht sehen - eineinhalb Minuten, nachdem er zum ersten Mal mit dieser Figur konfrontiert wurde. In einer Naheinstellung und als Profilaufnahme läßt uns Spielberg den Unbekannten taxieren (s. ०:04:47 h). »Ein gepflegter, überlegen lächelnder [...] Mann, der die Anwesenden sorgfältig mustert.« (Korte 1999: 171) Sehr viel Zeit wird uns jedoch für das genaue Lesen der Gesichtszüge nicht eingeräumt:

Die Kamera begleitet darauf den Kellner ins Foyer, wo er von Kollegen nach dem Neuankömmling gefragt wird, während sie ihn gemeinsam aus der Distanz beobachten (s. 0:04:55 h). Auf diese Weise inszeniert Spielberg die Figur für den Zuschauer als ebenso wichtig wie undurchsichtig und steigert dessen Wissensdurst: »Gemeinsam mit dem etwas irritierten Kellner [...] fragt man sich, wer dieser geheimnisvolle, betont selbstbewußte und offenbar wichtige Jemand ist [...].« (Korte 1999: 171)

Mit einem harten Schnitt wird die Perspektive des Nachtclub-Personals aufgegeben und von einem over-the-shoulder-shot abgelöst, vermutlich mit dem Unbekannten, der aufmerksam und genüßlich an einer Zigarette ziehend das bunte Treiben verfolgt.

465. Man beachte - neben der Einstellungsgröße (Detail) - das relativ lange Verharren der Kamera auf dem Abzeichen, die wiederholte Einrahmung des Ansteckers mit den Fingern, die Hervorhebung mit Hilfe des Lichteinfalls, der das Zeichen schillern läßt. Daß gleichzeitig mit dem Anstecken des Abzeichens die Musik - spitz - ausklingt, hebt dasselbe zusätzlich hervor (s. erneut 0:04:11 h).

466. Daß es sich hierbei lediglich - wie Korte schreibt - um ein Trinkgeld handeln sollte, ist aufgrund des geheimnisvollen Verhaltens unwahrscheinlich (Korte 1999: 171).

467. "Spielberg effectively presents details that suggest a mystery [...]. [...] When the camera is finally before his face, his hand hides it partly from our view. Cinematically speaking, the director establishes that his hero reveals little, especially about his motivations. " (Insdorf 2003: 261) 


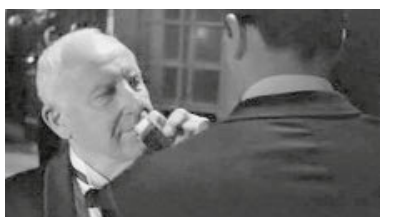

(421) $0: 04: 23 \mathrm{~h}$

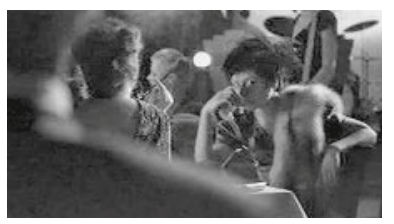

(424) $0: 05: 06 \mathrm{~h}$

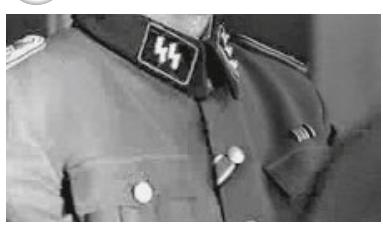

(427) $0: 05: 24 \mathrm{~h}$

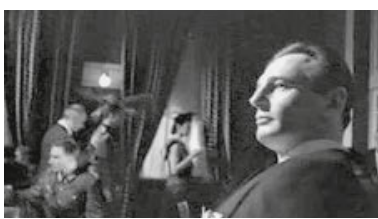

(422) $0: 04: 47 \mathrm{~h}$

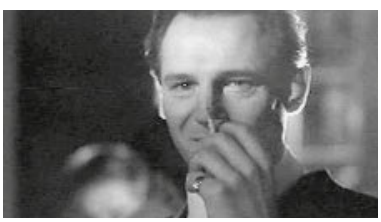

(425) $0: 05: 10 \mathrm{~h}$

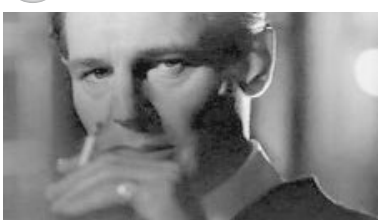

(428) $0: 05: 29 \mathrm{~h}$

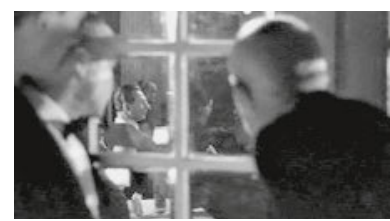

(423) $0: 04: 55 \mathrm{~h}$

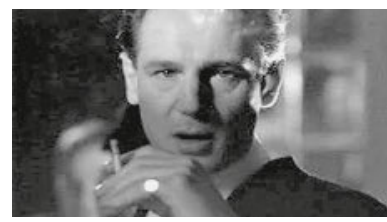

(426) $0: 05: 23 \mathrm{~h}$

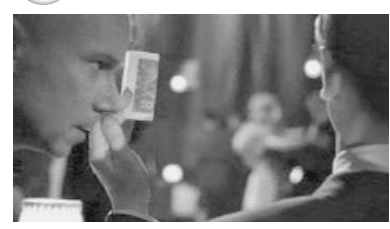

(429) $0: 05: 52 \mathrm{~h}$

Aus dieser angenäherten Figurenperspektive erlebt man, wie eine elegante junge Frau an einem gegenüberliegenden Tisch Blickkontakt aufnimmt bzw. erwidert (s. 0:05:06 h). Die sich anschließende, als Schuß- Gegenschuß inszenierte Situation bestätigt unsere Annahme: Äußerst durchdringend blickt der rätselhafte Mann in ihre Richtung - die Zigarette lässig in der Hand haltend -, bevor ein kurzes, undurchsichtiges Lächeln über sein Gesicht huscht (s. 0:05:10 h). Dieses wirkt ebenso geheimnisvoll auf den Zuschauer wie die gesamte Inszenierung dieser Figur. ${ }^{467}$ Sollte er sich fein gemacht haben, um eine Frau kennenzulernen, fragen wir uns. Jedenfalls scheint er auf das weibliche Geschlecht durchaus zu wirken und auch an ihm interessiert zu sein.

Anstatt den Flirt jedoch fortzusetzen, wird der Blick des Mannes offensichtlich von etwas anderem angezogen: Seine Aufmerksamkeit gilt nun einem Nachbartisch, an dem Männer in Uniform sitzen. Durch Blitzlicht einer Fotografin, welches auf diese Männer gerichtet ist, wird mit dem Blick des Unbekannten auch der des Zuschauers auf diese Gruppe gelenkt (s. 0:05:23 h). Mit durchdringendem Blick und vor Aufregung geöffnetem Mund fixiert der Mann die reflektierende SS-Applikation am Kragen der Uniformen (s. o:05:24 h). Man spürt, daß es dem Beobachtenden nicht auf die Personen, sondern vielmehr auf deren Status ankommt. Der Zuschauer vermag die Abzeichen zu interpretieren: Die SS steht für die systematische Judenvernichtung unter Hitler.

Daß der Blick der Hauptfigur lange auf den Uniformierten verweilt, läßt uns neue Vermutungen anstellen (0:05:29 h): Offensichtlich geht es ihm nicht primär um ein Vergnügen im Nachtclub. Ihn interessieren die SS-Männer augenscheinlich weitaus mehr. Will er vielleicht mit ihnen in Kontakt treten oder gar Geschäfte machen? Bestätigt wird diese Vermutung wenig später, als er erneut das Personal des Etablissements 
besticht (s. 0:05:52 h), dieses Mal, um die neu eingetroffenen hohen Offiziere mit spendierten Getränken zu erfreuen. Nun ist sicher: Er sucht den Kontakt ... und wird ihn auch bekommen, nicht jedoch ohne sein eigenes Zutun. Nach und nach lädt er galant alle anwesenden Offiziere inklusive deren Begleitungen zum Essen und Trinken ein (s. 0:09:44 h) ${ }^{468}$ und läßt sich mit ihnen ablichten (s. o:09:40 h). Erst nach neuneinhalb Minuten erfährt der Zuschauer explizit, daß es sich bei dem immer noch unbekannten Mann um die titelgebende Figur, Oskar Schindler, handelt. ${ }^{469}$

Unklar bleibt jedoch weiterhin, aus welchem Grund er diese erheblichen Kosten auf sich nimmt, was er sich von dem Kontakt zu führenden SS-Leuten verspricht und worauf der ranghöchste Offizier und Schindler in der letzten Einstellung der Exposition anstoßen (s. ০:09:45 h); zumindest wirkt es so, als besiegelten sie nicht nur einen gelungenen, amüsanten Abend.

468. Während sich der Gastgeber beim Kellner nach dem exquisitesten Wein erkundigt, verfolgen wir parallel die Unterhaltung unter verschiedenen Offizieren (s.u. A, B, C) über die Judendiskriminierung und beabsichtigte -vernichtung, die während der letzten fünf Minuten in den Hintergrund gedrängt worden war:

A: »[...] was ich mit kooperativ meine. Kaum, daß es Gesetz wurde, daß Juden einen Stern tragen müssen, haben jüdische Schneider ihnen Massen von Stoff auf den Markt gebracht, für drei Sloti das Stück. Als wüßten sie gar nicht, worauf das Gesetz abzielt, als wäre es das Abzeichen eines Reitvereins.«

B: »Das ist typisch. Sie passen sich an, um Schlimmeres zu verhindern.«

C: »Das machen die schon seit tausenden von Jahren. Es kann stürmen, es kann schneien, immer wieder schaffen sie es, zu überleben.«

A: »Aber dieser Sturm ist was anderes, es sind nicht die Römer. Dieser Sturm ist die SS!« (0:08:11-0:08:50 h)

469. Es ist hier Oehlenschläger zuzustimmen, der von der »Inszenierung des Titelhelden [spricht], die im Nachtlokal in seiner Namenverleihung kulminiert: >Das ist Oskar Schindler〈, wohingegen alle anderen Figuren dieser Szene namenlos bleiben.« (Oehlenschläger 2002: 100)

470. Siehe hierzu auch die Sequenz in den vermeintlichen Gaskammern in 3.2.6.

471. So ist die Sequenz um den Schlosser vergleichbar mit denen weiterer Einzelschicksale (Göhs Hausmädchen Helene Hirsch, die Eltern von Regina Perlmann), die jedoch nicht immer ein glückliches Ende nehmen - wie bei Göths Burschen Lisiek, der letztlich erschossen wird.

472. Vgl. Kortes treffende Interpretation der Sequenz um die Erschießung des einarmigen Schlossers während des erzwungenen Schneeschippens, die Schindler einem hohen SS-Offizier gegenüber mit »Ich habe einen Arbeiter verloren« quittiert: »Für den Betrachter bleibt der Zweifel: Ist es eine Ausrede von Schindler, um nicht in den Verdacht zu geraten, mit den Juden gemeinsame Sache zu machen, oder ist es ein ernstgemeinter Versuch, aus dem Tod des Einarmigen eine Entschädigung für sich herauszuschlagen?« (Korte 1999: 176)

473. Auch in der übernächsten Sequenz hilft Schindler der Tochter Regina Perlmann erst, nachdem diese sich für ihn hübsch gemacht hat.

474. »Göth ist ein böses, gelangweiltes Kind, das Lager Plaszow sein täglicher Spielplatz, das Töten seine Droge. Er spürt sich fast nur noch, wenn er schießt.« (Kilb 1995: 155f.)

475. „Denn dieser Itzhak Stern ist in der Tat der eigentliche Motor für die Rettung der sSchindler-Juden<.» (Korte 1999: 166, H.i.0.) 


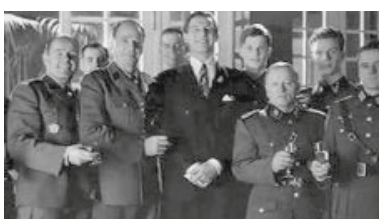

(430) $0: 09: 40 \mathrm{~h}$

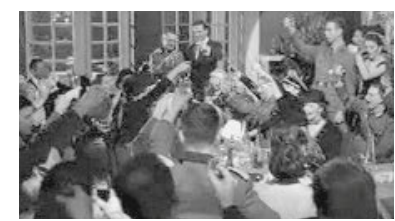

(431) $0: 09: 44 \mathrm{~h}$

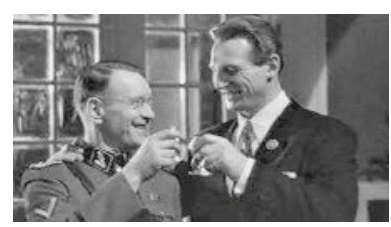

$0: 09: 45 \mathrm{~h}$

\subsubsection{Bangen mit und um den jüdischen Häftling und dessen mißglückte Hinrichtung} An der insgesamt fünfteiligen Sequenz um die mißglückte Hinrichtung eines jüdischen Schlossers durch Amon Göth kann eindringlich belegt werden, wie Spielberg das Potential von Spielfilmen im Gegensatz zu Dokumentationen systematisch nutzt: Über Schlimmes befürchtende Antizipation, Bestätigung derselben und sich stetig steigernde Dramatik wird der Zuschauer maximal in die für das Opfer lebensbedrohliche Situation einbezogen und entwickelt einen Sinn dafür, den Einzelnen im Gesamtzusammenhang zu sehen. Der Regisseur läßt uns mit und um den jüdischen Häftling wieder und wieder bangen und löst die extreme Anspannung durch entspannende Erleichterung wieder auf470: Im Unterschied zur späteren Sequenz in der vermeintlichen Gaskammer (s. 3.2.6) handelt sie von einem Einzelschicksal, nicht einer größeren Gruppe von Menschen, was den emotionalen Einbezug des Zuschauers erleichtert. ${ }^{471}$

An der vorliegenden Sequenz kann die den Film über weite Strecken kennzeichnende Faszination des Zuschauers in bezug auf Schindler deutlich aufgezeigt werden (s. 3.2.2 und 3.2.3.c). Wie zuvor bei Schindlers Reaktion auf die Erschießung »seines« einarmigen jüdischen Arbeiters ${ }^{472}$ sind wir uns auch hier nicht sicher, ob Schindler den Schlosser aus dem Lager freikauft, um einen guten Arbeiter für sich zu gewinnen oder um die Person vor dem weiterhin drohenden Tod zu bewahren. ${ }^{473}$ Jedenfalls ist der Schlosser der erste Häftling, den Schindler durch Bestechung in seine Fabrik und somit aus dem Lager holt. Er bildet den Auftakt zu weiteren Einzelrettungen (ein kleiner Junge in der nächsten, die Eltern von Regina Perlmann in der übernächsten Sequenz), deren Höhepunkt die titelgebende Liste darstellt.

Darüber hinaus läßt die Szenenfolge Göths nahezu perverse Lust an der Ausübung extremer Macht in Form von Hinrichtung bzw. Tötung eindringlich erfahren. ${ }^{474}$

Was das Verhältnis zwischen Schindler und Stern betrifft, macht die Sequenz die Wichtigkeit des letzteren für die Rettung einzelner Juden deutlich - schließlich übernimmt Schindler den Schlosser erst nach Sterns nachdrücklicher Intervention. 475

Aus den genannten Gründen ist es kein Zufall, daß Spielberg die Sequenz in der Mitte des Films, in dessen Zentrum plaziert hat.

Im übrigen kann anhand dieser Sequenz ein deutlicher Unterschied zwischen Schindlers Liste und Polanskis Der Pianist aufgezeigt werden. Wie bei Spielberg soll auch hier ein Jude von einem Nazi erschossen werden, doch die Pistole versagt bzw. das Magazin ist leer. Polanski läßt den Zuschauer vergeblich mit und um das Opfer bangen: Nachdem der Deutsche nachgeladen hat, kann er im Gegensatz zu Göth den tödlichen Schuß abgeben. Polanski läßt dem Zuschauer ausschließlich Hoffnung in bezug auf die titelgebende Figur. 


\section{Detaillierte Sequenzanalyse:}

Die erste Einstellung der Sequenz zeigt dem Zuschauer eine Räumlichkeit, die er noch nicht kennt. Noch bevor wir erschließen müssen, wo wir uns befinden, informiert eine Texteinblendung über den Ort des Geschehens: »Schlosserei im Zwangsarbeitslager Plaszow« (s. 1:22:45 h). Lagerkommandant Göth scheint zur Inspektion angetreten zu sein. Dies allein reicht aus, um den Zuschauer in Anspannung zu versetzen - schließlich steht er noch unter dem Schock der vorangegangenen halben Stunde, in der er Göth als eiskalten und willkürlichen Mörder kennengelernt hat. ${ }^{476}$

Bestätigt wird man in dieser Befürchtung des Schlimmsten, als sich der Lagerkommandant bei einem älteren Arbeiter nach dessen Arbeit erkundigt und hinzufügt: »Ich bekomme morgen wieder einen Schwung Arbeiter herein. [...] Ich muß Platz schaffen. Mach mir ein Scharnier!« (1:23:05 - 1:23:12 h; s. 1:23:12 h)477 So wie wir Göth kennengelernt haben, können wir uns die Bedeutung der Formulierung »Platz schaffen« vorstellen und bangen mit dem Häftling, er möge das gewünschte Scharnier rasch und gut anfertigen. Voller Hoffnung vernimmt der Zuschauer, wie der Deutsche den Juden bereits während der Arbeit lobt: »Nicht schlecht, was du da machst.« (1:23:50 h) Als er das Ergebnis mit »Gut, das ging ja schnell« (1:24:०० h; s. 1:24:02 h) quittiert, lehnt man sich erleichtert zurück und freut sich, daß der Lagerinsasse noch einmal davongekommen ist. Als Göth sich jedoch nicht von ihm abwendet, sondern in bedrohlichem Tonfall weiter spricht - »Aber eigenartig ist das schon, aber vielleicht kannst du's mir erklären. Also ich versteh' beim besten Willen nicht, daß du zwar seit in der Früh, seit etwa sechs, hier arbeitest, aber nur so wenig Scharniere gemacht hast « (1:24:02 - 1:24:19 h) -, ist unsere Angst mit und um den Schlosser mit einem Schlag zurück, wesentlich stärker noch als vorher (s. 1:24:22 h): Die Situation scheint völlig ausweglos; für etwaige Erklärungen ist Göth absolut nicht empfänglich, wie wir aus der Sequenz mit der jüdischen Ingenieurin wissen (Sequenz 12).

Die Bestätigung unserer Befürchtung läßt nicht lange auf sich warten; im Freien macht sich Göth bereit, den Schlosser, dem er Sabotage unterstellt, von hinten zu erschießen (s. 1:24:37 h). Nun ist es um ihn geschehen, ist sich der Zuschauer sicher. Wie durch ein Wunder versagt die Pistole des Lagerkommandanten, so daß man sich für den Bruchteil einer Sekunde über die Tücken der Technik freuen kann, die dem Juden zu-

476. Man denke in diesem Zusammenhang insbesondere an das Schicksal der jüdischen Ingenieurin (Sequenz 12), die unter seinem Kommando erfolgte Räumung des Ghettos (Sequenz 13) und vor allem an sein willkürliches Erschießen verschiedener Häftlinge vom Balkon aus (Sequenz 14).

477. Auch ohne diese recht eindeutigen Erläuterungen Göths hätte der Zuschauer ahnen können, daß Unheil droht.

478. »Herr Kommandant, ich bitte, melden zu dürfen, daß die Zahl meiner Scharniere so unbefriedigend ist, weil heute Morgen erst mal die Drehbänke justiert werden mußten. Deshalb mußte ich den ganzen Vormittag Kohlen schaufeln.« (1:25:04-1:25:19 h)

479. Man vergleiche in diesem Zusammenhang den Wechsel der Einstellungsgröße zwischen $1: 25: 12 \mathrm{~h}$ und $1: 25: 23 \mathrm{~h}$. 


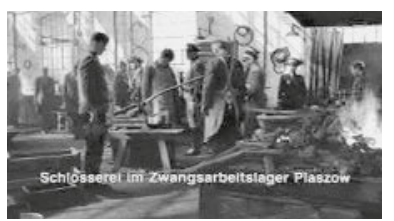

(433) $1: 22: 45 \mathrm{~h}$

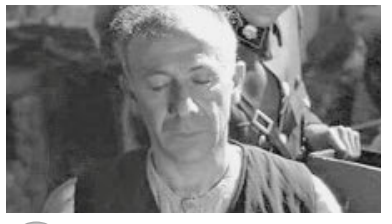

(436) $1: 24: 22 \mathrm{~h}$

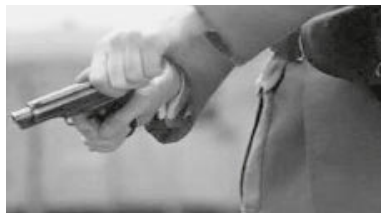

(439) $1: 25: 10 \mathrm{~h}$

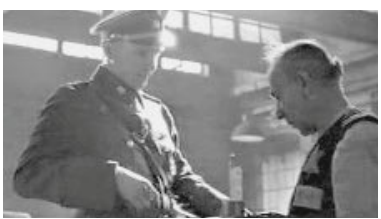

(434) $1: 23: 12 \mathrm{~h}$

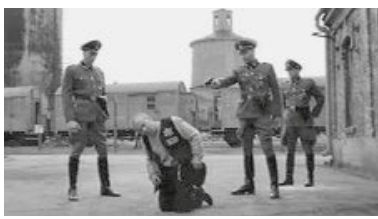

(437) $1: 24: 37 \mathrm{~h}$

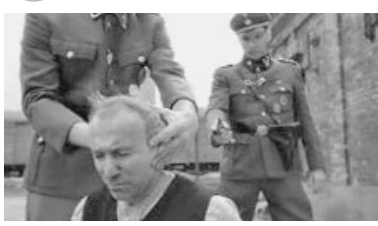

(440) $1: 25: 12 \mathrm{~h}$

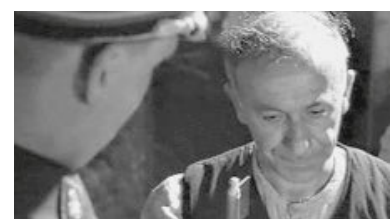

(435) $1: 24: 00 \mathrm{~h}$

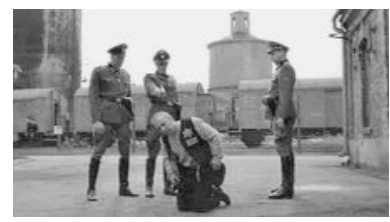

(438) $1: 24: 53 \mathrm{~h}$

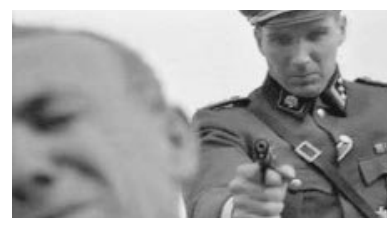

(441) $1: 25: 23 \mathrm{~h}$

mindest in diesem Moment das Leben rettet. Gleichzeitig sind wir uns Göths Hartnäkkigkeit sicher, zu Recht: Während endlos wirkender zehn Sekunden lädt der Deutsche seine Pistole geräuschvoll nach, doch auch der zweite Hinrichtungsversuch mißlingt. Mit einem ärgerlichen »Ach, Scheißdreck« (1:24:48 h) macht der Lagerkommandant seinem Unmut Luft. Als ginge es um eine Art Geschicklichkeitstest, fragt einer der beiden SS-Männer in auffälligem Dialekt: »Darf ich des mal versuche?« (1:24:49 h) Während die beiden Göth begleitenden Offiziere fachsimpeln - A: »Kuck dir den Kniehebel an, vielleicht isser verbogen. B: Nee, nee, nee, man würd' ke Klicke hörn, wenn des de Kniehebel wär’, des is de Schlachbolze.« (1:24:50 - 1:24:55 h) - schlägt auch der dritte Erschießungsversuch fehl (s. 1:24:53 h). Hierbei ist der Zuschauer vor allem von der kaltblütigen Beiläufigkeit des Abdrückens schockiert. Ganz offensichtlich steht für die Männer das technische Problem, nicht ein Menschenleben, im Vordergrund. Den Juden beachten sie nur in dem Maße, wie er als »Zielscheibe« dient. Wie zu befürchten war, will sich der Lagerkommandant mit diesem wiederholten Scheitern nicht abfinden und greift erneut ein.

Als die Pistole zum vierten Male nicht funktioniert, lenkt ein abrupter Wechsel der Einstellungsgröße die Aufmerksamkeit des Zuschauers auf die Hosentasche Göths. Nach einer gewissen spannungssteigernden Verzögerung - der Deutsche hat Mühe, den Gegenstand herauszuholen - kommt eine weitere Pistole zum Vorschein. Das Schicksal des Schlossers scheint nun endgültig besiegelt. Beinahe zelebrierend, lädt der Deutsche geräuschvoll durch (s. 1:25:10 h); der entschuldigenden Erklärung des Juden schenkt er keinerlei Beachtung (s. 1:25:12 h). ${ }^{478} \mathrm{Zu}$ unserer völligen Überraschung versagt auch diese, was Göth - entsprechend unserer Einschätzung - zunehmend in Wut versetzt: Hektisch, mit verzerrtem Gesicht, drückt er wieder und wieder vergeblich ab (s. 1:25:23 h). Filmisch unterstützt wird die Dramatik der sich zuspitzenden Situation durch eine Annäherung an die beiden zentralen Figuren ${ }^{479}$ sowie eine besondere 
Bildkomposition. Letztere konzentriert sich auf Aggressor und Opfer dadurch, daß zum ersten Mal die Umgebung ausgeblendet wird. Eine besondere Wirkung erzielt diese Einstellung aufgrund der Dynamik zwischen Bildvordergrund und -hintergrund: Links vorne ist zwar nur eine Teilaufnahme des groß eingefangenen, verzweifelten Gesichts zu sehen, doch spüren wir, wie sich die Todesangst des Juden (beim Nähern Göths) in Erwartung des tödlichen Schusses immer stärker auf seinem Gesicht abzeichnet (s. 1:25:27 h). Ein ums andere Mal will dieser jedoch nicht gelingen ${ }^{40}$, so daß Göth schließlich nach einem zornigen »Verdammt noch einmal« (1:25:27 h; 1:25:29 h) zähneknirschend zu einem anderen, »verläßlicheren « Mittel greift: Seine Hand saust durchs Bild (s. 1:25:31 h), das Ergebnis sieht man wiederum nach einem abrupten Wechsel der Einstellungsgröße.

Eine Totale zeigt, wie das Opfer zu Boden sinkt, offensichtlich von Göths Hieb am Kopf getroffen (s. 1:25:31 h). Ohne Regung entfernen sich Göth und seine Männer von dem leise stöhnenden, am Boden liegenden Juden. Trotz der brutalen Gewalt ist der Zuschauer auch ein wenig erleichtert, daß dieses »Wechselbad der Gefühle« ein zwar schmerzhaftes, aber vergleichsweise gutes Ende gefunden hat.

In der folgenden kurzen Szene, nachdem Schindler von Stern an den Stacheldraht gerufen wurde, hört der Zuschauer in der Folge nur noch den letzten Halbsatz des Buchhalters: »[...] deshalb schien es, er wäre zu langsam« (1:26:13 h). Offensichtlich berichtet er vom unmittelbar zurückliegenden Geschehen. Ungeduldig wird Stern von Schindler unterbrochen (s. 1:26:16 h): »Dieser Mann kann also in weniger als einer Minute ein Scharnier machen - warum die lange Rede?« (1:26:14 - 1:26:17 h) Auf diese Weise reduziert der Geschäftsmann den Vorfall auf die beeindruckende Arbeitsgeschwindigkeit des Schlossers, während - so entnehmen wir seiner Äußerung - Stern durchaus nicht nur davon gesprochen hat. Als Schindler nach einem wortlosen Blickkontakt dem Buchh alter sein Feuerzeug reicht (s. 1:26:27 h), kann man ahnen, wozu es dienen wird - schließlich hat Schindler seit Filmbeginn mit Bestechung Geschäfte gemacht. Aufgrund der wahrscheinlichen Antizipation des Zuschauers begnügt sich Spielberg in der Folge mit drei äußerst kurzen, absichernden Szenen.

Aus Sterns Händen (s. 1:26:33 h) geht das kostbare Feuerzeug in die Hände von Goldberg, einem jüdischen Opportunisten (s. 1:26:36 h), der inzwischen als Aufsichtsperson für Göth arbeitet. Nachdem er einen Namen in eine Liste eingetragen hat, versetzt uns ein weiterer Schnitt in die Fabrik Schindlers, in welcher der Schlosser freudestrahlend seinem neuen Arbeitgeber dankt: »Vielen Dank, Herr Direktor!« (1:26:47 h, s. 1:26:49) »Gern geschehen« (1:26:48 h) erwidert Schindler ebenso kurz wie überlegen. Ganz offensichtlich hat Schindler mit seinem Feuerzeug den jüdischen Schlosser aus dem Lager frei- und für seine Firma eingekauft. Unsicher ist man sich

480. »Aber die Pistole funktioniert nicht, obwohl er und sein SS-Gefolge es wieder und wieder versuchen und der Jude gekrümmt vor ihnen kniet - Sekunden, die zu Äonen werden.« (Giordano 1995: 172).

481. Vgl. Korte 1999: 177ff., der an dieser Sequenz insbesondere den »Newsreel-Effekt» verdeutlicht.

482. Diese war in der Registrierungsszene bestimmt durch »ständige Wechsel von alternierenden Einstellungslängen, ausgedehnten Plansequenzen, ruhigen Kamerabewegungen und rasanten Reißschwenks.« (Ebd. 177) 


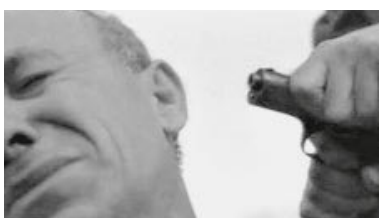

(442) $1: 25: 27 \mathrm{~h}$

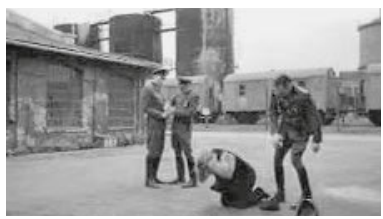

(445) $1: 25: 31 \mathrm{~h}$

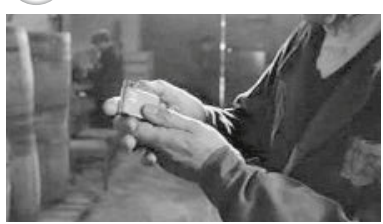

(448) $1: 26: 33 \mathrm{~h}$
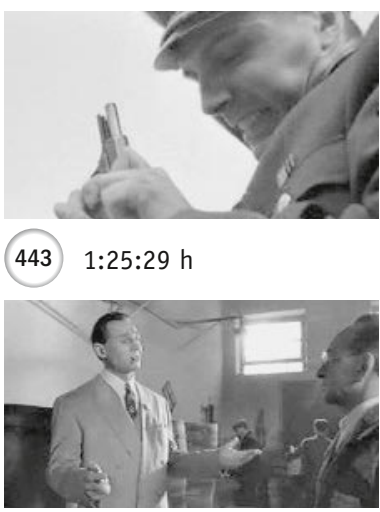

(446) $1: 25: 31 \mathrm{~h}$

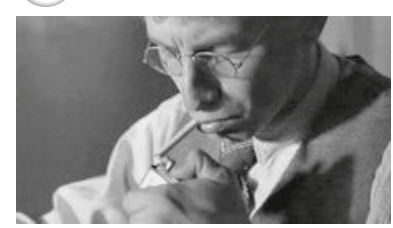

(449) $1: 26: 36 \mathrm{~h}$

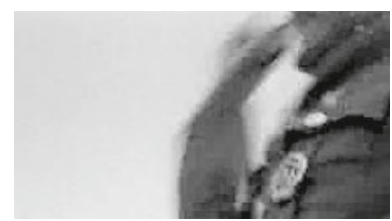

(444) $1: 25: 31 \mathrm{~h}$

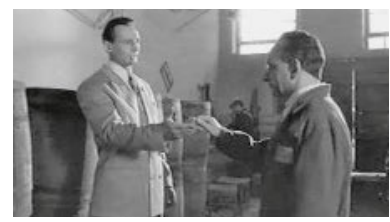

(447) $1: 26: 27 \mathrm{~h}$

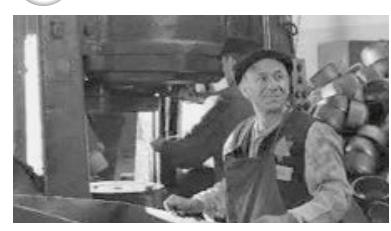

(450) $1: 26: 49 \mathrm{~h}$

jedoch, ob er dabei das Leben dieses Mannes bewußt retten wollte oder in ihm lediglich die ausgezeichnete Arbeitskraft sieht. Andererseits ist uns nicht bekannt, daß er für die Scharnierherstellung einen neuen bzw. besseren Arbeiter brauchte, sonst hätte er es Stern u.U. wissen lassen. Schindlers geschäftsmäßig-souveränes Verhalten könnte damit zusammenhängen, daß es ihm tatsächlich nur ums Geschäft geht oder aber daß er das Schicksal der Juden bewußt auf Distanz zu halten versucht. Vergleichbar mit der Sequenz um den einarmigen Schlosser (im ersten Drittel des Films), dem ersten ermordeten Juden, schwanken wir in der Beurteilung der Motivation Schindlers - sein Charakter bleibt hier noch ambivalent. Als Schindler kurz darauf und wiederum auf Anregung Sterns einen kleinen Jungen auf gleiche Weise aus dem Lager frei- und für seine Fabrik einkauft, erscheint es unwahrscheinlich, daß Schindler nur an das Geschäft denkt.

\subsubsection{Erzeugte Authentizität - die Selektion im Konzentrationslager}

Der bereits in der Eröffnungssequenz - im Rahmen der Registrierung - zum Tragen kommende Live-dabei-Effekt (s. 3.2.3.b) bestimmt noch deutlicher die Inszenierung der Selektion im Lager Plaszow. An dieser Sequenz, die stellvertretend für die Inszenierung der Ghettoräumung (Sequenz 13) analysiert wird, läßt sich besonders eindringlich belegen, wie der Zuschauer in die von Todesangst geprägte Hektik während der Selektion hineinversetzt wird und diese beinahe am eigenen Leib erfährt (Korte 1999: 177ff.). ${ }^{41}$ Dieses »Gefühl des unmittelbaren Dabeiseins« (ebd. 171) erreicht Spielberg durch eine virtuose Inszenierung, eine - verglichen mit der Eröffnungssequenz $\mathrm{z}^{48}$ - Radikalisierung des filmischen Diskurses: Es werden einige weitere »erprobte Faktoren eingesetzt: so die bewußte Konfrontation gegenläufiger Bewegungsrichtungen, das abrupte >Springen< zwischen extremen Einstellungsgrößen zu Beginn und die fließenden Übergänge durch gezielte Ausnutzung der Bildtiefe [...].« (Ebd. 180, H.i.O.) 
Wie bei der vorangegangenen mißglückten Hinrichtung des Schlossers (s. 3.2.4) und dem späteren Überleben der »Schindlerjüdinnen« in der vermeintlichen Gaskammer (s. 3.2.6), baut Spielberg auch die Selektionssequenz nach den Gesetzen der Spannungsdramaturgie auf.

So ist die Inszenierung der Selektion eingerahmt und unterbrochen von Szenen, die das Schicksal der »Schindlerjüdinnen« dem der anonymen Masse gegenüberstellen. Auf diese Weise bietet Spielberg dem Zuschauer wiederum die Möglichkeit, mit und um die ihm nach rund zwei Stunden Film vertrauten Figuren zu bangen.

Neben diesem Hin und Her zwischen vertrauten Figuren und anonymer Masse, zeichnet sich die Sequenz durch weitere rhythmische Spannungsverhältnisse aus, die zum Teil mit dem soeben beschriebenen einhergehen:

So läßt der Regisseur unterschiedliche Erzählperspektiven alternieren, insbesondere die figurenunabhängige mit der figurenabhängigen. Während erstere dem Zuschauer einen Überblick über die Situation verschafft bzw. ihn in eine Beobachterrolle versetzt, bietet letztere unterschiedliche Identifikationsmöglichkeiten - Distanz und »Live-dabei«-Eindruck wechseln sich ab und steigern sich wechselseitig in ihrer Wirkung.

Zudem nutzt Spielberg in dieser Szenenfolge, wie in 3.2.4 und 3.2.6, die Wirkmächtigkeit einer akuten Bedrohungssituation (s. Kortes Graphik in 3.2.2): »Obwohl es hier keine Erschießungen und offen brutalen Übergriffe wie zuvor gibt, sich die SS-Leute [...] im bürokratischen Sinne >korrekt< verhalten, ist es dennoch eine der erschütterndsten Situationen des gesamten Films.«(Korte 1999: 186, H.i.O.) ${ }^{483}$ Vielleicht hätte Korte den Satz mit »gerade weil« beginnen sollen, denn - wie er selbst betont (ebd. 181ff.) - genügen in der zweiten Filmhälfte die latenten und akuten Bedrohungssituationen, um das im ersten Filmdrittel inszenierte, willkürliche Morden in das Bewußtsein des Zuschauers zurückzurufen.

Vor der Sequenz in der vermeintlichen Gaskammer (s. 3.2.6) thematisiert Spielberg in der vorliegenden eine weitere Stufe der nationalsozialistischen Vernichtungsmaschinerie. ${ }^{484}$ Der bürokratische Charakter des Genozids wird anhand der Selektion besonders deutlich und für den Zuschauer erfahrbar, durch die Inszenierung der Dingsymbole wie Klappstühle und -tische, Schreibutensilien etc., die zuvor wiederholt $\mathrm{zu}$ solchen aufgeladen wurden (s. 3.2.3.b)..$^{48}$

483. Vgl. Malles vergleichbare Äußerungen in II.3.1.6.

484. »Ablauf und Moment der Selektion wurden zur Inkarnation des gesamten Vernichtungsprozesses. Dieser Moment war nachvollziehbar, er machte den komplexen Apparat zugleich in einer konkreten Handlung sichtbar, reduzierte ihn gleichsam auf eine Handbewegung. Dieser visuelle Angelpunkt des Tatnarrativs hatte ebenso Sensationspotenzial durch seine Dramatik [...] wie er synonym für die Modernisierung des Mordens stehen konnte. [...] Von den verschiedenen Phasen der Tat war [...] die Selektion der Moment höchster Dramatik:« (Knoch 2003: 110)

485. Dies erfolgte in der Eröffnungssequenz (s. 3.2.3.b), der Vergabe von Blauscheinen (Sequenz 7) und kurz vor der Räumung des Krakauer Ghettos (Sequenz 12).

486. „Während dem faul hingestreckten Göth von seinem Arzt geraten wird, den Wohlstandsbauch zu minimieren, laufen bei einer Selektionsaktion die abgemagerten Jüdinnen um ihr Leben. [...] Der Film lebt von diesen Kontrasten, er privilegiert die spiegelbildliche Struktur.« (Harms 2002: 59f.) 


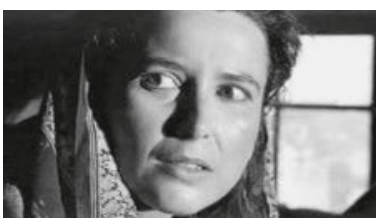

(451) $1: 54: 20 \mathrm{~h}$

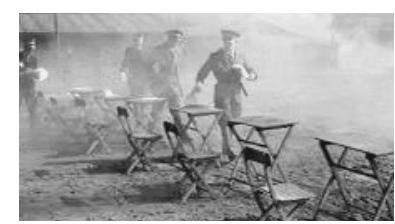

(452) $1: 54: 30 \mathrm{~h}$

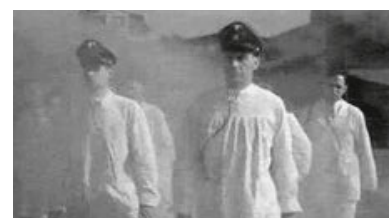

453

$1: 54: 31 \mathrm{~h}$

Im Unterschied zur Sequenz in der vermeintlichen Gaskammer, die innerhalb des Films vorbereitet wurde (s. 3.2.6), sieht sich der Zuschauer zu Beginn dieser Sequenz lediglich mit einem Signalwort konfrontiert (»Selektion«). Spielberg setzt in diesem Moment auf das Vorwissen des Publikums. Denjenigen, denen diese Bezeichnung nicht bekannt ist, bietet sich, mittels der angesprochenen Dingsymbole, die Möglichkeit zur Antizipation.

\section{Detaillierte Sequenzanalyse:}

Nachdem in der vorangegangenen Szene eine junge Frau ihren Leidensgenossinnen in der Frauenbaracke vor dem Einschlafen von dem Vergasungsgerücht erzählt hat, beginnt die Selektionssequenz mit dem morgendlichen Aneinanderkoppeln von Güterwagen, um kurz darauf wieder in die Frauenbaracke zurückzublenden: Eine dröhnende, nur teilweise verständliche und von Trillerpfeifen begleitete Lautsprecherdurchsage - »Achtung, Achtung [...] sofort zum Appellplatz« (1:54:01 - 1:54:07 h) reißt die Frauen aus ihrem Schlaf und versetzt sie in Aufruhr. »Kommt, wir müssen auf dem Appellplatz antreten, die Listenschreiber sind da« (1:54:10 - 1:54:13 h), erfaßt eine unter ihnen rasch die Situation. Noch bevor der Zuschauer Zeit hat, selbst zu erschließen, fährt die ihm aus vorangegangenen Szenen bekannte Frau fort: »Es wird eine Selektion geben.« (1:54:15 h). Dieses Signalwort hat auf uns höchst alarmierende Wirkung - schließlich geht es dabei um Leben und Tod, je nachdem, ob man von den SS-Ärzten für arbeitstauglich gehalten wird oder nicht. Die Aufregung in der Baracke wird filmtechnisch durch die Großaufnahme einer in Todesangst versetzten jungen Frau (s. 1:54:20 h), vor allem aber durch den Einsatz der leicht wackelnden Handkamera für den Zuschauer fühl- und erfahrbar.

Die folgenden Einstellungen zeigen die Vorbereitungen der Selektion auf dem Appellplatz: Die Dingsymbole lassen das Bevorstehende erahnen (s. 1:54:30 h).

Des weiteren taucht eine Gruppe von Männern in weißen Kitteln und einem, u.U. als solchem identifizierbaren, Stethoskop um den Hals aus Nebelschwaden auf - die aufgrund der Inszenierung auf uns wie ein »Todeskommando« wirkt (s. 1:54:31 h). »Diese ohnehin in recht kurzen Einstellungen gezeigten Aktivitäten werden durch ständig gegenläufige Bewegungsrichtungen im Bild, abrupte Wechsel der Einstellungsgrößen und entsprechende Kamerabewegungen in ihrer Hektik noch gesteigert.« (Korte 1999: 177)

Überraschenderweise tritt jedoch zunächst eine gewisse Beruhigung der Lage als retardierendes und kontrastives ${ }^{486}$ Moment ein. In einer längeren sowie mit statischer Kamera gefilmten Einstellung erklärt Lagerkommandant Göth seiner Freundin beiläufig die Notwendigkeit der Selektion und liefert so eine indirekte Begriffserklärung: Er bekäme einen ganzen Haufen ungarischer Juden und daher müsse man Platz im Lager schaffen, die Kranken von den Gesunden aussondern (s. 1:55:18 h). 
Nachdem die letzten Vorbereitungen getroffen sind - über Lautsprecher ertönt ironischerweise ein »gefühlvolles Abendlied« (»Guten Abend Mutter, gute Nacht ...«; 1:54:30 - 1:54:37 h) - beginnt die Selektion. Zunächst gewährleistet uns eine Art Vogelperspektive nur einen Überblick und hält uns auf Distanz (s. 1:54:31 h): Durch Brüllen und im Laufschritt werden die nackten Juden an den, am linken Bildrand hinter ihren Klapptischen sitzenden, Ärzten vorbeigetrieben. Das aus dem Lautsprecher dröhnende und die Szenerie akustisch beherrschende Lied steht in krassem Gegensatz zu den Vorgängen auf dem Appellplatz und mutet den Zuschauer unwirklich an.

Die folgende Einstellung bringt uns näher an das Geschehen, an das Brüllen der Wachmannschaften und die Reihe der entkleideten Lagerinsassen (s. 1:54:40 h). Wo man vorher aus extremer Aufsicht den Ablauf überblickte, beobachtet man nun aus einer Untersicht - als abrupter Wechsel besonders auffällig durch den Kontrast der Kameraposition. Dominiert wird diese kurze Einstellung durch das laute Brüllen des Soldaten im rechten Bildvordergrund, das durch den im Hintergrund die Menschenmenge anschreienden Uniformierten verdoppelt wird.

Aus der Perspektive der Ärzte (over-the-shoulder) verfolgt der Zuschauer nach einem weiteren harten Schnitt wenige Sekunden lang, wie nackte Jüdinnen an den Ärzten vorbeigejagt werden und manche aussortiert werden (s. 1:54:43 h); er ist nun wesentlich stärker in das Geschehen integriert als zu Beginn der Selektion.

Dramaturgisch konsequent versetzt uns Spielberg durch Parallelmontage in der folgenden Szene erneut in die Frauenbaracke - schließlich fragt man sich, was mit ihnen in der Zwischenzeit passiert ist. Eine wackelnde Kamera, die uns in Aufregung versetzt, fährt an den vor Todesangst zitternden Frauen entlang, bis sie auf Details verweilt: Eilig klatschen sich hier manche auf die Wangen, andere stechen sich mit einer Nadel in den Finger (s. 1:54:55 h). Die Ahnung, daß dieses Blut einen makabre Form von »Rouge « darstellt (s. 1: 55:10 h), wird mit dem Satz einer jungen Frau zur Gewißheit: »Damit du etwas lebendiger aussiehst [...] « (1:55:15 h). Da die Tonspur - leicht gedämpft - die Laute vom Appellplatz herüberträgt und uns an die Gefahr jenseits der Baracke erinnert, hoffen wir mit den Frauen, daß ihre »Verschönerungs«versuche zum Überleben beitragen.

Nachdem der Zuschauer die Selektions-Szenerie erneut aus der Vogelperspektive überblicken durfte, wird er in der Folge noch stärker als bisher in die Unruhe der Aussonderung einbezogen: »Die (Hand-)Kamera [...] begibt sich unmittelbar in das Geschehen hinein « (Korte 1999: 179), plaziert uns inmitten der über den Platz gejagten Juden (s. 1:55:36 und 1:55:37 h):

»Die auf unterschiedlichen Raumebenen ablaufenden Aktivitäten mit ihren gegensätzlichen Bewegungsrichtungen [s. 1: 56:36 u. 1:56:37 h] ${ }^{487}$ führen schließlich zu einer völligen Des-

487. Während die Männer im Hintergrund von rechts nach links durchs Bild laufen, bewegen sich die Frauen im Bildvordergrund von links nach rechts.

488. Zunächst noch (eigene Anm.).

489. Die Häftlinge umfahrend bzw. von oben nach unten musternd (eigene Anm.).

490. Oft jedoch auch entgegenlaufend (eigene Anm.); vgl. Korte zur »bewußten Konfrontation gegenläufiger Bewegungsrichtungen« (Korte 1999: 180). 


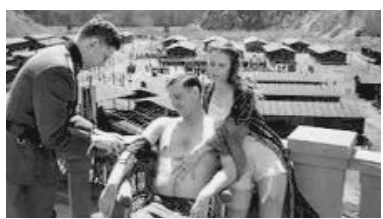

(454) $1: 55: 18 \mathrm{~h}$

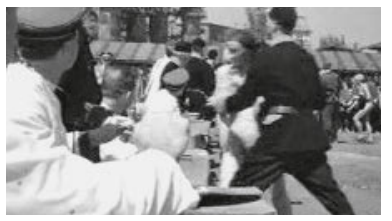

(457) $1: 54: 43 \mathrm{~h}$

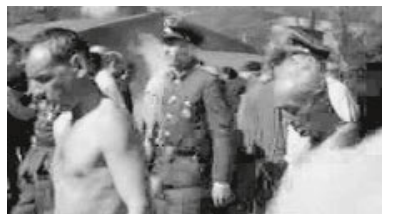

(460) $1: 55: 36 \mathrm{~h}$
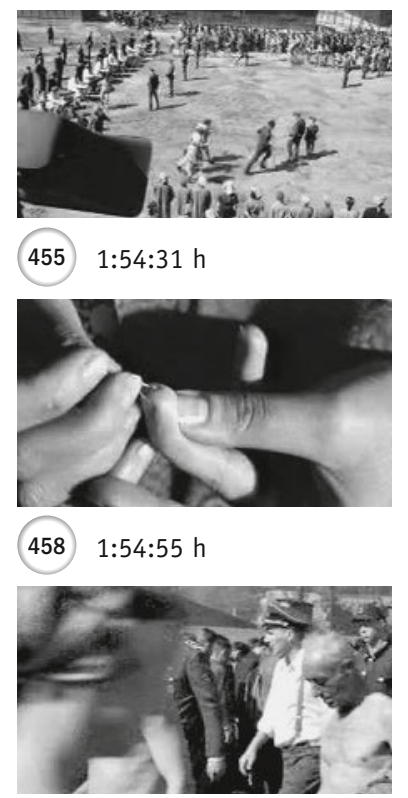

(461) $1: 55: 37 \mathrm{~h}$

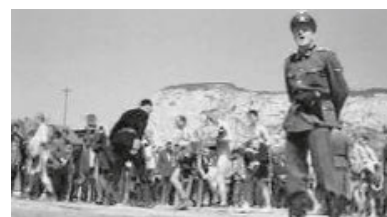

(456) $1: 54: 40 \mathrm{~h}$

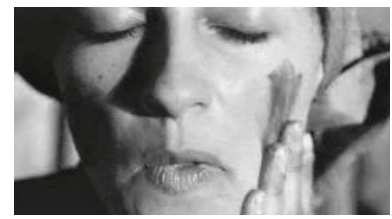

(459) $1: 55: 10 \mathrm{~h}$

orientierung des Betrachters, zumal die ständig im Vordergrund vorbeiziehenden Personen [s. insb. 1:56:37 h] den Blick auf das Geschehen im Mittel- oder Hintergrund nur für kurze Momente freigeben.« (Ebd. 179)

Als Göth (s. 1:55:37 h, rechter Bildrand) seinen Mechaniker unter den Aussortierten entdeckt und ihn aus dieser Gruppe herausholt, tritt vorübergehend eine kurze Beruhigung ein: Die Kamerafahrt verlangsamt sich allmählich, um schließlich auf Göth und dem Juden zur Ruhe zu kommen. Die kurze Erholungsphase für den Zuschauer wird abrupt beendet, indem er mitten in den über Leben und Tod entscheidenden Moment katapultiert wird. Der Betrachter hat das Gefühl, mit den einen weiterlaufen zu dürfen oder mit den anderen ausgesondert zu werden. Neben schnellen Schnitten ist hauptsächlich die außergewöhnliche Kameraführung für diese extreme Wirkung verantwortlich - die Realitätsillusion erreicht spätestens an dieser Stelle einen Grad, »in dem die Differenz von Fiktion und aktuell >erlebter< Aggression aufgelöst erscheint und das Geschehen als hautnahe >Realität< erfahren wird « (Korte 1999: 179, H.i.O.):

»Die Kamera >läuft ‘ ${ }^{488}$ mit den anderen [Lagerinsassen], bleibt stehen [s. 1:55:55 u. 1: 56:09 h], blickt nach links dann nach rechts, >geht in die Bildtiefe, >begutachtet die körperliche Konstitution einzelner aus dem Blickwinkel der SS-Leute [s. 1:56:05 u. 1:56:19 h] ${ }^{489}$ oder befindet sich in der Reihe der an den Tischen der Ärzte Vorbeigetriebenen. Die ohnehin schon chaotische Situation wird durch bewegungsbetonte Kamera fahrten< in die Bildtiefe und schnelle Reißschwenks, den Bewegungen der Akteure folgend 490 oder um satemloss verschiedene, gleichzeitig stattfindende Vorgänge zu zeigen, noch gesteigert.« (Ebd. 179, H.i.0.) 
»Vor allem aber die hier dominierenden, sehr spontan wirkenden und shastig den Handlungsraum durcheilenden Eigenbewegungen der Handkamera mit ihrem ständigen Wechsel der Blickperspektiven geben dem Betrachter das Gefühl, selbst aktiver Teil des Geschehens zu sein, dessen Sicht realistischerweise immer wieder durch die Körper der unmittelbar vor dem Objektiv agierenden Personen punktuell verstellt wird.« (Ebd. 180)

Auffällig ist an diesen Einstellungen die Einhaltung eines Rhythmus' zwischen Einbezug in die Reihe der Juden (s. 1:56:55 u. 1:57:09 h) und begutachtender Täterperspektive (s. 1:56: 03 u. 1:56:19 h). Insbesondere letztere läßt den Zuschauer das Ausmaß an Entwürdigung erfahren, wenn die abgemagerten ${ }^{491}$ Lagerinsassen in ihrer Nacktheit durch Übungen (s. 1:56:19 h) ihre Arbeitsfähigkeit unter Beweis stellen müssen. In diesen Momenten empfinden wir tiefe Scham und erkennen verständnislos, daß die Ärzte dieses Gefühl offensichtlich nicht besaßen oder verloren hatten.

Nachdem wir erneut in den bei der Aussonderung herrschenden Tumult hineingezogen wurden - in diesem Fall werden die Juden mit Schlägen vorangetrieben (s. 1:56:36 h) -, tritt mit der Szene um Göth zwar keine sonderliche Beruhigung ein, gleichwohl fungiert er als eine Art Bezugspunkt inmitten völlig entpersonalisierter Figuren. Wie zuvor, als er seinen Mechaniker aus der Gruppe der Selektierten »rettete«, revidiert Göth die Entscheidung eines Arztes und plädiert für die Arbeitsfähigkeit einer Lagerinsassin (s. 1:56:52 h). Der Zuschauer spürt, daß Göth lediglich auf eine ordnungsgemäße Durchführung des Aussonderns bedacht ist und diese Intervention - »Verstehen Sie nicht, Sie sollen die Kranken von den Gesunden trennen, je nach dem, ob sie arbeiten können oder nicht. Sie kann arbeiten!« (1:56:48 - 1:56:53 h) - keine Begnadigung darstellt.

Der Spannungsbogen um die in Parallelmontage in die Selektionssequenz eingebauten Frauen aus der Baracke wird mit gewisser Verzögerung geschlossen.

Gemäß den Anweisungen der Wachmannschaften hinsichtlich der nicht für den Transport Ausgewählten kleiden sich die offensichtlich zu den Nicht-Selektierten zählenden Frauen freudestrahlend wieder an (s. 1:59:33 h). Der Zuschauer teilt erleichtert diese Freude, denn die Kamera fängt aus vorherigen Einstellungen bekannte Gesichter

491. "Spielberg hat dünne Komparsen ausgewählt [...]. [...] Deshalb verweilt Spielbergs bewegliche Kamera nur einen kurzen Augenblick auf den einzelnen Körpern; lang genug jedoch, um die bekannten dokumentarischen Bilder als Zitate wachzurufen.« (Kramer 2003: 236f.)

492. Den absoluten Höhepunkt dieses Spiels mit befürchtender Antizipation und - in diesem Fall - Durchbrechung derselben stellt die Duschsequenz mit den »Schindlerjüdinnen« dar (s. 3.2.6).

493. „Die Gaskammern bezeichnen den Unterschied zwischen den Todeslagern und anderen Typen von Lagern. Was in ihnen geschah, wird somit zum Fluchtpunkt des Erinnerns von Auschwitz.« (Kramer 1999: 26) »[...] le gazage en camions ou en chambres marque l'extermination des juifs d'un caractère sdépartageantı qui situe le crime nazi au-delà de toute perspective morale ou idéologique. Et cette noire entreprise est justement caractérisée dans son déroulement par l'intention de ne laisser aucune trace. A partir de ce postulat, le fait de montrer et d'expliquer le fonctionnement des chambres à gaz à l'écran devient central dans tout projet cinématographique.« (Lowy 2001: 183f., H.i.0.). »[...] la chambre à gaz est le centre superlatif.« (Ebd. 184) »La chambre à gaz est le seul endroit infilmable où l'homme se soit rendu.« (Ebd. 197) 


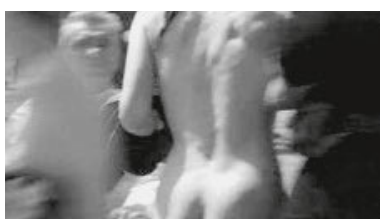

(462) $1: 55: 55 \mathrm{~h}$

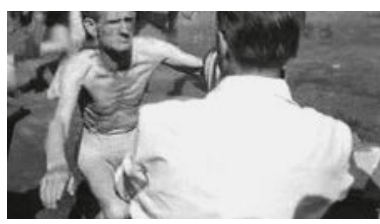

(465) $1: 56: 19 h$
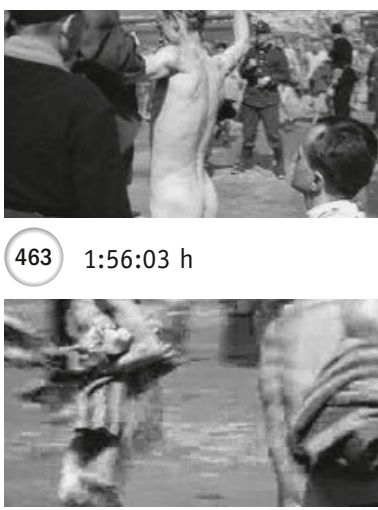

(466) $1: 56: 36 \mathrm{~h}$

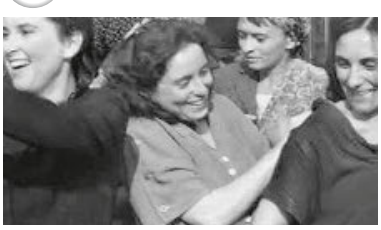

(468) $1: 59: 33 \mathrm{~h}$

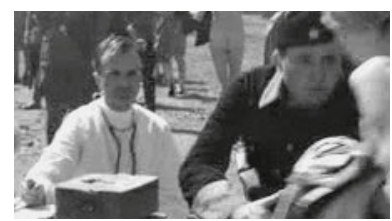

(464) $1: 56: 09 \mathrm{~h}$

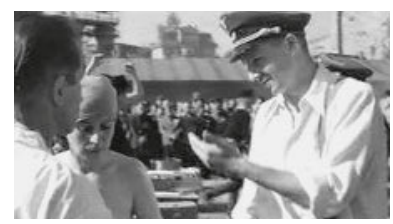

(467) $1: 56: 52 \mathrm{~h}$

ein. Die Bemühungen der Frauen, gesünder und tatkräftiger auszusehen, haben sich demnach gelohnt.

Ein deutliches Beispiel für Spielbergs ganz bewußtes Spiel mit Befürchtung, Hoffnung, Erleichterung und neuer Dramatisierung der Situation ${ }^{492}$ ist die Szene, als die gerade angekleideten Frauen bemerken, daß die Verladung der Kinderscharen, darunter ihre eigenen, bevorsteht.

\subsubsection{Miterlebte Todesangst in der vermeintlichen Gaskammer}

$\mathrm{Da}$ es sich bei der Sequenz in der vermeintlichen Gaskammer von Auschwitz um eine Schlüsselsequenz des Films handelt, ist Konsens unter den Rezensenten. Das heißt aber nicht, daß sie unumstritten wäre - im Gegenteil, an ihr entfachten sich kontroverseste Diskussionen.

Jenseits von Kritik oder Befürwortung steht fest, daß die Gaskammern-Sequenz den Zuschauer ins Zentrum sowohl des Genozids ${ }^{493}$ als auch der Frage nach der Darstellbarkeit des Holocaust versetzt:

»En plaçant consciemment cette scène au milieu de son film, Spielberg conduit le spectateur non seulement au centre de la machine d'extermination nazie, mais aussi au cœur de la problématique d'ordre éthique et esthétique que soulève la représentation de l'extermination.» (Gisinger 2001: 179f.)

Nicht zufällig plaziert Gisinger die Sequenz fälschlicherweise in der Filmmitte und weist ihr in seiner Erinnerung eine, wenn nicht gar die zentrale Position innerhalb eines filmischen Werks zu. Tatsächlich läutet die Sequenz jedoch die letzte halbe Stunde von Schinder Rs Liste ein und bildet, dramaturgisch gesehen, den Höhepunkt der 
akuten Bedrohung der sog. Schindlerjuden - so nah waren sie dem Tod als Gruppe noch nicht gewesen. Aufgrund der Fehlleitung des Frauenzugs nach Auschwitz, in die vermeintlichen Gaskammern, konnte Spielberg auch die letzte der »)Hauptstationen des Holocaust « thematisieren (Korte 1999: 181, H.i.O.).

Kritiker warfen Spielberg zurecht vor, er treibe ein »frivoles Spiel mit Zuschauererwartungen« (Köppen 1997: 160) und deren Angst, aus den Duschen könne Gas strömen: »Spielberg a d'ailleurs commis une faute morale en montrant les femmes dans une chambre à gaz reconstituée d'Auschwitz, et en osant créer autour un suspense cinématographique: sortira t-il de l'eau ou du gaz des pommeaux.« (Lanzmann

494. D.h. den historischen Fakten (eigene Anm.).

495. „Das Happy End in der Gaskammer, typisch Spielberg, und Spielbergs bisher gewagtester Special Effect.« (Martenstein 1995: 197)

496. A: »Das ist doch lächerlich, ich kann das einfach nicht glauben.« (1:53:11-1$: 53: 14 \mathrm{~h})$

B: »Aber wir sind ihre Arbeiter. Und was für einen Sinn sollte es haben, seine Arbeiter umzubringen. Wozu hätten die sich dann die Mühe gemacht, so viele Arbeiter zusammenzutreiben, nur um sie dann grrr [sie macht die Geste des Halsabschneidens].« (1:53:28-1:53:38 h)

C: »Nein, das kann nicht wahr sein. Wir sind wichtig für die, weil die großen Nutzen von uns haben.« (1:53:39-1:53:44 h)

In dieser Sequenz setzt Spielberg das die Eigenleistung des Zuschauers anregende Prinzip der Vorankündigung ein: „Vorankündigungen wollen wir es nennen, wenn dem Publikum ein Ereignis angekündigt wird, das einer Figur möglicherweise bevorsteht. [...] die beabsichtigte Wirkung ist, das Publikum dazu zu bringen, nach vorne zu sehen, zu antizipieren - und das ist der Schlüssel zum Erfolg, wenn man erreichen will, daß das Publikum bei der Stange bleibt.« (Howard/Mabley 1996: 99f.) »Antizipation dessen, was möglicherweise passiert, beruht auf Informationen und nicht auf Unwissen. Wenn wir nichts über die Wendungen zum Guten oder zum Bösen wissen, die der Handlungsverlauf der Geschichte nehmen kann, wenn wir nichts über die mit ihr verbundenen Gefahren wissen, dann können wir auch nicht vorhersehen, was möglicherweise passiert.« (Ebd. 61)

497. »Un spectateur qui ignorait tout des événements de cette période déduirait de la consécution des ces deux scènes que les craintes interrogatives dans la première sont démenties dans la seconde.« (Lowy 2001: 188f.)

498. »[...] wo sSchindlers« Frauen und Kinder Auschwitz verlassen können, nimmt ein Zug unbekannter, individuell nicht konturierter Menschen seinen Weg hinab in die Gaskammer unter dem symbolischen Zeichen des rauchenden Schornsteins. (Lange 1999: 156)

499. »Most troubling of all, of course, is the shower scene, since that mass of attractive, frightened, naked women, finally relieved from their anxiety [...], would be more appropriate to a soft-porn sadomasochistic film than to its context.« (Bartov 1997: 49) »The appeal to the audience's voyeurism is repeated in the shower scene at Auschwitz, a scene pornographic both for its depiction of terrified, naked Jewish women and for its use of the gas chamber to provoke the viewer's sense of suspense.« (Horowitz 1997: 128) »Das Auskleiden vor der vermeintlichen Gaskammer nutzt Spielberg für einen weiblichen Akt. [...] Für den Zweck der Identifikation mit den Opfern mobilisiert er den - überwiegend männlichen - erotischen Voyeurismus. Die durch die schönen Frauenkörper hervorgerufene Lust konfrontiert er mit der Möglichkeit des Untergangs dieser Körper [...].« (Kramer 2003: 237) 
zit.n. Lowy 2001: 190f.) Diese Sequenz zeigt, wie die zeichengelenkte Eigenleistung des Zuschauers - im Unterschied zu vielen anderen Szenen des Films (s. 3.2.4 u. 3.2.5) - irregeführt wird, in einem Kontext, der zum Spiel mit Erwartungen denkbar unangemessen ist.

Aufgrund der Tatsache, daß »hier die Diskrepanz zwischen dem Geschehenen ${ }^{494}$ und dem Gezeigten schlechterdings unendlich « (Schulz 2002: 171) ist, auch wenn sie der Romanvorlage entspricht (s.u.), bestätige Spielberg mit dieser Sequenz darüber hinaus die Haltung von Auschwitz-Revisionisten (Löffler 1995: 57ff. u. Horowitz 1997: 128) bzw. zeichne gerade für jüngere Zuschauer ein falsches Geschichtsbild:

»Werden also geschichtsunkundige Zuschauer durch SCHINDLERS LISTE dazu verführt zu denken, daß die zur Irreführung der Opfer so genannten Duschräume in Auschwitz tatsächlich zum Duschen benutzt wurden? [...] Der Regelfall, dies zeigt [...] ein Blick auf die Zahl der in Auschwitz Umgebrachten, es waren über eine Million, war jedoch die Ermordung." (Kramer 1999: 9ff. $)^{495}$

Dieses ist eine ernst zu nehmende Befürchtung - schließlich steht die Sequenz in unmittelbarem Zusammenhang mit einer zurückliegenden, in welcher der Wahrheitsgehalt des Gaskammern-Gerüchts unter den »Schindlerjüdinnen« kontrovers diskutiert wurde (Kramer 1999: 9). ${ }^{496}$ Da in der vorliegenden Sequenz aus den Duschköpfen kein Zyklon B, sondern Wasser strömt, gibt Spielberg gewissermaßen den Frauen Recht, die das Gaskammern-Gerücht als unwahrscheinlich abgetan hatten. ${ }^{497}$ Im Epilog der Sequenz macht Spielberg jedoch deutlich, daß es sich bei dem glücklichen Überleben der »Schindlerjüdinnen« um eine Ausnahme handelt, denn eine große Menschenmenge verschwindet in einem weiteren Gaskammern- und Krematoriumsschacht. ${ }^{48}$

Diverse Kritiker, wie Bartov, Horowitz und Kramer werten diese Sequenz als voyeuristisch, wenn nicht gar pornografisch, sie nutze bewußt die Nacktheit der mehrheitlich jungen attraktiven Frauen zu erotischer Effekthascherei und sei besonders verwerflich angesichts des Kontextes. ${ }^{499}$ Fraglich ist jedoch, ob die den historischen Tatsachen entsprechende Nacktheit der Opfer vom Zuschauer tatsächlich gesondert und in dem beschriebenen Sinne wahrgenommen wird. Angesichts des äußerst ernsten Kontextes (Gaskammer) verrät die Interpretation der Nacktheit als erotisches Moment möglicherweise mehr über die zweifelhafte Sichtweise dieser Kritiker als über Spielbergs Inszenierung.

Die Sequenz fand jedoch auch Verteidiger, darunter die Holocaust-Überlebende Ruth Klüger: Diese Szene sei realistisch und Spielberg habe »[...] hier den Versuch gemacht, ein genuines Dilemma zu lösen: nämlich die Gaskammern durch die Furcht vor den Gaskammern zu ersetzen, sie anzudeuten - ohne den Fehler zu begehen, sie darzustellen.« (Klüger zit.n. Weiß 1995: 96) »Der Film macht [...] einerseits die Angst vor dem Tod in der Gaskammer zum Kinoerlebnis, ohne das Tabu der Tötungsszene tatsächlich überschreiten zu müssen.« (Köppen 1997: 162)

Während Spielbergs Kamera die »Schindlerjüdinnen« in die vermeintlichen Gaskammern begleitet, machen andere Regisseure, die sich ebenfalls einer historischen Rekonstruktion des Holocaust verpflichtet fühlen, vor der Tür bzw. vor dem Guckloch zur Gaskammer meistens halt. 
Exkurs zur Inszenierung von Gaskammern in verschiedenen Holocaust-Spielfilmen In Marvin Chomskys TV-Serie Holocaust (USA 1978) gibt es zwei Sequenzen, die sich dem Sterben in der Gaskammer nähern: Zum einen durch die Vernichtung einer anonymen Gruppe von Opfern, beobachtet von einem Professor Pfannenstiel, zum anderen durch den Tod der Protagonistin Berta Weiss..$^{500} \gg$ Im ersten Fall, der Darstellung der Vernichtung aus der Täterperspektive, appelliert der voyeuristische Blick in die Gaskammer an die Imagination der Zuschauer, das - nicht gezeigte - Geschehen aus den Reaktionen der SS-Protagonisten zu rekonstruieren.« (Köppen 1997: 160) Statt die Vernichtung zu sehen, hört der Zuschauer folgenden Kommentar des Professors: »Das ist nicht zu fassen. Wie eine Szene aus Dantes >Inferno<. Wie das Klagen in einer Synagoge.« (Fohrmann 2002: 53) »Im zweiten Fall begleitet der Zuschauer - zuletzt aus der Perspektive einer Handkamera inmitten der Opfer - die trotz ihres Wissens um die Funktion dieses Ortes beherrscht bleibende Heldin, bis sich in einer letzten Naheinstellung auf ihr Gesicht die Tür der Gaskammer schließt.« (Köppen 1997: 160)

In Robert M. Youngs Spielfilm Triumph des Geistes (USA 1989) sieht der Zuschauer, wie eine große Gruppe von Opfern den Schacht in die Gaskammern und Krematorien hinabsteigen muß (s.u.), darunter eine Schwester des Protagonisten. Eine klassische Parallelmontage läßt unterirdische Auskleidungsszenen (s. 0:21:51 h) und banges Warten in den sogenannten Bad- und Desinfektionsräumen - meist in Nahaufnahmen (s. 0:22:17 h, 0:22:23 h, 0:22:25 h) - mit Einstellungen von SS-Männern, die sich Gasmasken überziehen und schließlich das Gift in die Öffnungen schütten (s. 0:22:48 h), alternieren - tragischer Höhe- und Endpunkt der Sequenz (Köppen 1997: 161). Insgesamt erinnert der Aufbau der Sequenz sowie deren Inszenierung stark an Spielbergs Form der Umsetzung: Young und Spielberg versuchen beide den Ablauf der Vernichtung spürbar zu machen, begleitet von auffällig hymnenartiger Musik. Beide Regisseure konzentrieren sich auf Frauen und Kinder, wobei Spielberg als zusätzliches Element das Scheren der Frauen einsetzt.

Um das Schicksal des Doktor Korczak und der Kinder in den Gaskammern von Treblinka zu thematisieren, gibt Andrzej Wajda am Ende seines Spielfilms KorCZAK (POL 1990) den bis zu diesem Zeitpunkt vergleichsweise realistisch-rekonstruierenden Diskurs auf und inszeniert in einer - unmißverständlich als solche gekennzeichneten - Traumsequenz die wundersame Rettung aller Beteiligten ${ }^{501}$; dagegen setzt in der letzten Einstellung des Films eine Texteinblendung (s. 1:50:16 h), die in dem Maße in den Bildvordergrund rückt, wie die befreiten Kinder, einem Siegeszug gleich, in den Bildhintergrund flüchten.

500. Insofern ist Loshitzkys folgende Äußerung in ihrer Ausschließlichkeit nicht zutreffend: »Spielberg was the first mainstream Hollywood Jewish filmmaker to break the taboo of explicitly imagining the Holocaust and the gas chambers as its ultimate sacred center and horrifying metaphor.« (Loshitzky 1997: 110f.)

501. Nichtsdestotrotz wurde Wajdas gerade aufgrund dieses Schlusses zum Teil harsch kritisiert.

502. Gemäß meiner Grundüberzeugung, daß ein gewisses $M a ß$ an Diskretion unerläßlich ist, wurde bei der Auswahl der Standbilder auf die indiskretesten verzichtet und die Größe der Abbildungen deutlich verringert. 

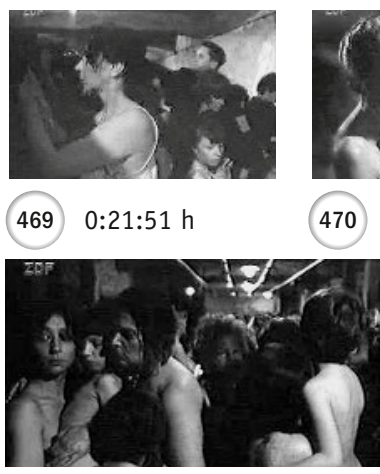

(473) $0: 22: 28 \mathrm{~h}$

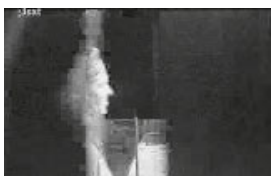

(476) $1: 22: 09 \mathrm{~h}$

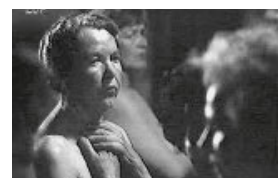

(470) $0: 22: 17 \mathrm{~h}$

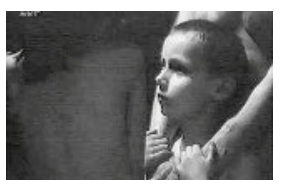

(471) $0: 22: 23 \mathrm{~h}$

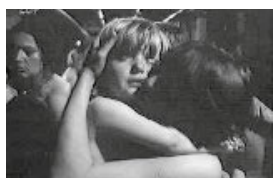

(472) $0: 22: 25 \mathrm{~h}$

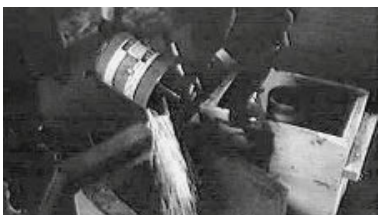

(474) $0: 22: 48 \mathrm{~h}$

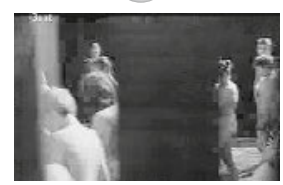

(477) $1: 22: 14 \mathrm{~h}$

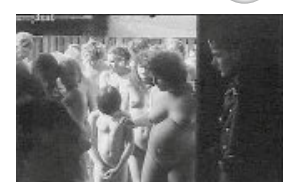

(478) $1: 22: 29 \mathrm{~h}$

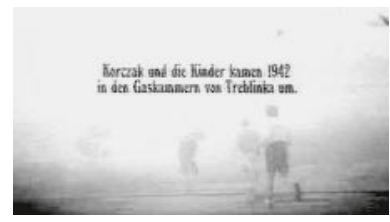

(475) $1: 50: 16 \mathrm{~h}$

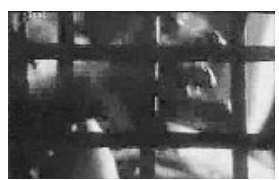

(479) $1: 22: 43 \mathrm{~h}$
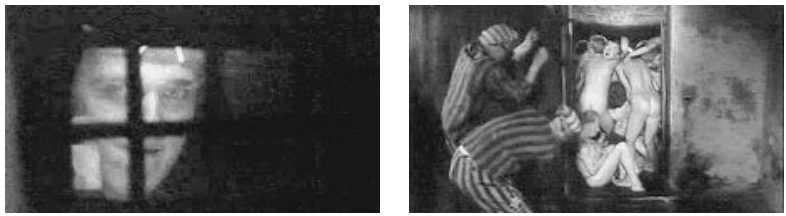

480.A 1:23:02 h

480.B $1: 23: 34 \mathrm{~h}$

In Costa-Gavras' Spielfilm Der Stellvertreter (F/D/ROM/USA 2002) wird »lediglich « die fassungslose Erstarrung des Protagonisten Kurt Gerstein eingefangen, nachdem er durch das Guckloch geblickt hat; was er gesehen hat, wird nicht visualisiert, sondern muß vom Zuschauer aus seinem Minenspiel erschlossen werden. Insofern erinnert diese Inszenierung an die erstgenannte Sequenz aus Holocaust (s.o.).

Nur ein Spielfilm, Leszek Wosiewiczs Kornblumenblau (POL 1988), visualisiert den Vorgang sowie das Ergebnis des Massenmordes in den Gaskammern, was Köppen richtig beobachtet hat: »Es gibt - nach meiner Kenntnis - lediglich einen Film, der die Grenze überschreitet, das Sterben in der Gaskammer zu zeigen [...].« (Köppen 1997: 161) Zu Beginn der Sequenz läßt der Regisseur noch eine gewisse Diskretion erkennen: Das Hineintreiben der nackten Opfer in die Gaskammer wird durch eine rasante Kamerafahrt hinter einer Bretterwand in entgegengesetzter Bewegungsrichtung inszeniert (s. 1:22:09 und 1:22:14 h). Mit dem Betreten der Gaskammer (s. 1:22:29 h) wird diese Zurückhaltung aufgegeben und von beinahe effekthascherischer Visualisierung des Todeskampfes in der Gaskammer sowie des Anblicks bei Öffnung der Eisentüren übertroffen (s. 1:22:43 h und 1:23:34) (52 $^{\text {, was von }}$ Köppen unverständlicherweise als »zynisch-groteske Inszenierung « bezeichnet wird (ebd. 162). Ähnlich wie Gersteins Antagonist in Der Stellvertreter, gibt es auch in diesem Film einen Nazi, der am Blick durch das Guckloch bzw. -fenster perversen Gefallen findet. 
Holocaust-Filme, sowohl Spiel- als auch Dokumentarfilme, die sich von ScHinderes LISTE deutlich unterscheiden, gehen mit den Gaskammern (ohnehin völlig) anders um bzw. behandeln dieses Zentrum der Vernichtung nicht explizit. Die Dokumentarfilme versuchen entweder über den Vernichtungsvorgang und die Installationen mittels Archivmaterial und durch Kommentar zu informieren (Dif TodesmüH Len, s. II.1.1.4) bzw. sich durch nachträgliche Aufnahmen von den Spuren des Todeskampfes und poetisierende Erläuterungen zu nähern (NACHT UND NEBEL, s. II.2.1.6) oder den Holocaust durch Augenzeugenberichte zu übermitteln ( sich von Schindere Liste bewußt distanzierenden Spielfilme behandeln die Vernichtung in den Gaskammern in einer Form des trauernden Gedenkens (BIRKENAU und Rosenfeld, S. II.5.5.f) oder auf indirekte Art und Weise, durch Inszenierung des Auskleidens sowie des übrig bleibenden Kleiderbergs (DAS LEBEN IST SCHÖN, s. II.4.1.4.ba), während andere die Thematisierung der Gaskammern vermeiden (ZUG DES LEBENS, S. II.4.2).

(Ende Exkurs)

An der Sequenz kann vor allem belegt werden, wie Spielberg das Potential des Genres Spielfilm systematisch nutzt, um den Holocaust für den Zuschauer erfahrbar zu machen: Wo der Autor der Buchvorlage dem überraschenden Ereignis lediglich einen Satz widmet - »Auch hier strömte kein Gas aus den Brausen, sondern zum Glück nur eisiges Wasser« (Keneally 1994: 261) -, inszeniert es Spielberg mit virtuoser Dramaturgie und filmischem Diskurs, einem sich über rund drei Minuten erstrecken-

503. »Wenn die Frauen im Duschraum angstvoll nach oben starren und es kommt Wasser aus den Brauseköpfen, weiß der Zuschauer, daß das die Ausnahme gewesen ist. Wissen ermöglicht in diesem Fall, das Nichtgezeigte hinzuzudenken.« (Thiele 2001: 467) »Erst das Wissen [der Zuschauer um den Massenmord in den Gaskammern; eigene Anm.] garantiert die maximale Spannungserzeugung, es ist dramaturgisch notwendig, weil es emotional involviert." (Kramer 1999: 9)

504. "Spielberg inszeniert das Geschehen in den Gaskammern als Verschränkung der Täter-, der Beobachter- und der Opferperspektive, wobei letztgenannten ein Übergewicht zukommt.« (Kramer 1999: 11)

505. »Gleichzeitig verbinden sich diese Zeichen [die aus der Eingangssequenz; eigene Anm.] mit anderen Facetten der Holocaust-Ikonographie, den Signifikanten des Transports (Schienen, Güterwagen, rauchende Lokomotiven), den Zeichen der Gefangenschaft (Barakken, Türme, Stacheldraht und geladene Zäune) und denen der Vernichtung in Gestalt einer Menschenkette, die den Weg zur Treppe des Krematoriums beschreitet - mit einer zweimal wiederholten Ansicht des feuerspeienden Schlotes. Selbst jene Relikte, die uns heute aus den Vitrinen der Gedenkstätten entgegenstarren, die geleerten Koffer, abgeschnittenen Haare, Goldzähne, werden im Bild des Filmes als Objekte der Handlung reanimiert.« (Köppen 1997: 157) »Die Wahrheit der historischen Ereignisse wird bei Spielberg [...] verbürgt [...] durch die Ausspielung der Szenen und visuellen Signifikanten, die im Fundus des gegenwärtigen - durch Filme, Museen, Gedenkstätten angereicherten - kulturellen Gedächtnisses lagern.« (Ebd. 157f.) »Alle Insignien des Holocaust sind vorhanden: Das berüchtigte Lagertor, das martialische Befehlsgebrüll, der qualmende Schlot des Krematoriums, die geschorenen Köpfe der Frauen und schließlich die >Desinfektionsräumeく [...].« (Korte 1999: 187, H.i.0.) 
den, systematischen Spannungsaufbau mit kontinuierlicher Zuspitzung der Situation und retardierenden Momenten. Hierbei setzt er ganz gezielt auf die Eigenleistung des Zuschauers, ermöglicht durch dessen Vorwissen ${ }^{503}$ und/oder die kurz zuvor im Film gelieferten Informationen (s.o.). Im Unterschied zu den angesprochenen, vergleichbaren Filmen gelingt es Spielberg durch die besondere Form der Inszenierung, den Zuschauer emotional extrem zu involvieren (Kramer 1999: 13). So bangt er in höchstem Maße mit und um die »Schindlerjüdinnen « und freut sich beim glücklichen Ende mit ihnen und für sie - stärker noch als bei der mißglückten Hinrichtung des Schlossers (s. 3.2.4), da sich der Spannungsbogen hier über eine etwa doppelt so lange Zeit erstreckt und es sich bei den Opfern um für den Zuschauer vergleichsweise vertraute Figuren handelt.

$\mathrm{Zu}$ Recht, wird auf den Modellcharakter der Sequenz hingewiesen, denn »es geht um Rettung, nicht um Auslöschung. Seine Rührung zieht ScHind de Rs Liste aus dem Überleben der Schindler-Juden« (Kramer 1999: 14).

Diesen extremen Einbezug des Zuschauers erreicht Spielberg jedoch nicht nur durch die angedeutete Spannungsdramaturgie, sondern auch durch dessen Versetzung in die panische Situation der Todesangst (s. 3.2.3.b und v.a. 3.2.5 zum Live-dabeiEindruck).

Wie in der Selektionssequenz (s. 3.2.5) ballen sich auch hier, neben dem Kontrast zwischen dem Gruppenschicksal der »Schindlerjüdinnen« und dem der anonymen Masse (s.o.), weitere Spannungsverhältnisse des gesamten Films.

In rhythmischem Wechsel läßt Spielberg den Zuschauer die jeweilige Situation vor allem aus der Perspektive der Opfer oder eines Beobachters erleben - Live-dabeiEffekt und Distanz alternieren und steigern sich wechselseitig in ihrer Wirkung. ${ }^{504}$ Je nachdem, ob uns Spielberg durch die Newsreel-Ästhetik einen Live-dabei-Eindruck oder durch eine ruhigere Inszenierung eine gewisse Distanz zu den Geschehnissen verschafft, bangen wir mit bzw. um die »Schindlerjüdinnen«.

Jenseits dieser inzwischen bekannten Ästhetik der Live-Kriegsberichterstattung (s. 3.2.3.b und 3.2.5) fällt die vorliegende Sequenz durch den gezielten Einsatz von die Dramaturgie unterstützender, nicht-diegetischer Musik auf. Sie kontrastiert mit »realistischen«, beinahe unerträglichen On-Geräuschen (Scheren). Darüber hinaus kann an dieser Sequenz das Schindef Rs Liste kennzeichnende Spiel mit Licht- und Schatten besonders gut nachvollzogen werden.

Um die Erinnerung an das Schicksal der anonymen Masse, das konträr zu den »Schindlerjüdinnen« seinen Verlauf nimmt, aufrecht zu erhalten, inszeniert Spielberg den Krematoriumsschacht als Ikone der allgemeinen Vernichtung. ${ }^{\circ 5}$

\section{Detaillierte Sequenzanalyse:}

Nachdem der Zuschauer in der vorangehenden Sequenz ebenso ängstlich wie verwundert verfolgt hatte, wie die »Schindlerjüdinnen« in Auschwitz angekommen waren, liefert der aufgebrachte Schindler nun die Erklärung: »Der Zug ist fehlgeleitet worden - Schreibfehler« (2:27:43 - 2:27:46 h). Die folgende Einstellung zeigt mit schnell hintereinander geschnittenen Bildern, wie ein Auto mit aufheulendem Motor das Fabrikgelände verläßt; Schindler ist auf der Hinterbank zu erahnen. Der Zuschauer schließt, daß dieser auf dem Weg ist, Schlimmstes zu verhindern, »daß ein Retter unterwegs ist« (Kramer 1999: 13). 
Die Befürchtung, Schindler könne zu spät kommen, dominiert die folgenden Einstellungen in Auschwitz. Zunächst inszeniert Spielberg das angesprochene Haareschneiden im Vorraum des sogenannten »Bad und Desinfektion«. Eine Kamerafahrt fängt ein, wie jeder Frau von Hilfsarbeiterinnen die Haare auf grobe Weise abgeschnitten werden. Das auffällig laut eingespielte, hektische Ratschen der Scheren geht dem Zuschauer durch Mark und Bein, während eine melancholische Solovioline aus dem Off die Szenerie musikalisch kommentiert. ${ }^{\circ 06}$ Daß man das Haareschneiden als Auftakt einer bevorstehenden Vernichtungsaktion interpretiert, wird zweifach nahegelegt: Zum einen erhascht unser Blick wiederholt sich entkleidende Frauen im Hintergrund (s. 2:28:00 h); zum anderen sehen wir das schmerzverzerrte, von Todesangst gezeichnete Gesicht einer Frau (s. 2:28:07 h). Die anschließende Einstellung zeigt, wie die geschorenen Frauen, angetrieben von den Befehlen der SS-Wächterinnen, ihre Schuhe in einen Korb legen und sich zur nächsten Station begeben, begleitet von einer langsamen Kamerafahrt.

Während im Bildvordergrund weiter Haare abgeschnitten werden und das beinahe unerträgliche Schneidegeräusch an Intensität gewinnt, läßt Spielberg den Zuschauer im Bildhintergrund für einen Augenblick das demütigende Entkleiden der Frauen verfolgen (s. 2:28: 24 h), bevor er deren zunehmende Todesangst erfahrbar macht.

Nach dem wiederum von den Befehlen der Aufseherinnen begleiteten Auskleiden tritt für die Frauen, ebenso wie für den Zuschauer, die sogenannte »Ruhe vor dem Sturm« ein. Dies läßt ihnen und uns ein wenig Zeit zum Nachdenken bzw. zur Erinnerung: Bis hierher entspricht die Situation dem Gerücht von den Gaskammern. Was den Frauen widerfährt, deckt sich sowohl mit den detaillierten Beschreibungen aus der zurückliegenden Szene als auch mit den historischen Fakten der Vernichtungsprozedur. So drängt sich die Erwartung des Todes für die Frauen und den Zuschauer geradezu auf. ${ }^{\circ 07}$ Unsere einzige und letzte Hoffnung richtet sich auf Schindler. Das angstvolle Bangen macht Spielberg mittels einer Großaufnahme erfahrbar, in welcher sich das Gesicht einer Frau, die ihr Kind an sich preßt, durch grelles Gegenlicht als Schattenriß abzeichnet (s. 2:28:41 h). Von den Konturen der Frauen neigt sich die Kamera langsam, um das Kindergesicht groß ins Bild zu rücken (s. 2:28:46 h). Aufgrund der Gegenlichtaufnahme kann der Zuschauer erneut nur die Umrisse erkennen, muß sich den Gesichtsausdruck angesichts des Kontextes selbst vorstellen. Dadurch, daß die Kamera auf dem Kind verweilt, hat

506. Sie wird alle Szenen um das Duschen begleiten.

507. „Die Zuschauer wissen, was nun kommen müßte, und sie wünschen die Rettung der Frauen herbei.« (Kramer 1999: 9f.)

508. »Was hingegen leitmotivisch wiederkehrt, ist das Leiden der Kinder.« (Seeßlen 1995: 164)

509. Auch die Off-Musik ikonisiert für kurze Zeit dieses Zittern, in dem sie die Ruhe abstreift; (kurz darauf nimmt sie jedoch wieder den getragenen Charakter an).

510. »Nun drängen sie sich ängstlich aneinander und gelangen ins Innere des Raumes, während wir Zuschauer - den Kamerablick teilend - mitten unter ihnen sind.« (Kramer 1999: 11)

511. »Wahrnehmungspsychologisch betrachtet droht das Schrecklichste nun nicht mehr smir<, sondern sihnen<. Kaum merklich werden die Zuschauer gezwungen, eine andere Perspektive einzunehmen. Aus der teilnehmenden Sicht der Opfer gelangen sie [die Zuschauer] in die Beobachterhaltung.« (Ebd., H.i.0.) 


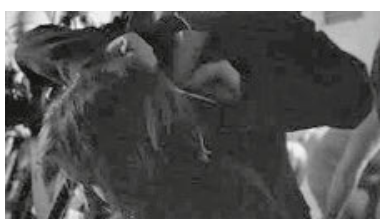

(481) $2: 28: 00 \mathrm{~h}$

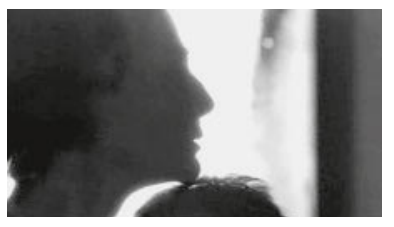

(484) $2: 28: 41 \mathrm{~h}$

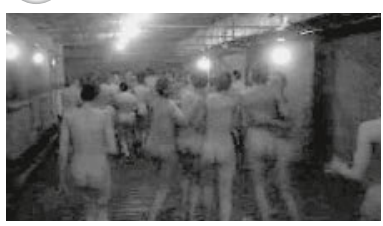

(487) $2: 29: 05 \mathrm{~h}$
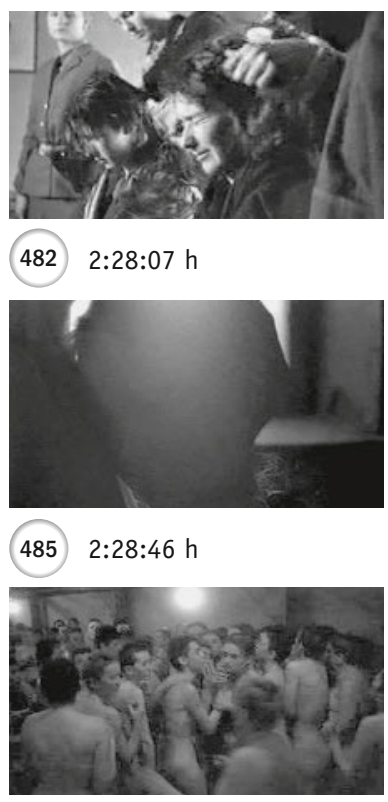

(488) $2: 29: 13 \mathrm{~h}$

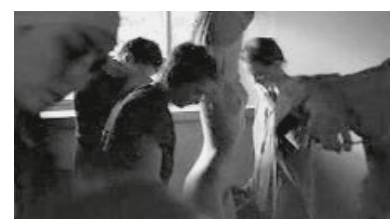

(483) $2: 28: 24 \mathrm{~h}$

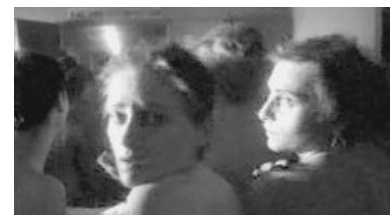

(486) $2: 28: 51 \mathrm{~h}$

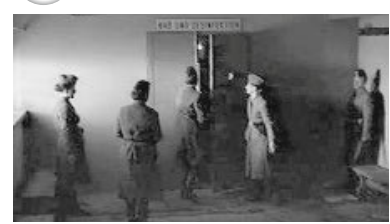

(489) $2: 29: 15 \mathrm{~h}$

man ein wenig Zeit, dem eigenen Entsetzen vor der Unmenschlichkeit der Judenvernichtung nachzugeben, die nicht einmal vor Kindern Halt machte508; zuvor hatten wir »nur« erwachsene Frauen gesehen. Sehnlichst wünscht sich der Zuschauer, Schindler möge wenigstens das Kind in letzter Minute retten.

Ein lautes Geräusch leitet die folgende Einstellung ein. Im Hintergrund wird eine Tür geöffnet, über welcher »Bad und Desinfektion« geschrieben steht. Jetzt beginnt die Kamera leicht nervös zu zittern und ikonisiert auf diese Weise die Todesangst der Frauen. ${ }^{\circ 09}$ Wo wir vorher eine beobachtende Position innehatten, versetzt uns Spielberg nun mitten ins Geschehen:

Am Ende der Frauenreihe stehend, die offensichtlich durch die angesprochene Tür getrieben werden soll, wird uns dieser qualvolle Gang besonders erfahrbar, verstärkt durch die angstvollen Blicke der Frauen, die sich nach uns umsehen (s. 2:28:51 h). Hier bricht der Regisseur bewußt mit der Fiktion - ein Tabu im Film - und läßt den Zuschauer Teil dieses entsetzlichen Geschehens sein, indem er ihn, angetrieben durch das gebellte »Schneller« (2:28:55 h) der Wächterinnen, mit den Frauen über die Schwelle und in den »Dusch- und Desinfektionsraum« treten läßt. Als auf der Türschwelle eine Drängelei entsteht, wird man sogar ein wenig geschubst. ${ }^{510}$

In der vermeintlichen Gaskammer bleibt die Kamera jedoch ein wenig zurück, so daß wir erneut eher eine beobachtende Perspektive einnehmen (s. 2:29:05 h)..$^{51} \mathrm{Zu}$ den Befehlen der Aufseherinnen und der unruhiger werdenden Off-Musik drängen die Frauen in die Raummitte. Voller Angst halten sie sich gegenseitig fest. Durch seine Beobachterposition bemerkt der Zuschauer, wie manche Frauen angstvoll nach oben blicken. Mit dem Vorwissen, den Gerüchten über die Gaskammern und dem Anblick der Duschköpfe (s. erneut 2:29:05 h) kann man die angstvollen Blicke deuten und mit den »Schindlerjüdinnen« bangen (s. 2:29:13 h). 
Anstatt die dramatische Situation auf- und den Zuschauer zu erlösen, baut Spielberg ein retardierendes Moment zur Spannungssteigerung ein: Die Kamera begibt sich erneut in den Vorraum, um zu zeigen, wie die Tür hinter den letzten Frauen ebenso sorgsam wie geräuschvoll geschlossen wird (s. 2:29:15) - die Rettung wird immer unwahrscheinlicher, zusätzlich gesteigert durch das dramatische Anschwellen der Off-Musik.

Nach einem erneut harten Schnitt zoomt die Kamera an das Guckloch in der Tür heran, um schließlich knapp sechs Sekunden »auf dem metallenen Rund des Durchblicks zu verweilen, [eine] Einstellung, deren Länge - nach den derzeitigen Konventionen filmischer Narration - deutlich die Grenze dessen überschreitet, was durch den Zuschauer lediglich halbbewußt wahrgenommen wird [...]« (Köppen 1997: 162). Aus der uns aufgezwungenen Perspektive der Täter müssen wir beobachten, wie die Frauen sich verängstigt im Rauminneren aneinanderdrücken und - erneut auch nach uns - umsehen ${ }^{512}$; das Guckloch ermöglicht eine Distanz zur Ausnahmesituation hinter der geschlossenen Tür (s. 2:29:23 h). Begleitet wird diese distanzierte Zeugenschaft durch das Einsetzen eines dumpfen musikalischen Raunens, das an einen langen Tunnel erinnert, durch den der Wind pfeift.

512. «Spielberg thematisiert also den Kamerablick und den in dieser Sequenz untrennbar mit ihm verbundenen Voyeurismus.« (Ebd. 11)

513. Ausnahmsweise muß Kramer in diesem Zusammenhang korrigiert werden; er schreibt: »Doch das Motiv des Blicks von außen wirft bei inm [Spielberg] nicht die Frage nach der Darstellbarkeit dessen auf, was in den Gaskammern passiert ist. Er gleitet - im Gegenteil - über dieses Problem hinweg, denn ohne die Heranfahrt zu stoppen geht der Kamerablick ohne sichtbaren Schnitt durch das Fenster hindurch auf die Frauen zu, so daß die Zuschauer abermals den Raum gewechselt haben und nun wieder, in einer Art teilnehmende Beobachterperspektive, bei den Opfern sind.« (Ebd. 11) Die Heranfahrt an das Guckloch wurde - wie von Köppen gezeigt wurde (s.o.) - sehr wohl gestoppt, der Positionswechsel ins Rauminnere erfolgte über einen deutlich wahrnehmbaren Schnitt und zunächst (d.h. vor der Lichtunterbrechung) ist die Perspektive des Zuschauers eher die eines distanzierten als die eines teilnehmenden Beobachters (vgl. Köppen 1997: 160).

514. »[...] eine unmotivierte Aktion, sofern die Opfer wirklich nur duschen, die aber ins Drehbuch genommen werden muß, um die Zuschauer in dem Glauben zu halten, die Frauen sollten getötet werden.« (Kramer 1999: 12) Vor allem jedoch dient dieser dramaturgische Trick aufgrund der retardierenden Funktion der zusätzlichen Spannungssteigerung - die Entspannung kann auf diese Weise noch weiter hinausgezögert werden.

515. Sie ist es, die von den sog. "Schindlerjüdinnen« bisher wohl am häufigsten eingeblendet wurde, so daß wir ihr im Verhältnis zu anderen Frauen näher stehen.

516. "Spielberg hat die Identifikation mit den Schindler-Juden schon über den gesamten Film aufgebaut, und auch in der Gaskammersequenz zieht er alle filmischen Register, um sie aufrechtzuerhalten. Immer wieder streut er Großaufnahmen von ihren ängstlichen Gesichtern ein.«(Kramer 1999: 10)

517. »Und er beweist, daß man mit der Kamera deren Todesangst und Panik einfangen kann. Dies in einem Spielfilm zu zeigen, ist keine Frage von Geschmack und Diskretion, sondern von Mut und Kunst." (Noack 1998: 89f.)

518. Die Art und Weise der Inszenierung erinnert hier an gewisse Szenen der Selektionssequenz (s. 3.2.5). 


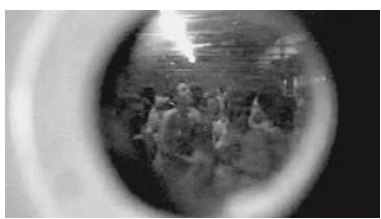

(490) $2: 29: 23 \mathrm{~h}$

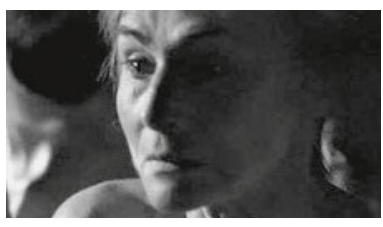

(492) $2: 29: 31 \mathrm{~h}$

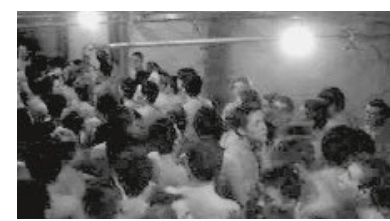

(491) $2: 29: 27 \mathrm{~h}$

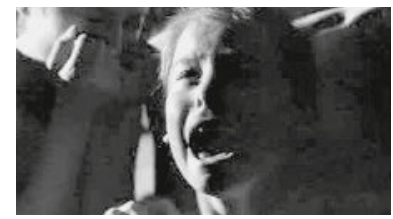

(493) $2: 29: 34 \mathrm{~h}$

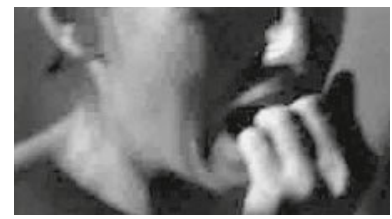

(494) $2: 29: 42 \mathrm{~h}$

Die folgende Einstellung versetzt den Zuschauer erneut ins Rauminnere ${ }^{513}$, ohne jedoch seine Beobachterhaltung zu gefährden, die im Vergleich zu vorher (s. 2:29:05 u. 2:29:13 h) mehr Distanz gewährleistet (s. 2:29:27 h). Aus einer spürbaren Aufsicht zeigt eine Totale sowohl die Frauen als auch die Duschen, »jene dramaturgischen Einheiten, die die folgenden schnellen Perspektivewechsel prägen« werden (Kramer 1999: 11f.). Dicht gedrängt erwarten die Frauen ihr Schicksal - ebenso wie wir unsere letzte Hoffnung begraben.

Wiederum spannt Spielberg den Zuschauer auf die Folter, denn völlig überraschend geht mit einem lauten Knall das Licht aus. Der Bildschirm ist schwarz. ${ }^{514}$ Die Angstschreie der Frauen verdrängen die Begleitmusik; den Zuschauer durchdringen sie aufgrund ihrer Intensität bis in sein Innerstes.

Auffällig langsam wird es wieder hell, wird das vor Todesangst zitternde, zur angstvollen Grimasse verzerrte Gesicht einer uns vertrauten »Schindlerjüdin« sichtbar (s. 2:29:31 h).515 Wo wir in der vorangegangenen Einstellung eine Distanz und den Überblick über die Situation hatten, führt uns Spielberg nun ganz nah an die Opfer heran. Die Groß- bzw. Detailaufnahmen der Gesichter ${ }^{516}$, die durch das plötzliche Seitenlicht beinahe gespenstisch wirken, lassen den Zuschauer die zunehmende panische Angst miterleben, wozu nicht zuletzt die sich erhöhende Schnittfrequenz und die anhaltenden, durchdringenden Angstschreie beitragen. ${ }^{57}$ In sie mischt sich verzweifeltes Jammern und Weinen, personalisiert durch die Großaufnahme eines kleinen Mädchens, das in Richtung Decke blickt (s. 2:29:34 h). Wie zuvor in der Entkleidungsszene stockt uns auch hier der Atem, steigert sich unser Entsetzen und Mitleiden, wenn wir Kinder entdecken; bewußt lenkt Spielberg die Aufmerksamkeit wiederholt auf die Wehrlosesten unter den Opfern.

Als werde sie durch das Zittern der Frauen ein wenig hin und her geschubst, sieht sich die Kamera in der Folge wackelnd um und fängt dabei eine sich auf die Finger beißende Frau ein (s. 2:29:42 h) - universelle Geste extremer Furcht. Die wieder stärker hörbare Off-Musik hat inzwischen beinahe hymnischen Charakter und läßt spüren, daß eine Auflösung naht.

Während die Tonspur sowie die Nervosität der Kamera unverändert bleiben, reißt ein weiterer harter Schnitt den Zuschauer aus der extremen Nähe zu den Opfern heraus. Für ca. drei Sekunden wird er zwischen die aufgeregt umherirrenden Körper versetzt (s. 2:29:45 h) ${ }^{518}$; wie die Frauen, wird man von dem Gegenlicht teilweise so stark 
geblendet, daß man sich kaum mehr orientieren kann. ${ }^{519}$ Gleichzeitig umgibt es die Jüdinnen mit einem auffälligen, fast wie ein Heiligenschein wirkendem Strahlenkranz.

Im weiteren folgt einen deutliche Wende: Zu sich dramatisch zuspitzender Off-Musik treten die Angstlaute hier in der Hintergrund, während die - im Vergleich zu vorher nun ruhigere - Kamera die in Todesangst sich aneinanderklammernden Frauen einfängt (s. 2:29:47 h). ${ }^{52}$ Der starr nach oben gerichtete Blick einer der Jüdinnen erinnert uns daran, von woher das Unheil droht.

Entsprechend verharrt die Kamera in der Folge auf einem an der Decke montierten Duschkopf (s. 2:29:52 h) und senkt sich danach wieder zu den Frauen, schwenkt an ihnen entlang, bevor sie auf dem Gesicht einer nach oben blickenden Jüdin verweilt (s. 2:29:12 h). ${ }^{521}$ Im Unterschied zu den vorangegangenen Großaufnahmen wirkt diese Person gefaßt, würdevoll ihr Schicksal tragend. Das einsetzende Streicherquartett signalisiert »ein schicksalhaftes Aufgehobensein in der Masse, das religiöse Dimensionen annimmt, denn in dieser Situation verschont zu werden wäre Zufall, der ja in einem anderen Kontext - den die Musik und die nach oben gerichteten Blicke aufrufen - Gnade genannt wird « (Kramer 1999: 12).522

»Dramaturgisch gesehen ist die Phase beendet, in der die Zuschauer die Furcht der Opfer am stärksten teilten. Wahrnehmungspsychologisch bleibt nur noch eine Möglichkeit: die Zuschauer verlangen nach der überstandenen Phase äußerster Angespanntheit nicht nach deren Wiederholung, sondern nach psychischer Abfuhr der aufgebauten Spannung. ${ }^{523}$ Und Spielberg, der das emotionale Bedürfnis hervorrief, bedient es auch [...].« (Ebd.)

In einer erneuten, mit statischer Kamera aufgenommenen Totalen verfolgen wir, wie aus den Duschköpfen nach und nach Wasser zu fließen beginnt (s. 2:29:59 h). ${ }^{524}$ Wo vorher Angstschreie die Szene beherrschten, hebt nun ein zunächst überraschtes, dann freudige Erleichterung indizierendes Jauchzen an.

519. »Der aufgeregten Schnittfolge entspricht die zunehmende Rastlosigkeit der subjektiven Kamera, die zuletzt zwischen den sich bewegenden Körpern umherirrt, so daß für kurze Zeit nur noch Licht- und Schattenflecken zu erkennen sind.« (Kramer 1999: 12)

520. In diesem Zusammenhang muß Kramer korrigiert werden; er schreibt: »Die plötzlich völlig statische Kamera zeigt zwei Frauen, die ihren ängstlichen Blick nach oben richten.« (Ebd.) Völlig statisch ist die Kamera jedoch nicht, sie hat sich lediglich im Vergleich zu ihrer vorangegangenen auffälligen Nervosität etwas beruhigt, zittert aber immer noch leicht.

521. »Die Zuschauer werden durch all dies darauf vorbereitet, daß die Zeit der Entscheidung gekommen ist.« (Ebd.)

522. In diesem Zusammenhang muß Köppen korrigiert werden, der schreibt: »Auf den Einsatz überhöhender oder gar grotesk kontrapunktischer Musik verzichtet Spielberg zugunsten eines angstvoll anschwellenden Stimmengemurmels als On-Ton.« (Köppen 1997: 162).

523. «Alle, die auf der Leinwand und die unten im Kinosaal, rechnen damit, daß die Mordmaschine losläuft, die Spannung steigt, und es ist, lügen wir uns nicht in die Tasche, tatsächlich Spannung, die diesen Kinomoment regiert." (Martenstein 1995: 197)

524. "Kommt Wasser oder Gas? - ehe es dann naß herunterrauscht, und der Zuschauer seiner eigenen Atemnot Herr zu werden versucht.« (Giordano 1995: 172) 


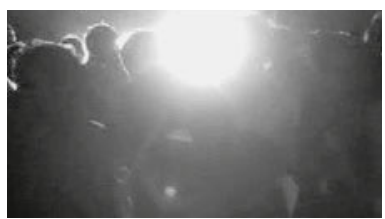

495

$2: 29: 45 h$

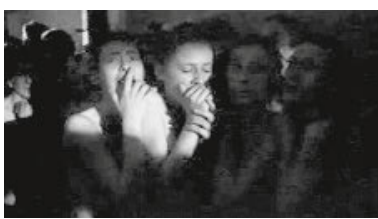

(496) $2: 29: 47 \mathrm{~h}$

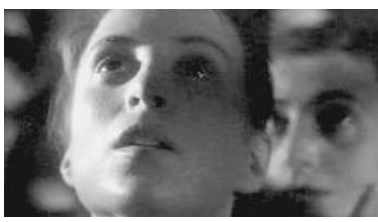

(498) $2: 29: 56 \mathrm{~h}$

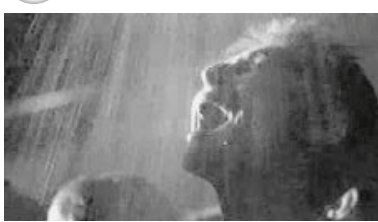

(500) $2: 30: 09 \mathrm{~h}$
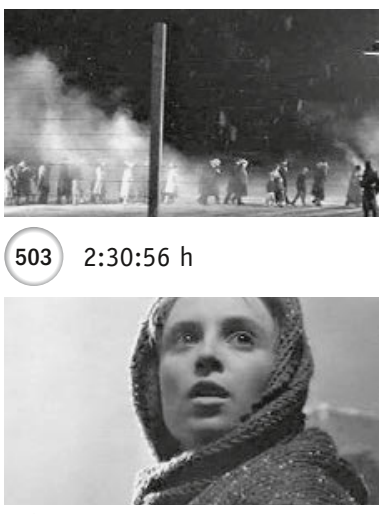

(506) $2: 31: 23 \mathrm{~h}$

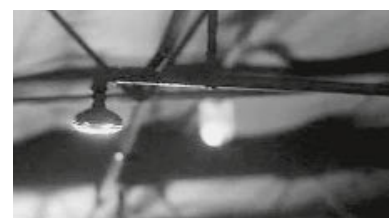

(497) $2: 29: 52 \mathrm{~h}$

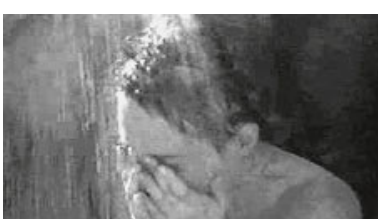

(501) $2: 30: 32 \mathrm{~h}$
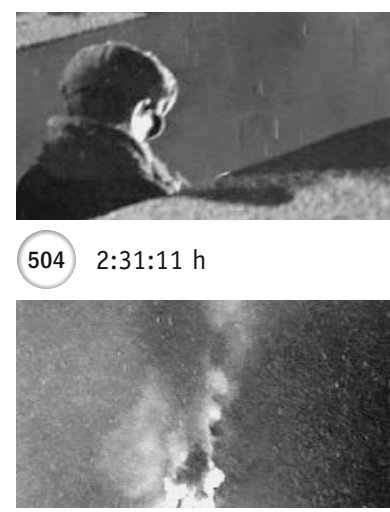

(507) $2: 31: 29 \mathrm{~h}$

(505) $2: 31: 20 \mathrm{~h}$

Eine rund vierzig Sekunden dauernde Serie recht zügig hintereinander geschnittener Nah- und Großaufnahmen läßt den Zuschauer die Erleichterung, parallel zu den Frauen, erfahren, unterstützt durch getragene Off-Musik. So können wir - während wir beinahe spüren, wie das Wasser auf unser Gesicht herunterprasselt - mit der einen Frau lachen, unserer Freude Ausdruck verleihen (s. 2:30:09 h), mit einer anderen weinen, uns der Erleichterung hingeben (s. 2:30:32 h).

In der folgenden Einstellung verlassen die inzwischen wieder bekleideten »Schindlerjüdinnen« zu getragener Streichermusik die unterirdischen Räumlichkeiten. Auf diese Weise sichert Spielberg ab, daß sie dem Tod entronnen sind. Im Freien registrieren einige der Frauen (s. 2:30:47 h), wie eine unbekannte Menschengruppe in einiger Entfernung in einen unterirdischen Schacht hinabsteigt (s. 2:30:56 h). Wie bereits zuvor und erneut aus der Sicht einer beobachtenden »Schindlerjüdin« zeigt 
Spielberg dem Zuschauer, daß auch Kinder unter den Opfern sind, und wählt zur Demonstration eine nahe Einstellungsgröße (s. 2:31:11 h). Vom Schacht schwenkt die Kamera in die Höhe und folgt damit dem ungläubig-entsetzten Blick der jungen Frau (s. 2:31:23 h), mit der wir verstehen bzw. wissen, wie und wo diese Menschen enden werden - als Rauch, der aus dem Schornstein quillt (s. 2:31:20), tiefschwarzer Rauch (s. 2:31:29 h).

»Ces gens accèdent à cet endroit par un escalier descendant [...] et le mouvement panoramique vertical qui nous montre ensuite la cheminée nous fait clairement comprendre que c'est par-là qu'ils en ressortent.« (Lowy 2001: 190)

»Die Filmfiguren, gerettet (fast) wie die Zuschauer, sehen die Menschenschlangen zu den Vernichtungsöfen ziehen, sehen die rauchenden Kamine: Diese Bilder verbieten nicht Phantasie, sondern lösen sie aus. [...] Der tiefste Schrecken, der zugleich die Wirkung des Films erklärt, bleibt das, was die Zuschauer in ihren Köpfen hinzuerfinden, das Ungezeigte. (Schulz-0jala 1995: 223f.; vgl. auch Insdorf 2003: 266) 525 $^{2}$

Während die »Schindlerjüdinnen« Glück im Unglück hatten, versucht Spielberg, dem Zuschauer mit diesem immerhin fast eine Minute dauernden Epilog zur Duschszene das Schicksal der Mehrzahl anzudeuten:

»Mais puisque c'est ainsi que les choses se sont passées pour ces femmes de LA LISTE ..., pourquoi ne pas le raconter? Et comme c'est l'eau qui sort des tuyaux et non le gaz dans ce cas précis, j'ai tenu à montrer les cheminées des fours afin de ne pas prêter le flanc aux révisionnistes. Je n'y étais pas obligé.« (Spielberg zit.n. Lowy 2001: 190) (26 $^{26}$

Insbesondere hinsichtlich der Wahl der Einstellungen und ihrer Abfolge ähnelt Spielbergs Epilog der zitierten Sequenz aus Triumph des Geistes (s.o.). Bereits Robert M. Young hatte dem Zuschauer vier Jahre zuvor das Schicksal der in den Schacht hinabsteigenden Menschenmenge (s. 0:20:53 h) durch die Inszenierung des Krematoriumsschlotes (s. 0:21:24 h) angedeutet, im Unterschied zu Spielberg jedoch zu Beginn der Sequenz in der Gaskammer und etwas weniger deutlich.

525. Vgl. Lowy hinsichtlich einer interessanten metaphorischen Analogie zwischen dieser Szene und dem Beginn der Eröffnungssequenz: »[...] la fin du parcours des victimes est symbolisée par une cheminée crachant des flammes quand le début de leur voyage vers la mort était représenté par le tournoiement de la vapeur d'une cheminée de locomotive.« (2001: 107)

526. »[...] wo sSchindlers« Frauen und Kinder Auschwitz verlassen können, nimmt ein Zug unbekannter, individuell nicht konturierter Menschen seinen Weg hinab in die Gaskammer unter dem symbolischen Zeichen des rauchenden Schornsteins. (Lange 1999: 156) 

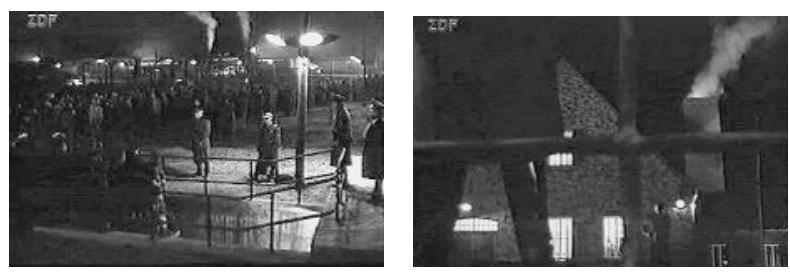

(508) $0: 20: 53 \mathrm{~h}$

(509) $0: 21: 24 \mathrm{~h}$ 
527. Zit. nach Naumann 1980: 171.

528. Zit. nach Kreimeier 1997: 27.

529. Vgl. Georg Seeßlens und Andreas Kilbs ähnliche Anmerkungen zu DeR PIANIST von Polanski aus dem Jahre 2002: »[...] jede Erzählung, die die Ikonografie des Grauens benutzt, ist auch Teil eines Prozesses der Gewöhnung, der Trivialisierung.« (Seeßlen 2002: 56) »Die Zeit [...] verändert die historischen Perspektiven, und so läßt sich nicht übersehen, daß THE PIANIST, der vor zwei Jahrzehnten ein Ereignis gewesen wäre, heute um ebenjene Jahrzehnte zu spät kommt, daß das, was er sagt und zeigt, bereits schlüssig gesagt und gezeigt worden ist - auch wenn man es nicht oft genug sagen und zeigen kann.« (Kilb 2002: 43)

530. „Ziel der Kunst ist es, ein Empfinden des Gegenstandes zu vermitteln, als Sehen, und nicht als Wiedererkennen; das Verfahren der Kunst ist das Verfahren der >Verfremdung der Dinge und das Verfahren der erschwerten Form, ein Verfahren, das die Schwierigkeit und Länge der Wahrnehmung steigert, denn der Wahrnehmungsprozeß ist in der Kunst Selbstzweck und muß verlängert werden. [...] Dinge, die man mehrere Male wahrnimmt, beginnt man durch Wiedererkennen wahrzunehmen [...].«(Sklovskij 1969: 12ff., H.i.0.)

531. »Die alte Form, die Shoa ausschließlich mit Tränen zu behandeln, hat das Publikum ein wenig ermüdet. Und wir haben nur eine neue Art gefunden, dieses Thema darzustellen.» (Mihaileanu zit.n. »Der Spiegel« 24/1999: 191)

"SCHINDLERS LISTE setzt auf die möglichst realitätsgetreue Darstellung einer authentischen Geschichte. Will man nach diesem Film dem Holocaust-Film etwas Neues hinzufügen, so muß man entweder in der Radikalität der abbildenden Darstellung noch weiter gehen als Spielberg oder aber ein völlig anderes, ein nicht-naturalistisches, die historische Realität bewußt verfremdendes Konzept wählen.« (Lorenz 2003: 268)

532. An dieser Stelle sei darauf hingewiesen, daß Kassovitz' Neuverfilmung die Komik weitaus stärker hervorhebt, als dies in Frank Beyers gleichnamiger Erstverfilmung (DDR 1974) der Fall ist, und zumindest in dieser Hinsicht das Potential des Romans von Jurek Becker besser nutzt.

533. Vgl. Insdorfs Kapitel zum »Ironic Touch« (2003: 276ff.).

Im Unterschied zu Filmen wie Der Grosse DikTATor (Charlie Chaplin, USA 1940) oder auch SEIN OdER NiCHTSEIN (Ernst Lubitsch, USA 1942) verwenden Benigni und Mihaileanu Komik nicht nur im Zusammenhang mit den Tätern, sondern auch in gewisser Weise mit den Opfern des Holocaust. 


\section{II.4 Komisch verkehrte Welt}

»Wer genug geweint hat, lacht.« (Heinrich Mann) ${ }^{527}$ »Der Weise lacht nur unter Zittern.« (Charles Baudelaire) $)^{528}$

Seit Kriegsende haben sich zahlreiche Filme mit dem Nationalsozialismus und der damit einhergehenden Judenvernichtung beschäftigt. Hierbei waren ernste, eher realistische Formen der Umsetzung vorherrschend (s. II.1 - II.3). Holocaust-Filme jüngeren Datums sind mit zwei hinzukommenden Problemen konfrontiert. Einerseits werden im Land der Täter seit den 199oer Jahren Schlußstrich-Forderungen laut (s. I.1), andererseits droht jede weitere konventionelle, realistische filmische Behandlung der »Verkörperung des Bösen « (Todorov 1993: 274), einem Gewöhnungsprozeß und somit einer Gefahr der Abstumpfung zu unterliegen.529 Dies gilt seit Ende des vergangenen Jahrhunderts in besonderem Maße, da Ende der achtziger bzw. Anfang der neunziger Jahre dem Darstellungsanspruch verpflichtete Spielfilme dominierten (s. II.3) und generell eine »Diskurswucherung « (Kramer 1999: 2) in bezug auf das Thema Holocaust festzustellen war (s. I.1).

Benignis (Das Leben ist schön, I 1997) und Mihaileanus (Zug des Lebens, F/B/ RO/NL 1998) Ziel war es daher, Gestaltungskonventionen bzw. herkömmliche Sehgewohnheiten zu durchbrechen und - insbesondere zu Beginn ihres Films - das Publikum spielerisch zu einem Wahrnehmen und Einlassen auf die Thematik zu bewegen.530 Als Überraschungselement (Deautomatisation) für den Zuschauer sowie als Gegengewicht zum Grauenhaften setzen beide Regisseure auf eine neue, besondere Kombination künstlerischer Verfahren. ${ }^{531}$

Gemeinsam ist diesen beiden Spielfilmen vor allem, daß sie sich dem Holocaust, trotz dessen unstrittigen Ernstes, mit Komik zu nähern versuchen - »das wohl deutlichste Novum der neueren Holocaust-Spielfilme« (Lorenz 2003: 269).

In bezug auf den prinzipiellen Umgang mit dem Holocaust sind sie damit beispielhaft für Filme wie Peter Kassovitz' Neuverfilmung von JАков DER LÜGNER (Frank Beyer, DDR 1974) ${ }^{532}$ als Jаков тHE Liar (USA/F/HU 1999), den tschechischen Spielfilm Wir müsSEn ZUSAMmenhalten (Jan Hrebejk, 2000), die europäische Koproduktion Tem mit Mussolini (Franco Zeffirelli, I/UK 1999) sowie den Spielfilm Gebü RTIG (Lukas Stepane/ik/Robert Schindel, A/D/POL 2002) oder auch die deutsche Fernsehproduktion Goebells und Geduldig (Kai Wessels, 2002).533

Bezüglich der fast zeitgleich erschienenen und am meisten beachteten Spielfilme von Benigni, Mihaileanu und Kassovitz wurde häufig von einer »Welle der HolocaustKomödien« (Žižek zit.n. Meyer 2002: 219), einem »Boom des Galgenhumors« gesprochen (»Berliner Morgenpost«, 26.10.99). Bieten diese » KZ-Komödien«« die Chance, »jenseits eines naiven Realismus die Dimension der Unfaßbarkeit der Vernichtung bewußt werden « zu lassen (Oster/Uka 2003: 251, H.i.O.)? Reflektieren diese mutigen Filme nicht die zentrale Problematik der medialen Vermittlung, während Filme, die sich »dem Gestus > So ist es gewesen< verpflichtet fühlen« (ebd. 251, H.i.O.), die Frage der Darstellungsmöglichkeit eher umgehen? Stellen Ernst und Humor sich ausschließende Gegensätze im Umgang mit dem Thema Holocaust dar?

Oder ist die Tendenz zur Komik in ihrer ursprünglichen Bedeutung eines guten Endes vielleicht sogar im Thema »begründet«, d.h. erfordert das Ausmaß des Grauen- 
haften nicht wenigstens eine zeitweise Distanzierung, wie von Primo Levi in »Ist das ein Mensch? « beschrieben und beim jüdischen Humor zu beobachten? U.U. ist die Herangehensweise über Komik gar die >authentischereく, wie Kertész dargelegt hat.534 An anderer Stelle wurde gezeigt, daß die Verwendung von Komik im Zusammenhang mit dem Holocaust einer Übernahme damaliger Verhaltensweisen und Überlebensstrategien entspricht. 535 Ihrem Verständnis von Witz entsprechend, versuchten sich damals zahlreiche Juden, mittels »Unernst« von der Unbegreiflichkeit des Grauens zu distanzieren, es als absurd zu entlarven (s.u. und II.4.2.1 zum jüdischen Humor bzw. Witz). ${ }^{536}$ Diese - von den zitierten Filmemachern übernommene - Grundhaltung vermag beim Zuschauer eine analoge Einstellung auszulösen; die komischen Momente bieten ihm die Möglichkeit, sich vom Grauenhaften zu distanzieren: Lachen als Möglichkeit, Hoffnung zu schöpfen?

Beruht der Publikumserfolg der »KZ-Komödien« möglicherweise darauf, daß die Komik »jetzt den Abschied von der >westdeutschen Betroffenheitsdidaktik der 7oer Jahre«« erlaubt (Weilnbröck zit.n. Meyer 2002: 231, H.i.O.) und/oder darauf, »daß Humor als Annäherung an den Holocaust weniger verbraucht ist als Trauer und Empörung « (Gallwitz zit.n. Bleicher 2002: 196)?537

534. »Daß es auf die Wirklichkeitstreue des Gegenständlichen gar nicht ankommt, sondern sich darin ein bloß vordergründiger Naturalismus ausdrückt, darauf hat Imre Kertész hingewiesen. Viel eher entspräche das Komische der grauenhaften Welt des Holocaust, weil diese selbst eine abgrundtief absurde gewesen sei. In seinem Plädoyer für Benignis LA VITA È BELLA schrieb er: >Hier geht es um etwas ganz anderes: der Geist, die Seele dieses Films sind authentisch, dieser Film berührt uns mit der Kraft des ältesten Zaubers, des Märchens.«" (Kertész zit.n. Fröhlich 2003: 246)

535. Vgl. Corell 2000: 109-117.

536. Vgl. auch Kertész 1996: 159: Kertész' Held erzählt einen Witz über das eigene Schicksal, der im KZ kursierte.

537. Vgl. Mihaileanus Bemerkungen in bezug auf Holocaust-Filme nach SCHINDLERS LISTE in II.4.2.1.

538. »[Der explosive Charakter des Komischen] könnte anzeigen, daß Komik auch eine Angelegenheit des Verstandes ist, kein sinteresseloses Ablachen<, sondern ein Erkenntnisakt, der auf dem Wahrnehmen des Widerspruchs beruht, den ein komischer Konflikt prinzipiell erzeugt.« (Kant zit.n. Oster/Uka 2003: 255, H.i.0.)

539. »0n ne peut sauter des étapes. Quand le choc est terrible, on ne peut pas se réveiller ni analyser les choses avec lucidité. Il a fallu du temps, que la deuxième génération mûrisse, digère l'histoire des parents. Il nous fallait nous rendre compte de l'importance de la transmission et que nos parents soient prêts à admettre cette manière. [...] On ne peut empêcher les gens de s'exprimer avec leur langage, à condition qu'ils ne trahissent pas la mémoire historique« (Mihaileanu zit.n. »L'Humanité« 16.09.1998).

540. Vgl. Loshitzky 2003: 23.

541. Vgl. Plessner 1982: 304 zur »abgründigen« Komik.

542. Kassovitz bereitet den Zuschauer bereits im Vorspann auf die Wichtigkeit des jüdischen Humors für den gesamten Film vor, indem er den Erzähler und Protagonisten, Jakob Heim, einen jüdischen Witz erzählen läßt. 
»Eine Möglichkeit, hinter den stereotypen 〉Bildern des Grauens überhaupt noch die Vorstellung der Individualität des Schreckens erreichen zu können, scheint ausgerechnet für das Komische zu bestehen, weil es vielleicht noch in der Lage ist, hinter den undurchdringlichen Ernst der Oberfläche jener >Bilder des Grauensı gelangen zu können, um sich in der Komödie auf seine Weise der Wirklichkeit wieder anzunähern.« (Paech 2003: 24, H.i.0.)

Vielleicht liegt der Erfolg zudem an der lebensbejahenden Botschaft dieser Filme (s.u.) oder an der Tatsache, daß »sie sich [...] der Substanz des Grauens über die Inszenierung einer grotesk-paradox gewordenen Welt mit dem Mittel der Komik nähern, um mit Hilfe eines kalkulierten Schocks, der sich durch die Konfrontation von Lachen und Leiden herstellt, ein vertiefendes Verständnis des Ungeheuren zu erreichen.«(Oster/ Uka 2003: 260) - Lachen mit »Erkenntnisfunktion« (Oster/Uka 2003: 249)?538 Offensichtlich bedurfte es einer gewissen historischen Distanz, um dem Holocaust mit Komik zu begegnen. 539

Mit der bewußten Rückbindung an zwei lebensbejahende Humortraditionen, den jüdischen Humor sowie die abendländische Lachkultur (s.u.), »demonstrieren beide Regisseure die potenziell unzerstörbare Menschlichkeit der Opfer angesichts der Unmenschlichkeit und Anonymität des realen Vernichtungsprozesses und betonen (als Gegenposition zum apokalyptischen Geschichtsverlauf) deren Würde und Individualität.« (Oster/Uka 2003: 265) Ist neben der Deautomatisierung dieses Bekenntnis zum Leben trotz bzw. aufgrund des vielfachen Todes für den auffälligen Erfolg der beiden Filme beim Publikum ausschlaggebend - schließlich stärkt es den Glauben an »Humanität jenseits und nach dem Schrecken« (ebd.)?540

Die zentrale Gemeinsamkeit von DAs Leben ist SChön und Zug Des Lebens bildet, wie angesprochen, das komische Element. Insbesondere in der Exposition werden die Wahrnehmungsgewohnheiten des Zuschauers im Hinblick auf konventionelle Holocaust-Filme durchbrochen.

Von Beginn an und über weite Strecken der ersten Hälfte von Benignis Film dominiert geradezu »flache« Komik (Plessner 1941: 331f.). Ebenso behutsam wie allmählich wird der Zuschauer in der Folge auf die Judenvernichtung vorbereitet. In der zweiten Hälfte des Films konkurriert dagegen die als »abgründig « ${ }^{541} \mathrm{zu}$ bezeichnende Komik zunehmend mit tragischen Momenten.

In ZUG DES LEBENS wird der Zuschauer vom Anfang bis zum Ende in die verrückte Situation der Selbstdeportation eines osteuropäischen Schtetls - mit all ihren komischen Folgeerscheinungen - hineingeworfen. Erst die letzte Einstellung des Films, die den Erzähler Schlomo hinter Stacheldraht im KZ zeigt, entlarvt ihn als Träumer.542

Der Einsatz komischer Stilmittel bewirkt, daß der Zuschauer - aufgrund seiner Kenntnis der historischen Tatsachen - dieses Wissen der fiktional-komischen, verkehrten Welt aktiviert und entgegenhält:

»Es sind in erster Linie filmische Komödien, die vom Holocaust erzählen, die in irgendeiner Weise das Problem der Fiktionalität ihres Erzählens thematisieren, um auf das Faktische als dessen Horizont zu verweisen. [...] Das Komische bis hin zum Absurden, entlastet keineswegs die Zuschauer von der Verantwortung für die sfactsı, die dahinter ihre Bedeutung behalten [...].» (Paech 2003: 24f., H.i.0.) 
Voraussetzung dafür, daß die Filme nicht als Verharmlosung mißverstanden werden, ist demnach ein gewisses Maß an Vorwissen. ${ }^{543}$

Insbesondere in der zweiten Hälfte von DAs LeBEN IST sснӧ N fordert die im Gewand ironischer Verkehrungen auftretende Komik den Zuschauer dazu auf, die dem Sohn unter größter Anstrengung vorenthaltene Lagerrealität mitzudenken. ${ }^{544}$

In ZUG DES LEBENS steht der Aberwitz, welcher die Binnengeschichte beherrscht, in krassem Gegensatz zu den damaligen Verhältnissen, so daß der Zuschauer den Hintergrund der Parodie vor allem unterschwellig spürt. Wäre dies nicht der Fall, könnte er die Absurdität der erzählten Geschichte nicht so dankbar annehmen. ${ }^{545}$

Während Benigni in seinem Film eher dazu tendiert, »die Interpretationsmacht über das eigene Schicksal zu behalten«, läßt Mihaileanu seinen Protagonisten träumen, »das Zeichensystem des Feindes ironisch zu adaptieren und dadurch, inmitten der Vernichtung, für die Deutschen praktisch unsichtbar zu werden« (Kniebe 2000: 19) - zentrales Verfahren der Parodie, die Bachtin als »die Herstellung eines profanierenden und dekouvrierenden Doppelgängers «, als »umgestülpte Welt« charakterisiert (1990: 54).

543. Vgl. hierzu Jurek Beckers pointierte Äußerungen hierzu im Bezug auf seinen Roman JAKOB DER LÜGNER (1969): »Mit so einer Geschichte kann ich mich nur an Leute wenden, die fünfundzwanzig oder dreißig Jahre lang geradezu bombardiert worden sind mit Informationen über diese Zeit.« (Becker zit.n. Meyer 2002: 214)

»Der geschichtliche Hintergrund von Deportation und Vernichtung, dessen Einzelheiten in vielfacher Weise belegt sind, wird in den beiden Filmen [...] als Faktizität vorausgesetzt. Benignis Film stellt die 1943 einsetzende Judenvernichtung in Italien dar. [...] Der Hintergrund von [...] ZUG DES LeBENS ist das Rumänien von 1941.« (Oster/Uka 2003: 260)

544. »Wichtig ist $[\ldots]$, daß die geistigen Wendungen, die wir zeichengesteuert vollziehen (Sympraxen), sehr unterschiedliche geistige ১Wendigkeit trainieren können. [...] Und die Ironie zwingt uns, umzuwerten.« (Kloepfer 2001a: 134, H.i.0.).

545. Durch Jakob Heims Lügen in ЈАКОВ THE LIAR scheint die zunehmende Hoffnungslosigkeit der Situation für die Ghettobewohner hindurch. Je schlimmer die Verhältnisse werden, desto vehementer wird Jakob aufgefordert, mutmachende Neuigkeiten zu berichten und desto lebensnotwendiger werden seine Lügen. Dies erklärt die vom Zuschauer verspürte Tragik jeder neuen Erfindung.

546. "In ZUG DES Lebens wird das Spiel - also die Umdeutung des Holocaust in etwas Harmloses - jedoch nicht mehr (wie bei Benigni) als eine von zwei Ebenen umgesetzt, die einander korrigieren, sondern als märchenhafte, geschlossene Erzählung.« (Lorenz 2003: 271)

547. »Die Balance zwischen Albernheit und Grausamkeit, die Roberto Benignis Film [...] auszeichnet, glückt Mihaileanu nicht.« (Beier 2000: 60)

548. „Das karnevalistische Leben ist ein Leben, das aus der Bahn des Gewöhnlichen herausgetreten ist. Der Karneval ist die umgestülpte Welt. Die Gesetze, Verbote und Beschränkungen, die die gewöhnliche Lebensordnung bestimmen, werden für die Dauer des Karnevals außer Kraft gesetzt. Das betrifft vor allem die hierarchische Ordnung und alle aus ihr erwachsenden Formen der Furcht, Ehrfurcht, Pietät und Etikette [...].«(Bachtin 1990: 48)

549. Lachend begegnet der Mensch der Unmöglichkeit gewohnten Verhaltens aufgrund »[...] unausgleichbarer Mehrsinnigkeit der Anknüpfungspunkte, [quittiert er das] vital, spirituell und existentiell >Widerısinnige« (Plessner 1941: 363ff., H.i.0). »So erweist das Lachen sich als ein Werturteil, ein negatives Werturteil über eine Wertdegradation«(Stern 1980: 44). 
Im Gegensatz zu Benigni, der dem Grauenhaften vor allem im Hauptteil durchaus Raum gewährt, dreht Mihaileanu »die Spirale des Absurden« »immer weiter und immer höher« (Bleicher 2002: 195f.). ${ }^{546}$ Mit dieser Radikalisierung in Richtung »total farce (Mathews 1999: 48), die zum Teil kritisiert wurde ${ }^{547}$, übertrifft er nicht nur Benignis Film, sondern geht weiter als alle bisherigen sog. Holocaust-Komödien.

Mit Das Leben ist schön nimmt Benigni eine mittlere Position ein. Dies ergibt sich aus der Tatsache, daß er im Vergleich zu Zug des Lebens konsequenter das Zusammenspiel von komischen und tragischen Szenen realisiert, insbesondere im Hauptteil seines Werks. Auf diese Weise verwirklicht der italienische Regisseur das tragikomische Prinzip am effektivsten, welches darin besteht,

$»[\ldots]$ daß das Tragische und das Komische [...] sich [...] gegenseitig steigern. Das heißt: einerseits verschärft die tragische Implikation das Komische, in dem sie ihm größere Tiefe, der komischen Sicht mehr Hindernisse gibt, die zu überwinden sind; sie macht also die komische Inkongruenz durch ihre gesteigerte Kraßheit um so wirkungsvoller. Auf der anderen Seite verschärft die unleugbar komische Konstellation - höhnisch gleichsam - die Bitterkeit des Tragischen. Und beide Arten von Wechselwirkung haben gleichzeitig statt, sind aneinander gebunden und steigern sich fortschreitend gegenseitig [...].« (Guthke 1968: 65)

Während DAS LEBEN IST SCHÖN den Zuschauer durch ein Nach- und Ineinander von Komik und Tragik zum Lachen und/oder Weinen bringt, kann dieser in ZUG DES LEBENS aufgrund geballter Komik vor allem lachen.

Von der negativen Kritik an der »Trivialisierung « durch die »Holocaust-Komödien« - »Holocaust-laughter« (Viano 1999: 27ff.), »Shoah-light« bzw. »Holocaust-Kitsch« (Tugend 1999: 24) - wird ein zentraler Aspekt nicht beachtet: Die von Komik gekennzeichnete filmische Auseinandersetzung mit dem Holocaust steht in der langen Traditionslinie des spezifisch jüdischen Humors, der das Leiden des eigenen Volkes in Witzen thematisiert, sowie der abendländischen, mittelalterlichen Lachkultur, die für die Entstehung und die Gestaltung der Commedia dell'arte von besonderer Bedeutung war (Bleicher 2002: 181f., Esrig 1985: 61). Komik gilt beide Male als Antwort auf die Frage, »welche Verfahren es [gibt], das nicht zu erduldende Unerträgliche zeitweise annehmbar zu machen und sei es auch nur, um einfach zu überleben«, eine »Strategie der Bewältigung des eigentlich Unerträglichen [...]. Die gemeinschaftliche Anerkennung dieses schwer oder überhaupt nicht Auszuhaltenden und seine Ab- oder Umwertung ist heilsam.« (Kloepfer 2000: XXII) Grundprinzip ist jeweils das, insbesondere mit der abendländischen Lachkultur verbundene, karnevaleske Prinzip der verkehrten Welt. ${ }^{54^{8}}$ Sowohl in der jüdischen als auch in der abendländischen Tradition fungiert das Lachen als »Überlebensmittel gegen die Tragödie« (Mihaileanu zit.n. Tegeler 1998), als »einzige Waffe gegen das Leiden« (Mihaileanu zit.n. Wergin 2000), als »Befreiung«, »Sieg über die Furcht [...], über jede Gewalt, über die irdischen Herrscher« (Bachtin 1980: 399), als »Exorzismus« (Blumenfeld 1998). .54

Dieser Tradition entsprechend, tragen die beiden Protagonisten Züge von Schelmen und Narren, den charakteristischen Figuren der mittelalterlichen Lachkultur (Bachtin zit.n. Esrig 1985: 34). Die »verrückten Helden« beider Filme (Oster/Uka 2003: 264) - inklusive Jakob in Kassovitz' Јаков тнЕ LIAR -, »weigern sich [...], die mit den Faschisten zunehmlich bedrohlicher werdende Welt anzuerkennen. Dadurch, 
daß sie sich unrealistisch verhalten, schaffen sie eine eigene Wirklichkeit - ein typisches Charakteristikum des Clowns. Diesen Kontrast ist der Zuschauer gezwungen auszuhalten.« (Ebd. 264) Gleichzeitig erlebt er die Unbeugsamkeit der Protagonisten gegenüber der Wirklichkeit des Holocaust als wohltuend, als lebensnotwendigen Widerstand, und wird dazu angeregt, das gewöhnliche Verständnis von Narrheit und Vernunft zu hinterfragen:

»Die beiden krassen Gegensätze Narrheit und Vernunft, die aber doch in einem spezifischen Verhältnis zueinander stehen, lassen sich spielend verkehren und dann bleibt fraglich, ob nicht die Vernunft zum Narren wird und der Narr die wahre Vernunft besitzt.« (Promies 1966: 79f.)

»Wie der Narr in der Elisabethanischen Komödie, der Narr in TRAIN DE VIE, [der Harlekin und Schelm in DAS Leben IST SCHÖN; eigene Anm.] und der Schlemihl JaKOB THE LIAR kann die Komödie dort die Wahrheit sagen, wo die dominanten Formen des Holocaust-Films - Tragödie und Melodram - ihr oft ausweichen und sie umgehen.« (Loshitzky 2003: 29)

Während Guido in DAS LeBEN IST SCHÖN als moderner Arlecchino unentwegt neue Erklärungen improvisiert, um seinem kleinen Sohn das Konzentrationslager als Spielplatz zu suggerieren55, gleicht Schlomo in Zug Des LeBens insbesondere dem ost-

550. »Arlequin ist nicht selten in der >Patscheく, aber er ist nie um phantasievolle Erklärungen verlegen, die ihm Erleichterung verschaffen und die Zuhörer amüsieren.« (Stackelberg 1996: 24f., H.i.0.)

551. Vgl. hierzu Benignis Erläuterungen: »[...] daß man am Rande des Abgrunds nicht hinunterschaut, weil der Schrecken unermeßlich ist. Wenn man ihn zeigt, ist er nur noch das, was man zeigt." (Benigni/Cerami 1998: 195f., H.i.0.) Vgl. auch einen Kommentar in Alain Resnais' essayistischem Film NACHT Und Nebel (s. II.2.1) in bezug auf die Unmöglichkeit der wirklichkeitsgetreuen Vermittlung der Lagerrealität: »Wer übrigens weiß schon etwas davon; die Wirklichkeit der Lager? Die sie geschaffen haben, ignorieren sie und die sie erleiden, können sie nicht fassen. Und wir, die wir nun zu sehen versuchen [...] kein Bild, keine Beschreibung gibt ihnen ihre wahre Dimension wieder.« (0:07:47-0:08:16 h)

552. »[...] nicht Fiktion, sondern einzig und allein Dokumentation, ob im Film oder in der Literatur.» (Wiesel 23.11.2000: 24). »Die Fiktion ist eine Übertretung, und es ist meine tiefste Überzeugung, daß jede Darstellung verboten ist.« (Lanzmann 1995: 175)

553. Vgl. hierzu Kertész, der u.a. die Kraft der Phantasie als überlebensnotwendig darstellt: »Tatsache ist, unser Vorstellungsvermögen bleibt auch in der Gefangenschaft frei. [...] meine Lieblingsbeschäftigung bestand darin, mir einen vollständigen, lückenlosen Tag zu Hause vorzustellen, immer wieder, möglichst vom Morgen bis zum Abend, und mich dabei nach wie vor in Bescheidenheit zu üben.« (1996: 173f.)

554. »Primo Levi spricht darüber in [...] >Ist das ein Mensch?« Er beschreibt den Morgenappell im KZ Auschwitz; alle Häftlinge sind nackt, stehen stramm; Levi schaut sich um und denkt: ıUnd wenn dies nur ein Witz wäre? Das kann doch alles nicht wahr sein...«.« (Benigni/Cerami 1998: 195f., H.i.0.)

555. Aus Jakobs anfänglicher Notlüge entsteht bei Kassovitz eine Folge hoffnungsspendender »Phantasie-Nachrichten«. Immer wieder wird er aufgefordert, seiner ersten Radionachricht neue folgen zu lassen. Dem tristen Alltag entflüchtet Jakob wiederholt, indem er in seiner Vorstellung Zwiegespräche mit seiner verstorbenen Frau Hanna führt. 
europäischen »Schlemiel« (s. II.4.2.1): Insofern fußt ZUG DES LEBENS stärker auf dem jüdischen Humor, während DAS LEBEN IST SCHÖN v.a. in der Tradition der italienischen Commedia dell'arte steht.

Mit der Wahl der Protagonisten geht einher, daß beide Filme (auch Јаков тнЕ LIAR) zu großen Teilen aus der »Perspektive des Unschuldigen« erzählt werden (Loshitzky 2003: 28): In DAS LEBEN IST SCHÖN sind es Guido und vor allem sein kleiner Sohn, in Zug Des LeBens ist es Schlomo (ebd. 28f.).

»Mit dem Tod (beziehungsweise der Inhaftierung) des Clowns verletzen beide Regisseure die gängigen Genre-Regeln, wonach der Zuschauer die Unverletzbarkeit des komischen Helden gewohnt ist - ein äußerster Bruch mit der Erwartungshaltung des Publikums«, gleichzeitig ein Tribut an die vernichtende Wirklichkeit des Holocaust (Oster/Uka 2003: 264).

Eng verbunden mit dem Einsatz lebensbejahender Komik ist die Entscheidung für eine fiktionale Herangehensweise an den Holocaust. Beide Regisseure erteilen der Frage nach wirklichkeitsgetreuer Darstellbarkeit im Sinne einer authentischen Rekonstruktion eine Absage. ${ }^{55}$ Übereinstimmend - und in Abgrenzung zu Elie Wiesels und Claude Lanzmanns gemeinsamer Ansicht552 - betonen sie in ihren Werken die bewußt gewählte Freiheit im Umgang mit den historischen Fakten. Ausgangspunkt hierfür ist die Überzeugung, daß das Negative nur durch Positivierung annehmbar wird. Auf diese Weise kann dem Zuschauer das Einlassen auf die schwer erträgliche und vermittelbare Thematik erleichtert sowie eine Verweigerungshaltung bzw. »SchlußstrichForderung « umgangen werden. Die deutlich markierte Fiktionalität - Reaktion auf die Absurdität des Holocaust - fungiert als Gegengewicht zum tatsächlichen Grauen und entspricht auch in diesem Fall damaligen Verhaltensweisen.533

Das, wie zahlreiche Überlebende bekunden, als unglaublich und teilweise unwirklich empfundene Geschehen in den Lagern wird von Benigni umgesetzt und wie folgt erläutert: Ich habe ausführliche Recherchen gemacht [...]. [...] Es ist so unfaßbar, daß es fast wieder einfach ist, glauben zu machen, daß das alles nur ein Spiel war.« (Benigni/Cerami 1998: 195f., H.i.O.) ${ }^{554}$ So läßt er seinen Hauptdarsteller dem zweifelnden Sohn die Lagerrealität als ein Spiel, einen Wettbewerb erklären, den es zu gewinnen gilt.

Während bei Benigni die Verhältnisse im Lager dennoch deutlich werden, zeigt Mihaileanu seinen Protagonisten nur in der letzten Einstellung als Häftling hinter Stacheldraht, die Vernichtungspolitik wird »lediglich« in Gestalt des niedergebrannten Nachbardorfes sowie der Konfrontationen mit den Nazis während der Flucht thematisiert. Ansonsten steht dieser Film ganz im Zeichen von Schlomos Wunschtraum, ist weit entfernt von einer historischen Rekonstruktion. 55

Für die deutlich markierte Fiktionalität beider Filme (inklusive Jаков тне LIAR) ist die »Metapher des Schauspielens und Inszenierens« von entscheidender Bedeutung. Mit diesem, als »Vertrag mit dem Zuschauer« fungierenden, Verfahren bezeichnet Loshitzky

»[...] das Gestaltungsmittel des Spiels im Spiel in TO BE OR NOT TO BE, dessen Handlung im Theatermilieu angesiedelt ist, das Gleichsetzen des Überlebens mit einem Spiel in LA VITA È BELLA, das Inszenieren eines Transports in TRAIN DE VIE und die Verwendung eines Radios als strukturierende Metapher in JAKOB THE LIAR. Die Dominanz der Metapher des Schauspielens und 
Inszenierens signalisiert den Zuschauern, daß hier kein Versuch der Wahrhaftigkeit unternommen wird, da es sich lediglich um eine Komödie handelt [...].« (2003: 29)

Die auffällige Fiktionalität ergibt sich zudem aus den märchenhaften Zügen beider Filme. ${ }^{56}$ Indem sie ihre Geschichte so erzählen, daß sie »den Anforderungen der naiven Moral« völlig entspricht, »also nach unserem absoluten Gefühlsurteil >gut` und >gerecht< ist« (Jolles 1982: 241, H.i.O.), erfüllen sie ein menschliches Grundbedürfnis.

Während Mihaileanu den Beginn seines Films mit der Standardformel »Es war einmal« beginnen läßt (s. 4.2.3.aa), wird die erste Hälfte von DAS LEBEN IST SCHöN von der Romanze zwischen dem Protagonisten Guido und seiner Prinzessin bestimmt (s. 4.1.3).

Mit der Entscheidung für eine fiktionale Herangehensweise geht eine besondere Diskretion in bezug auf die Darstellung der Schrecken einher. ${ }^{557}$ Schockierende Bilder, die abstumpfend auf den Zuschauer wirken könnten, werden bewußt vermieden.

Selbst im zweiten Teil des Films verzichtet Benigni auf explizite Gewaltdarstellungen, obwohl dieser ausschließlich im Vernichtungslager spielt. Das Schicksal des Onkels in der Gaskammer wird elliptisch inszeniert, Guidos Ermordung findet hinter einer Mauer statt. Benigni verweist lediglich in Form eines kaum erkennbaren, stilisierten Berges lebloser Körper auf die grausame Wirklichkeit, während bei Mihaileanu allein das niedergebrannte Dorf die Vernichtung visualisiert. In den Konfrontationen der falschen Nazis mit den echten ist das Grauen jedoch unterschwellig permanent präsent. $55^{8}$

556. Vgl. u.a. Distelmeyer 2000: 36, Insdorf 2003, Oster/Uka 2003: 262.

557. Vgl. auch Oster/Uka 2003: 263.

558. Kassovitz führt uns die Brutalität der Nazis im Vergleich zu Benigni und Mihailenau jedoch stärker vor Augen. Unmittelbar im Anschluß an den Vorspann entdeckt Jakob vier dem Galgentod zum Opfer gefallene Juden, die gleichwohl von hinten sowie aus einiger Distanz zu sehen sind. Neben alltäglichen Grausamkeiten zeigt Kassovitz den Tod Herschels aus der Entfernung, während Jakobs Folterung und Erschießung schonungslos inszeniert wird.

559. Vgl. auch II.3 und II.5.

560. Kassovitz zentriert seine Geschichte um den Protagonisten und eigentlichen AntiHelden Jakob Heim. Zufällig gerät dieser in die Lage, seiner unmittelbaren Umgebung - dem neugierigen Frisör, dem kleinen Mädchen und dem verliebten Mischa - Hoffnung machen zu können und ihnen so Mut zum Durchhalten zu schenken.

561. »[Das Leben ist schön] geht sehr dezidiert mit Genrewirkungen um. Charakteristisch für den Film ist jedoch, daß er dabei nicht den Bau- und Wirkungsgesetzen eines einzigen Genres folgt, sondern eine Hybridform aus mehreren Genres bildet, für die mir die Bezeichnung >Polygenre am treffendsten scheint, weil sie zum Ausdruck bringt, daß hier eine Art Polysemie waltet und die jeweiligen emotiven Genrewirkungen auch bewußt zueinander in Gegensatz gebracht werden können.« (Wuss 2002: 135, H.i.0.)

562. Vgl. Todorov zum Verhältnis des Dichters zur Geschichtsschreibung: »Wenn die Geschichte der Ausgangspunkt seiner Fiktionen ist, kann sich der Dichter gegenüber dem exakten Verlauf der Tatsachen zwar Freiheiten herausnehmen, dies aber nur, um deren verborgenes Wesen herauszustellen: darin beruht, wie schon die Alten sagten, die Überlegenheit der Dichtung über die Historie.« (1993: 296) 
Wie die meisten Spielfilme über den Holocaust erzählen auch diese beiden Regisseure (ebenso wie Kassovitz) die Geschichte einzelner Figuren und bieten dem Zuschauer auf diese Weise die Möglichkeit der Identifikation mit Einzelschicksalen, anstatt ihn mit massenhafter Vernichtung auf Distanz zu halten. 559

Benigni konzentriert sich auf das Schicksal der Familie Orefice, wobei er dem Zuschauer eine intensive Nähe zu Vater Guido und seinem Sohn Giosuè anbietet. Besonders verbunden fühlt man sich mit Guido, wenn er die grausame Realität unter größter Anstrengung von seinem Sohn fernzuhalten sucht.

In Zug Des LeBens begleitet der Zuschauer ein ganzes Schtetl auf der Flucht vor den Nazis. Dennoch rückt Mihaileanu einige Figuren in den Mittelpunkt, während andere eher im Hintergrund bleiben (s. II.4.2.1). Speziell zu Schlomo läßt der Regisseur eine besondere Beziehung entstehen, da dieser zum einen als Erzähler der Geschichte fungiert, zum anderen Teil derselben ist und sich die unwahrscheinliche Geschichte der Rettung erträumt..$^{60}$

Während Benigni insbesondere die persönliche Tragödie einer italienischen Kleinfamilie erzählt, »mit der sich jeder sofort identifizieren kann«, gelingt es Mihaileanu, »von der untergegangenen jüdischen Kultur [zu] erzählen, die Vernichtung eines ganzen Volkes spürbar [zu] machen« (Kniebe 2000:19; s. II.4.2.1).

Indem beide Regisseure Anleihen bei unterschiedlichen Genres machen, kann man sie als »Polygenres « bezeichnen (vgl. Wuss in bezug auf Benignis Film ${ }^{561}$ und s. II.4.2.1 zu Mihaileanus Film). Darüber hinaus erfüllen sie die Forderung Eisensteins, derzufolge ein Künstler durch besondere kompositorische Gestaltung seine eigene Einstellung zum Ausdruck bringen sollte und er so ein analoges Verhalten beim Adressaten auszulösen vermag: »Car il s'agit non seulement [...] de >représenter < par la référence l'attitude de l'auteur mais d'en produire une impression, une >Einstellung<, un comportement analogue chez le spectateur.« (Kloepfer nach Eisenstein 1998: 11, H.i.O.) An die Stelle des Versuchs einer realistischen Darstellung »Absoluter Realismus ist keineswegs die richtige Wiedergabe der Wahrnehmung.« (Eisenstein 1963: 271) - tritt also der Wunsch, die Thematik in ihren Prinzipien erfahrbar zu machen..$^{62}$ 


\section{II.4.1. LACHEN UND WEINEN - ARLECCHINO IM VERNICHTUNGSLAGER: »DAS LEBEN IST SCHÖN« (»LA VITA È BELLA«, ROBERTO BENIGNI, I 1997) 563}

»Ich habe keine Komödie über den Holocaust gemacht ich bin ein Komiker, der eine Tragödie gemacht hat.« (Roberto Benigni) ${ }^{564}$

4.1.1 Ein Märchen zwischen Horror und Komik « «65

Bereits mit der Wahl des - in allen Versionen gleichlautenden - Titels grenzt sich der italienische Regisseur, Drehbuchautor und Schauspieler Roberto Benigni von den Titeln vorangegangener Holocaust-Filme deutlich ab. Im Original lautet er LA VITA ì Bella, in der deutschen Version DAS LeBen IST SCHÖN und in der englischen LifE is BEAUTIFUL.

563. Das folgende Kapitel lehnt sich an zentrale Ergebnisse aus der Diplomarbeit der Verfasserin an (s. Bibliographie, Corell 2000).

564. Zit. nach Wuss in Sellmer/Wulff 2002: 137.

565. Distelmeyer 200: 36.

566. Insgesamt erfüllt der Titel zwei, von Schreitmüller analysierte, Funktionen: Zum einen informiert er den Zuschauer in bezug auf das Thema (1994: 126), zum anderen variiert er einen anderen Filmtitel, womit dem Publikum »suggeriert werden [soll], daß der neue Film ähnliche Eigenschaften aufweist« (ebd. 192).

567. ")My father was in the war, in a labor camp in Erfurt, in Germany<, Benigni told journalists in Jerusalem. >It was very different from a concentration camp, because the scope was work, and death was accidental. The way my father would tell the story to me and my three older sisters was exactly the way Guido was in the movie with his son: He didn't want to frighten us, so he told us the story in a very funny way. Not like slapstick - in a tragic way, but also funny.« (Benigni zit.n. Kotzin 1998: 40)

568. Vgl. Levi, Kertész, Semprún und Todorov (s. Bibliographie).

569. Benigni auf: www.lavieestbelle.com/entretien.html; vgl. auch Benigni in ders./Cerami 1998: $195 f f$.

570. Benigni auf: www.arte.fr/benigni.html. Mit dieser Idee der Vater-Sohn-Konstellation entfernte sich Benigni jedoch weniger weit von der Realität, als er zunächst angenommen hatte: »Après avoir écrit le scénario, j'ai lu un livre qui s'appelle >l'Enfant de Buchenwalds, et qui raconte une histoire très semblable. Ce qui m'a effrayé, c'est que la réalité est parfois surprenante, et quand on invente les situations les plus abominables, on découvre qu'elles ont existé.« (Benigni auf: www.lavieestbelle.com/entretien.html)

571. Zur Rezeption des Films im angloamerikanischen Sprachraum vgl. Laster/Steinert 2003.

572. »We don't see any brutality, either (though there is one ghostly image of corpses), and so the film, stylizing reality to an insane degree, treat us like children, too. In LIFE Is BEAUTIFUL, Benigni transforms the Holocaust into a grimly tidy postcard - he vacuums it of meaning. The film starts out as sentimental whimsy and ends as sentimental kitsch." (Gleibermann auf: www. ew.com/ew/re-view/archive/0, 1683, 359,00.html) Vgl. auch N.N. auf http://wsws.org/de/1998/ nov1998/ben-n17.shtml und N.N. auf http://members.tripod.com/ Kuroto/fk/lebenistschon. html.

573. N.N. auf: www.lavieestbelle.com/images/pages/presse/histoire.html. 
Auf diese Weise macht Benigni schon im Titel deutlich, daß den Zuschauer ein lebensbejahender Film erwartet (s. II.4). Die Filmüberschrift dürfte die Neugier des Publikums wecken, erscheint es doch als extremes Wagnis, angesichts des schwärzesten Kapitels in der Geschichte des 20. Jahrhunderts, ein filmisches Bekenntnis zur Schönheit des Lebens abzulegen.

Die lebensbejahende Botschaft sichert Benigni mit zwei intertextuellen Verweisen ab: Filmkenner verstehen Benignis Anspielung auf Frank Capras Melodram IT's A WONDERFUL LIFE/IST DAS LEBEN NICHT SCHÖN (USA 1946), in dem ein junger Mann durch Liebe und Freundschaft vom Selbstmord abgehalten wird. Weniger bekannt dürfte Benignis Anspielung auf ein Zitat Trotzkis gewesen sein, der seiner Frau, kurz vor der Ankunft seiner Mörder, die Zeilen »Das Leben ist schön« geschrieben haben soll..$^{66}$

Ausgangspunkt der Überlegungen Benignis bezüglich des unorthodoxen Umgangs mit der schwer zugänglichen Thematik war - neben anderen Aspekten (s. II.4) sowie persönlicher Erfahrung ${ }^{567}$ - die Aussage ehemaliger Lagerhäftlinge, daß selbst $>$ sie< nicht in der Lage waren, das Grauen zu begreifen..$^{56}$ Wenn weder heute noch damals Betroffene diese Zeit und deren Umstände begreifen können, wie soll eine Situation solchen Ausmaßes Außenstehenden oder gar Kindern vermittelt werden? Schließt dieses Überschreiten jeglichen Fassungsvermögens und die daher empfundene Unwirklichkeit der Lagerrealität nicht die Möglichkeit jeglicher Erklärungsversuche von vornherein aus? Vor diesem Hintergrund ist Benignis unorthodoxe, fiktionale Behandlungsweise des Holocaust zu beurteilen, die er wie folgt beschreibt: »Je n'ai jamais songé à faire une reconstitution exacte. [...] C'est une idée - au sens quasi platonicien - de camp, l'idée d'une antre du Mal, d'une antre du monstre. Comme dans un conte pour enfants. ${ }^{569}$

Zur dramaturgischen Umsetzung seiner Absage an jegliche realistische Vermittlung entschied sich Benigni dafür, den Protagonisten Guido - und mit ihm den Zuschauer - die Unmöglichkeit der Erklärung des Holocaust anhand der Fragen seines Sohnes Giosuè erfahren zu lassen:

»Dans une situation extrême, qui n'a plus rien de réel, plus rien d'humain, il faut cacher la vérité à l'enfant. Je dois lui dire: ১Ça n'existe pas, Ça n'aurait jamais du exister!«. Dans une situation extrême, je dois me comporter de manière extrême! [...] Je le sauve-garde pour qu'il conserve sa pureté. Qu'est-ce que je dis à un enfant de cinq ans dans un camp d'extermination? >Regarde, mon fils, ici, ils nous mettent dans un four et ils nous brûlent! «... Avant de le dire à mon fils, il faudra qu'ils me tuent d'abord! Après, je lui dirais! [...] Il finira par savoir! « ${ }^{570}$

Der - u.a. als Kunstgriff bezeichnete - Umweg über extreme Fiktion (s.u.) wurde Benigni gleichwohl von zahlreichen Kritikern erbittert vorgeworfen. ${ }^{571}$ Sie waren der Ansicht, einem solch gewichtigen Thema könne man unter keinen Umständen mit Fiktion und Komik begegnen, dies käme einer Verharmlosung der historischen Fakten gleich..$^{52}$ Nicht nur Verharmlosung, sondern auch Negierung der geschichtlichen Tatsachen wurde Benigni vorgehalten u.a. von der französischen Tageszeitung »Le Monde - »première comédie négationniste dans l'histoire du cinéma«.573 Daneben gab es Stimmen, die dem italienischen Regisseur - in Anbetracht des Versterbens 
der letzten Zeitzeugen sowie der Menschen, welche die historischen Fakten abstreiten - inadäquaten Umgang mit dem Thema vorwarfen: »In this climate, turning even a small corner of this century's central horror into feel-good popular entertainment is abhorrent. «574

Begrüßt wurde Benignis Entscheidung gegen einen realistischen Rekonstruktionsversuch der Lagerbedingungen und für eine extrem fiktionale Herangehensweise insbesondere von Personen, die von der Unmöglichkeit der »Darstellung des Undarstellbaren « ausgehen:

»Benigni a eu l'intelligence de ne pas chercher une reconstitution réaliste. C'est plutôt une idée du camp qu'il nous propose, une stylisation et non la représentation de l'immontrable - la solution finale. $\aleph^{575}$

»In diesem Falle ist entsprechend der Autorenintention unter der Maxime DAS LEBEN IST SCHÖN eine Parabel ıüber die Kraft der Liebe und die Macht der Vorstellungskraftı entstanden.« (Werneburg zit.n. Wuss 2002: 136) $)^{576}$

Ähnlich wie Zug Des LeBENs (s. II.4.2) zeichnet sich auch Benignis Spielfilm dadurch aus, daß er unterschiedliche Genrewirkungen aufweist (s. II.4 zum Polygenre):

574. Schickel auf: www.time.com/time/magazine/1998/dom/981109/the_arts.cinema. fascist4a.hmtl.

575. N.N. auf : www. lavieestbelle.com/images/pages/presse/positif.html.

576. Vgl. auch N.N. auf www.insideout.co.uk/movies2/beautiful.htm, Whipp auf: www. miramax.com/lifeis beautiful/life_review_01.html und Goldberger auf: www.film.u-net.com/ Movies/Reviews/Life_Is_Beautiful.html.

577. Georg Seeßlen auf: www.epd.de/film/welcome_small.html. Vgl. auch Wuss: »In einem frühen Arbeitsstadium sollte der Film »Guten Morgen, Prinzessin« heißen, und wenn man so will, enthält die Geschichte bis zum Schluß Anklänge an Legende und Märchen. Etwa, wenn nach der Flucht der Lagerwachen die Gefangenen plötzlich auf den Hof hinaustreten und dann scharenweise durch das weit geöffnete Tor von dannen ziehen, oder - eine ähnlich märchenhaftunwirkliche Wendung - wenn der versprochene Panzer, einem Fabelwesen gleich, auf dem Hofe auftaucht. Magische Gesten der Personnage, Zauberformeln und Rätsel sorgen für eine entsprechende Atmosphäre, die in die Mögliche Welt des Märchens führt. [...] Auch diese Mittel fördern eine bestimmte gefühlsmäßige Disposition des Zuschauers, die die Vorgänge ins Reich der Phantasie zu transponieren hilft.« (2002: 137)

578. Vgl. Lederle zur »quälenden `Komödien<-Form« auf: www.filmdienst.de/Das Leben ist schön.html (H.i.0.).

579. N.N. auf: www.lefigaro.fr/campus/interviewN1.htm.

580. N.N. auf: www.lavieestbelle.com/images/pages/presse/figaro.html.

581. Waldron-Mantgani auf: http://members.aol.com/ukcritic/LifeIsBeautiful.html.

582. Ebert auf: www.suntimes.com/ebert/ebert_reviews/1998/10/103003.html. Vgl. auch Ravaschino auf: www.primerplano.com/criticas/vida \%20es \%20bella, \%20la.htm.

583. Foxman auf: www.miramax.com/lifeisbeautiful/life_review_03.html.

584. Moinet auf: www.lavieestbelle.com/images/pages/presse/figaro.html. 
»Der Film vereint nicht nur Strukturbeziehungen und Reaktionsweisen von Parabel, Komödie und Tragödie, sondern er neigt auch zum aktionsbetonten Drama, das ebenso auf Spannung und Suspense wie auf dramatisches Pathos setzt. Für den Film charakteristisch ist, daß sich analog zum Finale - im Gesamtgeschehen Passagen mit ganz unterschiedlicher Genreaffinität einander ablösen. Punktuell zur Dominanz gebracht, sorgen sie für eine je spezifische emotionale Färbung.« (Wuss 2002: 137f.)

Der bewußt fiktionale Charakter von DAS LEBEN IST SCHöN ergibt sich v.a. aus seinen Anleihen beim Märchen und bei der Legende (s. 4.1.3.bb):

»Roberto Benigni hat das Kunststück fertiggebracht, ein Märchen zu erzählen, in einem Film, der nie vorgibt, etwas anderes zu sein als ein Märchen, in Bildern, die sich weniger aus der Rekonstruktion der Wirklichkeit als aus den vorhandenen Bildern entwickeln, aus Zitaten, Übermalungen, Stilisierungen, und gerade, weil er nicht vorgibt, den wahren Schrecken eines Konzentrationslagers beschreiben zu können, bleibt uns eben dies auch gegenwärtig: Es war viel schlimmer, es war schlimmer, als irgendein Mensch, irgendein Bild, irgendeine Erzählung aushalten kann. $\ll^{577}$

Auf Kritik stieß insbesondere die Tatsache, daß Benigni dem Holocaust mittels Komik bzw. Ironie begegnet und zum Teil »offen zur Komödie tendiert« (Wuss 2002: 137). .578

Die Annäherung an den Holocaust mittels Komik verteidigt der Regisseur, indem er darauf hinweist, daß er über den Holocaust keineswegs lacht, geschweige denn ihn abzustreiten versucht: »Nous ne rions pas de l'holocauste, ce serait horrible.«579 »On peut rire également dans la tragédie. [...] Mais je suis si loin du révisionnisme ... Ce film, c'est mon cri. $\aleph^{80}$

Befürworter des Films haben wiederholt darauf aufmerksam gemacht, daß die Debatte falsch geführt werde, da man im Falle von DAS LEBEN IST SCHÖN - vor allem in bezug auf die zweite Hälfte des Werks - nicht von einer reinen Komödie sprechen könne: »This film is not, as some reviews have called it, a comedy about the Holocaust. It's the Holocaust as told by a comedian. $\ll^{581} »$ He is a clown, and comedy is his weapon. $\ll^{582}$ Demnach muß zwischen dem Genre und den diskursiven Verfahren - dem Einsatz von Komik bzw. Ironie - klar unterschieden werden. Daß sich Benigni an die systematische Judenvernichtung mit Humor herangewagt hat, wird von etlichen Filmkritikern und Überlebenden sowohl hinsichtlich wirkungsästhetischer Gesichtspunkte als auch in Bezug auf die Form des Umgangs mit dem Thema durchaus positiv beurteilt - Komik als »Spezialfall von Verfremdung« (Wuss 2002: 137):

»The comedy in the film actually heightens the anxiety the viewer has about the horror that is occurring, humanizing the tragedy in ways that a more direct depiction may not. $\aleph^{583}$

»Tous les regards adultes, surtout à Jerusalem, perçoivent le rire comme une immense respiration, comme une solide protection contre l'impact de la tragédie. En rien sa négation. ${ }^{584}$

»Benigni $[\ldots]$ is not trying to get people to think >maybe it wasn't that bad after alk, but rather let us apply our own knowledge of the Holocaust to his vague imagery. This is effective. 
[...] our experience is not just limited to the horrors of the screen - a lot of the film is taking place in our own imagination, a place without bounds. $\aleph^{585}$

Insbesondere gegen Ende des Films fallen Genre-Anleihen bei der Tragödie (Guidos Tod) sowie dem aktionsbetonten Drama (Guidos verzweifelte Suche nach Dora) auf, in der Schlußsequenz überwiegt dramatisches Pathos (»Wir haben gewonnen!«) (Wuss 137).

Für die identifikatorische Betroffenheit des Zuschauers ist jenseits der spezifischen Genrewirkungen entscheidend, daß Benigni die Auswirkungen des Holocaust auf ein Einzelschicksal zeigt. ${ }^{56}$ Die vielfach gelobte Möglichkeit des besonderen Mitfühlens entspringt der Erfahrbarkeit sowohl väterlicher Liebe als auch der Kraft der Phantasie. ${ }^{87}$ Insofern bezeichnen zahlreiche Kritiker DAS LEBEN IST SCHÖN - gemäß dem Titel - als lebensbejahenden Film (s. II.4): »He [Benigni] does it by showing the human capacity to survive, to sacrifice, to find humour and hope - to show that life, indeed, is the most beautiful thing in the world. $\ll^{58}$

585. Waldron-Mantgani auf: http://members.aol.com/ukcritic/LifeIsBeautiful.html, H.i.0. Vgl. auch Means auf: www.film.com/film-review/1998/10745/27/default-review.html, Goldberger auf: www.film.u-net.com/Movies/Reviews/Life_Is_Beautiful.html, N.N. auf www.lavieestbelle. com/images/pages/presse/histoire.html, N.N. auf http://infilmau.iah.net/reviews/lifeis.htm.

586. Vgl. Means auf: www.film.com/film-review/1998/10745/27/default-review.html, N.N. auf www. fortunecity.com/lavendar/heat/435/life.htm, Waldron-Mantgani auf: http://members. aol.com/uk critic/LifeIs Beautiful.html.

587. Vgl. Adams auf: www.citypaper.net/movies/I/lifeisbeautiful.shtml.

588. Means auf: www.film.com/film-review/1998/10745/27/default-review.html. Vgl. auch N.N. http://apolloguide.com/mov_fullrev.asp?CID=845, Whipp auf: www.miramax.com/lifeisbeautiful/life_review_01. html, Mathews auf: www.miramax.com/lifeisbeautiful/life_review_01.html.

589. Vgl. Benigni in einem Interview mit ARTE auf die Frage, ob das Lager Thema des Films oder Schauplatz sei: »... C'est le sujet, sans doute. C'est plus qu'un camp de concentration, c'est un camp d'extermination! ... C'est le sujet du film, on ne peut y échapper. C'est tellement fort qu'un autre sujet aurait du mal à passer. Oui, bien sûr, l'histoire d'amour ... le sujet principal est l'histoire d'amour, mais c'est une histoire d'amour dans un camp d'extermination, et quand on parle d'un camp d'extermination, rien ne peut être plus fort que Ça! C'est tellement fort que les autres sujets sont subordonnées à cette idée ... C'est le vrai sujet du film, ce n'est pas simplement un décor.« (www.arte.fr/benigni/html)

590. »Man muß die Lager nur mit Gefängnissen vergleichen, um zu ermessen, inwiefern sie eine Inkarnation des Extremen sind. Man wird meist ohne Gerichtsurteil in sie geschickt, folglich gibt es auch keine Rechtsmittel, um herauszukommen. Man leidet unter der Kälte, dem Hunger und der kräftezehrenden Zwangsarbeit. Man ist der Gewalt und Willkür der Kapos, bzw. ihrer Äquivalente ausgeliefert, die unter den brutalsten Verbrechern rekrutiert werden. Man lebt ständig unter der Drohung (oder Wirklichkeit) von Schlägen, im Schatten des Todes. Daneben ist das Gefängnis ein Sanatorium. (Todorov 1993: 314) »The challenge of Benigni's work is that it binds two diametrically opposed subjects in a balanced and entertaining way. His tale of a >love that was meant to ber is told engagingly and whimsically in the first part of the movie. The second part of the movie delves into horror and tragedy which test the limits and meaning of such love (indeed any love).« (www.fortunecity.com/lavendar/heat/435/life.htm) 


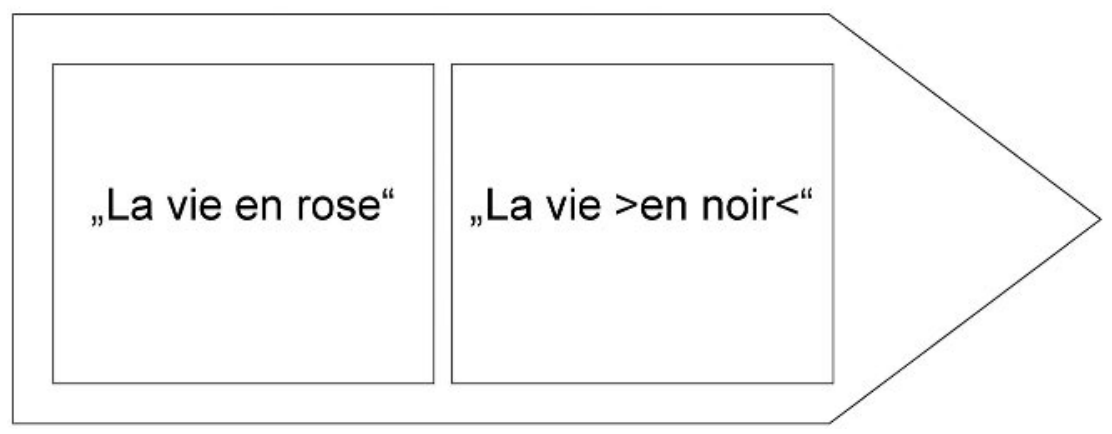

Abb. II.4.1.a

Abgesehen von der überwiegend positiven Resonanz in der Presse sprechen nicht zuletzt die zahlreichen Auszeichnungen für die Qualität von DAS LEBEN IST sChöN. Zu den bedeutendsten zählen der »Grand Prix de la Jury« in Cannes 1998, die Wahl zum »Besten europäischen Film 1998« anläßlich der Verleihung des Europäischen Filmpreises, die Auszeichnung mit dem »Best Jewish Award « beim Internationalen Filmfestival in Jerusalem 1998 und vor allem der »Oscar« für den besten ausländischen Film, den besten Schauspieler (Roberto Benigni) und die beste Musik im Zuge der Verleihung der amerikanischen »Academy Awards« (1999). Die unterschiedlichen Preise belegen die internationale - Europas Grenzen überschreitende - Anerkennung, die Benignis Werk zuteil wurde.

\subsubsection{Leitthesen}

Durch ein Nach- und Ineinander von Komik und Tragik wird in Roberto Benignis Spielfilm DAS LEBEN IST SCHÖN der Zuschauer alternierend zum Lachen oder Weinen veranlaßt. Den von zahlreichen Überlebenden, mittels des Vergleichs mit einem Streich bzw. einem Schauspiel, bekundeten Eindruck der Unwirklichkeit nimmt Benigni wörtlich. Um seinem Sohn die grausame Lagerwirklichkeit vorzuenthalten, erfindet Held Guido die Wettbewerbsgeschichte und verteidigt sie gegenüber dessen kritischen Fragen - »Lügen, die einer höheren Wahrheit entsprechen« (Benigni zit.n. Reichel 2004: 313). Obwohl der zweite Teil des Films ausschließlich im Vernichtungslager spielt, verzichtet Benigni weitgehend auf die Inszenierung und Visualisierung der grauenhaften Lagerbedingungen. So findet diese durch Rückübersetzung Guidos ironischer Verkehrungen im Kopf des Zuschauers statt. Über die - den Film charakterisierende - rhythmische Kompositionsstruktur zwischen extrem fiktionalen Elementen und vorsichtigen Verweisen auf den aufkommenden Faschismus bzw. die Lagerrealität wird das Sich-Einlassen seitens des Zuschauers auf die schwer zugängliche Thematik insgesamt erleichtert. Je nach Grad der Involvierung bietet DAS LEBEN IST SCHÖN dem Adressaten verschiedene Stufen des Umgangs an: Distanzierung durch Lachen und/oder mitfühlende Nähe durch Weinen.

Aus grobstruktureller Untersuchungsperspektive besteht Benignis Spielfilm DAS LEBEN IST SснӧN aus zwei nahezu gleich langen Abschnitten - dem Eingangsteil, der in einer italienischen Kleinstadt spielt, und dem Hauptteil, dessen Schauplatz ein nicht näher bezeichnetes Vernichtungslager ist. ${ }^{8}{ }^{9}$ Während der erste Teil ( 67 von 117 Filmminuten) die Liebesgeschichte zwischen Guido und Dora und das Leben der kleinen Familie beschreibt, sind die Protagonisten im zweiten Teil der Extremsituation eines nationalsozialistischen Vernichtungslagers mit all seinen Widrigkeiten ausgesetzt.590 
Diese evidente Zweiteilung ist für die sich wandelnde Beteiligung des Zuschauers von entscheidender Bedeutung. Während er über weite Strecken der ersten Hälfte des Films auf die angelegte Komik mit unbeschwertem Lachen reagieren kann, bleibt es ihm im zweiten Teil wohl eher »im Halse stecken« bzw. ist er möglicherweise den Tränen nahe. ${ }^{591}$

»Der als Loblieb auf die Kraft der Fantasie und den menschlichen (Über-)Lebenswillen gedachte Film beginnt als beschwingte Romanze mit märchenhaften Untertönen und endet in einer bitter-absurden Tragödie, in der das Lachen zum schmerzhaften Reflex gefriert. « ${ }^{592}$

\section{a) Polyfunktionalität der Exposition}

Der auffälligen Länge der Exposition des Films sind zwei zentrale Funktionen zuzuschreiben.

Einerseits ermöglicht sie Benigni, den sozio-historischen Kontext mit besonderer Behutsamkeit und in rhythmischer Dosierung sukzessiv einzuführen. Zunächst ordnet er die Anzeichen für den aufkommenden Faschismus der Komik unter und gestaltet sie auf subtile Weise, um uns in einem ersten Schritt zu sensibilisieren. Im weiteren Verlauf verweist er zunehmend explizit auf die Bedrohung der italienischen Juden. Gegen Ende des Eingangsteils wird die Bedrohung Realität, die anfänglich fröhlichbeschwingte Stimmung schwindet nach und nach, um in der tragischen Deportation der Juden zu münden.

Andererseits bereitet die Exposition den Zuschauer systematisch auf den fiktionalen Charakter des gesamten Films vor: Zum einen durch das komödiantische Verhalten des Protagonisten in den verschiedensten Lebenssituationen, zum anderen durch die entstehende - im Sinne von Jolles (s. II.4) - märchenhafte Romanze zwischen dem

591. Vgl. N.N. - »Le film est construit en deux parties: une cinglante satire du fascisme italien d'abord, puis une formidable fable sur la Solution finale. [...] On rit dans la première partie, on pleure dans la seconde.« (www.lavieestbelle.com/images/pages/presse/histoire.html) - sowie Ebert: »The film falls into two parts. One is pure comedy. The other smiles through tears." (www.suntimes.com/ebert/ebert_reviews/1998/10/103003.html)

592. Lederle auf: www.filmdienst.de/Das Leben ist schön.html.

593. »Damit Komik und Witz wirkliche Tiefe bekommen, muß der Humor auf die Probe gestellt sein.« (Plessner 1941: 280) Die Wirkung der abgründigen Komik steigert sich, »je näher sie dem Dunkel der Tragik« kommt (ebd. 304), was insbesondere für die zweite Hälfte des Films charakteristisch ist (s. 4.1.3.ba).

594. Vgl. Kloepfer zur »Lust an der menschlichen Plastizität« (Kloepfer 1996, 131). Man erinnere sich in diesem Zusammenhang an folgende Filmszenen: Begegnung mit der Prinzessin, listiges Entwenden des Hutes, Kellnerimprovisation, Erprobung von ıSchopenhauers Willenskraft<, Beeinflussung der Menüauswahl des Ministerialrates und Herbei->Zaubern< des Gerichts, Auftritt in der Grundschule, erste >Entführung< seiner Prinzessin.

595. Man denke hauptsächlich an folgende Szenen: die unzureichende Aufmerksamkeit des Polsterers bzw. des Ministerialrates, Ferruccios erbärmliche Kondition, erste »Entführung« Doras und die drei »Zufälle« (s. 4.1.3.ba)

596. Vgl. Kertész, Levi, Semprún und Todorov (vollständige Angaben in der Bibliographie).

597. Vgl. Benigni in ders./Cerami 1998: 195 in II.4. 
Helden und seiner »Prinzessin«. Während die ausführliche Präsentation des Helden und seiner Begabung die Plausibilität seines späteren Verhaltens im Lager erhöht, dramatisiert die romantische Liebesgeschichte die tragische Trennung der Geliebten im Lager.

Benigni erzeugt eine heiter-gelöste Atmosphäre, indem er dem Zuschauer zunächst hauptsächlich Momente oberflächlicher Komik anbietet (Plessner 1941: 331f.), vor allem hervorgerufen durch Wiederholungseffekte, analoge bzw. parallele Situationen, Wort- und Situationskomik. Auf diese Weise ermöglicht er uns, überwiegend befreit zu lachen. Die Dominanz fröhlicher Stimmung wird jedoch nach und nach von einem fein ausbalancierten Spannungsverhältnis zwischen der sich zuspitzenden politischen Lage einerseits und Guidos ironischen Verkehrungen der Realität andererseits abgelöst. Dies ergibt sich aus der zunehmenden faschistischen Bedrohung gegen Ende des Eingangsteils und aus dem damit einhergehenden Übergang von oberflächlicher zu abgründiger, mit einem bitteren Beigeschmack versehener Komik. 593

Insgesamt erzielt die Komik der ersten Hälfte des Films eine große Wirkung auf den Zuschauer: Die naheliegende Sympathie für den Helden lädt dazu ein, der Freude über Guidos Witze, Vitalität und kindliche Durchtriebenheit lachend Ausdruck zu verleihen. ${ }^{594}$ Die aus der Annahme des Identifikationsangebotes resultierende Nähe zu Guido ermöglicht es uns, während der Scherze bzw. »Zufälle« die Verblüffung anderer zu antizipieren und mit dem Protagonisten aus Freude über den Wissensvorsprung bzw. über körperliche oder geistige Trägheit zu lachen. ${ }^{595}$ So häufen sich z.B. in der Schlüsselsequenz des ersten Teils bei Guidos »Verkündung des Rassenmanifests « die turbulentesten Szenen und Slapstickeinlagen, welche beim Zuschauer Heiterkeit und Lachen auslösen (s. 4.1.3.ba).

Eine eher gegenteilige Reaktion entsteht gegen Ende des Eingangsteils, als Guidos zunehmend gezwungen und gekünstelt wirkendes Lachen die sich konkretisierende Gefahr spürbar macht.

\section{b) Kraft der Phantasie versus Lagerrealität - der Hauptteil des Films}

Die zweite Hälfte des Films zeichnet sich durch Benignis unorthodoxe Form des Umgangs mit dem Holocaust aus. Wie Lanzmann lehnt der italienische Regisseur jeden realistischen Repräsentationsversuch ab. Vergleichbar mit Mihaileanu und Kassovitz knüpft er nicht nur an die von Unernst und Unverständnis geprägte Einstellung verschiedener Überlebender an ${ }^{596}$, sondern macht sie sich zu eigen, indem er sich der Thematik indirekt zu nähern versucht (s. II.4).597

Um diese Haltung in seinen Film zu übertragen, konfrontiert Benigni seinen Protagonisten - und so indirekt uns - mit den drängenden Fragen seines Sohnes Giosuè. Um die Lagerrealität für den kleinen Jungen erträglich zu gestalten, erfindet Guido eine Wettbewerbsgeschichte: Guido täuscht seinem Sohn vor, das Lager sei ein großer »Wettkampfplatz«. »Ausgangspunkt ist das Prinzip, Traumata von Kindern fernzuhalten, die Reinheit zu schützen.« (Benigni in: ders./Cerami 1998: 197) Diese Motivation treibt den Vater zu permanenten, kräftezehrenden Anstrengungen.

Trotz der latenten Gegenwart der Lagerrealität sowie der damit einhergehenden, wachsenden Bedrohung liegt Benignis Schwerpunkt auch in diesem Hauptteil des Films auf den fiktionalen Elementen. Die schrecklichen Lagerverhältnisse sind auf zweierlei Art und Weise präsent: explizit durch die von Giosuè zufällig »aufgeschnappten« Informationen und Einschätzungen anderer Barackeninsassen, implizit durch 
Guidos wiederkehrenden ironischen Verkehrungen. Aufgrund des charakteristischen Wechselverhältnisses im Auftreten fiktionaler und realitätsnaher Szenen genügt insbesondere das Kernstück von DAS LEBEN IST SCHÖN dem von Eisenstein und Dewey - im Hinblick auf den Einbezug des Adressaten - geforderten Grundmuster des rhythmischen Aufbaus jeder künstlerischen Komposition. ${ }^{598}$

In Anlehnung an Eisensteins Forderung nach der durchgängigen Existenz des Gestus - den gesamten Film prägend und auch im Detail präsent - als Voraussetzung für die Entfaltung des Kunstvollen (s. Exkurs im Anhang), soll an dieser Stelle auf ein zentrales Moment des Hauptteils hingewiesen werden. Es ist das blitzschnelle Hin und Her zwischen realistischer Verkündung der Lagerrichtlinien und Guidos Interpretation derselben als Wettkampf - ein wirkungsvolles Ad-absurdum-Führen der Haftbedingungen (s. 4.1.4.bb). Mit Eisenstein und Dewey kann für diese exemplarische Szene festgestellt werden, daß deren kürzere Rhythmen Teile eines langen Rhythmus, des Globalgestus des Films, darstellen.599

Dank der - mit dem charakteristischen rhythmischen Wechsel zwischen dem einen und dem anderen Extrem einhergehenden - Existenz besagten Gegengewichts ist es dem Zuschauer eher möglich, sich den historischen Fakten zu stellen; er vermag kraft des Hoffnungsschimmers, das Grauenhafte zunächst zuzulassen und im weiteren auszuhalten. Darüber hinaus lädt uns die beißende Ironie des Protagonisten

598. »Die Zeitdauer dieser Abschnitte, das Tempo und ihre Reihenfolge vermittelt dem Zuschauer mit Hilfe dieses rein physiologischen Prozesses den Rhythmus und die Schnelligkeit der Assoziationen. Und genau dies ruft im Publikum eine echte Gemütsbewegung hervor.« (Eisenstein 1973: 192)

599. Siehe den Exkurs zum Phänomen des Rhythmus im Anhang.

600. Vgl. Kloepfer zum Phänomen des »inneren Films«: »Wirklich ist beim Film nur die Zeichenrealisation im geführten Bewußtsein (der sinnere Film), und hierbei spielt die gesteuerte Eigenleistung die entscheidende Rolle.« (Kloepfer nach Balázs 1996/97: 42)

601. Vgl. Kant zur ästhetischen Freiheit (»Ein Urteil über einen Gegenstand des Wohlgefallens kann ganz >uninteressiert،, aber doch sehr >interessantı sein, d.h. es gründet sich auf keinem Interesse, aber es bringt ein Interesse hervor; dergleichen sind alle reine moralische Urteile. Aber die Geschmacksurteile begründen an sich auch gar kein Interesse.« (Kant in: Frank/ Zanetti 1996: 524, H.i.0.)) sowie Kloepfers Aussagen in Anlehnung an den Existenzphilosophen F. Heinemann (»Das Maß der Respons hängt ab von meiner Teilhabe am jeweiligen Feld und von meiner Möglichkeit, verschieden gestimmt zu sein, sowie schließlich von der zunehmenden Freiheit, die Respons zu verzögern, sie umzustimmen oder zu übersetzen, sie vor allem mit anderen Resonanzen zu verbinden.«(Kloepfer 1982: 370f.))

602. Vgl. Plessner zum Aspekt des Maßverlusts (»Lachen und Weinen [...] sind besondere Formen des Ausdrucks, die einer Grenzerfahrung entsprechen, Antworten auf Situationen, in denen wir keine Antworten haben, sondern nur lachend und weinend solche sind. Es sind Antworten auf das Außerordentliche, auf das Unnormale, das Unmögliche [...] auf Grenzüberschreitungen. [...] Es geht dem Menschen das Maß verloren, das ihn sonst birgt.« (Kloepfer nach Plessner 1996: 167)) bzw. des Zulassens (»Es hängt ausschließlich vom Menschen ab, nicht aber von dem, was ihm da widerfährt, ob es ihn ergreift, packt, zur Kapitulation zwingt und ihm dergestalt losgelöst von allen Hinsichten in echter Sinnfreiheit begegnet.« (Plessner 1941: 281)). 


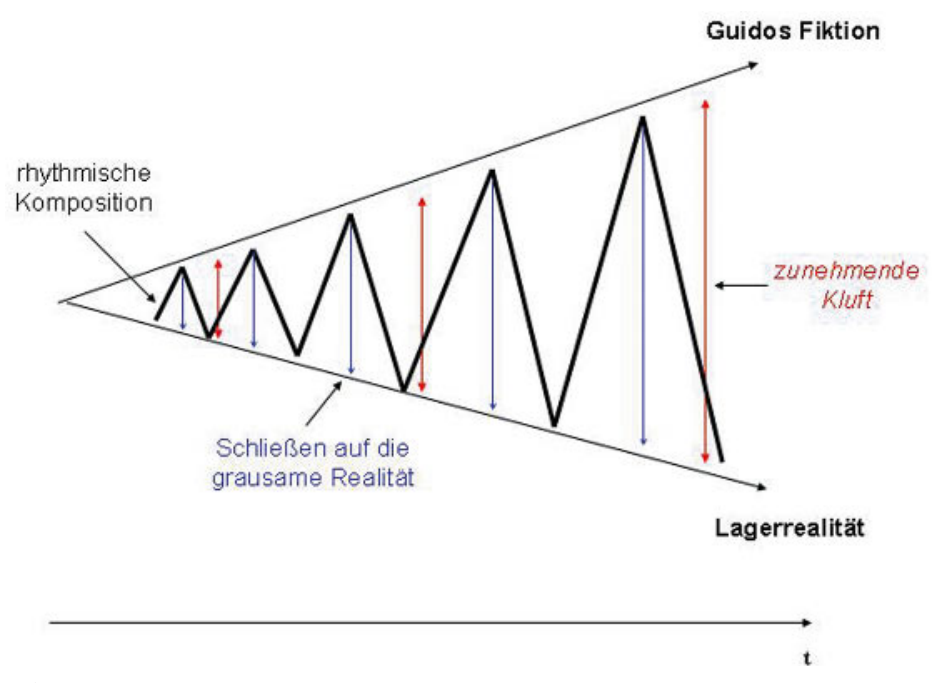

Abb

II.4.1.b

im Rahmen seiner permanenten Überzeugungsarbeit dazu ein, auf die unvermittelbare Lagerrealität als den Auslöser der kreativen Anstrengungen rückzuschließen. ${ }^{600}$ Diese Form der Eigenleistung gewinnt in dem Maße an Wirkkraft, wie die - durch Guidos immer skurrileren Einfälle angesichts der Zuspitzung der Lage hervorgerufene - Kluft zwischen den entgegengesetzten Energien im Verlauf des Hauptteils zunimmt.

Die Unwahrscheinlichkeit, dem Film bzw. der Thematik gegenüber eine ablehnende Haltung einzunehmen, ergibt sich aus der Freiheit des Zuschauers, das Maß des Zulassens von Unerträglichem selbst zu bestimmen ${ }^{601}$ : Anstatt in eine passive Haltung durch Reizüberflutung (mit Abstumpfung als möglicher Folge) zu geraten, kann er die durch Guidos ironische Verkehrungen angelegte Rückübersetzung genau in dem Umfang und in der Intensität ausführen, wie er es zu verkraften in der Lage ist. Weder auf verbaler noch auf visueller Ebene wird ihm explizit mehr zugemutet, als er ertragen kann. An die Stelle einer überfordernden Schockästhetik tritt somit ein respektvolles Umgehen mit dem Zuschauer. Anstatt ihn mit den historischen Fakten direkt zu konfrontieren, lädt Benigni eher dazu ein, sich dem schwierigen Thema zu öffnen - ohne jeglichen Zwang.

Das Maß der Beteiligung ist abhängig von der jeweiligen Reaktion auf die - sowohl im Film dargestellte, als auch durch die Thematik in uns ausgelöste - Grenzsituation. Während des gesamten Hauptteils von DAS LEBEN IST SCHÖN befindet sich der Zuschauer in einem wirkmächtigen Spannungszustand: Einerseits erlebt er die Absurdität des Lageralltags, andererseits deren unbestrittene Existenz und ihre extremen Auswirkungen. Diese Spannung kann sich beim Zuschauer im Lachen oder im Weinen lösen, je nach Grad und Intensität des Sich-Einlassens. ${ }^{602}$ Welche Form des spezifischen Grenzverhaltens auftritt, hängt vom Grad des Sich-Einlassens seitens des Zuschauers ab (s. 4.1.4).

Der Zuschauer hat die Chance, die Bedingungen des Lagers durch Rückschluß aus sich heraus zu entwickeln. Dies kann zu einer gewissen Erfahrung des im Nachhinein an sich Unerfahrbaren, zu einer Idee von der Bedeutung des Holocaust führen. Gerade Guidos zunehmend gequältes Lachen in Verbindung mit der wachsenden Kluft 
zwischen Lagerrealität und Fiktion kann im Zuschauer eine intensive mitfühlende Nähe zu dem Einzelschicksal und eine tiefe, innere (Be-)Rührung hervorrufen, welche sich u.U. im Weinen Ausdruck verschaffen muß. ${ }^{603}$

Obwohl der Regisseur betont, »daß es in seinem Film »keinen Humor mehr [gibt] von dem Moment an, wenn ich in das Lager komme. An diesem Punkt wird der Film tragisch.« (Benigni/Cerami 1998: 197f.), bieten Guidos ironische Verkehrungen der Realität dem Zuschauer auch die Möglichkeit, angesichts der aberwitzigen Lagerrealität mit dem Helden zu lachen. Hierbei handelt es sich um ein Sich-»Weglachen« (s. II.4): Schicksalsschlägen allgemein, hier dem spezifisch jüdischen Schicksal, kann man mit »Unernst « begegnen und so eine gewisse Distanzhaltung einnehmen. ${ }^{604}$ Auf diese Weise bietet Benigni eine heilsame Form des Umgangs mit dem Holocaust, u.U. gar eine Möglichkeit der Verarbeitung: »Lachen rettet uns; die andere, unwirkliche und amüsante Seite der Dinge zu sehen oder sich vorzustellen hilft uns, nicht zertreten zu werden. Sie gibt uns Kraft zum Widerstand, die Nacht zu überleben, selbst wenn sie sehr lang ist.« (Ebd. 195)

603. Dem Weinen liegt, gemäß Plessner, ein - im Vergleich zum quittierenden Lachen - antagonistisches Prinzip zugrunde, das sich nicht durch unvermittelte Distanz, sondern vermittelte Nähe, ein »Kapitulieren, Sich-besiegt-Geben, Sich-Loslassen, [einen] Akt der Selbstaufgabe« auszeichnet (ebd. 333). Das Gefühl der Ohnmacht ergibt sich aus dem Ausgeliefertsein gegenüber übermächtiger Gewalt, »der Ergriffenheit von etwas Positivem bzw. einer Situation« (Kloepfer nach Plessner 1996: 166). Nach Stern äußert sich im Weinen das »instinktive Werturteil über bedrohte, verlorene oder auch unverwirklichte und unverwirklichbare Werte« (Stern 1980: 55).

604. Vgl. Müller-Freienfels zum befreienden Lachen (»Auch im Lachen abstrahieren wir von der Wirklichkeit, wir distanzieren uns von ihr, wir erheben uns über sie. `Lachen befreitı, [...] es befreit uns auch von der Macht der Objektwelt. Im Lachen hat sich der Mensch eine Möglichkeit geschaffen [...], sich über die Dinge zu stellen, sich vom Ungeist der Schwere zu lösen, mit dem Ernst des Lebens ein anmutiges Spiel zu treiben; und das ist es, was man meint, wenn man von >weltüberwindendem Humor< spricht.« (1948: 14f., H.i.0.)) und Kloepfer zur kathartischen Funktion dieses Distanzverhaltens in II.4.

605. »C'est la seule chose où je montre directement quelque chose d'effrayant. [...] Mais l'image véritable, comme Spielberg l'a faite, aurait été trop forte.« (Benigni auf www.lefigaro. fr./campus/interviewN1.htm) »Noch im nebelverschwommenen Bild eines gespenstischen Leichenberges bleibt der Film eine - bittere - Mär, die mit den Mitteln einer abgründigen Komik an entmenschte Zeiten erinnert.« (Lederle auf: www.filmdienst.de/Das Leben ist schön.html) Vgl. auch Waldron-Mantgani auf: http://members.aol.com/ukcritic/LifeIsBeautiful.html, Adams auf: www.citypaper.net/movies/I/lifeis beautiful.shtml und Waldron-Mantgani auf: http://members. aol.com/ukcritic/LifeIsBeautiful.html.

606. »Wirklich ist beim Film nur die Zeichenrealisation im geführten Bewußtsein (der sinnere Film), und hierbei spielt die gesteuerte Eigenleistung die entscheidende Rolle.« (Kloepfer nach Balázs 1996/97: 42, H.i.0.)

607. \J'ai pensé à Trotski et à tout ce qu'il a enduré: enfermé dans Mexico, il attendait les tueurs à gages de Staline, et pourtant, sa femme dans le jardin, il écrivait que, malgré tout, la vie est digne d'être vécue. Le titre est venu de là.« (Benigni auf www.lavieestbelle.com/ entretien.html) 
In DAS LEBEN IST SCHÖN wird weder der Versuch unternommen, die unbeschreibliche Lagerrealität dominant bildlich, noch explizit verbal darzustellen. Die einzige Szene, welche das Grauen visuell andeutet, ist ein kaum erkennbarer Berg lebloser Körper gegen Ende des Films. Jeglicher Voyeurismus wird in diesem Fall durch die Stilisierung und Kürze der Einstellung vermieden (s. 4.1.4.ab). ${ }^{605}$ Gewaltdarstellungen bleiben dem Zuschauer erspart: Physische Gewalt ist nicht sichtbar, das Schicksal von Guidos Onkel in der Gaskammer wird elliptisch inszeniert, Guido wird hinter einem Pfeiler erschossen, wobei man die Todesschüsse »lediglich« hört.

Mittels dieses Kunstgriffs der indirekten Inszenierung führt Benigni den Zuschauer durch Rückübersetzung an die Realität heran, ein gewisses Vorwissen vorausgesetzt. Kloepfer spricht in diesem Zusammenhang vom Phänomen des »Films im Kopf « ${ }^{606}$ des Zuschauers und vom »Prinzip der erfüllten Leere«, als einer besonders wirkmächtigen sympraktischen Eigenleistung, hinsichtlich der Erfahrbarkeit eines Phänomens:

»Dans un texte littéraire il peut y avoir (cela dépend des genres) des vides qui veulent inviter le lecteur à devenir actif. Le smélanges entre le fait de le dire explicitement et de le laisser entendre, voire de ne pas le dire, est souvent considéré comme le centre du littéraire depuis le symbolisme. Ces vides laissés par l'auteur forcent le lecteur à des performances supplémentaires de sémiose.« (Kloepfer 1979: 643 - 645, H.i.0.)

»Le principe du vide rempli est également valable pour le film. Souvent l'essentiel a lieu sin absentia<, par les réponses que notre `Gemütı nous fournit - c'est la plus grande sémiotique.« (Kloepfer 1996: 15, H.i.0.)

»Pour réaliser les topes décrits dans la rhétorique, la participation dirigée par une ellipse (ajout) par exemple peut être simple ou complexe (métaphore filée, ironie etc.).« (Kloepfer 1998: 12)

Vor diesem Hintergrund, und im Einklang mit Benigni ${ }^{607}$, kann DAS LEBEN IST SCHÖN als ein lebensbejahender Film bezeichnet werden, in dem Sinne, daß er in einem ersten Schritt die Frage nach dem Zugang zu einer solch schwierigen Thematik und ihrer Behandlung - zwar über den Umweg der Fiktion, aber deshalb nicht weniger positiv beantwortet und in einem zweiten Schritt eine Akzeptanz der unbestrittenen grausamen Geschehnisse in Form verschiedener Verarbeitungsangebote und -niveaus ermöglicht.

\subsubsection{Exposition: Behutsame Einstimmung auf den Holocaust}

Führt man sich die außerordentliche Länge dieses ersten Teils von DAS LEBEN IST SCHÖN vor Augen, so drängt sich die Ergründung ihrer Funktionen förmlich auf. Virtuos führt Benigni den Zuschauer in die zwischen Komödie und Märchen schwankende, fiktionale Welt ein (s. 4.1.3.b), konfrontiert ihn jedoch gleichzeitig mit den Anzeichen für den aufkommenden Faschismus in Italien 1939 (s. 4.1.3.a). 
a) Rhythmisch-dosierte Einführung des Faschismus

Ein zentraler Grund für die überdurchschnittliche Länge des ersten Teils von DAS LEBEN IST SCHÖN ist die dadurch ermöglichte behutsame, rhythmisch-dosierte Einführung des faschistischen Kontextes und des damit einhergehenden Gefahrenpotentials für in Italien lebende Juden. Vergleichbar mit einem Schneeball, der einen Hang hinunter rollend an Volumen stetig zunimmt ${ }^{608}$, schwindet die anfangs heitere, lustiggelöste Stimmung ${ }^{609}$ nach und nach, um in der tragischen Deportation der jüdischen Bürger zu münden.

Das präzise Aufspüren der Indizien für den aufkommenden Antisemitismus beweist die mehr oder minder stark ausgeprägte Präsenz dieser Thematik, die jedoch nicht immer auf den ersten Blick erkennbar ist, sondern teilweise im kleinsten Detail ihren Ausdruck findet. So läßt die Analyse eine relative Häufung der Verweise auf den sozio-historischen Kontext zu Beginn wie gegen Ende der ersten Teils von DAS LEBEN IST SCHÖN erkennen, während dessen Mittelteil von Guidos Einfallsreichtum und der

608. Vgl. Bergsons Ausführungen zum Schneeballeffekt: »Voici [...] la boule de neige qui roule, et grossit en roulant. Nous pourrions aussi bien penser à des soldats de plomb rangés à la file les uns les autres: si l'on pousse le premier, il tombe sur le second, lequel abat le troisième, et la situation va s'aggravant jusqu'à ce que tous soient par terre." (1972: 61)

609. »The first half of the dual-natured film is a buoyant dance. Everything that is good about the world is outlined and celebrated through Guido's optimism and joie de vivre." (Goldberger auf: www.film.u-net. com/Movies/Reviews/Life_Is_Beautiful.html) »The first half of the movie, set in pre-war Italy, sets the tone for the events to follow by contrasting the evolving relationship between Guido and Dora, with the slow slide of Italy into the Nazis' Final Solution.« (N.N. auf: www.fortunecity.com/lavendar/heat/435/life.htm)

610. In Anlehnung an die Erkenntnisse der biologischen Psychologie betont Kloepfer die Verbindung zwischen künstlerischer Komposition und menschlichem Gedächtnis. In diesem Kontext weist er darauf hin, daß das für die Speicherung von mikrostrukturellen Reizen verantwortliche Arbeitsgedächtnis über eine Speicherdauer von ca. 3 bis 5 Minuten verfügt. Soll vermieden werden, daß mikrostrukturelle Impulse nach Ablauf dieser Zeit aus dem KZG fallen und somit verloren gehen, müssen sich diese Detailstrukturen im Rahmen dieser Dauer wiederholen, möglicherweise in transformierter Form. Auf diese Art und Weise kann ein mikrostruktureller Impuls in eine makrostrukturelle Gestalt übergehen, den Sprung ins LZG schaffen (Kloepfer 1999/2000).

611. Die 30-Sekunden-Grenze wird lediglich einmal - in der ersten Sequenz - knapp überschritten, ansonsten bewegt sich die Dauer der faschistischen Indizien zwischen einer und 15 Sekunden.

612. »Ich möchte dieses [...] Phänomen der kontinuierlichen Erinnerung an eine Prämisse der Bewußtseinsebene >Tönungく nennen. [...] Tönung ist ein Mittel, das gegenwärtige Bewußtsein erinnernd mit Vergangenem und antizipierend mit Künftigem zu erweitern.« Das Alltagswort »Tönung« ist insofern günstig als wissenschaftlicher Terminus, weil es in gleicher Weise die akustische wie die visuelle Durchdringung eines Ganzen mit einer leitenden Modifikation bezeichnet (Kloepfer 1996/97: 56).

613. Hier und im folgenden werden in Klammer die jeweiligen Sequenznummern angegeben (s. auch das entsprechende Sequenzprotokoll im Anhang).

614. Den Zuschauer können die beiden Namen an Mussolinis bzw. Hitlers Vornamen erinnern. 


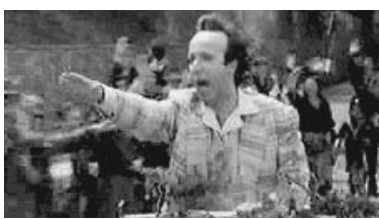

510 $0: 01: 14 \mathrm{~h}$
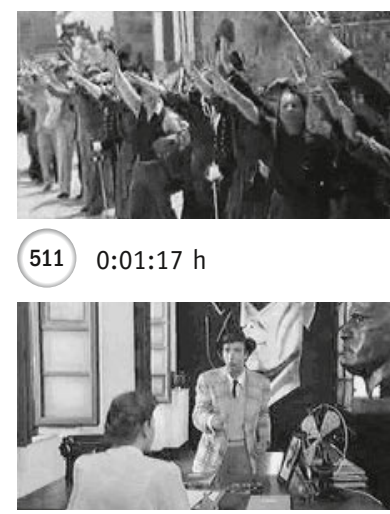

(513) $0: 08: 35 \mathrm{~h}$

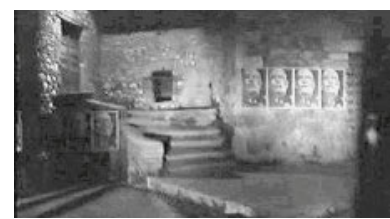

(512) $0: 04: 43 \mathrm{~h}$

sich anbahnenden bzw. entwickelnden Liebesgeschichte zwischen Guido und Dora dominiert wird.

aa) Filmanfang: Sensibilisierung für den italienischen Faschismus

Bereits die ersten zehn Minuten (0:00:03 - 0:10:06 h) des Films weisen insgesamt neun solcher mikrostruktureller Faschismus-Impulse auf. ${ }^{610}$ Obgleich diese Anzeichen ausnahmslos sehr kurz ausfallen ${ }^{611}$ und - mit Ausnahme des überfallenen Onkels von komischen Elementen überdeckt bzw. durchzogen sind, müßte ihr in Variation wiederholtes Auftreten auf engem zeitlichem Raum beim aufmerksamen Zuschauer zu einer dauerhaften Speicherung führen, zu sogenannten Chunk-Übertragungen vom Arbeits- ins Langzeitgedächtnis in Folge der Konsolidierung der Reizinhalte (Birbaumer/Schmidt 1999: 570ff.). Auf diese Weise wird das zentrale Thema des Films zwar dezent - aber dennoch nachweisbar und je nach Aufmerksamkeit bzw. Kompetenz wahrnehmbar - bereits zu Beginn angelegt. Der Zuschauer wird hinsichtlich des faschistischen Kontextes im Sinne einer Prägung sensibilisiert.

In den ersten Sequenzen sind die Indizien nahezu durchgängig von komischfiktionalen Elementen dominiert, die uns zum gelösten Lachen animieren. Die beschriebene Kürze, die komisch-irreale Tönung ${ }^{612}$ der faschistischen Verweise und ihre Einbettung in eine insgesamt heitere Atmosphäre relativieren deren bewußte Aufnahme durch den Zuschauer.

In der Eingangssequenz wird Guidos wildes Gestikulieren (s. o:01:14 h) von der den staatlichen Würdenträger anläßlich eines nationalen Festes erwartenden - Dorfgesellschaft als faschistischer Gruß interpretiert (s. 0:01:17 h; 1). ${ }^{613}$ Als die beiden Freunde am späten Abend die Stadt Arezzo erreichen, in der Guidos Onkel wohnt und sie bereits erwartet, beleuchten die Scheinwerfer ihres Wagens kurz faschistische Plakate, die Mussolini in Großformat zeigen (s. o:04:43 h; 3). Beim Onkel angekommen, finden sie diesen von »Barbaren« (0:05:20) - seine Bezeichnung für Faschisten, wie sich später herausstellen wird - »heimgesucht« (3); ebenso erging es dem Geschäftsführer der Polsterei, bei dem Guidos Freund Ferruccio am nächsten Morgen vorstellig wird: Er begnügt sich bewußt mit dem Kommentar, es herrschten »schlimme, sehr schlimme Zeiten« (0:07:33; 5). Seine balgenden Söhne ermahnt er laut rufend: »Benito, Adolfo! ${ }^{614}$ (0:07:40 h; 5); wenig später wendet er sich erneut 
streng an: Benito! (0:08:05 h; 5). Guidos Besuch im Rathaus, in der Hoffnung, die Eröffnung eines Buchladens genehmigt zu bekommen, ist hinsichtlich der dort herrschenden strengen Atmosphäre, vor allem durch die spezifische Raumgestaltung übergroßes Wandbild und Steinbüste des Duce (s. o:o8:35 h) - hervorgerufen, für die Zeit sprechend (6).

ab) Mitte des ersten Teils: Commedia dell'arte versus Faschismus

Die angesprochene, fortlaufende komisch-fiktionale Tönung und vor allem die Verweisarmut im mittleren Abschnitt des Eingangsteils von DAS LEBEN IST SCHÖN (o:10:06 - 0:39:01 h) sind wohl dafür verantwortlich, daß die erste Hälfte des Films einen überwiegend heiteren, unwirklichen Eindruck beim Zuschauer hinterläßt und auf diese Weise in relativ deutlichem Kontrast zum Hauptteil steht. ${ }^{615}$

Nur eine Szene zeichnet sich durch die erstmalige ${ }^{616}$ direkte Nennung des Faschismus und eine äußerst eindrucksvolle komödiantische Vorstellung des Protagonisten aus, in der er das ideologische Fundament des Rassismus wirkmächtig ad absurdum führt (s. 4.1.3.ba).

ac) Übergang zum Hauptteil: aufkommendes Unheil

Mit der Reduzierung der komischen Tönung ${ }^{617}$ in den dem Hauptteil vorangehenden zwölf Sequenzen (o:39:01 - 1:07:33 h) konkretisieren sich die Indizien der Gefahr für die italienischen Juden. In Übereinstimmung mit den Aussagen der biologischen Psychologie, insbesondere zu dem kontextabhängigen Abrufen von Langzeit-Gedächtnisinhalten, genügen zunehmend extrem kurze Szenen mit variierten Faschismus-

615. »Die Mißklänge faschistischer Willkür und Ideologie färben zwar die Ränder, tragen in der originellen Verkehrung durch den aufgeweckten Schalk Guidos aber ebenso zum Reiz dieser poetischen Fabel bei wie die wunderbar zelebrierte Liebesgeschichte eines scheinbar vorherbestimmten Paares, das auf einem von den Faschisten grün angestrichenen sjüdischen Pferd mitten aus dem Festbankett ins Glück entschwindet.« (Lederle auf: www.filmdienst.de/ Das Leben ist schön.html)

616. Hinsichtlich des entscheidenden Elements in einer Reihe von Montagestücken bemerkt Eisenstein: »Eine solche Reihe könnte noch sehr lange fortgesetzt werden, bis endlich jenes Filmstück kommt, das jenen Index bildet, der diese sgesamte< Reihe mit diesem oder jenen >Vorzeichen tauftı.«(Eisenstein 1984: 235, H.i.0.)

617. Reine bzw. flache Komik begegnet uns nur noch in folgenden Szenen: die wiederholten Begegnungsvermeidungen Guidos in bezug auf den Rathausangestellten; Doras anfängliches Weigern, sich zur Verlobungsfeier zu begeben; Guidos und Ferruccios gemeinsames Lachen über den »Idioten aus dem Rathaus«; dessen Getroffen-Werden vom Straußenei; das »laufende» Blumen-Schränkchen.

618. An dieser Stelle sei auf den Sprachwissenschaftler und Semiotiker Karl Bühler verwiesen, der dieses Prinzip der semiotischen Ökonomie mittels eines Vergleichs veranschaulicht: »Ein solcher zunehmend dosierter Umgang mit Zeichen gleicht mehr oder minder den Hilfen, die ein Reiter seinem Pferde und sonst geschickte Lenker dem gelenkten Lebewesen geben. Ist das Selbstdenken, -fühlen, -ergänzen etc. des Adressaten in Gang gebracht, dann lockert eine kommunikative vollendete Mitteilung die Zügel und setzt nur sparsam neue Impulse.« (Kloepfer nach Bühler 1996/97: 48) Voraussetzung für diese Eigenleistung des Adressaten ist jedoch ein gewisser Wille zur Versetzung. 


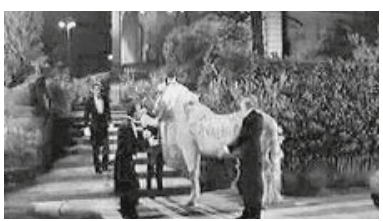

(514) $0: 42: 42 \mathrm{~h}$

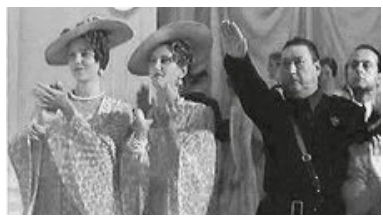

(517) $0: 52: 32 \mathrm{~h}$

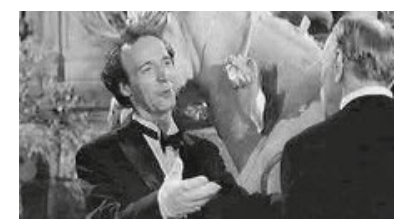

(515) $0: 42: 45 \mathrm{~h}$

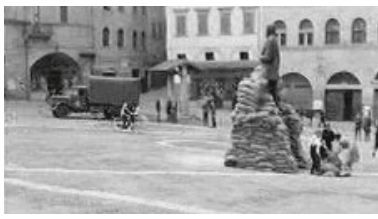

(518) $0: 56: 21 \mathrm{~h}$

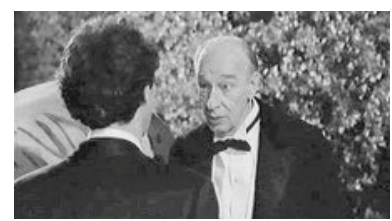

(516) $0: 43: 05 \mathrm{~h}$

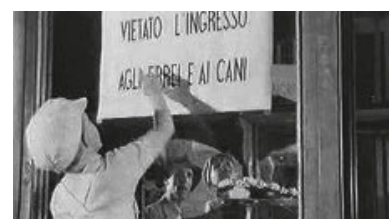

(519) $0: 57: 09 \mathrm{~h}$

Verweisen, um uns die bereits angelegte, dauerhaft gespeicherte Problematik einerseits in Erinnerung zu rufen ${ }^{618}$, andererseits durch die zunehmende Dramatisierung bzw. Konkretisierung des Konflikts naheliegende Antizipationsmöglichkeiten für das bevorstehende Schicksal der Familie Orefice anzubieten: Im »jüdischen Pferd« des Onkels, auf welchem Guido und Dora in das vermeintliche, gemeinsame Glück entschwinden, kann der aufmerk-same Zuschauer ein Antizipationsangebot für deren zukünftiges Schicksal sehen.

Ab dem Zeitpunkt, an dem der Onkel sein bemaltes Pferd entdeckt, im weiteren die Grundschuldirektorin von den rassistischen Rechenaufgaben berichtet, Guido seinem Sohn die tatsächliche Bedeutung des Schaufensterschildes vorenthält, er zum Präfekten muß, sein Buchladen von Faschisten beschmiert ist, er Giosuè die Deportation sowie das Zugfahren umdeutet, fällt uns das Lachen zunehmend schwerer.

Eisensteins Forderung nach der Manifestation des grundlegenden Gestus eines Films im Kleinen als Bedingung zur Entfaltung einer künstlerischen Ästhetik ist vor allem in folgender Sequenz verwirklicht: Als Giosuè die Beschriftung eines Schaufensterschildes - »Zutritt verboten für Juden und Hunde« (0:57:10 h) - vorliest und seinen Vater nach dessen Bedeutung fragt, erfindet dieser für seinen Sohn eine - sich der sich zuspitzenden Realität entziehende - harmlose Erklärung (Sequenz 19). Somit realisiert sich das - zumindest den Anfang sowie das Ende der ersten Hälfte und den Spielfilm insgesamt charakterisierende - Wechselspiel zwischen fiktionalen Elementen und den faschistischen Verweisen auf engstem Raum.

Anläßlich der Verlobungsfeier des hohen Rathausangestellten mit Dora im Grand Hotel erscheint der Stadtpräfekt in Militärkleidung (15). Der Schimmel des Onkels wird - erneut von den »Barbaren« - mit grüner Farbe beschmiert und mit der Aufschrift »Achtung! Jüdisches Pferd « (s. 0:42:42 h) versehen; während Guido die Bedeutung des Zwischenfalls herunterzuspielen versucht (s. 0:42:45 h), ist dem Onkel die Tragweite schmerzlich bewußt (s. 0:43:05 h) (15).

Bei Tisch tauschen sich die Direktorin der Grundschule und Doras zukünftiger Bräutigam voller bewundernder Anerkennung über die rassistischen Rechenaufgaben in deutschen Grundschulen aus (17). Zu den nächsten Freunden des Verlobten zählen ein Offizier und der Präfekt (17), beide in Militärkleidung. Das zelebrierte Hereintra- 
gen der übergroßen Verlobungstorte wird von einem Soldaten mit dem faschistischen Gruß begleitet (s. 0:52:32 h) (17). Auf dem »jüdischen Pferd « entführt und rettet der Prinz schließlich seine »geliebte Prinzessin« (17). Zuhause angelangt, hilft Guido Dora vom Pferd, auf dem ein Totenkopf prangt (18). Als Guido und Dora, nach dem Zeitsprung von ungefähr fünf bis sechs Jahren, mit ihrem Sohn die Piazza überqueren, ist das einst bunte Treiben einer nicht zu übersehenden Militärpräsenz gewichen (s. 0:56:21 h) (18).

Auf dem Schild einer Konditorei, vor welcher eine Gruppe von Soldaten im Gleichschritt vorbei marschiert, liest Giosuè: »Zutritt verboten für Juden und Hunde« (s. 0:57:09 h; 19). Auf höchst unfreundliche Art wird Guido vor den Augen seines Sohnes von zwei Männern zum Präfekten abgeführt (s. 0:58:47 h) (20). Der Rolladen von Guidos Buchladen wurde in der Zwischenzeit mit der Aufschrift »Negozio ebreo« (s. 1:00:39 h), jüdisches Geschäft, beschmiert (21).

Als Dora mit ihrer Mutter zuhause ankommt, findet sie das Wohnzimmer verwüstet vor; Giosuè, Guido und der Onkel sind verschwunden (23). Die drei werden mit zahlreichen anderen jüdischen Italienern in einem Lastwagen abtransportiert; Giosuè, sichtlich erstaunt und unzufrieden, fragt seinen Vater ungeduldig, wo sie denn hinführen (23). Nachdem Giosuè eingeschlafen ist, richtet sich Guido besorgt an seinen Onkel: »Wohin fahren wir? Wo bringen sie uns hin?« (s. 1:04:10) (23).

In schlimmer Vorahnung fährt Dora im Taxi zum Bahnhof, wo die LKW-Insassen bereits in die wartenden Zug »verladen « werden (s. 1:04:27 h) (24). Als sie vom Oberbefehlshaber der SS erfährt, daß alles seine Ordnung habe, läßt sie, um ihre Familie nicht im Stich zu lassen, den Zug anhalten (s. 1:06:45 h) (24).

Bei der Einführung des faschistischen Kontextes hat der Regisseur besonderen Wert auf relative Kontinuität der Indizien und behutsame Steigerung der dramatischen Situationen gelegt.

Über diese kontinuierliche Zunahme der »Faschismus-Dosierung« wird der Zuschauer schonend auf den Hauptteil des Films sowie die ihn kennzeichnenden Gefühlsschwankungen vorbereitet und eingestimmt. Dies geschieht auf eine Art und Weise, die - wenn überhaupt - den Zugang zu bzw. ein Einlassen auf diese schwierige Thematik ermöglichen kann (s. 4.1.4).

619. Vgl. Kloepfer zur emotiven Funktion von Filmmusik: »[...] daß Filmmusik fast von Anfang an den Film begleitet hat, um [...] (den Film syntaktisch zu gliedern), die emotive Einstellung abzusichern. [...] Dadurch bekam die Musik eine eigene Rolle, vor allem zur psychologischen Gestaltung von Szenen, Personen und Handlungen. [...] Die Tonspur des modernen Films kann extrem vielfältig genutzt werden. Es geht um die Möglichkeiten technisch vermittelter auditiver Wahrnehmung und ihrer semiotischen Gestaltung intern und vor allem in Korrelation mit dem Sehbaren. [...] Das Ohr ist das Organ absoluter Eindringlichkeit. (Kloepfer 1996/97: 31ff.)

620. In diesem Sinne äußert sich Hickethier zu einer der beobachteten Funktionen von Filmmusik: "Sie kann das visuell Gezeigte mit semotionalen Qualitäten< versehen und in spezifischer Weise interpretieren. [...] Sie wirkt häufig besonders dort, wo sie in ihrer Eigenschaft nicht bemerkt wird, sondern sich in das filmische Geschehen einschmiegt und ihm dadurch zugleich einen besonderen Akzent gibt.« (1996: 95) 


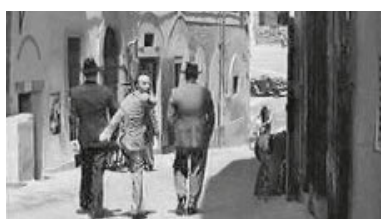

(520) $0: 58: 47 \mathrm{~h}$

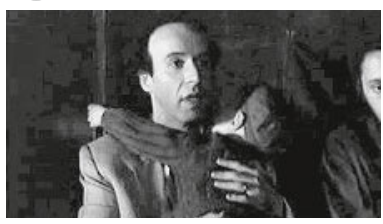

$5231: 04: 10 \mathrm{~h}$
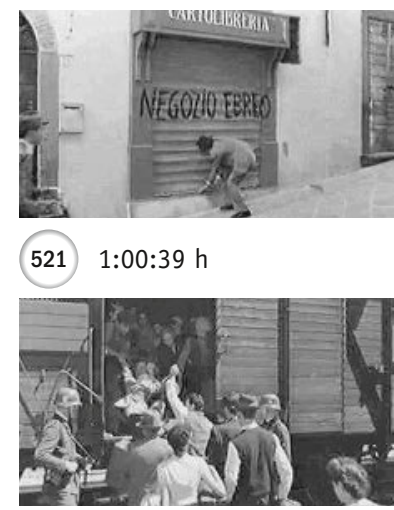

(524) $1: 04: 27 \mathrm{~h}$

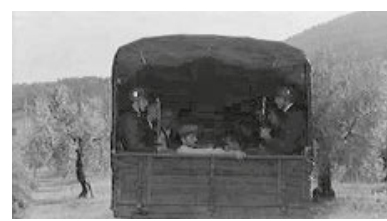

(522) $1: 02: 43 \mathrm{~h}$

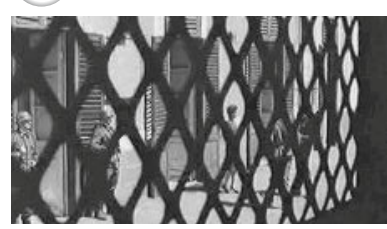

(525) $1: 06: 45 \mathrm{~h}$

Von besonderer Wichtigkeit für das Erkennen des faschistischen Gefahrenpotentials ist die Tatsache, daß das Auftreten dieser Verweise nahezu ausnahmslos mit dem Erklingen von Bedrohung indizierenden Tönen einhergeht. ${ }^{619}$ Parallel zum gesteigerten Auftreten der Faschismus-Hinweise gegen Ende des Eingangsteils nimmt auch die Dauer der besagten musikalischen Begleitung zu. Über die beschriebene Gleichzeitigkeit bietet uns Benigni eine Absicherung hinsichtlich der Einordnung der faschistischen Indizien im Unterschied zu den fiktionalen Elementen ${ }^{620}$; das visuell teilweise doch sehr dezente Erscheinen der Faschismus-Hinweise wird hierdurch relativiert, zumindest ein vorbewußtes Wahrnehmen seitens des Publikums scheint gewährleistet.

\section{b) Entfaltung des komisch-fiktionalen Charakters}

Der erste Teil von DAs LEBEN IST schön untermauert die Leitthese (s. 4.1.2) der Einführung und Entfaltung des fiktionalen, irrealen Charakters des gesamten Films. Die ausführliche Präsentation der Schlüsselfigur hilft dem Zuschauer, dessen besonderes Verhalten im Hauptteil zu verstehen und sich mit ihm zu identifizieren.

In der Hoffnung, »das Eis zu brechen«, entscheidet sich Benigni dafür, dem Publikum den gewichtigen Gegenstand des Films auf einer extrem fiktionalen Ebene vorsichtig anzubieten. Die Wahl einer fiktiven Form des Umgangs kann dahingehend interpretiert werden, daß durch sie die Einlassungsbarriere möglichst klein gehalten werden soll. In diesem Sinne bereitet die vorliegende Exposition systematisch den Boden für Benignis genialischen Kunstgriff im Hauptteil, die ironischen Verkehrungen der Realität im Rahmen einer Wettbewerbsgeschichte.

\section{ba) Komik und Kreativität des Protagonisten}

Ausnahmslos alle Sequenzen des Eingangsteils weisen komische Szenen auf. Vor diesem Hintergrund kann man in diesem Teil von einer durchgängigen wie charakteristischen komischen Dominanz sprechen.

Nach Plessner handelt es sich sowohl um »flache« als auch »tiefe, abgründige« Komik (Plessner 1941: 331f.). Was diese Art der Komik betrifft, so fällt auf, daß sie vorwiegend zu Beginn und im Mittelteil der ersten Hälfte von DAS LEBEN IST SCHÖN zu finden ist und in der Mehrzahl der Fälle über Wiederholungseffekte, analoge bzw. parallele Situationen, Wort- und Situationskomik erzeugt wird. 
In diesem Zusammenhang sei ein Auftritt erwähnt, in der das muntere, beinahe kindliche »Hin und Her« sich in vier Szenen mit Varianten wiederholt (beim Vertauschen eines Hutes). Gehäuft auftretende Zufälle, die keine wirklichen sind, bergen eine besondere Komik in sich, denn wir verfügen mit der Hauptfigur und gegenüber den »Opfern« über einen Wissensvorsprung. Auf diese Weise können wir deren Überraschung bzw. Fassungslosigkeit auskosten, z.B. die dreimalige Anrufung der heiligen María, das Herbei»zaubern« eines leichten Gerichts für den Ministerialrat sowie die Anwendung von Schopenhauers Willenskraft.

Auch Guidos Begegnungen mit dem »Idioten aus dem Rathaus« (0:16:56 h) sind ausnahmslos von Komik getragen. Schon beim ersten Aufeinandertreffen wirken der Magistraturbeamte, ebenso wie seine Sekretärin (s. o:o8:33 h), wie Personen, die das angesehene, bürokratisch-buchstabengetreue Benehmen - im Sinne von Bergsons »endurcissement professionnel« bzw. der spezifischen Berufslogik (Bergson 1972: 136) - völlig verinnerlicht haben: »Wir schließen jeden Mittag um eins, haben sie verstanden?!«(0:08:51 h) ${ }^{621}$

Dagegen legt Guido innerhalb des gesamten ersten Teils ein entgegengesetztes Verhalten an den Tag. Ganz den - in den Begriffen »tension et elasticité« gebündelten (Bergson 1972: 14) - Ansprüchen des Menschen an sich selbst genügend, erweist sich der Protagonist als besonders anpassungsfähig, flexibel, aufmerksam. Man denke in diesem Zusammenhang an seine Gabe, neue bzw. schwierige Situationen durch Optimismus, originelle Einfälle, Offenheit und Gewitztheit zu meistern. ${ }^{622}$ Das von Guido beim ersten Mal direkt verursachte (Blumenkübel, s. o:09:10 h; Eier, s. ०:०9:31 h), beim zweiten Mal indirekt ausgelöste (Straußenei) Mißgeschick weist eindeutig parallele Strukturen auf; in beiden Fällen wird der Rathausbeamte lächerlich gemacht: Erst zerschellt der Blumenkübel auf seinem Kopf, danach drückt er sich Guidos Eier ins Haar und schließlich zerspringt ihm das Straußenei auf dem Haupt. Der Zuschauer, der gegenüber dem »Opfer« als Gegenspieler von Guido - von der ersten Sekunde an eine

621. Vgl. Bergsons Beschreibung des Phänomens der beruflichen Verhärtung: »Toute profession spéciale donne à ceux qui s'y enferment certaines habitudes d'esprit et certaines particularités de caractère par où il se ressemblent entre eux, et par où aussi ils se distinguent des autres.« (1972: 135) Eine analoge komische Versteifung begegnet Guido in Gestalt der Schuldirektorin und ihrer Lehrerschaft, die in ihrem stereotypen Rahmen gefangen und erstarrt sind. Auch der faschistische Gruß eines Militärs angesichts der überdimensionalen Verlobungstorte zeugt von der beschriebenen beruflich bedingten Verhärtung. Bergsons Mechanik-These läßt sich vor allem an Ferruccio besonders treffend erläutern. Schon nachdem er vergeblich wegen seiner dichterischen Manuskripte nach Hause gelaufen war, insbesondere jedoch als ihn Guido - fast wie einen störrischen Esel - an der Hand hinter sich her zieht und zum Laufen antreibt, wird die Aufmerksamkeit des Zuschauers zwischenzeitlich auf die physische Natur gelenkt; Ferruccio - um es mit Plessner zu formulieren - IST nur noch sein Körper.

622. Mit diesem Talent einher geht das bereits angesprochene Provozieren von Überraschungsmomenten, welche die betroffenen Personen in aller Regel verdutzt blicken läßt.

623. »When Benigni hilariously impersonates a Mussolini-regime official, the scene owes an obvious debt to »The Great Dictator«, but Benigni earns the comparison. (Gleibermann auf: www. ew.com/ew/review/archive/0,1683,359,00.html) Siehe auch Sequenz 12 im Sequenzprotokoll.

624. Wie sich im weiteren Verlauf des Films herausstellen wird, ist Guido jüdischer Abstammung. 


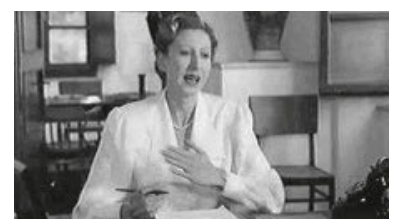

(526) $0: 08: 33 \mathrm{~h}$

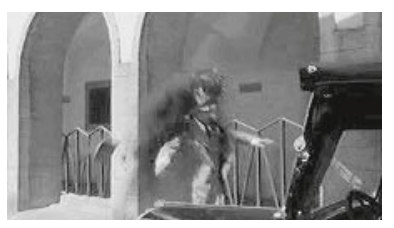

(527) $0: 09: 10 \mathrm{~h}$

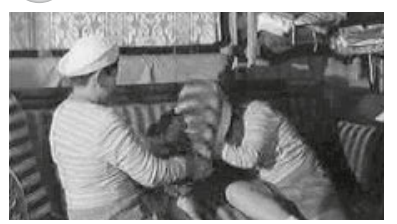

(530) $0: 06: 58 \mathrm{~h}$

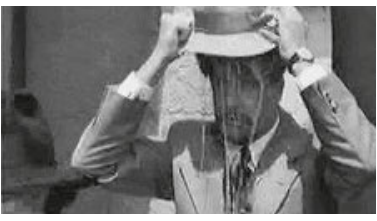

(528) $0: 09: 31 \mathrm{~h}$

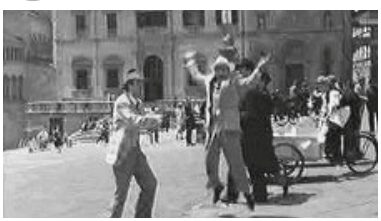

(531) $0: 06: 37 \mathrm{~h}$

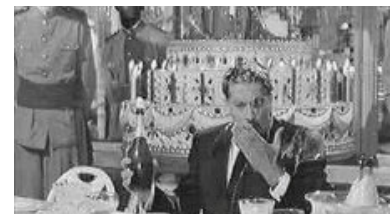

(529) $0: 54: 10 \mathrm{~h}$

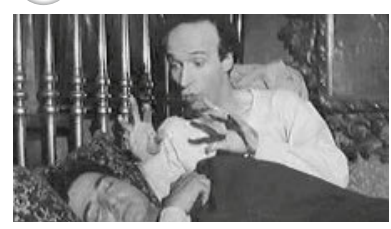

(532) $0: 13: 37 \mathrm{~h}$

deutliche Abneigung verspürt, empfindet diese Mißgeschicke als eine gerechte Strafe für unfreundlich-arrogantes Verhalten. Auch hinter den gelungenen »Begegnungsvermeidungen « mit dem Magistraturbeamten steht der angesprochene, sich verstärkende Wiederholungsmechanismus. Erneut ist bei den insgesamt vier Ausweichtaktiken eine stark ausgeprägte Analogie der Szenen festzustellen. Dank seiner Gewitztheit kann Guido durch jeweils neue Einfälle die »brenzligen« Situationen meistern.

Entsprechendes gilt für Guidos Begrüßungsformel für Dora. Das über weite Strekken den Eingangsteil wie einen roten Faden durchziehende »Bongiorno, geliebte Prinzessin!« (s. 0:23:26 h in bb) taucht in vergleichbaren und doch leicht unterschiedlichen Situationen auf, wobei der Steigerungseffekt in der Flucht des »Prinzenpaares« kulminiert.

Wortkomik erzeugt der Regisseur in der Gegenüberstellung von Begriffen und Sätzen, die einen wörtlichen und übertragenen Sinn haben (z.B. das Sprichwort »Sich etwas aus dem Kopf schlagen«, s. o:०6:58 und Sequenz 6), Feruccios »Wörtlich-Nehmen « von Guidos euphorischen Aussagen über die städtische Freiheit (s. 0.06:37 h und Sequenz 5) oder die Erprobung von »Schopenhauers Willenskraft« (s. o:13:37 h und Sequenz 8).

Bittere, abgründige Komik (s. 4.1.2) beherrscht den Übergang zum Hauptteil des Films. Insbesondere in der - an Charlie Chaplins Grossen Di kTATo R erinnernden - Schlüsselsequenz des Eingangsteils, Guidos eigenwilliger Verkündung des Rassenmanifests ${ }^{623}$, birgt bereits der Vorname des nicht-arischen Jungen, Roberto, eine gewisse Komik, vor allem für das italienische Publikum. Er stimmt mit dem des Regisseurs überein, denn auch Guido ist nicht-arischer Abstammung. ${ }^{624}$ Diese Schlüsselsequenz, in der Guido sich als der erwartete Ministerialbeamte ausgibt und mehrfach die Realitätsebenen wechselt, birgt, trotz ihrer Situationskomik und Wortkomik, düstere Aussichten. 
Guidos Versuch, sich zu entfernen, verhindert die Schulleiterin, indem sie die Wichtigkeit des Moments hervorhebt: Der Schulinspektor sei extra aus Rom angereist, um ihnen von dem von italienischen Wissenschaftlern entworfenen Rassenmanifest zu berichten und ihnen zu erklären, warum gerade ihre Rasse die überlegene sei. Die folgende Szene, die Lösung der Zwangslage, lädt Benigni extrem auf: Guido springt beidbeinig auf das Pult und schafft sich somit die Bühne für seinen Auftritt; alle starren ihn unentwegt an, die Schulleiterin und die gesamte Schülerschaft, Dora mit zunehmender Verzückung. Die einleitenden Bemerkungen der Schuldirektorin aufgreifend, beginnt Guido die Überlegenheit der »eigenen « Rasse an sich selbst zu beweisen. Ganz im Sinne Bergsons, der dem Körper als Träger komischer Eigenschaften eine Vorzugsrolle zuspricht, demonstriert er an seinem eigenen Körper - Ohr (s. o:26:06 h), Knie (s. ০:26:26 h), Schienbein, Bauchnabel (s. o:27:58 h), Hüfte, Armmuskulatur - die Perfektion der »arischen« Rasse, wobei er derartig übertreibt, daß sein Auftritt die rassistische Ideologie gründlich ins Lächerliche zieht.

»Deshalb wurde ich ... wurde ich von den rassistischen Wissenschaftlern aus Italien hergeschickt, um euch begreifbar zu machen, weshalb wir die überlegene Rasse sind und niemand anders. Wieso hat man mich, eh, damit beauftragt?« (Springt aus dem Stand beidbeinig auf das Pult.) »Wieso mich? Muß ich diese Frage wirklich beantworten?!« (Dreht sich zur Präsentation um die eigene Achse und lacht ssouverän<.) »Ich frage euch, wo gibt es auf dieser Welt einen Menschen, der noch schöner ist als ich?! Da verschlägt's euch die Sprache, denn vor euch steht ein Original der so überlegenen und vor allem reinen arischen Rasse. Ich möchte euch das mal an einem einfachen Beispiel erläutern: das Ohr.« (Faßt sich demonstrativ ans Ohr.) »Bitte achtet einmal auf diese Perfektion, die bei mir deutlich wird, mit formvollendeter linker Ohrmuschel und einem leicht beweglichen Ausläufer.« (Bewegt mit den Fingern sein Ohrläppchen.) »Probiert es jetzt mal bei euch! Beweglich, zusammenfaltbar!« (Alle Kinder `klimpern< mit ihren Ohrläppchen.) »Zeigt mir hübschere Ohren und ihr seid mich auf der Stelle los! Aber glaubt mir, wir haben die schönsten.« (Erstaunt sieht ihn die Schulleiterin an, was Guido nicht am Weiterreden hindert.) »Die Franzosen können von solchen Ohren nur träumen, haha! Und jetzt seht mal her, schaut genau hin, seht euch das mal an!« (Zieht sich mit der Hand ein Hosenbein hoch, bis das Knie bloßgelegt ist.) »Ich präsentiere euch ein überlegenes Bein, das absolut reinrassig ist! Ein Juwel von einem Bein!« (Beugt und streckt es im Wechsel.) »Es läßt sich bequem krümmen. Ich schlage vor, ihr versucht es selbst einmal. $\mathrm{Na}$, ist das nicht phantastisch?!« (Erneut gehorchen die Kinder aufs Wort und baumeln ausnahmslos mit den Beinchen.) »Das nennt man eine arische Beinkrümmung mit zirkularer Bewegung des italienischen Fußes.« (Beschreibt mit seinem Fuß kleine Kreise in der Luft.) »Etruskische Fessel auf römischem Schienbein. (Schlägt sich mit der flachen Hand auf das Schienbein, von verdutzten Blicken der Direktorin begleitet.) »Mit sehr starker Widerstandskraft!« (Hat die Stimme angehoben.) »Um so ein Bein beneidet uns die gesamte Welt. Wenn ihr groß seid, habt ihr mal

625. »As we giggle, though, the film's tone is changing, and we can feel it." (N.N. auf: http://infilmau.iah.net/reviews/lifeis.htm)

626. An dieser Stelle seien Bergsons Aussagen angeführt, wonach das Lachen nicht nur auf momentaner Empfindung beruht, sondern vergangene Freuden wiederzubeleben, an die - seit der Kindheit vertrauten - fröhlichsten Gefühle anzuknüpfen vermag: »Peut-être même devrionsnous pousser la simplification plus loin encore, remonter à nos souvenirs les plus anciens, chercher, dans les jeux qui amusèrent l'enfant, la première ébauche des combinaisons qui font 


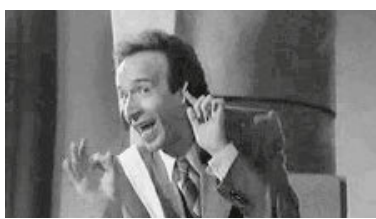

$5330: 26: 06 \mathrm{~h}$

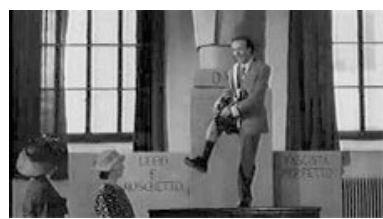

(534) $0: 26: 26 \mathrm{~h}$

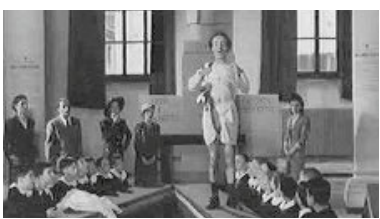

(535) $0: 27: 58 \mathrm{~h}$

ebenfalls so ein Bein. Was rede ich da!? Zwei, zwei solche Beine! Brecht ihr euch mal das eine, « (Springt von einem Bein auf das andere) »so verfügt ihr immer noch über das andere.« (Hüpft wieder zurück auf das ursprüngliche Bein.) »Brecht ihr euch das andere, bleibt euch noch das. Und wenn ihr euch beide brecht, das wäre dann Pech, das beweist überhaupt nichts! Liebe Freunde, die Rassen existieren, und wie, glaubt mir! Aber fahren wir fort, denn es kommt noch besser. Ich möchte euch etwas Wichtiges zeigen: ...« (Zieht sich das Jackett aus, während die Schulleiterin einen zunehmend verblüften Eindruck macht und der wahre Ministerialrat, in Begleitung des Hausmeisters, bereits über den Gang stürmt.) - »... Der Bauchnabel!« (Reißt sich das Unterhemd, unter schallendem Gelächter der Kinder, in die Höhe, um seinen Bauchnabel zu präsentieren.) »Ha, ha, ha, ha, ha!!! Betrachtet meinen Bauchnabel! Diesen Knoten, nicht mal mit den Zähnen kriegt den jemand auf! Diese Wissenschaftler haben es versucht, doch nichts zu machen! Pech gehabt! Denn das ist ein typischer überlegener Bauchnabel unsrer Rasse. Oder seht euch das an: diese überlegene Muskulatur! Zeps hier, Bizeps dort und Trizeps, wohin das Auge reicht! ( Hat sich begleitend auf die jeweilige Muskelgruppe geschlagen und reckt nun triumphierend beide Arme in die Höhe, während der eingetretene Ministerialrat seinen Augen nicht traut.) »Umwerfend, he?! Und erst die Hüfte! Seht nur!« (Tanzt und springt, sich in der Hüfte wiegend, ausgelassen umher.) »Wie sie sich bewegt, wie sie sich im Takte wiegt! Meine Damen ...« (Verstummt, da er den Ministerialrat erblickt hat.) »... und Herren, ich muß nun leider von Ihnen Abschied nehmen. Ich habe noch eine Verabredung, die ich beinahe vergessen hätte.« (Sammelt seine Kleidungsstücke auf.) »Laßt mich nun auf arische Art verschwinden.» (Läuft eilig über die Schreibtische in Richtung des geöffneten Fensters.) »Lebt wohl, Freunde. Arrivederci! Und hier ist er: der Nabel!« (Reißt sich noch einmal das Unterhemd hoch, erneut unter dem Gelächter der Kinder.) (0:25:16 - 0:28:01) (12)

Neben diesem »komödiantischen Höhepunkt« gibt es weitere Vorfälle, die auf die sich dramatisch zuspitzende Situation hindeuten (4.1.3.ac). Zutrittsverbote in Geschäften, Vorladungen, die Ereignisse um das »jüdische Pferd «, zwingen Guido, vor seinem Sohn das drohende Unheil zu verniedlichen. Hierbei basiert die Komik erneut auf dem starken Kontrast, der immensen Kluft zwischen Guidos verbalem bzw. mimischem Verhalten und der eigentlichen Realität, deren Absurdität bzw. Unkommunizierbarkeit uns auf diese Art und Weise erfahrbar gemacht wird.

Ob die beschriebene Komik beim Publikum letztlich auf fruchtbaren Boden fällt, den Zuschauer also zum Lachen reizt, hängt einerseits von ihrer Machart, andererseits vom Mitspielen des Adressaten, seinem Sich-Einlassen auf den Film ab.

So fällt das nahegelegte Lachen bis zur Mitte des Eingangsteils sowie dessen drastische Abnahme bis zum fast gänzlichen Versiegen (ab den Vorbereitungen zur Verlobungsfeier) auf. ${ }^{625}$ Während der Zuschauer zunächst erfreut über den Unernst des sympathischen Helden und in liebevoller Anerkennung für dessen Vitalität, Einfallsreichtum und kindliche Durchtriebenheit lachen $\mathrm{kann}^{626}$, sich überlegen fühlend und 
mit dem Helden über mechanische Verhaltensweisen bzw. körperliche wie geistige Trägheit lacht ${ }^{627}$, aus Genuß am Wissensvorsprung bzw. als Reaktion auf die Mehrdeutigkeit bestimmter Situationen mit Guido die gewohnten Verhaltensmuster sprengt und die Spannung im Lachen löst ${ }^{628}$, fällt ihm das Lachen - unter dem Aufkommen abgründiger Komik in Gestalt der ironischen Verkehrungen und der Zunahme der faschistischen Bedrohung - wohl zunehmend schwerer. ${ }^{629}$

In der beschriebenen Sequenz 12, »Guido als Ministerialrat in der Grundschule«, ballen sich unterschiedliche Anlässe, die ein Lachen auszulösen vermögen. Daher hebt sie sich sowohl hinsichtlich der Dauer des Lachens als auch in bezug auf dessen Intensität deutlich von den anderen Sequenzen des Eingangsteils ab und kann zweifelsohne als die komischste der ersten Hälfte des Films eingestuft werden. In latent revolutionärer, karnevalesker ${ }^{63}$ Freude kann der Zuschauer über Guidos Demonstration menschlicher Vitalität im Kontrast zur Starrheit der Situation lachen: Den steifen, zeremoniellen Rahmen sprengt der Protagonist, indem er in familiärem Ton und unpassender Weise das wissenschaftliche Manifest an seinen eigenen Körperteilen erläutert, wobei er vor maßloser Übertreibung nicht zurückschreckt. ${ }^{631}$ Durch Guido derart auf die Spitze getrieben, kann uns die Ironie der Situation und die Ab-

rire l'homme. (Bergson 1972: 51) Man denke in diesem Zusammenhang an folgende Szenen: Begegnung mit der Prinzessin, Hutstibitzen, Kellnerimprovisation, Erprobung von »Schopenhauers Willenskraft«, Beeinflussung der Menüauswahl und Herbei»zaubern« des Gerichts, Auftritt in der Grundschule, erste »Entführung« seiner Prinzessin.

627. Man erinnere sich an Sterns bzw. Bergsons Ausführungen in 2.2.2 und an folgende Szenen: der »Idiot aus dem Rathaus«, Ferruccios unzureichende Kondition, die unzureichende Aufmerksamkeit des Polsterers bzw. des Ministerialrats.

628. Man denke hier an Plessners Aussagen in 2.2.2 und an vor allem folgende Szenen: Stadt»freiheit», "Schopenhauers Willenskraft«, Lachs für den Ministerialrat, Verkündung des »Rassenmanifests«, erste »Entführung« Doras und die drei »Zufälle«.

629. Diese Art von Lachen wird vor allem im Rahmen der Analyse der analogen Sequenz des Hauptteils (»Übersetzung« der Lagerspielregeln) zur Schlüsselsequenz des Eingangsteils (Verkündung des »Rassenmanifests«) vorherrschen; siehe 4.1.4.bb.

630. Vgl. Bachtins Ausführungen zum Karnevalesken in Literatur und Karneval in II.4.

631. Man erinnere sich an Bergsons Ausführungen zur »transposition« und Parodie in 2.2.2: »Le risible naîtrait quand on nous présente une chose, auparavant respectée, comme médiocre et vile.« (1972: 95)

632. »Benigni's character is introduced during a long set of slapstick comedy scenes, all of which resemble the work of Charlie Chaplin or even Mr. Bean.« (N.N. auf : http://infilmau. iah.net/reviews/life is.htm)

633. Benigni auf: www.lavieestbelle.com/entretien.html. »L'humour fantasque de Guido, le héros de la fable, la loufoquerie des situations, le charme rêveur que lui confère Benigni en font un personnage mémorable et admirablement dessiné.« (www.lavieestbelle.com/images/ pages/presse/positif. html)

634. Den Helden in Heinrich Kleists »Der zerbrochene Krug« beschreibt Kloepfer mit sehr ähnlichen Attributen: »Adam hat karnevaleske Züge, ist ein Spitzbub, einer, der nicht auf den Kopf gefallen ist, sondern der sich windet wie ein Aal, ein Chamäleon der Anpassung, [...] ein Pikaro, [...] ein geborener Lebenskünstler. [...] Wir lachen mit ihm aus der Lust an der menschlichen Plastizität, aus Lust am Schelm.« (1996: 131) 
surdität des ideologischen Fundaments nicht entgehen; aus dieser spannungsreichen Mehr- bzw. Widersinnigkeit kann er sich im Lachen lösen, wobei diesem Lachen ein negatives Werturteil über die - dem tatsächlichen Manifest zugrundeliegende und aus menschlicher Sicht überaus inhumane - Degradation bestimmter Menschenrassen anhaftet.

Mit der beschriebenen Fiktionalität ist die ausführliche Einführung des Protagonisten verknüpft ${ }^{632}$, welche für den Hauptteil richtungsweisend ist. Der Zuschauer begleitet und beobachtet Guido in den unterschiedlichsten Situationen und lernt auf diese Art und Weise einen zur Identifikation anregenden Helden kennen: ideenund einfallsreich - Dr. Lessing nennt ihn anerkennend den »einfallsreichsten Kellner« (o:44:33 h), dem er je begegnet sei - geistig behende, gewitzt, clever, originell, mit reichlich Improvisationstalent ausgestattet, phantasievoll-poetisch, liebenswert charmant, wortgewandt, unbekümmert, lebenslustig bzw. -froh, optimistisch und friedlich-unpolitisch:

»Celui que j'ai créé est un juif intégré, assimilé, qui vit sa vie, qui ne s'occupe pas de politique, qui fait son travail, et dont la vie est tout d'un coup brisée par une hache, comme c'est arrivé dans la réalité. Un personnage avec lequel tout le monde puisse s'identifier. Dans le film, je suis antifasciste, non seulement au fond de mon cœur, mais aussi physiquement: dans ma façon d'apparaître, on comprend que je ne peux pas être fasciste, parce que mes sourcils, mes incisives, mon ventre sont antifascistes! Je représente la liberté totale, la générosité. Et également l'enfance. $\aleph^{633}$

Wie es dem Genie und »Traumtänzer« gelingt, das Herz seiner »geliebten Prinzessin« zu erobern, so wird ihm vermutlich ebenso unsere stetig wachsende Sympathie zuteil. Als sich die Lage gegen Ende des Eingangsteils zuspitzt, gelingt es Guido - angesichts der Fragen seines Sohnes - die nicht kommunizierbare Realität aufgrund seines besonderen Talents zu verdrehen und neu aufzubauen.

An dieser Stelle sei auf einen Aspekt hingewiesen, der - in Analogie zur festgestellten Verweisarmut im Mittelteil - die insgesamt positiv-verklärte Wahrnehmung des ersten Teils von DAs LeBEN IST SCHÖN entscheidend mitbeeinflußt. Die sympathisierende Nähe zum Helden führt dazu, daß der Zuschauer sich dessen poetisch-lebensfroher Sichtweise annähert; er IST sozusagen Guido in den Scherzen bzw. »Zufällen«, antizipiert mit dem Helden die Verblüffung anderer und lacht mit ihm. ${ }^{634}$ Das in der Figur des Protagonisten zweifelsohne angelegte Identifikationspotential wird normalerweise angenommen und begünstigt die bereits angedeutete relative Leichtigkeit des Sich-Einlassens seitens des Zuschauers auf das, vor allem im Hauptteil zur Entfaltung kommende, schwere Thema des Films.

Wie bereits hinsichtlich der auditiven Tönung der faschistischen Indizien festgestellt, fällt auch für die von Komik geprägten Elemente ein ausnahmslos synchrones Auftreten mit einem bestimmten musikalischen Motiv auf. Dieses zeichnet sich durch eine beschwingte Leichtigkeit und Heiterkeit aus, welche die fröhliche Komik absichernd verstärkt. Mit unserem seltener auftretenden Lachen bzw. der zunehmend getrübten Komik gegen Ende des Eingangsteils von DAs LEBEN IST SCHÖN reduziert sich auch die Häufigkeit des beschriebenen Musikmotivs. 
bb) Romantische Liebe zwischen Guido und seiner »Prinzessin«

Der romantische, beinahe märchenhafte, Charakter insbesondere des ersten Teils von DAS LEBEN IST SCHÖN beruht auf den besonderen Qualitäten des Helden, verbunden mit der Entwicklung der Liebesgeschichte. Unter dem Blickwinkel der Handlungsanalyse steht diese zweifelsohne im Zentrum der ersten Hälfte des Films. ${ }^{635}$ Obwohl die Liebesgeschichte im Hauptteil von dem Schauplatz der Vernichtung überlagert wird, ist sie für das Kernstück des Films äußerst funktional im Sinne der zusätzlichen Dramatisierung, der Erfahrbarmachung der Tragik und der möglichen Anteilnahme des Zuschauers (s. 4.1.4.ba). Auf diese Funktionalität soll im folgenden präzisierend eingegangen werden.

Die sich im Eingangsteil entfaltende Liebesgeschichte zwischen Guido und Dora steht unter dem Stern der Vorbestimmtheit. Beide sind von der ersten Sekunde an voneinander wie verzaubert. Angesichts dieser märchenhaften, intensiven Liebe springt der Funke auch auf den Zuschauer über; er vermag diese Glücksgefühle mit der Familie zu teilen. So kann er auch nachvollziehen, daß die junge Frau freiwillig den Zug besteigt, um ihrem deportierten Mann und Sohn zu folgen - Ausdruck ihrer großen Liebe.

Auch in bezug auf die Elemente romantischer Liebe läßt sich eine Parallelität zu einem bestimmten Musikmotiv beobachten. Diese unterstreicht den traum- bzw. märchenhaften Eindruck, welchen die Szenen der sich anbahnenden und entwikkelnden Liebe zwischen Guido und seiner Prinzessin beim Zuschauer hervorrufen.

Bereits in der zweiten Sequenz gaukelt Guido dem kleinen Mädchen eine Prinzenwelt vor (s. ०: 03:०० h), seine »Prinzessin« fällt ihm wie vorbestimmt vom Himmel in die Arme (s. 0:03:15 h) (2). ${ }^{636}$

Auch das Haus des Onkels macht, insbesondere von außen, einen romantischen Eindruck (3). Infolge seiner Tollpatschigkeit gegenüber dem hohen Rathausbeamten »landet« er - per Zufall oder Schicksal - mit Dora in einem aufgeschütteten Sandhaufen, in keineswegs unerwünschter Umarmung (s. o:09:50 h) (6).

Hoffnungslos verliebt und sich nach Dora verzehrend, überrascht er sie erst auf der Piazza (s. 0:17:58 h), kurz darauf und unter äußerster körperlicher Anstrengung in den Gassen der Stadt (s. o:18:35 und o:18:53 h) (10). In der Grundschule begrüßt er seine Traumfrau mit dem bekannten »Guten Tag, geliebte Prinzessin« (s. o:23:36 h) (12). Das Anbeten Doras, die in einer Loge auf der Empore gerührt Offenbachs »Barkarole« lauscht, erinnert an das typische Minnelyrikelement, in welchem der Held seine Dame besingt (s. 0:32:17 h) (13).

635. »Le film est clairement construit en deux parties. Et la première a pour fonction d'installer le climat de conte de fées, de montrer que Guido est un personnage poétique qui peut reconstruire la réalité ...« (http://lavieestbelle.com/entretien.html) Vgl. auch Lederle auf: www.filmdienst.de/Das Leben ist schön.html in 4.1.2, Ravaschino auf: www.primerplano.com/ criticas/vida \%20es \%20 bella, \%20la.htm sowie Jolles in II.4.

636. Hier und im folgenden werden die jeweiligen Sequenznummern in Klammern angegeben; vgl. das entsprechende Sequenzprotokoll im Anhang. 


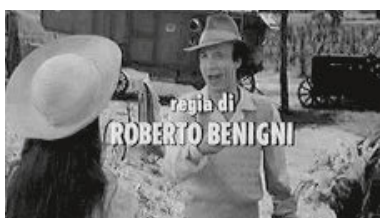

(536) $0: 03: 00 \mathrm{~h}$

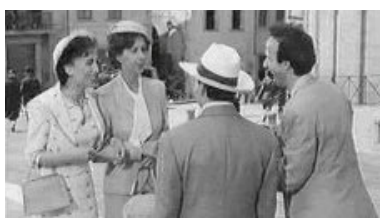

(539) $0: 17: 58 \mathrm{~h}$

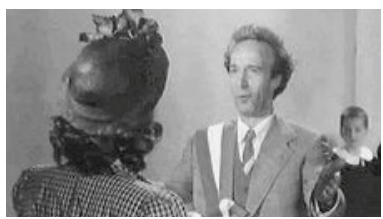

(542) $0: 23: 36 \mathrm{~h}$

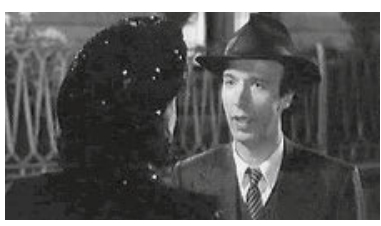

(545) $0: 37: 53 \mathrm{~h}$

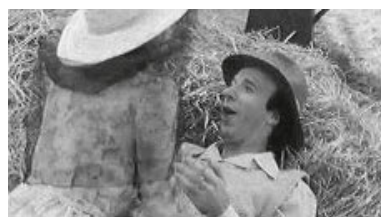

(537) $0: 03: 15 \mathrm{~h}$

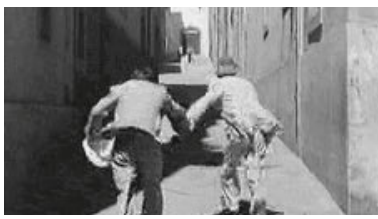

(540) $0: 18: 35 \mathrm{~h}$
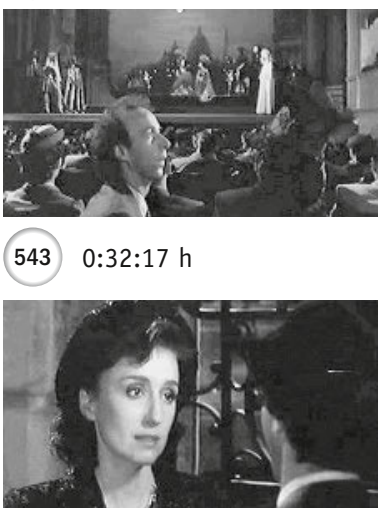

(546) $0: 38: 09 \mathrm{~h}$
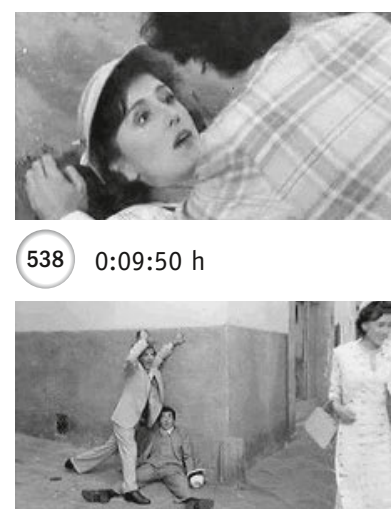

(541) $0: 18: 53 \mathrm{~h}$

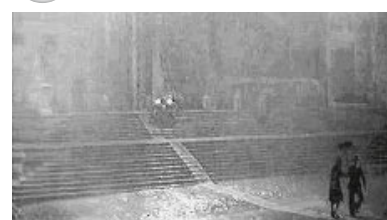

(544) $0: 35: 46 \mathrm{~h}$

Auch die erste »Entführungs«sequenz zeichnet sich durch eine besondere Romantik aus; vor allem als Guido den roten Teppich ausrollt (s. 0:35:46 h) und ihr »indirekt direkt« seine Liebe gesteht. Auf Doras Frage, wo sie sich denn überhaupt befänden, antwortet Guido in Anlehnung an den verregneten Abend und seine Wunschvorstellung:

»Wir beide waren schon mal zusammen hier.« - (Dora fragt:) »Sie und ich?« - »Ach, erinnern Sie sich denn nicht mehr?! An jenem verregneten Abend!? Ich hatte für Sie aus einem Kissen einen Regenschirm gemacht. Ein wunderbarer Abend! Ich legte mir das Lenkrad um die Schulter, machte zwei Walzerdrehungen und als ich vor Ihnen stehen blieb, da gaben Sie mir einen Kuß.« (0:35:30 - 0:35:46 h)

Vor ihrem Haus gibt Guido seiner Prinzessin ebenso charmant wie deutlich zu verstehen, wie gerne er sie ein ganzes Leben lang lieben würde (s. 0:37:53 h und o:38:09 h):

»Ich verspüre ein unbeschreibliches Verlangen, mit Ihnen zu schlafen. Aber das werde ich niemandem verraten, am wenigsten Ihnen. Um mir das zu entlocken, müßte man mich foltern.« - (Dora fragt:) »Was zu entlocken?« - »Daß ich mit ihnen schlafen möchte. Aber nicht bloß einmal, nein, ganz oft. Doch von mir erfahren Sie es nicht. Ich müßte doch völlig verrückt 
sein, wenn ich Ihnen gestehen würde, wie liebend gerne ich es ein Leben lang mit Ihnen tun würde.« (0:37:52 - 0:38:15 h) (14)

Als Guido seine Prinzessin erblickt, wünscht er sich nichts mehr, als sie erneut überraschen zu können (16). Die romantisch-märchenhafte Fiktionalität erfährt ihren Höhepunkt anläßlich der Verlobungsfeier im Grand Hotel: Guido überrascht Dora mit der ihr gewidmeten Torteninschrift. Unzählige Konfettis - wie in einem Schüttelspielzeug mit Schneeflöckchen - rieseln wenig später auf die Tanzenden herunter (17).

Nachdem die »Prinzessin « Guido unter dem Tisch zum ersten Mal geküßt (s. 0:51:53 h) und ihn gebeten hat, sie fortzubringen - Bring' mich weg!« (0:52:01) -, besteigt sie wenig später sein Pferd und reitet, unter dem Deckmantel der traditionellen Brautentführung, mit Guido auf und davon (s. 0:53:58 h) (17).

Am Traumhäuschen angekommen (s. 0:54:34 h), hilft Guido seiner »Prinzessin« vom Pferd, worauf ihre »Begegnung« im Gewächshaus und der ganz natürlich wirkende Zeitsprung von fünf bis sechs Jahren in Verbindung mit der Einführung des gemeinsamen Sohnes folgt (18).

\subsubsection{Hauptteil des Films: Kraft der Phantasie versus Lagerrealität}

Das mit Blick auf die Gesamtlaufzeit des Films geringfügig kürzer ausfallende Kernstück bringt Guido in die Verlegenheit, seinem etwa fünfjährigen Sohn das Vernichtungslager zu erklären, in welches sie deportiert wurden. Angesichts der grausamen Wirklichkeit und in konsequenter Fortführung des eingeschlagenen Verhaltens - die Deportation hatte er Giosuè kurzerhand als Geburtstagsüberraschung »verkauft « - erfindet der Vater die Wettbewerbsgeschichte, um die Unbekümmertheit des Jungen zu bewahren und ihn vor einem Trauma für das Leben zu schützen ${ }^{637}$ : Das KZ wird zum Ferienlager, die Inhaftierten und die Aufseher zu Gegenspielern; wer als erster 1000 Punkte gesammelt habe, dürfe einen echten Panzer - Giosuès Lieblingsspielzeug - mit nach Hause nehmen; da folglich alle Parteien in extremem Konkurrenzkampf stünden, sei hier alles strikt kontrolliert und reglementiert. Diese Präzisierung der »Geburtstagsüberraschung« bildet den Ausgangspunkt für Guidos stetige, kräftezehrende Anstrengungen, seinem Sohn immer wieder den Gewinn des Wettbewerbs in Aussicht zu stellen, auch wenn die Rivalen ihn vom Gegenteil zu überzeugen suchten. Mit immer skurrileren Einfällen, mittels seiner Einbildungskraft gelingt es dem Protagonisten, sein Phantasiegebilde vor dem Einsturz zu bewahren und letztlich den Jungen vor dem sicheren Tod zu retten. Der Versuch, seine Frau vor der Liquidierung zu warnen, kostet Guido am Ende des Films schließlich das Leben.

In Anlehnung an die - in den Leitthesen angesprochene (s. 4.1.2) und vor allem für den Hauptteil des Films zutreffende - unorthodoxe Umgangsweise mit dem schwieri-

637. Siehe Benignis Aussagen hierzu in 4.1.2. sowie seine folgende Äußerung: »Pour éviter qu'il ne prenne conscience de l'insoutenable réalité qui l'entoure, Guido lui fait croire que tout cela n'est qu'un grand voyage organisé, un jeu qu'il faut gagner.« (Auf: www.lavieestbelle.com/ images/pages/presse/histoire.html) 


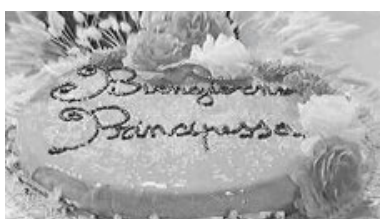

(547) $0: 46: 31 \mathrm{~h}$

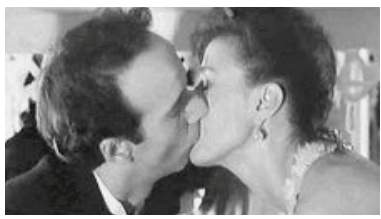

$5490: 51: 53 \mathrm{~h}$

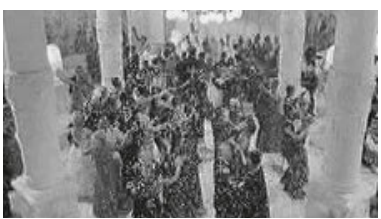

$0: 47: 25 \mathrm{~h}$

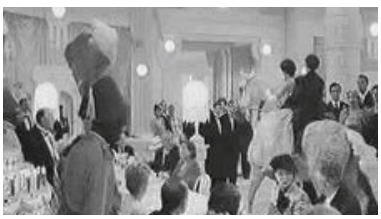

(550) $0: 53: 58 \mathrm{~h}$

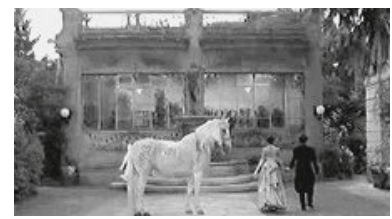

(551) $0: 54: 34 \mathrm{~h}$

gen Thema im Sinne des »Über die Bande-Spielens«, und der damit einhergehenden Absage an eine realistische Vermittlung des Unsag- und -zeigbaren, seien für das zu analysierende Kernstück folgende zentrale Aspekte genannt und im Anschluß daran ausgeführt.

Der Hauptteil von DAS LEBEN IST SCHÖN ist durch eine stringente rhythmische Komposition gekennzeichnet, mit - trotz latent allgegenwärtiger Lagerrealität und kontinuierlicher Dramatisierung der Situation - generellem Schwerpunkt auf den fiktionalen Elementen. Hieraus ergibt sich eine bemerkenswerte ästhetische Freiheit für den Zuschauer im Hinblick auf den Grad des Sich-Einlassens auf den schwer zugänglichen Gegenstand des Kunstwerks, wobei die Barriere der Anteilnahme vergleichsweise klein gehalten wird. Bei besonders ausgeprägter Hingabe an den Film ermöglicht der Umweg über Fiktion und das dadurch angelegte sympraktische Mitfühlen dem Zuschauer eine weitaus aktivere und somit intensivere Erfahrung dessen, was das Unbeschreibliche bedeuten könnte, als es ein realistischer Rekonstruktionsversuch zu leisten vermag.

\section{a) Rhythmus zwischen Fiktion und »Realität«}

Im Unterschied zur ersten Hälfte des Films zeichnet sich der Hauptteil durch ein regelmäßiges Wechselverhältnis zwischen fiktionalen und realistischeren Szenen aus.

Das auf der einen Seite gesteigerte Auftreten der wirklichkeitsnäheren Elemente erklärt sich bereits aus der Wahl des Schauplatzes, dem Vernichtungslager. Auf der anderen Seite ist die grausame Realität von Vernichtungslagern im allgemeinen implizit - doch deshalb potentiell nicht weniger wirkmächtig, im Gegenteil - in Gestalt von Guidos Verkehrungen gegenwärtig.

Parallel zu den Ausführungen hinsichtlich der behutsamen, rhythmischen Steigerung der realistischen »Dosis « im Eingangsteil kann festgestellt werden, daß diese Beobachtung auch für den Hauptteil des Films generelle Gültigkeit hat; dies jedoch in weniger ausgeprägter Form, da die Stimmung im Kernstück nicht allmählich schwindet, sondern mit dem Eintritt ins Lager getrübt ist - die Gefahr ist fortwährend präsent.

Aufgrund dieser Feststellungen läßt sich für den Hauptteil von einer permanenten - überwiegend impliziten, zum Teil aber auch expliziten - Präsenz bzw. Allgegenwart der Lagerrealität sprechen. 
Hinsichtlich der angesprochenen Rhythmik ist der Hauptteil, das Auftreten realistischer und irrealer Elemente betreffend, in drei Abschnitte zu unterteilen: Sein Beginn (1:07:33 - 1:19:29 h) steht unter dem vorherrschenden Eindruck der fiktionalen Szenen, der Mittelteil (1:19:28 - 1:43:13 h) weist ein durchgehendes Gleichgewicht zwischen beiden Elementen auf und der Schlußteil, bis zu Guidos Ermordung (1:43:13 - 1:52:13 h), ist von zunehmender Dramatik und schließlich unausweichlicher Bedrohung geprägt.

Im weiteren wird das Wechselverhältnis der - um es mit Dewey zu formulieren - antagonistischen Energien für die beobachteten Abschnitte untersucht/aufgezeigt. ${ }^{638}$

aa) Beginn des Hauptteils: »Geburtstagsüberraschung« versus Vernichtungslager

Der Beginn des Hauptteils (1:07:33 - 1:19:29 h) weist eine relative Dominanz an fiktionalen Momenten auf, vor allem im Hinblick auf die Eindringlichkeit der Szenen.

Grund hierfür ist Guidos anfänglich gesteigerter Erklärungsbedarf bezüglich der »Geburtstagsüberraschung « (25), die ausführliche Anpassung der Lagerbedingungen an seine Wettbewerbsgeschichte (26), sowie die erste schwierige Überzeugungsarbeit (28). In gewisser Hinsicht herrschen zu Anfang des Hauptteils Guidos Wirklichkeitsverkehrungen für seinen Sohn vor. Diese relative Dominanz stützt sich vor allem auf die extreme Intensität von Sequenz 26, in welcher Guido für seinen Sohn die Lagerverordnungen in Spielregeln eines Wettkampfes überträgt. In Analogie zur »verdrehten« Verkündung des Rassenmanifests in der Grundschule kann diese Sequenz ebenfalls als einer der Höhepunkte, einer der Dreh- und Angelpunkte des gesamten Spielfilms angesehen werden.

Aufgrund der dominierenden Wirklichkeitsverkehrungen zu Beginn des Kernstücks können wir antizipieren, daß diese - bereits gegen Ende der Exposition eingeschlagene (s. 4.1.3.ac) - Form des Umgangs mit der Realität sich während des gesamten Hauptteils fortsetzen wird.

In der Nacht und bei Scheinwerferlicht rollt der Zug langsam ins Konzentrationslager ein (s. 1:08:23 h) (R). Unter dem permanenten Brüllen der SS-Leute werden die Ankömmlinge aus den Viehwaggons getrieben (1:08:44 h) (R). Guido sucht aufgeregt nach Dora; als er nach ihr ruft, wird er von einem SS-Mann daran gehindert (s. 1:09:17 h) (R). Seinem Sohn, der sich über die unbequeme Zugfahrt beklagt, verspricht Guido, daß sie mit dem Bus und ordentlichen Sitzen nach Hause fahren würden und lobt die »hervorragende Organisation« (1:09:50 h) des Ganzen (F,iV). Auf die drängenden Fragen Giosuès nach der »Geburtstagsüberraschung« erfindet Guido

638. Hierbei werden die jeweiligen Sequenznummern sowie die Zugehörigkeit zu Fiktion/ Irrealität mit (F) bzw. Lagerrealität mit (R) in Klammern angegeben. Innerhalb der fiktionalen Elemente $(F)$ wird zusätzlich die Unterscheidung zwischen Komik $(F, K)$, ironischer Verkehrung $(F, i V)$ und romantischer Liebe $(F, r L)$ getroffen.

639. Im folgenden werden Giosuès Sätze mit (S.) für Sohn und Guidos mit (V.) für Vater gekennzeichnet.

640. Im folgenden wird diese zentrale Szene wörtlich festgehalten, wobei die Sätze des SS-Mannes mit (SS), die Guidos mit (G.) abgekürzt und in Klammer angegeben werden. 


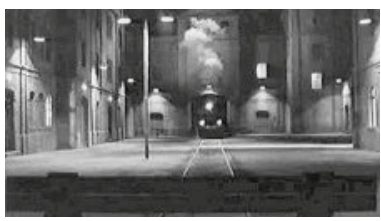

(552) $1: 08: 23 \mathrm{~h}$

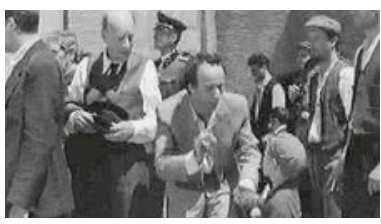

(555) $1: 10: 27 \mathrm{~h}$

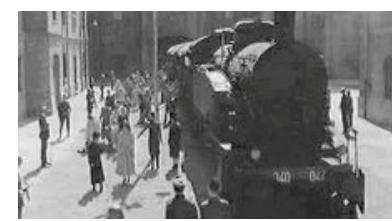

(553) $1: 08: 44 \mathrm{hh}$

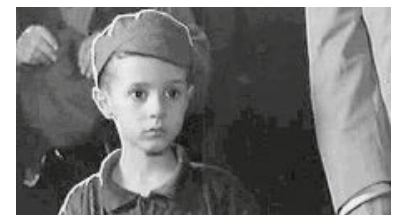

(556) $1: 11: 13 \mathrm{~h}$

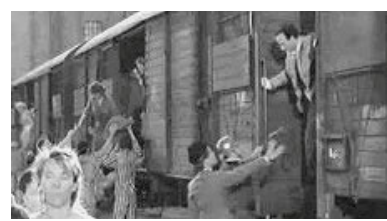

$1: 09: 17 \mathrm{~h}$

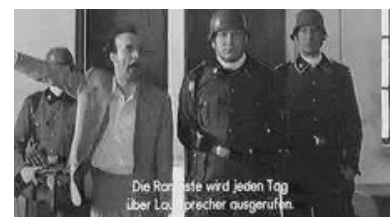

(557) $1: 13: 30 \mathrm{~h}$

die Wettbewerbsgeschichte mit einem echten, nagelneuen Panzer als Hauptgewinn (s. 1:10:27 h) $(\mathrm{F}, \mathrm{iV}){ }^{: 639}$

»Verrätst du mir endlich, was für ein Spiel das ist!?« (S.) - »Paß' auf, ich werd' dir sagen, was für ein Spiel das ist; das Spiel heißt, es heißt ... wir sind ... wir spielen ... Mannschaft gegen Mannschaft, klar?! Ich hab' das Spiel gut vorbereitet. Paß' auf, die Männer befinden sich hier und die Frauen dort. Eh, dann brauchen wir die Soldaten; sie geben uns den Zeitplan vor. Das Spiel ist nicht einfach. Es wird schwer werden, es zu gewinnen. Eh, wer ... wer einen Fehler macht, wird sofort nach Hause geschickt, sofort, ohne Pardon. Deshalb müssen wir gut aufpassen, Giosuè. Aber wenn wir gewinnen, dann bekommen wir den Hauptpreis. « (V.) »Was kann man denn bei dem Spiel gewinnen?«(S.) - »Eh ... den Hauptpreis, hab' ich doch gesagt!« (V.) - »Einen Panzer kann man gewinnen!« (Onkel) - »Aber Panzer hab' ich doch schon zuhause.«(S.) - »Nein, zu gewinnen gibt es einen echten, einen nagelneuen Panzer!« (V.) - »Was einen echten? Nein!?« (S.) - »Doch, eigentlich wollt' ich's dir nicht sagen.« (V.) $(1: 09: 58-1: 10: 46)$

Als der Onkel durch den schroffen Befehl eines SS-Mannes aufgefordert wird, sich in einer anderen Reihe anzustellen (R), erklärt Guido seinem Sohn, der Onkel käme in eine »andere Mannschaft« (F,iV) (25).

Giosuès Erschrockenheit angesichts der Barackeninsassen (s. 1:11:13 h) (R), versucht Guido mit einem »vergnügten« »Da staunst du, was, Giosuè?! « (1:11:23) und mit der Aussage, sie hätten zwei Einzelplätze reserviert, zu entkräften (F,iV). Giosuès Jammern - er findet es in der Baracke eklig und schmutzig, hat großen Hunger, möchte zur Mama und fragt, wann das Spiel endlich vorüber sei (R) - versucht sein Vater zu beschwichtigen, indem er die 1000 Punkte als Ziel erfindet und seinem Sohn einredet, den Mann mit den Marmeladenbrötchen hätten sie leider knapp verpaßt (F,iV). Als ein SS-Scherge lärmend die Baracke betritt und brüllend einen Italiener zum Übersetzen der Lagerregeln verlangt (R), tritt Guido vor (s. 1:13:30 h) (F,iV bzw. K) ${ }^{640}$ (s. 4.1.4.bb). Begeistert und entschlossen, die erforderlichen 1000 Punkte zu erzielen, wendet sich Giosuè nach dessen »Übersetzungsarbeit« an seinen Vater: »Mann, 1000 Punkte!« $(1: 15: 25$ h) (26). 
Sich unter der Last des Ambosses (s. 1:15:40 h) krümmend, klagt Guido gegenüber seinem Gefährten Vittorino, er könne keinen weiteren Amboß mehr schleppen (R). Bartolomeo, gewaltig am Arm blutend, hat sich bei der Schwerstarbeit verletzt und wird in barschem Ton zum Krankenbau geführt (R). Als Vittorino Guido klarmacht, daß ihm der Tod bevorsteht, sollte er den Amboß einfach zu Boden legen, quält er sich mit letzter Kraft weiter (R) (27).

Nach getaner Arbeit schleppen sich die Männer, unter Giosuès Blick, in die Barakke, wo sie völlig erschöpft in ihre Kojen fallen (R). Von SS-Schreien angetrieben, taucht Guido - vor Kraftlosigkeit wankend - als letzter in der Barackentür auf (s. 1:16:46 h) (R). Seine Häftlingsuniform preist er seinem Sohn mit den Worten an: »Sieh' mal, was ich Hübsches anhabe. Fein, he. Sieht schick aus, he?!« 1:17:04 h; s. 1:17:05 h) (F,iV) Die auf der Kleidung aufgenähte und auf dem Unterarm eintätowierte Nummer erklärt der Vater mit Schwierigkeiten, die es bei der Anmeldung gab und aus der Sorge heraus, sie zu vergessen (F,iV). Auf Guidos Frage, ob Giosuè denn mit den anderen Kindern gesprochen hätte, antwortet dieser sichtlich verunsichert -, daß sie von dem Punktesammeln und dem Panzer gar nichts wüßten (R), woraufhin Guido seinem Sohn weismacht, die anderen Kinder hätten versucht, ihn aus Konkurrenzgründen hereinzulegen (s. 1:18:03 h) (F,iV). Als Giosuè nachfragt, wie viele Punkte sie denn heute gesammelt hätten, erzählt sein Vater »ausgelassen« von den Fangspielen und den ergatterten 48 Punkten: »Heute, da hat es richtig Spaß gemacht. Ich freu' mich schon auf morgen, das glaubst du gar nicht!« (1:18:22) (F,iV). Dadurch, daß Giosuè kein Marmeladenbrötchen verlangt habe, kämen noch 12 Punkte hinzu, rechnet Guido seinem Sohn vor $(\mathrm{F}, \mathrm{iV})$. Als Bartolomeo die Baracke betritt und Guido nachfragt, wie es denn gewesen sei, antwortet dieser deprimiert: »Schlimm war's; und der Hunger macht es noch schlimmer!« (1:19:17) (R). Giosuè flüstert daraufhin seinem Vater ins Ohr, daß Bartolomeo nun wohl Punkte verloren habe, worauf Guido vorgibt, sie führten jetzt die Rangliste an (F,K) (28).

ab) Mitte des Hauptteils: Guidos »Wettkampfsregeln«, »Versteck- und Schweigespiele« Im mittleren Abschnitt des Hauptteils (1:19:28 - 1:43:13 h) ist das Wechselverhältnis zwischen fiktionalen und realistischeren Szenen insgesamt recht ausgeglichen.

641. In Anlehnung an Bergson arbeitet Kloepfer die Überlebenskompetenz des Helden in Kleists »Der zerbrochene Krug« heraus, welche mit der Guidos durchaus vergleichbar ist: »Je größer die Not, desto öfters scheint der sSpringteufek seiner Gewitztheit zu obsiegen. [...] die Sache wird ein immer größeres Lügengespinst.« (Kloepfer 1996: 131) »Au détour de chaque embuscade ou moment austère, Benigni s'efforce de relever la tête et à continuer le combat pour cacher à son Giosuè les détails sordides de l'Histoire.« (Guéret auf: www.cinopsis.com/ critics/lavitaeb.htm)

642. Der Held in Jurek Beckers »Jakob der Lügner« sieht sich zu ähnlichem Verhalten verpflichtet. Um die Hoffnung und den Überlebenswillen seiner jüdischen Ghettomitbewohner am Leben zu erhalten, erfindet er immer wieder neue Radionachrichten, welche den baldigen Einmarsch der Alliierten prophezeien. Nach und nach gerät Jakob - wie Guido - zunehmend unter Zugzwang: »Bloß es muß ihm genug einfallen, sie werden immer neue Fragen stellen, sie werden Einzelheiten wissen wollen [...] er muß die Antworten erfinden.« (Becker 1982: 75) 


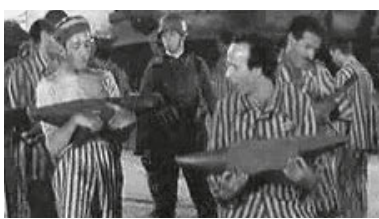

(558) $1: 15: 40 \mathrm{~h}$
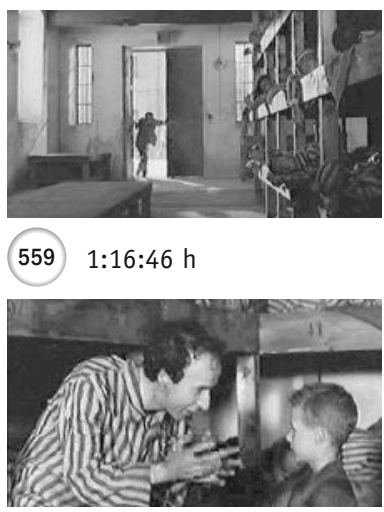

(561) $1: 18: 03 \mathrm{~h}$

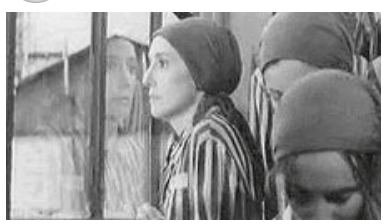

(563) $20: 24 \mathrm{~h}$

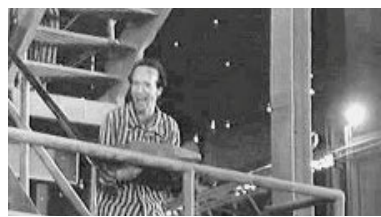

(566) $1: 21: 08 \mathrm{~h}$

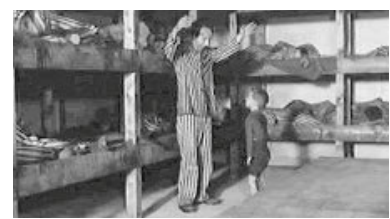

(560) $1: 17: 05 \mathrm{~h}$

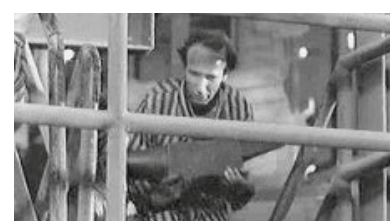

(564) $1: 20: 31 \mathrm{~h}$

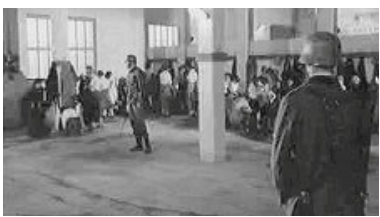

(567) $1: 21: 31 \mathrm{~h}$

(565) $1: 20: 45 \mathrm{~h}$

Die Dosierung des Schreckens nimmt im Mittelteil zu, vor allem durch Guidos immer grotesker werdende Einfälle ${ }^{641}$, sein Phantasiegebilde vor dem Einsturz zu bewahren. Besonders in Sequenz 37 versucht der Protagonist mit allen ihm zur Verfügung stehenden Mitteln, seinem an der Existenz des Wettspiels zweifelnden Sohn die bittere Wahrheit vorzuenthalten. ${ }^{642}$

Von Schreien angetrieben, verlassen die inhaftierten Frauen ihren Bau (R). Eine ältere Dame wird von einer Aufseherin in extrem barschem Ton aufgehalten: »Halt! War das nicht klar und deutlich genug. Alte und Kinder nicht. Los rein! Ihr werdet nicht arbeiten!« (1:19:35 h) (R). Eine Leidensgenossin erklärt Dora, daß diese Aufseherin die schlimmste sei und daß die Alten und Kinder in »Duschräumen« durch den Einsatz von Gas getötet würden (s. 1:20:10 h und 1:20:31) (R) (29).

Als Giosuè plötzlich bei seinem Vater, der sich unter der Last eines Ambosses mühsam vorwärts schleppt (R), auftaucht, weil er nicht - wie die anderen Kinder »duschen« möchte und seinen Vater fragt, was sie denn arbeiten, antwortet dieser (s. 1:20:45 h), sie bauten den Panzer und es mache viel Spaß (s. 1:21:08 h) (F,iV). Nachdem sich Giosuè vehement weigert, »duschen « zu gehen, rät ihm Guido - mit den Worten »Das macht Spaß, he?!« (1:21:26 h) - sich wenigstens gut zu verstecken (F,iV) (30). 
Mehrere deutsche Aufseher organisieren das bevorstehende »Duschen« der Alten und Kinder. Diese sollen sich - begleitet vom antreibenden Schreien der Aufseher rasch ihrer Kleider entledigen und sich deren Nummern einprägen, um sie »später« schnell wiederzufinden (s. 1:21:31 h) (R). Als die Aufseherin stolpert und der Onkel ihr aufzuhelfen versucht, straft sie ihn mit einem verächtlichen Blick (s. 1:22:03 h) (R) (31).

Seinem Sohn schärft Guido ein, daß er von nun an den ganzen Tag über versteckt bleiben müsse (s. 1:22:17 h) und ihn vor allem die »Männer von der bösen Mannschaft « (1:22:20 h) nicht entdecken dürften, sonst würden sie beide disqualifiziert; auf diese Weise könne Giosuè 120 Punkte am Tag beisteuern (F,iV). Um mit ihm das »Versteckspiel« zu üben (s. 1:22:53 h), erprobt es Guido spielerisch (s. 1:22:53 h): »Wo bist du, Giosuè, wo? Ich seh’ dich!« (1:22:54 h) (F,iV) (32).

Voller Sorge sucht Dora in einem Kleiderhaufen, den die Frauen zwecks Weiterverarbeitung sortieren müssen (s. 1:22:57 h), nach Spuren von Giosuè und dem Onkel (s. 1:23:15 h) (R) (33).

Während über den Lagerlautsprecher ertönt, daß der Osteingang für einige Tage geschlossen bleibe, schleppt sich Guidos Arbeitsgruppe unter SS-Bewachung in Richtung Baracke (R). Aus dem Schubkarren, den Guido vor sich herschiebt, ertönt plötzlich ein Geräusch - Giosuè liegt unter einer Decke darin und hat Schluckauf (s. 1:23:41 h) (F). Als Guido den leeren Lagerlautsprecher-Raum bemerkt, nutzt er die Gelegenheit, seiner Frau eine Liebeserklärung und ein Lebenszeichen von ihrem Sohn über das Mikrofon zukommen zu lassen (s. 1:24:33 h) (F,rL):

»Bongiorno, geliebte Prinzessin! Heute Nacht, da habe ich die ganze Zeit von dir geträumt. Wir waren im Kino und du hattest dieses rosafarbene Kleid an, das ich so mag. Ich denke die ganze Zeit nur an dich Prinzessin, nur an dich. Und jetzt: Mama, weißt du was: Papo nimmt mich in einem Schubkarren mit, aber er kann ihn gar nicht richtig schieben $(F, K)$. Es macht sehr viel Spaß, wir führen! Wie viel Punkte haben wir heute gekriegt, Papo?« (1:24:30 - 1:25:15 h)

Dora hat unterdessen ihre Arbeit unterbrochen und den beiden wehmütig gelauscht (s. 1:24:49 h) (F,rL) (34).

In Guidos Arbeitsgruppe sind erste Verluste zu verzeichnen; Alfonso, Vittorio und die anderen haben es nicht überlebt (R). Als alle Insassen - unter ihnen auch Guido - auf einen strengen Befehl hin die Baracke verlassen müssen, wendet Guido mit Giosuè erneut das »Versteckspiel« an (s. 1:25: 56 h und 1:25:55 h) (F,im Vergleich) (35).

Im Zuge der Untersuchung durch den KZ-Arzt wird der Gesundheitszustand eines jeden Häftlings diagnostiziert und schriftlich festgehalten (s. 1:25:59 h) (R). Bei Guido stellt Dr. Lessing einen leichten Leberschaden fest (R). Als er sich bereits dem nächsten Juden zuwendet, teilt ihm Guido die Lösung für das noch ausstehende Rätsel mit (s. 1:26:39 h), woraufhin sich der Arzt an den einstigen Kellner des Grand Hotels erinnert (F) und einen SS-Mann zu sich befiehlt (s. 1:26:54 h) (R) (36). 


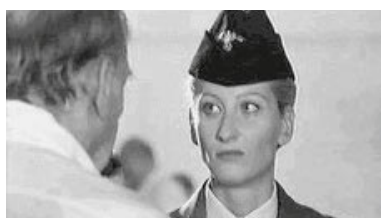

(568) $1: 22: 03 \mathrm{~h}$

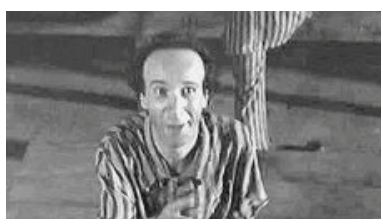

(571) $1: 22: 53 \mathrm{~h}$

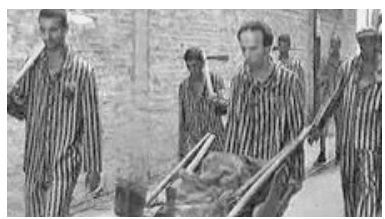

(574) $1: 23: 41 \mathrm{~h}$

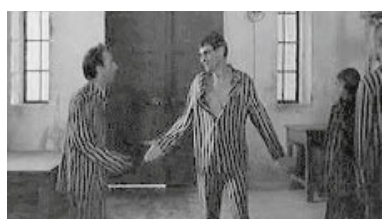

(577) $1: 25: 41 \mathrm{~h}$

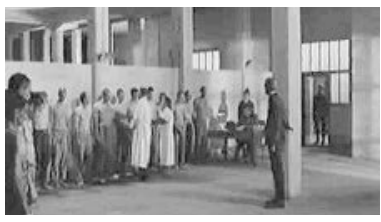

(580) $1: 25: 59 \mathrm{~h}$
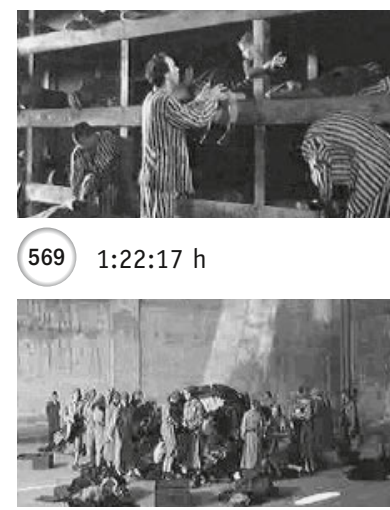

(572) $1: 22: 57 \mathrm{~h}$

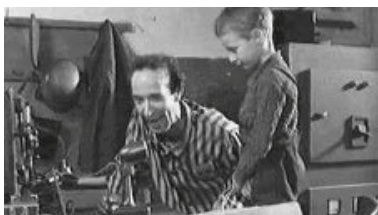

(575) $1: 24: 33 \mathrm{~h}$

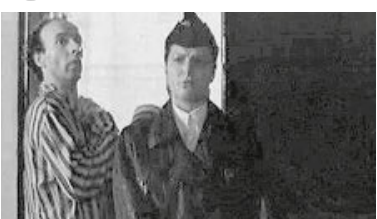

(578) $1: 25: 56 \mathrm{~h}$

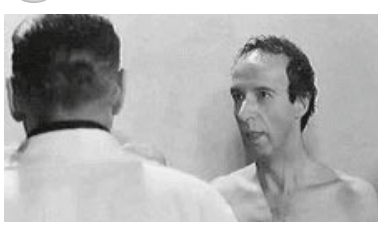

(581) $1: 26: 39 \mathrm{~h}$

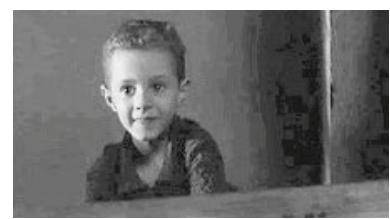

(570) $1: 22: 53 \mathrm{~h}$

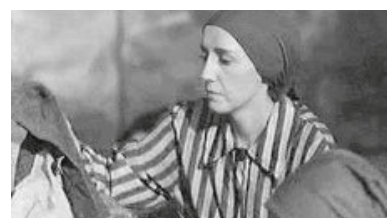

(573) $1: 23: 15 \mathrm{~h}$

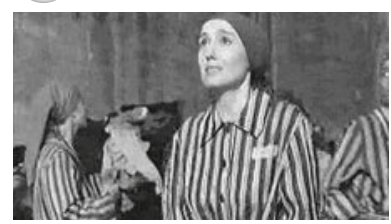

(576) $1: 24: 49 \mathrm{~h}$

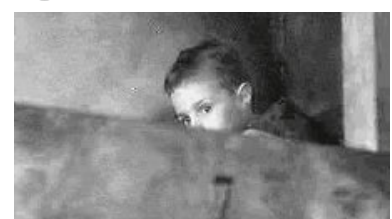

(579) $1: 25: 55 \mathrm{~h}$

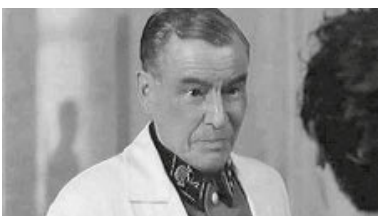

(582) $1: 26: 54 \mathrm{~h}$

Den verspätet in die Baracke zurückgekehrten Guido fragt Bartolomeo besorgt, wo er denn so lange geblieben sei. Dieser antwortet, daß ihn der KZ-Arzt möglicherweise aus dem Lager bringen könne, wenn er beim bevorstehenden Abendessen der Offiziere bediene (R). Nach mehrmaligem Rufen nach Giosuè bemerkt er seinen Sohn aufgrund dessen Schluckaufs und hilft ihm »gut gelaunt« aus seinem Versteck; doch Giosuè ist wenig erfreut - von einem Häftling hat er erfahren, daß aus ihnen Knöpfe und Seife hergestellt werden sollen (s. 4.1.4.ba). Trotz Guidos Bemühungen will der Junge unbedingt nach Hause, und zwar sofort. Als sein Vater sich anschickt, ihre Sachen zu packen, wundert sich Giosuè darüber, dass man sie so einfach gehen lassen wird. Auch die Tatsache, daß sie - laut Guido - die Rangliste anführen, kann Giosuè nicht von seinem Wunsch abbringen (F,iV). Erst als Guido Bartolomeo ausführliche Anweisungen bezüglich des Panzers gibt, willigt der Sohn ein, doch zu bleiben, um den Hauptpreis zu erstreiten (F) (37). 
Während Hitlers Stimme über den Lagerlautsprecher ertönt (R), bemerkt Guido beim Vorbereiten des SS-Abendessens die im Hof spielenden, deutschen Kinder. Um seinen Sohn von der Existenz anderer Kinder zu überzeugen, holt er ihn in der Baracke ab und zeigt ihm die Verstecken spielenden Kinder (s. 1:33:24 h) (F,iV). Eine Aufseherin ruft streng alle Kinder zu sich und entdeckt im letzten Moment auch Giosuè (R). Noch bevor sein Sohn abgeholt wird, schärft Guido ihm ein, er dürfe ab jetzt kein Wort mehr sagen, denn nun beginne das alles entscheidende »Schweigespiel« (F,iV). Dem von der Aufseherin »abgeführten « und zurückblickenden Giosuè zwinkert Guido aufmunternd zu (s. 1:34:54 h), was dieser erwidert (s. 1:34:53 h) (F,iV) (38).

Guido bedient anläßlich des gemeinsamen Kaffeetrinkens und Abendessens der hohen SS-Leute im Offiziersgebäude. Die laut und wild durcheinander rufenden Kinder werden von einem Offizier streng zur Ruhe aufgefordert (R). Dr. Lessing gibt Guido unbemerkt zu verstehen, daß er ihn unbedingt sprechen müsse (s. 1:35:43 h) (R). Als sich Giosuè bei dem, ihn mit einem Stück Kuchen bedienenden, deutschen Jungen mit »Grazie!« (1:36:05 h; s. 1:36:11 h) bedankt, eilt dieser aus dem Raum (R). Böses ahnend schaut Guido ihm mit sorgenvollem Blick nach. In Begleitung der Aufseherin kehrt der deutsche Junge zurück und ertappt Guido bei seinem Versuch, allen Kindern das Wort Grazie beizubringen (s. 1:36:39 h) (F,K). »Für dich ist das Sprechen in diesen Räumen verboten!« (1:36:49 h), herrscht ihn die Aufseherin an; den Kindern befiehlt sie: »Ihr eßt jetzt weiter, und zwar ohne ein Wort zu sagen!« (1:36:52 h) (R) (39).

Voller Hoffnung auf eine Möglichkeit zur Flucht teilt Guido Dr. Lessing mit, daß auch seine Frau Dora im Lager sei (R). Seinem Sohn schärft er erneut ein, langsam zu essen (s. 1:37:48 h) und keine Dummheiten zu machen, jetzt wo sie die Rangliste anführten (F,iV). Nachdem Dr. Lessing Guido durch absichtliches Verschütten von Alkohol an die Anrichte gelockt hat, berichtet er ihm in völliger Verzweiflung von einem Rätsel, welches er nicht zu lösen imstande sei (s. 1:39:20 h) (R). Wie gewohnt hofft er auf Guidos geistige Beweglichkeit: »Bitte hilf mir, Guido, ich flehe dich an!« (1:39:27 h). Fassungslos wendet dieser sich ab (s. 1:40:06 h) (40).

Nachdem Guido beim Wechseln der Schallplatte zufällig Offenbachs »Barkarole« entdeckt hat, richtet er den Lautsprecher ins Freie, um Dora ihr gemeinsames Liebeslied vorzuspielen (s. 1:42:03 h); zu Tränen gerührt, lauscht diese den bekannten Klängen (s. 1:42:22 h) $(\mathrm{F}, \mathrm{rL})(41)$.

Seinen schlafenden Sohn auf dem Arm tragend, spricht Guido teils zu ihm, teils mit sich (1:43:00 h):

»Vielleicht ist das alles bloß ein Traum, Giosuè, aus dem wir wieder erwachen werden. Morgen früh kommt dann die Mama und weckt dich. Und zum Frühstück macht sie uns Cappuccino und Milchkaffee. Wir essen Kekse dazu und dann werden wir uns lieben, zweimal, dreimal ... wenn ich es schaffe.« $(F, r L)(1: 42: 47-1: 43: 13$ h) $(42)$

\section{ac) Das »bitter-süße« Ende des Hauptteils}

Insbesondere unter dem Gesichtspunkt der Anzahl und der Länge der Parts herrschen die realistischeren Szenen gegen Ende des Hauptteils und Films (1:43:13 - 1:52:13 h) 


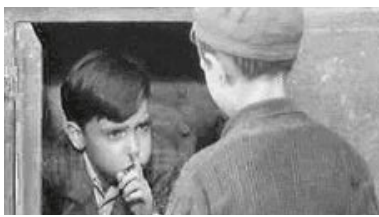

(583) $1: 33: 24 \mathrm{~h}$
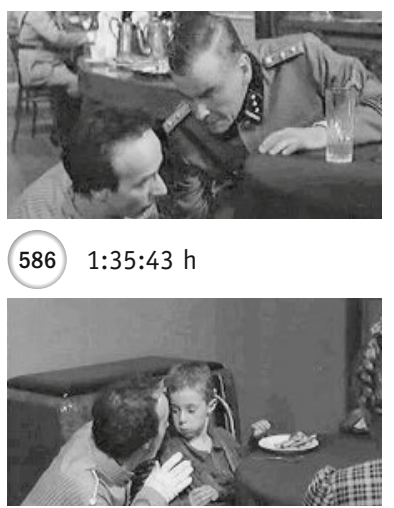

(589) $1: 37: 48 \mathrm{~h}$

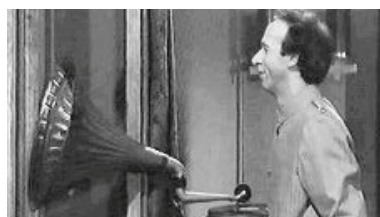

(592) $1: 42: 03 \mathrm{~h}$

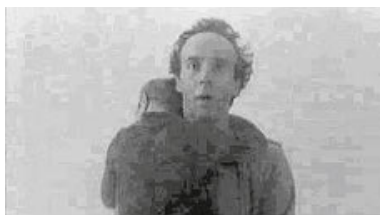

(595) $1: 43: 20 \mathrm{~h}$
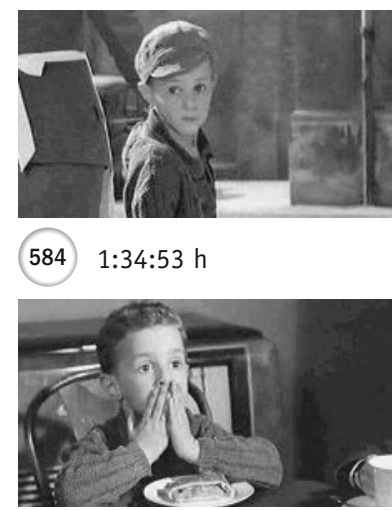

(587) $1: 36: 11 \mathrm{~h}$

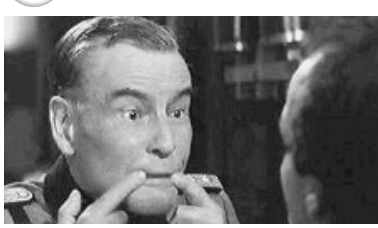

(590) $1: 39: 20 \mathrm{hh}$

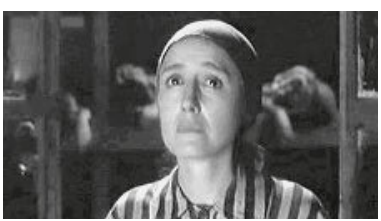

(593) $1: 42: 22 \mathrm{~h}$

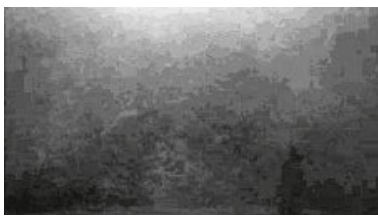

(596) $1: 43: 32 \mathrm{~h}$

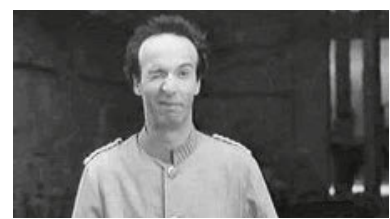

(585) $1: 34: 54 \mathrm{~h}$

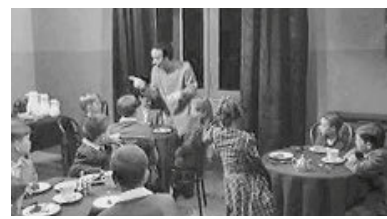

(588) $1: 36: 39 \mathrm{~h}$

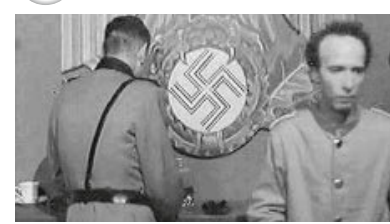

(591) $1: 40: 06 \mathrm{~h}$

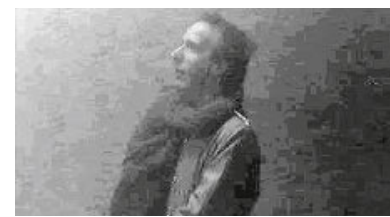

(594) $1: 43: 00 \mathrm{~h}$

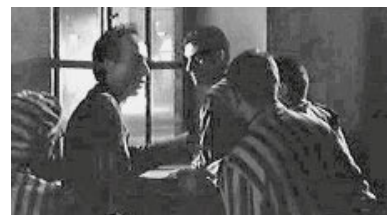

(597) $1: 44: 32 \mathrm{~h}$

zum ersten Mal vor. Diese Tatsache ist einerseits auf die unübersehbare Abnahme fiktionaler Momente sowie deren tragische Tönung zurückzuführen. Auf der anderen Seite ist die allgemeine Zuspitzung der Situation für die relative Dominanz der Lagerrealität verantwortlich: Guidos Abschied von seinem sich versteckenden Sohn (44), seine erfolglose Suche nach Dora (45) und sein tragisches Ende (46).

Auf dem Rückweg zur Baracke verläuft sich Guido im Nebel und findet sich plötzlich - voller Entsetzen (s. 1:43:20 h) - vor einem kaum erkennbaren Berg aufgeschütteter, nackter Leichen wieder (s. 1:43:32 h) (R) (42).

Nächtliches Hundegebell und Maschinengewehr-Salven reißen Guido aus dem Schlaf (R). Von Bartolomeo erfährt er, die Deutschen verließen kurz vor Kriegsende das Lager, nicht ohne vorher die Häftlinge zu ermorden (R). Mit den Worten - »Wir sehen 
uns in Viareggio. Dann gründen wir eine Firma und machen Ambosse!« (1:44:29 h) - beschließt Guido, sich »aus dem Staub zu machen« (s. 1:44:32 h) (F,K) (43).

Giosuè erklärt er, die Deutschen seien so aufgeregt (R), weil sie nur ihn - den voraussichtlichen Gewinner des Wettbewerbs - suchten; aus diesem Grund müsse er sich in dem Metallkästchen bis zum nächsten Morgen, dem Tag der Preisverleihung, verstecken (s. 1:45:24 und 1:45:53 h); ohne Fehler steuere er so die restlichen 40 Punkte bei (F,iV). Nachdem Guido beobachtet hat, daß die Frauen auf Lastwagen abtransportiert werden (R), bittet er seinen Sohn um die Decke und sein Strickjäckchen, »um die Deutschen auf eine falsche Fährte zu locken« (F,V). Giosuè läßt er wiederholen, daß er erst dann sein Versteck verlassen dürfe, wenn er keinen Lärm mehr höre - nur bei Beherzigung dieser Regel gewännen sie das Spiel (s. 1:47:06 h) (F,iV) (44).

Mit Hilfe von »Schopenhauers Willenskraft« gelingt es Guido aus einiger Entfernung, den bellenden Schäferhund von Giosuès Versteck zu vertreiben (s. 1:47:24 h und 1:47:47 h) (F,K). Mit der Decke als Rock und Giosuès Strickjäckchen um den Kopf als Frau verkleidet $(\mathrm{F}, \mathrm{K})$, begibt sich Guido auf die - zwar hartnäckige, doch letztlich vergebliche - Suche (s. 1:48:24 h) nach Dora, die sich nicht unter den abtransportierten Frauen befindet (R) (45). ${ }^{643}$

Als er im letzten Moment von der Aufseherin bemerkt wird (s. 1:49:43 h), versucht er zu fliehen und dem Lagerscheinwerfer zu entgehen - ohne Erfolg (s. 1:49:55 h); einen ihn unentwegt anbrüllenden Soldaten mit gezücktem Maschinengewehr im Rücken, überquert Guido den Hauptplatz des Lagers (R). Auch in dieser prekären Lage denkt er an Giosuès Versteck, von welchem aus man den Hof überblickt. Die sorgenvollen Blicke seines Sohnes förmlich spürend (s. 1:50:55 h), zwinkert er in Richtung Metallkästchen und greift das schon einmal angewandte, übertriebene Marschieren auf (s. 1:50:48 h) (F,iV). Hinter einer abgelegenen Steinwand wird er vom SS-Schergen erschossen (R) (46).

Am folgenden Morgen verlassen die letzten Deutschen in aller Eile das Lager (s. 1:51:48 h); einige Zeit darauf folgen die sich mühsam vorwärts schleppenden Überlebenden (s. 1:52:17 h) (R) (47).

Erst als völlige Ruhe eingetreten ist, traut sich Giosuè aus seinem Versteck heraus (s. 1:53:24). Wenig später rollt ein amerikanischer Panzer in den Hof ein (s. 1:54:35 h), den Giosuè mit einem »Ja, es stimmt! $(1: 54: 43$ h) begrüßt und mit Hilfe des GI - besteigen darf $(\mathrm{F})(48)$.

643. "C'est un hymne d'amour pour elle [Dora], je meurs parce que je vais la chercher, je n'arrive pas à l'oublier. Quand je suis avec l'enfant et que je lui envoie le message dans le film, je lui dis: ১Je pense toujours et seulement à toi!«. C'est en même temps un hommage à »Maus« de Spiegelmann, cette bande dessinée où les juifs sont des souris et les allemands des chats. Le personnage cherche toujours sa femme. C'est une très belle histoire d'amour.« (Benigni auf: www.arte.fr/benigni/html) 


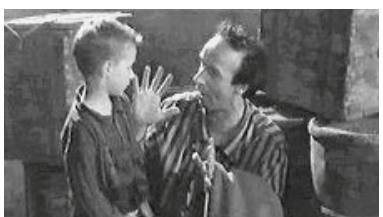

(598) $1: 45: 24 \mathrm{~h}$

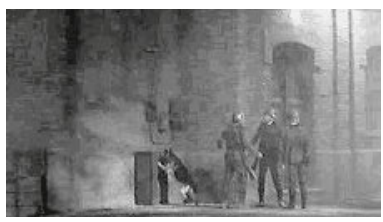

(601) $1: 47: 24 \mathrm{~h}$

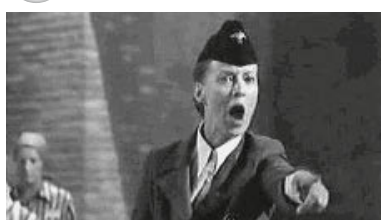

(604) $1: 49: 43 \mathrm{~h}$

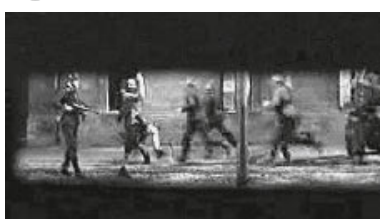

(607) $1: 50: 48 \mathrm{~h}$

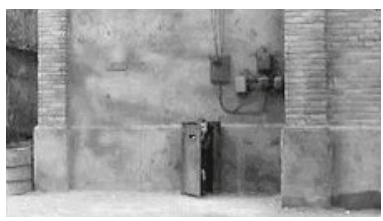

(610) $1: 53: 24 \mathrm{~h}$

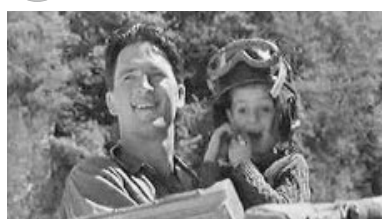

(613) $1: 55: 25 \mathrm{~h}$

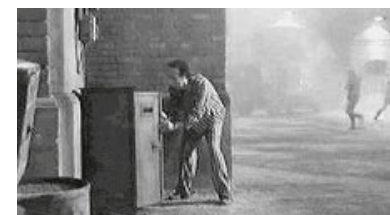

(599) $1: 45: 53 \mathrm{~h}$

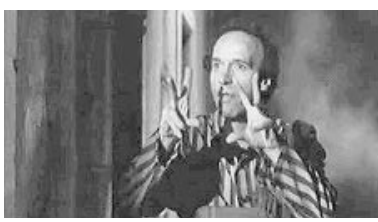

(602 $1: 47: 47 \mathrm{~h}$

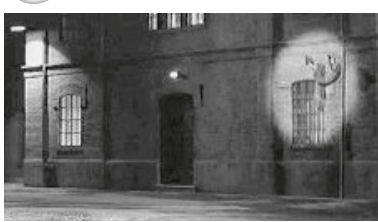

(605) $1: 49: 55 \mathrm{~h}$

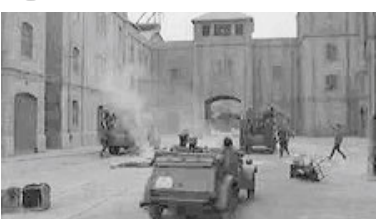

(608) $1: 51: 48 \mathrm{~h}$

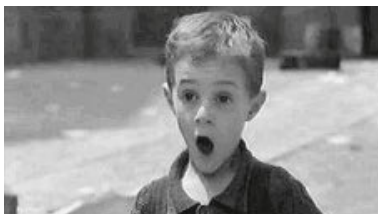

(611) $1: 54: 30 \mathrm{~h}$

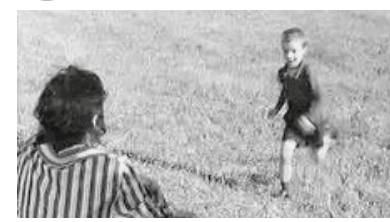

(614) $1: 56: 21 \mathrm{~h}$

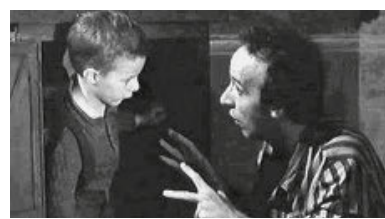

(600) $1: 47: 06 \mathrm{~h}$

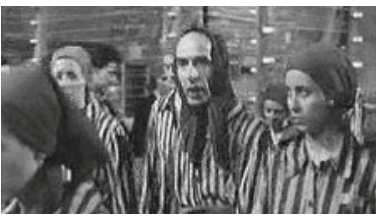

(603) $1: 48: 24 \mathrm{~h}$

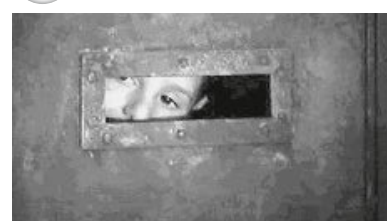

(606) $1: 50: 55 \mathrm{~h}$

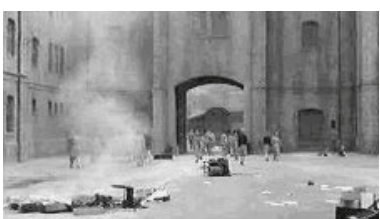

(609) $1: 52: 17 \mathrm{~h}$

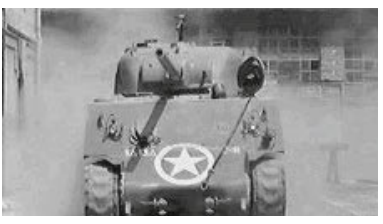

(612) $1: 54: 35 \mathrm{~h}$

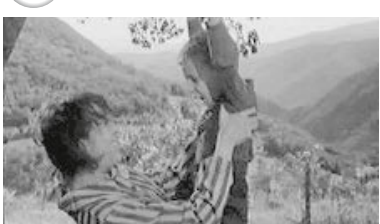

(615) $1: 56: 41 \mathrm{~h}$

Voller Stolz und mit dem Helm des amerikanischen Soldaten geschmückt (s. 1:55:25 h), rollt Giosuè in seinem »Hauptgewinn« an den Überlebenden vorbei, bis er seine Mutter erblickt (s. 1:56:21 h) und schließlich - in ihren Armen (s. 1:56:41 h) - »Wir haben gewonnen! $(1: 56: 38 \mathrm{~h})$ ruft $(\mathrm{F})(49)$. 
Hinsichtlich der zunehmenden Tragik der fiktionalen Szenen ist besonders Sequenz $46 \mathrm{zu}$ nennen, in welcher Guido, angesichts des nahen Todes, seinen Sohn durch das gespreizte Marschieren zum letzten Mal zum Lachen bringt und ihm damit das Gefühl von Sicherheit vermittelt. In die Freude über den glücklichen Ausgang für den kleinen Jungen, der das angestrebte Ziel mit dem Ausruf »Wir haben gewonnen!« (1:56:38 h) begleitet, mischen sich Mitgefühl und Bewegt-Sein über das Schicksal des Vaters, der aus unendlicher Liebe zu seinem Sohn diese ungeheueren Anstrengungen unternommen hat (s. 4.1.4.ba). So kann man den Ausgang des Films am ehesten als »bitter-süß bezeichnen.

\section{b) Weinen und Lachen - Grenzverhaltensweisen und Wertaussagen}

Der Zuschauer befindet sich während des Kernstücks von DAS LEBEN IST SCHÖN in einem wirkmächtigen Spannungszustand - zwischen Lachen und Weinen als den beiden Gegenpolen menschlichen Grenzverhaltens. ${ }^{644}$ Je nach unserem Einlassungsgrad mündet unsere übermäßige wie -mächtige Erfahrung in das eine oder andere Distanzverhalten.

In dem Maße, wie Guido die grausame Wirklichkeit für seinen Sohn ironisch verkehrt, um diesen von deren Absurdität zu überzeugen, steigt in der Mehrzahl der Fälle

644. »Nos yeux sont ébahis, on pleure, on rit, on vit...« (Guéret auf: www.cinopsis.com/ critics/lavita eb.htm). „Benigni knows how to make us laugh, but he has not yet figured out how to make us cry." (Kempley auf: www.washingtonpost.com/wp-srv/style/movies/reviews/ lifeisbe-autifulkempley.htm). »Faire rire ou pleurer, c'est la chose la plus belle au monde. C'est comme un état de grace, c'est une chose extraordinaire [...] Ce sont deux grands sentiments." (Benigni auf: www.arte.fr)

645. »La vie fait rire et pleurer. Comme pour Clinton, la farce touche la tragédie. Le rire et les pleurs sont si proches." (Benigni auf: www.lefigaro.fr./campus/_interviewN1.htm) Vgl. auch N.N. auf www. insideout.co.uk/movies2/beautiful.htm und auf http://infilmau.iah.net/ reviews/lifeis.htm.

646. »Es ist wohl mit Abstand der rührendste Film, den ich je gesehen habe. Mit anzusehen, wie ein von schwerer Arbeit gezeichneter Mann immer noch die Kraft aufbringt, seinem Sohn die heile Welt zu zeichnen und ihm auch das allerletzte Stück Brot überläßt, obwohl er selber nur noch aus Haut und Knochen besteht. Wie er sogar in der Gewißheit seines Todes noch die Kraft hat, seinem Sohn dieses Spiel vorzuspielen.« (Schröder auf: http://online.prevezanos.com/skf/filme/ filmdat/0269.shtml) »But you don't necessarily laugh as Guido repeatedly protects his son from the horrors of internment. Rather, you stare in awe, jaw agape as a cheerfully clowning Guido continually convinces a frightened Giosue that nothing is as it appears." (Goldberger auf: www.film.u-net.com/ Movies/Reviews/Life_Is_Beautiful. html) Vgl. auch N.N. auf www.lavieestbelle.com/images/pages/ presse/histoire.html und auf http://home.earthlink.net/ joeythorne/lifeis.htm.

Im weiteren werden Plessners, Bergsons und Sterns theoretische Erkenntnisse zum Lachen und Weinen auf das im Hauptteil des Films in besonderem Ausmaße angelegte sympraktische Potential angewandt. Hierbei wird in einem ersten Schritt auf das in bestimmten Szenen angelegte Angebot zum weinen, in einem zweiten Schritt auf die latente Komik eingegangen.

647. Hier und im folgenden werden die jeweiligen Sequenznummern in Klammern angegeben (s. das entsprechende Sequenzprotokoll im Anhang).

648. Aus diesem Grund sei an dieser Stelle zunächst auf das Weinen, in 4.1.4.bb auf das - im Sinne von abgründiger Komik - zum Lachen einladende Angebot in dieser Sequenz eingegangen. 
die Betroffenheit und Anteilnahme des Zuschauers. Während er über weite Strecken des ersten Teils von DAS LEBEN IST SCHÖN noch befreit und unbekümmert über Guidos Mißgeschicke bzw. Einfallsreichtum lachen konnte, bleibt ihm im Hauptteil größtenteils »das Lachen im Halse stecken«, geht in Ergriffenheit über und verschafft sich auch im Weinen Ausdruck.

Die unbestrittene Nähe zwischen den beiden Phänomenen ${ }^{645}$ zeichnet sich vor allem dadurch aus, daß gerade das Lachen in der dargestellten Welt im Sinne eines Lachens angesichts der absurden, unfaßbaren (Un-)Menschlichkeit im Zuschauer bei gesteigertem Einlassen - eine kaum steigerbare Anteilnahme bis hin zur tiefsten, innersten (Be-)Rührung im Weinen hervorrufen kann. ${ }^{646}$

\section{ba) Mitfühlendes Weinen}

Vor allem folgende Sequenzen laden den Zuschauer zu einer emotionalen Grenzerfahrung, einer »Implosion im offenen seelischen Innenraum« ein, die sich im Weinen Ausdruck verschafft (Kloepfer 1996: 166). Neben dem Versuch, die konkreten Anlässe für das Krisenverhalten zu ergründen, wird auf den Aspekt des rhythmischen Auftretens dieser Angebote eingegangen.

Die angesprochene Nähe zwischen den beiden Grenzreaktionen, allerdings bei Übergewicht zum Weinen, zeigt sich bereits zu Beginn des Hauptteils, als Guido versucht, seinen Sohn von der erfundenen Wettbewerbsgeschichte zu überzeugen, indem er die Lagerrichtlinien in die Wettkampfregeln übersetzt (26). ${ }^{647}$ Die durch den Protagonisten - über vier Sequenzen hinweg $(19,20,23,24)$ - eingeschlagene Richtung des »Überdie-Bande-Spielens« erreicht hier ihren ersten grandiosen Höhepunkt. Nach den zunehmenden Anspannungen der vorangegangenen Sequenzen ist ein Punkt erreicht, an dem der Zuschauer diese Spannungskurve möglicherweise nicht mehr aushalten kann und er eine Notwendigkeit verspürt, loszulassen. ${ }^{648}$ Angesichts der - aus der Not heraus geborenen - Anstrengungen des Vaters, die ihm sichtlich »alles abverlangen«, kann der Zuschauer eine positive Ergriffenheit verspüren. Diese Rührung entspringt der absoluten Zustimmung zu dem von Guido in aller Konsequenz verteidigten Wert, die Unbekümmertheit seines Jungen zu bewahren. Durch äußere Gewalt droht dieser kostbare Wert jedoch zerstört zu werden. Auch der Zuschauer teilt dieses Gefühl der Ohnmacht, angesichts der Chancenlosigkeit des Protagonisten gegenüber der Nazi-Gewalt. Vor dem Hintergrund seines geschichtlichen Wissens um die geringe Anzahl geretteter KZHäftlinge und um die Brutalität der SS-Schergen ist er in der Lage, einen ungewissen Filmausgang zu antizipieren. Das Ergriffensein, die Ohnmacht und die zu befürchtende Antizipation können - je nach Intensität - den Zuschauer so belasten, »daß er keinen Ausgleich mehr zwischen den beiden Ordnungen seiner physischen Existenz herzustellen in der Lage ist und durch das Weinen das Verhalten gegenüber sich selbst aufgeben kann« (Plessner 375/333ff.); der erste Spannungsbogen schließt sich.

Nachdem sich zwischenzeitlich (27-33) die Lagerrealität konkretisiert und unsere angespannte Haltung sich verstärkt hat, stellt Guidos spontanes Senden eines Lebenszeichens über den Lagerlautsprecher an Dora (34) eine Art Unterbrechung des Grauens dar. Seine Liebeserklärung über das Medium Lautsprecher knüpft an die Dominanz der Liebesgeschichte im ersten Teil des Films an (s. 4.1.3.bb) und läßt diese wieder aufleben. Das geschieht jedoch nur kurzfristig, so daß das Leid der Trennung 
den Augenblick des flüchtigen Glücks dominiert. Dennoch empfindet der Zuschauer in dieser rührenden Szene, in der Guido seiner »Prinzessin « Zeichen von Hoffnung und Liebe zukommen läßt ${ }^{649}$, ein Nachlassen des belastenden Spannungszustandes, so daß er mit einem »gesunden Weinen« reagieren kann.

Während die beiden folgenden Sequenzen ein Nebeneinander aus sich konkretisierender Gefahr (35) und einer gewissen Hoffnung auf Rettung (36) nahelegen, steht Sequenz 37 in deutlichem Kontrast zur - drei Sequenzen zurückliegenden - »Pause in der Schwere « und dem direkt vorangegangenen Hoffnungsschimmer. Vergleichbar mit der Sequenz, in der Guido die Lagerspielregeln in eine eigene Konstruktion überträgt (s. 4.1.4.bb), sieht er sich, in diesem Fall durch seinen Sohn, erneut mit der grausamen Wirklichkeit konfrontiert. ${ }^{60}$

\begin{tabular}{|c|c|}
\hline \multicolumn{2}{|l|}{ Wo warst du so lange? } \\
\hline & $\begin{array}{l}\text { Ich, ich, ich war ..., ich hab' dir doch gesagt, } \\
\text { ich muß noch eine Runde Karten spielen } \\
(F, i V) \text {. }\end{array}$ \\
\hline \multicolumn{2}{|l|}{$\begin{array}{r}\text { Aus uns machen sie Knöpfe und Seife (R)! } \\
\text { (s. 1:28:19 h) }\end{array}$} \\
\hline & Wer ..., was sagst du da \\
\hline \multicolumn{2}{|l|}{$\begin{array}{r}\text { Sie verbrennen uns alle in einem großen Ofen } \\
(\mathrm{R}) .\end{array}$} \\
\hline & Wer erzählt denn so was? \\
\hline \multicolumn{2}{|l|}{$\begin{array}{r}\text { Ein Mann vorhin; er hat geweint und er hat } \\
\text { gesagt, daß sie aus uns Knöpfe und Seife } \\
\text { machen (R)! }\end{array}$} \\
\hline & $\begin{array}{l}\text { Giosuè, so was hast du geglaubt?! (s. 1:28:28 } \\
\text { h) Er hat dich zum Narren halten wollen! } \\
\text { Mein Gott, bis jetzt hab' ich gedacht, mein } \\
\text { Sohn sei gewitzt, schlau, intelligent. Aus } \\
\text { Menschen Knöpfe und Seife, wie soll denn } \\
\text { so was funktionieren, frage ich dich, he?! } \\
\text { Und du hast das geglaubt. Stell' dir mal vor: } \\
\text { Morgen früh, das wasch' ich mir die Hände } \\
\text { mit Bartolomeo, gut einseifen, he?! Dann } \\
\text { knöpfe ich mich mit Francesco zu. [Reißt } \\
\text { sich einen Knopf von seiner Hemd, läßt ihn } \\
\text { zu Boden fallen, hebt ihn auf und hält ihn } \\
\text { vor Giosuè hin.] Oh, verflixt, was war denn } \\
\text { das ... Giorgio ist abgefallen. Wie, und das } \\
\text { hier soll ein Mensch sein?! Nicht doch, er hat } \\
\text { dich zum Narren gehalten und du bist darauf } \\
\text { reingefallen. Knöpfe und Seife ... was hat er } \\
\text { noch gesagt (F,iv)? }\end{array}$ \\
\hline
\end{tabular}

649. «Meanwhile, the princess gains heart and courage from the urgently romantic messages Benigni's endlessly imaginative character manages to send her in a place where romance [...].« (Stark auf: http://detnews.com/1998/entertainment/1030/life/life.htm)

650. Die linke Spalte gibt im folgenden Giosuès drängende Fragen, die rechte Guidos Antworten wieder. 


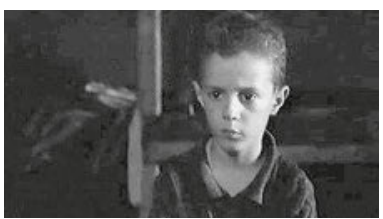

616

$1: 28: 19 h$

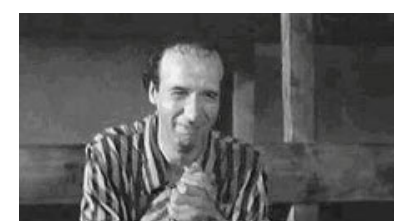

(617) $1: 28: 28 \mathrm{~h}$

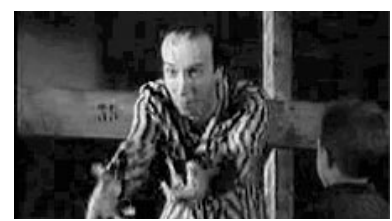

618

Daß sie uns alle im Ofen verbrennen [Guido biegt sich vor Lachen] ... Sie verbrennen uns alle in einem großen Ofen (S.) (R)!

Sie verbrennen ... [Guido kann vor Lachen gar nicht weitersprechen.] Oh Giosuè, darauf bist du wirklich reingefallen? Ich bitte dich. Von einem Kohleofen hab' ich gehört, aber von einem Menschenofen noch nicht. He, die Kohle ist alle, wie wär's hiermit, nimm' den Rechtsanwalt, wum. (s. 1:29:26 h) 0h, sieh' mal, was der für einen Qualm macht; der brennt aber nicht gut, ist bestimmt noch feucht, he! Ha Giosuè, glaub' doch nicht immer alles, was man dir sagt! (V.) (F,iV) $(1: 28: 05 h-1: 29: 26 h)$

In dem Maße, wie Guido seinen zweifelnden Sohn nur mit größter Mühe vom Ausstieg aus dem Wettbewerb abzuhalten vermag - über dessen aufgeschnappte, die Realität widerspiegelnden Tatsachen lacht er gespielt herzlich -, erlebt der Zuschauer die außerordentliche Absurdität und definitive Unsagbarkeit der Situation in einer Weise, daß er einer emotionalen Grenzerfahrung, einem Ohnmachtsgefühl ausgeliefert ist. Gleichzeitig macht diese Sequenz das überwältigende Ausmaß an Liebe und Kraft erfahrbar, die Guido für seine Interpretationsversuche aufbringen muß. Der sich einlassende Zuschauer kann hier in einer Form des »Solidarisierens« seiner Rührung durch Weinen nachgeben. Es schließt sich ein dritter, kleinerer Spannungsbogen, wobei man ebenfalls einen größeren zur Sequenz 26 zurückschlagen könnte, da der Held dort ähnliche Überzeugungsarbeit leistete.

In der folgenden Sequenz »beweisen« spielende deutsche Kinder zwar Guidos vorherige Beteuerungen, doch bereitet das Ende der Sequenz den Boden für die nächste konkrete Gefahr (38). Diese spitzt sich in der Folge extrem zu, wird aber vom Protagonisten gerade noch gebannt (39); ein tiefes Durchatmen setzt sowohl bei Guido als auch auf Seiten des Zuschauers ein. Der schwelende Hoffnungsschimmer aus Sequenz 36 wird im Anschluß aufgegriffen, verblaßt allerdings und hinterläßt mimetisch wie sympraktisch ein unwiderrufliches Gefühl der ohnmächtigen Ausweglosigkeit (40). Dieser Stimmungstiefpunkt wird erneut und parallel zur Sequenz 34 von einer zweiten Unterbrechung abgelöst. Für einen Moment unbewacht, nutzt Guido die Chance, seiner »geliebten Prinzessin« ihr gemeinsames Liebeslied durch den Lagerinnenhof vorzuspielen (41). Erneut reicht ein Detail aus, um an das hohe Gut ihrer gegenseitigen Liebe zu erinnern. Auch wir sind zu Tränen gerührt, ebenso ergriffen von Guidos unermeßlicher Liebe und Sehnsucht wie von diesem Ohnmachtsgefühl angesichts des 
Trennungsschmerzes und der ausweglosen Liebe. Hinzu kommt, daß im Vergleich zur Parallelsequenz hier ein Gefühl von Verzweiflung, Vergeblichkeit und Wehmut über dem Ganzen liegt; die Kontaktaufnahme Guidos mit Dora wirkt wie ein letztes Abschiednehmen. Der vierte Spannungsbogen umfaßt also die drei vorab zitierten Sequenzen, wobei auch hier ein größerer Rückwärtsbogen zur analogen Sequenz 34 gespannt werden könnte.

In der Folgesequenz wird der Aspekt des unmöglichen, verhinderten Glücks fortführt. Den schlafenden Giosuè tragend, träumt sich der Held in alte Zeiten zurück, ersehnt ein harmonisches Familienfrühstück und endlose liebevolle Begegnungen mit seiner, seit der Ankunft im Lager von ihm getrennten, Ehefrau (42). In Analogie zu dem bereits angeführten Gefühl von Wehmut und Vergeblichkeit kann der Zuschauer hier eine von großem Mitgefühl getragene Nähe zu Guido verspüren. Während vorher dieses emotionale Empfinden latent mitschwang, wird dieser Eindruck jetzt durch den Protagonisten verbal abgesichert. Es handelt sich um eine der seltenen Passagen, in der Guido seinen Gefühlen freien Lauf läßt, ohne sich für Giosuè »verbiegen « zu müssen. Der verbale Gefühlsausbruch Guidos läßt erahnen, welches Ausmaß an Kraft dieser aufbringen muß, um das lebensrettende Phantasiegebilde vor dem Einsturz zu bewahren. Spätestens am Ende der Sequenz, als der stets vorhandene, aber nun undeutlich sichtbare Berg von Leichen erkennbar wird, erreicht das »Sich-verhalten-Können« des Zuschauers vermutlich einen Punkt, an dem er seinen Gefühlen ausgeliefert ist und sie nur weinend »bewältigen « kann. Diese Szene enthält keinen Spannungsbogen, da keine Sequenzen übersprungen werden; man könnte sie als ein Kontinuum an »Megavalenz« charakterisieren (Kloepfer 1996: 167).

Während die nachfolgende Sequenz kontrastiv eine Zunahme der äußerlichen Bedrohung wie der sympraktischen Anspannung mit sich bringt (43), knüpft Sequenz 44 in gewissem Sinne an die extreme Überzeugungsarbeit aus Sequenz 37 an. Besonders gegen Ende ist Guidos fiktionales Bemühen vergleichbar mit seinen verbal und mimisch-gestuellen »Verrenkungen«, mit denen er Giosuè in der zitierten Situation letztlich beruhigen konnte. Der Zuschauer registriert hier mehr denn je

651. \... nur ein Blick, das letzte, was uns bleibt, der letzte Luxus des Menschen, ein freier Blick, über den sogar der SS-Mann keine Gewalt hat.« (Semprún 1981: 236)

652. »Giosuè soll bis zum Schluß nicht merken, dass es um Leben und Tod geht. Trotz allem: La vita è bella.« (Fiedler in: »Stern Magazin«: 287)

653. "In Benigni's words, >What is more tragic than to imagine the face of Stan Laurel before going to die?« (Waldron-Mantgani auf: http://members.aol.com/ukcritic/LifeIsBeautiful. html)

654. Vgl. in diesem Zusammenhang Sterns Ausführungen zur Größe des Menschen in der Not: »[...] daß der Mensch größer sein kann als sein Schicksal. [...] Indem er den hedonischen Wert seines Lebens riskiert oder opfert, um den moralischen Wert seines Ideals zum Triumph zu führen, verstärkt der tragische Held unseren Sinn für die höchsten Werte der Menschheit.« (1980: 211)

655. "[...] un enfant, qui passera ainsi à travers la nuit et le brouillard. Sans dommage.» (Moinet auf: www.lavieestbelle.com/images/pages/presse/figaro.html) 
Guidos unendlich großen Kraftakt, sein Ringen um Fassung angesichts der Gefahr, seinen Sohn möglicherweise nie wieder zu sehen. Hierin liegt zweifelsohne einerseits ein besonderes Antizipationspotential hinsichtlich Guidos Tod in Sequenz 46, andererseits ein Unvereinbarkeitskonflikt hinsichtlich der Verwirklichung gleichzeitiger Wünsche. Als Guido selbst auf die Gefahr hin, den SS-Männern zum Opfer zu fallen, den Versuch unternimmt, seine Frau zu retten, kann er nicht zeitgleich seine schützende Hand über den Sohn halten; er muß hoffen, daß Giosuè sich ein letztes Mal an seine Anweisungen hält. Mit dieser zunehmenden Dramatisierung der Lage und dem letzten Krafteinsatz des Helden konfrontiert, verfestigt sich für uns das Gefühl der Ohnmacht und das Ergriffen-Sein - im Weinen. Ist dies der Fall, so findet an dieser Stelle der fünfte, eine Sequenz überbrückende Spannungsbogen sein Ende.

In der Folgesequenz (45) findet der gefühlsmäßige Spannungszustand zwischen Hoffnung und Befürchtung seine Fortsetzung. Nachdem es für kurze Zeit so ausgesehen hatte, als könne mit Doras Rettung der gemeinsame Wunsch von Zuschauer und Protagonist in Erfüllung gehen, muß der Zuschauer nun jegliche Hoffnung begraben. Ein kaum steigerbarer Zumutungsgehalt kommt der Sequenz zu, in welcher der Held schließlich erschossen wird (46). Als Guido, von einem brüllenden SS-Soldaten mit Maschinengewehr vorangetrieben, in Giosuès Sichtfeld diesem zuzwinkernd $^{651}$ und zum letzten Mal marschierend die »heile Welt« vorgaukelt, wird - angesichts des unendlichen Durchhaltevermögens und der unerbittlichen Konsequenz des Vaters ${ }^{652}$ - die Schwelle der Belastbarkeit für den Zuschauer überschritten. Ergriffenheit und Rührung angesichts solcher Größe, ein nicht zu steigerndes Gefühl der Ohnmacht überwältigen ihn, so daß er weinend die einzige noch mögliche Antwort seinem Körper überläßt (Plessner 1996: 333ff.). ${ }^{653}$ Die Sequenz endet mit der Erschießung des Helden. In die vorherigen starken Empfindungen des Zuschauers mischt sich zusätzlich Trauer um den durch Guido vermittelten und vernichteten Wert, den er unter diesen Umständen um so mehr schätzt. ${ }^{654}$ Hiermit schließt sich der sechste Spannungsbogen, welcher erneut eine nur relativ kurze Zwischensequenz umfaßt.

Die Sequenz, in welcher die wenigen Überlebenden sich am folgenden Morgen aus dem Vernichtungslager schleppen (47), konsolidiert die, nach dem Tod des Protagonisten eingetretene, ernüchterte Entspannung. Es ist sozusagen die »Ruhe nach dem Sturm«, nach den sich überschlagenden Ereignissen. Diese »benommene Leere« wird von einer erneuten wechselseitigen Bedingtheit der Gefühle angesichts der tatsächlichen Preisverleihung - Lohn für den unermeßlichen Kraftakt Guidos im Nachhinein - abgelöst (48). Der Rettung Giosuès und dem »gelungenen Abschluß« des Wettbewerbs, welcher dessen kindliche Unbekümmertheit zu bewahren vermag, begegnen wir wohl mit einem lachenden und weinenden Auge. Das ist vor allem der Moment, als Giosuè triumphierend auf den Panzer, seinen »Hauptgewinn «, steigen darf, doch schwingt in diesem Moment die Erinnerung an die - im Hinblick auf den Jungen erfolgreiche ${ }^{655}$ - Anstrengung des Vaters mit. Schmerz über den Tod des Helden, Erleichterung über die Rettung des Kindes - der Zuschauer hat verschiedene »Bewältigungs«möglichkeiten: Vielleicht kann er unter Tränen lächeln. 
656. Stern untersucht die Möglichkeit der Entwertung vorangegangenen Leids, wobei er erkennt, daß diese nur unter bestimmten Voraussetzungen eintreten kann: »Meiner Ansicht nach kann die Erinnerung der Übel, die man erlitten hatte, ehe man einen hochgeschätzten Wert erreichte, >zwei< Arten von axiologischen Haltungen hervorbringen: sentweder man kann diese vergangenen Übel sentwerten<, sie minimisieren. Dann wird man vor Freude >lachen<. Oder man wird sie in ihrem richtigen negativen Wert einschätzen, sie mit all dem furchtbaren Gewicht abwägen, unter dem sie gedroht hatten, die angestrebten positiven Werte zu zermalmen. Dann wird man sich über den prekären Charakter der eben verwirklichten Werte Rechenschaft geben und begreifen, wie sehr sie bedroht waren und es noch sind. Dann wird man Tränen vergießen und vor Freude weinen.« (1980: 134, H.i.0.)

657. »Il y a eu plus de rires, bien plus de rires ici [Festival du film à Jerusalem] qu'à Cannes.« (Benigni auf: www.lavieestbelle.com/images/pages/presse/figaro.html). »J'ai vu un documentaire intitulé »Memoria«, auquel a participé Marcello Pezzetti, et il y a dedans des témoignages qui sont très amusants. Le peuple juif a quasiment inventé l'humour. Ça fait partie de leur ADN!« (Benigni auf: www.lavieest belle.com/entretien.html)

658. Anknüpfend an Bataille sowie Plessner weist Jurzik auf den distanzerzeugenden Effekt von Lachen angesichts einer Notlage hin: »Das Auslachen der Katastrophe ist ein Versuch, sie zu verkleinern. Das Sich-von-ihr-Anstecken-Lassen ein Versuch, sie in eigene Regie zu nehmen, auch wenn ihr dadurch die Leib-Seele-Einheit geopfert werden muß. Doch wo das Lachen der Katastrophe gilt und nicht der einzelnen Person, die ihr Opfer wird, ermöglicht es auch ein Stück Katastrophendistanz.« (1985: 44)

659. »[Benigni] croit à la puissance carthatique du rire.« (Ferenczi auf: www.lavieestbelle. com/images/pages/presse/positif.html). Vgl. auch Kloepfer in II.4 zur heilsamen Ab- und Umwertung durch Lachen.

660. Vgl. hierzu auch: »Plusieurs déportés ont expliqué que dans les camps l'humour les a aidés à survivre.« (Kommentar des Interviewenden auf: www.lavieestbelle.com/entretien.html) Auch Benignis Vater, der das Konzentrationslager überlebte, konnte im Nachhinein nur scherzend damit umgehen, so der Regisseur in einem Interview.

661. Siehe hierzu die mit $(F ; K)$ gekennzeichneten Beschreibungen in 4.1.4.a.

662. Siehe hierzu die mit (F;iV) gekennzeichneten Beschreibungen in 4.1.4.a; hinsichtlich des prinzipiellen Funktionierens bzw. des sympraktischen Wirkens sei auf die nachfolgende Besprechung von Sequenz 26 und auf die Anmerkungen bezüglich der gegen Ende des Eingangsteils dominierenden ironischen Verkehrungen verwiesen (s. 4.1.3.ac).

663. Am Beispiel von Kleists »Der zerbrochene Krug« äußert sich Kloepfer zur Ambivalenz des Lachens: „So befreit das Lachen und macht - möglicherweise - betroffen.« (Kloepfer 1996: 133). Im folgenden beschränkt sich die Arbeit auf diese beiden Sequenzen, welche zweifellos zwei überaus zentrale Momente des Kernstücks von DAS LEBEN IST SCHÖN hinsichtlich der sympraktischen Aufladung darstellen.

664. Im folgenden beschränkt sich die vorliegende Arbeit auf die ausführliche Behandlung der - in Analogie zur Verkündung des »Rassenmanifests« im Eingangsteil - zu sehenden Sequenz 26 (siehe hierzu den gesamten Dialog zwischen Vater und Sohn in 4.1.3.ab, Sequenz 26). In der zweiten zentralen Überzeugungs-Sequenz versucht Guido vor allem mit Ironie, seinen Sohn von der Absurdität bzw. Unmöglichkeit des Gehörten zu überzeugen. Um einer zu wirkmächtigen Nähe zu dieser Extremsituation, einem »Sich-Aufgeben an die Sache« zu entgehen, kann der Zuschauer der Macht, mit der er nicht fertig wird, mit Unernst begegnen (Kloepfer 1996: 166). Durch ein Lachen mit dem »sich amüsierenden« Helden ist ihm die Möglichkeit gegeben, sich zu lösen, »Freiheit und Distanz« (Kloepfer 1996: 165) zu gewinnen angesichts dieser »schweren Kost«. 
Diese Beschreibung trifft vermutlich auch auf die sich anschließende Schlußsequenz zu, in welcher Giosuè, wie in einem Triumphzug, mit seinem Panzer an den Häftlingen vorbeirollt, schließlich seine Mutter erkennt und in ihre Arme sinkt (49). So glücklich sich sein Ausruf »Wir haben gewonnen!« (1:56:38 h) auch anhört, ruft er doch - dem stolzen Besteigen des Panzers entsprechend - die diesem Erfolg vorausgegangenen Opfer schmerzhaft in Erinnerung. Wie in der vorangegangenen Sequenz überlagern sich in diesem Moment sowohl Erleichterung über das Zusammentreffen von Mutter und Sohn als auch quälendes Wissen um den Preis für das momentane Glück. Dieses Miteinander starker Gefühle und die Tatsache, daß der Film endet, bedingt möglicherweise ein Nachlassen der Anspannung, das sich durchaus im Weinen äußern kann. ${ }^{656}$

\section{bb) Distanzierendes Lachen}

Ist der Zuschauer jedoch, vielleicht als Überlebender des Holocaust ${ }^{657}$, nicht in der Lage, sich auf dieses Thema einzulassen, hat er die angesprochene Möglichkeit, sich einer übermäßigen Betroffenheit zu entziehen.

Über das quittierende Lachen, angesichts der Absurdität des Lageralltags, vermag er eine gewisse Verweigerungshaltung gegenüber dem schwer zugänglichen Gegenstand einzunehmen bzw. eine gewisse Distanz aufzubauen. ${ }^{658}$ Vor diesem Hintergrund kann dem sympraktischen Lachen während des Hauptteils von DAS LEBEN IST SснӧN eine befreiende, Abstand erzeugende und - durch die damit ermöglichte »Überwindung negativer Ereignisse« (Kloepfer 1996: 163) - eventuell heilende Wirkung im aristotelischen Sinne zugeschrieben werden. ${ }_{59}$ In diesem Sinne äußert sich auch Benigni zu der - im Kernstück seines Films angelegten und möglicherweise zu einem Lachen führenden - Komik (s. 4.1.2): »[Le rire] c'est un remède en effet, pas une arme contre. Le rire ce n'est pas se moquer de quelqu'un. Nous ne rions pas de l'holocauste, ce serait horrible. Comme disait Platon. C'est beau de croire au soleil pendant la nuit.« (www.lefigaro.fr./campus/interviewN1.htm) ${ }^{660}$

Diese gleichsam als positiv einzustufende Verarbeitungsmöglichkeit bzw. Überlebensstrategie kann in zahlreichen, - von besonderer komischer Fiktionalität ${ }^{661}$ bzw. ironischer Verkehrung ${ }^{662}$ charakterisierten - Momenten hilfreich sein. In Anlehnung an den Aspekt der Nähe zwischen den beiden Grenzphänomenen sei darauf hingewiesen, daß sich die Beispiele auf die gleichen Sequenzen beziehen, die unter anderem als exemplarisch für das kapitulierende Weinen herangezogen wurden ${ }^{663}$ : Es handelt sich jeweils um Situationen, in welchen der Vater - infolge der Erfindung einer Wettbewerbsgeschichte - extreme Überzeugungsarbeit angesichts der zunehmenden Zweifel seines Sohnes leisten muß.664

Die Sequenz, in welcher Guido die grausamen Haftbedingungen für Giosuè in die Wettkampfbedingungen überträgt, bietet uns die Möglichkeit, die komische Absurdität ${ }^{665}$ als Anlaß für ein Distanz erzeugendes, quittierendes - Ja, ich kann das Negative verlassen!« (Kloepfer 1996: 166) - Lachen zu nehmen. Dieses Grenzverhalten kann überdies der Freude des Zuschauers über Guidos rebellierenden Einfallsreichtum und der hieraus resultierenden karnevalesken »Umstülpung « der Situation - des »monde renversé« - entspringen (Bergson nach Bachtin 1972: 72). ${ }^{666}$ Seinem von der Wettbewerbsgeschichte noch nicht sonderlich überzeugten Sohn präsentiert er die eigentlich fürchterliche, angsteinflößende Lage in erheiternder Weise. Während der Kapo die unmenschlichsten und abscheulichsten Sätze herausbrüllt, spricht Guido von Marmeladenbrötchen, Lutschern und Versteckspielen. ${ }^{667}$ 


\begin{tabular}{|r|l|}
\hline Alles herhören, ich sage das nur einmal. & \\
\hline & $\begin{array}{l}\text { Das Spiel fängt an. Nur wer da ist, darf } \\
\text { mitmachen (s. 1:13:08 h). }\end{array}$ \\
\hline $\begin{array}{r}\text { Ihr seid nur aus einem einzigen Grund in } \\
\text { dieses Lager transportiert worden, ... }\end{array}$ & $\begin{array}{l}\text { - Man gewinnt mit 1000 Punkten: Der Preis } \\
\text { ist ein echter Panzer (s. 1:13:13 h). }\end{array}$ \\
\hline$\ldots$ um zu arbeiten. & \\
\hline $\begin{array}{r}\text { Jeder Versuch der Sabotage wird mit dem } \\
\text { soforigen Tode bestraft. Die Hinrichtungen } \\
\text { finden auf dem Hof durch Schüsse in den } \\
\text { Rücken statt. }\end{array}$ & Der Glückliche! \\
\hline & $\begin{array}{l}\text { Die Rangliste wird jeden Tag über } \\
\text { Lautsprecher ausgerufen. Der Rangletzte } \\
\text { bekommt ein Schild auf den Rücken, auf dem } \\
\text { »Esel« steht. }\end{array}$ \\
\hline
\end{tabular}

665. Vgl. hierzu auch Primo Levis Bemerkungen zum komisch-absurden Charakter der Lagersituation in II.4 und folgende Textpassage in Jurek Beckers »Jakob der Lügner«, als der noch vor kurzem angesehene Rechtsanwalt Leonard Schmidt die Ghettosituation noch nicht begreifen kann: »In Schmidts Kopf spukt das Ganze als idiotischer Witz, vielleicht wird man eines Morgens aufwachen, und die Klienten sitzen wieder im Wartezimmer ...« (1982: 128) bzw. den Textabschnitt, in welchem Jakob beobachtet, wie der Aufseher einem Arbeitskollegen, Mischa, einen Hieb versetzt: »Mischa dreht sich um, der Anführer ist einen Kopf kleiner als er, und es bereitet ihm einige Mühe, bis zu Mischas Gesicht hinaufzuschlagen. Es sieht beinahe ein bißchen komisch aus, nichts für die deutsche Wochenschau, eher wie ein Spaß aus der Stummfilmzeit, wenn der kleine Polizist Charlie versuchte, den Riesen mit den buschigen Augenbrauen zur Strecke zu bringen, und er müht sich ab, und der Große merkt es gar nicht.« (Ebd. 33)

666. Siehe hierzu auch II.4.2 bzw. Bachtins Auffassung von Parodie: »Parodieren ist die Herstellung eines profanierenden und decouvrierenden Doppelgängers, Parodie ist umgestülpte Welt.« (1990: 54)

667. In diesem Zusammenhang sei an Kloepfers Aussagen zur komplexen Ironie erinnert: „Einer redet von hochpolitischen Problemen und der andere gerade von Bauchschmerzen, und auf diese Weise entsteht eine komplexe Ironie.« (Kloepfer 1996: 125); siehe auch Bergsons Ausführungen zum Zeremoniellen, zur »transposition« (1972: 94ff.) und zur Parodie (s.o.).

668. Vgl. Dewey zur rhythmischen Wechselbeziehung antagonistischer Energien: »Eine jede gewinnt während einer bestimmten Dauer an Intensität, drängt jedoch dadurch eine gegensätzliche Energie zurück, bis diese andere, die sich gerade entspannt, während sie sich ausdehnt, überwältigen kann. Dann kehrt sich der Vorgang um, nicht unbedingt im gleichen Zeitabstand, aber doch in einem Verhältnis, das als geordnet empfunden wird. Widerstand staut Energie. Er wirkt so lange aufhaltend, bis Lockerung und Expansion folgen.« (1988: 180)

669. Vgl. in diesem Zusammenhang Bergsons These vom »diable à ressort«: »Imaginons maintenant un ressort plutôt moral, une idée qui s'exprime, qu'on réprime, et qui s'exprime encore, un flot de paroles qui s'élance, qu'on arrête et qui repart toujours. Nous aurons de nouveau la vision d'une force qui s'obstine et d'un autre entêtement qui la combat.« (1972: 54) 


\begin{tabular}{|c|c|}
\hline $\begin{array}{l}\text { - Ihr habt die Ehre, für unser großes, } \\
\text { deutsches Vaterland arbeiten zu dürfen und am } \\
\text { Bau des Großdeutschen Reiches teilzunehmen. }\end{array}$ & \\
\hline & $\begin{array}{l}\text { Wir sind bei den Bösen, die schreien. Wer } \\
\text { Angst hat, verliert Punkte. }\end{array}$ \\
\hline $\begin{array}{l}\text { Drei Grundregeln solltet ihr nie vergessen. } \\
\text { Erstens: Versuche nicht, zu fliehen. Zweitens: } \\
\text { Folge jedem Befehl ohne Fragen. Drittens: } \\
\text { Jeder Versuch eines Aufstandes wird mit dem } \\
\text { Tod durch Erhängen bestraft. Ist das klar?! }\end{array}$ & \\
\hline & $\begin{array}{l}\text { In drei Fällen verliert man Punkte. Es } \\
\text { verlieren sie erstens: diejenigen, die weinen. } \\
\text { Zweitens: diejenigen, die zu ihrer Mutter } \\
\text { wollen. Drittens: diejenigen, die etwas zu } \\
\text { essen wollen. Das gibt's nicht! }\end{array}$ \\
\hline $\begin{array}{r}\text { Ihr solltet glücklich sein, hier arbeiten zu } \\
\text { dürfen. Es wird niemanden etwas geschehen, } \\
\text { der die Vorschriften befolgt. }\end{array}$ & \\
\hline & $\begin{array}{l}\text { Wer Hunger hat, verliert leicht Punkte. Ich } \\
\text { selbst habe schon } 40 \text { Punkte verloren, weil } \\
\text { ich ein Marmeladenbrot wollte. }\end{array}$ \\
\hline Gehorsamkeit ist alles! & \\
\hline & Mit Aprikosenmarmelade! \\
\hline Und noch etwas: & \\
\hline & Er wegen Erdbeermarmelade. \\
\hline $\begin{array}{r}\text { Bei diesem Pfiff, alles raus auf den Hof, aber } \\
\text { schnell! }\end{array}$ & \\
\hline & $\begin{array}{l}\text { Fragt nicht nach Lutschern, ihr kriegt keine. } \\
\text { Die essen wir alle selber! }\end{array}$ \\
\hline Antreten in Zweierreihen! & \\
\hline & Gestern habe ich zwanzig gegessen. \\
\hline Schweigt! & \\
\hline & Hatte ich Bauchschmerzen! \\
\hline Jeden Morgen ... & \\
\hline & $\begin{array}{l}\text { Immerhin hat es geschmeckt. Aber lassen } \\
\text { wir das. }\end{array}$ \\
\hline $\begin{array}{r}\text {... is' Appell! So, das wollt' ich euch noch } \\
\text { sagen: Dort hinten werdet ihr arbeiten. Ihr } \\
\text { werdet die Dimensionen des Lagers leicht } \\
\text { begreifen. }\end{array}$ & \\
\hline & $\begin{array}{l}\text { Entschuldigt, daß ich so schnell verschwinde, } \\
\text { aber ich spiele Verstecken und will nicht } \\
\text { gefunden werden. }\end{array}$ \\
\hline
\end{tabular}

Besonders wirkmächtig ist in diesem Zusammenhang das - einem Schlagabtausch gleichende - »Hin und Her« zwischen der gebrüllten Bekanntmachung der Lagerspielregeln durch den SS-Schergen und der umgehenden Entlarvung und letztlichen Verhöhnung durch den »Übersetzer« Guido. ${ }^{668}$ Fast im Stile eines Springteufels ${ }^{669}$ 
bringt Guido - trotz erheblicher Dauer und Unerträglichkeit der Situation - immer wieder die Kraft auf, die einzelnen Haftbedingungen in seinen spezifischen Regelkanon zu übertragen. Dieser Schlagabtausch ist durch zwei filmische Mittel unterstützt: Auf der einen Seite setzt Benigni harte Schnitte zwischen die Sätze des Kapos und die des Vaters, auf der anderen zeigt er beide Akteure im gleichen Bildrahmen. Auf diese geballt präsentierte Kluft zwischen Rede und Gegenrede bzw. Guidos Kraft zur Rebellion können wir unter bestimmten Bedingungen auch und vermutlich vor allem lachend reagieren. In bezug auf den deutschen Kapo ist zu beobachten, daß er eine extreme Stereotypie verkörpert und - wie die Grundschuldirektorin bzw. der »Idiot aus dem Rathaus « - als Repräsentant des erstarrten Systems mechanisch funktioniert. »In dem Maße also, wie jemand durch soziale [...] Normen zum Element eines vorgegebenen Systems wird, sich demnach als Reduktion von Leben zeigt, wird er komisch.« (Kloepfer nach Bergson 1996: 125) Das Publikum kann über Personen und Situationen, die das Menschliche infolge nicht hinterfragter Mechanik vermissen lassen, lachen - und damit, im Sinne Sterns, ein negatives Werturteil über die Degradation des Wertes Mensch ausdrücken. ${ }^{670}$

670. Wie Plessner geht Stern in einem ersten Schritt auf Bergsons Mechanik-These (s.o.) ein. Stern geht jedoch über ein bloßes Aufgreifen von Bergsons Theorem hinaus, indem er es seiner axiologischen Untersuchung unterzieht. Bergsons These ist - so Stern - nur deshalb sinnvoll, weil die Mechanik im menschlichen Leben ein »plötzliches Wertevakuum«, ein »Abgleiten«, eine »Degradation der Werte« erzeugt (ebd. 43). Ursprung des Lachens ist, gemäß Stern, also die verursachte Wertdegradation. Diese kausale Bedingtheit impliziert jedoch eine positive Schätzung des degradierten Systems, da es ohne dieselbe keine Degradation geben könnte (ebd. 73). "So erweist das Lachen sich als ein Werturteil, ein negatives Werturteil über eine Wertdegradation.« (Ebd. 44) 


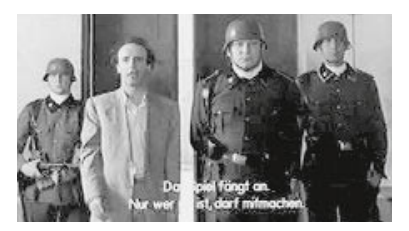

(619) $1: 13: 08 \mathrm{~h}$

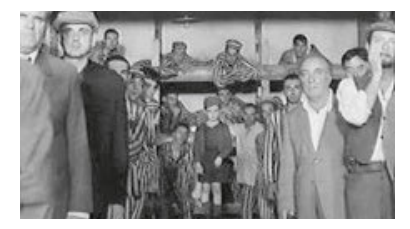

(620 $1: 13: 10 \mathrm{~h}$

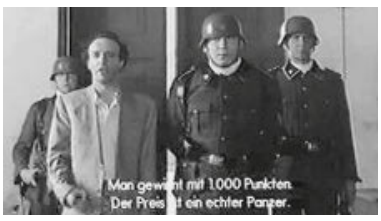

(621) $1: 13: 13 \mathrm{~h}$

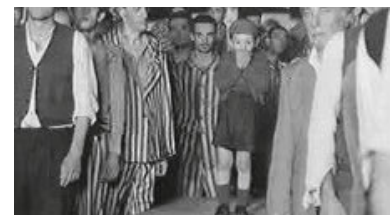

(622) $1: 13: 35 \mathrm{~h}$ 


\section{II.4.2 VER-RÜCKTER (ÜBER-)LEBENS-ZUG: »ZUG DES LEBENS« (»TRAIN DE VIE«, RADU MiHAILEANU, F/BEL/ROM/NL 1998)}

»Nur nebenbei sei angemerkt, daß es fürs Denken keinen besseren Start gibt als das Lachen. Und insbesondere bietet die Erschütterung des Zwerchfells dem Gedanken gewöhnlich bessere Chancen dar als die der Seele.«

(Walter Benjamin ${ }^{671}$ )

\subsubsection{Jüdischer Humor und nostalgischer Blick auf die Schtetl-Welt}

Bereits mit der Wahl des in allen Versionen gleichlautenden Titels grenzt sich der rumänisch-französische Regisseur und Drehbuchautor Radu Mihaileanu von den meisten Titeln vorangegangener Holocaust-Filme deutlich ab, auch wenn eine gewisse Nähe zu DAs LeBEN IST sCHÖn (s. II.4.1) spürbar ist. Im Original lautet Mihaileanus Titel Train de Vie, in der deutschen Version Zug des Lebens, in der englischen TRAIN OF LifE.

Zuschauern weltweit ist es möglich, die Verbindung der beiden Wortfelder >Zug< und >Leben< als Kontrast zu dem todernsten Hintergrund des Films, dem Holocaust mit seinen Todes-Zügen, wahrzunehmen. ${ }^{672}$

Das französischsprachige Publikum kann in >train de vie < den Ausdruck für eine Art zu leben, eine gewisse Verhaltens- und Lebensweise erkennen; > une conduite, [...] une manière de vivre, relativement aux dépenses de la vie courante que permet la situation< $\left(1373^{673}\right)$. Möglicherweise erinnert der Titel auch ex negativo an den Ausdruck >mener un train d'enfer<, >ein tolles Tempo, einen Zahn draufhaben (Pons 1995: 357). Innerhalb des Wortfeldes >train< liegen im Französischen literarische Assoziationen wie >le train du monde< nahe: >la manière d'aller<, >la marche des choses< (1373) - der Gang der Dinge. >Train< stammt sprachgeschichtlich von >traînée<, einer hinterlassenen Spur; >longue trace laissée [...] (1376), beispielsweise >une traînée de sang<, >une traînée lumineuse d'un comète<, >de longues traînées de lueurs< (1376). Das entsprechende Verb zu >train< lautet >traîner<, et-

671. Zit. nach Oster/Uka 2003: 256.

672. Vor allem, wenn sie das Filmplakat in Erinnerung haben, das in der Originalversion sowie der deutschen und englisch-amerikanischen Version in der unteren Bildhälfte einen fahrenden Güterzug zeigt, auf dessen Dach ein Clown bzw. Musiker mit einer Violine den Fahrtwind genießt; am unteren Bildrand wiederum scheint ein - u.U. als deutsch identifizierbarer - Soldat den Zug zu bewachen.

Mit der Wahl des Titels folgt Mihaileanu dem von Schreitmüller analysierten »Prinzip Assoziation« bei der Wahl eines Filmtitels, das sich durch besonderen Einbezug des Zuschauers auszeichnet (1994: 99f.).

673. Ich zitiere für das Französische nach »Le Grand Robert« 1998, Band 6, und gebe hier und im folgenden nur die Seitenzahl an. Vgl. Kortmann 2003: 312f.

674. Vgl. Duden 1999, Bd. 10: 4658f.; Wahrig 1974: 4126.

675. Nicht zufällig spielen Schlomo und Mordechai in einer Sequenz (Sequenz 51) eine Partie Schach, die - wie zu erwarten war - ersterer mit einem geschickten Zug für sich entscheidet.

676. Mihaileanu zit.n. Tegeler auf: www.morgenwelt.de/kultur/000320-zugdeslebens-film-p. htm: 2, H.i.0. 
was nach- bzw. hinter sich her schleppen, so daß man Spuren hinterläßt. Reflexiv verwendet bedeutet es zunächst, sich dahinschleppen, sich mühsam fortschleppen, im figurativen Sinne sich hinziehen, >se passer péniblement et lentement< (1378). Das Wortfeld > vie< ist ebenso breit gefächert. Es bezieht sich u.a. auf die Existenz, >le fait de vivre< (1820), aber auch auf das Am-Leben-Sein, >être en vie< (1820) im Sinne eines Überlebens, >être encore vivant< (1820); nicht zu vergessen das intensive Leben, das im Ausdruck >débordant de vie< (1821) mitschwingt. Das französischsprachige Publikum könnte darüber hinaus an Ausdrücke wie >sauver la vie de quelqu'un< oder auch >sauver sa vie< (1820) denken, jemandem das Leben bzw. seine eigene Haut retten. Auch die Frage von Leben und Tod - >question de vie ou de mort< $(1820)$ - liegt nicht sehr fern.

Der deutsche Zuschauer kann beim Wortfeld >Zug a an verschiedene Bedeutungsmuster anknüpfen: eine Gruppe, Reihe, Schar von Menschen, Tieren etc., ein Gespann (Lokomotive, Lastzug etc.), einen Charakterzug, ein Vorüberziehen und vieles mehr ${ }^{674}$ - oder an die unterschiedlichsten festen Ausdrücke denken: >in den letzten Zügen liegen $<$, >der Zug ist abgefahren $<$, >einen klugen, überlegten Zug tun ${ }^{675}$, >etwas Zug um Zug zurückgeben<, >sein Leben in vollen Zügen genießen Zug kommen< (ebd.). Die Verbindung mit dem Wortfeld >Leben< ermöglicht vor allem die Assoziation >Festzug ( Wahrig 1974: 4126), weniger die des >Trauerzugs< (ebd.). Mihaileanus Titel bietet demnach unterschiedliche Auslegungsmöglichkeiten und Sinnzusammenhänge.

Expliziter als Benigni grenzt Mihaileanu seinen Film von vorangegangenen Holocaust-Filmen ab und macht sich in diesem Zusammenhang Gedanken über die Beschränkungen im Medium Film:

»Filme wie [...] SHOAH, die Filme von Alain Resnais, [...] und auch SCHINDLERS LiSTE [...] verwenden die gleiche Sprache von Tränen und Trauer. Wir wollten diese Sprache nicht noch einmal benutzen, weil die Leute das heute nicht mehr hören möchten.« (Mihaileanu zit.n. Schwickert 2000)

»Es gibt aber noch einen anderen Grund für die Suche nach einer anderen künstlerischen Form, die Shoah zu erzählen. Wir müssen erkennen und wir müssen akzeptieren, daß niemand mehr Bücher liest, sich Fotos anschaut oder in Museen geht. Die herrschende Kommunikationsform ist die audiovisuelle. [...] Kino, Fernsehen, Internet, Radio. Das sind für mich sarmeく Künste, weil sie nur etwas repräsentieren können. Wir müssen diesen Künsten unsere Ideen, unsere Einbildungskraft seinverleiben<. [...] In einem Buch kann das Grauen eines Konzentrationslagers für denjenigen, der das liest, vorstellbar werden, weil man die Worte hat, aber 50 Prozent der Imagination im Kopf des Lesers entsteht. [...] Das Problem beim Kino ist, daß wir nur ein Bild haben, dem wir den Rahmen geben, den die Leinwand oder der Bildschirm bestimmt. [...] Das Bild ist beschränkt [...]. Und das Problem bei der Shoah und anderen Tragödien der Menschheit ist einfach: Sie sind größer als das Bild, das wir von ihnen zeichnen können. Wie können wir also dieser ’kleinen Kunstı, die aber die herrschende Kommunikationsform ist, solch eine riesige, solch eine komplexe Geschichte erzählen? [...] Es kann nur darum gehen, einen Weg zu suchen, anders zu erzählen. Denn wenn wir nicht erzählen, ist die Erinnerung abgeschnitten. $\ll^{676}$ 
»Ich gehe nicht in die Konzentrationslager. Nicht weil Claude Lanzmann sagt, das sei verboten. Sondern weil ich mit meiner kleinen, minderen Kunst, dem Kino, das dazu verdammt ist, die Geschichte nicht nur zu erzählen, sondern immer zugleich zu repräsentieren, die Lager nicht darstellen kann« (Mihaileanu zit.n. Werneburg 2000: 14, H.i.0.)

Vergleichbar mit Benigni, setzt er dem Irrwitz der Realität den Irrwitz seiner Fiktion gegenüber, nutzt er »comic madness as a window onto Nazi madness « (Mathews 1999: 48; s.u.).

Unter der komödiantischen Oberfläche erzählt Mihaileanu vom Holocaust, von der Vernichtung der osteuropäischen Schtetl-Kultur: »Mein Weg ist, diese Geschichte so zu erzählen, daß sie nicht in den Bildern, sondern zwischen den Bildern stattfindet. Es geht darum, eine Geschichte zu erzählen, ohne sie zu zeigen. [...] Während der ganzen eineinhalb Stunden meines Films wißt ihr, daß diese Menschen getötet werden, aber ich zeige es euch nicht! « ${ }^{677}$ - eine, verglichen mit Benigni, noch deutlichere Abgrenzung von darstellenden Filmen. ${ }^{678}$ Voraussetzung hierfür ist ein entsprechendes Vorwissen auf Seiten des Zuschauers:

»Der Zuschauer weiß durch seine Kenntnis der historischen Entwicklung besser als die Filmfiguren von ZUG DES LEBENS, was ihnen an Leiden bevorsteht, sollte ihre Flucht [...] zum Scheitern verurteilt sein. Der Horror entsteht im Unsichtbaren. Das Wissen um das Grauen im kollektiven Gedächtnis ist die Kulisse, vor der etwa der ZUG DES LEBENS seine Lebensfreude spielen läßt. Dieser Kontrast sichert die optimale Polarität der Emotionalisierung.« (Bleicher 2002: 182)

677. Mihaileanu zit.n. Tegeler, ebd.

678. »Der Film erscheint als eine Kritik an Darstellungsweisen, die die Vergangenheit hinter einer festgelegten und reduzierenden Ikonografie zum Verschwinden bringen. [...] Für die dritte Generation nach dem Zweiten Weltkrieg ist dieser Film ein Angebot, sich sauch zu amüsieren. Aber viel stärker ist er ein asymptotischer Annäherungsversuch ohne das Angebot einer Ein- oder Auflösung bei der Annäherung an die Grenzen des Faßbaren. In einer Zeit, in der ein zur Ikonografie erstarrtes Bild- und Begriffsrepertoire zur opaken Oberfläche zu verkommen droht, dient das Bildmedium Film als Ort der Reflexion über die ikonografische Konstruktion von Geschichte.« (Kortmann 2003: 312; H.i.0.) »Die Komik ist das Supplement der nicht repräsentierten Tragik, die eine Geschichte, die im Grunde eine Deportationsgeschichte ist, überschreibt (als Differenz wiederholt) oder überblendet und damit auch unterbricht. So berühren sich in dieser Überblendung die Tragödie bzw. das Erhabene und die Komödie (Plessner) auf einem Kontingenten des Absurden, ohne einen erlösenden Ausgang, wie Benignis Film ihn anbietet.« (Ebd. 311)

679. Mihaileanu zit.n. Kleinschmidt, Filmheft Zug des Lebens, Bundeszentrale für politische Bildung/Institut für Kino und Filmkultur, S. 12.

680. Mihaileanu zit.n. N.N. in: »L'Humanité«, 16.09.1998.

681. »Mein Vorbild ist natürlich der große jüdische Regisseur Ernst Lubitsch. Seine NaziKomödie SEIN ODER NICHTSEIN habe ich mindestens zehnmal gesehen. Ich liebe den jüdischen Humor.« (Mihaileanu zit.n. »Der Spiegel«, 20.3.2000: 191) 
Zudem versucht Mihaileanu insbesondere über die Inszenierung jüdischer Lebensfreude und Vitalität, »die Vernichtung eines ganzen Volkes spürbar zu machen« (Kniebe 2000: 19) - ein zentraler Unterschied zu Benignis DAS LEBEN IST SCHÖN:

»Viele haben den Tod gezeigt. Ich zeige das Leben, das da getötet wurde.« (Mihaileanu zit.n. Bleicher 2002: 195)

»Mein Film handelt gar nicht von der Shoah. Er handelt von einer vernichteten Kultur, der Schtetl-Kultur. Ich spreche vom Holocaust, indem ich ein wundervolles Bild der Humanität entwerfe.« (Mihaileanu zit.n. Werneburg 2000: 14)

»ZUG DES LEBENS ist kein Film über Juden, die fliehen, sondern über einen Menschen, der träumt, daß alle noch am Leben sind. Die Botschaft ist: So lange man sich noch an die Menschen erinnert, sind sie nicht tot. Wenn man sie vergißt, sterben sie ein zweites Mal.« ${ }^{679}$

Mit dem »Erzählen soz. zwischen den Zeilen« geht eine besondere Diskretion einher: »TRAIN DE VIE [...] ist ein Film über die Nazis und die Juden, in dem kein Blut fließt und kein Toter zu sehen ist.« (Broder 1999: 234) - eine ebenso bemerkenswerte wie seltene Tatsache für einen Film mit einem solchen Hintergrund. »Gerade seine schönsten Szenen sind genau kalkulierte Gegenentwürfe zu den Schreckensbildern des Holocaust.« (N.N. 2000: 25): In der direkten Konfrontation schlagen die falschen Nazis (die Juden) die echten (die Deutschen) wiederholt mit ihren eigenen Waffen. »Je n'admets pas que les barbares gagnent deux fois: qu'ils aient tué des Juifs, des Tziganes, des homosexuels et qu'on les combatte sur leur propre terrain, celui de la haine, avec leurs armes. ${ }^{680}$ Damit eröffnet Mihaileanu eine neue, vielleicht zeitgemäßere, in jedem Fall originelle Herangehensweise an das Thema Holocaust:

»Mit dem aus der Realität entlehnten Motiv >Deportationszug und dem Fluchtplan >Palästina verkehrt Mihaileanu seine Geschichte zielgerichtet ins Absurde. Während der Güterzug, der die Juden in die Vernichtungslager transportierte, als bekanntes Zeichen der HolocaustIkonographie zu dem Symbol der Vernichtung wurde (vergleiche zum Beispiel seine Bedeutung in Lanzmanns SHOAH oder das Mahnmal in Yad Vashem), wird aus dem Todessymbol in ZUG DES LEBENS ein Symbol des Über-Lebens der jüdischen Bevölkerung. Der Erwartungshaltung der Zuschauer, die die Funktion und die Richtung der historisch-realen Züge kennen, wird durchbrochen. Die Absurdität und Komik der Situationen könnte auch hier bewirken, daß sich über das Paradoxe jener Umkehrung eine Erkenntnis einstellt, die das Ungeheuerliche nicht erfassen kann, aber ihm ins Auge zu sehen genötigt wird.« (Oster/Uka 2003: 264, H.i.0.)

Mit der Sprache der Komödie will Mihaileanu dem Zuschauer »den Blick für die Tragödie [...] schärfen« - Lachen sei schließlich »eine andere Form des Weinens« (Mihaileanu zit.n. Bleicher 2002: 198).

Zentrale Mittel der Komik sind aufgrund der »verrückten« Idee der Selbstdeportation (s.u., Aspekt 1) das Rollenspiel und die Camouflage, Hommage an Lubitschs Parodie des Nationalsozialismus in To Be or NOt to BE/SEIn oder Nichtsein (USA 1942). ${ }^{681}$ »Das ausgeklügelte Camouflagespiel macht zum einen die Unterschiede zwischen echten und falschen Nazis deutlich, weicht aber zum anderen die >Substanz $<$ der kopierten Vorbilder durch die Imitation eines soldatischen Verhaltens auf und läßt die 
lächerliche Seite der Nazis hervortreten [...].« (Kortmann 2003: 295, H.i.O.; s. 4.2.4.aa) Wie in diesem Film-Vorbild gehen die Figuren, auch bei Mihaileanu, zunehmend in ihrer Rolle auf, womit der Kern der jeweiligen Rolle parodiert und entlarvt wird.

Neben diesen klassischen Formen der Situations- und Verwechslungskomik erzeugt Mihaileanu auch durch Wortwitz, Slapstick-Elemente (die kommunistischen Partisanen, der unfähige Lokführer) sowie den augenzwinkernden Umgang mit jüdischen Stereotypen ${ }^{682}$ komische Momente.

Im Unterschied zu Das LeBen ist Schön handelt es sich bei Zug Des Lebens um einen Film, der auf eine fast romantisierende Weise die jüdische, insbesondere die osteuropäische Schtetl-Kultur sowie den jüdischen Überlebenswillen feiert und den Holocaust erst indirekt thematisiert (s. 4.2.1).

»Die individuelle Menschlichkeit der kleinen Einheit (die Dorfgemeinschaft in ZUG DES LEBENS beziehungsweise die Familie in EIN HAUCH von SONNENSCHEIN) behauptet sich gegen die großen Ideologien des 20. Jahrhunderts. Diese Beobachtung deckt sich mit der Georg Seeßlens, daß es in den aktuellen Holocaust-Filmen immer darum gehe, reinen menschlichen Alltag gegen den Terror der Geschichte zu verteidigen<.» (Seeßlen zit.n. Lorenz 2003: 278)

682. Siehe 4.2.2.

683. »Die Selbstdeportation läßt sich als Mimikry betrachten, insofern sie dem Verhalten eines Lebewesens gleicht, das sich durch Anpassung an seine natürliche Umwelt unkenntlich macht und dadurch der Gefahr entzieht.« (Kortmann 2003: 298)

Ganz so abwegig wie es zunächst erscheint, ist das Grundmotiv der Selbstdeportation jedoch gar nicht. Es »verweist auf das Dilemma der Zwangsvertretungen der jüdischen Gemeinden [...], die Züge entweder selbst zu beladen und damit die zu Deportierenden zu selektieren, oder dies den Nazis zu überlassen. Während anfangs noch Hoffnung bestand, daß die Züge vielleicht doch nicht direkt in den Tod führen, redete man sich dies mit fortschreitendem Wissen nur noch ein (vgl. ebd. 304). Rumkowski, der Judenälteste von Lodz, ließ sich im Getto als zweiter Mordechai feiern; auch der falsche »Kommandant« in TRAIN DE VIE hört auf den Namen Mordechai, den Retter des Volkes aus dem Buch Esther und Helden des Purim-Spiels (vgl. ebd. 300; s.u., Aspekt 6). Darüber hinaus wußte Mihaileanu vom so genannten »Zug von Lasi«, einem 1941 ziellos in Rumänien herumfahrenden Todeszug, in dem über 2.000 jüdische Häftlinge den Hungertod starben (vgl. Oster/Uka 2003: 258).

684. Mihaileanu zit.n. Tegeler auf www.morgenwelt.de/kultur/000320-zugdeslebens-film-p. htm: 1

685. Vgl. Vishniac 1996.

686. Die filmischen Vorbilder hatten zum Ziel, aus der Perspektive der neuen Heimat Amerika das Schtetl (Figuren, Orte, Sprache und Musik) als Objekte einer verklärenden Erinnerung zu zeigen (vgl. Oster/Uka 2003: 262).

687. Vgl. u.a. Blumenfeld 1998, Distelmeyer 2000: 53, Kniebe 2000: 19 und Loshitzky 2003: 28.

688. »Die Protagonistenstruktur [...] folgt nicht nur in der Namensgebung nahezu religiösen Typisierungen. Der Dorftrottel wird durch seine Idee der Selbstdeportation in das >Gelobte Land Palästina zum >Heiligen Narren stilisiert, der in einigen Szenen wie ein Engel über dem Zug zu schweben scheint.« (Bleicher 2002: 191, H.i.0.) 


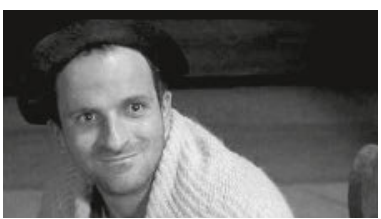

(623) $0: 05: 30 \mathrm{~h}$

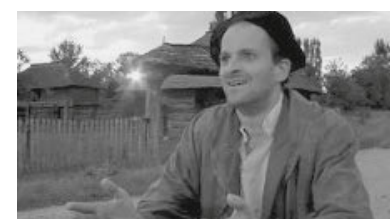

$624) 0: 07: 26 \mathrm{~h}$

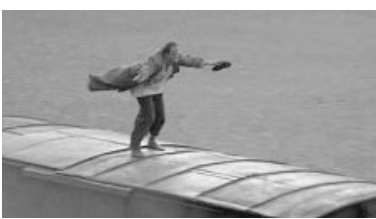

$0: 36: 24 \mathrm{~h}$

In jüdischer Tradition steht Zug DES LEBENS aufgrund der Integration zahlreicher jüdischer Elemente:

\section{(1) Jüdischer Humor:}

Mit der - den Film tragenden - Idee der Selbstdeportation ${ }^{683}$ weitet Mihaileanu das Grundprinzip des jüdischen Witzes, die ironische Distanz zum eigenen Schicksal zu wahren, auf die gesamte Handlung aus (vgl. Bleicher 2002: 195):

»Der jüdische Humor war immer traurig, er war immer Tragödie und Komödie in einem. [...] Wir Juden sterben nicht an dem Leid, wir versuchen weiter zu leben und nicht ganz verrückt zu werden an der Welt, und unsere einzige Waffe, unser Überlebensmittel gegen die Tragödie, ist unser Humor. [...] Jüdischer Humor bedeutet nicht, sich über die Shoah lustig zu machen [...]. [...] Es bedeutet auch nicht, sich über die Opfer zu amüsieren, nein, der jüdische Humor ist eine bestimmte Form der Tragödie und eine Form, das Leben zu erzählen.«684

Neben dem Grundmotiv, der Verkehrung der Verhältnisse durch Selbstdeportation, folgen viele Szenen der Pointenstruktur des jüdischen Witzes, beispielsweise die Protagonisten/Antagonistenstruktur - jüdische Opfer/nationalsozialistische Täter: »Beliebt waren auch Possen, in denen ein kluger Jude einen Andersgläubigen hereinlegt.« (Landmann zit.n. Bleicher 2002: 189; s. 4.2.4.aa)

\section{(2) Die Schtetl-Welt:}

In der Tradition jiddischer Filme der Dreißigerjahre (Yidl Mitn Fidl, PL/USA 1936; Mamele, POL 1938 u.a.) erweckt Mihaileanu, insbesondere im ersten Drittel des Films (s. 4.2. 3.b), »die jahrhundertealte Inselkultur der jüdischen Kleinstadt- und Dorfgemeinden zum Leben « (Oster/Uka 2003: 261f.) - er wollte ein Schtetl wie bei Chagall zeichnen, so der Regisseur (vgl. Steinberg 08.04.2000: 2; s. v.a. 4.2.3.b), eine nostalgische Erinnerung an die »verschwundene Welt« der Schtetl ${ }^{685}$, ermöglicht durch Idealisierung, d.h. den Verzicht auf die Darstellung der sozialen Nöte (extreme Armut, Hunger etc.; Oster/Uka 2003: 262). ${ }^{686}$

Mihaileanus Schtetl-Juden basieren teils auf folkloristischen Stereotypen (s. 4.2.3.ba), teils auf der Tradition des jiddischen Volkstheaters (s. 4.2.3) ${ }^{687}$ Wie in ZUG DEs LeBens gibt es dort »den Rabbi, den Reichen, den Heiratsvermittler, die Mutter, die Schöne« (Mihaileanu zit.n. N.N. 2000: 25, s. 4.2.3).

Tragende Figur ist Schlomo, der Dorfnarr - einer der zentralen Akteure des jüdischen Humors (vgl. Bleicher 2002: 190), ein zwischen Genialität und Wahnsinn oszillierender, faszinierender Charakter (s. hierzu 4.2.3, insb. 4.2.3.a sowie 4.2.4.b) ${ }^{688}$ : 
»Schlemiel heißt im Jiddischen der Pechvogel, der Verlierer, der Mitleid hervorruft. Bisweilen wird er als Luftmensch beschrieben, einer, der über der Erde schwebt, ohne den Boden mit den Füßen zu berühren, oder auch als Tramp, als heiliger Narr. In der Steigerungsform wird der Schlemiel zum iSchlimazek, dann ist er besonders unbeholfen und ungeschickt und wird endgültig zur traurigen Gestalt. [...] Er übersteht als >Mensch und ist unter diesem Aspekt eine Art stiller Held, ein Held wider Willen, der sogar in der Niederlage Würde bewahrt [...].« (Koebner 1997: 53, H.i.0.)

\section{(3) Volksmusik Klezmer:}

Lebensfreude und Vitalität der Schtetl-Juden macht Mihaileanu vor allem über den regelmäßigen Einsatz von Klezmer-Musik erfahrbar ${ }^{689}$ : Dieser lebendigen, ursprünglich jiddischen Hochzeitsmusik »vermag sich kaum ein Zuschauer zu entziehen « (Bleicher 2002: 195), insbesondere wenn Mihaileanu sie als eine Art Musikclip inszeniert (s. 4.2.3.bb) - Hommage an Norman Jewisons Film Fiddler on the Roof (USA 1971).

(4) Sprache Jiddisch:

Durch zahlreiche jiddische bzw. hebräische Worte - wie z.B. Rebbe (Rabbi) und Moische (Moses) -, deren Klang und Satzmelodie zum Schmunzeln einladen, erzeugt Mihaileanu in der deutschen Version des Films eine gewisse Komik. ${ }^{6}{ }^{\circ}$ Das anfängliche Unvermögen der Schtetl-Juden, Deutsch ohne jiddischen Akzent zu sprechen, vermittelt Mihaileanu mit einem unübersehbaren Augenzwinkern (s. 4.2.3.ba. e).

\section{(5) Religiöse Riten sowie kulturelle Sitten und Gebräuche:}

Neben dem rituellen Reinigungsbad jüdischer Frauen, der Mikwe, wird insbesondere dem Sabbat-Fest eine bedeutende Sequenz gewidmet - eine Inszenierung mit vielfachen ironischen Brüchen (s. 4.2.4.ab). Sachkundige Zuschauer können darüber hinaus zahlreiche Anspielungen auf den jüdischen Karneval, das Purim-Fest, erkennen. ${ }^{6}{ }^{1}$

689. Hierfür engagierte Mihaileanu den Filmkomponisten Goran Bregovic, der sich mit seinen mitreißenden Kompositionen in den Filmen des Rumänen Emir Kusturica einen Namen gemacht hat.

690. Aus diesem Grund werden die Filmzitate aus der deutschen Filmfassung angeführt und nicht aus der französischen Originalversion.

691. „Immer wieder wird auf das Purim-Fest angespielt: durch die Namen der Akteure, das Gebäck, das für die Reise bereitet wird, die Maskerade der Juden, die ihre fingierte Selbstdeportation organisieren. [...] Daß Mordechai in Mihaileanus Purim-Spiel zugleich in die Uniform Hamans [des persischen Wesirs, der nach dem Leben der Juden trachtet] schlüpfen muß, ist nicht nur absurd, sondern zugleich auf schreckliche Weise realistisch; realistischer, als es die vordergründige Absurdität des Films nahe legt.« (Kortmann 2003: 300)

692. »Historisch am korrektesten würde man es nach Rumänien, Galizien, legen. Aber ich wollte im Film nicht angeben, wo es genau liegt, sonst wäre es ja kein Märchen geworden. Viele glauben, daß ich die Spielregeln der Dokumentation verletze, wenn ich historisch ungenau bin. Aber ich entgegne, daß ich ja ein Märchen erzähle und keine Doku drehe.« (Mihaileanu zit.n. Kleinschmidt, Filmheft ZUG DES LEBENS, Bundeszentrale für politische Bildung/Institut für Kino und Filmkultur, S. 10)

693. Vgl. die Unterüberschrift von Bleichers Artikel: „ZUG DES LEBENS als Roadmovie ins KZ« (Bleicher 2002: 189ff.). Zu den Anleihen bei der Abenteuergeschichte vgl. ebd. 190: »Die Her- 


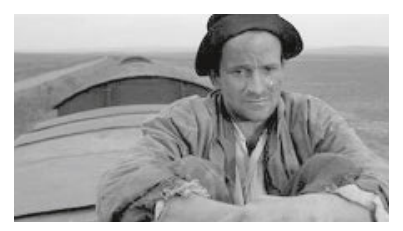

(626) $1: 30: 42$

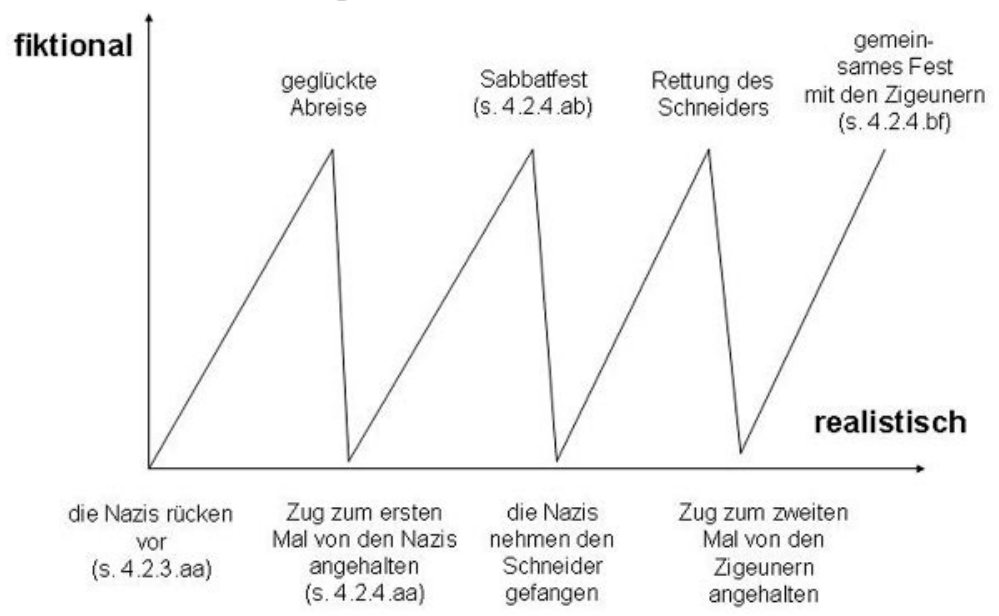

Abb. II.4.2.a

Ein zentrales Merkmal des karnevalistischen Prinzips (s. II.4 sowie 4.2.2), die Welt auf den Kopf zu stellen, dominiert als Grundidee diesen Film.

Wie Das Leben ist schön läßt sich auch Zug Des Lebens nicht nur einem Genre zuordnen. Insgesamt kann man Mihaileanus Film am ehesten als »bezaubernd poetisches Märchen« mit wiederkehrendem Musicalcharakter und der dramaturgischen Struktur eines Roadmovie beschreiben (Werneburg 1999: 23; s. II.4).

Neben der vagen Lokalisierung des Schtetls ${ }^{692}$ sowie der stereotypen Figurenzeichnung, verweist Mihaileanu zu Beginn des Films - im Unterschied zu Benigni - auch explizit auf das Märchenhafte, indem der Erzähler mit der Standardformel »Es war einmal« die Geschichte einleitet (s. 4.2.3.aa).

Vor allem die im Stile eines Musik-Clips inszenierten Szenen (s. 4.2.3.bb und 4.2.4.bf) sowie der regelmäßig Einsatz des Klezmer-Leitmotivs erinnern an ein Musical.

Das Grundprinzip des Roadmovies als »Genre des Kontrastes zwischen dem Freiheitswillen des Einzelnen und der herrschenden Gesellschaftsordnung « (Bleicher 2002: 194) entspricht der Idee der Selbstdeportation in besonderer Weise und wird darüber hinaus auf zahlreichen Unterebenen dekliniert: »Freiheit und Ordnung steigern ihre Bedeutsamkeit durch eine Vervielfachung des Konflikts zwischen den Freiheit suchenden Juden und den sie verfolgenden Nazis, den Konflikten innerhalb der Flüchtlinge zwischen den verkleideten Wächtern und den Deportierten, den gläubigen Juden und den Kommunisten, zwischen autoritären Eltern und ihren nach Unabhängigkeit strebenden Kindern.« (Bleicher 2002: 194)

Hinsichtlich des Aufbaus seines Films nutzt Mihaileanu die Dramaturgie populärer Erzählmuster, insbesondere des angesprochenen Roadmovies: ${ }^{693}$ 
Die Erzählstruktur des »klassischen« Roadmovies bringt einen vergleichsweise raschen Szenenwechsel mit sich, dessen rasantes Tempo Kurzweiligkeit erzeugt.

Während DAS LEBEN IST SCHÖN durch eine auffällige Zweiteilung auszeichnet, besteht Mihaileanus Film aus einem Rahmen (Erzähler) und einer darin eingebetteten Binnengeschichte. Der zentrale Mittelteil des Films zerfällt in ein erstes Drittel, das die Fluchtvorbereitungen des Schtetls beinhaltet (s. 4.2.3), und zwei weitere Drittel, welche die Odyssee des >Zug des Lebens < durch Osteuropa wiedergeben (s. 4.2.4). Diese rund einstündige Flucht bildet den zentralen Teil des Films.

Im Unterschied zu Benignis teils positivem Ausgang des Films läßt Mihaileanu das Märchen innerhalb der Binnengeschichte zwar glücklich enden, entlarvt es jedoch gleichzeitig in der Schlußsequenz als Schlomos tröstliche Fluchtphantasie - denn auf den Wunschtraum der gelungenen Flucht folgt das böse Erwachen (s.u.; vgl. Bleicher 2002: 189 und Kniebe 2000: 19): »Ein Happy End existiert nicht und wird auch nie existieren. [...] Es gibt kein Happy End, es darf keines geben. Und die, die eines daraus machen, sind Bastarde, weil die das Kapitel zuschlagen wollen. « ${ }^{694}$

Nachdem die Binnengeschichte der Selbstdeportation ein glückliches Ende gefunden hat, indem der >Zug des Lebens < dem Bombenhagel auf wundersame Wei-

ausforderung an den Protagonisten, seine Entscheidung, auf diese Herausforderung zu reagieren, die Integration einer Beraterfigur und die Bewährungsproben während einer Reise erinnern an Christian Voglers Erzählstruktur aus seinem für Hollywoodfilme geschriebenen Drehbuchratgeber >The Writer's Journeyı: Gewöhnliche Welt (das Schtetl), Ruf zum Abenteuer (Idee der Selbstdeportation), Zurückweisung des Rufes (Zweifel der Ältesten), Treffen mit dem Ratgeber (hier der Deutschlehrer, der mit der Sprache auch die deutsche Mentalität zu vermitteln versucht), Übertreten der ersten Schwelle, Abfahrt des Zuges, Prüfungen (Verfolgung durch Terroristen, Begegnungen mit den Deutschen), Verbündete (Treffen mit den Zigeunern), Feinde (die deutschen und die anarchistischen Verfolger), Annäherung an die äußerste Höhle (Befreiung des gefangenen Juden), Krise: kritischste Feuerprobe (der Zug zwischen den Fronten), Belohnung, der Weg zurück, Klimax: Auferstehung (die scheinbare Rettung aus dem Bombenhagel), Rückkehr mit dem Elixier.« (Bleicher 2002: 190)

694. Mihaileanu zit.n. Kleinschmidt, Filmheft Zug des Lebens, Bundeszentrale für politische Bildung/Institut für Kino und Filmkultur, S. 12. Auf diese Weise setzt sich Mihaileanu von einer neuen, dominierenden »Welle von Holocaust-Filmen« ab, »zu der etwa [...] HITLERJUNGE SALOMON zählt und die in SCHINDLER'S LIST kulminierte«. (Loshitzky 2003: 28)

695. »Die visuelle Stilisierung der durch die Lüfte zischenden Bomben per Computeranimation und im Stil des Zeichentrickfilms, die Abwendung vom Realfilmischen macht den fiktionalen Charakter hier offensichtlich.« (Kortmann 2003: 312)

696. Distelmeyer etwa stellt wie Beier und Bleicher die Frage nach der Relevanz des letzten Bildes: »)Holocaustく, >Konzentrationslager sagt dieses Bild ähnlich plakativ und mythisch, wie zuvor die Gegenüberstellung von Nazis und Kommunisten wirkte. Die Flucht ins Märchen mitsamt seinen Klischees und Wunschvorstellungen wird gebrochen, durch einen Verweis auf Realität, der hier jedoch ebenfalls nur über den Abruf eines anderen allgemeingültigen Bildes funktioniert. [...] Ist mit dem letzten Bild des KZ-Häftlings tatsächlich alles gesagt?« (2000: 53) 


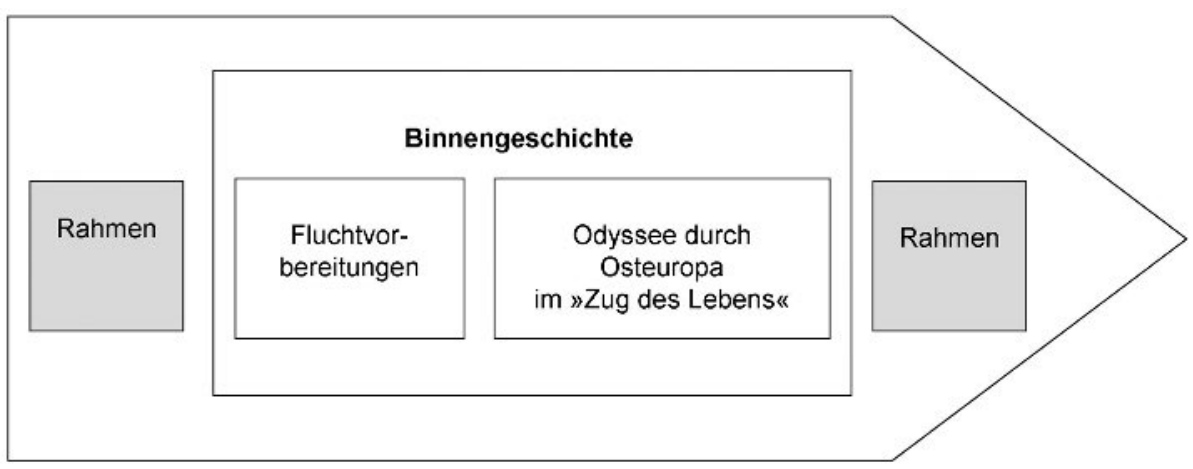

Abb. II.4.2.b
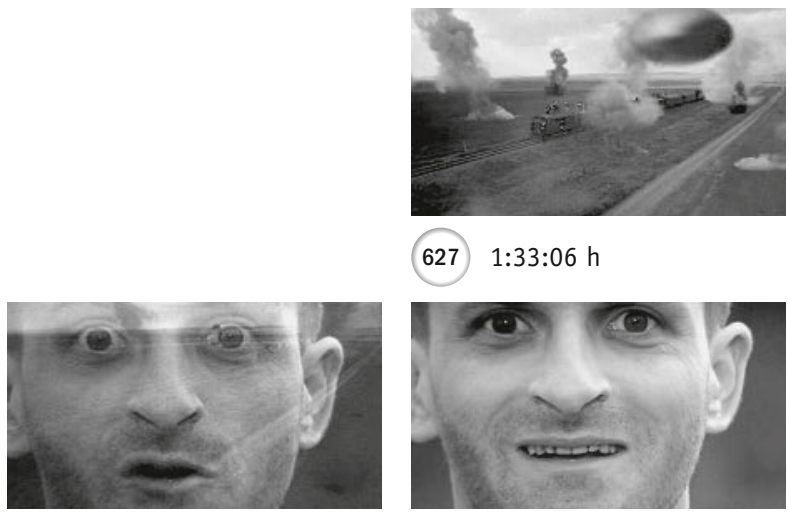

(629) $1: 33: 49 \mathrm{~h}$

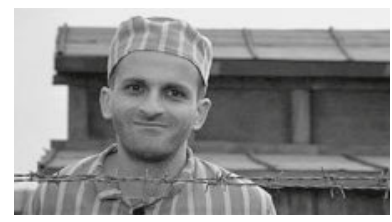

(630) $1: 34: 02 \mathrm{~h}$

se entgangen ist (s. 1:33:06 h) ${ }^{695}$, läßt Mihaileanu parallel zu einer Überblendung die überschwengliche Musik verstummen. Nach und nach wird Schlomo in einer Detailaufnahme sichtbar (s. 1:33:35), in der er seine Erzählerfunktion aus dem Vorspann aufnimmt und vom zufriedenen Leben der Schtetl-Juden nach der geglückten Flucht berichtet (s. 1:33:49). Das »gezeichnete« Aussehen des Protagonisten erklärt sich durch einen filmischen Kunstgriff: Im Anschluß an seine Erzählung erweitert die Kamera den Bildausschnitt zu einer distanzierteren Einstellungsgröße (s. 1:34:02 h), mit der sich die Hoffnung auf Rettung der Schtetl-Juden abrupt zerschlägt: Das Schlußbild des Films zeigt Schlomo in gestreifter Häftlingskleidung hinter Stacheldraht und vor Baracken, die der Zuschauer sofort als deutliche Merkmale eines nationalsozialistischen Lagers identifizieren kann.

»Zwar finden sich in dieser einzigen Sequenz die populären Elemente der Holocaust-Ikonographie, doch das bewegte Bild wird sofort zum Standbild. Das so erzeugte (eingefrorene) Bild [...] genügt vollkommen, jenen Kontrast gegen die fröhlich-optimistischen und selbstironischen Grundzüge der Filmhandlung zu setzen, um das Lachen über das groteske Vorhaben einer Selbstrettung der Juden erstarren zu lassen.« (Oster/Uka 2003: 263, vgl. auch Beier 2000: 60$)^{696}$ 
Mit diesem Kunstgriff, der die ersehnte Selbstrettung und die historische Realität hart aufeinander prallen läßt, macht Mihaileanu den »Ort des Horrors« als »Geburtsstätte der Komödie« erfahrbar (Bleicher 2002: 195). ${ }^{697}$ Das Einfrieren des Schlußbildes entspricht Mihaileanus Überzeugung, derzufolge die Lager nicht darstellbar sind (s.o.):

»Der >Freeze-frame`, mit dem unser Blick auf Schlomo endet, deutet die Unmöglichkeit des Weitererzählens an.« (Kortmann 2003: 298, H.i.0.)

»Mit dieser Wendung stellt sich der Film selbst in Frage, gleichzeitig aber auch den gesellschaftlichen Auftrag eines Mediums, das sich der darstellenden Aufarbeitung des Holocausts verschrieben hat, insofern es die Wahrheit ungeschminkt abzubilden vermag [...].« (Ebd. 312)

Das äußert kurze Ende (9० Sekunden) vermag jedoch nicht die - aufgrund der Umkehr der Machtverhältnisse wohltuende - Gesamtwirkung des Films (s. 4.2.2) zu verhindern: »Ergeben dreißig Sekunden Tragödie nach hundert Minuten Komödie eine Tragikomödie?« (Beier 2000: 60), fragt Beier zu Recht. ${ }^{698}$

Die internationale Kritik reagierte zwar insgesamt positiv auf ZUG DES LEBENS, beanstandet wurden jedoch das komische Genre sowie die klischeehafte, typisierte Gestaltung der Figuren (s.o.). ${ }^{699}$

Das Publikum hingegen reagierte von Anfang an mit großer Zustimmung auf den Film: 1998 demonstrierte es auf den Filmfestspielen von Venedig für weitere Aufführungen ${ }^{700}$, im gleichen Jahr erhielt der Film die Publikumspreise in Sao Paulo und in Cottbus, 1999 folgte - unter anderem - der des Sundance-Filmfestivals (vgl. Werne-

697. »Die tragisch-komische Inszenierung dieses Traums erinnert dann in schmerzhafter Weise daran, daß gerade aus der Diskrepanz zwischen Traum und Wirklichkeit die bittere Lehre der Geschichte hervorgeht.« (Oster/Uka 2003: 263)

698. »Auch der tragische Schluß vermag diesen Musicalcharakter nicht aufzuheben, denn mit der direkten Darstellung der maschinellen Vernichtung menschlichen Lebens wird in diesem Film niemand belästigt, auch wenn das verlassene sSchtetk von den Deutschen niedergebrannt wird.« (Bleicher 2002: 194, H.i.0.)

699. Die deutsche Kritik setzte sich insbesondere mit den Aspekten Balanceakt zwischen Komik und Ernst, (Holocaust-)Märchen, Menschlichkeit und Toleranz auseinander.

700. Dort gewann der Film darüber hinaus den »International Critics Award«.

701. Erst nach Broders begeisterter Kritik des Films im "Spiegel«, wurde ZUG DES LEBENS von der deutschen Arthouse-Verleihfirma »Movienet« zwei Jahre nach dessen Fertigstellung in die deutschen Kinos gebracht: »Die Vorbehalte der Verleiher waren nicht wirklich ideologischer Natur. Sie haben einfach nicht geglaubt, daß der Film in Deutschland ankommen würde. Sie meinten, in Deutschland wäre diese Art Film sehr schwierig, Deutschland werde eine solche Art von Komödie niemals akzeptieren." (Mihailenau zit.n. Steinberg 2000: 1)

702. »Jiddisch Sprechenden ging es besonders schlecht, weil ihre Sprache für die Ohren der Nazis eine verächtliche, korrupte Version der Sprache ihres Vaterlandes war. Wenn die Juden versuchten, Deutsch zu sprechen, wurde ihr jiddischer Akzent verhöhnt, und oft wurden sie für ihre Anstrengungen bestraft. Obwohl die Nazis die Juden zwangen, Deutsch zu sprechen, fanden sie nichts beleidigender als einen Juden, der Deutsch sprach.« (Weinstein 2003: 219) 
burg 2000: 14). Auch beim »Jüdischen Filmfestival« in Berlin (2000) wurde er mit Begeisterung aufgenommen. In Italien, Frankreich und Israel konnte er Erfolge verzeichnen, in Deutschland hatte er 230.000 Zuschauer und spielte etwa 2,4 Millionen Mark ein« (Oster/Uka 2003: 259) (701 $^{-}$ein durchaus beachtliches Ergebnis für einen »kleineren« Film. Aus seinem auffälligen Erfolg beim Publikum ergibt sich die Frage, ob Mihaileanus Herangehensweise einer karnevalesken Umstülpung der Welt (s. II.4, 4.2.3 und 4.2.4.a) sowie einer Feier der jüdischen Schtetl-Kultur nicht neue Möglichkeiten filmisch-fiktionaler Bearbeitung des Holocaust bietet. Die folgende Analyse des Films gibt Aufschluß über den Zusammenhang zwischen breiter Wirksamkeit und besonderer Form des Umgangs mit dem nach wie vor brisanten Thema.

\subsubsection{Leitthesen}

a) Verkehrte Welt versus menschliche Grundwerte

Verkehrte Welt (s. 4.2.4.a):

ZUG DES LEBENS bringt viele unserer Vorstellungen, Ansichten und vermeintlichen Gewißheiten - vor allem das Wissen um den Holocaust - ins Wanken. Ein jüdisches Schtetl deportiert sich selbst, um vor den vorrückenden Deutschen nach Palästina zu flüchten. Um mit einem Trick den Aggressor auszuschalten und eine perfekte Tarnung zu erreichen, muß ein Teil der Gemeinde in die Rolle der Nazis schlüpfen. Die Verkehrung der Verhältnisse wird dabei derart gesteigert und pointiert, daß der Zuschauer zeitweise Gefahr läuft, die Orientierung zu verlieren. Dies ist häufig der Fall, wenn die Juden auf ihrer Flucht die Konflikte, die extern existieren - Juden versus Nazis, Kommunisten versus Nazis - intern durchspielen. Die Rollen werden oft äußert originalgetreu interpretiert oder sogar übertroffen, wie im Fall von Mordechai (s. 4.2.4.aa).

Karnevaleske Umstülpung der Welt inszeniert der Regisseur in Zug DES LEBENS auf zahlreichen Ebenen:

- Es sind nicht der Rabbi oder ein Mitglied des Rates der Waisen, die in der Notsituation (die Nazis sind auf dem Vormarsch) die rettende Idee haben, sondern ausgerechnet Schlomo, der »Verrückte« (s. 4.2.3.a).

- Erstaunlicherweise finden die Vorbereitungen zur Flucht keineswegs in einer bedrückenden Atmosphäre statt, sondern in mitreißender Aufbruchsstimmung mit Klezmer-Musik (s. 4.2.3.bb).

- Im Unterschied zu den damaligen Gegebenheiten ${ }^{702}$ wird die deutsche Sprache gegenüber dem Jiddischen, hier durch Mordechai, abgewertet: »Wissen die Deitschen, daß wir ihre Sprache parodieren?« (o:17:20 - o:17:22 h; s. 4.2.3.ba. e)

- Als Yankele, der Buchhalter, Geld für den Zukauf zur Verfügung stellen soll, brüllt er Mordechais Gesandten an: »Die gehen mir auf die Nerven, deine Deitschen!« (o:18:11 - o:18:12 h)

- Während in der jüdischen Kultur die männliche Dominanz vorherrscht, stellt Mihaileanu die Frauen als das letztlich stärkere Geschlecht dar (s. 4.2.3.ba. b).

- Höhepunkte in bezug auf die Verkehrung der Verhältnisse bilden folgende Schlüsselsequenzen: die erste Konfrontation mit den echten Nazis (s. 4.2.4.aa), die Befreiung des Schneiders aus der Gefangenschaft sowie das konfliktüberschattete Sabbatfest (s. 4.2.4.ab). 
- Schlomo wollte eigentlich Rabbi werden; da der Posten bereits vergeben war, übernahm er die freie Rolle des »Verrückten«.

- Entgegen den historischen Ereignissen triumphieren die Juden in der Binnengeschichte über die Nazis, die vorgetäuschte Selbstdeportation glückt.

- Jede der verfolgten Gruppen versucht, in ihre mystische Heimat zu gelangen, die Juden nach Palästina, die Roma nach Indien. Mihaileanu ironisiert diese Sehnsucht, indem er Schlomo am Ende des Films erzählen läßt, daß die Juden in Indien, die Roma in Palästina angekommen sind (Loshitzky 2003: 27)

\section{Menschliche Grundwerte (s. 4.2.4.b):}

Trotz oder gerade aufgrund der zahlreichen Verkehrungen der Verhältnisse und der damit einhergehenden Verwirrungen beharrt Mihaileanu in seiner nur vermeintlich »verdrehten « Welt auf Grundwerten wie Menschlichkeit und Toleranz:703

_ »Meinetwegen sei a Kommunist, aber werd wieder normal, a Mensch!« - Yossis und Samis Bekehrung durch den »gesunden Menschenverstand« der Frauen (s. 4.2.4.ba)

- Schlomos weises Sabbat-Gebet (s. 4.2.4.bb)

- Schlomo - Dorfnarr wider Willen (s. 4.2.4.bc)

- Mordechais Desillusionierung als verhaßter »Nazi-Kommandant« (s. 4.2.4.bd)

- Schlomos enttäuschte Liebe (4.2.4.be)

- Verbrüderungs-Fest mit den Zigeunern (s. 4.2.4.bf)

Bei diesen Sequenzen handelt es sich gleichzeitig um die ruhigeren Passagen des Films, die allein aufgrund der Kontrastwirkung zu den schwungvoll-temporeichen Szenen auffallen und sich einprägen, obgleich seltener eingesetzt.

\section{b) Lachen der (An-)Nähe(rung) versus Lachen der Distanzierung}

In Zug DES LEBENs lädt Mihaileanu den Zuschauer häufig ein, aus unterschiedlichen Gründen zu lächeln oder zu lachen, was angesichts des ernsten thematischen Hintergrunds als wohltuend bezeichnet werden kann.704

Er bietet die Möglichkeit, ein- bzw. zustimmend zu lachen - ein Lachen der Anerkennung, Nähe, Freude, einerseits durch die mitreißend dargestellte Vitalität und

703. »Die Auseinandersetzung mit dem Faschismus ist einem Plädoyer für Menschlichkeit gewichen, das für sich selbst beansprucht, Ideologie überwunden zu haben. [...] so verteilt ZUG DES LEBENS im Sinne der Menschlichkeit Watschen nach >linksı und >rechtsı." (Distelmeyer 2000: 53, H.i.0.)

704. »Für die dritte Generation nach dem Zweiten Weltkrieg ist dieser Film ein Angebot, sich sauch zu amüsieren.« (Kortmann 2003: 312, H.i.0.)

705. Vgl. Senta Berger zur »Tradition, mit dem Entsetzen Scherz zu treiben. [...] Es sind gelungene Versuche, von Schrecklichem zu erzählen, so daß man diese Dinge nicht nur aushält, sondern ganz klar sieht - wie mit dem Brennglas vergrößert.« (in: »Arte Magazin« 1/2006)

706. Vgl. Broder in »Der Spiegel«, 14.06.1999: 234.

707. »[...] wir ziehen viel über uns selbst her, mehr als über andere« (Mihailenau zit.n. Steinberg 08.04.2000: 2). »Der jüdische Witz, Volks- und Bildungswitz in einem und hierin ganz einmalig, parodiert oft das eigene Schrifttum, den eigenen Kultus und Ritus, imitiert in Witzform kabbalistische und talmudistische Bibeldeutungen.« (Schmid zit.n. Bleicher 2002: 
Lebensfreude der Juden - insbesondere, wenn sie feiern (s. 4.2.3.bb und 4.2.4.bf) -, andererseits durch die Verkehrung der Verhältnisse innerhalb der Binnengeschichte (s. 4.2.2.a a). Der den Film beherrschende Aberwitz stemmt sich derart gewaltig gegen die historischen Tatsachen, daß der Zuschauer die Absurdität der erzählten Geschichte dankbar annimmt; man stellt sich gerne vor, daß zumindest diese Schtetl-Juden, ihr Schicksal aktiv abwenden könnten, auch wenn dies im Schlußbild als Fiktion entlarvt wird. ${ }^{05}$ Diese Variante ist dem Kinopublikum bisher nur selten präsentiert worden - und wenn, dann gab es einen Retter von außen (vgl. ScHindLERS LISTE in II.3.2). In der, als Märchen gekennzeichneten, Fiktion kann sich der Zuschauer mit den Opfern identifizieren und sich mit ihnen darüber freuen, was zwar in dieser Form nie hätte eintreten können, aber zumindest in Ansätzen möglich scheint: David gelingt es im Film wiederholt, den deutschen Goliath vorzuführen, ihn »mit seinen eigenen Waffen zu schlagen« (s. 4.2.4.aa und die Befreiung des Schneiders aus der Gefangenschaft). Der todernste Hintergrund der verkehrten Welt wird vom schwungvollen Roadmovie dominiert, er ist allenfalls unterschwellig vorhanden.

Des weiteren zeichnet sich Zug Des LeBEns dadurch aus, daß keine Seite von befreiender Kritik durch Ironie verschont bleibt. Als wohltuend kann das angebotene Verlachen deshalb empfunden werden, weil es straft, Distanz schafft und - vor allem für das Einlassen nachgeborener Deutscher nicht zu unterschätzen - nicht nur die Nazis, sondern jegliche Form geistigen Starrsinns und unmenschlicher Verhaltensweisen betrifft. Mihaileanu fokussiert allgemein-menschliche Unzulänglichkeiten und Schwächen - selbst jüdische »Eigenheiten« bleiben hiervon nicht verschont: ${ }^{706}$

- die Wortgefechte der Männer

- die strikte Rollenverteilung zwischen Mann und Frau

- das Hadern der Männer mit Gott

- der »Geiz« des Buchhalters (Yankele)

- das Deutsch mit jiddischem Akzent (Mordechai)

- die unreflektierte Übernahme und Verbreitung ideologischer Parolen (Yossi).

Daß vor dem Hintergrund des Holocaust über jüdische Eigenschaften und kulturelle Normen gelächelt und teilweise sogar gelacht werden darf, ist gänzlich neu. Mit Ausnahme von Yossis »Kommunismus «-Obsession handelt es sich um eine Mischung aus liebevollem Verlachen und anerkennendem Lachen.707

\subsubsection{Der erste Teil des Films: Schlomos geniale Idee und ihre Umsetzung}

Das erste Drittel des Films steht im Zeichen von Schlomos Plan der Selbstdeportation seines jüdischen Schtetls angesichts der vorrückenden Nazis.

\section{a) Exposition: Verwirrung und Chaos}

Wie bereits angeführt (s. 4.2.2.a) wird der Zuschauer in der Exposition mit einer Reihe verwirrender Begebenheiten konfrontiert, die er in manchen Fällen sogar als völlig verrückt empfinden kann - Mihaileanu bringt unsere Ansichten und vermeintlichen Gewißheiten ins Wanken. Dieser Aspekt, eine gewisse »Verrücktheit« - »folie« - muß, so die Botschaft des Films, im Zusammenhang mit der nationalsozialistischen Judenvernichtung neu interpretiert werden. 
aa) Vorspann: Schlomos Panik angesichts der Bedrohung

\section{Detaillierte Sequenzanalyse:}

Zug Des LeBens beginnt, im Hinblick auf die Bildspur, traditionell mit weißer Schrift auf schwarzem Hintergrund, so daß die Aufmerksamkeit des Zuschauers eher auf die auditive Ebene gelenkt wird: Zunächst sind hier leise getragene Töne zu vernehmen, a cappella vorgetragen von einer männlichen Stimme. Unterstützt von einem einsetzenden Chor, gewinnt diese zunehmend an Volumen und erzeugt eine starke Wirkung.

Erst durch die Einblendung des Filmtitels wird das Interesse von der Ton- auf die Bildspur verlagert. Der Titel - TRAIN DE VIE - nimmt nämlich nicht nur die gesamte Leinwand ein, sondern ist uneinheitlich gestaltet: Der Anfangsbuchstabe des letzten Titelwortes ist als einziger nicht weiß eingefärbt und sticht aufgrund der Signalfarbe rot besonders hervor. Zuschauer weltweit können darin das Zeichen für Sieg - victory - erkennen. Den französischsprachigen Zuschauer kann es an Redewendungen wie $>$ la vie avec un grand $\mathrm{V}<$ und $>\mathrm{V}$ comme victoire < denken lassen.

Nach dem vergleichsweise traditionellen Vorspann schiebt sich ein Erzähler ins Bild, der zunächst direkt in die Kamera, d.h. uns in die Augen, schaut und mit ruhiger Stimme, im Stile eines Märchenerzählers, zu sprechen beginnt (s. ০:০০:37 h):

»Es war einmal in einem kleinen Schtetl, einem jüdischen Marktfleck im Osten Europas, im Jahre 5701 oder 1941 nach dem neuen Kalender. Es war Sommer, Sommer 1941, im Juli glaub' ich. Ich bin geflohen, weil ich dachte, man kann fliehen vor dem, was man schon gesehen hat, zu oft gesehen hat.

Ich bin gerannt, um sie zu warnen, die Meinen, mein Schtetl, mein Dorf. Das ist die Geschichte meines Dorfes, so, wie wir alle sie erlebt haben.« (0:00:32 - 0:02:12 h)

Nach dem ersten Satz - gebrochener Hinweis auf das Genre des Märchens ${ }^{708}$ - erfolgt eine Überblendung, die die Beine eines durch den Wald hastenden Menschen erkennen läßt. Das Bild löst sich also von der Tonspur, um - wie wir durch die folgende Nahaufnahme des Gesichts erkennen können (s. o:০o:46 h) - den Erzähler als Teil der Figurenwelt einzuführen. ${ }^{709}$ Schon die Zeit- und Ortsangabe in Verbindung mit dem Wort

708. "In TRAIN DE VIE beinhaltet der ersten Satz (1) die sich widersprechenden Aussagen sil était une fois/es war einmak, also die Standardformel des Märchens, und die durch die Jahreszahl 1941 suggerierte historische Faktizität. Somit wird gleichzeitig ein Fiktionssignal (das einen guten Ausgang verspricht) gegeben als auch ein Wahrheitsanspruch formuliert.« (Kortmann 2003: 304)

709. Vgl. hierzu Kortmann 2003: 294ff.

710. Wir erinnern uns in diesem Zusammenhang an den Ausdruck sin den letzten Zügen liegen<, der im deutschen Titel des Films mitschwingt (s.o.) und sich konkret auf den Atemzug bezieht. Ob hierbei jedoch bereits, wie Kortmann schreibt, ein lebensrettendes Moment spürbar ist, sei stark bezweifelt: »Die lebensrettende Funktion des Zuges deutet sich bereits in der Tonspur dieser einleitenden Sequenz an, in der die Atemzüge, der erregte Herzschlag des keuchenden Schlomo und ein leises, schnaufendes Zuggeräusch einer Dampflok rhythmisch ineinander fließen. Schlomo läuft um das Leben seines Stetl; später wird der Zug diese Bewegung übernehmen.« (2003: 294)

711. Vgl. Eisenstein 1960: 88 zum Außer-sich-Sein. 


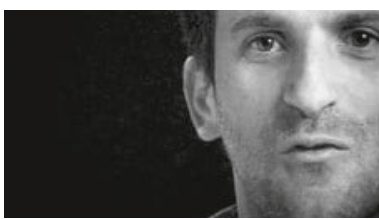

(631) $0: 00: 37 \mathrm{~h}$

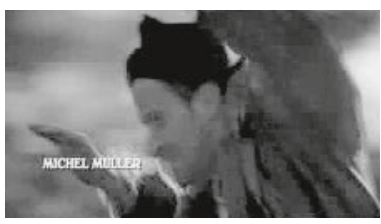

633

$0: 00: 51 h$

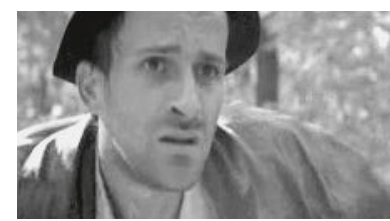

(632) $0: 00: 46 \mathrm{~h}$

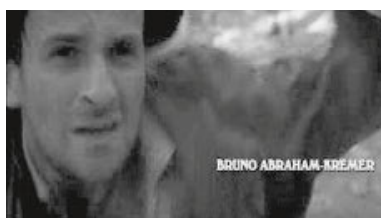

$0: 00: 59 h$

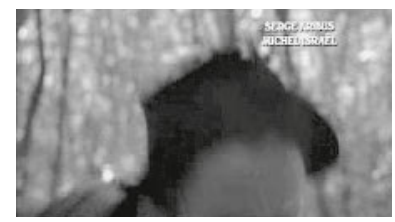

(635) $0: 01: 05 \mathrm{~h}$

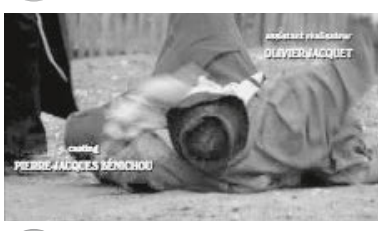

(636) $0: 01: 34 \mathrm{~h}$

»jüdisch« läßt Schlüsse auf den Holocaust, d.h. eine gefährliche Ausgangssituation, zu. Als die Sätze »[...] fliehen vor dem, was man schon gesehen hat, zu oft gesehen hat [...]« fallen, ahnt der Zuschauer, von welcher Gefahr hier die Rede ist. Zu den Worten des Erzählers macht die gesamte Inszenierung den Ernst der Lage spürbar: Der Gesichtsausdruck des Erzählers/Protagonisten sowie die Art und Weise, wie er durch das Gehölz hastet und dabei nach Luft ringt, lassen auf Todesangst schließen. Daß wir dieses Außersich-Sein in Ansätzen selbst erleben, liegt am Zusammenspiel zahlreicher filmischer Mittel. Zu stark rhythmisierter, von Klageschreien dominierter Musik hastet der Erzähler/Protagonist durch den Wald, wobei sein keuchender Atem - vergleichbar mit dem Vorspann von JАКов DER LÜGNER - auffällig laut zu hören ist. ${ }^{70}$ Hinzu kommt, daß die Kameraführung uns den Eindruck vermittelt, er schlage uns bei seinem Kampf durch das Unterholz die Äste ins Gesicht und stoße uns beinahe um. Schnelle, harte Schnitte tragen ihr übriges zur hektischen Wirkung bei, erzeugen jedoch auch Orientierungslosigkeit: Schlomo scheint sich im Kreis zu drehen, denn jede neue Einstellung läßt ihn in die gegensätzliche Richtung laufen - von rechts nach links, von links nach rechts und wieder von vorne ... (s. ০:००:51 u. ০:००:59 h). Abrupte Kamerabewegungen versuchen, den Erzähler/Protagonisten im Bild einzufangen, was durch seine hektisch-unkontrollierten Bewegungen nicht immer gelingt - wiederholt sprengt sein Kopf den Rahmen der Nahaufnahmen (s. ০:01:05 h): »Schlomo läuft um das Leben seines Schtetls. Auf der Tonspur wird Schlomos Eintreffen auf dem Dorfplatz von einem konzertierten Höllenlachen begleitet.« (Kortmann 2003: 294).

Im Schtetl, beim Rabbi angekommen, ist er nicht in der Lage, dessen Frage nach dem Geschehenen zu beantworten. Statt dessen sinkt er, wie besessen, wild gestikulierend zu Boden und bleibt, von Zuckungen gepeinigt, liegen (s. 0:01:34 h). ${ }^{71}$ Parallel hierzu ändert sich die Musik und nimmt katastrophenartige Klänge an. Auch die Reaktionen des Rabbi und anderer Dorfbewohner deuten auf drohendes Unheil hin: Kla- 
gerufe ausstoßend und die Arme zum Himmel reckend, eilen sie durch die Straßen des Schtetl (s. 0:02:02 h). Eine gewisse Komik entsteht dadurch, daß das Verhalten der Männer übertrieben inszeniert wird. Ohne genau zu wissen, was vor sich geht, schließen sich zahlreiche männliche Personen dem Klage-Zug an, wobei diese Art von Komik durch die Wiederholungen einen mechanischen Effekt $t^{72}$ und daher eine eher verunsichernde Wirkung auf den Zuschauer hat.

\section{ab) »Meschigge« oder genial ? - Schlomos Idee in der Eröffnungssequenz}

\section{Detaillierte Sequenzanalyse:}

Im Anschluß an den ca. zweiminütigen Vorspann tritt mit der Eröffnungssequenz Ruhe und Erholung ein: Die unheilverkündende Musik bricht jäh ab und der Rabbi fordert Schlomo zum Sprechen auf: »Nun erzeyl schoin!« (०:02:13 h) Doch anstatt die ungeduldige Aufforderung des Rabbis, sowie die Neugier des Zuschauers, zu befriedigen, drückt sich Schlomo - ähnlich wie in der Rahmenerzählung (s. 4.2.3.aa) - unklar aus:

»Er hat es zugelassen. Gott hat zugelassen, daß sie es tun. Sieh, hat er mir gesagt, sieh dir das an. Du bist ja schon verrückt. Wie soll man verschmutzte Äugen reinwaschen - Äugen, die zuviel gesehen haben? Die Vegel, die hier waren und sangen, verstummten pletzlich und flogen fir immer fort. Sie wollten nicht länger bei uns bleiben, bei uns Menschen. [...] Eines Tags werden wir kommen in das Himmelreich, ich weiß es jetzt. Er ist nicht mehr in unseren Herzen. Wir missen ihn suchen.« $(0: 02: 20-0: 03: 13)^{713}$

Im Vergleich zu seinem Ausbruch in der vorangegangenen Szene wirkt Schlomo hier erstaunlich ruhig, beinahe abwesend. Aufgrund der spezifischen Inszenierung hat der Zuschauer den Eindruck, Schlomo sei verrückt, wahnsinnig. Die Kamera haftet an Schlomos Lippen und umfährt ihn unmerklich, während sie gleichzeitig an ihn heranzoomt (s. ०: 02:38 h). Auf diese Weise wirkt Schlomo wie ein Visionär, dessen »Bericht« weder der Rat der Weisen (s. 0:03:02 h) noch wir verstehen können.

Als der Rabbi schließlich Schlomo unterbricht, um die Situation zu erklären, bestätigt sich die Vermutung des Zuschauers.

»Ich erzähl's ihnen, ich übersetz: Die Nazis sind aufgetoicht, nicht in unserem Schtetl, noch nicht, im Schtetl jenseits der Berg. [...] Schlomo bringt uns a schreckliche Nachricht. Alle jidischen Familien werden von den Nazis umgebracht oder deportiert, mit unbekanntem Ziel. Alle, Männer, Frauen, Kinder, Alte, ganze Dörfer. Offensichtlich stimmen die Gericht, keiner ist jeh zurickgekommen und hat je einen ein zigen Brief geschrieben. Was sollen wir nun machen, frag ich euch. Bald wird unser Dorf dasselbe Schicksal derleiden.« (0:03:15 - 0:03:51 h)

712. Vgl. Bergson 1972: 29 zu seiner Mechanik-These.

713. »Er [Schlomo] hat die Nazis vor der Ortschaft entdeckt und macht es sich zur Aufgabe, dies seinen Freunden - und auf der übergeordneten narrativen Ebene dem Kinopublikum - zu erzählen.« (Kortmann 2003: 294)

714. »Die drohende Gefahr wird chaotisch debattiert, es geht sprichwörtlich zu >wie in der Judenschul.» (Lorenz 2003: 270, H.i.0.) 


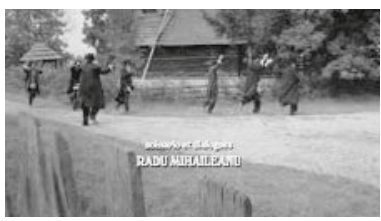

(637) $0: 02: 02 \mathrm{~h}$

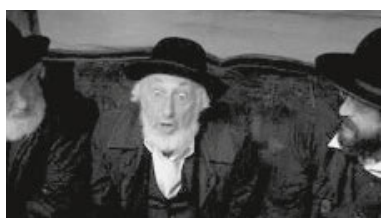

(640) $0: 03: 56 \mathrm{~h}$

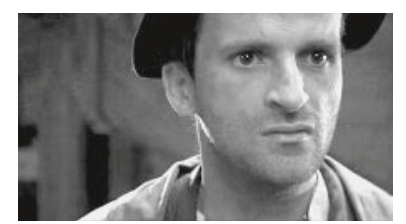

(638) $0: 02: 38 \mathrm{~h}$

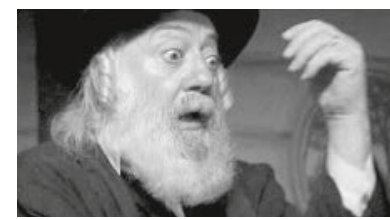

(641) $0: 04: 34 \mathrm{~h}$

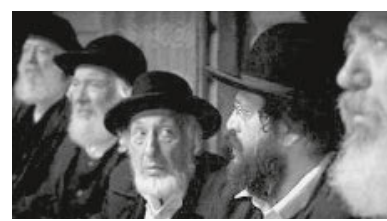

(639) $0: 03: 02 \mathrm{~h}$

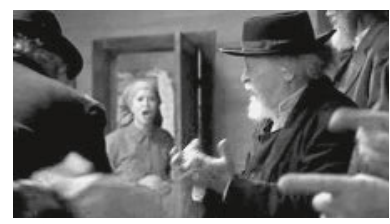

(642) $0: 04: 35 \mathrm{~h}$

Die quälende Ungewißheit in bezug auf den Auslöser der bedrohlichen Situation wird also aufgelöst (nach ca. dreieinhalb Filmminuten), die einzelnen Mosaiksteinchen jüdischer Marktfleck im Osten Europas, Sommer 1941, akute Bedrohung für Schlomos Schtetl, Todesangst - fügen sich zu einem Gesamtbild: Die Vernichtung der Juden durch die Nazis hat längst begonnen und breitet sich beharrlich und unaufhaltsam aus.

Des Rabbis Übersetzung von Schlomos Worten enthält genaue Angaben und Informationen, welche diesen eigentlich nicht zu entnehmen waren. Im Gegensatz zu einem Mann, der an Schlomos Glaubwürdigkeit zweifelt - »Wir werden doch nicht 'em Verrickten gloiben, oder?!« (s. o:03:56 h) -, nimmt der Rabbi ihn ernst und drängt auf eine Lösung. Auch wir fragen uns, ob Schlomos Verhalten nun verrückt oder durchaus glaubwürdig ist. Wir haben vor allem den Eindruck, daß er ein besonderer Mensch ist und daß sein Außer-sich-Sein authentisch wirkt (s. 4.2.3.aa).

Als der Rabbi die Männer, wie er Mitglieder des Rats der Weisen, nach einer Lösung fragt, wird die ernste Situation erneut von Komik aufgelockert. Im Chor stöhnen und klagen die Männer auf der Suche nach der rettenden Idee. Dabei schneiden sie unbeabsichtigte Grimassen, reißen die Augen weit auf, gestikulieren wild mit den Händen und laufen so dicht an der Kamera vorbei, daß uns diese Details nicht entgehen (s. ०:04:34 h). Unterbrochen wird diese, zwischen Unwillen und Hilflosigkeit schwankende, Lösungssuche durch die Frau des Rabbi, die plötzlich in dem Raum erscheint und die Männer streng und energisch zur Ruhe mahnt, damit die bereits schlafenden Kinder nicht aufwachen (s. o:04:35 h). ${ }^{714}$ Der energische Auftritt der Frau, die den Männern »befiehlt«, kann den mit den jüdischen Sitten vertrauten Zuschauer amüsieren, denn sie verkehrt die normalen Verhältnisse. Aus Filmen wie beispielsweise YENTL (1983) ist bekannt, daß die Männer in der jüdischen Kultur das Sagen haben, während die Frauen praktische Tätigkeiten rund um das Haus und die Familie verrichten. Hier jedoch regiert die Frau als offensichtlich stärkeres Geschlecht - eine Beobachtung, die für den gesamten Film gilt und als Beispiel für Mihaileanus augenzwinkernde Kritik an der strikten Rollenverteilung zwischen Mann und Frau dient (s. hierzu insb. 4.2. 3.ba). Auch die Art und Weise, wie die Männer miteinander umgehen, erheitert den Zuschauer: Während sie nach einer rettenden Idee suchen, entfacht sich plötzlich 
ein Streit, dessen Ursachen in der Vergangenheit liegen - einer der Männer wollte der Heirat seiner Enkelin mit dem Enkel des anderen nicht zustimmen. ${ }^{75}$ Dieses im Augenblick unbedeutende Thema, das in einer so bedrohlichen Situation Anlaß zum Streit und gegenseitigen Beleidigungen gibt, verdeutlicht die Rolle und das Verhalten der jüdischen Männer.

Schlomo, der aufgrund der verbalen Auseinandersetzungen unter den Männern (s. o: 05:01 h) ein wenig in Vergessenheit geraten war, meldet sich plötzlich wieder zu Wort: »A falscher Deportationszug!« (0:05:11 h) Erneut reagiert einer ablehnend auf Schlomo: »[...] der Meschiggene, wer sonst. Der Verrickte hat gesprochen.« (0:05:15 - 0:05:18 h) Wird dies dem Protagonisten wirklich gerecht, fragt sich der Zuschauer zwangsläufig. Unbeeindruckt von der abfälligen Bemerkung über den »Meschiggenen«, ist es wieder der Rabbi, der sich Schlomo zuwendet und um eine Erklärung bittet (s. 0:05:27 h); er scheint zu spüren, daß dieser etwas Wichtiges zu sagen hat (s. o:05:30 h). »Mir deportieren die Ziegen, die Kih, die Gäns ins heilige Land, nach Eretz Israel. Und die Kinder [...] Ja, mir, die Kinder. Mir werden die Deportierten und die Deitschen sein. Schtetl, Ukrain, Rußland, Palästinä, unser daheim - und frei wie die Vegel.« (0:05:11 - 0:05:59)

Die Reaktionen auf Schlomos Aussagen sind erneut widersprüchlich, auch der Zuschauer schwankt in der Beurteilung derselben. Einerseits klingt die Idee völlig absurd und nicht realisierbar, was einer der Männer mit den Worten quittiert: »[...] der Mann is wirklich meschigge. Mir nehmen ihnen die ganze Arbeit ab, mir deportieren uns selbst. Ebbes Dimmeres gibt es gor nicht. Wenn sie uns schon deportieren, sollen sie sich weynigsten anstrengen« (0:06:01 - 0:06:09 h) - eine erneute Einladung zum Schmunzeln, nicht zuletzt aufgrund des lustig klingenden Jiddisch (s. 0:05:59 h). Andererseits muß tatsächlich eine Lösung für die akute Bedrohung gefunden werden. So bezeichnet jener Mann, der Schlomo zuvor noch abgewertet hatte, dessen Idee als »genial« (०:06:09 h). Dieser abrupte Gesinnungswechsel, vor allem jedoch die erneuten Wortgefechte unter den Männern, bergen Komik. Nachdem die Frau des Rabbi zum dritten Mal intervenierte, erreicht die Komik in dieser Auseinandersetzung ihren Höhepunkt durch die Äußerung von Schlomos hauptsächlichem Kritiker: »A Zug? [...] Warum nicht gleich a Schiff, wenn wir schon dabei sind. Nehmen wir doch das ganze Land mit.«(০:০6:33 - o:०6:40 h) Wieder ist es der Rabbi, der Schlomo beipflichtet ${ }^{716}$ und auch die anderen beeinflußt: Im Chor sprechen ihm erst die sechs Männer und dann eine unerwartet von der Kamera eingefangene Kinderschar nach: »A Zug!« (o:06:45 - o:06:46 h) - ein ebenso komischer wie irreal anmutender Moment, in dem sich die Bedrohung in Wohlgefallen aufzulösen scheint.

715. A: »'S ist so schlecht, weil ich nicht wollte daß meine Enkelin deinen schwachsinnigen Engekel heiratet. « - B: »Das ist a Sind (=Sünde), so was zu sagen! Behalt se doch deine hibsche kleine Esther, die schenste von allen und rohm (=rahm) se dir ein.« (0:04:57-0:05:06 h)

716. »Er hat recht. A Zug!« (0:06:42-0:06:45 h)

717. Die folgenden Abkürzungen bedeuten Männer (M.), Schlomo (S.) und Rabbi (R.). 


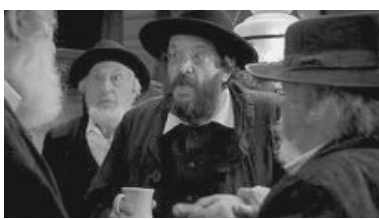

(643) $0: 05: 01 \mathrm{~h}$

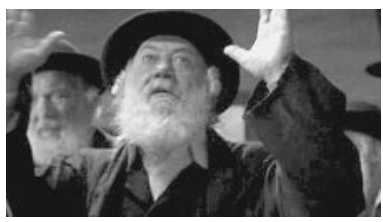

(646) $0: 05: 59 \mathrm{~h}$
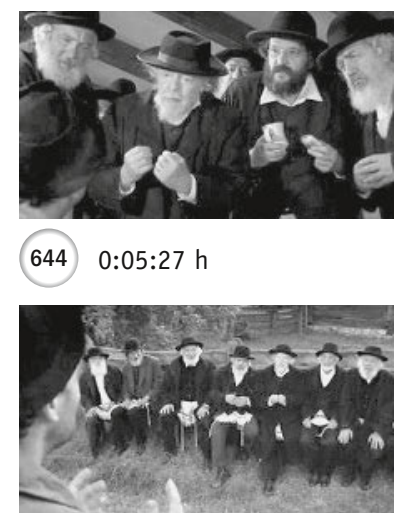

(647) $0: 06: 53 \mathrm{~h}$

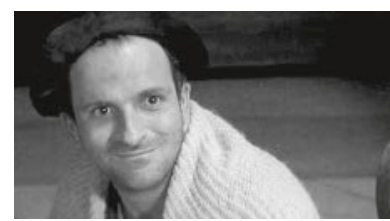

645

$0: 05: 30 h$

ac) Schlomo als Visionär - Konkretisierung des Fluchtplans

Detaillierte Sequenzanalyse:

In der folgenden Szene hat sich das Blatt endgültig gewendet: Wo vorher der Rat der Ältesten auf Schlomo eher herabsah (s.0. 0:05:27 und 0:05:30 h), wird er nun als der unangefochtene Wegweisende inszeniert (s. o:०6:53 h): Fast wie Schulkinder sitzen die Männer auf der Bank, schauen zu Schlomo auf und fragen ihn nach den Einzelheiten seines Fluchtplans. ${ }^{717}$ Hierbei fällt auf, daß dieser um keine Antwort verlegen ist:

M.: »Wie besorgt ma sich a Zug?«

S.: „Wir werden ihn uns käufen, beim Händler, Waggon für Waggon, und werden ihn aufs Gleis stellen«.

M.: »Und mit was fer a Geld?«

S.: $\quad$ »Mit dem von der Gemeinde und den Spenden. A jeder wird spenden.«

M.: »Wieviel?«

M.: »Was ist mit die Uniformen?«

S.: »Wer sind die besten Schneider auf der Welt? Die Jiüden. Wir nähen sie selbst.«

M.: »Und die Woffen und die falschen Papiere?«

S.: »Waffen - wofir Waffen? Falsche Papiere, ja, verrickte Papiere. Da muß ma nur was hinschreiben, was Falschs, Verricktes.«

R.: $\quad$ Mer missen aber Deitsch sprechen ohne den geringsten jidischen Akzent.«

S.: „Die Abfahrt vorbereiten und das Dorf räumen, ohne daß jemand was davon merkt, fort. Genauso machen wir's. Wir fliegen davon, Himmel und Erd werden eins und die Vegel kommen zürick.«(o:06:21 - 0:07:28 h)

Aufgrund der spezifischen Inszenierung wirkt Schlomo bei seinen letzten Sätzen fast wie ein »Prophet « (s. 0:07:18 und 0:07:26 h): Eingeleitet werden seine abschließenden Worte mit einem Hahnenschrei, der von getragener Filmmusik abgelöst wird. Wie bei seinem »Bericht« vom Ungeheuerlichen umfährt die Kamera Schlomo ganz dezent, um in einer bestimmten Position zu verharren (s. 0:07:26 h): Vor aufgehender Sonne, 
mit in die Ferne gerichteten glänzenden Augen, in der Kleidung eines Habenichts prophezeit Schlomo mit beschwörender Gestik: »Wir fliegen davon, Himmel und Erd werden eins und die Vegel kommen zürick.«(0:07:24 - 0:07:27 h) $)^{718}$ Die bedrohliche Ausgangssituation ist in den Hintergrund getreten; wir sind ganz bei Schlomo und seiner hoffnungsvollen Vision, die wir dankbar annehmen. Eine Verlagerung ins Komische erfährt diese ernste und wahrhaftig wirkende Szene wiederum durch die Frau des Rabbi. Die Männer durch das Fenster beobachtend (s. 0:07:29 h), hadert sie mit Gott: »Lieber Gott, warum host du die Männer dazu bestimmt, die Welt zu regieren. Und a Verrickten, ihnen den Weg zu weisen?« (0:07:28 - 0:07:32 h) Nachdem der Zuschauer Schlomo für seine Vorschläge in gewisser Weise bewundert hatte, ist er durch den wiederholten Hinweis auf das Verrücktsein erneut verunsichert: Wie ist Schlomo zu beurteilen - schließlich war er zu einer genialen Idee fähig?! Wird sie sich tatsächlich realisieren lassen?

b) Die »verschwundene Welt« der Schtetl mit einem Augenzwinkern betrachtet Mitreißende Vitalität eines Schtetls in Abreisevorbereitungen

Nach der Exposition tritt der ernste Kontext (vorrückende Nazis) zwischenzeitlich in den Hintergrund. Bis zur Flucht mit Schlomos »Zug des Lebens« dominieren die konkreten Abreisevorbereitungen, die der Regisseur mit einem Augenzwinkern betrachtet und inszeniert. So läßt er den Zuschauer ganz bewußt über jüdische Stereotypen und Sitten und Gebräuche schmunzeln (s. 4.2.3.ba). Freudiges Mit-Lachen erzeugt er in einer mitreißenden Sequenz im Stile eines Musikclips mit Klezmer-Klängen (s. 4.2.3.bb).

ba) Wohlwollendes Schmunzeln über und angesichts jüdischer Sitten und Gebräuche Während der Vorbereitungen der Flucht laden verschiedene jüdische Stereotypen zum Schmunzeln, teilweise gar zum Lachen ein, wobei es sich vor allem um eine Mischung von wohlwollendem Verlachen und anerkennendem Lachen, bisweilen hervorgerufen durch karnevaleske Verkehrungen, handelt.

Daß der Zuschauer in einem Film, der Juden vor dem Hintergrund des Holocaust zeigt, auch über »typisch« jüdische Eigenschaften und kulturelle Normen schmun-

718. "Schlomo [...] malt die Zukunft, die eben noch völlig hoffnungslos schien, mit großen Worten und Gesten aus. Hinter ihm, über dem Dach eines Hauses, leuchtet die rötliche Sonne, von der wir nicht wissen, ob sie gerade auf- oder untergeht. Sie sendet ihre wärmenden Strahlen über die Szenerie - ein echter Hoffnungsschimmer oder nur der falsche Schein?« (Beier 2000: $60)$

719. In bezug auf die Hauptfigur (Schlomo) siehe 4.2.1 und 4.2.3.a bzw. 4.2.3.ab hinsichtlich der Komplementarität zwischen ihr und dem Rabbi.

720. Vgl. Bleicher 2002: 190 und Distelmeyer 2000: 53.

721. Mordechai: »Mit dir diskutieren, des is ...« (0:13:54-0:13:56)

722. »Mihaileanu greift für die Protagonisten seines Films nicht nur auf Rollenstereotypen des jüdischen Witzes, sondern auch auf die Namenssymbolik der jüdischen Religion zurück.« (Bleicher 2002: 190)

723. Yossi: »Esther, heirate mich, heirate mich bitte, noch bevor wir fahren, ich fleh' dich an.« - Esther: »Yossi, nein. Du bist alt, du bist häßlich, du bist schwach, a Muttersehnchen und der Knecht vom Rabbin [...].« 


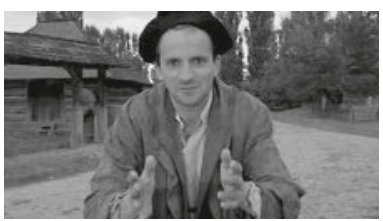

(648) $0: 07: 18 \mathrm{~h}$

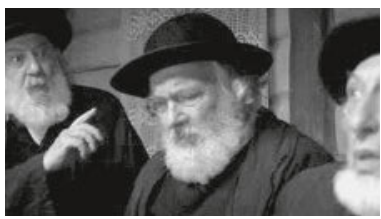

(651) $0: 06: 28 \mathrm{~h}$
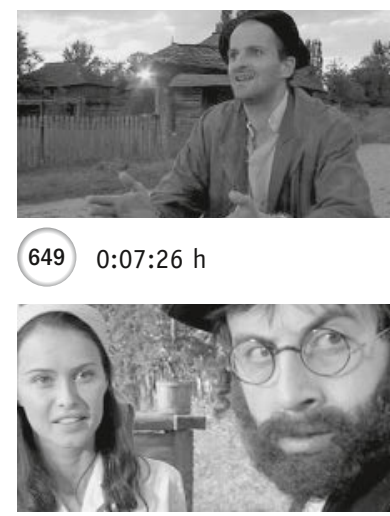

$6520: 14: 49 \mathrm{~h}$

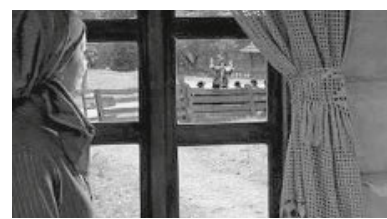

650

$0: 07: 29 \mathrm{~h}$

zeln/lächeln und teilweise sogar lachen darf, ist gänzlich neu. In der Vergangenheit wurde von ihm uneingeschränkte Betroffenheit erwartet, wurden die Juden ohne menschliche Schwäche - nahezu unantastbar - dargestellt.

Darüber hinaus dienen diese Szenen der Vorstellung bzw. charakterlichen Vertiefung weiterer zentraler Figuren des Schtels - Figuren aus einer »einfachen, beinah verklärten Welt, [...] Typen einer verlorenen Folklore« (Kniebe 2000:19). ${ }^{719}$

Die Wortgefechte der Männer sind in gewisser Weise amüsant, obwohl sie angesichts der ernsten Situation unangemessen wirken und reichlich schroff, bis hin zu gegenseitigen Beleidigungen, geführt werden (s. insb. 4.2.3.a und o:o6:28 h). Hier macht sich Mihaileanu ein wenig lustig über die den Talmudisten auszeichnende Kunst der Auslegung von Worten. Gleichzeitig spüren wir, daß in diesen Diskussionen kreatives Potential freigesetzt wird; das jeweilige Ergebnis ist die Frucht intensiven Abwägens und damit qualitativ hochwertig.

a) Die strikte Rollenverteilung zwischen Mann und Frau wird vor allem im ersten Teil des Films entfaltet. ${ }^{20}$ In der Exposition, aber auch während der konkreten Vorbereitungen der Flucht wird die in der jüdischen Kultur traditionelle Arbeitsteilung vom Regisseur mit einem warmherzigen und gleichzeitig schelmenhaften Blick bedacht. Letztlich sind es jedoch die Frauen, die »die Hosen anhaben«. Darüber kann sich der Zuschauer amüsieren, denn auf diese Weise untergraben die Frauen die Autorität der sich allzu wichtig nehmenden Männer. Nicht der Rabbi, sondern seine Frau mahnt die Weisen zur Ruhe (s. 4.2.3.ab) und greift ein und durch, um Schlomo während des Sabbatfestes das Gebet sprechen zu lassen und um ihm dafür zu danken (s. 4.2.4.ab); andere Frauen setzen sich bei der Festlegung des Reiseproviants durch ${ }^{721}$; die »stolze Dorfschönheit« (Distelmeyer 2000: 53), Esther ${ }^{722}$, läßt den »häßlichen intellektuellen Vogel« (Werneburg 2000: 14), Yossi, »abblitzen« (s. o:14:49 h) ${ }^{723}$ und schafft es, ideologisch »Besessene« wie Sami - zumindest zeitweise - für irdische Genüsse $\mathrm{zu}$ begeistern und diesen die so schmerzlich vermißte Geborgenheit zu schenken (s. 4.2.4.bf).

b) Mit der Inszenierung des Haderns mit Gott greift Mihaileanu eine weitere Eigenschaft auf, die jüdischen Männern nachgesagt wird (s. 0:05:59 h und o:07:44 h). Wie 
im Rahmen der Exposition bereits analysiert (s. 4.2.3.a), wirkt dieses Klagen auf den Zuschauer stark übertrieben und automatisiert. Dieser Mechanismus, Gott grundsätzlich für alle Schwierigkeiten verantwortlich zu machen, lädt zum »Verlächeln« ein. In glücklichen Situationen wird Gott ebenso unverzüglich und pathetisch gedankt. »A Wunder!«, ruft der Rabbi, als ein entgegenkommender Zug dank einer Weiche nicht mit dem ihren zusammenstößt (s. o:41:11 h).

c) Mit der Figur des Buchhalters inszeniert Mihaileanu das Klischee, Juden seien geizig. So bekommt Yankele wiederholt Magengeschwüre, als man ihn um Geld für den Zugkauf bittet (s. o:26:49 h). Schon sein Arbeitsplatz läßt uns, durch die übertriebene Inszenierung, schmunzeln (s. o:17:26 h): Inmitten seiner, jeden Quadratzentimeter des Büros bedeckenden, gestapelten Unterlagen wirkt der Buchhalter noch kleiner als er an sich schon ist - selbst das Fenster verschwindet teilweise hinter den Papieren. Gleichzeitig spürt man, daß er durch seinen Beruf eine nicht zu unterschätzende Macht innerhalb der Gemeinde hat. Er ist derjenige, der über die Finanzen des Schtetls entscheidet und der das Geld nach einigen harten Verhandlungen zur Verfügung stellt; das Stereotyp wird von Mihaileanu durchaus relativiert. Wenig später stellt sich heraus, er wäre besser »geizig « geblieben. Als er die Lok zu sehen bekommt (s. 0:27:56 h), fällt Yankele verständlicherweise in Ohnmacht (s. o:28:03 h) - schließlich gleicht das teuere Objekt eher einem Schrotthaufen als dem wichtigsten Element eines Zugs.

d) Das - vor allem anfängliche - Unvermögen Mordechais ${ }^{724}$, gewählter »Nazikommandant« des falschen Deportationszuges«, Deutsch ohne jiddischen Akzent zu sprechen, veranlaßt den Zuschauer zu schmunzeln oder zu lachen. Besonders in der Sequenz, in welcher der Holzhändler Einzelunterricht genießt, ballen sich verschiedene Komik erzeugende Verfahren (s. 0:17:02 h und o:17:13 h).

Zunächst gelingt es Mordechai nicht, den jiddischen Akzent beim Nachsprechen vorgegebener Sätze abzulegen.

Trotz dieser Schwierigkeiten, die ihn zwischenzeitlich resignieren lassen, stellt er eine kuriose »Verwandt«schaft zwischen dem Jiddischen und dem Deutschen fest ${ }^{725}-$ Ismael Schmecht, Schneider und Deutschlehrer in einer Person, präzisiert:

S.: »Das Deutsche ist sehr hart, Mordechai, präzise und traurig. Jiddisch ist eine Parodie des Deutschen, hat jedoch obendrein Humor. Ich verlange also nur von Ihnen, wenn Sie perfekt deutsch sprechen wollen, ohne eine Spur von jiddischem Akzent, den Humor wegzulassen... sonst nichts.«

724. Vgl. Kortmann zur Bedeutung dieses Namens als Retter des Volkes aus dem Buch Esther und als Held des Purim-Spiels, des jüdischen Karnevals (2003: 300).

725. »Es [das Deutsche] ist dem Jiddischen sehr ähnlich. Ich verstey alles.« (0:16:58 h) Historisch gesehen ist dies völlig korrekt, da das Jiddische im 12. Jahrhundert auf der Basis des Mittelhochdeutschen entstand (vgl. Ortag 1997: 33).

726. »Mordechai glaubt nun die eigentliche Ursache für die Judenverfolgung zu wissen. Schließlich machen sich die Juden ständig über die deutsche Sprache lustig.« (Bleicher 2002: 191) 


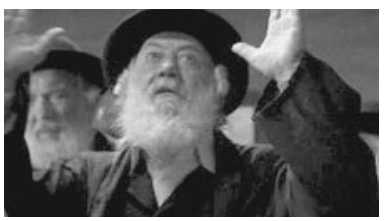

(653) $0: 05: 59 h$
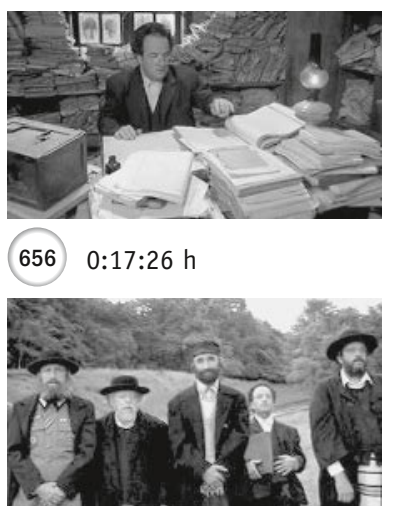

(659) $0: 28: 03 \mathrm{~h}$

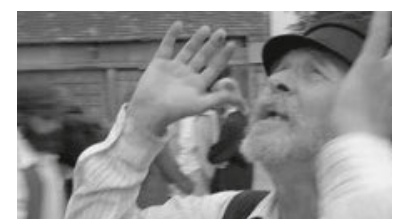

(654) $0: 07: 44 \mathrm{~h}$

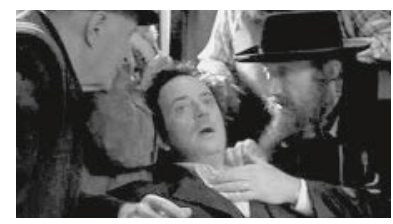

(657) $0: 26: 49 \mathrm{~h}$

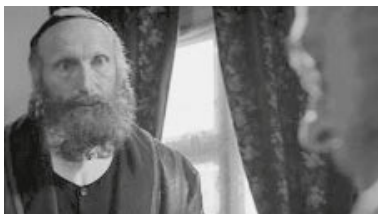

(660) $0: 17: 02 \mathrm{~h}$

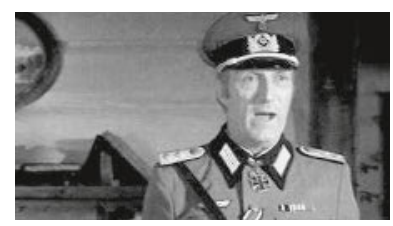

(662) $0: 30: 04 \mathrm{~h}$

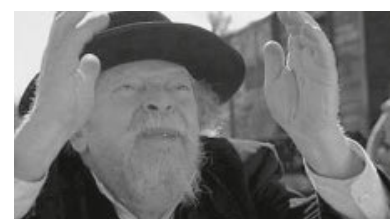

(655) $0: 41: 11 \mathrm{~h}$

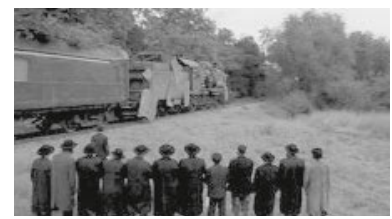

(658) $0: 27: 56 \mathrm{~h}$

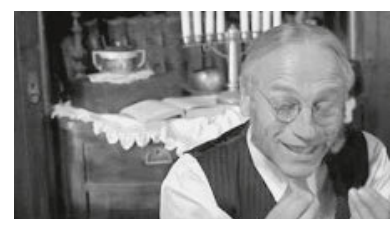

(661) $0: 17: 13 \mathrm{~h}$

M.: »Wissen die Deitschen, daß wir ihre Sproch parodieren? Vielleicht ist doas der Grund für 'n Krieg.«(o:17:03 - 0:17:25 h) ${ }^{726}$

Hier liegt hier nicht nur eine - die damaligen Gegebenheiten verkehrende - Abwertung des Deutschen gegenüber dem Jiddischen vor: »Jiddisch ist eine Parodie des Deutschen.« Der deutschen Sprache wird jeglicher Humor abgesprochen, während das Jiddische sich gerade dadurch auszeichnet. Auf diese explizite Weise charakterisiert Mihaileanu die Grundhaltung des Films und des jüdischen Volkes gegenüber ihrem Schicksal.

Einige Sequenzen später, als die Abreise vorverlegt werden soll, brüllt Mordechai in überzeugend Nazi-deutscher Manier und ohne jeglichen jiddischen Akzent: »Ich bin bereit!« (s. 0:30:04 h) Der ehemalige Holzhändler, inzwischen in Uniform und glatt rasiert, steigert sich derartig in seine Rolle hinein, daß er zum »Hyper«-Nazi »mutiert« und auf diese Wiese von echten Deutschen bewundert, ja sogar kopiert wird (s. 4.2.4.aa).

e) Die Figur des Yossi läßt den Zuschauer über die unreflektierte Übernahme und Verbreitung ideologischer Parolen lachen. Jenseits allgemeiner Kritik an ideologischer »Besessenheit«, liefert Mihaileanu eine komödiantische Antwort auf die Frage, warum 
viele Juden Kommunisten waren: Auslösendes Moment für Yossis Anfälligkeit für den »Kommunismus « ist die Tatsache, daß die schöne Esther seinen Heiratsantrag zurückweist und ihn zudem noch beleidigt, die Partei wird für ihn zur Ersatzbefriedigung (s.o., b). Umringt von einigen männlichen Dorfbewohnern und begleitet von verschwörerisch klingender Filmmusik, plappert Yossi die Schlagworte, die er von seinem Vetter behalten hat, nach: »Proletarier aller Länder, vereinigt euch ... vereinigt euch!« (0:22:21 h) Dabei erhascht sein Blick die den Dorfplatz überquerende Angebetete (s. 0:22:32 h). Schwärmerisch stöhnt er »vereinigt euch « und fügt hinzu: »Ist das ein schöner Hintern!« (0:22:31 h) - das einsetzende vitale Klezmer-Motiv aus dem Off kommentiert die Szene und verleiht ihr eine erheiternde Tönung.727 Besonders auffällig ist, daß auch Yossis bisher typisch jüdisches Äußeres von einer auf die andere Szene (vgl. 0:21:53 h mit 0:23:04 h) einem kommunistischen weichen mußte: Der Bart, inklusive der Schläfenlocken, ist verschwunden, die schwarze Kleidung gegen eine modernere getauscht und die Kippa durch eine kommunistische Mütze ersetzt. Weiterhin begleitet vom angesprochenen Klezmer-Motiv, fährt Yossi mit seinen »Bekehrungsversuchen« fort:

Y.: $\quad$ »Der Messias ist do, ich bin sicher. [...] Er erschafft den neuen Menschen!«

M. 1: „Was macht er dann mit dem alten?«

M. 2: »Gibt's an Altergrenz', um neu zu werden?«

M. 3: »Mir sind doch keine Proletarier, Yossi, mir sin' Jiden. [...]«

Y.: »Mir sind incognito, im Untergrund. Revolutionäre. Mir sind Utopisten, Abenteurer ...« $(0: 22: 34-0: 23: 18 \mathrm{~h})$

Abgesichert wird die Kritik an blinder ideologischer Gefolgschaft durch das Eingreifen des Rabbis. Erbost über Yossis »Missionierungseifer« und intensive »Rekrutierungsbestrebungen«, nennt er ihn vor allen einen Taugenichts und schickt ihn unverzüglich nach Hause. Auch Yossis äußerliche Wandlung prangert der Rabbi explizit an - eine weitere Absicherung des von uns Bemerkten.

bb) Lachen der Mit-Freude - »Abreise«vorbereitungen zu Klezmer-Musik

Zum Mit-Freuen und ausgelassenem Lachen lädt die Sequenz ein, in welcher das ganze Dorf mit musikalischer Begleitung und voller Tatendrang mit den konkreten Vorbereitungen zur Abreise beginnt (Sequenz 6). ${ }^{728}$ Die Lebensfreude und Vitalität des Schtetls überträgt sich vor allem durch die mitreißende Klezmer-Musik, die, ähnlich einem Musikclip, die Szenenfolge beherrscht. Man kann diese Sequenz als eine Hommage des Regisseurs an die »verschwundene Welt« der jüdischen, osteuropäischen Schtetl und somit auch an Norman Jewisons Fiddle on THE Roof (USA 1971) bezeichnen, ein Musical, das wie kein zweiter Film das Bild von jüdischer Kultur im Kino prägte:

727. „Yossi versteht den revolutionären Schlachtruf [...] im sexuellen Sinne und blickt dabei auf Esther, das Objekt seiner Begierde. Sein eigentliches revolutionäres Ziel sind die weichen Betten im Zugwaggon der deutschen >bourgeoisen Faschisten«." (Bleicher 2002: 191) Vgl. auch Kortmann: "So fordert der Aufruf [...] des Nachwuchskommunisten [...] nicht zur politischen Solidarität auf, sondern zu sexuellen Orgien.« (2003: 310)

728. Siehe die vergleichbare Sequenz des Hauptteils, in welcher sich Juden und Zigeuner verbrüdern (4.2.4.bf). 


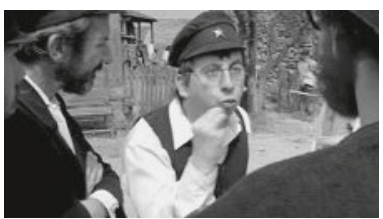

(663) $0: 23: 04 \mathrm{~h}$

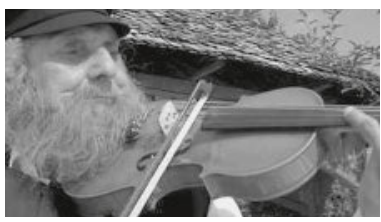

(666) $0: 11: 36 \mathrm{~h}$

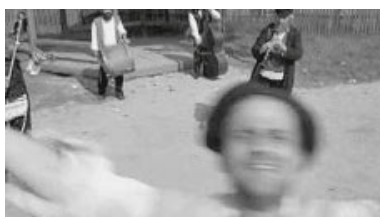

(669) $0: 11: 57 \mathrm{~h}$

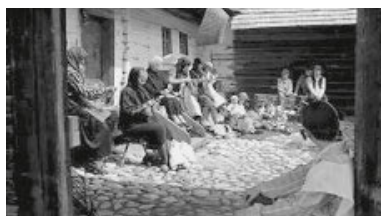

(672) $0: 12: 18 \mathrm{~h}$
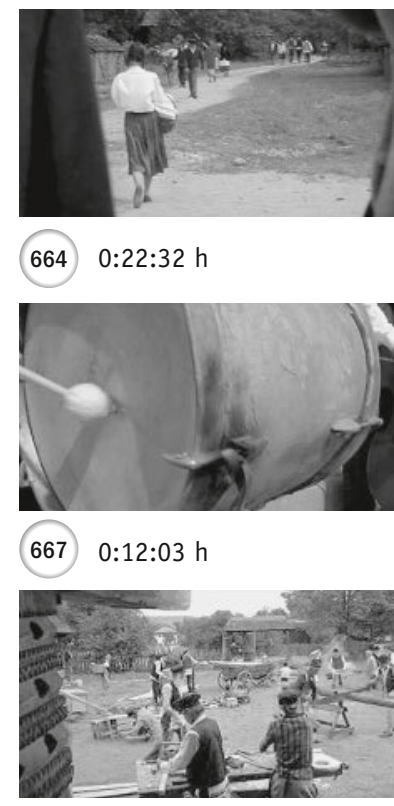

(670) $0: 12: 00 \mathrm{~h}$

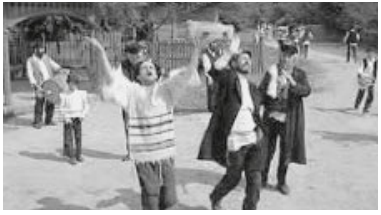

(673) $0: 12: 32 \mathrm{~h}$

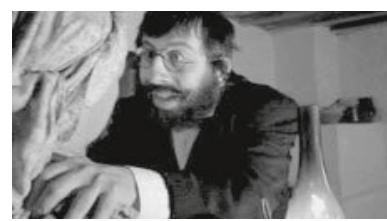

(665) $0: 21: 53 \mathrm{~h}$

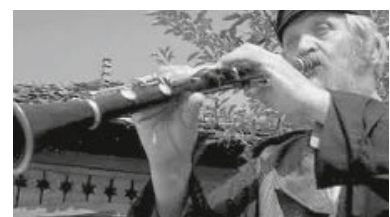

(668) $0: 11: 39 \mathrm{~h}$

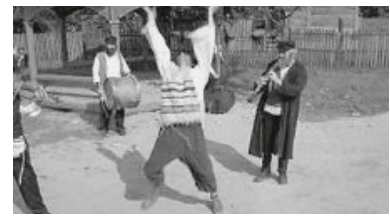

(671) $0: 12: 07 \mathrm{~h}$

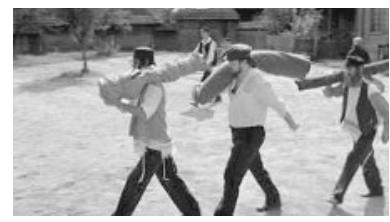

(674) $0: 12: 12 \mathrm{~h}$

»Eine Sequenz, in der die Einwohner zu musikalischer Begleitung alle handwerklichen Fähigkeiten aufbieten, ist eine Reminiszenz an die legendäre >Tradition<-Nummer in FIDDLER ON THE ROOF, in der im Rhythmus der Musik Fleisch geklopft, Teig gerollt und Eisen geschmiedet wird. Gleitet die Kamera bei Jewison von einem Soldaten auf seinem Pferd hinab zu den Menschen auf der Straße und bahnt sich dann einen Weg zu zwei Schachspielern, die alle Zeit der Welt zu haben scheinen, so setzt auch Mihaileanu das Geschehen in langen Einstellungen in Szene [...].« (Beier 2000: 60, H.i.0.)

Detaillierte Sequenzanalyse:

Unsere Annahme, die Gemeinde würde voller Schwermut und Düsterkeit ans Werk gehen, widerlegt Mihaileanu wirkmächtig: In ausgelassener Aufbruchsstimmung macht das gesamte Dorf mobil, begleitet von - vor Lebensfreude strotzender - Musik der Gemeindekapelle (s. ০:11:36, o:11:39 u. o:12:03 h). Durch taktgenaue Montage unterstreicht Mihaileanu den ansteckenden Rhythmus. Der ausgelassen tanzende Schlomo (s. o:11:57, 0:12:07 u. 0:12:23 h) lädt zum Mitmachen ein, eine Szene, deren atemberaubende Wirkung sich der Zuschauer kaum entziehen kann. Schnell und abwechselnd wird zwischen den Musikern, dem außer Rand und Band geratenen Protagonisten und den Vorbereitungen (s. 0:12:०० u. 0:12:18 h) hin und her geschnitten. Ganz nebenbei zeichnet der Regisseur auf diese Weise ein liebevolles Porträt der »verschwundenen Welt« der Schtetl. Nicht 
nur der Schnitt und Schlomos Tanz, selbst die Arbeiten erfolgen im Takt, was diesen Einstellungen zusätzlich eine amüsante Note verleiht. Die Teppichträger marschieren gemäß dem Rhythmus (s. o:12:12 h), und auch der Mann an der Nähmaschine betätigt diese entsprechend (s. 0:12:22 h). Durch diese äußerst aufwendig inszenierte Sequenz erreicht Mihaileanu, daß wir - aufgrund dieser Prägung - das im Verlauf des Films wiederkehrende Klezmer-Motiv automatisch mit praller Vitalität verbinden. Neben dem besonderen Aufwand innerhalb der Szene ist sie auch aus musik-kompositorischen Gründen wirkmächtig. Auf der Tonspur ging zunächst dramatisch-getragene Filmmusik voraus; in der vorhergehenden Sequenz wurde ausschließlich gesprochen. Der lebensbejahende »Musikclip« steht demnach in krassem Kontrast zum überwiegend ernsten Filmanfang und konfrontiert uns zum ersten Mal mit der ausgelassenen, lebensfrohen jüdischen Musik.

\subsubsection{Hauptteil des Films: »Zug um Zug« nach Palästina}

Während der Flucht im Zug erteilt der Film - im Sinne der Menschlichkeit - vor allem Verweise an die »Linke« und »Rechte«, dennoch gibt es Momente, in denen »unsere Seele gestreichelt« wird und unser Herz vor Freude mithüpfen kann.

\section{a) Verkehrte Welt durch Rollentausch}

Im Hauptteil des Films treibt Mihaileanu die karnevaleske Verkehrung der Verhältnisse (s. 4.2.2.a a) auf die Spitze und bringt somit die Ansichten und Vorstellungen des Zuschauers ins Wanken (s. 4.2.4.aa und 4.2.4.ab).

aa) Mordechai als »Nazi«kommandant-erste Konfrontation mit den Deutschen Nachdem die Zuschauer bei vitalen Klezmer-Motiven schon ausgiebig, aber »oberflächlich« (Plessner 1941: 331f.) lachen konnten, da die Schtetl-Juden wiederholt Sabotageakte der Kommunisten vereitelten und lächerlich machten (s. 0:41:34, 0:46:26 h und Sequenz 36 ), stellt die erste Konfrontation mit den echten Nazis einen der Höhepunkte des Hauptteils dar. Mordechai, der falsche Nazikommandant, düpiert ${ }^{29}$ den echten, eine Szenenfolge, die zum intensivsten Lachen des ganzen Films einlädt.730

\section{Detaillierte Sequenzanalyse:}

Eingeleitet wird die erste Konfrontation mit echten Nazis auf der Tonspur. Während wir uns noch darüber freuen, daß den Juden nichts passiert ist, und über die permanente Unfähigkeit der Partisanen lachen, schlägt die fröhlich-beschwingte Musik in eine getragene, Gefahr indizierende um. Zu dumpf nachhallenden Tönen vermischt sich das Rattern des Zuges mit hechelndem, lautem Atmen - es kann jedoch keiner bestimmten Person zugeordnet werden (s. 0:47:38 h). ${ }^{731}$ Dem Zuschauer wird un-

729. Vgl. Landmann zu den Charakteristika des jüdischen Witzes und Bleichers Anmerkungen im Zusammenhang mit dieser Sequenz: »>Beliebt waren auch Possen, in denen ein kluger Jude einen Andersgläubigen hereinlegtı [...]. Diesem thematischen Grundmuster folgt die Protagonisten/Antagonistenstruktur des Films: jüdische 0pfer/Nazis als Täter. Gesteigert wird die Wirkung der Konfrontation dadurch, daß ein intelligenter jüdischer Dorftrottel die Nazis hereinlegt.« (zit.n. Bleicher 2002: 189)

730. Vgl. James in »The Advertiser«, 06.10.2001: M24.

731. Unwillkürlich erinnern wir uns an Schlomos Hecheln zu Beginn des Films. 


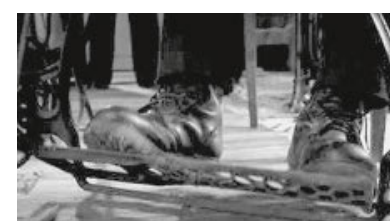

(675) $0: 12: 22 \mathrm{~h}$

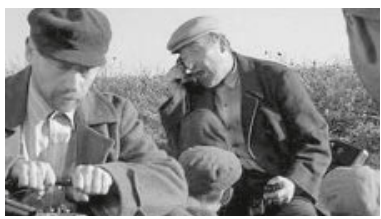

(676) $0: 41: 34 \mathrm{~h}$

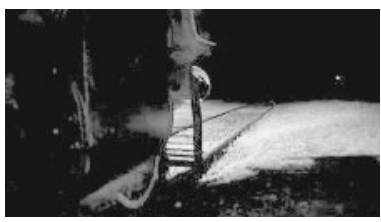

(679) $0: 48: 06 \mathrm{~h}$

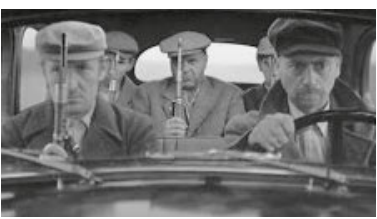

(677) $0: 46: 26 \mathrm{~h}$

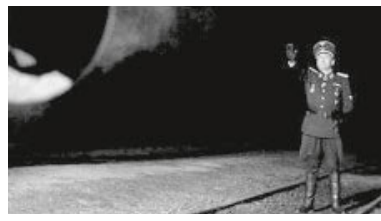

(680) $0: 48: 17 \mathrm{~h}$

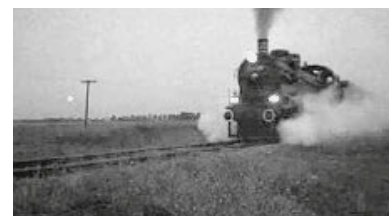

(678) $0: 47: 38 \mathrm{~h}$

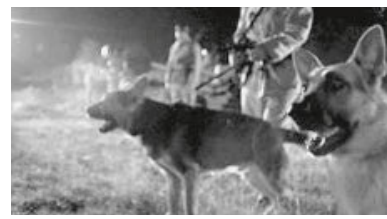

(681) $0: 48: 28 \mathrm{~h}$

heimlich zumute, zumal die Nacht hereinbricht und die Leichtigkeit der vorangegangenen Minuten plötzlich verflogen ist. Als Mihaileanu uns in gleicher Geschwindigkeit mit dem verlangsamenden Zug mitfahren läßt und dabei acht - uns sehr lang erscheinende - Sekunden vergehen, nimmt unsere Furcht zu (s. 0:48:06 h) schließlich ist die Filmmusik in spitze, unangenehme Töne übergegangen, wodurch das heftige, keuchende Atmen verstärkt wird. Die Einblendung des angsterfüllten Lokführers bestätigt unsere Vermutung. Die nächste Einstellung zeigt den Auslöser der Furcht:

Ein Nazikommandant steht breitbeinig auf den Gleisen, um den Zug anzuhalten (s. o:48:17 h). Mit einem die Stille zerreißenden Lärm hellen grelle Scheinwerfer die pechschwarze Nacht plötzlich auf, während Schäferhunde laut anschlagen (s. $0: 48: 28$ h). Wie die Zuginsassen schrecken auch wir auf. Erst jetzt gewährt uns Mihaileanu einen Überblick über die Situation. Der Zug ist von den Deutschen umstellt, die Maschinengewehre werden deutlich hörbar geladen. »Mein Gott, jetzt bin ich dran« (०:48:40 - o:48:43 h), murmelt Mordechai, als er einen Moment in der Waggontür verweilt - auch wir befürchten für unser Schtetl inzwischen das Schlimmste. Ebenso angespannt verfolgen wir, wie Mordechai auf den echten Offizier zugeht. Als er dessen Hitlergruß erwidert, reißt der Ärmel seiner maßgeschneiderten Jacke in der Achsel auf - so übertrieben stürmisch hatte er beim Salutieren den Arm ausgestreckt (s. o:48:54 h). Über diese Slapstick-Nummer müssen wir ungewollt lächeln bzw. lachen, was uns, angesichts der todernsten Situation, gleichzeitig unangenehm berührt. Der nächste Anlaß zum Schmunzeln läßt jedoch kaum auf sich warten. Während der Deutsche Mordechais Papiere prüft, bemerkt und behebt dieser an sich eine gefährliche Unzulänglichkeit: Die Fransen eines für jüdische Männer charakteristischen Kleidungsstücks waren nämlich verräterisch unterhalb seines Jackensaums 
sichtbar (s. o:48:58 h). Durch subjektive Kameraführung wird unsere Aufmerksamkeit auf die Mütze des Nazis gelenkt, auf der ein Totenkopf prangt (s. 0:49:02 h). Als retardierendes Moment zeigt Mihaileanu dem Zuschauer die Situation im Zuginneren. Der Rabbi spricht zu Gott und fleht ihn zunächst an, wenigsten die Jungen zu retten. Daß er während seines Gebetes Argumente findet, Gott davon zu überzeugen, auch den Eltern und Alten zu helfen, beinhaltet eine gewisse Komik - sein Flehen ist vergleichbar mit einem Feilschen. Die nächste Einstellung zeigt wieder Mordechai, der mit der barsch vorgetragenen Frage konfrontiert wird, weshalb der Zug nicht im Fahrplan stehe:732

M.: »Dies ist ein hochgeheimer Auftrag, der nicht im Fahrplan steht. Wir transportieren außerordentliche Juden.«

N.: »Ein Jude ist ein Jude. Was haben diese da so Außerordentliches?«

M.: »Es sind kommunistische Juden - [die Schäferhunde schlagen prompt an] sehr gefährlich; zweimal so gefährlich, da sie zur gleichen Zeit Juden und Kommunisten sind, in einem einzigen Zug transportiert. Sehr vorteilhaft für das Reich, da man nicht die Juden in einem Zug und die Kommunisten in einem anderen transportieren muß. Da diese ja beides sind, Juden und Kommunisten, sie können nicht getrennt werden. So sparen wir einen Zug, Sie verstehen, was ich meine? Stellen Sie sich vor, wie viele Leute, Juden und Kommunisten, sich wünschen, daß wir nicht zum Ziel kommen. Also ohne Fahrplan - Gespensterzug ... sehr, sehr geheim.«

N.: »Verstehe!« (0:49:46 - 0:50:45 h)

In dem Maße, wie Mordechai zu argumentieren beginnt (s. 0:50:19 h), gewinnt er, nach anfänglicher Unsicherheit, rasch an Souveränität. Wie alle jüdischen Männer fühlt er sich auf diesem Gebiet sicher, er macht sein Gegenüber fast mundtot (s. 0:50:22 h). ${ }^{733}$ In diesem Moment demonstriert Mihaileanu mit einem Augenzwinkern die Überlegenheit der jüdischen über die arische Rasse auf dem Gebiet der Rhetorik und Argumentation - eine wohltuende Verkehrung der Verhältnisse. Daß dem SS-Mann nicht auffällt, daß Mordechais Argumentation an sich reichlich hanebüchen ist, degradiert den Nazi in unseren Augen zur nicht denkenden, Befehle blind ausführenden Marionette; es kann als heilsam empfunden werden, ihn verlachen zu dürfen.

N.: »Ich hätte noch etwas. Vielleicht können Sie uns helfen. Alle Juden aus dem Nachbardorf sind verschwunden. Haben Sie sie nicht zufällig gesehen?« [subjektive Kamera mit Mordechai, der die Juden sieht, wie sie von Deutschen auf Lastwagen getrieben werden]

M.: »Das Nachbardorf? [erneute subjektive Kamera auf die Juden des Nachbardorfes] Verschwunden, sagen Sie? [...] Machen Sie sich keine Sorgen. Wahr-

732. Im folgenden wird Mordechai mit M., der Nazi mit N. abgekürzt.

733. Wie wir später explizit erfahren werden (s. die Rettung des Schneiders in Sequenz 58), ist Mordechai ein großer Talmudist, d.h. er beherrscht die Kunst des Auslegens.

734. Vgl. Sequenz 34: Rast - Heiratsgedanken (Esther); die »Kommunisten« proben den »Aufstand«; Strategiebesprechung. 


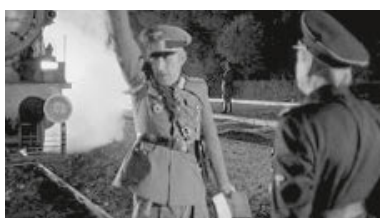

(682) $0: 48: 54 \mathrm{~h}$

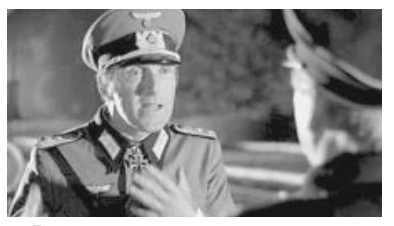

$685) 0: 50: 19 \mathrm{~h}$

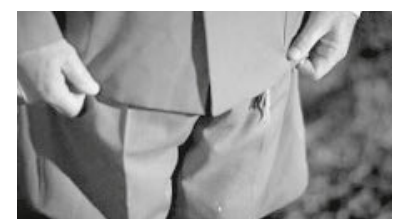

(683) $0: 48: 58 \mathrm{~h}$
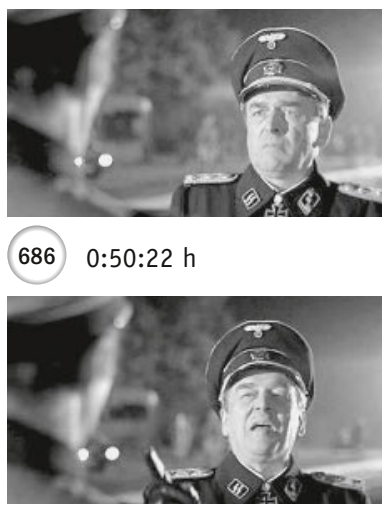

(688) $0: 51: 49 \mathrm{~h}$

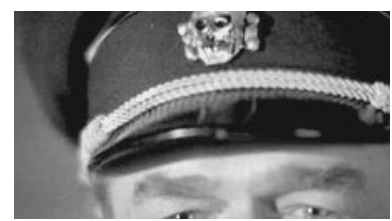

$6840: 49: 02 \mathrm{~h}$

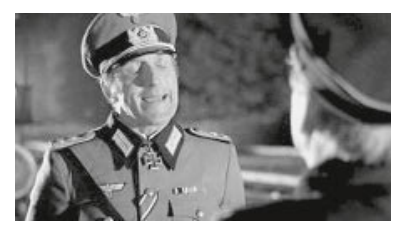

(687) $0: 51: 21 \mathrm{~h}$

scheinlich sind sie auf Besuch in der Nähe. Sie halten sehr zu ihren Familien, wissen Sie, sie wandern nie alleine, sie zurückkommen.«

N.: »Meinen Sie?«

M.: »Jawohl, sicher. Ich weiß irgendwas über sie. Sie kehren zurück zum Ort, wo sie hinausgezogen sind. Die kehren zurück. Es ist zweifellos die Sehnsucht nach dem Stammort.«

N.: »Sie sind intelligent, Herr Major. Sie haben die Psychologie des Feindes studiert.«

M.: »Dem können Sie sicher sein, Tag und Nacht!« (०:50:49 - 0:51:57 h)

Bei der Beantwortung der zweiten Frage des Deutschen kommt Mordechai so richtig in Schwung und scheint sich in der durchaus gefährlichen Situation beinahe wohl zu fühlen. Im Grunde spielt er mit dem Feuer, als er in überlegener Manier (s. 0:51:21 h) jüdische Verhaltensweisen erklärt. Der Nazi zollt ihm hierfür ausnahmslos Anerkennung und Lob; Mimik und Gestik zeugen von Bewunderung und Respekt (s. o:51: 49 h). Aufgrund Mordechais an Übermut grenzender Selbstsicherheit und der geistigen Beschränktheit des SS-Mannes kann der Zuschauer den zweiten Teil des Gesprächs schon beinahe genießen. Die erste Bewährungsprobe hatte Mordechai schließlich überzeugend bestanden, so daß wir ihm auch in der Folge einiges zutrauen konnten. Die Mischung aus anerkennendem Lachen über Mordechais Ausspielen jüdischer Qualitäten und strafendem Verlachen des SS-Marionette kann der Zuschauer als wohltuend empfinden.

Während Mordechais überzeugende Identifikation mit seiner Rolle als »Nazikommandant« von uns bisher mitunter ironisch belächelt wurde ${ }^{734}$, macht die Szene deutlich, daß diese perfekte Verkörperung durchaus ihre guten Seiten hat, sie verhindert, daß die Täuschung entlarvt und die Gemeinde getötet wird. 
Während wir noch den echten Deutschen auslachen, gibt dieser in der nächsten Szene brüllend den Befehl, das Schtetl niederzubrennen. Nach kürzester Zeit steht alles in Flammen: das Hochzeitsfoto von Mordechai (s. o:52:54 h) ebenso wie die Synagoge (s. 0:52:57 h).735 Abrupt wird des Zuschauers Lachen beendet, die Furcht vor der NaziHerrschaft gewinnt vorübergehend die Oberhand.

Eine Überblendung zeigt Schlomo, der nach dem Zusammentreffen mit den Deutschen allein auf dem Dach des Zuges sitzt (s. 0:53:06 h). Als wüßte er, was dem Schtetl widerfahren ist, starrt er verstört in die nächtliche Ferne. Dieser Augenblick und die Tonspur - erneut ist das bereits bekannte Atemgeräusch deutlich zu vernehmen erinnern uns an Schlomos Todesangst zu Beginn des Films sowie an seine Worte: »Augen, die zuviel gesehen haben ...«(s. 4.2.3.ab). Das Rattern des Zuges erweckt den Eindruck, als zittere der Protagonist vor Angst. Daß der Zuschauer diese verschiedenen Elemente wahrnehmen kann, liegt an der Dauer der Szene; Mihaileanu gibt uns ganze zehn Sekunden zur Beobachtung (0:53:03 - 0:52:13 h).

\section{ab) Höhepunkt der Absurdität - konfliktüberschattetes Sabbatfest}

Einen weiteren Höhepunkt des Hauptteils stellt das Sabbatfest dar. Neben der Verfremdung des religiösen jüdischen Rituals ${ }^{736}$ wird hier - insbesondere durch Schlomos Gebet - die, inzwischen eingetretene, ideologische Verhärtung (»Nazis« vs. »Kommunisten «, »Nazis « vs. orthodoxe Juden, orthodoxe Juden vs. »Kommunisten «) $)^{737}$ intensiv erfahrbar sowie scharf kritisiert.

Dabei dreht der Regisseur die Spirale des Absurden immer weiter, so daß sich eine »mise en abîme«-Struktur mit intensivem Wirkungspotential entfaltet:

»Geht man davon aus, daß die im Komischen zusammengeschlossenen Positionen sich wechselseitig negieren, so bewirkt dieses Verhältnis ein wechselseitiges Zusammenbrechen dieser Positionen. Jede Position läßt die andere kippen. Daraus folgt die Instabilität komischer Verhältnisse, nicht zuletzt, weil das Kollabieren der einen Position nicht notwendigerweise die andere triumphieren läßt, sondern diese in die Kettenreaktion ständigen Umkippens miteinbezieht.« (Iser zit.n. Kortmann 2003: 311)

735. Das Standbild zitiert eine Einstellung aus der TV-Serie HoLOCAUST und ist zeichenhaft für die Vernichtung der jüdischen Kultur durch den Nationalsozialismus.

736. Vgl. Bleicher 2002: 191 sowie Schmid zit.n. ebd.: »Der jüdische Witz, Volks- und Bildungswitz in einem und hierin ganz einmalig, parodiert oft das eigene Schrifttum, den eigenen Kultus und Ritus, imitiert in Witzform kabbalistische und talmudistische Bibeldeutungen.«

737. »Auch im Zuginnern stehen sich bald zwei karikierte Fronten gegenüber: die >Nazis« unter Mordechai auf der einen, die `Kommunisten unter Führung des ehemaligen Rabbi-Knechts Yossi auf der anderen Seite. Keiner von ihnen vertritt ernsthaft irgendwelche Inhalte (außer in der Frage, wer in den weichen Betten schlafen darf). [...] Die jüdischen Kommunisten dagegen haben weder Marx, Engels noch Lenin gelesen, opponieren schlicht gegen die sbourgeoisen Faschisten<, und Yossi versteht den Aufruf >Proletarier aller Länder, vereinigt euch! in einem eher sexuellen Sinne." (Distelmeyer 2000: 53)

738. Im folgenden Dialog wird Mordechai mit M., der Rabbi mit R. abgekürzt. 


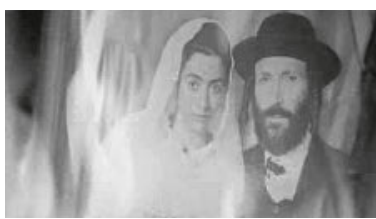

689

$0: 52: 54 \mathrm{~h}$
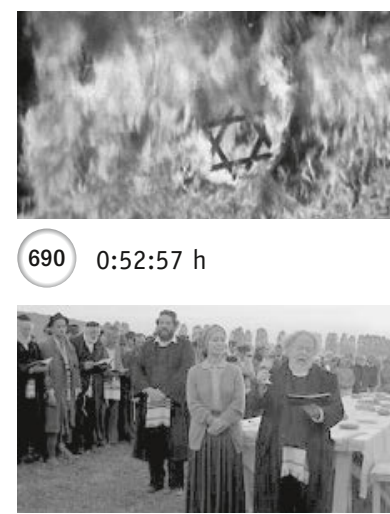

692

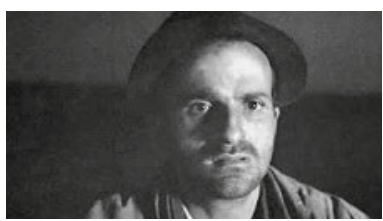

691

$0: 53: 06 \mathrm{~h}$

Detaillierte Sequenzanalyse:

Nachdem die Vorbereitungen zu den Feierlichkeiten sowie die Zeremonie selbst (s. 0:57:32 h) zunächst friedlich verlaufen waren, drohen die internen Konflikte, die sich bereits abgezeichnet hatten, zu eskalieren.

Zuerst geraten Mordechai und der Rabbi über die Entscheidungshoheit in Streit. Während der rituellen Handlungen tragen der unechte Kommandant und seine Männer anstelle der traditionellen Kippa die militärische Kopfbedeckung, bis der Rabbi den Frevel bemerkt: $73^{8}$

R.: \Mordechai, setz' deine Mitz' (Mütze) ab und befehl' deinen Männern, ich mein', sie sollen diese Nazi-Helme obneyhmen, und du oich, wenn ich bitten doarf! Es reicht schoin, daß wir eure Uniformen ertragen missen.«

M.: $\quad$ Kommt nit in Froag (Frage), unsre Kepp (Köpfe) bleiben bedeckt. 'S steht nirgendwo, daß es untersoagt is, Nazi-Helme zu troagen.

R.: $\quad$ Mordechai, [zu seiner Frau] soag' doch ebbes (etwas)!«

Frau: „Oameyn (Amen)!«

R.: $\quad$ Oameyn.«

M.: »Außerdem entscheid' ich ganz oalleyn (allein), was meine Männer zu tun hoaben und was nicht. Dasselbe gilt für die Deportierten, sie unterliegen meinem Befehl [wühlt in den gefälschten Papieren]. Hier is' mein Ausweis. Ich gestatt' also den Deportierten, die Kippa oiffzusetzen (aufzusetzen), doch meine Männer lassen ihre Helme oif (auf)! Wenn die Luftwaffe über den Zug fliegt oder die Deitschen überraschend oiftauchen (auftauchen), dann sind die Uniformen vorschriftsmäßig und die Gemeinde ist gerettet, bleibt am Leben und doas zählt!«

R.: »Mordechai, du bist kein echter Befehlshaber, dein Ausweis ist gefälscht, die Deportation ist vorgeteischt (vorgetäuscht)!«

M.: »So, glaubt ihr?! Mir treffen a jeden Toag auf echte Nazi-Deitsche, also brauch' ma' (man) 'n echten Befehlshoaber! Oamen!«

Gemeinde: »Oamey!«

R.: $\quad[$ leise $] » O a m e y n . \ll(0: 57: 56-0: 58: 52 \mathrm{~h})$ 
Während dieses verbalen Schlagabtausches zwischen Mordechai und dem Rabbi kann sich der Zuschauer aus unterschiedlichen Anlässen amüsieren. Spürbar gestärkt durch seinen vorangegangenen Triumph über die Deutschen (s. 4.2.4.aa), macht Mordechai hier nämlich seinen Anspruch auf die Führungsrolle innerhalb der Gemeinde deutlich. Daß er dies mit einem, der Situation völlig unangemessenem, Nazi-Gestus (s. o:58:28 h) tut, belächeln wir normalerweise. Mordechai ist inzwischen so intensiv in die Nazi-Rolle geschlüpft, daß er dem Rabbi die gefälschten Papiere zeigt, um seine Befehlsgewalt über die Deportierten zu belegen. Dies empfindet der Zuschauer als übertrieben und lächerlich, gleichzeitig jedoch auch als gefährlich: Mordechai ist ganz offensichtlich nicht mehr in der Lage, zwischen seiner Rolle und den tatsächlichen Verhältnissen zu unterscheiden"39; es wird in dieser Szene erfahrbar, daß zuviel Macht negative Folgen hat. Wenig später, als einige Deportierte flüchten, verkündet er, daß seine Männer in Zukunft auf die Abtrünnigen schießen werden - eine doppelt verkehrte Welt. In der Tat muß er darauf bedacht sein, daß er und seine Männer nicht als falsche Nazis entlarvt werden können; Mütze und Helme haben demnach ihre Berechtigung. Unser »Verlachen« mischt sich mit Anerkennung, denn Mordechais konsequente Rollenübernahme kann für die Gemeinde lebensrettend sein.

Als schließlich das Freitagabend-Gebet von Juden und »Nazis « gemeinsam gesprochen wird (s. 0:59:23 h), verzweifeln die kommunistischen Saboteure (s. 0:58:57 h; s. 4.2.4.aa) endgültig - »Scheiß Krieg!« (0:59:05 h) Auch ihr Chef, von dem sie sich per Feldtelefon Aufklärung versprechen, weiß in dieser Situation nicht mehr weiter: »Es handelt sich vielleicht um Deutsche mit jüdischem Glauben. [...] Geht nach Hause, das wird zu kompliziert. Ich weiß nicht, ob man Deutsche mit jüdischem Glauben als Nazis oder als Juden betrachtet [...] Ich habe Auslegungsschwierigkeiten.« (0:59: $15-0: 59: 28 \mathrm{~h}$ )

Auch unser Verständnis wird auf die Probe gestellt. Einerseits scheint Mordechai nicht mehr zu wissen, daß die Deportation vorgetäuscht ist und er eine Rolle spielt, andererseits nimmt er mit seinen Männern am Freitagabend-Gebet teil. Und: Versteht der Rabbi nicht, daß er das Leben seiner Gemeinde aufs Spiel setzt, wenn er von den »Nazis« das Kippa-Tragen verlangt?

Nachdem das gemeinsame Gebet doch noch in Ruhe gesprochen werden konnte, eskaliert der Konflikt von neuem, zunächst zwischen Yossi und dem Rabbi, später zwischen Yossi und Mordechai.

739. Vgl. in diesem Zusammenhang Bergsons Mechanik-These (1972: 29).

»In TRAIN DE VIE gibt es etwas zu lachen, wenn eine Erscheinung wissentlich nicht mit dem Wesen der Sache übereinstimmt, sondern sich auf ihre Erscheinung beschränkt, eine Parodie von etwas anderem darstellt: [...] wenn sich jüdische Rituale und soldatisches Erscheinungsbild ineinander verschränken, so daß die in Soldatenuniformen und Helmen betenden Juden, regelmäßig gruppiert und in ihre rhythmischen und synchronen Verbeugungsbewegungen des Schabbesgebets versunken: Das visuelle Aufeinanderprallen von einander ausschließenden Ideologien und ihrer Symbole im Verschmelzen der Bilder von Kriegsbereitschaft und einem friedlichen Gebet.« (Kortmann 2003: 308)

740. Im folgenden Dialog wird Mordechai mit M., Yossi mit Y. abgekürzt. 


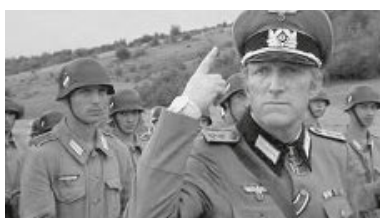

693

$0: 57: 56 h$

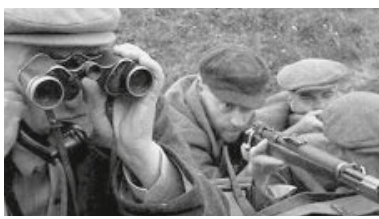

$696) 0: 58: 57 \mathrm{~h}$

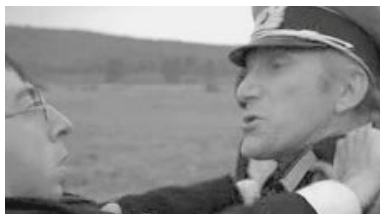

(698) $1: 00: 33 \mathrm{~h}$
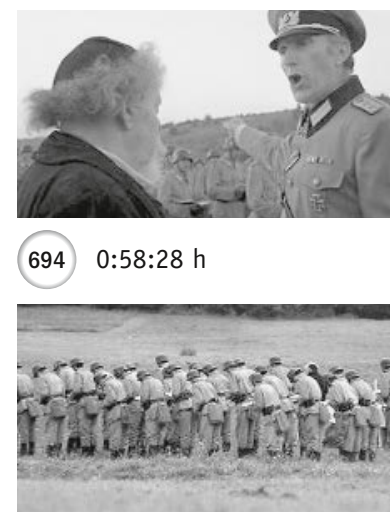

(697) $0: 59: 23 \mathrm{~h}$

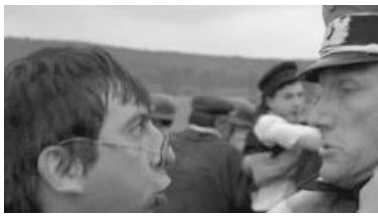

(699) $1: 00: 38 \mathrm{~h}$

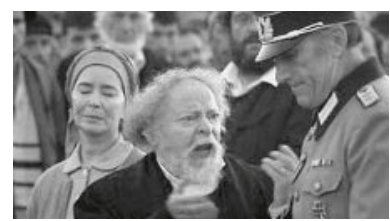

$6950: 58: 41 \mathrm{~h}$

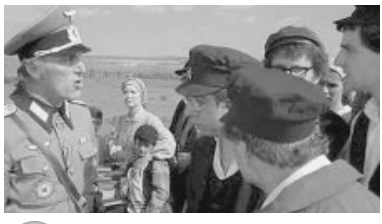

(700) $0: 44: 11 \mathrm{~h}$

Als der Rabbi mit den rituellen Handlungen fortfährt, beginnen die »Kommunisten «, Teile des Proviants zu beschlagnahmen und zu essen: »Betet ruhig weiter. Wir essen Rabbei, sonst verspäten wir uns. [...] Und jetzt ist aus mit der Religion. Wir sind marxistischleninistische Materialisten. Fer uns ist der Messias schon do und a Gott gibt's nicht« (1:00: ०6 - 1:00:24 h), schleudert Yossi dem entsetzten Rabbi erregt entgegen. Mit dieser Kumulation an ideologischen Schlagwörtern wird der Zuschauer erneut erheitert.

Als es dem Rabbi nicht gelingt, die Provokation der »Kommunisten « zu beenden, schreitet Mordechai ein, indem er Yossi packt und ihn in Nazi-Manier anherrscht (s. 1:00:33 u. 1:00:38 h):740

M.: »Materialistenschwein! Du abtrünniger Hund, kommst du wohl zum Gebet und läßt die anderen auch mitbeten?! Du bist a (ein) schlechtes Beispiel für die Kinder, Dreckskommunist!«

Y.: Ah ja?! Dreckiger Nazi! Gott existiert nit (nicht)! Ich sag' es noch einmal laut und deitlich (deutlich), damit die Kinder die Wahrheit hören (Schlomo geht dazwischen ...).«(1:00:26 - 1:00:42 h)

Trotz der beängstigenden Aggressivität, mit der die beiden aufeinander losgehen, birgt diese Szene auch eine gewisse Komik in sich. Innerhalb der Gemeinde existiert eine Gegnerschaft, die auch die Welt außerhalb kennzeichnet (Nazis vs. Kommunisten; s.o. zur verkehrten Welt). Demnach verfolgen wir die Auseinandersetzung zwischen Mordechai und Yossi mit Besorgnis, denn beide sind derartig in ihren Rollen gefangen, daß sie nicht mehr zurück können. Wie gefährlich und schädlich die Macht von Funktionen und Ideologien für jedermann sein kann, ist hier klar erkennbar. Erneut ist es Schlomo, der die Situation rettet, indem er die beiden Kampfhähne trennt und das eigentliche Sabbat-Gebet spricht (s. 4.2.4.bb). 
Der Konflikt zwischen den »Nazis « und den »Kommunisten« stand schon bei Beginn der Flucht vor der Eskalation. Schon damals griff Mordechai ein, nachdem der Rabbi Yossi und seinen Genossen nicht besänftigen konnte (s. o:44:11 h, Sequenz 34):
R.:
Y.:
»Wo liegt dein Probleym?«
Die
R.: »Mein Problem?! Daß uns die Deutschen besser behandelt hätten [...] genau das is' mein Problem. Mir (Wir) verlangen Gerechtigkeit!« »Kommunisten«: »Ja, und weiche Betten!« »Oi, oi, oi, oi, oi, doas (das) hoat (hat) uns groad' (gerade) noch gefeyhlt. Meine Gemeinde entzweit sich.«
Frau des Rabbi: Mir hätten niemals fortgehn sollen.«
M.:
[schreit] »Ruhe! Du da, komm her! Du willst in meinem Waggon schlafen, in meinem Bett? Dann sprich mir nach: Jawohl, Herr Major!«
Ein »Kommunist«: $\quad$ Deiwohl, meine Majorele.
M.:
»Bitte sehr! Habt ihr's gehert, kapiert ihr's jetzt?! Er hätte schon längst eine Kugel im Kopf bei dem Akzent und die ganze Gemeinde wäre in Gefahr! Man kann nicht einfach Deitscher werden, man muß sich das Deitsch-Sein verdie- nen, man muß sich anstrengen, um a (ein) Deitcher zu werden! «
Die »Kommunisten «: »Faschist, Faschist! ${ }^{\prime}$
R.:
»Oooooh! Mir dirfen uns nicht streiten! Ich versprech' eich weiche Betten in Palästine.« (0:43:24 - 0:44:28)

Während Mordechai in einer früheren Situation noch mit Worten überzeugen konnte, mußte er hier anläßlich des Sabbatfestes hart durchgreifen (s.o.). Die »Kommunisten« waren zu diesem Zeitpunkt etwas kleinlauter und auch der Zuschauer konnte, trotz des Aberwitzes der Situation, -»[...] man muß sich das Deitsch-Sein verdienen [...]«sich der logischen Argumentation Mordechais nicht ganz entziehen. Gleichzeitig sind wir uns bereits hier unsicher, wie weit Mordechais Identifikation mit seiner Rolle als Nazikommandant reicht; schon in dieser Szene wirkt er sehr authentisch, als er den »Kommunisten« die Folgen ihres Anliegens ausmalt: »Er hätte schon längst eine Kugel im Kopf bei dem Akzent [...].« Spätestens hier bleibt dem Zuschauer das Lachen im Halse stecken, denn er weiß, wie sehr das von Mordechai Ausgesprochene in der Zeit des Nationalsozialismus an der Tagesordnung war.

\section{b) Menschliche Grundwerte - Wiederherstellung der Ordnung}

Trotz oder gerade wegen der zahlreichen Verkehrungen der Verhältnisse (s. 4.2.4.a) stellt Mihaileanu die Ordnung in gewisser Weise wieder her, indem er Grundwerte wie Menschlichkeit und Toleranz erfahrbar macht. 


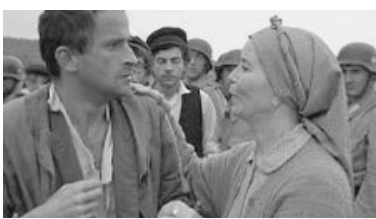

(701) $1: 00: 54 \mathrm{~h}$

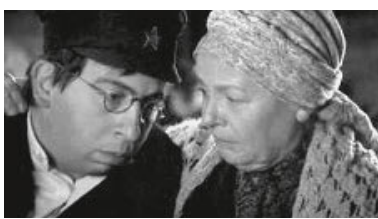

(702) $1: 22: 56 \mathrm{~h}$

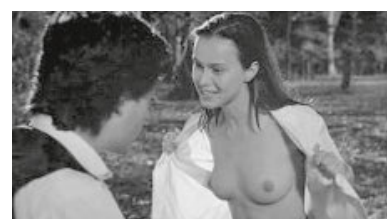

(703) $1: 04: 59 \mathrm{~h}$

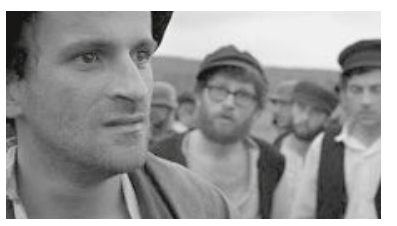

(704) $1: 01: 17 \mathrm{~h}$

ba) »Sei a Kommunist, aber werd wieder a Mensch!«

Wiederholt sind es die Frau des Rabbi, die Dorfschönheit Esther und Yossis Mutter, welche die in ihren Rollen aufgehenden Männer auf den Boden der Tatsachen zurückholen.

Bereits in der Exposition hatte die Frau des Rabbi sich über die »Hybris« der Männer hinweggesetzt, zur Ruhe ermahnt und beklagt, daß Gott die Männer dazu bestimmt hat, die Welt zu regieren (s. 4.2.3.ab und 4.2.3.ac). Als während des Sabbatfestes die internen Konflikte zu eskalieren drohen, ist sie es, die Schlomo Gehör verschafft (s. 1:00:54 h). Ihren Sohn Yossi, der, nach seinen eigenen Worten, die kommunistische Partei geheiratet hat, beschwört die Mutter, wieder ein Mensch zu werden (s. 1:22:56 h). ${ }^{741}$ Mit diesem für die Botschaft des Films zentralen Satz demaskiert sie den gefährlichen geistigen Starrsinn der in ihren Rollen aufgehenden Männer, die aus Mangel an Liebe und Anerkennung versuchen, sich in einer bestimmten Rolle auf Kosten anderer zu profilieren. Ein weiteres Indiz für die Macht der Frauen liefert Esther, der es gelingt, den ideologisch indoktrinierten Sami für konkrete Werte zu gewinnen. Als ihr Angebeteter sich aufgrund der Partei-Vorschriften ihr zunächst verweigert, reißt sie sich kurzerhand die Bluse auf und spricht: »... ist das nicht besser als alle Marx und Engels dieser Welt?!«(s. 1:04:59 h) So stellt der Regisseur die Frage, was Ideologien im Vergleich zu irdischen Genüssen und Geborgenheit wert sind.

\section{bb) Schlomos »Gebet«zum Sabbat}

Wenn er nicht - wie in der Exposition - für zusätzliche Verwirrung sorgt, gehen mit Schlomo häufig besonders wahrhaftig wirkende Szenen besonderer Menschlichkeit einher.

In diesen bringt er seine Gesprächspartner - vor allem Mordechai - dazu, zumindest vorübergehend die Maske fallen zu lassen.

»Gott schuf den Menschen nach seinem Bild. Ah, wie sche (schön) - Schlomo das Abbild Gottes. Oaber wer schrieb diesen Satz in die Thoire (Thora)? ... Der Mensch, nicht Gott, der Mensch! Er hat sich, unbescheiden wir er war, mit Gott verglichen. Gott hat den Menschen vielleicht erschaffen, aber der Mensch, der Mensch, das Kind Gottes, hoat sich Gott oisgedacht, nur um sich selbst zu erklären.« - (Rabbi:) »Koannst Du das noch mal soagen?« - »Der Mensch hat die Thoire geschriebn, ois Angst, vergessen zu werden, Gott war ihm egal. - (Rabbi:) »Schlomo, mer hoaben schon genug Ärger genug!« - »Räbbey, weder lieben wir noch beten wir zu Gott! Oder besser: Mir flehen ihn an, uns hier auf Erden zu helfen. Oaber Gott is doch jedem von uns 
allen egal, mir sorgen uns nur um uns alleyn! Die Frage is also nit, ob Gott existiert oder nischt, vielmehr ob denn mir, ob mir existieren ...« (1:01:04 - 1:02:11 h)

Mit seinem spontanen Sabbat-»Gebet« rückt Schlomo den Männern den Kopf zurecht. Während der kurzen Ansprache (s. 1:01:17 h) haben wir den Eindruck, daß die Zeit still steht und hier - im Unterschied beispielsweise zu Yossis Reden - auch für uns wirkliche, wertvolle Inhalte auf wahrhaftige und unprätentiöse Art und Weise angesprochen werden. Wie bei seinem »Bericht« vom Unglück zu Beginn des Films (s.o.) dominiert Schlomo die Leinwand: Die Großaufnahme lenkt unsere Aufmerksamkeit ausschließlich auf sein Gesicht. So können wir in seinen Zügen lesen. Schlomos Blick geht erneut seherisch ins Leere. Auch die Tonspur widmet sich, wo kurz vorher noch laut und heftig gestritten wurde, ganz seinen Worten; es herrscht andächtige Stille. Durch den Kontrast zur vorangehenden Szene wirkt diese Ruhe besonders. Die Wirkmächtigkeit von Schlomos »Gebet « wird zweifach abgesichert. Mit einem Kuß auf die Wange dankt die Frau des Rabbi dem Protagonisten für sein wundervolles Gebet, eine Geste, die auch wir als wohltuend empfinden. Die vorher verfeindeten Parteien (die »Nazis« und die »Kommunisten«) gehen unvermittelt aufeinander zu, um sich - zumindest in diesem Moment - zu versöhnen.

\section{bc) Dorfnarr wider Willen}

Auch die folgende Sequenz beginnt ruhig und nachdenklich. Während des gemeinsamen Schachspiels legt Mordechai den Finger in Schlomos Wunde - wir erfahren zum ersten Mal etwas Persönliches über die Hauptfigur:742

M.: »Schlomo, wieso bist du der Verrickte?«

S.: $\quad$ »Durch Zufall, ich wollt Rabbi werden, aber die Stelle war vergeben. Und weil a Verrickter fehlte, dacht ich mir, eh hier jemand anders verrickt wird, werd ich verrickt.«

M.: »Fühlst du dich nich ebbes allein?«

S.: $\quad$ Nein, nein, es gibt ja genug Verrickte.«

M.: »Nein, ich mein doch a Frau! Wieso hattest du nie a Frau Schlomo, und Kinder, a Familie?«

S.: »Ach, ich bin doch nit verrickt! Ich muß jetzt deine Dame nehmen! [schlägt die Dame von Mordechai auf dem Schachbrett vor ihnen] Ich hätt sie zuviel geliebt, ich wär vor Lieb gestorben oder verrickt geworden.« $(1: 02: 43-1: 03: 17 \mathrm{~h})$

Aus der Art und Weise, wie und was er auf Mordechais wiederholte Frage antwortet, spüren wir, wie tief und schmerzhaft Schlomos Wunde ist. Obgleich er zunächst noch in der Lage ist, Mordechai mit einem guten Schachzug743 in Bedrängnis zu bringen, wirkt der Protagonist bei der Beantwortung der Frage äußerst in sich gekehrt (s. 1:03:13 h): Der Blick hat sich von Mordechai bzw. dem Schachbrett gelöst und geht ins Leere, der ansonsten so lebendige Körper ist unbeweglich. Was er spricht, kommt aus seinem

742. Im folgenden Dialog wird Mordechai mit M., Schlomo mit S. abgekürzt.

743. Man erinnere sich an die vielen Assoziationen, die der Filmtitel auszulösen vermag, darunter seinen guten Zug tun<. 


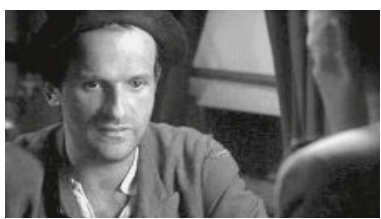

(705) $1: 03: 13 \mathrm{~h}$

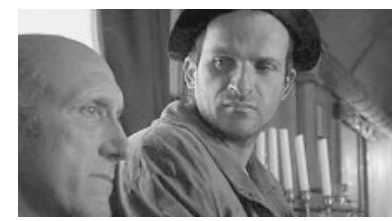

(706) $1: 15: 46 \mathrm{~h}$

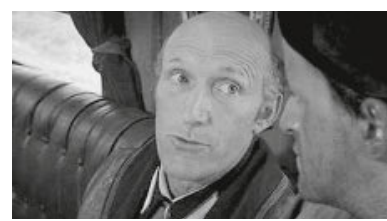

(707) $1: 16: 32 \mathrm{~h}$

tiefsten Inneren und läßt auf ein großes Herz und die Fähigkeit zu leidenschaftlicher Liebe schließen. Gerührt von Schlomos verborgenen Wesenszügen, wünscht ihm der Zuschauer, er möge doch eine liebe Frau finden, um wie die anderen Schtetlbewohner eine Familie gründen zu können. Gleichzeitig befürchtet er jedoch, daß es äußerst schwierig sein dürfte, einen ebenso verträumt-romantischen wie intensiv-liebensfähigen Menschen zu finden. Im übrigen scheint sich Schlomo mit seinem Zustand abgefunden zu haben, denn er spricht im Tempus der Vergangenheit: »Ich hätte sie zu viel geliebt.«

\section{bd) Mordechais Desillusionierung als verhaßter »Nazi«-Kommandant}

Im Anschluß an Mordechais bravouröse Rettung des Schneiders, der den Deutschen in die Hände gefallenen war, vertraut er Schlomo seine Enttäuschung an (s. 1:15:46 und 1:16:32 h).

\section{S.: $\quad$ Mir sind stolz auf dich. [...]«}

M.: »Stolz auf mich? Keiner mag mich hier, egal, was ich tu. [...] Fir mich würd keiner von uns a Finger rihren im Ernstfall - keiner, verstehst Du, nicht einmal Sami, mein eigener Sohn! Wenn ich in vorderster Linie stehe, vor den Nazis, dann spir ich sie alle hinter mir im Ricken, die ganze Gemeinde, wenn der Oatem stockt. Denkst du, sie hoaben Angst um mich? Nein! Sie hoffen natirlich, daß ich es schoaff, damit der Zug weiterfährt. Doch sie malen sich oich (auch) das Schlimmste ois (aus). Und weißt du, was ihnen daran gefälltt? Daß ich meinen Kopp zuerscht hinhalten mißt!«

S.: $\quad$ Das stimmt nicht, das weißt du genau.«

M.: »Ich hoab mich nur dem Willen des Räbbey und dem Roat der Weisen unterworfen, und Gott. Ich bin nicht ein echter Nazi geworden, weil ich wollt, sondern aus Liebe zu den Meinen, um sie nach Palästine zu fihren. Warum wird mir das jetzt vorgeworfen?«

S.: »Du bist verrickt! Würdest du deine [...] verbrennen oder sie wie Vieh behandeln, sie voneinander trennen, Kinder von Eltern, Brider von Schwestern, Männer von Weibern? Nur weil es der Rabbi und der Roat der Weisen von dir verlangen, ja? «

M.: »Bist du verrickt, von was redst du? Ich verbrenn keinen und tu auch keinem weh, Unsinn. Der Zug is verrickt, er moacht uns alle verrickt [...].« $(1: 15: 39-1: 17: 13 \mathrm{~h})$

Zum ersten Mal lernt der Zuschauer den Anführer der Juden als nachdenklich und verletzlich kennen. Mordechais Mimik und Gestik lassen erkennen, daß er in diesem Moment eben nicht seine Rolle spielt, sondern sein Innenleben preisgibt. Daß er sich längst nicht so souverän fühlt, wie es über weite Strecken des Films, aufgrund der 
gefährlich weitreichenden Identifikation mit seiner Rolle, den Anschein hat, macht ihn für uns mit einem Mal liebenswert. Sein überzeugendes Rollenverhalten erweist sich daher eher als menschliche Schwäche, die Lust, sich zu profilieren, denn als Charakterzug.

\section{be) Schlomos enttäuschte Liebe}

Gegen Ende des Films ist eine Sequenz um Schlomo in der Lage, den Zuschauer zu Tränen zu rühren. Schauplatz ist der Zugwaggon für die Tiere, in welchen sich ein junges Liebespaar zurückgezogen hat, um ungestört zu sein. Am anderen Ende des Abteils sitzt Schlomo, verloren, und beobachtet die beiden. Es handelt sich um Esther und einen gut aussehenden Zigeuner, den sie in der Zwischenzeit kennengelernt hat (s. insb. Sequenz 70). Nachdem sie Schlomo bemerkt haben, fragt Esther den Protagonisten in kecker Weise nach der Liebe (s. 1:29:31 h): »Eine Frag, Schlomo, wollst du nie a Frau haben, sie lieben und mir ihr zusammenleyben?« (1:29:30 - 1:29:39 h) Die Antwort läßt einige Zeit auf sich warten.

Währenddessen fixiert Schlomo mit unbewegter Miene die Fragende und macht dabei einen bedrückten Eindruck (s. 1:29:42 h). »Doch« (1:29:43 h), stößt er schließlich tonlos aus.

Es vergehen einige Sekunden, bis Esther mitfühlend fragt, ob er schon einmal verliebt gewesen sei: »Warst du schon a mal verliebt?« (s. 1:29:50 h) - ahnt sie etwas? Schlomo, nun näher zu sehen (Nahaufnahme), hat sichtlich Mühe, zu antworten: Wortlos, antwortet er, indem er die Augenbrauen hochzieht, die Lippen aufeinanderpreßt und mit dem Kopf nickt (s. 1:29:54 h). Als die junge Frau wissen möchte, ob es denn schon lange her sei, flüstert Schlomo niedergeschlagen ein Nein, begleitet von einem traurigen Kopfschütteln. Schlomo sitzt nach dieser Szene weinend auf dem Dach des Zuges (s. 1:30:42 h); auch Esther hat Tränen in den Augen (s. 1:30:42 h).

\section{bf) Verständigung und »Vereinigung« mit den Zigeunern}

Vergleichbar mit der Klezmermusik-Szene im ersten Teil von Zug Des LeBens, lädt uns auch das gemeinsame Fest der Juden und Zigeuner gegen Ende des Films zu MitFreude und ausgelassenem Lachen ein. ${ }^{744}$

Die Vereinigung beider Minoritäten erfolgt auf drei Ebenen: Zunächst schließen sich die beiden Trecks zusammen, dann erfolgt eine Kultursymbiose beim nächtlichen Begrüßungsfest (Musik und Tanz), schließlich findet die sexuelle Vereinigung bei zwei ethnisch gemischten Pärchen statt (Lorenz 2003: 294).

\section{Detaillierte Sequenzanalyse:}

Noch bevor das Fest in Gang kommt, nutzen die jungen Leute bereits die Gelegenheit, die andere Gruppierung genauer kennenzulernen, und zwar auf ganz kon-

744. Vgl. Loshitzky zur Erweiterung des Diskurses über die Opfer des Holocaust (2003: 25f.) sowie zur stereotypen Figurenzeichnung der Zigeuner: »Und so basieren auch die leidenschaftlichen Roma in diesem Film auf romantischen Stereotypen, etwa dem der sinnlichen, aufreizenden und promiskuitiven Zigeunerin [...] sowie dem verführerischen und verwegenen Zigeuner.« (Ebd. 28) 


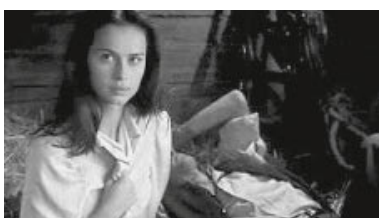

(708) $1: 29: 31 \mathrm{~h}$

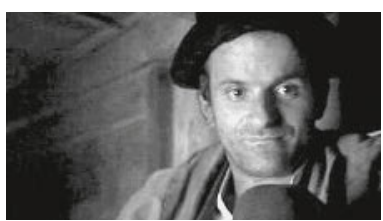

(711) $1: 29: 54 \mathrm{~h}$

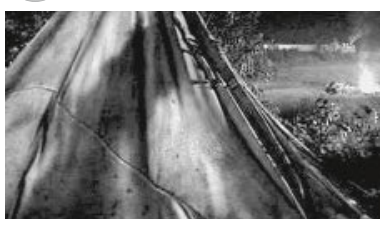

(714) $1: 23: 30 \mathrm{~h}$

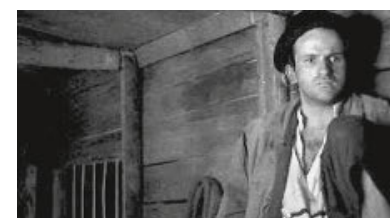

(709) $1: 29: 42 \mathrm{~h}$

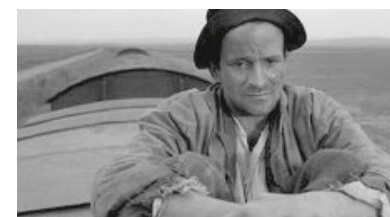

(712) $1: 30: 42 \mathrm{~h}$

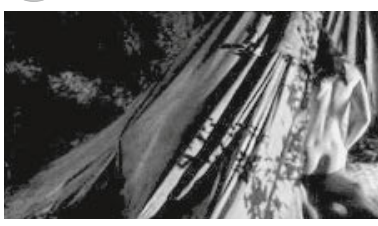

(715) $1: 23: 44 \mathrm{~h}$

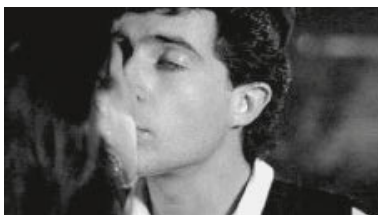

(717) $1: 24: 51 \mathrm{~h}$

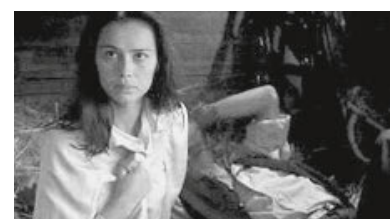

(710) $1: 29: 50 \mathrm{~h}$

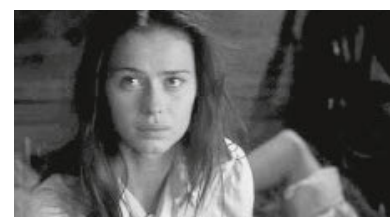

(713) $1: 30: 40 \mathrm{~h}$

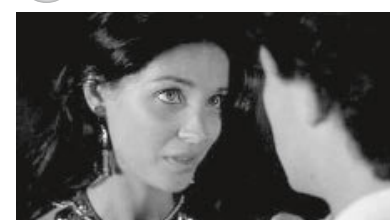

(716) $1: 24: 08 \mathrm{~h}$

krete Art und wiese. Fernab des großen Lagerfeuers hat sich Esther mit ihrem Zigeunerfreund in ein Zelt zurückgezogen (s. 1:23:30 u. 1:23:44 h). Den Zuschauer amüsiert, daß Esther ihrem ehemaligen Freund Sami offenbar wenig nachtrauert, sowie die Art und Weise, wie sie den erschöpften neuen Liebhaber zu weiteren Sinnesfreuden überredet. Die ästhetischen und relativ dezenten Bilder lassen den Zuschauer in diesem Augenblick möglicherweise von einer »LagerfeuerRomantik« träumen.

Der eifersüchtige Sami wird von einer ebenso hübschen wie rassigen Zigeunerin davon abgehalten, aus Eifersucht und Kränkung Esthers Liebesnest anzuzünden (s. 1:24:08 h). Ohne zu zögern, unterbreitet ihm die junge Frau ein »unmoralisches Angebot«. Auf Samis Einwand, die Partei untersage »die freie Liebe ohne die reine Lehre des Proletariats « (1:24: 25 - 1:24.29 h), reagiert die Zigeunerin, indem sie den jungen Mann an sich drückt und ihn küßt (s. 1:24:51 h).

Erheiternd ist in dieser Szene die Unbeirrbarkeit, mit der die »moderne Eva « ans Werk geht. Ganz nebenbei wird kommunistische Verblendung hier erneut aufs Korn genommen, als sie ihn betört:

»Mach' dich bereit, schöner Junge. Heute nacht werde ich euch lieben, dich und deine Partei, wie ihr noch nie geliebt worden seid - eine echte Revolution. Der Idee muß die Tat folgen; verstehst du, was ich meine?!« (1:24:30 - 1:24:48 h) 
Das große Fest beginnt mit gegenseitigem Imponiergehabe. Begleitet von einem Xylophon entlockt ein Zigeuner seiner Geige auf ungewöhnliche Art und Weise interessante Töne. Triumphierend blickt er dabei zu den versammelten Juden hinüber (s. 1:25:०9 h). Ermuntert vom Rabbi gibt der jüdische Violinist eine musikalische Antwort (s. 1:25:58 h).

Nach und nach stimmen weitere Instrumente mit ein, die Musiker spielen gemeinsam. Diese ansteckend rhythmische und Lebenslust verbreitende Musik hält die beiden Gruppen nicht mehr auf ihren Plätzen. Im Wechsel führen die jüdischen Männer und die Zigeunerfrauen ihre Tänze und Gesänge vor (s. 1:26:49 u. 1:26:54 h).

Im Laufe der Feier vermischen sich die beiden Gruppen, aus anfänglicher Rivalität wird ein gemeinsames rauschendes Fest der Verbrüderung: Die Trennung ist überwunden, die Musiker bilden ein großes Ensemble (s. 1:27:35 h), jüdische Männer tanzen eng umschlungen mit Zigeunerinnen (s. 1:27:47 h). Selbst die Anführer beider Gruppen tanzen miteinander (s. 1:27:51 h) - die Verschmelzung ist perfekt, spürt und freut sich der Zuschauer. Er erlebt die Realisierung eines tief im Menschen verwurzelten Bedürfnisses und Wunsches: das Überwindung scheinbarer Barrieren zugunsten von Menschlichkeit. 


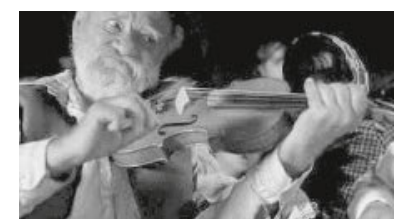

(718) $1: 25: 09 \mathrm{~h}$

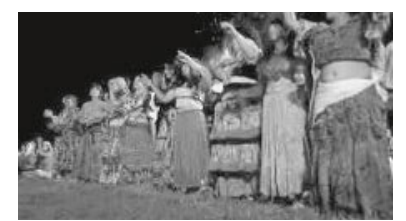

(721) $1: 26: 54 \mathrm{~h}$

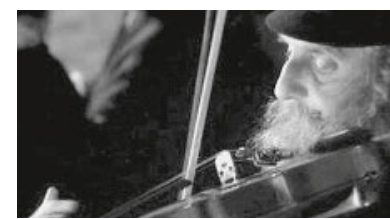

(719) $1: 25: 58 \mathrm{~h}$

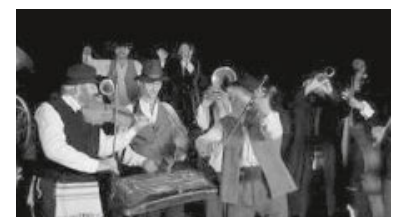

(722) $1: 27: 35 \mathrm{~h}$

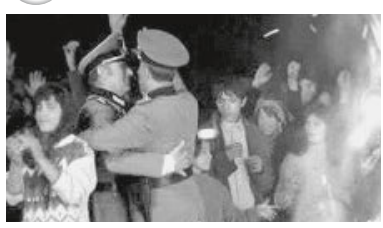

(724) $1: 27: 51 \mathrm{~h}$

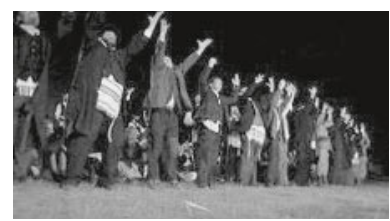

(720) $1: 26: 49 h$

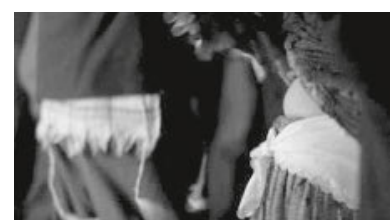

(723) $1: 27: 47 \mathrm{~h}$ 


\section{II.5 Rückkehr an den Ort des Schreckens, die Gegenwart der Vergangenheit zu be-greifen:}

Birkenau und Rosenfeld

\section{(La Petite Prairie aux Bouleaux, Marceline Loridan-Ivens, F/D/P0L 2003)}

\section{II.5.1 ERSCHRECKENDE BESCHAULICHKEIT}

Bereits der Titel verweist auf einen zentralen Aspekt des Films und macht den Zuschauer aufgrund seines Rätselcharakters neugierig. Während der französische Originaltitel La Petite Prairie aux Bouleaux die wörtliche Übersetzung des polnischen >Brzezinska< und die sinngemäße Übersetzung des deutschen >Birkenau< darstellt (Loridan-Ivens 2003: 11), weicht der deutsche Titel vom Original ein wenig ab: Unter dem Titel Birkenau und Rosenfeld kam er in die deutschen Kinos. Damit greift er einerseits den von den Nazis für den Standort des Lagers erfundenen Namen auf (>Birkenau<) und spielt andererseits mit den botanischen Konnotationen des jüdischen Nachnamens der Protagonistin. Ohne Vorwissen könnte der französische Zuschauer, aufgrund des Titels, einen romantischen Heimatfilm erwarten. ${ }^{745}$ Auch das deutsche Publikum könnte so reagieren, vorausgesetzt, >Birkenau< wirkt bei ihm insbesondere

745. »0b möglicherweise auch der Klang des Wortes Birkenau bei der Wahl für den Standort des Vernichtungslagers eine Rolle gespielt hat, ist nicht bekannt, aber es entspräche dem kranken Humor der Mörder, wenn sie ausgerechnet den schrecklichsten Bau der Welt an einer Stelle mit einem so idyllischen Namen errichtet hätten ...» (Heine 2004). »0b die Nazis die deutsche Romantik sarkastisch verhunzen wollten, wenn sie den Lagern die hübschen Namen gaben? Oder waren Buchenwald und Birkenau nur die natürlichen Einfälle des Kitschdenkens, wenn es vertuschen oder verharmlosen will? Ein Unwissender könnte nämlich schlafwandelnd >Birkenau und Buchenwald mit Volksliedmelodie vor sich hin trällern und auch mühelos naturbezogene Verse dazureimen.« (Klüger 2001: 114)

746. Loridan-Ivens zit.n. N.N. in The International Herald Tribune auf: www.partisanfilm. de/index/61136, 75093.

747. »Ich war nie nach Weimar zurückgekommen, nie hatte ich dazu Lust verspürt. Ich hatte mich immer geweigert, wenn sich eine Gelegenheit dazu geboten hatte.« (Semprún 1995: 331)

748. Loridan-Ivens zit.n. N.N. 2002 in Le Monde, 09.07.2002, auf: www.partisanfilm.de/ index/61136, 75093.

749. "She comes to win back her energy, to triumph over the camp.« (Loridan-Ivens zit.n. N.N. in The International Herald Tribune auf: www.partisanfilm.de/index/61136,75093)

750. »Hatte ich nun ein reines Herz? Hatte ich mich genügend von mir losgelöst? In diesem Augenblick kam es mir so vor. Mein ganzes Leben war durchsichtig für mich geworden, in einer Art glücklichem Schwindelgefühl. Hier war ich zwanzig Jahre alt gewesen, und hier vollendete sich mein Leben durch diese Rückkehr in die Zeit, wo es nur Zukunft gewesen war.« (Semprún 1995: 348)

751. Vgl. Semprúns Empfindungen bei Betreten des Lagers Buchenwald Jahrzehnte nach seiner Befreiung: »Ich konnte nichts sagen, ich bin stehengeblieben, ergriffen von der dramatischen Schönheit des Raums, die sich meinem Blick bot.« (1995: 343) 
durch den Zusatz > Rosenfeld < nicht als Signalwort für den Holocaust. Im Verlauf des Films, wenn die Protagonistin zur >kleinen Birkenwiese $<$, dem heutigen, fast idyllischen Lager zurückkehrt, offenbart der Titel seine euphemistische Bedeutung - »auf dem ehemaligen Moorgebiet sind zahlreiche Birken groß geworden « (Lüthge 2004: 3), ge»düngt« durch die Asche der in den Krematorien verbrannten Opfer: »nature that has become more beautiful, nourished by the corpses buried there ${ }^{746}$

Im Zentrum des Films steht die Konfrontation der Protagonistin Myriam Rosenfeld, einer Überlebenden von Auschwitz-Birkenau, mit dem einstigen Schreckensort und ihr Umgang mit den Ruinen und Relikten sowie dem Fehlen von deutlichen Spuren der Massenvernichtungen.

Vermittelt durch ihr filmisches Alter ego Myriam (gespielt von Anouk Aimée), verfilmt Marceline Loridan-Ivens ihre eigene Geschichte auf autobiographische Weise. So berichtet die Regisseurin von:

- sich selbst als Überlebende des Holocaust;

- der Realität ihrer Erinnerung - und »objektiviert« sich selbst;

- ihren traumatischen Kindheits-Erlebnissen als Inhaftierte von Auschwitz-Birkenau: Loridan-Ivens war 15 Jahre alt, als sie zusammen mit ihrem Vater festgenommen, nach Drancy und schließlich nach Auschwitz-Birkenau deportiert wurde - von diesem Transport wurden lediglich 35 der 1500 Menschen gerettet, ihr Vater war nicht darunter (Loridan-Ivens 2003: 11);

- ihrer späten Rückkehr nach Auschwitz-Birkenau:

Ebenso wie der Buchenwald-Überlebende Jorge Semprún 747 hatte Loridan-Ivens über Jahrzehnte hinweg die Konfrontation mit dem Ort unermeßlichen eigenen Leids gemieden. Knapp ein halbes Jahrhundert (46 Jahre) nach ihrer Befreiung näherte sie sich mit einem beinahe therapeutischen Ziel dem Ort: »Ich möchte mein Gedächtnis wiederfinden, um alles vergessen zu können.«748 - ein Ziel, das sie auch ihrer Protagonistin gibt ${ }^{749}$, das an Semprúns Gefühl der Lebensvollendung gegen Ende seines Buchenwald-Besuchs erinnert.750 Darüber hinaus versuchte sie mit dem Film »eine Spur zu hinterlassen, um zu verhindern, daß das Lager nach uns [dem Tod der letzten Überlebenden; eigene Anm.] für immer hoffnungslos leer bleibt«. (Ebd.)

Knapp 50 Jahre nach Kriegsende ist das Lager an sommerlichen Tagen »sehr schön«, so August Diehl, der die männliche Hauptrolle, den jungen Deutschen Oskar, spielt: »Eine Aue mit Birken. Es wächst Gras über die Sache, im wahrsten Sinn des Wortes, ganz hohes Gras. Es war eine schöne Jahreszeit und es hat geblüht. [...] Das war so seltsam: diese ständige Diskrepanz zwischen dem Ort und dem, was man dort erlebt

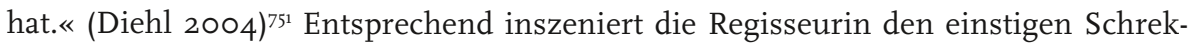
kensort bei Myriams erstmaligem Betreten des Lagers (s. 5.4.b) wie auch in späteren Sequenzen (s. insbesondere 5.4.c und 5.5.7): »[es] herrscht herrlichster Sonnenschein, die Vögel zwitschern, ein leichter Wind weht über endlose Wiesen, und auf dem ehemaligen Moorgebiet sind zahlreiche Birken groß geworden«. (Lüthge 2004: 3)

Aufgrund der Inszenierung des beinahe idyllischen Erinnerungsortes ist BIRKENAU und Rosenfeld mit Resnais' Nacht und Nebel (s. II.2.1), Lanzmanns Shoah (s. II.2.2) und dem weniger bekannten Dokumentarfilm KitTy's RETU Rn To AusCHwitz (1979) vergleichbar. Auch Loridan-Ivens begibt sich an den einstigen Schreckensort 
und versucht, sich ihm als ehemalige Lagerinsassin zu nähern. Verglichen mit NACHT und Nebel und ShoAh wirkt Loridan- Umgang mit den Erinnerungsorten nüchterner $75^{2}$ und facettenreicher; sie thematisiert wesentlich stärker die Schwierigkeiten im Umgang mit den von der Natur zurückeroberten Lagern.

Da es sich bei Loridan-Ivens' Protagonistin um ihr filmisches Alter ego handelt, drängt sich der Vergleich zwischen Birkenau und Rosenfeld und KitTY'S RETURN TO Auschwitz bzw. bestimmten Sequenzen aus Lanzmanns Sнонн (s. die Sequenzen mit Simon Srebnik, insb. 2.2.6) auf. Aufgrund der knapp zehnjährigen Herstellungszeit von S HоAн wirkt es so, als hatten Lanzmann und Kitty Hart (mehr oder weniger) gleichzeitig den Gedanken, die Konfrontation von Überlebenden mit dem einstigen Schreckensort im Film zu inszenieren. Loridan-Ivens jedoch greift das Motiv der inneren Bindung des Opfers an den Ort seiner Qualen auf und erinnert daher auch an PREIS Des ÜBERLEBens (2003), einen Dokumentarfilm des Niederländers Louis van Gasteren.

Wie Nacht und Nebel und Kitty's return to Auschwitz stammen auch die Aufnahmen in BirkenAu und Rosenfeld ausschließlich aus dem Lager Auschwitz. Aus diesem Grund können diese Filme hinsichtlich der Auswahl der Aufnahmen und ihres Arrangements verglichen werden. Dabei fällt die eine oder andere inszenatorische Anleihe bei Resnais auf, insbesondere was die visuelle Inszenierung des Ausmaßes der Vernichtung angeht. Deutlich wird aber auch, daß erst Loridan-Ivens das Potential gewisser Gestaltungsansätze zur Entfaltung bringt (s. insb. 5.5.c und 5.6.a). Gleiches gilt auch für inszenatorische Parallelen zu Lanzmanns Sнонн (s. 5.5.6 und 5.6.a).

\section{II.5.2 LEITTHESEN}

Aufgrund dieser angesprochenen Parallelen hinsichtlich des Verfahrens der Rückkehr an die einstigen Schreckensorte, insbesondere jedoch der Unterschiede, kann BiRKENAU Und Rosenfeld als Antwort vor allem auf Lanzmanns SHoAH, aber auch auf die Gegenwartsebene von Resnais' NACHT und NEBEL verstanden werden.

752. Myriam verzehrt im Lager ihren Proviant und verrichtet nach der dort verbrachten Nacht ihre Notdurft zwischen den Baracken im Gras.

753. N.N. auf: www.academy-films.com/deutsch/neuefilme/20040218190542.3.html. »Wir sehen äußerlich nur die Gegenwart, aber die Regisseurin schafft es, vor dem inneren Auge nicht nur der Protagonisten, sondern auch des Zuschauers, Bilder entstehen zu lassen, die das heutige Lager, all die Backsteinruinen, das grasüberwucherte Krematorium oder den aschenen See erst recht bitter erscheinen lassen.« (Burggrabe 2003)

754. Loridan-Ivens zit.n. N.N. in The International Herald Tribune, zit.n.: www.partisanfilm. de/index/6113 6,75093.

755. Der Film »[...] ist zwar ein Spielfilm aber hat die bekannte Struktur jener Dokumentarwerke, bei denen die Kamera einen Protagonisten bei der Suche nach der Vergangenheit verfolgt. Mangels anderer Begrifflichkeit könnte man von >Erinnerungsessaysı sprechen.« (Heine 2004, H.i.0.). Vgl. auch Jeismann 2004: 33.

756. Dies wird bereits in der Texteinblendung am Ende des Vorspanns spürbar: »Cette histoire appartient à l'Histoire. Le temps viendra où l'on dira ... >Il était une fois la planète des cendresı. Moi, je dis aujourd'hui, sil était une fois une petite fille de quinze ansı.» 
Im Unterschied zu NACHT Und NeBEL und SHOAH ermöglicht und erleichtert Loridan-Ivens' Film dem Zuschauer das Einlassen auf die Holocaust-Thematik, er involviert ihn wesentlich stärker und unterbreitet ihm intensive Erfahrungsangebote. Damit liefert er auch die Antwort auf viele Fragen der ästhetischen Inszenierung mit dem Ziel der Erfahrbarmachung des Holocaust:

»Die Kraft der Bilder vereint sich mit der Kraft ihrer Darstellung [Anouk Aimées; eigene Anm.] zu einer suggestiven Wucht von zwingender Wirkung. Jede Phase ihres Kampfes zwischen der Furcht, die Erinnerung würde alles Entsetzen der Entmenschlichung auferstehen lassen, und dem Verlangen nach Erlösung, die sie sich aus der wiedererweckten Erinnerung erhofft, macht diese große Schauspielerin spürbar. [...] auf unvergleichliche Weise macht sie das Unsichtbare sichtbar: Plötzlich füllt sich das Lager. Plötzlich sehen wir sie, die gedemütigten kahlgeschorenen Frauen, die Todesangst in sich und den altäglichen Tod vor Augen. Das Unfaßbare macht sie faßbar. $\ll^{753}$

In vergleichbarer Weise äußert sich die Regisseurin zur beabsichtigten Sympraxis (s. I.2.1) des Zuschauers: »Images of the camps have become stereotyped in the minds of at least two generations. [...] It's up to today's audience to do their work, to see between the emptiness that I show and the images in their heads.«754

Die Kluft zwischen den traumatischen Erlebnissen der Überlebenden und dem Zuschauer überbrückt Loridan-Ivens, indem es ihr gelingt, »de pénétrer à l'intérieur de l'âme du spectateur«, »de l'obliger peut-être à comprendre ce qui lui échappe.« (Loridan-Ivens auf DVD o:22:13 h) Im Unterschied zu Erzählungen bzw. Büchern versucht sie, insbesondere durch die Visualität des Mediums Film, beim Zuschauer starke Emotionen auszulösen (Loridan-Ivens auf DVD o:22:38 h).

Dieser Dialog mit dem Zuschauer gelingt der Regisseurin aufgrund konzeptioneller, inszenatorischer und kompositorischer Entscheidungen und Schwerpunktsetzungen:

- Im Unterschied zu den Dokumentarfilmen von Resnais und Lanzmann ist BIRKENAU UND RoSENFELD ein Spielfilm.

Zweifel daran räumt die Regisseurin zu Beginn des Abspanns aus: »Ce film est une fiction «, läßt sie den Zuschauer wissen. Aufgrund seines teilweise stark dokumentarischen Charakters präzisiert die Regisseurin jedoch im Zusammenhang mit SCHINDLERS LISTE: »Mais ce n'est qu'à moitié de la fiction: elle ne >reconstitue< rien.« (LoridanIvens 2003: 11, H.i.O.) ${ }^{755}$ Daß die zentralen Sequenzen des Films im heutigen Lager Auschwitz-Birkenau zwischen Spiel- und Dokumentarfilm oszillieren, hängt auch mit dem autobiografischen Charakter des Projekts zusammen: »Es war ja ihr erster Spielfilm, [...] ein Film über sie selber, eine Art Tagebuch.« (Diehl 2004) $)^{756}$

Von Anfang an erzeugt Loridan-Ivens beim Zuschauer eine große Nähe zu ihrem filmischen Alter ego, der Protagonistin Myriam Rosenfeld. Diese steht im Verlauf des Films vor einer immensen Herausforderung: der Konfrontation mit dem einstigen Schreckensort und dem Überwinden ihrer traumatischen Lagererfahrung als Kind. Im Unterschied zu den zahlreichen Überlebenden in Sнонн erleichtert die Konzentration auf eine Hauptfigur dem Zuschauer das Einlassen auf ihre tragische Geschichte und über diese Figur auf den Holocaust allgemein. 
Trotz Anouk Aimées beeindruckender darstellerischer Leistung757 ist es aus dramaturgischen Gründen und hinsichtlich des Einbezugs des Zuschauers (s.u. detailliert) äußerst wichtig, der Hauptfigur einen Antagonisten gegenüberzustellen. Dies geschieht in Person eines jungen Deutschen, Enkel eines Nazis, der eine Fotoserie über das Lager anfertigt, um für seinen Großvater »zu büßen« (Loridan-Ivens 2003: 11). Nachdem Myriam zu Beginn ihres Lagerbesuchs diesem Deutschen, Oskar, zufällig kurz begegnet ist, unterhalten sich beide erst in der Mitte des Films ausführlicher. Dabei geht es um ihre unterschiedlichen Formen der Annäherung an das Lager, was auch visuell spürbar wird: Im Verlauf ihres Gesprächs nähern sie sich, auf den Gleisen gehend, physisch dem Haupteingang von Auschwitz-Birkenau, dem in zahlreichen Filmen inszenierten Lagertor (s. o:37:53 h). Während Oskar versucht, »objektive« Bilder vom Lager zu machen - »Je photographie, enfin j'essaie de photographier les traces, les signes, tout ça. Je cherche à faire quelque chose d'objectif.« (0:39:09 - 0:39: 20 h) -, sucht Myriam das Unsichtbare: »Moi, je cherche l'invisible.« (०:39:22 h), »l'invisible de sa subjectivité«, präzisiert die Regisseurin (0:21:45 h auf DVD). .78 Durch diese explizite Gegenüberstellung konträrer Herangehensweisen und Ziele (»objektive« Fotobilder versus mentale Erinnerungsbilder), stellen sich für den Zuschauer, spätestens hier, einige Fragen hinsichtlich des Umgangs mit den sogenannten Erinnerungsorten: Welche Form der Annäherung ist für unterschiedliche Besucher jeweils möglich? Wie sollen diese »objektiven« Bilder vom Lager aussehen und weshalb soll gerade Oskar dafür geeignet sein, sie aufzunehmen? Was können Lagerfotografien überhaupt aussagen (s. 5.2.4.1)? Wieso muß Myriam das Lager besuchen, um das Unsichtbare zu suchen: Hätte sie es nicht auch in Paris finden können? Und was bedeutet es für den Zuschauer, im Filmverlauf dem Aufspüren ihrer subjektiven Erfahrungen beizuwohnen?

757. »Allein in ihrem Gesicht, an einigen wenigen Worten und Gedanken, an Blicken und Gesten sehen wir Myriams Erinnern, Myriams Kampf mit Erinnerungen, [...].« (Burggrabe 2003) »[...] es ist doch einzigartig, wie sie [Aimée] hier auf unaufdringliche Weise den Zuschauer erfaßt und mit sich nimmt und ahnen läßt, daß man nicht von Erinnerung reden sollte, wenn man keine hat. Es ist viel, wenn man gedenken kann.« (Jeismann 2004: 33)

758. Insofern könnte Ruth Klüger Recht haben, wenn sie über diejenigen, die nach Auschwitz reisen, schreibt: »Wer dort etwas zu finden meint, hat es wohl schon im Gepäck mitgebracht.» (Klüger zit.n. Assmann 1996: 21)

759. Vgl. den Exkurs in Kloepfer 2006, Kapitel IV.

760. "Ich beispielsweise sehe nichts im Lager, und genauso geht es 0skar. In derselben Art und Weise wie Marceline L.-I. mich hat spüren lassen, daß das Lager voll ist, läßt es Myriam Oskar spüren.« (Diehl 2004)

761. Diese Konstellation erinnert in gewisser Weise an Semprúns Besuch im ehemaligen Lager in Begleitung zweier Wahlenkel: »Mit ihnen war es möglich geworden, die frühere Erfahrung, das Erlebnis jenes einstigen Todes heraufzubeschwören, ohne daß es anstößig oder mißglückt wirkte.« (Semprún 1995: 331) »[...] lag es, weit banaler, daran, daß ihr Alter und ihr Verhältnis zu mir - voll von Bedürfnissen und Ansprüchen, aber frei von jedem Zwang - es ihnen erlaubte, Fragen zu stellen, die zu stellen ein Sohn sich nie getrauen würde [...]?« (Ebd. 332)

762. Auch auf der französischen Original-DVD werden diese Sequenzen als (Kapitel-)Einheit aufgefaßt. 


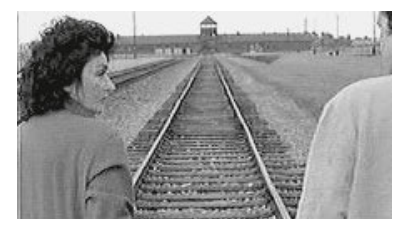

725 $0: 37: 53 \mathrm{~h}$

Oder liegt gerade in ihrer Subjektivität für den Zuschauer ein wirkmächtiges Erkenntnis- und Erfahrungspotential gemäß Novalis' These: >je subjektiver, desto universeller<?759

Trotz oder gerade aufgrund der gegensätzlichen Vorgehensweisen bittet Oskar die Überlebende, sie bei ihrer physischen und psychischen Rückkehr an diesen Ort begleiten zu dürfen. Offenbar scheint er zu spüren, daß ihm Myriam im wahrsten Sinne des Wortes »die Augen öffnen« könnte, daß Fotografien ohne Lenkung nicht genug aussagen, sinnleer bleiben: »C'est avec vous que mon travail pourrait prendre plus de ... plus de sens.«(o:50: $30-0: 50: 33 \mathrm{~h})^{760}$, erneuert der junge Deutsche wenig später seine Bitte, der Myriam schließlich nachgibt, eine Konstellation, aus der »so etwas wie eine produktive Dynamik« entsteht (Heine 2004). Bei ihren gemeinsamen Besuchen des Lagers hilft sie, seinen Blick zu schärfen, die Spuren der Vergangenheit der Erfahrung zugänglich zu machen ${ }^{761}$ : »Vous allez être condamné à le voir à travers mon regard « (1:11:10 h), äußert sie, im Anschluß an eine zentrale Sichtbarmachung des Unsichtbaren (s. 5.4.e). Da die Zuschauer in der Mehrzahl zu den Nachgeborenen und nicht zu den Holocaust-Überlebenden zählen, öffnet Myriam letztlich vor allem ihnen die Augen, bringt Erinnerungsorte für sie zum Sprechen - kurz: wir sind Oskar, die Absicherung der Sinnpotentiale erfolgt über Myriam und den jungen Deutschen. Als Zeichen für Oskars Lernprozeß und seine Abkehr vom naiven Abbildglauben verzichtet er in einer bestimmten Situation bewußt auf ein weiteres Foto der Protagonistin, um sich ganz auf die mit besonderer Wucht auf sie hereinstürzenden Erinnerungen zu konzentrieren (s. 5.6.c) - eine Entscheidung, die der Zuschauer begrüßt, denn auch er empfindet die stärkere Wirkkraft von Myriams Erinnerungen im Vergleich zu Oskars Lagerfotografie.

- Der Anfang des Films zeichnet sich durch eine rätselhafte und dadurch behutsame Einführung der Holocaust-Thematik aus (s. 5.3). Die gezielte Zurückhaltung von expliziten Informationen weckt die Neugier des Publikums und vermag, auch der Thematik überdrüssige Zuschauer einzubeziehen. Insbesondere die längste Sequenz der Exposition (s. 5.3.a) zwingt den Zuschauer förmlich, auf jedes Detail zu achten und daraus Vermutungen hinsichtlich der Ausgangssituation abzuleiten. Diese werden im Verlauf der Exposition, insbesondere der Sequenzen zwei bis vier $^{762}$, durch systematische Absicherung zunehmend konkreter. Insofern ist die Exposition von Birkenau und Rosenfeld insbesondere mit Louis Malles Auf Wiedersehen, Kinder (s. II.3.1.3), hinsichtlich der behutsamen Einführung auch mit Roberto Benignis DAS LeBEN IST SCHÖN (s. II.4.1.3) vergleichbar.

- Im Unterschied zu Resnais' Nacht und Nebel ist Birkenau und Rosenfeld ein insgesamt ruhiger und diskreter Film, der sich einzelne, nicht zu gräßliche Aspekte des Lageralltags herausgreift, diese stellvertretend für andere inszeniert und 
dem Zuschauer genügend Zeit einräumt, sie auf sich wirken und in ihm entwikkeln zu lassen. Wie Lanzmanns S нонн, verzichtet Loridan-Ivens dabei auf jegliche Integration historischen Archivmaterials und sucht den Zugang zur Vergangenheit ausschließlich im Hier und Jetzt, im Trauma sowie den aufkommenden Erinnerungen der Protagonistin: ${ }^{63}$ »Je voulais aller dans l'intériorité des choses et non pas dans l'extériorité, c'est-à-dire partir de l'intériorité pour faire sentir la violence que nous portons toutes en nous de cette période là et aussi l'aspect unique des souvenirs de chacune de nous, c'est-à-dire de redonner la place à la personne dans cette histoire.« (Loridan-Ivens auf DVD o:12:45 h) ) $^{64}$ Vorausgesetzt, der Zuschauer läßt sich auf diesen bedächtigen Film ein, unterbreitet ihm BIRKENAU und RoSENFELD ein Erfahrungsangebot in bezug auf die Lagerrealität, wie zum Beispiel die Nacktheit der Neuankömmlinge (s. 5.6.c) bzw. der tagtägliche Hunger (s. 5.5.c). Loridan-Ivens geht es keineswegs um Informationsfülle - wie vor allem NACHT und Nebel oder auch ShoAh - sondern um Sinntiefe. ${ }^{765}$

- Im Unterschied insbesondere zu Resnais, der die Lagerinsassen als anonyme Gruppe behandelt, individualisiert Loridan-Ivens Überlebende und Opfer des Holocaust: Neben der besonderen Nähe des Zuschauers zur Auschwitz-Überlebenden Myriam werden die Leidensgenossinnen, die verstorbenen Familienmitglieder der Protagonistin und die unzähligen Opfer des Holocaust, dadurch greifbarer, daß sie benannt werden (s. 5.4.b und 5.5.6), tatsächlich ein Gesicht bekommen (s. 5.6.b). Des weiteren verzichtet die Regisseurin, im Gegensatz zu Resnais und Lanzmann,

763. Dadurch, daß die Regisseurin nicht einmal (wie Lanzmann) das Modell der Krematorien im Museum Auschwitz inszeniert, verwirklicht sie die Ablehnung jeglichen Darstellungsversuchs konsequenter als ihr Landsmann.

764. Im Unterschied zu Alan Pakulas Spielfilm SOPHIES CHOICE (USA 1982) sieht LoridanIvens auch von die Erinnerungen visualisierenden Rückblenden ab.

765. »Während jedoch Bedeutung quantitativ zu erfassen ist (es ist mehr oder weniger >breit<), ist Sinn eher qualitativ zu bezeichnen (und ist entsprechend mehr oder weniger stief<).» (Kloepfer 1995: 31)

Wo Loridan-Ivens auf Sinnerzeugung durch Einfühlung setzt, indem sie unsere Vorstellungskraft mittels indirekter Thematisierung zu wecken vermag (Träume von reichlichem Essen; s. 5.5.c), vermittelt die vergleichbare Sequenz in NACHT UND NEBEL den Eindruck von Kälte und Distanz (sarkastischer Ton und extreme Künstlichkeit), ebenso wie die abschreckenden Aufnahmen menschlicher Skelette in DIE TODESMÜHLEN.

766. »Ich habe mit der Hand über die Buchstaben der aus dem Schmiedeeisen des Eingangsgitters geschnittenen Inschrift gestrichen: ১Jeden das Seineく. [...] Ich wußte, daß ich nach Hause zurückkehrte.« (Semprún 1995: 343)

767. »[...] uns lassen sie nicht locker, die Gespenster, mein ich. Wir erwarten, daß Ungelöstes gelöst wird, wenn man nur beharrlich festhält an dem, was übrig blieb, dem Ort, den Steinen, der Asche. Nicht die >Toten< ehren wir mit diesen unschönen, unscheinbaren Resten vergangener Verbrechen, wir sammeln und bewahren sie, weil >wir sie irgendwie brauchen: Sollen sie etwa unser Unbehagen erst beschwören, dann beschwichtigen? Der ungelöste Knoten, den so ein verletztes Tabu wie Massenmord, Kindermord hinterläßt, verwandelt sich zum unerlösten Gespenst, dem wir eine Art Heimat gewähren, wo es spuken darf.« (Klüger 2001: 70, H.i.0.) 
auf die Thematisierung der nationalsozialistischen Verwertungsmaschinerie und beschränkt sich aus Diskretion auf die nicht minder wirkungsvolle Aufbewahrung der den Opfern abgenommenen Fotos - bereits Spielberg hatte diese Aufnahmen in besonderer Weise inszeniert (s. 5.6.b).

- Sie stellt, im Unterschied zu Lanzmanns Sнолн, die Erinnerungen ihres filmischen Alter ego nicht nur dar, sondern zeigt auch den schwierigen Weg dorthin. Im Zentrum des Films inszeniert sie zwei Möglichkeiten - insbesondere für Überlebende -, mit den sogenannten Erinnerungsorten »Sinn-voll« umzugehen bzw. die Erinnerung an das Erlebte wieder aufleben zu lassen, der Toten zu gedenken:

(I) In insgesamt fünf Schlüssel-Sequenzen widmet sich die Regisseurin den Spuren der Vergangenheit und dem Be-Greifen derselben als Myriams Mittel, ihre Erinnerungen »heraufzubeschwören« (Klüger 2001: 79; s. 5.4). Be-Greifen meint hier das ganz konkrete Aufnehmen eines Zeichenkörpers vermittels des Tastsinns - des intensivsten Nahsinns des Menschen. Auf diese Weise nimmt Loridan-Ivens das von Resnais entdeckte Sinnpotential von Spuren der Vergangenheit auf und bringt es in einer anderen Form der Inszenierung und Kontextualisierung zur Entfaltung. Durch diese Schwerpunktverlagerung hin zur sinnlichen Erfahrung ${ }^{766}$ wird Aleida Assmanns theoretische Überlegung zum auratischen Erinnerungsort für den Zuschauer mitvollziehbar: »Die eigentümliche Verbindung von Nähe und Ferne macht diese zu auratischen Orten, an denen man einen unmittelbaren Kontakt mit der Vergangenheit sucht. Die Magie, die den Erinnerungsorten zugeschrieben wird, erklärt sich aus ihrem Status als Kontaktzone.« (1996: 25)

Entsprechend ihrer Erfahrung bei erstmaliger Konfrontation mit dem einstigen Lager, beispielsweise an der Todesmauer - »Toucher cette brique, pour moi ça a un tel sens.« -, läßt Loridan-Ivens ihr filmisches Alter ego die Relikte der Vergangenheit abtasten, um sie in ihrer Erinnerung zum Sprechen zu bringen und so für den sich identifizierenden Zuschauer erfahrbar zu machen (Loridan-Ivens auf DVD). Später vertraut Myriam ihrem Tagebuch an, daß sie die Erinnerung an früher heraufbeschwören möchte:

»Je suis venu vous chercher. J'ai besoin de vous. Vous n'êtes pas des fantômes. Toi, Françoise, aux yeux si bleus qui chantait les chansons de Piaf, les berceuses de ta mère. Ensemble, on lisait le soleil qui nous disait les heures si dures, si longes. Toi, la Hongroise avec qui je portais des pierres, tu es devant moi. Toi, la petite Renée, toi, Ida et toi, Clepsi-Clepsi de Salonique. Je ferme les yeux, j'ai quinze ans, puis seize.« $(0: 52: 26-0: 53: 09 \mathrm{~h})$

Daß Myriam sagt, die Personen ihrer Erinnerungen seien keine Gespenster, steht im Gegensatz zu Ruth Klügers Bezeichnung der ehemaligen Lager als »Gespenstergelände $\ll^{767}$ und streift deren Überlegungen zu den Erinnerungsorten - in erster Linie eine therapeutische Stütze für die Überlebenden:

Durch die spezifische filmische Inszenierung der angesprochenen fünf Sequenzen

- kann der Zuschauer nachvollziehen, wie Erinnerung funktioniert (s. 5.4.b und 5.4.d),

- wird er in das Bewußtsein der Protagonistin versetzt (s. 5.4.a und 5.4.c) und 
- kann er sich mir ihr vorstellen, was sich hinter den Spuren der Vergangenheit verbirgt (s. 5.4.c und 5.4.e). Einfühlungsvermögen wird hier verstanden als eine Bereitschaft mitzugehen, ein Er-Schließen und ein Er-Fühlen (von Werten).

Nachdem der Zuschauer genug Zeit hatte, sich seine eigenen Gedanken zu machen, wird ihm Myriams Erinnerung absichernd durch einen On-ton (Selbst-/Zwiegespräche) bzw. Off-Ton (Gedanken/Bewußtsein) vermittelt.

(2) In insgesamt sieben Schlüssel-Sequenzen inszeniert Loridan-Ivens unterschiedliche Formen der Annäherung an und des Umgangs mit dem heutigen Lager (s. 5.5). Dies reicht von Myriams Vordringen ins Lagergelände (s. 5.5.a) über mehrere Situationen, in denen die Protagonistin bewußt in sich geht (s. 5.5.b5.5.6) hin zur von vornherein zum Scheitern verurteilten Fixiertheit auf äußere Spuren (s. 5.5.d und 5.5.7). Besonders deutlich wird der Unterschied im Umgang mit den heutigen Orten, wenn mehrere Formen der Annäherung in einer Sequenz miteinander kontrastieren (s. 5.5.d). Die mit vier Sequenzen dominierende Form des In-sich-Gehens und der An-dacht steht im Gegensatz zum Heraufbeschwören der Erinnerung durch Be-Greifen (s. 5.4). Darüber hinaus macht die Regisseurin erfahrbar, daß Erinnerung bzw. Ge-Denken ohne Anlässe, ohne gegenständliche

768. In einer Sequenz mischen sich beide Herangehensweisen; als sie gegen Ende des Films nach jüdischen Trauerbrauch einen Stein auf den Ruinen der Gaskammer ablegt, inn intensiv berührt und ihren Blick ins Leere schweifen läßt.

769. "'This is the place where I was loved the most<, is Myriam's most surprising line in the film. You think you didn't hear it right. >People are surprised, < says Loridan-Ivens, >but I put that line in because even in catastrophe, there's love, closeness and solidarity. Hope is as human as violence. The girls weren't always nice to each other, but they shared suffering.» She thinks that most people don't understand horror. >They think it should be simple, sheer horror, but I lived this in my flesh, this contradiction - the nostalgia for the friendship we shared during that terrible times." (Zit.n. N.N. in The International Herald Tribune auf: www.partisanfilm.de/ index $/ 61136,75093)$

770. »Auch im weitaus größeren Lager der Opfer beobachtet man ein Abdriften der Erinnerung, aber hier fehlt ganz offensichtlich der Vorsatz. [...] Es wurde zum Beispiel beobachtet, daß viele Kriegsheimkehrer und überhaupt Menschen, die äußerst komplexe und traumatische Erfahrungen hinter sich haben, dazu neigen, ihre Erinnerungen unbewußt zu filtern. Wenn sie sie untereinander wieder heraufbeschwören oder dritten Personen erzählen, ziehen sie es vor, sich bei den Waffenstillständen, den Atempausen, bei den grotesken oder merkwürdigen oder entspannten Momenten aufzuhalten und über die schmerzlicheren Episoden hinwegzugehen. Diese letzteren werden nicht gerne aus dem Speicher der Erinnerung hervorgeholt, und deshalb neigen sie dazu, sich im Lauf der Zeit im Dunst aufzulösen, ihre Konturen zu verlieren.« (Levi 1990: 29)

771. Vgl. Levis Äußerungen hinsichtlich der Täter, die jedoch auch auf die Überlebenden zutreffen: „Der beste Weg, sich vor dem Ansturm belastender Erinnerungen zu schützen, ist der, sie gar nicht erst hereinzulassen und eine Hygieneschranke entlang der Grenze zu errichten. Es ist leichter, einer Erinnerung den Eintritt zu verwehren, als sie loszuwerden, wenn sie erst einmal registriert worden ist.« (1990: 27f.) 
Spur kaum möglich ist (s. 5.5.7) und daß im Umkehrschluß die Ruinen und Relikte der Vergangenheit dem Gedenken einen Ort geben bzw. die Erinnerung anzuregen vermögen. $7^{68}$

- In insgesamt drei Schlüssel-Sequenzen stellt Loridan-Ivens die Möglichkeiten den Schwierigkeiten besonderer visueller bzw. musealer Inszenierung gegenüber (s. 5.6). Dabei begeht sie nicht den Fehler, letzteren von vornherein zu ablehnend zu begegnen (s. II.2), sondern geht differenziert mit dieser Thematik um. Während sie das Potential gewisser musealer Formen durch filmische Inszenierung besonders entfaltet und dadurch erfühlen läßt (s. 5.6.b), macht sie ebenso eindringlich die Schwierigkeiten anderer Formen der Gestaltung deutlich: Zum einen kontrastiert die Regisseurin Oskars Lagerfotografie mit den Aufnahmen der Autofahrt am Lager entlang; auf diese Weise macht sie das Ausmaß der Vernichtung dem Zuschauer erfahrbar (s. 5.6.a). Zum anderen führt sie ihm die Problematik bestimmter musealer Inszenierung des Holocaust vor Augen und sensibilisiert ihn damit für die existierende Kritik an der »Museumskultur der KZs« (Klüger 2001: 69; s. 5.6.c) Die von Ruth Klüger und Claude Lanzmann formulierte Kritik an der sogenannten Musealisierung der einstigen Lager (s. II.2) basiert auf einer Schwierigkeit, die Aleida Assmann nüchtern beschreibt: »Die zu Gedenkstätten und Museen umgestalteten Erinnerungsorte unterliegen einem tiefgreifenden Paradox: Die Konservierung dieser Orte im Interesse der Authentizität bedeutet unweigerlich einen Verlust an Authentizität. Indem der Ort bewahrt wird, wird er bereits verdeckt und ersetzt.« (1996: 22)

- Im Unterschied zu den die Vernichtungsmaschinerie beschreibenden Zeugenberichten aus Sнон erinnert sich Myriam durchaus auch an positive Erlebnisse der Solidarität, Nähe und Liebe unter den Leidensgenossinnen - an die, auch für den Zuschauer wohltuenden, nicht versiegenden Momente gemeinsamer Hoffnung angesichts äußerster Bedrohung (s. 5.2.2.2; vgl. Kertész $1996) \cdot{ }^{769}$

Dies entspricht offensichtlich nicht dem von Primo Levi beschriebenen Filtern von Erinnerungen durch Überlebende, $77^{\circ}$ denn Loridan-Ivens kontrastiert in der Sequenz über die Ankunft im Lager Menschlichkeit, Überleben, zufällige Rettung mit Unmenschlichkeit, Ermordung, Selektion der Schwachen (s. 5.4.a), entsprechend der komplexen Wahrnehmung der Regisseurin. Die Balance zwischen Grauen und Hoffnung - im Gegensatz zur Horrorszenerie in der entsprechenden Sequenz bei Nacht und Nebel - erleichtert es dem Zuschauer, sich auf das Geschehen einzulassen und erzielt eine stärkere Wirkung.

- Im Unterschied zu Lanzmanns Sнонн inszeniert Loridan-Ivens jedoch nicht nur das Erinnern, sondern auch das »notwendige« Vergessen - eine, wie sie selbst sagt, mutige Entscheidung zugunsten der Aufrichtigkeit, denn sie könnte von Revisionisten mißbraucht werden (Loridan-Ivens auf DVD). Von der Exposition bis zum Ende des Films kämpft die Protagonistin mit dem Vergessen ${ }^{771}$ und dem Erinnern, schwankt zwischen dem Wunsch zu vergessen und den als letztlich heilsam empfundenen Erinnerungen: »Erinnerung ist keine gemütliche, badewasserlaue Annehmlichkeit, sondern ist eigentlich immer ein Graus, eine Zumutung [...].« 
(Klüger 1995: B4) $77^{2} \mathrm{Daß}$ dies für den Zuschauer beinahe am eigenen Leib spürbar wird, hängt stark mit der ergreifenden darstellerischen Leistung der Schauspielerin, Anouk Aimée, zusammen (s.o.). Obgleich sich die Protagonistin nach ca. zwei Dritteln des Films an vieles erinnern konnte, vertraut sie ihrem Tagebuch an: »Ma mémoire n'est pas comme le livre de Gutek. Souffrance de l'oubli. Brume, brume de l'oubli.« (o:53:18 - o:53:27 h) In bezug auf das Schlimmste (Ausheben der Massengräber) und das Ergreifendste (die Worte ihres Vaters) stößt Myriam so Loridan-Ivens (auf DVD) - an die Grenzen ihres Erinnerungsvermögens: Als Oskar Myriam am Ende des Films fragt, was ihr Vater auf den Zettel geschrieben hatte, antwortet sie: »Je m'en souviens pas. Je m'en suis jamais souvenu.« (1:24:50 - 1:24:54 h) Ihre Zerrissenheit zwischen Vergessen- und Erinnern-Wollen wird vor allem im Zusammenhang mit dem angesprochenen schlimmsten Erlebnis erfahrbar, dem Ausheben der Massengräber im Freien:773 Während sie, angetrieben

772. »Erinnerung ist offensichtlich nicht nur eine Sache der nötigen Konservierung oder künstlichen Restitution dessen, was längst vergangen und verloren ist, sondern auch eine Kraft, die sich gegen den Wunsch des Vergessens und Verdrängens eigenmächtig zur Geltung bringt. Nach Heiner Müller sind Traumata mnemischer Explosivstoff, der in Langzeitwirkung zum Ausbruch kommt.« (Assmann 1996: 24)

773. »For there are things she has forgotten: She can't remember exactly where they were forced to bury the bodies of fellow inmates, and this haunts her. >That's how memory behaves, the director says. >We all hide things from ourselves; we suffer both from remembering and forgetting the past. I was caught in that painful contradiction: I had to remember and I had to forget. I had to put things away where I couldn't find them, or I wouldn't have been able to survive.« (Zit.n. N.N. in The International Herald Tribune auf: www.partisanfilm.de/ index $/ 61136,75093)$ Primo Levi hat in »Das periodische System« paradigmatisch gezeigt, »wie es mit dem Gedächtnis steht, wie es jedem von uns in unserer Wahrheitssuche unentrinnbare Fallen stellt. Natürlich nicht dieselben Fallen: Der Täter hat Schandtaten, der Häftling Leidensmomente zu verdrängen. Gemeinsam ist innen der Filter der Erinnerung, der die dazwischenliegenden Jahre mit dem Damals vermischt und eine Vergegenwärtigung erschwert.« (Klüger 1995: B4)

774. »Und wenn ich mich gar nicht erinnern will?!« (s. Untertitel)

775. »[...] wenn sie in einem Krakauer Lokal den Lageplan der Baracken aufs Tischtuch zeichnet, während neben ihr die Paare über die Tanzfläche wirbeln« (Rother 2004: 24) und Ginette von ihrem Tanzpartner gefragt wird, ob die Nummer auf ihrem Arm ihre Telefonnummer sei.

776. Vgl. Kertész in »Kaddisch für ein nicht geborenes Kind«.

777. Mit diesem positiven Ausblick grenzt sich die Überlebende Loridan-Ivens darüber hinaus von pessimistischeren Einschätzungen von Primo Levi ab: „Wieder müssen wir, trauernd, feststellen, daß die Verletzung unheilbar ist: sie überdauert die Zeiten, und die Erinnyen, an die man schließlich doch glauben muß, [...] führen sein Werk [das des Peinigers] noch fort, indem sie dem Gepeinigten den Frieden versagen.« (Levi 1990: 20f.)

778. An den beiden Standbildern aus NaCht und Nebel (s. 0:14:07 h, II.2.1) bzw. Die TodesMüHLEN (s. 0:05:55 h, II.1.1) wird deutlich, daß Loridan-Ivens ihre Protagonistin ganz bewußt den Blick der Täter einnehmen läßt.

779. Vgl. Semprún oben sowie im folgenden: »[...] eine lange, endlose Arbeit der Askese, eine Art und Weise, sich von sich selbst zu lösen, indem man sich selbst überwindet: indem man sich selbst wird, weil man den anderen, der man stets ist, erkannt und zur Welt gebracht haben wird.«(1995: 347) 


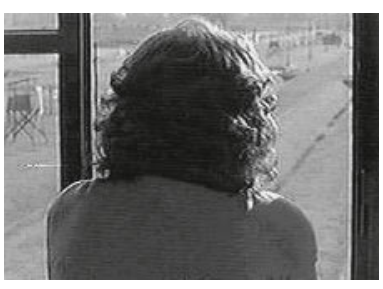

(726) $1: 23: 13 \mathrm{~h}$

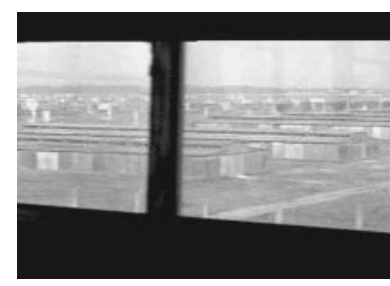

(727) $0: 14: 07 \mathrm{~h}$ (II.2.1)

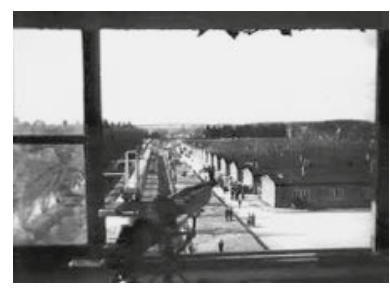

(728) 0:05:56 h (II.1.1)

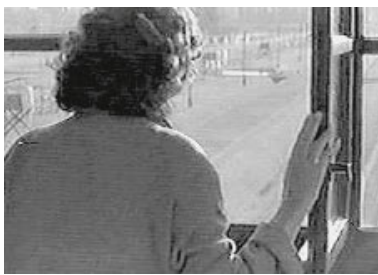

(729) $1: 22: 40 \mathrm{~h}$

durch den Vorwurf ihrer Leidengenossin Ginette, (»A Paris, Ginette, tu m'as dit: >Myriam, comment tu as pu oublier? «; 0:53:30 - 0:53:35 h) ebenso hartnäckig wie vergeblich nach den Spuren dieser Gräben sucht (s. 5.5.7), schreit sie wenige Sequenzen später ihren deutschen Begleiter an: »Et si je ne veux pas m'en souvenir, moi?!« (1:18:39 h)774 - neben ihrem inneren Kampf auch ein Kampf mit Oskar um die »Deutungs-hoheit«, denn dessen Angaben zu den Gräben stimmen nicht mit den ihren überein. Auffällig ist darüber hinaus, daß die Regisseurin gerade im Zusammenhang mit den grauenhaften Massengräbern gezielt Komik einsetzt ${ }^{775}$, was ansatzweise an die groteske Komik in Benignis DAS LEBEN IST SCHÖN erinnert (s. II.4.1), im gesamten Film jedoch eher selten vorkommt. Vermutlich beabsichtigt sie auf diese Weise, dem Zuschauer die Auseinandersetzung auch mit der belastenden Lagerrealität zu ermöglichen.

- Ganz anders und stärker als in Shoah wird in Birkenau und Rosenfeld die extreme Traumatisierung der Überlebenden ${ }^{776}$ durch den beschriebenen Kampf um die Erinnerung bzw. das Vergessen erfahrbar. Obgleich über weite Teile de Films diese innere Zerrissenheit zu spüren ist, wird am Ende des Films deutlich, daß sie im Verlauf des mehrtägigen Besuchs von Auschwitz-Birkenau mit ihrem Trauma umzugehen gelernt und ihre Erinnerung größtenteils wiedererlangt hat. »Je suis vivante, vivante!«, läßt Loridan-Ivens die Protagonistin über das Lager hinweg rufen (s. 1:23:13 h)777: »On la voit même, à la fin, oser monter sur le mirador pour avoir, sur >la planète des cendres<, le point de vue du bourreau guide.« (Loridan-Ivens 2003: 11, H.i.O. $)^{778}$ - Sinnbild ihrer wieder gewonnenen Stärke aufgrund ihrer Selbst-Überwindung, die auch den Zuschauer mit einem positiven Ausblick, einer intensiven Hoffnung entläßt und die an Semprúns Fazit zur heilenden Wirkung seines Schreibens über Buchenwald bzw. zu seiner Rückkehr an den einstigen Schreckensort erinnert.779 Als Absicherung dafür, daß der Prozeß ihrer Selbst-Findung vorläufig abgeschlossen ist, öffnet Myriam in der zentralen Schlußsequenz das Fenster des Wachturms (s. 1:22:40 h), während sie in der ersten Nacht im Lager die Barackentür geschlossen hatte. 


\section{II.5.3 EXPosition: Geheimnisvolle EINfüHRUNG DES Holocaust}

Der Anfang des Films ist bestimmt durch die rätselhafte und dadurch behutsame Einführung der Holocaust-Thematik - behutsam im Sinne von dezent lenkend, diskret und auf diese Weise respektvoll. Durch gezielte Zurückhaltung von expliziten Informationen weckt Loridan-Ivens die Neugier des Publikums und vermag auch der Thematik überdrüssige Zuschauer einzubeziehen.

\section{a) Myriams schwieriges Einlassen auf die Vergangenheit}

Nachdem in der rund zweiminütigen Eröffnungssequenz Myriams Ankunft in einem Pariser Hotel gezeigt wurde, inszeniert die folgende, ca. sieben Minuten andauernde, Sequenz das Treffen des »Freundeskreises der ehemaligen Deportierten von Auschwitz«. Der Anlaß dieses Empfangs wird dem Zuschauer jedoch erst im letzten Drittel explizit mitgeteilt. In den ersten vier Minuten dieser insgesamt längsten Sequenz des Films wird er über den Grund des Zusammentreffens im unklaren gelassen: Nach anfänglicher Verunsicherung durch das Fehlen genauer Informationen häufen sich zunehmend die Indizien dafür, welche gemeinsame Vergangenheit diese Personen teilen. Durch die systematische Lenkung werden verschiedene Kompetenzen aufgerufen, genutzt und entwickelt, die dem wenig informierten Zuschauer teilweise zwar rätselhaft sind, ihn aber neugierig machen.

Von Beginn der Sequenz an ist jedoch spürbar, daß die Protagonistin im Vergleich $\mathrm{zu}$ den anderen Personen wesentlich unsicherer wirkt und daß sie sich mit der gemeinsamen Vergangenheit weniger auseinandergesetzt hat als die anderen. ${ }^{700} \mathrm{Im}$ weiteren Verlauf des Empfangs registriert man, daß das Zusammentreffen mit einstigen Weggefährtinnen in Myriam etwas auslöst, daß sie sich augenscheinlich zum ersten Mal nach langer Zeit mit der gemeinsamen, offenbar verdrängten Vergangenheit wieder zu beschäftigen beginnt. ${ }^{81}$

Das Ende der Sequenz wird von der zentralen Frage beherrscht, ob die Fahrt in die Nähe des einstigen Schreckensortes zu befürworten oder abzulehnen sei. Während die Freundinnen diese negativ beantworten, legt sich Myriam nicht fest.

\section{Detaillierte Sequenzanalyse:}

$\mathrm{Zu}$ Beginn der Sequenz sehen wir die Protagonistin auf dem Weg zu einer Veranstaltung, jedoch vor Betreten des Raums sichtlich zögernd und sich unsicher umsehend (s. ०:03:59 h). ${ }^{782}$ Da der Zuschauer sie bei der Ankunft in Paris (Taxi, Rezeption) weder unentschlossen noch zögerlich erlebt hat, fällt dieser Kontrast besonders auf.

780. Wie Semprún scheint Myriam über ihre gräßliche Vergangenheit lange Zeit geschwiegen zu haben: »Und ich selbst schwieg zu diesem Thema, für lange Zeit. Es war kein gekünsteltes Schweigen, auch kein schuldbewußtes oder ängstliches Schweigen. Vielmehr ein Schweigen des Überlebens. Ein vor Lebenshunger rauschendes Schweigen.« (Ebd. 131)

781. Zur Natürlichkeit des Verdrängens traumatischer Erlebnisse vgl. beispielsweise den Auschwitz-Überlebenden Primo Levi: »[...] die Erinnerung an ein Trauma, ob es nun erlitten oder zugefügt wurde, ist an sich schon traumatisch, denn es schmerzt oder stört zumindest, wenn man es ins Gedächtnis zurückholt. Wer tief verletzt worden ist, neigt dazu, die Erinnerung daran zu verdrängen, um den Schmerz nicht zu erneuern [...].« (1990: 20)

782. Vgl. Lotman 1972: 332. 


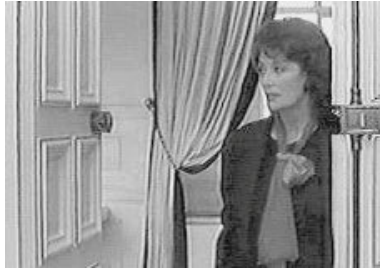

(730) $0: 03: 59 \mathrm{~h}$

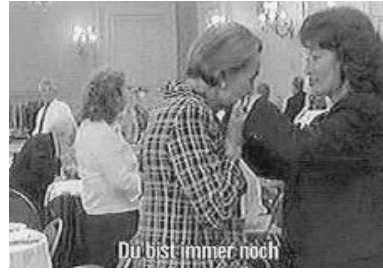

(731) $0: 04: 38 \mathrm{~h}$

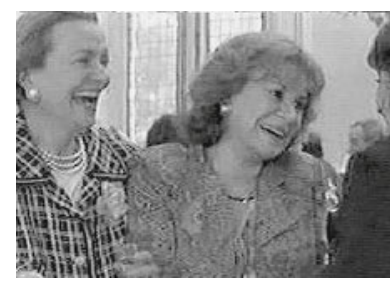

(732) $0: 05: 54 \mathrm{~h}$

Während sich die Menschen auf dem Empfang angeregt unterhalten und sich wohl zu fühlen scheinen, irrt die Protagonistin einige Zeit verloren umher, bis sie schließlich auf eine Bekannte trifft. Die herzliche Begrüßungsgeste (Suzanne küßt Myriams Hände; s. o:04:38) werten wir als Ausdruck größter Freude über das Wiedersehen. Die Bemerkung - »T'es toujours aussi belle, toi.« (0:04:37 h) - bestätigt, daß sich beide Frauen längere Zeit nicht mehr gesehen haben. An dem sich anschließenden Gespräch zwischen den Freundinnen läßt sich ablesen, daß die Hauptfigur noch andere Frauen wiedererkennen könnte. »Il y en a qui était avec nous? « (0:04:55 h), fragt die Protagonistin ihre Freundin. Diese bejaht und nennt ihre Namen: »Ginette, Pierette, Rachel.« (0:04:58 - 0:05:00 h) Dann lenkt Suzanne die Aufmerksamkeit der Hauptfigur auf eine bestimmte Frau und fragt sie, ob sie diese wiedererkenne. »Ah non, je me souviens pas. Mais après cinquante ans, comment veux-tu que je les reconnaisse? « (0:05:04 - 0:05:08 h), lautet die Antwort der Heldin. Die Vermutung des Zuschauers, daß sich die Frauen lange Zeit nicht gesehen haben, wird explizit bestätigt.

Nachdem beide Frauen gutgelaunt Lose für die bevorstehende Tombola erstanden haben, tritt eine dritte Frau hinzu und fragt die Protagonistin, ob sie sie wiedererkenne. Das zögernd fragende »Ginette« (0:05:38 h) bedeutet, daß Myriam die Existenz ihrer damaligen Weggefährtinnen stärker verdrängt oder gar vergessen hat, während sie selbst von Ginette mit dem Vornamen angesprochen wird. Man kann allerdings aus Myriams Bemerkung - »Non, mais attends, la dernière fois que je t’ai vu, t'étais si maigre, t’avais une tête à finir au crématoire.« (0:05:49 - 0:05:53 h) - ahnen, wann sie sich das letzte Mal begegneten. Die Zuschauer, welche das Thema des Films kennen und die knappe Anspielung auf die Naziverbrechen verstehen, empfinden bei diesem Satz, vor allem aufgrund des Gelächters der drei Frauen (s. o:05:54 h), Unbehagen und fragen sich eher irritiert, wie diese Betroffenen über [732] ein solches Thema scherzen können.

Als die drei Frauen in der Folge ihre Tombola-Preise auspacken und Myriam unter anderem Socken gewonnen hat, kommentiert Ginette knapp: »Eh bien, si on en avait eu là-bas ...« (०:०6:38 h) - ein weiteres, im allgemeinen Trubel um die Preise beinahe untergehendes Indiz, woher sie sich kennen. Trotz des angesprochenen Unbehagens kommt der Zuschauer nicht umhin, die Vitalität der Frauen zu bewundern.

Das noch unbestimmte »là-bas« wird in der sich anschließenden Szene konkretisiert. Nachdem eine verstört wirkende Frau grußlos an den Dreien vorbeigegangen ist, fragt Myriam nach, wer diese Person sei; erneut kann sie sich nicht von alleine erinnern und Suzanne erklärt: »Elle est arrivé enceinte dans le camp. Les SS lui ont pris le bébé pour le jeter dans la chambre à gaz« (0:07:09 - 0:07:15 h, s. 0:07:13 h). Zwei Sätze, die drei entscheidende Signalworte enthalten (Lager, SS, Gaskammer) und so die Lösung des Rätsels, woher sich diese Frauen kennen, liefern. Im Unterschied 
zur vorhergehenden Szene herrscht in diesem Augenblick betretene Stille zwischen den Freundinnen. Der Zuschauer vermutet, daß es sich um ein Treffen HolocaustÜberlebender handelt.

Als Myriam die merkwürdige Frau fragt, welche Nummer sie denn gezogen habe, antwortet diese auffällig laut, mechanisch und in deutscher Sprache: »75745!« (0:07:26). »Et vous?« (0:07:31 h), fragt die verstörte Frau und Myriam antwortet: "75750. On est du même transport. Vous vous souvenez de moi? Myriam ... - Non, je ne vous connais pas.«(0:07:32 - 0:07:44 h) Das kurze Gespräch zwischen beiden Frauen bestärkt unseren Verdacht, verwirrt jedoch wegen dieser Zahlenangabe. Der informierte Zuschauer könnte die den Lagerinsassen eintätowierte Häftlingsnummer vermuten.

Nachdem Suzanne Myriam erklärt hat, daß die sonderbare Frau in einer psychiatrischen Klinik lebt - weiterer Hinweis auf die traumatische Vergangenheit der Anwesenden -, wird der Anlaß des Zusammentreffens explizit angesprochen. Während wir die Hauptfigur am Buffet sehen, hören wir aus dem Off eine Stimme: »Au nom des amicales des anciens déportés d'Auschwitz je passe la parole à [...] Jean-Michel, Maire adjoint.« (০:07:59 - ০:08:04 h) Da die Einführung des stellvertretenden Bürgermeisters im allgemeinen Stimmengewirr beinahe untergeht, nimmt die Lautstärke beim Aussprechen des Toasts erheblich zu; der Sprechende wird durch eine Kamerafahrt sukzessive ins Bild gerückt: »Et maintenant, je bois à toutes les survivantes et à tous les survivants et bonheur de nous retrouver ensemble.« (0:08:10 - o:०8:16 h) Nach diesem Toast ist klar, daß es sich um ein Treffen von Auschwitz-Überlebenden handelt, die sich aufgrund ihrer verschiedenen Lebenswege seit Kriegsende zum Teil nicht mehr gesehen haben. So ließe sich auch nachvollziehen, daß einige - wie Myriam - die Vergangenheit stärker vergessen bzw. verdrängt haben als andere, daß manche aufgrund der traumatisierenden Erfahrungen unter medizinischer Aufsicht leben und daß sich Myriam zu Beginn der Sequenz auffällig unsicher in den Veranstaltungsraum begeben hat.

Nachdem der städtische Repräsentant auf das Wohl der Überlebenden getrunken hat, provoziert ihn die hinzugetretene Myriam mit einer rhetorischen Frage: »A votre avis,

783. Vgl. Ruth Klüger zum von außen erhobenen Vorwurf an ehemalige Lagerinsassen: »Ein Bekannter, ein Jude in Cleveland, verlobt mit einer Deutschen, sagt mir ins Gesicht: >Ich weiß, was ihr getan habt, um euch am Leben zu erhalten.८ [...] Er meinte: ^Ihr seid über Leichen gegangen.८ (2001: 72) Und in Wirklichkeit war es Zufall, daß man am Leben geblieben ist.« (Ebd. 73) Vgl. auch Semprún zum zufälligen Überleben: »Aber das Überleben war keine Frage des Verdienstes, es war eine Frage des Glücks.« (1995: 168)

784. "Ich habe nie verstanden, warum man sich schuldig fühlen sollte, überlebt zu haben. Im übrigen hatte ich nicht wirklich überlebt. [...] Ich war durch den Tod hindurchgegangen.» (Semprún 1995: 167) »Ich hätte mich schuldig fühlen können, wenn ich geglaubt hätte, daß andere es mehr als ich verdient hätten zu überleben. [...] Die Würfel waren für mich gut gefallen, sonst nichts.« (Ebd. 168) Letzteres bestätigt auch Ruth Klüger: »Fast jeder Überlebende hat seinen `Zufalk, das Besondere, Spezifische, das ihn oder sie unvermutet am Leben erhalten hat. Meiner hat die Besonderheit, daß sich eine Fremde einmischte. [...] Ja, sagen die Leute leichtfertig, sie verstünden sowas recht gut, viele Menschen seien altruistisch, das war so eine. - Warum wollt ihr nicht lieber mit mir staunen?« (2001: 134, H.i.0.) 


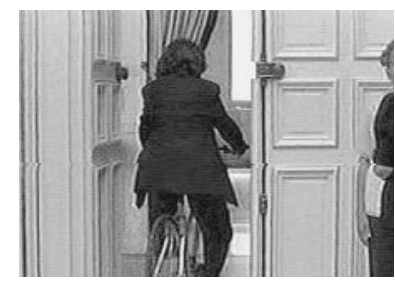

(733) $0: 10: 17 \mathrm{~h}$

on a survécu parce qu’on [...] plus accroché au corps que les autres ou parce qu'on a laissé mourir les autres à notre place?« (0:08:19 - 0:08:25 h) Da sie auf diese schwierige Frage ohnehin keine Antwort erwartet, läßt die Protagonistin den Gastredner kurzerhand stehen, um weitere Lose zu kaufen. Diese rhetorische Frage spielt auf ein offenbar geläufiges Vorurteil an bzw. gibt die den Überlebenden eigenen Schuldgefühle wieder. ${ }^{783}$ Marceline Loridan-Ivens gibt dem Zuschauer Zeit, die Provokation in sich nachhallen zu lassen: Knapp zehn Sekunden lang schont sie dessen Aufmerksamkeit, indem sie die Heldin lediglich durch die Menge laufen läßt, während in anderen Filmen, vor allem in NACHT UND NEBEL (s. II.2.1.4), die Informationen in wesentlich schnellerem Rhythmus erfolgen.

Als Ginette bei der Vergabe der Gewinne eine Fahrkarte nach Krakau erhält und Suzanne fragt, ob sie daran interessiert sei, antwortet diese leicht entrüstet und sehr ernst: »Non, merci pour les cadeaux, retourner à coté d'Auschwitz« (0:09:30 - 0:09:33 h; s. o:09:29 h). Auch der Zuschauer empfindet die Brisanz eines solchen Preises für Auschwitz-Überlebende, da er die Verbindung zwischen der polnischen Stadt und Auschwitz herstellen kann. Auf Suzannes Gegenfrage antwortet Ginette ebenso bestimmt wie tonlos: »Moi? Je retournerai jamais en Pologne, jamais.« (0:09:35 - 0:09:37 h) Schweigend, aber aufmerksam hat Myriam das Geschehen verfolgt. Als hätte sie sich bisher mit dieser schwierigen Frage noch nicht auseinandergesetzt, ist in ihren Zügen eine gewisse Nachdenklichkeit erkennbar. Ein Zeichen, daß sich in ihr etwas bewegt, daß sie sich in Bewegung setzt, ist ihr Hauptgewinn, nämlich ein Fahrrad, mit welchem sie durch die versammelte Menge und schließlich aus dem Raum radelt (s. 0:10:17 h).

\section{b) Myriams schamvolle Erinnerung}

Die sich anschließende Sequenz greift die zuvor angerissenen Vorwürfe Überlebenden gegenüber auf und thematisiert deren Schuldgefühl ihren toten Leidensgenossen gegenüber, eine Belastung, die aus Äußerungen zahlreicher survivors bekannt ist. Im Unterschied zu Jorge Semprún $7^{84}$ beschreibt Primo Levi dieses Schuldgefühl, diese »Scham« als:

»[...] die Selbstbezichtigung oder der Vorwurf, unter dem Aspekt der menschlichen Solidarität gefehlt zu haben. Wenige Überlebende fühlen sich schuldig, einem Leidensgenossen absichtlich Schaden zugefügt [...] zu haben: [...] andererseits fühlen sich beinahe alle der unterlassenen Hilfeleistung schuldig. Daß neben dir ein schwächerer oder unerfahrenerer oder älterer oder viel zu junger Leidengenosse steht, der dir mit seinen Bitten um Hilfe oder ganz einfach durch seine bloße Gegenwart, die schon an und für sich eine Bitte ist, auf die Nerven geht, ist eine Konstante im Lagerleben. Die Bitte um Solidarität, um ein freundliches Wort, um Rat 
oder einfach um Gehör wurde ständig und überall geäußert, aber nur selten entsprach man ihr. Es fehlte die Zeit, der Raum, die private Sphäre, die Geduld, die Kraft, und zumeist befand sie der, an den sich die Bitte richtete, selber in einem Zustand der Bedürftigkeit, brauchte selber Zuspruch.« (Levi 1990: 77)

»Aber ich erinnere mich auch, und mit Unbehagen, daß ich angesichts anderer Bitten weitaus öfter ungeduldig die Schultern gezuckt habe, und zwar, nachdem ich schon ein Jahr im Konzentrationslager war und infolgedessen eine gehörige Portion Erfahrung angesammelt hatte: aber ich hatte mir auch die wichtigste Regel dieses Ortes von Grund auf zu eigen gemacht, die vorschrieb, zuallererst an sich selbst zu denken.« (Ebd. 78)

Aus dieser Szenenfolge geht hervor, daß Myriam v.a. aus Scham und Schmerz bislang geschwiegen hat. Daher gehörte sie, weiterhin gemäß Primo Levi, zu denjenigen Überlebenden, die »mit sich selbst nicht in Frieden [sind], ihre Wunden brennen noch« (ebd. 152):

»Kommt deine Scham daher, daß du an Stelle eines anderen lebst? Und vor allem an Stelle eines großherzigeren, sensibleren, verständigeren, nützlicheren, des Lebens würdigeren Menschen als du? [...] Es handelt sich nur um eine Vermutung, aber sie nagt an dir; sie hat sich in deinem tiefsten Inneren eingenistet wie ein Holzwurm. Von außen kann man sie nicht erkennen, aber sie nagt und bohrt.« (Levi 1990: 81)

»Überlebt haben vorwiegend die Schlimmsten, die Egoisten, die Gewalttätigen, die Gefühllosen, die Kollaborateure der `Grauzone`, die Spione. Das war zwar keine zuverlässige Regel [...], aber doch eine Regel. Gewiß, ich fühlte mich ohne Schuld, aber gleichzeitig war ich den Geretteten zugesellt und daher auf der ständigen Suche nach einer Rechtfertigung vor mir selbst und den anderen. Überlebt haben die Schlimmsten, und das heißt die Anpassungsfähigsten. Die Besten sind alle gestorben.« (Ebd. 82, H.i.0.)

\section{Detaillierte Sequenzanalyse:}

Dieser sich andeutende Wandel der Protagonistin wird in der folgenden Sequenz abgesichert. Am Abend nach der Veranstaltung sitzen Myriam und Suzanne am Ufer der Seine, ein Musikant spielt Akkordeon. Das Lied erinnert Suzanne an eine frühere, vermutlich gemeinsame Leidensgenossin, die nicht überlebte. ${ }^{785}$ Myriam hört nachdenklich zu, es scheint, als kenne sie die Geschichte nicht:

»C'est la chanson que chantait Françoise, nue devant sa koya, après avoir été sélectionné pour la chambre à gaz. Le chef de block s'est approché d'elle et lui a dit: ১Quelle belle voix! Pourquoi tu n'a pas chanté avant? Je t'aurais évité la sélection. Maintenant, c'est trop tard, ils ont pris ton numéro.« (0:10:46 - 0:11:00 h)

785. Eine äußerst plausible Situation, schließlich sind es häufig bestimmte Lieder, die Erinnerungen wecken.

786. Siehe 5.5.g zur Auseinandersetzung zwischen Myriam und Ginette über den exakten Ort der Massengräber. 


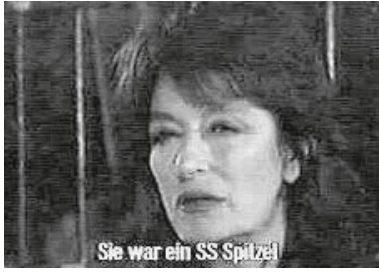

(734) $0: 11: 33 \mathrm{~h}$

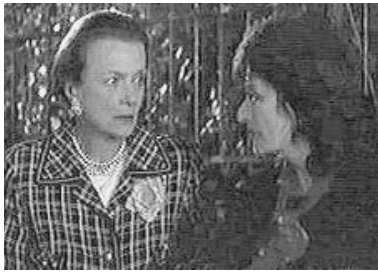

(735) $0: 12: 46 \mathrm{~h}$

Während die leicht beschwingte Akkordeon-Musik (Musette) weite Teile der Erzählung begleitet hat, bricht sie beim letzten Satz abrupt ab. Die schreckliche Tatsache von Françoise' Tod wird hierdurch hervorgehoben.

Mit leiser und unsicherer Stimme und gesenktem Blick gesteht die Protagonistin: »Françoise, si elle est morte, c'est de ma faute.«(o:11:23 h) Auf Suzannes bestürztes Nachfragen, erzählt Myriam den Grund für Françoise' Tod. Im Unterschied zu der Freundin fällt ihr das Erinnern sichtlich schwerer: Um die damalige Situation zu rekonstruieren, kneift sie mehrfach die Augen zusammen - ein mimisches Zeichen, das man im Zusammenhang mit dem Heraufbeschwören von Vergangenem häufig beobachten kann (s. o:11:33 h):

»Un jour, une Polonaise, une coursière des SS [...] m'a demandé mon numéro de matricule. Françoise était derrière moi et elle a chuchoté dans mon oreille: >Dis que je suis ta sœur ! $\mathrm{J}$ 'ai rien dit ... Et puis, il y a eu cet appel, un SS est arrivé, il a crié mon numéro, ton numéro, mais pas son numéro. On était choisi pour le triage des vêtements, le ২Kanadar, paradis. Si j'avais dit son nom, elle serait encore avec nous aujourd'hui.« (0:11:23 - 0:12:14 h)

Aus Myriams Erinnerung spricht das bereits zuvor in der provokativen Frage an den Bürgermeister angeklungene Schuldgefühl der Überlebenden den toten Leidensgenossen gegenüber. Bestätigt wird dieser Eindruck durch ihr folgendes, Suzannes Einwände ignorierendes Eingeständnis: »Cette histoire, je ... je la ressasse depuis cinquante ans ... comme une faute terrible.«(o:12:27 - o:12:33 h) Dem Zuschauer kommt es jedoch so vor, als habe die Protagonistin diese Geschichte bisher niemandem erzählt, als brächen plötzlich ihre nur dürftig vernarbten Wunden durch die Konfrontation mit ihrer Vergangenheit wieder auf. Trotz des erneuten Widerspruchs der Freundin, deren Version im übrigen glaubhafter wirkt, läßt sich Myriam nicht überzeugen, sondern spricht mit ihrem Fazit das Problem der unterschiedlichen Erinnerungen und der generellen »Erinnerungshoheit« an - Aspekte, die im Verlauf des Films wiederkehren: »Tu vois, on n'a pas les mêmes souvenirs. Qu'est-ce qui me prouves que c'est toi qu'a raison? «(0:12:39 - 0:12:48 h; s. 0:12:46 h) ${ }^{786}$ Da es sich bei dieser Frage um den letzten Satz der Sequenz handelt und sie unbeantwortet bleibt, hallt sie besonders stark im Zuschauer nach, der seinerseits dieses Problem nachvollziehen kann. Hat Myriam unrecht, wenn sie aufgrund dieses einschneidenden Erlebnisses massive Schuldgefühle und immenses Leid belasten?

Die letzte in Paris spielende Sequenz greift erneut die Frage nach der Rückkehr Überlebender an einstige Schreckensorte auf und bestätigt unseren Eindruck, daß Myriam, im Unterschied zu ihren Freundinnen, darauf noch keine eigene Antwort gefunden hat. 
Nachdem sich wiederum gezeigt hat, daß Myriam weniger Erinnerung an früher abrufen kann als Suzanne, fragt sie diese relativ unvermittelt: »T'as jamais pensé y retourner un jour là-bas?«(o:13:28 h) Dieser Gedanke beschäftigt Myriam offensichtlich seit dem Nachmittag, doch hat sie sich - im Unterschied zu den Freundinnen - die Frage einer Rückkehr bisher noch nicht gestellt und somit auch noch keine Antwort. Suzanne hingegen entgegnet ebenso knapp wie klar: »Pour quoi faire?« (0:13:32 h) Auch hier bildet die unbeantwortete Frage den Schluß der Sequenz und fordert den Zuschauer auf, sich - parallel zur nachdenklichen Heldin (s. o:13:54 h) - eigene Gedanken zu machen.

\section{II.5.4 SPUREN DER VERGANGENHEIT - BE-GREIFEN, UM ZU ERINNERN}

In insgesamt fünf Sequenzen widmet sich die Regisseurin den Spuren der Vergangenheit und dem Be-Greifen derselben als Mittel, ihre eigenen Erinnerungen heraufzubeschwören (s. 5.2).

a) Auf dem Weg ins Lager: »Stolpern « über Gleise

Der Zuschauer wird zunächst in das Bewußtsein der Protagonistin versetzt: Die Bahngleise rufen Myriams Erinnerung an ihre Ankunft im Lager wach. Wir hören mit ihr das Pfeifen eines imaginären Zuges, danach wohnen wir aus dem Off ihrer Erinnerung an die erste Selektion und die Rettung durch Françoise bei.

Des weiteren gibt es Parallelen zu Resnais' Nacht und Nebel hinsichtlich der Art und Weise der Annäherung an das Lager.

\section{Detaillierte Sequenzanalyse:}

Zu Beginn sieht und hört der Zuschauer die Protagonistin durch eine große, menschenleere Wiese mit hohem Gras gehen, mit ihren Augen auffällig lange (20 Sekunden) den Boden absuchend.

Das Rätsel um den für den Zuschauer nicht identifizierbaren Ort wird lösbar, als die Heldin auf nicht mehr benutzte Bahngleise stößt und bei deren Anblick wie gebannt stehenbleibt (s. o:21:18 h). Nach wenigen Sekunden sind aus dem Off zunächst das Pfeifen und danach das Rollen eines Zuges zu vernehmen. Die Nahaufnahme der Protagonistin läßt uns erkennen, daß sie auf dieses anschwellende Geräusch ebenfalls aufmerksam geworden ist und ihm besonderes Interesse widmet - der Zug im Bildhintergrund hingegen ist nicht in Bewegung (s. 0:21:27 h).

Nachdem die Regisseurin dem Zuschauer beinahe eine halbe Minute Zeit zum Nachdenken bzw. -fühlen und Sich-Vorstellen eingeräumt hat, bestätigt sie die Vermutung. Myriam, die sich inzwischen auf den Gleisen mit bedächtigem Schritt in eine unbestimmte Richtung bewegt, spricht plötzlich aus dem Off. Wir nehmen an ihrem, sich an den Bahngleisen - »der Sackgasse im Amoklauf einer besessenen

787. Vgl. die Bemerkungen der Holocaust-Überlebenden Ruth Klüger zur zufälligen Rettung in ihrem autobiographischen Roman »Weiter leben«: »Fast jeder Überlebende hat seinen `Zufall, das Besondere, Spezifische, das ihn oder sie unvermutet am Leben erhalten hat.« (2001: 134, H.i.0.) 


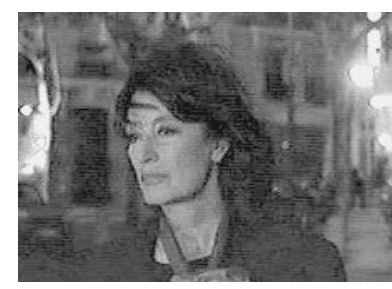

(736) $0: 13: 54 \mathrm{~h}$

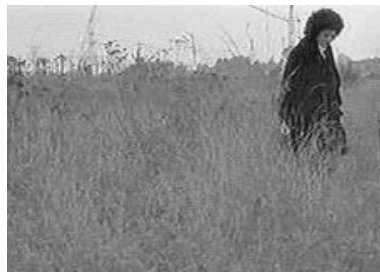

(737) $0: 21: 18 \mathrm{~h}$

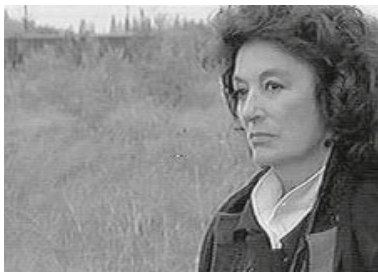

(738) $0: 21: 27 \mathrm{~h}$

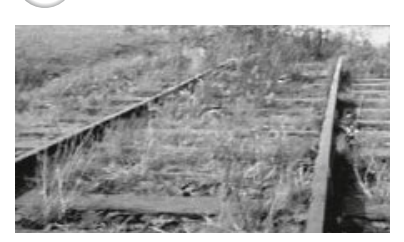

(740) $0: 07: 22 \mathrm{~h}$

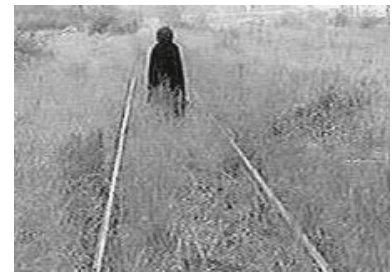

(739) $0: 22: 10 \mathrm{~h}$

Kultur« (Klüger 2001: 113) - entzündendem Erinnern teil und ahnen, daß das Lager nicht weit ist:

»A l'aube ils ont ouvert les portes. On entendait des hurlements, des chiens qui aboyaient. Devant on criait: 'Les gens fatigués, les vieillards, les enfants, prenez les camionsı. Moi, j'avais mal au pied, j'allais monter. Françoise m'a retenu de force: >Ne me quitte pas!^ (s. 0:22:10 h) ... C'était la première sélection. Elle m'a sauvé la vie.« (0:21:57-0:22:29 h)

Aufgrund dieser Erinnerung an die erste Selektion beginnt man, Myriams Gefühl der Überlebensschuld gegenüber Françoise besser zu verstehen - auch wenn es eher Zufall bzw. Angst war, die zur ihrer »Rettung « führte. ${ }^{787}$ Wie der Zuschauer weiß, führten die Lastwagen in den sofortigen Tod; Selektion hieß, schwache und ältere Menschen sowie Kinder von den Arbeitstauglichen zu trennen.

Während die Bilder von diesem glücklichen Ausgang der gefährlichen Situation an der Protagonistin vorüberziehen, vermittelt die Landschaft in ihrer Stille einen friedlichen Eindruck. Das Gras ist zwischen den Gleisen hoch gewachsen, ein Bild, das an eine Kamerafahrt aus Resnais' NACHT und NeBEL erinnert. In beiden Filmen dienen diese Szenen der Annäherung an das Lager Auschwitz, im direkten wie im übertragenen Sinn: Das Sinnbild des Holocaust als bildkompositorischer Fluchtpunkt. Die Polarisierung Menschlichkeit gegen Unmenschlichkeit erleichtert es dem Zuschauer - im Unterschied zu NACHT und NeBEL -, sich auf das Entsetzliche der Vernichtung einzulassen, da er als positives Gegengewicht das Überleben der Protagonistin erfährt (s. III). 
Gegen Ende der Sequenz gibt die Regisseurin dem Zuschauer ein neues Rätsel auf, dem er im Verlauf des Films noch einmal begegnet, es aber erst im Schlußbild zu lösen vermag. Ein junges Mädchen kreuzt mit einem Fahrrad die überwucherten Bahngleise und schaut der Protagonistin auffällig nach (s. 0:22:47 h). Auffallend ist, daß das Mädchen - wie das im Vorspann genannte - ca. 15 Jahre alt ist und vor allem rote Haare hat, wie Myriam, was die Heldin während des Nachtreffens erwähnte. In einer der letzten Sequenzen des Films begegnet Myriam dem jungen Mädchen im Lager, wortlos gehen sie aneinander vorbei (s. 1:19:46 h). Im Unterschied zur ersten Inszenierung des Mädchens mutet diese Begegnung unwirklich an, als fände sie in einer Art Traum statt. Das Schlußbild bestätigt diesen Eindruck und insbesondere die Vermutung des Zuschauers: In einer Doppelbelichtung verschmilzt Myriams nachdenklicher Blick beim Verlassen von Polen mit dem Bild des rothaarigen Mädchens - es kann als eine Art Alter ego von Myriam/Marceline Loridan-Ivens verstanden werden, denn die Protagonistin war zur Zeit ihrer Internierung zwischen 15 und 16 Jahren alt (s. 5.1).

\section{b) Myriam in ihrer Baracke: Ab-Tasten der Schlafstätten}

In der Sequenz der Annäherung, besonders aber während des Aufenthaltes in ihrer einstigen Schlafbaracke wird für den Zuschauer deutlich erfahrbar, wie Myriams Vergangenheit vor ihrem inneren Auge auflebt. Über im Selbstgespräch aufflackernden Erinnerungen füllt sich auch für uns der leere Raum mit Personen und Situationen. Voraussetzung hierfür ist jedoch, daß wir uns der Anregung unserer Vorstellungskraft nicht verschließen. Dies ist jedenfalls von der Regisseurin durch die minimalistische Inszenierung systematisch angelegt: Im Unterschied zu den Außengeräuschen, wie Vogelgezwitscher und Wind, herrscht im Barackeninneren absolute Stille. Die Aufmerksamkeit des Zuschauers wird ganz auf Myriams Selbstgespräch sowie ihr vorsichtiges Tasten und Greifen gelenkt. Es wirkt, als wolle die Protagonistin die Vergangenheit, die Abende in den Schlafbaracken heraufbeschwören (s. 5.2.2).

Nachdem ihr beim Anblick der Bahngleise die Selektion bei Ankunft im Lager wieder bewußt wurde, erinnert sie sich, knapp fünf Minuten später, sichtlich gerne an ihre Genossinnen in der Schlafbaracke - ein wirkungsvoller Kontrast, in dem sich die Erinnerung an Schrecklichstes und Hoffnungsvolles wechselseitig steigern. ${ }^{78}$

Hinsichtlich der Art und Weise der Inszenierung erinnert diese Szenenfolge an die entsprechende aus Resnais' Nacht und Nebel (s. 2.1.5). Ansatzweise vergleichbar ist die bildkompositorische Gestaltung der aneinander gereihten Schlafkojen aus Stein. Während Resnais jedoch das Ausmaß der Einpferchung durch eine extreme Weitwinkelperspektive (s. Standbild o:09:28 h), verbunden mit einer Kamerafahrt, dem Zuschauer vor Augen zu führen versucht, läßt Loridan-Ivens ihre Protagonistin die Namen ihrer Kameradinnen aufzählen - eine durchaus identifikationsfördernde Individualisierung, im Unterschied zu den anonymen Lagerinsassen in NACHT UND NeBEL.

In zweiten Teil der Sequenz führt Loridan-Ivens das im weiteren Verlauf des Films zunehmend bestimmendere Prinzip des In-sich-Gehens ein (s. 5.5.b). Dies ist kompositorisch geschickt, denn auf diese Weise sensibilisiert sie den Zuschauer im Hinblick auf Myriams zentrale Formen der Annäherung, der Wieder-Aneignung des Lagers.

788. Man erinnere sich an den Aspekt der positiven Erinnerungen in 5.2. 


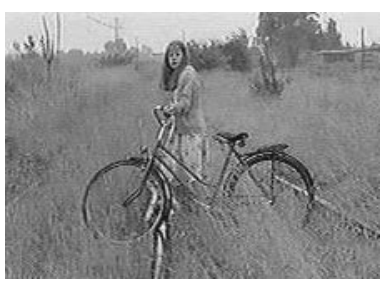

(741) $0: 22: 47 \mathrm{~h}$

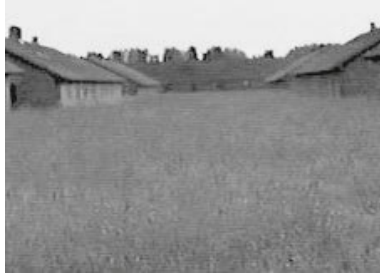

(744) $0: 24: 37 \mathrm{~h}$

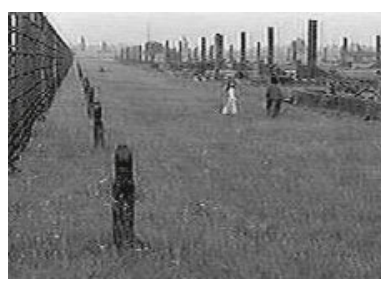

(742) $1: 19: 46 \mathrm{~h}$
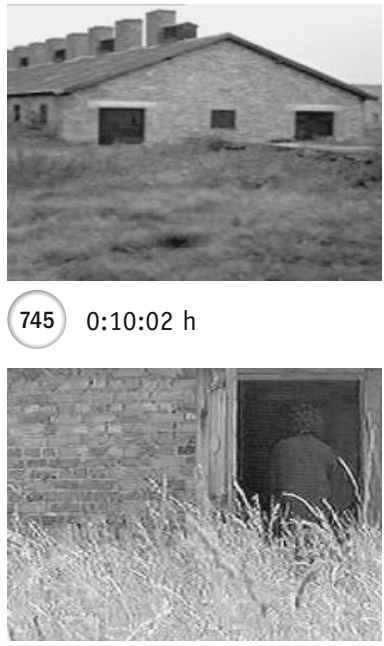

(747) $0: 24: 58 \mathrm{~h}$

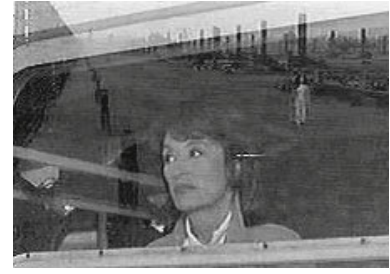

(743) $1: 25: 28$

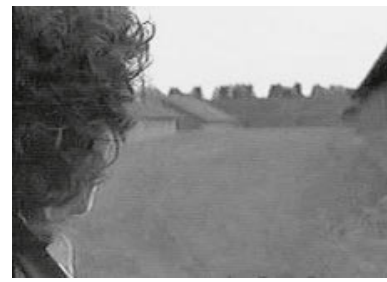

(746) $0: 24: 46 \mathrm{~h}$

Detaillierte Sequenzanalyse

Die folgende Einstellung inszeniert mittels einer langsamen Kamerafahrt den von Gras überwucherten Raum zwischen zwei verlassenen, beinahe friedlich anmutenden Baracken (s. o:24:37 h) - und erinnert daher in gewisser Weise an NACHT UND NEBEL (s. ०:10:02 h).

Noch bevor die Protagonistin im Bild zu sehen ist, hören wir sie zählen. Sie sucht - und mit Hilfe des Zählens findet sie ihre damalige Baracke wieder: »Neuf - mon block!« (s. 0:24:46 h) Das Rätsel ist vergleichsweise rasch gelöst.

Anschließend inszeniert Marceline Loridan-Ivens eine weitere Schwelle: Während in der gesamten unteren Bildhälfte die dichten, in der Sonne glänzenden Gräser auffällig im Wind rascheln - hohes Gras ist über die einst platt getretene Erde gewachsen -, nähert sich die Heldin äußerst behutsam dem Eingang zu ihrem Block. Bevor sie im Schatten, schließlich im Schwarz des Eingangs verschwindet, verharrt sie auffällig lange auf der Türschwelle (s. 0:24:58 h). Die Regisseurin versucht auf diese Weise dem Zuschauer Myriams Überwindung erfahrbar zu machen, ihn dafür zu sensibilisieren, wie schwer es für Myriam ist, in das Dunkel ihrer Erinnerung einzutauchen - die spezifische Bildkomposition mit ihrem Hell-Dunkel-Kontrast unterstützt diese Sinndimension. 
Im Inneren des Blocks herrscht absolute Stille, nur die langsamen Schritte, vor allem das Schlurfen der Heldin ist vernehmbar. Langsam und stumm schaut sie sich um, berührt mit der Hand auffällig intensiv die Holzkante einer Schlafkoje. Etwa eine halbe Minute vergeht auf diese Weise, bis sie an die Kante einer anderen Koje faßt und dazu den Namen ihrer Freundin (s. 0:25:37 h) und viele weitere Frauennamen ausspricht: Simone, sa mère, Madame Jacob, Victoire, Renée, Mireille, ma tonne de bordel, ma petite Marie, Henriette, la voyante, Madeleine, Michelle, Rachel et moi, Myriam (s. 0:26:27 h).« (0:25:36 $0: 26: 29 \mathrm{~h})$

Der Zuschauer versteht, daß es sich um die Namen ihrer Leidensgenossinnen handelt. Mit jedem Namen, den sie nennt, greift sie an die entsprechende Koje, woraus hervorgeht, daß sich mindestens drei Frauen einen Schlafplatz teilen mußten. »Der leere Raum belebt sich für einen Augenblick, und alle sind wieder da, um sie herum.«(Jeismann 2004: 33) Entgegen den auf gängigen Darstellungen beruhenden Erwartungen des Zuschauers scheint Myriam nicht nur negative Erinnerungen an die damalige Zeit im Lager zu haben, denn sie lächelt beim Nennen ihres eigenen Namens und dem einer Prostituierten (s. erneut 0:26:27 h).

c) Verrostete Notenständer - sichtbare Spuren der absurden Lagerrealität Neben dem zufälligen Finden und Ent-Decken von Relikten der grauenhaften Vergangenheit, Auslöser für Myriams Erinnerungen, gibt es in dieser Sequenz eine Szene besonderer Art. Die Protagonistin verleiht ihrer Erinnerung Ausdruck im »Nachspielen« eines Erlebnisses, ausgelöst durch das Auftreten eines Notenständers.

Zwischen dem Entdecken der Relikte und Myriams Verkörperung ihrer Erinnerung läßt Loridan-Ivens dem Zuschauer viel Zeit, nach- oder sich auszudenken, wozu es im Lager Notenständer gab. Das Versetzen des Zuschauers in Myriams Bewußtsein durch kurzes Einblenden des Radetzky-Marsches lenkt seine Antizipation. Diese wird im zweiten Teil der Sequenz abgesichert, als die Protagonistin das Marschieren auf der Lagerstraße nachspielt.

Im Unterschied zur vergleichbaren Szene in Nacht und Nebel vermag die Art und wiese der Inszenierung dem Zuschauer die Absurdität der Nazi-Inszenierungen sowie die damit einhergehenden Wunden der Überlebenden erfahrbar zu machen. ${ }^{789}$

Im Gegensatz zu Resnais' »leeren« Relikten am Ende von NACHt und Nebel (s.u.) und vor allem den unerträglichen Spuren des Todeskampfes in den Gaskammern (s. II.2.1.6) wählt Marceline Loridan-Ivens in der vorliegenden Sequenz ein weitaus dezenteres Zeichen der Vergangenheit zur Erfahrbarmachung der absurden SS-Praktiken.

789. »Im übrigen scheint es mir offenkundig, daß die Welt der Konzentrationslager in vielen ihrer quälendsten und absurdesten Aspekten nur eine Version, eine Adaptation der deutschen Militärpraxis war. Das Heer der Lagerhäftlinge sollte eine ruhmlose Kopie des eigentlichen Heeres oder, genauer gesagt, seine Karikatur sein. [...] Ein Heer marschiert im Militärschritt, als geschlossene Formation, beim Klang der Militärkapelle: aus diesem Grund muß es auch im Lager eine Musikkapelle geben, und das Vorbeidefilieren muß nach allen Regeln der Kunst ausgeführt werden, mit >Achtung! Augen links! ‘ vor der Tribüne der hochgestellten Persönlichkeiten, zum Klang der Musik.« (Levi 1990: 117f., H.i.0.) 


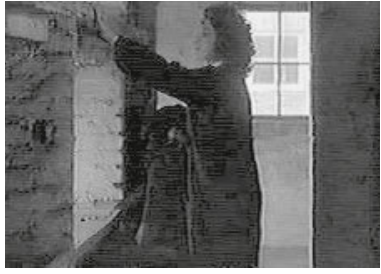

(748) $0: 25: 37 \mathrm{~h}$

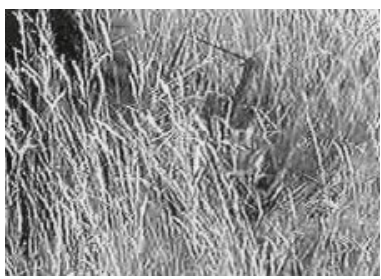

(750) $0: 30: 16 \mathrm{~h}$

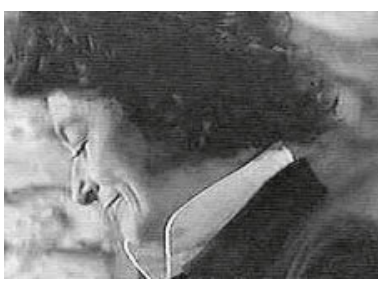

(749) $0: 26: 27 \mathrm{~h}$

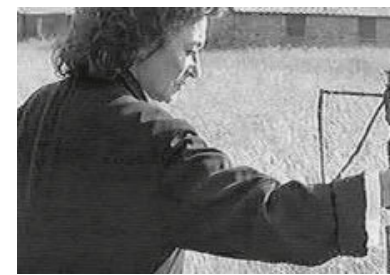

(751) $0: 30: 21 \mathrm{~h}$

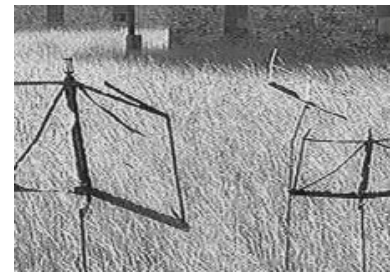

(752) $0: 31: 12 \mathrm{~h}$

Aufgrund der Greifbarkeit der Relikte ist die vorliegende Sequenz besonders vergleichbar mit der späteren Aschensee-Sequenz (s. 5.4.e) und steht in Opposition zu Myriams verzweifelter Suche nach Spuren der Massengräber (s. 5.5.7).

\section{Detaillierte Sequenzanalyse:}

Die erste Einstellung zeigt zunächst vor allem satt-grünes, in der Sonne glänzendes Gras; am oberen Bildrand erahnt der Zuschauer hinter den Gräsern Myriams Schritte, die nach kurzer Zeit einen Gegenstand berühren (s. 0:30:16 h). Da dieser durch die dichten Grashalme nicht identifizierbar ist, steigt unsere Neugier. Als Myriam das Objekt vom Boden aufhebt, ist ein von der Witterung verrosteter Notenständer erkennbar (s. o:30:21 h), offensichtlich eine Spur der Vergangenheit, denn Myriam wirkt von dem zufälligen Fund sichtlich berührt. Aufgrund des langsamen Rhythmus sowie der Rätselstruktur dieser Szene wird der Zuschauer angeregt, eigene Vermutungen über die Verbindung von Musik und Lager anzustellen. Bedächtig hebt die Protagonistin zwei weitere Notenständer aus dem Gras auf - Indiz für ein Orchester. Gestützt wird diese Vermutung durch eine besondere Gestaltung der Tonspur: Nachdem Myriam den zweiten Notenständer aufgerichtet hat, ist äußerst kurz und undeutlich der Auftakt einer Marschmusik (Trommeln) zu vernehmen. Da - knapp zehn Minuten zuvor - das Pfeifen eines Zugs ebenfalls ohne visuelle Entsprechung geblieben war, liegt der Schluß nahe, daß wir durch die Musik in Myriams Bewußtsein versetzt werden. Nachdem wieder Ruhe eingekehrt ist, die Heldin einen dritten Notenständer aufgestellt und das Bild verlassen hat (s. 0:31:12 h), wird - nach kurzer Stille - tatsächlich Marschmusik eingeleitet, es ertönt der Radetzky-Marsch. Myriam wird zunehmend von in ihrer Erinnerung gefangen genommen.

Dieser leitet über zur folgenden Einstellung, dem zweiten Teil der Sequenz: Von dieser Erinnerung übermannt, marschiert die Protagonistin wie einst im Gleichschritt mit der lauten Marschmusik die Lagerstraße entlang (s. 0:31:26 h). »Zwo, drei, vier! Links! Links! Und links! Und links. Eins, zwo, drei, vier! Links! Links! Und links! Links! Eins, zwei, drei! Links! Links! Links! Links und links und links ...« (o:31:19 - o:31:30 h), imitiert Myriam während ihres ca. 30-sekündigen Marschierens 
den Kommandoton der Nazis. Die Vermutung des Zuschauers aus dem ersten Teil der Sequenz wird demnach bestätigt: Der zufällige Fund von greifbaren Überresten aus der grausamen Vergangenheit reißt Myriams Narben auf; wie getrieben, durchlebt sie erneut die absurde Situation des Ausrückens zur Zwangsarbeit bei Marschmusik, gespielt von einem jüdischen Orchester. Inmitten des leeren Lagers, des Sonnenscheins und des sattgrünen Grases mutet dieser Szene etwas Gespenstisches an (s. 0:31:47). ${ }^{790}$

Im Unterschied zu Resnais widmet Marceline Loridan-Ivens der Tatsache, daß die Häftlinge bei Marschmusik im Gleichschritt zur Zwangsarbeit ausrücken mußten, eine ganze Sequenz. In Nacht und Nebel hingegen geht die Nennung dieser Begebenheit als Erklärung der äußerst kurz eingeblendeten Archivaufnahme (s. 0:13:21 h) unter:

"Chaque camp réserve des surprises: un orchestre symphonique (s. 0:13:03 h). Un zoo. Des serres où Himmler entretient des plantes fragiles. Le chêne de Goethe à Buchenwald. On a construit le camp autour, mais on a respecté le chêne. Un orphelinat éphémère, constamment renouvelé. Un block des Invalides.« (0:13:20 - 0:13:40 h; eigene Hervorhebung)

Während in Birkenau und Rosenfeld die Notenständer als Auslöser für Myriams Verkörperung der Vergangenheit in der Gegenwart dienen, bleibt die filmische Inszenierung der Überreste eines einstigen Foltergerätes (s. 0:29:14) in der Schlußsequenz von Nacht und Nebel blaß und leblos; auch der knappe Kommentar - »Un village abandonné en-core plein de menaces.«(0:29:08 h) - vermag die Vorstellungskraft des Zuschauers hinsichtlich dieses greifbaren Reliktes kaum anzuregen. Im Unterschied zu Marceline Loridan-Ivens läßt Resnais vorhandenes Potential ungenutzt vorüberziehen, denn die sich direkt anschließende Einstellung zeigt verfallene Ruinen, statt beim Foltergerät zu verweilen.

\section{d) Myriam im Waschraum: Be-Fühlen des Beckenrandes}

In diesem ersten Teil der Sequenz im Waschraum verdeutlicht Loridan-Ivens das BeGreifen von Überresten der Vergangenheit als Mittel, dieselbe heraufzubeschwören. Während sie in der Schlafbaracken-Sequenz das Berühren der Bettgestelle filmisch nicht besonders hervorgehoben hatte (s. 5.4.b), lenkt sie die Aufmerksamkeit des Zuschauers in der vorliegenden Sequenz verstärkt auf Myriams sinnliche, taktile Kontaktherstellung mit der Vergangenheit. In besonders wirkungsvollem Kontrast hierzu thematisiert der zweite Teil die von vornherein zum Scheitern verurteilte Fixierung zweier Besucherinnen auf äußerliche Spuren der Vergangenheit (s. 5.5.d).

790. Zur Absicherung der Antizipation hätte die Regisseurin u.U. auch bei ihrer bisherigen Inszenierungsweise bleiben können (Myriam erinnert sich im On oder 0ff), denn das Marschieren wirkt seltsam, künstlich und vor allem wenig plausibel.

791. Dabei greift Loridan-Ivens auf eine eigene Erfahrung bei ihrem Besuch des Lagers zurück: Als sie im Boden kratzte, stieß sie ausschließlich auf Asche, die durch den einsetzenden Regen zudem ihren spezifischen Geruch entfaltete (Loridan-Ivens auf DVD). 


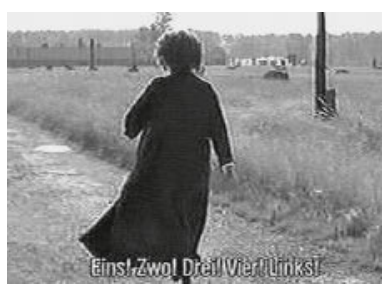

(753) $0: 31: 26 \mathrm{~h}$

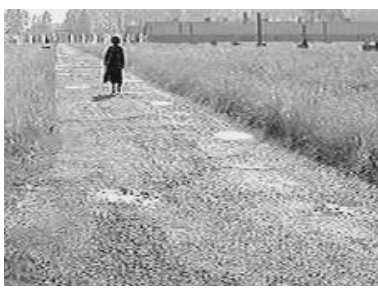

(754) $0: 31: 47 \mathrm{~h}$

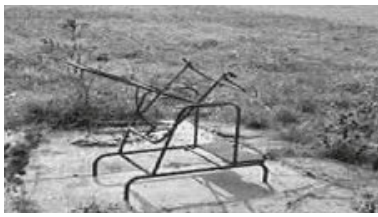

(756) $0: 29: 14 \mathrm{~h}$

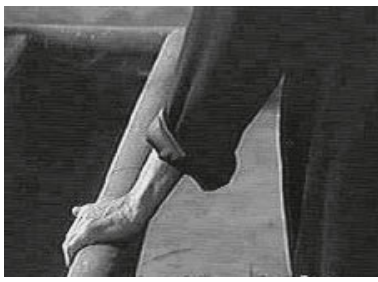

(758) $0: 33: 37 \mathrm{~h}$

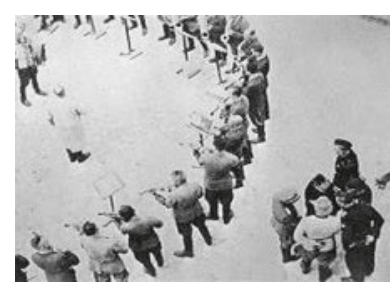

(755) $0: 13: 21 \mathrm{~h}$

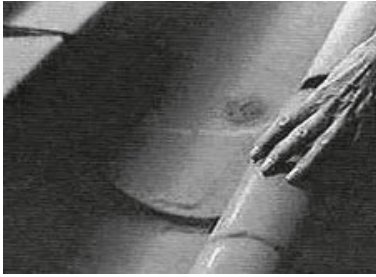

(757) $0: 33: 20 \mathrm{~h}$

Detaillierte Sequenzanalyse:

In der folgenden Einstellung geht eine Person langsam an der Waschanlage mit den aneinandergereihten Spülsteinen entlang. Die Fingerkuppen gleiten tastend über den Beckenrand (Detailaufnahme; s. o:33:20 h). Nach einigen Sekunden der Stille wird der Zuschauer in Myriams aufkommende Erinnerung einbezogen: »Chaque matin, on se battait pour arriver à un [...] d'eau [...]. Je voulais tellement rester propre, ne pas m'abandonner, exister encore, jour après jour.« (0:33:19 - o:33:31 h) Vor allem gegen Ende dieser ca. 20 Sekunden andauernden Berührung umfaßt Myriams ganze Hand die Kante und drückt sie parallel zu den letzten Worten: »Jour par jour.« (s. 0:33:37 h) Hatte das Umklammern des Beckenrandes vorher wie die Suche nach Halt ausgesehen, so wirkt es hier beinahe wie das liebkosende Drücken eines alten Bekannten, den man länger nicht gesehen hat. Im Anschluß an dieses Wiederaufbrechen der Erinnerung lehnt sich die Heldin stumm an die steinerne Barackenwand und starrt in Gedanken versunken ins Leere (s. 0:33:48 h). Mit ihr hat auch der Zuschauer Zeit, diese Erinnerungen auf sich wirken zu lassen, in sie einzutauchen und sie als Kampf um das letzte Aufrechterhalten der menschlichen Würde zu verstehen. Es ist aus vielen Berichten, insbesondere von Überlebenden, bekannt, daß sich in dieser unter unmöglichen Bedingungen versuchten Körperpflege der Überlebenswille der Häftlinge manifestierte.

e) Mit Oscar am Aschensee: (un)sichtbare Spuren der Vernichtung

In dieser Sequenz inszeniert die Regisseurin erst »auf den zweiten Blick« erkennbare Überreste der Vergangenheit. ${ }^{791}$ Aufgrund der Greifbarkeit der Relikte steht die 
vorliegende Sequenz in Opposition zu Myriams verzweifelter Suche nach Spuren der Massengräber (s. 5.5.7), ist jedoch gleichzeitig mit der früheren Notenständer-Sequenz (s. 5.4.c) vergleichbar: Hier wie dort wird der Zuschauer aufgrund einer zunächst zurückgehaltenen Information systematisch zur Irritation, sodann zur Antizipation angeregt und erst gegen Ende der Szene explizit informiert oder in seinen Vermutungen bestätigt. Im Unterschied zur Notenständer-Sequenz entdeckt die Protagonistin hier nicht zufällig Überreste der Vergangenheit, sondern macht das Unsichtbare auch für ihren Begleiter und somit auch uns mit den Worten sichtbar: »Vous allez être condamné à le [le camp; eigene Anm.] voir à travers mon regard« (1:11:10 h). In einem ersten längeren Gespräch hatte die Protagonistin Oskar erläutert, daß sie das Unsichtbare suche (s. 5.2).

Die vorliegende Sequenz ist mit der Gaskammer-Sequenz aus Nacht und NeвеL (s. II.2.1.6) und der Aschensee-Sequenz aus Sнонн (s.u.) vergleichbar. Während sich Resnais und Lanzmann allegorisch verhalten, verfährt Loridan-Ivens symbolisch, jeweils im Sinne Goethes. Anstatt per Setzung das Bild (Spuren/Aschensee) auf einen Begriff zu bringen (Todeskampf/Unsichtbarmachung der Vernichtung), lädt die Regisseurin das lebendige, leibhaftige Bild so auf, daß wir ganz bei der Idee sind, unsere Vorstellungskraft maximal einbringen: »Symbolisch kommen wir bei Einzelerscheinungen in eine besondere Verstehensbewegung, wenn wir beginnen, in ihnen und somit in der besonderen Konkretion die prinzipielle Übereinstimmung mit einem letzten, nur in Annäherung erfahrbaren Prinzip zu ahnen: die Idee.« (Kloepfer 2005: 4, H.i.O.) Wenn es dem Künstler gelingt, unseren Analogiesinn auf den richtigen Weg zu lenken, dann kann er - das Bild ist von Karl Bühler - wie bei einem guten Pferd die Zügel locker lassen oder, filmisch gesprochen, minimalistisch inszenieren, denn: »Wir denken uns aus.« (Ebd.) Entscheidend ist hierbei die Doppeldeutig- bzw. -wertigkeit:

»Indem wir das Andere ausdenken, denken wir uns aus. Indem wir uns aneignen, erfahren wir uns geeignet. Indem wir einen Sinn für etwas entwickeln, entwickeln wir nicht nur unsere Sinne, sondern auch die Fähigkeit für den entsprechenden Wert. Dazu gehört aber die Not. Werden wir sonst (not-)wendig? [...] Entwickeln wir sonst unsere Vermögen. >Die Not macht erfinderisch.く Also muß auch der Künstler Nöte entwickeln - beispielsweise durch Leerstellen und die vielen künstlerischen Verfahren, die uns auf den Weg bringen. Beim Symbol(prozeß) müssen wir also alle unsere entwickelten und während dem Prozeß entwickelbaren Vermögen in eine kompetente Beziehung verwandeln, aus der wir dann den Reiz der Idee, die Freude an der Befähigung und den Genuß im Vollzug (und als Wirkung des Gelernten bzw. Erfahrenen bis zur Änderung unserer Gewohnheiten) immer wieder erleben können.« (Ebd.)

Im Vergleich mit der entsprechenden Szene aus Sнон kann man sehen, daß Lanzmann mit seiner Vorgehensweise das Potential des Aschensees zum Erfahrbarmachen des Ausmaßes der Vernichtung kaum nutzt. Der Off-Bericht des Zeugen Filip Müller paßt nicht unmittelbar zu den Bildern (s. 0:15:12 h), weshalb in der deutschen

792. »IV« zeigt an, daß die Sequenz im letzten Viertel des Films lokalisiert ist und bei der Zeitangabe des Standbilds von Beginn dieses vierten Viertels an gezählt wurde. Vgl. II.2.2.

793. Vgl. 5.5.7 zur »Tönung« nach Kloepfer.

794. »Das ist vielleicht die schwierigste Szene, die ich spielen mußte.» (Diehl 2004) 


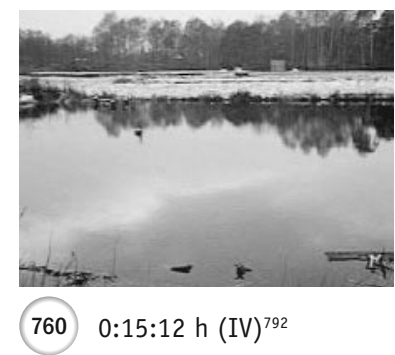

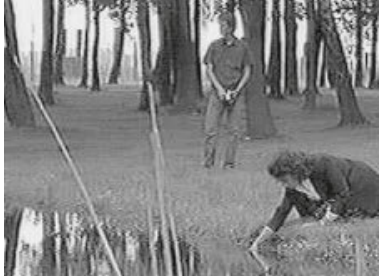

(761) $1: 09: 40 \mathrm{~h}$

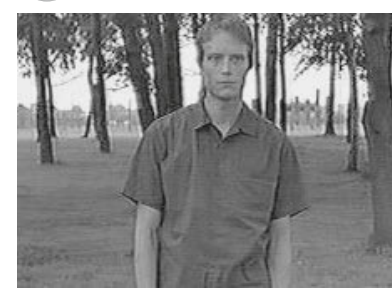

(762) $1: 10: 00 \mathrm{~h}$

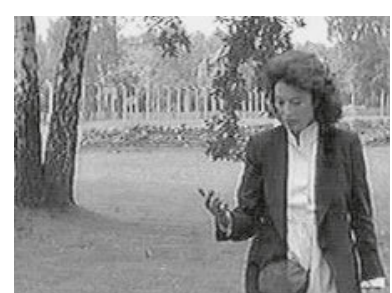

(763) $1: 10: 02 \mathrm{~h}$

TV-Version des Films Schriftinserts die Aufnahmen erklären müssen: »Der Aschensee. Dort wurde die Asche der Verbrannten hineingeworfen«. Auch das Heranzoomen an den See vermag nicht annähernd die Wirkung von Loridan-Ivens' Inszenierungsweise zu erzielen. Deren Komposition, vor allem die Entscheidung, Myriam den jungen Deutschen an die Seite zu stellen, ist für die Wirkkraft dieser Szene ausschlaggebend: Oskar und Myriam richten sich daher auch und vor allem an den Zuschauer.

\section{Detaillierte Sequenzanalyse:}

$\mathrm{Zu}$ Beginn durchqueren die Protagonistin und Oskar wortlos einen Birkenhain, das Zwitschern der Vögel und das Rauschen der Blätter im Wind bestimmen unsere Wahrnehmung. ${ }^{793}$ Die folgende Einstellung zeigt Myriam, die vor einem Teich kniet und mit der Hand etwas Schlamm herausholt (s. 1:09:40 h). Trotz lauten Bienensummens ist die Heldin vollkommen auf den Schlick konzentriert, der durch ihre Finger rinnt; mehrere Sekunden haftet ihr Blick darauf. Auch der im Hintergrund wartende junge Deutsche ist inzwischen auf Myriams seltsames Verhalten aufmerksam geworden und der Zuschauer fragt sich mit ihm nach der Bedeutung dieses Morastes. Die Unwissenheit zeichnet sich auf Oskars Gesicht deutlich ab, während er Myriam intensiv beobachtet (s. 1:10:00 h). Aus seiner Perspektive (subjektive Kamera) verfolgen wir, wie sich die Protagonistin bedächtig und wortlos auf ihn zu bewegt, die Augen unablässig auf ihre mit Schlamm bedeckte, ausgestreckte Hand gerichtet (s. 1:10:02 h). Oskar ist noch immer ratlos (s. 1:10:10 h)794, während der Zuschauer den Hintergrund von Myriams sonderbarem Verhalten erahnen kann. Ermöglicht wird dieses sukzessive Erschließen der Sinnhaftigkeit des Schlamms insbesondere dadurch, daß Loridan-Ivens dem Zuschauer feinsinnige Lenkung und ausreichend Zeit (35 Sekunden) einräumt, seine Vorstellungskraft zu entwickeln. Das Verfahren der schrittweisen Aufdeckung von Sinnpotentialen ist dem Zuschauer aus verschiedenen vorangehenden Sequenzen bekannt und daher vertraut. Zudem hat ihm die Regisseurin in einer knapp 30 Minuten zurückliegenden Sequenz das Ergebnis der Massenvernichtung (Asche) eindringlich eingeprägt (s. 5.5.6). 
»Tu sais ce que c'est? «, fragt die Heldin schließlich ihren Begleiter und so auch uns (1:10:12 h). Während der folgenden Auflösung dieses Rätsels zeigt die Kamera die Erklärungen Myriams in Großaufnahme (Oskars Sicht), so daß wir in ihren Gesichtszügen lesen können und förmlich an ihren Lippen kleben: »Des cendres. Des cendres d'hommes, de femmes, d'enfants.« (1:10:15 h), erläutert sie und kann dabei ihre Augen nicht vom Schlamm in ihrer Hand lösen (s. 1:10:16 h). Mit einem in der Folge teils auf Oskar ruhenden (s. 1:10:39 h), teils in die Ferne schweifenden Blick vermittelt sie einen Eindruck von ihrem Seelenleben: »Je pourrais jamais oublier. Il y a pas un jour que je n'y pense pas. Quelquefois le soir je me dis: >Tiens, t'y as pas pensé.< Et forcément, je me remets à y penser.« (1:10:43 - 1:10:49 h) Damit macht die Protagonistin insbesondere dem Zuschauer klar, daß sie keineswegs alles verdrängt hat, sondern daß sie täglich daran denkt.

\section{II.5.5 »ANNÄHERUNGEN《 AN DAS LAGER - GE-DENKEN UND IN-SICH-GEHEN VERSUS »SPURENVERSESSENHEIT«}

In insgesamt sieben Sequenzen inszeniert Loridan-Ivens unterschiedliche Formen der Annäherung an und des Umgangs mit dem heutigen Lager (s. 5.2). Dies reicht von Myriams Vordringen ins Lagergelände (s. 5.5.a) über mehrere Situationen, in denen die Protagonistin bewußt in sich geht (s. 5.5.b - 5.5.6) bis hin zur von vornherein zum Scheitern verurteilten Fixiertheit auf äußere Spuren (s. 5.5.d und 5.5.7).

\section{a) Vordringen ins Lager}

Nachdem die Protagonistin bereits einen unüblichen Weg zum Lager gewählt hat (s. 5.4.a), verschafft sie sich den Zutritt zum Lager auf unorthodoxe Weise: Anstatt, wie jeder Besucher von Auschwitz-Birkenau, das berühmt-berüchtigte Lagertor zu passieren, dringt sie durch ein normalerweise verschlossenes Seitentor ein. Hierdurch wird deutlich, daß sie sich dem Lager auf ganz persönliche Art und Weise nähern wird. Die Tatsache, daß das Überschreiten dieser Grenze einem Fallenlassen von Hüllen, Schutzschichten entspricht, wird dem Zuschauer hierbei eindrucksvoll vor Augen geführt.

\section{Detaillierte Sequenzanalyse:}

$\mathrm{Zu}$ Beginn der Sequenz sieht der Zuschauer, wie die Protagonistin bedächtig an einem Stacheldrahtzaun entlang geht und unentwegt in das umzäunte Gelände starrt (s. 0:23:20 h). Obgleich nur hohes, vom Wind umspieltes Gras zu sehen ist, legen die vorangegangenen Szenen, der Stacheldraht sowie Myriams Anspannung den Schluß nahe, daß sie am Lager angekommen ist. Bestätigt wird dies (nach ca. 15 Sekunden), als die Heldin zu einem Seitentor gelangt und die Kamera den Blick auf einige Lagerbaracken freigibt (s. 0:23:36 h).

Nachdem sich die Protagonistin auf der Schwelle zum Lager vorsichtig umgesehen hat, lockert sie die laut rasselnde Torkette und versucht, sich durch den Spalt ins Innere des Lagers zu zwängen. Dieses Vorgehen löst beim Zuschauer eine Reihe von Fragen aus: Weshalb wählt Myriam diesen offensichtlich für Besucher nicht vorgesehenen Seiteneingang? Ist es nicht beinahe absurd, daß sie heute versucht, in das Lager einzudringen? Will sich die Protagonistin dem ehemaligen 

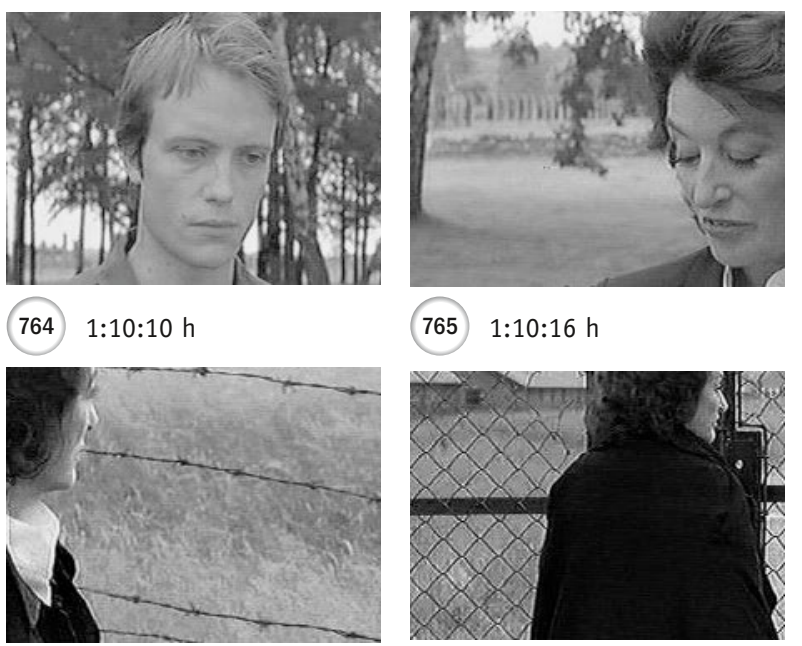

(767) $0: 23: 20 \mathrm{~h}$

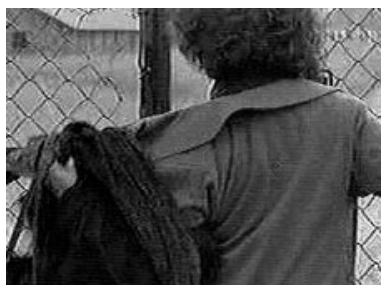

(769) $0: 23: 50 \mathrm{~h}$

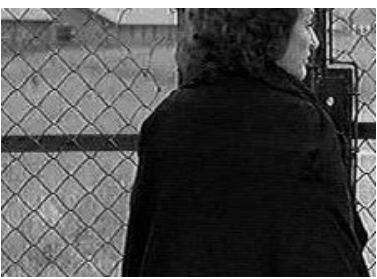

(768) $0: 23: 36 \mathrm{~h}$

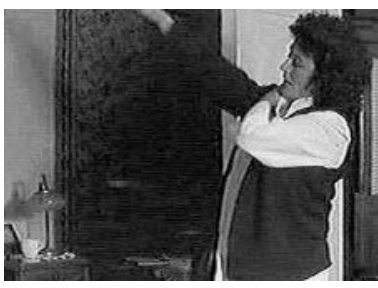

(770) $0: 19: 37 \mathrm{~h}$

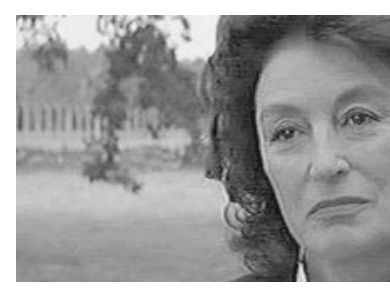

(766) $1: 10: 39 h$

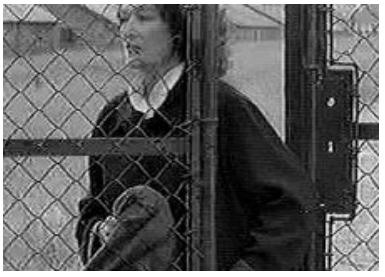

(771) $0: 24: 01 \mathrm{~h}$

Schreckensort bewußt anders nähern und nicht durch das berühmt-berüchtigte Eingangstor geschleust werden? Bedeutet für sie der Seiteneingang eine behutsamere, sanftere Annäherung an ihre einstige Leidensstätte? Jedenfalls setzt sie alles daran, auf diese sonderbare Weise ins Innere zu gelangen: Sie ist sogar dazu bereit, zwei ihrer Kleidungsstücke abzulegen, um so den Türspalt passieren zu können (s. o:23:50 h). Dieser Akt des Enthüllens steht im Kontrast zum wenige Minuten zurückliegenden Verhüllen, zum sorgfältigen Anlegen vieler Kleidungsteile vor dem Verlassen des Hotels (s. 0:19:37 h). Auch an dieser rätselhaft inszenierten Stelle hatte Marceline Loridan-Ivens dem Zuschauer viel Zeit gelassen, sich seinen eigenen Gedanken über dieses sonderbare Verhalten zu machen. Im Zusammenhang mit der Vermutung, daß die Protagonistin ihre einstige Leidensstätte aufsuchen wird, wirken die zahlreichen Kleidungsstücke wie Schutzschichten. Vor dem Hintergrund der einstigen Demütigung durch Entkleiden bis zur völligen Nacktheit kann dieses heutige Sich-Einhüllen als Schutzmechanismus und reflexhafte Gegenreaktion erlebt werden.

Beide Mäntel abgelegt, gelingt Myriam das Eindringen ins Lager. Durch das erneut laute, nachscheppernde Kettengeräusch wird diese Schwelle auch beim zweiten Mal auffällig inszeniert. Die Wichtigkeit dieses Moment wird dadurch verdeutlicht, daß die Protagonistin ihre rechte Hand an der Außenseite des Tores kurz verweilen läßt (s. 0:24:01 h). »Soll ich oder soll ich nicht?«, scheint sie sich $\mathrm{zu}$ fragen. 
Nachdem sie sich nochmals vergewissert hat, daß ihr »Eindringen « unbemerkt geblieben ist, verfolgen wir eine halbe Minute lang, wie sie sich mit langsamen, zaghaften Schritten in das Lager vortastet, wobei die auffällige Stille und Friedlichkeit auch von dem leisen Vogelgezwitscher nicht gestört werden kann (s. 0:24:16 h). Die Kamera folgt Myriam in dieser Einstellung nicht ins Lager, sondern nimmt sie durch den Maschendraht des Seiteneingangs auf - ein Sinnbild für sukzessives Eintauchen in die einstige Welt als Internierte.

\section{b) Myriam in ihrer Baracke: »Rückkehr« der traumatischsten Erfahrung}

Wie bereits im ersten Teil der Sequenz (s. 5.4.b) fällt auch im zweiten die durch minimalistische Inszenierung erzeugte Konzentration auf Myriams Selbst- bzw. imaginierte Zwiegespräche auf.

Nachdem sich die Protagonistin an die Haupteindrücke von der Lagerrealität erinnert hat, führt sie auf dem dramatischen Höhepunkt der Szene ein imaginiertes Zwiegespräch mit ihrem im Lager verstorbenen Vater: Diese zufällige und einmalige Begegnung mit ihrem Vater im Lager wurde durch einen SS-Schergen brutal unterbrochen - eine Situation mit schockierender Wirkung für den Zuschauer, der sich den Verlust des letzten Familienangehörigen aus der Sicht eines 15-jährigen Mädchens vorstellt.

\section{Detaillierte Sequenzanalyse:}

Myriam sitzt in ihrer Schlafkoje mit nachdenklich gesenktem Blick, die Hände um die angezogenen Knie geschlungen. Der Tag geht zur Neige, das durch das Fenster hereinfallende Licht ist nur noch schwach. »Ils avaient fait de nous des rats«, sagt die Heldin plötzlich vor sich hin und schaut danach direkt in die Kamera (s. o:26:36 h), als wolle sie den Zuschauer zu einer Reaktion auf die Aussagen auffordern. Noch ehe dieser nachdenken kann, hört er aus dem Off und mit einer leicht hallenden Verzerrung die Antwort von Suzanne: »Non, Myriam, nous n'étions pas des rats. Souviens-toi. Les nuits de grand froid, tu nous racontais des si belles histoires.«»Quelles histoires? « (0:26:38 - 0:26:49 h), fragt die Heldin und blickt dabei wiederum in die Kamera. Auch diese Auseinandersetzung mit der Vergangenheit bestätigt, daß es selbst unter extremen Bedingungen positive Elemente gab - die Solidarität unter den Leidengenossen.795

In der gleichen zusammengekauerten Haltung blickt die Protagonistin mit nachdenklichem Gesichtsausdruck durch die Fensterluke nach draußen (s. 0:26:53 h). Während der Zuschauer unmittelbar in Myriams Wahrnehmung versetzt wird (subjektive Kamera), indem er auf eine in der Abenddämmerung liegende Wiese mit zwei Wachtürmen schaut (s. o:26:54 h), hört er ihren inneren Monolog, der das Ende des-

795. Einige Sequenzen später schreibt Myriam abends in ihr Tagebuch: »C'est peut-être ici que j'étais le plus aimé« (0:53:13 h). - ein beinahe unheimlicher Satz, denn er drückt aus, daß Menschen mitunter gerade in Extremsituationen zu besonderer Mitmenschlichkeit in der Lage sind.

796. "I remember an interview of two young girls, 10 years ago, when the Iraqis hunted down the Kurds. >How do you manage to survive? asked the journalist. >We tell each other our dreams, < they answerred." (Loridan-Ivens zit.n. N.N. in The International Herald Tribune, zit.n.: www. partisanfilm.de/index/61136,75093) 


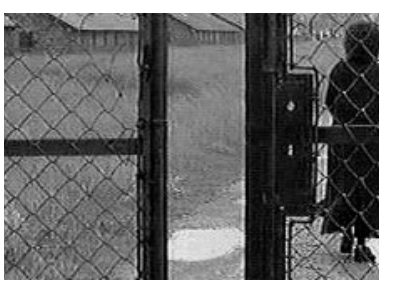

(772) $0: 24: 16 \mathrm{~h}$

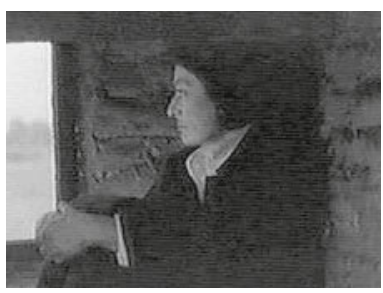

(774) $0: 26: 53 \mathrm{~h}$

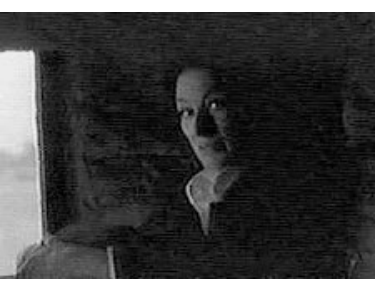

(773) $0: 26: 36 \mathrm{~h}$

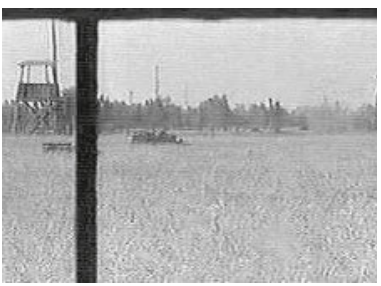

(775) $0: 26: 54 \mathrm{~h}$

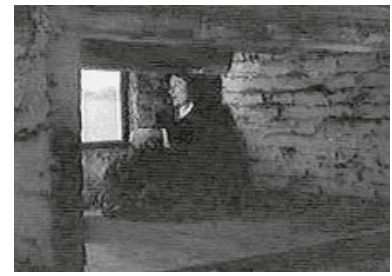

(776) $0: 27: 32 \mathrm{~h}$

versiegten Zwiegesprächs aufgreift: »Je me rappelle seulement les flammes, les odeurs de chair brûlée, nos yeux vides, l'entasse-ment de nos corps vieillis trop vite, la peur, la mort, toujours partout.« Die Aufzählung vermag das Grauenhafte auch vor dem inneren Auge des Zuschauers wachzurufen.

Gegen Ende der Sequenz führt die Heldin ein scheinbares Zwiegespräch mit ihrem im Lager verstorbenen Vater, weiterhin in unveränderter Haltung (s. 0:27:32 h):

»Papa. Tu te souviens qu'on s'est rencontré une fois. Faisait six mois qu'on était ici. Tu m'as demandé: >Et maman, et Michelle?^ Je me suis jetée dans tes bras et un allemand m'a tapé dessus. Je me suis évanouie. Quand je me suis réveillée, tu avais disparu. Je t'aimais tellement que j'étais heureuse d'être déporté avec toi.« (0:27:31 - 0:28:05 h)

Zum ersten Mal spricht die Protagonistin von ihren Familienmitgliedern, vor allem von einer ebenso »glücklichen« wie unglücklich endenden, zufälligen Begegnung mit ihrem geliebten Vater im Lager. Durch bewußt minimalistische filmische Gestaltung - in der Dunkelheit sitzt Myriam regungslos in ihrer Koje, ohne musikalische Untermalung - gerät der Zuschauer in den Bann der erzählten Erinnerung von der kaum vorstellbaren Lage einer damaligen Jugendlichen. Der Einstellungsgrößenwechsel, von halbnaher Einstellung zu einer Totalen, unterstützt das tragische Erinnern der Protagonistin, läßt sie »verloren« wirken.

\section{c) Myriam im Latrinenblock und ihre Erinnerung an damalige Essensträume} In der Sequenz im Latrinenblock macht Loridan-Ivens den extremen Hunger der Lagerhäftlinge für den Zuschauer erfahrbar. Während Myriam auf den Latrinen sitzt und dabei teilweise die Augen schließt, erinnert sie sich daran, wie sich ihre Leidengenossinnen in ihren Essensträumen »satt aßen«.796

Im Unterschied zur extrem kurzen Einblendung eines aufgeschriebenen Rezepts in Nacht und Nebel widmet Loridan-Ivens den Essensträumen der Lagerinsassen eine ganze Sequenz. Außerdem wählt sie im Zusammenhang mit den Latrinen einen 
anderen Aspekt als Resnais, nicht den der Ausscheidungen, sondern den der Nahrungsaufnahme bzw. des Hungers. Der Einsatz einer extremen Weitwinkelperspektive zur Erfassung des gesamten Raumes hingegen gleicht visuell stark der entsprechenden Aufnahme aus NACHT und Nebel (s.u.). Während Resnais den Zuschauer gleichzeitig mit unterschiedlichen Eindrücken konfrontiert, lenkt Loridan-Ivens die Konzentration ganz auf das Visuelle. Auf diese Weise läßt sie dem Zuschauer Zeit, die besondere Bildkomposition auf sich wirken zu lassen und sich das Ausmaß des »Eingepfercht-Seins« der Häftlinge vorzustellen. Diese Form der visuellen Gestaltung vermag dem Zuschauer das Ausmaß der Menschenmenge und deren Vernichtung erfahrbar zu machen.

\section{Detaillierte Sequenzanalyse:}

Die erste Einstellung dieser Sequenz (s. 0:32:31 h) erinnert deutlich an das Schlußbild der »Abortanlage«-Sequenz in NACHT UND NeBEL (s. o:13:01 h): Aufgrund des extremen Weitwinkeleinsatzes wirkt es in beiden Aufnahmen so, als nähme die Aneinanderreihung von Latrinen kein Ende. Neben der visuellen Vergleichbarkeit sind es besonders die Unterschiede in der weiteren Gestaltung, die dafür verantwortlich sind, ob das Wirkpotential der Weitwinkelaufnahme zur Entfaltung kommt.

Während Resnais den Zuschauer gleichzeitig mit unterschiedlichen Eindrücken konfrontiert797, lenkt Marceline Loridan-Ivens die Konzentration ganz auf das Visuelle. Abgesehen von einem Geräusch, das im folgenden zugeordnet wird, herrscht zehn Sekunden lang absolute Stille; der Zuschauer hat so Zeit, die besondere Bildkomposition auf sich wirken zu lassen. Die Bündelung seiner Aufmerksamkeit auf die unendliche Aneinanderreihung von Latrinen wird dadurch unterstützt, daß Myriam am Ende der Installation zu erahnen ist.

Im Gegensatz zu entsprechenden Passagen in Resnais' Film (s.u.), hilft die zweite Einstellung dieser Sequenz von Birkenau und Rosenfeld dem Zuschauer, sowohl das

797. Im Unterschied zu Marceline Loridan-Ivens fordert Resnais auf mehreren Ebenen die Aufmerksamkeit des Zuschauers. Auf der Kommentar-Ebene konfrontiert er ihn mit dem rastlos vorgetragenen Fazit der vorangegangenen detaillierten Informationsfülle: »Les latrines, les abords. Des squelettes au ventre de bébés y venait sept fois, huit fois par nuit. La soupe était durétique. Malheur à celui qui rencontrait un Kapo ivre au clair de lune. On s'y observait avec crainte, on y guettait des symptômes bientôt familier: faire du sang, c'était signe de mort. Marché clandestin, on y vendait, on y achetait, on y tuait en douce, on s'y rendait visite, on se passait les vraies et les fausses nouvelles, on y organisait des groupes de résistance. Une société y prenait forme, une forme sculpté dans la terreur, moins folle pourtant que l'ordre des SS $[\ldots]$ (0:12:26-0:13:05 h). In bezug auf die musikalische Begleitung fällt eine Beruhigung derselben parallel zur Öffnung des Blicks in den Raum auf; während der vorangehenden Kamerafahrt nah und in Aufsicht an der Abortanlage entlang hatte die stark rhythmisierte Musik den Aufzählungscharakter des Kommentars unterstützt.

798. Vgl. auch Ruth Klügers Äußerungen zu den Angewohnheiten ihrer Leidensgenossinnen: »Sie tauschten Kochrezepte aus, so wie ich Gedichte aufsagte. Es war ein Lieblingsspiel, sich abends beim Backen von Phantasiekuchen mit großzügigen Mengen von Butter, Eiern und Zucker zu übertreffen.« (2001: 149) 


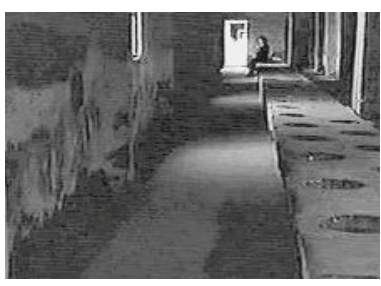

(777) $0: 32: 31 \mathrm{~h}$

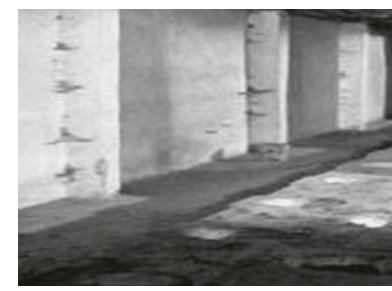

(778) $0: 13: 01 \mathrm{~h}$

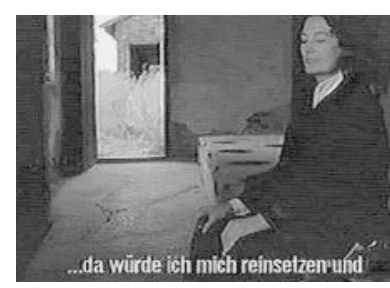

(779) $0: 32: 54 \mathrm{~h}$

Ausmaß des Hungers als auch eine Überlebensstrategie der Lagerinsassen zu erahnen: Sich-weg-Träumen, die Hoffnung auf bessere Zeiten - eine Überlebensstrategie, die Benigni in DAs LeBEN IST SCHön thematisiert (s. II.4.1) und die Mihaileanu in ZUG DES LEBENS zum Rahmen seiner gesamten Filmhandlung macht (s. II.4.2).

Nachdem am Ende der Weitwinkel-Einstellung der Off-Text bereits eingesetzt hatte, bestimmt er die halbnahe Aufnahme von Myriam, die sich ganz offensichtlich - darauf deuten insbesondere ihre teilweise geschlossenen Augen hin (s. 0:32:54 h) an ein kollektives Träumen unter Leidensgenossinnen erinnert:

»Qu'est-ce qu'on ... - Alors qu'est-ce qu'on boufferait? - Moi, je voudrais des harengs avec des pommes de terre et des oignons dessus. - Et moi, je voudrais une baignoire pleine de bouillon de bœuf [...]. Je rentre dedans, je bois tout et je mange tout. Et toute une baguette de pain, coupée en deux, remplie de beurre et de miel. Non, deux baguettes de pain et des grand bols de café aussi. - Des oignons frits avec des tomates et des œufs cassés dessus avec de l'ail. - Et du poulet. Dix grand poulets, le plus grand poulet qui existe.« $(0: 32: 59-0: 33: 28 \mathrm{~h})^{798}$

Der Inhalt sowie die Art und Weise, wie sich die Frauen beinahe ins Wort fallen, um ihre Essenssehnsüchte zu artikulieren, lassen den Zuschauer das Ausmaß ihres Hungers erschließen. Im Unterschied zur Einblendung eines eher ausgefallenen Rezepts in NACHT UN D NEBEL (écrevisses à la basquaise), handelt es sich bei den Essenträumen nicht um sonderlich ausgefallene Gerichte: Hering mit Kartoffeln und Zwiebeln; Baguette mit Butter und Honig; große Schalen mit Kaffee; Zwiebeln mit Tomaten, Eiern und Knoblauch; Hühnchen. Der Mangel an Nahrung, die Sehnsucht nach Essen, verstärkt durch die quantitativen Übertreibungen bei den Wunschvorstellungen (eine Badewanne voller Rinderbrühe, zehn große Hühner, das größte Hühnchen, das es gibt) macht erfahrbar, daß die Versorgung der Häftlinge katastrophal, ihr Hungerleiden entsetzlich war.

Im Unterschied zu Marceline Loridan-Ivens, die sich diesem unvorstellbaren Hunger der Lagerinsassen über deren Träume nähert und das Potential dieser Sehnsucht im Hinblick auf die Erfahrbarmachung der Lagerverhältnisse erkannt und zur Entfaltung gebracht hat, geht Resnais' Ansatz in einer Fülle von Informationen, in der Aufzählung und entsprechenden Bebilderung unterschiedlicher Ausdrucksformen des Überlebenswillens unter:

»Mais c'est incroyablement résistant un homme. Le corps brûlé de fatigue, l'esprit travaille, les mains couvertes de pansements travaillent. On fabrique des cuillères, des marionnettes qu'on dissimule, des monstres, des boîtes. On réussit à écrire, à prendre des notes, à exercer sa mémoire avec des rêves, on peut penser à Dieu [...]« (0:15:29 - 0:15:37 h, eigene Hervorhebung). 
Lediglich vier Sekunden dauert die Aufnahme des Rezeptes (s. 0:15:35 h), so daß der Zuschauer nicht einmal die Zeit hat, die einzelnen Arbeitsschritte zu lesen. Darüber hinaus muß er gegen Ende der Einstellung bereits dem Text für die sich anschließende Aufnahme folgen (siehe die Hervorhebung im Zitat, die den parallel zur Rezepteinblendung gesprochenen Kommentar markiert). Im Gegensatz zu BirkenAu Und RoSENFELd, läßt uns Resnais keine Zeit, dieses an sich äußerst sprechende Detail auf uns wirken zu lassen; zudem wirkt die auffällig rhythmisierte Musik einem meditativen Verweilen entgegen.

Auch die erste Erwähnung des Hungers in NACHt und Nebel reicht an die Wirkmächtigkeit Marceline Loridan-Ivens' Inszenierung nicht heran. Eine explizit dem Essen gewidmete Szene beginnt zwar mit dem Kommentar: »Le déporté, lui, retrouve l'obsession qui dirige sa vie et ses rêves: manger.« (0:11:48 - o:11:52 h) Im weiteren Verlauf der Szene konzentrieren sich Resnais und Cayrol jedoch weniger auf die Träume, auf Erfahrbarmachung des extremen Hungers, als auf Information über die Nahrungsaufnahme, den Tauschhandel (Zigaretten gegen Suppe) und den Kampf um Lebensmittel. ${ }^{999}$

\section{d) Myriam im Waschraum:}

\section{Spurenfixiertheit zweier Besucherinnen versus Myriams Innehalten}

Während der erste Teil der Sequenz dem taktilen Be-Greifen als Mittel zur Kontaktherstellung mit der Vergangenheit gewidmet war (s. 5.4.d), inszeniert Loridan-Ivens im zweiten Teil die gegenteilige Form des Umgangs mit den Überresten der Vergangenheit, das Innehalten und In-sich-Gehen. Im Unterschied zu zwei nachgeborenen Besucherinnen, die nach äußerlichen Zeichen suchen, und ebenfalls im Unterschied zu Myriams späterer, nahezu verzweifelter Suche nach Spuren der Massengräber (s. 5.5.7), gedenkt sie nun, in sich versunken, mit geschlossenen Augen. Durch die kontrastive Gegenüberstellung beider Herangehensweisen werden verschiedene Fragen gestellt, jedoch nicht beantwortet: Wie kann mit den einstigen Schreckensorten adäquat umgegangen werden? Ist die Suche nach greifbaren Spuren der Vergangenheit nicht von vornherein zum Scheitern verurteilt? Wie können diese Orte zum Sprechen gebracht werden, wenn sie dies offenbar von selbst nicht tun? Was können diese Orte nicht unmittelbar Betroffenen überhaupt »sagen «, wenn sich selbst Überlebende und nachgeborene Angehörige nur zum Teil zu ihnen in Beziehung setzen können?

Neben diesen zentralen Fragen in bezug auf die sogenannten Erinnerungsorte kann an dieser Sequenz gezeigt werden, daß Loridan-Ivens bestimmte filmische Formen der Inszenierung aus NACHT UND Nebel übernimmt und in ihren Film integriert.

\section{Detaillierte Sequenzanalyse:}

Der zweite Teil der Sequenz zeigt zwei unbekannte Frauen, die den Waschraum betreten und sich umsehen; Besucherinnen des Lagers. Kaum eingetreten, bemerkt die Frau, die weniger intensiv geschaut hat: „C'est dingue, je ressents rien du tout

799. „La soupe. Chaque cuillère n'a pas de prix. Une cuillère de moins, c'est un jour de moins à vivre. On troque deux, trois cigarettes contre une soupe. Beaucoup, trop faibles, ne peuvent défendre leur ration contre des coups et des voleurs. Ils attendent que la boue, la neige les prenne.« $(0: 11: 53-0: 12: 11 \mathrm{~h})$ 


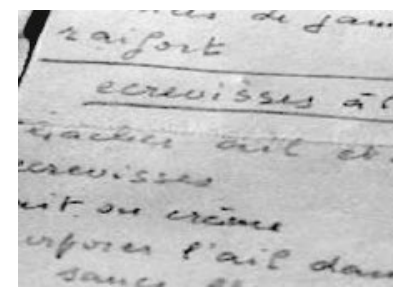

(780) $0: 15: 35 \mathrm{~h}$

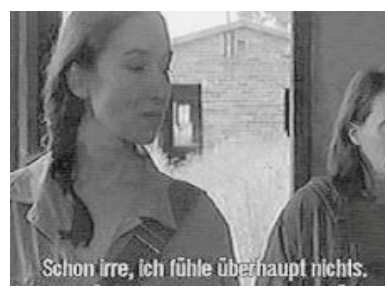

(781) $0: 34: 05 \mathrm{~h}$

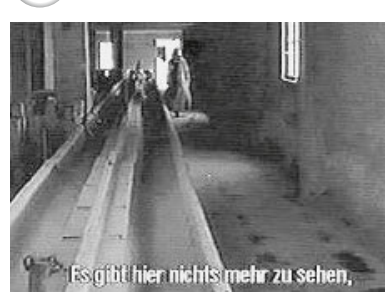

783

$0: 34: 44 \mathrm{~h}$

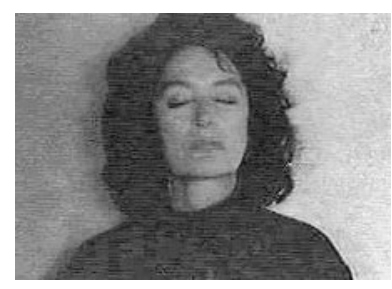

(782) $0: 34: 48 \mathrm{~h}$

(s. 0:34:05 h). Pourtant, je devrais ressentir quelque chose. Ma grand-mère n'est jamais revenu. Et toi? Tu sens quelque chose? - Je ne sais pas. - Il n'y a rien ici. Si vide, complètement vide ... Il n'y a rien à voir. Il n’y a plus rien à voir ici.« (0:34:03 - 0:34:21 h) Aus dem Gespräch erfahren wir, daß es sich um eine Nachgeborene handelt, die ihre Großmutter in Auschwitz-Birkenau verloren hat. Aufgrund dieser familiären Betroffenheit ist sie erstaunt, wie wenig sie dieser Ort berührt, »[...] es sei ja gar nichts mehr da, alles leer, gerade so, als hätten sie Grund, beleidigt zu sein, daß die Geschichte ihnen das Grauen nicht besser vorzuführen versteht« (Jeismann 2004: 33).

Nach dem Hinweis auf ihre Großmutter und der Frage nach den Gefühlen ihrer Begleiterin sehen wir kurz die sich im Dunkel des Raums befindliche Myriam, mit nachdenklichem Blick. Diese Einblendung erinnert daran, daß sich die Heldin diesem Ort auf ganz andere Weise näherte und mit ihm umging. Gemäß ihrer Motivation, die sie wenig später dem jungen Deutschen mitteilen wird, (»Je cherche l'invisible«; 0:33:22 h) hatte sie sich dem Raum weniger über den Sehsinn als über den Tastsinn genähert - ein im Zusammenhang mit dem Erinnern durchaus übliches und dem Zuschauer geläufige Verhalten. Daher ist es auch stimmig, daß die Protagonistin, im Unterschied zu den Besucherinnen, die Augen geschlossen hält (s. 0:34:48 h). Die Kamera zeigt den Waschraum zum ersten Mal im Überblick und erinnert durch die Weitwinkel-Aufnahme an Gestaltungsmuster aus Resnais' NACHT UND NEBEL (s. 0:34:44 h). Wie zuvor in der Latrinen-Sequenz (s. 5.5.c) handelt es sich eine Kameraperspektive, die dem Zuschauer die unfaßbare Länge der WasserhahnInstallation in einer einzelnen Aufnahme vor Augen zu führen vermag und somit erfahrbar macht.

\section{e) An der Todesbaracke: Solidarität im trauernden Ge-Denken}

Im Unterschied zu den beiden Besucherinnen, die zuvor ausschließlich nach sichtbaren Überresten der Vergangenheit suchten (s. 5.5.d), inszeniert Loridan-Ivens hier die gegenteilige Form des Umgangs mit dem einstigen Schreckensort: An der Todesbaracke versammelte junge Menschen, in der Mehrzahl Nachgeborene, stehen in sich 
gekehrt und bewegungslos vor der Baracke. Während wir dieses stumme Ge-Denken sehen und Myriams Erinnerung an die Todesbaracke hören, betont ein jüdischer Acappella-Gesang (»La Prière pour les Morts d’Auschwitz«) die Atmosphäre der stillen Andacht. Dieses Lied aus dem Off fällt besonders auf, weil es, nach dem RadetzkyMarsch, das zweite in den Lagerszenen eingesetzte Musikstück darstellt und weil es äußerst bewegend vorgetragen wird. Neben dem eher ruhigen Rhythmus der Sequenz trägt vor allem dieser ergreifende Gesang dazu bei, daß der Zuschauer von der Atmosphäre der Trauer und des Schmerzes ergriffen wird.

\section{Detaillierte Sequenzanalyse:}

$\mathrm{Zu}$ Beginn der Sequenz bewegt sich Myriam mit nachdenklich gesenktem Blick zwischen den Baracken, bis sie unvermittelt auf andere Lagerbesucher trifft. Aus ihrer Perspektive (over-the-shoulder) sieht der Zuschauer zahlreiche junge Menschen, die andächtig und bewegungslos zwischen zwei Baracken stehen (s. ০:40:40 h). »Le block de la mort« (o:40:40 h) sagt uns Myriams Stimme aus dem Off.

Während der folgenden knapp eineinhalb Minuten fährt die Kamera an die einzelnen Personen heran, während wir die Erinnerung der Protagonistin weiterhin aus dem Off hören:

»0n n'avait pas le droit de s'approcher (s. 0:40:52 h) ... Celles qui entraient là avaient été sélectionnées pour la chambre à gaz (s. 0:41:14 h) ... Elles le savaient (s. 0:41:17 h) ... Nous aussi on savait ... On entendait les cris des femmes qui ne voulaient pas mourir ... (0:41:38 h) et le bruit des camions qui les emportaient dans la nuit ... Ici, le ciel était toujours rouge« $(0: 40: 52-0: 41: 52 h)$

Aufgrund der auffälligen Pausen in Myriams Erinnerung hat der Zuschauer Zeit, die Details insbesondere gegen Ende des Off-Textes auf sich wirken zu lassen, sich die Schreie der Frauen, den Lärm der Lastwagen und den roten Himmel vorzustellen. Dies unterstützt auch der am Ende des ersten Satzes einsetzende und die Szene extrem prägende, hebräische A-cappella-Gesang aus dem Off. Aufgrund seines klagenden Charakters erinnert er nicht zufällig an ein Gebet; es handelt sich um die »Prière pour les Morts d'Auschwitz«, vorgetragen von Schalom Katz. Im Unterschied zu den beiden Besucherinnen, die enttäuscht waren über die geringe Zahl äußerer Zeichen und Spuren, fällt auf, daß die jungen Menschen ganz im Gedenken versunken sind. Zum Teil geht ihr Blick nachdenklich ins Leere, zum Teil schauen sie auch direkt in die Kamera und damit zu uns wie zur Protagonistin mit der Frage (s. o:41:17 und 0:41:38 h): »Wie konnte das nur geschehen?«. Vielleicht handelt es sich aber auch um einen solidarischen Blickkontakt mit der Überlebenden, denn einige unter den jungen Menschen sind offensichtlich jüdischer Nationalität (Kippa, israelische Flagge).

Die letzte Einstellung der Sequenz zeigt, wie eine junge Frau, die in die Kamera geblickt hatte, auf Myriam zugeht, ihren Blick sucht und schließlich ihre Umarmung erwidert (s. 0:42:21 h). Besonders anrührend an dieser Begegnung und solidarischen Geste zwischen den Generationen ist, daß sie ohne jedes Wort auskommt, dezent begleitet durch das musikalische Gebet. Als sich beide Frauen umarmen, sind die Worte »Auschwitz, Majdanek, Treblinka in dem ansonsten hebräischen Gesang identifizierbar, Orte der Vernichtung und des Grauens. 


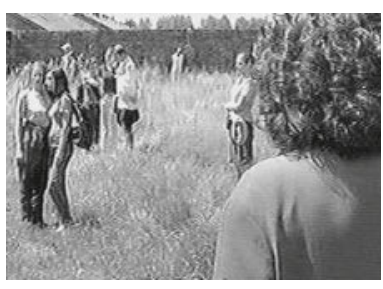

(784) $0: 40: 40 \mathrm{~h}$

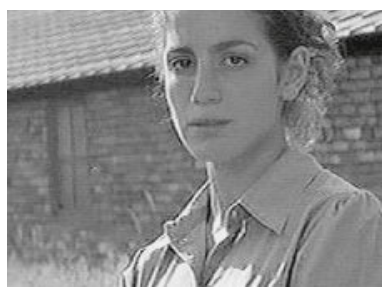

(787) $0: 41: 17 \mathrm{~h}$

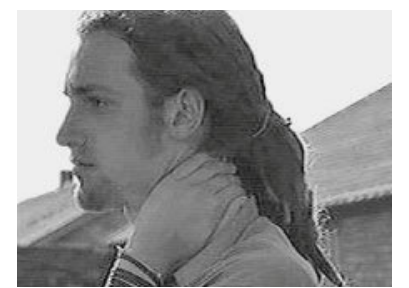

(785) $0: 40: 52 \mathrm{~h}$

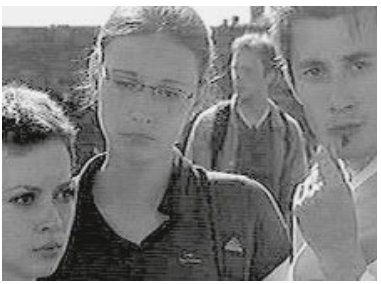

(788) $0: 41: 38 \mathrm{~h}$

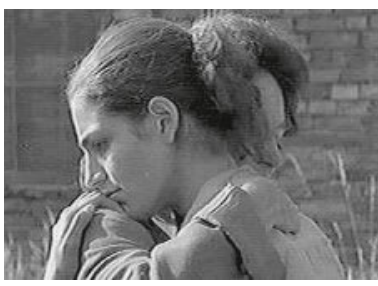

(790) $0: 42: 21 \mathrm{~h}$

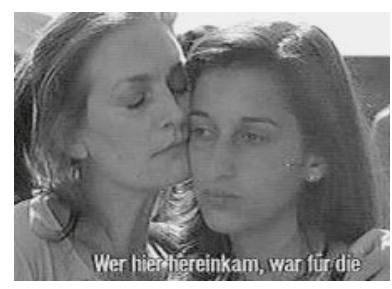

(786) $0: 41: 14 \mathrm{~h}$

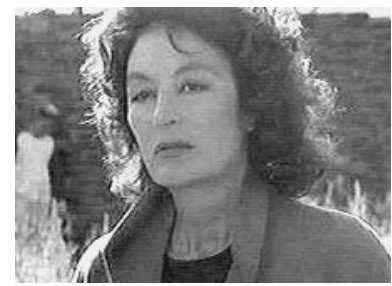

(789) $0: 42: 01 \mathrm{~h}$

\section{f) Auf der Treppe zur Gaskammer: Myriams Totenklage}

Im Unterschied zu Resnais (s. II.2.1.6) und Lanzmann (s. II.2.2.4), versucht LoridanIvens in der Sequenz der Gaskammer erst gar nicht, die Vorstellung des Zuschauers auf den Todeskampf (Nacht und Nebel) bzw. die Ankunft in den Gaskammern (Sнолн) zu richten. Auf diese Weise grenzt sie sich von den zitierten Vorgängerfilmen $\mathrm{ab}$ und führt auch hier ihren dezenten Umgang mit dem Thema zugunsten einer behutsamen Involvierung des Publikums fort. Mittels spezifisch künstlerischer Gestaltung versetzt die Regisseurin den Zuschauer in einen meditativ-trauernden Zustand und macht den Schmerz über die Auslöschung einer gesamten Familie für ihn erfahrbar. Daß sich der Zuschauer tatsächlich auf das immense Leid einlassen kann, hat drei Gründe: Erstens handelt es sich bei den Opfern um die Familie der Protagonistin, zweitens werden sie durch die Nennung ihrer Namen individualisiert und drittens ist die Totenklage aufgrund ihrer Poetik extrem wirkungsvoll.

In dieser Sequenz greift Loridan-Ivens ein visuelles Gestaltungsmuster aus $\mathrm{SHонн}_{\mathrm{H}}$ auf: das Hinabsteigen in den Auskleideraum der Gaskammer aus subjektiver Kameraperspektive (s. II.2.2.3).

Detaillierte Sequenzanalyse:

Die erste Einstellung beginnt damit, daß der Zuschauer - mit einer leicht wackelnden Kamera - zwei Treppen hinuntersteigt. Aufgrund der unruhigen Kameraführung könnte er vermuten, daß es sich um die Perspektive der Protagonistin handelt. 
Dieser Art der Inszenierung, in Verbindung mit dem Gezeigten, erinnert an Szenen aus Lanzmanns Sнонн (s. II.2.2.3). Auf verschiedenen Wegen - Lanzmann nimmt die steinernen Überreste unter grauem Himmel auf, während Loridan-Ivens die den Boden des Krematoriums bedeckende Wasseroberfläche bei Sonnenschein und blauem Himmel darstellt (s. 0:43:26 h) - gelangen beide rasch zu dem Symbol: Asche. In könnte, nicht einmal im kleinsten, sich vorstellen, daß er vielleicht in drei, vier Stunden in Asche verwandelt würde.« (0:55:14 - 0:55:24 h) Wenige Sekunden nach dem Sequenzauftakt läßt Loridan-Ivens Myriam ihre poetische Totenklage beginnen:

»Cendre: tante Ida, oncle Samuel et leurs filles, mes cousines Sura et la jolie (s. 0:43:51 h) petite Estoucha. Cendre: oncle Haïm, tante Ryvka, leurs fils Zelig et Jacob, leurs filles Féla et Chana, mes cousins et cousines: cendre. Cendre: tous ceux dont je ne connais pas le nom, gazés, brûlés ici ou dans d'autres crématoires. Et mon père Schloime Salomon: cendre.« (0:43:27 - 0:44:11 h, eigene Hervorhebung)

Während die Leichenverbrennungen in Sнонн explizit und in der Form des sachlichinformierenden, eher unpersönlichen Zeugenberichts (Filip Müller) angesprochen werden, wählt die Regisseurin von BIRKENAU UND RosENFELD eine poetischere, auf Empathie zielende Form der Thematisierung, sie läßt den Zuschauer an Myriams Gedenken teilhaben. 45 Sekunden wohnt er ihrem inneren Monolog bei, der sich aus zwei Elementen zusammensetzt: der rhythmisch wiederkehrenden Nennung des furchtbaren Ergebnisses der Vernichtung (Asche; siehe die Hervorhebungen im Zitat) und der Aufzählung der Namen der Opfer, ihrer Verwandten. Wie die spätere Autofahrt am Lager vorbei (s. 5.6.a), scheint die Liste der Ermordeten kein Ende zu nehmen - trauriger Höhepunkt ist der Verlust des Vaters, dessen Wichtigkeit für die damals 15-jährige Myriam zuvor verdeutlicht wurde (s. 5.5.b). Durch die Reduktion auf die Eckpunkte und Aussparung des - in SHOAH mit beinahe wissenschaftlicher Exaktheit geschilderten (s. II.2.2.4) - Vernichtungsablaufes bleibt es dem Zuschauer überlassen, welche Vorstellung er sich von den Details aus Auskleideraum und Gaskammer macht. Vor allem jedoch fühlt er mit der auf den Treppen der Gaskammer kauernden, in sich versunkenen, ihren Begleiter ignorierenden Protagonistin, die offenbar als einziges Familienmitglied den Holocaust überlebt hat (s. 0:43:51 h). Sie vermittelt in dieser Szene das Bild tiefster Trauer, vielleicht auch mitschwingender Scham, als einzige überlebt zu haben (s. 5.3).

g) Tragische Spurlosigkeit:

Myriams verzweifelte und vergebliche Suche nach Spuren der Massengräber Im Unterschied zu den vorangegangen Sequenzen (s. 5.5.b - 5.5.6), in denen sich Myriam ihren grauenhaften Erlebnissen insbesondere durch bewußtes In-sich-Gehen genähert hat, sucht sie hier wesentlich hartnäckiger, aber ebenso vergeblich nach den

800. Vgl. Kloepfer 1995: 56 zur Tönung durch akustische Inszenierung in II.4.1.

801. Vgl. Semprún: »Und da habe ich das vielfältige Gezwitscher der Vögel gehört. Sie waren auf den Ettersberg zurückgekehrt. Das Brausen ihres Gesangs umfing mich wie Meeresrauschen. Das Leben war auf den Hügel des Ettersbergs zurückgekehrt.« (1995: 348) 


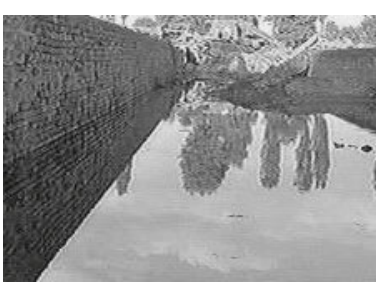

(791) $0: 43: 26 \mathrm{~h}$

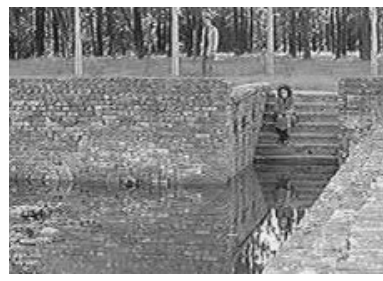

(792) $0: 43: 51 \mathrm{~h}$

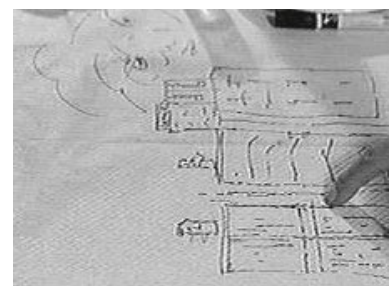

(793) $0: 53: 47 \mathrm{~h}$

Spuren der Vergangenheit (s. 5.5.d). In der vorliegenden Sequenz fehlt von den Massengräbern jegliche Spur: Dort, wo Myriam mit ihren Leidengenossinnen die Gräben ausgehoben zu haben glaubt, bedeckt hohes, satt-grünes Gras die Lichtung, färben Vogelgezwitscher und Krähenrufe unsere akustische Wahrnehmung. ${ }^{800}$ Aufgrund der extremen Grauenhaftigkeit des einstigen Erlebnisses hat sie dieses am stärksten verdrängt. Um zu dieser traumatischen Erfahrung, die sie wohl am stärksten verdrängt hat, wieder Zugang zu finden, sucht sie verbissen nach sichtbaren Zeichen der Vergangenheit. Diese Verzweiflung macht Loridan-Ivens für den Zuschauer durch eine besondere filmische Inszenierung erfahrbar. Ohne jeglichen visuellen bzw. taktilen Anhaltspunkt scheint es für Myriam unmöglich, die Erinnerung an eines ihrer schlimmsten Erlebnisse heraufzubeschwören.

Die auffallend lange (3 Minuten) Szenenfolge bildet den Höhepunkt eines Spannungsbogens, der mehrere Sequenzen miteinander verbindet.

Nachdem Myriam bereits drei Tage im Lager verbracht hat, erinnert sie sich abends im Hotelzimmer an die Bestürzung einer Leidensgenossin (Ginette) angesichts Myriams blasser bzw. falscher Erinnerung: In einem Tanzlokal diskutierten beide Überlebende die Frage, wo genau sie damals die Gruben für die Massengräber ausheben mußten. Während Myriam sich auf einen Ort nahe der Küchen versteift, ist Ginette davon überzeugt, daß sie damals in der Nähe des Krematoriums graben mußten (s. 0:53:47 h). »Comment t’as pu oublier tout ça?« (o:53:44 h), fragt die sich offensichtlich besser erinnernde Ginette mit deutlicher Bestürzung. Myriams wiederholtes telefonisches Nachfragen bei Suzanne bestätigt Ginettes Erinnerung. Trotz der Rekonstruktionshilfe war Myriam von ihrer Erinnerung betrogen worden.

\section{Detaillierte Sequenzanalyse:}

Die vorliegende Schlüsselsequenz beginnt mit auffälligen Krähenschreien und Vogelgezwitscher ${ }^{801}$ sowie einem vertikalen Reißschwenk am Stamm einer hohen Birke entlang. Unten angekommen beruhigt sich die Kamera und fängt die Protagonistin aus erheblicher Distanz (weite Einstellungsgröße) auf einer in der Sonne glänzenden Lichtung ein (o:57:34 h). Aufgrund des sachten horizontalen Kameraschwenks wird Myriam zwischenzeitlich und wiederholt von den Birkenstämmen verdeckt. In Verbindung mit der Supertotalen fordert diese Kamerabewegung den Zuschauer auf, genauer auf die Heldin zu achten: Myriam scheint sich, nach unten blickend, nach Spuren der Vergangenheit umzusehen. Im Kontext mit den vorhergehenden Szenen kann der Zuschauer ahnen, daß sie nach Zeichen für die Gräben sucht. Zehn Sekunden später bestätigt die Tonspur diese Ahnung: »Le crématoire est là?« (०:57:34 h), fragt sich 
Myriam mit unsicherer Stimme und macht ein paar Schritte, sich unruhig umsehend. »Est là?« (0:57:35: h), murmelt sie leise und zaghaft. Die Einstellung zeigt weiterhin die sonnendurchflutete Lichtung mit sattgrünem hohem Gras, umgeben von Birken und im Hintergrund der Stacheldrahtzaun mit dem Holzwachturm. Überreste eines Krematoriums sind weder für den Zuschauer noch für Myriam erkennbar.

Die folgende Szene kontrastiert mit der beschriebenen auf mehreren Ebenen: Statt einer extrem weiten Einstellungsgröße dominiert hier die nahe. Die figurenunabhängige Perspektive wird von einer der Heldin angenäherten Perspektive (over-theshoulder) abgelöst, wobei Myriams Unsicherheit filmisch durch eine leicht wackelnde Handkamera betont wird. Als stünden wir in beklemmend geringer Distanz links neben und leicht hinter ihr, können wir beobachten, wie sie eine Hand an den Mund führt (s. 0:57:37 h) - Zeichen von Unsicherheit -, heftig den Kopf schüttelt und dann laut ihre Schritte zu zählen beginnt, den Blick nach unten gerichtet: »Un, deux, trois.« (o:57:39 h) Offenbar versucht Myriam durch eine gewisse Anzahl von abmessenden Schritten, den einstigen Ort der Krematorien und von dort aus der Gräben bestimmen zu wollen - ein nahezu hoffnungslosen Unterfangen.

Die nächste Einstellung führt die Annäherung an die Figurenperspektive fort und steigert sie ins Extrem: Mit den auf den Boden gerichteten Augen der Protagonistin (subjektive Kamera) sehen wir nur dichtes, grünes und in der Sonne glänzendes Gras (o:57:41 h). Daher löst Myriam ihren Blick ruckartig vom Boden (Reißschwenk nach oben) und schaut sich erneut suchend nach dem Krematorium und den Gräben um. Aus dieser Perspektive wirkt die Lichtung, mit wilden Blumen im Bildvordergrund (s. o:57:43 h), beinahe noch idyllischer.

Die nächste Einstellung versetzt den Zuschauer erneut in eine der Protagonistin extrem nahe Position und etwas weniger deutlich in ihre Perspektive (over-the-shoulder). Zunehmend verunsichert und vergeblich nimmt sie nun ihren Arm zu Orientierungszwecken zu Hilfe, während sie irritiert mit sich spricht: »C'était pas, c'était là (s. ○:57:45 h). C'était ..., non.« Tief seufzend erkennt sie ihre wiederholten Irrtümer: »Mais non.«(0:57:48 h), so daß der Zuschauer mutmaßt, daß Myriams weitere Versuche scheitern werden.

Anstatt aufzugeben, setzt die Heldin ihre Suche verzweifelt fort - Indiz für ihre Getriebenheit. Erneut versucht sie es mit einer ganz bestimmten Anzahl abmessender Schritte. Eine Aufnahme der Füße zeigt, wie sie anhand einer bestimmten Anzahl von Schritten zum Ziel kommen möchte (0:57:51 h); wiederum steht sie vor üppigem Gras.

»C'est pas là, c'est pas possible.«(0:57:53 h), lautet Myriams Urteil, erneut in der Form des Selbstgesprächs. Die zunehmende Rastlosigkeit der Protagonistin wird hier besonders spürbar: Verloren blickt sie von der einen in die andere Richtung, so daß sie zum Teil den Bildrahmen verläßt (s. 0:57:57 h). Durch ihre hektischen Bewegungen nimmt der ohnehin schon geringe Abstand zur Kamera weiter ab, der Zuschauer dreht sich mit ihr im Kreis.

Es folgen die abmessenden Schritte in Detailaufnahme, nun jedoch einmal von rechts nach links und direkt im Anschluß von links nach rechts, danach sehen wir einmal mehr die Heldin in Nahaufnahme, in alle Richtungen blickend. »Ils sont sortis là!«, behauptet sie plötzlich mit festerer Stimme und zeigt in eine bestimmte Richtung 


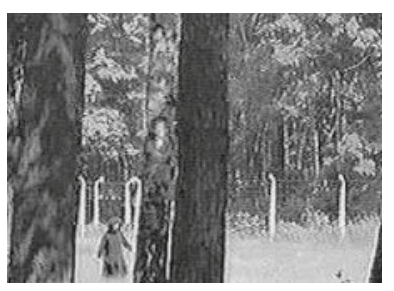

(794) $0: 57: 34 \mathrm{~h}$

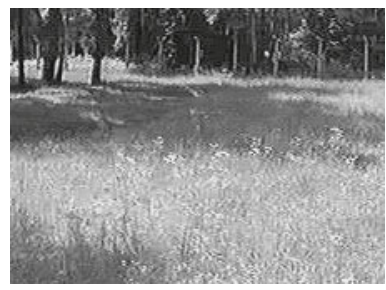

(797) $0: 57: 43 \mathrm{~h}$

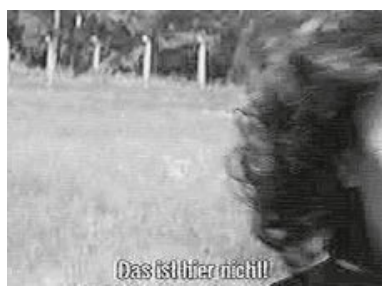

(800) $0: 57: 57 \mathrm{~h}$

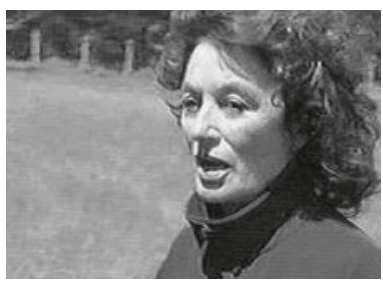

(803) $0: 58: 16 \mathrm{~h}$

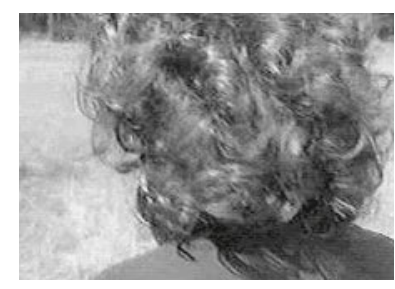

(795) $0: 57: 37 \mathrm{~h}$

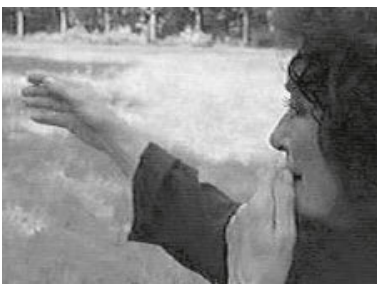

(798) $0: 57: 45 \mathrm{~h}$

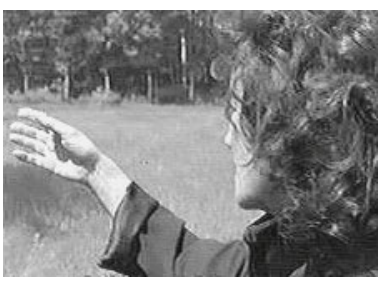

(801) $0: 58: 09 \mathrm{~h}$

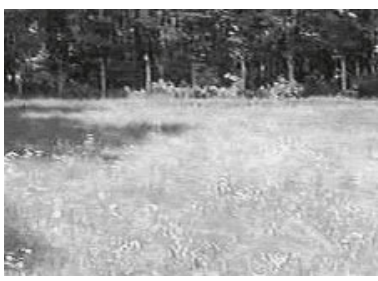

(804) $0: 58: 19 \mathrm{~h}$

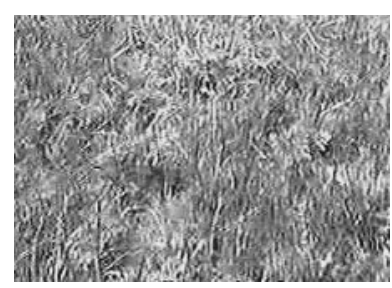

(796) $0: 57: 41 \mathrm{~h}$

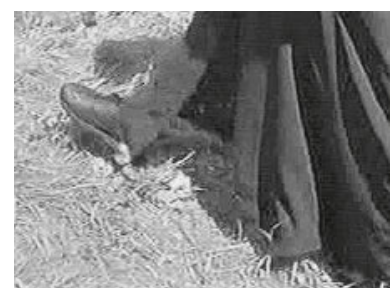

(799) $0: 57: 51 \mathrm{~h}$

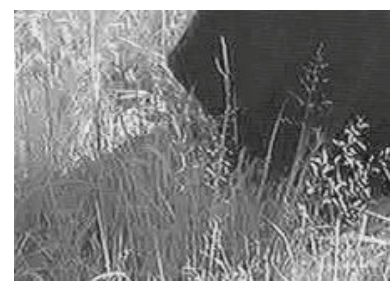

(802) $0: 58: 11 \mathrm{~h}$

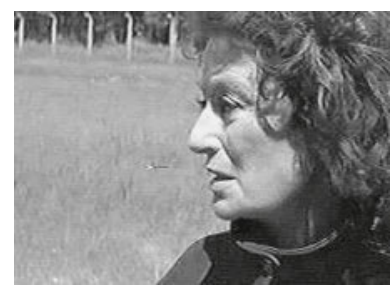

(805) $0: 58: 20 \mathrm{~h}$

(s. o:58:09 h). Die Detailaufnahme ihrer Beine und Füße verrät jedoch, daß diese vermeintliche Gewißheit ihr nicht wirklich weiterzuhelfen vermag. Hin- und hergerissen tritt sie auf der Stelle, während die Gräser in der Sonne leuchten (s. 0:58:11 h). Plötzlich dreht sie sich in die entgegengesetzte Richtung, macht einige zaghafte Schritte und wirft suchende Blicke auf die gegenüberliegende Seite: »Là?« haucht sie fragend mit angestrengt-verlorenem Gesichtsausdruck (s. 0:58:16 h). Die Kamera umrundet die Protagonistin, uns in ihr Suchen einbeziehend und schließlich ihren gehetzten Blick offenbarend: Einmal mehr liegt die Lichtung friedlich und ohne Spur von Krematorien oder Gräben in der Sonne (s. 0:58:19 h). Wieder schnellt ihr Kopf von rechts nach links, um mit einem ernüchterten »Là ...? « (0:58:21 h) zu enden. Die wackelnde Kamera mach erneut ihre unsicheren Schritte und ihre aufkommende Verzweiflung erfahrbar: »Il n'y a plus rien ici!« (0:58:23 h; s. 0:58:24 h), »C'est que ...«(0:58:25 h), »Krematorium« (0:58:26 h) flüstert sie beinahe resignierend, wäh- 
rend die Kamera ihren Abstand zu Myriam variiert, um die innere Unruhe der Heldin auch auf den Zuschauer zu übertragen. Während sie ratlos verstummt, kommt Wind auf, der die Birkenblätter fast beruhigend rascheln läßt. Diese auditive Untermalung setzt sich, ebenso wie das Vogelgezwitscher und die Krähenschreie, in der Folgesequenz fort. In großer Entfernung - weiter als in der ersten Einstellung - sehen wir die Heldin kurz auf der sonnigen Lichtung stehen, um darauf, in extremem Kontrast zur Totalen, mit ihr auf das sattgrüne Gras zu starren (s. 0:58:38 h): »Il n'y plus rien ...«, wiederholt die Protagonistin die bereits zuvor geäußerte Erkenntnis.

Erschüttert sitzt die Protagonistin auf der Lichtung, über das üppige Gras gebeugt. Nach einem nachdenklichen und gequälten Blick in die Ferne (s. o:58:50 h) sieht sie sich erneut unsicher um und richtet den Blick wieder zu Boden.

Die hektisch von rechts nach links schwenkende Kamera (Reißschwenks und subjektive Kamera) versetzt den Zuschauer unmittelbar in Myriams suchende Blicke (s. 0:58:56 h).»On creusait ici?« (0:58:59 h), zweifelt sie mit zaghafter Stimme.

Auf dem Höhepunkt ihrer Verzweiflung und Ratlosigkeit versucht die Protagonistin, durch das Riechen an einem herausgerissenen Grasbüschel die Vergangenheit heraufzubeschwören (o:58:59 h) - ein ausdrucksstarkes und im Zusammenhang mit Erinnerungen durchaus geläufiges Verhalten. Das Prinzip erinnert an Lanzmanns Sнонн, als der Überlebende Simon Srebnik zum ersten Mal mit dem einstigen Ort des Schreckens (er hatte ebenfalls auf einer Lichtung, gleichwohl außerhalb des Lagers, Massengräber ausheben müssen) konfrontiert wird, die idyllische Lichtung ungläubig betrachtet und eine Hand voll Erde durch die Finger rieseln läßt (s. II.2.2.6). Als auch dieser letzte Versuch der Heldin mißlingt, schüttelt sie den Kopf, läßt das Gras resignierend zu Boden fallen und wischt sich mit der Hand die aufkommenden Tränen aus dem Gesicht (s. 0:59:05 h): »On était couvert de cendres.« (0:59:07 h), flüstert sie - heute jedoch scheint die Sonne kräftig vom Himmel und das Gras glänzt darin.

»Même le ciel était noire.«(0:59:02 h), erinnert sich Myriam, während sie in die Baumkronen hinaufsieht, durch die heute das Sonnenlicht bricht (s. 0:59:09 h). Dabei wakkelt die Kamera so auffällig, daß einem mit der Protagonistin fast schwindelig wird, und die Sonnenstrahlen sind derart kräftig, daß wir geblendet werden. Der Gegensatz zwischen Vergangenheit und Gegenwart könnte kaum größer sein.

Verzweifelt über die Unvereinbarkeit des Heute mit dem Gestern sinkt die Heldin zunächst kraftlos in sich zusammen. Wenig später verschafft sie ihrer extremen Enttäuschung Ausdruck, indem sie mit der Hand wiederholt heftig ins Gras schlägt (s. o:59:18 h). Auch ihr Schluchzen trägt dazu bei, daß der Zuschauer ihren seelischen Kummer nach- und mitvollziehen kann: »Je sais plus« (0:59:21 h), endet sie voller Verzweiflung.

Nachdem sie sich schwerfällig aus dem Gras erhoben hat, einen letzten Grashalm beinahe unwillig von der Hand geschüttelt hat, überrascht die folgende Einstellung durch die Beruhigung der Kamera und deren neue Position. Aus dem Wachturm heraus, somit aus erheblicher Distanz, verfolgt der Zuschauer, wie Myriam sich erschöpft vom Kampf um ihre Erinnerung ins sonnige Gras fallen läßt und entkräftet ausstreckt (s. 0:59:55 h). 


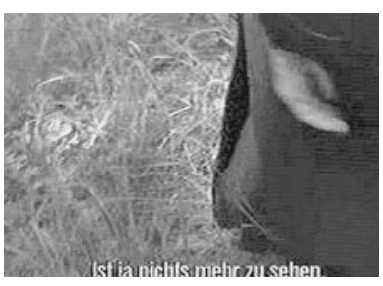

(806) $0: 58: 24 \mathrm{~h}$

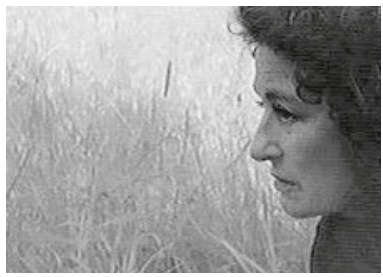

(809) $0: 58: 50 h$

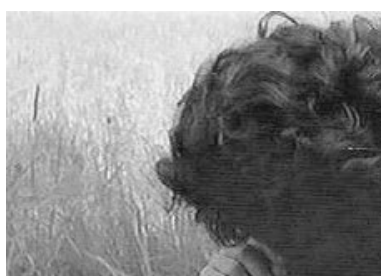

(812) $0: 59: 05 \mathrm{~h}$

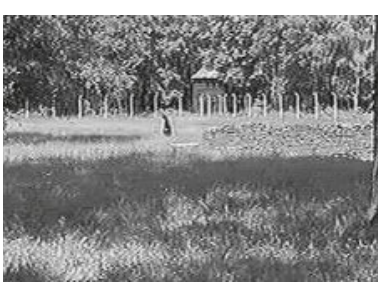

(807) $0: 58: 33 \mathrm{~h}$

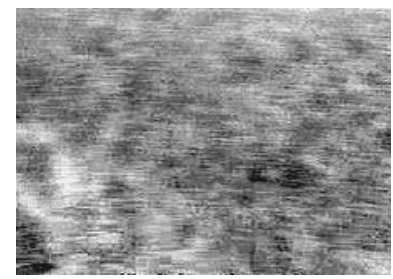

(810) $0: 58: 56 \mathrm{~h}$

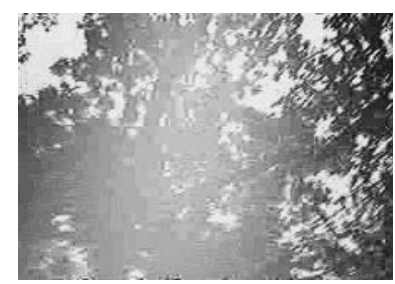

(813) $0: 59: 09 \mathrm{~h}$

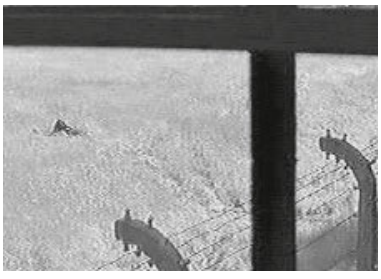

(815) $0: 59: 55 \mathrm{~h}$

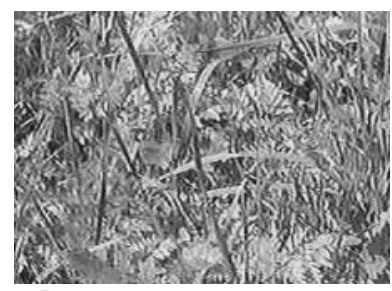

(808) $0: 58: 38 \mathrm{~h}$

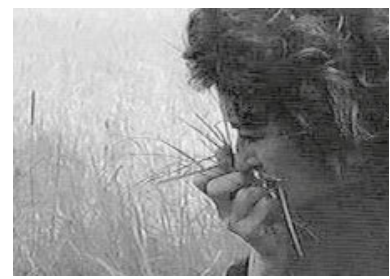

(811) $0: 58: 59 \mathrm{~h}$

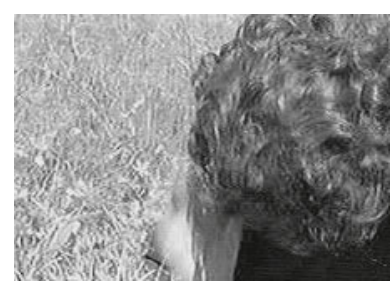

(814) $0: 59: 18 \mathrm{~h}$

\section{II.5.6 MÖGLICHKEITEN UND SCHWIERIGKEITEN BESONDERER VISUELLER BZW. MUSEALER INSZENIERUNG}

In insgesamt drei Schlüssel-Sequenzen stellt Loridan-Ivens die Möglichkeiten den Schwierigkeiten besonderer visueller bzw. musealer Inszenierung gegenüber (s. 5.2).

a) Gemeinsame Autofahrt am Lager entlang:

das Ausmaß der Vernichtung versus Oskars »stumme« Lagerfotografie

Zwei kontrastierende Formen der visuellen Inszenierung des einstigen Schreckensortes werden in der Sequenz, die der gemeinsamen Autofahrt entlang des Lagers gewidmet ist, einander gegenübergestellt.

$\mathrm{Zu}$ Beginn und in der zweiten Hälfte der Sequenz macht Loridan-Ivens' auffällige filmische Inszenierung das unfaßbare Ausmaß der Vernichtung für den Zu- 
schauer erfahrbar: Wie zu Beginn von Nacht und Nebel (s. II.2.1.3) und in Shoah (s. II.2.2.4) setzt die Regisseurin zunächst eine zügige Kamerafahrt am Lager entlang ein. Während Resnais und Lanzmann die Aufnahmen jedoch von einem Off-Kommentar bzw. -Bericht hatten begleiten lassen, läßt Loridan-Ivens auffallend lange die Bilder sprechen. Unterstützend begleitet sie die Kamerafahrt mit einer - hier erstmals im Film verwandten - melancholisch-klagenden Off-Musik. Obgleich mit der musikalischen Begleitung in Nacht und Nebel vergleichbar (Violine, Pizzicati), kann hier der entscheidende Unterschied zwischen beiden Filmmusiken exemplarisch verdeutlicht werden.

Der kürzere Mittelteil der vorliegenden Szenenfolge ist Oskars künstlerischen Lagerfotografien gewidmet. Aufgrund der spezifischen Inszenierung werden diese Fotos dem Zuschauer so vorgeführt, daß er deren Aussagekraft in Frage stellt.

\section{Detaillierte Sequenzanalyse:} meist auf Off-Musik verzichtet, fällt dieser Einsatz besonders stark auf. Zudem handelt es sich um eine ausgefallene Streichermusik (im Vordergrund eine Violine mit zum Teil spitzen Tönen, im Hintergrund ein Cello), mit getragen-melancholischem Charakter. Sie begleitet die halbminütige Kamerafahrt außen am Lager entlang mit Blickrichtung auf die vorüberziehenden Reihen von Häftlingsbaracken (s. 1:02:54, 1:02:57, 1:03:02 h).

Mit Myriam, so unsere Vermutung, sehen wir uns die Fotos des jungen Deutschen an, Aufnahme für Aufnahme. Diese - der zeitgenössischen, künstlerischen Lagerfotografie entsprechenden Bilder ${ }^{802}$ - zeigen die Schlafbaracken (s. 1:03:13 h und die Eisenbahnschienen 1:03:22 h) in jeweils charakteristischer Zentralperspektive. Eine weitere Fotografie erinnert den Zuschauer an NACHT Und NebeL (s. 0:10:02 h), denn sie zeigt Baracken unter blauem Himmel, umgeben von saftigem grünem Gras (s. 1:03:17). In ihrer künstlerischen Bildkomposition entspricht diese Aufnahme einer späteren Fotografie Oskars von Myriam (s. 1:11:21 h). Auch hier inszeniert der junge Deutsche unter anderem Säulen und Pfeiler des Stacheldrahtzauns. Da der Zuschauer über Myriam und andere Lagerbesucher persönliche Formen des Gedenkens und Erinnerns kennengelernt hat, konfrontieren ihn diese Fotografien mit der Frage nach deren Aussagekraft und den Grenzen dieses Mediums.

Nachdem Myriam von Oskar eine Erklärung für das letzte Foto verlangt hat (den Auskleideraum konnte sie nicht wiedererkennen; wenig später wird sie ihn mit dem jungen Deutschen aufsuchen; vgl. 5.6.c), greift die zentrale und letzte Einstellung der Sequenz die erste wieder auf und führt sie fort. Knapp zwei Minuten lang zieht das Lager aufgrund der Kamerafahrt rasant an den Augen des Zuschauers vorbei (s. 1:03:57 h, 1:04:10 h, 1:05:32 h), während die melancholisch-klagende Streichermusik erneut die Aufnahmen des nicht enden wollenden Lagers begleitend kommentiert. Wie in der ersten Einstellung, erinnert die Solovioline aufgrund ihres Zirpens, der mit ihr zum Teil verbundenen Dissonanz und des punktuellen Pizzicati an die unorthodoxe musikalische Begleitung in NACHT und NeBEL. Zentraler Unterschied zu den entsprechenden Kompositionen Eislers ist jedoch der eindeutig melancholisch-klagende

802. Siehe hierzu I.1. 


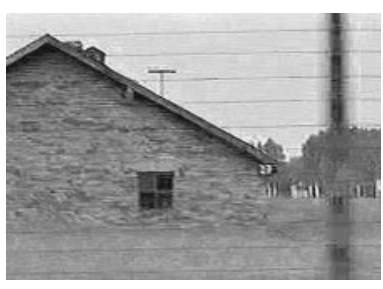

(816) $1: 02: 54 \mathrm{~h}$

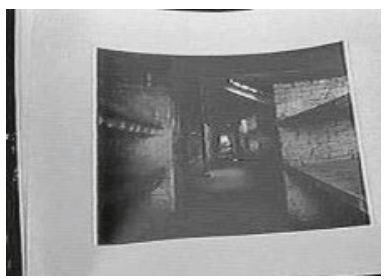

(819) $1: 03: 13 \mathrm{~h}$

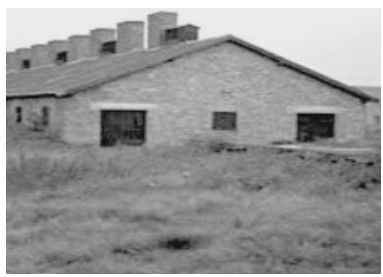

(822) $0: 10: 02 \mathrm{~h}$

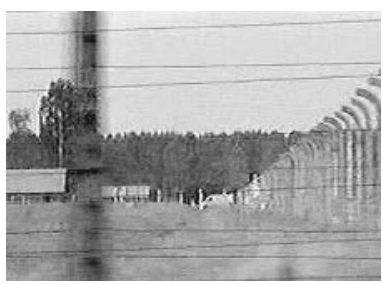

(824) $1: 03: 57 \mathrm{~h}$

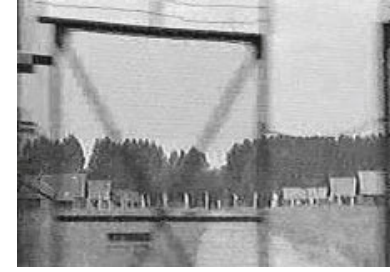

(817) $1: 02: 57 \mathrm{~h}$

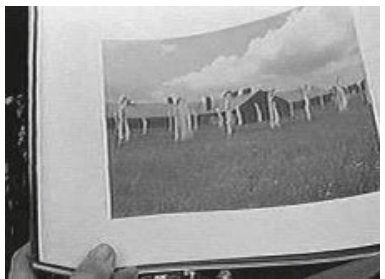

(820) $1: 03: 17 \mathrm{~h}$

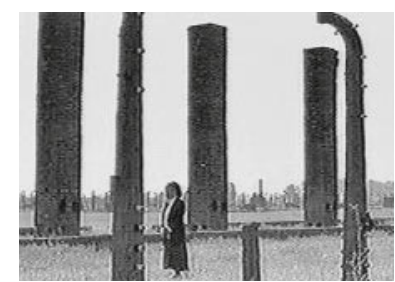

(823) $1: 11: 21 \mathrm{~h}$

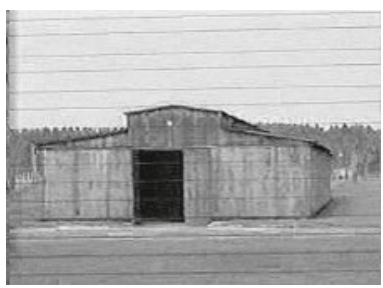

825.A $1: 04: 10 h$

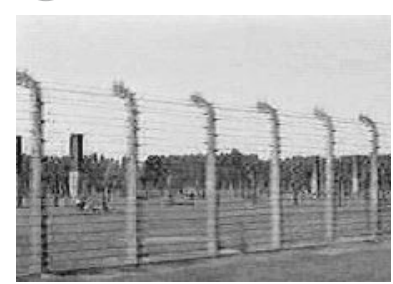

(826) $1: 05: 32 \mathrm{~h}$

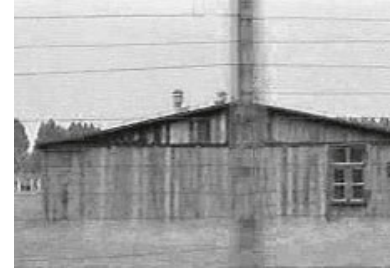

(818) $1: 03: 02 \mathrm{~h}$

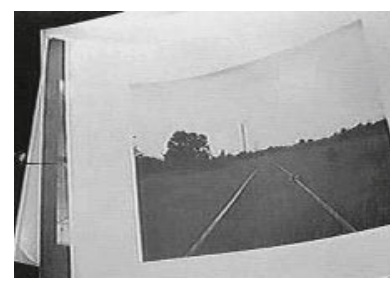

(821) $1: 03: 22 \mathrm{~h}$

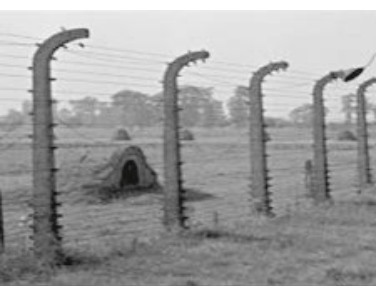

825.B $0: 02: 36 \mathrm{~h}$

Charakter dieser Musik von Birkenau und Rosenfeld, der die intendierte Wirkung der Bilder unterstützt. Auf der visuellen Ebene fällt bei genauerer Betrachtung auf, daß die letzten Bilder dieser Sequenz (s. 1:05:32 h) mit Aufnahmen aus Resnais' Film (s. o:02:36 h) beinahe identisch sind, in beiden Fällen inszeniert mittels einer Kamerafahrt von links nach rechts. 
b) Myriam vor der Fotowand: Erfahrbare Vernichtung durch Pars pro toto Verglichen mit Nacht und Nebel und Shoah macht Loridan-Ivens in dieser Sequenz das Ausmaß der Vernichtung für den Zuschauer mittels spezifischer Inszenierung (Kamerafahrt, Bildkomposition, Musik) stärker erfahrbar und ermöglicht ihm darüber hinaus ein Gedenken an die Ermordeten.

Im Unterschied zu Resnais und Lanzmann wählt die Regisseurin von BIRKENAU UND RoSENFELD eine weniger abstrakte Form des pars pro toto für die Massenvernichtung und übernimmt dabei die Konzeption eines Raumes im Museum Auschwitz-Birkenau. Durch die filmische Inszenierung der den Opfern abgenommenen Fotos aus früheren Zeiten gibt Loridan-Ivens den Verstorbenen ein Gesicht und macht über die Anzahl dieser Fotos die massenhafte Auslöschung erfahrbar.

Hinsichtlich der besonderen Inszenierung dieser gegenständlichen Überreste ist Birkenau und Rosenfeld mit Schindlers Liste (s. 0:46:45 h) vergleichbar. Schon Spielberg erkannte das Wirkungspotential dieser Fotos. ${ }^{803} \mathrm{Im}$ Unterschied $\mathrm{zu}$ ihm konzentriert sich Loridan-Ivens auf eine einzige Form der Aufbewahrung des den Opfern Abgenommenen. ${ }^{804}$

\section{Detaillierte Sequenzanalyse:}

In umgekehrter Bewegungsrichtung und geringerer Geschwindigkeit wird das auffällige filmische Mittel der Kamerafahrt in der folgenden Sequenz, »Myriam vor der Fotowand «, fortgesetzt. ${ }^{805}$ Hier entspricht die Kamerabewegung Myriams Betrachten der unzähligen Fotos im Museum von Auschwitz (subjektive Kamera) - Erinnerungsstücke an bessere Zeiten, die den Deportierten bei ihrer Ankunft im Lager abgenommen wurden (s. 1:05:50 h, 1:06:31 h, 1:06:51 h).

Noch stärker als bei der vorangegangenen Autofahrt, macht Marceline Loridan-Ivens' Art und Weise der Inszenierung dem Zuschauer das unfaßbare Ausmaß der Vernichtung erfahrbar: Bedächtig tastet die Kamera etwa eine Minute lang Foto um Tote ab und vermag doch nur einen Bruchteil der Opfer einzufangen. Begleitet werden diese Aufnahmen von der aus der vorangegangenen Sequenz bekannten Off-Musik, hier in noch getragenerer Weise (vor allem Bratsche, weniger dissonante und spitze Töne, langsameres Tempo). Im Unterschied zu Resnais, der den Zuschauer gegen Ende seines Films mit Leichenbergen konfrontiert, setzt Loridan-Ivens auf den Kontrast zwischen den Fotos glücklicher Familien und deren späteren Schicksal. Diese fotografischen Überreste haben eine ähnliche Funktion wie die als Pars pro toto ein-

803. Seine abtastende Kamerafahrt verweilt bei den Fotos deutlich länger als bei anderen Überresten, mit Ausnahme der herausgerissenen Goldzähne.

804. Sie zeigt keine weiteren Berge von Brillen, Schuhen, Spielzeugen etc.

805. „À Auschwitz, après la guerre, près de 2400 photographies de famille ayant appartenu à des déportés furent retrouvées dans une valise. Il est difficile de savoir exactement comment, pourquoi et par qui elles avaient été conservées. En tout cas, elles échappèrent à la destruction. Ce qui ne fut pas le cas de la plupart de ceux qu'elles représentaient dans le bonheur de l'avant-guerre. Ces photographies srescapéesı sont souvent l'ultime trace de ceux qui y périrent.« (Chéroux 2001: 23)

806. Vgl. hierzu Klügers sowie Lanzmanns Äußerungen in II.2. 


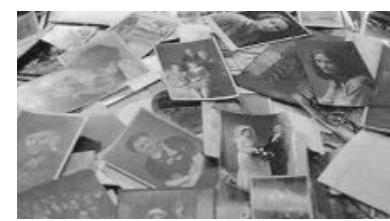

(827) $0: 46: 45 \mathrm{~h}$

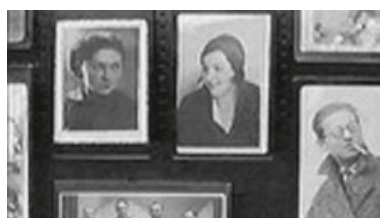

828 1:05:50 h

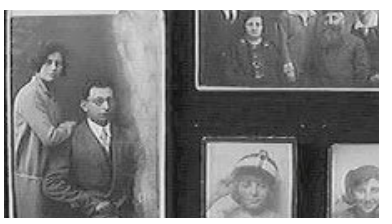

(829) $1: 06: 31 \mathrm{~h}$

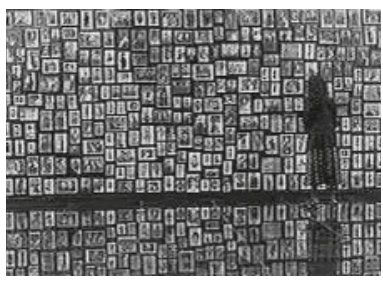

(831) $1: 05: 38 \mathrm{~h}$

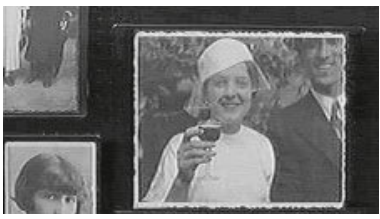

(830) $1: 06: 51 \mathrm{~h}$

gesetzten Gegenstände (Brillen, Schuhe, Goldzähne, Haare etc.) in den die Verwertungsmaschinerie der Nazis thematisierenden Sequenzen von DiE Todes-MÜHLEN (s. II.1.1.4), NACht und Nebel (s. II.2.1.7) und Sноан (s. Exkurs in II.2.1.7). Im Unterschied zu diesen Filmen handelt sich bei der in BIRKENAU Und RosenFELD gewählten Darstellungs- und Herangehensweise nicht um die Annäherung über eine zwangsläufig anonym bleibende Masse, sondern um die Präsentation von Individuen, von denen jedes »sein Gesicht« hat. Auf diese Weise erleichtert Loridan-Ivens dem Zuschauer die Erinnerung an die tatsächlichen Opfer, anstelle eines abstrakten Gedenkens.

Neben der beschriebenen Kamerafahrt dient hierzu bereits die erste Einstellung der vorliegenden Sequenz (s. 1:05:38 h): Sie zeigt Myriam vor einer mit Fotos »gepflasterten « Wand, die sich im glatten Fußboden spiegelt - eine gezielte Bildkomposition, aus der das Ausmaß der Vernichtung spricht.

\section{c) Steriler Auskleideraum versus Erfahrbarmachung der Demütigung}

In der Sequenz im Auskleideraum thematisiert Loridan-Ivens zunächst das Problem einer sterilen und daher die Erinnerung verstellenden musealen Inszenierung. ${ }^{806}$ Der Beginn steht im krassen Gegensatz zum vorangegangenen wirkungsvollen Fotoraum des Museums Auschwitz-Birkenau (s. 5.6.b). Gleichzeitig greift die Regisseurin hier Myriams wenige Minuten zurückliegende Verwunderung auf (s. 5.6.a): Bereits auf den Fotografien von Oskar hatte sie diesen Ort nicht wiederkennen können. Wenn der hergerichtete Raum jedoch selbst für Überlebende nicht wiedererkennbar ist, was soll er dann einem alltäglichen Besucher des Lagers »sagen«?

Im zweiten Teil der Sequenz macht Loridan-Ivens deutlich, daß Myriams leibhaftige Erinnerung wirkungsvoller ist als Oskars Fotografien. Des weiteren macht sie die 
den Opfern aufgezwungene und extrem demütigende Nacktheit erfahrbar ${ }^{807}$, während Resnais sie lediglich als ein Detail unter vielen aufzählt (s. II.2.1.4).

\section{Detaillierte Sequenzanalyse:}

Im ersten Teil der Sequenz befinden sich die Protagonistin und der junge Deutsche in einem steril wirkenden Raum: Er ist leer, extrem sauber, in ein bläuliches Weiß getaucht (s. 1:07:10 h). Die Weitwinkelaufnahme läßt die beiden Figuren ein wenig verloren in der Mitte des Raumes stehen. »Où on est ici?« (1:07:10 h), richtet Myriam die Frage an Oskar. Mit Befremden beantwortet dieser die Frage: »Les déportés se déshabillaient dans cette pièce ...C'est là qu'on leur prenait tout ce qu'ils avaient avec eux: vêtements, bijoux, argent, photos, tout!«, während sich Myriam verunsichert umsieht: »Je reconnais pas«, gesteht die Überlebende, ihre Augen finden keinen Anknüpfungspunkt an die Vergangenheit (s. 1:07:34 h). »J'uis passé par ici, forcément ... Non. Il y avait pas de vitres dans le sauna, c'était tout gris. On dirait un musée.« (s. 1:07:47 h). Während sie Oskar beinahe ungläubig anstarrt (s. 1:07:47 h), entspricht insbesondere ihr letzter Satz dem Eindruck des Zuschauers und erinnert darüber hinaus an die Kritik der KZ-Überlebenden Ruth Klüger an der »Museumskultur der KZs« (2001: 69; vgl. auch ebd. 77 in II.2).

Obgleich der zweite Teil der Sequenz in ebenso sterilen, hellen Nebenräumen spielt, beginnt Myriam sich zu erinnern. Nachdem Oskar sie in dem tunnelartigen Gang fotografiert hat (s. 1:07:55 und 1:08:07 h), beginnt die Protagonistin zu erzählen, daß sie in diesem Raum geschoren und tätowiert wurden. »Quand on s'est retrouvé toute nue avec le crâne rasé, y en a eu qui pleuraient, d'autres qui rigolaient, ça avait quelque chose de ridicule« (1:08:21 - 1:08:34 h), berichtet Myriam von den unterschiedlichen Reaktionen ihrer Leidensgenossinnen auf die Praktiken der Entmenschlichung (geschorener Kopf, eingebrannte Tätowierung). ${ }^{808}$

Während sie bis zu diesem Zeitpunkt nur von hinten zu sehen war - durch Oskars Kamera -, ist Myriam auf dem Höhepunkt der Sequenz in Großaufnahme zu sehen. ${ }^{809}$ So läßt sich jede mimische Regung im Verlauf ihres Erinnerns an den Sadismus der Nazis in diesen Räumen wahrnehmen; besonders wirkungsvoll, da Myriam - von ihrer Erinnerung eingeholt - zum Teil in die Rolle der Leidengenossin schlüpft:

»Des femmes SS sont rentrées et elles ont demandé s'il y avait des musiciennes (s. 1:08:43 h). Une petite voix a répondu: >Moi, je suis danseuse à l'opéra.< Une femme SS a dit: >C'est bien, montre-nous ce que tu sais faire.ı Et elle s'est mise à faire des pointes [...], tout nue avec son crâne rasé dans un silence total ... Laurette (s. 1:09:14 h), c'est ça, elle s'appelait Laurette, elle devait avoir à peu près 15 ans comme moi, Laurette ...« (1:08:38 - 1:09:25 h)

807. »Diese Ankunft war demütigend: Das ist, was man spüren soll.« (Loridan-Ivens zit.n. N.N. in: Le Monde, 09.07.2002, auf: www.partisanfilm.de/index/61136,75093) Vgl. auch Levi 1990: 114f. und Klüger: »[...] die auferlegte Nacktheit ist das Gegenteil, nämlich Selbstentfremdung. Verlust an Identität. [...] Wer gezwungen wird, sich nackt bloßzustellen, verliert sich streckenweise.« (2001: 143f.)

808. Auch Primo Levi und Imre Kertész äußerten, daß einige der Betroffenen mit Galgenhumor reagierten.

809. Zu Beginn hatten wir sie maximal in Nahaufnahme beobachten können. 


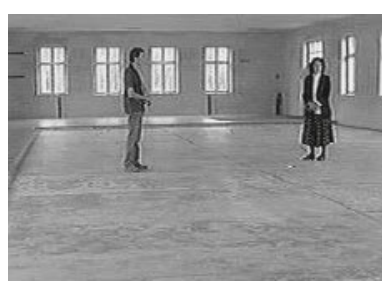

(832) $1: 07: 10 \mathrm{~h}$

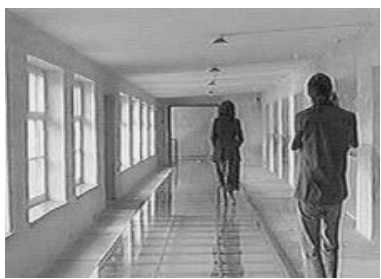

(835) $1: 07: 55 \mathrm{~h}$

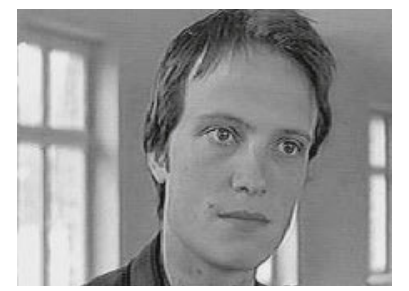

(833) $1: 07: 34 \mathrm{~h}$

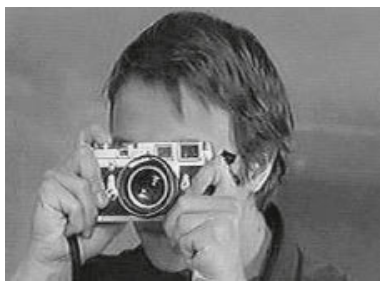

(836) $1: 08: 07 \mathrm{~h}$

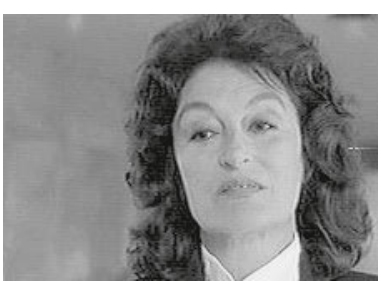

838 1:09:25 h

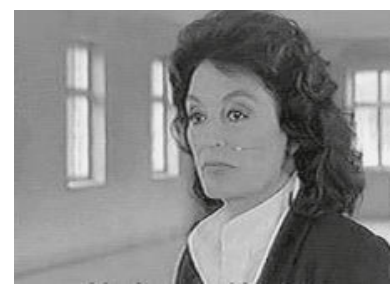

(834) $1: 07: 47 \mathrm{~h}$

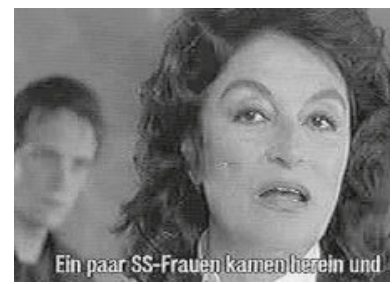

(837) $1: 08: 43 \mathrm{~h}$

Dem Zuschauer geht es während dieser Geschichte wahrscheinlich ebenso wie dem jungen Deutschen, der von Myriams vergegenwärtigter Erinnerung so ergriffen ist, daß er den Fotoapparat absetzt, ohne den Auslöser zu betätigen. Indem sie in die Rolle der gleichaltrigen Leidensgenossin schlüpft, die nackt und kahlgeschoren die Launen der Nazi-Schergen ertragen mußte, verkörpert die Protagonistin die erlittene Vergangenheit und macht sie für den Zuschauer auf eindringlichste Weise spür-, erfahr- und mitvollziehbar. 
1. »Noch vor dem Lesen lernen die meisten Kinder heute, den Fernsehapparat zu bedienen und Filme zu verstehen.« (Hickethier 1996: 1) »Daß Bilder die Imagination töten sei wahr, aber auch >...daß nur Bilder imstande sind, die Erinnerungen [der Überlebenden] wenigstens in Bruchstücken einer fernseh-süchtigen Nachwelt zu überliefern«.« (Kilb zit.n. Thiele 2001: 456)

2. Angesichts der Thematisierung von Gewalt und Unmenschlichkeit »wird der Kinobesuch für einen selbst zu einer Leistung des Aushaltens und Durchstehens. [...] Auf diese Weise werden die Zuschauer mit ihren eigenen Belastungsgrenzen konfrontiert. Sie können sich im Kino fragen, was sie im Leben ertragen können.«(Blothner 1999: 33) 


\section{Auf- und Annahme des Holocaust im Spielfilm}

A.

Die Analyse aktueller Formen des Holocaust-Gedenkens bestätigt, daß das Erinnern inzwischen nicht mehr nur nationalstaatlich, sondern zunehmend nationen-übergreifend erfolgt. Levy/Sznaider stellen in diesem Zusammenhang eine allgemeine Visualisierungstendenz durch Ausstellungen, Filme und Gedenkstätten fest und zeigen, wie sich der Holocaust in den vergangenen Jahren durch seine massenmediale Verarbeitung - vor allem durch die amerikanische TV-Serie Holocaust (USA 1978) oder auch Spielbergs Spielfilm Schindlers Liste (USA 1993; s. II.3.2) - aus dem »nationalstaatlichen >Container « herauslöste (2001: 30, H.i.O.). Populäre Formen des Gedenkens seien - trotz oder aufgrund der zunehmenden historischen Distanz - in der Lage, breite Bevölkerungsschichten zu erreichen und Historikern deren bisheriges Deutungsmonopol streitig zu machen. Wie läßt sich diese breite Wirkkraft insbesondere audiovisueller Erinnerungsformen erklären, auf die u.a. der Regisseur von ZuG DES LEBENS (F/BEL/ROM/NL 1998; s. II.4.2) pointiert verweist: »Wir müssen erkennen und wir müssen akzeptieren, daß niemand mehr Bücher liest, sich Fotos anschaut oder in Museen geht. Die herrschende Kommunikationsform ist die audiovisuelle.« (Mihaileanu zit.n. Tegeler 1999: 2) ${ }^{1}$ - der Film als das erste audiovisuelle Medium »nach den Menschmedien« (Faulstich 2004: 119), »das kulturelle Leitmedium der Moderne des vergangenen Jahrhunderts« (Paech 2003: 22).

Nicht nur gesamtgesellschaftlich betrachtet, sondern auch für den einzelnen stellt die Auseinandersetzung mit dem Holocaust eine außergewöhnliche Herausforderung dar, was ich bei der Wahl und Beschäftigung mit dieser Thematik selbst verspürte. Angesichts der Tatsache, daß der Holocaust im negativen Sinne das »Äußerste« (Todorov 1993) darstellt und als »Zivilisationsbruch« (Diner 1998) bzw. schwärzestes Kapitel der jüngeren Vergangenheit bezeichnet wird, liegt die Frage nahe, was Menschen - neben Gründen allgemeiner Erinnerungsarbeit und -kultur - dazu bewegt, sich dem Holocaust freiwillig und intensiv über einen längeren Zeitraum oder auch »nur« für die Dauer eines Films zu widmen: Entsteht in diesem Zusammenhang ein Spannungszustand zwischen »Angezogen- und Abgestoßen-Sein«? Während die Ablehnung nicht weiter kommentiert werden muß, bedarf die »Anziehung « der Erläuterung. Fordert eine gewisse Unfaßbarkeit nicht gerade zu dem Versuch auf, das Geschehene zumindest ansatzweise zu erfassen? Und liegt im Blick aus dem Kinosessel in (un)menschliche Abgründe nicht die Chance, mit der eigenen »natürlichen« Angst bzw. dem »natürlichen « Selbstschutz vor dem Schlimmsten umgehen zu lernen? ${ }^{2}$ Kann die Tatsache, daß die ganze Bandbreite menschlichen Verhaltens erfahrbar wird, das 
Individuum persönlich »bereichern«? Nach Kant (1972: 623ff.) läßt die Größe eines negativen Ereignisses den Adressaten sich selbst als menschlicher erfahren, so daß er in der Lage ist, das Negative zu ertragen. Es ist daher kein Zufall, daß insbesondere Holocaust-Spielfilme ein positives Gegengewicht zum Genozid aufbauen und es phasenweise dominieren lassen (s.u., C). An Filmen, die Retter (Schindlers Liste, Das Leben ist SChÖn) und Rettungsversuche (Auf Wiedersehen Kinder, Zug des LEBENS) ins Zentrum rücken, kann dieser Aspekt leicht nachvollzogen werden. Diese positiven Verhaltensbeispiele im Umgang mit den Geschehnissen können - sofern entsprechend inszeniert - Wertvorstellungen vermitteln und lebensbejahende Kräfte im Zuschauer wecken, die er in seinen Alltag übertragen kann.

B.

Aus der Untersuchung der ausgewählten Filme geht hervor, daß es im Umgang mit dem Holocaust seit der Nachkriegszeit Fortschritte gibt. Während ältere filmische Auseinandersetzungen, besonders die Entnazifizierungsfilme unmittelbar nach Kriegsende (s. II.1), dem Publikum jegliche Freiheit im Umgang mit den Greueltaten nahmen, es teilweise zum Hinsehen zu zwingen versuchten, fällt bei jüngeren Filmen (s. II.3 - II.5) eine tendenzielle Entwicklung zu mehr Offenheit, zu größerer Behutsamkeit in bezug auf den Zuschauer auf.

Die Schockästhetik der Umerziehungsfilme wurde als kontraproduktiv erkannt (s. II.1). Burgers Entnazifizierungsfilm Die TodesmüHLEN (USA 1945; s. II.1.1), jedoch auch Resnais' Nacht und Nebel (F 1955; s. II.2.1) und Lanzmanns Shoah (F 1985; s. II.2.2) ist gemeinsam, dem Publikum in erzieherischer Weise ihre Sichtweise des Holocaust aufzudrängen. Sie vermitteln den Eindruck, insbesondere ihre - spezifische - Art der Dokumentation könne diese Thematik dem Zuschauer näher bringen. Während die Umerziehungsfilme die Wahrnehmung durch Aufnahmen von höchster Brutalität, teils in Großaufnahme, zu erzwingen suchten (s. insb. II.1.1.2), setzt Resnais auf Verfremdung durch vielfältige Kontrastwirkungen. Dabei steigert er jedoch die Anzahl der ästhetischen Verfahren bis hin zur gegenseitigen Schwächung und zur Überreizung des Zuschauers (s. insb. II.2.1.4). Zudem versucht er, das Publikum zum Sich-Vorstellen des Grauenhaftesten zu bewegen (s. II.2. 1.6), indem er zum Teil noch schockierenderes Bildmaterial als Die TodesmüHLen einsetzt (s. II.2.1.1 und II.2.1.7). Vordergründig wenig inszeniert und puristisch wirkend, ist Lanzmanns Sнон von streckenweise erheblicher Inszenierung getragen (s. insb. II.2.2.5). Der Druck, den Lanzmann wiederholt auf die Zeugen, die Überlebenden, ausübt, indem er sie drängt, ihre Berichte trotz massivster psychischer Belastung fortzusetzen, kann beim Publikum - verstärkt durch das indiskrete Heranzoomen an die aufgewühlten Gesprächspartner - eine kontraproduktive Wirkung erzielen (s. erneut II.2.2.5). Auch hinter seinem explizit formulierten Anspruch (s. II.2.2.1), den Zuschauer durch die Dauer des Films und aufgrund der zahlreichen Augenzeugenberichte in die Vernichtung zu »versenken«, verbirgt sich ein aufnötigendes Ansinnen.

3. Žižek 2000: 15 in II.2.2.

4. »Weil er durch die Lebenden zur Vernichtung vordringen will, interessiert er sich auch nicht für die Errettung eines einzelnen. Das ist eine fast tyrannische Herangehensweise, und wir haben in Israel Überlebende getroffen, die darunter sehr gelitten haben.« (Hartman zit.n. Niroumand, 15.01.1997: 13) 
Die Fülle an Einzelschicksalen und die Konzentration auf die Vernichtungsabläufe erzeugen - trotz »positiven« Ausgangs für die Befragten - die Empfindung von Hoffnungslosigkeit und erschweren so das Betrachten dieses Films ${ }^{3}$, im Gegensatz zu Loridan-Ivens' Spielfilm BirkenAu Und RosenfeLd (F/D/POL 2003, s.u. sowie II.5). ${ }^{4}$

Eine deutliche Wende im Rahmen der in der vorliegenden Arbeit untersuchten Filme stellt Louis Malles Spielfilm Auf Wiedersenen Kinder dar (F 1987; s. II.3.1). Im Gegensatz zu den drei Dokumentarfilmen zeichnet sich Malles Werk durch besondere Bescheidenheit und Behutsamkeit sowie durch einen deutlich nicht-erzieherischen Gestus aus. Obwohl nur zwei Jahre nach Lanzmanns Dokumentation erschienen, unterscheidet sich Malles Spielfilm fundamental: Während Lanzmann, wie Resnais und Burger, auf den Charakter der Massenvernichtung abzielt und zahlreiche Schicksale aufzeigt bzw. inszeniert, beschränkt sich Malle auf die »kleine« Geschichte der Bewußtwerdung eines pubertierenden Jungen. Dahinter steht die Überzeugung, daß die für den Zuschauer im Miterleben des individuellen, schmerzlichen Verlustes gemachte Erfahrung intensiver sein kann als das »Vor-Augen-Führen« zahlreicher Schicksale. Malles hundertminütiger Film beschränkt sich auf einen Hauptschauplatz, während Lanzmann verschiedenste Inszenierungsorte präsentiert und dem Zuschauer neuneinhalb Stunden Aufmerksamkeit abverlangt. Wo Lanzmann Überlebende drängt, ihre grauenhaften Lagererlebnisse preiszugeben, gelingt es Malle mit großem Einfühlungsvermögen, das Schicksal eines jüdischen Jungen näherzubringen.

Mit dem Spielfilm Schindlers Liste (USA 1993; s. II.3.2) spricht Steven Spielberg insbesondere junge Menschen an, die den Krieg und dessen unmittelbare Auswirkungen nicht selbst erlebt haben. Vor diesem Hintergrund versucht er mit zahlreichen ästhetischen Verfahren, die Zuschauer in typische Situationen der Vernichtungsmaschinerie zu versetzen, damit sie den Holocaust »spüren« (Spielberg zit.n. Reichel 2004: 315). Angesichts der Tragweite des Genozids ist ein derart hoher Anspruch kaum realisierbar und darüber hinaus problematisch (s. insb. II.3.2.6). Authentisch wirkt SCHINDLERS LiSTE aufgrund der Kombination zahlreicher ästhetischer Verfahren, vor allem einer gewissen Nachrichten-Ästhetik (s. insb. II.3.1), sowie der »Beglaubigung « der erzählten Geschichte durch die realen Personen am Ende des Films. Die Authentizität in Malles Film hingegen ergibt sich aus dessen Anknüpfen an unser generelles Wissen um die Beziehung zwischen Eltern und Kindern, um Freundschaft und den Umgang unter Kindern. Beide Filme lassen den Holocaust durch mögliche Versetzung des Zuschauers in die Hauptfiguren intensiv erfahren. Im Unterschied zu Auf Wiedersehen Kinder arbeitet Schindiers Liste wesentlich stärker mit Spannung und damit einhergehender Hoffnung des Publikums auf ein »glückliches Ende«, die mit der Rettung der sog. Schindlerjuden auch erfüllt wird, während der jüdische Junge am Ende von Malles Film den Nazis zum Opfer fällt. Während in der TV-Serie Holocaust (1978/79) noch zahlreiche Mitglieder der im Zentrum stehenden jüdischen Familie ermordet werden, überleben beinahe alle dem Zuschauer vertrauten Schindlerjuden - ein ermutigender und für das Sich-Einlassen auf den Genozid zentraler Aspekt, der durch den gelungenen Spannungsaufbau des Regisseurs unterstützt wird.

Im Unterschied zu den Spielfilmen von Spielberg und Malle handelt es sich bei Roberto Benignis Das LeBen IST SCHÖN (I 1997; s. II.4.1) und Radu Mihaileanus 
Zug DES LEBENS (F/ B/ROM/NL 1998; s. II.4.2) nicht um traditionell-fiktionale Filme, sondern um >Radikal-Fiktionen< (s. II.4). Dem Übermaß an Bedrohung und Grauenvollem setzen sie ein Übermaß an Kreativität und Hoffnung entgegen. Auf ihre Weise demonstrieren sie - im krassen Gegensatz zu Vorgängerfilmen -, daß der Holocaust inkommensurabel ist. Sie teilen damit auch die Meinung zahlreicher Überlebender von der exorbitanten Absurdität des Holocaust und machen diese durch den Einsatz abgründiger Komik für den Zuschauer erfahrbar. Der Radikalität der Vernichtung setzen sie mit Hilfe des jüdischen Witzes die Radikalität des Überleben-Wollens entgegen.

Marceline Loridan-Ivens' dokumentarisch anmutender Spielfilm BI RKENAU UND RosenFELD (F/D/POL 2003; s. II.5) stellt eine Öffnung im Umgang mit dem Holocaust dar. Wie Louis Malles Film, zeichnet sich dieses Werk durch besondere Bescheidenheit und Diskretion aus: Mit und über die Protagonistin, eine Auschwitz-Überlebende, erfährt der Zuschauer, wie schwierig einerseits und wie heilsam andererseits es sein kann, sich auf die nationalsozialistische Vernichtung, genauer auf Momente des Lagerlebens, einzulassen. Hierbei ist entscheidend, daß die Hauptfigur dem Publikum die Verarbeitung in gewisser Weise abnimmt, es entlastet. In BIRKENAU Und RosenFELD begleiten wir die fiktive Zeugin Myriam in ihren Erinnerungs»erfolgen « und -mißerfolgen, denn es gelingt selbst der Protagonistin nicht immer, sich an Erlebtes und Gesehenes zu erinnern. Eine besondere Wirkung erzielt die Regisseurin, indem sie Myriam nicht nur das Ausmaß der Vernichtung, sondern auch Momente der Liebe und Solidarität erinnern läßt. Diese Darstellungsweise erleichtert dem Zuschauer die Annäherung an den Holocaust und er teilt mit der Protagonistin die Freude des »AmLeben-Seins« am Ende des Films.

\section{C.}

Angesichts des Ausmaßes an Grauenhaftem besteht bei »stummen« (Semprún 1995: 239) ${ }^{5}$ Archivaufnahmen von der Befreiung der Lager sowie möglichst realistischen

5. Siehe I.1 zum vollständigen Zitat.

6. Heute kann sich ein Holocaust-Film potentiell an vier Generationen richten: a) die heute ca. 80-Jährigen, die der Kriegsgeneration angehören, denn sie waren damals 20; b) die heute 60-Jährigen, die Nachkriegsgeneration, die im bzw. kurz nach dem Krieg geboren sind; c) die heute 40-Jährigen, die Enkelgeneration, die in den sechziger Jahren auf die Welt kamen; d) die heute 20-Jährigen, die Nach-Enkelgeneration, die in den achtziger Jahren geboren sind. Während die Kriegsgeneration sich in bezug auf die Thematisierung der Kriegszeit zunächst verständlicherweise - verweigerte, kämpfte die Nachkriegsgeneration, genauer die 68er, gegen das Schweigen der Eltern an. Die beiden jüngsten Generationen sind allein aufgrund der historischen Distanz nicht »vorbelastet« und könnten sich daher u.U. unbefangener mit der Thematik auseinandersetzen.

7. Vgl. auch Darmstädter 1995: 132.

8. »En même temps, chacun s'habitue sournoisement à l'horreur, cela rentre un peu dans les mœurs, et fera bientôt partie du paysage mental de l'homme moderne; qui pourra, la prochaine fois, s'étonner ou s'indigner de ce qui aura cessé en effet d'être choquant?« (Rivette zit.n. Lowy 2001: 181).

9. Vgl. auch Schulz 2002: 171. 
Rekonstruktionsversuchen des Holocaust die Gefahr, daß das von Jorge Semprún angesprochene Zuhören bzw. Zusehen unerträglich ist (s. das der Arbeit vorangestellte Zitat), »intolérable pour la sensibilité« des Zuschauers (Bazin zit.n. Raskin 1987: 139):

»Die Brutalität und Unmenschlichkeit der Naziverbrechen können, insbesondere wenn sie realistisch und detailreich dargestellt werden, psychische und soziale Schutzmechanismen auslösen. [...] Die Überflutung der individuellen Wahrnehmung mit brutalen Details aus den Randzonen menschlicher Existenz, wie sie uns in Bildern und verbalen Schilderungen der Quälereien und Tötungen in den Konzentrationslagern entgegentreten, kann dazu führen, daß man Informationen trotz körperlicher Anwesenheit im kognitiven Wachzustand nicht mehr an sich heranläßt. [...] Weder böswillige Negation noch Ignoranz sind die Motive ihres Verhaltens, sondern die Unerträglichkeit dessen, was ihnen andere oder sie sich selbst zumuten wollen.« (Silbermann/ Stoffers 2000: 84f.)

Daher, so der Erziehungswissenschaftler Ido Abraham, zeuge es »von Naivität zu glauben, daß Schüler ${ }^{6}$ eine größere Nähe zu den Opfern entwickeln, wenn man ihnen die Leiden dieser Opfer in allen Einzelheiten vor Augen führt« (zit.n. Heyl 2003: 2207) eher das Gegenteil, Antipathie gegenüber den Opfern, sei der Fall.

Eine weitere Gefahr realistischer Rekonstruktionsversuche besteht im Gewöhnungs- bzw. Abnutzungseffekt schockierend brutaler Bilder. ${ }^{8}$ Einerseits verlieren diese in der Flut inzwischen täglicher Abbildungen von Grausamkeiten ihre Wirkung (Baer 2000: 242), andererseits wächst auch die Gefahr der Abnutzung mit der zunehmenden Medienpräsenz des Themas (Valentin 2001: 127): »[...] >Gewöhnung< und ihr Ergebnis, die >Gewohnheit< $[. .$.$] ist zwar im Normalfall nötig und ungeheuer ökonomisch, doch$ bedeutet es auch, daß man nicht mehr über das Gewohnte hinaus und nicht mehr zu Neuem gelangt, sondern immer nur wiedererkennt.« (Kloepfer 1999: 34, H.i.O.)

Seit dem Scheitern der Schockästhetik der Entnazifizierungsfilme (s. II.1) versuchen insbesondere Holocaust-Spielfilme, dem Zuschauer ein Einlassen auf die schwierige Thematik durch ausbalancierende Gegengewichte zu ermöglichen: »Le metteur en scène est tenu d'affadir, pour que ce qu'il ose présenter comme la >réalité< soit physiquement supportable pour le spectateur [...].« (Rivette zit.n. Lowy 2001: 181, H.i.O.) Diese »gedämpften« bzw. »gemilderten« Darstellungen, »ob in Film oder Literatur, sollten noch erträglich sein«, damit sich die Menschen nicht »entsetzt von den Büchern abwenden oder gar aus den Kinos fliehen« (Reich-Ranicki 2002: 35).

Die ästhetischen Mittel, um den Holocaust kommensurabel zu machen oder der Thematik gar eine »mutmachende Wendung « zu geben, sind ebenso vielfältig wie wiederkehrend (Kramer 2000: 52).9 Zentral ist hierbei das besondere Potential narrativer Kunst (s. Kloepfer 2005: 93 in I.1).

- In den untersuchten Spielfilmen wird der Holocaust äußerst vorsichtig, manchmal beiläufig eingeführt, um den Zuschauer behutsam auf die schwierige Thematik einzustimmen. Zum Teil versuchen die Regisseure, die Gestaltungskonventionen und Sehgewohnheiten in bezug auf konventionelle Holocaust-Filme ganz bewußt zu durchbrechen und so das Publikum durch gesteigerte Aufmerksamkeit zu tatsächlicher, neuer Wahrnehmung und letztlich einem wirklichen Sich-Einlassen auf den Holocaust zu bewegen (s. I.2.2): »Offenbar geht es darum, daß neben dem 
Verstand (Erkenntnisvermögen mit Antizipation und Erinnerung) auch das Gefühl (von Lust und Unlust, Zweifel und Beruhigung) und vor allem der Wille (Begehrungsvermögen: Neugier, Interesse, Lust auf Wissen) aktiviert werden.« (Kloepfer 1990: 140)

Durchaus häufig ist die Einführung dieser ernsten Thematik in Rätselform, die den Zuschauer zu gesteigerter Eigenleistung auffordert - zum »Enträtseln« als dem »eigentlichen und einziges Zweck des Rätsels« (Jolles 1982: 134f.):

»Weil der Anfang [der Filme] so irritierend ist, stimuliert er ein verstärktes Mitgehen und Mithandeln des Zuschauers (Sympraxis), weshalb sich dieser wiederum mehr erwartet, wahrnimmt und verarbeitet an Informationen über die dargestellte Welt (Mimesis), was wiederum seine Antizipationen oder sonstigen Handlungen bestätigt, verstärkt und sein Lernen anregt und so weiter.« (Kloepfer 1994: 62)

In Auf Wiedersehen Kinder (s. II.3.1) gewinnt die Holocaust-Thematik erst ganz allmählich an Bedeutung - und zwar in dem Maße, wie sich die Gefahr für den vor der deutschen Besatzungsmacht bzw. den französischen Kollaborateuren versteckten jüdischen Jungen konkretisiert. In der ersten halben Stunde des Films muß sich der Zuschauer die gesamte Situation mit Hilfe zahlreicher Indizien eigenständig erschließen. Steven Spielberg hingegen führt den Holocaust in ScHinder RS LISTE (s. II.3.2) zwar symbolisch bereits im Vorspann ein und deutet die bürokratischen Vorbereitungen hierzu auch in der Eröffnungssequenz an, rückt jedoch zunächst den wirtschaftlichen Aufstieg des Kriegsgewinnlers Oskar Schindler ins Zentrum. Ähnlich wie Louis Malle stimmt Roberto Benigni den Zuschauer in DAS LEBEN IST SCHÖN (s. II.4.1) äußerst behutsam auf das grausame Geschehen ein, indem er diesem erst die zweite Hälfte des Films widmet. Zu Beginn sensibilisiert er das Publikum mit zunehmend deutlicheren Anzeichen für den aufkommenden Faschismus in Italien. In Radu Mihaileanus Zug Des Lebens (s. II.4.2) wird der Zuschauer von Anfang an in die verrückte Situation der Selbstdeportation des osteuropäischen Schtetls hineinversetzt, was sich bis zur letzten Einstellung des Films nicht ändert - der Holocaust bildet hier eher den geschichtlichen Hintergrund, vor dem Mihaileanu die Vitalität und Lebensfreude der jüdischen SchtetlKultur feiert. Insbesondere die Exposition verweigert dem Zuschauer gesicherte Informationen und steigert so seine Aufmerksamkeit. Auch Marceline LoridanIvens gelingt es durch gezielte Zurückhaltung expliziter Informationen zu Beginn von Birkenau und Rosenfeld (s. II.5), die Neugier des Publikums zu wecken und es im weiteren Verlauf des Films in den Selbstfindungs- und Heilungsprozeß der Protagonistin einzubeziehen.

- Die künstlerische Herausforderung und Voraussetzung für die Annahme des Holocaust liegt häufig in der Individualisierung, d.h. im Erfahrbarmachen von Einzelschicksalen bzw. der Geschichte kleiner Gruppen, während in Dokumentarfilmen das Augenmerk auf die Massenvernichtung gerichtet ist. Damit entsprechen Holocaust-Spielfilme i.a.R. der pointiert formulierten Forderung Marcel Ophüls':

10. Vgl. stellvertretend Brussig 1998: 45; Visser 2002: 202. 
»Die Leichen in Bergen-Belsen, das sind immer nur dieselben Archivaufnahmen. Die haben wir gesehen. Auch mit poetischem Kommentar, auch mit naturalistischem Kommentar, auch ohne Kommentar, auch nur mit Musik, aber gesehen haben wir es. Sie wirken nicht mehr, wenn man auch noch beim Abendessen - sozusagen zwischen Käse und Kaffee - die äthiopischen Kinder sieht. [...] Man muß es individualisieren. Man muß das Einzelschicksal sehen. [...] Es ist leichter, sich mit der [Familie] zu identifizieren als mit jemandem aus dem russischen Ghetto, den man nicht kennt und dessen Lebensweise zu weit von einem entfernt ist.« (Zit.n. Köppen 1993: 112)

Diese Forderung basiert auf der Überzeugung, daß sich der Zuschauer eher von der Bedrohung bzw. vom Tod einzelner Menschen erschüttern läßt als vom millionenfachen Sterben ${ }^{10}$ : Die höchstmögliche Identifikation bewirkt, »daß wir bei drohender Gefahr, Furcht oder beim Eintreten des Schrecklichen Horror empfinden« (Kloepfer 2005: 104).

So stehen im Zentrum von Auf Wiedersehen Kinder zwei Kinder, Julien und sein jüdischer Freund Jean, der am Ende von der Gestapo aufgespürt wird. Mit der Titelfigur Oskar Schindler in Schindere Liste ist das Schicksal der sog. Schindlerjuden verbunden, fokussiert auf Itzhak Stern und Helene Hirsch. Benigni konzentriert sich in DAS LEBEN IST SCHÖN auf die Familie Orefice, den Protagonisten Guido, seinen Sohn Giosuè und seine Frau Dora, deren Leben im Vernichtungslager äußerst gefährdet ist. In ZUG DES LEBENs steht das (Über)Leben eines osteuropäischen Schtetls unter der Führung des Dorf»narren« Schlomo auf dem Spiel. In Birkenau und Rosenfeld begleitet Loridan-Ivens ihr filmisches Alter ego, Myriam Rosenfeld, zusammen mit einem jungen deutschen Fotografen zu dem einstigen Schreckensort.

Mit der Konzentration auf wenige Hauptfiguren - dramaturgisches Stilmittel der Regisseure - fällt auf, daß dem Protagonisten häufig ein Antagonist gegenüber steht, der meist zur positiven Identifikation mit der Hauptfigur beiträgt, indem er ihr bei der Zielerreichung im Weg steht. Empathie und ihre positive Gestalt der Sympathie sowie ihre negative Gestalt der Antipathie müssen hierbei ganz grundlegend als »Formen der Reziprozität« des Zuschauers gegenüber den Figuren verstanden werden (Kloepfer 2005: 122, H.i.O.), als Möglichkeit der Transponierung historischer Ereignisse in gegenwärtiges (Mit-)Erleben (Bleicher 2002: 183).

Dabei nutzen die Regisseure die »universelle Fähigkeit von Menschen, sich in einen anderen zu versetzen oder auch in einen eigenen, vergangenen oder künftigen Zustand. Das Wort >Ver-Stehen< impliziert nicht zufällig, daß man den Platz des Anderen einnehmen kann und damit im Prinzip seine Seh-, Hör- etc. und Verarbeitungsweisen bis hinein in die psychische Dimension, welche schon das Wort >Ein-Stellung< nahelegt.« (Kloepfer 2001b: 1, H.i.O.) Je nach Figur, mit der wir wahrnehmen, entsteht eine andere Sinnwelt, denn wir »übernehmen mehr oder weniger zwangsläufig deren Wahrnehmung, Rolle und Verarbeitungsform« (Kloepfer 1999: 25).

Während der französische Junge den jüdischen in der ersten Hälfte von AuF Wiedersehen Kinder als Rivalen im Kampf um die Position des Klassenbesten wahrnimmt, leidet er - und mit ihm der Zuschauer - bei der Deportation am Ende unter dem Verlust des Freundes. In Schindlers Liste kämpft Oskar Schindler 
insbesondere mit Amon Göth, dem Kommandanten des Plaszower Konzentrationslagers, um das Leben »seiner « Juden. In Das LeBEN IST schön muß sich Guido bei der Eroberung seiner Prinzessin zunächst gegen einen faschistischen Beamten, später gegen die Widrigkeiten des nationalsozialistischen Vernichtungslagers durchsetzen. Auch Zug Des LeBens weist mehrere Kontrastkonstellationen auf: zwischen der Flucht des Schtetls im Geisterzug und den Verfolgern, insbesondere den Nazis; zwischen den jüdischen »Nazis« unter Führung von Mordechai und den »Kommunisten « um Yossi; zwischen den Männern und den Frauen; zwischen den Töchtern und den Vätern etc. In Birkenau und Rosenfeld entsteht aus der Begegnung zwischen Myriam und Oskar ein häufig kontroverser, jedoch durchaus fruchtbarer deutsch-jüdischer Dialog.

- Die Konzentration auf wenige Hauptfiguren ist vielfach mit der Hoffnung auf das - zumindest partielle - Überleben derselben verbunden: »Und nur darum kann es in einem Spielfilm gehen: um das Überleben, und vielleicht noch darum, was das Überleben in den Menschen anrichtet« (1995: 209), so Hanno Loewy im Zusammenhang mit SCHINDleRs Liste.

Der Verlauf der Filme wird hierbei durch eine Spannungsdramaturgie bestimmt, die den Zuschauer dergestalt involviert, daß er - inmitten ungeheuerer Vernichtung - um und mit den jüdischen Protagonisten um deren Leben bangt und auf Rettung hofft. Auf diese Weise entsteht eine gewisse Balance, ein Rhythmus aus Schrecken und Hoffnung mit positiver Wirkung auf den Zuschauer." Ruth Klüger erläutert am Beispiel von SCHInders Liste: »Die konsequent durchgehaltene Dramaturgie kurzer Szenenfolgen und >Kontrastkonstellationen< sei im übrigen das einzig angemessene Mittel, den Zuschauer nicht zu erdrücken, ihm vielmehr im Wechsel von Erschütterung, Erleichterung und Empörung Raum für verstehende Einfühlung zu lassen.«(Klüger zit.n. Reichel 2004: 310, H.i.O.) ${ }^{12}$

In manchen Fällen verdanken die jüdischen Protagonisten ihr Überleben einem Retter aus den eigenen Reihen (Insdorf 2003: 258ff.), wie in ZUG DES LEBENS. Damit kommen diese Werke, so Bartov, einer der beiden Hauptforderungen von Zuschauern an Holocaust-Filme nach: »First is the demand for a >human< story of will and determination, decency and courage, and final triumph over the forces of evil.« (1997: 46, H.i.O.) Kommt die Hilfe von außen, zeigt sich dem Publikum die wohltuende Erfahrung des Guten im Menschen inmitten der nationalsozialistischen Unmenschlichkeit (s.u. sowie II.3.2). Gelingt es den Opfern, sich bzw. Angehörige vor der Nazi-Barbarei zu retten (s. II.4.1), - und sei es »nur« in der Phantasie (s. II.4.2) -, so bedient diese Verkehrung das Bedürfnis des Zuschauers nach zumindest punktueller Umkehr der Machtverhältnisse. Nicht immer wird jedoch die Hoffnung des Publikums auf Überleben der jüdischen Protagonisten

11. Zum Rhythmus-Prinzip in der Kunst siehe den entsprechenden Exkurs im Anhang.

12. "Spielberg bewältigt die Ereignisse durch eine schnelle und sehr gekonnte Folge von kontrastierenden Szenen, in denen der Horror, bevor er zur Abstumpfung der Zuschauersensibilität führt, abwechselt mit Einblicken in das Luxusleben eines 0pportunisten, der eine positive Charakterentwicklung durchmacht." (Klüger in FAZ, 02.12.1995: B4)

13. Vgl. Kommunismus, Marxismus, Antisemitismus, Sozialismus/Faschismus, Rassismus/ Kapitalismus, Wirtschaftsimperialismus. 
erfüllt; doch selbst in diesen Fällen wird es mit einem gewissen positiven Ausblick aus dem jeweiligen Film entlassen.

Obwohl in Auf Wiedersehen Kinder Julien eine der schmerzvollsten Erfahrungen seines jungen Lebens macht, birgt diese die Chance, seine kindliche Selbstbezüglichkeit zu überwinden und eigenes Leid zu relativieren (s. II.3.1.6.d). In Schindlers Liste bangt das Publikum mit und um die in verschiedenen Lagern internierten sog. Schindlerjuden. Während unzählige anonyme Juden den Nazis zum Opfer fallen, wird die Hoffnung des Zuschauers auf das Überleben der Schindlerjuden weitgehend erfüllt. Die definitive Rettung erfolgt hierbei durch die zunehmend geläuterte Titel- und Identifikationsfigur; zwischenzeitliches Überleben entspringt jedoch auch wundersamen Wendungen (s. II.3.2.4 und II.3.2.6) und bestimmten Überlebensstrategien der Betroffenen (s. II.3.2.5). Im gesamten zweiten Teil von Das LeBEN Ist schön hofft das Publikum auf das Überleben der Familie Orefice, insbesondere des in einer Baracke versteckten kleinen Sohnes, dessen Leben wiederholt in Gefahr gerät. Infolge der außergewöhnlichen Gewitztheit und des Improvisationstalents seines Vaters übersteht der Sohn alle gefährlichen Situationen, während dieser den Nazis zum Opfer fällt. Dennoch erzeugt das Filmende eine teils positive Wirkung, da, nach der Befreiung des Lagers durch die Amerikaner, Mutter und Sohn im Schlußbild in inniger Umarmung vereint sind (s. II.4.1.4.ba). Mit dem jüdischen Schtetl in Zug Des Lebens wünscht sich das Publikum, daß die Flucht vor den näherrückenden Nazis gelänge. Zur großen Freude der Juden und des Zuschauers glückt dies innerhalb des Erzählrahmens, nicht jedoch jenseits desselben: Die Flucht erweist sich letztlich als ein Phantasiegebilde des im Lager internierten Protagonisten und Erzählers. Das glücklose Ende kann jedoch die wohltuende Wirkung, erzielt durch die Inszenierung der Umkehr der Machtverhältnisse, nicht verhindern (s. II.4.2.1 und 4.2.2). In BIRKenau und Rosenfeld hofft das Publikum mit der Protagonistin, daß durch die intensive Konfrontation mit dem einstigen Schreckensort ein Selbstfindungs- und Heilungsprozeß in Gang gesetzt und im besten Fall abgeschlossen wird. Nach dem schmerzhaftem Kampf zwischen Erinnern- und Vergessen-Wollen, ruft die Protagonistin am Ende des Films mit voller Kraft »Je suis vivante!« - Ausdruck ihrer wiedergewonnenen Selbst-Sicherheit.

- In zunehmendem Maße zeichnen sich Holocaust-Spielfilme dadurch aus, daß der nationalsozialistischen Barbarei Menschlichkeit, Solidarität und Liebe entgegengesetzt werden. Zum Teil ist es »die individuelle Menschlichkeit der kleinen Einheit«, die sich gegen die großen Ideologien des 20 . Jahrhunderts ${ }^{13}$ behauptet (Seeßlen zit.n. Lorenz 2003: 278), zum Teil sind es Begegnungen zwischen Personen, die in einer Freundschaft unter schwierigen Bedingungen münden. In beiden Fällen verhindern diese »Inseln der Menschlichkeit« inmitten allgegenwärtiger Vernichtung ein einseitiges, entkräftendes Verzweifeln. Sie ermöglichen den Glauben an das Gute im Menschen bzw. bekräftigen die Notwendigkeit von Mitmenschlichkeit angesichts von Unmenschlichkeit.

In Auf Wiedersehen Kinder wird zum einen Solidarität mit Verfolgten erfahrbar (Internatsleiter Pater Jean versteckt jüdische Kinder sowie Arbeitsdienstverweigerer), zum anderen erlebt der Zuschauer das Entstehen, Wachsen und Sich-Bewähren von Freundschaft angesichts zunehmender Bedrohung. Inmitten 
allgegenwärtiger Vernichtung ist die Wandlung Schindlers vom kaltblütigen Kriegsgewinnler zum warmherzigen Retter Lichtblick und Hoffnungsanker - sowohl für die sog. Schindlerjuden als auch für das Publikum. Der Optimismus des Protagonisten Guido in DAS LEBEN IST SCHÖN stellt einen wohltuenden »Strohhalm« der Menschlichkeit angesichts der Nazi-Barbarei dar. Aus Zug Des Lebens spricht eine tiefe humanistische Grundhaltung, vor deren Hintergrund einerseits jegliche Form menschlicher Schwäche bis hin zur schlimmsten Verfehlung angeprangert, andererseits Solidarität und Völkerverständigung in ihrem unschätzbaren Wert gepriesen werden. Neben deutsch-jüdischer Versöhnung - die französische Jüdin Myriam läßt sich nach anfänglichem Zögern doch auf den Austausch mit Oskar, dem Nazi-Enkel, ein -, macht Loridan-Ivens in Birkenau und Rosenfeld Solidarität und Menschlichkeit intensiv erfahrbar.

- Überträgt man die der vorliegenden Arbeit vorangestellte Aussage Jorge Semprúns über Literatur - »[...] das wirkliche Problem ist nicht das Erzählen, wie schwierig es auch sein mag ... sondern das Zuhören« (1995: 150) - auf den Film, rückt die Erreichbarkeit der Menschen allgemein, v.a. aber die Frage nach der Visualisierung des Grauenhaften, ins Zentrum des Interesses. Im Gegensatz zu Dokumentarfilmen sind Spielfilme mehr oder weniger deutlich um visuelle Diskretion bzw. Erträglichkeit bemüht. Einige entsprechen der »Weisheit« klassischer Poetiken und vermeiden direkte Repräsentationen von Gewalt und Leid (Hartman 1997: 63). Sie versuchen $\mathrm{zu}$ verhindern, daß »visualisierte Unmenschlichkeit zum Wegsehen verleitet, stumm macht oder gar zu Verweigerung, im Extremfall zur Leugnung von Tatsachen führt« (Noack 1998: 116f.; s. insb. II.1. und II.1.1).

Malle konzentriert sich in Auf Wiedersehen Kinder insbesondere auf die psychische Macht der Nazis bzw. der Kollaborateure, die er für wesentlich unerträglicher hält als die Inszenierung körperlicher Gewalt. ${ }^{14}$ Spielberg hingegen visualisiert die Brutalität der Nazis im ersten Drittel von Schindle Rs Liste, während er in der Folge, durch geschickte Inszenierung, die Angst der sog. Schindlerjuden spürbar und erfahrbar macht, ohne sie darstellen zu müssen (s. insb. II.3.2.5 und 3.2.6). Obwohl der zweite Teil von DAs LeBEN Ist Schön ausschließlich im Vernichtungslager spielt, setzt auch Benigni auf visuelle Diskretion: Bildlich verweist Benigni lediglich in Form eines stilisierten, verschwommen dargestellten Berges lebloser Körper auf die grausame Wirklichkeit (s. II.4.1.4.ac; das Schicksal des Onkels in der Gaskammer wird ausgespart, Guidos Erschießung findet hinter einer Mauer statt). Mihaileanu verzichtet in ZUG DES LEBENS beinahe gänzlich auf Visualisierung: Grausamkeiten werden - mit Ausnahme des niedergebrannten Nachbardorfes - durch die Konfrontationen der falschen Nazis mit den echten lediglich angedeutet. In Loridan-Ivens' BirKenAu und RosenfFeld sind Grausamkeiten ausschließlich und punktuell durch Myriams verbale Erinnerungen präsent, werden jedoch nicht visualisiert.

14. »Malle admitted that he deleted the real slapping of a boy by a member of the Gestapo at the end because sit's more frightening if the Germans are so >correct $[\ldots]$ this rather ordinary side of fascism is precisely what renders it unbearables." (Malle zit.n. Insdorf 2003: 86, H.i.0.)

15. Vgl. Klüger 2001: 127 in I.1 sowie folgende Äußerung: »Wer mitfühlen, mitdenken will, braucht Deutungen des Geschehens. Das Geschehen allein genügt nicht.« (Ebd. 128) 
- Insbesondere bei neueren Holocaust-Spielfilmen ist eine Tendenz zur »Entsakralisierung « feststellbar, die als wahrhaftiger und aufrichtiger empfunden werden kann als das Beharren auf bzw. Einhalten von ohnehin fragwürdigen Darstellungsnormen und -verboten ${ }^{15}$ - »Methoden der Profanisierung als eine Art Befreiung von der symbolischen Bedeutungslast des Auschwitz-Komplexes« (Köppen/Scherpe 1997: 5). Dabei spielt Komik als Gegengewicht zum allem bewußten Ernst der Thematik sowie als Mittel zur Deautomatisation eine zentrale Rolle (s. II.4; Lorenz 2003: 269):

»Wo angesichts eines Stoffes laute Töne und grelle Farben gänzlich versagen und wo Elegisches statt die Leser aufzurütteln sie eher ermüdet, da bleibt dem Schriftsteller nichts anderes übrig, als mit besonders leiser Stimme zu sprechen, konsequente Zurückhaltung zu üben und dem Understatement und der Ironie zu vertrauen. Bei einem so düsteren Thema läßt sich mit Düsterkeit am wenigsten ausrichten, eher schon mit hellen und heiteren Kontrasteffekten, mit Witz und Komik. Das allerdings ist sehr schwierig und nahezu waghalsig.« (Reich-Ranicki 1989: 174)

Während die Komik in DAS LEBEN IST SCHÖN vor allem die Absurdität nationalsozialistischer Ideologie erfahrbar macht, darf der Zuschauer in ZuG DES LEBENS über geistigen Starrsinn lachen, auch den einiger Schtetl-Juden - absolutes Novum im Holocaust-Spielfilm, das insofern zu einer ehrlich wirkenden Ausgewogenheit beiträgt, als es menschliche Schwächen - jenseits von Herkunft und Klasse - anprangert.

Bei den beschriebenen Formen der ästhetischen Lenkung ist jeweils entscheidend, daß sie nicht normativ erfolgen (s. II.1 zur kontraproduktiven Entnazifizierungspolitik der Alliierten), sondern dem Zuschauer ein freiwilliges Mitgehen ermöglichen (s. insb. II.3.1, II.4 und II.5). Die in der vorliegenden Arbeit analysierten Spielfilme betonen den unschätzbaren Wert geistiger Freiheit - im realen wie übertragenen Sinne -, die trotz Unterdrückung durch die nationalsozialistische Diktatur die Oberhand behält.

Ästhetische Freiheit wird in der kantischen Tradition als grundlegend angenommen (s.u.). Nur auf dieser Grundlage ist der Adressat zu einem, wie Sartre formuliert, »pacte de générosité« mit dem jeweiligen Werk bereit (1950).

»Das Kino, als ein Ort der Vergegenwärtigung, der Geistesgegenwart und der individuellen Phantasieteilhabe benötigt nicht die exaltierte Ästhetisierung der Realität. Das Kino, das auf die Kraft der menschlichen Wahrnehmung und Erfahrung setzt, kann seinen Adressaten die eigene Beschäftigung, die emotionale und geistige Phantasiearbeit nicht abnehmen. Das Kino, das das Vergangene nicht ins Historische verbannt, verlangt von denen, die es sehen und ihm zuhören, daß sie seine Gegenwärtigkeit selbst produzieren: seine vergessenen Spuren, seine erstickten Schreie, seine Verzweiflungen und seine Hoffnungen, kurz: seine Bilder und Töne. Nur ein Kino, das seinem Zuschauer und -hörer diese Freiheit läßt und zugleich zumutet, kann dem inhärenten Drang des Mediums zum eigenen Totalitarismus entgehen.« (Schütte 1992: 18, H.i.0.) 
Insbesondere künstlerische Produkte sind in der Lage, »ein Rezeptionsangebot [zu machen], das die Adressaten am ehesten erreicht, wenn es freiwillig wahrgenommen und nicht in verordneten Pflichtlektionen verabreicht wird « (Denkler 1993: $173) \cdot{ }^{16}$

Auf die Schwierigkeit der Auf- und Annahme des Holocaut hat Semprún wiederholt verwiesen - insbesondere in bezug auf literarische Werke: »[...] das wirkliche Problem ist nicht das Erzählen, wie schwierig es auch sein mag ... sondern das Zuhören« (1995: 150). Übertragen auf das (audio-) visuelle Medium Film wurde in der vorliegenden Arbeit der Versuch unternommen, in diesem Sinne anhand der ausgewählten Filme aufzuzeigen, inwiefern diese das >Zusehen < bzw. das Sich-Vorstellen ermöglichen oder erschweren.

16. Kloepfer weist auf einen Zusammenhang hin, der für den Dialog zwischen Film und Zuschauer - die übergreifende Fragestellung der vorliegenden Arbeit (s. I.2.2) - von entscheidender Bedeutung ist: „Das Kantische sinteresselose Wohlgefallen< [...] und die Freiheit, sich zu diesem spezifischen Universum zu verhalten, wie es einem behagt, sind Voraussetzungen für das größere Maß des Sich-Einlassens. (Kloepfer 1999: 13)

1. Die Unterpunkte orientieren sich an der Gliederung der vorliegenden Arbeit.

2. Siehe hierzu auch die Angaben im nächsten Unterpunkt »Umgang mit dem Holocaust«. 


\section{Anhang}

\section{A) Bibliographie ${ }^{1}$}

\section{I.1 UMGANG MIT DEM HolocAuST VON 1945 BIS HEUTE² / I.2 (FILM-)THEORIE}

Assmann, Aleida/Assmann, Jan, »Das Gestern im Heute. Medien und soziales Gedächtnis«, in: Medien und Kommunikation. Konstruktionen von Wirklichkeit, Weinheim/Basel (Beltz) 1990, Studienbrief 5 (Funkkolleg Medien und Kommunikation), S. 3-20.

Assmann, Jan, »Kollektives Gedächtnis und kulturelle Identität«, in: Assmann, Jan/ Hölscher, Tonio (Hg.), Kultur und Gedächtnis, Frankfurt a.M. (Suhrkamp) 1988, S. 9-19.

Aristoteles, Poetik, Stuttgart (Reclam) 1982.

Arnheim, Rudolf, Film als Kunst, Berlin (Rowohlt) 1932.

Bachtin, Michail M., Literatur und Karneval. (Zur Romantheorie und Lachkultur), Frankfurt a.M. (Fischer Taschenbuch Verlag) 1990.

Balázs, Béla, Der Geist des Films oder die Kultur des Films (1924), Frankfurt a.M. (Suhrkamp) 2001.

Barthes, Roland, Die helle Kammer. Bemerkung zur Photographie, Frankfurt a.M. (Suhrkamp) 1989.

Bateson, Gregory, Ökologie des Geistes. Anthropologische, psychologische, biologische und epistemologische Perspektiven, Frankfurt a.M. (Suhrkamp) ${ }^{4} 1983$.

Baudelaire, »Die Fotografie und das moderne Publikum« (1859), in: Helmes, Günter/ Köster, Werner (Hg.), Texte zur Medientheorie, Stuttgart (Reclam) 2002, S. 109-114. Bergson, Henri, Le rire, Paris (Presses Universitaires de France) 1972.

Berkenbusch, Gisela, Zum Heulen. (Kulturgeschichte unserer Tränen), Berlin (:Transit Buchverlag) 1985 .

Birbaumer, Niels/Schmidt, Robert F., Biologische Psychologie, Berlin/Heidelberg/New York (Springer-Verlag) ${ }^{4} 1999$.

Bordwell, David/Thompson, Kristin, Film Art. An Introduction, New York (The McGraw-Hill Companies, Inc.) ${ }^{5} 1997$.

Bordwell, David, Making meaning. Inference and rhetoric in the interpretation of cinema, Cambridge (Harvard University Press) 1989.

Borstnar, Niels/Pabst, Eckhard/Wulff, Hans Jürgen, Einführung in die Film- und Fernsehwissenschaft, Konstanz (UVK) 2002.

Bühler, Karl, Die Krise der Psychologie (1929), Frankfurt a.M. (Suhrkamp) 1978. 
Bulgakowa, Oksana, »Nachahmung und Beherrschung«, in: Bulgakowa, Oksana (Hg.), Arbeitshefte - Herausforderung Eisenstein, Berlin (Akademie der Künste der Deutschen Demokratischen Republik) 1989, S. 57-62.

Chéroux, Clément, »Du bon usage des images«, in: ders. (Hg.), Mémoire des camps. Photographies des camps de concentration et d'extermination nazis (1933-1999), Paris (Marval) 2001, S. 11-21.

Chéroux, Clément, »Les chambres noires ou l'image absente?«, in: ders. (Hg.), Mémoire des camps. Photographies des camps de concentration et d'extermination nazis (1933-1999), Paris (Marval) 2001, S. 213-217.

Damasio, Antonio, Descartes' Irrtum. Fühlen, Denken und das menschliche Gehirn, München (dtv) 1994.

Damasio, Antonio, The feeling of what happens. Body and emotion in the making of consciousness, San Diego (Harcourt) 1999.

Deleuze, Gilles, Kino. Band 1: Das Bewegungs-Bild. Frankfurt a.M. (Suhrkamp) 1997.

Deleuze, Gilles, Kino. Band 2: Das Zeit-Bild. Frankfurt a.M. (Suhrkamp) 1997.

Dewey, John, Kunst als Erfahrung (1934), Frankfurt a.M. (Suhrkamp) 1988.

Eder, Jens, Dramaturgie des populären Films. Drehbuchpraxis und Filmtheorie, Hamburg (LIT) 2000.

Eisenstein, Sergej, Das dynamische Quadrat. Schriften zum Film, Köln (Röderberg) 1988.

Eisenstein, Sergej, Vom Theater zum Film, Zürich (Arche Zürich) 1960.

Eisenstein, Sergej, Schriften 2. (PAnZerkreuzer Potemkin), hg. von Schlegel, Hans Joachim, München (Carl Hanser Verlag) 1973.

Eisenstein, Sergej, Schriften 3. (Oktober), hg. von Schlegel, Joachim, München (Carl Hanser Verlag) 1975.

Eisenstein, Sergej, Schriften 4. (Das Alte und das Neue [Die GeneraldiNie]), hg. von Schlegel, Joachim, München/Wien (Carl Hanser Verlag) 1984.

Eisenstein, Sergej, »Hinter der Leinwand«, in: Hesse, Eva (Hg.), NO - vom Genius Japans, Zürich (Die Arche) 1963, S. 264-282.

Faulstich, Werner, Medienwissenschaft, Paderborn (Fink) 2004.

Gibson, James J., Wahrnehmung und Umwelt. Der ökologische Ansatz in der visuellen Wahrnehmung München (Urban und Schwarzenberg) 1982.

Gisinger, Arno, »La photographie: de la mémoire communicative à la mémoire culturelle«, in: Chéroux, Clément (Hg.), La mémoire des camps. Photographies des camps de concentration et d'extermination nazis (1933-1999), Paris (Marval) 2001, S. 179-203.

Gisinger, Arno, »Für eine Kulturgeschichte der fotografischen Erinnerung am Beispiel visueller Darstellungen des Holocaust«, in: Diendorfer, Gertraud/Jagschitz, Gerhard/Rathkolb, Oliver (Hg.), Zeitgeschichte im Wandel. 3. Österreichische Zeitgeschichtetage 1997, Innsbruck/Wien (Studien-Verlag) 1998, S. 472-477.

Goethe, Johann Wolfgang von, Werke, Hamburger Ausgabe, 4, 1960, XII, Maximen und Reflexionen (S.15, 21, 749ff.)

Grübel, Rainer (Hg.), Michail M. Bachtin - Die Ästhetik des Wortes, 1979.

Hickethier, Knut, Film- und Fernsehanalyse, Stuttgart/Weimar (Metzler) ${ }^{2} 1996$.

Hickethier, Knut/Winkler, Hartmut (Hg.), Filmwahrnehmung, Berlin (Ed. Sigma Bohn) 1990.

Hartmann, Britta, »Anfang, Exposition, Initiation. Perspektiven einer pragmatischen Texttheorie des Filmanfangs«, in: montage/av, 4/2/1995. 
Howard, David/Mabley, Edward, Drehbuchhandwerk. Techniken und Grundlagen mit Analysen erfolgreicher Filme, Köln (Emos), 1996.

Heinrich, Dieter/Iser, Wolfgang (Hg.), Theorien der Kunst, Frankfurt (Suhrkamp) 1999. Ivanov, Vjac V., Einführung in allgemeine Probleme der Semiotik, Tübingen 1985.

Jakobson, Roman, Semiotik. Ausgewählte Texte 1919-1982, München 1991.

Jolles, André, Einfache Formen. (Legende, Sage, Mythe, Rätsel, Spruch, Kasus, Memorabile, Märchen, Witz), Tübingen (Niemeyer) ${ }^{6} 1982$.

Jost, Dominik, »Des Menschen Maß«, in: Kaltenbrunner, Gerd-Klaus (Hg.), Rhythmen des Lebens. (Das kosmische Gesetz von Polarität und Wiederkehr), München (Herderbücherei Initiative) 1983, S. 12-23.

Jost, François/Chateau, Dominique, Nouveau cinéma, nouvelle sémiologie, Paris (Editions de Minuit) 1979.

Jurzik, Renate, Der Stoff des Lachens. (Studien über Komik), Frankfurt/New York (Campus Verlag) 1985 .

Kaltenbrunner, Gerd-Klaus, »Vorwort des Herausgebers«, in: ders. (Hg.) Rhythmen des Lebens. (Das kosmische Gesetz von Polarität und Wiederkehr), München (Herderbücherei Initiative) 1983, S. 7-11.

Kant, Immanuel, »Der Kritik der Urteilskraft« (1790), in: Frank, Manfred/Zanetti, Véronique, (Hg.), Immanuel Kant. Schriften zur Ästhetik und Naturphilosophie - Werke III, Frankfurt a.M. (Deutscher Klassiker Verlag) 1996.

Kant, Immanuel, »Der Kritik der Urteilskraft«, zit.n.: R. Homanns, »Das Erhabene«, in: Ritter, Joachim (Hg.), Historisches Wörterbuch der Philosophie, Bd. II, Basel 1972, S. 623-635.

Kanzog, Klaus, Einführung in die Filmphilologie, München (Schaudig) 1991.

Kertész, Imre, Roman eines Schicksalslosen, Berlin (Rowohlt) 1996.

Kieser, Adriane, Die filmische Konstruktion von lebendiger Erinnerung. Vergleichende Analyse der Filme Es war einmal in Amerika von Sergio Leone und Beltenebros von Pilar Miró, Mannheim (Magisterarbeit) 1997.

Kinder, Ralf/Wieck, Thomas, Zum Schreien komisch, zum Heulen schön. Die Macht des Filmgenres, Bergisch Gladbach (Bastei Lübbe) 2001.

Kloepfer, Rolf, Prinzipien der Literatur. Grundlagen einer pragmatischen Literaturtheorie, Heidelberg (Synchron) 2005/2006, in Druck.

Kloepfer, Rolf, Materialien zum Camus Seminar: Goethe - Allegorie versus Symbol, Mannheim 2005 (unveröffentlicht).

Kloepfer, Rolf, »Die Konzeption einer neuen Blickweise für die eigene Geschichte - Sauras Film Cría Cuervos «, in: Teuber, Bernhard/Weich, Horst (Hg.), Iberische Körperbilder im Dialog der Medien und Kulturen, Frankfurt (Vervuert) 2002, S. 269-294.

Kloepfer, Rolf, »Tragende Filmwirkung, unbewußt?«, in: Frieß, Jörg/Hartmann, Britta/Müller, Eggo (Hg.), Nicht allein das Laufbild auf der Leinwand ..., Beiträge zur Film- und Fernsehwissenschaft, Band 6o, Berlin (Vistas GmbH) 2001a, S. 47-63.

Kloepfer, Rolf, Ergänzungen zu den Prinzipien der Literatur: Erzählinstanzen, Mannheim 2001 (unveröffentlicht).

Kloepfer, Rolf, »Ästhetische Gewalt und verführerische Unträchtigkeit. (Griffiths INTOLERANCE als Wiegenlied des Films)«, in: Kloepfer, Rolf/Dücker, Burckhard (Hg.), Kritik und Geschichte der Intoleranz, Heidelberg (Synchron) 200ob, in Druck.

Kloepfer, Rolf, »Vorwort des Herausgebers)«, in: Kloepfer, Rolf/Dücker, Burckhard (Hg.), Kritik und Geschichte der Intoleranz, Heidelberg (Synchron) 2000a, in Druck. 
Kloepfer, Rolf, »Semiotische Aspekte der Filmwissenschaft: Filmsemiotik« (1999), in: Posner, R. (Hg.), Semiotik=Semiotics. Ein Handbuch zu den zeichentheoretischen Grundlagen von Natur und Kultur, Band III, Berlin/New York (de Gruyter), in Druck.

Kloepfer, Rolf, »Film als Dialog - Östliche Semiotik (Bachtin, Jakobson u.a.) und das ästhetische Experiment (Kurosawas Rashomon)« (1999), in: Koch, Johann et al. (Hg.), Strukturalismus. Osteuropa und die Entstehung einer universalen Wissenschaftskultur der Moderne, Heidelberg (Synchron), in Druck.

Kloepfer, Rolf, Filmische Gestaltung als Wirkungsorganisation, Mannheim, DFG-Antrag 1999 .

Kloepfer, Rolf, Skript zur Einführungsvorlesung in die Filmwissenschaft, Mannheim 1995 (unveröffentlicht).

Kloepfer, Rolf, »Intuition. Semiotische Anschauung eines Grenzbereichs«, in: BirkenSilverman, Gabriele/Rössler, Gerda et al. (Hg.), Paradigmawechsel in der Romanistik? Beiträge zur sprachlichen, literarischen und kulturellen Vielfalt in den Philologien. Festschrift für Rupprecht Rohr zum 70. Geburtstag, Stuttgart (Steiner), S. 475-492.

Kloepfer, Rolf, Theatralität, Dramatik, Inszenierung. (Grundlagen einer Theatertheorie), Mannheim (ask) $1996^{2}$.

Kloepfer, Rolf, »La puissance des prémisses anthropologiques dans la théorie du film de Serguei M. Eisenstein«, in: Château, Dominique/Jost, François/Lefebre, Martin (Hg.), Eisenstein, l'ancien et le nouveau, Colloque de Cérisy, 1998, in Druck.

Kloepfer, Rolf, »Die Poetik eines Lebensfilms. Zur Semiotik der Zeit von Jaco van Dormaels Toto DeR Held (1994), in: Kodikas-Code. Ars Semiotica, 17 I/II.

Kloepfer, Rolf, »Narrative Kooperationen - Semiotische Anmerkungen zum ästhetischen Genuß«, in: Zeitschrift für französische Sprache und Literatur, 100, Band C, 1990, S. 138-153.

Kloepfer, Rolf, »Grundlagen des >dialogischen Prinzips< in der Literatur«, in: Köhler, Erich/Krauss, Henning (Hg.), Romanistische Zeitschrift für Literaturgeschichte, Heidelberg (Carl Winter Universitätsverlag) 1982, (Sonderdruck), S. 358-379.

Kloepfer, Rolf, »Fluchtpunkt >Rezeption<. (Gemeinsamkeiten >szientistischer und >hermeneutischer< Konzeptionen in Bielefeld und Konstanz)«, in: Kloepfer, Rolf (Hg.), Bildung und Ausbildung in der Romania, München (Wilhelm Fink Verlag) 1979, Bd. I, S. 621-658.

Knilli, Friedrich/Zielinski, Siegfried (Hg.), Betrifft: HoLocAust. Zuschauer schreiben an den WDR, Berlin (Spiess) 1983.

Korte, Helmut, Einführung in die systematische Filmanalyse, Berlin (Erich Schmidt) 1999.

Kracauer, Siegfried, Theorie des Films. Die Errettung der äußeren Wirklichkeit, Frankfurt a.M. 1985 .

Kuchenbuch, Thomas, Filmanalyse. Theorien, Modelle, Kritik, Köln (Prometh) 1978.

Lavandier, Yves, La dramaturgie, Cergy (Le clown et l'enfant) ${ }^{2} 1997$.

Lotman, Jurij M., Die Struktur literarischer Texte, München (Fink) 1972.

Lotman, Jurij M., Probleme der Kinoüsthetik. Einführung in die Semiotik des Films, Frankfurt/M. (Syndikat) 1973.

Marie, Michel/Aumont, Jacques, L'Analyse des Films, Paris (Nathan) 1989.

Monaco, James, Film verstehen, Reinbeck (Rowohlt) 1998.

Mukařovský, Jan, Studien zur strukturalistischen Ästhetik und Poetik, Frankfurt/Berlin/ Wien (Ullstein) 1977. 
Mukařovský, Jan, »Beabsichtigtes und Unbeabsichtigtes in der Kunst«, in: ders. 1977.

Müller-Freienfels, Richard, Das Lachen und das Lächeln. (Komik und Humor als wissenschaftliche Probleme), Bonn (Leuchtturm-Verlag) 1948.

Münsterberg, Hugo, »Why we go to the movies« (1915), in: Elling, Elmar/Möller, KarlDietmar (Hg.), Untersuchungen zur Syntax des Films, 2, Münster (Maks) 1985.

Ohler, Peter, »Kognitive Theorie der Filmwahrnehmung«, in: Hickethier, Knut/Winkler, Hartmut (Hg.), Filmwahrnehmung, Berlin (Ed. Sigma Bohn) 1990, S. 43-57.

Rabenalt, Peter, Filmdramaturgie, Berlin (Vistas) ${ }^{2} 2000$.

Sartre, Jean-Paul, Was ist Literatur?, Reinbek bei Hamburg (Rowohlt Taschenbuch Verlag) 1981.

Schreitmüller, Andreas, Filmtitel, Münster (MAkS Publikationen Münster) 1994.

Schweikle, Günther/Schweikle, Irmgard (Hg.), Metzler Literatur Lexikon. Begriffe und Definitionen, Stuttgart (Metzler) ${ }^{2} 1990$.

Schütte, Oliver, Die Kunst des Drehbuchlesens, Bergisch-Gladbach (Bastei) 1999.

Seidel, Wilhelm, Rhythmus. Eine Begriffsbestimmung, Darmstadt (Wissenschaftliche Buchgesellschaft) 1976.

Semprún, Jorge, Schreiben oder Leben, Frankfurt a.M. (Suhrkamp) ${ }^{2} 1995$.

Sklovskij, Viktor, »Die Kunst als Verfahren«, in: Striedter, Jurij (Hg.), Texte der russischen Formalisten, München (Fink) 1969, S. 4-35.

Sontag, Susan, Über Fotografie, München/Wien (Hanser) ${ }^{2} 1978$.

Stern, Alfred, Philosophie des Lachens und Weinens, Wien/München (R. Oldenbourg Verlag) 1980.

Suckfüll, Monika, Film erleben. Narrative Strukturen und physiologische Prozesse - DAS PIANo von Jane Campion, Berlin (Sigma) 1997.

Souriau, Etienne, »Die Struktur des filmischen Universums und das Vokabular der Filmologie«, in: montage-av 6, 2, 1951/1997, S. 140-157.

Souriau, Etienne, »Les grand caractères de l'univers filmique« und »Rythme et unanimité«, in: ders. (Hg.), L'univers filmique, Paris (Flammarion) 1953, S. 11-31 und 203-207.

Peirce, Charles Sanders, Collected Papers I-VII, Cambridge, MA 1931-1958.

Peirce, Charles Sanders, Semiotische Schriften, 3 Bd. Frankfurt a.M. (Suhrkamp) 1983.

Peters, Jan Marie, »Bild und Bedeutung. Zur Semiologie des Films«, in: Knilli, Friedrich (Hg.), Semiotik des Films, Frankfurt a.M. (Fischer) 1971, S. 56-69.

Plessner, Helmuth, »Lachen und Weinen« (1941), in: Dux, Günter/Marquard, Odo/ Ströker, Elisabeth (Hg.), Helmuth Plessner. Gesammelte Schriften VII - Ausdruck und menschliche Natur, Frankfurt a.M. (Suhrkamp) 1982.

Pfister, Manfred, Das Drama. Theorie und Analyse, München (Fink) ${ }^{10} 2000$.

Strosetzki, Christoph et al. (Hg.), Geschichte der spanischen Literatur, Tübingen (Niemeyer) 1991.

Todorov, Tzvetan, Mikhail Bakhtine le principe dialogique, Paris (Éd. du Seuil) 1981.

Türschmann, Jörg, Film - Musik - Filmbeschreibung. Zur Grundlegung einer Filmsemiotik in der Wahrnehmung von Geräusch und Musik, Münster (MAkS-Publikationen) 1994 .

Wiener, Ralph, Als das Lachen tödlich war. Erinnerungen und Fakten 1933-1945, Rudolstadt (Greifenverlag) 1988.

Winckelmann, Yvonne, Ultradiane Rhythmik kognitiver Funktionen. Eine experimentelle Studie, München (Profil) 1990. 
Wulff, Hans J., »Semiotik der Filmanalyse. Ein Beitrag zur Methodologie und Kritik filmischer Werkanalyse«, in: Kodikas/Code. Ars Semiotica, 21/1998 (1-2), S. 19-35.

Wuss, Peter, Filmanalyse und Psychologie. Strukturen des Films im Wahrnehmungsprozeß, Berlin (Sigma) 1993.

Wuss, Peter, »Filmische Wahrnehmung und Vorwissen des Zuschauers. Zur Nutzung eines Modells kognitiver Invariantenbildung bei der Filmanalyse«, in: Hickethier, Knut/Winkler, Hartmut (Hg.), Filmwahrnehmung, Berlin (Ed. Sigma Bohn) 1990, S. 67-82.

Wygotski, Lew S., Psychologie der Kunst, Dresden (Verlag der Kunst) 1976.

\section{Umgang mit dem Holocaust}

Abendroth, Elisabeth, »>Holocaust< im Unterricht. Möglichkeiten einer Annäherung«, in: Lichtenstein, Heiner/Romberg, Otto R. (Hg.), Täter - Opfer - Folgen. Der Holocaust in Geschichte und Gegenwart, Bundeszentrale für politische Bildung, Schriftenreihe, Band 335, S. 212-222.

Apitzsch, Ursula, »Ein deutsches Gewissen. Oder: Wie Martin Walser missverstanden wurde. Betrachtungen nach einem Jahr der Kontroverse«, in: Fechler, Bernd/Kößler, Gottfried/Liebertz-Groß (Hg.), »Erziehung nach Auschwitz « in der multikulturellen Gesellschaft. Pädagogische und soziologische Annäherungen, Weinheim/München (Juventa) 2000, S. 31-47.

Assmann, Jan/Assmann, Aleida, »Das Gestern im Heute. Medien und soziales Gedächtnis«, in: Merten, Klaus/Schmidt, Siegfried J., Weischenberg, Siegfried (Hg.), Die Wirklichkeit der Medien. Eine Einführung in die Kommunikationswissenschaft, Opladen (Westdeutscher Verlag) 1994, S. 114-129.

Barg, Werner, »Die Revolution in Großaufnahme. Filmästhetik und Historizität in Sergej M. Eisensteins und Grigori Alexandrovs Октовев sowie Sergio Leones Todesmelodie. Ein Plädoyer für das Nachdenken über neue Formen der Filmgeschichtsschreibung «, in: Hickethier, Knut/Müller, Eggo/Rother, Rainer (Hg.), Der Film in der Geschichte. Dokumentation der GFF-Tagung, Berlin (Ed. Sigma) 1997, S. 241-254.

Benz, Wolfgang, »Bestrafung der Schuldigen«, in: Informationen für politische Bildung: Deutschland 1945-1949. Besatzungszeit und Staatengründung, Heft 259 (2. Quartal 1998), S. 20-23.

Benz, Wolfgang, »Demokratisierung durch Entnazifizierung und Erziehung«, in: Informationen für politische Bildung: Deutschland 1945-1949. Besatzungszeit und Staatengründung, Heft 259 (2. Quartal 1998), S. 23-31.

Berg, Nicolas, »>Auschwitz< und die Geschichtswissenschaft - Überlegungen zu Kontroversen der letzten Jahre«, in: Berg, Nicolas/Jochimsen, Jess/Stiegler, Bernd (Hg.), Shoah - Formen der Erinnerung: Geschichte, Philosophie, Literatur, Kunst, München (Fink) 1996, S. 31-52.

Bracher, Karl Dietrich, »Geschichte und Medium. Gedanken zum Verhältnis von Fernsehen und Geschichtsbewußtsein«, in: Bundeszentrale für politische Bildung (Hg.), Aus Politik und Zeitgeschichte. Beilage zur Wochenzeitung »Das Parlament«, B 8/80, 23. Februar 1980, S. 3-9.

Brink, Cornelia, Ikonen der Vernichtung. Öffentlicher Gebrauch von Fotographien aus nationalsozialistischen Konzentrationslagern nach 1945, Berlin (Akademie Verlag) 1998. 
Broszat, Martin, »Das Dritte Reich als Gegenstand historischen Fragens«, in: Broszat, Martin/Frei, Norbert, Das Dritte Reich im Überblick. Chronik, Ereignisse, Zusammenhänge, München (Piper) 1989, S. 12.

Brumlik, Micha, »Trauerarbeit und kollektive Erinnerung«, in: Köppen, Manuel (Hg.), Kunst und Literatur nach Auschwitz, Berlin (Erich Schmidt Verlag) 1993, S. 197203.

Bubis, Naomi, »Die jüdischen Generationen nach dem Holocaust«, in: Lichtenstein, Heiner/Romberg, Otto R. (Hg.), Täter - Opfer - Folgen. Der Holocaust in Geschichte und Gegenwart, Bundeszentrale für politische Bildung, Schriftenreihe, Band 335, S. $198-203$.

Denkler, Horst, »Gedächtnisstütze. Binsenweisheiten über die bescheidenen Möglichkeiten der Deutschen Literatur im Rückblick und in Hinsicht auf den Holocaust«, in: Köppen, Manuel (Hg.), Kunst und Literatur nach Auschwitz, Berlin (Erich Schmidt Verlag) 1993, S. 171-177.

Domansky, Elisabeth, »Die gespaltene Erinnerung«, in: Köppen, Manuel (Hg.), Kunst und Literatur nach Auschwitz, Berlin (Erich Schmidt Verlag) 1993, S. 178-196.

Dubiel, Helmut, Niemand ist frei von der Geschichte. Die nationalsozialistische Herrschaft in den Debatten des Deutschen Bundestages, München/Wien (Carl Hanser Verlag) 1999.

Erler, Hans (Hg.), Erinnern und Verstehen. Der Völkermord an den Juden im politischen Gedächtnis der Deutschen, Frankfurt a.M./New York (Campus) 2003.

Ferro, »Gibt es eine filmische Sicht der Geschichte«, in: Rother, Rainer (Hg.), Bilder schreiben Geschichte: Der Historiker im Kino, Berlin (Wagenbach) 1991, S. 17-36, insb. S. $17-26$.

Frei, Norbert/Steinbacher, Sybille, Beschweigen und Bekennen. Die deutsche Nachkriegsgesellschaft und der Holocaust, Göttingen (Wallstein Verlag) 2001.

Grosser, Alfred, Deutschland in Europa, Weinheim/Basel (Beltz Quadriga Verlag) 1998.

Heller, Heinz B., »Vergangenheit im filmischen Präsens. Anmerkungen zum Verhältnis von Dokumentarfilm und Geschichte«, in: Hickethier, Knut/Müller, Eggo/Rother, Rainer (Hg.), Der Film in der Geschichte. Dokumentation der GFF-Tagung, Berlin (Ed. Sigma) 1997, S. 220-227.

Herzog, Roman, »Wir tragen Verantwortung. Ansprache während der Gedenkveranstaltung in Bergen-Belsen am 27. April 1995«, in: Lichtenstein, Heiner/Romberg, Otto R. (Hg.), Täter - Opfer - Folgen. Der Holocaust in Geschichte und Gegenwart, Bundeszentrale für politische Bildung, Schriftenreihe, Band 335, S. 265-268.

Hickethier, Knut/Müller, Eggo/Rother, Rainer (Hg.), Der Film in der Geschichte. Dokumentation der GFF-Tagung, Berlin (Ed. Sigma) 1997.

Hickethier, Knut/Müller, Eggo/Rother, Rainer, »Geschichte und Film. Zur Einleitung«, in: Hickethier, Knut/Müller, Eggo/Rother, Rainer (Hg.), Der Film in der Geschichte. Dokumentation der GFF-Tagung, Berlin (Ed. Sigma) 1997, S. 8-10.

Huyssen, Andreas, »Von Mauschwitz in die Catskills und zurück: Art Spiegelmans Holocaust-Comic Maus«, in: Köppen, Manuel/Scherpe, Klaus R. (Hg.), Bilder des Holocaust. Literatur - Film - Bildende Kunst, Köln/Weimar/Wien (Böhlau) 1997, S. 171-189.

Kaes, Anton, From Hitler to Heimat. The Return of History as Film, Cambridge (Harvard University Press) 1989. 
Karpf, Ernst, »Geschichte sehen. Zur Wahrnehmung des Historischen im Film«, in: Evangelische Akademie Arnoldshain/Gemeinschaftswerk der Evangelischen Publizistik e.V. (Hg.), Arnoldshainer Filmgespräche Band 9: Filmmythos Volk. Zur Produktion kollektiver Identitäten im Film, Frankfurt a.M. (Gemeinschaftswerk der Evangelischen Publizistik, Abteilung Verlag) 1992, S. 13-20.

Klüger, Ruth, »Kitsch, Kunst und Grauen«, in: Frankfurter Allgemeine Zeitung, 02.12.1995, S. B4.

Knigge, Volkhard/Frei, Norbert (Hg.), Verbrechen erinnern. Die Auseinandersetzung mit Holocaust und Völkermord, München (Beck) 2002.

Kramer, Sven, Auschwitz im Widerstreit. Zur Darstellung der Shoah im Film, Philosophie und Literatur, Wiesbaden (Deutscher Universitätsverlag) 1999.

Köhler, Anja, Vichy und die Intellektuellen. Die sannées noires im Spiegel autobiographischer Texte, Tübingen (Narr) 2001.

Le Goff, Jacques, Geschichte und Gedüchtnis, Frankfurt/New York (Campus) 1992.

Levi, Primo, Ist das ein Mensch, München/Wien (Carl Hanser Verlag) 1988.

Levy, Daniel/Sznaider, Natan, Erinnerung im globalen Zeitalter: Der Holocaust, Frankfurt a.M. (Suhrkamp) 2001.

Lichtenstein, Heiner, »NS-Prozesse. Zum Ende eines Kapitels deutscher Justizgeschichte«, in: Lichtenstein, Heiner/Romberg, Otto R. (Hg.), Täter - Opfer - Folgen. Der Holocaust in Geschichte und Gegenwart, Bundeszentrale für politische Bildung, Schriftenreihe, Band 335, S. 114-124.

Loewy, Hanno (Hg.), Holocaust. Die Grenzen des Verstehens - eine Debatte über die Besetzung der Geschichte, Reinbek bei Hamburg (Rowohlt) 1992.

Marek, Michael/Schmitz, Matthias, »>Survivors of the Shoahく. Wie zeigt man, dass Auschwitz stattgefunden hat«, in: Tribüne. Zeitschrift zum Verständnis des Judentums, Heft 158, 40. Jahrgang, 2001, S. 145-156.

Martínez, Martías (Hg.), Der Holocaust und die Künste. Medialität und Authentizität von Holocaust-Darstellungen in Literatur, Film, Video, Malerei, Denkmälern, Comic und Musik, Bielefeld (Aisthesis) 2004 .

Nettelbeck, Colin, »Kurskorrektur: Die Darstellung des Zweiten Weltkrieges in Frankreich ab 1968«, in: Hirschfeld, Gerhard/Marsh, Patrick (Hg.), Kollaboration in Frankreich. Politik, Wirtschaft und Kultur während der nationalsozialistischen Besatzung 1940-1944, Frankfurt a.M. (Fischer) 1991, S. 266-309.

Piper, Ernst (Hg.), Gibt es wirklich eine Holocaust-Industrie. Zur Auseinandersetzung um Norman Finkelstein, Zürich (Pendo) 2001.

Rother, Rainer, Die Gegenwart der Geschichte. Ein Versuch über Film und zeitgenössische Literatur, Stuttgart (Metzler) 1990.

Rother, Rainer, »Film und Geschichtsschreibung«, in: Bock, Hans-Michael/Jacobson, Wolfgang (Hg.), Recherche: Film. Quellen und Methoden der Filmforschung, München (text + kritik) 1997, S. 242-246.

Schildt, Axel, »Politische Entscheidungen und Einstellungen«, in: Informationen für politische Bildung: Deutschland in den 5oer Jahren, Heft 256 (3. Quartal 1997), S. 21-23.

Schildt, Axel, »Gesellschaft, Alltag und Kultur in der Bundesrepublik«, in: Informationen für politische Bildung: Deutschland in den 7oer und 8oer Jahren, Heft 270 (1. Quartal 2001), S. 40-42.

Schmidt, Thomas E., »Wer globalisiert wen? Der Antiamerikanismus paßt sich der neuen Weltlage an«, in: Die Zeit, 07.03.02, S. 37 (Feuilleton). 
Schörken, Rolf, »I. Das Prinzip Vergegenwärtigung«, in: ders., Begegnungen mit Geschichte: vom außerwissenschaftlichen Umgang mit der Historie in Literatur und Medien, Stuttgart (Klett-Cotta) 1995, S. 11-14.

Semprún, Jorge, Schreiben oder Leben, Frankfurt a.M. (Suhrkamp) ${ }^{2} 1995$.

Simons, Oliver, »Gedächtnislandschaften, Erinnerungsbilder, Spurensicherung - Nachbilder des Holocaust«, in: Köppen, Manuel/Scherpe, Klaus R., Bilder des Holocaust. Literatur - Film - Bildende Kunst, Köln/Weimar/Wien (Böhlau) 1997, S. 191-213.

Steinbach, Peter, »Der Historikerstreit«, in: Lichtenstein, Heiner/Romberg, Otto R. (Hg.), Täter - Opfer - Folgen. Der Holocaust in Geschichte und Gegenwart, Bundeszentrale für politische Bildung, Schriftenreihe, Band 335, S. 101-113.

Steinbach, Peter, »NS-Prozesse und historische Forschung «, in: Lichtenstein, Heiner/ Romberg, Otto R. (Hg.), Täter - Opfer - Folgen. Der Holocaust in Geschichte und Gegenwart, Bundeszentrale für politische Bildung, Schriftenreihe, Band 335, S. 136-153.

Strümpel, Jan, Vorstellungen vom Holocaust. George Taboris Erinnerungs-Spiele, Göttingen (Wallstein) 2000.

Sywottek, Arnold, »Film und Geschichte - ein Problemaufriß«, in: Hickethier, Knut/ Müller, Eggo/Rother, Rainer (Hg.), Der Film in der Geschichte. Dokumentation der GFF-Tagung, Berlin (Ed. Sigma) 1997, S. 11-18.

Wenzel, Eike, »Aktualität der Erinnerung. Deutschland im Herbst als kollektiver Versuch einer filmischen Gedächtnisproduktion für die Gegenwart«, in: Hickethier, Knut/Müller, Eggo/Rother, Rainer (Hg.), Der Film in der Geschichte. Dokumentation der GFF-Tagung, Berlin (Ed. Sigma) 1997, S. 228-240.

Wiesel, Elie, »Die Trivialisierung des Holocaust: Halb Faktum und halb Fiktion«, in: Märthesheimer, Peter/Frenzel, Ivo (Hg.), Im Kreuzfeuer: Der Fernsehfilm HoLoCAUST. Eine Nation ist betroffen, 1979, S. 25-30.

Williams, Val, »Shadows on the body. Photography and the Holocaust«, in: dies., Warworks. Women, photography and the iconography of war, London (Virago Press) 1994, S. $33-45$.

Young, James E., Beschreiben des Holocaust. Darstellung und Folgen der Interpretation, Frankfurt a.M. (Jüdischer Verlag) 1992.

Žižek, Slavoj, »Du sollst dir Bilder machen! Der Holocaust zwischen Schweigen und Lachen«, in: Süddeutsche Zeitung, 31.08.2000, S. 15 .

Zuckermann, Mosche, »Perspektiven der Holocaust-Rezeption in Israel und Deutschland «, in: Aus Politik und Zeitgeschichte. Beilage zur Wochenzeitung »Das Parlament«, B 14/98, 27.03.1998, S. 19-29.

\section{Holocaust und Film}

Arning, Matthias: »Die bequeme Arbeitsteilung beim Erinnern des Holocaust. Antisemitismusforscher Benz plädiert für neue Formen«. In: Frankfurter Rundschau, 27.01.2001, S. 7 .

Avisar, Screening the Holocaust. Cinema's image of the unimaginable, Bloomington (Indiana University Press) 1988.

Baron, Lawrence, Projecting the Holocaust into the present. The changing focus of contemporary Holocaust cinema, Lanham (Rowman \& Littlefield Publishers) 2005.

Bergman, Werner, »Kapitel V. Die TV-Serie Holocaust als Medienereignis«, in: ders., Antisemitismus in öffentlichen Konflikten. Kollektives Lernen in der politischen Kultur der Bundesrepublik 1949-1989, Frankfurt a.M./New York (Campus) 1997, S. 351-381. 
Braese, Stephan, »Das deutsche Objektiv. Der Holocaust im Film und der deutsche Literaturbetrieb 1945-1956«, in: Kramer, Sven (Hg.), Die Shoah im Bild, München (edition text+kritik) 2003, S. 71-85.

Darmstädter, Tim, »Die Verwandlung der Barbarei in Kultur. Zur Rekonstruktion der nationalsozialistischen Verbrechen im historischen Gedächtnis, in: Werz, Michael (Hg.), Antisemitismus und Gesellschaft. Zur Diskussion um Auschwitz, Kulturindustrie und Gewalt, Frankfurt a.M. (Neue Kritik) 1995, S. 115-139.

Deutsches Filminstitut (Hg.), Die Vergangenheit in der Gegenwart. Konfrontationen mit den Folgen des Holocaust im deutschen Nachkriegsfilm, München (edition text+kritik) 2001.

Doneson, Judith E., The Holocaust in American Film, Syracuse, New York (Syracuse Univ. Press) ${ }^{2} 2002$.

Düwell, Susanne/Schmidt, Matthias (Hg.), Narrative der Shoah. Repräsentationen der Vergangenheit in Historiographie, Kunst und Politik, Paderborn/München/Wien/Zürich (Schöningh) 2002.

Festenberg, Nikolaus von, »Fabeln hinterm Flammenkreis«, in: Der Spiegel, 29.03.1999, S. 238-239.

Frieß, Jörg, »Filme aus Filmen, Filme über Filme. Zur Rhetorik historischen Bildmaterials in Filmen über die Shoah«, in: Kramer, Sven (Hg.), Die Shoah im Bild, München (edition text+kritik) 2003, S. 199-223.

Frieß, Jörg, »Spuren von Spuren von Spuren. Vorgefundene Bilder in drei Dokumentationen über die Shoah«, in: Frieß, Jörg/Hartmann, Britta/Müller, Eggo (Hg.), Nicht allein das Laufbild auf der Leinwand ... Strukturen des Films als Erlebnispotentiale, Berlin (Vistas) 2001, S. 161-176.

Fröhlich, Margit/Loewy, Hanno/Steinert, Heinz (Hg.), Lachen über Hitler - AuschwitzGelächter? Filmkomödie, Satire und Holocaust, (edition text + kritik) 2003.

Gerhard/Green, Gerald, »Zur Verteidigung von >Holocaust««, in: Märthesheimer, Peter/Frenzel, Ivo, Im Kreuzfeuer: Der Fernsehfilm >Holocaust<. Eine Nation ist betroffen, Frankfurt a.M. (Fischer Taschenbuch Verlag) 1979, S. 31-34.

Giesenfeld, Günter/Koebner, Thomas (Hg.), Augen-Blick. Marburger und Mainzer Hefte zur Medienwissenschaft, Heft 36: »Zur neuen Kinematographie des Holocaust«, Dezember 2004.

Gisinger, Arno, »La photographie: de la mémoire communicative à la mémoire culturelle«, in: Chéroux, Clément (Hg.), La mémoire des camps. Photographies des camps de concentration et d'extermination nazis (1933-1999), Paris (Marval) 2001, S. 179-203.

Gregor, Erika und Ulrich (Hg.), Jüdische Lebenswelten im Film, Berlin (Freunde der Deutschen Kinemathek) 1992.

Haggith, Toby (Hg.), Holocaust and the moving image. Representations in film and television since 1933, London (Wallflower Press) 2005.

Heller, Heinz B., »Vergangenheit im filmischen Präsens. Anmerkungen zum Verhältnis von Dokumentarfilm und Geschichte«, in: Hickethier, Knut/Müller, Eggo/Rother, Rainer (Hg.), Der Film in der Geschichte. Dokumentation der GFF-Tagung, Berlin (Ed. Sigma) 1997, S. 220-227.

Hickethier, Knut, »Die Darstellung des Massenmordes an den Juden im Fernsehen der Bundesrepublik von 1960-1980«, in: Kramer, Sven (Hg.), Die Shoah im Bild, München (edition text+kritik) 2003, S. 117-131.

Hirsch, Joshua, Afterimage. Film, trauma, and the Holocaust, Philadelphia (Temple Univ. Press) 2004. 
Holcman, Robert, »La Shoah dans le domaine public?«, in: Le Monde, 31.10.1998, o.S. Insdorf, Annette, Indelible shadows. Film and the Holocaust, Cambridge (Cambridge University Press) ${ }^{3} 2003$.

Jochimsen, Jess, »>Nur was nicht aufhört, weh zu thun, bleibt im Gedächtnis.<Die Shoah im Dokumentarfilm«, in: Berg, Nicolas/Jochimsen, Jess/Stiegler, Bernd (Hg.), Shoah - Formen der Erinnerung: Geschichte, Philosophie, Literatur, Kunst, München (Fink) 1996, S. 215-233.

Kaes, Anton, »Holocaust and the End of History: Postmodern Historiography in Cinema«, in: Friedländer, Saul (Hg.), Probing the Limits of Representation. Nazism and the >Final Solution<, Cambridge (Mass.)/London 1992, S. 106-223.

Kilb, Andreas; »Der Stellvertreter«, in: Frankfurter Allgemeine Zeitung, 31.05.2002, S. 51.

Kilb, Andreas: »Das Unzerstörbare. Irréversible von Gaspard Noé und The Pianist von Roman Polanski beim Filmfestival in Cannes«. In: Frankfurter Allgemeine Zeitung, 25.05.2002, S. 43.

Knilli, Friedrich/Zielinski, Siegfried (Hg.), Holocaust zur Unterhaltung. Anatomie eines internationalen Bestsellers. Fakten - Fotos - Forschungsreportagen, Berlin (Verlag für Ausbildung und Studium in der Elefanten Press) 1982.

Kogon, Eugen, »Über die innere Wahrheit des Fernsehfilms HolocausT«, in: Märthesheimer, Peter/Frenzel, Ivo, Im Kreuzfeuer: Der Fernsehfilm HoLосаust. Eine Nation ist betroffen, Frankfurt a.M. (Fischer Taschenbuch Verlag) 1979, S. 66-69.

Köppen, Manuel, »Holocaust im Fernsehen - Die Konkurrenz der Medien um die Erinnerung«, in: Wende, Waltraud >Wara< (Hg.), Geschichte im Film. Mediale Inszenierungen des Holocaust und kulturelles Gedächtnis, Stuttgart/Weimar (Metzler) 2002, S. 307-327.

Köppen, Manuel, »Holocaust und Unterhaltung. Eine Diskussion mit: Edgar Hilsenrath, Michael Komar, Ursula Link-Heer, Egon Monk und Marcel Ophüls. Diskussionsleitung: Rüdiger Steinlein«, in: Köppen, Manuel (Hg.), Kunst und Literatur nach Auschwitz, Berlin (Erich Schmidt Verlag) 1993, S. 107-112.

Köppen, Manuel/Scherpe, Klaus R., »Zur Einführung: Der Streit um die Darstellbarkeit des Holocaust«, in: Köppen, Manuel/Scherpe, Klaus R., Bilder des Holocaust. Literatur - Film - Bildende Kunst, Köln/Weimar/Wien (Böhlau) 1997, S. 1-12.

Kramer, Sven, »Vorwort«, in: ders. (Hg.), Die Shoah im Bild, München (edition text+kritik) 2003, S. 7-12.

Kramer, Sven, »Nacktheit in Holocaust-Fotos und -Filmen«, in: ders. (Hg.), Die Shoah im Bild, München (edition Text+kritik) 2003, S. 225-248.

Kramer, Sven, Auschwitz im Widerstreit. Zur Darstellung der Shoah im Film, Philosophie und Literatur, Wiesbaden (Deutscher Universitätsverlag) 1999.

Krankenhagen, Stefan, Auschwitz darstellen. Ästhetische Positionen zwischen Adorno, Spielberg und Walser, Köln/Weimar/Wien (Böhlau) 2001.

Lange, Sigrid, »Zeugnisse und Zeugen. Der Holocaust in Film und Literatur«, in: dies., Authentisches Medium. Faschismus und Holocaust in ästhetischen Darstellungen der Gegenwart, Bielefeld (Aisthesis Verlag) 1999, S. 133-174.

Leiser, Erwin, »Holocaust und Film«, in: Weigel, Sigrid/Erdle, Birgit, Fünfzig Jahre danach. Zur Nachgeschichte des Nationalsozialismus, Zürich (vdf Hochschulverlag) 1996, S. 91-115.

Lietzmann, Sabine, »Die Judenvernichtung als Seifenoper. Holocaust - eine Serie im amerikanischen Fernsehen«, in: Märthesheimer, Peter/Frenzel, Ivo, Im Kreuz- 
feuer: Der Fernsehfilm HoLocaust. Eine Nation ist betroffen, Frankfurt a.M. (Fischer Taschenbuch Verlag) 1979, S. 35-39.

Lorenz, Matthias N., »Der Holocaust als Zitat. Tendenzen im Holocaust-Spielfilm nach Schindle R's List«, in: Kramer, Sven (Hg.), Die Shoah im Bild, München (edition text+kritik) 2003, S. 267-296.

Lowy, Vincent, Les camps d'extermination nazis à l'écran, Paris (L' Harmattan) 2002.

Mandelbaum, Jacques, »Films et Shoah, l'écriture du désastre«, in: Le Monde, 20.10.1999, o.S.

Märthesheimer, Peter/Frenzel, Ivo (Hg.), Im Kreuzfeuer: Der Fernsehfilm HoLocaust. Eine Nation ist betroffen, Frankfurt a.M. (Fischer) 1979.

Meyer, Paul, »Aufklärung zur rechten Zeit. Bewegende Geschichte: die ZDF-Serie Holokaust erschließt das Thema mit neuen Bildern«, in: Die Woche, 20.10.2000, S. 45 (Medien).

Müller, Hans-Jürgen, SHOAH - ein Film. Erinnerungsarbeit in der Erwachsenenbildung mit dem Mittel der Kunst, Oldenburg (Bibliotheks- und Informationssystem der Universität Oldenburg) 1991.

Müller, Jan, »Hunger nach Memoria«, in: Frankfurter Allgemeine Zeitung, 24.04.1999, S. 46 .

Noack, Johannes-Michael, SCHindLeRs LISTE - Authentizität und Fiktion in Spielbergs Film. Eine Analyse, Leipzig (Leipziger Universitätsverlag) 1998.

Nutt, Harry, »Verbotene Liebe. Der Wille zum Holocaust-Film. In ihrem Film Meschugge produzieren Dani Levy und Maria Schrader schwere Zeichen. Denn wir können auch anders. Nach der Komödiewelle kommen jetzt die neue Ernsthaftigkeit und ein neuer Versuch in Vergangenheitspolitik«, in: Die Tageszeitung, 11.03.1999, S. 15 .

Ophuls, Marcel, »Les trains«, in: Cuau, Bernard (Hg.), Au sujet de SHoAH, Paris (Belin) 1990, S. $175^{-187}$.

Paech, Joachim, »Ent/setzte Erinnerung«, in: Kramer, Sven (Hg.), Die Shoah im Bild, München (edition text+kritik) 2003, S. 13-29.

Paech, Anne/Paech, Joachim, »Trümmerkinos«, in: dies., Menschen im Kino. Film und Literatur erzählen, Stuttgart/Weimar (Metzler) 2000, S. 162-172.

Paech, Joachim, »Erinnerungs-Landschaften«, in: Köppen, Manuel, Kunst und Literatur nach Auschwitz, Berlin (Erich Schmidt Verlag) 1993, S. 124-136.

Reichel, Peter, Vergangenheitsbewältigung in Deutschland. Die Auseinandersetzung mit der NS-Dikatur von 1945 bis heute, München (Beck) 2001, S. 205.

Reich-Ranicki, Marcel, »Polanskis Todesfuge. Was ich nicht zu hoffen wagte, ist hier gelungen - Der PiAnist ist eine meisterhafte Wiedergabe unseres Alltags im Warschauer Ghetto«, in: Frankfurter Allgemeine Zeitung, 23.10.2002, S. 35.

Rousso, Henri, »L'écran des années noires«, in: ders., Le syndrome de Vichy, Paris (Seuil) 1987, S. 241-254.

Siedler, Joachim, Holocaust. Die Fernsehserie in der deutschen Presse. Eine Inhalts- und Verlaufsanalyse am Beispiel ausgewählter Printmedien, Münster (LIT) 1984 .

Schröder, Nicolaus, 50 Klassiker Film. Die wichtigsten Werke der Filmgeschichte, Hildesheim (Gerstenberg) 2001.

Schulz, Georg-Michael, »Docu-Dramas - oder: Die Sehnsucht nach der >Authentizität<. Rückblicke auf Holocaust von Marvin Chomsky und Schinderers Liste von Steven Spielberg«, in: Wende, Waltraud >Wara<(Hg.), Geschichte im Film. Mediale 
Inszenierungen des Holocaust und kulturelles Gedächtnis, Stuttgart/Weimar (Metzler) 2002, S. 159-179.

Seeßlen, Georg, »Die Seele im System. Roman Polanskis Der PiAn ist oder: Wie schön darf ein Film über den Holocaust sein?«, in: Die Zeit, 24.10.2002, S. 56.

Silbermann, Alphons/Stoffers, Manfred, Auschwitz: Nie davon gehört? Erinnern und Vergessen in Deutschland, Berlin (Rowohlt) 2000.

Strickhausen, Waltraud, »(Gegen) die Wiederholung des Grauens. Erinnerungen von Holocaust-Überlebenden«, in: Felix, Jürgen/Marschall, Susanne/Stiglegger, Markus (Hg.), Die Wiederholung, Marburg (Schüren) 2001, S. 239-267.

Thiele, Martina, Publizistische Kontroversen über den Holocaust im Film, Münster (LIT) 2001.

Thiele, Martina, »Publizistische Kontroversen über den Holocaust im Film: von Morituri bis Schindlers LiSTE«, in: Medienbilder. Dokumentation des 13. Film- und Fernsehwissenschaftlichen Kolloquiums an der Georg-August-Universität Göttingen Oktober 2000, Hamburg (Verlag Dr. Kovac) 2001, S. 197-217.

Van der Knaap, Ewout, »Monument des Gedächtnisses - Der Beitrag von NACHT UnD Nebel zum Holocaust-Diskurs«, in: Wende, Waltraud > Wara< (Hg.), Geschichte im Film. Mediale Inszenierungen des Holocaust und kulturelles Gedächtnis, Stuttgart/Weimar (Metzler) 2002, S. 67-77.

Weiß, Matthias, »Sinnliche Erinnerung. Die Filme Holocaust und Schindle Rs Liste in der bundesdeutschen Vergegenwärtigung der NS-Zeit«, in: Frei, Norbert/Steinbacher, Sybille, Beschweigen und Bekennen. Die deutsche Nachkriegsgesellschaft und der Holocaust, Göttingen (Wallstein Verlag) 2001, S. 71-102.

Welzer, Harald, »Die Bilder der Macht und die Ohnmacht der Bilder. Über Besetzung und Auslöschung von Erinnerung«, in: ders. (Hg.), Das Gedächtnis der Bilder. Ästhetik und Nationalsozialismus, Tübingen (edition diskord) 1995, S. 165-194.

Wende, Waltraud >Wara<, »Medienbilder und Geschichte - Zur Medialisierung des Holocaust«, in: dies. (Hg.), Geschichte im Film. Mediale Inszenierungen des Holocaust und kulturelles Gedüchtnis, Stuttgart/Weimar (Metzler) 2002, S. 8-29.

Wergin, Clemens: »Haben Sie die Holocaust-Komödie erfunden, Herr Mihailenau?«, in: Der Tagesspiegel, 22.3.2000, o.S.

Wiesel, Elie, »Die Trivialisierung des Holocaust: Halb Faktum und halb Fiktion«, in: Märthesheimer, Peter/Frenzel, Ivo, Im Kreuzfeuer: Der Fernsehfilm HoLocaust. Eine Nation ist betroffen, Frankfurt a.M. (Fischer Taschenbuch Verlag) 1979, S. 25-30.

Wuss, Peter, »DAs LeBEn ISt sChön ... aber wie lassen sich die Emotionen des Films objektivieren?«, in: Sellmer, Jan/Wulff, Hans J. (Hg.), Film und Psychologie - nach der kognitiven Phase?, Marburg (Schüren) 2002, S. 123-142.

Zur Nieden, Susanne, » >...stärker als der Tod< - Bruno Appitz' Roman >Nackt unter Wölfen « und die Holocaust-Rezeption in der DDR«, in: Köppen, Manuel/Scherpe, Klaus R. (Hg.), Bilder des Holocaust. Literatur - Film - Bildende Kunst, Köln/Weimar/Wien (Böhlau) 1997, S. 97-109.

\section{II.1 / II.1.1 »DIE TODESMÜHLEN《}

Avisar, Screening the Holocaust. Cinema's image of the unimaginable, Bloomington (Indiana University Press) 1988. 
Baer, Ulrich, »Zum Zeugen werden. Landschaftstradition und Shoah oder Die Grenzen der Geschichtsschreibung im Bild«, in: ders. (Hg.), >Niemand zeugt für den Zeugen<. Erinnerungskultur und historische Verantwortung nach der Shoah, Frankfurt a.M. (Suhrkamp) 2000, S. 236-254.

Barthes, Roland, »Schockphotos«, in: ders., Mythen des Alltags, Frankfurt a.M. (Suhrkamp) ${ }^{3} 1974$, S. 55-58.

Bartov, Omer, »Spielberg's Oskar. Hollywood tries evil«, in: Loshitzky, Yosefa (Hg.), Spielberg's Holocaust. Critical Perspectives on SCHINDLER's LIST, Bloomington/Indianapolis (Indiana University Press) 1997, S. 41-60.

Beier, Lars-Olav, »Odysseus in Ruinenfeldern. Mit dem Film Der Pianist triumphierte Roman Polanski in Cannes. Nun kommt die ergreifende Überlebens-Story eines jüdischen Musikers in die Kinos«, in: Der Spiegel, 43/2002 (21.10.02), S. 202.

Bernstorff, Madeleine, »Geschwenkte Kameras zeigen die Wahrheit«, in: Die Tageszeitung, 11.12.2002, S. 16.

Blechschmidt, Andreas, »Verdrängung forciert«, in: Die Tageszeitung, 05.12.2002, S. 23 .

Bonhomme, Pierre/Chéroux, Clément, »Introduction«, in: Chéroux, Clément (Hg.), Mémoire des camps. Photographies des camps de concentration et d'extermination nazis (1933-1999), Paris (Marval) 2001, 9-10.

Brink, Cornelia, »Bilder vom Feind. Das Scheitern der >visuellen Entnazifizierung «, in: Kramer, Sven (Hg.), Die Shoah im Bild, München (edition text+kritik) 2003, S. 51-69.

Brink, Cornelia, Ikonen der Vernichtung. Öffentlicher Gebrauch von Fotographien aus nationalsozialistischen Konzentrationslagern nach 1945, Berlin (Akademie Verlag) 1998.

Bühler, Philip, »Zur Strafe ins Kino«, in: Die Tageszeitung, 30.06.1999, S. 23.

Chéroux, Clément, »Du bon usage des images«, in: ders. (Hg.), Mémoire des camps. Photographies des camps de concentration et d'extermination nazis (1933-1999), Paris (Marval) 2001, S. 11-21.

Darmstädter, Tim, »Die Verwandlung der Barbarei in Kultur. Zur Rekonstruktion der nationalsozialistischen Verbrechen im historischen Gedächtnis, in: Werz, Michael (Hg.), Antisemitismus und Gesellschaft. Zur Diskussion um Auschwitz, Kulturindustrie und Gewalt, Frankfurt a.M. (Neue Kritik) 1995, S. 115-139.

Doneson, Judith E., The Holocaust in American Film, Syracuse, New York (Syracuse Univ. Press) ${ }^{2} 2002$.

Feindt, Hendrik, »>Mais ici les paroles s'arrêtent<. Der französische Dokumentarfilm Les Camps de la Mort (1945)«, in: Roß, Heiner (Hg.), Lernen Sie diskutieren! Re-education durch Film. Strategien der westlichen Alliierten nach 1945, Babelsberg (Cinegraph) 2005, S. 97-102.

Gallwitz, Tim, »Sitzen machen!«, in: Die Tageszeitung, 19.04.2000, S. 23.

Gisinger, Arno, »La photographie: de la mémoire communicative à la mémoire culturelle«, in: Chéroux, Clément (Hg.), La mémoire des camps. Photographies des camps de concentration et d'extermination nazis (1933-1999), Paris (Marval) 2001, S. 179-203.

Gisinger, Arno, »Für eine Kulturgeschichte der fotografischen Erinnerung am Beispiel visueller Darstellungen des Holocaust«, in: Diendorfer, Gertraud/Jagschitz, Gerhard/Rathkolb, Oliver (Hg.), Zeitgeschichte im Wandel. 3. Österreichische Zeitgeschichtetage 1997, Innsbruck/Wien (Studien-Verlag) 1998, 472-477. 
Hahn, Brigitte, J., Umerziehung durch Dokumentarfilm? Ein Instrument amerikanischer Kulturpolitik im Nachkriegsdeutschland (1945-1953), Münster (LIT) 1997.

Heller, Heinz B., »Vergangenheit im filmischen Präsens. Anmerkungen zum Verhältnis von Dokumentarfilm und Geschichte«, in: Hickethier, Knut/Müller, Eggo/Rother, Rainer (Hg.), Der Film in der Geschichte. Dokumentation der GFF-Tagung, Berlin (Ed. Sigma) 1997, S. 220-227.

Hickethier, Knut, »Die Darstellung des Massenmordes an den Juden im Fernsehen der Bundesrepublik von 1960-1980«, in: Kramer, Sven (Hg.), Die Shoah im Bild, München (edition text+kritik) 2003, S. 117-131.

Hoffmann, Detlef, »Auschwitz im visuellen Gedächtnis«, in: Fritz-Bauer-Institut (Hg.), Auschwitz: Geschichte, Rezeption und Wirkung. Jahrbuch 1996 zur Geschichte und Wirkung des Holocaust, Frankfurt a.M./New York (Campus) 1996, S. $223-257$.

Hoffmann, Detlef, »Ein Foto aus dem Ghetto Lodz oder: Wie die Bilder zerrinnen«, in: Loewy, Hanno (Hg.), Holocaust: Die Grenzen des Verstehens. Eine Debatte über die Besetzung der Geschichte, Reinbek bei Hamburg (Rowohlt) 1992, S. $233-247$.

Hüppauf, Bernd, »Der entleerte Blick hinter der Kamera«, in: Heer, Hannes/Naumann, Klaus (Hg.), Vernichtungskrieg. Verbrechen der Wehrmacht 1941-1944, Frankfurt a.M. (Zweitausendeins) 1995, S. 504-527.

Insdorf, Annette, Indelible shadows. Film and the Holocaust, Cambridge (Cambridge University Press) ${ }^{3} 2002$.

Jochimsen, Jess, »>Nur was nicht aufhört, weh zu thun, bleibt im Gedächtnis<. Die Shoah im Dokumentarfilm«, in: Berg, Nicolas/Jochimsen, Jess/Stiegler, Bernd (Hg.), Shoah - Formen der Erinnerung. Geschichte, Philosophie, Literatur, Kunst, München (Fink) 1996, S. 215-231.

Kilb, Andreas, »Des Teufels Saboteur«, in: Weiß, Christoph (Hg.), >Der gute Deutsche Dokumente zur Diskussion um Steven Spielbergs SCHINDLERS LISTE in Deutschland, St. Ingbert (Röhrig Universitätsverlag) 1995, S. 147-157.

Klee, Ernst/Dreßen, Willi/Rieß, Volker, »Schöne Zeiten«. Judenmord aus der Sicht der Täter und Gaffer, Frankfurt a.M. (S. Fischer) ${ }^{3} 1988$.

Knoch, Habbo, »Die Grenzen des Zeigbaren. Fotografien der NS-Verbrechen und die westdeutsche Gesellschaft«, in: Kramer, Sven (Hg.), Die Shoah im Bild, München (edition text+kritik) 2003, S. 87-116.

Köppen, Manuel, »Holocaust und Unterhaltung. Eine Diskussion mit: Edgar Hilsenrath, Michael Komar, Ursula Link-Heer, Egon Monk und Marcel Ophüls. Diskussionsleitung: Rüdiger Steinlein«, in: Köppen, Manuel (Hg.), Kunst und Literatur nach Auschwitz, Berlin (Erich Schmidt Verlag) 1993, S. 107-112.

Köppen, Manuel/Scherpe, Klaus R., »Zur Einführung: Der Streit um die Darstellbarkeit des Holocaust«, in: Köppen, Manuel/Scherpe, Klaus R., Bilder des Holocaust. Literatur - Film - Bildende Kunst, Köln/Weimar/Wien (Böhlau) 1997, S. 1-12.

Kramer, Sven, »Nacktheit in Holocaust-Fotos und -Filmen«, in: ders. (Hg.), Die Shoah im Bild, München (edition text+kritik) 2003, S. 225-248.

Kramer, Sven, Auschwitz im Widerstreit. Zur Darstellung der Shoah im Film, Philosophie und Literatur, Wiesbaden (Deutscher Universitätsverlag) 1999.

Krankenhagen, Stefan, Auschwitz darstellen. Ästhetische Positionen zwischen Adorno, Spielberg und Walser, Köln/Weimar/Wien (Böhlau) 2001. 
Leiser, Erwin, »Holocaust und Film«, in: Weigel, Sigrid/Erdle, Birgit, Fünfzig Jahre danach. Zur Nachgeschichte des Nationalsozialismus, Zürich (vdf Hochschulverlag) 1996, S. 91-115.

Lowy, Vincent, L'histoire infilmable. Les camps d'extermination nazis à l'écran, Paris (L'Harmattan) 2001, S. 38-56.

Matz, Reinhard, Die unsichtbaren Lager. Das Verschwinden der Vergangenheit im Gedenken, Reinbek bei Hamburg (Rowohlt) 1993.

Mitscherlich, Thomas, »>Diese Bilder sind unerträglich, doch ich lebe mit ihnen««, in: Dehnborstel, Karin (Hg.), Thomas Mitscherlich. Bilder - Medium des Erinnerns. Der Blick des Filmemachers Thomas Mitscherlich auf unsere Vergangenheit, Marburg (Schüren) 2001, S. 47-64.

Nagl, Tobias, »In den Todesmühlen«, in: Die Tageszeitung, 03.06.1999, S. II.

N.N., »Von deutscher Erinnerungskraft. Die Kollektivschuldthese in der Nachkriegszeit«, in: Neue Zürcher Zeitung, 12.07.1997, S. 61.

N.N., »Was bleibt, ist das Bild«, in: SonntagsZeitung, 01.04.2001, S. 59. (Kultur)

Paech, Joachim, »Ent/setzte Erinnerung«, in: Kramer, Sven (Hg.), Die Shoah im Bild, München (edition text+kritik) 2003, S. 13-30.

Paech, Anne/Paech, Joachim, »Trümmerkinos«, in: dies., Menschen im Kino. Film und Literatur erzählen, Stuttgart (Metzler) 2000, S. 162-172.

Patalas, Enno, »Stummer Dialog. Dagmar Barnouw liest amerikanische Deutschlandphotos von 1945«, in: Süddeutsche Zeitung, 13.09.1997, o.S.

Reichel, Peter, Vergangenheitsbewältigung in Deutschland. Die Auseinandersetzung mit der NS-Diktatur von 1945 bis heute, München (Beck) 2001, S. 205.

Reifahrth, Dieter/Schmidt-Linsenhoff, Viktoria, »Die Kamera der Täter«, in: Heer, Hannes/Naumann, Klaus (Hg.), Vernichtungskrieg. Verbrechen der Wehrmacht 19411944, Frankfurt a.M. (Zweitausendeins) 1995, S. 475-503.

Roß, Heiner (Hg.), Lernen Sie diskutieren! Re-education durch Film. Strategien der westlichen Alliierten nach 1945, Babelsberg (Cinegraph) 2005.

Schoenberner, Gerhard, Der gelbe Stern. Die Judenverfolgungen in Europa 1933 bis 1945, Hamburg (Rütten \& Loening Verlag) 1960.

Silbermann, Alphons/Stoffers, Manfred, Auschwitz: Nie davon gehört? Erinnern und Vergessen in Deutschland, Berlin (Rowohlt) 2000.

Valentin, Joachim, »Das Komische als Dekonstruktion des Schreckens. Philosophischtheologische Überlegungen zu DAS LEBEN IST SCHÖN von Roberto Benigni, in: Orth, Stefan/Valentin, Joachim/Zwick, Reinhold (Hg.), Göttliche Komödien. Religiöse Dimensionen des Komischen im Kino, Köln (KiM) 2001, S. 125-141.

Wagner, Gerald, »Trümmerregisseure«, in: Frankfurter Allgemeine Zeitung, 09.09.1999, S. BS6.

Welzer, Harald, »Die Bilder der Macht und die Ohnmacht der Bilder. Über Besetzung und Auslöschung von Erinnerung«, in: ders. (Hg.), Das Gedächtnis der Bilder. Ästhetik und Nationalsozialismus, Tübingen (edition diskord) 1995, S. 165-194.

Wende, Waltraud >Wara $<$, Medienbilder und Geschichte - Zur Medialisierung des Holocaust«, in: dies. (Hg.), Geschichte im Film. Mediale Inszenierungen des Holocaust und kulturelles Gedächtnis, Stuttgart/Weimar (Metzler) 2002, S. 8-29.

Young, James E., »Das Erinnern und die Rhetorik des Fotos - Reinhard Matz«, in: Matz, Reinhard, Die unsichtbaren Lager. Das Verschwinden der Vergangenheit im Gedenken, Reinbek bei Hamburg (Rowohlt) 1993; S. 15-19. 


\section{II.2 / II.2.1 »NACHT UND NEBEL« / II.2.2 »SHOAH«}

Ash, Timothy Garton, »La vie de la mort«, in: Cuau, Bernard (Hg.), Au sujet de SHOAH, Paris (Belin) 1990, S. 236-255.

Assmann, Aleida, Erinnerungsräume. Formen und Wandlungen des kulturellen Gedächtnisses, München (Beck'sche Verlagsbuchhandlung) 1999.

Assmann, Aleida, »Erinnerungsorte und Gedächtnislandschaften«, in: Loewy, Hanno/ Moltmann, Bernhard (Hg.), Erlebnis - Gedächtnis - Sinn. Authentische und konstruierte Erinnerung, Frankfurt a.M./New York (Campus) 1996, S. 13-29.

Avisar, Ilan, Screening the Holocaust. Cinema's image of the unimaginable, Bloomington (Indiana University Press) 1988.

Baer, Ulrich, »Zum Zeugen werden. Landschaftstradition und Shoah oder Die Grenzen der Geschichtsschreibung im Bild«, in: ders. (Hg.), >Niemand zeugt für den Zeugen<. Erinnerungskultur und historische Verantwortung nach der Shoah, Frankfurt a.M. (Suhrkamp) 2000, S. 236-254.

Bartov, Omer, »Spielberg's Oskar. Hollywood tries evil«, in: Loshitzky, Yosefa (Hg.), Spielberg's Holocaust. Critical Perspectives on SCHINDLER's LIST, Bloomington/Indianapolis (Indiana University Press) 1997, S. 41-60.

Boillat, André, La fiction au cinéma, Paris (L'Harmattan) 2001.

Borsdorf, Ulrich/Grütter, Heinrich Theodor (Hg.), Orte der Erinnerung. Denkmal, Gedenkstätte, Museum, Frankfurt a.M./New York (Campus) 1999.

Braese, Stephan, »Das deutsche Objektiv. Der Holocaust im Film und der deutsche Literaturbetrieb 1945-1956«, in: Kramer, Sven (Hg.), Die Shoah im Bild, München (edition text+kritik) 2003, S. 71-85.

Brun, Patrick, » Shoah ou la mise à l'épreuve de la poétique «, in: ders., Poétique(s) du cinéma, Paris (L'Harmattan) 2003, S. 191-207.

Brussig, Thomas, »DAS LEBEN IST SCHÖN. Eine Empfehlung, ins Kino zu gehen«, in: Frankfurter Allgemeine Zeitung, 31.12.1998, S. 45.

Cayrol, Jean, » De la mort à a la vie «, in: Cayrol, Jean, Nuit et brouillard, Paris (Libres Fayard) 1997, S. 45-113.

Chéroux, Clément, »Du bon usage des images«, in: ders. (Hg.), Mémoire des camps. Photographies des camps de concentration et d'extermination nazis (1933-1999), Paris (Marval) 2001, S. 11-21.

Chéroux, Clément, »>L'épiphanie négativeく. Production diffusion et réception des photographies de la libération des camps «, in: ders. (Hg.), Mémoire des camps. Photographies des camps de concentration et d'extermination nazis (1933-1999), Paris (Marval) 2001, S. 103-127.

Colombat, André, The Holocaust in French Film, Metuchen (Scarecrow) 1993, S. 299-343.

Cuau, Bernard (Hg.), Au sujet de SHоAн, Paris (Belin) 1990.

Cuau, Bernard, »Dans le cinéma une langue étrangère«, in: ders. (Hg.), Au sujet de SноАн, Paris (Belin) 1990, S. 13-19.

Darmstädter, Tim, »Die Verwandlung der Barbarei in Kultur. Zur Rekonstruktion der nationalsozialistischen Verbrechen im historischen Gedächtnis«, in: Werz, Michael (Hg.), Antisemitismus und Gesellschaft. Zur Diskussion um Auschwitz, Kulturindustrie und Gewalt, Frankfurt a.M. (Neue Kritik) 1995, S. 115-139.

Dayan-Rosenman, Anny, »ShoAн: L'écho du silence «, in: Cuau, Bernard (Hg.), Au sujet de Sноан, Paris (Belin) 1990, S. 188-197. 
Deguy, Michel, »Une œuvre après Auschwitz«, in: Cuau, Bernard (Hg.), Au sujet de SHOAH, Paris (Belin) 1990, S. 21-48.

de Beauvoir, Simone, »Das Gedächtnis des Grauens. Vorwort von Simone de Beauvoir«, in: Lanzmann, Claude, Shoah, Düsseldorf (claasen) 1986, S. 5-9.

de Fontenay, Elisabeth, »Un monumental et incandescent aide-mémoire«, in: Cuau, Bernard (Hg.), Au sujet de SноAн, Paris (Belin) 1990, S. 146-149.

Doneson, Judith E., The Holocaust in American Film, New York (Syracuse University Press) ${ }^{2} 2002$.

Dümling, Albrecht, »Musikalische Kontrapunkte zur filmischen Darstellung des Schreckens«, in: Köppen, Manuel (Hg.), Kunst und Literatur nach Auschwitz, Berlin (Erich Schmidt Verlag) 1993, S. 113-123.

Ertel, Rachel, » Le noir miracle«, in: Cuau, Bernard (Hg.), Au sujet de SHоAн, Paris (Belin) 1990, S. 49-55.

Felman, Shoshana, »Im Zeitalter der Zeugenschaft: Claude Lanzmanns SноAн«, in: Baer, Ulrich (Hg.), >Niemand zeugt für den Zeugen<. Erinnerungskultur und historische Verantwortung nach der Shoah, Frankfurt a.M. (Suhrkamp) 2000, S. 173-193.

Felman, Shoshana, »A l'âge du témoignage«, in: Cuau, Bernard (Hg.), Au sujet de SноAн, Paris (Belin) 1990, S. 55-145

Festenberg, Nikolaus von, »Fabeln hinterm Flammenkreis«, in: Der Spiegel, 29.03.1999, S. 238-239.

Gregor, Erika und Ulrich (Hg.), Jüdische Lebenswelten im Film, Berlin (Freunde der Deutschen Kinemathek) 1992.

Gantheret, Francois/Lanzmann, Claude, »Les non-lieux de la mémoire«, in: Cuau, Bernard (Hg.), Au sujet de Sнолн, Paris (Belin) 1990, S. 280-292.

Garbe, Detlef, »Gedenkstätten: Orte der Erinnerung und die zunehmende Distanz zum Nationalsozialismus«, in: Loewy, Hanno (Hg.), Holocaust: Die Grenzen des Verstehens. Eine Debatte über die Besetzung der Geschichte, Reinbek bei Hamburg (Rowohlt) 1992, S. 260-284.

Hölscher, Lucian, »Erinnern und Vergessen. Vom richtigen Umgang mit der nationalsozialistischen Vergangenheit«, in: Borsdorf, Ulrich/Grütter, Heinrich Theodor (Hg.), Orte der Erinnerung. Denkmal, Gedenkstätte, Museum, Frankfurt a.M./New York (Campus) 1999, S. 111-127.

Huppert, Elisabeth, »Voir (Sнонн)«, in: Cuau, Bernard (Hg.), Au sujet de SHоAн, Paris (Belin) 1990, S. 150-156.

Hanika, Iris, »Film«, in: Frankfurter Allgemeine Zeitung, 19.01.2002, S. BS 6 (Berliner Seiten).

Hattendorf, Manfred, Dokumentarfilm und Authentizität, Konstanz (Olschläger) 1994 .

Heller, Heinz B., »Traumatische Vergangenheit - filmisches Präsens. Zur Vergegenwärtigung der Shoah im Film«, in: Bauer, Barbara/Strickhausen, Waltraud (Hg.), $>$ Für ein Kind war das anders<. Traumatische Erfahrungen jüdischer Kinder und Jugendlicher im nationalsozialistischen Deutschland, Berlin (Metropol) 1999, o.S.

Heller, Heinz B., »Vergangenheit im filmischen Präsens. Anmerkungen zum Verhältnis von Dokumentarfilm und Geschichte«, in: Hickethier, Knut/Müller, Eggo/Rother, Rainer (Hg.), Der Film in der Geschichte. Dokumentation der GFF-Tagung, Berlin (Ed. Sigma) 1997, S. 220-227. 
Hoffmann, Detlef, »Auschwitz im visuellen Gedächtnis«, in: Fritz-Bauer-Institut (Hg.), Auschwitz: Geschichte, Rezeption und Wirkung. Jahrbuch 1996 zur Geschichte und Wirkung des Holocaust, Frankfurt a.M./New York (Campus) 1996, S. 223-257.

Insdorf, Annette, Indelible shadows. Film and the Holocaust, Cambridge (Cambridge University Press) ${ }^{3} 2003$.

Jacobson, Wolfgang (Hg.), Alain Resnais, München (Hanser) 1990.

Jochimsen, Jess, »>Nur was nicht aufhört, weh zu thun, bleibt im Gedächtnis<. Die Shoah im Dokumentarfilm«, in: Berg, Nicolas/Jochimsen, Jess/Stiegler, Bernd (Hg.), Shoah - Formen der Erinnerung. Geschichte, Philosophie, Literatur, Kunst, München (Fink) 1996, S. 215-231.

Jutz, Gabriele, Geschichte im Kino. Eine Semio-Historie des französischen Films: Rohmer, Resnais, Godard, Allio, Münster (Nodus) 1991.

Kilb, Andreas, »Auf diesen Felsen baue ich meinen Film«, in: Frankfurter Allgemeine Zeitung, 31.05.2002, S. 51. (Feuilleton)

Kilb, Andreas, »Des Teufels Saboteur«, in: Weiß, Christoph (Hg.), >Der gute Deutsche<.

Dokumente zur Diskussion um Steven Spielbergs SCHINDLERS LISTE in Deutschland,

St. Ingbert (Röhrig Universitätsverlag) 1995, S. 147-157.

Klüger, Ruth, Weiter leben. Eine Jugend, München (dtv) 1995.

Knoch, Habbo, »Die Tat als Ort der Erinnerung: Alain Resnais' Film NAcht Und NeBEL«, in: ders., Die Tat als Bild. Fotografien des Holocaust in der deutschen Erinnerungskultur, Hamburg (Hamburger Edition) 2001, S. 518-528.

Koch, Gertrud, »Transformations esthétiques dans la représentation de l'inimaginable«, in: Cuau, Bernard (Hg.), Au sujet de Sнолн, Paris (Belin) 1990, S. 157-166.

Koch, Gertrud, »Die ästhetische Transformation der Vorstellung vom Unvorstellbaren. Claude Lanzmanns Film Sнонн«, in: dies., Die Einstellung ist die Einstellung. Visuelle Konstruktionen des Judentums, Frankfurt a.M. (Suhrkamp) 1992, S. 143-184.

Korte, Helmut, »3. Hollywoodästhetik und die deutsche Geschichte: Schindiers LISTE (Spielberg 1993)«, in: ders., Einführung in die systematische Filmanalyse, Berlin (Erich Schmidt) 1999, S. 147-194.

Köppen, Manuel, »Holocaust im Fernsehen - Die Konkurrenz der Medien um die Erinnerung«, in: Wende, Waltraud >Wara< (Hg.), Geschichte im Film. Mediale Inszenierungen des Holocaust und kulturelles Gedächtnis, Stuttgart/Weimar (Metzler) 2002, S. 307-327.

Köppen, Manuel/Scherpe, Klaus R., »Zur Einführung: Der Streit um die Darstellbarkeit des Holocaust«, in: Köppen, Manuel/Scherpe, Klaus R., Bilder des Holocaust. Literatur - Film - Bildende Kunst, Köln/Weimar/Wien (Böhlau) 1997, S. 1-12.

Köppen, Manuel, »Von Effekten des Authentischen - Schindlers Liste: Film und Holocaust«, in: Köppen, Manuel/Scherpe, Klaus R., Bilder des Holocaust. Literatur - Film - Bildende Kunst, Köln/Weimar/Wien (Böhlau) 1997, S. 145-170.

Kramer, Sven, Auschwitz im Widerstreit. Zur Darstellung der Shoah im Film, Philosophie und Literatur, Wiesbaden (Deutscher Universitätsverlag) 1999.

Krankenhagen, Stefan, Auschwitz darstellen. Ästhetische Positionen zwischen Adorno, Spielberg und Walser, Köln/Weimar/Wien (Böhlau) 2001.

Lange, Sigrid, »Zeugnisse und Zeugen. Der Holocaust in Film und Literatur«, in: dies., Authentisches Medium. Faschismus und Holocaust in ästhetischen Darstellungen der Gegenwart, Bielefeld (Aisthesis Verlag) 1999, S. 133-141.

Lange, Sigrid, »Dokumentation als Filmepos: Claude Lanzmann. SноAн«, in: dies., 
Authentisches Medium. Faschismus und Holocaust in ästhetischen Darstellungen der Gegenwart, Bielefeld (Aisthesis Verlag) 1999, S. 142-148.

Lanzmann, Claude, »Ihr sollt nicht weinen. Einspruch gegen SCHIN DLERs LISTE«, in: Frankfurter Allgemeine Zeitung, 05.03.1994, S. 27.

Lanzmann, Claude, »J'ai enquêté en Pologne«, in: Cuau, Bernard (Hg.), Au sujet de SноAн, Paris (Belin) 1990, S. 211-217.

Lanzmann, Claude in: Kulturamt der Stadt Marburg (Hg.), Formen von Erinnerung. Eine Diskussion mit Claude Lanzmann. Ein anderer Blick auf Gedenken, Erinnern und Erleben. Eine Tagung, Marburg (Jonas Verlag) 1998, S. 11-32.

Lanzmann, Claude, »Les non-lieux de la mémoire«, in: Cuau, Bernard (Hg.), Au sujet de Sнонн, Paris (Belin) 1990, S. 280-292.

Lanzmann, Claude, »Le lieu et la parole«, in: Cuau, Bernard (Hg.), Au sujet de SноAн, Paris (Belin) 1990, S. 293-305.

Lanzmann, Claude, »De l' Holocauste à Holocauste ou comment s'en débarrasser «, in: Cuau, Bernard (Hg.), Au sujet de SноAн, Paris (Belin) 1990, S. 306-316.

Lanzmann, Claude, Shoah, Düsseldorf (claasen) 1986.

Leiser, Erwin, »Holocaust und Film«, in: Weigel, Sigrid/Erdle, Birgit, Fünfzig Jahre danach. Zur Nachgeschichte des Nationalsozialismus, Zürich (vdf Hochschulverlag) 1996, S. 91-115.

Loshitzky, Yosefa, »Holocaust others. Spielberg's Schin d LE R's List versus Lanzmann's SHоAн«, in: dies. (Hg.), Spielberg's Holocaust. Critical Perspectives on SCHINDLER'S LIST, Bloomington/Indianapolis (Indiana University Press) 1997, S. 104-118.

Lowy, Vincent, L'histoire infilmable. Les camps d'extermination nazis à l'écran, Paris (L'Harmattan) 2001.

Magel, Eva-Maria, »Pünktlichkeit als Höflichkeit der Mörder«, in: Frankfurter Allgemeine Zeitung, 15.01.2002, S. 43 (Feuilleton).

Marek, Michael/Schmitz, Matthias, »>Survivors of the Shoahく. Wie zeigt man, dass Auschwitz stattgefunden hat«, in: Tribüne. Zeitschrift zum Verständnis des Judentums, Heft 158, 40. Jahrgang, 2001, S. 145-156.

Mergner, Gottfried, »Vorwort«, in: Müller, Hans-Jürgen, SноАн - ein Film. Erinnerungsarbeit in der Erwachsenenbildung mit dem Mittel der Kunst, Oldenburg (Bibliotheksund Informationssystem der Universität Oldenburg) 1991, I-XII.

Müller, Filip, Sonderbehandlung: Drei Jahre in den Krematorien und Gaskammern von Auschwitz, München (Steinhausen) 1979.

Müller, Hans-Jürgen, SноАн - ein Film. Erinnerungsarbeit in der Erwachsenenbildung mit dem Mittel der Kunst, Oldenburg (Bibliotheks- und Informationssystem der Universität Oldenburg) 1991.

Naïr, Sami, » $\mathrm{S}$ нолн, une leçon d'humanité », in: Cuau, Bernard (Hg.), Au sujet de SноАн, Paris (Belin) 1990, S. 167-174.

Nicodemus, Katja, » Ich will den Heroismus zeigen««, in: Die Tageszeitung, 17.05.2001, S. 4. Niroumand, Miriam, »Vorhang, Licht, Person«, in: Die Tageszeitung, 15.01.1997, S. 13. Noack, Johannes-Michael, SCHINDLERS LISTE - Authentizität und Fiktion in Spielbergs Film. Eine Analyse, Leipzig (Leipziger Universitätsverlag) 1998.

Ophuls, Marcel, »Les trains«, in: Cuau, Bernard (Hg.), Au sujet de Sнолн, Paris (Belin) 1990, S. $175-187$.

Paech, Joachim, »Ent/setzte Erinnerung«, in: Kramer, Sven (Hg.), Die Shoah im Bild, München (edition text+kritik) 2003, S. 13-30. 
Paech, Joachim, »Erinnerungs-Landschaften«, in: Köppen, Manuel, Kunst und Literatur nach Auschwitz, Berlin (Erich Schmidt Verlag) 1993, S. 124-136.

Pateau, Michel, »Préface«, in: Cayrol, Jean, NUit ET BROUILLARD, Paris (Libres Fayard) 1997, S. 45-113.

Raskin, Richard, NUIT ET BROUILLARd by Alain Resnais, Aarhus University (Aarhus University Press) 1987.

Resnais, Alain, »Les photos jaunies ne m’émeuvent pas«, in: Cahiers du cinéma, Hors série 11/2000, S. 70-75.

Reichel, Peter, »Shoah: Zu sagen, was unsagbar ist«, in: ders., Erfundene Erinnerung. Weltkrieg und Judenmord in Film und Theater, München/Wien (Carl Hanser Verlag) 2004, S. 286-300.

Reinecke, Stefan, »>Die Pflicht zu töten<. Revolte im Vernichtungslager: Claude Lanzmann über Helden, Hitchcock, die Historisierung des Holocaust - und seinen neuen Film Sовгвов«, in: Die Tageszeitung, 15.02.2002, S. 25.

Rousso, Henri, »L'écran des années noires«, in: ders., Le syndrome de Vichy, Paris (Seuil) 1987, S. 241-254.

Schneider, Silke, »Vorwort«, in: Kulturamt der Stadt Marburg (Hg.), Formen von Erinnerung. Eine Diskussion mit Claude Lanzmann. Ein anderer Blick auf Gedenken, Erinnern und Erleben. Eine Tagung, Marburg (Jonas Verlag) 1998, S. 7-9.

Schoenberner, Gerhard, Der gelbe Stern. Die Judenverfolgungen in Europa 1933 bis 1945, Hamburg (Rütten \& Loening Verlag) 1960.

Schörken, Rolf, »I. Das Prinzip Vergegenwärtigung«, in: ders., Begegnungen mit Geschichte: vom außerwissenschaftlichen Umgang mit der Historie in Literatur und Medien, Stuttgart (Klett-Cotta) 1995, S. 11-14.

Schröder, Nicolaus, Sнонн, in: ders., 50 Klassiker - Film. Die wichtigsten Werke der Filmgeschichte dargestellt von Nicolaus Schröder, Hildesheim (Gerstenberg Verlag) 2000, S. 270-275.

Thiele, Martina, Publizistische Kontroversen über den Holocaust im Film, Münster (LIT) 2001.

Todorov, Tzvetan, Angesichts des Äußersten, München (Fink) 1993, S. 294-302.

Torner, Carles, Sнонн. Une pédagogie de la mémoire, Paris (Les éditions de l'atelier) 2001.

Truffaut, François, »NuIT ET BRouillard« (1955), in: Fischer, Robert (Hg.), François Truffaut. Die Filme meines Lebens, Frankfurt a.M. (Verlag der Autoren) 1997, S. $407 f$.

Valentin, Joachim, »Das Komische als Dekonstruktion des Schreckens. Philosophischtheologische Überlegungen zu DAS LeBen ist schön von Roberto Benigni, in: Orth, Stefan/Valentin, Joachim/Zwick, Reinhold (Hg.), Göttliche Komödien. Religiöse Dimensionen des Komischen im Kino, Köln (KiM) 2001, S. 125-141.

Van der Knaap, Ewout, »Monument des Gedächtnisses - Der Beitrag von NACHT UnD NeBEL zum Holocaust-Diskurs«, in: Wende, Waltraud >Wara< (Hg.), Geschichte im Film. Mediale Inszenierungen des Holocaust und kulturelles Gedächtnis, Stuttgart/Weimar (Metzler) 2002, S. 67-77.

Vidal-Naquet, Pierre, »L'épreuve de l'historien: Réflexions d'un généraliste«, in: Cuau, Bernard (Hg.), Au sujet de SноAн, Paris (Belin) 1990, S. 198-208.

Žižek, Slavoj, »Du sollst dir Bilder machen! Der Holocaust zwischen Schweigen und Lachen«, in: Süddeutsche Zeitung, 31.08.2000, S. 15. 


\section{II.3 / II.3.1 »AUF WIEDERSEHEN KINDER« / II.3.2 »SCHINDLERS LISTE«}

Ader, Wolfgang, »Nachwort«, in: ders., Louis Malle. Au REVOIR, LES ENFANTS. Scénario, Stuttgart (Reclam) 1993, S. 128-140.

Baier, Lothar, »Wir, die Judenretter. Über den neuen >volkseigenen Film< der Deutschen« (1994), in: Weiß, Christoph (Hg.), >Der gute Deutscher. Dokumente zur Diskussion um Steven Spielbergs SCHINDLERS LISTE in Deutschland, St. Ingbert (Röhrig Universitätsverlag) 1995, S. 230-237.

Bartov, Omer, »Spielberg's Oskar. Hollywood tries evil«, in: Loshitzky, Yosefa (Hg.), Spielberg's Holocaust. Critical Perspectives on SCHINDLER's LIST, Bloomington/Indianapolis (Indiana University Press) 1997, S. 41-60.

Baruch, Marc Olivier, Das Vichy-Regime. Frankreich 1940-1944, Stuttgart (Reclam) 1999.

Baudelaire, »Die Fotografie und das moderne Publikum« (1859), in: Helmes, Günter/ Köster, Werner (Hg.), Texte zur Medientheorie, Stuttgart (Reclam) 2002, S. 109-114.

Berg-Ganschow, Ute, »Das Problem der Authentizität im Dokumentarfilm«, in: Heller, Heinz B./Zimmermann, Peter (Hg.), Bilderwelten. Weltbilder. Dokumentarfilm und Fernsehen, Marburg 1990, S. 85-88.

Broder, Henryk M., »Kritik der dummen Kerls« (1994), in: Weiß, Christoph (Hg.), >Der gute Deutscher. Dokumente zur Diskussion um Steven Spielbergs SCHINDLERS LISTE in Deutschland, St. Ingbert (Röhrig Universitätsverlag) 1995, S. 183-188.

Broder, Henryk M., »Deutsch wie ein Lodenmantel«, in: Weiß, Christoph (Hg.), >Der gute Deutscher. Dokumente zur Diskussion um Steven Spielbergs SCHINDLERS Liste in Deutschland, St. Ingbert (Röhrig Universitätsverlag) 1995, S. 238-241.

Brussig, Thomas, »DAS LEBEN IST SCHÖN. Eine Empfehlung, ins Kino zu gehen«, in: Frankfurter Allgemeine Zeitung, 31.12.1998, S. 45.

Colombat, André, »8.a. Louis Malle's Lacombe Lucien and Goodbye Children «, in ders.: The Holocaust in French Film, Metuchen (Scarecrow) 1993, S. 261-287.

Ebert, Roger, »AU REVOIR LES ENFANTS«, auf: http://suntimes.com/ebert/ebert_reviews/1988/03/ 284661. html, S. 1-2, (letzter Zugriff: 14.02.2003).

Edvardson, Cordelia, »Der Film verletzt mich«, in: Weiß, Christoph (Hg.), >Der gute Deutscher. Dokumente zur Diskussion um Steven Spielbergs SCHINDLERS LISTE in Deutschland, St. Ingbert (Röhrig Universitätsverlag) 1995, S. 266-270.

Festenberg, Nikolaus von, »Fabeln hinterm Flammenkreis«, in: Der Spiegel, 29.03.1999, S. 238-239.

French, Philip (Hg.), Louis Malle über Louis Malle, Berlin (Alexander Verlag) 1998.

Frodon, Jean Michel, L'âge moderne du cinéma français. De la Nouvelle Vague à nos jours, Paris (Flammarion) 1995.

Giordano, Ralph, »Szenen, wie es sie nie zuvor auf der Leinwand gab«, in: Weiß, Christoph (Hg.), >Der gute Deutsche<. Dokumente zur Diskussion um Steven Spielbergs SCHINDLERS LISTE in Deutschland, St. Ingbert (Röhrig Universitätsverlag) 1995, S. $171-173$.

Göckenjan, Gunter, »Noch immer kein Mitleid« (1994), in: Weiß, Christoph (Hg.), $>$ Der gute Deutscher. Dokumente zur Diskussion um Steven Spielbergs SCHINDLERS LISTE in Deutschland, St. Ingbert (Röhrig Universitätsverlag) 1995, S. 199-201.

Günther, Egon, »Spielbergs Juden«, in: Weiß, Christoph (Hg.), >Der gute Deutsche . Dokumente zur Diskussion um Steven Spielbergs SCHINDLERS LISTE in Deutschland, St. Ingbert (Röhrig Universitätsverlag) 1995, S. 192-196. 
Hamacher, Alaric, »Das Märchen vom Spielberg und den sieben Oscars«, in: Weiß, Christoph (Hg.), > Der gute Deutscher. Dokumente zur Diskussion um Steven Spielbergs SCHINDLERS LISTE in Deutschland, St. Ingbert (Röhrig Universitätsverlag) 1995, S. 270-283.

Hansen, Myriam Bratu, »Schindler's List is not ShoAh. Second Commandment, Popular Modernism, and Public Memory«, in: Zelizer, Barbie (Hg.), Visual Culture and the Holocaust, London (Rutgers, The State University) 2001, S. 127-151.

Harms, Ingeborg, »SCHindleRs Liste: eine Parabel des kollektiven Narzismus«, in: Berghahn, Klaus L./Fohrmann, Jürgen/Schneider, Helmut J. (Hg.), Kulturelle Repräsentationen des Holocaust in Deutschland und den Vereinigten Staaten, New York [u.a.| 2002, S. 59-68.

Hattendorf, Manfred, Dokumentarfilm und Authentizität, Konstanz (Olschläger) 1994. Hartman, Geoffrey H., »The Cinema Animal«, in: Loshitzky, Yosefa (Hg.), Spielberg’s Holocaust. Critical Perspectives on SCHINDLER's LIST, Bloomington/Indianapolis (Indiana University Press) 1997, S. 61-76.

Hartmann, Claus Peter, »2. Das Vichy-Regime von Pétain und Laval«, in: ders., Geschichte Frankreichs, München (Beck) 1999, S. 90-92.

Holcman, Robert, »La Shoah dans le domaine public?, in: Le Monde, 31.10.1998, o.S.

Horowitz, Sara R., »But is it good for the Jews? Spielberg's Schindler and the aesthetics of atrocity«, in: Loshitzky, Yosefa (Hg.), Spielberg's Holocaust. Critical Perspectives on SCHINDLER'S LIST, Bloomington/Indianapolis (Indiana University Press) 1997, S. 119-139.

Insdorf, Annette, Indelible Shadows. Film and the Holocaust, Cambridge (Cambridge University Press) ${ }^{3} 2003$.

Jansen, Peter W./Maerker, Christa, »Das verbotene Ich des Bürgers: Louis Malle«, in: Kogel, Jörg-Dieter (Hg.), Europäische Filmkunst. Regisseure im Porträt, Frankfurt a.M. (Fischer Taschenbuch) 1990, S. 93-104.

Karasek, Hellmuth, Mein Kino. Die 100 schönsten Filme, München (dtv) 1995.

Keneally, Thomas, SCHindLERS LISTE, München (Goldmann) ${ }^{2} 1994$.

Kilb, Andreas, »Des Teufels Saboteur«, in: Weiß, Christoph (Hg.), >Der gute Deutsche<. Dokumente zur Diskussion um Steven Spielbergs SCHINDLERS LISTE in Deutschland, St. Ingbert (Röhrig Universitätsverlag) 1995, S. 147-157.

Knoch, Habbo, »Die Grenzen des Zeigbaren. Fotografien der NS-Verbrechen und die westdeutsche Gesellschaft«, in: Kramer, Sven (Hg.), Die Shoah im Bild, München (edition text+kritik) 2003, S. 87-116.

Koar, Jürgen, »Grauen in schlichtem Schwarzweiß. Steven Spielbergs Film SchindLERS LISTE beschwört dokumentarisch die Wirklichkeit des Holocaust « (1993), in: Weiß, Christoph (Hg.), >Der gute Deutscher. Dokumente zur Diskussion um Steven Spielbergs SCHINDLERS LISTE in Deutschland, St. Ingbert (Röhrig Universitätsverlag) 1995, S. 23-26.

Köhler, Anja, Vichy und die Intellektuellen. Die sannées noires im Spiegel autobiographischer Texte, Tübingen (Narr) 2001.

Korte, Helmut, "3. Hollywoodästhetik und die deutsche Geschichte: Schindle Rs Liste (Spielberg 1993)《, in: ders., Einführung in die systematische Filmanalyse, Berlin (Erich Schmidt) 1999, S. 147-194.

Köppen, Manuel/Scherpe, Klaus R., »Zur Einführung: Der Streit um die Darstellbarkeit des Holocaust«, in: Köppen, Manuel/Scherpe, Klaus R., Bilder des Holocaust. Literatur - Film - Bildende Kunst, Köln/Weimar/Wien (Böhlau) 1997, S. 1-12. 
Köppen, Manuel, »Von Effekten des Authentischen - Schindlers Liste: Film und Holocaust«, in: Köppen, Manuel/Scherpe, Klaus R., Bilder des Holocaust. Literatur - Film - Bildende Kunst, Köln/Weimar/Wien (Böhlau) 1997, S. 145-170.

Kramer, Sven, »Nacktheit in Holocaust-Fotos und -Filmen«, in: ders. (Hg.), Die Shoah im Bild, München (edition Text+kritik) 2003, S. 225-248.

Kramer, Sven, Auschwitz im Widerstreit. Zur Darstellung der Shoah im Film, Philosophie und Literatur, Wiesbaden (Deutscher Universitätsverlag) 1999.

Lange, Sigrid, »Dokudrama: Steven Spielbergs Schind de RS LisTE«, in: dies., Authentisches Medium. Faschismus und Holocaust in ästhetischen Darstellungen der Gegenwart, Bielefeld (Aisthesis Verlag) 1999, S. 148-158.

Loewy, Hanno, »Fiktion und Mimesis. Holocaust und Genre im Film«, in: Fröhlich, Margit/Loewy, Hanno/Steinert, Heinz (Hg.), Lachen über Hitler - Auschwitz-Gelächter? Filmkomödie, Satire und Holocaust, (edition text + kritik) 2003, S. 36-64.

Loewy, Hanno, »Der Spieler« (1994), in: Weiß, Christoph (Hg.), >Der gute Deutsche<. Dokumente zur Diskussion um Steven Spielbergs SCHINDLERS LISTE in Deutschland, St. Ingbert (Röhrig Universitätsverlag) 1995, S. 208-214.

Loshitzky, Yosefa, »Introduction«, in: dies. (Hg.), Spielberg's Holocaust. Critical Perspectives on SCHINDLER's LIST, Bloomington/Indianapolis (Indiana University Press) 1997, S. 1-17.

Loshitzky, Yosefa, »Holocaust others. Spielberg's Schin D LER's List versus Lanzmann's Sноан«, in: dies. (Hg.), Spielberg's Holocaust. Critical Perspectives on SCHINDLER's LIST, Bloomington/Indianapolis (Indiana University Press) 1997, S. 104-118.

Loth, Wilfried, »8. Das Regime von Vichy und die Résistance«, in: ders., Geschichte Frankreichs im 20. Jahrhundert, Frankfurt a.M. (Fischer) 1992, S. 115-129.

Lowy, Vincent, L'histoire infilmable. Les camps d'extermination nazis à l'écran, Paris (L'Harmattan) 2001.

Löffler, Sigrid, »Kino als Ablaß. Spielbergs mißlungener Holocaust-Film« (1994), in: Weiß, Christoph (Hg.), >Der gute Deutsche<. Dokumente zur Diskussion um Steven Spielbergs SCHINDLERS LISTE in Deutschland, St. Ingbert (Röhrig Universitätsverlag) 1995, S. 57-60.

Malle, Louis, in: Positif, 10/1987, zit.n.: http://nef-louismalle.com/aurevoir.htm (letzter Zugriff: 24.12.2003).

Martens, Stefan, »Der Zweite Weltkrieg: Vichy-Regime und Résistance (1940-1944)«, in: Hinrichs, Ernst (Hg.), Kleine Geschichte Frankreichs, Stuttgart (Reclam) 2000, S. $403-410$.

Martenstein, Harald, »Zehn Oscars«, in: Weiß, Christoph (Hg.), >Der gute Deutsche<. Dokumente zur Diskussion um Steven Spielbergs SCHINDLERS LISTE in Deutschland, St. Ingbert (Röhrig Universitätsverlag) 1995, S. 196-198.

Moos, Tilo/Frank, Klaus (Hg.), Au REVOIR LES ENFANTS. Un film de Louis Malle (1987). Texte intégral du scénario avec annotations de vocabulaire, questions et documentation, Stuttgart (Landesinstitut für Erziehung und Unterricht Stuttgart) 1992.

Müller-Lobeck, Christiane, »Recht auf Ausdruck«, in: Die Tageszeitung, 29.01.2000, S. 27.

Noack, Johannes-Michael, SCHindLeRs LISTE - Authentizität und Fiktion in Spielbergs Film. Eine Analyse, Leipzig (Leipziger Universitätsverlag) 1998.

Oehlenschläger, Eckhart, »Steven Spielbergs Film Schindens Liste; >Based on the novel by Thomas Keneally«, in: Berghahn, Klaus L./Fohrmann, Jürgen/Schneider, 
Helmut J. (Hg.), Kulturelle Repräsentationen des Holocaust in Deutschland und den Vereinigten Staaten, New York [u.a.] 2002, S. 97-109.

Philippe, Pierre, Louis Malle, un cinéaste français, Arte France, BBC, Zeta Productions 2002 (Fernseh-Dokumentation).

Prédal, René, Louis Malle, Paris (Edilig) 1989.

Reich-Ranicki, Marcel, »Polanskis Todesfuge. Was ich nicht zu hoffen wagte, ist hier gelungen - DER PIANIST ist eine meisterhafte Wiedergabe unseres Alltags im Warschauer Ghetto«, in: Frankfurter Allgemeine Zeitung, 23.10.2002, S. 35 (Feuilleton).

Rother, Rainer, »Die Hölle als Inszenierung« (1994), in: Weiß, Christoph (Hg.), >Der gute Deutscher. Dokumente zur Diskussion um Steven Spielbergs SCHINDLERS Liste in Deutschland, St. Ingbert (Röhrig Universitätsverlag) 1995, S. 106-108.

Rousso, Henri, »L'écran des années noires«, in: ders., Le syndrome de Vichy, Paris (Seuil) 1987, S. 241-254.

Schirrmacher, Frank, »Schindelers Liste« (1994), in: Weiß, Christoph (Hg.), >Der gute Deutscher. Dokumente zur Diskussion um Steven Spielbergs SCHINDLERS LISTE in Deutschland, St. Ingbert (Röhrig Universitätsverlag) 1995, S. 103-106.

Schlüter, Bettina, »Erzählstrategische Funktionen der Filmmusik in Schindlers ListE«, in: Berghahn, Klaus L./Fohrmann, Jürgen/Schneider, Helmut J. (Hg.), Kulturelle Repräsentationen des Holocaust in Deutschland und den Vereinigten Staaten, New York/Washington D.C./Baltimore/Bern/Frankfurt a.M./Berlin/Brussels/ Vienna/Oxford (Lan) 2002, S. 83-96.

Schneider, Helmut J., »Den Toten ein Gesicht geben? Zum Problem der ästhetischen Individualisierung in SCHINDLERS Liste und der Holocaust-Serie«, in: Berghahn, Klaus L./Fohrmann, Jürgen/Schneider, Helmut J. (Hg.), Kulturelle Repräsentationen des Holocaust in Deutschland und den Vereinigten Staaten, New York/Washington D.C./Baltimore/Bern/Frankfurt a.M./Berlin/Brussels/Vienna/Oxford (Lan) 2002, S. 69-82.

Schörken, Rolf, »I. Das Prinzip Vergegenwärtigung«, in: ders., Begegnungen mit Geschichte: vom außerwissenschaftlichen Umgang mit der Historie in Literatur und Medien, Stuttgart (Klett-Cotta) 1995, S. 11-14.

Schulz, Georg-Michael, »Docu-Dramas - oder: Die Sehnsucht nach der >Authentizität<. Rückblicke auf Holocaust von Marvin Chomsky und Schindle RS Liste von Steven Spielberg«, in: Wende, Waltraud >Wara< (Hg.), Geschichte im Film. Mediale Inszenierungen des Holocaust und kulturelles Gedächtnis, Stuttgart/Weimar (Metzler) 2002, S. 159-179.

Schulz-Ojala, Jan, »Herausforderung an die Phantasie«, in: Weiß, Christoph (Hg.), $>$ Der gute Deutscher. Dokumente zur Diskussion um Steven Spielbergs SCHINDLERS LISTE in Deutschland, St. Ingbert (Röhrig Universitätsverlag) 1995, S. 221-224.

Schultz, Tanjev, »Sensibel und unmoralisch. Die Geschichte des Juden-Retters Oskar Schindler«, in: Süddeutsche Zeitung, 2006/Nr. 24, S. 15 .

Seeßlen, Georg, »Shoah, oder die Erzählung des Nichterzählbaren«, in: Weiß, Christoph (Hg.), >Der gute Deutsche<. Dokumente zur Diskussion um Steven Spielbergs SCHINDLERS LISTE in Deutschland, St. Ingbert (Röhrig Universitätsverlag) 1995, S. 158-167.

Sontag, Susan, Über Fotografie, München/Wien (Hanser) ${ }^{2} 1978$.

Thiele, Martina, Publizistische Kontroversen über den Holocaust im Film, Münster (LIT) 2001. 
Valentin, Joachim, »Das Komische als Dekonstruktion des Schreckens. Philosophischtheologische Überlegungen zu Das LeBEN IST SCHÖN von Roberto Benigni, in: Orth, Stefan/Valentin, Joachim/Zwick, Reinhold (Hg.), Göttliche Komödien. Religiöse Dimensionen des Komischen im Kino, Köln (KiM) 2001, S. 125-141.

Visser, Anthonya, »>Du sollst dir (k)ein Bildnis machen<: Zur Überlieferung von überlieferter Geschichte in Art Spiegelmans Maus, Roberto Benignis LA VITA È BELLA und Doron Rabinovics Die Suche nach M.«, in: Wende, Waltraud >Wara< (Hg.), Geschichte im Film. Mediale Inszenierungen des Holocaust und kulturelles Gedächtnis, Stuttgart/Weimar (Metzler) 2002, S. 200-213.

Wende, Waltraud >Wara<, »Medienbilder und Geschichte - Zur Medialisierung des Holocaust«, in: dies. (Hg.), Geschichte im Film. Mediale Inszenierungen des Holocaust und kulturelles Gedächtnis, Stuttgart/Weimar (Metzler) 2002, S. 8-29.

Weiß, Matthias, »Sinnliche Erinnerung. Die Filme Holocaust und Schindle Rs Liste in der bundesdeutschen Vergegenwärtigung der NS-Zeit«, in: Frei, Norbert/Steinbacher, Sybille, Beschweigen und Bekennen. Die deutsche Nachkriegsgesellschaft und der Holocaust, Göttingen (Wallstein Verlag) 2001, S. 71-102.

Weiß, Christoph (Hg.), >Der gute Deutscher. Dokumente zur Diskussion um Steven Spielbergs SCHINDLERS LISTE in Deutschland, St. Ingbert (Röhrig Universitätsverlag) 1995.

Weiß, Christoph, »Nachwort (zu einem >Abschlußbericht<)《, in: ders. (Hg.), >Der gute Deutscher. Dokumente zur Diskussion um Steven Spielbergs SCHINDLERS LISTE in Deutschland, St. Ingbert (Röhrig Universitätsverlag) 1995, S. 291-306.

Wilder, Billy, »Man sah überall nur Taschentücher« (1994), in: Weiß, Christoph (Hg.), $>$ Der gute Deutscher. Dokumente zur Diskussion um Steven Spielbergs SCHINDLERS LISTE in Deutschland, St. Ingbert (Röhrig Universitätsverlag) 1995, S. 42-44.

Zelizer, Barbie, »Every once in a while. SchindLER's List and the shaping of history«, in: Loshitzky, Yosefa (Hg.), Spielberg's Holocaust. Critical Perspectives on SCHINDLER's LIST, Bloomington/Indianapolis (Indiana University Press) 1997, S. 18-35.

\section{II.4 / II.4.1 »DAS LEBEN IST SCHÖN« / II.4.2 »ZUG DES LEBENS«}

Adams auf: www.citypaper.net/movies/I/lifeisbeautiful.shtml (letzter Zugriff: 25.10.1998).

Adorján, Johanna, »Dem Himmler so nah«, in: Frankfurter Allgemeine Zeitung, 17.11.2002, S. 33 .

AH, »TRAIN DE VIE«, auf: www.tu-darmstadt.de/hg/sfk/programm/ws99/991102. html, S. 1-3, (letzter Zugriff: 14.08.2003).

Amstutz, Bruno, »Train DE viE. Ein lachendes und ein weinendes Auge «, auf: www. cineman.ch/movie/ 1999/TrainDeVie/, S. 1-2, (letzter Zugriff: 14.08.2003).

Becker, Jurek, Jakob der Lügner, Frankfurt a.M. (Suhrkamp) 1982.

Beier, Lars-Olav, »Bis zur letzten Seite«, in: Frankfurter Allgemeine Zeitung, 23.03.2000, S. 60.

Benigni, Roberto/Cerami, Vincenzo, DAS LEBEN IST SCHÖN, Frankfurt a.M. (Suhrkamp) 1998.

Benigni auf: www.arte.fr/benigni.html (letzter Zugriff: 25.10.1998).

Benigni auf: www.lavieestbelle.com/entretien.html (letzter Zugriff: 25.10.1998).

Benigni auf: www.lefigaro.fr./campus/interviewN1.htm (letzter Zugriff: 25.10.1998). 
Berger, Senta, »Zug Des LeBens«, in: Arte Magazin, 1/2006, o.S.

Bermejo, Alberto, »Benigni, und bufón ambicioso«, in: El Mundo, 18.10.2002, S. 55.

Bleicher, Joan Kristin, »Zwischen Horror und Komödie. DAs LeBEN IST SCHöN von Roberto Benigni und Zug Des LeBens von Radu Mihaileanu«, in: Wende, Waltraud >Wara< (Hg.), Geschichte im Film. Mediale Inszenierungen des Holocaust und kulturelles Gedächtnis, Stuttgart/Weimar (Metzler) 2002, S. 181-199.

Blumenfeld, Samuel, »Roberto Benigni, fabuliste des camps de la mort. LA VIE EST BELLE« in Le Monde, 22.10.1998, o.S.

Blumenfeld, Samuel, »Convoi de l'espoir dans la nuit nazie, Train DE viE. Le périple imaginaire et humoristique des habitants d'un schtetl à travers l'Europe centrale«, in: Le Monde, 17.09.1998, o.S.

Bole, Richard Michel/Mandelbaum, Jacques, »Une comédie italienne dans un camp d'extermination«, in: Le Monde, o9.01.1998, o.S.

Bole, Richard Michel, »La presse italienne enthousiaste de Roberto Benigni«, in: Le Monde, 27.03.1999, o.S).

Broder, Henryk M., »Spirale des Absurden«, in: Der Spiegel, 14.06.1999, S. 234.

Buss, Christian, »Eine Liebe in Dachau. Identität ist, was du trotzdem bist: Sean Mathias' Schwulen-Melodram BENT. Bekanntlich ist auch das Leben im KZ schön«, in: Die Tageszeitung, 26.11.1998, S. 2.

Brussig, Thomas, »DAS LEBEN IST sCHöN. Eine Empfehlung, ins Kino zu gehen«, in: Frankfurter Allgemeine Zeitung, 31.12.1998, S. 45.

Celli, Carlo, The divine comic. The cinema of Roberto Benigni, Lanham/Maryland/London (The Scarecrow Press) 2001.

Cervino, Mercedes, »Radu Mihaileanu. EL TREN DE LA vidA, fabula imaginativa sobre el holocausto«, in: Spanish Newswire Services, 31.01.2000, o.S.

Clark, John, »Fall sneaks; reveling in a comedy of terrors, for Roberto Benigni of Italy, the man behind a film about a comic in the holocaust, Life is dolce«, in: Los Angeles Times, 13.09.1998, S. 29.

Corell, Catrin, »Holocaustfilme an der Schwelle zum 21. Jahrhundert - neue Wege des Umgangs mit der Vergangenheit«, in: Nolte, Andrea (Hg.), Mediale Wirklichkeiten. Dokumentation des 15. Film- und Fernsehwissenschaftlichen Kolloquiums Universität Paderborn März 2002, Marburg (Schüren) 2003, S. 121-131.

Corell, Catrin, »Kompositorische und wirkungsästhetische Spannungsverhältnisse in LA Vita ̀̀ Bella von Roberto Benigni«, in: Medienbilder. Dokumentation des 13. Filmund Fernsehwissenschaftlichen Kolloquiums an der Georg-August-Universität Göttingen Oktober 2000, Hamburg (Verlag Dr. Kovac) 2001, S. 81-91.

Corell, Catrin, Kompositorische und sympraktische Spannungsverhältnisse in LA VITA ̀̀ BELLA von Roberto Benigni, Mannheim (Diplomarbeit) 2000.

Colombat, André, The Holocaust in French Film, Metuchen (Scarecrow) 1993.

Darmstädter, Tim, »Die Verwandlung der Barbarei in Kultur. Zur Rekonstruktion der nationalsozialistischen Verbrechen im historischen Gedächtnis, in: Werz, Michael (Hg.), Antisemitismus und Gesellschaft. Zur Diskussion um Auschwitz, Kulturindustrie und Gewalt, Frankfurt a.M. (Neue Kritik) 1995, S. 115-139.

Díaz, Rosa, »Veber: >La comedia, el mejor medio para transmitir un mensaje««, in: Spanish Newswire Sevices, 04.10.2001, o.S.

Distelmeyer, Jan, »Flucht ins Märchen. Die Auseinandersetzung des Kinos mit dem Holocaust wird immer unpolitischer«, in: Die Zeit, 23.03.2000, S. 53. 
Dreyfus, Alain, »Pinoclown«, in: Libération, 25.03.2003, S. 40.

Duden. Das große Wörterbuch der deutschen Sprache - in zehn Bänden, Mannheim (Duden) ${ }^{3} 1999$.

Dwyer, Michael, »Bitter sweet. Making a slapstick comedy concerning the Holocaust was a potentially touchy business, but Italian actor-director Roberto Benigni has been rewarded with the recognition of Hollywood and the freedom of Jerusalem «, in: The Irish Times, 06.02.1999, S. 62.

Ebert, Roger auf: www.suntimes.com/ebert/ebert_reviews/1998/10/103003.html (letzter Zugriff: 25.10.1998).

Elsaesser, Thomas, »Tarnformen der Trauer: Herbert Achternbuschs Das LETZTE LocH«, in: Fröhlich, Margit/Loewy, Hanno/Steinert, Heinz (Hg.), Lachen über Hitler - Auschwitz-Gelächter? Filmkomödie, Satire und Holocaust, München (edition text + kritik) 2003, S. 155-180.

Erstić, Marijana, »Zwischen >fingere sempre di avere capito $<$ und >belle nuit d'amour $<$ : Theaträlität und Improvisation in Roberto Benignis Film LA VITA غ̀ BELLA«, in: Lommel, Michael/Maurer Queipo, Isabel/Rißler-Pipka, Nanette (Hg.), Theater und Schaulust im aktuellen Film, Bielefeld (transkript) 2004, S. 33-54.

Ferenczi, Aurélien auf: www.lavieestbelle.com/images/pages/presse/positif.html (letzter Zugriff: 25.10.1998).

Ferrero, Jesús, »LA vidA Es BELla, Roberto Benigni. El humor contra el horror«, in: El Mundo, 18.10.2002, S. 54 .

Fiedler, Teja, »Lachen in der Hölle. Der italienische Starkomiker Roberto Benigni wagt eine Komödie im KZ - und kommt zum trotzigen Schluß: DAS LEBEN IST SCHÖN«, in: Stern Magazin, 10 (1998), S. 287.

Foxman, Abraham auf: www.miramax.com/lifeisbeautiful/life_review_o3.html (letzter Zugriff: 25.10.1998).

Frodon, Jean Michel, »Auschwitz, l'éthique et l'innocence. Le film rompt l'interdit de manière plus significative que LA LiSTE DE SCHindler. Roberto Benigni, fabuliste des camps de la mort«, in: Le Monde, 22.10.1998, o.S.

Frodon, Jean Michel, »La Shoah comme un gag absurde. LA VIE EST Belle: Un film habile mais dérangeant «, in: Le Monde, 19.05.1998, o.S.

Frois, Emmanuele, »TRAIn DE viE. Radu Mihaileanu au-delà des tabous«, in: Le Figaro, 16.09.1998, o.S.

Gallwitz, Tim, »Lachen oder nicht war für Lubitsch keine Frage: SEIN ODER NichtSEIN wird wieder gezeigt«, in: Die Tageszeitung, 14.09.2000, S. 2.

Gelie, Philippe, »LA viE EST Belle sort aujourd'hui sur les écrans français. Tom Segev, un brevet de >légitimité««, in: Le Figaro, 21.10.1998, o.S.

G., M., »Radu Mihaileanu n'admet pas que les barbares gagnent deux fois«, in: L'Humanité, 16.09.1998. (Seite ausgedruckt auf: www.humanite.fr, letzter Zugriff: 14.08.2003)

Gleibermann auf: www.ew.com/ew/review/archive/o,1683,359,00.html (letzter Zugriff: $25 \cdot 10.1998)$.

Goddard, Peter, »Filmmakers stretch limits of what's taboo«, in: The Toronto Star, 07.08.1998, S. D3.

Grass, Günter, »Schwierigkeiten eines Vaters, seinem Kind Auschwitz zu erklären«, in: Tagesspiegel, 27.05.1970.

Goldberger, M. S. auf: www.film.u-net.com/Movies/Reviews/Life_Is_Beautiful.htm (letzter Zugriff: 25.10.1998). 
Groß, Bernhard, »Den Holocaust neu erfinden. Defa-Remake. JAков DER LÜGNER von Peter Kassovitz erzählt aus einem unerhörten Blickwinkel«, auf: http://freitag.de/1999/46/99461502.htm: 1-3 (letzter Zugriff: 24:03.2003; in: Freitag, 46, 12.11.1999;).

Gruber, Ruth Ellen, »An unusual holocaust film is a controversial hit in Italy«, in: International Herald Tribune, 21.01.1998, S. 10.

Guéret, O. auf: www.cinopsis.com/critics/lavitaeb.htm (letzter Zugriff: 25.10.1998).

Gumbel, Andrew, »The dream factory: Tears and joy from death-camp film«, in: The Independent (London), 07.02.1999, S. 16.

Hanning, James, »The film that brings slapstick to Auschwitz«, in: The Evening Standard (London), 10.02.1999, S. 10.

Hage, Volker/Mohr, Reinhard, in: Der Spiegel, 17.05.1999, S. 308-312.

Hammerschmidt, in: medien praktisch, auf: www.medienpraktisch.de/amedienp/mp199/1-99hamm.htm (letzter Zugriff: 12.03.2005).

Holcman, Robert, »La Shoah dans le domaine public?«, in: Le Monde, 31.10.1998, o.S.

Holden, Stephen, »Film review. Master of their fate: a Holocaust fantasy«, in: The New York Times, 03.11.1999. S. E5.

Insdorf, »The ironic touch «, in: dies., Indelible shadows. Film and the Holocaust, ${ }^{2} 2003$, S. 276-292.

James, Stan, »Humour from tragedy«, in: The Advertiser, o6.10.2001, S. M24.

Kempley, R. auf: www.washingtonpost.com/wp-srv/style/movies/reviews/lifeisbeautifulkempley.htm (letzter Zugriff: 25.10.1998).

Keil, Christopher, »Das erste Mal. Nach zwei Jahren interner Diskussion zeigt die ARD Gozbbels und Geduldig, eine Komödie über den Nationalsozialismus«, in: Süddeutsche Zeitung, 20.11.2002, S. 19.

Kleinschmidt, Michael M., Filmheft ZUG DES LEBENS, Bundeszentrale für politische Bildung/Institut für Kino und Filmkultur.

Kniebe, Thomas, »Der Traum, unsichtbar zu sein«, in: Süddeutsche Zeitung, 23.03.2000, S. 19 .

Klüver, Henning, »Kritik der paradoxen Vernunft. Der italienische Komiker Roberto Benigni läßt seinen neuesten Film in einem KZ spielen«, in: Süddeutsche Zeitung, 23.01.1998, o.S.

Kortmann, Géraldine, »Das Absurde als Element der Komik. Anmerkungen zum Film Train DE Vie von Radu Mihaileanu«, in: Fröhlich, Margit/Loewy, Hanno/Steinert, Heinz (Hg.), Lachen über Hitler - Auschwitz-Gelächter? Filmkomödie, Satire und Holocaust, (edition text + kritik) 2003, S. 293-313.

Kotzin, Daniel, »A clown in the camps«, in: The Jerusalem Report, 26.10.1998, S. 40.

Krankenhagen, Stefan, Auschwitz darstellen. Ästhetische Positionen zwischen Adorno, Spielberg und Walser, Köln/Weimar/Wien (Böhlau) 2001.

Laster, Kathy/Steinert, Heinz, »Von der Schmierenkomödie zur Broadway-Show: To

BE OR NOT TO BE und der polnische Widerstand. Mel Brooks' Nazi-Spott und seine exzentrische Position«, in: Fröhlich, Margit/Loewy, Hanno/Steinert, Heinz (Hg.), Lachen über Hitler - Auschwitz-Gelächter? Filmkomödie, Satire und Holocaust, München (edition text + kritik) 2003, S. 225-244.

Lattes, Wanda, »Ossessione«, in: The Jerusalem Report, 02.04.1998, S. 42.

Lederle, Josef auf: www.filmdienst.de/Das Leben ist schön/html (letzter Zugriff: $25.10 .1998)$. 
Lorenz, Matthias N., »Der Holocaust als Zitat. Tendenzen im Holocaust-Spielfilm nach Schindlen's List«, in: Kramer, Sven (Hg.), Die Shoah im Bild, München (edition text+kritik) 2003, S. 267-296.

Loshitzky, Yosefa, »Verbotenes Lachen. Politik und Ethik der Holocaust-Filmkomödie«, in: Fröhlich, Margit/Loewy, Hanno/Steinert, Heinz (Hg.), Lachen über Hitler - Auschwitz-Gelächter? Filmkomödie, Satire und Holocaust, München (edition text + kritik) 2003, S. 21-35.

Lowy, Vincent, L'histoire infilmable. Les camps d'extermination nazis à l'écran, Paris (L'Harmattan) 2001.

Lyons, Charles, »Do the hustle«, in: Daily Variety, 26.02.1999, S. A13.

Mathews, Jack, »New Movie Digest«, in: Daliy News, 03.11.1999, S. 48.

Mathews auf: www.miramax.com/lifeisbeautiful/life_review_o1.html (letzter Zugriff: 25.10.1998).

Means auf: www.film.com/film-review/1998/10745/27/default-review.html (letzter Zugriff: 25.10.1998).

Meder, Thomas, »Die Vergangenheit im Kino. Kollektive und individuelle Erinnerungen an die deutsche Geschichte in Filmen der neunziger Jahre«, in: Wettengl, Kurt (Hg.), Das Gedächtnis der Kunst. Geschichte und Erinnerung in der Kunst der Gegenwart, Ostfildern-Ruit (Hatje Cantz Verlag) 2000, S. 247-256.

Meyer, Franziska, »>Die Amerikaner haben uns unsere Geschichte weggenommen Frank Beyers und Peter Kassovitz' JАков DER LÜGNER«, in: Wende, Waltraud >Wara<, »Medienbilder und Geschichte - Zur Medialisierung des Holocaust«, in: dies. (Hg.), Geschichte im Film. Mediale Inszenierungen des Holocaust und kulturelles Gedächtnis, Stuttgart/Weimar (Metzler) 2002, S. 214-251.

Meyers, Peter Alexander, »Oui, la vie est belle«, in: Le Monde, 31.10.1998, o.S.

Moinet, J-Ph. auf: www.lavieestbelle.com/images/pages/presse/figaro.html (letzter Zugriff: 25.10.1998).

Müller-Lobeck, Christiane, »Recht auf Ausdruck«, in: Die Tageszeitung, 29.01.2000, S. 27 .

N.N. auf: http://apolloguide.com/mov_fullrev.asp?CID=845 (letzter Zugriff: 25.10.1998).

N.N. auf: http://home.earthlink.net/ joeythorne/lifeis.htm (letzter Zugriff: 25.10.1998).

N.N. auf: http://infilmau.iah.net/reviews/lifeis.htm (letzter Zugriff: 25.10.1998).

N.N. auf: http://members.tripod.com/ Kuroto/fk/lebenistschon.html (letzter Zugriff: 25.10.1998).

N.N. auf: www.fortunecity.com/lavendar/heat/435/life.htm (letzter Zugriff: 25.10.1998).

N.N. auf: www.insideout.co.uk/movies2/beautiful.htm (letzter Zugriff: 25.10.1998).

N.N. auf: http://wsws.org/de/1998/nov1998/ben-n17.shtml (letzter Zugriff: 25.10.1998).

N.N. auf: www.lavieestbelle.com/images/pages/presse/histoire.html (letzter Zugriff: 25.10.1998).

N.N. auf: www.lavieestbelle.com/images/pages/presse/positif.html (letzter Zugriff: 25.10.1998).

N.N., »Die Tränen hinter dem Humor«, in: Der Spiegel, 20.03.2000, S. 191.

N.N., »Ein Schtetl deportiert sich selbst«, in: Die Tageszeitung, 18.03.2000, S. 25.

N.N., »Humorist der Hölle. KZ und Komödie: Roberto Benigni bricht in DAS LeBEN IST SCHÖN vermeintliche Tabus«, in: Focus Magazin, o2.11.1998, S. 168-170.

N.N., »>Le Kerfany<. Un autre regard sur la Roumanie«, in: Le Telegramme, 14.12.2002, o.S. 
N.N. in: »L'Humanité«,16.09.1998.

N.N., »TRAIN OF LIFE«, auf: http://efilmcritic.com/review.php?movie=1966, S. 1-3, (letzter Zugriff: 14.08.2003).

N.N., »Und doch in Arkadien. Holocaust als Komödie? Roberto Benignis LA VITA ì BELLA, in: Frankfurter Allgemeine Zeitung, 11.11.1998, S. 45.

N.N., »Unterm Strich«, in: Die Tageszeitung, 14.07.1998, S. 16.

N.N., »Zug Des LeBens«, in: Die Tageszeitung, 23.03.2000, S. 24.

Nutt, Harry, »Verbotene Liebe«, in: Die Tageszeitung, 11.03.1999, S. 15.

Nutt, Harry, »Walser, Bubis etc.; Moralische Autoritäten. Der Streit um das HolocaustGedenken bleibt Mediendeutung«, in: Die Tageszeitung, 21.11.1998, S. 18.

Ortag, Peter, Jüdische Geschichte und Kultur. Ein Überblick, Bonn (Bundeszentrale für politische Bildung) 1997.

Orth, Stefan/Valentin, Joachim/Zwick, Reinhold, »Vorwort«, in: dies., Göttliche Komödie. Religiöse Dimensionen des Komischen, Köln (KIM) 2001, S. 9-14.

Oster, Anja/Uka, Walter, »Der Holocaust als Filmkomödie. Komik als Darstellung des Undarstellbaren«, in: Kramer, Sven (Hg.), Die Shoah im Bild, 2003 (edition text+kritik) 2003, S. 249-266.

Paech, Joachim, »Das Komische als reflexive Figur im Hitler- oder Holocaust-Film«, in: Fröhlich, Margit/Loewy, Hanno/Steinert, Heinz (Hg.), Lachen über Hitler Auschwitz-Gelächter? Filmkomödie, Satire und Holocaust, München (edition text + kritik) 2003 , S. 65-79.

Paech, Joachim, »Ent/setzte Erinnerung«, in: Kramer, Sven (Hg.), Die Shoah im Bild, München (edition text+kritik) 2003, S. 13-30.

Place, Dendy Martin, »Just a trivial train ride«, in: Sydney Morning Herald, 29.12.2000, S. 4 .

Platthaus, Andreas, »Da geht der Deutsche in die Knie. Francesco Rosis Film DiE AtemPAuSE«, in: Frankfurter Allgemeine Zeitung, 31.03.1999, S. 53.

Rabenalt, Peter, Filmdramaturgie, Berlin (Vistas) ${ }^{2} 2000$.

Ravaschino, G. auf: www.primerplano.com/criticas/vida \%2oes \%2obella, \%2ola.htm (letzter Zugriff: 25.10.1998).

Reichel, Peter, »Giosuè oder Auschwitz als Abenteuerspiel«, in: ders., Erfundene Erinnerung. Weltkrieg und Judenmord in Film und Theater, München/Wien (Carl Hanser Verlag) 2004, S. 320-324.

Roman, Monica, »Miramax wraps >Life<deal«, in: Daily Variety, 17.02.1998, S. 1.

Romney, Jonathan, »Not film of the week: LifE IS BEAUTIFUL«, in: The Guardian (London), 12.02.1999, S. 6 .

Ruggle, Walter, »Der Mann, der immer lachte«, in: Tages-Anzeiger, o8.04.1999, S. 67.

Schickel auf: www.time.com/time/magazine/1998/dom/981109/the_arts.cinema.fascist 4a.html (letzter Zugriff: 25.10.1998).

Schröder, J. auf: http://online.prevezanos.com/skf/filme/filmdat/o269.shtml (letzter Zugriff: 25.10.19 98).

Schwickert, Martin, »Der Witz der Tragödie. Ein Gespräch mit Radu Mihaileanu über den Zug Des LeBens«, in: Stuttgarter Zeitung, 23.3.2000, o.S.

Seeßlen, Georg, »DAS LeBen IST SснӧN«, in: epd Film, 11/1998, S. $36 f$.

Seeßlen, Georg auf: www.epd.de/film/welcome_small.html (letzter Zugriff: 25.10.1998).

Sibony, Yaelle/Sibony, Daniel, »A propos de LA vie est belle. La Shoah et le jeu de la vie«, in: Le Figaro, 05.11.1998, S. o.S. 
Stark, S. auf: http://detnews.com/1998/entertainment/1030/life/life.htm (letzter Zugriff: 25.10.1998).

Steinberg, Stefan, »Interview mit Radu Mihaileanu, Regisseur von Zug Des Lebens (08.04.2000)«, auf: www.wsws.org/de/2000/apr2000/inte-ao8_prn.html, S. 1-4, (letzter Zugriff: 14.08.2003).

Tegeler, Hartwig, »Film im Gespräch. >Größer als ein Bild<. Radu Mihaileanu und seine Komödie ZUG DES LEBENS«, auf: www.morgenwelt.de/kultur/o00320-zugdeslebens-film-p.htm, S. 1-3, (letzter Zugriff: 14.08.2003).

Thomas, Dana/Brown, Corie, »The death-camp game«, in: Newsweek, o1.06.1998, S. 59.

Tsur, Shai, »Benigni >hears the silence«, in: The Jerusalem Post, 13.07.1998, S. 7.

Tugend, Tom, »Holocaust humor back in spotlight«, in: The Jerusalem Post, 03.12.1999: 24 .

Valentin, Joachim, »Das Komische als Dekonstruktion des Schreckens. Philosophischtheologische Überlegungen zu Das LeBEN IST SCHÖN von Roberto Benigni, in: Orth, Stefan/Valentin, Joachim/Zwick, Reinhold (Hg.), Göttliche Komödien. Religiöse Dimensionen des Komischen im Kino, Köln (KiM) 2001, S. 125-141.

Vishniac, Roman, Verschwundene Welt, München (Kindler) 1996.

Visser, Anthonya, »> Du sollst dir (k)ein Bildnis machen «: Zur Überlieferung von Überlieferter Geschichte in Art Spiegelmans Maus, Roberto Benignis LA VITA ì BELLA und Doron Rabinovics Die Suche nach M.«, in: Wende, Waltraud >Wara< (Hg.), Geschichte im Film. Mediale Inszenierungen des Holocaust und kulturelles Gedächtnis, Stuttgart/Weimar (Metzler) 2002, S. 200-213.

Wach, Margarete, »Der Narr zeigt den Weg im Zug Des Lebens«, in: Die Welt, 23.03.2000, o.S.

Wahrig, Gerhard, Deutsches Wörterbuch, Gütersloh (Bertelsmann-Lexikon-Verlag) 1974 .

Waldron-Mantgani, I. auf: http://members.aol.com/ukcritic/LifeIsBeautiful.html (letzter Zugriff: 25.10. 1998).

Walker, Alexander, »Winning the war games«, in: The Evening Standard (London), 11.02.1999, S. 27.

Wende, Waltraud >Wara<, »Medienbilder und Geschichte - Zur Medialisierung des Holocaust «, in: dies. (Hg.), Geschichte im Film. Mediale Inszenierungen des Holocaust und kulturelles Gedächtnis, Stuttgart/Weimar (Metzler) 2002, S. 8-29.

Wergin, Clemens, »Haben Sie die Holocaust-Komödie erfunden, Herr Mihailenau?«, in: Der Tagesspiegel, 22.3.2000, o.S.

Werneburg, Brigitte, »Das Leben ist ungerecht«, in: Die Tageszeitung, 15.06.1999, S. 23. Werneburg, Brigitte, »Bißchen davongekommen«, in: Die Tageszeitung, 23.03.1999, S. 14. Werneburg, Brigitte, »Benigni allein im KZ. Von gewiß großem Charme und doch problematisch: Roberto Benignis Tragikomödie DAS LeBen IST SCHÖN«, in: Die Tageszeitung, 12.11.1998, S. 15-16.

Wischnewski, Klaus, »Werkstattgespräch mit Frank Beyer. Über Jakob und andere«, in: Film und Fernsehen, H. 2/75, S. 18-24.

Wiegand, Wilfried, »Mit Humor der Vernichtung entgegen«, in: Frankfurter Allgemeine Zeitung, 20.05.1998, S. 45.

Whipp auf: www.miramax.com/lifeisbeautiful/life_review_o1.html (letzter Zugriff: 25.10.1998).

Williams, Evan, »A comedy of terrors«, in: The Weekend Australian, 26.12.1998, S. R12. 
Wuss, Peter, »DAS LEBEN IST SCHÖN ... aber wie lassen sich die Emotionen des Films objektivieren?«, in: Sellmer, Jan/Wulff, Hans J. (Hg.), Film und Psychologie - nach der kognitiven Phase?, Marburg (Schüren) 2002, S. 123-142.

Žižek, Slavoj, »Du sollst dir Bilder machen! Der Holocaust zwischen Schweigen und Lachen«, in: Süddeutsche Zeitung, 31.08.2000, S. 15.

\section{II.5 »BIRKENAU UND ROSENFELD«}

Assmann, Aleida, Erinnerungsräume. Formen und Wandlungen des kulturellen Gedächtnisses, München (Beck'sche Verlagsbuchhandlung) 1999.

Assmann, Aleida, »Erinnerungsorte und Gedächtnislandschaften«, in: Loewy, Hanno/ Moltmann, Bernhard (Hg.), Erlebnis - Gedächtnis - Sinn. Authentische und konstruierte Erinnerung, Frankfurt a.M./New York (Campus) 1996, S. 13-29.

Burggrabe, Hartmut, »Das erzählende Gesicht (14.2.2003). Ehren-Bär für Anouk Aimée und Uraufführung ihres neuen Films Birkenau und RosenFeld«, in: Le Monde, zit.n.: www.partisanfilm.de/index/61143 (letzter Zugriff: 13.08.2003).

Brumlik, Micha, »Individuelle Erinnerung - kollektive Erinnerung. Psychosoziale Konstitutionsbedingungen des erinnernden Subjekts«, in: Loewy, Hanno/Moltmann, Bernhard (Hg.), Erlebnis - Gedächtnis - Sinn. Authentische und konstruierte Erinnerung, Frankfurt a.M./New York (Campus) 1996, S. 31-45.

Chéroux, Clément, »Les photographies >rescapées « «, in: ders. (Hg.), Mémoire des camps. Photographies des camps de concentration et d'extermination nazis (1933-1999), Paris (Marval) 2001, S. 23.

Diehl, August, »Wächst schon Gras über die Sache? Ein junger deutscher Schauspieler dreht mit einer Holocaust-Überlebenden in Auschwitz«, in: Die Welt, 15.04.2004, zit.n.: www.welt.de/data/2004/04/15/264326.html (letzter Zugriff: 13.03.2006).

Jeismann, Michael, »Die Schale der Erinnerung. Birkenau und Rosenfeld, ein Film von Marceline Loridan-Ivens«, in: Frankfurter Allgemeine Zeitung, 15.04.2004, S. 33 .

Heine, Matthias, »Die Erinnerung ist eine Lawine. 50 Jahre nach der Befreiung zurück im KZ: Birkenau und RosenfeLD«, in: Die Welt, 15.04.2004, zit.n.: www.welt.de/ data/2004/04/15/ 264325.html (letzter Zugriff: 13.03.2006).

Kertész, Imre, Kaddisch für ein nicht geborenes Kind, Reinbek bei Hamburg (Rowohlt) $2002^{2}$.

Klüger, Ruth, Weiter leben. Eine Jugend, München (dtv) ${ }^{10} 2001$.

Klüger, Ruth, »Kitsch, Kunst und Grauen«, in: Frankfurter Allgemeine Zeitung, 02.12.1995, S. B4.

Levy, Primo, Die Untergegangenen und die Geretteten, München/Wien (Hanser) 1990.

Loridan, Marceline, »La planète des cendres. LA PETITE PRAIRIE AUX BouleAUX «, in: Les Echos, 12.11.2003, S. 11.

Loridan, Marceline im »Bonus«-Feature der französischen Original-DVD.

Lüthge, Katja, »Ein leichter Wind weht über Wiesen. BirkenAu und Rosenfeld ist der erste Spielfilm über das KZ Auschwitz, der am Originalschauplatz gedreht wurde«, in: Berliner Zeitung, 15.04.2004, S. 3.

N.N. auf: www.academy-films.com/deutsch/neuefilme/20040218190542.3.html (letzter Zugriff: 13.08.2003). 
N.N. auf: www.partisanfilm.de/index/61136 (letzter Zugriff: 13.08.2003).

N.N. in: The International Herald Tribune, zit.n.: www.partisanfilm.de/index/61136,75093 (letzter Zugriff: 13.03.2006).

N.N., »Marceline Loridan-Ivens findet in Auschwitz ihr Gedächtnis wieder«, in: Le Monde, 09.07.2002, zit.n.: www.partisanfilm.de/index/61136,75093 (letzter Zugriff: 13.03.2006).

Semprún, Jorge, Schreiben oder Leben, Frankfurt a.M. (Suhrkamp) ${ }^{2} 1995$.

Rother, Hans-Jörg, »Die Erinnerung besiegen. Marceline Loridan-Ivens stellt sich in Birkenau und Rosenfeld ihrem Trauma von Auschwitz«, in: Der Tagesspiegel, 15.04.2004, S. 24.

Zander, Harald, »Erinnern müssen und vergessen wollen: der Film BIRKENAU UND ROSENFELD« auf: www.hr-online.de/website/tools/printsite.jsp?key=standard... (letzter Zugriff: 23.09.2004).

Wittlich, Angelika, »Birkenau und Rosenfeld «, auf: http://www.br-online/de/Kultur-szene/Film/Kino/0312/02292/druckversion (letzter Zugriff: 12.05.2005).

Wittlich, Angelika, »Interview mit Anouk Aimée«, auf: http://www.br-online/de/Kultur-szene/stars-interviews/0404/028.../druckversion (letzter Zugriff: 12.05.2005).

\section{Auf- und AnNahme des Holocaust im SPIELfilm}

Bartov, Omer, »Spielberg's Oskar. Hollywood tries evil«, in: Loshitzky, Yosefa (Hg.), Spielberg's Holocaust. Critical Perspectives on SCHINDLER's LIST, Bloomington/Indianapolis (Indiana University Press) 1997, S. 41-6o.

Blothner, Dirk, Erlebniswelt Kino. Über die unbewußte Wirkung des Films, Bergisch Gladbach (Bastei Lübbe) 1999.

Brussig, Thomas, »DAS LeBEN IST sCHön. Eine Empfehlung, ins Kino zu gehen«, in: Frankfurter Allgemeine Zeitung, 31.12.1998, S. 45.

Darmstädter, Tim, »Die Verwandlung der Barbarei in Kultur. Zur Rekonstruktion der nationalsozialistischen Verbrechen im historischen Gedächtnis«, in: Werz, Michael (Hg.), Antisemitismus und Gesellschaft. Zur Diskussion um Auschwitz, Kulturindustrie und Gewalt, Frankfurt a.M. (Neue Kritik) 1995, S. 115-139.

Denkler, Horst, »Gedächtnisstütze. Binsenweisheiten über die bescheidenen Möglichkeiten der Deutschen Literatur im Rückblick und in Hinsicht auf den Holocaust«, in: Köppen, Manuel (Hg.), Kunst und Literatur nach Auschwitz, Berlin (Erich Schmidt Verlag) 1993, S. 171-177.

Diner, Dan, Zivilisationsbruch, Frankfurt a.M. (Fischer) 1998.

Faulstich, Werner, Medienwissenschaft. Ein systematischer Überblick. München (Wilhelm Fink Verlag) 2004.

Hartman, Geoffrey H., »The Cinema Animal«, in: Loshitzky, Yosefa (Hg.), Spielberg's Holocaust. Critical Perspectives on SCHINDLER'S LIST, Bloomington/Indianapolis (Indiana University Press) 1997, S. 61-76.

Hickethier, Knut, Film- und Fernsehanalyse, Stuttgart/Weimar (Metzler) ${ }^{2} 1996$.

Heyl, Matthias, »Was ist und zu welchem Ende studiert man die Geschichte des Holocaust? >Aufarbeitung der Vergangenheit< heute«, in: Erler, Hans (Hg.), Erinnern und Verstehen. Der Völkermord an den Juden im politischen Gedächtnis der Deutschen, Frankfurt a.M./New York (Campus) 2003, S. 202-222. 
Insdorf, Annette, Indelible shadows. Film and the Holocaust, Cambridge (Cambridge University Press) ${ }^{3} 2003$.

Jolles, André, Einfache Formen. (Legende, Sage, Mythe, Rätsel, Spruch, Kasus, Memorabile, Märchen, Witz), Tübingen (Niemeyer) $1982^{6}$.

Kant, Immanuel, »Die Kritik der Urteilskraft«, zit.n.: R. Homanns, »Das Erhabene«, in: Ritter, Joachim (Hg.), Historisches Wörterbuch der Philosophie, Bd. II, Basel 1972, S. 623-635.

Kloepfer, Rolf (siehe erster Abschnitt der Bibliographie).

Klüger, Ruth, Weiter leben. Eine Jugend, München (dtv) 1995.

Köppen, Manuel/Scherpe, Klaus R., Bilder des Holocaust. Literatur - Film - Bildende Kunst, Köln/Weimar/Wien (Böhlau) 1997.

Köppen, Manuel (Hg.), Kunst und Literatur nach Auschwitz, Berlin (Erich Schmidt Verlag) 1993 .

Niroumand, Miriam, »Vorhang, Licht, Person«, in: Die Tageszeitung, 15.01.1997, S. 13.

Noack, Johannes-Michael, SCHINDLERS LISTE - Authentizität und Fiktion in Spielbergs Film. Eine Analyse, Leipzig (Leipziger Universitätsverlag) 1998.

Levy, Daniel/Sznaider, Natan, Erinnerung im globalen Zeitalter: Der Holocaust, Frankfurt a.M. (Suhrkamp) 2001.

Lorenz, Matthias N., »Der Holocaust als Zitat. Tendenzen im Holocaust-Spielfilm nach Schindler's List«, in: Kramer, Sven (Hg.), Die Shoah im Bild, München (edition text+kritik) 2003, S. 267-296.

Lowy, Vincent, Les camps d'extermination nazis à l'écran, Paris (L' Harmattan) 2002.

Paech, Joachim, »Ent/setzte Erinnerung«, in: Kramer, Sven (Hg.), Die Shoah im Bild, München (edition text+kritik) 2003, S. 13-29.

Reich-Ranicki, Marcel, »Polanskis Todesfuge. Was ich nicht zu hoffen wagte, ist hier gelungen - Der PIANist ist eine meisterhafte Wiedergabe unseres Alltags im Warschauer Ghetto«, in: Frankfurter Allgemeine Zeitung, 23.10.2002, S. 35.

Reichel, Peter, »Shoah: Zu sagen, was unsagbar ist«, in: ders., Erfundene Erinnerung. Weltkrieg und Judenmord in Film und Theater, München/Wien (Carl Hanser Verlag) 2004, S. 286-300.

Sartre, Jean-Paul, Was ist Literatur?, Reinbek bei Hamburg (Rowohlt Taschenbuch Verlag) $1981 / 1950$.

Semprún, Jorge, Schreiben oder Leben, Frankfurt a.M. (Suhrkamp) ${ }^{2} 1995$.

Schulz, Georg-Michael, »Docu-Dramas - oder: Die Sehnsucht nach der >Authentizität<. Rückblicke auf Holocaust von Marvin Chomsky und Schindere Rs Liste von Steven Spielberg«, in: Wende, Waltraud >Wara< (Hg.), Geschichte im Film. Mediale Inszenierungen des Holocaust und kulturelles Gedächtnis, Stuttgart/Weimar (Metzler) 2002, S. 159-179.

Schütte in: Gregor, Erika und Ulrich (Hg.), Jüdische Lebenswelten im Film, Berlin (Freunde der Deutschen Kinemathek) 1992.

Silbermann, Alphons/Stoffers, Manfred, Auschwitz: Nie davon gehört? Erinnern und Vergessen in Deutschland, Berlin (Rowohlt) 2000.

Thiele, Martina, Publizistische Kontroversen über den Holocaust im Film, Münster (LIT) 2001. Todorov, Tzvetan, Angesichts des Äußersten, München (Fink) 1993, S. 294-302.

Valentin, Joachim, »Das Komische als Dekonstruktion des Schreckens. Philosophischtheologische Überlegungen zu DAS LEBEN IST sCHÖN von Roberto Benigni, in: Orth, Stefan/Valentin, Joachim/Zwick, Reinhold (Hg.), Göttliche Komödien. Religiöse Dimensionen des Komischen im Kino, Köln (KiM) 2001, S. 125-141. 
Visser, Anthonya, »> Du sollst dir (k)ein Bildnis machen : Zur Überlieferung von Überlieferter Geschichte in Art Spiegelmans Maus, Roberto Benignis LA vita È BeLLA und Doron Rabinovics Die Suche nach M.«, in: Wende, Waltraud >Wara < (Hg.), Geschichte im Film. Mediale Inszenierungen des Holocaust und kulturelles Gedächtnis, Stuttgart/Weimar (Metzler) 2002, S. 200-213.

Žižek, Slavoj, »Du sollst dir Bilder machen! Der Holocaust zwischen Schweigen und Lachen«, in: Süddeutsche Zeitung, 31.08.2000, S. 15.

\section{Exkurse}

Mandler, George, Cognitive psychology. An essay in cognitive science, Hillsdale NJ (Erlbaum) 1985 .

Möller-Naß, Karl-Dietmar, Filmsprache. Eine kritische Theoriegeschichte, Münster (Nodus) 1986.

Norman, Donald A./Rumelhart, David E., Strukturen des Wissens. Wege der Kognitionsforschung, Stuttgart (Klett-Cotta) 1978.

Ohler, Peter, »Kognitive Theorie der Filmwahrnehmung«, in: Hickethier, Knut/Winkler, Hartmut (Hg.), Filmwahrnehmung, Berlin (Ed. Sigma Bohn) 1990, S. 43-57.

Saussure, Ferdinand de, Grundfragen der allgemeinen Sprachwissenschaft, Berlin (de Gruyter) 1967 (Erstdruck franz. 1915).

Seidel, Wilhelm, Rhythmus. (Eine Begriffsbestimmung), Darmstadt (Wissenschaftliche Buchgesellschaft) 1976.

3. Auf ein Sequenzprotokoll für Lanzmanns Shoah (II.2.2) wurde aufgrund der neuneinhalbstündigen Dauer des Films verzichtet. Die Zeitangabe nach dem Titel der Sequenz gibt die Startzeit der Sequenz, die Zeitangabe in Klammer gibt die Dauer der jeweiligen Sequenz an. 


\section{B) Sequenzprotokolle ${ }^{3}$}

\section{»DIE TODESMÜHLEN« (II.1.1) - SEQUENZPROTOKOLL}

1 Vorspann o:००`००“०० (0०'16“16)

21100 Kreuze für frische Gräber 00 '16“17 (००‘15“01)

3 Die KZs als Gefängnis o०‘31"19 (0०‘33“19)

4 Freude über die Befreiung der Lager 01‘05“14 (00‘53“07)

5 Essen für die (halb)verhungerten Insassen $011^{\prime} 5$ '“21 (0०'33"18)

6 Erste Hilfe für die Überlebenden 02 '32"15 (0०‘53“o6)

7 Alliierte Doktoren untersuchen die Überlebenden 03‘25“21 (00‘30“05)

8 Besichtigung der Lager durch alliierte Offiziere, Kirchenvertreter und die alliierte Untersuchungskommission 03 ‘56"O2 (O1'51“ㅇ)

9 Folterkammern u. -geräte, Gaskammern $05^{\prime} 47^{\prime \prime 03 ~(0 \circ 449 “ 24) ~}$

10 Verwertung, »Warenlager « o6'37”o3 (01'40”17)

11 Liquidierungen kurz vor der Befreiung o8'17"21 (01'18“15)

12 Lagerwachen, SS-Offiziere und -Ärzte 09 '36“11 (01'15“15)

13 Leichenmassen 10'52"02 (03'24"24)

14 Überlebende 14 ' 17 “이 (O2'50"02)

15 Deutsche müssen das Desaster betrachten 17‘07“03 (02‘43“07)

16 Ende 1: Überblendung bzw. Mehrfachbelichtung der Deutschen 1945 und 1933 $19{ }^{\prime} 50$ “11 (0०‘44“07)

17 Ende 2: die Kreuze für die frischen Gräber 20‘34“18 (००‘25“01)

\section{»NACHT UND NEBEL« (II.2.1) - SEQUENZPROTOKOLL}

1 Vorspann ०:००‘००“०० (01'०8“०6)

2 »Ruhiges Land« 01 ‘08“०6 (01'14“02)

3 »1933 - die Maschine setzt sich in Bewegung 02 “22"08 (01‘29“17)

4 Aushebungen, -siedlungen, Razzien, Deportation O3‘52“ㅇ (O2‘55“23)

5 Bahnstrecke und Eingang von Auschwitz heute 06“47"24 (00‘42“04)

6 Zeichen der Entwürdigung u. Hierarchie im Lager 07'30“03 (00‘54“०9)

7 Unfaßbar!: die Baracken und die schwierigen Nächte 08 '24“12 (01‘51“21)

8 Zwangsarbeit bei jeder Witterung u. unter widrigen Umständen 10'16“o9 (01'11“o8)

9 »Der KZ-Häftling hat jetzt nur einen Gedanken - essen!«; manche wollen nur noch sterben $11^{\prime} 27^{\prime \prime} 18$ (0०'38“22)

10 Die Abortanlage 12“o6"15 (00‘40"14)

11 Sinnsprüche der Nazis 12 '47"04 (0०'13"15)

12 Erstaunliches in den Lagern: Musikkapelle, Zoo, Goethe-Eiche, Gewächs- u. Waisenhaus, Invalidenblock 13'00"19 (0०‘26“22)

13 Die abgeschlossene Welt der Häftlinge 13‘27“17 (0०`25“16)

14 Demütigung, stundenlanger Appell, Bestrafung, Erschießung, Abtransport 13 '53"08 (00'58“02)

15 Menschlichkeit untereinander 14‘51"11 (00‘52“13) 
16 Der Krankenbau, das Revier 15‘44“०० (००‘38“००)

17 Der chirurgische Block 16'22"00 (01'12“20)

18 Die »Stadt« der Nazis 17'34“21 (01'59“11)

19 Planung der Vernichtung durch Krematorien 19‘34"०8 (००‘49“12)

20 Deportationen in ganz Europa 20'23“20 (00'23“01)

21 Kurz vor der Liquidierung $20^{\prime} 46^{\prime \prime} 22\left(00^{\prime} 28 “ 10\right)$

22 Vergasung 21'15“07 (01'12“22)

23 Exhumierung bzw. Beseitigung der Leichen 22‘28“05 (00‘28“13)

24 Die Krematoriumsöfen 22‘56"18 (00‘55“o6)

25 Verwertungsmaschinerie: aus X wird Y hergestellt 23‘52"o० (01'47“16)

26 1945: letzte Kriegsphase; Beteiligung der Industrie 25‘39"16 (0०‘35"21)

27 Als die Alliierten die Tore öffnen ... 26'15“12 (01'22“16)

28 Die Schuldfrage 27‘38“03 (0०‘37“19)

29 »Der Krieg schlummert nur; es wächst wieder Gras«; die Mörder sind unter uns; wir verdrängen, daß der Schrei nicht verstummt 28`15“22 (01`46“16)

\section{»AUf WiedERSEHEN, KINDER巛 (II.3.1) - SEQUENZPROTOKOLL}

1 Bahnhof (Januar 1944, Verabschiedung von der Mutter) ০:००‘০০“०० (०2‘01“05)

2 Aufspann mit weißer Schrift (Zugfahrt, Weg zum Internat »Convent des Carmes, Petit College «) O2“O1“O5 (O2‘13“03)

3 Schlafsaal (1. Abend, Marmelade, Jean wird als Neuer präsentiert, 1. Begegnung Julien-Jean) 04 ‘ 14 “०8 (02‘47“23)

4 Waschraum (1. Morgen, Piesacken, »Einweihungszeremonie«) 07'02“०6 (००`29“००)

5 Morgenmesse (Kapelle, Schwächeanfall, Frieren, Hunger) o7‘31“07 (००‘44“17)

6 Unterricht (Frz., Péguy) ०8‘16"०० (01‘56“13)

7 Schulhof (Stelzenkampf) 10'12“14 (02'17“04)

8 Küche (Juliens blutendes Knie wird verarztet, Deal mit Marmelade) 12‘29“18 (01'08“20)

9 Speisesaal (Proviantteilen, Wurst, Jeans Großzügigkeit, Vitaminkekse) 13‘38“13 (02'35“24)

10 Schulhof (Mittagspause, Marmelade gegen Briefmarken) 16“14"13 (01'12“22)

11 Unterricht (Mathe: Jean glänzt fachlich, Fliegeralarm, im Bunker) 17‘27“10 (03'16"19)

12 Schlafsaal (Julien als Bettnässer, Jean schläft unruhig) 20‘44"O4 (O2‘36"O2)

13 Sportstunde (die attraktive Klavierlehrerin) 23'20"07 (0०‘49"13)

14 Klavierstunde (Juliens Neid auf Jean) 24'09"20 (01'54"21)

15 Unterricht (Julien liest Brief von Jeans Mutter) 26“04"17 (O1'O2“21)

16 Beichten bei Pater Jean (Julien kriegt Telefongespräch mit) 27‘07“13 (02‘09“०6)

17 Badeanstalt (Schülergespräche, die Deutschen, Juliens Tagtraum)) 29‘16“19 (04'18“18)

18 Schlafsaal (Julien ertappt Jean beim nächtlichen Beten) 33‘35"13 (01'०0“23)

19 Sportstunde (der Erzieher und Jean verstecken sich) 34'36"11 (01'46"14)

20 Unterricht (Jean kommt später, hat bessere Note als Julien) 36'23"01 (00'52“22)

4. Vgl. Korte 1999: 157ff. 
21 Nach dem Mittagessen (Murmeln von Josef, Brief von Mutter, Jean Kippelstein) $37^{\prime} 15$ “23 (04‘02“10)

22 Klassenzimmer (Griech.-Unterricht: Jean malt, Julien fragt Jean aus in der Pause) 41'18“og (02‘46“03)

23 Schulhof (Julien fragt Bruder nach Juden, Josef wird gedemütigt) 44 “ 04 “ 12 (01'42“12)

24 Pfadfinderspiel 45‘46"24 (09‘13“०6)

25 Krankenzimmer (Brief von Juliens Mutter, Jean mag Paté nicht, Rangelei zwischen beiden) 55'00“05 (03‘28“20)

26 Waschraum (die Eltern kommen) 58'29"01 (0०'23“22)

27 Messe und Abendmahl (Pater Jean kritisiert die geizigen Reichen, verwehrt Jean die Hostie) 58‘52“23 (03“01“08)

28 Schulhof (Rangelei zwischen Julien und Jean und Versöhnung) 1:01‘54“o7 (01'10“05)

29 Restaurant (eingeschränkte Menuauswahl, dt. Soldaten am Nebentisch, Mutter plappert drauf los, Jean sieht sie bewundernd an, Zwischenfall mit dem Juden) 1:03“04"13 (05'00“23)

30 Nach dem Essen (Francois ärgert die dt. Soldaten, Julien will sich nicht von der Mutter trennen) 1:08'05“11 (01‘54“00)

31 Kinoabend (die beiden essen zusammen Marmelade und verfolgen nebeneinander den Film) 1:09'59“12 (04‘32“22)

32 Waschraum (2. Bettnässen, Jean verteidigt Julien) 1:14‘32“09 (00‘38“24)

33 Schlafsaal (Julien berichtet vom Bettnässen) 1:15'11“o8 (0०`23“16)

34 Schulhof (Julien zeigt Jean das Stelzenlaufen, Josef kriegt wieder sein Fett ab) 1:15‘35"00 (0०‘45“13)

35 Standpauke von Pater Jean (Josef wird entlassen) 1:16‘20“13 (01'51“14)

36 Kirche Singstunde 1:18‘12“03 (००`51“10)

37 Klavierzimmer: gemeinsames Spielen während des Alarms) 1:19“03“18 (02‘15“19)

38 Küche (beide beobachten Josef) 1:21'19"12 (0०‘45"22)

38 Schlafsaal (Julien liest Jean vor) 1:22'05"10 (01'15"16)

40 Unterricht (Mathe: Jean wird abgeholt) 1:23“21"04 (04‘25"13)

41 Schlafsaal (Jean packt schnell, Buchgeschenk) 1:27‘46“17 (02‘06“10)

42 Krankenzimmer (Kollaborateure vs. Julien als Widerständler) 1:29‘53“03 (O2‘24"12)

43 Schulhof (Konfrontation Julien-Josef) 1:32‘21"09 (01'35“07)

44 Schulhof (Au revoir les enfants + abgeführter Jean) 1:33‘56“17 (04‘28“o1)

45 Abspann (schwarz mit weißer Schrift) 1:38'24"18 (01'30“14)

\section{»SCHINDLERS LISTE« (II.3.2) - SEQUENZPROTOKOLL4}

1 Das Sabbatgebet in Farbe (Kerze); 1939: Polen ist von Deutschen besetzt 0०'21“०9 (02'53“13)

2 Nachtclub: Schindler freundet sich mit SS-Offizieren an 03'14“22 (06‘32"07)

3 Schindler beim Judenrat: Stern soll helfen, jüdische Geldgeber für den Firmenkauf zu finden 09 ‘7"04 (04‘27“19)

4 Kirche: Schindler sucht Kontakt zu jüdischen Schwarzhändlern 14‘14"24 (02‘30"24) 
5 März 1941: Zwangsumsiedlung der Juden ins Krakauer Ghetto 16‘45“24 (01'34“10)

6 Schindler übernimmt die vornehme Wohnung der jüdischen Familie 18'20"10 (02'28“21)

7 Schindler und die jüdischen Bankiers. Stern wirbt Arbeitskräfte für die neue Fabrik an, Schindler kümmert sich um die Auswahl der Sekretärinnen 20 49"o6 (08‘33“०9)

8 Durch großzügige Geschenke an die entsprechenden Entscheidungsträger erhält Schindler umfangreiche Wehrmachtsaufträge. Die Firma floriert. Schindler bedankt sich bei Stern 29'22"16 (03‘36"20)

9 Frau Schindler besucht ihren Mann in Krakau 32‘59“12 (04‘42“००)

10 Schindler und der einarmige Schlosser. Auf dem Weg in die Fabrik werden die Schindler-Arbeiter zum Schneeräumen gezwungen. Der Einarmige wird von den SSLeuten erschossen. Schindler beschwert sich bei der Dienststelle 37"41"13 (04“46“17)

11 Stern ist verhaftet worden und bereits in einem der Deportationszüge. Schindler schüchtert die Verantwortlichen ein und kann Stern im letzten Moment herausholen. Während sie den Bahnhof verlassen, werden die Koffer der Deportierten ausgewertet

12 Winter 1942: Untersturmführer Amon Göth besichtigt das Ghetto und das im Bau befindliche Arbeitslager Paszow. Er wählt Helene Hirsch als neues Hausmädchen aus, läßt eine jüdische Ingenieurin erschießen und hält eine Rede über den bevorstehenden Judenmord

13 Getto-Räumung 54'25“19 (04‘04"16)

14 Das Arbeitslager Plaszow. Göth erschießt willkürlich einige Häftlinge vom Balkon seiner Villa 1:10“43“17 (03"12“20)

15 Essen bei Göth. Schindler will für seine Arbeiter ein eigenes Lager einrichten. Gegen eine entsprechende finanzielle >Entschädigung>stimmt Göth zu 1:13‘56“12 (04‘ $53^{\prime \prime 21)}$

16 Stern aber muß jetzt bei Göth arbeiten, soll für dessen Gewinn sorgen. Schindler hat Mühe, die Fabrik alleine weiterzuführen 1:18“50"09 (03“40"13)

17 Göth kontrolliert die Arbeitsleistung eines älteren Schlossers. Er will ihn wegen Sabotage erschießen, doch die Pistole versagt. Ein jugendlicher Hühnerdieb soll erschossen werden. Stern sorgt dafür, daß die beiden von Schindler angefordert werden

18 Eine junge Frau bittet Schindler, ihre im Lager Plaszow lebenden Eltern (die Perlmanns) anzufordern. Schindler lehnt zunächst aufgrund des Risikos brüsk ab. Schließlich ist er doch dazu bereit 1:28'15"08 (06'19"11)

19 Schindler versucht, Helene Hirsch zu trösten, die unter Göths Brutalität und Unberechenbarkeit zu leiden hat 1:34‘34"19 (04‘31“o9)

20 Schindler und Göth: Diskussion über Macht und Gnade. Göth versucht sich im >Begnadigen $<$ Seinen Burschen Lisiek läßt er jedoch nur zunächst laufen (Unterkapitel) 1:39"06"03 (06'01"19)

21 Göth läßt sich von Helene maniküren. Im Keller kommt er ihr näher, mißhandelt sie jedoch letztlich. Parallel: eine jüdische Hochzeitszeremonie im Lager, Schindler feiert Geburtstag - küßt eine Jüdin 1:45“07“23 (07‘03“16)

22 In der Frauenbaracke wird von den als Duschen getarnten Gaskammern erzählt - Unglauben. Lagerappell: alle müssen sich ausziehen, die Alten und Kranken werden >aussortiert< 1:52"11"14 (05446"02) 
23 Die Kinder werden auf Lastwagen verladen und weggebracht. Ein kleiner Junge versucht, sich zu verstecken, letztlich in der Latrine 1:57'57“17 (03440“०6)

24 Die >Aussortierten Schindler versucht, mit Wasserschläuchen Linderung zu verschaffen 2:01'37"24 (03'14“०o)

25 Schindler wird wegen des Kusses mit der Jüdin verhaftet. Seine SS-Freunde setzen sich für ihn ein und sorgen für seine Freilassung (Unterkapitel) 2:04'52"oo (03'24"10)

26 April 1944: Die bei der Ghetto-Räumung Erschossenen werden exhumiert und auf großen Scheiterhaufen verbrannt, das Lager P. aufgelöst. Die Insassen sind für die >Endlösung< vorgesehen, doch Schindler hat mit Stern anderes vor (Unterkapitel) 2:08'16“10 (05'35“19)

27 Schindler erhält gegen Bezahlung Göths Zustimmung, seine Fabrik mitsamt den Arbeitern und deren Kindern nach Westen zu verlagern. Stern und Schindler stellen die Namenslisten zusammen 2:13'52"04 (01'14“24)

28 Schindler bedrängt Göth, auch dessen Haushälterin mitgehen zu lassen. Entscheidung durch Kartenspiel 2:15'07“04 (05‘38“24)

29 Die Schindler-Juden steigen in die Waggons. Der Männerzug erreicht Brünnlitz, wo Schindler wartet 2:20“46"03 (03'57“16)

30 Der Frauen-/Kinderzug wird versehentlich nach Auschwitz geleitet. DuschraumSzene. Schindler kauft >seine< Juden frei (Unterkapitel) 2:24“43"20 (13“43“24)

31 Schindler versöhnt sich mit seiner Frau, hat aber kein Geld mehr (Unterkapitel) 2:38'27"19 (05'25“04)

32 Kapitulation der Deutschen und Abschiedsrede Schindlers vor den Arbeitern $2: 43$ '52"24 (04'20“21)

33 Schindlers muß fliehen. Die Juden überreichen ihm ein Entlastungsschreiben und einen beschrifteten Ring. Schindler bricht weinend zusammen 2:48‘13“20 (०6‘04“02)

34 Ein russischer Soldat erklärt den Schindler-Juden, daß die Rote Armee sie befreit habe 2:54'17"22 (01'08“16)

35 Epilog bzgl. Göth und Schindler. Die Juden kommen singend einen Hügel herab auf die Kamera zu, später farbig $\Rightarrow$ heute (Unterkapitel) 2:55`26“14 (05‘35“15)

36 Abspann 3:01'02"05 (0548“01)

\section{»DAS LEBEN IST SCHÖN« (II.4.1) - SEQUENZPROTOKOLL}

1 Der Bremsenausfall (०:00:03-0:01:41)

2 Guidos Begegnung mit der Prinzessin (0:01:41-0:04:41)

3 Ankunft bei Guidos Onkel (0:04:41-0:06:24)

4 Freiheit in der Stadt (0:06:24-0:06:56)

5 In der Polsterei (0:06:56-0:08:07)

6 Im Rathaus (0:08:07-0:10:06)

7 »Kellner-Schnell-Lehrgang« (०:10:०6-0:12:31)

8 Willenskraft nach Schopenhauer (0:12:31-0:14:58)

9 Treffen der bekannten Verlegerin Guicciardini (o:14:58-0:16:46)

10 »Zufalls«begegnungen mit Dora (o:16:46-0:19:0)

11 Lachs für den Ministerialrat (0:19:00-0:22:49) 
12 Guido als Ministerialrat in der Grundschule (0:22:49-0:28:07)

13 In der Oper (0:28:07-0:32:10)

14 Vorläufige »Entführung « Doras (0:32:10-0:39:01)

15 Feiervorbereitungen im Grand Hotel und das beschmierte jüdische Pferd des Onkels (0:39:01-0:43:21)

16 Die Abreise von Dr. Lessing (0:43:21-0:45:12)

17 Die Verlobungsfeier und die endgültige Entführung Doras durch Guido (०:45:120:54:28)

18 Familienglück (0:54:28-0:56:53)

19 »Zutritt verboten für Juden und Hunde« (0:56:53-0:57:56)

20 Guido muß zum Präfekten (o:57:56-0:58:57)

21 Giosuè sieht seine Oma zum ersten Mal (0:58:57-1:00:44)

22 Vorbereitung für Giosuès Geburtstagsfeier (1:00:44-1:02:05)

23 Abtransport im LKW (1:02:05-1:04:13)

24 »Verladung« in den Zug (1:04:13-1:07:33)

25 Ankunft im KZ (1:07:33-1:11:05)

26 Guido erklärt die »Spielregeln« (1:11:05-1:15:30)

27 Beim Amboß-Schleppen (1:15:30-1:16:19)

28 Erster »Feierabend « (1:16:19-1:19:29)

29 Dora auf dem Weg zur Arbeit (1:19:29-1:20:24)

30 Giosuè will nicht duschen (1:20:24-1:21:31)

31 Das »Duschen « (1:21:31-1:22:12)

32 Die neue »Versteckregel« (1:22:12-1:22:57)

33 Der Kleiderberg (1:22:57-1:23:27)

34 Liebeserklärung über Lautsprecher (1:23:27-1:25:17)

35 Erste Verluste in der Barackenmannschaft (1:25:17-1:25:59)

36 Arztvisite (1:25:59-1:27:09)

37 Giosuè mit letzter Kraft zurückgehalten (1:27:09-1:31:51)

38 Spielende Kinder (1:31:51-1:34:58)

39 »Grazie!« (1:34:58-1:37:04)

40 Enttäuschte Hoffnungen (1:37:04-1:40:09)

41 Offenbachs Barkarole (1:40:09-1:42:26)

42 Der Leichenberg (1:42:26-1:43:35)

43 Aufbruchsstimmung (1:43:35-1:44:35)

44 Beginn des entscheidenden »Versteckspiels « (1:44:35-1:47:21)

45 Verzweifelte Suche nach Dora (1:47:21-1:49:38)

46 Ermordung Guidos (1:49:38-1:51:41)

47 Der Morgen danach (1:51:41-1:53:16)

48 »Preisverleihung« (1:53:16-1:55:24)

49 »Wir haben gewonnen!« (1:55:24-1:56:42)

\section{»ZUG DES LEBENS« (II.4.2) - SEQUENZPROTOKOLL}

1 Aufspann: Rahmen - Sommer 1941 ०:00‘00“०० (02“12“19)

2 Beim Rabbi: Schlomo überbringt die Nachricht vom Vorrücken der Nazis und hat die entscheidende Idee: Selbstdeportation per Zug 02“12“19 (04‘36“23) 
3 Im Freien: Schlomo konkretisiert die Durchführung des Plans ०6‘49“17 (००‘43“०2)

4 Im Freien: Aufregung nach Bekanntwerden des Plans 07‘32“20 (00‘59“14)

5 Im Bürgerhaus: Bestimmung der »Nazis« - Mordechai wird »Nazi-Anführer« 08 '32"11 (03“04"01)

6 Im Dorf: ausgelassene Stimmung (Tanz) und konkrete Vorbereitungen überall $11^{\prime} 36$ 6"12 (02‘24"20)

7 Frauenbad: Organisation und Heiratsgespräch 14“01“07 (००`26“20)

8 Im Freien: Spendensammlung 15'06"20 (00‘58“o6)

9 Im Gemeinderaum: Israel Schmecht wird Deutschlehrer 16‘0 “01 (00‘45“15)

10 Deutschunterricht für Mordechai: Deutsch ist ähnlich wie Jiddisch, aber ohne Humor! 16‘50“17 (00‘34“o8)

11 Beim Finanzverwalter: Yankele verzweifelt am Zugkauf 17'25“०० (01'13“13)

12 Im Freien: Ankunft des ersten Zugabteils 18‘38“14 (००'19“००)

13 Im Freien: Deutschunterricht für die »deutschen« Soldaten 18‘57“15 (00‘28“13)

14 In der Synagoge: der Rabbi schickt seinen Sohn falsche Papiere besorgen 19 '26"02 (01'04"08)

15 Im Freien: Reparatur des Zugs 20'30"10 (00'13“15)

16 Yossi ist zurück und ist kommunistisch geprägt 20'44"01 (01'33“22)

17 Im Freien: Yossi verbreitet die neue Lehre (Revolution); der Vater löst die »Versammlung « auf 22'17“24 (O1'21“O2)

18 Im Freien: die Zugvorbereitungen schreiten voran 23‘39“o1 (0०'26“13)

19 Beim Schuhmacher: der wird beauftragt, einen Lokführer zu finden 24 '05"15 (0०‘43“22)

20 Im Freien: Ankunft des »Lokführers« im Dorf 24“49“13 (01'29“02)

21 Beim Finanzverwalter: Aufregung 26'18“15 (0०‘34"06)

22 Nachts im Freien: Ankunft der Lokomotive 26‘52"21 (01'17“००)

23 Am Tag im Freien: Arbeiten an der Lok 28'09"22 (01'05“19)

24 In der Synagoge: Aufregung in der Gemeinde: der Bürgermeister fragt den Rabbi, ob die Juden tatsächlich weggehen wollen 29'15“17 (0०‘30“23)

25 Beim Rabbi: Rat der Weisen - der Rabbi beschließt, daß es in der Nacht losgeht 29 46"15 (00‘29“22)

26 Aufbruch und Abschied vom Zuhause, Segnung des Zugs, Einsteigen und Abfahrt 30'16“12 (05'17“12)

27 Postbote bemerkt die Flucht des gesamten Dorfes 35'33“24 (00‘37“24)

28 Der Zug rollt: Freude Schlomos 36'11“24 (00'33“18)

29 Der Lokführer lernt 36“45"17 (0०'23“17)

30 Im Zug: der Rabbi mahnt zur Zuversicht 37॰09"10 (००‘14“12)

31 Partisanen wollen den Zug in die Luft sprengen 37‘23“22 (0०‘27“03)

32 Im Zug: Yossi sammelt seine Genossen 37‘51“01 (0०‘49“०9)

33 Panik: ein Bahnhof wurde durchfahren (Parallelmontage: Juden - Deutsche Partisanen) 38‘40"10 (02‘57“04)

34 Rast: Heiratsgedanken (Esther); die »Kommunisten« mucken auf; Strategiebesprechung $41^{\prime} 37^{\prime \prime} 14\left(03^{\prime} 42^{\prime \prime} 18\right)$

35 Die Deutschen auf der Suche nach den Juden beim Bürgermeister 45‘20"o8 (O०'24“21)

36 »Katz und Maus« mit den Partisanen (Parallelmontage: fahrender Zug - Partisanen im Auto) 45“45"04 (O1'43"19) 
37 Von den Deutschen angehalten: Mordechai rettet die Situation 47`28“23 (05‘09“01)

38 Die Deutschen brennen das Dorf nieder, Schlomo sitzt auf dem Dach des Zuges 52 '38“०० (0०‘35"23)

39 Im Zug: eine Mutter erzählt ihren verängstigten Kindern das Märchen von Rotkäppchen 53'13“24 (00'55"24)

40 Rollender Zug 54'09“24 (००‘17“०9)

41 Im Zug: »Postenvergabe « unter den Kommunisten - Sammy kommt in ein anderes Abteil, Esther ist sauer 54'27“०8 (00‘43“03)

42 Rollender Zug 55'10“12 (0०‘25“०8)

43 Im Zug: Mutter und Kinder sprechen vom Heiligen Land 55‘35“21 (00'26“03)

44 Verlassen des Zugs und Versammeln auf einer Wiese 56'01"24 (0०‘28“05)

45 Vorbereitungen für die Zeremonie 56‘30"04 (00‘56“13)

46 Die Zeremonie 57‘26“18 (0०‘24“12)

47 Störung der Zeremonie durch die »Nazis « 57‘51“05 (01'02“01)

48 Das Freitagabend-Gebet und die Aufgabe der Partisanen 58‘53"o6 (00‘45“02)

49 Erneute Störung der Zeremonie durch die »Kommunisten«; Konfrontation »Kommunisten vs. Faschisten« 59‘38“o9 (01'21“10)

50 Schlomos »Gebet « und allgemeine Versöhnung 1:00‘59“19 (01'32“24)

51 Im Zug: Schachspiel zwischen Schlomo und Mordechai; Problem der Verpflegung 1:02'32"18 (01'41"00)

52 Esther und ihr Liebster im Wald 1:04‘13"18 (00‘50"15)

53 Fahrender Zug 1:05'04“09 (00'19“09)

54 Nächtliche Flucht der »Kommunisten «1:05‘23"18 (००‘31"11)

55 Suche nach und Einfangen der Geflüchteten 1:05‘55“04 (02‘19“०8)

56 Der Schneider fällt den Deutschen in die Hände 1:08‘14“13 (0०‘34“16)

57 Schlomo berichtet vom Schicksal des Schneiders und hat eine Idee 1:08‘49"०4 (0०'33"06)

58 Rettung des Schneiders durch Mordechai 1:09‘22"11 (02‘42“14)

59 Bestrafung der Nazis: die Juden lassen sich kulinarisch verwöhnen 1:12 ‘05"०० $\left(02\right.$ ' $\left.15^{\prime \prime} 20\right)$

60 Im Zug: der Schneider erzählt von den deutschen Bestien; er wird von Yossi aus der Partei ausgeschlossen und mit Hausarrest bestraft 1:14'20"21 (0०`47"14)

61 Die Deutschen bemerken die List 1:15‘08“11 (0०'25“०o)

62 Im Zug: Mordechai fühlt sich von den Seinen ungeliebt 1:15'33"12 (01'52"04)

63 Erneut versperren »Deutsche« den Weg 1:17‘25“17 (००‘18“15)

64 Im Zug: der Rabbi betet 1:17‘44“07 (0०‘18“21)

65 Alle müssen aus dem Zug 1:18`o3"04 (००‘17“11)

66 Im Freien: Zuspitzung der Gefahr und erstaunliche Auflösung: die »Deutschen« sind Zigeuner 1:18'20"16 (01'58“12)

67 Die Zigeuner dürfen mit in den Zug 1:20'19"03 (0०'26"16)

68 Mordechai und sein Homologe im Abteil 1:20‘45"20 (००‘18“०o)

69 Der Zug rollt wieder 1:21'03“21 (00'32“०6)

70 Im Zug: Esther eröffnet ihrem Vater, sie habe nun einen Zigeuner als Freund 1:21'36"02 (00‘44“24)

71 Im Zug: Yossis Mutter bittet ihren Sohn, wieder ein Mensch zu werden 1:22‘21“02 (0०'38“01)

72 Gemeinsames Fest mit Lagerfeuer 1:22‘59“03 (००‘31“०3) 
73 »Gemischte Liebe«: Esther und ihr neuer Lover im Zelt, Sami und eine Zigeunerin 1:23'30“07 (01'28“22)

74 Gemeinsame Musik am Lagerfeuer und auch Tanz 1:24‘59“05 (03‘03“16)

75 Fahrender Zug 1:28'02“21 (0०'26“22)

76 Im Zug: Strategiebesprechung bzg. der Reiseroute 1:28‘29“18 (0०‘40“20)

77 Im Zug: Schlomo unterbricht Esther und ihren Lover, sie reden miteinander $1: 29$ '10"14 (01'39“20)

78 Voller Hoffnung in Richtung Grenze 1:30'50"09 (01'11“13)

79 Man ist auf der Frontlinie 1:32“01“23 (00‘55“07)

80 Weiterfahrt 1:32‘57“05 (0०‘33“22)

81 Schlomo im KZ !!! - die Geschichte war phantasiert 1:33'31"O2 (O1'O2“11)

82 Abspann 1:34‘33"13 (03'52“12)

\section{»BIRKENAU UND ROSENFELD« (II.5) - SEQUENZPROTOKOLL}

1 Vorspann ०:००`००“०० (01'15"०6)

2 Myriams Ankunft in Paris (Taxi, Hotel) o1'32“13 (O2‘12“22)

3 Myriam bei dem Nachtreffen Überlebender 03“45"og (06‘35"22)

4 Nächtliches Gespräch mit Suzanne am Seine-Ufer 10‘21"06 (O2‘28“02) \& Myriam u. Suzanne sagen sich »Gute Nacht«12“49"og (01'05"15)

5 Myriam und Suzanne verabschieden sich und wünschen sich eine »Gute Nacht« 12 ‘49"09 (01'05“15)

6 Myriams Ankunft in Polen 13'55"०० (0०‘47"15)

7 Myriam im falschen »Cafe Alef « 14‘42“15 (01'20"15)

8 Myriam u. der Jude 16'03"06 (03'13“18)

9 Myriam bei Anziehen für den Tagesausflug 19‘17“०० (01‘01“22)

10 Myriam klaut sich Frühstück im Hotel 20'18“22 (00‘35"19)

11 Myriam auf dem Weg ins Lager 20‘54“16 (02‘20“21)

12 Myriam schleicht sich ins Lager 23'15"13 (01'20"19)

13 Myriam in ihrem Block 24'36"07 (04'21“04)

14 Erstes zufälliges Treffen mit Oscar 28'57"12 (01'11“23)

15 Myriam marschiert auf Lagerstraße 30'09"10 (01'38“24)

16 Lachende polnische Kinder neben dem KZ 31'48“10 (0०‘42“24)

17 Myriam in dem Latrinenblock 32'31"og (00'44"24)

18 Myriam im Waschsaal 33'16“o9 (00‘35“22)

19 Myriam belauscht enttäuschte, unberührte Besucher 33'52"06 (01'07"24)

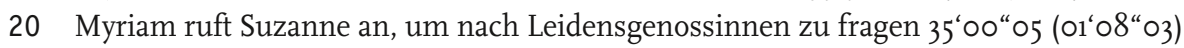

21 Myriam trifft nachdenklichen Mann 36“08"09 (01'02"23)

22 1. Gespräch mit Oscar 37'11“08 (03'08“20)

23 Begegnung mit anderen Gedenkenden, Überlebenden 40‘20"03 (03'03“02)

24 Begegnung mit einer Überlebenden an der Gaskammer 42‘37"16 (0०‘45"14)

25 Myriam auf der Treppe zur Gaskammer (»Asche.«) 43'23“०6 (००‘54"11)

26 Myriam und der Jude: Besuch ihres Elternhauses 44'17“18 (05‘34“14)

27 Myriam und Oscar in einem Cafe 49‘52“o7 (02‘26“o6)

28 Myriam auf ihrem Zimmer, Tagebuch schreibend (»brume de l'oubli«) 52`18“14 (01'28“05) 
29 Erinnerung: Myriam u. Ginette im Tanzlokal 53446"20 (03“02“09)

30 Myriam ruft Suzanne an 56'49"05 (00'25“00)

31 Myriam auf der Suche nach den Spuren (»Il y a plus rien.«) 57‘14“05 (O2‘47“16)

32 Myriam nachts im Lager bei fernem Hundegebell 1:00“01“21 (००`48“16)

33 Oscar abends bei Myriam 1:00'50"12 (01'50"08)

34 Autofahrt mit Oscar am Lager entlang 1:02‘40"21 (02'52“12)

35 Myriam vor der Fotowand 1:05‘33“08 (01‘28“22)

36 Mit Oscar im Auskleideraum 1:07‘02"05 (02‘24"04)

37 Mit Oscar am »Aschensee« 1:09‘26“10 (01'14“07)

38 Oscar fotografiert Myriam 1:10“40"18 (00‘43"19)

39 Myriam rastet im Imbiß aus 1:11'24"13 (02'51"15)

40 Gemeinsames Abendessen 1:14'16“03 (0०‘38“20)

41 Zusammen in der Disco 1:14‘54“24 (01'34“०6)

42 Gemeinsam auf einer Bank nachts 1:16‘29"06 (01'05“00)

43 Letzte Spurensuche im Lager 1:17‘34“07 (01'38“22)

44 Myriam legt einen Stein an einer Gedenkstätte ab u. begegnet einem jungen Mädchen 1:19“13“04 (00'58“13)

45 Myriam verläßt das Lager u. erzählt Oscar von ihrem Vater 1:20‘11"17 (01‘35“12)

46 Myriam schreit ins Lager: »Je suis vivante!« 1:21'47“04 (01'48“०7)

47 Bahnhof: Verabschiedung 1:23“35“12 (02‘15“17)

48 Abspann: »Ce film est une fiction [...]« 1:25'51“04 (02‘33“24)

5. Die folgenden Ausführungen beziehen sich v.a. auf den Artikel »100. Peirce and his followers« im HSK (insbes. die Grafik zu den Universalkategorien auf S. 2018). Peirce gilt als Begründer des Pragmatismus und der modernen Semiotik. Seine Zeichentheorie beeinflußte vor allem die Arbeiten von R. Jakobson, U. Eco und R. Kloepfer und bildet heute die Grundlage semiotischer Wissenschaft.

6. Mit dem Theorem »Aliquid stat pro aliquio« gründete Ferdinand de Saussure die Basis für die sémiologie. Sein »Cours de linguistique générale« (hg. 1916, dt. »Grundfragen der allgemeinen Sprachwissenschaft«) leitete eine neue Epoche der Sprachwissenschaft ein, die von dem Gedanken eines systematischen Zusammenhangs zwischen Erscheinungen (»signifié») und sprachlichem Zeichen (»signifiant«) geprägt war.

7. Siehe die zahlreichen Artikel im ersten Abschnitt der Bibliographie.

In Betonung des gleichzeitig gesellschaftlichen und subjektiven Charakters von Kunst bzw. Literatur entsprachen die Prager Strukturalisten den Forderungen Michail Bachtins, der Textstruktur als die Aufführungsform von Dia- bzw. Polylogizität zu sehen lehrte (=Volosinov 1930=1975: 83-7; 175f.). Es liegt hier ein gemeinsames romantisches Erbe vor (s.u. zu Schleiermacher und der Relation von Hermeneutik und Semiotik), nicht ein direkter Einfluß. 


\section{C) Exkurse}

\section{C1) Exkurs zu Peirce' Konzept der Semiose und seiner Unterscheidung DER DREI INTERPRETANTEN-TYPEN 5}

Entgegen der semiologischen Tradition nach de Saussure, die einen dyadischen 1:1Zusammenhang zwischen »Signifikant « und »Signifikat « annimmt ${ }^{6}$, entwickelt Charles Sanders Peirce ein Konzept der Semiose, das den prozessualen Charakter des Zeichens betont und sich auf die potentiell immer weiter verweisende Zeichenbildung einläßt. Bei diesem triadischen Zeichenmodell erzeugt der Zeichenträger (Repräsentamen) in Verbindung mit dem Zeichenobjekt eine Modifikation, den sog. Interpretanten (Zeichenwirkung im Bewußtsein des Interpretierenden).

Künste - insbesondere narrative - kompensieren die Trennung der Kommunikationspartner durch Integration von Kontextbedingungen - u.a. »Norm und Wert« bei Mukařovský - dergestalt, daß die wechselseitige Steuerung der Versetzung in Zeiträume, Beziehungssysteme (z.B. empathetisch) und Konstruktionsbedingungen teilweise die Referenzfunktion überformen (vgl. Souriau 1954 zum filmischen (Diskurs-)Universum und Möller 1986 zum »Kontexttheorem«). Die triadische Relation (Zeichenkörper - modifiziertes Bewußtsein - Objekt) gibt es nur als Einheit, als Funktionsrelation und in Abhängigkeit vom jeweiligen Kontext.

Um den Semioseprozeß zu strukturieren, formuliert Peirce drei Interpretantentypen. Er erkennt bereits den Eindruck des Zeichens als Interpretanten und nennt ihn den emotionalen Interpretanten, der eine innere Gestalt erweckt. »The first proper significate effect of a sign is a feeling « (Peirce 1965, V: 475). Es kann beispielsweise in einer Musiksequenz eine bestimmte Bezogenheit spürbar sein. Ist der Eindruck nicht konkret, so zwingt er zur Füllung. Dies übernimmt der energetische Interpretant, indem er die Bezogenheit durch Anstrengung des Bewußtseins erfüllt, »an exertion upon the Inner World, a mental effort.« (Ebd.) Schließlich führt Peirce den logischen Interpretanten ein und definiert »The deliberately formed, self-analyzing habit [...] is the living definition, the veritable and final logical interpretant.« (1965: 491) Er schafft eine Bewußtseinsgestalt, die sich in der permanenten Auseinandersetzung mit der Interpretationsgemeinschaft verfestigt. Ein Begriff ist in einem Spannungszustand zwischen seiner Bildung in der Vergangenheit und seiner Zukunftsbezogenheit, da er, sobald ein Zeichenkörper an ihn erinnert, wieder auf- bzw. abgerufen werden muß. Dieser dreistufige Prozeß findet stets von neuem statt.

\section{C2) EXKurs ZUM Dialog ZWischen Sender Und EMPFÄngeR UND DER DAMIT EINHERGEHENDEN SYMPRAKTISCHEN DIMENSION IN KÜNSTLERISCHEN WERKEN NACH KLOEPFER}

Unter Bezugnahme auf den Philosophen Martin Buber, den Russischen Formalisten Bachtin und den Prager Strukturalisten Mukařovský arbeitet Kloepfer die Grundlagen des >dialogischen Prinzips < des »Dialogs zwischen Autor und Leser « zunächst für literarische (Kloepfer 1982: 358), später für filmische Texte heraus (Kloepfer7). 
Das Konzept des Dialogs in künstlerischer Kommunikation impliziert »die stete Einbeziehung des Gesagten und der expliziten Voraussetzungen«, wobei der Prozeßcharakter hierbei von entscheidender Bedeutung ist (Kloepfer nach Mukařovský 1982: 361). Dies versucht Kloepfer, am Beispiel der alltäglichen Kommunikation zu erläutern: »Manchmal greifen wir auf vergangene Gespräche zurück und vertiefen Argumente, als wenn nichts gewesen wäre«, was jedoch nur aufgrund eines gewissen gemeinsamen Wegs möglich ist (ebd.: 362). Neben der Erinnerung zeichnet sich ein Dialog gleichermaßen bzw. insbesondere durch die Erwartung von etwas Zukünftigem aus ${ }^{8}$. Diese doppelte Ausrichtung beschreibt Kloepfer, wie folgt: »In die perspektivelose Momentaneität kommt durch Gedächtnisleistung die gelernte Erfahrung (das Vorangegangene) und mit der Phantasie der prospektive Zugriff auf die Zukunft: >Die Erwartung, daß was geschieht, ist das wahre Wesen des Dialogs «.« (Ebd.: 373, H.i.O.)

Voraussetzung hierfür ist jedoch die Intensivierung der Kommunikation durch die dynamisierende Wirkung der ästhetischen Kommunikationsfunktion. Ist ein Text vom Autor künstlerisch, d.h. ästhetisch reich gestaltet, (so) kann er die Vermögen des Adressaten zur Entfaltung bringen, anstatt ihn Bekanntes nur wiedererkennen zu lassen:

»Die angedeutete Auffassung vom dialogischen Prinzip beruht auf der Annahme, daß der dialogische Austausch mehr in dem >Wecken der Produktivität des jeweils Anderen beruht, denn auf dem Hin und Her von Informationen. [...] daß gerade im Dialog >das Verstehen ganz auf der inneren Selbsttätigkeit beruht, und [daß] das Sprechen miteinander nur ein gegenseitiges Wecken des Vermögens des Hörenden< ist.« (Kloepfer nach Humboldt 1982: 368f., H.i.0.)

8. Sich auf M. Buber beziehend macht Kloepfer einschränkend auf die besondere Natur dieser Erwartung aufmerksam: »Nur die Erwartung, die nicht auf die Erfüllung eines Gewußten lauert, ist dialogisch wirkungsvoll, nur sie fördert im Wartenden die Bereitschaft, sich auf seine Möglichkeiten zu konzentrieren und sich für Neues zu öffnen, sich sansprechbarく zu halten." (Kloepfer nach Buber 1982: 374, H.i.0.).

9. Vgl. in diesem Zusammenhang die Ausführungen des Existenzphilosophen F. Heinemann hinsichtlich der Besonderheit des Menschen: »Er definiert den Menschen als das Lebewesen mit den größten Resonanz- und Respons-Möglichkeiten. [...] Ein so komplexes Zeichen wie ein literarischer Text kann nacheinander und sogar gleichzeitig Verschiedenstes als Respons hervorrufen.« (Kloepfer nach Heinemann 1982: 370)

10. »Zeichen sind nämlich nicht nur bedeutend, sondern vor allem sanimierendı: Nicht was über die Zeichenprozesse in mein Bewußtsein kommt, ist primär wichtig, sondern, daß ich innerlich angeregt werde.« (Kieser nach Kloepfer 1997: 20)

11. Vgl. hierzu Sartres Aussagen zur Ko-Autorschaft des Lesers: »Es ist also nicht wahr, daß man für sich selbst schreibt. [...] Aber der Vorgang des Schreibens schließt den des Lesers ein als sein dialektisches Korrelat, und diese beiden zusammenhängenden Handlungen erfordern zwei verschiedene Handelnde. Die gemeinsame Anstrengung von Autor und Leser wird jenen konkreten und imaginären Gegenstand auftauchen lassen, der das Werk des Geistes ist. Kunst gibt es nur für und durch andere. [...] So appelliert der Schriftsteller an die Freiheit des Lesers, daß sie an der Produktion seines Werks mitarbeite [...] (Sartre 1981: 39 ff.)

12. Entsprechend der Differenzierung der Interpretantentypen müssen beide Bewußtseinsebenen beansprucht werden, wenn mehr Welt erfahren werden soll (s.u. und I.2.3).

13. Roloff versucht, dieses Ineinanderwirken mit der Definition der Intermedialität zu erfassen: »so kann man Intermedialität als Formel einerseits für die Präsenz und Produktivität 
Diese Möglichkeit der besonderen Nutzung der poetischen Funktion in der ästhetischen Kommunikation hat zur Folge, daß der Autor mehr der Inspirierende als der Inspirierte ist (ebd.: $367 f$.). Demnach geht es beim Dialog zwischen Autor und Leser »auch um eine besondere Zeichensetzung, die mehr oder weniger die ganze Person der Beteiligten mit ihrer Geschichte aktiviert, also um eine besondere Form der >Aneignung<.«(Ebd.: 366)

Das Maß, in dem ein Text auf den Adressaten einwirkt, hängt folglich nicht nur von seiner Qualität, sondern insbesondere vom Mithandeln des Kommunikationspartners ab. ${ }^{9}$ Die Wichtigkeit dieser Eigenleistung entspringt der Auffassung, daß »Kunstwerke Aufforderungen sind, zeichengesteuert mitzuhandeln, mitzufühlen, mitzuverwirklichen wie - pointiert formuliert - ein dressierter Affe oder souverän in der (Ko-)Autorschaft« (Kloepfer 2000: 374). Dieses Wechselverhältnis aus angelegter Aufforderung zum Sich-Einbringen ${ }^{10}$ und Annahme derselben durch Teilhabe am Erschaffen des Werks $^{11}$ belegt, daß ästhetisch hochwertige Kommunikation im Prinzip »alle Formen der Zwiesprache zu realisieren vermag « (Kloepfer 1982: 375).

Dem Ästhetischen wie dem Dialogischen liegt ein besonderes Spannungsverhältnis, eine dynamische Energie, zugrunde. Bezüglich der Komplexität mit dem Roman, als »der ausgeprägtesten dialogischen Gattungsform «, durchaus vergleichbar, bietet auch der künstlerische Spielfilm dem gewillten Zuschauer, unterschiedliche Ebenen des Mitspielens an (ebd.: $367 f$.): Erstens »kann das dialogische Alternieren in der einander zugeordneten >Zeichensetzung > vielfältig sein, die Gegenrede des Zuschauers kann im Ausdenken unausgesprochener Sätze«, ungezeigter Bilder bestehen. Zweitens ist es »wichtig, daß das jeweils mit dem Text Gelernte wieder Teil der textinternen Interaktion wird«. Drittens kann es zu einer »Konfrontation verschiedener Welt>sichten« «ommen, so »daß der Zuschauer nicht nur verschiedene Weltsichten einbringen kann, sondern ihre Inkompatibilität aushalten muß «; wobei er sich an den Spannungen zwischen den ideologischen und moralischen Systemen entfalten kann (Kloepfer 1982: $367 f .$, H.i.O.).

Texte jeglicher Art sind, Kloepfer zufolge, dann sehr dialogisch angelegt, wenn sie in einer Wechselrede den Leser derart einbeziehen, daß dieser sich kraft seines vorbewußten und bewußten Vorwissens ${ }^{12}$ und seines sympraktischen Verhaltens in das Kunstwerk sinnfüllend investieren kann. Dabei wird ein progressiver Lernprozeß aktiviert, in dessen Verlauf vergangene Kommunikation immer wieder in die Gegenwart einfließt. Todorov formuliert:

»Intentionellement ou non, chaque discours entre en dialogue avec les discours antérieurs tenus sur le même objet, ainsi qu'avec les discours à venir, dont il pressent et prévient les réactions. La voix individuelle ne peut se faire entendre qu'en s'intégrant au chœur complexe des autres voix déjà présentes. «(Todorov 1981: 8)

Es kommt im besten Fall zu einer reziproken Durchdringung von (Welt-)Bildern, die immer wieder ein-gesetzt werden, um Künftiges zu verstehen. Der Mensch erkennt in der Kunst nicht nur mit steigender Kompetenz immer mehr Bilder sprachlicher und nichtsprachlicher Art, sondern, durch die Teilhabe am ästhetischen Prozeß, die Vielfalt der Welt und der eigenen Vermögen.13 Intermedialität darf darüber nicht nur als 
potentiell unendliches Verweisen von Zeichen auf andere Zeichen verstanden werden. Für die Theorie der Dialogizität ist vor allem wichtig, daß dies ein fortschreitender Prozeß ist; das Erlernen der »Sprache der Welt«, d.h. der Sprache des Anderen (hier: des spezifischen Texts), ermöglicht uns, hieraus die eigene neue Sprache zu formulieren.14 Diese ist wiederum eine kreative Basis für das Anknüpfen an neue Zeichengebräuche - ästhetisch-künstlerischer oder alltäglicher Gestaltung. Kunst erweitert damit nicht nur die kreativ-künstlerischen Vermögen, sondern kann für den Umgang mit der Alltagswelt genutzt werden. Wichtig ist der Transfer des künstlerisch Erlebten auf die eigene Lebenswelt. In diesem Zusammenhang verweist Kloepfer auf einen Film, der die angesprochenen Aspekte deutlich macht. Jaco van Dormaels Toto DER HeLD »[...] gibt dem Zuschauer durch den autoreferenziellen Umgang die Gelegenheit, sich des eigenen Lernens bewußt zu werden und eine dem Helden analoge Täuschung zu erleben und Selbstaufklärung zu leisten« (Kloepfer 1999 c: 45).

Semiose ist jedoch kein Perpetuum mobile. Sie verlangt die Selbstinvestition in den Zeichenge-brauch, damit das Mangelwesen Mensch aus der Fülle des ZeichenSeins das Zeichen-Haben, nämlich semiotische Kompetenz, generiert.

von Bildern und Texten im literarischen Text, und andererseits von Texten und Bildern im Bild bezeichnen. Der Begriff Intermedialität entspricht der Erkenntnis, daß wir in einer Kultur der Einbildungen leben, nicht nur in dem Sinne, daß Bilder endlos Bilder widerspiegeln, sondern Bilder zugleich auch, im Sinne einer komplementären Phantasie, die verschiedenen Sinne aktivieren: Geschichten und Texte produzieren Bilder, genau so wie umgekehrt Texte eine komplementäre Bildphantasie, innere Filme hervorrufen." (Roloff in Strosetzki/Stoll 1991: 1)

14. Diesen Prozeß illustriert Kloepfer mit der Analyse des Films »Toto der Held« von Jaco von Dormael. Sie ist veröffentlicht in Kodikas/Code 1994: 47-72 sowie in Auszügen in Kino-/ (Ro)Mania I 1999 c: $43 \mathrm{ff}$.

15. Ich fasse nach Dewey, John, »Kunst als Erfahrung«, Frankfurt a.M. (Suhrkamp) 1988 zusammen und gebe nachfolgend nur die jeweilige Seite an.

16. Vgl. u.a. Kaltenbrunner 1983 zum »Rhythmus des Lebens«, Winckelmann 1990 zur Chronobiologie, Seidel 1976 zum Rhythmus in der Musik.

17. Siehe unten (b).

18. Seidel bemerkt hinsichtlich umfangreicher und mannigfaltiger Ereignisse wie beispielsweise einem Sonatensatz, »daß sie ihr Dasein der bewußten Erinnerung des Vergangenen und der gespannten Erwartung des Kommenden verdanken.« (1976: 2) »Aristides [...] weiß, daß daran [am Rhythmus] mehr Geisteskräfte beteiligt sind als die im Moment verhaftete Wahrnehmung, das bloße Hören, Fühlen und Sehen: das Gedächtnis des Vergangenen nämlich und die davon geprägte Erwartung des Kommenden. Es tritt der Geist also den Bewegungen aktiv gegenüber; er versucht, sie zu erfassen in ihren Abmessungen, in ihrem Auf und Ab.« (Ebd. 21) 


\section{C3) EXKURS ZUM RHYTHMUS IN KÜNSTLERISCHEN WERKEN UND DESSEN AUSWIRKUNGEN AUF DAS MENSCHLICHE BEWUSSTSEIN}

a) Die Allgegenwart von Rhythmus in der Kunst und die variierte Wiederkehr von Elementen als Kompositionsprinzip nach John Dewey ${ }^{15}$

Ausgangspunkt der Überlegungen des amerikanischen Philosophen und Psychologen John Dewey zum Rhythmus in künstlerischen Werken ist dessen Allgegenwart in der Natur. Ausdrücklich weist er auf die enge Verknüpfung zwischen den breiteren Rhythmen in der Natur und den elementaren Daseinsbedingungen des Menschen hin (171). ${ }^{16}$ Nach Dewey ist Rhythmus als Wesensmerkmal der Umwelt überhaupt Voraussetzung für die Existenz künstlerischer Form.

»Weil Rhythmus ein allgemeingültiges Daseinsschema darstellt, das einer jeglichen Verwirklichung von Ordnung innerhalb des Wandels zugrunde liegt, durchzieht er sämtliche Gattungen der Kunst: Literatur, Musik, Bildhauerei, Architektur ebenso wie den Tanz. [...] Dem Rhythmus einer jeden Kunst und eines jeden Kunstwerks liegt, gleichsam als Substrat in den Tiefen des Unbewußten, das Schema der Beziehungen des Lebewesens zu seiner Umwelt zugrunde.« (174)

Aufbauend auf diesen Beobachtungen - die Eisenstein unter dem Begriff des organischen Prinzips zusammenfaß $\mathrm{t}^{17}$ - definiert Dewey Rhythmus im angesprochenen Sinne der Bedingung für Form folgendermaßen: »Er ist die geordnete Variation des Wandels«, wobei er betont, daß dieser Wandel am rechten Ort, d.h. an einer bestimmten Stelle innerhalb des Ganzen stattfinden müsse (179).

Dabei macht Dewey darauf aufmerksam, daß die sich rhythmisch abwechselnden Teile in enger Beziehung zueinander stehen: »Indem ein jeder Taktschlag einen Teil innerhalb des Ganzen hervorhebt, trägt er zur Stärke des Vorangegangenen bei, wobei er eine Spannung erzeugt, die zugleich die Forderung nach etwas Nachfolgendem ist.« $(179)^{18}$ Demnach zeichnet sich Rhythmus durch »natürlich einander Widerstand leistende Energien « aus (180). Das Entstehungsschema des rhythmischen Wandels antagonistischer Kräfte skizziert Dewey wie folgt:

»Eine jede gewinnt während einer bestimmten Dauer an Intensität, drängt jedoch dadurch eine gegensätzliche Energie zurück, bis diese andere, die sich gerade entspannt, während sie sich ausdehnt, überwältigen kann. Dann kehrt sich der Vorgang um, nicht unbedingt im gleichen Zeitabstand, aber doch in einem Verhältnis, das als geordnet empfunden wird. Widerstand staut Energie. Er wirkt so lange aufhaltend, bis Lockerung und Expansion folgen.« (180)

Die trotz klarer Abgrenzung zwischen den sich abwechselnden Energien bestehende Beziehung läßt sich schematisch wie folgt darstellen:

Jede Wiederkehr einer der antagonistischen Kräfte trägt sowohl den Charakter der Erinnerung im Sinne einer Anknüpfung an vorhergehende Manifestationen dieser Energie, als auch den Charakter der Innovation im Sinne einer Fortführung dieses Energiestranges, jedoch in Variation. Dem Aspekt der modifizierten Wiederkehr wird insofern Rechnung getragen, als die beiden Energien durchgehend in Abwandlung auftreten und sich somit nie identische Szenen wiederholen. Diese Tatsache - so Dewey - unterscheidet eine ästhetische, lebendige Wiederkehr von einer statischen, identischen Wiederholung ohne Rhythmuscharakter. 
Ästhetische Wiederkehr ist somit eine Frage von Beziehungen, wobei diese wiederkehrenden Energien einerseits der Festlegung und Abgrenzung der einzelnen Teile dienen, andererseits jedoch auch verbinden und auf diese Weise von entscheidender Bedeutung für die Kompositionsstruktur sind: »[...] die individuellen Gebilde, die sie abgrenzen, erfordern gerade wegen der Beziehung Assoziation und Interaktion mit anderen individuellen Einheiten. Insofern dienen die einzelnen Teile in lebenswichtiger Weise der Konstruktion eines ausgebreiteten Ganzen.« (193) Seine Definition von Rhythmus aufgreifend, unterstreicht Dewey die Wichtigkeit der Variation und gerade nicht die »buchstäblichen Wiederkehr mit regelmäßiger Wiederholung identischer Elemente«, welche er als statische »Tick-Tack-Theorie« bezeichnet (189). ${ }^{19} \mathrm{Ihm}$ geht es bei der Wesensbestimmung von Rhythmus vielmehr um eine funktionale Wiederkehr von Elementen, die jedoch beständigen Modifikationen als Voraussetzung für Wachstum unterliegen:

»Nach der Definition von Rhythmus als geordneter Variation einer Manifestation von Energie ist die Variation nicht nur ebenso wichtig wie die Ordnung; sie ist vielmehr ein unerläßlicher Koeffizient einer ästhetischen Ordnung. Je größer die Variation, desto interessanter der Effekt, vorausgesetzt, die festgesetzte Ordnung wird beibehalten.« (190)

Sein Verständnis von ästhetischer Wiederkehr präzisiert Dewey wie folgt, wobei er den Aspekt der Mannigfaltigkeit versus Ordnung als Verlangen eines jeden Organismus abschließend auf den Punkt bringt:

»Ästhetische Wiederkehr ist lebendig, physiologisch und funktional. Es handelt sich dabei eigentlich um Beziehungen und nicht um Elemente, die wiederkehren, und zwar wiederholen sie sich in verschiedenen Zusammenhängen und mit verschiedenen Konsequenzen, so daß jede Wiederkehr den Charakter einer Innovation wie auch den einer Erinnerung trägt. Während sie noch eine erweckte erfüllt, erregt sie gleichzeitig ein neues Verlangen, ruft eine ungesättigte Neugierde wach und begründet eine veränderte Spannung.« (196)

Hinsichtlich der Gegenüberstellung von Kunst und Wissenschaft leistet Dewey einen wichtigen Beitrag. Obgleich beide das Interesse an Rhythmus in gewisser Weise verbindet, besteht ein zentraler Unterschied im Hinblick auf die Form und Tiefe der Erkenntnis des Adressaten. Während die Naturwissenschaften die Naturgesetze dem Denken zugänglich machen wollen, versucht die Kunst, verschiedene Rhythmen der »Wahrnehmung in der unmittelbaren Erfahrung« anzubieten (174). Um von einer ästhetischen Erfahrung sprechen zu können, müssen die Rhythmen des künstlerischen Werks - so Dewey - zu einem Rhythmus in der Erfahrung selber werden, einem »Rhythmus im Erfahrungsinhalt« (188). Ein ästhetischer Rhythmus basiert demnach auf Perzeption und schließt folglich all das ein, was durch das Subjekt im Akt der Wahrnehmung eingebracht wird:

19. »Rhythmus ist also Wiederkehr von Ähnlichem in ähnlichen Abständen [...]. Der Rhythmus gestattet im Gegensatz zum Takt sehr wohl einen Wechsel der Zeiteinheit wie des Tempos. [...] Das Metrum ist rational, der Rhythmus irrational. Der irrationale Rhythmus ist lebendige Bewegung und als solche sinnlich faßbar.« (Jost 1983: 15)

20. »Der Mensch erfreut sich an rhythmischer Darstellung und Verkörperung, denn solches ist beispielhaft für die Beziehungen, die - ob auf natürlichem Wege oder künstlich herbeigeführt - den Lauf des Lebens bestimmen.«(1988: 174). Siehe oben (a). 
»Die gegenseitige Erhellung von Teilen und einem Ganzen, die [...] ein Objekt zu einem Kunstwerk macht, wird erreicht, wenn alle Konstituenten eines Werks in rhythmischer Verbindung stehen mit allen anderen Teilen derselben Art [...] und wenn alle diese besonderen Faktoren ihrerseits einander wechselseitig verstärkt als Variationen zur Geltung bringen, die eine integrierte und komplexe Erfahrung aufbauen.«(198f.)

\section{b) Rhythmus als zentrales Struktur- und Steuerungselement in der filmischen Komposition nach Eisenstein}

Vor Dewey weist bereits der russische Filmregisseur und -theoretiker Sergej Eisenstein auf die grundlegende Verknüpfung zwischen den Naturgesetzmäßigkeiten bzw. -rhythmen und dem menschlichen Organismus hin, wobei er diese Erkenntnis in erster Linie auf die filmische Komposition und deren spezifisches Wirkpotential anwendet.

Im Rahmen seiner Ausführungen zur Komposition eines Kunstwerks spricht Eisenstein von der Möglichkeit, eine Haltung zu einer dargestellten Tatsache durch die Art und Weise darzustellen, in welcher diese wiedergegeben wird: »Eines der wirksamsten Mittel, diese Haltung wiederzugeben, liegt in der Komposition.« (1960: 72) Dabei geht es, gemäß Eisenstein, nicht so sehr um die Haltung des Protagonisten zur Tatsache, sondern vielmehr um die Einstellung des Autors und dessen Wunsch, wie »der Zuschauer die dargestellte Tatsache aufnehme, empfinde und auf sie reagiere.« (1960: 72) »Die Komposition ist - so Eisensteins wiederholte These - wie ein großer Gestus, über den der Autor sein Verhältnis zu den Phänomenen entwickelt und dem Publikum ein entsprechendes Verhalten anbietet.« (Kloepfer nach Eisenstein 2000: 377)

Komposition als »ein Grundgesetz für die Gestaltung einer Darstellung« erreicht besondere Wirkmacht durch die künstlerische Montage des aufgenommenen Filmmaterials im Rahmen der Post-Produktion (1960: 72). Diese spezifische Form der Montage bezeichnet Eisenstein als »das stärkste Kompositionsmittel für die künstlerische Realisierung eines Sujets, als die Syntax des richtigen Aufbaus aller Einzelfragmente eines künstlerischen Films.« (1973: 142) Dem Prinzip der ästhetischen Montage versucht er durch die Untersuchung der japanischen Hieroglyphik auf die Spur zu kommen. Am Beispiel kurzer poetischer Texte beobachtet Eisenstein, wie die Kombination zweier materieller Bildzeichen eine »transzendentale Resultante, einen Begriff entstehen lassen« (1975: 206). Die Einzel-Hieroglyphen »zünden zum - Ideogramm« (1963: 265f.); das Bildzeichen für Wasser verbunden mit dem eines Auges bedeutet beispielsweise weinen. Die Entstehung des Begriffs hängt jedoch unabdingbar vom Leser ab, welcher die Aneinanderreihung zur Vollendung bringen muß (1963: 268). Das prinzipielle Funktionieren der japanischen Begriffsbildung versucht Eisenstein wie folgt in die filmische Syntax zu übertragen: »Meiner Ansicht nach ist aber Montage nicht ein aus aufeinanderfolgenden Stücken zusammengesetzter Gedanke, sondern ein Gedanke, der im Zusammenprall zweier voneinander unabhängiger Stücke >entsteht<.« (1975: 2o6, H.i.O.) Hierbei wird die Spannung wiederum durch den Grad der Nicht-Übereinstimmung bestimmt. Im Zusammenhang mit dem darauf folgendem Element wird sie - so Eisenstein - zum wirklichen Element des Werkrhythmus.

Aufgrund der Tatsache, daß der Mensch an Rhythmen gebunden ist, die seinem Bewußtsein zwar nicht unmittelbar zugänglich sind, gleichwohl sein Sehen und Erleben der Welt bestimmen, legt Eisenstein - in Analogie zu Dewey ${ }^{2 \circ}$ - besonderes Augenmerk auf die Korrespondenz »des Rhythmus im Aufbau der filmischen Proportionen 
mit dem Rhythmus der Gesetzmäßigkeiten in den Erscheinungen in der Natur« hinsichtlich der Verwirklichung einer organischen Filmstruktur (1973: 158). Das kompositorisch spannende Phänomen des Rhythmus stellt für Eisenstein somit ein zentrales Strukturelement im Hinblick auf das Filmganze dar und hat darüber hinaus eine entscheidende Steuerungsfunktion für die Eigenleistung des Zuschauers: »Die Zeitdauer dieser Abschnitte, das Tempo und ihre Reihenfolge vermittelt dem Zuschauer mit Hilfe dieses rein physiologischen Prozesses den Rhythmus und die Schnelligkeit der Assoziationen. Und genau dies ruft im Publikum eine echte Gemütsbewegung hervor.« (1973: 192) Die direkte Aus- bzw. Einwirkung des kompositorischen Rhythmus, der »Spannungs-Phasen«, auf den Zuschauer beschreibt Eisenstein mit einem In-Bewegung-Setzen desselben (1975: 203): »Der [...] Rhythmus erfaßt den Zuschauer, >nimmt ihn gefangen und setzt ihn in Bewegung «.« (1984: 225, H.i.O.)

Die - bereits mit Dewey analysierte - rhythmisch-funktionale Wiederkehr als Kompositionsprinzip ermöglicht dem geneigten Zuschauer eine genußvolle Vermögensentfaltung in der Ekstase. Diesen Zustand des Außer-Sich-Seins beschreibt Eisenstein folgendermaßen:

»Das Pathos tut seine Wirkung - wenn der Zuschauer gezwungen wird, von seinem Sitz aufzuspringen. Wenn er gezwungen wird, auf der Stelle zusammenzubrechen, wenn er gezwungen wird, zu klatschen, zu schreien. Wenn seine Augen gezwungen werden, vor Begeisterung zu leuchten, bevor sie Tränen der Begeisterung vergießen... Kurz, wenn der Zuschauer gezwungen wird, saus sich herauszugehen<. [...] ex-tasis - wörtlich sausserhalb seiner selbst stehen<, was besagen will, [...] >sich aus seinem gewohnten Zustand entfernen«.» (1960: 88)

Die Wirkung des Pathos besteht für Eisenstein also in allem, was den Adressaten in den beschriebenen »Extremzustand « versetzt, wobei er den besagten Qualitätssprung als Voraussetzung für die Verwirklichung einer pathetischen Kompositionsstruktur ansieht (1984: 218). Dieser kompositorisch ermöglichte Sprung aus sich heraus bewirkt »le passage à quelque chose d'autre, à quelque chose d'une qualité différente, quelque chose de contraire à ce qui précède« (Kloepfer nach Eisenstein 1998: 7), »einen Sprung in eine neue Qualität, und erreicht meistens den Umfang eines Sprunges in den Gegensatz« (1960: 93f.). Eine pathetische Struktur muß demnach in all ihren Merkmalen diesen Übergang in eine andere Dimension anbieten. Nur in diesem Fall kann man - so Eisenstein - von einem wahrhaftigen Kunstwerk sprechen, welches seine Adressaten mittels kalkulierter Steuerung einzubeziehen, zu ergreifen vermag (160: 89).

»Une véritable œuvre d'art est une organisation par laquelle à la fois l'auteur - par toutes ses facultés, toutes ses compétences, tout son travail - et le spectateur - par toutes ses énergies appliquées - arrivent » à la forme la plus haute de l'organique: le pathétique ». Une œuvre est vivante proportionnellement à la participation du spectateur au processus de la création." (Kloepfer nach Eisenstein 1998: 8f.)

21. Vgl. Norman/Rumelhart 1978, Mandler 1985, Ohler 1990. 


\section{C4) Exkurs zu den Perzeptions-, KonzePt- und Stereotypengeleiteten FiLmStrukTUREN NACH WUSS}

Auf Basis des in den Kognitionswissenschaften damals verbreiteten Schema-Ansat$z^{21}$ arbeitete Wuss systematisch ein Modell aus, wonach innerhalb der filmischen Gestaltung drei unterschiedliche Strukturangebote $\mathrm{zu}$ unterscheiden sind, die jeweils verschiedene Rezeptionsstrategien nutzen. Der Regisseur steuert demnach das Semioseverhalten der Adressaten, indem er perzeptive, konzeptuelle und stereotype Leistungen einfordert. Zentral ist hierbei die systematische Verbindung dieser drei Dimensionen der Verarbeitung.

Die drei filmischen Struktur-Typen unterscheiden sich nach Auffälligkeits- und Evidenzgrad, Bewußtheitsgrad bei der Rezeption, Lernverhalten im Rezeptionsprozeß, semantischer Stabilität, Speicherung im Gedächtnis, Zeichenhaftigkeit, Auftrittshäufigkeit und der Nutzung des Wiederholungsprinzips.

\begin{tabular}{|l|c|c|c|}
\hline $\begin{array}{l}\text { Kognitive } \\
\text { Invariantenbildung }\end{array}$ & $\begin{array}{c}\text { Perzeptiv geleitete } \\
\text { Filmstruktur }\end{array}$ & $\begin{array}{c}\text { Konzeptuell geleitete } \\
\text { Filmstruktur }\end{array}$ & $\begin{array}{c}\text { Stereotypengeleitete } \\
\text { Filmstruktur }\end{array}$ \\
\hline Evidenzgrad & Kaum evident & $\begin{array}{c}\text { Invarianten des } \\
\text { Denkens }\end{array}$ & $\begin{array}{c}\text { Invarianten der } \\
\text { Motive }\end{array}$ \\
\hline Lernverhalten & $\begin{array}{c}\text { Wahrscheinlichkeits- } \\
\text { lernen }\end{array}$ & $\begin{array}{c}\text { Lernen durch freie } \\
\text { Kombination }\end{array}$ & Beide Formen \\
\hline Bewußtheitsgrad & Un-/vorbewußt & Bewußt & $\begin{array}{c}\text { Unbewußt } \\
\text { (Gewöhnung) }\end{array}$ \\
\hline Auffälligkeit & Gering & Maximal & Abnehmend \\
\hline Semantische & Instabil & Stabil & Stabil \\
\hline Gtabilität & Arbeitsgedächtnis & Langzeitgedächtnis & Tertiärgedächtnis \\
\hline Zeichenhaftigkeit & Latent & Deutlich & Verblassend \\
\hline Auftrittshäufigkeit & Intratextuelle & Intratextuelle & Intertextuelle \\
Pluralität & Singularität & Pluralität \\
\hline Wiederholung & Im Werk & Einmalig im Werk & In der Kultur \\
\hline
\end{tabular}

Abb. I.2.2.a: Drei Strukturtypen der ästhetischen Komposition (angelehnt an Wuss 1993: 64)

Wuss erlaubt mit diesem Modell, die semiotisch-ästhetische Struktur, in Verbindung mit der sympraktischen Herausforderung, als Ausgangspunkt für die Typologisierung von Filmen zu nehmen. Ist beispielsweise die Aufforderung, über Wahrscheinlichkeiten Neues zu erschließen, in einem Werk früh und vorbewußt angelegt, so kann das Bewußtsein mit Hilfe der latenten Zeichen perzeptive Invarianten ausbilden, d.h. auf Strukturen antworten, die das sinnliche Wahrnehmen als erste Stufe zur Erkenntnis ansprechen. Ist eher bewußte, gelenkte Kombinatorik dominant, kann vor allem das Langzeitgedächtnis die deutlich auffälligen und bewußten Zeichen verarbeiten und Invarianten des Denkens, d.h. Konzepte erkennen. Handelt es sich um stereotypengeleitete Strukturen, d.h. werden bestimmte Motive in einem Kulturkreis wiederholt, wird der Adressat durch die Automatisierung (abnehmende Zeichenhaftigkeit) weniger gefordert. 
Gleichzeitig werden mit der jeweils spezifischen Komposition unterschiedliche »Lernmodelle« (Wuss 1990, 1993 u.a.) bzw. sympraktische Anforderungen (Kloepfer 1985 ff.) realisiert. Um von den das Kurzzeit- bzw. Arbeitsgedächtnis betreffenden perzeptionsgelenkten Strukturen zu den Konzepten zu gelangen, mit denen dann die dargestellte Welt (Handlungen, Konstellationen, Chronotopoi) gemäß kognitiven Mustern längerfristig geordnet wird, müssen die Adressaten psychische Leistungen erbringen, die vielfach genutzt werden können.

Das Wiedererkennen konzeptgeleiteter Strukturen und das unbewußte Reagieren auf stereotypengelenkte »Anweisungen« können um so kreativer in ein Spannungsverhältnis zu den innovativen Strukturen gebracht werden, wenn mit der paratextuellen Ausstattung (Genette 1994) und der Exposition (als Initiation oder Priming; s. Hartmann 1995) eine große Sicherheit für den Adressaten aufgebaut wird.

Der praktische Wert dieses sog. PKS-Modells besteht darin, daß neben den auffälligen und relativ bewußt rezipierten filmischen Strukturen, auf welche die Filmanalyse traditionellerweise rekurriert (wenn sie klassische Narration beschreibt), nun auch solche einbezogen werden, die sich bisher erfolgreich einem analytischen Zugriff entzogen hatten, weil sie relativ unbewußt rezipiert wurden (etwa im Rahmen offener Erzählformen). Letztere nennt Wuss im Unterschied zur bewußten Oberflächenstruktur Tiefenstruktur. Dabei darf der Begriff der Oberflächenstruktur nicht etwa damit gleich gesetzt werden, daß der Film an der Oberfläche des Bewußtseins bleibe. Es kann durchaus, wirkmächtig, genußvoll und lehrreich sein, bestimmte diegetische Strukturen wie Handlungen, Figurentypen oder konfliktgeladene Situationen wieder zu erkennen und damit ein schlußfolgerndes Handeln zu aktivieren. 


\section{Film}
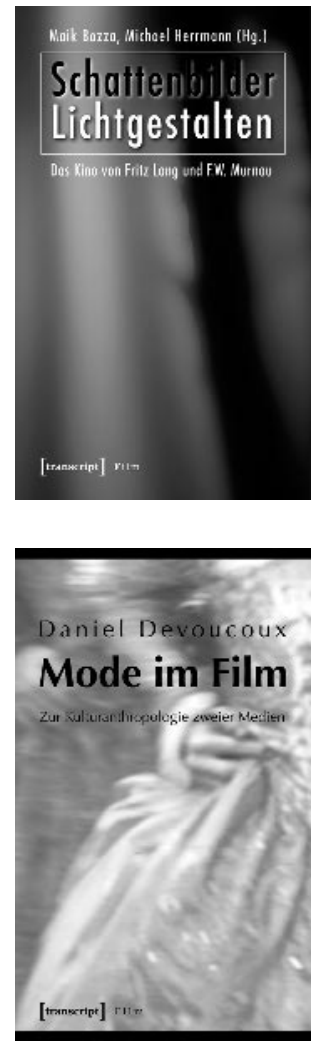

Gesthe Joost

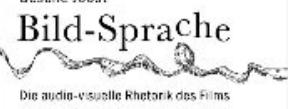

Maik Bozza, Michael Herrmann (HG.)

Schattenbilder - Lichtgestalten

Das Kino von Fritz Lang und F.W. Murnau.

Filmstudien

September 2009, ca. 220 Seiten, kart., zahlr. Abb., ca. 25,80€, ISBN 978-3-8376-1103-8

\section{Daniel Devoucoux}

\section{Mode im Film}

Zur Kulturanthropologie zweier Medien

2007, 350 Seiten, kart., zahlr. Abb., 34,80€,

ISBN 978-3-89942-8I3-I

\section{Gesche Joost}

Bild-Sprache

Die audio-visuelle Rhetorik des Films

2008, 264 Seiten, kart., zahlr. Abb., 25,80€, ISBN 978-3-89942-923-7 


\section{Film}

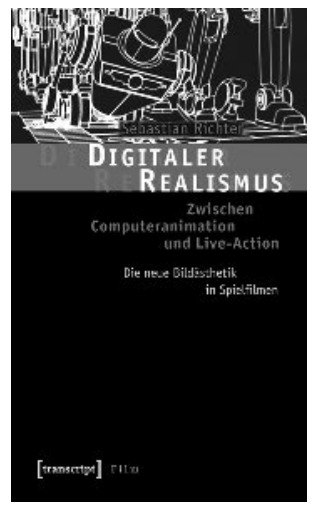

SEBASTIAN RichteR

Digitaler Realismus

Zwischen Computeranimation und Live-Action.

Die neue Bildästhetik in Spielfilmen

2008, 230 Seiten, kart., zahlr. z.T. farb. Abb., 25,80€,

ISBN 978-3-89942-943-5

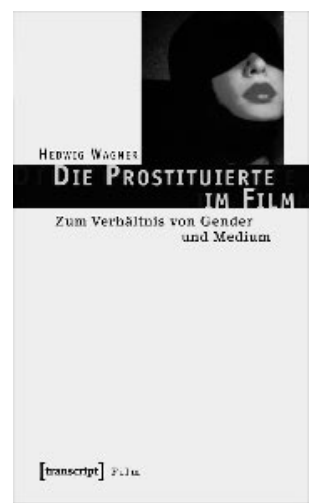

HEDWig WAGNER

Die Prostituierte im Film

Zum Verhältnis von Gender und Medium

2007, 324 Seiten, kart., 29,80€,

ISBN 978-3-89942-563-5

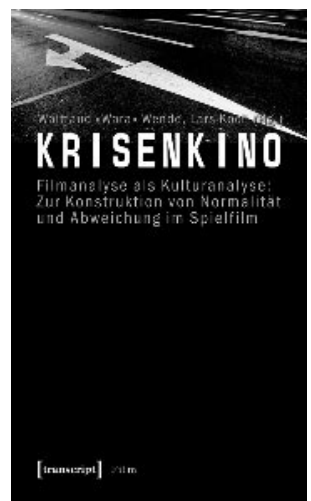

Waltraud »WARA« Wende, LaRs Koch (Hg.)

Krisenkino

Filmanalyse als Kulturanalyse: Zur Konstruktion von Normalität und Abweichung im Spielfilm

Juli 2009 , ca. 400 Seiten, kart., zahlr. Abb., ca. 29,80€, ISBN 978-3-8376-II35-9 


\section{Film}

Doris Agotai

\section{Architekturen in Zelluloid}

Der filmische Blick auf den Raum

2007, I84 Seiten, kart., zahlr. Abb., 24,80€,

ISBN 978-3-89942-623-6

\section{JOANNA BARCK}

Hin zum Film - Zurück zu den Bildern

Tableaux Vivants: »Lebende Bilder «

in Filmen von Antamoro, Korda,

Visconti und Pasolini

2008, 340 Seiten, kart., zahlr. Abb., 32,80€,

ISBN 978-3-89942-8I7-9

DUNJA BRÖTZ

Dostojewskis »Der Idiot « im Spielfilm

Analogien bei Akira Kurosawa,

Sasa Gedeon und Wim Wenders

2008, 320 Seiten, kart., zahlr. z.T. farb. Abb., $29,80 €$, ISBN 978-3-89942-997-8

Tina Hedwig Kaiser

Aufnahmen der Durchquerung

Das Transitorische im Film

2008, 230 Seiten, kart., zahlr. Abb., 27,80€,

ISBN 978-3-89942-93I-2

\section{Klaus Kohlmann}

Der computeranimierte Spielfilm

Forschungen zur Inszenierung

und Klassifizierung des

3-D-Computer-Trickfilms

2007, 300 Seiten, kart., 29,80€,

ISBN 978-3-89942-635-9

Ulrich Meurer,

Maria OiKonomou (Hg.)

Fremdbilder

Auswanderung und Exil

im internationalen Kino

April 2009, 250 Seiten, kart., zahlr. Abb., 27,80€, ISBN 978-3-8376-II22-9

\section{Katrin Oltmann}

Remake | Premake

Hollywoods romantische Komödien und ihre Gender-Diskurse, I930-1960

2008, 356 Seiten, kart., 29,80€,

ISBN 978-3-89942-700-4
Nadja Sennewald

Alien Gender

Die Inszenierung von Geschlecht

in Science-Fiction-Serien

2007, 3I4 Seiten, kart., zahlr. Abb., 29,80€,

ISBN 978-3-89942-805-6

Catherine Shelton

Unheimliche Inskriptionen

Eine Studie zu Körperbildern

im postklassischen Horrorfilm

2008, 384 Seiten, kart., $34,80 €$,

ISBN 978-3-89942-833-9

SANDRa Strigl

Traumreisende

Eine narratologische Studie der Filme von Ingmar Bergman, André Téchiné und Julio Medem

2007, 236 Seiten, kart., 27,80€,

ISBN 978-3-89942-659-5

Thomas Weber

Medialität als Grenzerfahrung

Futurische Medien im Kino der 8oer und goer Jahre

2008, 374 Seiten, kart., 33,80€,

ISBN $978-3-89942-823-0$

DANiel WinkleR

Transit Marseille

Filmgeschichte einer

Mittelmeermetropole

2007, 328 Seiten, kart., 29,80€,

ISBN 978-3-89942-699-I 
